NUREG/CR-4550/Volume 4

SAND86-2084

AN

\title{
Analysis of Core Damage Frequency From Internal Events: Peach Bottom, Unit 2
}

Alan M. Kolaczkowski, John A. Lambright, Walter L. Ferrell, Nathan G. Cathey, Bijan Najafi, Frederick T. Harper 


\section{NOTICE \\ This report was prepared as an account of work sponsored by an agency of the United States Government Neither the United States Government nor any agency thereof, or any of their employ- ees, makes any warranty, expressed or implied, or assumes any legal liability or responsibility for any third party's use, or the results of such use, of any information, apparatus product or process disclosed in this report, or represents that its use by such third party would not infringe privately owned rights}

Avallable from

Superintendent of Documents

U S Government Printing Office

Post Office Box 37082

Washington, D C 20013-7982

and

National Technical Information Service

Springfield, VA 22161

\section{DISCLAIMER}

This report was prepared as an account of work sponsored by an agency of the United States Government. Neither the United States Government nor any agency thereof, nor any of their employees, makes any warranty, express or implied, or assumes any legal liability or responsibility for the accuracy, completeness, or usefulness of any information, apparatus, product, or process disclosed, or represents that its use would not infringe privately owned rights. Reference herein to any specific commercial product, process, or service by trade name, trademark, manufacturer, or otherwise does not necessarily constitute or imply its endorsement, recommendation, or favoring by the United States Government or any agency thereof. The views and opinions of authors expressed herein do not necessarily state or reflect those of the United States Government or any agency thereof. 


\section{DISCLAIMER}

This report was prepared as an account of work sponsored by an agency of the United States Government. Neither the United States Government nor any agency Thereof, nor any of their employees, makes any warranty, express or implied, or assumes any legal liability or responsibility for the accuracy, completeness, or usefulness of any information, apparatus, product, or process disclosed, or represents that its use would not infringe privately owned rights. Reference herein to any specific commercial product, process, or service by trade name, trademark, manufacturer, or otherwise does not necessarily constitute or imply its endorsement, recommendation, or favoring by the United States Government or any agency thereof. The views and opinions of authors expressed herein do not necessarily state or reflect those of the United States Government or any agency thereof. 


\section{DISCLAIMER}

Portions of this document may be illegible in electronic image products. Images are produced from the best available original document. 

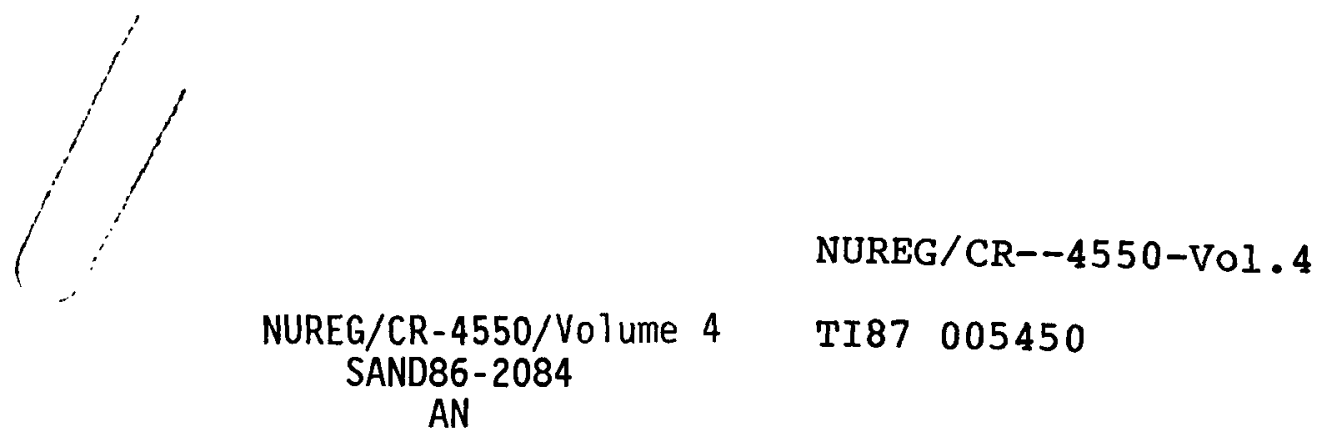

ANALYSIS OF CORE DAMAGE FREQUENCY
FROM INTERNAL EVENTS: PEACH BOTTOM, UNIT 2

Alan M. Kolaczkowskil, John A. Lambright ${ }^{3}$, Walter L. Ferre111, Nathan G. Cathey 2 , Bijan Najaf ${ }^{1}$, Frederick T. Harper 3

Program Manager: Allen L. Camp

Principal Investigator: Frederick T. Harper

Team Leader: Alan M. Kolaczkowski

Printed October 1986
Sandia National Laboratories
Albuquerque, NM 87185
Operated by
Sandia Corporation
for the
U.S. Department of Energy

\author{
Prepared for \\ Division of Reactor System Safety \\ Office of Nuclear Regulatory Research \\ U.S. Nuclear Regulatory Commission \\ Washington, DC 20555 \\ Under Memorandum of Understanding DOE 40-550-75 \\ NRC FIN A1228
}

1 Science Applications International Corporation

2 Idaho National Engineering Laboratory, EG\&G

3 Sandia National Laboratories

DISTRIBUTION OF THIS DOCUMENT IS UNLIMITED 
•

- 


\section{ABSTRACT}

This document contains the internal event initiated accident sequence analyses for Peach Bottom, Unit 2; one of the reference plants being examined as part of the NUREG-1150 effort by the Nuclear Regulatory Commission. NUREG-1150 will document the risk of a selected group of nuclear power plants. As part of that work, this report contains the overall core damage frequency estimate for Peach Bottom, Unit 2, and the accompanying plant damage state frequencies. Sensitivity and uncertainty analyses provide additional insights regarding the dominant contributors to the Peach Bottom core damage frequency estimate.

The mean core damage frequency at Peach Bottom was calculated to be 8.2E-6. Station blackout type accidents (loss of all AC power) were found to dominate the overall results. Anticipated Transient Without Scram accidents were also found to be non-negligible contributors.

The numerical results are largely driven by common mode failure probability estimates and to some extent, human error. Because of significant data and analysis uncertainties in these two areas (important, for instance, to the most dominant scenario in this study), it is recommended that the results of the uncertainty and sensitivity analyses be considered before any actions are taken based on this analysis. 
-

0

0 


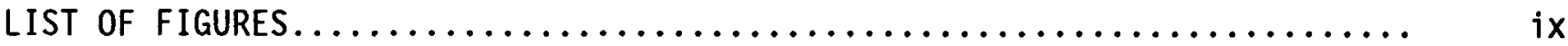

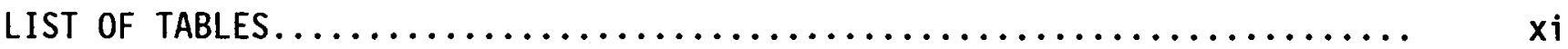

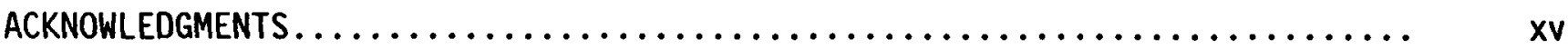

RELATED DOCUMENTATION.................................... xvii

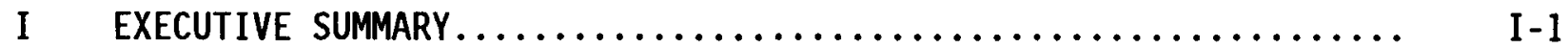

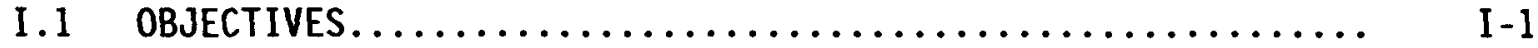

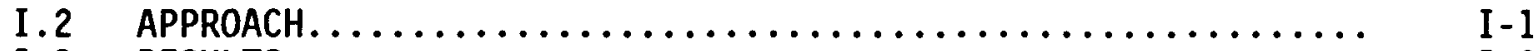

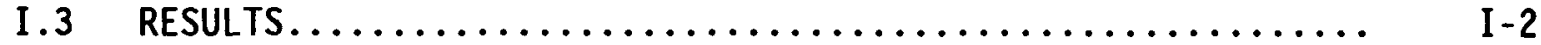

I.3.1 Characterization of Core Damage Frequency at Peach Bottom.......................... I-2

I.3.2 Characterization of Plant Damage State Frequencies.............................. I 5

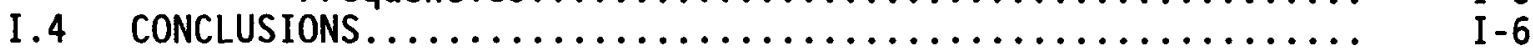

I.4.1 Accident Type Conclusions.................... I-7

I.4.2 Uncertainty Considerations.................... I-8

II PROGRAM SCOPE AND LIMITATIONS $\ldots \ldots \ldots \ldots \ldots \ldots \ldots \ldots \ldots \ldots \ldots \ldots \ldots \ldots \ldots$ II -1

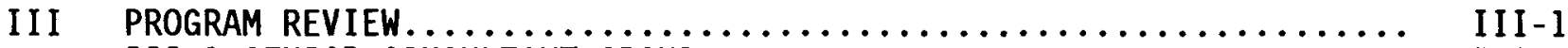

III.1 SENIOR CONSULTANT GROUP........................... III-1

III.2 QUALITY CONTROL GROUP............................. III-1

III 3 UTILITY INTERFACE. $\ldots \ldots \ldots \ldots \ldots \ldots \ldots \ldots \ldots \ldots \ldots \ldots$, III -2

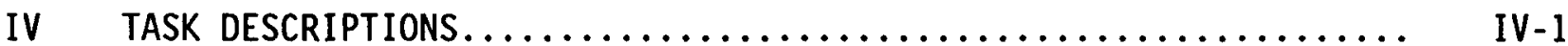

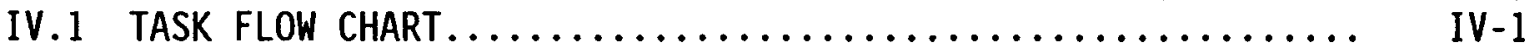

IV.2 PLANT FAMILIARIZATION. $\ldots \ldots \ldots \ldots \ldots \ldots \ldots \ldots \ldots \ldots, \ldots \ldots \ldots$, IV-1

IV.2.1 Initial Plant Visit........................ IV -1

IV.2.2 Final Plant Visit.......................... IV -4

IV.3 INITIATING EVENT IDENTIFICATION AND GROUPING $\ldots \ldots \ldots \ldots \ldots$, IV -5

IV.3.1 Identification of Initiators.................. IV -5

IV.3.2 Initiating Event Assumptions.................. IV -11

IV.3.3 Initiating Event Nomenclature................ IV-11

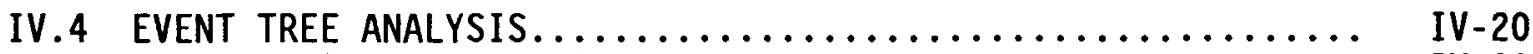

IV.4.1 Plant Damage States........................ IV-21

IV.4.2 General Event Tree Assumptions................... IV

IV.4.3 Discussion of Success Criteria................. IV-22

IV.4.4 Large LOCA Event Tree........................ IV -23

IV.4.5 Intermediate LOCA Event Tree................... IV -28

IV.4.6 Small LOCA Event Tree........................ IV

IV.4.7 Smal1-Sma11 LOCA Event Tree...................... IV-55

IV.4.8 Loss of Offsite Power Event Tree................. IV-58

IV.4.9 Loss of Power Conversion System (PCS)

Event Tree.................................. IV 73 
TABLE OF CONTENTS (CONTINUED)

IV.4.10 Transient with PCS Initially Available Event Tree............................ IV -74

IV.4.11 Inadvertent Open Relief Valve Transient Event Tree..................................... IV 78

IV.4.12 Loss of Feedwater Event Tree................. IV 80

IV.4.13 Loss of an AC or DC Bus Event Tree............ IV-81

IV.4.14 "V" Sequence........................... IV 8 .

IV.4.15 Event Tree Nomenclature................. IV-83

IV. 4.16 ATWS Event Tree........................ IV -87

IV.5 SYSTEM ANALYSIS .......................... IV -87

IV.5.1 System Modeling and Scope................... IV -87

IV.5.2 High Pressure Coolant Injection System........... IV-87

IV.5.3 Reactor Core Isolation Cooling System............. IV 98

IV.5.4 Control Rod Drive System...................... IV -105

IV.5.5 Standby Liquid Control System................. IV-108

IV.5.6 Automatic Depressurization System................. IV-112

IV.5.7 Low Pressure Core Spray System............... IV-116

IV.5.8 Low Pressure Coolant Injection System............ IV-121

IV.5.9 Residual Heat Removal: Shutdown Cooling System..... IV-126

IV.5.10 Residual Heat Removal: Suppression Pool Cooling

System............................... IV -131

IV.5.11 Residual Heat Removal: Containment Spray System.... IV-135

IV.5.12 Electric Power System..................... IV-140

IV.5.13 Emergency Service Water System............... IV 145

IV.5.14 High Pressure Service Water System.............. IV 152

IV.5.15 Emergency Ventilation System................. IV -157

IV.5.16 Instrument Air system...................... IV 163

IV.5.17 Primary Containment Venting System............. IV -168

IV.5.18 Reactor Protection System................ IV 171

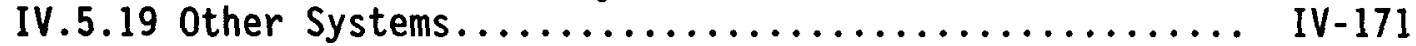

IV.5.20 System Analys is Nomenclature.............. IV -171

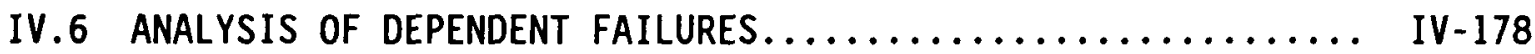

IV.6.1 Subtle Interactions........................ IV -178

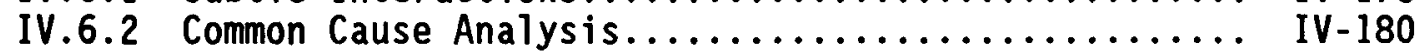

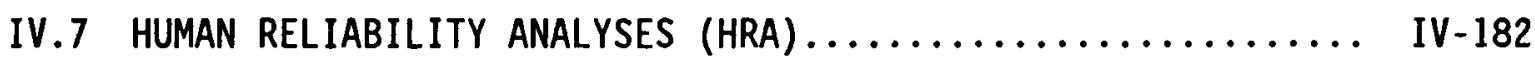

IV.7.1 Human Actions Analyzed..................... IV 182

IV.7.2 Results of HRA.............................. IV 182

IV.7.3 Assumptions Associated with the HRA............ IV -186

IV.7.4 HRA Nomenclature...................... IV-186

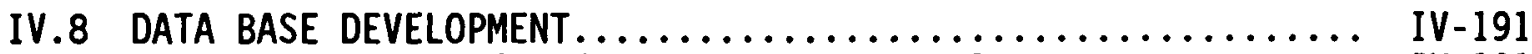

IV.8.1 Sources of Information for Data Base............ IV-191

IV.8.2 Assumptions and Limitations in the Data

Base............................... IV-191

IV.8.3 Uncertainty Distributions................. IV -191 


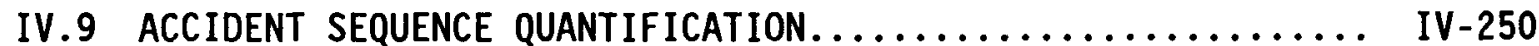

IV.9.1 Sequence Quantification Process............... IV -250

IV.9.2 Plant Specific Quantification Issues............. IV-251

IV. 10 ANTICIPATED TRANSIENT WITHOUT SCRAM (ATWS) ANALYSIS...... IV-255

IV.10.1 Case A ATWS Analysis...................... IV-255

IV. 10.2 Case B ATWS Analysis.................... IV-289

IV.11 UNCERTAINTY/SENSITIVITY ANALYSIS ................ IV-319

IV.11.1 Treatment of Uncertainties.................... IV 319

IV.11.2 Sources of Uncertainty.................... IV 320

IV.11.3 Uncertainty/Sensitivity Analysis.............. IV-320

IV.11.4 Integrated Sensitivity/Uncertainty Analysis....... IV-323

IV.11.5 Other Sensitivities..................... IV -323

v RESULTS $\ldots \ldots \ldots \ldots \ldots \ldots \ldots \ldots \ldots \ldots \ldots \ldots \ldots \ldots \ldots \ldots \ldots \ldots$

V.1 CHARACTERIZATION OF CORE DAMAGE FREQUENCY AT

PEACH BOTTOM. ............................. $\quad v-1$

V.2 CHARACTERIZATION OF RESULTS BY PLANT DAMAGE STATE........

V.2.1 Plant Damage State TBUX.................... V 18

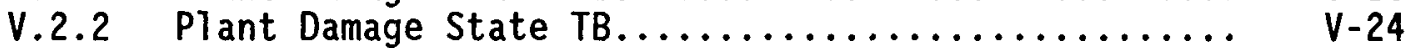

V.2.3 Plant Damage State TCUX.................... V-31

V.2.4 Plant Damage State TCSR................... V-37

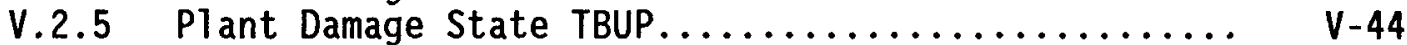

V.2.6 Plant Damage State TCSX.................. V-49

V.2.7 Plant Damage State TBU.................... V-53

V.2.8 Plant Damage State TBP..................... V-58

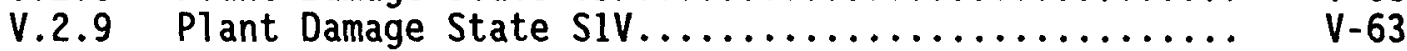

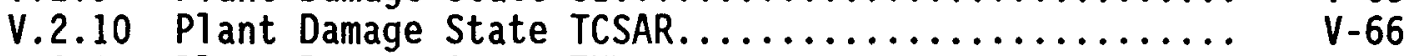

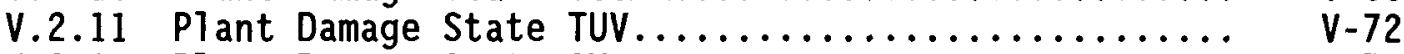

V.2.12 Plant Damage State AV.................... V -75

V.2.13 Plant Damage State TUX.................... V-77

V.3 DERIVING INDIVIDUAL SEQUENCE FREQUENCIES ..............

V.4 COMPARISON OF RESULTS WITH WASH $-1400 \ldots \ldots \ldots \ldots \ldots \ldots \ldots \ldots \ldots . \ldots . . \ldots 3$

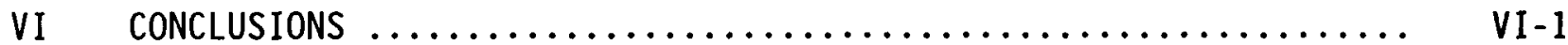

VI.1 GENERAL CONCLUSIONS ......................... VI 1

VI.2 ACCIDENT SPECIFIC CONCLUSIONS $\ldots \ldots \ldots \ldots \ldots \ldots \ldots \ldots \ldots \ldots \ldots . \quad$ VI -1

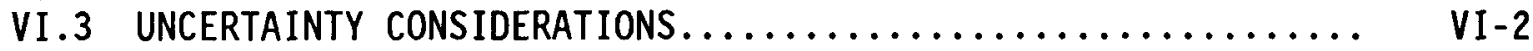

VI.4 OTHER INSIGHTS.......................... VI -3

VII REFERENCES .............................. VII-I

VIII GLOSSARY OF ABBREVIATIONS ..................... VIII-1 


\section{TABLE OF CONTENTS (CONCLUDED)}

Section

Page

APPENDIX A: PEACH BOTTOM SYSTEM FAULT TREES .................. A-1

APPENDIX B: IMPORTANCE VALUES FOR CUT SET EVENTS ............... B-1

APPENDIX $c:$ PHILADELPHIA ELECTRIC COMPANY REVIEW............... c-1 


\section{LIST OF FIGURES}

Figure

Page

1

I.3-1

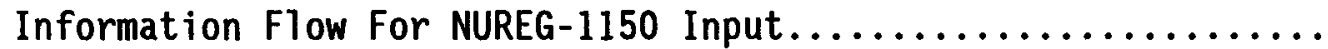

IV. $1-1$

IV. $4-1$

IV. $4-2$

IV. $4-3$

IV. $4-4$

IV. $4-5$

IV. $4-6$

IV. $4-7$

IV. $4-8$

IV. $4-9$

IV. $5.1-1$

Peach Bottom Total

xvi i i

$\mathrm{I}-4$

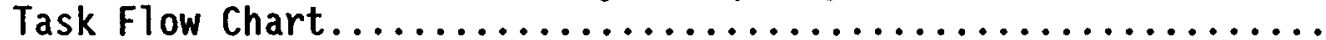

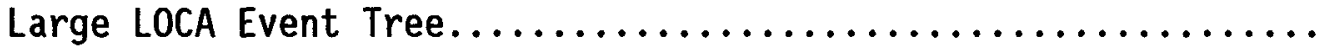

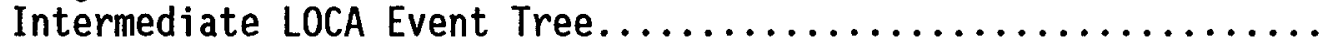

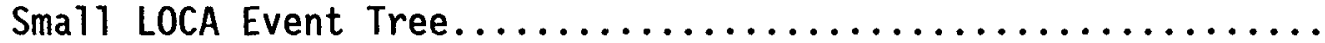

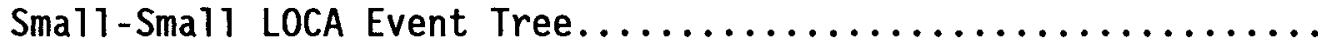

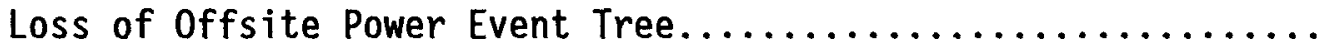

Transient with PCS Initially Available Event Tree............

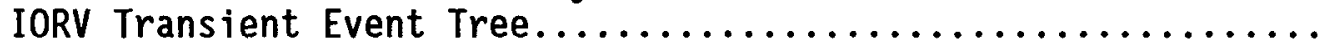

Typical Valve Arrangement for High-Low Pressure Interface......

Large LOCA: Sequence Designator Example.

IV -2

IV -25

IV -31

IV -37

IV -57

IV -61

IV -77

IV -79

IV -82

IV -86

IV. $5.2-1$

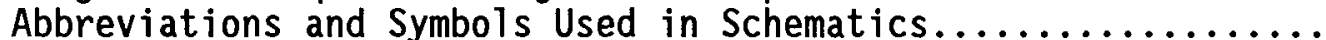

IV -89

IV. 5.2-2

High Pressure Coolant Injection System Schematic..............

IV. $5.2-3$

High Pressure Coolant Injection System Dependency Diagram......

IV. $5 \cdot 3-1$

IV. 5.3-2

Emergency Core Cooling System Actuation Dependency Diagram.....

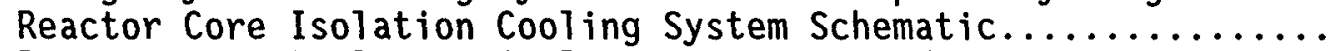

IV. 5. $4-1$

IV. 5. 4-2

IV. 5. $5-1$

IV. 5.5-2

Reactor Core Isolation Cooling System Dependency Diagram.......

Control Rod Drive System Schematic.

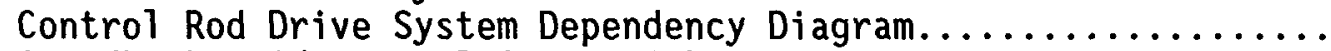

Standby Liquid Control System Schematic.

IV -92

IV -93

IV -94

IV -100

IV -101

IV -106

IV -107

Standby Liquid Control System Dependency Diagram...............

IV. $5.6-1$

IV. 5.6-2

IV. $5.7-1$

IV. 5. 7-2

IV. 5. $8-1$

IV. 5.8-2

IV. 5. $9-1$

IV. 5.9-2

IV.5.10-1

Automatic Depressurization System Valves and Safety Relief

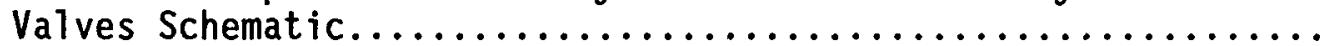

Reactor Depressurization Dependency Diagram.................

Low Pressure Core Spray System Schematic..................

Low Pressure Core Spray System Dependency Diagram..............

Low Pressure Coolant Injection System Schematic....................

Low Pressure Coolant Injection System Dependency Diagram........ Residual Heat Removal System--Shutdown Cooling Mode Schematic.. Residual Heat Removal System--Shutdown Cooling Mode Dependency Diagram........................................

Residual Heat Removal System--Suppression Pool Cooling Mode

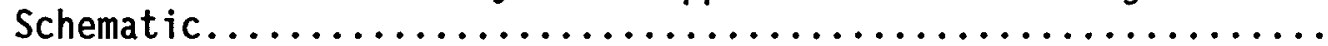

IV.5.10-2 Residual Heat Removal System--Suppression Pool Cooling Mode

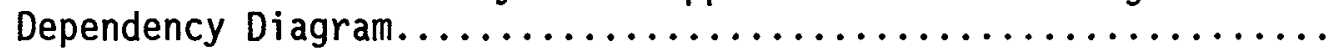

IV.5.11-1 Residual Heat Removal System--Containment Spray Mode Schematic. IV.5.11-2 Residual Heat Removal System--Containment Spray Mode Dependency

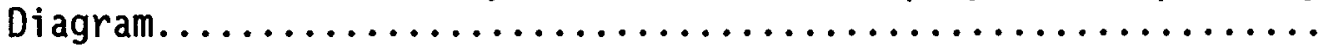

IV.5.12-1 Emergency Electric Power System Schematic..................

IV. $5.12-2$

IV. $5.13-1$

IV. 5.13-2

IV.5.14-1

IV. 5. 14-2

IV. $5.15-1$

IV. 5. 15-2

Emergency Electric Power Dependency Diagram.................

Emergency Service Water System Schematic....................

Emergency Service Water System Dependency Diagram...............

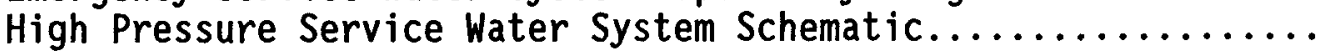

High Pressure Service Water System Dependency Diagram..........

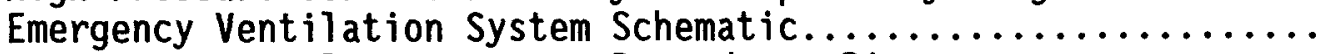

Emergency Ventilation System Dependency Diagram.

IV -110

IV-111

IV -113

IV -115

IV -117

IV -119

IV-122

IV-124

IV-127

IV-128

IV -132

IV -133

IV -137

IV -138

IV-141

IV -143

IV-146

IV-149

IV -154

IV- 155

IV-159

IV-161 
IV.5.16-1

IV.5.16-2

IV. 5.17-1

IV.10.1-1

IV.10.1-2

IV.10.2-1

IV. 10.2-2

V. $1-1$

V. $2-1$

V. $2-2$

V. $2-3$

V. $2-4$

V.2-5

V.2-6

V. $2-7$

V. 2-8

V. $2-9$

V. $2-10$

V. 4-1

V. 4-2
Instrument Air/Nitrogen System Schematic.

Instrument Air System Dependency Diagram.

Primary Containment Venting System Schematic...

Peach Bottom Case A MSIV closure ATWS Event Tree...

Peach Bottom Case A MSIV Open ATWS Event Tree....

Peach Bottom Case B MSIV Closure ATWS Event Tree.

Peach Bottom Case B MSIV Open ATWS Event Tree..

Peach Bottom Total Core Damage Frequency

Peach Bottom TBUX Core Damage Frequency

Peach Bottom TB Core Damage Frequency...

Peach Bottom Core Damage Frequencies of TCSRX2, TCSRX3, TCSRV23 in Sequence Group TCSR...............................

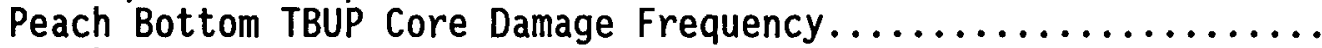

Peach Bottom TCSX Core Damage Frequency..................

Peach Bottom TBU Core Damage Frequency.......................

Peach Bottom TBP Core Damage Frequency......................

Peach Bottom TCSAR Core Damage Frequency......................

Peach Bottom TUX Core Damage Frequency...

Core Damage Frequency Comparison.............

Comparison of Accident Type Contributions...
IV-165

IV -167

IV- 169

IV -258

IV -259

IV -293

IV-294

V-14

$V-22$

$V-29$

V-34

V -43

$V-47$

V-52

V-56

$v-61$

V-71

V -80

V-86

$V-87$ 


\section{LIST OF TABLES}

Table

Page

I.3-1 Definition of Core Damage Characterizations................

I.3-2 Plant Damage States Representing $91 \%$ of the Total Core Damage

IV. $3-1$

IV. $3-2$

IV. $3-3$

IV. $3-4$

IV. $4-1$

IV. $4-2$

IV. 4-3

IV. 4-4

IV. 4-5

IV. 4-6

IV. 4-7

IV. 5-1

IV. 5. 20-1

IV.5.20-2

IV. 5.20-3

IV. 7-1

IV.7-2

IV. 7-3

IV. 7-4

IV. 7-5

IV. 8-1

IV. 10.1-1

IV. 10.1-2

IV.10.1-3

IV. 10.1-4

IV.10.1-5

IV.10.1-6

IV.10.1-7

IV. 10.1-8

IV.10.1-9

IV. 10.2-1

IV. 10.2-2

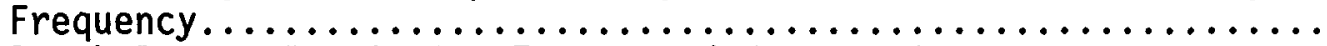

Peach Bottom Initiating Events and Frequencies...............

Primary Information Sources Used to Identify Initiators........

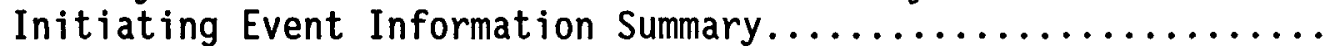

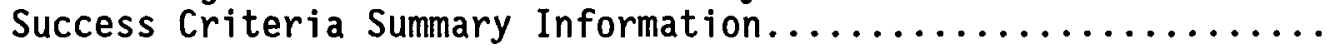

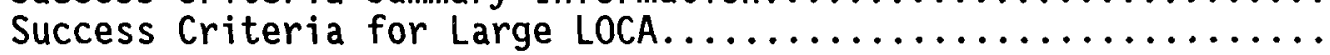

Success Criteria for Intermediate LOCA....................

Success Criteria for Small LOCA.

IV -7

IV -12

IV -14

IV -24

IV -29

IV -35

Success Criteria for Loss of Offsite Power..................

Success Criteria for Loss of Power Conversion System...........

Success Criteria for Transient With PCS Initially Available....

Event Tree Nomenclature...............................

Systems Included in the Peach Bottom Study.................

System Identifiers..................................

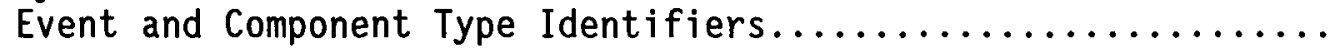

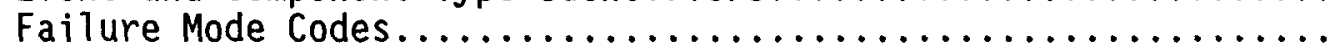

Recovery Actions Considered in the Peach Bottom Study...........

Summary of Important Pre-Accident Human Error

Probabilities...

IV -59

IV -75

IV -76

IV -84

IV -88

IV -173

IV -175

IV -177

IV -183

Summary of Important Post-Accident Human Error

Probabilities (Non-Recovery Values)...

IV-187

IV -188

IV-189

Important Recovery Actions Explicitly Modeled in System

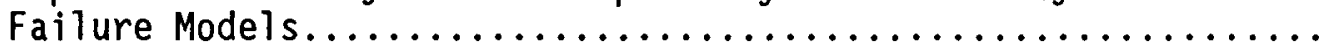

IV -190

Peach Bottom Event Data................................ IV 193

Initiate Standby Liquid Control Human Error Probability

Sensitivity to Time Availability and Reluctance Factor for

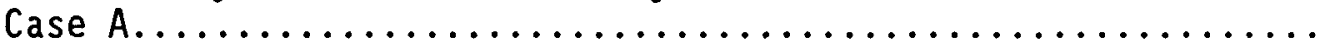

Human Error Probability Estimates to Defeat Automatic

Depressurization System Initiation for Case A...............

Human Error Probability Estimates to Establish and Maintain

Water Level at TAF while at High Pressure for Case A..........

Human Error Probability Estimates for Manual Depressurization

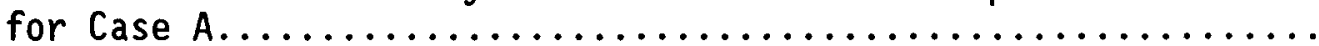

Human Error Probability Estimates to Establish and Maintain

Water Level at TAF while at Low Pressure for Case A..........

LTAS Code Runs for Various ATWS Scenarios at Peach Bottom......

Summary of LTAS ATWS with MSIV Closure Runs Performed at ORNL

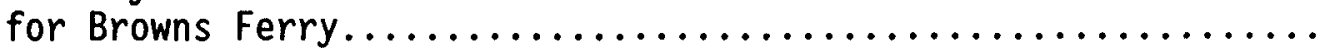

Peach Bottom ATWS Data Used for Quantification for Case A......

ATWS Case A Dominant Sequences for Peach Bottom..............

Initiate Standby Liquid Control Human Error Probability

Sensitivity to Time Availability and Reluctance Factor for

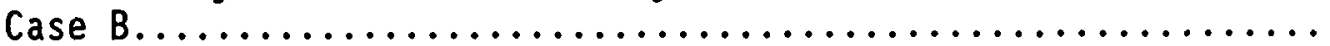

IV-271

IV -272

IV -273

IV-274

IV -276

IV -280

IV -281

IV -283

IV -290

Human Error Probability Estimates to Defeat Automatic

Depressurization System Initiation for Case B...

IV -305

IV -306 


\section{LIST OF TABLES (CONTINUED)}

$\underline{\text { Table }}$

IV.10.2-3 Human Error Probability Estimates to Establish and Maintain Water Level at TAF while at High Pressure for Case B..........

IV.10.2-4 Human Error Probability Estimates for Manual Depressurization for Case B.................................... IV -308

IV.10.2-5 Human Error Probability Estimates to Establish and Maintain Water Level at TAF while at Low Pressure for Case B............

IV.10.2-6 Values Used for Top Events in Case B MSIV Closure ATWS Event

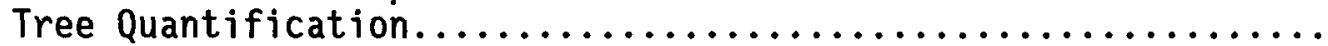

IV.10.2-7 Values Used for Initiating Events in Case B Event Tree

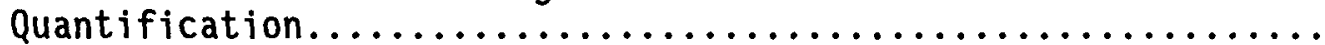

IV.10.2-8 Values Used for Top Events in Case B MSIV Open ATWS Event Tree Quantification..................................... IV -317

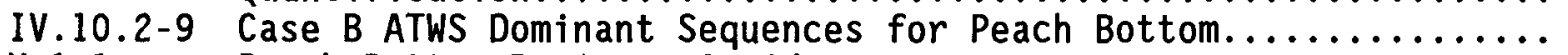
V. $1-1$ Peach Bottom Dominant Accident Sequences.

V.1-2 Accident Scenarios Greater Than 1E-8/Reactor Year at Peach

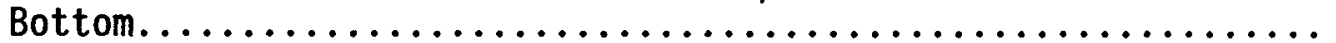
Core Damage Frequency Contributors by Type of Accident........ Importance Measures... Important Contributors to Core Damage Based on Results of Summary of Core Damage Frequency Estimates Including Sensitivity Studies............................... Core Damage Importance Measure Results For Each Sensitivity.... TBUX Dominant Cut Sets.

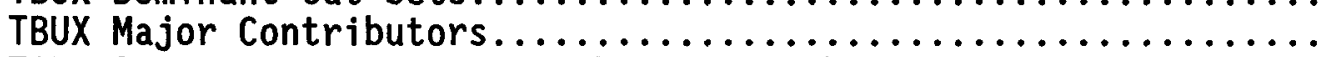

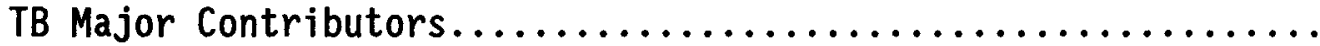

V. $2-8$

V. $2-9$

V. $2-10$

V. $2-11$

V. $2-12$

V. $2-13$

V. $2-14$

V. $2-15$

TB Importance Measure Results for Each Sensitivity............

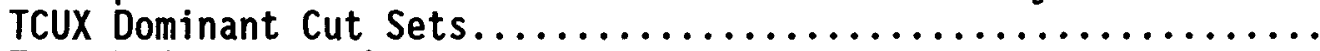

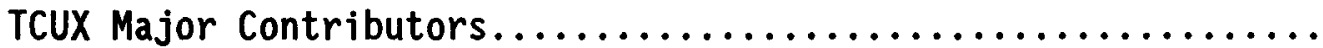

TCUX Importance Measure Results for Each Sensitivity..........

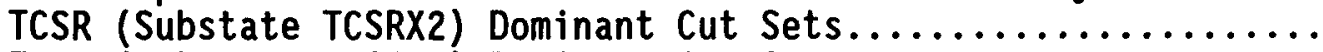

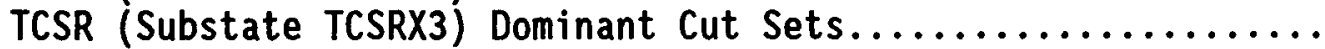

TCSR (Substate TCSRV23) Dominant Cut Sets.................

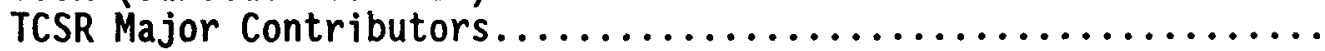

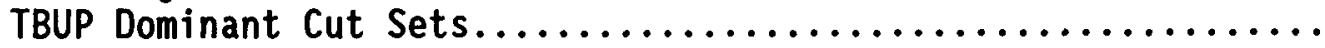

V. $2-16$

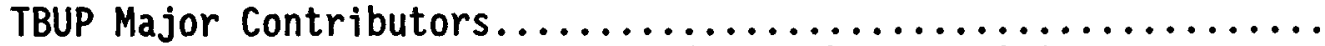

V.2-17

TBUP Importance Measure Results for Each Sensitivity..........

V.2-18

V.2-19

TCSX Dominant Cut Sets. 
Table

Page

V.2-23 TBP (Sequences T1-T2-T3(Q) PW2W3U3V1V2V3V4 and T1-T2-T3(Q)

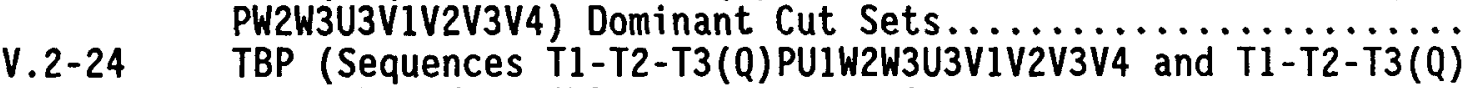
U1W2W3U3V1V2V3V4Y) Dominant Cut Sets................. V-60

V.2-25

V. $2-26$

TBP Importance Measure Results for Each Sensitivity...........

SIV Dominant Cut Sets............................ V-64

SIV Major Contributors............................ V 65

TCSAR (Substate TCSARX2) Dominant Cut Sets............... V-68

V. $2-28$

V. $2-29$

TCSAR (Substate TCSARX3) Dominant Cut Sets.

$V-69$

V. $2-30$

TCSAR Major Contributors.

$V-70$

V. $2-31$

V. $2-32$

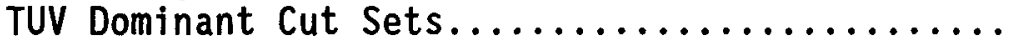

$V-73$

TUV Major Contributors........................ V V 74

AV Dominant Cut Sets................................ V-76

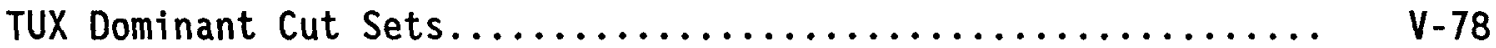

V. $2-34$

V. $2-35$

V. $3-1$

TUX Major Contributors.

$V-79$

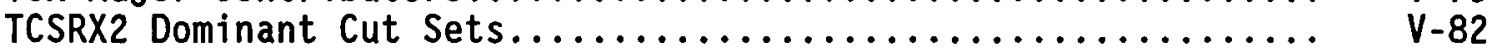

V. $4-1$

Comparison of NUREG/CR-4550 Update/WASH-1400 Sequences.

$V-85$ 
0

0

0 


\section{ACKNOWLEDGMENTS}

The authors wish to acknowledge the efforts of the entire analysis team and the directional guidance provided by the Nuclear Regulatory Commission, the Sandia program manager and principal investigator, and the various quality review organizations. Persons not listed explicitly in the report but whose efforts should be noted include Peter Appignani and Mark Jacobs of Joseph Fragola's staff for their data analysis work, Lanny Smith and Gordon Medford for their work on the ATWS thermal-hydraulic code simulations, Ron Iman and Michael Shortencarier who performed the final TEMAC code sequence quantification runs, Mary Drouin and Bonnie Shapiro who provided technical support in finalizing the documentation, Pat Sims who edited the written report, and to the people who provided secretarial support during the publication of this report. These people include Nancy Cabber, Capri Corlis, Lorri Howe, and Vickie Lucero.

Also, the efforts of Greg Krueger of Philadelphia Electric Company (PECO) and other PECO staff are greatly appreciated for providing us with the voluminous information that was required to perform this study. Their continuous interaction with the analysis team and PECO's comments on the report enhanced the quality of the work and the perspectives which are provided by the study. 
O

0

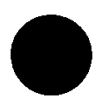




\section{RELATED DOCUMENTATION}

This is one of several documents that will present information to the (NRC) Office of Regulatory Research about Light Water Reactor (LWR) risk. The Office of Regulatory Research will use this information to prepare NUREG-1150. NUREG-1150 will examine risk from a selected group of nuclear power plants and will provide the basis for both comparison of NRC research to industry results and the resolution of numerous severe accident issues.

Figure 1 represents the process that was used to calculate risk. As can be seen by this figure, there are three interfacing programs performing this work: the Accident Sequence Evaluation Program (ASEP), the Severe Accident Risk Reduction Program (SARRP), and the PRA Uncertainties Estimation Program (PRUEP). As a result of these programs, several reports are being written that will document the ongoing work.

In this section we will briefly describe the content of the different reports and will list the titles of those relevant to the Peach Bottom NUREG-1150 analyses.

\section{ASEP Reports}

The ASEP reports will present the methodology and results of the systems analyses for the LWRs studied. Estimates of core damage frequency and estimates of severe accident sequence frequencies are summarized in these reports.

NUREG/CR-4550, SAND86-2084, Vol. 1, "Analysis of Core Damage Frequency From Internal Events: Methodology Guidelines, " F. T. Harper, et al., Sandia National Laboratories (to be published).

NUREG/CR-4550, SAND86-2084, Vo1. 2, "Analysis of Core Damage Frequency From Internal Events: Summary Report, "F. T. Harper, et al., Sandia National Laboratories (to be published).

SAND86-1996, "Accident Sequence Evaluation Program Human Reliability Analysis Procedure," A. D. Swain, III, Sandia National Laboratories (to be published).

Technical Report A-3272, "A Human Reliability Analysis for the ATWS Accident Sequence with MSIV Closure at the Peach Bottom Atomic Power Station," W. J. Luckas, Jr., et a1., Brookhaven National Laboratory (May 1986).

\section{Containment Event Tree Reports}

These reports document analyses performed under the SARRP to investigate the response of containments at the respective plants:

NUREG/CR-4700, SAND86-1135, Vo1. 2, "Containment Event Analysis for Postulated Severe Accidents at the Peach Bottom Nuclear Power Plant," A. S. Benjamin, et al., Sandia National Laboratories (to be published). 

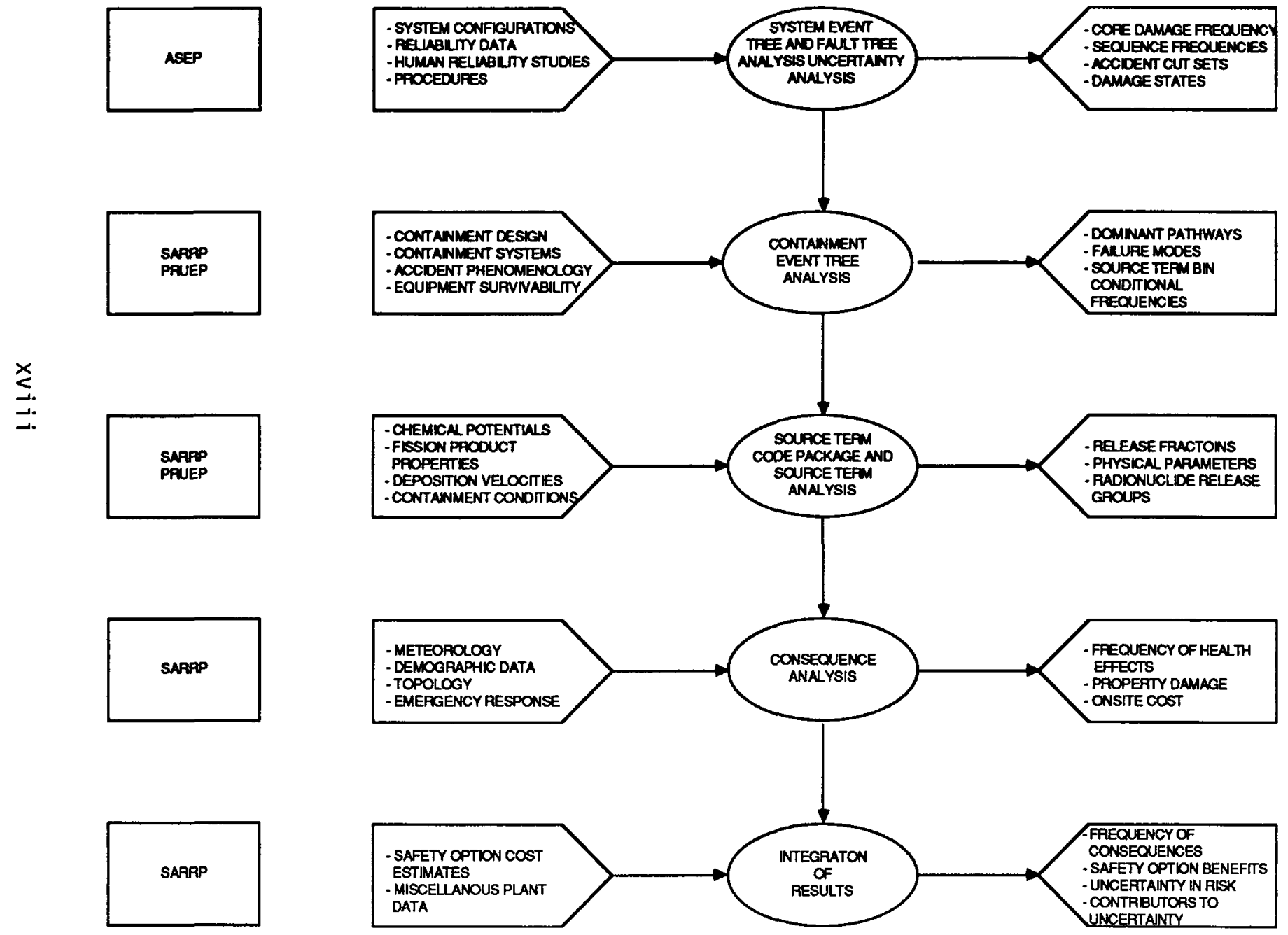

ASEP REPOFTS

CONTANMENT

REPORTS.

CONTAMMENT EVENT

REPOFT

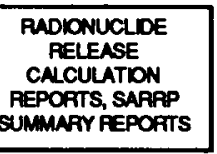

SAPRP

SUMMAFY

PEPORTS

SARRP
SUMMARY PEPOFTS

Figure 1. Information Flow for NUREG-1150 Input. 


\section{Containment Event Tree Review Report}

This report documents the review of the development and construction of the SARRP containment event trees, the containment failure probabilities, the containment failure modes, the containment failure timing, and the computer model used to construct and evaluate the trees:

NUREG/CR-4569, "A Review of the Severe Accident Risk Reduction Program (SARRP) Containment Event Trees," University of Wisconsin, Madison, WI (May 1986).

\section{Radionuclide Release Calculation Reports}

These reports present results of analyses of the environmental release of fission products (source terms) for severe accident scenarios in the containment designs chosen for study for NUREG-1150:

NUREG/CR-4624, BMI2139, Vol. 1, "Radionuclide Release Calculations for Selected Severe Accident Scenarios: BWR, Mark 1 Design," R. S. Denning, et al., Battelle Columbus Laboratories (July 1986).

\section{SARRP Summary Reports}

These reports summarize the research represented in Figure 1 . These reports present (1) the risk insights that have been generated as a result of recent research into severe accident systems behavior and physical phenomena, (2) an evaluation of the current level of plant safety, and (3) a discussion of the potential benefits and costs of measures intended to enhance safety.

NUREG/CR-4551, SAND86-1309, Vo1. 2, "Evaluation of Severe Accident Risks and the Potential for Risk Reduction: Peach Bottom, Unit 2," A. S. Benjamin, et a1., Sandia National Laboratories (to be published). 
This document presents the results from one of several studies that will provide information to the Nuclear Regulatory Commission (NRC) Office of Research about Light Water Reactor (LWR) risk. The Office of Research will use the results of this work, along with other input, to prepare NUREG-1150 which will examine risk from a selected group of nuclear power plants by incorporating the results of wide-ranging research efforts that have taken place over the past several years. These results will provide the bases for updating our perception of risk from selected plants, developing methods for extrapolation to other plants, comparing NRC research to industry results, and resolving numerous severe accident issues.

Peach Bottom has been chosen as one of the reference plants which will be analyzed to accomplish these goals. The Peach Bottom Atomic Power Station is located in southeastern Pennsylvania in York County on the west shore of Conowingo Pond and contains two Boiling Water Reactor (BWR) units of 1150 megawatts (electrical) capacity. The reactors are both housed in Mark I containments. Peach Bottom Unit 2, analyzed in this study, began commercial operation in July 1974 and is operated by Philadelphia Electric Company (PECO). The Peach Bottom plant was previously analyzed in WASH-1400. Other plants that have been chosen as reference plants are Surry, Sequoyah, Grand Gulf, Zion and LaSalle.

\section{I.1 OBJECTIVES}

Our objective was to perform an analysis that approximated a detailed, state-ofthe-art, Level 1 Probabilistic Risk Assessment (PRA). For most of the project, we worked under severe time and resource constraints which made it necessary to take shortcuts in some areas.

This document presents the initial part of the risk equation -- the frequency of scenarios involving system failures which lead to severe core damage.*

Neither external nor special events were analyzed in this study. Containment and consequence analysts have taken our results and integrated them into the risk equation. The corresponding Peach Bottom containment and consequence analyses can be found under separate cover.

\section{I.2 APPROACH}

To meet program objectives in the time available, we used all currently available information about Peach Bottom and took "intelligent" shortcuts. Because Peach Bottom has been the subject of many studies, there is a wealth of information in existence. To recognize appropriate shortcuts, an experienced PRA team was selected. The team analyzed only those aspects of the plant that they felt to be important. Time was not spent analyzing areas that had been shown to be unimportant in the past. Also, if the analyst felt that a system could be represented adequately with a simplified model rather than a detailed fault tree,

*Core damage is defined as a significant core uncovery occurrence with re-flooding of the core not imminently expected. The result is a prolonged uncovery of the core which leads to damaged fuel and an expected release of fission products from the fuel. 
the simplified approach was chosen. However, if the analyst felt that a system was important enough to warrant extreme modeling detail, he chose the appropriate modeling techniques. Using this approach, we have produced results which we feel meet the program objectives without excessive effort.

The standard PRA approach was used in this analysis. We formulated event trees, modeled the top events using large fault trees where required, and quantified the results using available computer codes. In order to maintain high quality, this work was reviewed by four different groups: an independent Senior Consultant Group (SCG), an independent Quality Control Group (QCG), an internal Sandia review group, and an internal NRC review group. In addition, staff at PECO were given an opportunity to comment on the first draft of this report. Some of PECO's comments were received too late, in the light of time and resource constraints, for explicit incorporation (i.e., certain comments would have required significant re-analysis). In such cases, we have tried to address their most important comments in a qualitative manner and estimate their potential impact. In addition, sensitivity analyses were conducted which bound the probabilistic effects of PECO's major comments. Appendix C contains discussions regarding PECO input which should be considered along with the results of this work to provide a more complete perspective on this study's insights.

\section{I.3 RESULTS}

A summary of the quantitative results of the analysis is presented in this section. The results are presented at two levels: the plant level and the plant damage state level. A more detailed description of the results, including key assumptions and sensitivities, is presented in Section $V$.

\section{I.3.1 Characterization of Core Damage Frequency At Peach Bottom}

The Peach Bottom PRA identified two major accident types (see Table I.3-1 for description of accident type) which dominate the results of the analysis. These accident types, station blackout and Anticipated Transients Without Scram (ATWS), as well as other less important types of accidents, collectively cover a variety of plant damage states (see Table I.3-1). The mean core damage frequency at Peach Bottom was calculated to be $8.2 E-6$. The WASH- 1400 value for core damage frequency is $2.5 \mathrm{E}-5$, a sum of individual sequence median values which cannot be readily compared to our results.

Uncertainty and sensitivity analyses were also performed. The results of these analyses are presented on the "box and whisker" graphic (Figure I.3-1). The "box" represents the range of the means of the sensitivity studies that were performed to identify the impact of data selection and modeling assumptions on core damage frequencies. Some of the sensitivity issues considered were the values of common cause factors such as DC power common mode, the maintenance unavailability of a particular service water valve, operator actions during ATWS sequences, and failure modes of the Emergency Service Water (ESW) system. (A complete list is presented in Section IV.11.) The "whiskers" associated with the box and whisker charts represent ranges of uncertainty arising from the uncertainty in the values of the parameter estimates. The inner bars on the whiskers indicate the 95th and 5th percentiles of the probability distribution calculated for the base case. The outer bars indicate the following: the upper bar is the 95th percentile of the 
Table I.3-1

Definition of Core Damage Characterizations

ACCIDENT TYPE - A combination of accident sequences which generally display similar characteristics regarding effects of the accident on the plant. This combination has no specific technical use for either the sequence or containment response analyses. It serves as a convenient way to discuss similar accident scenarios.

PLANT DAMAGE

STATE

- A grouping of accident sequence cut sets* most useful for those analyzing containment response and subsequent risk analyses. This grouping combines "1ike" sequence cut sets which have similar properties (vessel pressure, power level, timing, and containment system status) such that essentially the same vessel and containment response is expected from any sequence cut set within the damage state.

Table I.3-2

Plant Damage States Representing $91 \%$ of the Total Core Damage Frequency

\begin{tabular}{cccc}
\hline $\begin{array}{c}\text { ACCIDENT } \\
\text { TYPE }\end{array}$ & $\begin{array}{c}\text { PLANT } \\
\text { DAMAGE } \\
\text { STATE }\end{array}$ & $\begin{array}{c}\text { FREQUENCY } \\
\text { (MEAN VALUE) }\end{array}$ & $\begin{array}{c}\text { \% OF TOTAL } \\
\text { CORE DAMAGE } \\
\text { FREQUENCY }\end{array}$ \\
\hline $\begin{array}{l}\text { Loss of a17 } \\
\text { AC power }\end{array}$ & TBUX & $4.2 \mathrm{E}-6$ & $51 \%$ \\
& TB & $2.3 \mathrm{E}-6$ & $28 \%$ \\
ATWS & TBUP & $2.0 \mathrm{E}-7$ & $2 \%$ \\
& TCUX & $4.8 \mathrm{E}-7$ & $6 \%$ \\
& TCSR & $3.1 \mathrm{E}-7$ & $4 \%$ \\
\hline
\end{tabular}

*A cut set is the minimal number of individual component, human and other, failures which will fail the systems required to mitigate an accident. 


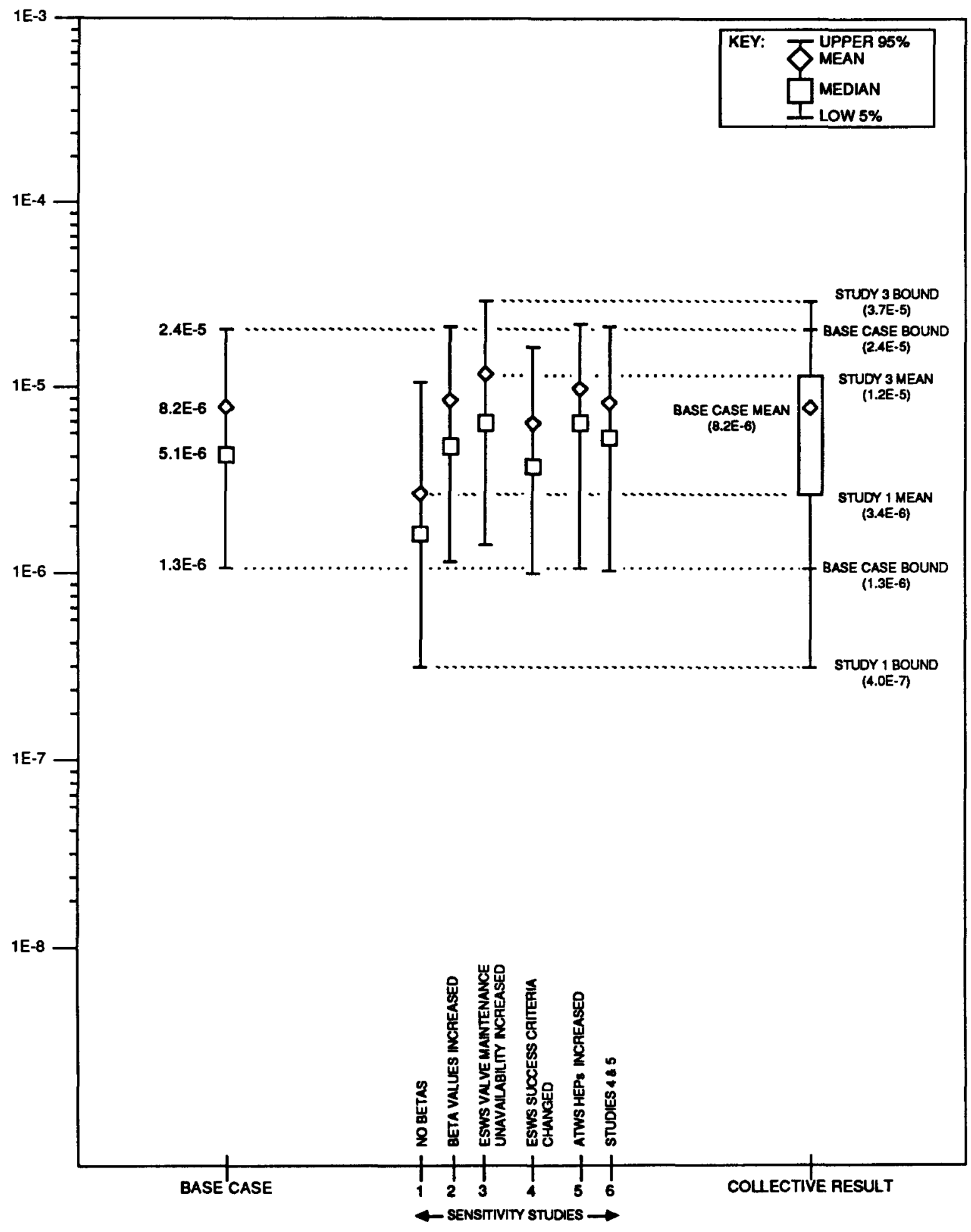

Figure I.3-1. Peach Bottom Total Core Damage Frequency. (including sensitivity study effects) 
probability distribution on the results of the sensitivity study whose mean value corresponds to the top of the box; the lower bar is the 5th percentile of the probability distribution on the result of the sensitivity study whose mean value corresponds to the bottom of the box.

\section{I.3.2 Characterization of PTant Damage State Frequencies}

The plant damage states representing $91 \%$ of the total core damage frequency at Peach Bottom are presented in Table I.3-2. The plant damage states are described briefly below.

\section{I.3.2.1 Plant Damage State TBUX}

This plant damage state is characterized by transients leading to station blackout (loss of all AC power to all four divisions) as a result of coincident DC power failures. The loss of DC power causes the failure of the diesels and subsequent failure of both the High Pressure Coolant Injection (HPCI) and Reactor Core Isolation Cooling (RCIC) systems. These failures result in the loss of all core and containment cooling. The recovery of $A C$ power is also severely hampered by the loss of DC power.

If $A C / D C$ power is not restored in thirty to forty minutes, Reactor Coolant System (RCS) inventory boils off and core damage results. The core degradation process may occur under high or low pressure conditions depending on the number of failed $D C$ batteries. This is because a sufficient loss of DC power would disable the Automatic Depressurization System (ADS) and the Safety Relief Valves (SRVs) and make depressurization of the reactor vessel unlikely. In this analysis, failure of a sufficient number of batteries is considered to occur based on the treatment of common mode failures.

The dominant contributors to this plant damage state are DC battery common mode failures (at least five batteries) and the subsequent loss of offsite power after a reactor trip because of some other initiator.

\section{I.3.2.2 Plant Damage State TB}

This plant damage state is characterized by transients leading to a long term station blackout (loss of all AC power to all four divisions). Failures of Diesel Generators B and C cause failure of the ESW system pumps, which causes loss of jacket cooling to Diesels $A$ and $D$ and subsequent loss of all AC power. The core is cooled by either the HPCI or RCIC system (both turbine-driven injection systems) until six hours into the sequence. By that time, the batteries have depleted and the ability to continue operation of the HPCI and RCIC systems is affected. If $A C$ power is not recovered within three hours after battery depletion, core damage results. While the RCS may be initially at relatively low pressures, depletion of the batteries causes loss of ADS/SRV control. The vessel will therefore repressurize and core damage will occur under high pressure conditions.

The dominant contributors to this plant damage state are recovery of $A C$ power as well as Diesel Generator $B$ and $C$ and ESW hardware failures and maintenance outages. 


\section{I.3.2.3 Plant Damage State TCUX}

This plant damage state is characterized by an ATWS with the Main Steam Isolation Valves (MSIVs) closed. The primary system is isolated under high power conditions causing a rapid increase in pressure and temperature within the RCS and the containment. The Standby Liquid Control (SLC) system is started within four minutes, but initial HPCI failure and operator failure to rapidly depressurize the vessel lead to core damage.

The dominant contributors to this plant damage state are mechanical failure of the control rods, operator failure to depressurize the vessel, and HPCI system failures.

\section{I.3.2.4 Plant Damage State TCSR}

This plant damage state is characterized by an ATWS with the MSIVs closed. The RCS is isolated under high power conditions which increase the pressure and the temperature in the primary system and containment. The SLC system either fails or is not initiated in time. The core is cooled by the HPCI system until high suppression pool temperature fails HPCI forcing the operator to use his low pressure cooling systems. The containment is not successfully vented which leads to containment failure by leakage, or no containment failure, or catastrophic containment failure. In all three cases, the low pressure systems are postulated to fail -- through loss of SRV control and subsequent repressurization of the RCS in the first two cases and through other failures of the low pressure coolant systems in the third case.

The dominant contributors to this plant damage state are mechanical failure of the control rods, failure to start SLC, and failure to vent.

\section{I.3.2.5 Plant Damage State TBUP}

This plant damage state is characterized by transients leading to a station blackout (loss of all AC power to all four divisions) as a result of a variety of AC/DC power failures. HPCI and RCIC fail in the short term. An SRV sticks open and reduces the RCS system pressure. If the power is not restored in thirty minutes, core damage will occur.

The dominant contributors to this plant damage state are (1) a stuck open SRV, (2) DC battery common mode failure, (3) loss of offsite power after a trip, and (4) failure to recover offsite power.

\section{I.4 CONCLUSIONS}

In the ten years between the WASH-1400 analysis of Peach Bottom and the present study, both the Peach Bottom plant configuration and our understanding of reactor operation and safety have changed. WASH-1400 calculated a total core damage frequency of approximately $2.5 \mathrm{E}-5$, which is a sum of individual sequence median values. The present study calculated a median core damage frequency at Peach Bottom of 5.1E-6 and a mean value of $8.2 \mathrm{E}-6$. The modifications in plant configuration and procedures at Peach Bottom, as well as the evolution of analysis insights since WASH-1400, have reduced the results of WASH-1400 considerably. The two dominant scenarios from the WASH-1400 study (transient with loss of long-term decay heat removal [TW] and ATWS [TC]) have been decreased by approximately a 
factor of 1000 and at least 10, respectively. However, more complete consideration of failures of DC-powered systems during station blackout and a more comprehensive treatment of common mode failures and support system failures (e.g., power, cooling, etc) combine to increase the core damage frequency to a mean value of $8.2 \mathrm{E}-6$. Some of the significant comparisons leading to these insights are presented below:

- Transients with loss of long term decay heat removal are dominant in WASH- 1400 but not in this study because we consider the containment venting procedures now in place at Peach Bottom and the possibility of survival of core cooling systems after containment failure.

- ATWS sequence frequencies are about an order of magnitude lower in this study than in WASH-1400 because of the new procedures and plant modifications that have been implemented at Peach Bottom and the more detailed analysis performed here.

- Loss of all AC type sequences is estimated to be almost two orders of magnitude higher than in WASH-1400 because of a more complete consideration of potential failures of DC-powered systems, a more complete common mode failure analysis, and a more complete analys is of support system effects on the $A C$ power system (e.g., diesel cooling). Also, WASH-1400 did not properly consider the long term station blackout accident.

- Al1 other transient and loss-of-coolant (LOCA) sequences are similarly on the order of 1E-7 or less in both studies.

0 Based on the above, both studies conclude that transients, and not LOCAs, dominate the core damage frequency (and risk) at Peach Bottom. However, the types of transients are significantly different. WASH-1400 is dominated by ATWS and long term heat removal failure sequences while this study is dominated by loss of al1 AC power scenarios (ATWS contributes approximately $12 \%$ to the core damage frequency).

\section{I.4.1 Accident Type Conclusions}

The core damage profile is made up of primarily two general types of accidents as indicated below:

$\begin{array}{lc}\text { ACCIDENT TYPE } & \text { CONTRIBUTION TO } \\ \text { MEAN FREQUENCY CORE DAMAGE FREQUENCY }\end{array}$

Station Blackout

$\begin{array}{lrr}\text { (loss of all AC power) } & 7.0 \mathrm{E}-6 & 86 \% \\ \text { ATWS } & 1.0 \mathrm{E}-6 & 12 \% \\ \text { A11 0thers } & 1.8 \mathrm{E}-7 & 2 \%\end{array}$


Because the results are dominated by one particular type of accident, we would expect that elimination or reduction of that accident type would have a large effect on the total core damage frequency. Unfortunately, this conclusion may be a bit premature. The core damage frequency found in this study is low by PRA standards and is partially dominated by common cause events. If the calculated frequency is further reduced, issues normally neglected may become important. Furthermore, there is much uncertainty in common cause analyses. It is therefore difficult to make concrete conclusions about accident types with frequencies that are as low as those presented in this study and that are dominated by common cause events.

\subsubsection{Uncertainty Considerations}

The above conclusions are incomplete without considering the results of the uncertainty and sensitivity calculations. The total base case mean core damage frequency (8.2E-6) has a 95\% upper bound value of $2.4 \mathrm{E}-5$ and a $5 \% 10$ wer bound of $1.3 E-6$ because of statistical uncertainty in the failure data.

Since the results show a significant contribution from $A C$ and $D C$ power system common cause failures, it is not surprising that changes to the common cause values used to assess common mode failures contribute most to the range of values from the sensitivity studies (about a factor of three). Other sensitivities generally have a smaller effect (typically a factor of two or less). Some of the less dominant types of accidents are affected considerably by particular sensitivities (factor of ten) but, because of their low overall contribution, still have no major impact on the general conclusions of the study. 
An objective of this study was to perform a Probabilistic Risk Assessment (PRA) as near to the state-of-the-art as possible within the time and resource constraints. Whereas a typical Level 1 PRA can take over a year, we were asked to produce one in less than six months. We did have the advantage of starting with a plant that had been studied previously. To give the reader an idea for the scope of our work, we have gone through a typical 1ist of PRA tasks and explained what was done in our analysis. To simplify things, we have compared our level of detail to a "state-of-the-art" PRA. We have also graded our level of detail for each task as (1) improved state-of-the-art, (2) state-of-the-art, (3) slightly abbreviated, (4) abbreviated, and (5) nonexistent.

- Initial information Collection -- We collected information from past Peach Bottom studies and the Final Safety Analysis Report (FSAR) and put together an initial set of event trees, fault trees, and questions for plant personnel. The pre-visit information gathering took a month. We spent a week at the plant gathering information first hand and maintained regular contact with the plant throughout the course of the study. (Slightly abbreviated)

o Initiating Event Identification -- We used initiating event information from plant-specific records and past studies and conducted a thorough search for support system initiators. (State-of-the-art)

- Event Tree Development (Non-ATWS, Anticipated Transient Without Scram) - Because the plant has been studied thoroughly, we did not develop functional event trees. Past studies and current NUREG-1150 containment analyses were used to identify the non-ATWS event tree headings necessary to model all reactor functions. No significant shortcuts were used to develop the non-ATWS system event trees. (State-of-the-art)

- Event Tree Development (ATWS) -- Detailed examinations of the plant, procedures, and updated thermal-hydraulic calculations were performed to identify the ATWS event tree headings and to develop the ATWS sequences. (Improved state-of-the-art)

- System Modeling -- The level of modeling detail was at the discretion of the analyst. If a system was considered relatively unimportant, or if a detailed model would have taken an unreasonable amount of time, simplifications were made. If the system was considered important, a detailed modeling effort was undertaken. The models are therefore a combination of detailed fault trees, simplified Boolean expressions, and black box models. (Ranges from abbreviated to state-of-the-art depending on what system is modeled)

- Analysis of Dependent Failures -- A significant effort was made to identify, model, and quantify dependent failures. Intersystem dependencies were identified and modeled in the system analysis. Subtle interactions found in past PRAs were reviewed for their applicabilities to Peach Bottom. A review of licensee event reports (LERs) and other plant specific reports for Peach Bottom 
was made to identify any unexpected interactions or common cause failures. Beta factors for common cause failures were systematically applied to sequence cut sets involving failures of redundant equipment. (Slightly abbreviated)

- Human Reliability Analysis (HRA) -- Except for the ATWS scenarios, a screening procedure was developed to calculate human error probabilities. Although an HRA specialist was present during the plant visit, he was not able to spend as much time interviewing operators as he would have liked. The screening procedure was somewhat conservative and values that yielded high results were flagged and reconsidered. Only errors of omission were considered in this analysis. The ATWS HRA was, on the other hand, extremely detailed with three specialists spending full time on nothing but ATWS operator responses. (Abbreviated and State-of-the-art)

Data Base Development - - A data specialist was present during the plant visit. A week cannot be considered adequate for a thorough job; however, we did produce reasonable plant-specific data. Where plant-specific data were lacking, generic data were used. (S1ightly Abbreviated)

Accident Sequence Quantification -- No significant shortcuts were taken in this area. Our task was made easier by the fact that some of our system models were relatively simple. (State-of-the-art)

Physical Process of Reactor Meltdown Accidents -- For the most part, we relied on past thermal-hydraulic calculations and calculations performed for us by the NUREG-1150 containment analysts. New ATWS related calculations were run, however, by the team analysts. (Slightly abbreviated)

- Radionuclide Release and Transport -- This was handled by the NUREG-1150 consequence analysts.

- Environmental Transport and Consequence Analysis -- This was handled by the NUREG-1150 consequence analysts.

Seismic Risk Analysis -- This is outside the present scope. (Nonexistent)

Fire Risk Analysis -- This is outside the present scope. (Nonexistent)

- Flood Risk Analysis -- This is outside the present scope. (Nonexistent)

- Other External Hazards (e.g...Tornadoes) -- This is outside the present scope. (Nonexistent)

- Treatment of Uncertainties - - We treated statistical uncertainty in the failure data, uncertainty associated with the application of the failure data, and uncertainty caused by modeling assumptions and success criteria. (State-of-the-art) 
In addition to the comparison of our analysis with a state-of-the-art PRA, we felt it would be helpful to identify factors that PRAs don't normally treat. The following list of items not usually included in PRAs is reprinted from NUREG-1115 [1]:

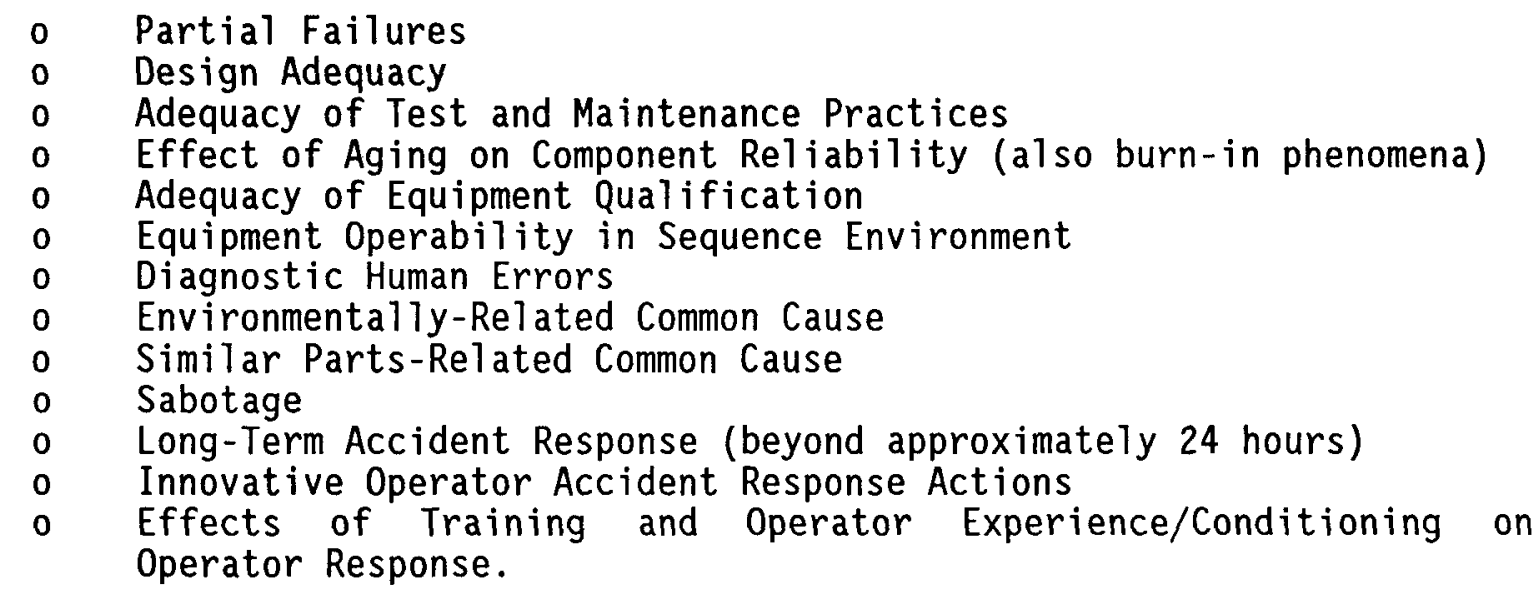

The makeup of the Peach Bottom PRA team is provided here for the reader's information.

$\begin{array}{ll}\text { Team Leader } & \text { - Alan Kolaczkowski (SAIC) } \\ \text { System Analysts } & - \text { Nathan Cathey (EG\&G) } \\ & - \text { Walter Ferrell (SAIC) } \\ & - \text { John Lambright (SNLA) } \\ & - \text { Bijan Najafi (SAIC) } \\ \text { Human Factor Support } & - \text { Alan Swain (SNLA) } \\ \text { Data Support } & - \text { Joseph Fragola (SAIC) } \\ \text { ATWS Human Reliability Analysts } & - \text { Willian Luckas, Jr. (BNL) } \\ & - \text { John O'Brien (BNL) } \\ & - \text { Richard Perline (BNL) } \\ & - \text { Claire Spettell (BNL) }\end{array}$


0

-

- 
III.

To assure quality, we chartered several groups with the responsibility of reviewing our work and providing timely feedback. Because the time available to complete our analysis was short, these reviews had to be intense, and Probabilistic Risk Assessment (PRA) team response time had to be almost instantaneous. The different review groups are described in this section.

\section{III.1 SENIOR CONSULTANT GROUP}

The purpose of the Senior Consultant Group (SCG) was to provide a broad scope review of the methods and results of the reference plant PRAs. This high-level review was to further assure the validity and applicability of the products. The SCG was not expected to provide detailed quality control or assurance of the products.

The members of the SCG are listed below:

Dennis C. Bley, PL\&G,

Michael P. Bohn, SNLA, Gregory J. Kolb, SNLA, Joseph A. Murphy, NRC, William E. Vesely, SAIC (formerly of $B C L$ ).

\section{III.2 QUALITY CONTROL GROUP}

The goals of the Quality Control Group (QCG) are the following:

- to provide guidance regarding the methodologies to be utilized in the PRAs,

0 to assure the consistent application of the methodologies by all PRA teams, and

0 to assure the technical adequacy of the work.

These goals were met via periodic review meetings with the PRA teams. At these meetings, the QCG discussed the methodologies and reviewed, in detail, all technical work performed.

The QCG is composed of the individuals listed below; also shown is each individual's technical specialty:

- Gregory J. Kolb, SNLA (QCG team leader, systems analysis),

0 Gareth W. Parry, NUS (uncertainty analysis, systems analysis, and containment and consequence analysis interface),

- Barbara J. Bell, BCL (human reliability analysis),

- Arthur C. Payne, Jr., SNLA (systems analysis, reliability data),

0 Eddie A. Krantz, INEL (systems anatysis). 


\section{III.3 UTILITY INTERFACE}

A constant interface was maintained with the utility throughout the duration of the analysis. The Peach Bottom PRA team leader was in constant contact with Peach Bottom engineering and plant personnel to ask questions and verify information. The Peach Bottom contacts also reviewed the results presented in the first draft of the study but did not necessarily approve them. 
IV. TASK DESCRIPTIONS

This section contains information on the major tasks performed for this study. Section IV.1 provides a brief overview of the tasks. The remaining subsections within Section IV address each individual task as it applies to the Peach Bottom analysis. Sections $V$ and VI provide the information covered by the last task entitled "Interpretation of Results."

\section{IV.1 TASK FLOW CHART}

The major tasks performed for this study are indicative of the general tasks performed in any Leve1 1 PRA. Figure IV.1-1 displays the major tasks carried out in this analysis and shows the primary information flow paths between each task. Volume 1 of this document provides more detailed descriptions of the methodology used in carrying out each task [2]. The reader is referred to that volume and the subsections which follow in order to obtain a comprehensive description of how the Peach Bottom analysis was conducted.

\section{IV.2 PLANT FAMILIARIZATION}

This task included two major subtasks: (1) an initial plant visit and (2) a final plant visit including continued communication/contact with the plant and the engineering staff. Prior to the initial plant visit, the Peach Bottom team reviewed the original Accident Sequence Evaluation Program (ASEP) analyses applicable to Peach Bottom [3], the fault tree and event tree sections of WASH-1400 [4], and Probabilistic Risk Assessment type studies related to Peach Bottom. Preliminary event trees, system fault trees, and simplified system schematics were constructed; preliminary success criteria and dependency matrices were developed to identify specific areas where information was needed for accurate models. Based on these initial activities, a package was prepared that identified the required plant specific information and data and gave a sampling of generic and specific questions the team would ask concerning system design and plant operation. This package was sent to PECO so that their staff might better understand the team's needs. The following sections provide brief descriptions of each plant visit and the information obtained.

\section{IV.2.1 Initial Plant Visit}

The purposes of the initial plant visit were to (1) gain specific knowledge of those Peach Bottom aspects which had been identified as important to safety/risk and (2) collect the necessary data. The visit occurred July 22-25, 1985. Two days were spent at PECO's main headquarters in Philadelphia, a third day at the Peach Bottom plant, and a fourth day at the Limerick simulator (Peach Bottom's operators are trained at this simulator). The Peach Bottom analysis team consisted of the overall program leader, the team leader, two system analysts, a data analyst, a containment analyst, and four human reliability analysts (three of whom were Anticipated Transient Without Scram, ATWS, specialists). The team visited with PECO mechanical engineering staff members and various personnel in operations, training, and maintenance. 


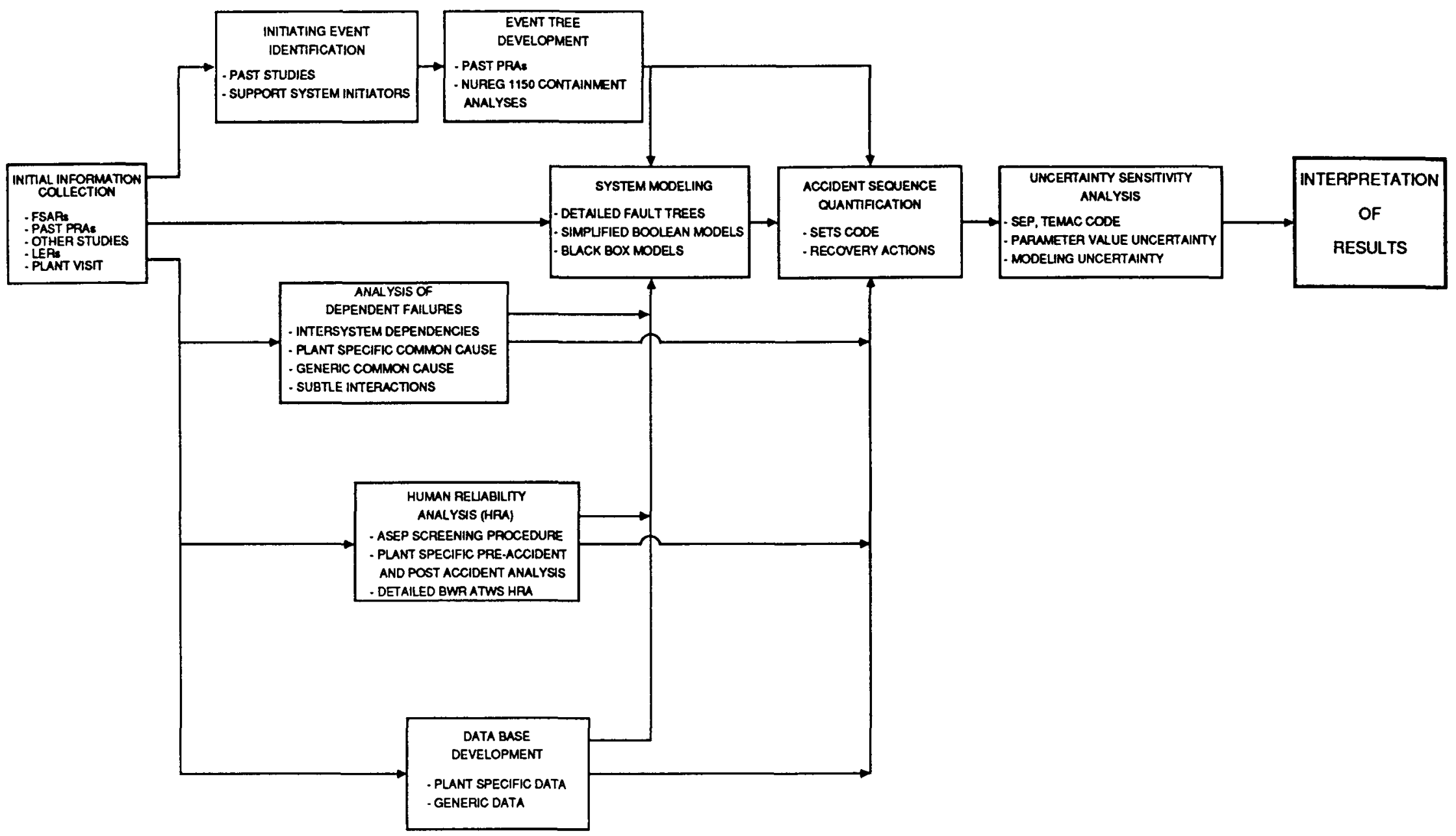

Figure IV.1-1. Task Flow Chart. 
The preparatory package for the initial plant visit consisted generally of the following items:

0 Request for Piping and Instrumentation Diagrams and Functional Control Diagrams (all front line systems and their support systems),

- Request for Elementary Wiring Diagrams (one lines),

- Request for Layout Drawings (the reactor and control buildings),

- Request for Emergency Operating and Test/Maintenance Procedures,

- Request for Data Information (maintenance logs, LERs, etc.),

- Request for Post-Three Mile Island (TMI) and PRA modifications, and

- Lists of Questions (related to system design and plant operation).

The initial plant visit included the following events:

- Discussions with PECO engineering staff concerning

-normal and emergency configurations and operation of the various systems of interest,

- system interdependencies, and

-design changes implemented at the plant;

- Discussions with PECO engineering and operational staff concerning -automatic and manual actions taken in response to various emergency conditions, -operational problem areas identified by plant personnel which might impact the analysis, and -detailed discussions regarding ATWS procedures;

$0 \quad$ Discussions with PECO engineering and maintenance staff concerning -data: maintenance logs, LERS, etc., and

-implementation regarding test/maintenance procedures;

- Discussions with PECO training staff concerning -training practices regarding various emergency conditions, and - detailed discussions regarding ATWS training.

The information obtained consisted of the following data:

0 Information requested in the pre-visit package,

o Peach Bottom "hi-spot" reports which summarize plant performance and provide information on every plant shutdown, and

- Updated Final Safety Analysis Report on Peach Bottom. 


\section{IV.2.2 Final Plant Visit}

The purpose of the final plant visit was to present the preliminary results of the analysis and to confirm our knowledge regarding Peach Bottom. The plant visit occurred December $3 \& 4,1985$. One day was spent at PECO's main headquarters and one day at the Peach Bottom plant. The Peach Bottom analysis team consisted of the overall program leader, the team leader, and three system analysts. The team visited with members of the PECO mechanical engineering staff and with various personnet in operations.

The final plant visit included the following activities:

- A presentation of overall preliminary results,

- Discussions with engineering staff on major contributors and assumptions, and

- Discussions with operational staff on 'gray' areas concerning operator actions.

Additional information was supplied to the analysis team by PECO in response to issues raised during the final plant visit. 
Following the initial plant familiarization stage of the analysis, the initiating events were identified. Initiating events are those disruptions to the normal operation of the plant which cause a rapid shutdown of the plant, or a need to trip the plant, so as to challenge the safety systems in order to remove heat still being generated by the reactor core. The initiators included in this study are summarized in Table IV.3-1 along with their frequencies.

The scope of this work encompasses only the so-called internal initiators, i.e., those which directly affect the systems within the plant. External events such as fires, seismic events, and flooding are outside the scope of the effort presented here.

In the following subsection, the selection of the initiators examined in this study is described. Discussions are included regarding information sources used, the initiating event selection process, the resulting list of initiators, and the underlying assumptions. The nomenclature used to identify each initiator is provided in Section IV.3.3. The final list of initiators forms the basis for the event tree task which defines the possible accident sequences that could occur for each initiator. It is these accident sequences that identify the possible scenarios leading to core damage (from internal initiators) for Peach Bottom Unit 2.

\section{IV.3.1 Identification of Initiators}

Since a number of Probabilistic Risk Assessments (PRAs) on Boiling Water Reactor (BWR) plants have already been performed, this study made use of the combined list of initiators in those studies to derive its initiating event 1 ist. It should be noted that manual orderly shutdowns for refueling or administrative reasons were not considered. Table IV.3-2 summarizes the primary information sources used to identify the initiators examined in this study. The original WASH-1400 study, the Grand Gulf RSSMAP study, the IREP Browns Ferry study, and the Limerick and Shoreham PRAs were al1 reviewed for the lists of initiators in those studies based on actual events as reported in EPRI NP801 [13] and NP2230 [14]. In addition, success criteria implications from GE-NEDO $24708 \mathrm{~A}$ and the initiators formerly covered by the Accident Sequence Evaluation Program (ASEP) were also used to assist in the identification of initiators for this analysis. This information was supplemented with actual plant trip data for both Peach Bottom units covering March 1976 to June 1985 as reported in PECO's monthly "hi-spot" reports. These actual plant shutdowns were reviewed to ensure that all initiating events that had occurred while at power at Peach Bottom were represented by the initiating event list. Finally, a review of the Peach Bottom design for special initiators was also undertaken. Plant design information from the Peach Bottom Updated Final Safety Analysis Report (UFSAR), coupled with information gained during the initial plant visit and subsequent telephone discussions, was used for the examination of special initiators. Special initiators are those events not typically included in general lists of initiating events. Special events are specific initiators, unique to the plant being analyzed, which cause a plant trip and the need for decay heat removal. Examples would be loss of a particular DC bus or loss of service water.

PRAs typically divide initiating events into two major classes of events: 1oss of coolant accidents (LOCAs) and transients. While LOCAs of appreciable size have not occurred, as evidenced by operating experience, LOCAs are still examined as 
Table IV.3-1

Peach Bottom Initiating Events and Frequencies

\begin{tabular}{|c|c|c|}
\hline $\begin{array}{l}\text { INITIATOR } \\
\text { NOMENCLATURE }\end{array}$ & DESCRIPTION & $\begin{array}{c}\text { MEAN } \\
\text { FREQUENCY } \\
\text { (per year) }\end{array}$ \\
\hline $\mathrm{T} 1$ & Loss of offsite power (LOSP) transient & 0.07 \\
\hline T2 & $\begin{array}{l}\text { Transient with the Power Conversion System (PCS) } \\
\text { unavailable }\end{array}$ & 1.5 \\
\hline \multirow[t]{3}{*}{ T3 } & $\begin{array}{l}\text { Transient with the PCS initially available } \\
\text { made up of: } \\
\text { T3A Transients of the T3 group other than } \\
\text { those below }\end{array}$ & 2.6 \\
\hline & $\begin{array}{l}\text { T3B Transients due to an Inadvertent Open } \\
\text { Relief Valve (IORV) in the primary } \\
\text { system }\end{array}$ & \\
\hline & $\begin{array}{l}\text { T3C Transient involving loss of feedwater } \\
\text { (LOFW) but with the steam side of the } \\
\text { PCS initially available }\end{array}$ & \\
\hline $\mathrm{TAC} / \mathrm{X}$ & Transient caused by loss of safety AC Bus " $x$ " & $9.0 \mathrm{E}-4$ \\
\hline$T D C / x$ & Transient caused by loss of safety DC Bus " $x$ " & $9.0 \mathrm{E}-4$ \\
\hline$A$ & Large LOCA & $2.7 E-4$ \\
\hline S1 & Intermediate LOCA & $8.0 \mathrm{E}-4$ \\
\hline S2 & Sma11 LOCA & $2.7 \mathrm{E}-3$ \\
\hline S3 & Sma11-smal1 LOCA & $2.7 \mathrm{E}-2$ \\
\hline "V" & $\begin{array}{l}\text { Interfacing system LOCA } \\
\text { (failure of a high/low pressure interface in the } \\
\text { primary system) }\end{array}$ & $\begin{array}{l}<1 \mathrm{E}-8 \\
\text { (see Section } \\
\text { IV.4.14) }\end{array}$ \\
\hline
\end{tabular}


Table IV.3-2

Primary Information Sources Used to Identify Initiators

- ASEP prior work [3]

o WASH-1400 [4]

- Grand GuTf RSSMAP [5]

- IREP Browns Ferry [6]

- Limerick PRA [7]

- Shoreham PRA [8]

- GE-NEDO 24708A [9]

o PECO monthly "hi-spot" reports [10]

- Peach Bottom UFSAR [11]

- Minarick [12] 
possible initiators since they would cause a plant trip, require the need for emergency cooling if the PCS were lost, and represent a possible threat to both the core and containment. During review of the above mentioned information sources, it was found that the Shoreham and Limerick plant analyses and General Electric's study of typical BWR 4 designs in NEDO 24708A supported the use of three LOCA sizes. These sizes are based on different mitigation success criteria as was done in the original WASH-1400 study of Peach Bottom.

The large LOCA, labeled $A$, is a steam or a liquid break in which the reactor vessel will rapidly depressurize. Low pressure system injection will be automatic, restoring water level in the reactor vessel. High pressure system injection flow rates are either inadequate to restore level (10w pressure systems have much higher flow rates) or the high pressure turbine-driven systems cannot be run efficiently because of low steam pressure. Break sizes of approximately 0.1 square feet or larger are typical of this size LOCA.

The intermediate LOCA, labeled $S 1$, is a steam or liquid break in which high pressure injection with the High Pressure Coolant Injection (HPCI) system is possible for a limited time period. This turbine-driven system can supply sufficient flow to the reactor until vessel pressure can no longer be maintained for successful HPCI operation. Low pressure injection must then be used to maintain water inventory in the core. Should HPCI fail initially, depressurization of the reactor vessel is required to allow for timely low pressure injection. Break sizes of approximately 0.004 to 0.1 square feet are typical of this size LOCA, depending on whether a steam or liquid break exists.

The small LOCA, labeled $\mathrm{S2}$, is small enough to allow for long-term successful mitigation by either HPCI or the Reactor Core Isolation Cooling (RCIC) system (a smaller capacity, turbine-driven system). Should both systems fail, depressurization is required for successful low pressure injection. This size LOCA can be approximated by a stuck-open Safety Relief Valve (SRV) for Peach Bottom. The break is typically less than approximately 0.004 or 0.01 square feet, depending on whether a steam or liquid break exists.

In addition, a fourth LOCA category was defined to include the special recirculation pump seal leak. Such leaks have occurred in power plants, primarily because of the wearing-out of the pump seals during normal operation. Such leaks are well-instrumented and can be easily isolated. Leaks up to a maximum of -50-100 gpm could occur on a per pump basis although less than $5 \mathrm{gpm}$ is more typical. Because the relative frequency of these leaks is considerably larger than for other LOCAs, and since these occurrences are easily detected and isolated, this type of LOCA was categorized as a separate small-small LOCA category, labeled S3.

A brief examination of possible LOCAs within mitigating systems was also performed. One LOCA source, in particular, received more attention than others since it could cause a plant trip and affect multiple safety systems. This was a LOCA in the Normal Service Water (NSW) piping where the piping interfaces with the Emergency Service Water (ESW) system piping to feed a number of emergency core cooling loads and the diesels (see the ESW system write-up in Section IV.5). A pipe break in this location could disturb normal service water flow so as to cause a plant trip along with possible loss of the NSW system. Subsequent ESW initiation would feed the break instead of cooling certain safety system loads. 
However, since (a) operation of HPCI, RCIC, Control Rod Drive (CRD), and High Pressure Service Water (HPSW) would be virtually unaffected; (b) such a break could potentially be isolated; and (c) the probability of a LOCA having to occur in a specific location in a low pressure system is considered relatively low $(<I E-4)$, we concluded that this initiator was not as important as other initiators of interest. Even with a coincident loss of offsite power, core damage would require the failure of HPCI and $R C I C$ and the failure to recover $A C$ power to systems such as the CRD system. Using arguments such as this, it was decided that LOCAs in the mitigating systems were probabilistically unimportant and, therefore, they were not included in this study. This finding is consistent with the scope of LOCAs analyzed in other PRAs.

Possible interfacing system LOCAs were also examined for inclusion in this study. Interfacing system LOCAs, or the so-called " $V$ " sequence, are a breach of a high pressure to low pressure interface point which communicates with the primary system. Such a breach could cause significant low pressure system leaks or even a pipe rupture and cause a loss of inventory from the primary system while at the same time failing a low pressure mitigating system. Possible bypass of the containment through the ruptured interface also represents a fission product escape path which could result in serious consequences. Based on actual experience as reported in Reference 12, focus for identifying sources for a possible "V" sequence included review of the high to low pressure interface in the Low Pressure Core Spray (LPCS) and Residual Heat Removal (RHR) systems. Precursors to the "V" sequence have occurred in BWRs during testing of both high and low pressure system valves which provide isolation from the primary system. Focus on the above low pressure systems is a result of the lower pressure design conditions of these systems which increases the chance of a significant loss of primary system inventory through a pipe break, relief valve, or pump seal rupture. Such a sequence has been examined as part of this study.

Transient initiators were selected primarily on the basis of the considerable prior work in BWR PRAs. In this earlier work, actual events have been grouped into major transient categories depending on the plant response to each transient. Where "like" responses are expected (i.e., the same systems are effectively failed or otherwise degraded resulting in similar overall plant effects), transients are grouped into major categories with each category identified as a transient initiator for analysis purposes. This categorization process significantly decreases the amount of analys is effort without affecting the results. Using the original WASH-1400 categories (T1, T2, T3) as a guide, the previously mentioned PRAS and the interim ASEP work were reviewed to determine whether expansion of these categories was necessary. In addition, actual operating history for Peach Bottom was reviewed as reported in PECO's monthly "hi-spot" reports which summarize, among other things, the causes for plant shutdowns. This information was coalesced into the list of transient initiators.

In general, it was found that transient events could remain grouped into the three main WASH-1400 transient categories. T1 events are those which involve a loss of offsite power to the plant. T2 events are those involving loss of the PCS and include, for example, Main Steam Isolation Valve (MSIV) closure events and loss of condenser vacuum. T3 events are those in which the PCS initially remains operational and allows for core heat to be removed as steam to the main condenser shortly after plant shutdown. Such events include turbine trips and IORV events. The T3 events were further subcategorized into three groups: IORV events, loss of feedwater events, and all other events of the T3 type. This is because the IORV event additionally represents a breach of the primary system and, hence, requires 
unique consideration. Loss of feedwater events must include the unique consideration that the steam side of the PCS and condensate may be initially operable following the transient.

Besides these transient initiator categories, two special initiators were identified and called TAC and TDC initiators. During the review of the Peach Bottom electrical design, it was noted that safety and non-safety loads are eventually shared off buses that ultimately derive their power from the 4160 VAC and 125/250 VDC safety buses. Loss of these buses could possibly cause a trip of the plant and simultaneous degradation of safety systems depending on the specific loads off each bus. While specific pathways to a plant trip were not explicitly identified for either the loss of a 4160 VAC or a 125/250 VDC safety bus, it was noted that an actual occurrence of the de-energization of a 4160 VAC safety bus on January 27, 1983 did indeed require a rapid shutdown of one of the units based on subsequent condenser water level anomalies. This fact and the sharing of safety and non-safety loads at Peach Bottom were used as sufficient argument to conservatively treat the loss of any of the above buses as a possible special initiator.

A search for other special initiators was also performed and included three major categories: loss of any service water system, loss of instrument air, and loss of heating and ventilation equipment. The NSW system, Turbine Building Cooling Water (TBCW) system, Reactor Building Cooling Water (RBCW) system, ESW system, and HPSW system were reviewed as possible sources for special initiators. Possible pipe breaks, the potential for causing a plant trip, and effects on safety systems such as loss of cooling or flooding were considered during the review. While detailed analyses were not possible because of severe time constraints for the study, no special initiators worthy of examination involving these systems were identified. This is based in part on the generally sharp separation between safety and non-safety cooling water systems (ESW, HPSW, and RBCW are standby safety systems; NSW and TBCW are normally running non-safety systems) and, therefore, the difficulty of achieving both a plant trip and degrading safety systems at the same time (see earlier discussion on a LOCA for the NSW system). Possibilities of flooding seem small based on the low pressure operation of these systems and their locations with respect to most other safety systems.

Loss of instrument air/nitrogen can cause a plant trip through the dependency of the PCS on air supplies. Air or nitrogen is also supplied to the following accident mitigating systems: (1) the Automatic Depressurization System (ADS) valves, (2) the Emergency Ventilation System (EVS) dampers which provide room cooling for the diesels, switchgear, and DC systems, (3) the CRD full flow path, (4) some containment vent valves used for containment venting, and (5) the MSIVs. However, the MSIVs and ADS valves can remain open for significant periods of time since they are backed by accumulators and other air/nitrogen supplies (these have been tested to show they reliably hold air to the valves for rone hour). The critical EVS dampers each have a dedicated air bottle. The CRD system can achieve near full flow conditions without air through an alternate passive path. Containment vent valves each have a separate air bottle which can be used to operate the valve locally. These points along with the expected low probability of loss of air/nitrogen as an initiator (from pipe break or the required failure of multiple compressors) were used to delete loss of air/nitrogen as a special initiator on probabilistic grounds. This finding is further supported by the conclusions in a report on the effects of a loss of instrument air [15] and based on a discussion with one of the principal authors of that report. 
Finally, heating and ventilation systems were reviewed but discarded as possible special initiators. This is again based on the degree of separation in the design of these systems at Peach Bottom, the low heat loads in critical equipment areas such as the AC bus rooms, and the generally slow effects of loss of heating and ventilation equipment which allow time for corrective action before a plant trip would occur.

Based on the above described process, the resulting 1 ist of initiators identified in Table IV.3-3 represents the output of this task. These initiators form the categories of events which were examined to determine the possible accident sequences. Frequencies are also provided in the table for easy reference (see Section IV.8). Note that each initiator affects the plant differently or requires some change in the plant success criteria as evidenced by Table IV.3-4. A more detailed review of the success criteria associated with each initiator is in Section IV.4.

\section{IV.3.2 Initiating Event Assumptions}

The following represent the primary assumptions used in the identification and categorization of initiating events for this analysis:

- All initiators are assumed to originate while the plant is at high power operation.

- Manual shutdown in an orderly manner is not included.

- The initiator list is reasonably complete. Disregarding external events, the wide range of sources used and the inclusion of actual operation history allows for a "reasonably complete" argument to be used. Any additional initiators would add further possibilities for core damage but should be of very low probability.

- Losses of Divisions A, B, C, or D of the 4160 VAC or $125 / 250$ VDC safety buses are conservatively assumed to lead to a loss of the PCS (including condensate) and are included as TAC/ $x$ and $T D C / x$ initiators where " $x$ " represents the divisional bus which is failed. Since explicit pathways for failing the PCS were not found for these bus losses (see Section IV.3.1), this analysis has taken a conservative stance by including these as possible initiators.

0 The non-rigorous search for special initiators (caused by resource constraints) adequately ruled out the need to include such initiators except for $\mathrm{TAC} / \mathrm{x}$ and $\mathrm{TDC} / \mathrm{x}$.

\section{IV.3.3 Initiating Event Nomenclature}

This subsection addresses the nomenclature used to identify each type of initiator. Table IV.3-1 presented the initiators actually examined in the analysis. Other initiators were reviewed but deleted from the analysis effort as explained earlier. The nomenclature in the table defines the short-hand identification of each initiator that is used in the remainder of the report. 
Table IV. 3-3

Initiating Event Information Summary

\begin{tabular}{|c|c|c|c|c|c|}
\hline IMITIATOR & $\begin{array}{l}\text { MEAN } \\
\text { FREQUENCY }\end{array}$ & & COMHENTS & & $\begin{array}{l}\text { SOURCE OF } \\
\text { INFORMATION }\end{array}$ \\
\hline $\mathrm{T} 1$ & 0.07 & o & Major transient groups considered in original WASH-1400 PRA & 0 & WASH -1400 \\
\hline $\mathrm{T} 2$ & 1.5 & 0 & Typical in BWR PRAs and in ASEP & 0 & ASEP Interim Reports \\
\hline \multirow[t]{8}{*}{ T3 } & 2.6 & o & Limerick PRA used: & 0 & Limerick PRA Section 3.2 \\
\hline & & & MSIV closure (1ike T2) & & \\
\hline & & & Turbine trip (1ike T3) & & \\
\hline & & & $\operatorname{LOSP}(T 1)$ & & \\
\hline & & & LOFW (1ike T2 or T3) & & \\
\hline & & & Manual shutdown (like T3) & & \\
\hline & & & IORV (Iike T3) & & \\
\hline & & 0 & Shoreham PRA used above, and Loss of Condenser (1ike T2) & o & Shoreham PRA Section 3.2 \\
\hline $\mathrm{TAC} / \mathrm{A}$ & $9.0 E-4$ & 0 & Safety 480 VAC buses (fed by $4160 \mathrm{~V}$ buses) share safety and & 0 & Peach Bottom UFSAR Rev. 3 , \\
\hline $\mathrm{TAC} / \mathrm{B}$ & $9.0 E-4$ & & PCS-related loads (Peach Bottom UFSAR) & & Section 8 \\
\hline $\mathrm{TAC} / \mathrm{C}$ & $9.0 E-4$ & o & Actual de-energization of 4160 VAC emergency bus caused need & ○ & PECO "Hi-Spot" Reports \\
\hline \multirow[t]{3}{*}{$T A C / D$} & $9.0 \mathrm{E}-4$ & & for scram $(1-27-83)$ & & \\
\hline & & $\circ$ & Examined in ASEP, Shoreham PRA as an initiator & 0 & Shoreham PRA Section A.1.3.6.6 \\
\hline & & ○ & $\begin{array}{l}\text { Loss of any } 4160 \text { VAC safety bus treated as a possible } \\
\text { initiator for Peach Bottom }\end{array}$ & o & ASEP Interim Reports \\
\hline
\end{tabular}


Table IV.3-3

Initiating Event Information Summary (Concluded)

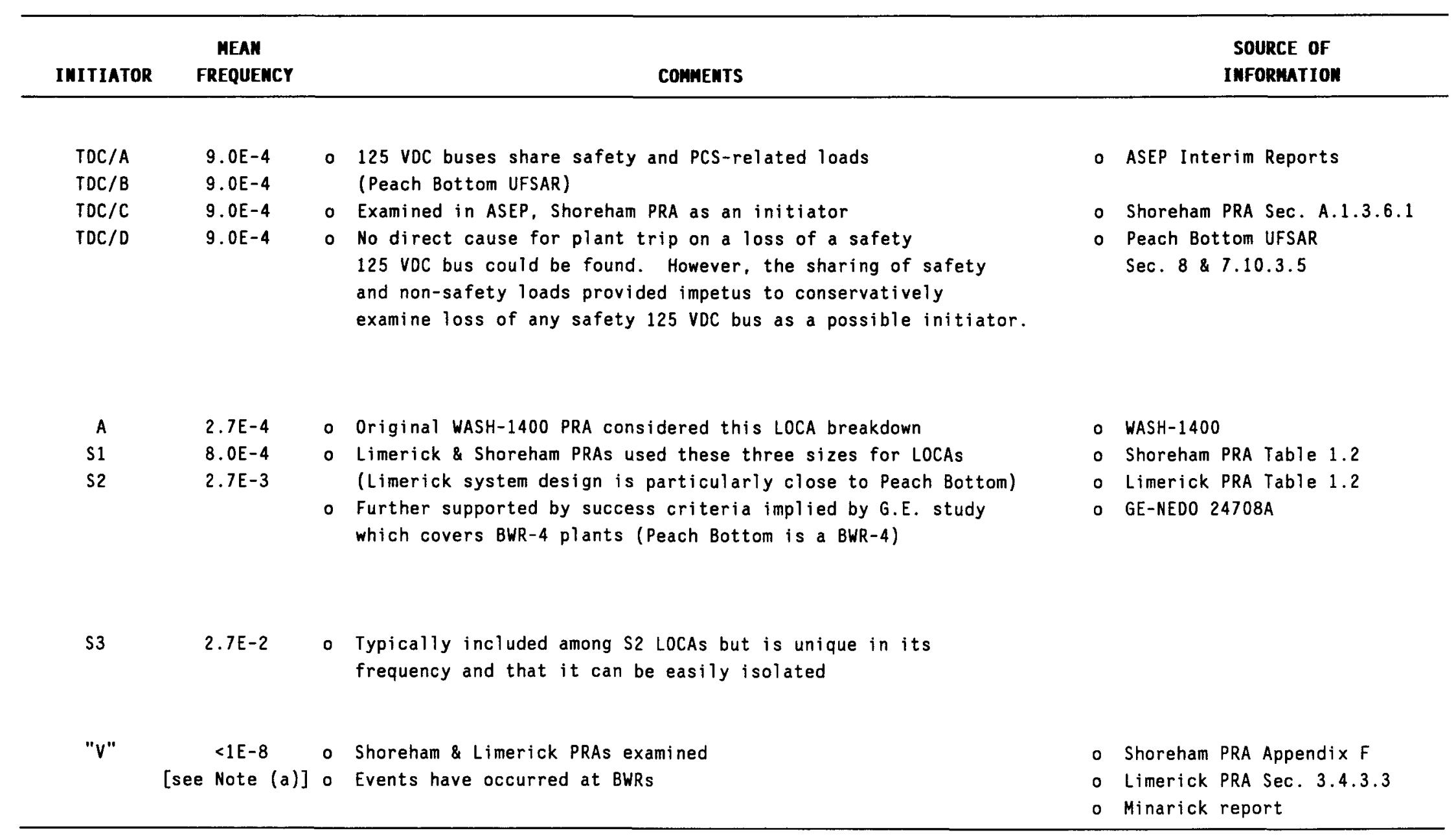

NOTE:

(a) See analysis covered in Section IV.4.14. 
Table IV. 3-4

Success Criteria summary Information

(see Glossary for acronym definitions)

\begin{tabular}{|c|c|c|c|c|c|}
\hline INITIATOR & $\begin{array}{c}\text { REACTOR } \\
\text { SUBCRITICAL }\end{array}$ & $\begin{array}{l}\text { EMERGEMCY } \\
\text { CORE COOLIMG }\end{array}$ & $\begin{array}{c}\text { EARLY } \\
\text { CONTAINMENT } \\
\text { OVERPRESSURE } \\
\text { PROTECTION }\end{array}$ & $\begin{array}{c}\text { LATE } \\
\text { CONTAIMHEWT } \\
\text { OVERPRESSURE } \\
\text { PROTECTION }\end{array}$ & $\begin{array}{c}\text { POST } \\
\text { ACCIDENT } \\
\text { RADIOACTIVITY } \\
\text { REMOYAL }\end{array}$ \\
\hline
\end{tabular}

A

RPS $\quad 1$ of 4 LPCI

or

ARI \& RPT

or

Manual Rods

and RPT

吉

$$
\text { or }
$$

any 2 LPCS pumps

政

(n)

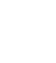

$\begin{array}{cc}1 \text { of } 4 \text { RHR \& HtX } & \text { VSS } \\ \text { (SPC or Spray modes) } & \text { or } \\ \text { and } & 1 \text { of } 4 \\ \text { associated HPSW } & \text { RHR in Spray }\end{array}$

associated HPSW

or

Containment Venting

1 of 4 RHR \& HtX

(SPC or Spray modes)

and

associated HPSW

or

Containment Venting
ARI \& RPT DEP $w / 2$ valves and

or

Manual Rods

and RPT

DEP $w / 2$ valves and

1 of 4 LPCI

or

DEP $w / 2$ valves and

1 HPSW (inject mode)
RHR in Spray Mode

$\begin{array}{cl} & \text { VSS } \\ & \text { or } \\ 1 & \text { of } 4 \\ \text { RHR in } & \text { Spray Mode }\end{array}$


Table IV. 3-4

Success Criteria summary Information (Continued)

\begin{tabular}{|c|c|c|c|c|c|}
\hline IMITIATOR & $\begin{array}{l}\text { REACTOR } \\
\text { SUBCRITICAL }\end{array}$ & $\begin{array}{l}\text { EMERGEMCY } \\
\text { CORE COOLIMG }\end{array}$ & $\begin{array}{c}\text { EARLY } \\
\text { CONTAINMENT } \\
\text { OVERPRESSURE } \\
\text { PROTECTION }\end{array}$ & $\begin{array}{c}\text { LATE } \\
\text { CONTAIMNENT } \\
\text { OVERPRESSURE } \\
\text { PROTECTION }\end{array}$ & $\begin{array}{c}\text { POST } \\
\text { ACCIDEMT } \\
\text { RADIOACTIVITY } \\
\text { REMOVAL }\end{array}$ \\
\hline s2 & $\begin{array}{c}\text { RPS } \\
\text { or } \\
\text { ARI \& RPT } \\
\text { or } \\
\text { Manual Rods } \\
\text { and RPT } \\
\text { or } \\
\text { Timely SLC } \\
\text { and RPT } \\
\text { (for steam break) }\end{array}$ & $\begin{array}{c}\text { HPCI } \\
\text { or } \\
\text { RCIC } \\
\text { or } \\
1 \text { FW } \\
\text { or } \\
\text { DEP } w / 2 \text { valves and } \\
\text { Any } 2 \text { LPCS pumps } \\
\text { or } \\
\text { OEP } w / 2 \text { valves and } \\
1 \text { of } 4 \text { LPCI } \\
\text { or } \\
\text { DEP } w / 2 \text { valves and } \\
1 \text { Condensate } \\
\text { or } \\
\text { DEP } w / 2 \text { valves and } \\
1 \text { HPSW (inject mode) }\end{array}$ & vss & $\begin{array}{c}1 \text { of } 4 \text { RHR \& HtX } \\
\text { (SPC or Spray Modes) } \\
\text { and } \\
\text { associated HPSW } \\
\text { or } \\
\text { Containment Venting } \\
\text { or } \\
\text { PCS }\end{array}$ & $\begin{array}{c}\text { VSS } \\
\text { er } \\
1 \text { of } 4 \\
\text { RHR in Spray Mode }\end{array}$ \\
\hline S3 & \multicolumn{3}{|c|}{$\begin{array}{l}\text { If detected and isolated, treat like } \mathrm{T} 3 \text {. } \\
\text { If not isolated, treat like S2 liquid LOCA. }\end{array}$} & & \\
\hline
\end{tabular}


Table IV.3-4

Success Criteria Summary Information (Continued)

\begin{tabular}{|c|c|c|c|c|}
\hline IMITIATOR & $\begin{array}{c}\text { REACTOR } \\
\text { SUBCRIIICAL }\end{array}$ & $\begin{array}{l}\text { RCS OVERPRESSURE } \\
\text { PROTECTIION }\end{array}$ & $\begin{array}{c}\text { EMERGEMCY } \\
\text { CORE COOLING }\end{array}$ & $\begin{array}{l}\text { RESIDUAL } \\
\text { HEAT REMOVAL }\end{array}$ \\
\hline $\mathrm{T} 1$ & $\begin{array}{l}\text { RPS } \\
\text { or } \\
\text { ARI \& RPT } \\
\text { or } \\
\text { Manual Rods } \\
\text { and RPT } \\
\text { or } \\
\text { Timely SLC } \\
\text { and RPT }\end{array}$ & SRVs open \& close & $\begin{array}{c}\text { HPCI } \\
\text { or } \\
\text { RCIC } \\
\text { or } \\
\text { CRD ( full flow) } \\
\text { or } \\
1 \mathrm{FW} \\
\text { [see Note (a)] } \\
\text { or } \\
\text { DEP w/2 valves and } \\
\text { Any } 2 \text { LPCS pumps } \\
\text { or } \\
\text { DEP w/2 valves and } \\
1 \text { of } 4 \text { LPCI } \\
\text { or } \\
\text { DEP w/2 valves and } \\
1 \text { Condensate } \\
\text { [see Note (a)] } \\
\text { or } \\
\text { DEP w/2 valves and } \\
1 \text { HPSW (inject mode) }\end{array}$ & $\begin{array}{c}1 \text { of } 4 \text { RHR \& HtX } \\
\text { (SDC. SPC. Spray Modes) } \\
\text { and } \\
\text { associated HPSW } \\
\text { or } \\
\text { PCS } \\
\text { [see Note (a)] } \\
\text { or } \\
\text { Containment Venting }\end{array}$ \\
\hline
\end{tabular}

NOTE:

(a) Only available if offsite power is restored. 
Table IV.3-4

Success Criteria Summary Information (Continued)

\begin{tabular}{|c|c|c|c|c|}
\hline IMITIATOR & $\begin{array}{c}\text { REACTOR } \\
\text { SUBCRITICAL }\end{array}$ & $\begin{array}{l}\text { RCS OVERPRESSURE } \\
\text { PROTECTION }\end{array}$ & $\begin{array}{c}\text { EMERGEMCY } \\
\text { CORE COOLING }\end{array}$ & $\begin{array}{l}\text { RESIDUAL } \\
\text { HEAT REMOVAL }\end{array}$ \\
\hline $\begin{array}{l}\stackrel{2}{\leftarrow} \\
\stackrel{2}{v}\end{array}$ & $\begin{array}{l}\text { RPS } \\
\text { or } \\
\text { ARI \& RPT } \\
\text { or } \\
\text { Manual Rods } \\
\text { and RPT } \\
\text { or } \\
\text { Timely SLC } \\
\text { and RPT }\end{array}$ & $\begin{array}{c}\text { PCS } \\
\stackrel{\text { or }}{\text { SRVs open \& close }}\end{array}$ & $\begin{array}{c}\text { HPCI } \\
\text { or } \\
\text { RCIC } \\
\text { or } \\
\text { CRD ( full flow) } \\
\text { or } \\
1 \text { FW } \\
\text { or } \\
\text { OEP } w / 2 \text { valves and } \\
\text { Any } 2 \text { LPCS pumps } \\
\text { or } \\
\text { DEP } w / 2 \text { valves and } \\
1 \text { of } 4 \text { LPCI } \\
\text { or } \\
\text { DEP } w / 2 \text { valves and } \\
\text { Condensate } \\
\text { or } \\
\text { DEP } w / 2 \text { valves and } \\
1 \text { HPSW (inject mode) }\end{array}$ & $\begin{array}{c}1 \text { of } 4 \text { RHR \& HEX } \\
\text { (SDC, SPC, Spray modes) } \\
\text { and } \\
\text { associated HPSH } \\
\text { or } \\
\text { PCS } \\
\text { or } \\
\text { Containment Venting }\end{array}$ \\
\hline
\end{tabular}


Table IV.3-4

Success Criteria Summary Information (Continued)

\begin{tabular}{|c|c|c|c|c|}
\hline INITIATOR & $\begin{array}{l}\text { REACTOR } \\
\text { SUBCRIIICAL }\end{array}$ & $\begin{array}{l}\text { RCS OVERPRESSURE } \\
\text { PROTECTION }\end{array}$ & $\begin{array}{l}\text { EMERGENCY } \\
\text { CORE COOLING }\end{array}$ & $\begin{array}{l}\text { RESIDUAL } \\
\text { HEAT REWOVAL }\end{array}$ \\
\hline 12 & $\begin{array}{l}\text { RPS } \\
\text { or } \\
\text { ARI \& RPT } \\
\text { or } \\
\text { Manual Rods } \\
\text { and RPT } \\
\text { or } \\
\text { Timely SLC } \\
\text { and RPT }\end{array}$ & SRVs open \& close & $\begin{array}{c}\text { HPCI } \\
\text { or } \\
\text { RCIC } \\
\text { or } \\
\text { CRD ( full flow) } \\
\text { or } \\
1 \text { FW } \\
\text { [see Note (a)] } \\
\text { or } \\
\text { DEP } W / 2 \text { valves and } \\
\text { Any } 2 \text { LPCS pumps } \\
\text { or } \\
\text { DEP } w / 2 \text { valves and } \\
1 \text { of } 4 \text { LPCI } \\
\text { or } \\
\text { DEP } w / 2 \text { valves and } \\
1 \text { Condensate } \\
\text { or } \\
\text { DEP } w / 2 \text { vaives and } \\
1 \text { HPSW (inject mode) }\end{array}$ & $\begin{array}{c}1 \text { of } 4 \text { RHR \& HtX } \\
\text { (SDC. SPC. Spray Modes) } \\
\text { and } \\
\text { associated HPSW } \\
\text { or } \\
\text { PCS } \\
\text { [see Note (b)] } \\
\text { or } \\
\text { Containment Venting }\end{array}$ \\
\hline
\end{tabular}

NOTES:

(a) Since feedwater is likely lost as part of the 12 initiator, feedwater must first be restored.

(b) T2 is a loss of the PCS so the PCS must first be restored. 
Table IV. 3-4

Success Criteria summary Information (Concluded)

\begin{tabular}{ccccc}
\hline & REACTOR & RCS OVERPRESSURE & EMERGEMCY & RESIDUAL \\
IMITIATOR & SUBCRITICAL & PROTECTION & CORE COOLIMG & HEAT REMOVAL \\
\hline
\end{tabular}

TAC/X Like T2 except Emergency Core Cooling \& Residual Heat Removal have fewer AC pumps available to operate.

TDC/X Like T2 except Emergency Core Cooling \& Residual Heat Removal have fewer AC pumps available to operate and HPCI or RCIC may be unavailable depending on which $D C$ bus is affected.

NOTE: Any transient with a stuck open relief valve will be treated as:

One valve stuck open -..--.- S2 steam LOCA

Two valves stuck open ------ S1 steam LOCA

Three valves stuck open ----- A steam LOCA 
The next task involved the identification of the possible accident sequences for each initiator. This was done using the event tree approach which is commonly used in Probabilistic Risk Assessments (PRAs). The event trees are logic diagrams at the system level of detail which represent the combinations of system successes and failures leading to the possible sequences of events following each initiator. The philosophy behind the event tree analysis for Peach Bottom was to depict system successes and failures until it was resolved that core damage had occurred and to display the status of other systems sufficiently to describe the plant damage state (see Section IV.4.1) applicable to each accident sequence.

The construction of the event trees was performed using the knowledge and experience base already represented by other Boiling Water Reactor (BWR) PRAs and with consideration of the generic event trees created as part of earlier ASEP efforts. Two major expansions of previous BWR event tree work were included, however, in this study.

(1) Formal analysis was conducted of more systems capable of core and containment cooling than considered before. Specifically, credit for the Control Rod Drive (CRD) system and the High Pressure Service Water (HPSW) system as injection sources to the reactor vessel were explicitly included in the success criteria and treated in the event trees and accompanying analyses. In addition, the Shutdown Cooling (SDC), Suppression Pool Cooling (SPC), and Containment Spray (CS) modes of the Residual Heat Removal (RHR) system, as well as the latest containment venting procedures (called containment injection and venting in the tree, (I\&V), were explicitly analyzed.

(2) The event tree analyses explicitly displayed and covered possible system success and failure paths beyond successful containment venting or containment failure. Therefore, the success or failure probabilities associated with continued core cooling were explicitly and formally analyzed rather than, for instance, assume loss of injection following containment failure.

The above expansion features of the event tree analyses provide, in general, more realistic analyses subject to less overall conservatism than previous analyses. However, as will become evident in the following subsections, conservative assumptions were still included in portions of the analyses so that the core damage potential would not be inadvertently underestimated. The above features of the analyses tend to provide lower core damage frequencies for some sequences than the reader may be accustomed to seeing in analyses for plants of similar design.

The following subsections address other aspects of the event tree analyses. Section IV.4.1 introduces the subject of plant damage states into which the dominant accident sequences were binned. Overall assumptions for the event tree analyses and a discussion of system success criteria are contained in Sections IV.4.2 and IV.4.3. Each event tree used in the Peach Bottom-2 analysis is then presented in subsequent sections. These sections contain specific success criteria considerations, assumptions and notes, and a description of the sequences displayed by each tree. The reader is referred to Section IV.4.15 for the nomenclature used in the event tree headings and resulting sequence identifiers. 


\section{IV.4.1 Plant Damage States}

In order to more efficiently perform the containment failure and subsequent fission product release analyses, the accident sequences from the event trees were binned or grouped into plant damage states. Each state has unique characteristics which represent boundary conditions for the containment failure analyses. Therefore, the sequences grouped into a plant damage state have similar characteristics allowing them to be treated as one set of sequences with an overall frequency. Use of the plant damage states served as a liaison mechanism between the so-called "front-end" analyses (accident sequence analyses) and the "back-end" analyses which begin with the containment failure analyses. In theory, the use of plant damage states would eliminate the need to explicitly quantify every sequence since only the top frequency sequences of each plant damage state would need to be formally analyzed. In practice, however, this did not work well for the Peach Bottom study. The containment analysis boundary conditions provided by the "back-end" analysts required so many variables that the degree of sequence grouping into plant damage states was minimal.

While this section of the report will not address all the possible plant damage states, the damage states for the dominant sequences are discussed in the results section (Section $V$ ) of this report.

\section{IV.4.2 General Event Tree Assumptions}

There are a number of assumptions which generically apply to the event tree analyses performed for Peach Bottom-2 regardless of the specific initiator being examined. These assumptions are listed below with brief explanations as required.

(1) Low Pressure Core Spray (LPCS), Low Pressure Coolant Injection (LPCI), and RHR (a11 modes) pumps are assumed to fail following successful containment venting or containment failure by overpressure/temperature conditions.

The suppression pool is assumed to reach near atmospheric saturated conditions shortly after either successful venting or containment failure. Partial boiling of the pool water is assumed to decrease the net positive suction head (NPSH) for the LPCS/LPCI/RHR pumps such that these pumps cavitate, if running, causing subsequent failure.

(2) LPCS/LPCI/RHR (a11 modes) pumps, which use the suppression pool for suction, will successfully operate using pool water at a temperature approaching $3500 \mathrm{~F}$ (corresponding saturation condition near point of containment failure by overpressure).

This assumption is based on (a) the corresponding pressure conditions of the containment which will assure adequate NPSH, (b) the pump seals and bearings being cooled by the Emergency Service Water system, (c) the findings of General Electric as reported in Section 5 of Reference 16, and (d) the fact that the RHR pumps normally pump water approaching such temperatures during the early phases of plant shutdown. 
(3) Loss of the Vapor Suppression System (VSS) was considered but eliminated from the event trees as relatively improbable.

Loss of the VSS function could affect the ability of the Mark I containment to withstand steam release from the primary system through either a break or the opening of Safety Relief Valves (SRVs). The three most probable failure mechanisms appear to be downcomer pipe failure, stuck open wetwell/drywell vacuum breakers, or a broken SRV tail pipe. Based on References 4 and 17, best estimates for downcomer pipe or SRV pipe failures are $<1 \mathrm{E}-5$ and $\sim 1 \mathrm{E}-7$ respectively. Additionally, discussions with containment analysis personnel suggest that wetwe 11/drywe11 vacuum breaker demand is not expected in most scenarios of interest. Considering these probabilities in the context of other system failure probabilities led to the conclusion that vSS failure could be excluded from further analysis.

(4) High Pressure Coolant Injection (HPCI) and Reactor Core Isolation Cooling (RCIC) will fail at pool temperatures of $\sim 210-$ to-2600 $\mathrm{F}$.

In all the accidents of interest, the HPCI system will eventually switch suction source from the condensate storage tank to the suppression pool automatically on high pool water level. Following procedures at Peach Bottom, the operator switches the RCIC system when he sees HPCI switch [18]. Switching back requires overriding certain circuits and therefore would not normally be performed. If, while the systems are running, the pool water should reach the $210-2600 \mathrm{~F}$ range (nominally $-2300 \mathrm{~F}$ ), pump failure for both systems is assumed since these pumps are not externally cooled. This is supported, in part, by information supplied by Philadelphia Electric Company (PECO) [19].

\section{IV.4.3 Discussion of Success Criteria}

The success criteria for the initiators of interest were presented earlier in Section IV.3.1. In the following subsections, the system success criteria for each initiator are presented again with additional explanatory notes for clarification. The identification of initiators and the construction of the corresponding event trees is a very interactive process. Hence, many of the same information sources listed in Section IV.3 were used in the development of the success criteria and the event trees for each initiator [3-12].

New or additional thermal-hydraulic analyses were not performed (except for Anticipated Transients Without Scram (ATWS) scenarios as described in Section IV.10) since it was expected that little new information would be gained and available resources would not permit such investigations. For the most part, the success criteria follow closely those used in the Limerick Probabilistic Safety Study [7] since Limerick and Peach Bottom have similar plant thermal ratings and similar emergency core cooling system designs and capacities. Any specific peculiarities in the criteria are noted for each initiator in subsequent subsections. 


\section{IV.4.4 Large Loss of Coolant Accident (LOCA) Event Tree}

This section contains information on the large LOCA event tree. Success criteria considerations are presented along with the event tree and its description.

\section{IV.4.4.1 Success Criteria}

Table IV.4-1 duplicates that portion of the success criteria presented in Table IV.3-4 that pertains to the large LOCA initiator. Additional clarification is provided with accompanying notes. Besides the criteria presented, an additional criterion specific to the large LOCA initiator is described below.

For scenarios where core cooling is successful up to the time of containment venting or containment failure: one Condensate, one HPSW, or two CRD pump operation is assumed to be adequate to continue successful core cooling. This is based on the low decay heat loads reached by that time (many hours) and the fact that only small flow rates should be required to maintain sufficient vessel inventory and adequate core cooling.

\section{IV.4.4.2 Event Tree}

Figure IV.4-1 displays the event tree for the large LOCA initiator. The following discussions define the event tree headings and describe the sequences presented.

\section{Event Tree Headings}

The following event tree headings appear on the tree in the approximate chronological order that would be expected following a large LOCA.

A: $\quad$ Initiating event, Iarge LOCA.

C: $\quad$ Success or failure of the Reactor Protection System (RPS). Success implies automatic scram by the control rods.

V2: Success or failure of the LPCS system. Success implies operation of any two of the four LPCS pumps through either or both LPCS injection lines.

V3: Success or failure of the LPCI mode of the RHR system. Success implies operation of one of four LPCI pumps through either LPCI injection line to the reactor vessel.

W2,W3: Success or failure of the RHR in the SPC mode or CS mode, respectively. Success implies at least one RHR pump operating in either the SPC or CS mode with the appropriate heat exchanger in the loop along with the HPSW system in operation to the ultimate heat sink.

Y: $\quad$ Success or failure of containment venting. Success implies that the 6" integrated leak test line or larger size line is open so as to prevent containment failure by overpressure. As necessary, water makeup is al so eventually supplied to the suppression pool. 
Table IV.4-1

Success Criteria for Large LOCA (see Glossary for acronym definitions)

\begin{tabular}{|c|c|c|c|c|c|}
\hline IMITIATOR & $\begin{array}{c}\text { REACTOR } \\
\text { SUBCRITICAL }\end{array}$ & $\begin{array}{l}\text { ENERGENCY } \\
\text { CORE COOLIMG }\end{array}$ & $\begin{array}{c}\text { EARLY } \\
\text { CONTAIMHEMT } \\
\text { OVERPRESSURE } \\
\text { PROTECTION }\end{array}$ & $\begin{array}{c}\text { LATE } \\
\text { CONTAIMHEMT } \\
\text { OVERPRESSURE } \\
\text { PROTECTION }\end{array}$ & $\begin{array}{l}\text { POST } \\
\text { ACCIDENT } \\
\text { RADIOACTIVITY } \\
\text { REMOVAL }\end{array}$ \\
\hline A & $\begin{array}{c}\text { RPS } \\
\text { or } \\
\text { ARI \& RPT } \\
\text { or } \\
\text { Manual Rods } \\
\text { and RPT } \\
\text { [see Note (a)] }\end{array}$ & $\begin{array}{c}1 \text { of } 4 \text { LPCI } \\
\text { or } \\
\text { any } 2 \text { LPCS pumps } \\
\text { [see Notes (b), (c), (d)] }\end{array}$ & $\begin{array}{c}\text { VSS } \\
\text { [see Note }(e)]\end{array}$ & $\begin{array}{c}1 \text { of } 4 \text { RHR \& HtX } \\
\text { (SPC or Spray modes) } \\
\text { and } \\
\text { associated HPSW } \\
\text { [see Note }(f)] \\
\text { or } \\
\text { Containment Venting } \\
\text { [see Note }(g)]\end{array}$ & $\begin{array}{c}\text { VSS } \\
\text { see Note (e) } \\
\text { or } \\
1 \text { of } 4 \\
\text { RHR in Spray Mode }\end{array}$ \\
\hline
\end{tabular}

(a) Assumes SLC goes out the break and is ineffective. Probably conservative for steam breaks.

(b) Any 2 of 4 LPCS pumps is different from past PRA criteria of 2 pumps needed in the same LPCS injection loop. This is based on latest analyses per Reference 9.

(c) Feedwater/Condensate could initially provide makeup but the condenser hotwell is considered likely to reach low levels because of insufficient makeup flow rate. Also MSIV closure is likely thus preventing use of the turbine-driven feedwater pumps.

(d) Recent preliminary GE analyses suggest that for recirculation line breaks, injection flows may cause sufficient sub-cooling in the lower portions of the core so as to eliminate steam cooling in the upper $1 / 3$ of the core possibly resulting in damage. Since considerable doubt as to the accuracy of such findings exists at this time, LPCI is still considered a success path (as in other PRAs) pending further investigation. LPCS would spray down on the top of the core and hence is not subject to the same concerns.

(e) The equivalent area of 2 stuck-open drywell/wetwell vacuum breakers is required for failure per Reference 4.

(f) HPSW operation is needed for the operating RHR heat exchanger.

(g) At least the 6 " integrated leak test line or larger size line is considered required for success. Criteria based on discussions with containment analysis personnel at Sandia. May be conservative. 


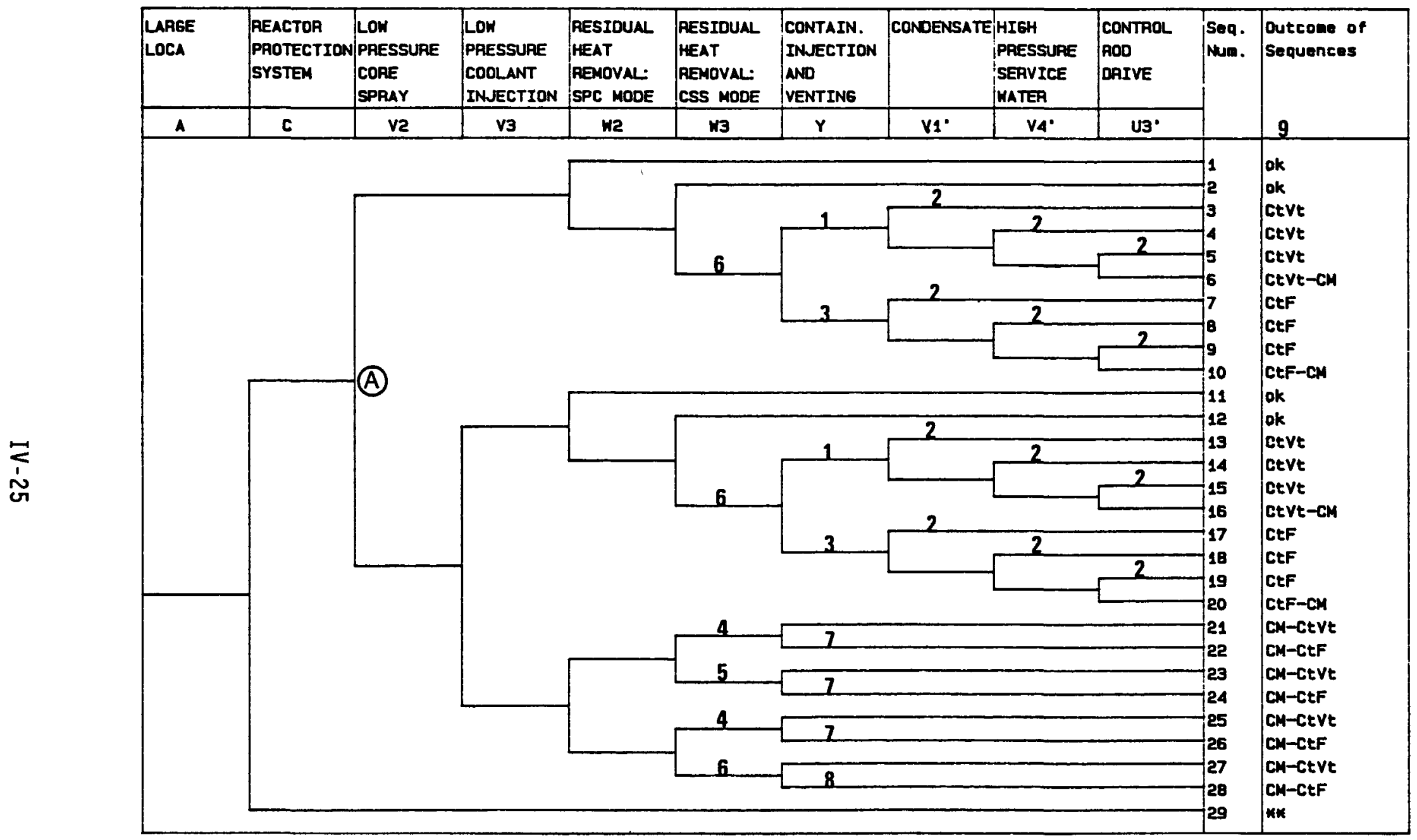

$\star \star A C$ Sequence Not Examined Due to Low Frequency $\leq$ E-9 and Therefore Not Developed.

Figure IV.4-1. Large LOCA Event Tree. 
(1) With no containment heat removal, venting is eventually required. When successful venting occurs, the LPCS/LPCI/RHR pumps are assumed to fail (see generic assumptions).

(2) See additional criterion consideration, section IV.4.4.I.

(3) Containment fails by overpressure. The suppression pool achieves saturated conditions failing LPCS/LPCI/RHR (see generic assumptions).

(4) Containment is being cooled by RHR with the CS mode operating to assist in fission product removal.

(5) Containment is being cooled by RHR in SPC mode but the CS mode is inoperable.

(6) No containment cooling or spray exists.

(7) Containment can fail only if non-condensible formation is adequate to reach failure pressure of containment. Otherwise, venting is not even needed and failure sequences cannot occur.

(8) Choice is based on the assumption that containment failure pressure will finally be reached based on no containment cooling and build-up of non-condensibles.

(9) "Outcome" key:

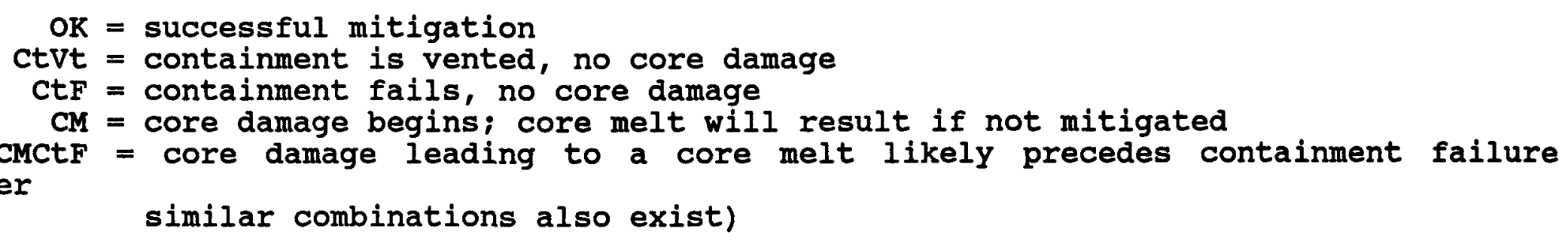


V1**: Success or failure of the Condensate system. Success implies at least one pump operating with sufficient makeup to the condenser hotwell for a continuing water supply.

V4': $\quad$ Success or failure of the High Pressure Service Water (HPSW) system as an injection source to the reactor. Success implies at least one pump operating through the LPCI injection line and into the reactor.

U3': $\quad$ Success or failure of the CRD system as an injection source. Success implies two pumps operating at these latter stages of the scenario so as to keep the core at least $2 / 3$ covered.

\section{Sequences}

The following descriptions refer to the sequences found in Figure IV.4-1.

Sequences 1-2:

Following the large LOCA, successful reactor scram and core coolant injection with LPCS have occurred. Containment cooling is provided by the SPC or CS mode of RHR resulting in successful mitigation of the event.

Sequences 3-5:

Reactor scram and LPCS injection to cool the core are successful. Containment cooling has failed creating a core vulnerable condition since containment failure could lead to loss of cooling and hence core damage. The pressure rise in containment, because of the heat loss through the break, is mitigated by successful containment venting. Following venting, LPCS failure is assumed because of $10 \mathrm{~W}$ NPSH. The operator then successfully uses Condensate, HPSW, or the CRD to continue to cool the core. The core is not damaged but containment integrity has been violated because of venting. There is no significant fission product release.

Sequence 6:

As above for Sequences 3-5 except coolant injection is not restored because of random system failures or maintenance, phenomenological failures, or operator error. Core damage occurs following the venting of containment.

*Events with a ' designate that choices for these events occur after the choice for event "Y." Both success and failure of "Y" potentially lead to saturated conditions in the suppression pool which conservatively are assumed to result in the loss of all systems using the pool as the injection source (see first general assumption--Section IV.4.2). This places the reactor core in a so-called "core vulnerable" state since core damage will occur unless injection is restored by one of the systems designated with a - (These systems do not use the suppression pool as the injection water source.) 
Sequences 7-10:

As above for Sequences 3-6 except containment venting fails leading to containment failure by overpressure.

Sequences 11-20:

Correspond to Sequences 1-10 except that core cooling is provided initially by LPCI subsequent to LPCS failure.

Sequences $21,23,25$ :

Reactor scram occurs but core cooling has failed resulting in core degradation. These sequences involve successful containment cooling by either or both the SPC and CS modes of RHR. Containment venting is successful, if required, to prevent overpressurization because of non-condensible formation.

Sequences $22,24,26$ :

As above for Sequences 21,23 , and 25 except venting, if required, is unsuccessful leading to core damage followed by containment failure.

Sequences 27-28:

Core cooling and containment cooling fail following a reactor scram. Containment venting is or is not successful, resulting in core degradation with either the containment vented or failed.

\section{IV.4.5 Intermediate LOCA Event Tree}

This section contains information on the intermediate LOCA event tree. Success criteria considerations are presented along with the event tree and its description.

\section{IV.4.5.1 Success Criteria}

Table IV.4-2 duplicates that portion of the success criteria presented in Table IV.3-4 that pertains to the intermediate LOCA initiator. Additional clarification is provided with accompanying notes. Besides the criteria presented, an additional criterion specific to the intermediate LOCA initiator is described below.

For scenarios where core cooling is successful up to the time of containment venting or containment failure: one Condensate, one HPSW, or two CRD pump operation is assumed to be adequate to continue successful core cooling. This is based on the low decay heat loads reached by that time (many hours) and the fact that only small flow rates should be required to maintain sufficient vessel inventory and adequate core cooling. 


\begin{tabular}{|c|c|c|c|c|c|}
\hline & & $\begin{array}{l}\text { Table } \\
\text { Success Criteria t } \\
\text { (see Glossary for }\end{array}$ & $\begin{array}{l}\text { IV.4-2 } \\
\text { or Interme } \\
\text { acronym de }\end{array}$ & $\begin{array}{l}\text { LOCA } \\
\text { ons) }\end{array}$ & \\
\hline IMITIATOR & $\begin{array}{c}\text { REACTOR } \\
\text { SUBCRITICAL }\end{array}$ & $\begin{array}{l}\text { EMERGENCY } \\
\text { CORE COOLING }\end{array}$ & $\begin{array}{c}\text { EARLY } \\
\text { CONTAIMHENT } \\
\text { OVERPRESSURE } \\
\text { PROTECTION }\end{array}$ & $\begin{array}{c}\text { LATE } \\
\text { CONTAIMNENT } \\
\text { OVERPRESSURE } \\
\text { PROTECTION }\end{array}$ & $\begin{array}{c}\text { POST } \\
\text { ACCIDENT } \\
\text { RADIOACIIVITY } \\
\text { REMOVAL }\end{array}$ \\
\hline S1 & $\begin{array}{c}\text { RPS } \\
\text { or } \\
\text { ARI \& RPT } \\
\text { or } \\
\text { Manual Rods } \\
\text { and RPT } \\
\text { [see Note (a)] }\end{array}$ & $\begin{array}{c}\text { HPCI (2 hours only) } \\
\text { [see Note (b)] } \\
\text { or } \\
\text { DEP w/2 valves and } \\
\text { Any } 2 \text { LPCS pumps } \\
\text { or } \\
\text { DEP } w / 2 \text { valves and } \\
1 \text { of } 4 \text { LPCI } \\
\text { or } \\
\text { DEP w/2 valves and } \\
1 \text { HPSW (inject mode) } \\
\text { [see Notes (c), (d)] }\end{array}$ & $\begin{array}{c}\text { VSS } \\
\text { [see Note }(e)]\end{array}$ & $\begin{array}{c}1 \text { of } 4 \text { RHR \& HtX } \\
\text { (SPC or Spray modes) } \\
\text { and } \\
\text { associated HPSW } \\
\text { [see Note (f)] } \\
\text { or } \\
\text { Containment Venting } \\
\text { [see Note }(g)]\end{array}$ & $\begin{array}{c}\text { VSS } \\
\text { [see Note }(e)] \\
\text { or } \\
1 \text { of } 4 \\
\text { RHR in Spray Mode }\end{array}$ \\
\hline
\end{tabular}

NOTES:

(a) Assumes SLC goes out the break and is ineffective. Probably conservative for steam breaks.

(b) Depressurization because of the break and due to HPCI operation will cause insufficient steam pressure to allow HPCI to run after $\sim 2$ hours (see Reference 7 ). Without initial HPCI operation, depressurization with at least 2 safety relief valves is required. Following either successful HPCI operation or depressurization, the indicated low pressure systems can be used.

(c) Any 2 of 4 LPCS pumps is different from past PRA criteria of 2 pumps needed in the same LPCS injection loop. This is based on latest analyses per Reference 9 .

(d) Feedwater/Condensate could initially provide makeup but the condenser hotwell is considered likely to reach low levels because of insufficient makeup flow rate. Also MSIV closure is likely thus preventing use of the turbine-driven feedwater pumps.

(e) The equivalent area of 1 stuck-open drywell/wetwell vacuum breaker is required for failure per Reference 4.

(f) HPSW operation is needed for the operating RHR heat exchanger.

(g) At least the 6" integrated leak test line or larger size line is considered required for success. Criteria based on discussions with containment analysis personnel at Sandia. May be conservative. 


\section{IV.4.5.2 Event Tree}

Figure IV.4-2 displays the event tree for the intermediate LOCA initiator. The following discussions define the event tree headings and describe the sequences presented.

\section{Event Tree Headings}

The following event tree headings appear on the tree in the approximate chronological order that would be expected following an intermediate LOCA. For convenience, high and then low pressure injection systems are shown first, followed by containment-related systems, and finally by systems capable of long-term continued coolant injection.

S1: $\quad$ Initiating event, intermediate LOCA.

C: $\quad$ Success or failure of the RPS. Success implies automatic scram by the control rods.

U1: Success or failure of the HPCI system. Success implies operation of the HPCI system for $-1-2$ hours until low primary system pressure causes isolation of HPCI either automatically or manually.

X: $\quad$ Success or failure of primary system depressurization. Success implies automatic or manual operation of the Automatic Depressurization System (ADS) or manual operation of other SRVs such that two valves or more are opened allowing low pressure injection.

V2: Success or failure of the LPCS system. Success implies operation of any two of the four LPCS pumps through either or both LPCS injection 1 ines.

V3: $\quad$ Success or failure of the LPCI mode of the RHR system. Success implies operation of one of four LPCI pumps through either LPCI injection line to the reactor vessel.

V4: Success or failure of the HPSW system in the inject mode to the reactor vessel through a LPCI injection line. Success implies manual operation of this injection source such that one HPSW pump successfully provides coolant to the reactor.

W2,W3: Success or failure of the RHR in the SPC mode or CS mode, respectively. Success implies at least one RHR pump operating in either the SPC or CS mode with the appropriate heat exchanger in the loop along with the HPSW in operation to the ultimate heat sink.

Y: $\quad$ Success or failure of containment venting. Success implies that the 6" integrated leak test line or larger is open so as to prevent containment failure by overpressure. As necessary, water makeup is also eventually supplied to the suppression pool. 


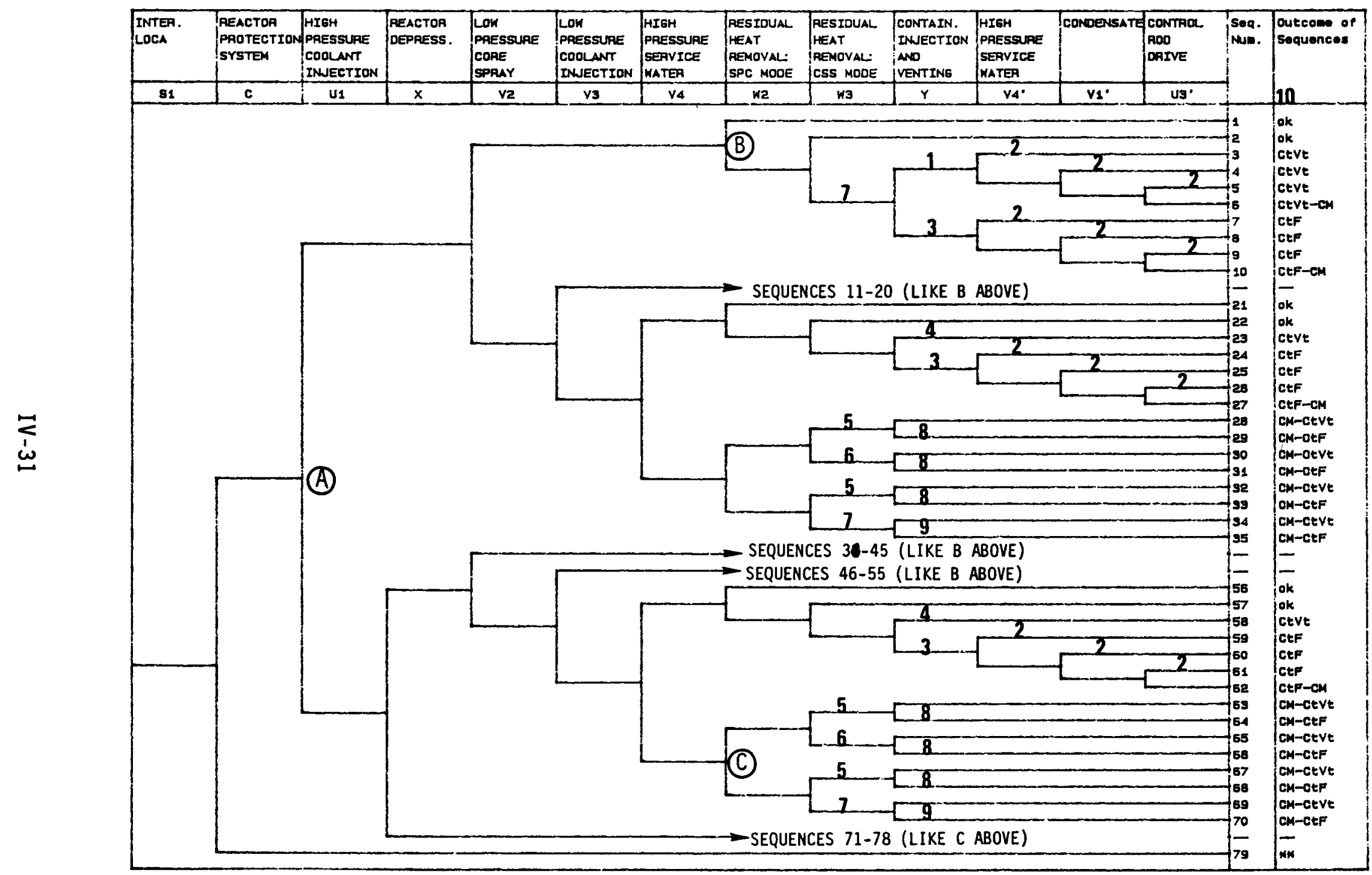

**SIC Sequence Not Examined Due to Low Frequency $\leq$ and Therefore Not Developed.

Figure IV.4-2. Intermediate LOCA Event Tree. 
(1) With no containment heat removal, venting is eventually required. When successful venting occurs, the LPCS/LPCI/RHR pumps are assumed to fail (see generic assumptions).

(2) See additional criterion consideration, section IV.4.5.1.

(3) Containment fails by overpressure. The suppression pool achieves saturated conditions failing LPCS/LPCI/RHR (see generic assumptions).

(4) Successful venting is assumed to lead directly to a non-core damage sequence since venting should have little effect on the continued success of HPSW which is already operating.

(5) Containment is being cooled by RHR with the CS mode operating to assist in fission product removal.

(6) Containment is being cooled by RHR in SPC mode but the cs mode is inoperable.

(7) No containment cooling or spray exists.

(8) Containment can fail only if non-condensible formation is adequate to reach failure pressure of containment. Otherwise, venting is not even needed and failure sequences cannot occur.

(9) Choice is based on assumption that containment failure pressure will finally be reached based on no containment cooling and build-up of non-condensibles.

(10) "Outcome" key:

$\mathrm{OK}=$ successful mitigation

ctVt = containment is vented, no core damage

$C t F=$ containment fails, no core damage

$\mathrm{CM}=$ core damage begins; core melt will result if not mitigated

CMCtF = core damage leading to a core melt likely precedes containment failure (other similar combinations also exist) 


\section{V4'*: $\quad$ See V4.}

V1': $\quad$ Success or failure of the Condensate system. Success implies at least 1 pump operating with sufficient makeup to the condenser hotwell for a continuing water supply.

U3': $\quad$ Success or failure of the CRD system as an injection source. Success implies 2 pump operation.

\section{Sequences}

The following descriptions refer to the sequences found in Figure IV.4-2.

Sequences 1-2:

Following the intermediate LOCA, successful reactor scram and core coolant injection with first HPCI and then LPCS have occurred. Containment cooling is provided by the SPC or CS mode of RHR resulting in successful mitigation of the event.

Sequences 3-5:

Reactor scram and coolant injection are initially successful but containment cooling has failed. The pressure rise in containment because of the heat loss through the break is mitigated by successful containment venting. Following venting, LPCS failure is assumed because of low NPSH. The operator then successfully initiates Condensate, HPSW, or the CRD to continue to cool the core. The core is not damaged but containment integrity has been violated because of venting. There is no significant fission product release.

Sequence 6:

As above for Sequences 3-5 except coolant injection is not restored because of random system failures or maintenance, phenomenological failures, or operator error. Core damage occurs following the venting of containment.

Sequences 7-10:

As above for Sequences 3-6 except containment venting fails leading to containment failure by overpressure.

*Events with a' designate that choices for these events occur after the choice for event "Y." Both success and failure of "Y" potentially lead to saturated conditions in the suppression pool which conservatively are assumed to result in the loss of all systems using the pool as the injection source (see first general assumption--Section IV.4.2). This places the reactor core in a so-called "core vulnerable" state since core damage will occur unless injection is restored by one of the systems designated with a ' (These systems do not use the suppression pool as the injection water source.) 
Sequences 11-20:

Correspond to Sequences 1-10 except that core cooling is initially provided by HPCI and LPCI with LPCS failure.

Sequences 21-27:

Correspond to the types of scenarios depicted by Sequences 1-10 except that core cooling is initially provided by HPCI and HPSW, with LPCS and LPCI failure. Sequence 27 is the only sequence that leads to core damage.

Sequences $28,30,32$ :

Reactor scram occurs but core cooling fails after HPCI isolates in -2 hours. These sequences involve core degradation and successfur containment cooling by either or both the SPC and CS modes of RHR. Containment venting is successful, if required, to prevent overpressurization because of non-condensible formation.

Sequences 29,31,33:

As above for Sequences 28,30 , and 32 except venting, if required, is unsuccessful leading to core damage followed by containment failure.

Sequence 34,35 :

Core cooling eventually fails as does containment cooling following reactor scram. Containment venting is or is not successful, resulting in core degradation with either the containment vented or failed.

Sequences 36-70:

Correspond to Sequences 1-35 above except HPCI fails initially followed by successful reactor vessel depressurization.

Sequences 71-78:

Correspond to Sequences 28-35 above except core degradation occurs sooner due to early HPCI and depressurization failure.

\section{IV.4.6 Small LOCA Event Tree}

This section contains information on the small LOCA event tree. Success criteria considerations are presented along with the event tree and its description.

\section{IV.4.6.1 Success Criteria}

Table IV.4-3 duplicates that portion of the success criteria presented in Table IV.3-4 that pertains to the small LOCA initiator. Additional clarification is provided with accompanying notes. Besides the criteria presented, two additional criteria specific to the small LOCA initiator are described below. 
Table IV.4-3

Success Criteria for Small LOCA

(see Glossary for acronym definitions)

\begin{tabular}{|c|c|c|c|c|c|}
\hline INITIATOR & $\begin{array}{c}\text { REACTOR } \\
\text { SUBCRITICAL }\end{array}$ & $\begin{array}{c}\text { EMER6ENCY } \\
\text { CORE COOLING }\end{array}$ & $\begin{array}{c}\text { EARLY } \\
\text { CONTAINMENT } \\
\text { OVERPRESSURE } \\
\text { PROTECTION }\end{array}$ & $\begin{array}{c}\text { LATE } \\
\text { CONTAINMENT } \\
\text { OVERPRESSURE } \\
\text { PROTECTION }\end{array}$ & $\begin{array}{c}\text { POST } \\
\text { ACCIDENT } \\
\text { RADIOACTIVITY } \\
\text { REMOVAL }\end{array}$ \\
\hline $\mathrm{S} 2$ & $\begin{array}{c}\text { RPS } \\
\text { or } \\
\text { ARI } \& P T \\
\text { or } \\
\text { Manual Rods } \\
\text { and RPT } \\
\text { or } \\
\text { Timely SLC } \\
\text { and RPT } \\
\text { (for steam break) } \\
\text { [see Note (a)] }\end{array}$ & $\begin{array}{c}\text { HPCI } \\
\text { RCIC } \\
\text { or } \\
1 \text { FW } \\
\text { [see Note (b)] } \\
\text { or } \\
\text { DEP } w / 2 \text { valves and } \\
\text { Any } 2 \text { LPCS pumps } \\
\text { Or } \\
\text { DEP } w / 2 \text { valves and } \\
1 \text { of } 4 \text { LPCI } \\
\text { DEP W/2 valves and } \\
1 \text { Condensate } \\
\text { DEP w/2 valves and } \\
1 \text { HPSW (inject mode) } \\
{[\text { see Note (c)] }}\end{array}$ & $\begin{array}{c}\text { VSS } \\
\text { [see Note }(d)]\end{array}$ & $\begin{array}{c}1 \text { of } 4 \text { RHR \& HtX } \\
\text { (SPC or Spray Modes) } \\
\text { and } \\
\text { associated HPSW } \\
\text { [see Note (e)] } \\
\text { or } \\
\text { Containment Venting } \\
\text { [see Note (f)] } \\
\text { or } \\
\text { PCS } \\
\text { [see Note (b)] }\end{array}$ & $\begin{array}{c}\text { VSS } \\
\text { [see Note (d)] } \\
\text { or } \\
\text { of } 4 \\
\text { RHR in Spray Mode }\end{array}$ \\
\hline
\end{tabular}

NOTES:

(a) Conservatively assumes SLC goes out liquid break and is ineffective.

(b) MSIV closure considered relatively unlikely $(\sim 0.01)$ since pressure in reactor vessel will remain high. Operator will likely bypass low steam pressure signal which closes MSIVs by placing reactor mode switch in shutdown immediately after reactor scram. Even with subsequent containment isolation on high drywell pressure (which isolates plant nitrogen to MSIVs), MSIVs will remain open for $\sim 1$ hour because of valve accumulators (based on tests at Peach Bottom). This provides time for the operator to restore plant nitrogen to the MSIVs to keep them open (one of the first steps in the emergency procedures). This in turn allows for the possibility of continuous feedwater flow to the reactor as well as use of the entire PCS to mitigate the event.

(c) Any 2 of 4 LPCS pumps is different from past PRA criteria of 2 pumps needed in the same LPCS injection loop. This is based on latest analyses per Reference 9 .

(d) The equivalent area of 1 stuck-open drywell/wetwell vacuum breaker is required for failure per Reference 4.

(e) HPSW operation is needed for the operating RHR heat exchanger.

(f) At least the 6" integrated leak test line or larger size line is considered required for success. Criteria based on discussions with containment analysis personnel at Sandia. May be conservative. 
(1) For scenarios in which core cooling has been provided for a period of a few hours or more, two CRD pump operation is considered adequate for continued success of core cooling should the other cooling systems then fail. This is based on the low decay heat levels and relatively small flow rates required by that time to make up for the small break.

(2) For scenarios in which core cooling is successful up to the time of containment venting or containment failure, two CRD pumps or depressurization with operation of either one Condensate or one HPSW pump is considered to be adequate to continue successful core cooling.

\section{IV.4.6.2 Event Tree}

Figure IV.4-3 displays the event tree for the small LOCA initiators. The following discussions define the event tree headings and describe the sequences presented.

\section{Event Tree Headings}

The following event tree headings appear on the tree in the approximate chronological order that would be expected following a small LOCA. For convenience, the Residual Heat Removal (RHR) containment cooling choices are shown early in the tree to decrease the size of the event tree. Otherwise, the tendency is to show high and then low pressure injection systems, followed by containment venting, and finally long-term continued core cooling possibilities.

S2: $\quad$ Initiating event, small LOCA

C: $\quad$ Success or failure of the RPS. Success implies automatic scram by the control rods.

Q: $\quad$ Success or failure of the Power Conversion System (PCS). Success implies operation of the balance of plant by removing heat through at least one Main Steam Isolation Valve (MSIV) with operation of the condenser and circulating water system as well as one feedwater train.

U1: $\quad$ Success or failure of the HPCI system. Success implies operation of the HPCI pump train so as to maintain sufficient coolant injection.

U2: Success or failure of the RCIC system. Success implies operation of the RCIC pump train so as to maintain sufficient coolant injection.

W2,W3: Success or failure of the RHR system in the SPC mode or CS mode, respectively. Success implies at least one RHR pump operating in either the SPC or CS mode with the appropriate heat exchanger in the loop along with the HPSW system in operation to the ultimate heat sink.

U3: Success or failure of the CRD system as an injection source. Success implies two pump operation. 


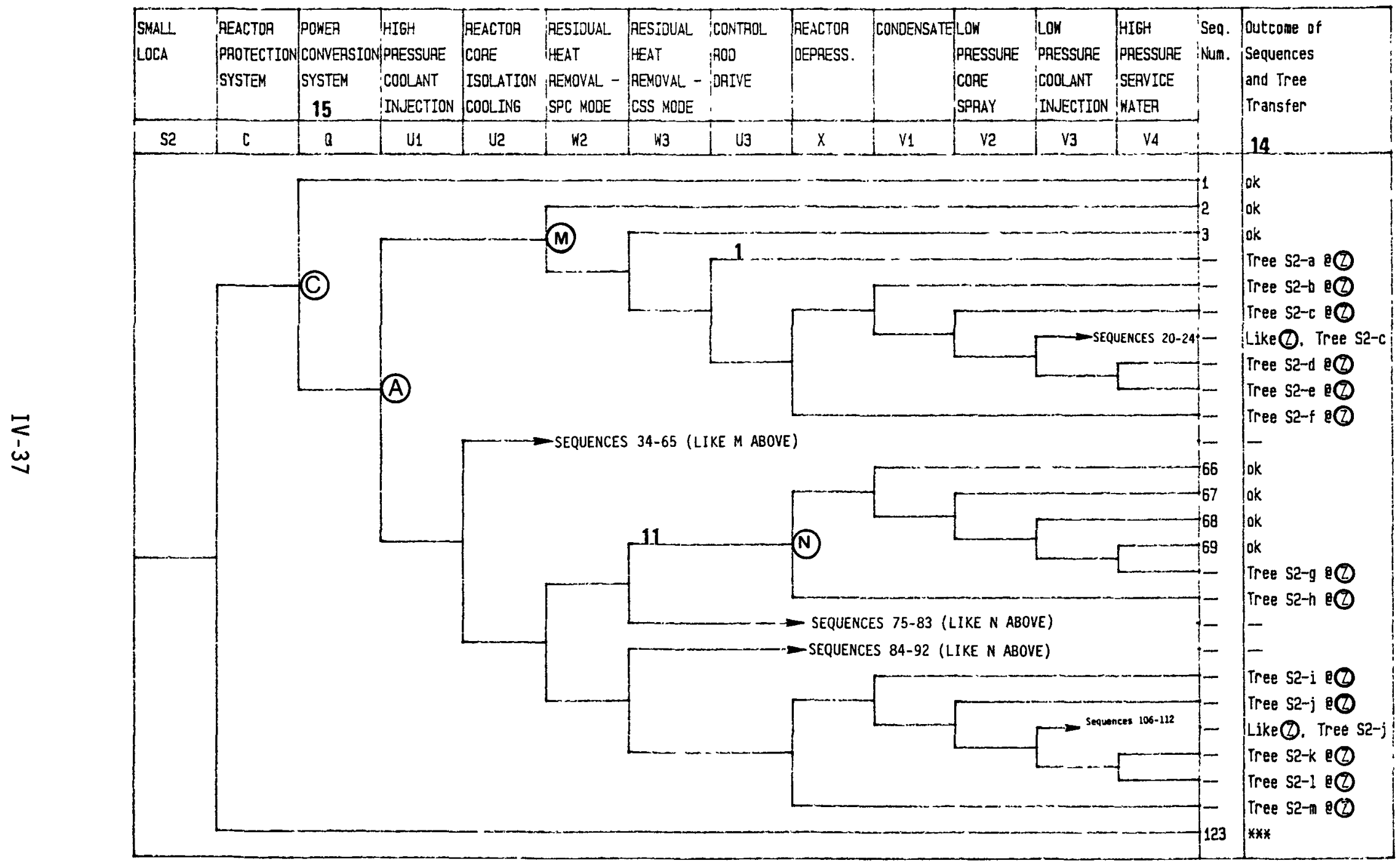

***S2C Sequence Not Examined Due to Low Frequency $\leq \mathrm{E}-8$ and Therefore Not Developed. Figure IV.4-3. Small LOCA Event Tree (Page 1 of 14). 


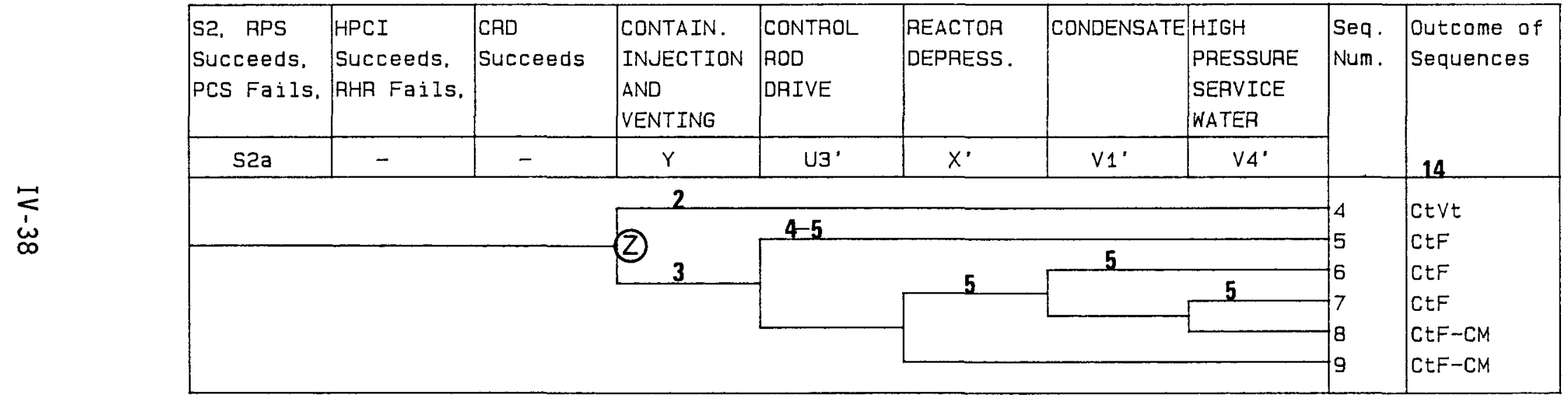

Figure IV.4-3. Small LOCA Event Tree (Transfer Tree S2a, Page 2 of 14). 


\begin{tabular}{|c|c|c|c|c|c|c|c|c|c|c|}
\hline \multirow{6}{*}{ 苫 } & $\begin{array}{l}\text { HPCI } \\
\text { Succeeds, } \\
\text { RHR } \\
\text { Fails. }\end{array}$ & $\begin{array}{l}\text { CAD Fails, } \\
\text { Heactor } \\
\text { Depress.. }\end{array}$ & $\begin{array}{l}\text { Condensate } \\
\text { Succeeds }\end{array}$ & $\begin{array}{l}\text { CONTAIN. } \\
\text { INJECTION } \\
\text { AND } \\
\text { VENTING }\end{array}$ & $\begin{array}{l}\text { CONTAOL } \\
\text { HOD } \\
\text { DRIVE }\end{array}$ & $\begin{array}{l}\text { OPERATOR } \\
\text { DEPRESS. }\end{array}$ & CONDENS & \begin{tabular}{|l} 
HIGH \\
PRESSUAE \\
SERVICE \\
WATER \\
\end{tabular} & \multirow[t]{2}{*}{$\begin{array}{l}\text { Seq. } \\
\text { Num. }\end{array}$} & \multirow[t]{2}{*}{$\begin{array}{l}\text { Outcome of } \\
\text { Sequences }\end{array}$} \\
\hline & - & - & - & $Y$ & 143' & $x^{\circ}$ & $V_{1} 1^{\prime}$ & $\mathrm{VA}^{\circ}$ & & \\
\hline & \multicolumn{8}{|c|}{2} & \multirow{2}{*}{$\mid \begin{array}{l}10 \\
11\end{array}$} & \multirow{4}{*}{$\begin{array}{l}\text { CtVt } \\
\text { CtF } \\
\text { CtF } \\
\text { CtF-CM } \\
\text { CtF-CM }\end{array}$} \\
\hline & & & & \multirow{2}{*}{\multicolumn{2}{|c|}{ (2) }} & \multicolumn{3}{|c|}{5} & & \\
\hline & & & & & & & & b & \multirow{2}{*}{$\begin{array}{l}12 \\
13 \\
14\end{array}$} & \\
\hline & & & & & & & & & & \\
\hline
\end{tabular}

Figure IV.4-3. Small LOCA Event Tree (Transfer Tree S2b, Page 3 of 14). 


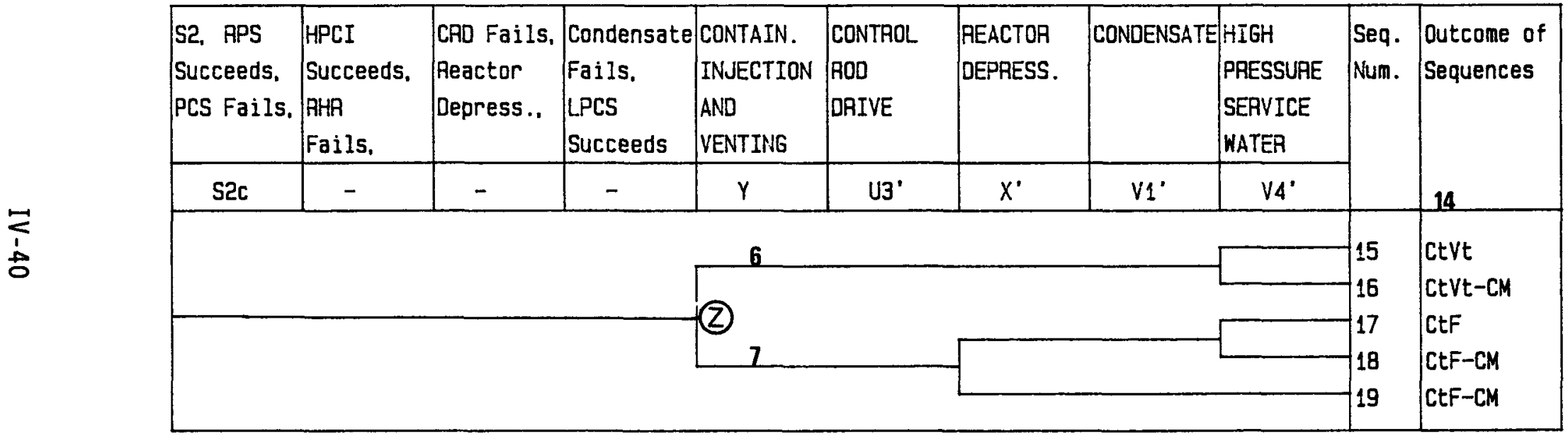

Figure IV.4-3. Small LOCA Event Tree (Transfer Tree S2C, Page 4 of 14). 


\begin{tabular}{|c|c|c|c|c|c|c|c|c|c|c|}
\hline $\begin{array}{l}\text { S2, RPS } \\
\text { Succeeds, } \\
\text { PCS Fails, }\end{array}$ & $\begin{array}{l}\text { HPCI } \\
\text { Succeeds. } \\
\text { RHA Fails, } \\
\text { CRD Fails, }\end{array}$ & $\begin{array}{l}\text { Reactor } \\
\text { Depress.. } \\
\text { Condensate } \\
\text { Fails. } \\
\end{array}$ & $\begin{array}{l}\text { LPCS and } \\
\text { LPCI Fail, } \\
\text { HPSWS } \\
\text { Succeeds }\end{array}$ & $\begin{array}{l}\text { CONTAIN. } \\
\text { INJECTION } \\
\text { AND } \\
\text { VENTING }\end{array}$ & $\begin{array}{l}\text { CONTAOL } \\
\text { ROD } \\
\text { DRIVE }\end{array}$ & $\begin{array}{l}\text { REACTOR } \\
\text { DEPRESS. }\end{array}$ & \multicolumn{2}{|c|}{\begin{tabular}{|l|l} 
CONDENSATE & HIGH \\
& PRESSURE \\
& SERVICE \\
& WATER \\
\end{tabular}} & \multirow[t]{2}{*}{$\begin{array}{l}\text { Seq. } \\
\text { Num. }\end{array}$} & \multirow{2}{*}{$\begin{array}{l}\text { Outcome of } \\
\text { Sequences } \\
14\end{array}$} \\
\hline S2d & - & - & - & $Y$ & U3' & $x^{\circ}$ & $v_{1}{ }^{\prime}$ & $V 4^{\circ}$ & & \\
\hline & & & & 2 & & & & & 25 & ctvt \\
\hline & & & & & & & & & 27 & CtF-CM \\
\hline & & & & & & & & & & $\mathrm{CtF}-\mathrm{CM}$ \\
\hline
\end{tabular}

Figure IV.4-3. Small LOCA Event Tree (Transfer Tree S2d, Page 5 of 14). 


\begin{tabular}{|c|c|c|c|c|c|c|c|c|c|c|c|}
\hline $\begin{array}{l}\text { S2, RPS } \\
\text { Succeeds, } \\
\text { PCS Fails, }\end{array}$ & $\begin{array}{l}\text { HPCI } \\
\text { Succeeds, } \\
\text { RHA Fails, } \\
\text { CAD Fails, }\end{array}$ & $\begin{array}{l}\text { Reactor } \\
\text { Depress., }\end{array}$ & $\begin{array}{l}\text { Condensate } \\
\text { Fails, } \\
\text { LPCS and } \\
\text { LPCI Fail. }\end{array}$ & $\begin{array}{l}\text { HPSWS } \\
\text { Fails } \\
\end{array}$ & \begin{tabular}{|l} 
CONTAIN. \\
INJECTION \\
AND \\
VENTING \\
\end{tabular} & $\begin{array}{l}\text { CONTROL } \\
\text { ROD } \\
\text { DRIVE }\end{array}$ & $\begin{array}{l}\text { REACTOA } \\
\text { DEPRESS. }\end{array}$ & \multicolumn{2}{|c|}{\begin{tabular}{|l} 
CONDENSATE \\
$\qquad \begin{array}{l}\text { HIGH } \\
\text { PRESSURE } \\
\text { SEAVICE } \\
\text { WATER }\end{array}$ \\
\end{tabular}} & \multirow[t]{2}{*}{$\begin{array}{l}\text { Seq. } \\
\text { Num. }\end{array}$} & \multirow[t]{2}{*}{$\begin{array}{l}\text { Outcome of } \\
\text { Sequences }\end{array}$} \\
\hline S2e & - & - & - & - & $Y$ & U $9^{\circ}$ & $x^{\prime}$ & $\mathrm{VI}^{\circ}$ & $14^{\circ}$ & & \\
\hline \multicolumn{10}{|c|}{8} & \multirow{2}{*}{$\begin{array}{l}29 \\
30 \\
31\end{array}$} & \multirow{2}{*}{$\begin{array}{l}C M-C t V t \\
C M-C t F \\
C M-C t F\end{array}$} \\
\hline & & \\
\hline
\end{tabular}

Figure IV.4-3. Small LOCA Event Tree (Transfer Tree S2e, Page 6 of 14). 


\begin{tabular}{|c|c|c|c|c|c|c|c|c|c|c|}
\hline $\begin{array}{l}\text { S2, RPS } \\
\text { Succeeds, } \\
\text { PCS Fails, }\end{array}$ & $\begin{array}{l}\text { HPCI } \\
\text { Succeeds, } \\
\text { RHR } \\
\text { Fails, } \\
\end{array}$ & $\begin{array}{l}\text { CAD } \\
\text { Fails, }\end{array}$ & $\begin{array}{l}\text { Depress. } \\
\text { Fails }\end{array}$ & $\begin{array}{l}\text { CONTAIN. } \\
\text { INJECTION } \\
\text { AND } \\
\text { VENTING } \\
\end{array}$ & $\begin{array}{l}\text { CONTAOL } \\
\text { ROD } \\
\text { DRIVE }\end{array}$ & $\begin{array}{l}\text { AEACTOR } \\
\text { DEPRESS. }\end{array}$ & CONDENS & $\begin{array}{l}\text { HIGH } \\
\text { PRESSURE } \\
\text { SERVICE } \\
\text { WATER } \\
\end{array}$ & \multirow[t]{2}{*}{$\begin{array}{l}\text { Seq. } \\
\text { Num. }\end{array}$} & \multirow[t]{2}{*}{$\begin{array}{l}\text { Outcome of } \\
\text { Sequences }\end{array}$} \\
\hline S2f & - & - & - & $Y$ & U3' & $x^{\prime}$ & $V_{1}{ }^{\prime}$ & V4' & & \\
\hline \multicolumn{9}{|c|}{8} & \multirow{2}{*}{32} & \multirow{2}{*}{$\begin{array}{l}C M-C t V t \\
C M-C t F\end{array}$} \\
\hline \multicolumn{9}{|c|}{ (2) 10} & & \\
\hline
\end{tabular}

Figure IV.4-3. Small LOCA Event Tree (Transfer Tree S2f, Page 7 of 14). 


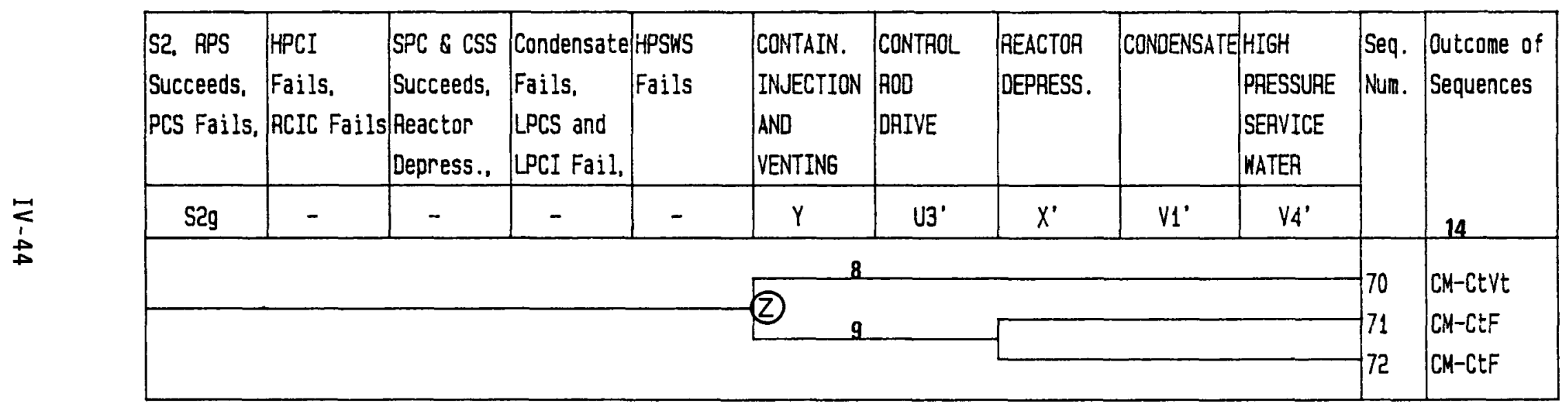

Figure IV.4-3. Small LOCA Event Tree (Transfer Tree S2g, Page 8 of 14). 


\begin{tabular}{|c|c|c|c|c|c|c|c|c|c|}
\hline $\begin{array}{l}\text { S2, APS } \\
\text { Succeeds, } \\
\text { PCS Fails, }\end{array}$ & $\begin{array}{l}\text { HPCI and } \\
\text { RCIC Fail, } \\
\text { SPC \& CSS } \\
\text { Succeeds, }\end{array}$ & $\begin{array}{l}\text { Depress. } \\
\text { Fails }\end{array}$ & $\begin{array}{l}\text { CONTAIN. } \\
\text { INJECTION } \\
\text { AND } \\
\text { VENTING } \\
\end{array}$ & $\begin{array}{l}\text { CONTROL } \\
\text { ROD } \\
\text { DRIVE }\end{array}$ & $\begin{array}{l}\text { REACTOR } \\
\text { DEPRESS. }\end{array}$ & CONDENSATE & \begin{tabular}{|l} 
HIGH \\
PRESSURE \\
SERVICE \\
WATER \\
\end{tabular} & \multirow[t]{2}{*}{$\begin{array}{l}\text { Seq. } \\
\text { Num. }\end{array}$} & \multirow[t]{2}{*}{$\begin{array}{l}\text { Outcome of } \\
\text { Sequences }\end{array}$} \\
\hline S2h & - & - & $Y$ & U3' & $x^{\prime}$ & $V 1^{\prime}$ & $\mathrm{V}^{\prime}$ & & \\
\hline \multicolumn{8}{|c|}{8} & \multirow{2}{*}{-73} & \multirow{2}{*}{$\begin{array}{l}C M-C t V t \\
C M-C t F\end{array}$} \\
\hline & & & \multicolumn{5}{|l|}{ (2) 10} & & \\
\hline
\end{tabular}

Figure IV.4-3. Small LOCA Event Tree (Transfer Tree S2h, Page 9 of 14). 


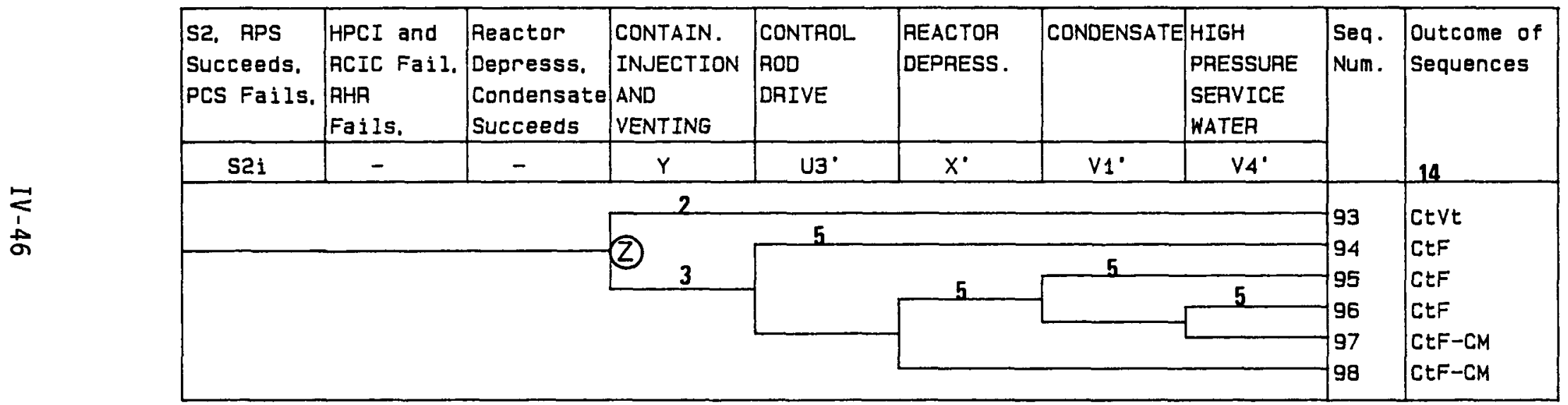

Figure IV.4-3. Small LOCA Event Tree (Transfer Tree S2i, Page 10 of 14). 


\begin{tabular}{|c|c|c|c|c|c|c|c|c|c|c|}
\hline $\begin{array}{l}\text { S2, RPS } \\
\text { Succe日ds, } \\
\text { PCS Fails. }\end{array}$ & $\begin{array}{l}\text { MPCI and } \\
\text { HCIC fail. } \\
\text { RHA } \\
\text { Fails. } \\
\end{array}$ & \begin{tabular}{|l|} 
Reactor \\
Depress.. \\
Condensate \\
Fails \\
\end{tabular} & $\begin{array}{l}\text { LPCS } \\
\text { Succeeds } \\
\end{array}$ & $\begin{array}{l}\text { CONTAIN. } \\
\text { INJECTION } \\
\text { AND } \\
\text { VENTING } \\
\end{array}$ & $\begin{array}{l}\text { CONTAOL } \\
\text { ROD } \\
\text { DAIVE }\end{array}$ & $\begin{array}{l}\text { REACTOR } \\
\text { DEPRESS. }\end{array}$ & \multicolumn{2}{|c|}{ 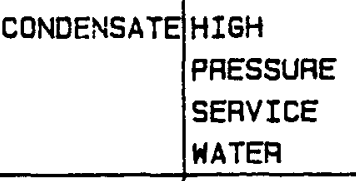 } & \multirow[t]{2}{*}{$\begin{array}{l}\text { Seq. } \\
\text { Num. }\end{array}$} & \multirow[t]{2}{*}{$\begin{array}{l}\text { Outcome of } \\
\text { Sequencess }\end{array}$} \\
\hline 521 & - & - & - & $Y$ & U3. & $x^{\circ}$ & $v_{1}$. & $V_{4}{ }^{\circ}$ & & \\
\hline & & & & 12 & & & & & 99 & CtVt \\
\hline & & & & & & & & & & \\
\hline & & & & & & & & & & \\
\hline & & & & & & & & & 105 & CtF-CM \\
\hline
\end{tabular}

Figure IV.4-3. Small LOCA Event Tree (Transfer Tree S2j, Page 11 of 14). 


\begin{tabular}{|c|c|c|c|c|c|c|c|c|c|c|}
\hline $\begin{array}{l}\text { S2, RPS } \\
\text { Succeeds. } \\
\text { PCS Fails. }\end{array}$ & $\begin{array}{l}\text { HPCI and } \\
\text { RCIC fail. } \\
\text { AHR } \\
\text { Fails. }\end{array}$ & $\begin{array}{l}\text { Reactor } \\
\text { Derress.. } \\
\text { Condensate } \\
\text { Fails. }\end{array}$ & $\begin{array}{l}\text { LPCS and } \\
\text { LPVI Fail. } \\
\text { HPSWS } \\
\text { Succeeds }\end{array}$ & $\begin{array}{l}\text { CONTAIN. } \\
\text { INJECTION } \\
\text { AND } \\
\text { VENTING } \\
\end{array}$ & $\begin{array}{l}\text { CONTROL } \\
\text { ROD } \\
\text { DRIVE }\end{array}$ & $\begin{array}{l}\text { REACTOA } \\
\text { DEPRESS. }\end{array}$ & CONDENSAT & \begin{tabular}{|l} 
HIGH \\
PRESSURE \\
SERVICE \\
WATER \\
\end{tabular} & \multirow[t]{2}{*}{$\begin{array}{l}\text { Seq. } \\
\text { Num. }\end{array}$} & \multirow{2}{*}{$\begin{array}{l}\text { Outcome of } \\
\text { Sequences } \\
14\end{array}$} \\
\hline sek & - & $1-$ & - & $Y$ & U3' & $x^{\prime}$ & $v_{1}^{\prime}$ & $V_{4}$ & & \\
\hline \multicolumn{9}{|c|}{2} & \multirow{2}{*}{$\begin{array}{l}113 \\
114\end{array}$} & \multirow{3}{*}{$\begin{array}{l}\text { CtVt } \\
\text { CtF } \\
\text { CtF } \\
\text { CtF-CM } \\
\text { CtF-CM }\end{array}$} \\
\hline & & & & (2) & & & & & & \\
\hline & & & & & & & & & 117 & \\
\hline
\end{tabular}

Figure IV.4-3. Small LOCA Event Tree (Transfer Tree S2k, Page 12 of 14). 
(1) 2 pump CRD operation is considered (see section IV.4.6.1) since HPCI (Or RCIC) operation would cool the core for $\sim 8$ hours or more before HPCI/RCIC fail on high pool temperature. By this time, the decay heat load is low and flow out the break is low because of vessel depressurization effects.

(2) With no containment heat removal, venting is eventually required. When successful venting occurs, the LPCS/LPCI/RHR pumps are assumed to fail (see generic assumptions). The cooling system operating before venting takes place should not be affected by venting operation; hence, no other event choices are shown.

(3) Containment fails by overpressure. The suppression pool achieves saturated conditions failing LPCS/LPCI/RHR (see generic assumptions). Since survivability of other previously operating systems is in question, choices are provided following this point in the tree for previously successful systems. Also, SRV considerations per NOTE (7) apply.

(4) Since containment failure has occurred, success or failure of continued CRD operation is considered because of the possible phenomenological effects (e.g., damage to the system as a result of containment failure) or failure to run considerations (note CRD was operating earlier).

(5) See additional criteria considerations, section IV.4.6.1.

(6) With venting success (at $\sim 60$ psig in containment), continued depressurization success is assumed since air pressure to SRVs is $100-t 0-125$ psig. With assumed LPCS/LPCI failure at pool saturated conditions, only HPSW success is considered since failures of CRD and Condensate are already part of this sequence.

(7) With containment failure and the earlier or subsequent assumed loss of LPCS and LPCI, depressurization success is reconsidered because of the containment failure at 2150 psig. Before the containment fails, a loss of SRV control is expected since the SRV air pressure capabilities are $100-t o-125$ psig. Hence, the valves will close because of the containment back pressure until the containment pressure drops below 125 psig. Simple calculations by sandia personnel show that core damage should not occur before SRV control and coolant injection are reestablished. Only HPSW is considered as a late injection source since CRD and condensate failures occurred earlier in the sequence. 
(8) Core damage occurs. Venting can only save the containment.

(9) Core damage and containment failure occur. Depressurization success or failure (X' event) only provides information as to vessel pressure conditions at vessel breach.

(10) Like NOTE 9 (above) except depressurization has already failed and is assumed to remain failed (could be conservative).

(11) W3 event is given a choice even though RHR-SPC mode is successful so as to consider fission product removal capability of sprays for subsequent sequences leading to core damage.

(12) CRD and HPSW are considered after venting success since LPCS and LPCI are assumed to fail and the condition of both CRD and HPSW have not yet been determined in the sequence.

(13) Like NOTE 12 (above) except containment has failed and so depressurization must be reconsidered due to phenomena explained by NOTE 7 (above) .

(14) "Outcome" key:

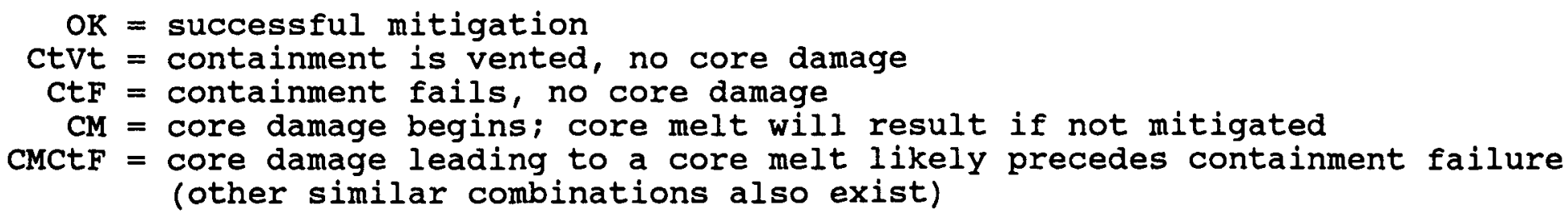

(15) A containment isolation signal will be present once drywell pressure reaches approximately $2 \mathrm{psig.} \mathrm{This} \mathrm{will} \mathrm{close} \mathrm{off} \mathrm{the} \mathrm{nitrogen} \mathrm{supply} \mathrm{to} \mathrm{the} \mathrm{MSIVs.}$ However, the MSIVs do not isolate on high drywell pressure and will remain open for approximately 1 hour (based on actual tests at Peach Bottom) because of the accumulators on the valves. One of the first steps in the Emergency Procedure Guidelines (EPGs) is to re-open the nitrogen supply lines so as to maintain the PCS as the preferred heat sink. Therefore, PCS availability for a small LOCA is considered. 
$\underline{x}: \quad$ Success or failure of primary system depressurization. Success implies automatic or manual operation of the ADS or manual operation of other SRVs such that two valves or more are opened allowing low pressure injection.

V1: Success or failure of the Condensate system. Success implies at least one pump operating with sufficient makeup to the condenser hotwell for a continuing water supply.

V2: Success or failure of the LPCS system. Success implies operation of any two of the four LPCS pumps through either or both LPCS injection lines.

V3: $\quad$ Success or failure of the LPCI mode of the RHR system. Success implies operation of one of four LPCI pumps through either LPCI injection line to the reactor vesse?.

V4: Success or failure of the HPSW system in the inject mode to the reactor vessel through a LPCI injection line. Success implies manual operation of this injection source such that one HPSW pump successfully provides coolant to the reactor.

Y: $\quad$ Success or failure of containment venting. Success implies that the 6" integrated leak test line or larger size line is open so as to prevent containment failure by overpressure. As necessary, water makeup is also eventually supplied to the suppression pool.

$\underline{\mathrm{U}^{\prime}, \mathrm{X}^{\prime}, \mathrm{V}^{\prime}, \mathrm{V}^{\prime}{ }^{*}}$ : $\quad$ See U3, X,V1,V4

\section{Sequences}

The following descriptions refer to the sequences found in Figure IV.4-3.

Sequence 1:

Following the small LOCA, successful reactor scram has occurred. The PCS remains operable, successfully mitigating the event before containment temperature and pressure reach levels of concern (Note: some heat goes out the break.)

*Events with a' designate that choices for these events occur after the choice for event "Y." Both success and failure of "Y" potentially lead to saturated conditions in the suppression pool which conservatively are assumed to result in the loss of all systems using the pool as the injection source (see first general assumption--Section IV.4.2). This places the reactor core in a so-called "core vulnerable" state since core damage will occur unless injection is restored by one of the systems designated with a - (These systems do not use the suppression pool as the injection water source.) 
Sequences 2-3:

Like Sequence 1 above except PCS fails. Coolant injection is supplied by HPCI with successful containment cooling by the SPC or CS mode of RHR.

Sequence 4 :

Reactor scram and coolant injection with HPCI are initially successful but containment cooling is failed. HPCI subsequently fails because of the auto transfer of its suction source to the suppression pool on high pool level followed by rising pool temperatures into the $210-260 \mathrm{~F}$ range. The operator initiates (or already has initiated) two pump CRD flow which is adequate to cool the core. Containment venting subsequently takes place when the containment pressure rises to 60 psig. Since venting should not affect the continued operation of the CRD as an injection source (the pumps, critical valves, and controls are outside the reactor building), the sequence leads to a vented containment with no core damage.

Sequences 5-7:

Like Sequence 4 above except venting failure occurs. This leads to containment failure but with continued success of core cooling by CRD, Condensate, or HPSW and hence no core damage occurs.

Sequences 8-9:

Like Sequences 5-7 above except core cooling subsequently fails with the reactor vessel at low or high pressure respectively.

Sequences 10-28:

Similar to Sequences 4-9 above except after HPCI failure, core cooling is subsequently supplied by depressurization and success of one of the following: Condensate, LPCS, LPCI, HPSW. Containment venting or containment failure then occurs since containment cooling by RHR is failed. Sequences then result in no core damage or core damage depending on the success or failure of long term core cooling after the containment is either vented or failed.

Sequence 29:

The reactor scrams and core cooling is provided by HPCI until the pool temperature reaches 210 - $2600 \mathrm{~F}$ since all containment cooling has failed. All core cooling then fails leading to core damage. The containment is successfully vented.

Sequences 30-31:

Like Sequence 29 except venting fails, containment failure occurs, and the reactor vessel is likely to be at low or high pressure, respectively, when vessel breach occurs. 
Sequences 32-33:

The reactor is not depressurized following HPCI failure when the pool temperature reaches the 210 - 2600 F range and CRD failure. Core damage occurs with the containment either vented or failed, respectively.

Sequences 34-65:

Correspond to Sequences 2-33 above except HPCI fails initially but RCIC is successful. RCIC is manually transferred to the pool for suction and so also fails on high pool temperature.

Sequences 66-69:

HPCI and RCIC initially fail after successful reactor scram. Containment cooling is provided. The operator successfully depressurizes and uses Condensate, LPCS, LPCI, or HPSW for coolant injection.

Sequences 70-74:

After reactor scram, no core cooling is provided resulting in early core damage. Containment cooling is successful but it is assumed that non-condensible formation ultimately results in the need for containment venting. Venting is successful in Sequences 70 and 73 ; otherwise, containment failure subsequently occurs. Note that Containment Spray (CS mode of RHR) is available up until the time of containment venting or failure. Then RHR pump failure on low NPSH is assumed from saturated conditions in containment.

Sequences 75-83:

Like Sequences 66-74 except the CS mode of RHR is not available.

Sequences 84-92:

Like Sequences 66-74 except the SPC mode of RHR is unavailable.

Sequences 93-122:

Similar to Sequences 4-33 above. Note that HPCI and RCIC initially fail and containment cooling fails. Outcomes then depend on success or failure of alternate core cooling, containment venting, and continued long-term cooling of the core.

IV.4.7 Small-Small (Recirculation Pump Seal) LOCA Event Tree

IV.4.7.1 Introduction

The recirculation pump seal LOCA (S3) was treated as either a small (S2) liquid LOCA or a transient with PCS initially available (T3A) depending on early actions of the operator (see Table IV.3-4 for corresponding success criteria). Experience suggests that the small-small LOCA category is dominated by recirculation pump seal failures. Such a leak would be easily identifiable for two reasons. First, the sources of such leaks are well-instrumented on recirculation pumps. Secondly, 
the Peach Bottom Emergency Procedure Guidelines (EPGs) call for the operator to first suspect a pump seal leak if drywell pressure begins to rise or unidentified leakage is detected. Procedures call for slowdown of the problem pump and then isolation of the pump. PCS operation would probably not be interrupted and power operation could possibly continue for a period of time.

\section{IV.4.7.2 Event Tree}

The Smal1-Small LOCA event tree is depicted by Figure IV.4-4. The S3 LOCA analysis and the corresponding event tree assume that conditions proceed to the need for a reactor scram. Otherwise, if the operator should detect and isolate the leak before a reactor trip, the plant simply "rides" through the event resulting in no real challenge to the plant.

\section{Event Tree Headings}

The events in the tree include the following:

$$
\begin{aligned}
& \text { S3: Initiating event, small-small LOCA ( } 50 \text {-to-100 gpm maximum) } \\
& \text { ․: } \\
& \text { Success or failure of the Reactor Protection System (RPS). } \\
& \text { Success implies scram by the control rods. } \\
& \text { Success or failure of leak detection and isolation. Success } \\
& \text { implies the operator detects and isolates the leaky pump thus } \\
& \text { stopping the LOCA. With the reactor scrammed, the event } \\
& \text { becomes a transient with PCS most likely available. } \\
& \text { The course of events then follows the S2 LOCA or T3A } \\
& \text { transient tree as shown. See those tree descriptions for } \\
& \text { more information. }
\end{aligned}
$$

\section{Sequences}

The following descriptions refer to the sequences found in Figure IV.4-4.

Sequence 1:

Reactor trip occurs and the operator successfully isolates the leak. The scenario proceeds like a T3A transient.

Sequence 2:

Reactor trip occurs but the leak is not isolated. The scenario proceeds similar to a S2 LOCA.

Sequence 3:

This sequence represents an S3-ATWS scenario. Since conditions were assumed not to be significantly worse than for a transient-caused ATWS (SRVs are likely to be open during a transient causing a small "LOCA"), this sequence was not specifically analyzed. Because of the relative probabilities of transients to $S 3$ LOCAs ( $-5 / y r$ to $\sim 1 E-2 / y r)$, it was judged that the $\$ 3$ scenario could be reasonably neglected. 


\begin{tabular}{|c|c|c|c|l|}
\hline $\begin{array}{l}\text { SMALL- } \\
\text { SMALL } \\
\text { LOCA }\end{array}$ & $\begin{array}{l}\text { REACTOR } \\
\text { PROTECTION } \\
\text { SYSTEM }\end{array}$ & $\begin{array}{l}\text { OPERATOR } \\
\text { ISOLATES } \\
\text { LEAK }\end{array}$ & $\begin{array}{l}\text { Seq. } \\
\text { Num. }\end{array}$ & $\begin{array}{l}\text { OutCome of } \\
\text { Sequences } \\
\text { and Tree } \\
\text { Transfer }\end{array}$ \\
\hline S3 & C & L & 1 & $\begin{array}{l}\text { Tree T3A at } \mathbb{8} \\
\text { S2 Tree at } \mathbb{O} \\
\text { See Text }\end{array}$ \\
\hline
\end{tabular}

Figure IV.4-4. Small-Small LOCA Event Tree. 


\section{IV.4.8 Loss of Offsite Power Event Tree}

This section contains information on the Loss of Offsite Power event tree. Success criteria considerations are presented along with the event tree and its description.

\section{IV.4.8.1 Success Criteria}

Table IV.4-4 duplicates that portion of the success criteria presented in Table IV.3-4 that pertains to the loss of offsite power initiator. Additional clarification is provided with accompanying notes. Besides the criteria presented, two additional criteria specific to the loss of offsite power initiator are described below.

(1) For scenarios in which core cooling has been provided for a period of approximately 6-8 hours or more, one CRD pump operation is considered adequate for continued success of core cooling. This is based on the low decay heat levels reached by that time with no significant breach of the primary system. While the CRD failure model explicitly treats only the two pump criteria for success, single pump operation was treated as success during these long term scenarios by eliminating (by hand) failures of the CRD system which would fail only one pump.

(2) For scenarios in which core cooling is successful up to the time of containment venting or containment failure, one CRD pump or depressurization with one HPSW pump operation is considered to be adequate to continue successful core cooling.

\section{IV.4.8.2 Event Tree}

Figure IV.4-5 displays the event tree for the loss of offsite power initiator. The entire PCS, Feedwater, and Condensate systems are not shown in the tree since loss of offsite power also prevents operation of these systems. Should offsite power be restored, these systems could be used to mitigate the event. The following discussions define the event tree headings and describe the sequences presented.

\section{Event Tree Headings}

The following event tree headings appear on the tree in the approximate chronological order that would be expected following a loss of offsite power. For convenience, the RHR containment cooling choices are shown early in the tree to decrease the size of the event tree. Otherwise, the tendency is to show high and then low pressure injection systems, followed by containment venting, and finally long-term continued core cooling possibilities. In addition, onsite $A C$ is shown as a specific event so that station blackout sequences can be explicitly depicted.

$$
\begin{aligned}
& \text { I1: Initiating event, loss of offsite power } \\
& \text { C: } \\
& \begin{array}{l}
\text { Success or failure of the RPS. Success implies automatic } \\
\text { scram by the control rods. }
\end{array}
\end{aligned}
$$

(Text continued on page IV-70) 
Table IV.4-4

Success Criteria for Loss of offsite Power

(see Glossary for acronym definitions)

\begin{tabular}{|c|c|c|c|c|}
\hline IMITIATOR & $\begin{array}{c}\text { REACTOR } \\
\text { SUBCR ITICAL }\end{array}$ & $\begin{array}{l}\text { OVERPRESSURE } \\
\text { PROTECTION }\end{array}$ & $\begin{array}{l}\text { EMERGENCY } \\
\text { CORE COOLING }\end{array}$ & $\begin{array}{c}\text { RESIDUAL } \\
\text { HEAT REMOVAL }\end{array}$ \\
\hline $\mathrm{T} 1$ & $\begin{array}{l}\text { RPS } \\
\text { or } \\
\text { ARI \& RPT } \\
\text { or } \\
\text { Manual Rods } \\
\text { and RPT } \\
\text { or } \\
\text { Timely SLC } \\
\text { and RPT }\end{array}$ & SRVs open and close & $\begin{array}{c}\text { HPCI } \\
\text { or } \\
\text { RCIC } \\
\text { or } \\
\text { CRD ( full flow) } \\
\text { [see Note (a)] } \\
\text { or } \\
1 \text { FW } \\
\text { [see Note (b)] } \\
\text { or } \\
\text { DEP w/2 valves and } \\
\text { Any } 2 \text { LPCS pumps } \\
\text { or } \\
\text { DEP w/2 valves and } \\
1 \text { of } 4 \text { LPCI } \\
\text { or } \\
\text { DEP w/2 valves and } \\
1 \text { Condensate } \\
\text { [see Note (b)] } \\
\text { or } \\
\text { DEP w/2 valves and } \\
1 \text { HPSW (inject mode) } \\
\text { [see Note (c)] }\end{array}$ & $\begin{array}{c}1 \text { of } 4 \text { RHR \& HtX } \\
\text { (SDC. SPC. Spray Modes) } \\
\text { and } \\
\text { associated HPSW } \\
\text { [see Note (d)] } \\
\text { or } \\
\text { PCS } \\
\text { [see Note (b)] } \\
\text { or } \\
\text { Containment Venting } \\
\text { [see Note (e)] }\end{array}$ \\
\hline
\end{tabular}

(a) 2 CRD pump operation is considered to be required for success if CRD is the only injection source to the reactor This is based on a flow of $\sim 175-t o-200 \mathrm{gpm}$ (at high vessel pressure) needed to initially maintain core coverage

(b) These would be avallable only upon restoration of offsite power

(c) Any 2 of 4 LPCS pumps is different from past PRA criteria of 2 pumps needed in the same LPCS injection loop This is based on latest analyses per Reference 9

(d) HPSW operation is needed for the operating RHR heat exchanger

(e) At least the 6" integrated leak test line or larger size line is considered required for success Criteria based on discussions with containment analysis personnel at Sandia May be conservative 


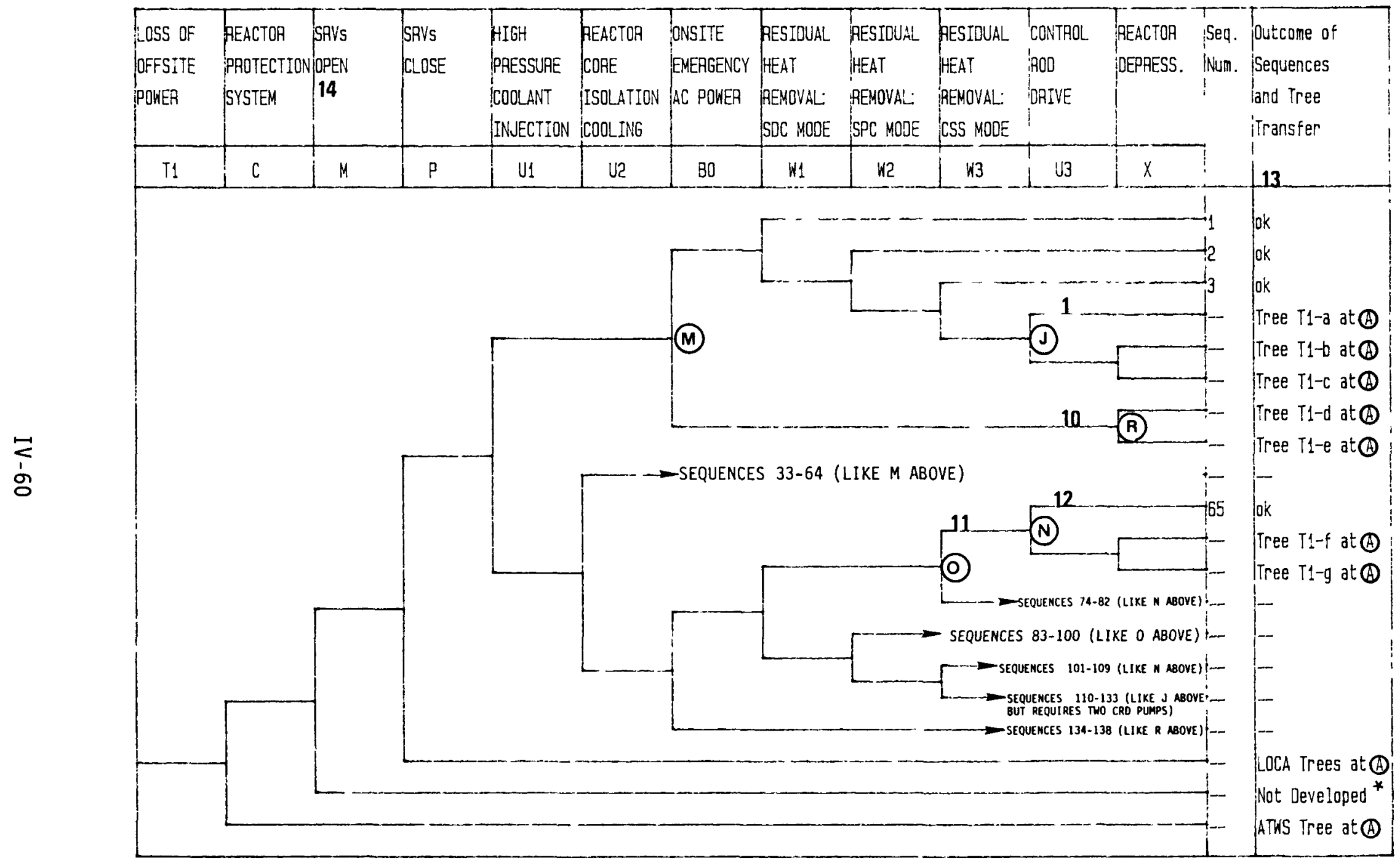

*Negligible Probability, Not Analyzed.

Figure IV.4-5. Loss of offsite Power Event Tree (Page 1 of 8 ). 


\begin{tabular}{|c|c|c|c|c|c|c|c|c|c|c|}
\hline \multirow{6}{*}{$\begin{array}{l}\underset{1}{\alpha} \\
\text { óv }\end{array}$} & $\begin{array}{l}\text { Onsite AC. } \\
\text { CAD } \\
\text { Succeeds. } \\
\text { RHA Fails }\end{array}$ & \begin{tabular}{|l} 
LOW \\
PRESSURE \\
CORE \\
SPRAY \\
\end{tabular} & $\begin{array}{l}\text { LON } \\
\text { PRESSURE } \\
\text { COOLANT } \\
\text { INJECTION } \\
\end{array}$ & \begin{tabular}{|l} 
HIGH \\
PRESSURE \\
SERVICE \\
WATER \\
\end{tabular} & $\begin{array}{l}\text { CONTAIN. } \\
\text { INUECTIION } \\
\text { AND } \\
\text { VENTING } \\
\end{array}$ & $\begin{array}{l}\text { CONTAOL } \\
\text { AOD } \\
\text { DRIVE }\end{array}$ & $\begin{array}{l}\text { REACTOR } \\
\text { DEPRESS. }\end{array}$ & $\begin{array}{l}\text { HIGH } \\
\text { PRESSURE } \\
\text { SERVICE } \\
\text { WATER } \\
\end{array}$ & \multirow[t]{2}{*}{$\begin{array}{l}\text { Seq. } \\
\text { Num. }\end{array}$} & \multirow{2}{*}{$\begin{array}{l}\text { Outcome } \\
\text { of } \\
\text { Sequences } \\
13\end{array}$} \\
\hline & - & V2 & V3 & 64 & $Y$ & U3' & $x^{\prime \prime}$ & $V 4^{\circ}$ & & \\
\hline & \multicolumn{8}{|c|}{ ) } & & \multirow{4}{*}{$\begin{array}{l}\text { CtVt } \\
C t F \\
C t F \\
C t F-C M \\
C t F-C M\end{array}$} \\
\hline & & & & & \multicolumn{4}{|c|}{$4-5$} & & \\
\hline & & & & & 3 & & 5 & 5 & \multirow{2}{*}{$\begin{array}{l}6 \\
7 \\
8\end{array}$} & \\
\hline & & & & & & & & & & \\
\hline
\end{tabular}

Figure IV.4-5. Loss of Offsite Power Event Tree (Transfer Tree T1-a, Page 2 of 8 ). 


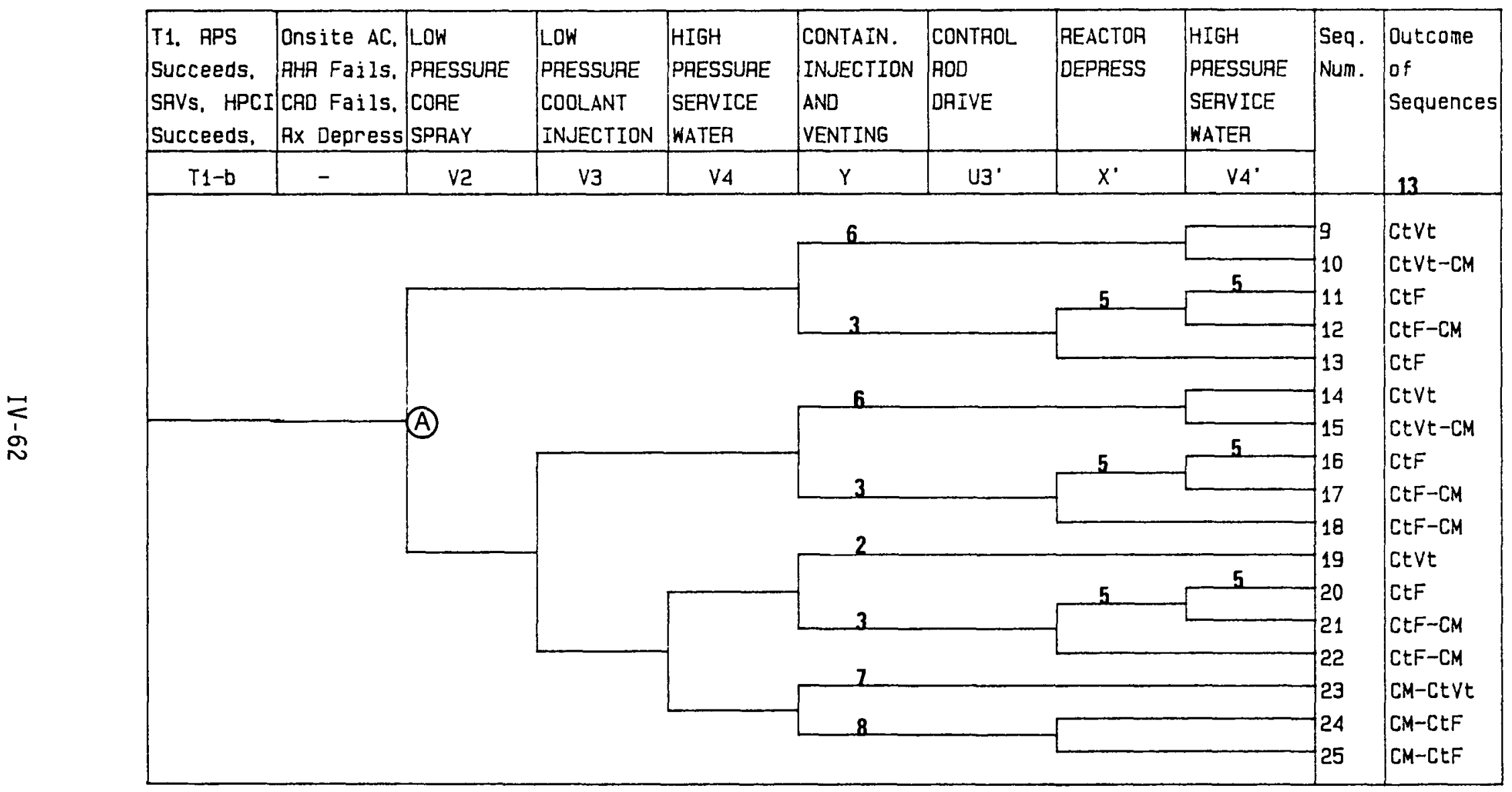

Figure IV.4-5. Loss of offsite Power Event Tree (Transfer Tree Tl-b, Page 3 of 8 ). 


\begin{tabular}{|c|c|c|c|c|c|c|c|c|c|c|}
\hline $\begin{array}{l}\text { T1, RPS } \\
\text { Succeeds, } \\
\text { SAVs, HPCI } \\
\text { Succeed, }\end{array}$ & $\begin{array}{l}\text { Onsite AC, } \\
\text { AHA \& CAD } \\
\& \text { Depress } \\
\text { Fail }\end{array}$ & $\begin{array}{l}\text { LOW } \\
\text { PRESSURE } \\
\text { CORE } \\
\text { SPRAY } \\
\end{array}$ & $\begin{array}{l}\text { LOW } \\
\text { PAESSUARE } \\
\text { COOLANT } \\
\text { INJECTION } \\
\end{array}$ & \begin{tabular}{|l} 
HIGH \\
PRESSURE \\
SEAVICE \\
WATER \\
\end{tabular} & $\begin{array}{l}\text { CONTAIN. } \\
\text { INJECTION } \\
\text { AND } \\
\text { VENTING } \\
\end{array}$ & $\begin{array}{l}\text { CONTHOL } \\
\text { ROD } \\
\text { DRIVE }\end{array}$ & $\begin{array}{l}\text { REACTOR } \\
\text { DEPRESS. }\end{array}$ & \begin{tabular}{|l} 
HIGH \\
PRESSURE \\
SERVICE \\
WATER \\
\end{tabular} & \multirow[t]{2}{*}{$\begin{array}{l}\text { Seq. } \\
\text { Num. }\end{array}$} & \multirow[t]{2}{*}{$\begin{array}{l}\text { Outcome } \\
\text { of } \\
\text { Sequences }\end{array}$} \\
\hline$T 1-c$ & - & V2 & V3 & V4 & Y & U3' & $x^{\circ}$ & $\mathrm{VA}^{\prime}$ & & \\
\hline \multicolumn{9}{|c|}{ (1) 7} & \multirow{2}{*}{$\begin{array}{l}26 \\
27\end{array}$} & \multirow{2}{*}{$\begin{array}{l}\text { CM-CtVt } \\
\mathrm{CM}-\mathrm{CtF}\end{array}$} \\
\hline \multicolumn{9}{|c|}{ (A) 9} & & \\
\hline
\end{tabular}

Figure IV.4-5. Loss of Offsite Power Event Tree (Transfer Tree Tl-C, Page 4 of 8 ). 


\begin{tabular}{|c|c|c|c|c|c|c|c|c|c|c|}
\hline \multirow[t]{2}{*}{$\begin{array}{l}\text { T1. APS } \\
\text { Succeeds, } \\
\text { SRVs, HPCI } \\
\text { Succeed. }\end{array}$} & $\begin{array}{l}\text { Onsite AC } \\
\text { Fails. } \\
\text { Reactor } \\
\text { Depress. }\end{array}$ & $\begin{array}{l}\text { LOW } \\
\text { PRESSURE } \\
\text { CORE } \\
\text { SPRAY }\end{array}$ & $\begin{array}{l}\text { LOW } \\
\text { PAESSURE } \\
\text { COOLANT } \\
\text { INJECTION }\end{array}$ & $\begin{array}{l}\text { HIGH } \\
\text { PAESSURE } \\
\text { SERVICE } \\
\text { WATER }\end{array}$ & $\begin{array}{l}\text { CONTAIN. } \\
\text { INJECTION } \\
\text { AND } \\
\text { VENTING }\end{array}$ & $\begin{array}{l}\text { CONTAOL } \\
\text { ROD } \\
\text { DAIVE }\end{array}$ & $\begin{array}{l}\text { REACTOR } \\
\text { DEPRESS. }\end{array}$ & $\begin{array}{l}\text { HIGH } \\
\text { PAESSUAE } \\
\text { SERVICE } \\
\text { WATER }\end{array}$ & \multirow[t]{2}{*}{$\begin{array}{l}\text { Seq. } \\
\text { Num. }\end{array}$} & \multirow{2}{*}{$\mid \begin{array}{l}\text { Outcome } \\
\text { of } \\
\text { Sequences } \\
13\end{array}$} \\
\hline & - & $\sqrt{2}$ & v3 & $V_{4}$ & $Y$ & U3' & $x^{\prime}$ & $V 4^{\prime}$ & & \\
\hline 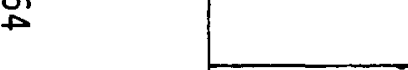 & & & & & & & & & 28 & CM-CtVt \\
\hline & & & & & & & & & 30 & $C M-C t F$ \\
\hline
\end{tabular}

Figure IV.4-5. Loss of Offsite Power Event Tree (Transfer Tree Tl-d, Page 5 of 8 ). 


\begin{tabular}{|c|c|c|c|c|c|c|c|c|c|c|}
\hline $\begin{array}{l}\text { T1. APS } \\
\text { Succeeds, } \\
\text { SAVs, HPCI } \\
\text { Succeed, }\end{array}$ & $\begin{array}{l}\text { Onsite AC } \\
\text { and } \\
\text { Depress. } \\
\text { Fail }\end{array}$ & $\begin{array}{l}\text { LOW } \\
\text { PAESSURE } \\
\text { CORE } \\
\text { SPAAY } \\
\end{array}$ & \begin{tabular}{|l} 
LOW \\
PRESSURE \\
COOLANT \\
INJECTION
\end{tabular} & \begin{tabular}{|l} 
HIGH \\
PRESSURE \\
SERVICE \\
WATER \\
\end{tabular} & $\begin{array}{l}\text { CONTAIN. } \\
\text { INJECTION } \\
\text { AND } \\
\text { VENTING } \\
\end{array}$ & $\begin{array}{l}\text { CONTAOL } \\
\text { ROD } \\
\text { DRIVE }\end{array}$ & $\begin{array}{l}\text { REACTOR } \\
\text { DEPRESS }\end{array}$ & \begin{tabular}{|l} 
HIGH \\
PRESSURE \\
SERVICE \\
WATER \\
\end{tabular} & \multirow[t]{2}{*}{$\begin{array}{l}\text { Seq. } \\
\text { Num. }\end{array}$} & \multirow[t]{2}{*}{$\begin{array}{l}\text { Outcome } \\
\text { of } \\
\text { Sequences }\end{array}$} \\
\hline$T 1-\mathrm{e}$ & - & V2 & V3 & $V_{4}$ & $Y$ & U3' & $x^{\prime}$ & $\mathrm{VA}^{\prime}$ & & \\
\hline & & & & & (A) & & & & 31 & CM-CtVt \\
\hline
\end{tabular}

Figure IV.4-5. Loss of Offsite Power Event Tree (Transfer Tree T1-e, Page 6 of 8 ). 


\begin{tabular}{|c|c|c|c|c|c|c|c|c|c|c|c|}
\hline \multirow{7}{*}{ そ } & $\begin{array}{l}\text { HPCIERCIC } \\
\text { Fail. } \\
\text { Onsite AC } \\
\text { Succeeds. }\end{array}$ & $\begin{array}{l}\text { RHA \& } \\
\text { Depress. } \\
\text { Succeed. } \\
\text { CAD Fails }\end{array}$ & $\begin{array}{l}\text { LOW } \\
\text { PRESSURE } \\
\text { CORE } \\
\text { SPRAY } \\
\end{array}$ & $\begin{array}{l}\text { LOW } \\
\text { PRESSURE } \\
\text { COOLANT } \\
\text { INJECTION }\end{array}$ & \begin{tabular}{|l} 
HIGH \\
PRESSURE \\
SERVICE \\
WATER \\
\end{tabular} & $\begin{array}{l}\text { CONTAIN. } \\
\text { INJECTION } \\
\text { AND } \\
\text { VENTING } \\
\end{array}$ & $\begin{array}{l}\text { CONTROL } \\
\text { ROD } \\
\text { DRIVE }\end{array}$ & $\begin{array}{l}\text { REACTOR } \\
\text { DEPRESS. }\end{array}$ & \begin{tabular}{|l} 
HIGH \\
PRESSURE \\
SERVICE \\
WATER \\
\end{tabular} & \multirow[t]{2}{*}{$\begin{array}{l}\text { Seq. } \\
\text { Num. }\end{array}$} & \multirow{2}{*}{$\begin{array}{l}\text { Dutcome } \\
\text { of } \\
\text { Sequences } \\
13\end{array}$} \\
\hline & - & - & ve & v3 & V4 & $Y$ & U3' & $\mathrm{X}^{\circ}$ & $V_{4}{ }^{\prime}$ & & \\
\hline & & & & & & & & & & 66 & lok \\
\hline & & & (A) & & & & & & & 67 & ok \\
\hline & & & & & & 7 & & & & 0 & oK \\
\hline & & & & & & 8 & & & & 70 & CM-CtF \\
\hline & & & & & & & & & & & CM-CtF \\
\hline
\end{tabular}

Figure IV.4-5. Loss of Offsite Power Event Tree (Transfer Tree Tl-f, Page 7 of 8 ). 


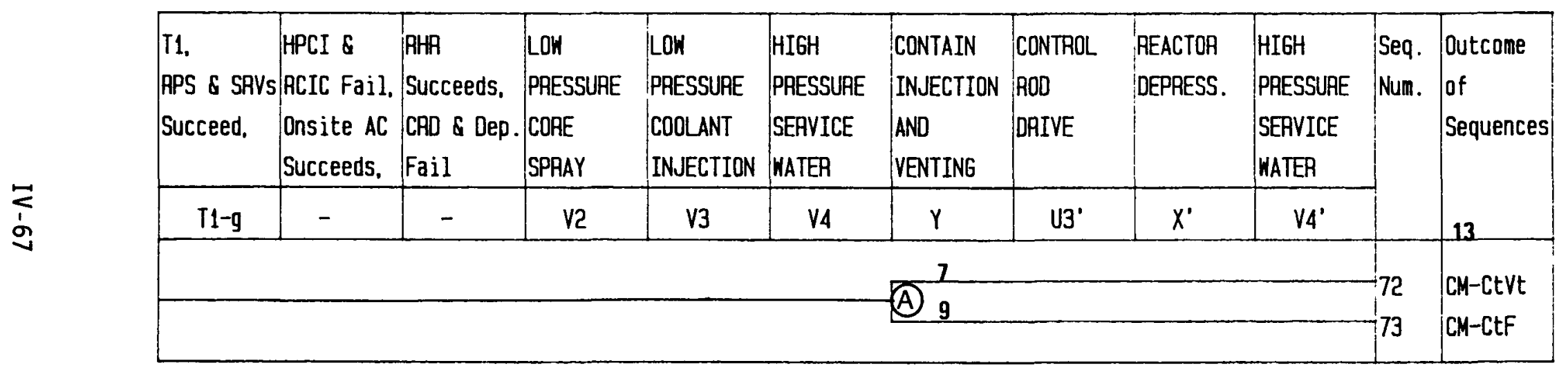

Figure IV.4-5. Loss of Offsite Power Event Tree (Transfer Tree Tl-g, Page 8 of 8 ). 
(1) 1 pump CRD operation is considered here (see section IV.4.8.1) since HPCI (Or RCIC) operation would cool the core for $\sim 8$ hours or more before HPCI/RCIC fail on high pool temperature. By this time, the decay heat load is low and there is no significant breach of the primary system.

(2) With no containment heat removal, venting is eventually required. When successful venting occurs, the LPCS/LPCI/RHR pumps are assumed to fail (see generic assumptions). The cooling system operating before venting takes place should not be affected by venting operation; hence, no other event choices are shown.

(3) Containment fails by overpressure. The suppression pool achieves saturated conditions failing LPCS/LPCI/RHR (see generic assumptions). Since survivability of other previously operating systems is in question, choices are provided following this point in the tree for previously successful systems. Also note that since air capacity to the SRVs for depressurization is $100-125$ psig and containment failure is at $\sim 150$ psig, loss of SRV control is expected until containment failure occurs.

(4) Since containment failure has occurred, success or failure of continued CRD operation is considered due to possible phenomenological effects (e.g., damage to the system as a result of containment failure) or failure to run considerations (note CRD was operating earlier).

(5) See additional criteria considerations, section IV.4.8.1.

(6) With venting success (at -60 psig in containment), continued depressurization success is assumed since air pressure to sRVs is -100-125 psig. with assumed LPCS/LPCI failure at pool saturated conditions, only HPSW is available for success.

(7) Core damage occurs. Venting can only save the containment.

(8) Core damage and containment failure occur. Depressurization success or failure (X' event) only provides information as to vessel pressure conditions at vessel breach. 
(9) Like NOTE 8 (on previous page) except depressurization has already failed and is assumed to remain failed (could be conservative).

(10) Station blackout leads to core damage. Depressurization choices only provide information as to vessel pressure at time of breach and venting choices depict whether containment is vented or failed.

(11) W3 event is given a choice even though another mode of RHR is successful so as to consider fission product removal capability of sprays for subsequent sequences leading to core damage.

(12) 2 pump CRD operation is considered here since no other successful coolant injection has occurred and it is still early in the sequence when decay heat loads are relatively high.

(13) "Outcome" Key:

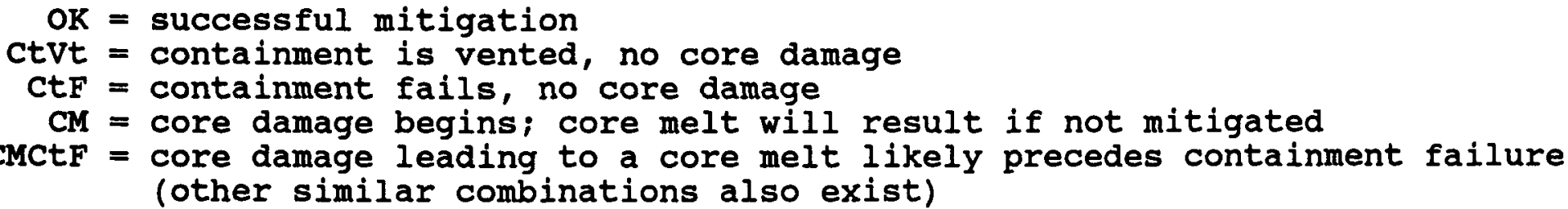

(14) SRV demands are assumed on a loss of offsite power to control any initial pressure rise in the primary system. 
M: $\quad$ Success or failure of Reactor Coolant System (RCS) overpressure protection (if required) by automatic operation of the SRVs. Success implies prevention of RCS overpressure so as to avoid damage to the primary system.

P: $\quad$ Success or failure associated with reclosing of any SRVs which should open in response to reactor vessel pressure rises throughout the sequence. Success implies reclosure of all valves when vessel pressure drops below the closure setpoints.

U1: Success or failure of the HPCI system. Success implies operation of the HPCI pump train so as to maintain sufficient coolant injection.

U2: Success or failure of the RCIC system. Success implies operation of the RCIC pump train so as to maintain sufficient coolant injection.

B0: Success or failure of the onsite AC power system (diesel generators and associated equipment and emergency buses) in response to the loss of offsite power. Success implies operation of at least one emergency $A C$ power division so that $A C$-powered mitigating systems can be utilized. Failure implies loss of all AC, or station blackout.

W1,W2,W3: Success or failure of the RHR system in the SDC mode, SPC mode, or CS mode, respectively. Success implies at least one RHR pump operating in any one of the three modes with the appropriate heat exchanger in the loop along with the HPSW system in operation to the ultimate heat sink.

U3: $\quad$ Success or failure of the CRD system as an injection source. Success implies two pump operation unless other cooling systems have provided injection for at least 6-8 hours or more. Then single pump operation is adequate for success.

X: $\quad$ Success or failure of primary system depressurization. Success implies automatic or manual operation of the ADS or manual operation of other SRVs such that two valves or more are opened allowing low pressure injection.

V2: Success or failure of the LPCS system. Success implies operation of any two of the four LPCS pumps through either or both LPCS injection lines.

V3: Success or failure of the LPCI mode of the RHR system. Success implies operation of one of four LPCI pumps through either LPCI injection 1 ine to the reactor vessel.

V4: Success or failure of the HPSW system in the inject mode to the reactor vessel through a LPCI injection line. Success implies manual operation of this injection source such that one HPSW pump successfully provides coolant to the reactor. 
Y: $\quad$ Success or failure of containment venting. Success implies that the 6" integrated leak test line or larger size line is open so as to prevent containment failure by overpressure. As necessary, water makeup is also eventually supplied to the suppression pool.

$\underline{U_{3}^{\prime}, X^{\prime}, V^{\prime}{ }^{*}}$ : See U3,X,V4

\section{Sequences}

The following descriptions refer to the sequences found in Figure IV.4-5.

Sequences 1-3:

Following the loss of offsite power, successful reactor scram has occurred. The SRVs have properly cycled to control primary pressure and core cooling is provided by HPCI. Containment cooling is provided by the SDC, SPC, or CS mode of RHR resulting in successful mitigation of the event.

Sequence 4:

Like Sequences 1-3 above except all containment cooling is failed. HPCI subsequently fails because of the auto transfer of its suction source to the suppression pool on high pool level followed by rising pool temperatures into the $210-2600 \mathrm{~F}$ range. The operator initiates (or already has initiated) CRD flow which is adequate to cool the core. Containment venting is performed when the containment pressure rises to 60 psig. Since venting should not affect the continued operation of the CRD as an injection source (the pumps, critical valves, and controls are outside the reactor building), the sequence leads to a vented containment with no core damage.

Sequences 5-6:

Like Sequence 4 above except venting fails. This leads to containment failure but with continued success of core cooling by CRD or with depressurization and HPSW.

Sequences 7-8:

Like Sequences 5-6 above except core cooling subsequently fails with the reactor vessel at low or high pressure respectively.

*Events with a' designate the choices for these events occur after the choice for event "Y." Both success and failure of "Y" potentially lead to saturated conditions in the suppression pool which conservatively are assumed to result in the loss of all systems using the pool as the injection source (see first general assumption--Section IV.4.2). This places the reactor core in a so-called "core vulnerable" state since core damage will occur unless injection is restored by one of the systems designated with a $\because$ (These systems do not use the suppression pool as the injection water source.) 
Sequences 9-22:

Similar to Sequences 4-8 except after HPCI failure, core cooling is subsequently supplied by depressurization and success of LPCS, LPCI, or HPSW. Containment venting or containment failure then occurs since containment cooling by RHR is failed. Sequences then result in no core damage or core damage depending on the success or failure of long term core cooling after the containment is either vented or failed.

Sequence 23:

The reactor scrams and core cooling is provided by HPCI until the pool temperature reaches $210-260^{\circ} \mathrm{F}$ since all containment cooling has failed. All core cooling then fails leading to core damage. The containment is successfully vented.

Sequences 24-25:

Like Sequence 23 except venting fails, containment failure occurs, and the reactor vessel is likely to be at low or high pressure respectively when vessel breach occurs.

Sequences 26-27:

The reactor is not depressurized following HPCI failure when the pool temperature reaches the 210 - 2600F range and CRD failure. Core damage occurs with the containment either vented or failed, respectively.

Sequences 28-32:

Station blackout occurs and HPCI continues to operate until failure by battery depletion (assumed as 6 hours with input from PECO) or possibly a variety of other reasons such as high pool temperature, isolation on high temperature sensed by steam line monitors, etc. All instrumentation and injection are lost leading to core damage. Other choices indicate status of containment venting and pressure of vessel during most of the sequence. Note that when batteries are lost, SRV control is lost so that vessel repressurization will occur.

Sequences 33-64:

Correspond to Sequences 1-32 above except HPCI fails initially but RCIC is successful. RCIC is manually transferred to the pool for suction and so also fails on high pool temperature. For the station blackout scenarios, RCIC failure ultimately occurs because of battery depletion, just as in the case for HPCI.

Sequences 65-68:

HPCI and RCIC initially fail after successful reactor scram. Containment cooling is provided. The operator successfully uses CRD or depressurization with LPCS, LPCI or HPSW for coolant injection. 
Sequences 69-73:

After reactor scram, no core cooling is provided resulting in early core damage. Containment cooling is successful but it is assumed that non-condensible formation ultimately results in the need for containment venting. Venting is successfur in Sequences 69 and 72; otherwise containment failure subsequently occurs. Note that Containment Spray (CS mode of RHR) is available up until the time of containment venting or failure. Then RHR pump failure on low NPSH is assumed from saturated conditions in containment.

Sequences 74-109:

Like Sequences 65-73 above except accounting for different modes of RHR being operable for containment cooling.

Sequences 110-133:

Like Sequences 4-27 above except HPCI and RCIC have failed initially.

Sequences 134-138:

Like the station blackout scenarios described as Sequences 28-32 above except HPCI and RCIC fail initially leading to early core damage.

Sequence T1P:

Involves at least one stuck-open relief valve following the loss of offsite power. This sequence transfers to a LOCA tree (S2 tree for one valve, S1 tree for two valves, A tree for three valves stuck open) for further analysis.

Sequence T1M:

Would be conservatively assumed to lead to core damage because of the high pressure achieved in the primary system. However, the probability is considered negligible and therefore no further analysis has been performed.

Sequence TIC:

Failure of automatic reactor scram. This sequence is covered under the ATWS analyses.

IV.4.9 Loss of the Power Conversion System (PCS) Event Tree

IV.4.9.1 Introduction

Transients involving initial loss of the PCS (T2) have similar effects on the plant as the loss of offsite power (T1) transient. Two noticeable differences, however, do exist. First, Condensate is highly likely to succeed in the T2 transient. While this would dictate another event tree structure than that for the Tl transient, a conservative simplification was employed to facilitate the 
analysis under the resource constraints of the study. It was assumed that loss of PCS also led to loss of Condensate with recovery of Condensate treated similarly to recovery of PCS. Secondly, loss of AC power sequences resulting from a $T 2$ transient must first have a subsequent failure of offsite power and then a loss of onsite power (these failures can be handled at the fault tree level of analysis). Consideration of these two points allowed the analysts to use the Tl event tree structure to represent the T2 scenarios by treating Condensate as initially failed along with the initiator and the loss of power scenarios in the fault tree analyses as failures following the initial PCS loss. Therefore, the T2 initiator was analyzed using the Tl event tree.

The success criteria for T2 transients is shown in Table IV.4-5. As already discussed, Condensate was treated as initially failed even though it is shown as a likely success path for Emergency Core Cooling in the table. As part of the recovery analysis, recovery of either Condensate or the entire PCS were included as possible means to prevent core damage and/or continue long-term core cooling. At the conclusion of the study, it was found that the above conservative assumption (initial loss of Condensate) did not have a significant impact on the results.

\section{IV.4.9.2 Event Tree}

As already described, the event tree for $T 1$ transients was used for the $T 2$ transient. The event tree headings and sequence descriptions are identical except the initiator is a $T 2$ event and the $B 0$ event includes two failures (failure of offsite power and failure of onsite power) instead of just the one event (failure of onsite power).

\section{IV.4.10 Transient with PCS Initially Available Event Tree}

\section{IV.4.10.1 Introduction}

Transients in which the PCS remains initially available do not represent significant concerns for the plant unless the PCS is subsequently lost while the plant is being shutdown. Should the PCS be lost, the sequence of events then proceeds similar to a transient in which the PCS was unavailable from the start. T3A represents all the transients of this type except Inadvertent Open Relief Valve (IORV) events and a loss of feedwater which can have somewhat different effects on plant conditions. The success criteria for transients of this type are shown in Table IV.4-6.

\section{IV.4.10.2 Event Tree}

The T3A transient event tree is depicted by Figure IV.4-6. The following discussions define the event tree headings and the sequences.

\section{Event Tree Headings}

The events in the tree include:

T3A: Initiating event, transient with PCS initially available.

C: Success or failure of the RPS. Success implies automatic scram by the control rods. 
Table IV.4-5

Success Criteria for Loss of Power Conversion System (see Glossary for acronym definitions)

\begin{tabular}{|c|c|c|c|c|}
\hline T2 & $\begin{array}{l}\text { RPS } \\
\text { or } \\
\text { ARI \& RPT } \\
\text { or } \\
\text { Manual Rods } \\
\text { and RPT } \\
\text { or } \\
\text { Timely SLC } \\
\text { and RPT }\end{array}$ & $\begin{array}{c}\text { SRVs } \\
\text { open and close }\end{array}$ & $\begin{array}{c}\text { HPCI } \\
\text { or } \\
\text { RCIC } \\
\text { or } \\
\text { CRD ( full flow) } \\
\text { [see Note (a)] } \\
\text { or } \\
1 \mathrm{FW} \\
\text { [see Note (b)] } \\
\text { or } \\
\text { DEP w/2 valves and } \\
\text { Any } 2 \text { LPCS pumps } \\
\text { or } \\
\text { DEP w/2 valves and } \\
1 \text { of } 4 \text { LPCI } \\
\text { or } \\
\text { DEP w/2 valves and } \\
1 \text { Condensate } \\
\text { or } \\
\text { DEP w/2 valves and } \\
1 \text { HPSW (inject mode) } \\
\text { [see Note (c)] }\end{array}$ & $\begin{array}{c}1 \text { of } 4 \text { RHR \& HIX } \\
\text { (SDC, SPC, Spray Mode) } \\
\text { and } \\
\text { associated HPSW } \\
\text { [see Note (d)] } \\
\text { or } \\
\text { PCS } \\
\text { [see Note (b)] } \\
\text { or } \\
\text { Containment Venting } \\
\text { [see Note (e)] }\end{array}$ \\
\hline
\end{tabular}

NOTES:

(a) 2 CRD pump operation is considered to be required for success if CRD is the only injection source to the reactor. This is based on a flow of $\sim 175-$ to-200 gpm (at high vessel pressure) needed to initially maintain core coverage.

(b) These would be available only upon restoration of the PCS.

(c) Any 2 LPCS pumps is different from past PRA criteria of 2 pumps needed in the same LPCS injection loop. This is based on latest analyses per Reference 9 .

(d) HPSW operation is needed for the operating RHR heat exchanger.

(e) At least the 6" integrated leak test line or larger size line is considered required for success. Criteria based on discussions with containment analysis personnel at Sandia. May be conservative. 
Table IV.4-6

Success Criteria for Transient With PCS Initially Available (see Glossary for acronym definitions)

\begin{tabular}{|c|c|c|c|c|}
\hline IMITIATOR & $\begin{array}{c}\text { REACTOR } \\
\text { SUBCRITICAL }\end{array}$ & $\begin{array}{l}\text { RCS OVERPRESSURE } \\
\text { PROTECTION }\end{array}$ & $\begin{array}{l}\text { EMERGEMCY } \\
\text { CORE COOLIMG }\end{array}$ & $\begin{array}{c}\text { RESIDUAL } \\
\text { HEAT REMOVAL }\end{array}$ \\
\hline$T 3$ & $\begin{array}{l}\text { RPS } \\
\text { or } \\
\text { ARI \& RPT } \\
\text { or } \\
\text { Manual Rods } \\
\text { and RPT } \\
\text { or } \\
\text { Timely SLC } \\
\text { and RPT }\end{array}$ & $\begin{array}{c}\text { PCS } \\
\text { or } \\
\text { SRVS } \\
\text { open and close }\end{array}$ & $\begin{array}{c}\text { HPCI } \\
\text { or } \\
\text { RCIC } \\
\text { or } \\
\text { CRD ( full flow) } \\
\text { [see Note (a)] } \\
\text { or } \\
1 \mathrm{FW} \\
\text { or } \\
\text { DEP w/2 valves and } \\
\text { Any } 2 \text { LPCS pumps } \\
\text { or } \\
\text { DEP } w / 2 \text { valves and } \\
1 \text { of } 4 \text { LPCI } \\
\text { or } \\
\text { DEP } w / 2 \text { valves and } \\
1 \text { Condensate } \\
\text { or } \\
\text { DEP } w / 2 \text { valves and } \\
1 \text { HPSW (inject mode) } \\
\text { [see Note (b)] }\end{array}$ & $\begin{array}{c}1 \text { of } 4 \text { RHR \& HtX } \\
\text { (SDC, SPC. Spray Mode) } \\
\text { and } \\
\text { associated HPSW } \\
\text { [see Note (c)] } \\
\text { or } \\
\text { PCS } \\
\text { or } \\
\text { Containment Venting } \\
\text { [see Note (d)] }\end{array}$ \\
\hline
\end{tabular}

\section{NOTES:}

(a) 2 CRD pump operation is considered to be required for success if CRD is the only injection source to the reactor. This is based on a flow of $-175-$ to-200 $\mathrm{gpm}$ (at high vessel pressure) needed to initially maintain core coverage.

(b) Any 2 LPCS pumps is different from past PRA criteria of 2 pumps needed in the same LPCS injection loop. This is based on latest analyses per Reference 9.

(c) HPSW operation is needed for the operating RHR heat exchanger.

(d) At least the 6" integrated leak test line or larger size line is considered required for success. Criteria based on discussions with containment analysis personnel at Sandia. May be conservative. 


\begin{tabular}{|c|c|c|c|c|}
\hline $\begin{array}{l}\text { TAANSIENT } \\
\text { WITH PCS } \\
\text { INITIALLY } \\
\text { AVAILABLE }\end{array}$ & $\begin{array}{l}\text { REACTOR } \\
\text { PROTECTION } \\
\text { SYSTEM }\end{array}$ & $\begin{array}{l}\text { POWER } \\
\text { CONVEASION } \\
\text { SYSTEM }\end{array}$ & $\begin{array}{l}\text { Seq. } \\
\text { Num. }\end{array}$ & $\begin{array}{l}\text { Outcome of } \\
\text { Sequences } \\
\text { and Tree } \\
\text { Transfer }\end{array}$ \\
\hline T3A & C & 0 & & \\
\hline & & & $\begin{array}{l}1 \\
2 \\
3\end{array}$ & $\begin{array}{l}\text { ok } \\
\text { T2 Tree } \theta^{*} \\
\text { ATWS Tree } 8\end{array}$ \\
\hline
\end{tabular}

*T2 Sequences Were Actually Analyzed Using Tl Event Tree (See Section IV.4.9).

Figure IV.4-6. Transient with PCS Initially Available (T3A) Event Tree. 
Q: $\quad$ Continued success or subsequent failure of the PCS. Success implies continued operation of the PCS such that a safe cooldown of the plant is achieved using the PCS.

\section{Sequences}

The following descriptions refer to the sequences found in Figure IV.4-6.

Sequence 1:

Following the transient, reactor scram occurs and the PCS is successfully used to shutdown the plant.

Sequence 2:

The PCS is subsequently lost leading to a transient with a delayed failure of the PCS. The scenario proceeds similar to a T2 transient and, therefore, is transferred to the T2 tree (see T2 event tree Section IV.4.9--the T2 type analysis is actually carried out using the Tl event tree as explained therein. Again, Condensate is conservatively assumed to be initially lost with failure of the PCS).

Sequence 3:

An ATWS-type scenario. This sequence of events is analyzed as part of the ATWS analyses described later.

IV.4.11 Inadvertent Open Relief Valve Transient Event Tree

\section{IV.4.11.1 Introduction}

Should a primary system SRV inadvertently open during power operation, steam will be discharged to the suppression pool through the SRV tail pipe line. An open SRV will be easily detected by acoustical and temperature monitors on these lines. Procedures call for attempts to close the valve and, if unsuccessful, manually trip the plant and start shutdown procedures. Since the PCS is likely to be initially available, this event is categorized as another T3-type of transient (T3B).

It is separately analyzed since the open SRV will allow containment conditions to be at a somewhat higher stress level than other T3-type transients because of the initial steam release to the pool. It is, therefore, treated as a S2 steam LOCA and so is ultimately analyzed using the S2 success criteria (already described).

\section{IV.4.11.2 Event Tree}

The T3B event tree is depicted by Figure IV.4-7. The following discussions define the event tree headings and the sequences.

\section{Event Tree Headings}

The events in the tree include:

T3B: Initiating event, inadvertent open relief valve transient. 


\begin{tabular}{|c|c|c|c|l|}
\hline IORV & $\begin{array}{l}\text { MANUAL OR } \\
\text { AUTOMATIC } \\
\text { SCRAM }\end{array}$ & $\begin{array}{l}\text { POWER } \\
\text { CONVERSION } \\
\text { SYSTEM }\end{array}$ & $\begin{array}{l}\text { Seq. } \\
\text { Num. }\end{array}$ & $\begin{array}{l}\text { Outcome of } \\
\text { Sequences } \\
\text { and Tree } \\
\text { Transfer }\end{array}$ \\
\hline T38 & C1 & 0 & 1 & \begin{tabular}{l} 
ok \\
S2 Tree \\
\hline
\end{tabular} \\
\hline & & 3 & ATWS Tree \\
\hline
\end{tabular}

Figure IV.4-7. Inadvertent Open Relief Valve Event Tree. 
C1: Success or failure of reactor scram. Success implies manual trip of the reactor or automatic scram by the RPS.

Q: $\quad$ Continued success or subsequent failure of the PCS. Success implies continued operation of the PCS such that cooldown of the plant is successfully achieved before containment conditions reach challenging levels from steam discharge from the stuck-open SRV.

\section{Sequences}

The following descriptions refer to the sequences found in Figure IV.4-7. Sequence 1:

Following the transient, reactor scram occurs and the PCS is successfully used to shutdown the plant.

Sequence 2:

The PCS is subsequently lost leading to a transient with a delayed failure of the PCS. The scenario proceeds similar to a S2 steam LOCA from the stuck-open SRV and so transfers to the S2 event tree for analysis.

Sequence 3:

An ATWS-type scenario. This sequence of events is analyzed as part of the ATWS analyses described in Section IV.10.

\section{IV.4.12 Loss of Feedwater Event Tree}

\section{IV.4.12.1 Introduction}

A loss of feedwater event (T3C) is, in part, similar to a loss of PCS event except that only the feedwater is definitely lost from the balance-of-plant. It is possible that the steam side of the PCS to the condenser may still be operable as well as the Condensate system. Coolant injection could be performed with systems such as HPCI, RCIC, or Condensate (as well as others) and heat removal might still be possible with the steam portion of the plant if condenser level and vacuum can be controlled. The success criteria would be as indicated for all T3-type transients already discussed.

To facilitate the analysis under the resource constraints of the study, the T3C event was conservatively analyzed as if the loss of feedwater event also included loss of the entire PCS as well as the Condensate system. Therefore, the T3C event was actually analyzed as a T2 transient which is described in Section IV.4.9.

While this "short-cut" is conservative, it was found at the conclusion of this study that this treatment of the T3C transient did not have a significant impact on the results. 


\section{IV.4.12.2 Event Tree}

As described above, the event tree for T2 transients (which actually used a T1 tree--see Section IV.4.9) was conservatively used for the loss of feedwater initiator.

\section{IV.4.13 Loss of an $A C$ or $D C$ Bus Event Tree}

\section{IV.4.13.1 Introduction}

A loss of an emergency $A C$ or $D C$ bus as an initiator was assumed to lead to a total loss of the PCS including the Condensate system (refer to Section IV.3.1 for discussion of the TAC, TDC special initiators). While it is not known for certain that the loss of any one such bus would lead to the scenario above, this conservative treatment allowed the T2 event tree to be used for the analysis of these events. Of course, the analysis had to consider the loss of power effects of these initiators on mitigating systems analyzed with the $T 2$ event tree. This is done by failing the appropriate bus power feeds in the various system fault trees depending on which bus is failed (the initiator). Each major power division was analyzed separately; that is, the 4160 VAC buses and 250/125 VDC buses were failed one at a time. Each failure was propagated through the event and fault tree analysis to determine the core damage contributions from these initiators.

It was found, at the conclusion of this study, that this potentially conservative treatment of the TAC, TDC initiators did not have a significant effect on the results.

\section{IV.4.13.2 Event Tree}

As described above, the TAC, TDC initiators were treated as special forms of a loss of PCS transient. Therefore, the discussion of the T2 event tree applies here; see Section IV.4.9.

\section{IV.4.14. "V" Sequence}

This type of a scenario typically involves the failure of a high-to-low pressure interface such that reactor pressure causes failure within a low pressure system. This could possibly create an unmitigatable LOCA (worst case) with a fission product release path through the low pressure system, thereby bypassing the suppression pool and containment. Reference 12 suggests that, on the basis of precursor events, such a failure is most likely to occur while performing stroke valve testing of isolation valves during power operation.

Review of the piping interfaces with the primary system showed that the two LPCS injection lines and two LPCI injection lines were possible areas where the "V" sequence, as described, might occur. Testing procedures were reviewed. In each case, because of the equipment configuration and testing procedures, it was found that two hardware failures and two human errors would have to occur to cause the "V" sequence during testing (refer to Figure IV.4-8 for typical arrangements). First, the testable check valve must leak or rupture and go undetected. With stroke testing occurring at least quarterly, and using $8 \mathrm{E}-7 / \mathrm{hr}$ (mean) and $2.7 \mathrm{E}-8 / \mathrm{hr}$ (mean) based on WASH-1400 data for leak and rupture failure rates [4], the probability that such failures have occurred between tests is $-9 \mathrm{E}-4$ (mean value). The operator must then fail to close the normally open Motor-Operated Valve (MOV) used to maintain the high-low pressure interface during the test. 


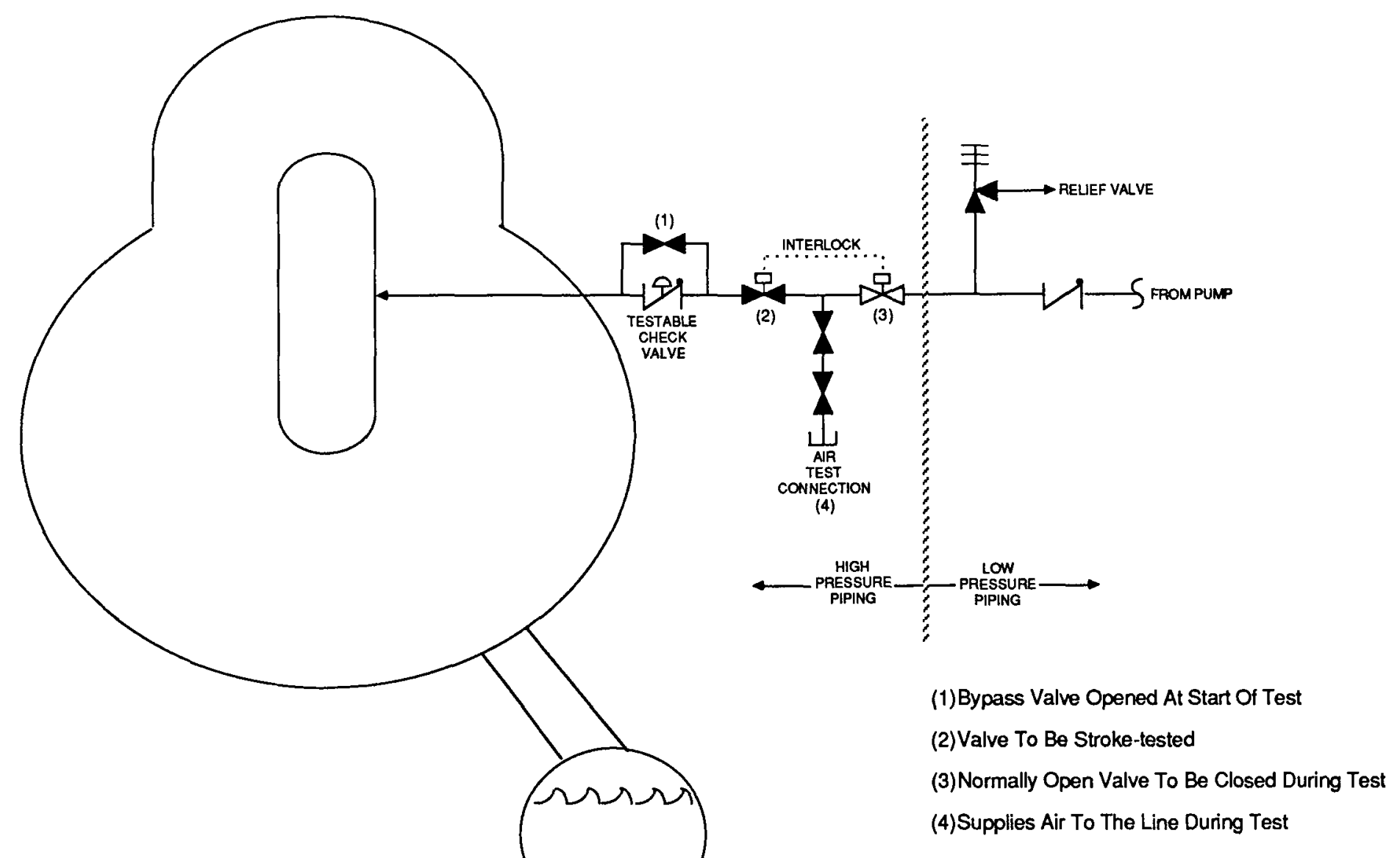

Figure IV.4-8. Typical Valve Arrangement for High-Low Pressure Interface. 
Using ASEP's nominal Human Reliability Analysis (HRA) value of 0.02 for failure of a step-by-step task performed under moderate stress [26], and further reducing it by a factor of at least five to account for the clarity in the procedure and the non-stress situation, yields an operator failure probability to close the MOV of 4E-3 (mean). Following procedures, the operator is to open the bypass valve and then pressurize the line segment using the air test connection to near reactor pressure before opening the MOV being stroke-tested. Such a process would be virtually impossible if the previously mentioned MOV had not been closed to hold the pressure since the relief valve would lift before the pressure in the line could reach high pressure. Therefore, a non-recovery probability is applied to failure to close the normally open MOV. This probability must be very small; estimated at $1 E-4$ to account for a possible plug in the line such that the operator could still pressurize the line segment. Then, an interlock exists between the normally open MOV and the MOV to be stroked such that both valves cannot be open at the same time. Failure of this interlock would have to occur and is estimated at $2.5 \mathrm{E}-2$ based on possible limit switch failure $(2.4 \mathrm{E}-2$ per Indian Point study data [20]) or failure of the circuitry (1E-3 per ASEP generic data). Combining all these failures leads to a very small probability for the " $V$ " sequence's occurring in this way ( $<<1 E-8$ per year).

Other lines were examined, such as the RHR shutdown cooling path and HPCI and RCIC lines. In such cases, these paths also appeared to offer low chances for the "V" scenario, considering similar interlock failure requirements or, in the case of HPCI and RCIC, the fact that high pressure piping exists for much of the system and these rooms are normally secured closed and leak tight so that only one room (and system) should be affected.

Also reviewed was the chance that two valves in series (typically a check valve and one MOV) leaked or ruptured between tests and went unnoticed (again refer to Figure IV.4-8). Allowing leak or rupture of the check valve and the MOV within a quarter year time period results in a probability of such an occurrence as approximately 8E-7 (mean) during any one quarter, or about 3E-6 per year. However, with pressure switches located in each line so as to detect such a dual failure, the probability of going undetected appears small. In addition, a catastrophic failure to create the LOCA would have to occur, and more than one room would have to be affected, in order to prevent successful mitigation. These last two considerations would appear to suggest that at least another factor of 1E-2 should be applied before the "V" sequence actually leads to core damage.

On the basis of this review and the quantitative and qualitative arguments supplied above, it appears reasonable that the " $V$ " scenario can be estimated at or below 1E-8 per year. This is the threshold value used in the Peach Bottom analysis for defining dominant accident sequences, and so the " $V$ " sequence is not examined any further.

\section{IV.4.15 Event Tree Nomenclature}

Table IV.4-7 contains a summary of the nomenclature used to identify the systems on the event trees. Care should be taken not to confuse this nomenclature with that used for systems at the fault tree level of analys is described later in Section IV.5. 


\begin{tabular}{|c|c|c|}
\hline BO & - & Failure of all AC power (station blackout) \\
\hline C & - & Failure of the Reactor Protection System (RPS) \\
\hline C1 & - & Failure of manual scram or auto scram by the RPS \\
\hline $\mathbf{L}$ & - & Failure of operator to isolate S3 "leak" \\
\hline M & - & Failure of Safety Relief Valves (SRVs) to open \\
\hline $\mathbf{P}$ & - & Failure of SRVs to close \\
\hline Q & - & Failure of the Power Conversion System (PCS) \\
\hline U1 & - & Failure of the High Pressure Coolant Injection (HPCI) system \\
\hline U2 & - & Failure of the Reactor Core Isolation Cooling (RCIC) system \\
\hline U3 & - & Failure of the Control Rod Drive (CRD) system \\
\hline V1 & - & Failure of the Condensate system \\
\hline V2 & - & Failure of the Low Pressure Core Spray (LPCS) system \\
\hline V3 & - & $\begin{array}{l}\text { Failure of the Low Pressure Coolant Injection (LPCI) mode of the } \\
\text { Residual Heat Removal (RHR) system }\end{array}$ \\
\hline V4 & - & $\begin{array}{l}\text { Failure of the High Pressure Service Water (HPSW) system as an } \\
\text { injection source to the reactor. }\end{array}$ \\
\hline W1 & - & Failure of the Shutdown Cooling (SDC) mode of RHR \\
\hline W2 & - & Failure of the Suppression Pool Cooling (SPC) mode of the RHR \\
\hline W3 & - & Failure of the Containment Spray (CS) mode of the RHR \\
\hline$X$ & - & $\begin{array}{c}\text { Failure to depressurize the primary system via SRVs or the Automatic } \\
\text { Depressurization System (ADS) }\end{array}$ \\
\hline$Y$ & - & $\begin{array}{l}\text { Failure of Containment Venting (including makeup to the pool as } \\
\text { required) }\end{array}$ \\
\hline , & - & $\begin{array}{l}\text { Any system identifier followed by a' designates failure of that } \\
\text { system following a core vulnerable condition. A core } \\
\text { vulnerable condition is defined as the core initially being } \\
\text { cooled but continued core cooling is in jeopardy since contain- } \\
\text { ment venting or failure has occurred which in turn affects the } \\
\text { survivability of some long-term core cooling systems (thereby } \\
\text { placing the core in a "core vulnerable" state). }\end{array}$ \\
\hline
\end{tabular}


This nomenclature is also used to identify the accident sequences represented by each event tree. Figure IV.4-9 displays a sequence from one of the trees described previously. Accident sequences are identified by using the initiator designator along with the event tree system identifiers for each failed system in the tree. The resulting sequence identifier is, therefore, defined as shown. The "results" section of this report (see Section $V$ ) identifies the core damage dominant sequences using this approach.

\section{IV.4.16 ATWS Event Trees}

Prior to the start of this analysis, considerable attention was expected to be given to the ATWS scenarios. This was because ATWS sequences were expected to be among the dominant sequences for Peach Bottom and because of the high visibility of such sequences in light of the recent NRC ATWS rule. As a result, extensive analyses of ATWS were conducted. In line with this focused attention on ATWS sequences, the ATWS analyses and the corresponding event trees are provided separately (Section IV.10). Also, because of the many system/operator successes (as well as the failures) involved in the core damage sequences for ATWS, the sequence identifiers include both successful and failed systems as opposed to only the failed systems as described above. This is done to facilitate the understanding of the core damage ATWS sequences. 


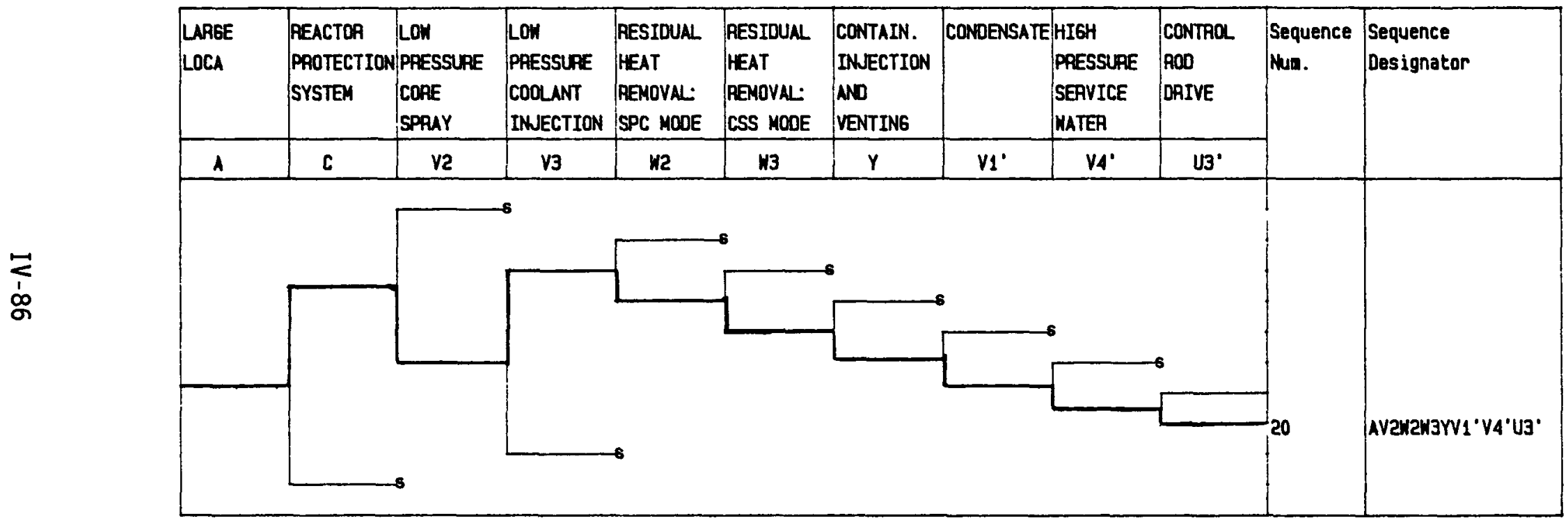

Figure IV.4-9. Large LOCA Event Tree: Sequence Designator Example. 


\section{IV.5}

\section{SYSTEM ANALYSIS}

Section IV.5.1 provides an introduction to the system modeling performed in the Peach Bottom analysis. Sections IV.5.2 through IV.5.19 describe the modeling effort for each system. These subsections contain a system description, identification of interfaces and dependencies, discussion of operational constraints, a description of the models developed, specific assumptions used in modeling, and a discussion of any unique operational experience for each of the systems. The systems which were modeled in the Peach Bottom study are shown in Table IV.5-1. This table also 1ists prominent plant systems which were not explicitly modeled in the study and identifies the reasons they were not modeled. The nomenclature used to identify system failures is described in Section IV.5.20.

\section{IV.5.1 System Modeling and Scope}

System models were developed for each of the front line systems identified in the event tree headings and for all support systems required to operate the front 1 ine systems. Fault tree models were constructed for most of the systems except as noted in subsequent subsections. For those systems where fault tree models were not constructed, it was determined that simple Boolean expressions could be used to represent the dominant failures of the systems (including interactions). These failure models were developed with top events corresponding to the success criteria used in the event tree analysis. Some systems have different success criteria in different circumstances and hence different top events.

Modeling of the systems was performed at the pipe segment level. A pipe segment is a series collection of components within the system which can be modeled as one super-component independent from the rest of the system. The failure probability associated with the pipe segment is the sum of the individual failure probabilities of the components within the segment. Operator actions in response to plant conditions were included in the models where specific procedures for these actions were available. Operator errors of commission were not included in the fault tree analysis. Recovery actions for each accident sequence are handled at the sequence level of analysis and are covered in Section IV.7.

Groundrules and assumptions were made throughout the system analysis process. The assumptions about each specific system are provided in the specific system write-ups.

System schematics are provided for most of the systems analyzed. Figure IV.5.1-1 provides symbols and related abbreviations used in the schematics.

\section{IV.5.2 High Pressure Coolant Injection (HPCI) System}

\section{IV.5.2.1 HPCI Description}

The function of the HPCI system is to provide a makeup coolant source to the reactor vessel during accidents in which system pressure remains high (event tree nomencl ature--U1).

The HPCI system consists of a single train with motor-operated valves and a turbine-driven pump. Suction is taken from either the Condensate Storage Tank (CST) or the suppression pool. Injection to the reactor vessel is via a feedwater line. The HPCI pump is rated at $5000 \mathrm{gpm}$ flow with a discharge head of $1135 \mathrm{psig}$. 
Table IV.5-1

Systems Included in the Peach Bottom study

\begin{tabular}{|c|c|c|}
\hline $\begin{array}{c}\text { SYSTEM } \\
\text { (see glossary) }\end{array}$ & $\begin{array}{c}\text { TYPE OF MODEL } \\
\text { (where appropriate) }\end{array}$ & COMHEnTS \\
\hline HPCI & Fault Tree & - \\
\hline RCIC & Fault Tree & - \\
\hline CRD & Boolean Expression & Dominated by operator error and pump unavailabilities \\
\hline SLC & Boolean Expression & Dominated by operator errors and pump unavailabilities \\
\hline ADS & Fault Tree & - \\
\hline LPCS & Fault Tree & - \\
\hline LPCI & Fault Tree & - \\
\hline SDC & Fault Tree & - \\
\hline SPC & Fault Tree & - \\
\hline CS & Fault Tree & - \\
\hline EPS & Fault Tree & - \\
\hline ESWS & Fault Tree & - \\
\hline HPSW & Fault Tree & - \\
\hline EVS & Fault Tree & - \\
\hline IAS & Fault Tree & - \\
\hline PCVS & Black Box & see Section IV. 5.17 \\
\hline RPS & Black Box & see Section IV. 5.18 \\
\hline PCS/Condensate/Feedwater & Black Box & see Section IV.5.19 \\
\hline Instrument Nitrogen & Not Modeled & see Note (a) \\
\hline TBCW & Black Box & see Note (b) \\
\hline RBCW & Black Box & see Note (b) \\
\hline
\end{tabular}

NOTES:

(a) Instrument nitrogen is the primary source of air to the MSIVs and ADS valves. Since (1) these valves have storage accumulators associated with them should the nitrogen supply be lost, (2) instrument air backs up the nitrogen supply, (3) instrument air serves other loads as well, and (4) instrument nitrogen supply failures are dominated by containment isolation signals for the initiators of interest, instrument air (and not the nitrogen system) was of more interest and so it was modeled. The analysis was conducted as if instrument nitrogen essentially did not exist to save resources. This treatment should not be construed as any indication of the relative importance of the instrument nitrogen system to the instrument air system.

(b) The TBCW and RBCW systems are modeled superficially as part of the instrument air fault tree for cooling the compressors. 

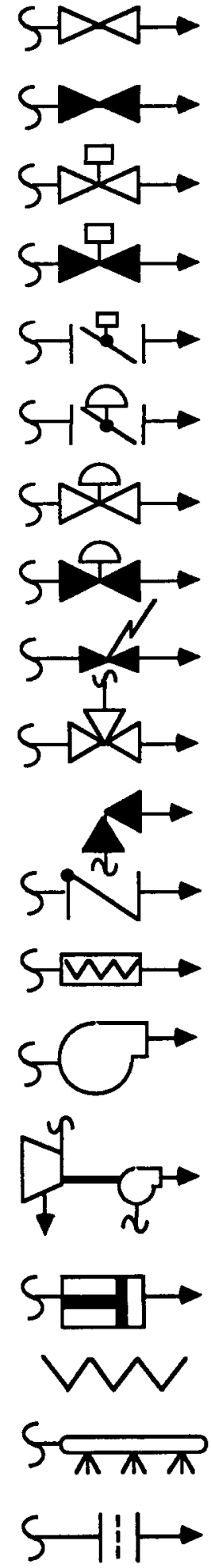

Normally Open Manual Valve

Normally Closed Manual Valve

Normally Open Motor Operated Valve

Normally Closed Motor Operated Valve

Motor Driven Butterfly Valve

Testable Check Valve

Normally Open Air Operated Valve

Normally Closed Air Operated Valve

Normally Closed Explosive Valve

Three Way Valve

(Safety) Relief Valve (Normally Closed)

Check Valve

Heat Exchanger Or Cooler

Motor Driven Pump

Turbine Driven Pump

Positive Displacement Pump

Heater

Spray Header

Orifice

Figure IV.5.1-1. Abbreviations and Symbols Used in Schematics. 


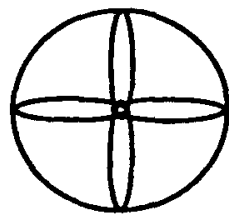

Fan

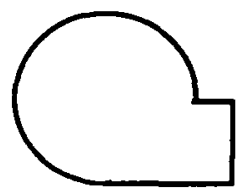

Compressor

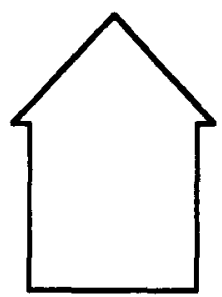

Tank

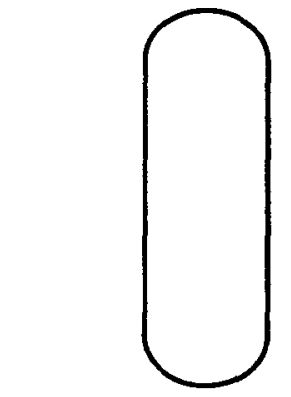

Reactor
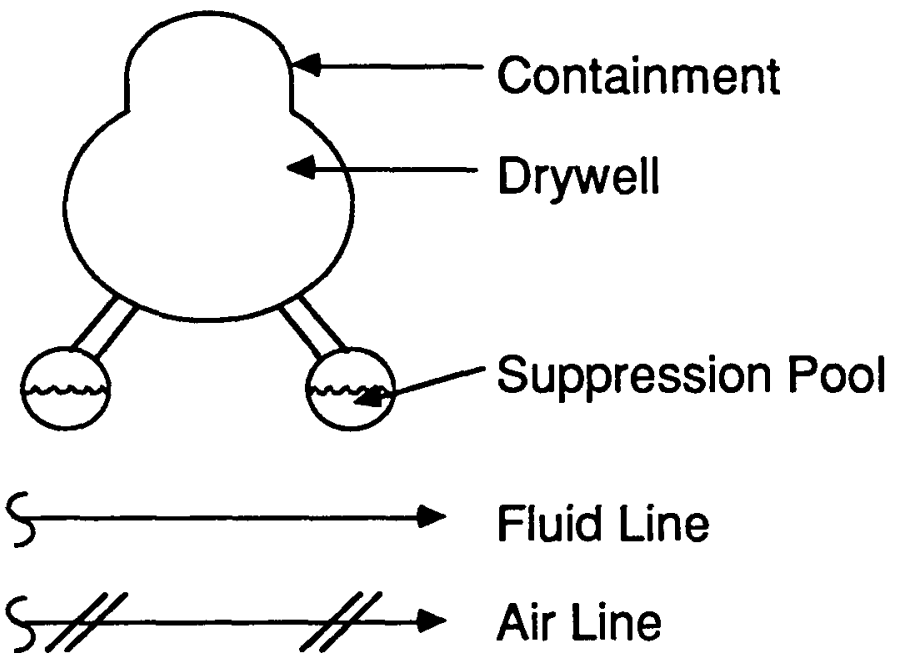

Duct Work

Figure IV.5.1-1. Abbreviations and symbols Used in Schematics. (Continued) 


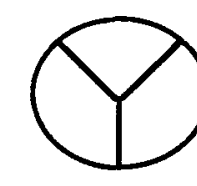

C

三

1

$\mathrm{S}$

$\boldsymbol{m}$

LO

LC
Diesel Generator

\author{
Charger
}

Battery

Inverter

Transfer Switch

Bus

Locked Open

Locked Closed

Figure IV.5.1-1. Abbreviations and Symbols Used in Schematics. (Concluded) 


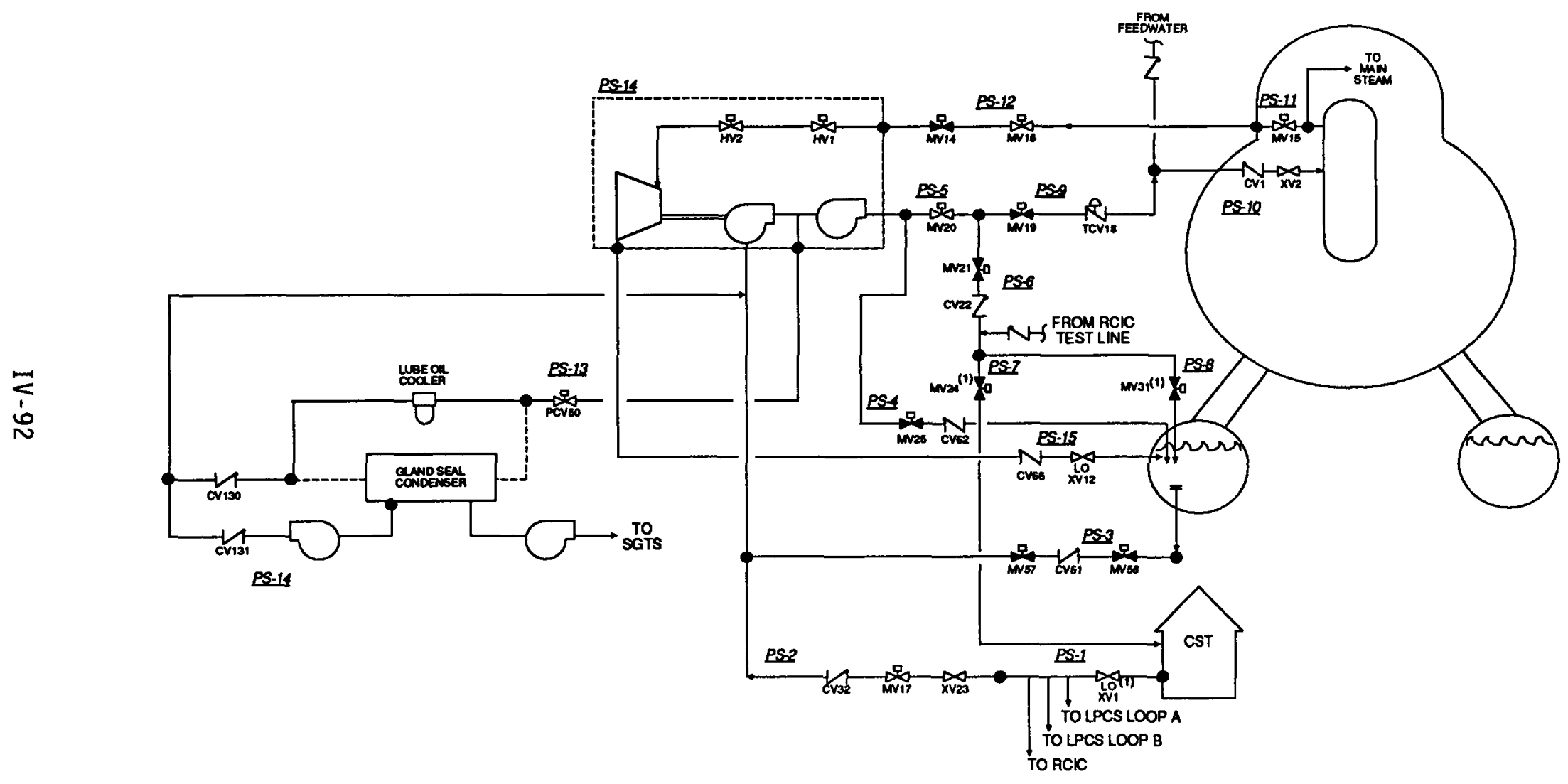

VALVE POSTIONS ARE SHOWN IN THERSTANDBY MODE
(1) VALVE ALSO SHOWN ON RCIC SCHEMATC 


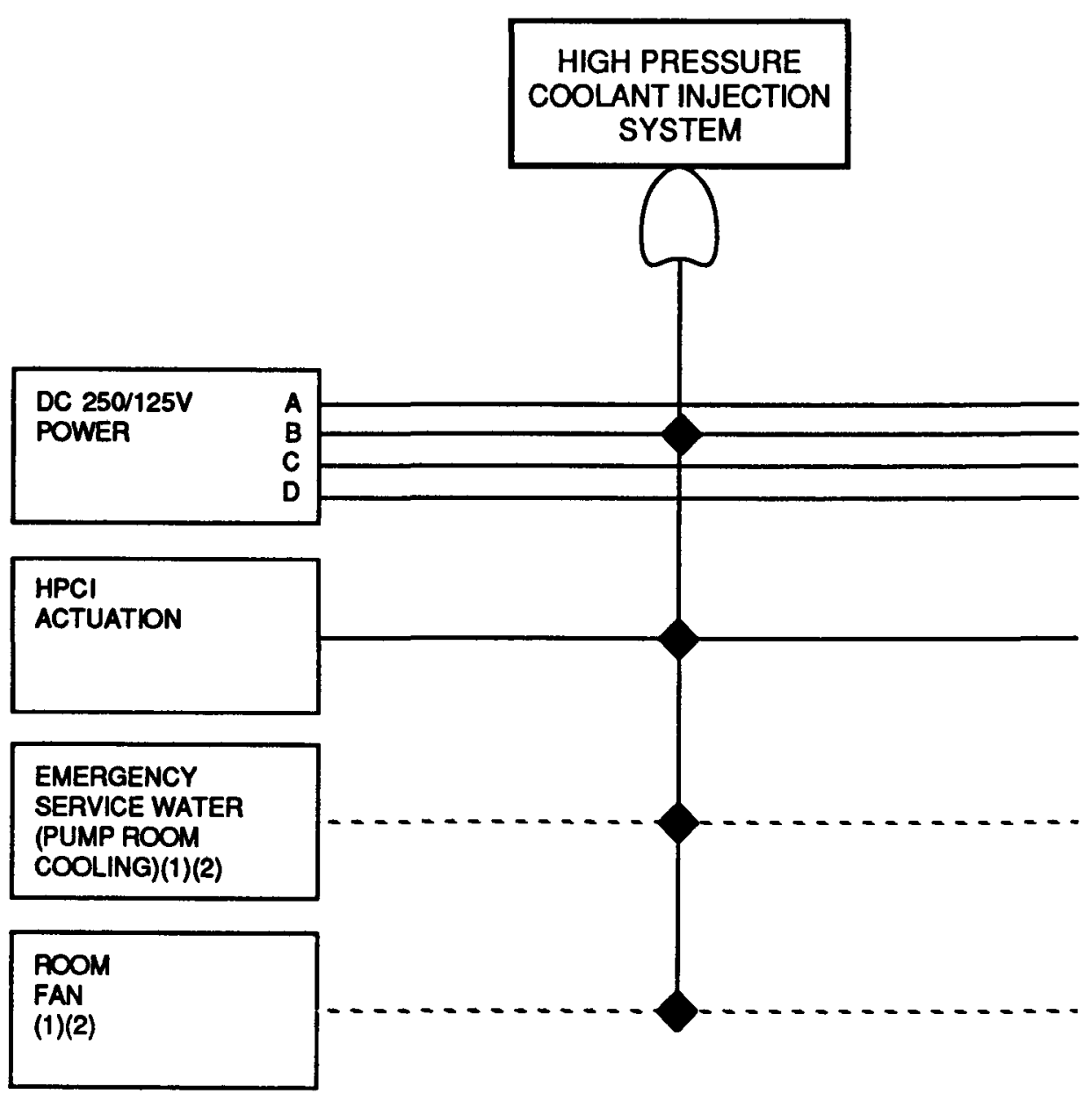

Dependency Diagram Is Shown Using Failure Logic.

(1) Dependency Not Required During Short Term Operation.

(2) Room Cooling Can Also Be Performed by Opening Doors.

Figure IV.5.2-2. High Pressure Coolant Injection system Dependency Diagram. 


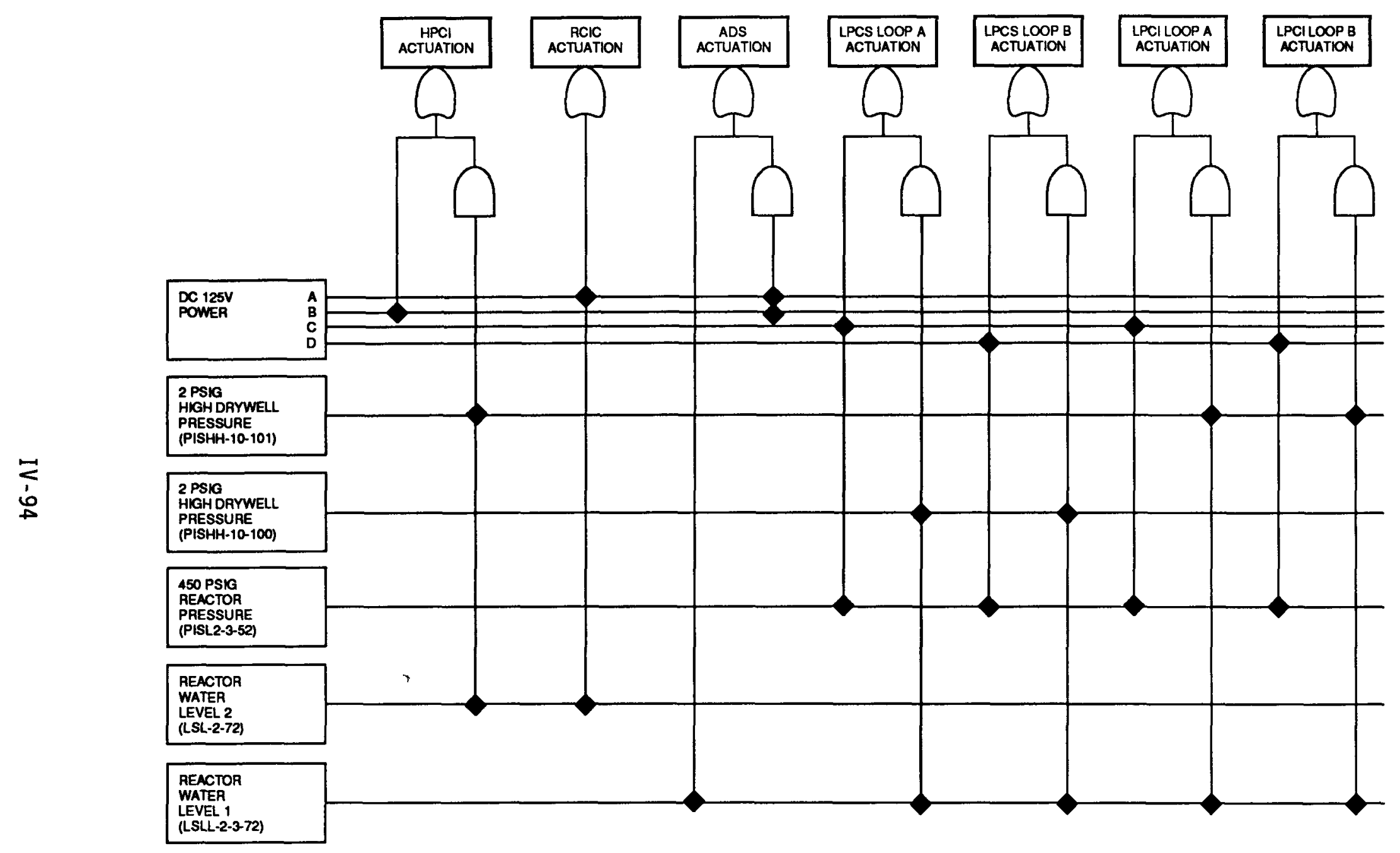

Dependency Diagram Is Shown Using Failure Logic. Refer To The Fault Trees For Actual Failure Logic Details.

Figure IV.5.2-3. Emergency Core Cooling System Actuation Dependency Diagram. 
A simplified schematic of the HPCI system is provided by Figure IV.5.2-1. Major components are shown as well as the pipe segment definitions (e.g., PS-12) used in the system fault tree.

The HPCI system is automatically initiated and controlled. Operator intervention is required as follows: (a) to prevent either vessel overfill or continuous system trip/restart cycles, (b) to manually start the system given an auto-start failure, and (c) to setup the system for continuous operation when battery depletion is imminent.

The success criteria for the HPCI system is injection at rated flow to the reactor vessel. For further information, refer to success criteria discussions in Section IV.4.

Most of the HPCI system is located in a separate room in the reactor building. Local access to the HPCI system could be affected by either containment venting or containment failure should steam be released to the reactor building area. Room cooling failure is assumed to fail the HPCI pump in four hours. Refer to Section IV.5.13 for further information on room cooling.

\section{IV.5.2.2 HPCI Interfaces and Dependencies}

The HPCI system major dependencies are DC power for short term operation and room cooling for long term operation. Although there are AC-powered motor-operated valves, these valves are not required to change state during normal system operation since they are only used to isolate the system if it is required. A simplified dependency diagram of the HPCI system is provided by Figure IV.5.2-2. Shown are the major support needs for the HPCI system as indicated by the solid diamonds at the appropriate places in the diagram.

The HPCI system requires both $250 \mathrm{VDC} / \mathrm{B}$ and $125 \mathrm{VDC} / \mathrm{B} .125 \mathrm{VDC} / \mathrm{B}$ is used for actuation and control power while an injection and a supply valve are powered from $250 \mathrm{VDC} / \mathrm{B}$.

The HPCI and RCIC systems share a common CST suction valve. This is a normally open manual valve and is identified as PS-1 on the HPCI schematic. Failure of this valve will fail the CST as a suction source to both the HPCI and Reactor Core Isolation Cooling (RCIC) systems.

Upon system actuation, HPCI injection valves receive a signal to open and HPCI test valves receive a signal to close. The HPCI system is automatically initiated on the receipt of either a high drywell pressure (2 psig) or low reactor water level (490 inches above vessel zero) signal. The low reactor water level sensors are shared with the RCIC system. A simplified actuation dependency diagram of the major emergency coolant actuation subsystems is provided by Figure IV.5.2-3.

The CST is the initial suction source for the HPCI system. Suction is automatically switched to the suppression pool upon either low CST level or high suppression pool level. Automatic switchover will not occur if there is an automatic isolation signal present. The CST suction valve does not close until both of the suppression pool suction valves are fully open.

The HPCI system is automatically isolated by high steam line space temperature, steam line high differential pressure (dP), or high turbine exhaust pressure (150 psig). Both the high temperature and high dP signals are used to detect a steam line break. 
The HPCI turbine trips on high exhaust pressure, high reactor water leve1, low pump suction pressure, low steam pressure, or an auto isolation signal.

\section{IV.5.2.3 HPCI Test and Maintenance}

The HPCI system surveillance requirements are the following: (1) pump operability--once/month, (2) motor-operated valve operability--once/month, (3) pump capacity test--once/three months, (4) simulated automatic actuation test--once/operating cycle, and (5) logic system functional test--once/six months.

\section{IV.5.2.4 HPCI Technical Specifications}

If the HPCI system is made or found to be inoperable for any reason, continued reactor operation is permissible for seven days provided that the Automatic Depressurization System (ADS), RCIC, Low Pressure Cooling Injection (LPCI) system, and both loops of the Low Pressure Core Spray (LPCS) system are operable. If this requirement cannot be met, the reactor is to be shut down.

\section{IV.5.2.5 HPCI Logic Model}

The HPCI system was modeled using a fault tree for the injection of coolant to the reactor vessel. The major active components and most passive components were modeled using pipe segments which were defined for the HPCI system. Components within a pipe segment were grouped together to form a single basic event. Generally a pipe segment is that run of pipe from one junction to another junction. A separate pipe segment was defined when components within a run of pipe had different dependencies or potentials for recovery and at a penetration of the containment. The fault tree model representing the HPCI system is presented in Appendix A.

Piping ruptures were considered to be negligible compared to other system failures. Only the piping with a diameter of greater than or equal to $1 / 3$ of the main system piping was considered as a potential diversion path.

The gland seal condensate pump and the gland seal vacuum pump were not modeled since their operation is not essential to system operation.

Six human errors were incorporated into the HPCI fault tree model. These errors are (1) failure to trip the HPCI system and realign its suction source, (2) failure to realign the suction source for the HPCI and RCIC systems, (3) failure to control HPCI flow (reactor level), (4) failure to manually backup automatic HPCI actuation, (5) miscalibration of CST level sensors, and (6) miscalibration of Emergency Safeguard (ESF) sensors.

\section{IV.5.2.6 HPCI Assumptions}

(1) The HPCI test return lines were not considered as potential diversion paths because the probability of two normally closed motor operated valves (MOVs) failing to prevent flow was felt to be negligible compared to other system faults.

(2) Failure of the system to isolate given certain conditions was not considered since the system is effectively "non-operational." 
These conditions are: (a) high steam line space temperature, (b) high steam line dP, (c) low steam pressure, (d) high steam line exhaust pressure, and (e) manual isolation.

(3) Failure of the minimum flow line to open does not constitute system failure since the time between pump start and opening of the injection valve is small.

(4) The gland seal condensate pump and vacuum pump are not necessary for system operation. Therefore, their failures were not modeled.

(5) Spurious signals are felt to be negligible compared to other system failures because of their low probability of occurrence.

(6) The HPCI system is assumed to fail in a non-recoverable state if it fails to trip on low suction pressure or high reactor water level because of expected damage to the pump or turbine.

(7) HPCI pump bearing cooling fails if pump suction is from the suppression pool and the working fluid temperature reaches between 210 and $2600 \mathrm{~F}$.

(8) The HPCI turbine auxiliary oil pump, stop valve, and governor valve failures were included in turbine failure data.

(9) System failure because of valves being left in the wrong position after test or maintenance is felt to be negligible because the position of all manual and motor-operated valves is indicated in the control room and the motor-operated valves receive signals to realign.

(10) Testing of TCV18 will not prevent flow to the reactor vessel, nor will it prevent TCV18 from stopping flow to the reactor vessel.

(11) During construction of the fault tree, it was necessary to determine which components could be taken out of service (00S) for maintenance. It was assumed that maintenance would require components to be effectively removed from the system. Standard safety precautions of component isolation were used to decide which components could be taken o0s for maintenance while the plant was at power or normal operating pressure. The general guidelines used for component isolation were double blockage for high pressure piping or components and single blockage for low pressure piping or components.

(12) An event for depletion of the CST was included for those cases where HPCI and/or RCIC operation was judged to be sufficiently long.

(13) Failure of the suppression pool by random failure or the plugging of its strainers is felt to be negligible compared to other system failures. 
(14) If the HPCI or RCIC minimum flow line has been demanded open and subsequently fails to close on a system trip, there is the possibility that the CST will drain to the suppression pool because of their differences in elevation.

(15) Lube oil cooling is required for bearing cooling.

(16) The HPCI actuation circuitry was not modeled to a great degree of detail. Only elements which were felt to be potentially important were included in the fault tree model. The initiating signal sensors and their support systems were explicitly modeled since they are shared between various ESF systems. The power supply for the actuation circuitry was also included. Hardware failures of relays and certain permissives were grouped into one basic event.

(17) It is assumed that calibration of the low and low-low reactor vessel water level sensors is performed at the same time. Miscalibration of these sensors is assumed to be the same event.

(18) Failure to recover an initial loss of the normal suction source (the CST) will be treated as a recovery action. Operator error appears to dominate failures of suppression pool valves and their manual actuation circuitry. Failure of suppression pool valves from maintenance outages or support system failures appears el sewhere in the fault tree.

(19) Failure of the system to automatically realign the suppression pool after a loss of the normal suction source (the CST) is treated explicitly with manual switchover being treated as a recovery action.

(20) The suction pressure trip is "ANDed" with a dummy event to account for the probability that low suction pressure exists.

\section{IV.5.2.7 HPCI Operating Experience}

Nothing was peculiar in the operational history of the HPCI system which would affect system modeling. Plant operational data indicates a higher value for Turbine-Driven Pump (TDP) failure to run than the generic data base. The difference is that the generic value was calculated using plant operational hours instead of HPCI operational hours. The values compare closely when HPCI operational hours are used in the generic calculation. Therefore, the plant specific value for TDP failure to run is used.

\section{IV.5.3 Reactor Core Isolation Cooling System}

\section{IV.5.3.1 RCIC Description}

The function of the RCIC system is to provide a makeup coolant source to the reactor vessel during accidents in which system pressure remains high (event tree nomenclature--U2). 
The RCIC system consists of a single train with motor-operated valves and a turbine-driven pump. Suction is taken from either the CST or the suppression pool. Injection to the reactor vessel is via a feedwater 1ine. The RCIC pump is rated at $600 \mathrm{gpm}$ flow with a discharge head of $1135 \mathrm{psig}$. A simplified schematic of the RCIC system is provided by Figure IV.5.3-1. Major components are shown as well as the pipe segment definitions (e.g., PS-9) used in the system fault tree.

The RCIC system is automatically initiated and controlled. Operator intervention is required as follows: (1) to prevent either vessel overfill or continuous system trip/restart cycles, (2) to manually start the system given an auto-start failure, and (3) to set up the system for continuous operation when battery depletion is imminent.

The success criteria for the RCIC system is injection at rated flow to the reactor vesse1. For further information, refer to success criteria discussions in Section IV.4.

Most of the RCIC system is located in a separate room in the reactor building. Local access to the RCIC system could be affected by either containment venting or containment failure should steam be released to the reactor building area. Room cooling failure is assumed to fail the RCIC pump in four hours. Refer to Section IV.5.13 for further information on room cooling.

\section{IV.5.3.2 RCIC Interfaces and Dependencies}

The RCIC system major dependencies are DC power for short term operation and room cooling for long term operation. Although there are AC powered motor-operated valves, these valves are not required to change state during normal system operation since they are only used to isolate the system if it is required. A simplified dependency diagram of the RCIC system is provided by Figure IV.5.3-2. Shown are the major support needs for the RCIC system as indicated by the solid diamonds at the appropriate places in the diagram.

The RCIC system requires both $250 \mathrm{VDC} / \mathrm{A}$ and $125 \mathrm{VDC} / \mathrm{A}$. The $125 \mathrm{VDC} / \mathrm{A}$ is used for actuation and control power while an injection and a supply valve are powered from $250 \mathrm{VDC} / \mathrm{A}$.

The RCIC and HPCI systems share a common CST suction valve. This is a normally open manual valve and is identified as XVI on the RCIC schematic. Failure of this valve will fail the CST as a suction source to both the RCIC and HPCI systems.

Upon system actuation, RCIC injection valves receive a signal to open and RCIC test valves receive a signal to close. The RCIC system is automatically initiated on the receipt of a low reactor water level signal (490 inches above vessel zero). The low reactor water level sensors are shared with the HPCI system. A simplified actuation dependency diagram of all major emergency coolant actuation subsystems is provided by Figure IV.5.2-3.

The CST is the initial suction source for the RCIC system. Suction is automatically switched to the suppression pool on low CST level. Automatic switchover will not occur if there is an automatic isolation signal present. The CST suction valve does not close until both of the suppression pool suction valves are fully open. 


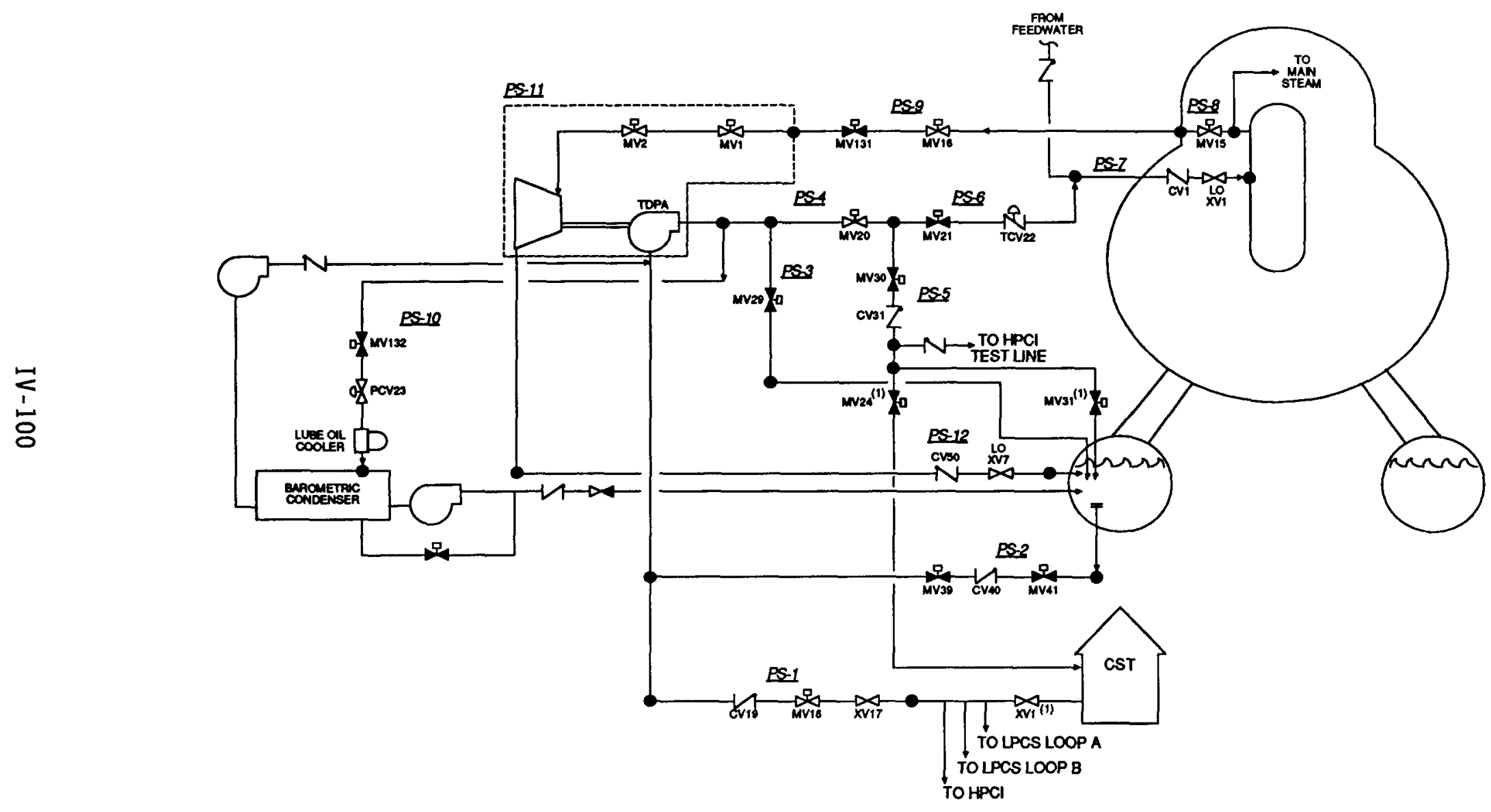

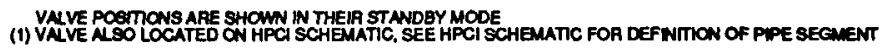

Figure IV.5.3-1. Reactor Core Isolation Cooling system Schematic. 


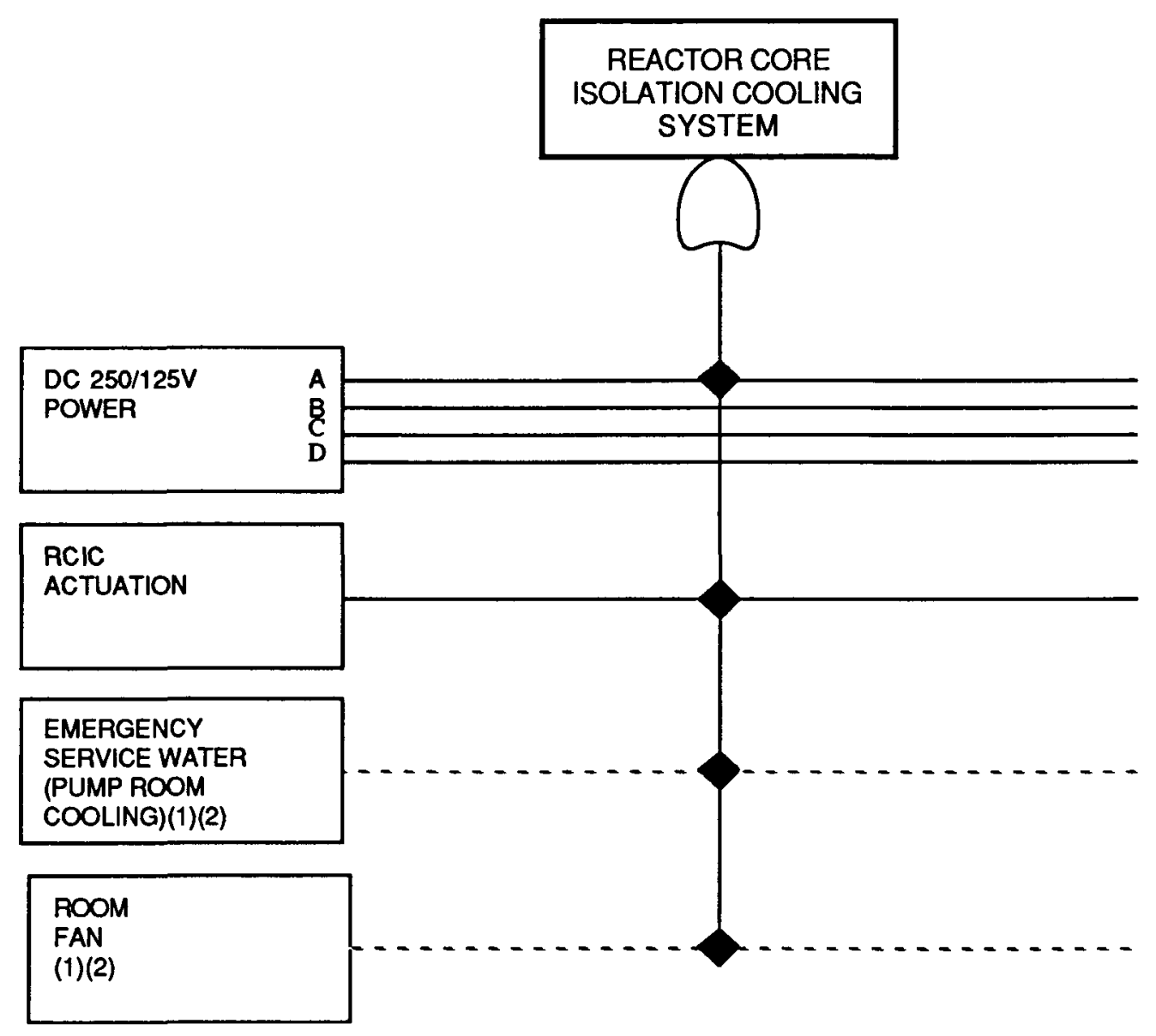

Dependency Diagram Is Shown Using Failure Logic.

(1)Dependency Not Required During Short Term Operation.

(2) Room Cooling Can Also Be Performed By Opening Doors. 
The RCIC system is automatically isolated by high steam line space temperature, steam line high $\mathrm{dP}$, or high turbine exhaust pressure (50 psig). Both the high temperature and high dP signals are used to detect a steam line break.

The RCIC turbine trips on high exhaust pressure, high reactor water level, low pump suction pressure, low steam pressure, or an auto isolation signal.

\section{IV.5.3.3 RCIC Test and Maintenance}

The RCIC system surveillance requirements are the following: (1) pump operability--once/month, (2) motor-operated valve operability--once/month, (3) pump capacity test--once/three months, (4) simulated automatic actuation test--once/operating cycle, and (5) logic system functional test--once/six months.

\section{IV.5.3.4 RCIC Technical Specifications}

If the RCIC system is made or found to be inoperable for any reason, continued reactor operation is permissible for seven days provided that ADS, HPCI, LPCI, and both loops of the LPCS system are operable. If this requirement cannot be met, the reactor is to be shut down.

\section{IV.5.3.5 RCIC Logic Mode1}

The RCIC system was modeled using a fault tree for the injection of coolant to the reactor vessel. The major active components and most passive components were modeled using pipe segments which were defined for the RCIC system. Components within a pipe segment were grouped together to form a single basic event. Generally a pipe segment is that run of pipe from one junction to another junction. A separate pipe segment was defined when components within a run of pipe had different dependencies or potentials for recovery and at a penetration of the containment. The fault tree model representing the RCIC system is presented in Appendix $A$.

Piping ruptures were considered to be negligible compared to other system failures. Only the piping with a diameter of greater than or equal to $1 / 3$ of the main system piping was considered as a potential diversion path.

The barometric condenser condensate pump and vacuum pump were not modeled since their operation is not essential to system operation.

Seven human errors were incorporated into the RCIC fault tree model. These errors are (1) failure to trip the RCIC system and realign its suction source, (2) failure to realign the suction source for the RCIC and HPCI systems, (3) failure to control RCIC flow (reactor level), (4) failure to manually backup automatic RCIC actuation, (5) miscalibration of CST level sensors, (6) miscalibration of ESF sensors, and (7) failure to isolate the RCIC system given high exhaust pressure.

\section{IV.5.3.6 RCIC Assumptions}

(1) The RCIC test return lines were not considered as potential diversion paths because the probability of two normally closed MOVs failing to prevent flow was felt to be negligible compared to other system faults. 
(2) Failure of the system to isolate given certain conditions was not considered since the system is effectively "non-operational." These conditions are (a) high steam line space temperature, (b) high steam line dP, (c) low steam pressure, (d) high steam line exhaust pressure, and (e) manual isolation.

(3) Failure of the minimum flow line to open does not constitute system failure since the time between pump start and opening of the injection valve is small.

(4) The barometric condenser condensate pump and vacuum pump are not necessary for system operation. Therefore, their failures were not modeled.

(5) Spurious signals are felt to be negligible compared to other system failures because of their low probability of occurrence.

(6) The RCIC system is assumed to fail in a non-recoverable state if it fails to trip on low suction pressure or high reactor water level because of expected damage to the pump or turbine.

(7) RCIC pump bearing cooling fails if pump suction is from the suppression pool and the working fluid temperature reaches between 210 and $2600 \mathrm{~F}$.

(8) The RCIC turbine shaft-driven oil pump, stop valve, and governor valve failures were included in turbine failure data.

(9) System failure because of valves' being left in the wrong position after test or maintenance is felt to be negligible because the position of all manual and motor-operated valves is indicated in the control room and the motor-operated valves receive signals to realign.

(10) Testing of TCV22 will not prevent flow to the reactor vessel, nor will it prevent TCV-22 from stopping flow to the reactor vessel.

(11) During construction of the fault tree, it was necessary to determine which components could be taken oos for maintenance. It was assumed that maintenance would require components to be effectively removed from the system. Standard safety precautions of component isolation were used to decide which components could be taken OOS for maintenance while the plant was at power or normal operating pressure. The general guidelines used for component isolation were double blockage for high pressure piping or components and single blockage for low pressure piping or components.

(12) An event for depletion of the CST was included for those cases where RCIC and/or HPCI operation was judged to be sufficiently long.

(13) Failure of the suppression pool by random failure or the plugging of its strainers is felt to be negligible compared to other system failures. 
(14) If the HPCI or RCIC minimum flow line has been demanded open and subsequently fails to close on a system trip, there is the possibility that the CST will drain to the suppression pool due to their difference in elevation.

(15) Lube $0 i 1$ cooling is required for bearing cooling.

(16) The RCIC actuation circuitry was not modeled to a great degree of detail. Only elements which were felt to be potentially important were included in the fault tree model. The initiating signal sensors and their support systems were explicitly modeled since they are shared between various ESF systems. The power supply for the actuation circuitry was also included. Hardware failures of relays and certain permissives were grouped into one basic event.

(17) It is assumed that calibration of the low and low-low reactor vessel water level sensors is performed at the same time. Miscalibration of these sensors is assumed to be the same event.

(18) Failure to recover an initial loss of the normal suction source (the CST) will be treated as a recovery action. Operator error appears to dominate failures of suppression pool valves and their manual actuation circuitry. Failure of suppression pool valves from maintenance outages or support system failures appears elsewhere in the fault tree.

(19) Failure of the system to automatically realign to the suppression pool after a loss of the normal suction source (the CST) is treated explicitly with manual switchover being treated as a recovery action.

(20) The suction pressure trip is "ANDed" with a dummy event to account for the probability that low suction pressure exists.

(21) The operator is required to manually reset the RCIC turbine trip valve if either high steam flow or high steam line temperature occurs. Manual reset is not required for either high reactor water level or low suction pressure.

\section{IV.5.3.7 RCIC Operating Experience}

Nothing was peculiar in the operational history of the RCIC system which would affect system modeling. Plant operational data indicates a higher value for TDP failure to run than the generic data base. The difference is that the generic value was calculated using plant operational hours instead of RCIC operational hours. The values compare closely when RCIC operational hours are used in the generic calculation. Therefore, the plant specific value for TDP failure to run is used. 


\section{IV.5.4 Control Rod Drive (CRD) System}

\section{V.5.4.1 CRD Description}

The CRD system was modeled as a backup source of high pressure injection (event tree nomenclature- $U 3$ ).

The CRD pumps take suction from the condenser hotwell in the Condensate system or the CST. A flow control station is installed downstream of the tap from the Condensate system and ties into the CRD pump suction line before the CRD suction filter. The flow control station will divert $250 \mathrm{gpm}$ from the Condensate system. This will supply the CRD system with the remainder of the water being passed on to the CST. In the event that flow from the Condensate system is interrupted, the CST provides a backup source of water to ensure CRD system operability without operator action being required. A simplified schematic of the CRD system is provided by Figure IV.5.4-1.

The CRD pumps, together, can achieve a flow rate of approximately $210 \mathrm{gpm}$ with the reactor fully pressurized and approximately $300 \mathrm{gpm}$ with the reactor depressurized. Two discharge paths are provided for the CRD pumps. One discharge path is through an air-operated valve control station. When instrument air is lost, this path is blocked. With both CRD pumps running and the reactor at nominal pressure, the second discharge path restricts flow, by means of an orifice, to approximately $180 \mathrm{gpm}$.

Normally one CRD pump is running, with the suction and discharge valves to the standby pump being blocked. Should the operator be required to realign the CRD ystem as a sole source of early high pressure injection, the standby CRD pump must be placed into operation to achieve sufficient flow to the reactor vessel.

In general, the CRD success criteria (as a sole injection source to the reactor) require both pumps running and one of the two discharge paths available. For further information, refer to success criteria discussions in Section IV. 4.

Most of the CRD system is located in the turbine building. Any physical impact of accident conditions on the ability of the CRD system to perform its function would be minimal. Since the system is located in a large open area, room cooling failure is not applicable to the CRD pumps.

\section{IV.5.4.2 CRD Interfaces and Dependencies}

CRD Pump $A$ is powered from 4160 VAC/A with control and actuation power supplied by $125 \mathrm{VDC} / \mathrm{A}$. CRD Pump $B$ is powered from $4160 \mathrm{VAC} / D$ with control and actuation power supplied by $125 \mathrm{VDC} / \mathrm{D}$. A simplified dependency diagram of the CRD system is provided by Figure IV.5.4-2. Shown are the major support needs for achieving full flow operation of the CRD system as indicated by the solid diamonds at the appropriate places in the diagram.

The CRD pumps receive no automatic initiation signals.

Although the CRD pumps are cooled by either the Turbine Building Cooling Water (TBCW) or Reactor Building Cooling Water (RBCW) system (as shown on the dependency jagram), the pumps are realistically assumed not to require pump cooling (even uring prolonged pump use). The small size of the pumps and the fact that relatively low temperature water is being pumped are the basis for the assumption 


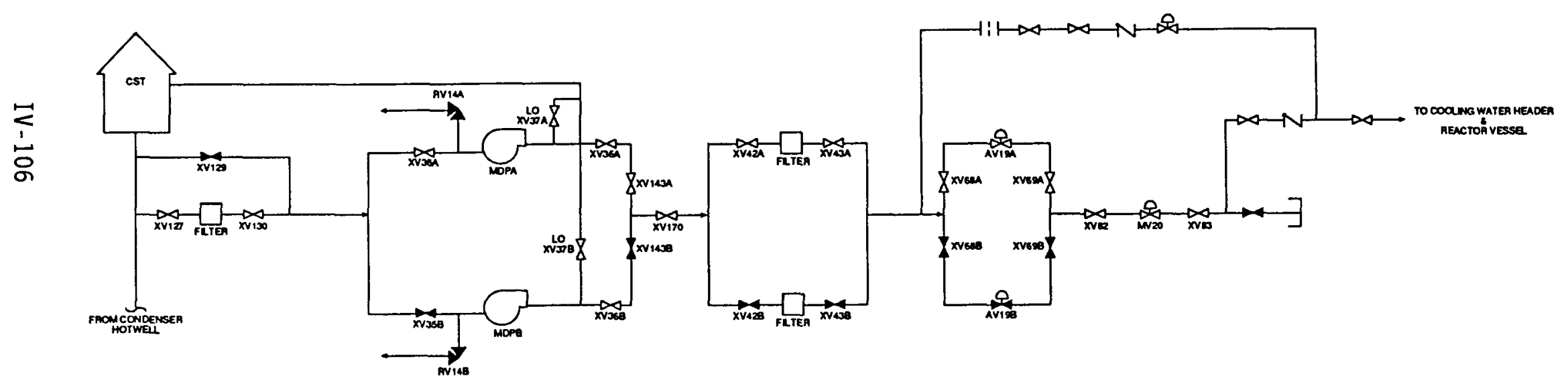

VALVE POSTIONS ARE SHOWN IN THEIR OPERATING MODE

Figure IV.5.4-1. Control Rod Drive System Schematic. 


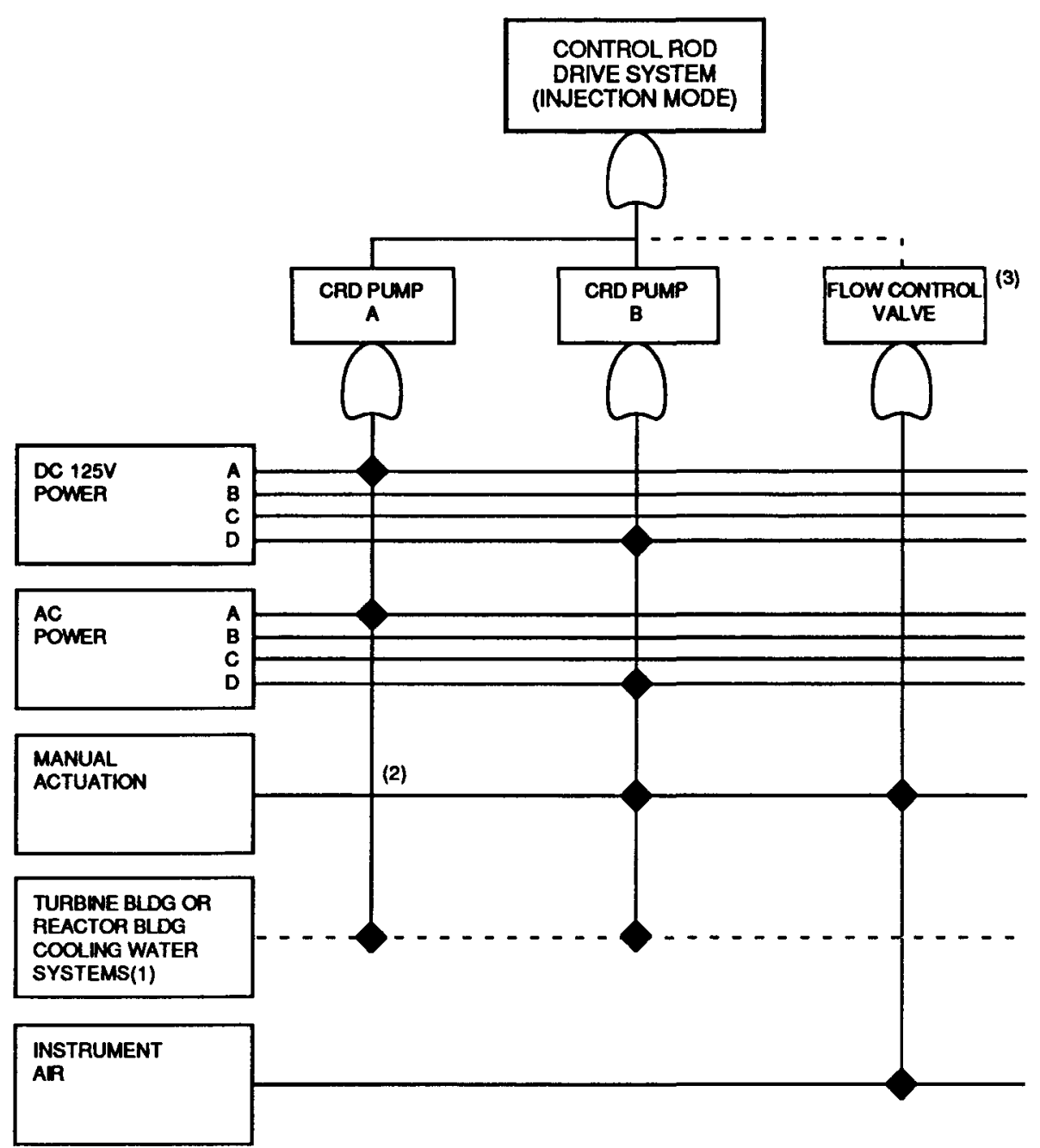

Dependency Diagram is Shown Using Failure Logic.

(1) Dependency Not Required During Short Term Operation.

(2) CRD Pump A Normally Operating.

(3)Failure Of Flow Control Valve Does Not Fail Injection To Reactor Via CRD Because An Altemate Flow Path Is Available.

Figure IV.5.4-2. Control Rod Drive System Dependency Diagram. 
that cooling is not realistically required. In addition, even a non-operating TBCW or RBCW system would still act as somewhat of a heat sink to the operating CRD pumps for a significant time period. This assumption is examined as a sensitivity issue in Section IV.11.

\section{IV.5.4.3 CRD Test and Maintenance}

No CRD (in the high pressure injection mode) test and maintenance requirements are identified in the Peach Bottom technical specifications.

\section{IV.5.4.4 CRD Technical Specifications}

No reference is made to the CRD high pressure injection mode in the Peach Bottom technical specifications.

\section{IV.5.4.5 CRD Logic Mode1}

The CRD system was modeled using a simplified failure equation for its high pressure injection mode. Dominant failures were considered to be unavailabilities associated with the pumps and human error to align the second pump into operation to achieve full flow conditions when necessary.

As indicated above, one human error was incorporated into the CRD system failure model. This error is the operator failing to properly align the CRD system for full flow in the high pressure injection mode.

\section{IV.5.4.6 CRD Assumptions}

(1) Pipe segments less than $1 / 3$ of the main system pipe diameter are not considered to be diversion paths.

(2) Both CRD pumps are generally required for system success. See Section IV. 4 for further details.

(3) CRD pumps do not require pump cooling.

(4) The orificed discharge path provides sufficient flow for successful high pressure injection.

\section{IV.5.4.7 CRD Operating Experience}

Nothing was peculiar in the operational history of the CRD system which would affect either system modeling or failure data.

\section{IV.5.5 Standby Liquid Control (SLC) System}

\section{IV.5.5.1 SLC Description}

The SLC system provides a backup method, which is redundant but independent of the control rods, to establish and maintain the reactor subcritical (Anticipated Transient Without Scram, ATWS, event tree nomenclature--SLC). 
The suction for the SLC system comes from a control tank. The control tank has sodium pentaborate in solution with demineralized water. Two, in parallel, positive displacement pumps are each sized to inject the sodium pentaborate solution into the reactor. Two, in parallel, explosive valves are downstream of the pumps' combined discharge. Downstream of the explosive valves, the system combines to a common discharge line. SLC discharge enters the reactor vessel near the bottom of the core shroud where it mixes with cooling water rising through the core. A simplified schematic of the SLC system is provided by Figure IV.5.5-1.

The operator manually activates the SLC system with a three-position keylock switch on the control room console. If the pump lights or the explosive valve light indicate that liquid may not be flowing, the operator can turn the keylock switch to the other side to operate the other pump.

The success criteria for the SLC system are one of two pumps running and one of two explosives valves open. For further information, refer to Section IV.10.

Most of the SLC system is located in the reactor building outside of the drywell. Local access to the SLC system could be affected by a containment failure or containment venting scenario.

\section{IV.5.5.2 SLC Interfaces and Dependencies}

SLC Pump $A$ is powered from 480 VAC/A with control and actuation power supplied by $125 \mathrm{VDC} / \mathrm{A}$. SLC Pump $B$ is powered from $480 \mathrm{VAC} / \mathrm{B}$ with control and actuation power supplied by $125 \mathrm{VDC} / \mathrm{B}$. Both pumps are self-cooled and do not require room cooling. A simplified dependency diagram of the SLC system is provided by Figure IV.5.5-2. Shown are the major support needs for the SLC system as indicated by the solid diamonds at the appropriate places in the diagram.

The SLC system has a common test return line. This piping originates at the pumps combined discharge. If this line is not isolated following a test, pump discharge in the event of system actuation would preferentially flow to either the test or control tanks.

Switching from "Off" to either "Pump A" or "Pump B" on the three-position keylock switch starts the respective pump, opens both explosive valves, and closes the Reactor Water Cleanup (RWCU) system isolation valves. The RWCU isolation valves are closed to prevent loss or dilution of the boron.

The SLC pumps have control room informational lights. A green light indicates that power is available to the pump motor contactor but the contactor is open and the pump is not running. A red light indicates the contactor is closed and the pump is running.

The explosive valve shearing plunger is actuated by an explosive charge having dual ignition primers. Ignition circuit continuity is monitored by a trickle current. If either explosive valve circuit opens, a control room alarm actuates.

\section{IV.5.5.3 SLC Test and Maintenance}

Once per month each pump loop is functionally tested by recirculating demineralized water to the test tank. The SLC system is tested once every operating cycle as follows: (1) relief valve settings are checked, (2) the system 


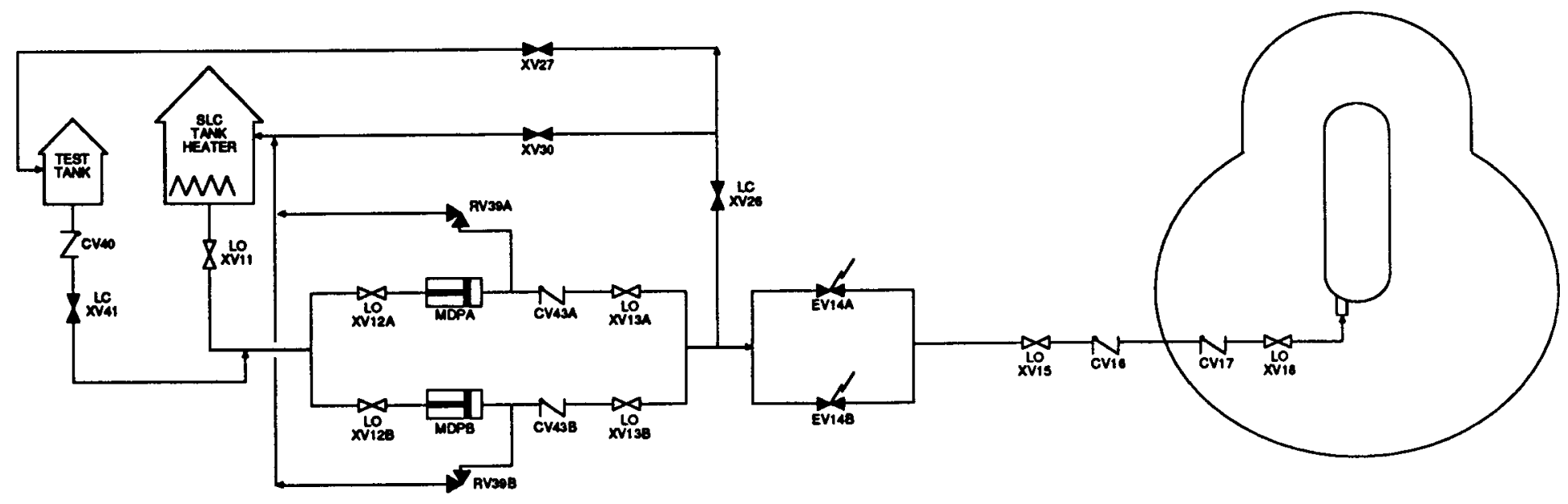

VALVE POETIONB ARE SHOWN WN THEIA STMDOCY MOOE 


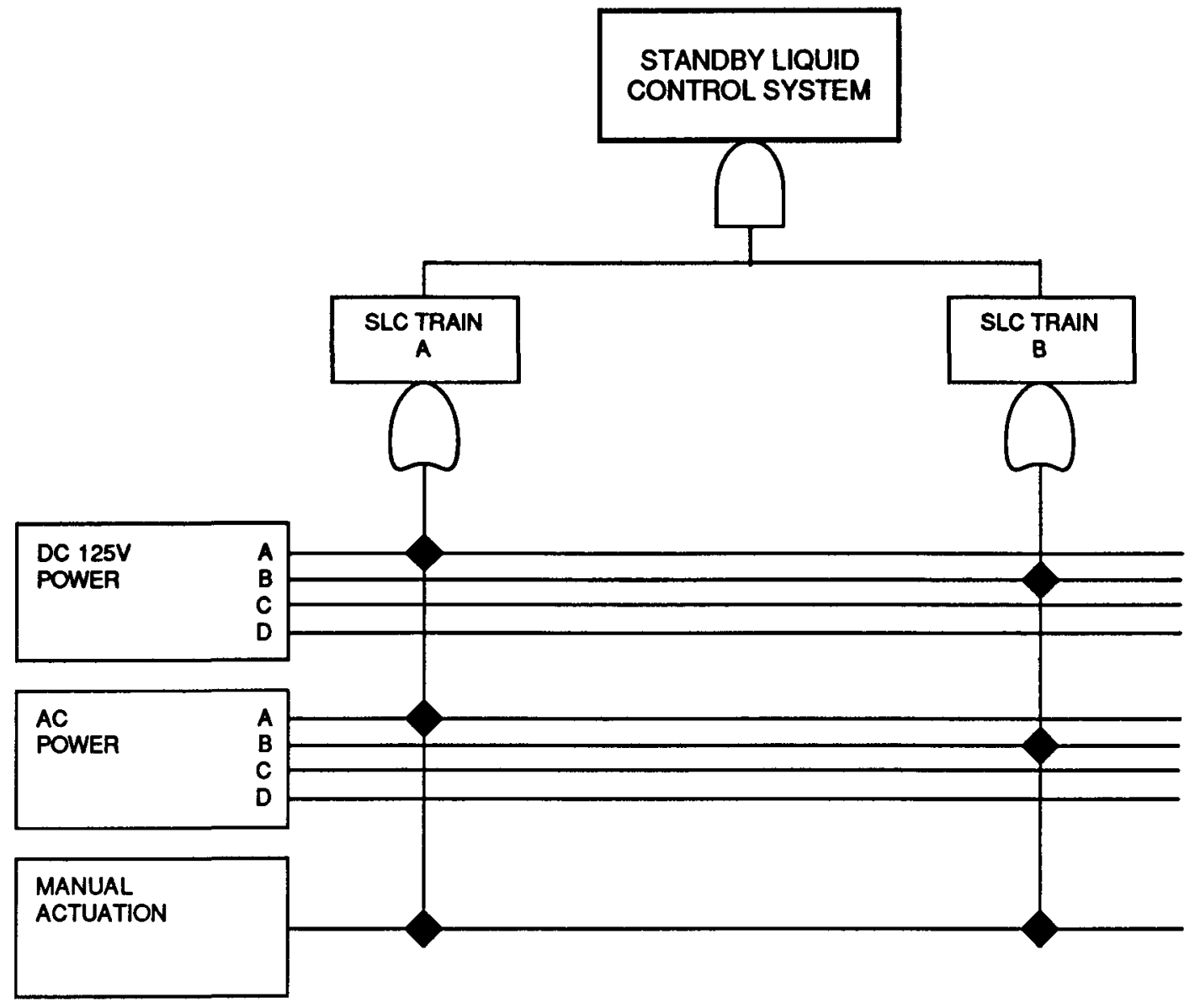

Dependency Diagram is Shown Using Failure Logic.

Figure IV.5.5-2. Standby Liquid Control System Dependency Diagram. 
is manually initiated except for the explosive valves, and (3) one SLC pump takes a suction from the test tank and discharges demineralized water into the reactor vessel. Both systems, including both explosive valves, are tested in the course of two operating cycles. When a component is found to be inoperable, its redundant component is to be demonstrated operable immediately and on a daily basis thereafter until the inoperable component is repaired.

\section{IV.5.5.4 SLC Technical Specifications}

When fuel is in the reactor and prior to cold startup, the SLC system must be operable. With a redundant component inoperable, continued reactor operation is allowed for seven days.

\section{IV.5.5.5 SLC Logic Model}

The SLC system was modeled using a simplified failure equation. Dominant failures were considered to be failure to start the system and failure to properly close off the test return line valves after test.

As indicated above, two human errors were incorporated into the SLC system fault tree equation. These errors are the operator fails to start the system and the operator fails to properly restore the system following testing.

\section{IV.5.5.6 SLC Assumptions}

(1) Pipe segments less than $1 / 3$ of the main system pipe diameter are not considered to be diversion paths.

(2) Failure to heat the sodium pentaborate solution is not assumed to fail the system, based on information in the Peach Bottom UFSAR. [11]

\section{IV.5.5.7 SLC Operating Experience}

Nothing was peculiar in the operational history of the SLC system which would affect either system modeling or failure data.

\section{IV.5.6 Automatic Depressurization System}

\section{IV.5.6.1 ADS Description}

The ADS is designed to depressurize the primary system to a pressure at which the low pressure injection systems can inject coolant to the reactor vessel (event tree nomenclature- $-X$ ).

The ADS consists of five relief valves capable of being manually opened. Each valve discharges via a tailpipe line through a downcomer to the suppression pool. Relief valve capacity is approximately $820,000 \mathrm{lb} / \mathrm{hr}$. A simplified schematic of the ADS is provided by Figure IV.5.6-1.

The ADS is automatically initiated. The operator may manually initiate the ADS or may depressurize the reactor vessel using the six relief valves that are not connected to ADS logic. If a spurious ADS signal occurs, the operator can inhibit ADS operation. 


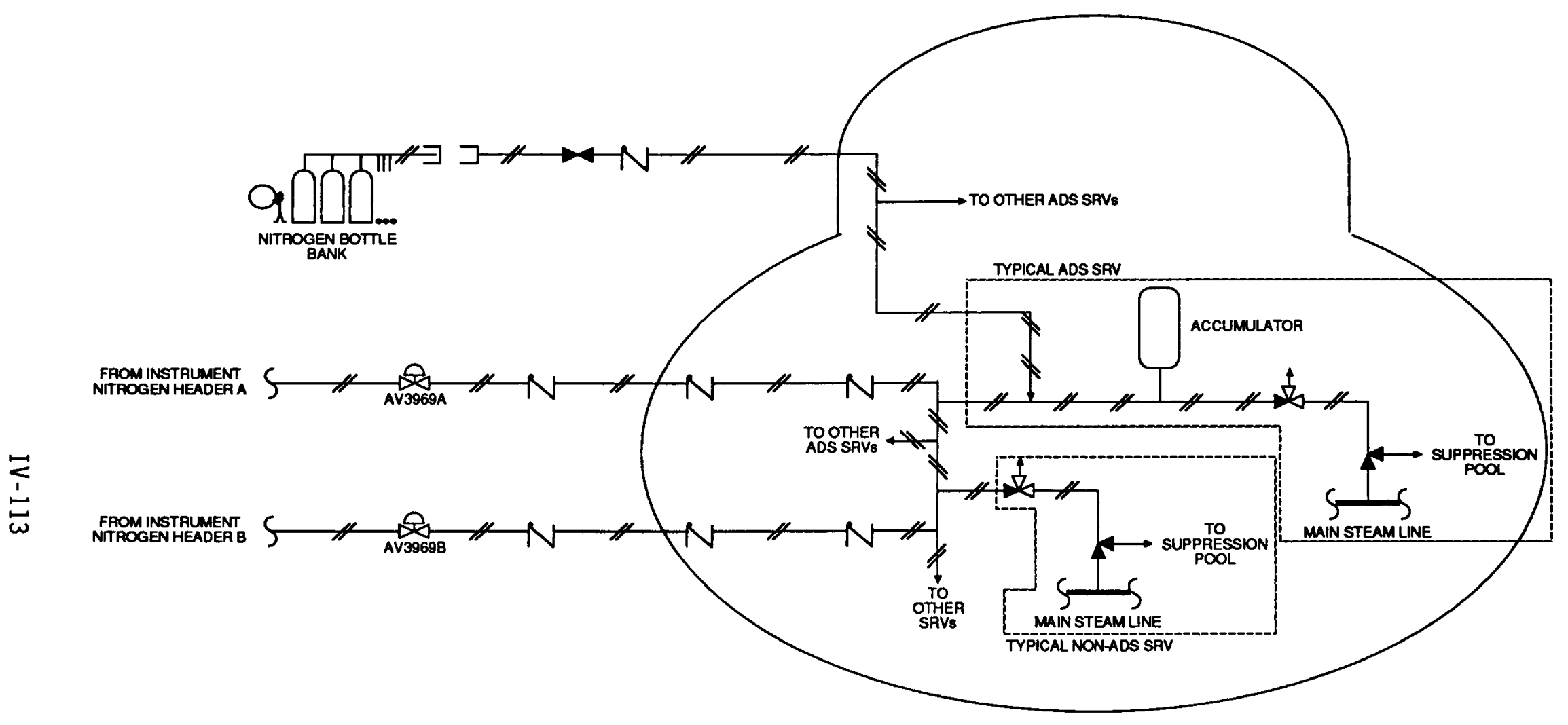

VALVES POSITIONS ARE SHOWN IN THEIR STANDBY MODE 
The success criterion for the ADS is two of five valves opening to depressurize the reactor. For further information, refer to success criteria discussions in Section IV.4.

The ADS valves are located inside the containment. ADS performance is not normally affected by accident conditions since the equipment is qualified for accident conditions and the air/nitrogen supply pressure is judged to be sufficiently high to allow valve operation under most containment conditions. However, should containment pressure be near the containment failure point ( $150 \mathrm{psig})$, the valves could not be kept open since the air/nitrogen supply pressure is limited to -125 psig based on discussions with Philadelphia Electric Company (PECO) personnel indicating the supply is orificed to that limit.

\section{IV.5.6.2 ADS Interfaces and Dependencies}

The ADS depends upon air/nitrogen and 125 VDC power sources. A simplified dependency diagram of the ADS is provided by Figure IV.5.6-2. Shown are the major support needs for the ADS as indicated by the solid diamonds at the appropriate places in the diagram. Air/nitrogen pressure is used to open the ADS valves. Accumulators for each ADS valve contain enough pressure for approximately five valve operations. In addition to the accumulators, there is a nitrogen bottle supply that can be manually valved in.

ADS logic consists of two divisions. Power dependencies for each division are the $125 \mathrm{VDC} / \mathrm{A}$ bus as a primary source and the $125 \mathrm{VDC} / \mathrm{B}$ bus as a backup source. ADS valve power is from either $125 \mathrm{VDC} / \mathrm{A}$ (the primary DC supply) or $125 \mathrm{VDC} / \mathrm{D}$ (backup DC supply). ADS logic is failed if $125 \mathrm{VDC} / \mathrm{A}$ and the relay that switches power fail. However, each relief valve has its own relay that switches power for solenoid operation.

Automatic ADS initiation occurs upon receipt of a low-low reactor water level signal (with an -eight-minute time delay), a low-low level and high drywell pressure signal, or notice that one LPCI or two LPCS pumps are running.

Low-10w reactor water level sensors are shared with the LPCS and LPCI systems.

\section{IV.5.6.3 ADS Test and Maintenance}

A simulated automatic actuation of the ADS is performed prior to startup after each refueling.

\section{IV.5.6.4 ADS Technical Specifications}

If any one ADS valve is made or found to be inoperable for any reason, continued reactor operation is permissible for seven days provided that the HPCI system is operable. If this requirement cannot be met, the reactor is to be shut down.

\section{IV.5.6.5 ADS Logic Model}

The ADS was modeled using a fault tree for the depressurization of the reactor either automatically or manually (see Appendix A).

Piping ruptures were considered to be negligible compared to other failures. 


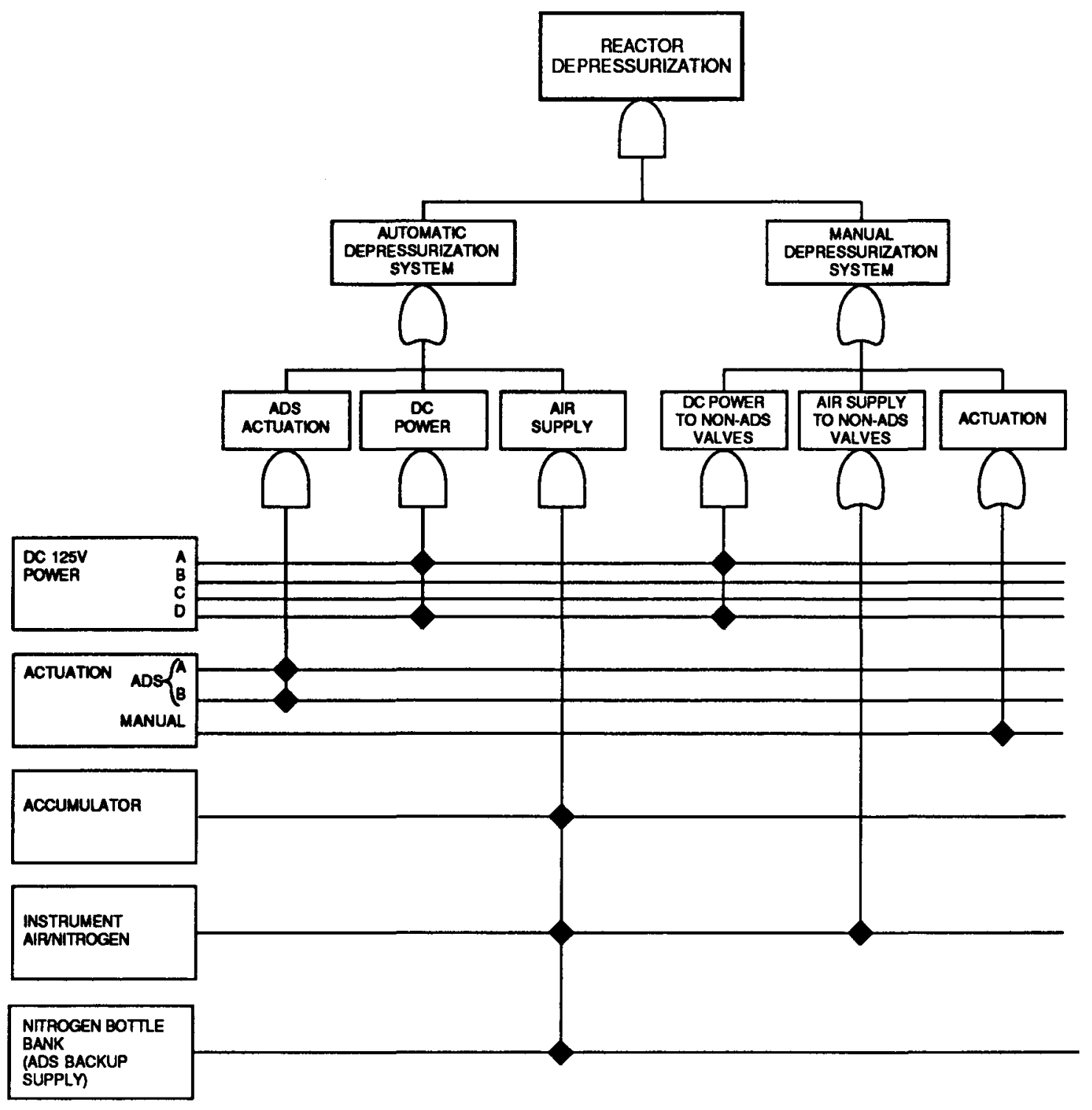

Dependency Diagram is Shown Using Failure Logic.

Figure IV.5.6-2. Reactor Depressurization Dependency Diagram. 
Three human errors were incorporated into the ADS fault tree model. These errors are (1) failure to valve in the backup nitrogen supply, (2) sensor miscalibration, and (3) failure to manually depressurize.

\section{IV.5.6.6 Assumptions in the ADS Model}

(1) Although the random independent hardware failure of a significant number of either the ADS safety/relief valves or the non-ADS safety/relief valves is felt to be negligible compared to other system failures, an event for the hardware failure of these valves is included. Common mode failure of the valves is treated separately per the methodology guidelines.

(2) Failure of the operator to manually initiate the ADS and/or to manually depressurize the reactor vessel are felt to be strongly coupled and are assumed to be the same event.

(3) Failure of the accumulator is included in the undeveloped event representing ADS valve hardware failure.

\section{IV.5.6.7 ADS Operating Experience}

Nothing was peculiar in the operational history of the ADS which would affect either system modeling or failure data.

\section{IV.5.7 Low Pressure Core Spray System}

\section{IV.5.7.1 LPCS Description}

The function of the LPCS system is to provide a makeup coolant source to the reactor vessel during accidents in which system pressure is low (event tree nomenclature--V2.). The ADS can be used in conjunction with the LPCS system to attain a low enough system pressure for injection to occur.

The LPCS system is a two-10op system consisting of motor-operated valves and motor driven pumps. There are two fifty percent capacity pumps per 10op, with each pump rated at $3125 \mathrm{gpm}$ with a discharge head of $105 \mathrm{psig}$. The LPCS system normal suction source is the suppression pool. Pump suction can be manually realigned to the CST. A simplified schematic of the LPCS system is provided by Figure IV.5.7-1. Major components are shown as well as the pipe segment definitions (e.g., PS-27) used in the system fault tree.

The LPCS system is automatically initiated and controlled. Operator intervention is required to manually start the system given an auto-start failure and to stop the system or manually control flow during an ATWS if required.

The success criterion for the LPCS system is injection of flow from any two pumps to the reactor vesse1. For further information, refer to success criteria discussions in Section IV.4.

Most of the LPCS system is located in the reactor building. Local access to the LPCS system could be affected by either containment venting or failure. Room cooling failure is assumed to fail the LPCS pumps in four hours. 


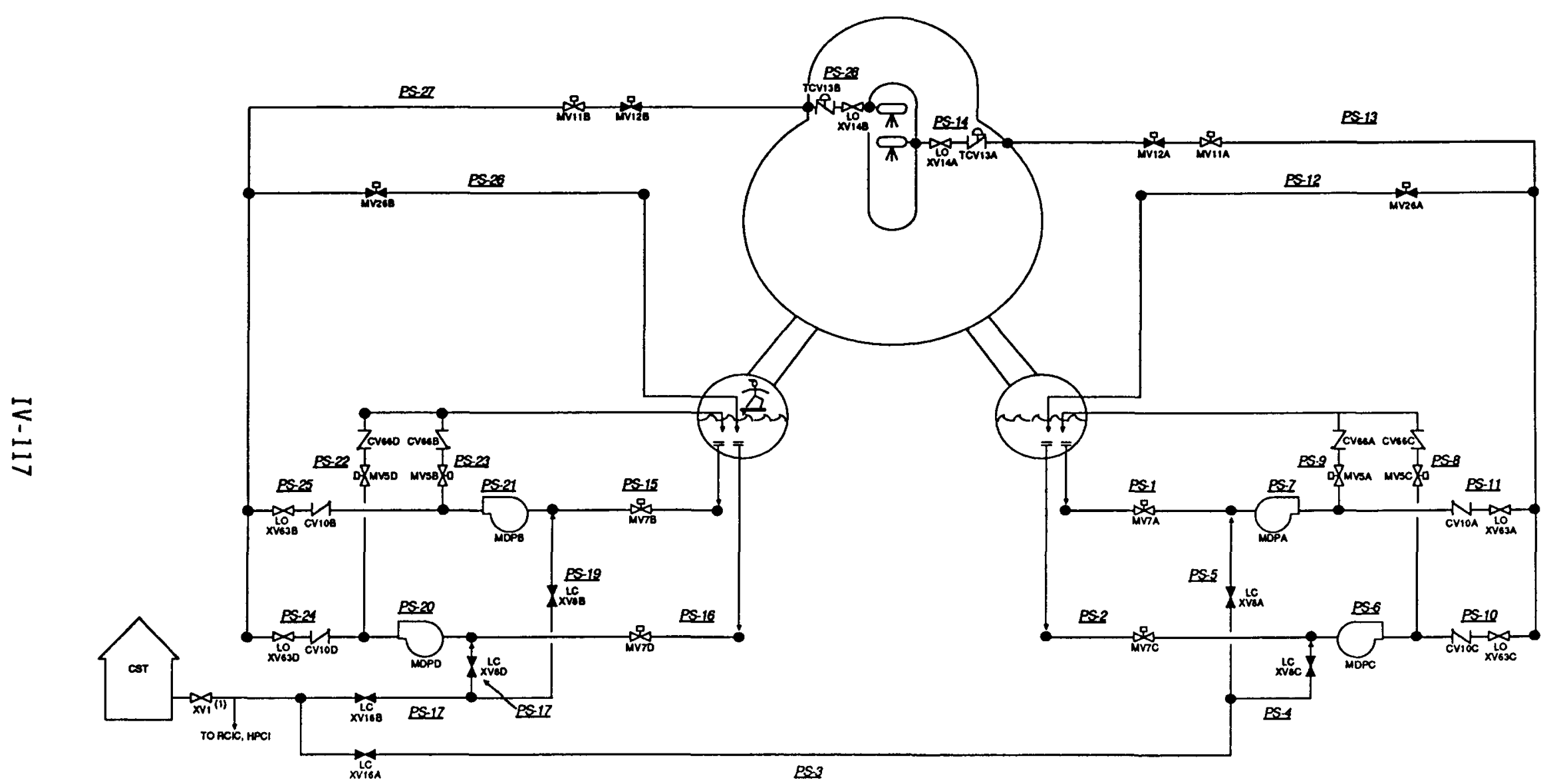

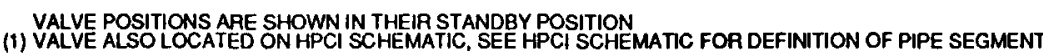

Figure IV.5.7-1. Low Pressure Core Spray System Schematic. 


\section{IV.5.7.2 LPCS Interfaces and Dependencies}

Each LPCS pump is powered from a separate 4160 VAC bus with control and actuation power being supplied by a separate 125 VDC bus. All pumps require pump cooling. For further information on pump cooling, refer to Section IV.5.13.8.

Each loop's normally closed injection valve receives its motive power from a separate 480 VAC bus (480 VAC/C for Loop A, $480 \mathrm{VAC} / D$ for Loop B). A simplified dependency diagram of the LPCS system is provided by Figure IV.5.7-2. Shown are the major support needs for the LPCS system as indicated by the solid diamonds at the appropriate places in the diagram.

Upon the receipt of a LPCS injection signal, start signals are sent to all LPCS pumps, both injection valves are demanded to open, and the test return valves are demanded to close. The LPCS system is automatically initiated on the receipt of either a low-low reactor water level (378 inches above vessel zero) or high drywell pressure (2 psig) and low reactor pressure (450 psig). A simplified dependency diagram of the major emergency coolant actuation subsystems is provided by Figure IV.5.2-3. All actuation sensors are shared with the LPCI system.

LPCS actuation and control circuitry is divided into two divisions. Division $A$ is associated with the actuation and control of the components in Loop $A$, and Division $B$ is associated with the actuation and control of the components in Loop B.

Each LPCS pump has a minimum flow line valve (normally open) which is demanded to open given a pump start.

Both injection valves are prohibited from opening unless a low reactor pressure permissive (450 psig) is met.

\section{IV.5.7.3 LPCS Test and Maintenance}

The LPCS system surveillance requirements are the following: (1) pump operability--once/month, (2) MOV operability--once/month, (3) pump capacity test--once/three months, (4) simulated automatic actuation test--once/operating cycle, and (5) logic system functional test--once/six months.

\section{IV.5.7.4 LPCS Technical Specifications}

If any one LPCS loop is made or found to be inoperable for any reason, continued reactor operation is permissible for seven days provided that the remaining LPCS loop and the LPCI system are operable. If this requirement cannot be met, the reactor is to be shut down.

\section{IV.5.7.5 LPCS Logic Mode1}

The LPCS system was modeled using a fault tree for the injection of coolant to the reactor vessel. The major active components and most passive components were modeled using pipe segments which were defined for the LPCS system. Components within a pipe segment were grouped together to form a single basic event. Generally a pipe segment is that run of pipe from one junction to another junction. A separate pipe segment was defined when components within a run or 


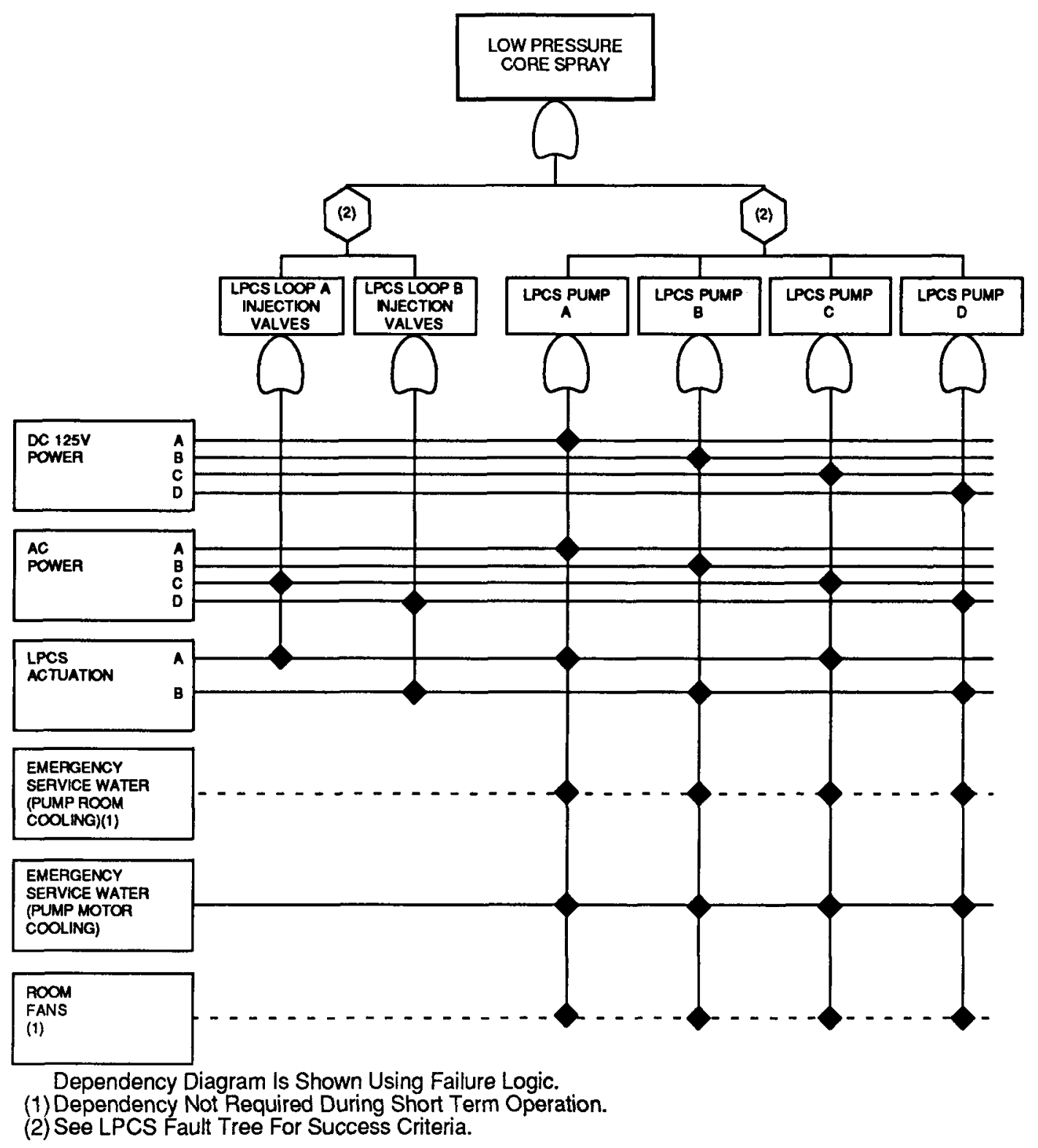

Figure IV.5.7-2. Low Pressure Core Spray System Dependency Diagram. 
pipe had different dependencies or potentials for recovery and at a penetration of the containment. The fault tree model representing the LPCS system is presented in Appendix A.

Piping ruptures were considered to be negligible compared to other system failures. Only piping with a diameter of greater than or equal to $1 / 3$ of the main system was considered as a potential diversion path.

Two human errors were incorporated into the LPCS fault tree model. These errors are miscalibration of various sensors and failure to manually backup automatic actuation.

\section{IV.5.7.6 LPCS Assumptions}

(1) LPCS system failure because of valves being left in the wrong position after testing or maintenance is felt to be negligible because the position of all manual and motor operated valves is indicated in the control room.

(2) During construction of the fault tree, it was necessary to determine which components could be taken 005 for maintenance. It was assumed that maintenance would require components to be effectively removed from the system. Standard safety precautions of component isolation were used to decide which components could be taken $00 \mathrm{~S}$ for maintenance while the plant was at power or normal operating pressure. The general guidelines used for the component isolation were double blockage for high pressure piping or components and single blockage for low pressure piping or components.

(3) Pump isolation because of spurious signals is assumed to be negligible compared to other system faults.

(4) The LPCS actuation circuitry was not modeled at a great level of detail. Only elements which were felt to be potentially important were included in the fault tree model. Hardware failures of relays and permissives were grouped into one term. The initiating signal sensors and their support systems were explicitly modeled since they are shared between various ESF systems.

(5) Based on a PECO response, it is assumed that the LPCS pumps wi11 fail because of insufficient net positive suction head (NPSH) once the suppression pool has reached saturated conditions.

(6) LPCS system failure because of a test diverting flow is felt to be negligible because valves receive signals to close from both Divisions $A$ and $B$ actuation circuitry.

(7) The CST is an alternate suction source which must be manually valved in and therefore is not explicitly included in the model but can be handled as a recovery action.

(8) The LPCS pumps do not trip on low pump suction pressure. 
(9) Failure of the suppression pool because of random failure or the plugging of all its strainers is assumed to be negligible compared to other system failures.

(10) It is assumed that calibration of the low and low-low reactor water level sensors is performed at the same time. Miscalibration of these sensors is considered to be the same event.

\section{IV.5.7.7 LPCS Operation Experience}

Nothing was peculiar in the operational history of the LPCS system which would affect either system modeling or failure data.

IV.5.8 Low Pressure Coolant Injection System

\section{IV.5.8.1 LPCI Description}

The function of the LPCI system is to provide a makeup coolant source to the reactor vessel during accidents in which system pressure is low (event tree nomenclature--V3). The ADS can be used in conjunction with the LPCI system to attain a low enough system pressure for injection to occur. The LPCI system is but one mode of the Residual Heat Removal (RHR) system and, as such, shares components with other modes.

The RHR system is a two-loop system consisting of motor-operated valves and motor-driven pumps. There are two pump/heat exchanger trains per loop, with each pump rated at $10,000 \mathrm{gpm}$ with a discharge head of $450 \mathrm{psig.} \mathrm{Cooling} \mathrm{water} \mathrm{flow} \mathrm{to}$ the heat exchangers is not required for the LPCI mode. The LPCI suction source is the suppression pool. A simplified schematic of the LPCI (RHR) system is provided by Figure IV.5.8-1. Major components are shown as well as the pipe segment definitions (e.g., PS-19) used in the system fault tree.

The LPCI system is automatically initiated and controlled. Operator intervention is required to manually start the system given an auto-start failure and to stop the system or control flow during an ATWS if required.

The success criterion for the LPCI system is injection of flow from any one pump to the reactor vessel. For further information, refer to success criteria discussions in Section IV.4.

Most of the LPCI system is located in the reactor building. Local access to the LPCI system could be affected by either containment venting or failure. Room cooling failure is assumed to fail the LPCI pumps in four hours.

\section{IV.5.8.2 LPCI Interfaces and Dependencies}

Each LPCI pump is powered from a separate 4160 VAC bus with control and actuation power being supplied by a separate 125 VDC bus. All pumps require pump cooling. For further information on pump cooling refer to Section IV.5.13.8.

Each loop's normally closed injection valve can receive motive power from one of two $480 \mathrm{VAC}$ sources. The Loop A injection valve sources are either $480 \mathrm{VAC} / \mathrm{A}$ or $480 \mathrm{VAC} / \mathrm{C}$, and the Loop $B$ injection valve sources are either $480 \mathrm{VAC} / \mathrm{B}$ or 


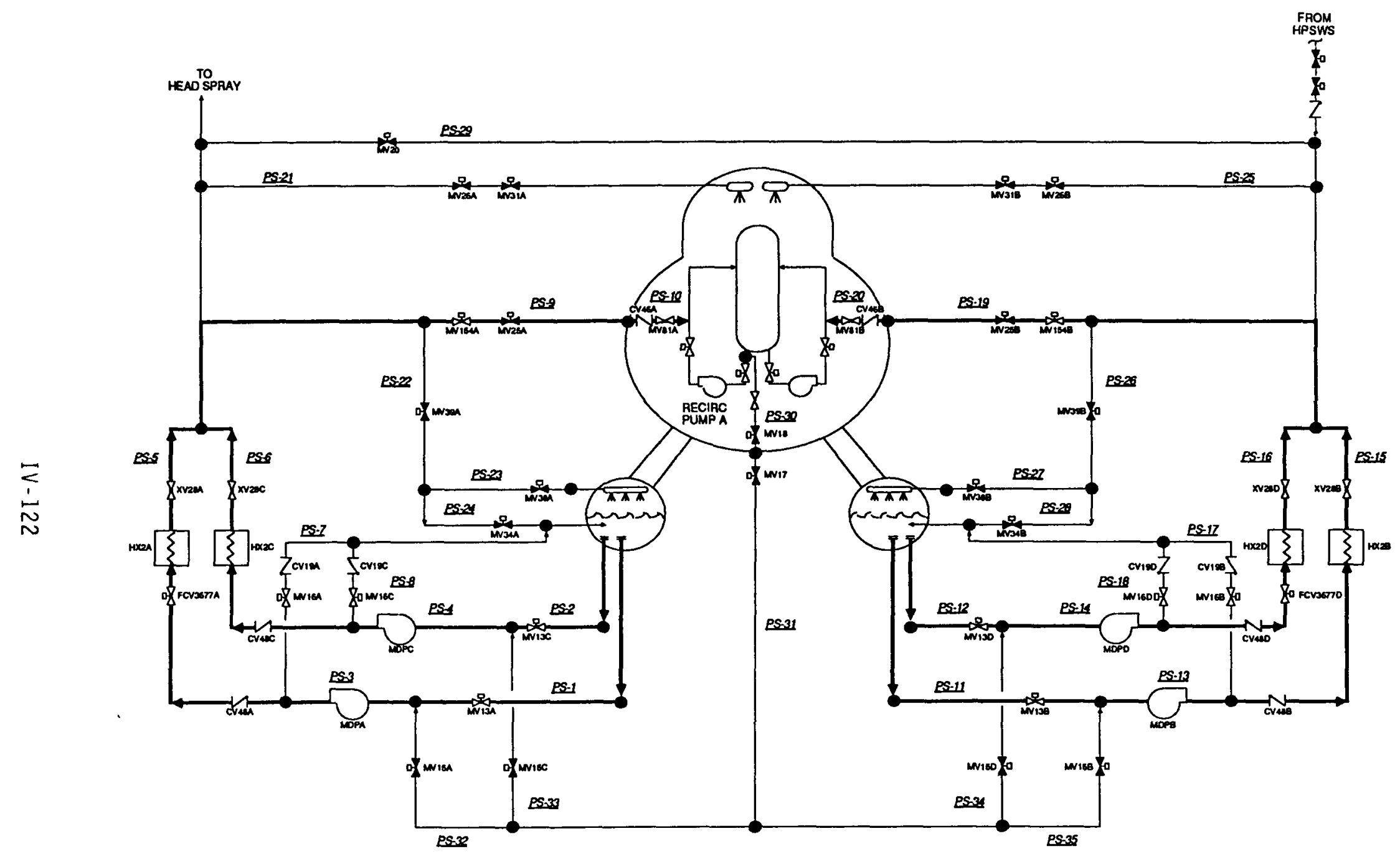

VALVE POSITIONS ARE SHOWN IN THEIR STANDBY MODE

Figure IV.5.8-1. Low Pressure coolant Injection system Schematic. 
$480 \mathrm{VAC} / \mathrm{D}$. A simplified dependency diagram of the LPCI is provided by Figure IV.5.8-2. Shown are the major support needs for the LPCI system as indicated by the solid diamonds at the appropriate places in the diagram.

Many components of the LPCI system are shared with the different modes of the RHR system. These commonalities are as follows: (1) the RHR pumps are common to the LPCI, Suppression Pool Cooling (SPC), Containment Spray (CS), and Shutdown Cooling (SDC) modes; (2) the suppression pool suction valve for each pump train is common to the LPCI, SPC, and CS modes; and (3) LoopS A and B injection valves are common to the LPCI, SDC, and High Pressure Service Water (HPSW) injection modes.

Upon the receipt of a LPCI injection signal, start signals are sent to all pumps, Loops $A$ and $B$ injection valves are subsequently demanded to open when reactor pressure is low enough, and the test return valves are demanded to close. The LPCI system is automatically initiated on the receipt of either a low-low reactor water level (378 inches above vessel zero) or high drywell pressure (2 psig) and low reactor pressure (450 psig). A simplified actuation dependency diagram of all major emergency coolant actuation subsystems is provided by Figure IV.5.2-3. All actuation sensors are shared with the LPCS system.

LPCI actuation and control circuitry is divided into two divisions. Division $A$ is associated with the actuation and control of components in Loop A, and Division $B$ is associated with the actuation and control of components in Loop B. Each LPCI pump and loop injection valve receives an actuation signal from both divisions.

Although the LPCI system has no isolation signals, there are permissives which will prevent the operation of certain components. LPCI pumps are demanded to stop or prevented from starting if the suppression pool suction valve or any of three SDC suction valves is not fully open.

Loops A and B injection valves are prohibited from opening unless a low reactor pressure permissive (450 psig) is met.

\section{IV.5.8.3 LPCI Test and Maintenance}

The LPCI surveillance requirements are the following: (1) pump operability--once/month, (2) MOV operability--once/month, (3) pump capacity test--once/three months, (4) simulated automatic actuation test--once/operating cycle, and (5) logic system functional test--once/six months.

\section{IV.5.8.4 LPCI Technical Specifications}

If any one LPCI pump is made or found to be inoperable for any reason, continued reactor operation is permissible for seven days provided that the remaining LPCI components and both loops of the LPCS system are operable. If this requirement cannot be met, the reactor is to be shut down.

\section{IV.5.8.5 LPCI Logic Mode1}

The LPCI system was modeled using a fault tree for the injection of coolant to the reactor vessel. The major active components and most passive components were modeled using pipe segments which were defined for the LPCI system. Components ithin a pipe segment were grouped together to form a single basic event. 


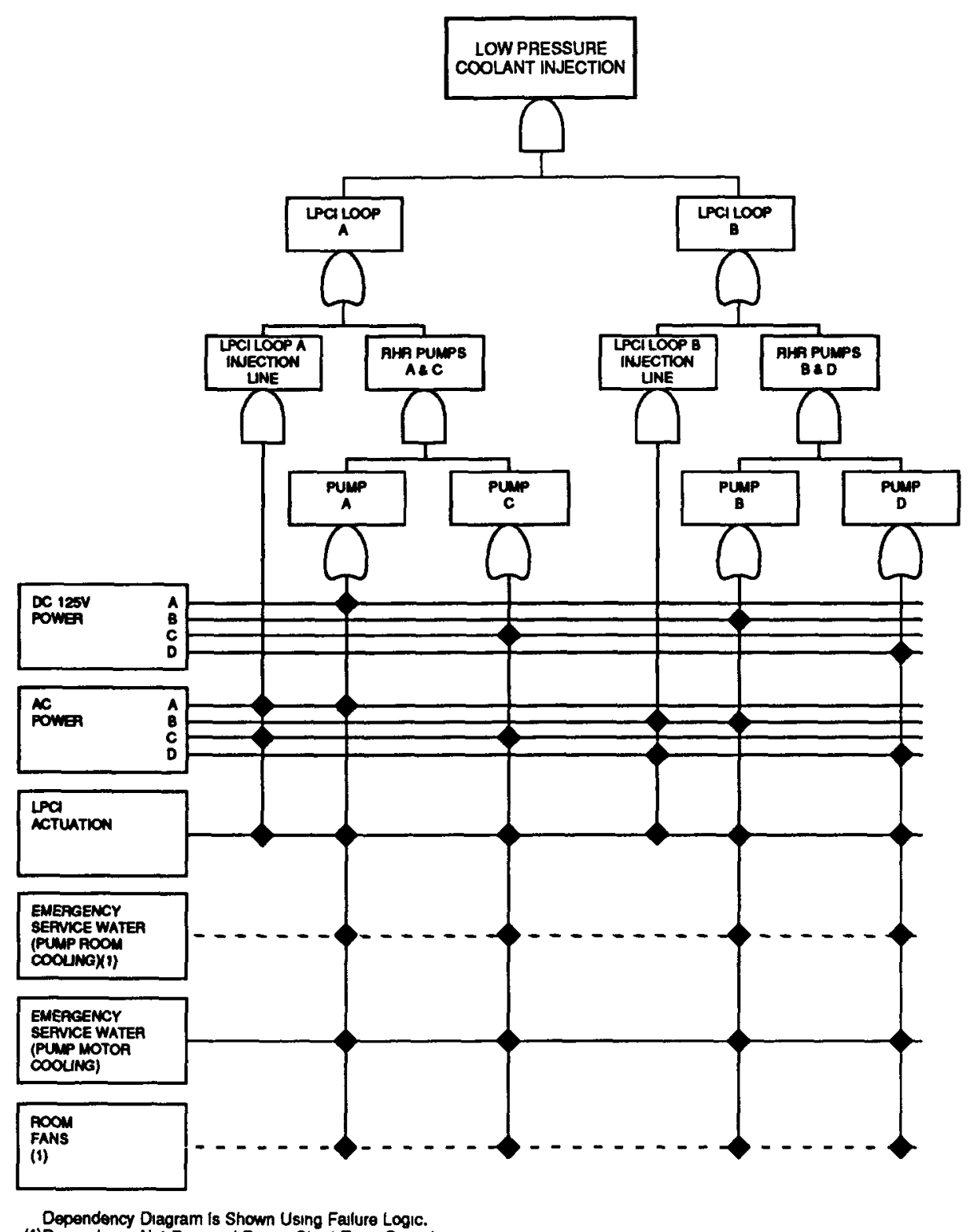

Dependency Diagram is Shown Using Falure Logic.
(1)Dopendency Not Required Durns Short Term oporation.

Figure IV.5.8-2. Low Pressure Coolant Injection System Dependency Diagram. 
Generally a pipe segment is that run of pipe from one junction to another junction. A separate pipe segment was defined when components within a run of pipe had different dependencies or potentials for recovery and at a penetration of the containment. The fault tree model representing the LPCI system is presented in Appendix A.

Piping ruptures were considered to be negligible compared to other system failures. Only piping with a diameter of greater than or equal to $1 / 3$ of the main system piping was considered as a potential diversion path.

Two human errors were incorporated into the LPCI fault tree model. These errors are miscalibration of various sensors and failure to manually backup automatic actuation.

\section{IV.5.8.6 LPCI Assumptions}

(1) LPCI system failure because of valves being left in the wrong position after testing and maintenance is felt to be negligible because the position of all manual and motor operated valves is indicated in the control room.

(2) During construction of the fault tree, it was necessary to determine which components could be taken oos for maintenance. It was assumed that maintenance would require components to be effectively removed from the system. Standard safety precautions of component isolation were used to decide which components could be taken 00S for maintenance while the plant was at power or normal operating pressure. The general guidelines used for component isolation were double blockage for high pressure piping or components and single blockage for low pressure piping or components.

(3) Pump isolation because of spurious signals is assumed to be negligible compared to other systems faults.

(4) The LPCI actuation circuitry was not modeled at a great level of detail. Only elements which were felt to be potentially important were included in the fault tree model. Hardware failure of relays and permissives is grouped into one term. The initiating signal sensors and their support systems were explicitly modeled since they are shared between various ESF systems.

(5) Based on a PECO response, it is assumed that the LPCI pumps will fail because of insufficient NPSH once the suppression pool has reached saturated conditions.

(6) LPCI system failure because of a test diverting flow is felt to be negligible because valves receive signals to close from both Divisions $A$ and $B$ actuation circuitry.

(7) A suction path must be available from either the suppression pool or the SDC path to start a LPCI pump. 
(8) Failure of the suppression pool because of random failure or the plugging of all its strainers is assumed to be negligible compared to other system failures.

(9) It is assumed that calibration of the low and low-low reactor water level sensors is performed at the same time. Miscalibration of these sensors is considered to be the same event.

\section{IV.5.8.7 LPCI Operating Experience}

Nothing was peculiar in the operational history of the LPCI system which would affect either system modeling or failure data.

IV.5.9 Residual Heat Removal: Shutdown Cooling System

IV.5.9.1 SDC Description

The function of the SDC system is to remove decay heat during accidents in which reactor vessel integrity is maintained (event tree nomenclature--W1). The SDC system is but one mode of the RHR system and, as such, shares components with other modes.

The RHR system is a two-loop system consisting of motor-operated valves and motor-driven pumps. There are two pump/heat exchanger trains per 1oop, with each pump rated at $10,000 \mathrm{gpm}$ with a discharge head of $20 \mathrm{psid}$. Cooling water flow to the heat exchanger is required for the SDC mode. The SDC system suction source is one recirculation pump's suction line. A simplified schematic of the SDC (RHR) system is provided by Figure IV.5.9-1. Major components are shown as well as the pipe segment definitions (e.g., PS-9) used in the system fault tree.

The SDC system is manually initiated and controlled.

The success criterion for the SDC system is injection of flow from any one pump/heat exchanger train to the reactor vesse1. For further information, refer to success criteria discussions in Section IV. 4.

Most of the SDC system is located in the reactor building. Local access to the SDC system could be affected by either containment venting or failure. Room cooling failure is assumed to fail the SDC pumps in four hours.

\section{IV.5.9.2 SDC Interfaces and Dependencies}

Each SDC pump is powered from a separate 4160 VAC bus with control and actuation power being supplied by a separate 125 VDC bus. A11 pumps require pump cooling. For further information on pump cooling, refer to Section IV.5.13.8. A simplified dependency diagram of the SDC system is provided by Figure IV.5.9-2. Shown are the major support needs of the SDC system as indicated by the solid diamonds at the appropriate places in the diagram.

Each loop's normally closed injection valve receives motive power from one of two $480 \mathrm{VAC}$ sources. The Loop $A$ injection valve sources are either $480 \mathrm{VAC} / \mathrm{A}$ or $480 \mathrm{VAC} / \mathrm{C}$, and the Loop $\mathrm{B}$ injection valve sources are either $480 \mathrm{VAC} / \mathrm{B}$ or $480 \mathrm{VAC} / \mathrm{D}$. 


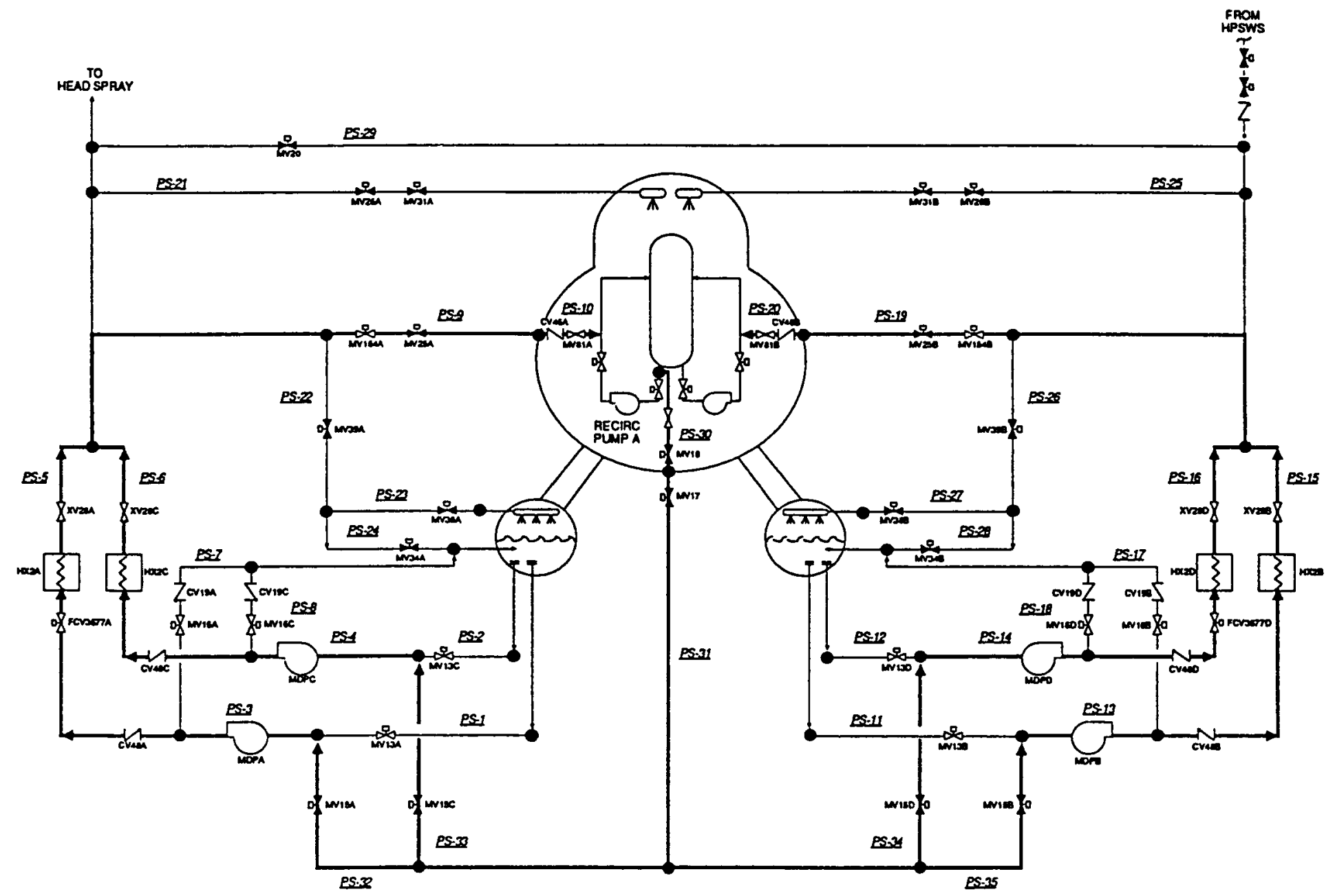

VALVE POSITONS ARE SHOWN IN THEIR STANOBY MODE

Figure IV.5.9-1. Residual Heat Removal System--Shutdown Cooling Mode Schematic. 


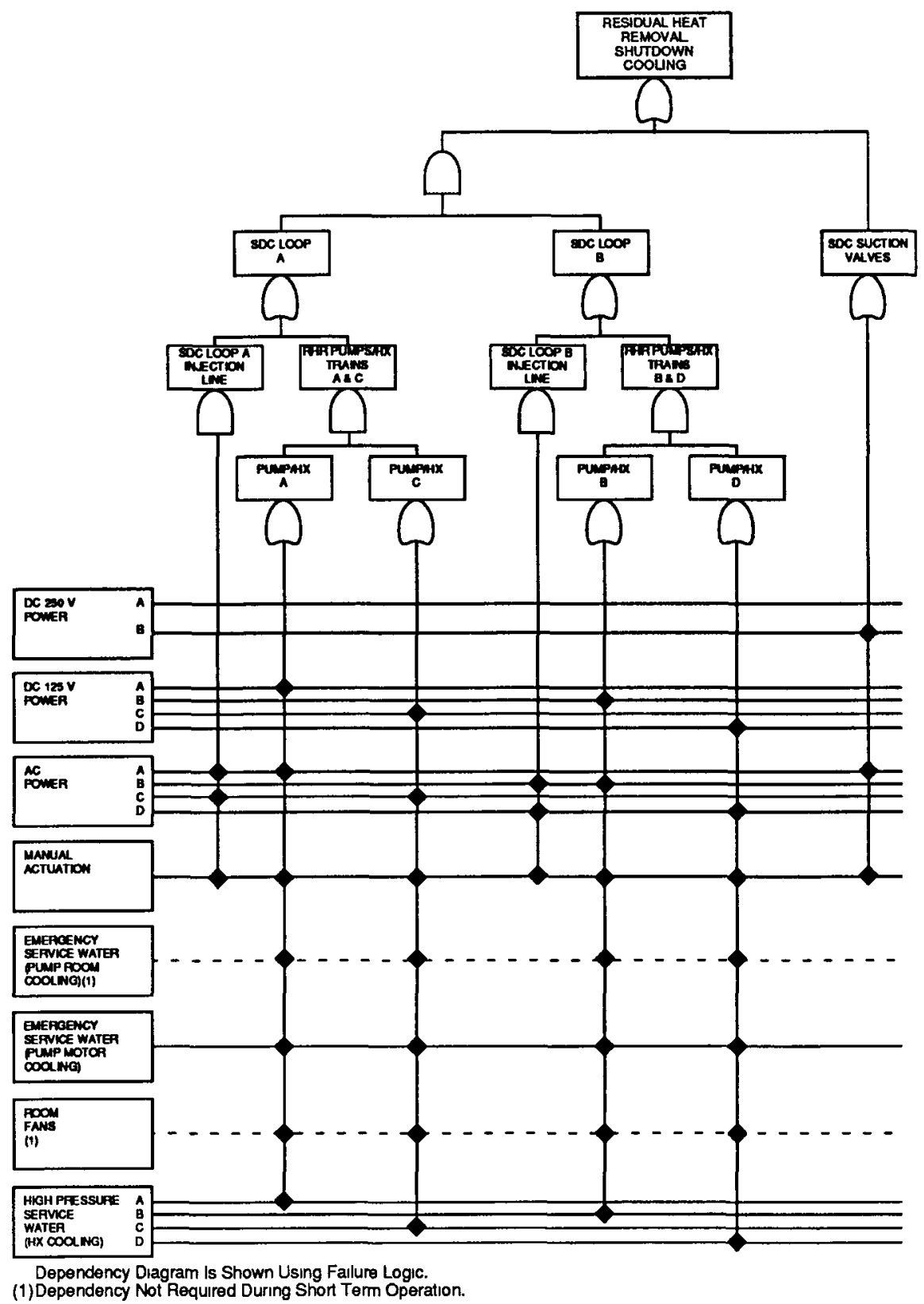

Figure IV.5.9-2. Residual Heat Removal Systam--Shutdown Cooling Mode Dependency Diagra 
Many components of the SDC system are shared with the different modes of the RHR system. These commonalities are as follows: (1) the RHR pumps are common to the SDC, SPC, CS, and LPCI modes; (2) Loops $A$ and $B$ injection valves are common to the SDC, LPCI, and HPSW injection modes; and (3) heat exchanger cooling is common to the CS, SDC, and SPC modes.

The two SDC suction valves (MV18 and MV17) are common to all four SDC pumps. MV18 requires $480 \mathrm{VAC} / \mathrm{A}$ and $\mathrm{MV} 17$ requires $250 \mathrm{VDC} / \mathrm{B}$. Complete failure of the SDC system will occur if either of these valves fails to open.

Each pump's suppression pool suction valve and SDC cooling suction valve are interlocked. One valve must be fully closed before the other valve can be opened.

SDC is initiated after emergency core injection is successfal and reactor pressure is low. If an injection signal subsequently occurs, the RHR system will automatically be realigned to the LPCI mode. SDC cannot be initiated if any of the following conditions exist: (a) reactor pressure greater than $225 \mathrm{psig}$, (b) high drywell pressure (scram pressure), or (c) low reactor water level.

SDC pumps will stop or be prevented from starting if a suction path is not available.

\section{IV.5.9.3 SDC Test and Maintenance}

The SDC surveillance requirements are the following: (1) pump operability-once/month, (2) MOV operability--once/month, (3) pump capacity test--once/three months, (4) simulated automatic actuation test--once/operating cycle, and (5) logic system functional test--once/six months.

\section{IV.5.9.4 SDC Technical Specifications}

To the extent that the SDC and LPCI modes are shared, certain technical specifications are required because of the LPCI mode of the RHR system. If any one LPCI pump is made or found to be inoperable for any reason, continued reactor operation is permissible for seven days provided that the remaining LPCI components and both loops of the LPCS system are operable. If this requirement cannot be met, the reactor is to be shut down.

\section{V.5.9.5 SDC Logic Model}

The SDC system was modeled using a fault tree for removal of decay heat from the reactor vessel following transients. The major active components and most passive components were modeled using pipe segments which were defined for the SDC system. Components within a pipe segment were grouped together to form a single basic event. Generally a pipe segment is that run of pipe from one junction to another junction. A separate pipe segment was defined when components within a run of pipe had different dependencies or potentials for recovery and at a penetration of the containment. The fault tree model representing the SDC system is presented in Appendix A.

Piping ruptures were considered to be negligible compared to other system failures. Only piping with a diameter of greater than or equal to $1 / 3$ of the main ystem piping was considered as a diversion path. 
Two human errors were incorporated into the SDC fault tree model. These errors are miscalibration of various sensors and failure of manual initiation.

\section{IV.5.9.6 SDC Assumptions}

(1) SDC system failure because of valves being left in the wrong position after testing and maintenance is felt to be negligible because the position of all manual and motor operated valves is indicated in the control room.

(2) During construction of the fault tree, it was necessary to determine which components could be taken $00 \mathrm{~S}$ for maintenance. It was assumed that maintenance would require components to be effectively removed from the system. Standard safety precautions of component isolation were used to decide which components could be taken $00 \mathrm{~S}$ for maintenance while the plant was at power or normal operating pressure. The general guidelines used for component isolation were double blockage for high pressure piping or components and single blockage for low pressure piping or components.

(3) Pump isolation because of spurious signals is assumed to be negligible compared to other system faults.

(4) The SDC control circuitry was not modeled at a great level of detail. Only elements which were felt to be potentially important were included in the fault tree model. Hardware failure of relays and permissives is grouped into one term. The permissive/isolation signal sensors and their support systems were explicitly modeled since they could be potentially important to system failure.

(5) Based on a PECO response, it is assumed that the SDC pumps will fail because of insufficient NPSH once the suppression pool has reached saturated conditions.

(6) SDC failure because of a test diverting flow is felt to be negligible because this mode is manually initiated and aligned.

(7) A suction path must be available from either the suppression pool or the SDC path to start a SDC pump.

(8) Failure of the suppression pool because of random failure or the plugging of all its strainers is assumed to be negligible compared to other system failures.

\section{IV.5.9.7 SDC Operating Experience}

Nothing was peculiar in the operational history of the SDC system which would affect either system modeling or failure data. 


\section{IV.5.10 Residual Heat Removal: Suppression Pool Cooling System}

\section{IV.5.10.1 SPC Description}

The function of the SPC system is to remove decay heat from the suppression pool during accidents (event tree nomenclature--W2). The SPC system is but one mode of the RHR system and, as such, shares components with other modes.

The RHR system is a two-1oop system consisting of motor-operated valves and motor-driven pumps. There are two pump/heat exchanger trains per loop, with each pump rated at $10,000 \mathrm{gpm}$ with a discharge head of $20 \mathrm{psid}$. Cooling water flow to the heat exchanger is required for the SPC mode. The SPC suction source is the suppression pool. A simplified schematic of the SPC (RHR) system is provided by Figure IV.5.10-1. Major components are shown as well as the pipe segment definitions (e.g., PS-26) used in the system fault tree.

The SPC system is manually initiated and controlled.

The success criterion for the SPC system is injection of flow from any one pump/heat exchanger train to the suppression pool. For further information, refer to success criteria discussions in Section IV. 4.

Most of the SPC system is located in the reactor building. Local access to the SPC system could be affected by either containment venting or failure. Room cooling failure is assumed to fail the SPC pumps in four hours.

\section{IV.5.10.2 SPC Interfaces and Dependencies}

Each SPC pump is powered from a separate 4160 VAC bus with control and actuation power being supplied by a separate 125 VDC bus. All pumps require pump cooling. For further information on pump cooling, refer to Section IV.5.13.8. Each loop's normally closed suppression pool inlet valve receives motive power from one 480 VAC source. A simplified dependency diagram of the SPC system is provided by Figure IV.5.10-2. Shown are the major support needs of the SPC system as indicated by the solid diamonds at the appropriate places in the diagram.

Many components of the SPC system are shared with the different modes of the RHR system. These commonalities are as follows: (1) the RHR pumps are common to the SPC, LPCI, CS, and SDC modes; (2) the suppression pool suction valve for each pump train is common to the SPC, LPCI, and CS modes; and (3) heat exchanger cooling is common to the CS, SDC, and SPC modes.

SPC control circuitry is divided into two divisions. Division $A$ is associated with control of components in Loop A, and Division B is associated with control of components in Loop B.

The SPC mode is manually initiated. If an injection signal is generated subsequent to the initiation of the SPC system, the SPC system will automatically realign to the LPCI mode. Besides a time delay, a permissive indicating that the reactor water level is above the shroud ( 312 inches above vessel zero) must be present prior to aligning to the SPC mode. However, this permissive may be overridden by a switch in the control room. 


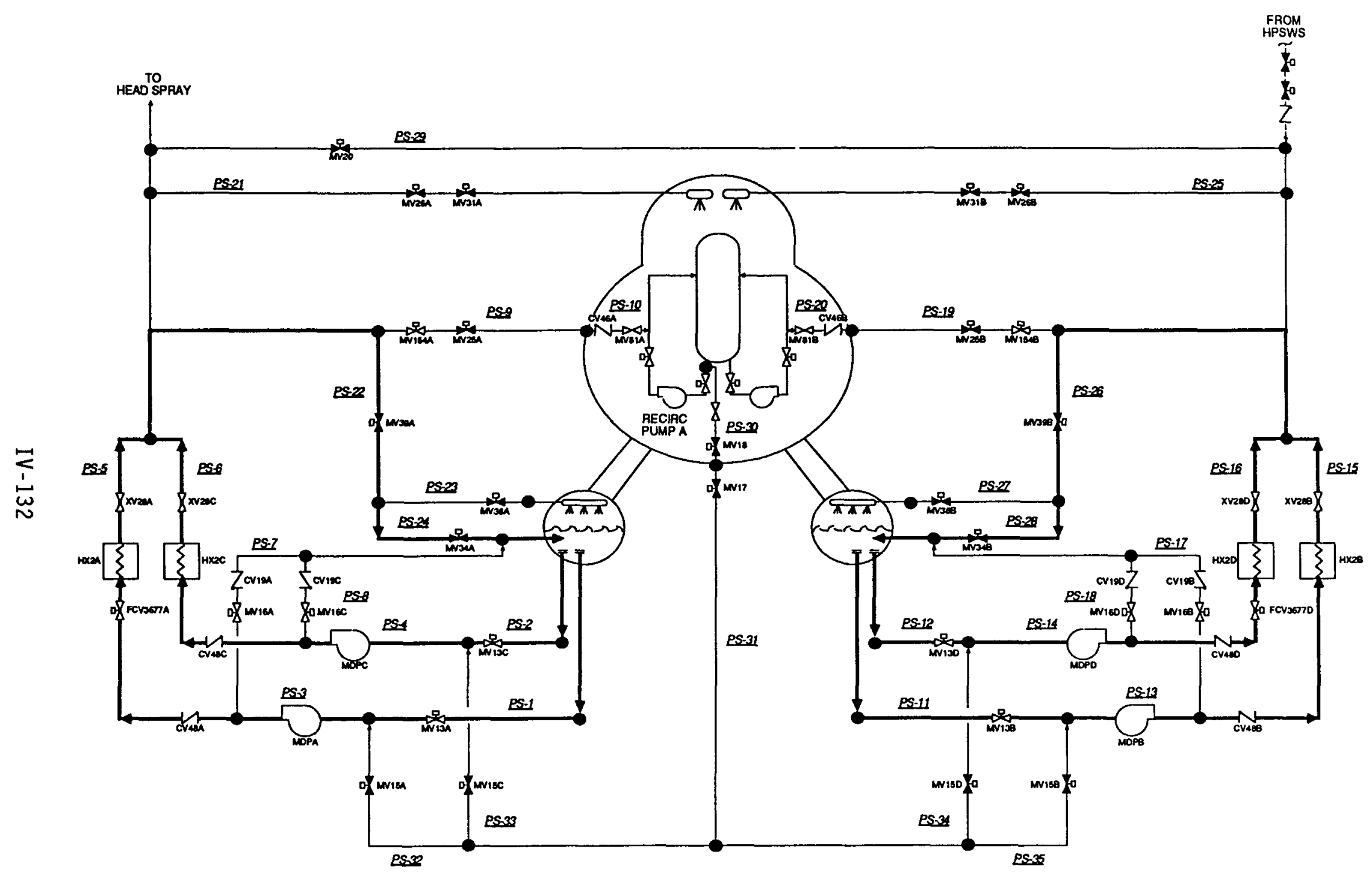

VALVE POSITIONS ARE SHOWN IN THEIR STANDBY MODE

Figure IV.5.10-1. Residual Heat Removal System--Suppression Pool Cooling Mode Schematic. 


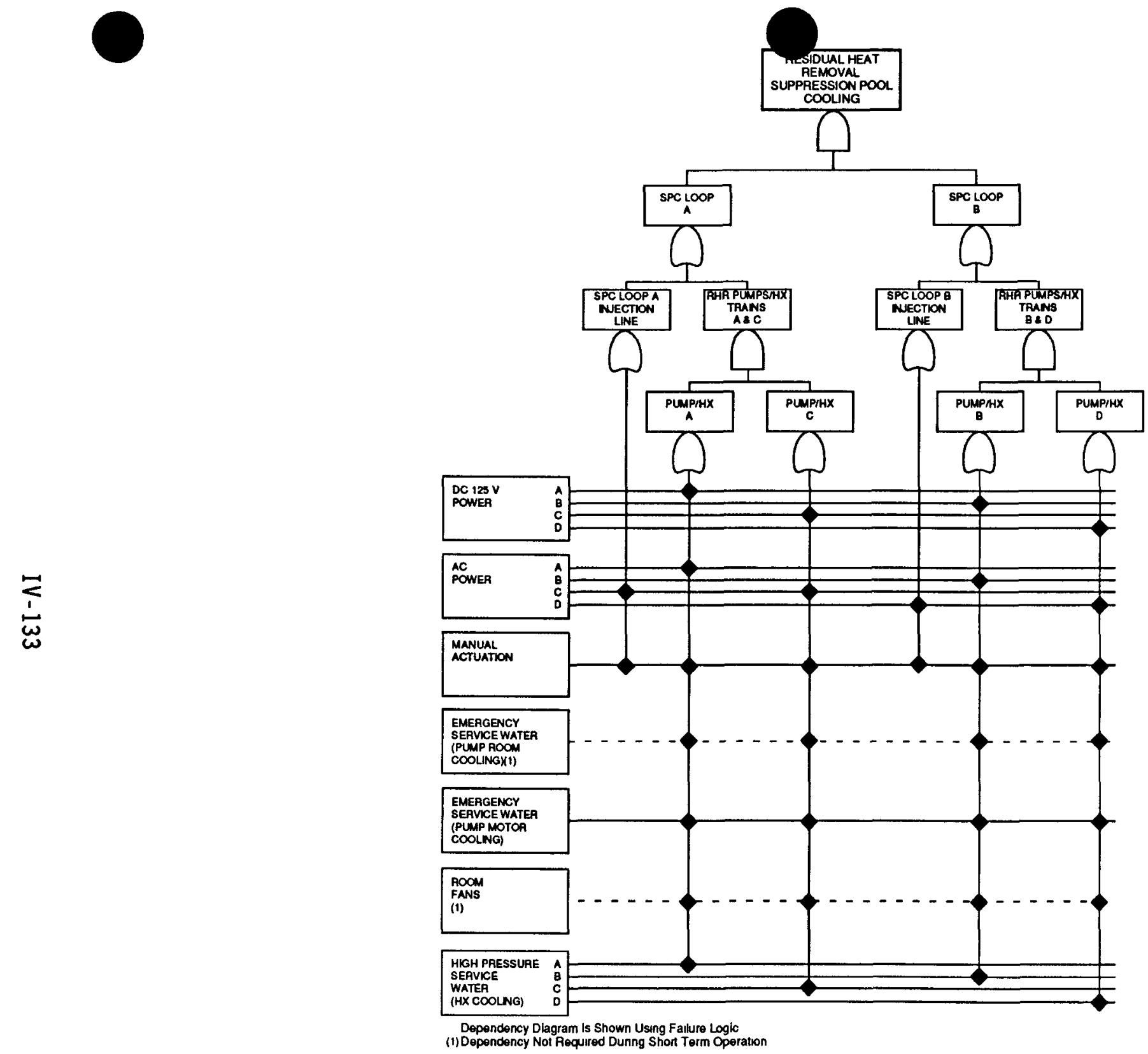

Figure IV.5.10-2. Residual Heat Removal System--Suppression Pool Cooling Mode Dependency Diagram. 
The SPC control circuitry is not common to the LPCI actuation and control circuitry but is shared with the CS mode. Reactor water level sensors are shared with the CS system.

Although the SPC system has no isolation signals, there are permissives which will prevent the operation of certain components. SPC pumps are demanded to stop or prevented from starting if the suppression pool suction valve or any of three SDC suction valves is not fully open.

\section{IV.5.10.3 SPC Test and Maintenance}

The SPC surveillance requirements are the following: (1) pump operability-once/month, (2) MOV operability--once/month, (3) pump capacity test--once/three months, (4) simulated automatic actuation test--once/operating cycle, and (5) logic system functional test--once/six months.

\section{IV.5.10.4 SPC Technical Specifications}

Technical specifications exist because of sharing of the SPC and LPCI modes of the RHR system. If any one LPCI pump is made or found to be inoperable for any reason, continued reactor operation is permissible for seven days provided that the remaining LPCI components and both loops of the LPCS system are operable. If this requirement cannot be met, the reactor is to be shut down.

\section{IV.5.10.5 SPC Logic Model}

The SPC system was modeled using a fault tree for the removal of decay heat from the suppression pool. The major active components and most passive components were modeled using pipe segments which were defined for the SPC system. Components within a pipe segment were grouped together to form a single basic event. Generally a pipe segment is that run of pipe from one junction to another junction. A separate pipe segment was defined when components within a run of pipe had different dependencies or potentials for recovery and at a penetration of the containment. The fault tree model representing the SPC system is presented in Appendix A.

Piping ruptures were considered to be negligible compared to other system failures. Only piping with a diameter of greater than or equal to $1 / 3$ of the main system piping was considered as a potential diversion path.

Two human errors were incorporated into the SPC fault tree mode1. These errors are failure of manual initiation and failure to override an erroneous shroud level permissive signal.

\section{IV.5.10.6 SPC Assumptions}

(1) SPC system failure because of valves being left in the wrong position after testing and maintenance is felt to be negligible because the position of all manual and motor-operated valves is indicated in the control room. 
(2) During construction of the fault tree, it was necessary to determine which components could be taken o0s for maintenance. It was assumed that maintenance would require components to be effectively removed from the system. Standard safety precautions of component isolation were used to decide which components could be taken OOS for maintenance while the plant was at power or normal operating pressure. The general guidelines used for component isolation were double blockage for high pressure piping or components and single blockage for low pressure piping or components.

(3) Pump isolation because of spurious signals is assumed to be negligible compared to other systems faults.

(4) The SPC control circuitry was not modeled at a great level of detail. Only elements which were felt to be potentially important were included in the fault tree model. Except for the shroud water level permissive, high drywell pressure permissive, pump power permissive, and pump suction source relay, the hardware failures of relays and permissives are grouped into one term. The initiating signal sensors and their support systems were explicitly modeled since they are shared between various ESF systems.

(5) Based on a PECO response, it is assumed that the SPC pumps will fail because of insufficient NPSH once the suppression pool has reached saturated conditions.

(6) Diversion of flow to the containment spray line is felt to be negligible compared to other system failures.

(7) A suction path must be available from either the suppression pool or the SDC path to start a SPC pump.

(8) Failure of the suppression pool because of random failure or the plugging of all its strainers is assumed to be negligible compared to other system failures.

\section{IV.5.10.7 SPC Operating Experience}

Nothing was peculiar in the operational history of the SPC system which would affect either system modeling or failure data.

\section{IV.5.11 Residual Heat Removal: Containment Spray System}

\section{IV.5.11.1 CS Description}

The function of the CS system is to suppress pressure in the drywell during accidents (event tree nomenclature--W3). The CS system is but one mode of the RHR system and, as such, shares components with other modes.

The RHR system is a two-loop system consisting of motor-operated valves and hotor-driven pumps. There are two pump/heat exchanger trains per loop, with each 
pump rated at $10,000 \mathrm{gpm}$ with a discharge head of $20 \mathrm{psid}$. Cooling water flow to the heat exchanger is required for the CS mode. The CS suction source is the suppression pool. A simplified schematic of the CS (RHR) system is provided by Figure IV.5.11-1. Major components are shown as we11 as the pipe segment definitions (e.g., PS-25) used in the system fault tree.

The CS system is manually initiated and controlled.

The success criterion for the CS system is injection of flow from any one pump/heat exchanger train to the spray ring. For further information, refer to success criteria discussions in Section IV.4.

Most of the CS system is located in the reactor building. Local access to the CS system could be affected by either containment venting or failure. Room cooling failure is assumed to fail the CS pumps in four hours.

\section{IV.5.11.2 CS Interfaces and Dependencies}

Each CS pump is powered from a separate 4160 VAC bus with control and actuation power being supplied by a separate 125 VDC bus. All pumps require pump cooling. For further information on pump cooling, refer to Section IV.5.13.8. Each loop's normally closed spray valves receive motive power from one 480 VAC source. simplified dependency diagram of the CS system is provided by Figure IV.5.11-2. Shown are the major support needs of the CS system as indicated by the solid diamonds at the appropriate places in the diagram.

Many components of the CS system are shared with the different modes of the RHR system. These commonalities are as follows: (1) the RHR pumps are common to the CS, SPC, LPCI, and SDC modes; (2) the suppression pool suction valve for each pump train is common to the CS, SPC, and LPCI modes; and (3) heat exchanger cooling is common to the CS, SDC, and SPC modes.

CS control circuitry is divided into two divisions. Division $A$ is associated with control of components in Loop $A$, and Division $B$ is associated with control of components in Loop B.

Reactor water level above the shroud (312 inches above vessel zero) and high drywell pressure (2 psig) permissive signals must be present before the CS system can be manually initiated. The water level signal can be overridden.

Although the CS has no isolation signals, there are permissives which will prevent the operation of certain components. CS pumps are demanded to stop or prevented from starting if the suppression pool suction valve or any of three SDC suction valves is not fully open.

\section{IV.5.11.3 CS Test and Maintenance}

The CS surveillance requirements are the following: (1) pump operability-once/month, (2) MOV operability--once/month, (3) pump capacity test--once/three months, (4) simulated automatic actuation test--once/operating cycle, and (5) logic system functional test--once/six months. 


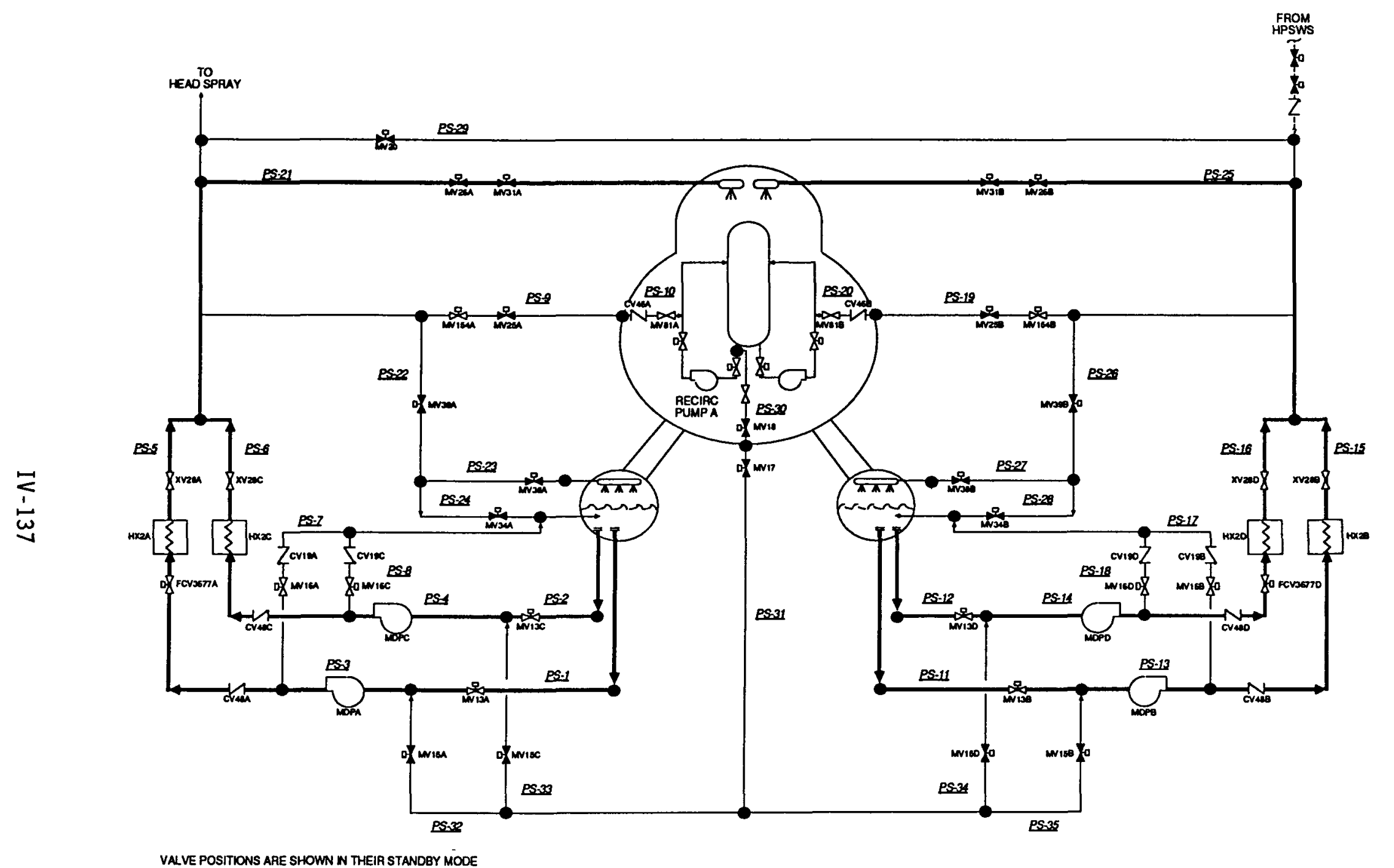

VALVE POSITIONS ARE SHOWN W THEIR STANDBY MODE

Figure IV.5.11-1. Residual Heat Removal System--Containment spray Mode Schematic. 


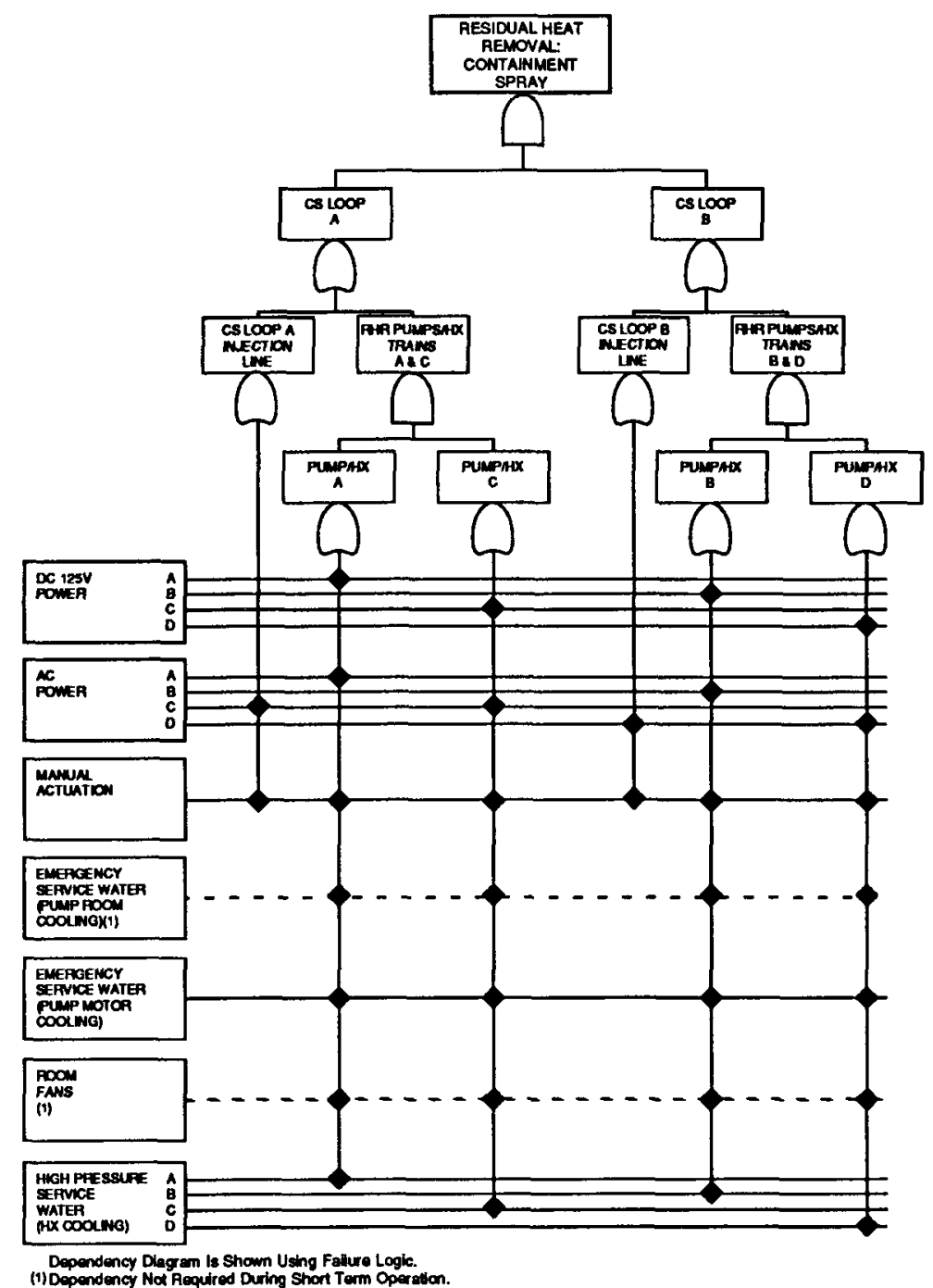

Figure IV.5.11-2. Residual Heat Removal system--Containment Spray Mode Dependency Diagram. 


\section{IV.5.11.4 CS Technical Specifications}

Technical specifications exist based on sharing of the CS and LPCI modes. If any one LPCI pump is made or found to be inoperable for any reason, continued reactor operation is permissible for seven days provided that the remaining LPCI components and both loops of the LPCS system are operable. If this requirement cannot be met, the reactor is to be shut down.

\section{IV.5.11.5 CS Logic Mode1}

The CS system was modeled using a fault tree for pressure suppression in the drywe11. The major active components and most passive components were modeled using pipe segments which were defined for the CS system. Components within a pipe segment were grouped together to form a single basic event. Generally a pipe segment is that run of pipe from one junction to another junction. A separate pipe segment was defined when components within a run of pipe had different dependencies or potentials for recovery and at a penetration of the containment. The fault tree model representing the CS system is presented in Appendix A.

Piping ruptures were considered to be negligible compared to other system failures. Only piping with a diameter of greater than or equal to $1 / 3$ of the main system piping was considered as a potential diversion path.

Two human errors were incorporated into the CS fault tree model. These errors are failure of manual initiation and failure to override an erroneous shroud level permissive signal.

\section{IV.5.11.6 CS Assumptions}

(1) CS system failure because of valves being left in the wrong position after testing and maintenance is felt to be negligible because the position of all manual and motor operated valves is indicated in the control room.

(2) During construction of the fault tree, it was necessary to determine which components could be taken oos for maintenance. It was assumed that maintenance would require components to be effectively removed from the system. Standard safety precautions of component isolation were used to decide which components could be taken $00 \mathrm{~S}$ for maintenance while the plant was at power or normal operating pressure. The general guidelines used for component isolation were double blockage for high pressure piping or components and single blockage for low pressure piping or components.

(3) Pump isolation because of spurious signals is assumed to be negligible compared to other systems faults.

(4) The CS control circuitry was not modeled at a great level of detail. Only elements which were felt to be potentially important were included in the fault tree model. Except for the shroud water level permissive, high drywell pressure permissive, pump power permissive, and pump suction source relay, the hardware failures of relays and permissives are grouped into one term. The 
initiating signal sensors and their support systems were explicitly modeled since they are shared between various ESF systems.

(5) Based on a PECO response, it is assumed that the CS pumps will fail because of insufficient NPSH once the suppression pool has reached saturated conditions.

(6) Diversion of flow to the suppression pool is felt to be negligible compared to other system failures.

(7) A suction path must be available from either the suppression pool or the SDC path to start a CS pump.

(8) Failure of the suppression pool because of random failure or the plugging of all its strainers is assumed to be negligible compared to other system failures.

\section{IV.5.11.7 CS Operating Experience}

Nothing was peculiar in the operational history of the CS system which would affect either system modeling or failure data.

\section{IV.5.12 Electric Power System (EPS)}

\section{IV.5.12.1 EPS Description}

The EPS is designed to provide a diversity of dependable power sources which are physically isolated from each other.

The Peach Bottom station receives power from two separate offsite sources. If both offsite sources are lost, auxiliary power is supplied to both Unit 2 and Unit 3 from four onsite diesel generators shared between the two units. Loads important to plant safety are split and diversified. Station batteries provide control power for specific engineered safeguards and for other required functions when AC power is not available. A simplified schematic of the EPS is provided by Figure IV.5.12-1.

Each diesel generator unit consists of a diesel engine, a generator, and the associated auxiliaries mounted on a common base. The continuous rating of the diesel generators is $2,600 \mathrm{~kW}$. The engine is rated for a ten percent overload for any two of every twenty-four hours.

There are two independent 125/250 VDC systems per unit. Each system is comprised of two 125-V batteries, each with its own charger. Each 125-V battery is a lead-calcium type with 58 cells. The chargers are full wave, silicon-controlled rectifiers. The two batteries for each unit are redundant. Loads are diversified between these systems so that each system serves loads which are identical and redundant. Power for larger loads, such as DC motor-driven pumps and valves, is supplied at $250 \mathrm{~V}$ from two $125-\mathrm{V}$ sources. Selected batteries from Unit 2 and and from Unit 3 are needed to start Diesel Generators 1, 2, 3 and 4 respectively. 


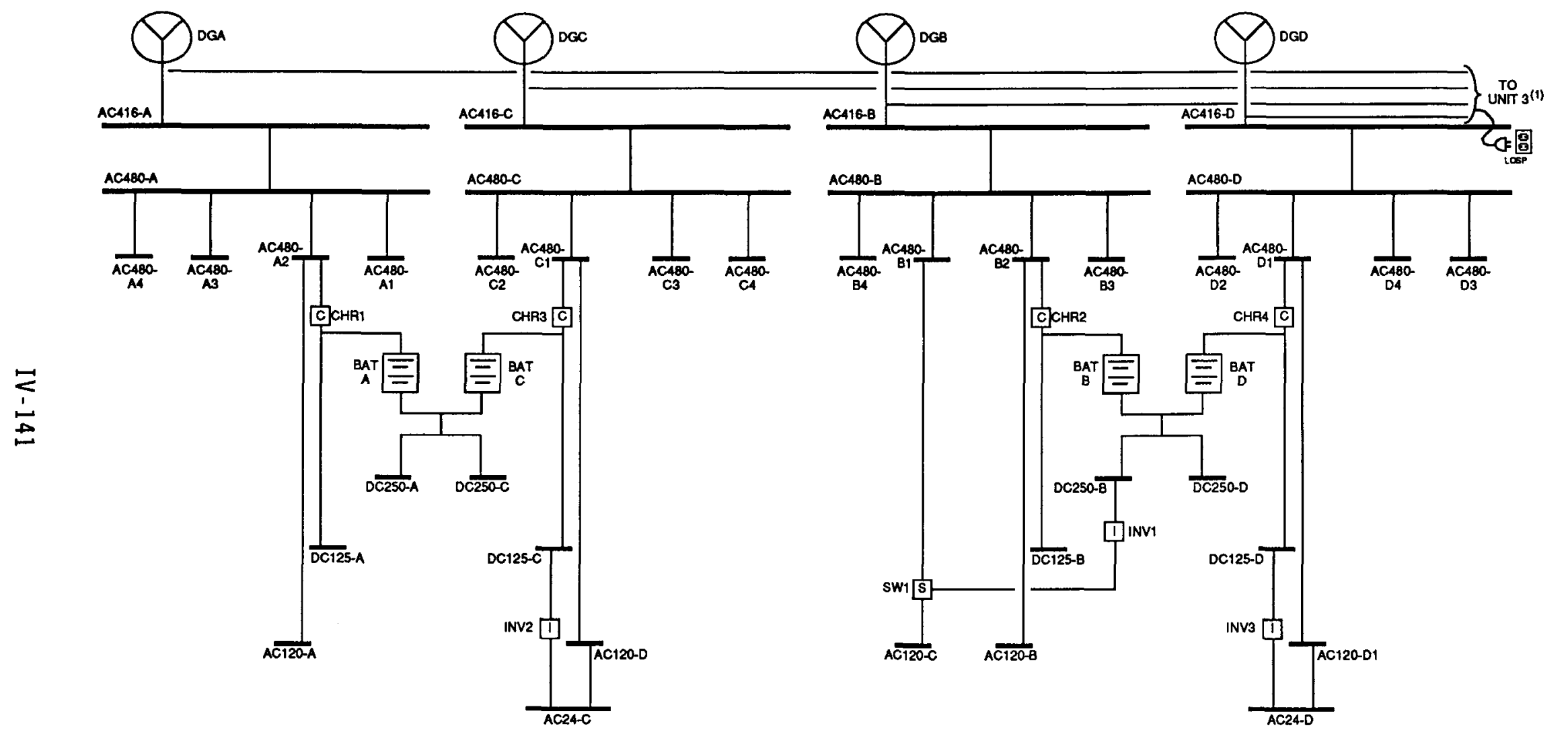

(1) GOES TO UNIT 3 BUSES (DG A, B, C, AND D ARE ARE SHARED BETWEEN UNITS 2 AND 3).

Figure IV.5.12-1. Emergency Electric Power System Schematic. 
Each standby diesel generator automatically starts. The diesel generator may be stopped by the operator after determining that continued operation of the diesel is not required.

Most of the EPS is located in the diesel building and in compartmentalized rooms within the reactor building. Any physical impact of accident conditions on the ability of the EPS to perform its function would be minimal. As a conservative screening analysis, it is assumed that there is a ten percent chance that room cooling failures could fail switchgear and batteries in four hours, based on the low heat loads, but allowing for particularly warm weather conditions. Diesel generators are assumed to fail in less than 30 minutes without room cooling although it is recognized that diesel performance would derate before actual failure of the diesel and provide a warning to the operators that a problem existed. Possible recovery actions (by opening doors) could therefore take place. Complete failure of the EPS would cause a station blackout. After a total loss of $A C$ power, DC-driven components could operate until the station batteries are depleted (estimated at about 6 hours based on PECO input).

\section{IV.5.12.2 EPS Interfaces and Dependencies}

Each standby diesel generator automatically starts on total loss of offsite power, low reactor water level, or high drywell pressure coincident with low reactor pressure. Two sources of offsite power are available to each 4-kV emergency bus. The failure of one offsite power source results in the automatic transfer to the other offsite source. When the diesel generators are demanded, essential loads are automatically sequenced onto the emergency bus. Nonessential $480 \mathrm{~V}$ loads are prevented from being automatically sequenced. Each diesel generator can be started locally, but can be electrically connected to its bus only from the main control room. A simplified dependency diagram of the EPS is provided by Figure IV.5.12-2. Shown are the major support needs of the EPS as indicated by the solid diamonds at the appropriate places in the diagram.

The diesel generator circuit breaker is tripped by protective devices under the following abnormal conditions: (1) engine overspeed, (2) jacket coolant high temperature, (3) jacket coolant low pressure, (4) lube oil high temperature, (5) lube oil low pressure, (6) crank case high pressure, (7) aftercooler coolant low pressure, (8) fuel oil low pressure, and (9) $\mathrm{CO}$ fire extinguishing system discharge. Protective tripping of the diesels is announced in the main control room and locally at the unit. A two-out-of-three tripping logic prevents spurious trips of the diesels. These protective trips are overridden on a loss of coolant accident (LOCA) signal.

Both the control and power battery systems operate ungrounded, with a ground detector alarm in the main control room.

\section{IV.5.12.3 EPS Test and Maintenance}

When it is determined that one diesel generator is inoperable, the other diesel generators are to be demonstrated operable immediately and daily thereafter. The diesel generators are tested by starting one generator each week. During these tests the starting air compressor, diese1 fuel oil transfer pumps, and diesel starting time are checked. The diesel is started and brought up to full speed while isolated from its loads. Since the auto sequencing is turned off during the test, the operator needs to close the breaker to load the diesel. Therefore, no test unavailability was modeled. Once per operating cycle, the condition under 


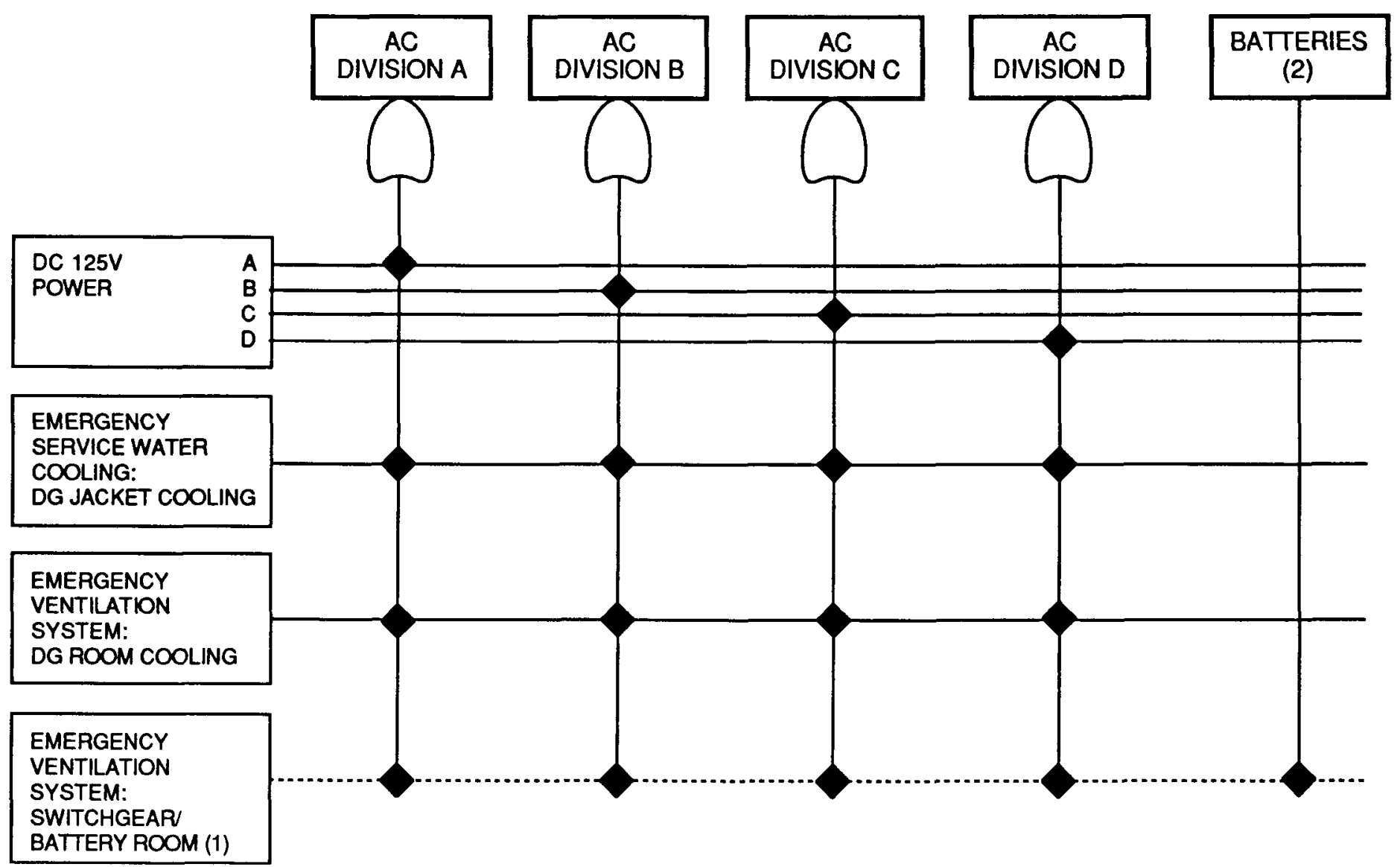

Dependency Diagram Is Shown Using Failure Logic.

(1) Dependency May Not Be Required At All.

(2) Batteries Need Ac Power For Continuous Charging.

Figure IV.5.12-2. Emergency Electrical Power Dependency Diagram. 
which the diesel generator is required will be simulated. This test demonstrates that the diesel will start and accept the emergency load within a specified time sequence. Each diesel generator is given an annual inspection in accordance with instructions based on the manufacturer's recommendations.

Unit batteries' specific gravity, voltage and temperature of the pilot cell, and overall battery voltage are measured weekly. Every three months, the voltage and specific gravity of each cell are checked. This test also includes temperature measurement of every fifth cell. Once per operating cycle, unit batteries are load discharge tested.

\section{IV.5.12.4 EPS Technical Specifications}

During any period when one diesel generator is inoperable, continued reactor operation is permissible for seven days if the remaining diesel generators are operable. If this requirement is not met, the reactor is to be placed in a cold shutdown condition within twenty-four hours.

The reactor cannot be taken critical unless all of the following conditions are satisfied: (1) both offsite sources and startup transformers are available and capable of automatically supplying power to the 4-kV emergency buses, (2) the 4 diesel generators are operable with a minimum of 104,000 gallons of diesel fuel on site, (3) the 4-kV emergency buses and the $480 \mathrm{~V}$ emergency load centers are energized, and (4) the 4-unit 125-V batteries and their chargers are operable.

\section{IV.5.12.5 EPS Logic Models}

The EPS was modeled using fault trees for its $A C$ and $D C$ power portions. Only the major buses and power sources were modeled in the fault trees. No human error was incorporated into the fault tree mode?. Human/EPS interactions were considered part of the recovery analysis. The fault tree model representing the EPS is presented in Appendix A.

\section{IV.5.12.6 EPS Assumptions}

(1) A simplified lumped $A C$ model is used. This is judged to be adequate since the failure of all $A C$ buses is dominated by diesel generator failure.

(2) All valves powered from $480 \mathrm{~V}$ motor control center (MCC) buses take their control power from the $120 \mathrm{~V}$ control bus associated with the same MCC bus.

(3) No safety load is connected to 120 VAC Buses 20Y33, 20Y34, 20Y35, 20Y50, and $00 Y 03$ with the exception of accident monitoring sensors. The accident monitoring sensors are powered by 24 VAC buses.

(4) If an $A C$ bus from Unit 3 is used by modeled equipment, the comparable bus from Unit 2 is used instead. Since the same diesel generator feeds the same emergency $A C$ buses of both units, it is very likely that failure of one bus in Unit 3 is followed by failure of the similar bus in Unit 2. 
(5) If a DC bus from Unit 3 supplies modeled equipment, the battery is assumed to be the sole source of power for that component.

(6) Short circuit faults and the potential effects of fault propagation are not modeled.

(7) Loss of ventilation can affect the diesel generators, emergency switchgear, and batteries as previously indicated.

\section{IV.5.12.7 EPS Operating Experience}

The operational history of the Peach Bottom diesel generators justifies using plant specific failure data. In particular, the last five years of operational data indicate the diesels at Peach Bottom are achieving a much better reliability than the industry average.

\section{IV.5.13 Emergency Service Water (ESW) System}

\section{IV.5.13.1 ESW Description}

The function of the ESW system is to provide a reliable supply of cooling water to selected equipment during a loss of offsite power.

The ESW system is common to both Units 2 and 3 . The system has two full capacity pumps installed in parallel. The normal water supply to the suction of the ESW pumps is from Conowingo pond. The pump discharge consists of two headers with service loops to the diesel-engine coolers and selected equipment coolers. The modeled components supplied with cooling water are the LPCS pumps and pump room coolers, the RHR pumps and pump room coolers, the HPCI pump room cooler, and the RCIC pump room cooler. Valves in the supply headers provide loop isolation. A common discharge header directs effluent to Conowingo pond. A simplified schematic of the ESW system is provided by Figure IV.5.13-1. Major components are shown as well as the pipe segment definitions (e.g., PS-8) used in the system fault tree.

The ESW pumps are vertical, single-stage, turbine types with an $8,000 \mathrm{gpm}$ capacity. Their normal discharge head is $96 \mathrm{ft}$ and their shutoff head is $132 \mathrm{ft}$.

The cooling for all modeled equipment, with the exception of the diesel generator coolers, is normally provided by the Normal Service Water (NSW) system which operates on offsite $A C$ power only.

Should the preferred flow paths described above be unavailable or the bay level preclude normal flow path operation, the ESW system may also be operated in conjunction with the Emergency Heat Sink (EHS) in a closed loop fashion. Two ESW booster pumps take return water from various coolers, boost it in pressure, and deliver the water to the emergency cooling tower structure. The booster pumps are horizontal split types, with $8,000 \mathrm{gpm}$ flow at a head of $100 \mathrm{psig.} \mathrm{One} \mathrm{Emergency}$ Cooling Water (ECW) pump then takes suction from the cooling tower structure. It delivers water through a motor-operated gate valve to the ESW heat loads. The ECW pump and motor are identical to those of the ESW pumps. The only difference between the ECW pump and the ESW pumps is pump column length. 


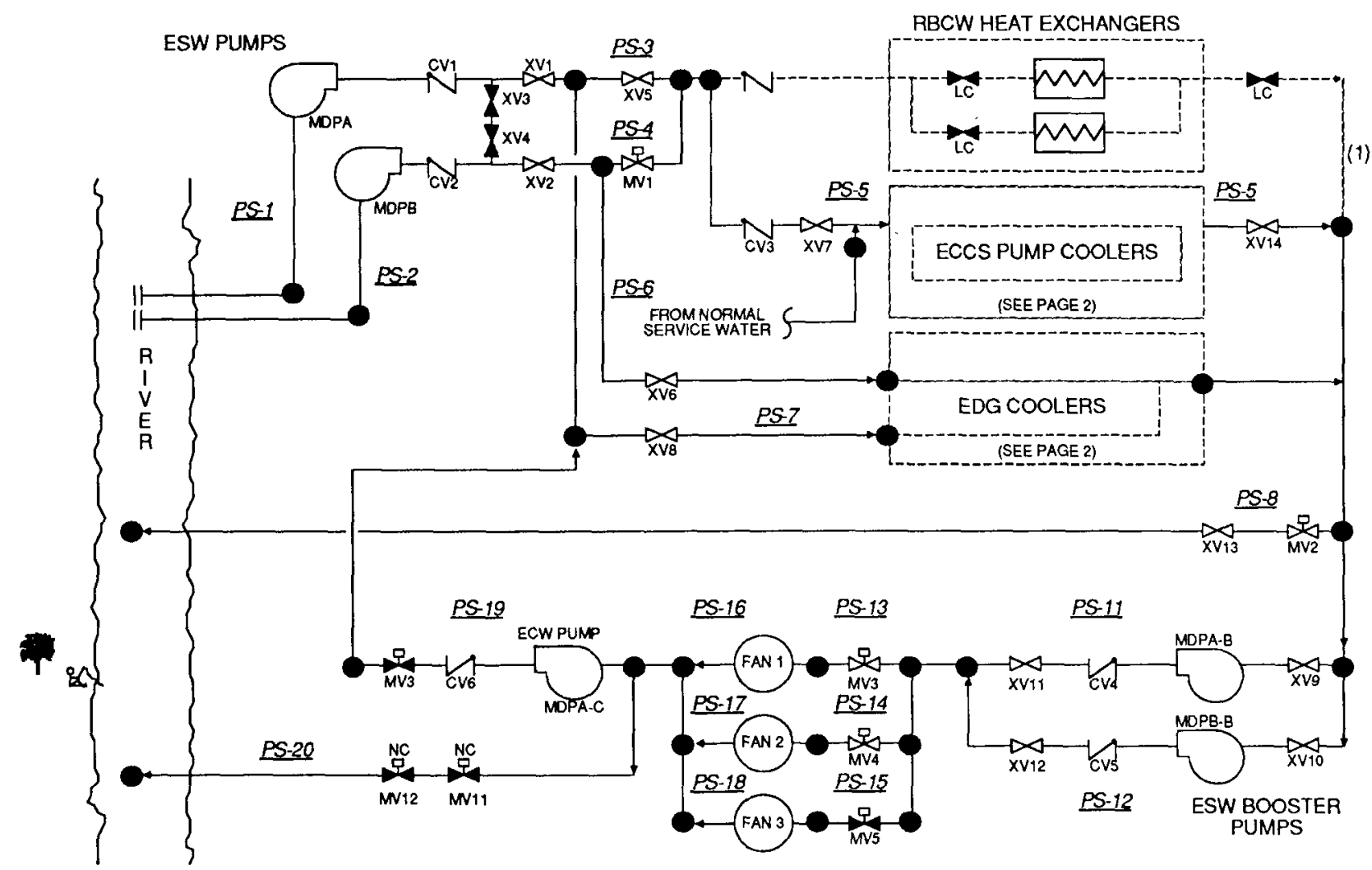

(1) VALVE POSITIONS ARE SHOWN IN THEIR STANDBY POSITION
NOPLCTLY MODELED IN FAULT TREE

Figure IV.5.13-1. Emergency Service Water System Schematic. (Page 1 of 2 ) 


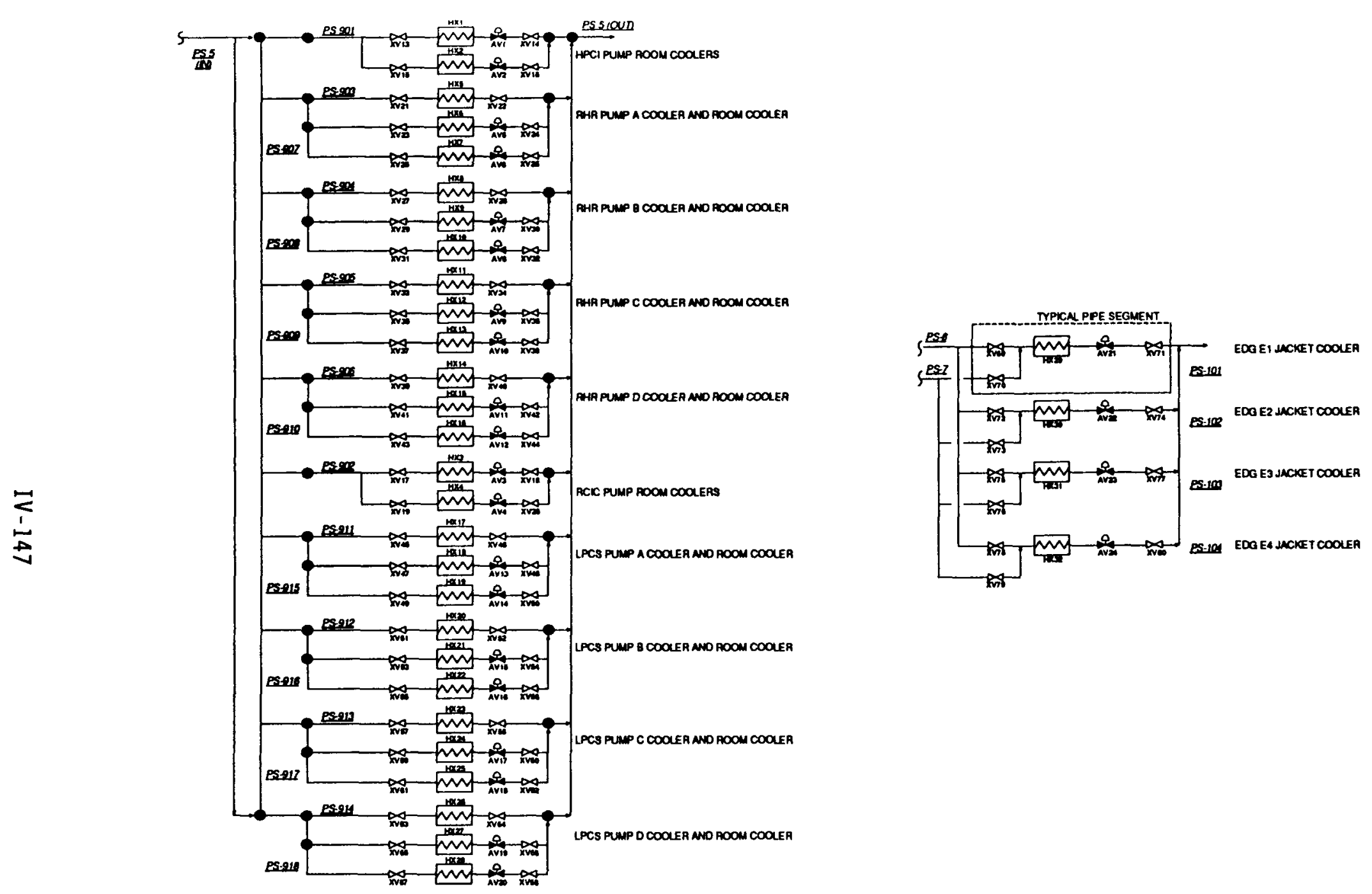

VNUE POSITIONS ARE SHOWN IN THEIR STANDQY MODE

Figure IV.5.13-1. Emergency Service Water system Schematic. (Page 2 of 2) 
Upon system automatic initiation, the operator checks discharge pressure for the two primary ESW pumps. If discharge pressure appears norma1, the operator turns off one ESW pump and the ECW pump (the ECW pump also has an automatic trip in -45 seconds if the discharge pressure is adequate). At some later time, if the operating ESW pump trips and the standby ESW pump fails to start, the operator must manually start the ECW pump. In the EHS mode, cooling tower fans must be manually started.

The success criterion for the ESW system is either of the ESW pumps or the ECW pump supplying cooling water to system heat loads. If the ECW pump is being used, one ESW booster pump and two cooling tower fans must be operational.

Most of the ESW system is located in pump rooms external to the reactor and turbine buildings. Any physical impact of accident conditions on the ability of the ESW system to perform its function would be minimal. Room cooling failure is assumed not to fail the ESW pumps, ESW booster pumps, and ECW pump.

Failure of the ESW system would quickly fail operating diesel generators and potentially fail the LPCS pumps and RHR pumps. The HPCI pump and RCIC pump would fail by a loss of their room cooling four hours after a loss of the ESW system if other recovery actions were not taken.

\section{IV.5.13.2 ESW Interfaces and Dependencies}

The ECW pump, ESW booster pumps, and ESW pumps are all self-cooled. ESW pump A and ESW booster pump $A$ are powered from $4160 \mathrm{VAC} / \mathrm{B}$ with control and actuation power supplied by $125 \mathrm{VDC} / \mathrm{B}$. ESW pump $B$ and ESW booster pump $B$ are powered from $4160 \mathrm{VAC} / \mathrm{C}$ with control and actuation power supplied by $125 \mathrm{VDC} / \mathrm{C}$. The ECW pump is powered from $4160 \mathrm{VAC} / \mathrm{D}$ with control and actuation power supplied by $125 \mathrm{VDC} / \mathrm{D}$. A simplified dependency diagram of the ESW system is provided by Figure IV.5.13-2. Shown are the major support needs for the ESW system as indicated by the solid diamonds at the appropriate places in the diagram.

Cooling tower fans are shared with the HPSW system. These fans are used in the EHS mode should the normal bay level be either too high or too low.

The ESW has a common discharge path. Maintenance on the ESW pump combined discharge valve M0-0498 (labeled MV2 in the system schematic), if it is closed, is assumed to affect system performance (see Section IV.5.13.8).

The power supplies to the ESW pumps and ESW booster pumps are Buses $B$ and $C$. It is assumed that failure of the ESW booster pumps fails the EHS mode. When offsite power is lost, failure of Buses $B$ and $C$ will lead to station blackout because of failure of the ESW system.

Both ESW pumps and the ECW pump start on a diesel start signal or a LOCA signal (low water level/high drywell pressure). If all three pumps start successfully, the operator will shut off one ESW pump and the ECW pump. If the running ESW pump fails, the other ESW pump will receive an auto start signal on low discharge pressure. 


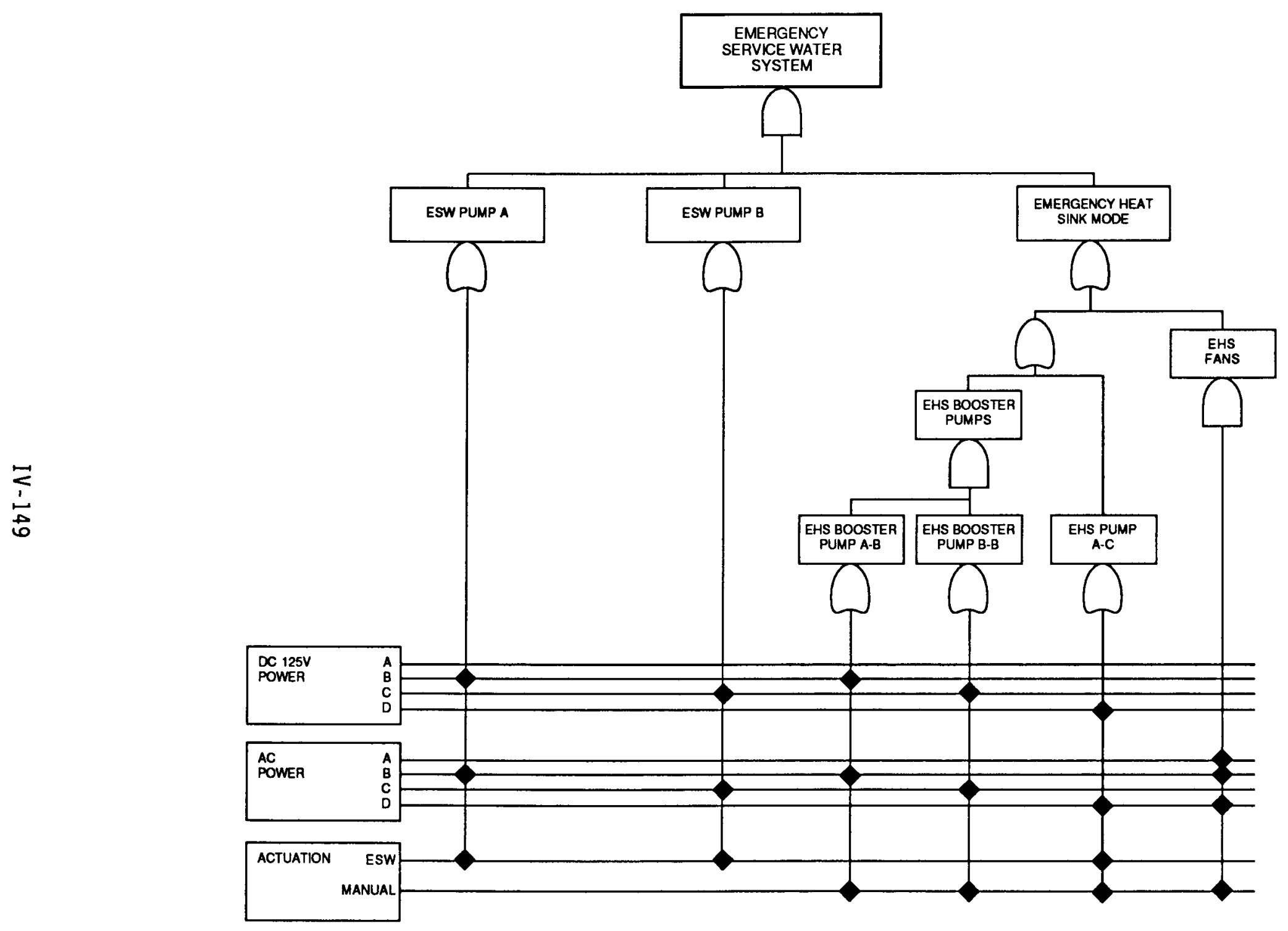

Dependency Diagram Is Shown Using Failure Logic.

Figure IV.5.13-2. Emergency Service Water system Dependency Diagram. 
When both an ESW pump low discharge pressure signal and a diesel generator auto start signal occur, after a 30 second delay, the ECW pump discharge valve M0-0841 (labeled MV3 in the system schematic) opens and the ESW pump combined discharge valve M0-0498 shuts. One ESW booster pump automatically starts when M0-0498 shuts and the other booster pump aligns to standby.

If an emergency cooling tower fan fails to start or trips on high vibration, its associated inlet valve automatically closes. High vibration alarms actuate in the control room.

\section{IV.5.13.3 ESW Test and Maintenance}

The ESW system is tested once every three months as follows: (1) pump operability--the pump is manually started and flow capability checked and (2) valve operability--the automatic valves are stroked individually from their control switches. The associated pump room fans are tested for operability every three months. The ECW pump, ESW booster pumps and emergency cooling tower fans are tested once per operating cycle to verify operability. Because of diesel generator test requirements, the ESW system is realistically tested more often ( weekly).

\section{IV.5.13.4 ESW Technical Specifications}

The ESW system shall be operable at all times when the reactor coolant temperature is greater than $212^{\circ} \mathrm{F}$. If two ESW pumps become inoperable, the reactor may remain in operation for a period not to exceed one month. To consider the ECW pump operable as an equivalent ESW pump, at least one ESW booster pump and two emergency cooling tower fans must be operable. To consider the ESW pump operable, the associated pump room fans must be available for normal operation except that (1) one pump room supply and/or exhaust fan for each compartment may be out of service for one month or (2) temporary fans may be used in place of permanently installed fans to provide room temperatures of less than $1200 \mathrm{~F}$.

\section{IV.5.13.5 ESW Logic Models}

The ESW system was modeled using fault trees for both its normal heat removal mode and its EHS mode. The major active and some passive components were modeled using pipe segments which were defined for the ESW system. Components within a pipe segment were grouped together to form a single basic event. Generally, a pipe segment is that run of pipe from one junction to another junction. A separate pipe segment was defined when components within a run of pipe had different dependencies or potentials for recovery and at a penetration of the containment. The fault tree model representing the ESW system is presented in Appendix $A$.

Piping ruptures were considered to be negligible compared to other system failures. Only piping with a diameter of greater than or equal to $1 / 3$ of the main system piping was considered as a potential diversion path.

Three human errors were incorporated into the ESW fault tree model. These errors are (1) operator failure to operate the EHS (fans), (2) common mode failure of the emergency cooling tower fans because of miscalibration of the vibration sensors, and (3) operator failure to restart the ECW pump should the preferred path have a delayed failure. 
IV.5.13.6 ESW Assumptions

(1) The ESW pumps do not require room cooling. These pumps are located in the service water pump structure which is a large building. By opening the door (which is not likely to be required) adequate cooling can be provided.

(2) The cross-tie valves between the two ESW pumps are not modeled. Each pump feeds into a common header; therefore, the cross-tie does not have significant impact on the dominant failure modes of the system. The only time the cross-tie is important is when manual valve 507A (XV1) plugs and ESW Pump B fails or manual valve 507B (XV2) plugs and ESW Pump A fails. These failures are judged to be negligible compared to the failure of both-pumps.

(3) Diesel generator E1, E2, E3, and E4 jacket cooling failures, by means of one header failing because of valve plugging and the other because of ESW pump failure, are not modeled. This simplification was made since the likelihood of a manual valve's plugging and a pump's failing is insignificant compared to two pump failures.

(4) A system initiation signal starts both ESW pumps and the ECW pump. The operator shuts off one ESW pump and the ECW pump after checking discharge pressure. Failure of the operator to trip the two pumps is not considered a system failure mode.

(5) Cooling for the ECCS pump rooms is provided by fan cooling units. Operation of both the fan and coolant flow through the coil is needed for cooling the room.

(6) All of the air-operated valves in the ESW system fail open on loss of air.

(7) Both fan-coil units for each pump room receive the same operational signal and are supplied from the same power source.

(8) Test unavailability is not considered for the ESW system. The system starts automatically and all the motor operated valves will reposition to the start signal even if they are changed from auto to manual position during the test.

(9) No need for makeup is modeled for the EHS mode. This assumption is made because the amount of evaporation in the emergency cooling towers is expected to be low.

(10) Plugging of the strainers in the service water pump bay is considered insignificant. Since the Normal Service Water pumps are normally operating in the same bay, plugging of strainers would be easily detected prior to ESW operation. Plugging of strainers during ESW operation is considered very small since it would have to happen within minutes. After a few minutes, the EHS mode may be initiated. 
(11) Maintenance of M0-0498 (if closed) is assumed to affect the flow rate of the ESW pumps and ECW pump without use of the booster pumps (see Section IV.5.13.8).

\section{IV.5.13.7 ESW Operating Experience}

Nothing was peculiar in the operational history of the ESW system which would affect either system modeling or failure data.

\section{IV.5.13.8 ESW Special Issues}

After the initial quantification of sequences was completed, PECO responded to a number of different issues affecting the ESW system.

The first issue deals with maintenance on the ESW pump combined discharge valve M0-0498 (MV2 on the schematic). PECO states that it is hard to hypothesize a reason that this valve would ever be closed for maintenance. A plant specific maintenance value based on operational experience is used in this study. It is felt that the plant specific value is not unreasonable. A sensitivity is done using the generic ASEP maintenance unavailability value bounding this data value on the upper end.

The second issue deals with ESW pump and ECW pump capabilities without operation of both ESW booster pumps. PECO has implied that with M0-0498 shut and both booster pumps inoperative, either of the ESW pumps or the ECW pump can provide sufficient cooling to the ESW loads. Under such conditions, PECO states that sufficient head exists to pump water to the loads and the cooling tower structure. PECO has determined that there are no high pressure pump trips associated with the ESW system and that these pumps can operate at shutoff head without damage. This implies that closure of M0-0498 has no effect on ESW loads and failure of Buses B and $C$ will not lead to station blackout following a loss of offsite power. While it is felt there is significant validity to these arguments, insufficient analysis exists to incorporate these comments into the base case study. However, a bounding sensitivity analysis has been performed to show the effects of these comments on the core damage frequency.

The third issue involves whether or not the LPCS/LPCI pumps really require ESW cooling. PECO has stated that these pumps are designed to operate with working fluid temperatures approaching $160^{\circ} \mathrm{F}$ without pump cooling. This implies that in scenarios where the ESW system has been lost, the RHR pumps (all modes) could still operate; some RHR pumps would be placed in the suppression pool cooling mode and therefore keep the working fluid at less than $1600 \mathrm{~F}$. Again, it is felt that there is significant validity to these arguments. However, because it is uncertain whether the suppression pool water can be maintained below $160^{\circ} \mathrm{F}$ in some sequences and whether PECO has properly accounted for pump heat addition to the system, the base case analysis assumes the RHR pumps will fail upon loss of ESW cooling. In a sensitivity analysis, PECO comments are incorporated, thus bounding this issue.

\section{IV.5.14 High Pressure Service Water System}

\section{IV.5.14.1 HPSW Description}

The HPSW system is designed to supply cooling water from the ultimate heat sink to the RHR system heat exchangers under post-accident conditions and can provide an 
additional source of water to the reactor vessel (event tree nomenclature-- $V_{4}$ ) through a cross-tie to the RHR injection lines.

The HPSW system consists of four 4,500 gpm pumps installed in parallel. The pumps are a vertical multi-stage turbine type with a discharge head of $700 \mathrm{ft}$. Each pump is sized to the design heat removal capacity of one RHR heat exchanger. Normal water supply to the suction of the pumps is from Conowingo Pond. In the EHS mode of system operation, suction and discharge comes from the emergency cooling towers. The pump discharge is split into two headers with two pumps in each header. The headers are split by a normally closed, motor-operated gate valve. Each header delivers water to two RHR heat exchangers in parallel. The pump discharge head is sufficient to maintain the HPSW system at a higher pressure than the RHR system, thus precluding leakage of radioactivity and permitting operation in conjunction with the emergency cooling towers. As an injection source to the reactor vesse1, the HPSW discharge to the RHR injection lines is from the pump B/D header. This connects to the RHR header. A simplified schematic of the HPSW system is provided by Figure IV.5.14-1. Major components are shown as well as the pipe segment definitions (e.g., PS-10) used in the system fault tree.

The operator is required to initiate the HPSW system. To initiate the system in the RHR cooling mode, the operator must start the appropriate HPSW pump and open the appropriate motor operated discharge valve depending on which RHR heat exchanger(s) is being used. These discharge valves are arranged as one valve downstream of each of the four RHR heat exchangers. To inject water into the reactor vessel via the RHR system, the operator starts B and/or D HPSW pumps and opens M0-176 and M0-174 (1abeled MV13 and MV14 in the schematic).

The success criteria for the HPSW system in the RHR cooling mode is one of four pumps supplying flow to the appropriate one of four heat exchangers. This is based upon the RHR system success criteria. As a last effort injection source, either B or D pump must supply flow through the cross-tie and corresponding RHR injection line under depressurized conditions in the reactor vessel. For further information, refer to the success criteria discussions in Section IV.4.

Most of the HPSW system is located in pump rooms external to the reactor and turbine buildings. Any physical impact of accident conditions on the ability of the HPSW system to perform its functions would be minimal. Room cooling failure is assumed not to fail the HPSW pumps.

Failure of the HPSW system in the RHR cooling mode would fail the RHR cooling function. Failure of the HPSW system in the injection mode would fail one source of water for reactor makeup and containment spray.

\section{IV.5.14.2 HPSW Interfaces and Dependencies}

The HPSW pumps have both a normal and a standby power supply. In the event of a loss of offsite power, each pump is powered by a different diesel generator. Corresponding DC power is required for all pumps for actuation purposes. The pumps are self-cooled and room cooling is not required. A simplified dependency diagram of the HPSW is provided by Figure IV.5.14-2. Shown are the major support needs for the HPSW system as indicated by the solid diamonds at the appropriate places in the diagram. 


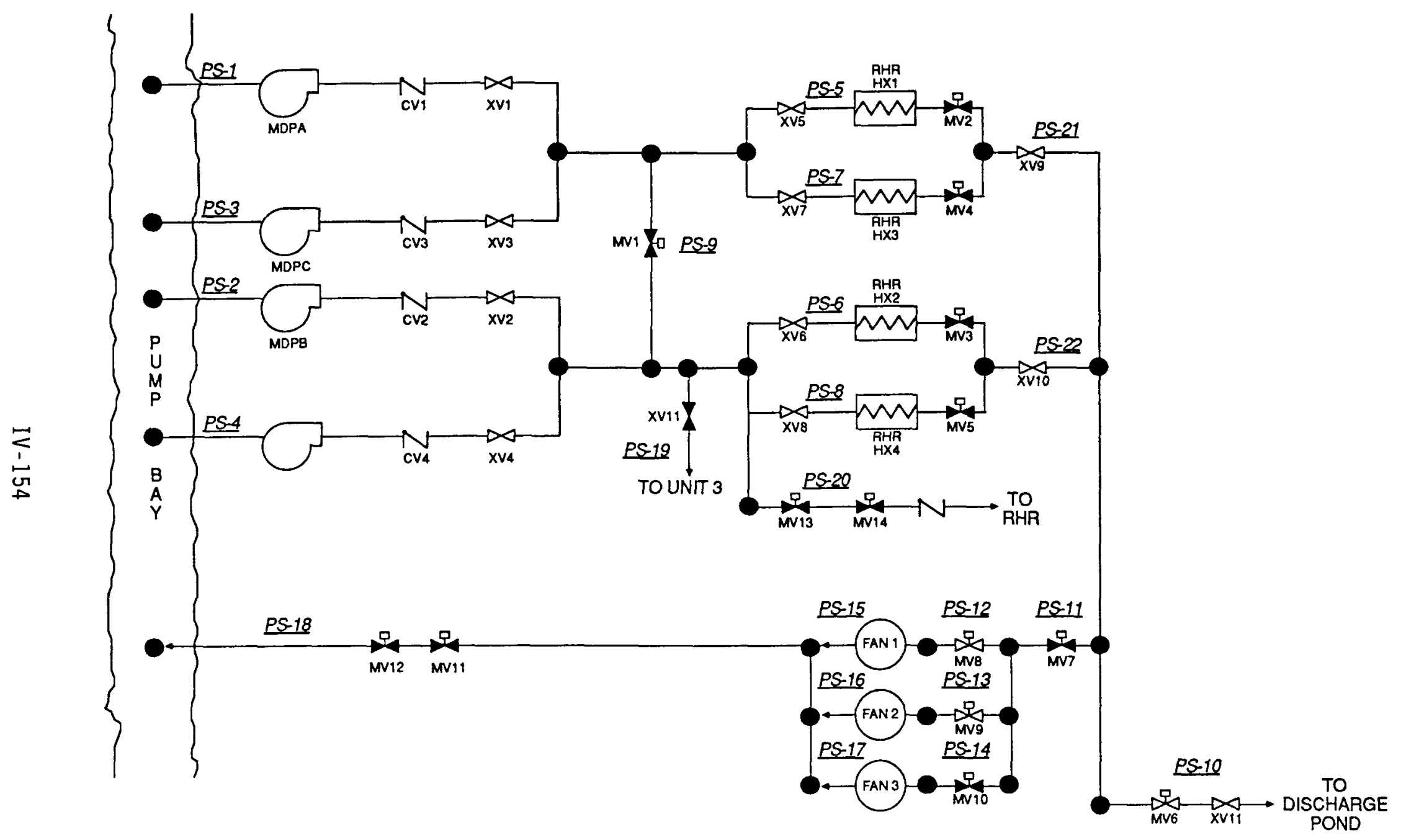

VALVE POSTIONS ARE SHOWN IN THEIR STANDBY MODE

Figure IV.5.14-1. High Pressure Service Water system Schematic. 


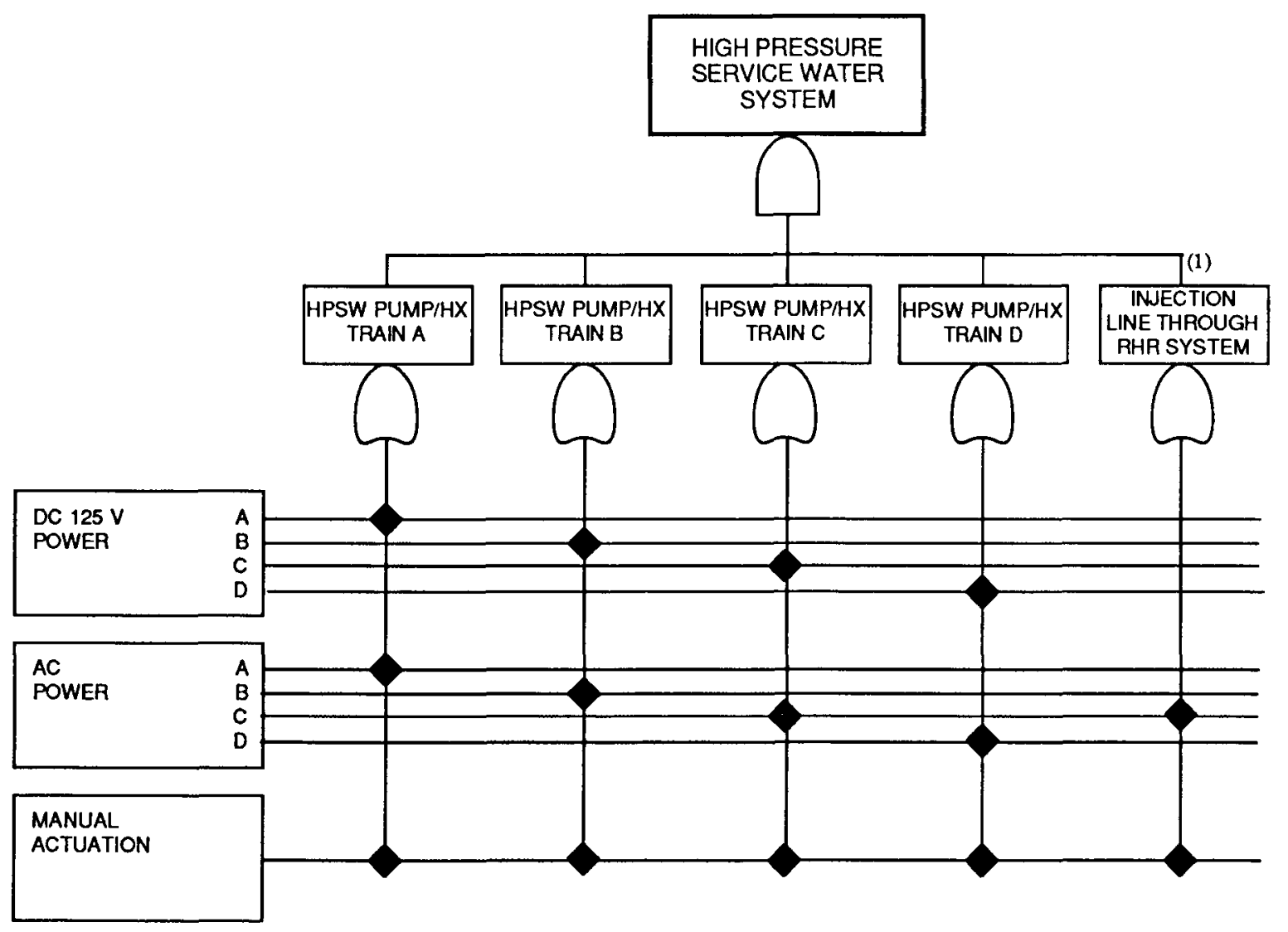

Dependency Diagram is Shown Using Failure Logic.

(1) Used Only When The System is Used As An Injection Source To The Reactor. 
The HPSW system can inject water from the B/D header to the RHR system B header through a line containing two normally closed, motor-operated gate valves and check valve.

Cooling tower fans are shared with the ESW system. These fans are used in the EHS mode of operation should the normal bay level be either too high or too $10 \mathrm{w}$. The EHS mode requires power from three of the four divisions to operate the inline motor-operated valves.

The HPSW system is initiated manually, either locally or from the main control room.

\section{IV.5.14.3 HPSW Test and Maintenance}

The HPSW surveillance requirements are the following: (1) pump operability-once/month, (2) motor-operated valve operability--once/month, and (3) pump capacity test--after pump maintenance and every three months.

Unavailability of the system because of testing is considered negligible. This is because the time required to complete a test is so small with respect to the testing frequency. Therefore, of the test and maintenance contributions, maintenance is postulated to be the dominant contributor. All maintenance values for the HPSW system were taken from the generic data base.

\section{IV.5.14.4 HPSW Technical Specifications}

The HPSW system shall be operable whenever irradiated fuel is in the reactor vessel and the reactor coolant temperature is greater than $212^{\circ} \mathrm{F}$, as well as prior to reactor startup from a cold shutdown condition.

If any two HPSW pumps are made or found to be inoperable for any reason, continued reactor operation is permissible for thirty days. If three HPSW pumps are made or found to be inoperable, continued reactor operation is permissible for fifteen days. If three HPSW trains are made or found to be inoperable, the reactor can continue to operate for seven days. If these requirements cannot be met, the reactor is to be shut down.

\section{IV.5.14.5 HPSW Logic ModeTs}

The HPSW system was modeled using fault trees for both its heat removal mode (including the EHS configuration) and its vessel injection mode. The major active and some passive components were modeled using pipe segments which were defined for the HPSW system. Components within a pipe segment were grouped together to form a single basic event. Generally, a pipe segment is that run of pipe from one junction to another junction. A separate pipe segment was defined when components within a run of pipe had different dependencies or potentials for recovery and at a penetration of the containment. The fault tree model representing the HPSW system is presented in Appendix A.

Piping ruptures were considered to be negligible compared to other system failures. Only the piping with a diameter of greater than or equal to $1 / 3$ of the main system piping was considered as a potential diversion path.

The only human error modeled was failure of the operator to initiate the system. Any other human action was considered part of recovery. 


\section{IV.5.14.6 HPSW Assumptions}

(1) The HPSW pumps do not require room cooling. These pumps are located in a large building. By opening some doors (which is likely not to be necessary), adequate cooling can be provided for the pumps.

(2) The system is switched to the EHS mode when the sluice gates in the pump bay are closed and the water level drops. It is assumed that the EHS mode can also be switched on if MO-2486 (MV6 in the schematic) to the discharge pond fails closed.

(3) The design basis criteria follow. The emergency cooling towers require the fans for adequate heat removal. One induced-draft cooling tower is needed for heat removal from one RHR heat exchanger. One cooling tower is also needed for removal of heat from ESW loads. The cooling towers may be able to remove heat without induced-draft, but the success criteria would be different and would require further analysis. This has a negligible effect on system reliability since the emergency cooling towers are the secondary source of heat sink for the RHR heat exchangers.

(4) The emergency cooling tower reservoir is needed for successful operation of the HPSW system in the EHS mode. The HPSW system is switched to the EHS mode when the water level in the pump bay is already low. Without added water from the reservoir, the pumps will not have adequate NPSH either at the time of switchover or after when there will be further drainage from the pump bay.

(5) If the reservoir is providing water to the pump bay, failure of the pond discharge valve M0-2486 (MV6) to close during the EHS mode of operation does not result in system failure. If this valve fails to close and the reservoir is supplying make up water, the reservoir will be depleted faster. Reservoir depletion will take $31 / 2$ days instead of 7 days since approximately half the flow is diverted into the pond. This is considered easily recoverable.

(6) Test unavailability for the HPSW system is considered insignificant. The system is aligned close to its desired configuration for test.

\section{IV.5.14.7 HPSW Operating Experience}

Nothing was peculiar in the operational history of the HPSW system which would affect either system modeling or failure data.

\section{IV.5.15 Emergency Ventilation System (EVS)}

\section{IV.5.15.1 EVS Description}

The objective of the EVS is to maintain suitable temperatures in equipment rooms to preclude component failures. 
The EVS cools the following:

(1) emergency switchgear and battery rooms, (2) standby diesel generator rooms, (3) pump structure service water pump rooms, and (4) pump rooms for the RHR, RCIC, HPCI and LPCS pumps. The pump rooms use small individual fan coolers in each room. A simplified schematic of the rest of the EVS is provided by Figure IV.5.15-1. Major components are shown as well as the pipe (duct) segment definitions (e.g., PS-4) used in the system fault tree.

The service water pumps are assumed not to require room cooling. Pump room cooling loss for the RHR, RCIC, HPCI, and LPCS pumps is incorporated into the ESW and individual system models. Therefore, the EVS system model does not include ESW, RHR, RCIC, HPCI, and LPCS pump room cooling.

Room cooling for the emergency switchgear and battery rooms consists of a common air supply system and separate exhaust systems. Outdoor air is filtered, conditioned by heating coils when required, and discharged by one of two supply fans. One of the two return air fans exhausts air to the atmosphere at the radwaste building roof or back to the suction of the supply fans.

Each standby diesel generator room is provided with ventilation air supply fans and an exhaust relief damper.

The success criteria for emergency switchgear and battery room cooling are one of two supply fans and one of two exhaust fans being operational. Diesel generator room cooling requires operation of one of two supply fans. Any physical impact of accident conditions on the ability of the EVS to perform its function would be minimal.

It is assumed that failure of the EVS would fail operating diesel generators in less than 30 minutes. The emergency switchgear and batteries are conservatively assumed to have a ten percent chance (as a screening value) of failure in four hours after a loss of the EVS.

\section{IV.5.15.2 EVS Interfaces and Dependencies}

The standby diesel generator room fans are powered from their respective diesels. Emergency switchgear and Battery Room Fans 1, 3, and 5 are powered from $480 \mathrm{VAC} / \mathrm{C}$ with control and actuation power supplied by $120 \mathrm{VAC} / \mathrm{C}$. Emergency switchgear and Battery Room Fans 2, 4, and 6 are powered from $480 \mathrm{VAC} / \mathrm{D}$ with control and actuation power supplied by $120 \mathrm{VAC} / \mathrm{D}$. A simplified dependency diagram of the EVS is provided by Figure IV.5.15-2. Shown are the major support needs for the EVS as indicated by the solid diamonds at the appropriate places in the diagram.

A11 four fans used for switchgear room cooling are tripped on a low duct temperature signal. This signal is generated by thermal switches 00024-1 and 00024-2. Normally one of two supply fans and one of two exhaust fans are running. On a low duct pressure signal, the standby fans will automatically start. The emergency switchgear and battery room pneumatic-operated dampers fail closed on a loss of instrument air.

Diesel Generator Room Fans 7, 9, 11, and 13 outside air supply dampers open on $650 \mathrm{~F}$ fan discharge temperature and fail open on a loss of instrument air. Diesel Generator Room Fans 7, 9, 11, and 13 room air supply dampers close on $650 \mathrm{~F}$ fan discharge temperature and fail closed on a loss of instrument air. Dampers AV27, AV30, AV33, and AV36 open on Fans 7, 9, 11, and 13, starting respectively and 


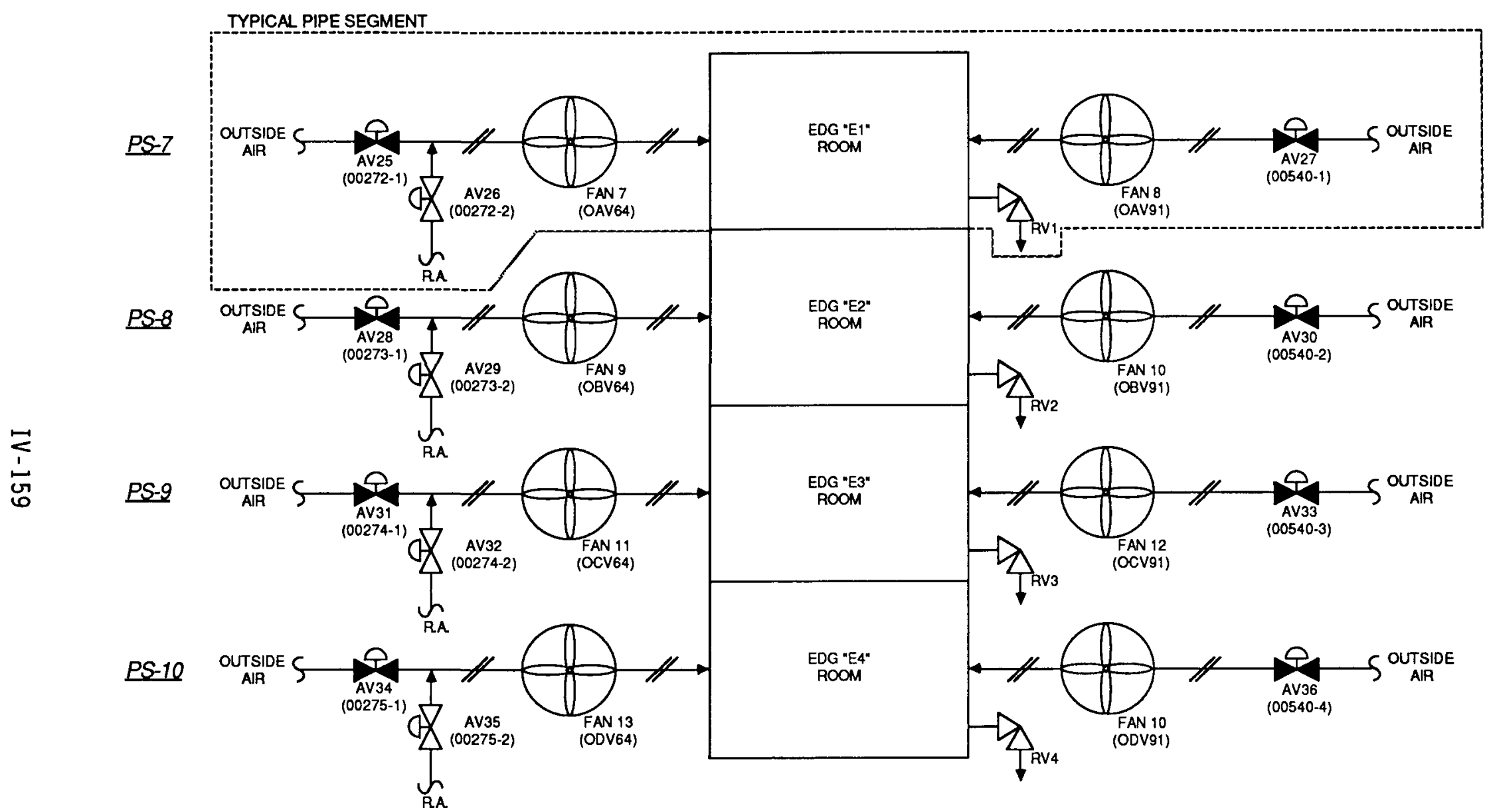

VALVE (DAMPER) POSITIONS ARE SHOWN IN THEIR STANDBY MODE

Figure IV.5.15-1. Emergency Ventilation System Schematic.

(Page 1 of 2) 


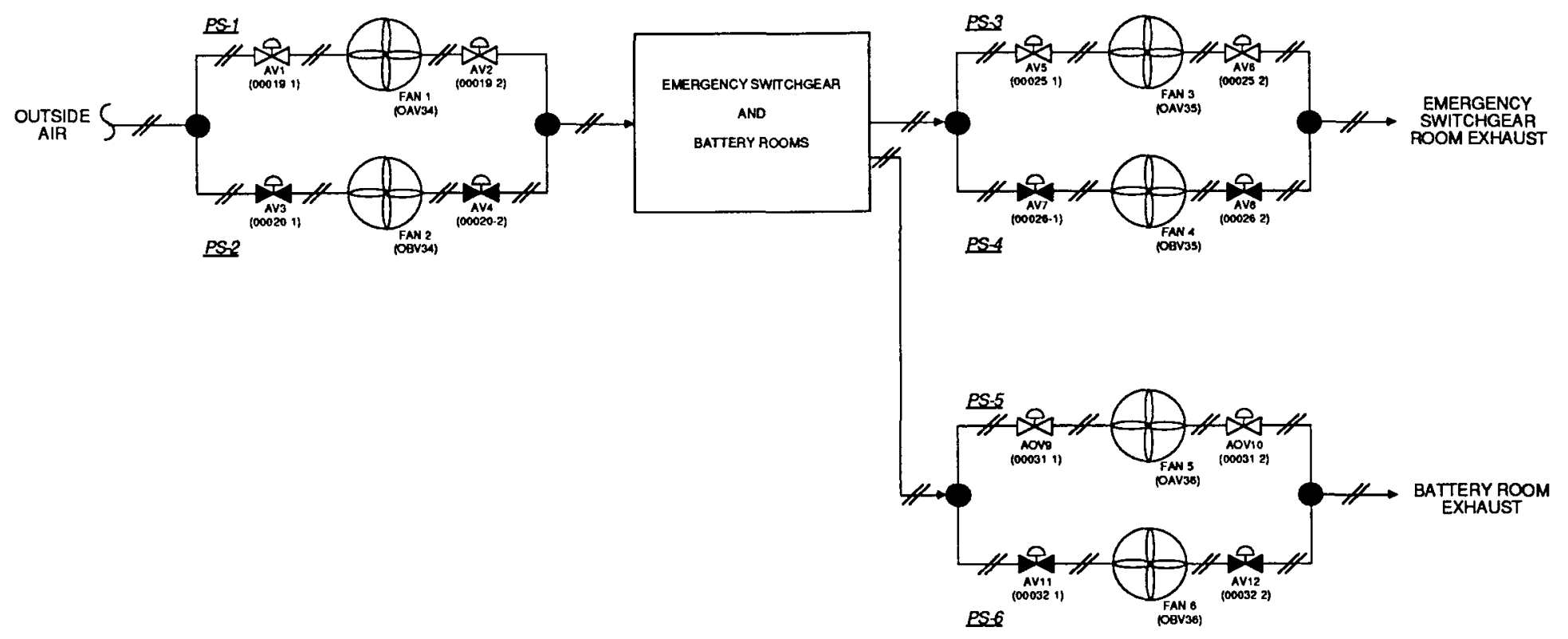

VALVE (DAMPER) POSTIONS ARE SHOWN IN THEIR STANDEY MODE

Figure IV.5.15-1. Emergency Ventilation System Schematic. 


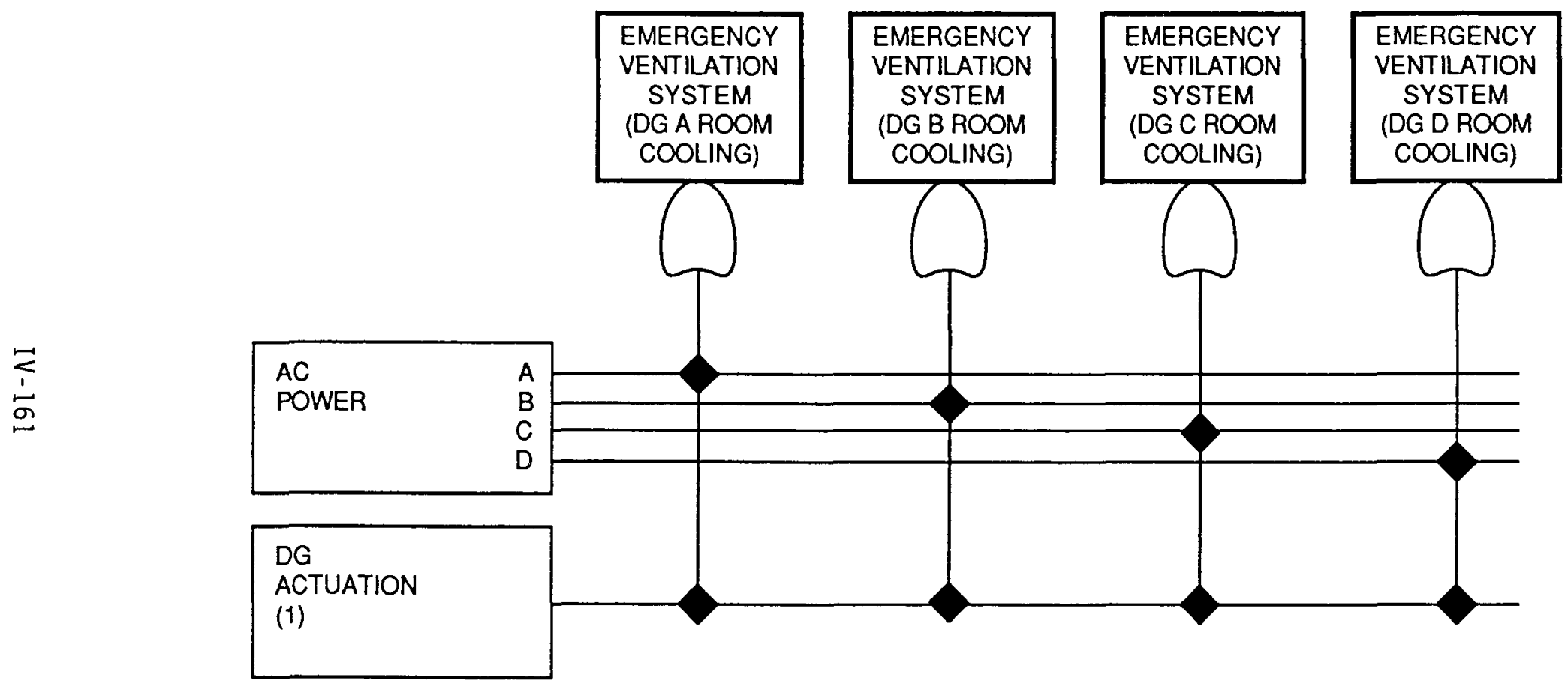

Dependency Diagram Is Shown Using Failure Logic.

(1) Each DG EVS Fan Is Auto Actuated By The Start Signal Of Its Corresponding DG.

Figure IV.5.15-2. Emergency Ventilation System Dependency Diagram. (for diesels) (Page 1 of 2 ) 


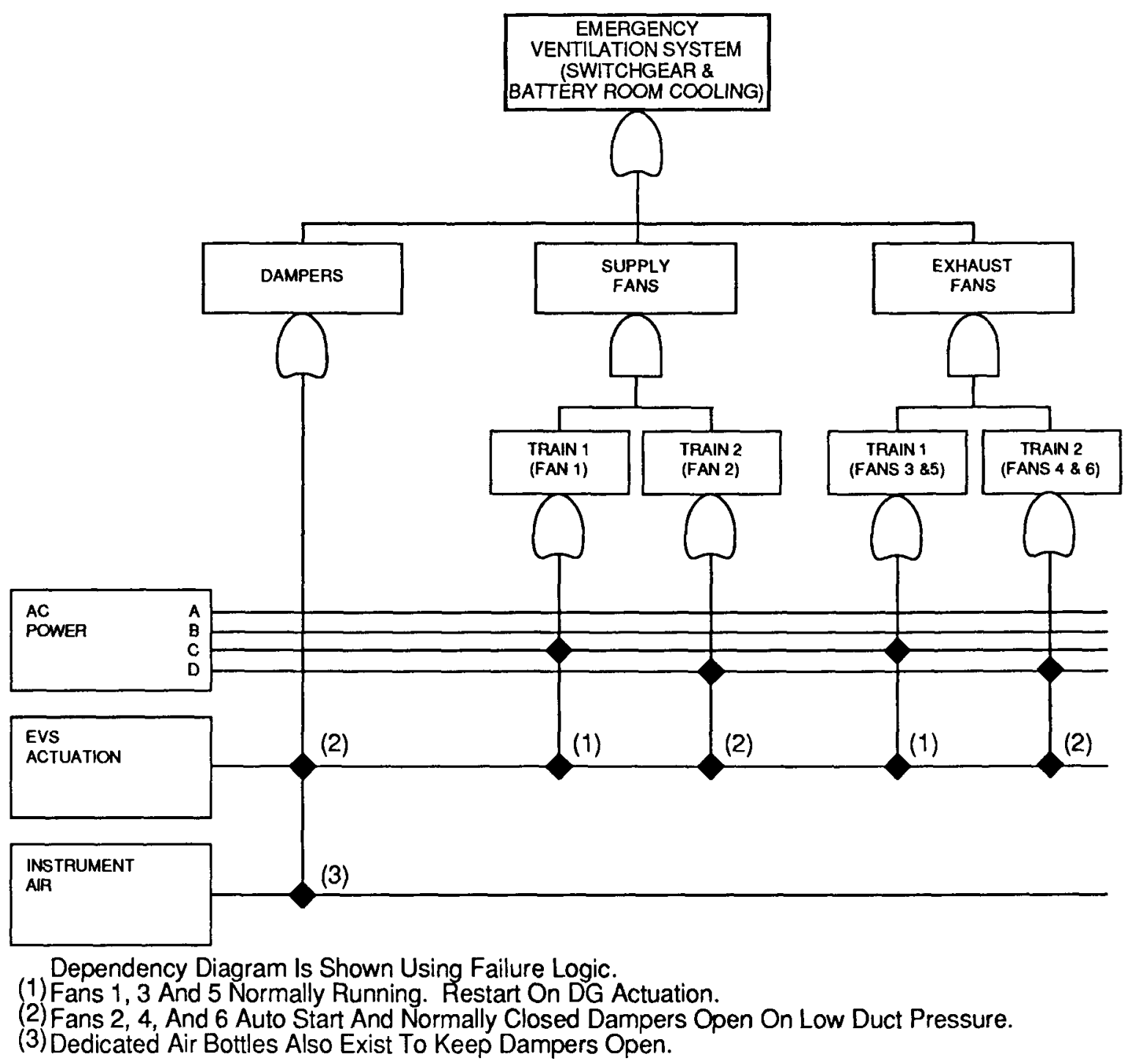

Figure IV.5.15-2. Emergency Ventilation System Dependency Diagram. (for switchgear and battery rooms) (Page 2 of 2) 
failing open on a loss of instrument air. Fans 7, 9, 11, 13 automatically start on a diesel generator actuation signal. Fans $8,10,12$, and 14 automatically start on an automatic start of Fans $7,9,11$, and 13 respectively. Diese 1 generator room supply fans trip on a carbon dioxide discharge signal except when a LOCA signal is already present.

\section{IV.5.15.3 EVS Test and Maintenance}

No EVS test and maintenance requirements are identified in the Peach Bottom technical specifications.

\section{IV.5.15.4 EVS Technical Specifications}

No reference is made to the EVS in the Peach Bottom technical specifications.

\section{IV.5.15.5 EVS Logic Models}

The EVS was modeled using a fault tree. The major active and some passive components were modeled using duct segments which were defined for the EVS. Components within a duct segment were grouped together to form a single basic event. A separate duct segment was defined when the components within a run of ducting have different dependencies or potentials for recovery. The fault tree model representing the EVS is presented in Appendix $A$.

Duct ruptures were considered to be negligible compared to other system failures.

One human error was incorporated into the EVS fault tree model. This error is miscalibration of thermal switches 00024-1 and 00024-2.

\section{IV.5.15.6 EVS Assumptions}

(1) All of the pneumatic-operated switchgear and battery room dampers close on a loss of air pressure. These dampers have backup air bottles to keep them open in the event of loss of instrument air pressure.

(2) EVS failure is dominated by failure of fans and failure of closed dampers to open when demanded.

\section{IV.5.15.7 EVS Operating Experience}

Nothing was peculiar in the operational history of the EVS which would affect either system modeling or failure data.

\section{IV.5.16 Instrument Air System (IAS)}

\section{IV.5.16.1 IAS Description}

The IAS provides a pneumatic supply to support short-term and long-term operations of safety equipment.

The IAS and Service Air System (SAS) consist of three, in parallel, air compressors supplying a common discharge header via individual air receiver tanks, iping, valves, and instrumentation. A fourth air compressor is tied into the SAS 
header and is common to both units. Two compressors, one IAS and one SAS, normally supply all compressed air requirements. The other IAS compressor serves in a standby capacity. A simplified schematic of the IAS is provided by Figure IV.5.16-1. Shown is the tie-in with the Instrument Nitrogen System which is the preferred supply to the MSIVs and ADS/SRVs.

Each of the three parallel compressors is a vertical, single-stage, double-acting, non-lubricated, reciprocating compressor rated at $377 \mathrm{scfm}$ at $100 \mathrm{psig}$. Each has an aftercooler, moisture separator, and air receiver tank.

The standby SAS compressor consists of a non-lubricated compressor, aftercooler, moisture separator, and two receivers. This compressor is rated at $400 \mathrm{scfm}$ at 100 psig.

The IAS supplies clean, dry, oil-free air to EHV system air valves, the CRD control system, and containment venting air valves and is a backup to the Instrument Nitrogen System.

When offsite power is lost, the air compressors trip. The operator is required to manually restart the air compressors when power is restored.

The success criterion for the IAS is either of the IAS compressors or the SAS compressor supplying air to system pneumatic loads.

Any physical impact of accident conditions on the ability of the IAS to perform its functions would be minimal. Room cooling failure is assumed not to fail the IAS and SAS compressors.

Failure of the IAS does not directly fail any safety systems because (1) accumulators are on the MSIVs and ADS valves, (2) instrument nitrogen is the preferred source to the MSIVs and ADS valves, and (3) other safety systems "fail-safe" on loss of air or have dedicated air bottles.

\section{IV.5.16.2 IAS Interfaces and Dependencies}

Cooling requirements of system air compressors and aftercoolers are normally supplied by the TBCW system. In the event of offsite power failure, the RBCW system cools the air compressors and aftercoolers.

Motor-driven air compressor $A$ is powered from $480 \mathrm{VAC} / \mathrm{C}$ with control and actuation power supplied by $120 \mathrm{VAC} / \mathrm{C}$. Air Compressor $B$ is powered from $480 \mathrm{VAC} / \mathrm{D}$ with control and actuation power supplied by $120 \mathrm{VAC} / \mathrm{D}$. Air Compressors $C$ and $D$ are powered from non-safety Buses $20 \mathrm{~B} 13$ and 20B31, respectively. Their control and actuation power comes from 120 VAC non-safety buses. Following a loss of offsite power, standby onsite power is provided to the air compressors to replenish compressed air storage as required. A simplified dependency diagram of the IAS is provided by Figure IV.5.16-2.

\section{IV.5.16.3 IAS Test and Maintenance}

No IAS test and maintenance requirements are identified in the Peach Bottom technical specifications. 
PS-1

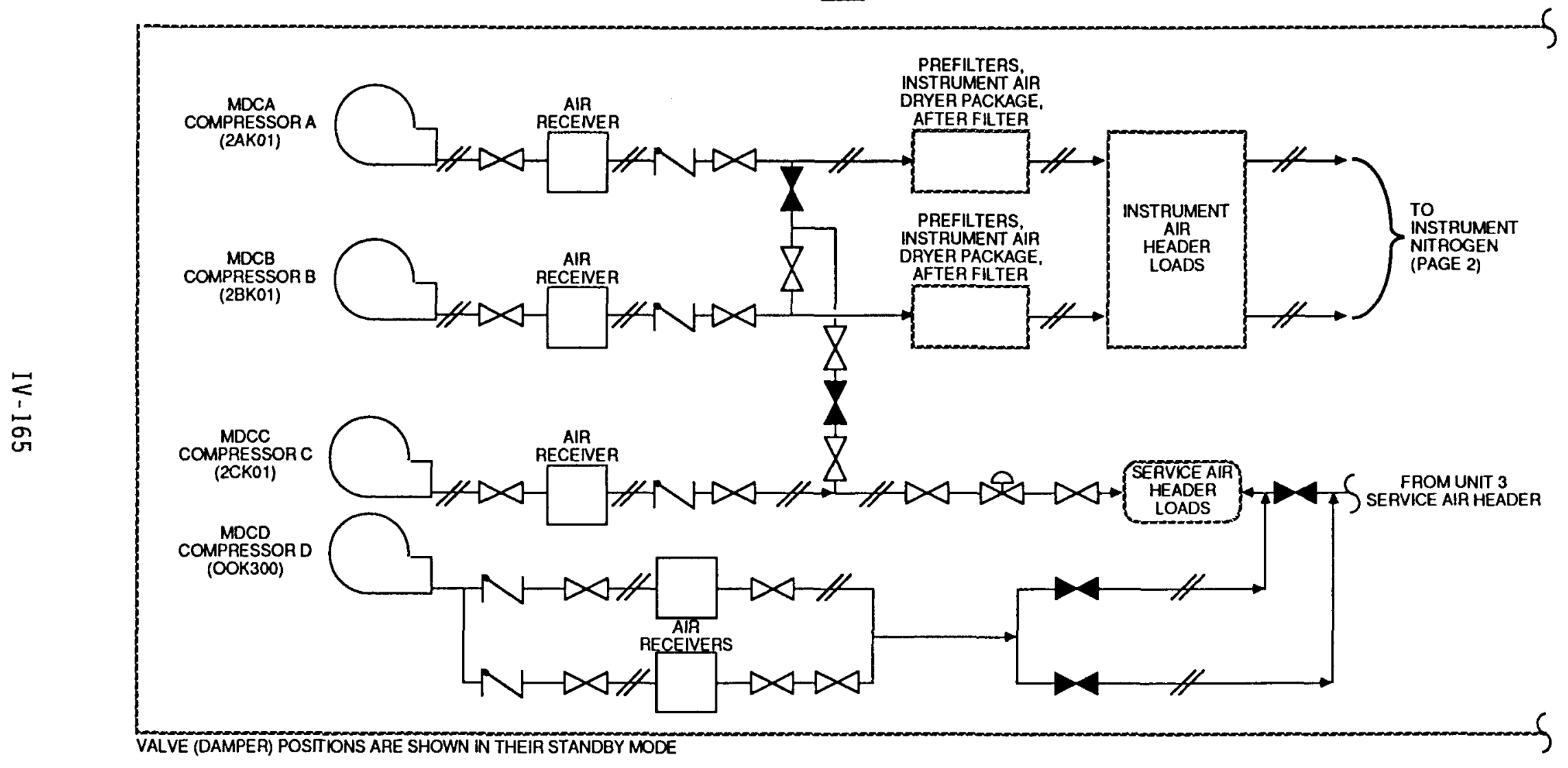

Figure IV.5.16-1. Instrument Air/Nitrogen system Schematic.

(Page 1 of 2) 


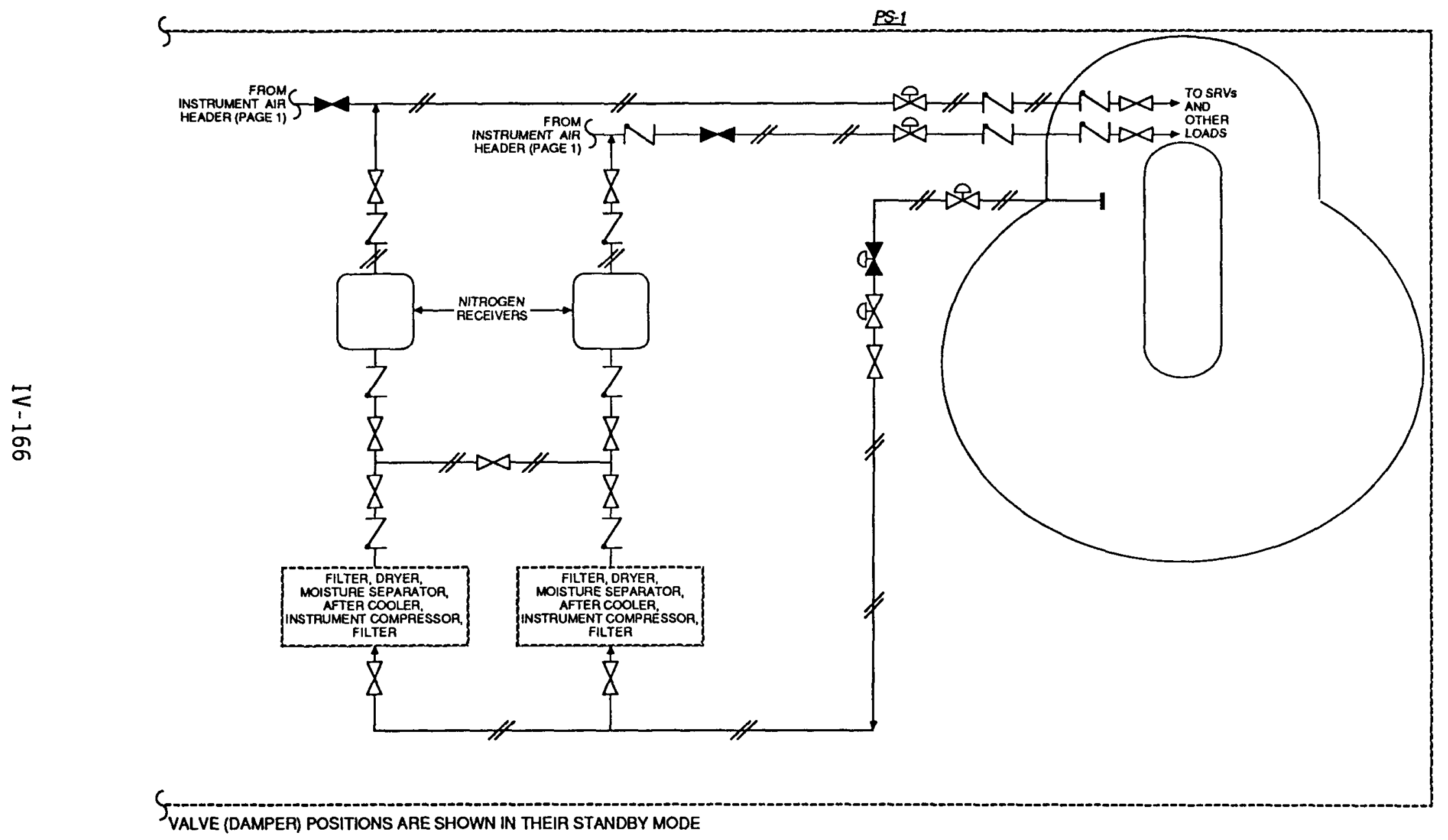

Figure IV.5.16-1. Instrument Air/Nitrogen system Schematic. (Page 2 of 2) 


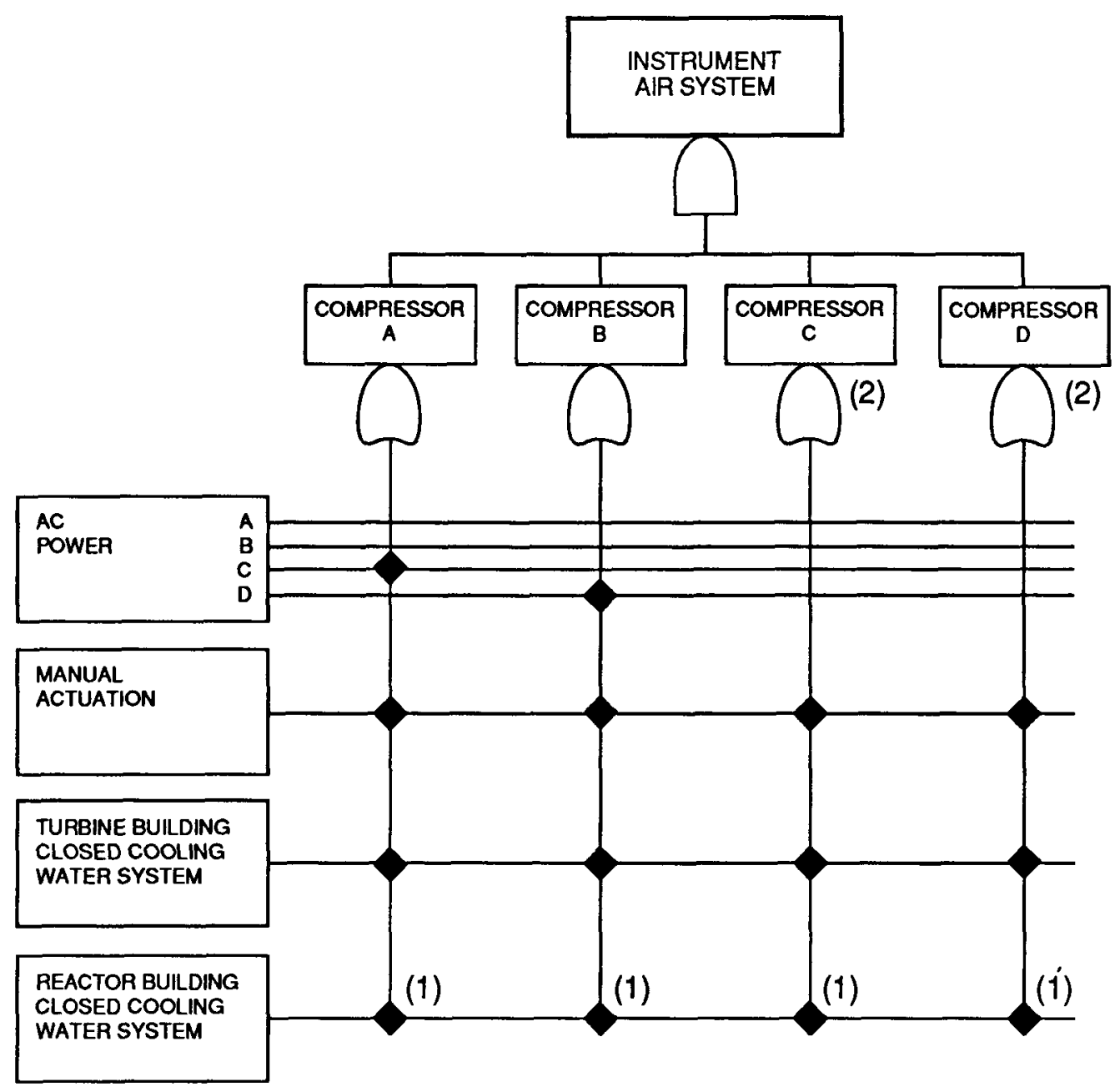

Dependency Diagram Is Shown Using Failure Logic.

(1) RBCW Is A Backup If The TBCW Fails.

(2) Powered By Non-Safety Buses.

Figure IV.5.16-2. Instrument Air system Dependency Diagram. 


\section{IV.5.16.4 IAS Technical Specifications}

IAS degradation does not limit plant operations.

\section{IV.5.16.5 IAS Logic Models}

The IAS was modeled using a very simple fault tree covering only the failures of the compressors and loss of support system needs. The fault tree model representing the IAS is presented in Appendix A. This simplified modeling approach was used since the importance of this system to other systems modeled in the study is limited. Therefore, a detailed analysis was not warranted.

Piping ruptures were considered to be negligible compared to other system failures. Only piping with a diameter of greater than or equal to $1 / 3$ of the main system piping was considered as a potential diversion path.

One human error was incorporated into the IAS fault tree model. This error is the operator's failing to restart the system following a loss of offsite power.

\section{IV.5.16.6 IAS Assumptions}

(1) Al1 IAS loads can be supplied from both IAS headers.

(2) The IAS trips on loss of offsite power and needs to be restarted manually.

(3) Failure of the TBCW system to provide cooling is dominated by TBCW pump failures.

(4) Failure of the RBCW system to provide cooling is dominated by RBCW pump failures and failure of switchover.

\section{IV.5.16.7 IAS Operating Experience}

Nothing was peculiar in the operational history of the IAS which would affect either system modeling or failure data.

\section{IV.5.17 Primary Containment Venting System (PCVS)}

\section{IV.5.17.1 PCVS Description}

When torus and containment sprays have failed to reduce primary containment pressure, the PCVS is used to prevent a primary containment pressure limit from being exceeded (event tree nomenclature--Y).

The preferential order for primary containment vent paths is as follows: (1) 2-in torus vent to the Standby Gas Treatment System (SGTS), (2) 6-in integrated leak rate test (ILRT) line from the torus, (3) deflate seals on 18 -in torus vent and supply paths, (4) 18-in torus vent path, (5) 18-in torus supply path, (6) 2 -in drywell vent to the SGTS, (7) two 3 -in drywell sump drain lines, (8) 6-in ILRT line from the drywell, (9) deflate seals on 18-in drywell vent and supply paths, (10) 18-in drywell vent path, and (11) 18-in drywell supply path. A simplified schematic of the PCVS is provided by Figure IV.5.17-1. 


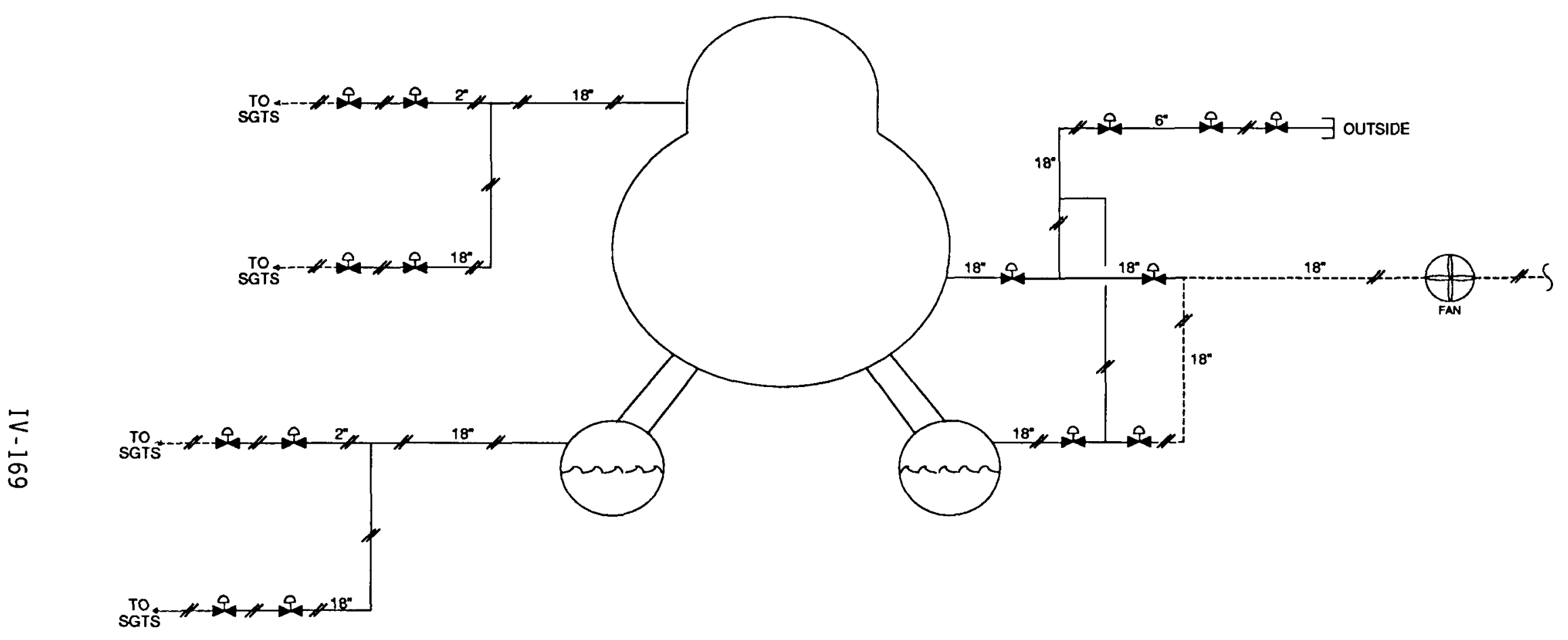

VALVE POSITIONS ARE SHOWN IN THEIR STANDBY MODE

Figure IV .5.17-1. Primary Containment Venting system schematic. 
For decay heat loads alone it is expected that the drywell pressure rise will be relatively slow. PCVS success in this case is the 6-in vent path (or larger) being operational. However, if the rate of pressure rise is significantly faster as in the ATWS scenarios, success criteria dictate two 18 -in vent paths as a minimum (assuming power levels $15 \%$ ) based on discussions with Sandia containment analysis personnel. For further information, refer to success criteria discussions in Section IV.4.

Venting procedure requires a vent path to be established if containment pressure rises to $60 \mathrm{psig.} \mathrm{In} \mathrm{the} \mathrm{case} \mathrm{of} \mathrm{an} \mathrm{ATWS,} \mathrm{or} \mathrm{if} \mathrm{it} \mathrm{can} \mathrm{be} \mathrm{inferred} \mathrm{that} \mathrm{the}$ suppression pool is being bypassed, the operator is required to directly establish 18-in vent paths (i.e., Step 4 in the preferred order is performed first).

IV.5.17.2 PCVS Interfaces and Dependencies

If station blackout occurs, a preferred vent path is a 6 -in ILRT line from the torus. To open this path, a flange must be removed from the line. Also, two motor-operated valves and two air-operated valves must be opened locally.

The drywell and torus vent paths to the SGTS are assumed to be successful whether or not the SGTS dampers are open. With the dampers closed, a rupture of the SGTS ducting in the reactor building is assumed to occur.

With a loss of instrument air, all air-operated valves fail closed. Backup air bottles are installed to facilitate opening air-operated valves locally.

With a loss of power, motor-operated valves fail in an "as is" position. These valves can still be opened with a handwheel or wrench on the stub protruding at the top of the motor operator.

\section{IV.5.17.3 PCVS Technical Specifications}

No reference is made to PCVS in the Peach Bottom technical specification. ATso, no test and maintenance procedures are identified. However, the vent paths are used for inerting and de-inerting the containment as well as leak testing of the containment during refuelings.

\section{IV.5.17.4 PCVS Logic Models}

The PCVS was modeled basically as a recovery action. As such, recovery values were assigned on sequence timing and difficulty to establish vent path considerations. Even without power or air, local opening of the appropriate valves was considered as per the Peach Bottom EPGs.

\section{IV.5.17.5 PCVS Operational Experience}

Nothing was peculiar in the operational history of the PCVS which would affect recovery value assignments. 


\section{IV.5.18 Reactor Protection System (RPS)}

\section{IV.5.18.1 RPS Description}

The function of the RPS is to provide timely protection against the onset and consequences of conditions that threaten the integrities of the fuel barrier and the nuclear system process barrier (event tree nomenclature--C).

The RPS includes the motor-generated power supplies with associated control and indicating equipment, sensors, relays, bypass circuitry, and switches that cause rapid insertion of control rods (scram) to shut down the reactor. The process computer system and annunciators are not part of the RPS.

\section{IV.5.18.2 RPS Interfaces and Dependencies}

Power to each of the two reactor protection trip systems is supplied, via a separate bus, by high inertia $A C$ motor-generator sets. Alternate power is available to either RPS bus from an electrical bus that can receive standby electrical power. The alternate power switch prevents simultaneously feeding both buses from the same source. DC power is supplied to the backup scram valve solenoids from the station batteries. Power is not needed to scram the reactor.

IV.5.18.3 RPS Logic Models

The RPS was not modeled in any detail. RPS electrical failure and mechanical failure probabilities on demand were assigned values of $2 E-5$ and $1 E-5$ respectively (i.e., the system was simply treated as a data value).

\section{IV.5.18.4 RPS Operational Experience}

Nothing was peculiar in the operational history of the RPS which would affect either system modeling or failure data.

\section{IV.5.19 0ther Systems}

The Power Conversion System (PCS) and Condensate system were treated as recovery actions. No system modeling was done.

Anytime the PCS was lost, it was assumed that the Condensate was also lost. While it is known that this assumption is highly conservative, it did not contribute to any dominant sequence being significantly higher in value.

With offsite power, any $A C$ bus, or any $D C$ bus transient initiators, it was assumed that the PCS and Condensate tripped. Their recovery was linked to power restoration.

Recovery values for the PCS and Condensate are based on historical data for PCS and offsite power recovery with sequence timing determining the exact value.

\section{IV.5.20 System Analysis Nomenclature}

In order to assure that the naming of failure events is done consistently throughout the fault tree coding process, a standard coding scheme was stabiished. This consistency is necessary to assure that the dependencies and 
interfaces between the systems are properly accounted for when the individual system fault trees are merged with their support systems and the merged fault trees are linked together to perform the accident sequence quantification. In addition, the standard coding scheme provides the analyst or reviewer a traceability of the events from the cut sets resulting from the accident sequence quantification to the individual fault trees.

The standard coding scheme developed utilizes a sixteen character identifier. Each individual event code is composed of four parts: a system identifier, an event or component type identifier, a failure mode code, and a unique event identifier. Each of these parts is separated by a dash for readability. The system identifier is composed of three characters which were selected to readily convey the system to the reader. The list of system identifiers is provided in Table IV.5.20-1. The event or component type identifier is composed of three characters which identify the component type if a component fault or the event type if other than a component fault. The list of event or component identifiers is included in Table IV.5.20-2. The failure mode code is composed of two characters which identify the failure mode associated with the fault. The list of failure mode codes is included in Table IV.5.20-3. The unique event identifier is composed of up to five characters which utilize a portion of the utility ID for a component or, in the case of non-component faults or grouped faults, convey information about the fault type.

A few special events were identified using a modification of the above coding scheme. These were specific common cause failures which were added to the sequence cut sets (per the methodology guidelines-see Reference [2]). For these cases, the common cause failures were identified in two ways:

(1) For identification purposes, the common cause failure used the system identifier, then the term "CCF" for common cause failure, and finally a unique identifier. An example includes ADS-CCF-VALVES for common cause failure of the ADS valves.

(2) For the actual quantification analysis, the above identifier was separated into its independent identifier and a Beta-factor term (see discussion of common cause analysis in IV.6). For example, the above identifier was separated into two terms:

$$
\text { ADS-VLV-FO-VALVE * B-ADS-FO-VALVES }
$$

In this way, importance measures and uncertainty analysis of the Beta factor itself could also be performed. 
Table IV.5.20-1

System Identifiers

SYSTEM
IDENTIFIER

\begin{tabular}{|c|c|}
\hline$\overline{A C C}$ & Accumulators \\
\hline ACP & AC Power System \\
\hline ADS & Automatic Depressurization System \\
\hline AFW & Auxiliary Feedwater System or Emergency Feedwater System \\
\hline ARF & Air Return Fan System \\
\hline $\mathrm{CCU}$ & Containment Atmosphere Cleanup \\
\hline $\mathrm{CCW}$ & Component Cooling Water System \\
\hline $\operatorname{CDS}$ & Condensate System \\
\hline CFC & Containment Emergency Fan Cooler System \\
\hline CGC & Containment Combustible Gas Control \\
\hline CHP & Charging Pump System \\
\hline CHW & Chilled Water System \\
\hline CIS & Containment Isolation System \\
\hline CLS & Consequence Limiting Control System \\
\hline CPC & Charging Pump Cooling System \\
\hline CRD & Control Rod Drive System \\
\hline $\csc$ & Closed Cycle Cooling System \\
\hline CSR & Containment Spray Recirculation System \\
\hline CSS & Containment Spray System \\
\hline CVC & Chemical and Volume Control System \\
\hline DCP & DC Power System \\
\hline DWS & Drywe11 (Wetwe11) Spray Mode of RHR System \\
\hline EHV & Emergency Heating, Ventilation, \& Air Conditioning System \\
\hline ESF & Engineered Safety Feature Actuation System \\
\hline ESW & Emergency Service Water System \\
\hline FHS & Fuel Handling System \\
\hline $\mathrm{HCI}$ & High Pressure Coolant Injection System \\
\hline HCS & High Pressure Core Spray System \\
\hline HPI & High Pressure Safety Injection System \\
\hline HPR & High Pressure Recirculation System \\
\hline HSW & High Pressure Service Water System \\
\hline IAS & Instrument Air System \\
\hline
\end{tabular}


Table IV.5.20-1

System Identifiers (Concluded)

\section{SYSTEM IDENTIFIER}

\section{SYSTEM NAME}

\begin{tabular}{|c|c|}
\hline ICS & Ice Condenser System \\
\hline ISO & Isolation Condenser System \\
\hline ISR & Inside Containment Spray Recirculation System \\
\hline LCI & Low Pressure Coolant Injection System \\
\hline LCS & Low Pressure Core Spray System \\
\hline LPI & Low Pressure Safety Injection System \\
\hline LPR & Low Pressure Recirculation System \\
\hline MCW & Main Circulating Water System (main condenser cooling water) \\
\hline MFW & Main Feedwater System \\
\hline MSS & Main Steam System \\
\hline NHV & Normal Heating, Ventilation, \& Air Conditioning System \\
\hline OEP & Onsite Electric Power System \\
\hline OSR & Outside Containment Spray Recirculation System \\
\hline PCS & Power Conversion System \\
\hline PPS & Primary Pressure Relief System (PORV/SRV) \\
\hline RBC & Reactor Building Cooling Water System \\
\hline $\mathrm{RCI}$ & Reactor Core Isolation Cooling System \\
\hline RCS & Reactor Coolant System \\
\hline RGW & Radioactive Gaseous Waste System \\
\hline RHR & Residual Heat Removal System \\
\hline RLW & Radioactive Liquid Waste System \\
\hline RMT & Recirculation Mode Transfer System \\
\hline RPS & Reactor Protection System \\
\hline SDC & Shutdown Cooling Mode of RHR \\
\hline SGT & Standby Gas Treatment System \\
\hline SIS & Safety Injection Actuation System \\
\hline SLC & Standby Liquid Control System \\
\hline SPC & $\begin{array}{l}\text { Suppression Pool Cooling System (or suppression pool cooling mode } \\
\text { of the RHR system) }\end{array}$ \\
\hline SPM & Suppression Pool Makeup System \\
\hline SWS & Service Water System \\
\hline $\mathrm{TBC}$ & Turbine Building Cooling Water System \\
\hline
\end{tabular}


Event and Component Type Identifiers

Air Cooling Heat Exchanger

$A C X$

Sensor/Transmitter Units:

Flow

Level

Physical Position

Pressure

Radiation

Temperature

Flux

ASF

ASL

ASO

ASP

ASR

AST

ASX

Circuit Breaker

CRB

Calculational Unit

CAL

Electrical Code

CBL

Signal Conditioner

CND

Control Rods:

Hydraulically-Driven

CRH

Motor-Driven

CRM

Ducting

DCT

Motor-Driven Compressor

MDC

Motor-Driven Fan

FAN

Fuse

FUS

Diesel Generator

DGN

Hydrogen Recombiner Unit

HRU

Heat Exchanger

HTX

Inverter

INV

Electrical Isolation Device

ISO

Air Cleaning Unit

ACU

Load/Relay Unit

LOD

Logic Unit

LOG

Local Power Supply

LPS

Motor-Generator Unit

MGN

Motor-Operated Damper

MOD

Pumps:

Engine-Driven

EDP

Motor-Driven

MDP

Turbine-Driven

TDP

lanual Control Switch

XSW 
Table IV.5.20-2

Event and Component Type Identifiers (Concluded)

\begin{tabular}{lc}
\hline \multicolumn{1}{c}{ COMPONENT } & IDENTIFIER \\
\hline Rectifier & REC \\
Transfer Switch & TSW \\
Transformer & TFM \\
Tank & TNK \\
Bistable Trip Unit & TXX \\
Air Heating Unit & AHU \\
Electrical Bus--VDC & BDC \\
Electrical Bus--VAC & BAC \\
Manual Damper & XDM \\
Pneumatic/Hydraulic Damper & PND \\
Battery & BAT \\
Valves: & \\
Check Valve & CKV \\
Hydraulic Valve & HDV \\
Safety/Relief Valve & SRV \\
Solenoid-Operated Valve & SOV \\
Motor-Operated Valve & MOV \\
Manual Valve & XVM \\
Air-Operated Valve & AOV \\
Testable Check Valve & TCV \\
Explosive Valve & EPV \\
Filter & FLT \\
Instrumentation and Control Circuit & ICC \\
Strainer & STR \\
Heater Element & HTR \\
Pipe Segment Fault & PSF \\
Pipe Train Fault & PTF \\
Actuation Segment Fault & ACS \\
Actuation Train Fault & ACT \\
AC Electrical Train Fault & TAC \\
DC Electrical Train Fault & TDC \\
Human Error & XHE \\
Common Cause Fault & CCF \\
Miscellaneous Aggregation of Faults & VFC \\
\hline & \\
\hline & \\
\hline
\end{tabular}


Table IV.5.20-3

Failure Mode Codes

(see Note a)

FAILURE MODE

CODE

Valves, Contacts, Dampers

Fail To Transfer

FT

Normally Open, Fail Open 00

Normally Open, Fail Closed (Position) OC

Normally Closed, Fail Closed

$\mathrm{CC}$

Normally Closed, Fail Open

$\mathrm{CO}$

Valves, Filters, Orifices, Nozzles

Plugged

$P G$

Pumps, Motors, Diesels, Turbines, Fans, Compressors

Fail to Start

FS

Fail to Continue Running

FR

Sensors, Signal Conditioners, Bistable

Fail High

Fail Low

$\mathrm{HI}$

No Output

LO

NO

Segments, Trains and Miscellaneous Agglomerations

Loss of Flow, No Flow

Loss of Function

$\mathrm{LF}$

Actuation Fails

No Power, Loss of Power

Failure (for miscellaneous fault agglomerations

Hardware not based on segments or trains) VF

$\mathrm{HW}$

Battery, Bus Transformer

No Power, Loss of Power

Short

Open

LP

ST

$\mathrm{OP}$

Tank, Pipes, Seals, Tubes

Leak

LK

Rupture

$\mathrm{RP}$

Human Errors

Fail to Operate FO

Miscalibrate

Fail to Restore from Test or Maintenance

$M C$

$\mathrm{RE}$

Normal Operations (unavailable due to planned activity) Maintenance

Test

Test and Maintenance

MA

TE

TM

OTE:

(a) Events or components are only suggestions. The failure modes listed may be used for any applicable event or component type. 
The system failure models and analyses explicitly accounted for the various system dependencies such as the need for power, room cooling, etc. These dependencies can be a source of possible system interaction as well as representing a common cause failure potential for the accident mitigating systems. In addition, specific tasks were performed as part of this study to address particularly subtle interactions as well as common cause failures among components based on available failure data. The following subsections address each of these tasks performed as part of a more comprehensive dependent failure analysis.

\section{IV.6.1 Subtle Interactions}

Past Probabilistic Risk Assessments (PRAs) and actual events are available information sources for identifying particularly subtle failures which an analyst might normally overlook. As part of this effort, other knowledgeable experts in analyzing power plant safety were asked to identify subtle system interactions which they were aware of and which could cause mitigating system failures [21,22]. To the extent possible, recognizing resource and priority constraints, these interactions were to be reviewed for applicability to the Peach Bottom analysis. Any found to apply were appropriately accounted for in the analysis. The remainder of this section summarizes the Boiling Water Reactor (BWR)-related subtle interactions identified and their corresponding resolutions by the Peach Bottom analysts.

\section{Air binding of cooling water systems}

The two most critical service water systems (Emergency Service Water, ESW, and High Pressure Service Water, HPSW) do not interface with air systems. Does not seem to be significant at Peach Bottom. (See Item \#1 of Reference 21.)

Steam-1ine break isolation circuitry

Failure modeling of High Pressure Coolant Injection (HPCI) and Reactor Core Isolation Cooling (RCIC) have accounted for this potential problem. (See Item \#2 of Reference 21.)

Passive common-cause failures

These were considered. One source as a possible initiator (pipe break in normal service water line near ESW interface) is discussed in Section IV. 3 but deemed insignificant. (See Item \#3 of Reference 21.)

Isolation of nonessential cooling water loads

Diversion paths considered for all systems, including cooling water systems. (See Item \#4 of Reference 21.)

Cross-tied pumps' discharge check valve failures

Resources did not permit detailed review of testing procedures. Five years of plant data on major important systems reviewed for failure data did not mention problems of this type. Not believed to be of significance at Peach Bottom. (See Item \#5 of Reference 21.) 
Failures following station blackout

Seal loss of coolant accidents (LOCA) not so significant for BWRs because of HPCI and RCIC capabilities. Battery depletion considered--used 6 hour time based on Philadelphia Electric Company conservative estimate. (See Item \#6 of Reference 21.)

Dependent events

Methodology calls for a modified use of EPRI NP-3967. Beta factor approach was used for all type components given in that report. Refer to Section IV.6.2 for more information. (See Item \#7 of Reference 21.)

Main feedwater availability

With recent change to Leve1 1 trip for Main Steam Isolation Valves (MSIVs), little experience exists. Many initiators will cause MSIV closure and hence loss of feedwater (turbine pumps). A conservative analysis was performed for Peach Bottom in which feedwater and condensate were assumed lost for most initiators. See Section IV.4 for further details regarding feedwater availability for initiators analyzed. (See Item \#8 of Reference 21.)

Turbine-driven pump failure by overfill

HPCI and RCIC were modeled for this potential failure mode. Feedwater was already conservatively assumed lost for most sequences. (See Item \#12 of Reference 21.)

DG load sequence problem

Peach Bottom uses individual time delay relays for most safety loads. The problem described here does not appear to be important for Peach Bottom. (See Item \#1 of Reference 22.)

Sneak circuits

Problem requires that some isolation-related control circuitry for HPCI/RCIC be AC powered. All such circuitry at Peach Bottom is DC powered and no problem. (See Item \#2 of Reference 22.)

Bus switching problems

Resources did not permit detailed review of bus switching at Peach Bottom. Methodology called for "simple" modeling of onsite bus arrangement. Since there are not similar bus-to-bus cross feeds at Peach Bottom and a diesel exists on all four division safety $4160 \mathrm{~V}$ buses, problem does not appear important for Peach Bottom. (See Item \#3 of Reference 22.)

Normal operating configuration

There is little ambiguity in the normal operating configuration for most systems at Peach Bottom. In any case, most systems that were modeled are strictly standby systems. (See Item \#4 of Reference 22.)

Room cooling

Peach Bottom predominantly uses slave relay type circuits. There are typically numerous ways to detect loss of room cooling: steam detection circuitry, cooling trouble alarms, separate fire detection circuitry, etc. Failure of all indications seems small. Isolation caused by high 
temperatures in rooms was considered for systems where appropriate (e.g., HPCI, RCIC). Staff will recover room cooling failure (such as opening doors to critical areas normally locked) to save the core. (See Item \#5, \#6, \#7 of Reference 22.)

\section{Voltage droop}

Did not rigorously pursue. Effects of voltage droop and/or surges are subject to much uncertainty and speculation. In addition, nearly all of the systems analyzed in this study are normally in standby mode; therefore, their fuses should remain intact. Balance-of-plant loads are normally powered by the unit generator and are not immediately affected by a grid voltage droop. There are also redundant means of separating the plant from the grid when the voltage and frequency are out of tolerance. Experience at Peach Bottom (no total losses of offsite power) makes this less important as well. Therefore, this interaction was not considered further. (See Item \#8 of Reference 22.)

Terminal blocks in containment

Virtually all electrical portions of safety equipment are outside containment in BWRs. Even if this were not the case, or if they could be affected by steam in the reactor building in some sequences, the sensitivity of successful venting leading directly to core damage (refer to Section IV.11.5) bounds the effects of this concern. That sensitivity analysis estimates that the overall core damage frequency would only increase by about a factor of two. Does not appear significant. (See Item \#9 of Reference 22.)

\section{Alternate core cooling systems}

Some systems, particularly Control Rod Drive (CRD) and HPSW, are considered in the Peach Bottom analysis. (See Item \#11 of Reference 22.)

Level instrument error caused by high containment temperatures

Level instruments could read high upon flashing of the reference legs when containment temperatures are high and the primary system is being depressurized. Peach Bottom operators are very aware of this potential problem. The Emergency Procedure Guidelines (EPGs) call for maintaining primary pressure $>80$ psi above containment pressure so as to avoid this problem. As a further back-up, EPGs call for reflooding of reference legs if anomalies develop (there are ways to do this). Discussions with 0ak Ridge personnel further substantiate that this is not a serious problem and will, at worst, only cause momentary anomalies if the vessel is rapidly depressurized. Everything considered, this does not seem to be significant at Peach Bottom. (Verbal quality assurance meeting.)

\section{IV.6.2 Common Cause Analysis}

The inclusion of common cause failures was based on a review of plant specific failures and generic failure information. A review of Peach Bottom maintenance logs, "hi-spot" reports, and LERs was conducted to search for significant common cause events in the past five years of experience. No significant common caus failures were identified. 
After initial sequence quantification, cut sets were examined for multiple failures of similar intra-system components. Some cut sets containing this type of combination of basic events were either truncated or much lower in value than the dominant cut sets. Therefore, system schematics were also reviewed in an effort to identify potential common cause failures. A list of potential common cause failures was identified. These failures were assumed not to affect more than one system. In the case of the Residual Heat Removal (RHR) valves, the general methodology provided guidance that the form of the data did not support failures affecting more than one system function.

Too few Peach Bottom failure data were available to quantify plant-specific Beta factors. Therefore, EPRI report NP-3967 "Classification and Analys is of Reactor Operating Experience Dependent Events" was used [23]. This report was used to quantify all Beta values with the exception of common mode battery failure. The generic Beta values in the EPRI report were assumed to be 95-percent bounding values. This was a general assumption made for all the PRA updates on the basis that the failures in the EPRI report did not appear to be always applicable to the plant specific analyses. Therefore, mean Beta values were calculated assuming an error factor of 3 .

A battery failure Beta value was determined utilizing the DC power study (NUREG-0666 [24]). Since Peach Bottom's DC power system is better than the minimum system analyzed in the $D C$ power study, the report recommended that a Beta factor reduction of 10 be used.

With a list of potential common cause failures available, sequences were identified where single common cause events, combinations of common cause failures, or combinations of common cause failures and system failures would be applicable. These quantified combinations were added in cut set form to the sequences. Therefore, a common cause inclusive failure probability for each sequence was determined. 
This section contains a summary of the human reliability analyses performed for the Peach Bottom study. Details of the methodology are described in the general methodology document [2] and particularly References 25 and 26 . In summary, three major types of human error were included: (1) pre-accident errors such as instrument miscalibration or component misalignment after test, (2) post-accident errors such as failing to start a system which contributes to the accident, and (3) failure to recover from the accident before significant core damage occurs.

The Peach Bottom analyses made use of the nominal HRA procedures provided in References 25 and 26. Many recovery action failures were estimated using actual plant experience as covered by existing Accident Sequence Evaluation Program (ASEP) generic work. Examples are recovering offsite power, recovering diesel failures, etc. These are explicitly noted in Section IV.7.2. Also, the Anticipated Transient Without Scram (ATWS) analysis used a detailed HRA performed by Brookhaven National Laboratory specialists. The ATWS HRA is discussed in Section IV.10 along with the rest of the ATWS analyses.

\section{IV.7.1 Human Actions Analyzed}

The above discussion included an overview of the type of human errors analyzed in this study. The specific actions are identified in either the system failure models or in the recovery actions discussed below.

The system write-ups in Section IV.5 summarize the human actions analyzed for each system and depicted in the system failure models. In general, these include such actions as misalignment after test, failure to backup auto start failure, system realignment failures, and manual start failure.

In addition, other recovery actions were applied to the accident sequence expressions recognizing that the operators could successfully mitigate the on-going accident, if proper actions were taken in time, to prevent core damage or containment failure. Table IV.7-1 lists the recovery actions applied in the Peach Bottom study. Also shown are the time periods used to assess the failure of operator recovery actions. It was found that many of the recovery actions and the time periods used in the ASEP generic studies were sufficient for this study. Further breakdown or more detail in the time period definitions seemed unjustified since the HRA methodology being used is a "short-cut" approach which is meant to provide reasonable but approximate values for human error. Therefore, a detailed time period breakdown did not seem compatible with the HRA methodology in the opinion of the Peach Bottom analysts.

\section{IV.7.2 Results of HRA}

\section{IV.7.2.1 Pre-Accident Errors}

Because of certain aspects of many of the system designs and the nature of system testing, few important pre-accident errors were identified. For example, most valve positions for the emergency core cooling systems are continuously indicated in the control room, which tends to lower the possibility of leaving such valves in incorrect positions after tests or maintenance. High Pressure coolant Injection (HPCI) and Reactor Core Isolation Cooling (RCIC), for example, provide signals to all critical valves upon system actuation so that valves in a "wrong" 
Table IV.7-1

Recovery Actions Considered in the Peach Bottom Study

DESIGNATOR
(NOMENCLATURE)
(see Notes $a$ and $b)$
RA - 1x
Failure to recover offsite power by time $x$
RA - $2 x$
Failure to recover the Power Conversion System (PCS) by time $x$
$R A-9 x$
Failure to realign (start) the High Pressure Service Water (HPSW) system from control room by time $x$.
RA - 14x Failure to recover from a DC hardware failure (typically battery-related) by time $x$
RA - 15x Failure to recover from a DC common mode failure (i.e., get one $D C$ bus back) by time $x$
RA - 16x Failure to recover from a diesel generator (DG) hardware failure by time $x$
RA - 17x Failure to recover from a DG common mode failure (i.e., get one diesel back) by time $x$
RA - 18x Failure to recover from a DG test/maintenance unavailability by time $x$
RA - 19x Failure to recover from a DG actuation failure by manually starting from the control room by time $x$
RA - 20x Failure to recover offsite power and then PCS by time $x$
RA - 32x Failure to recover room cooling loss by time $x$
RA - 35x Failure to realign systems (except HPSW) from control room by time $x$
RA - 36x Failure to realign systems locally by time $x$

(a) Nomenclature is exactly the same as used in generic ASEP work. Since not all generic recoveries apply to Peach Bottom (e.g., some are PWR related), omissions exist in the numbering scheme used here.

(b) $x$ equals:

Designator

D

G

H

J

K

\section{Time Period}

30 - 40 minutes

70 - 120 minutes

2 - 4 hours

6 - 8 hours

IV -183

-24 hours 
position are realigned automatically. Other systems, like the Emergency Service Water (ESW) system, require no unusual alignments for most tests; the system ca simply be started and its performance monitored. These insights, coupled with the fact that a brief review of example test procedures showed that most failure probabilities would be -0.003 or less (according to Reference 25), resulted in identification of only two important pre-accident failures:

(1) Miscalibration of reactor pressure sensors shared by the Low Pressure Core Spray (LPCS) and Low Pressure Cooling Injection (LPCI) systems, and

(2) Failure to restore the correct standby alignment of the Standby Liquid Control (SLC) system after test.

For the miscalibration case, it was judged that Case VI of Table 7 in Reference 25 probably applied although information from operator interviews during the initial plant visit indicated that Case IX could be interpreted as applicable. With at least three of the four sensors having to be miscalibrated, and with elements of either zero dependence or high dependence applicable depending on interpretation, use of Tables 8 and 9 in Reference 25 resulted in human error values ranging from approximately $1 \mathrm{E}-3$ to less than $1 \mathrm{E}-5$. It was judged that a reasonable estimate of $1 \mathrm{E}-4$ should, therefore, be used as representative of this range.* This value has no arithmetic relation to the range of values above. While this is a point estimate value, it was interpreted as a mean for purposes of calculation based on the guidance supplied by the quality assurance team and the general methodology. While such a value is quite low, it is important because this error could cause failure of LPCS, LPCI, and the HPSW system (which injects through the LPCI Tine) since low reactor pressure permissives to open the injection valves in thes. systems would potentially be unavailable. It, therefore, represents a key common mode failure.

For the SLC case, it was noted that failure to restore certain valves after tests of the SLC system could cause the system to recirculate the borate solution rather than inject into the vessel upon a real demand. With no indication of the test valves' positions in the control room (although it should be noted that the valves are painted as reminders to lock them closed after test), such an error seemed potentially high, with again a common cause effect, since both SLC pumps would recirculate. Based on a limited review, it appeared that Case I or Case III of Table 7 in Reference 25 would apply depending on interpretation. With two valves having to be left open and judging that either high or complete dependence applied, use of Tables 8 and 9 in Reference 25 yields error probabilities to properly restore the valves as 0.02 to 0.001 . An estimate of 0.01 was used in the analysis similarly interpreted as a mean value for sequence calculations. Again, this value was chosen as representative of the range but has no arithmetic relation to the values above.

\section{IV.7.2.2 Post-Accident Errors and Non-Recovery Estimates}

The majority of the recovery error probabilities did not use the general HRA methodology but instead were based on actual events and were therefore provided in

*Effect of using 1E-3 would be less than a factor of ten increase in the AV and SIV plant damage states which are presently in the E-8 range (se Section V). 
earlier ASEP generic work. RA-1, -2, -14,-15,-16,-17,-18,-19, and -20 are of this type. These values were interpreted as means for purposes of the analysis. This is based on guidance provided by the quality control group (QCG). Values for RA-9, $-32,-35$, and -36 were derived using the guidance provided by the general methodology and particularly Tables 7 and 9 of Reference 26. In interpreting the use of these two tables, a conservative position was taken. First of all, it was assumed that following the initiator, subsequent system failures acted as additional "initiators" to the operating staff causing further opportunities to misdiagnose the plant response and hence fail in the correct actions to be taken. Such an interpretation caused the predominate use of the third and sometimes second column of Table 7 in Reference 26 rather than the first column. Such an interpretation results in conservative estimates for the human error probabilities associated with misdiagnosis. Secondly, after discussions with the Sandia HRA specialist, it was agreed that while a step-by-step interpretation for operators following the Emergency Procedure Guidelines (EPGs) was more correct when using Table 9 in Reference 26, elements of a "dynamic" situation when responding to an accident did exist. To be conservative, the Peach Bottom analysts assumed a dynamic situation for post-accident tasks when using Table 9. This resulted in conservative values for human error associated with carrying out recovery actions once properly diagnosed. Summing both the diagnostic and post-diagnostic error probabilities yielded the final estimates used in the Peach Bottom study. Further, as the allowable time period for recovery actions significantly lengthened ( -24 hours), the lowest value presented in Table 9 of Reference 26 $(0.001)$ was used.

The value for $\mathrm{RA}-32 \mathrm{H}$ is unique in that it was estimated with assistance from the quality control HRA specialist in a different way. It is expected that any innunciation of room cooling failure in most of the accidents of interest would be one of many annunciators competing for attention. Table 11 of Reference 26 suggests that operator error associated with responding to the room cooling alarm under such conditions is in the range of 0.1 to 0.25 or greater. Further, Table 7 of Reference 26 shows that as the allowable time for recovery is lengthened, a several orders-of-magnitude drop in the error to respond can be expected. Assuming that 4 hours was a typical response time associated with room heatup in order to prevent equipment failure (probably conservative based on PECO information supplied later in the study) suggested that the 0.1 to 0.25 value should be reduced by several orders of magnitude. The Peach Bottom analysts further considered the actual activity associated with restoring room cooling (opening doors, providing portable fans, etc.) to be a step-by-step task with recovery under, at most, moderate high stress using Table 9 in Reference 26 (this yields a value of $4 \mathrm{E}-3$ using $0.02 \times 0.2$ from that table). Comparing these two approaches resulted in the mean estimate of $4 \mathrm{E}-3$ for the $\mathrm{RA}-32 \mathrm{H}$ value.

In addition to the above recovery actions, four other values are important to the Peach Bottom results. The first of these involves operator failure to start the Emergency Cooling Water (ECW) pump in the emergency heat sink path of the Emergency Service Water (ESW) system given a delayed failure of the primary cooling path. With the judgment that some of the emergency loads (LPCS, LPCI pump cooling) and the diesel generators (for loss of offsite power sequences) would be damaged in five minutes or less without cooling, it was estimated that the above operator failure to respond in time was -1.0 based on guidance in Reference 26 . The other errors involve the failure to vent under conditions of a station lackout, ATWS, and relatively long-term scenarios (e.g., TW-type sequences). A 0.9 value was assessed for both the station blackout and ATWS-type sequences. 
This was because of the potentially high radiation and high temperature environments associated with the station blackout sequences (10cal operator actions at the vent valves are required) and because of the timing required to jumper-out containment isolation signals and open a sufficient number of valves under ATWS-type scenarios. On the other hand, a 0.001 failure probability was assessed for long-term sequences (-ten hours or more) since under most of these sequences, sufficient sources of power, time and equipment redundancy exist to diagnose and carry out the venting process. After most of the work on this study was completed, the results of an independent assessment of the failure-to-vent probabilities during station blackout and ATWS became available [27]. In that work, the corresponding probabilities were estimated as 1.0 and 0.3 . While these values differ somewhat from the 0.9 value used for both cases in this study, the uncertainty bounds in this study encompass the other estimates. (The upper bound for the station blackout failure-to-vent case is 1.0 and the lower bound for the ATWS failure-to-vent case is 0.1 ). Since the differences in the values do not result in significant changes to the core damage frequency estimates and since the uncertainty bounds in this study encompass the other estimates, no changes to the analysis were implemented.

The important* human error probabilities resulting from the above analyses are summarized in Tables IV.7-2, IV.7-3, IV.7-4, and IV.7-5. It should be noted that some human errors explicitly modeled as part of the system failures (e.g., ESF-XHE-FO-CRDRL meaning failure to locally realign and operate the Control Rod Drive (CRD) system using both pumps) actually are "recovery" actions and so take on the corresponding value used in the recovery table (e.g., values for RA-36x are used for the CRDRL term cited above depending on the time period).

\section{IV.7.3 Assumptions Associated With the HRA}

The assumptions having the largest impact on the HRA are those associated with the interpretations used by the Peach Bottom analysts when utilizing the tables in References 25 and 26 . These interpretations have been described above and should result in a conservative HRA analysis having been performed for the Peach Bottom study.

\section{IV.7.4 HRA Nomenclature}

Two forms of HRA nomenclature were used in the Peach Bottom study. Events explicitly modeled as human errors in the system failure models use "XHE" (for human error) in the event identifier term as part of the system failure nomenclature (see Section IV.5.20). For example, ESF-XHE-FO-CRDRL indicates a failure of the plant staff to operate the CRD system in a realigned mode using both pumps. For failure to perform other recovery actions, RA terms were added to the sequence failure expressions. These used the RA nomenclature already presented in Table IV.7-1. For example, RA-IJ is the failure to restore offsite power within 6-8 hours.

* Important" means appearing in dominant sequences or being critical determining which sequences are dominant. 
Table IV.7-2

Summary of Important Pre-Accident Human Error Probabilities

\begin{tabular}{|c|c|c|c|}
\hline NOMENCLATURE & DESCRIPTION & $\begin{array}{l}\text { MEAN VALUE } \\
\text { (see Note a) }\end{array}$ & $\begin{array}{l}\text { UPPER/LOWER } \\
\text { BOUNDS } \\
\text { (see Note a) }\end{array}$ \\
\hline ESF-XHE-MC-RXPRS & $\begin{array}{l}\text { Miscalibration of reactor } \\
\text { pressure instrumentation } \\
\text { (permissives for LPCS, LPCI } \\
\text { valves) }\end{array}$ & $1 E-4$ & $1 E-3 / 1 E-6$ \\
\hline SLC-XHE-REL & $\begin{array}{l}\text { Failure to realign SLC system } \\
\text { back to "ready" state after } \\
\text { test }\end{array}$ & $1 E-2$ & $1 E-1 / 1 E-3$ \\
\hline
\end{tabular}

NOTE :

(a) A maximum entropy distribution was used to define the uncertainty distributions with the bounds as indicated. (See Section IV.8.3 for further discussion.) 
Table IV.7-3

Summary of Important Post-Accident Human Error Probabilities (Non-Recovery Values)

\begin{tabular}{|c|c|c|c|c|c|c|c|c|c|c|c|c|c|c|}
\hline \multirow{2}{*}{ TIMEFRAME } & \multirow[b]{2}{*}{ DESIGMATOR } & \multirow{2}{*}{$\begin{array}{c}\text { OFFSITE } \\
\text { POUER } \\
\\
\text { RA-1 } \\
\text { (b) }\end{array}$} & \multirow{2}{*}{$\begin{array}{r}\text { PCS } \\
\begin{array}{r}\text { RA-2 } \\
\text { (b) }\end{array}\end{array}$} & \multirow{2}{*}{$\begin{array}{c}\text { RE-ALIGM } \\
\text { HPUS } \\
\text { (CR) } \\
\\
\begin{array}{r}\text { RA-9 } \\
\text { (a) }\end{array}\end{array}$} & \multirow{2}{*}{$\begin{array}{c}\text { DC WN } \\
\begin{array}{c}\text { RA-14 } \\
\text { (b) }\end{array}\end{array}$} & \multirow{2}{*}{$\begin{array}{l}\text { DC CM } \\
\text { RA-15 } \\
\text { (b) }\end{array}$} & \multirow{2}{*}{$\begin{array}{c}\text { DG WN } \\
\text { RA-16 } \\
\text { (b) }\end{array}$} & DG CH & DG MAD & DG ACT & $\begin{array}{c}\text { OFFSITE } \\
\text { POUER } \\
\text { PCS }\end{array}$ & $\begin{array}{c}\text { ROOH } \\
\text { COOLIMG }\end{array}$ & \multirow{2}{*}{$\begin{array}{c}\text { RE-ALIGK } \\
\text { SYSTEMS } \\
\text { EXCEPT } \\
\text { HPSUS (CR) } \\
\text { RA-35 }\end{array}$} & $\begin{array}{l}\text { RE-ALIGM } \\
\text { SYSTEMS } \\
\text { (Local) }\end{array}$ \\
\hline & & & & & & & & $\begin{array}{c}\text { RA-17 } \\
\text { (b) }\end{array}$ & $\begin{array}{l}\text { RA-18 } \\
\text { (b) }\end{array}$ & $\begin{array}{l}\text { RA-19 } \\
\text { (b) }\end{array}$ & $\begin{array}{c}\text { RA-20 } \\
\text { (b) }\end{array}$ & $\begin{array}{l}R A-32 \\
(c)\end{array}$ & & $R A-36$ \\
\hline $30-40$ min & 0 & 0.4 & 0.9 & 0.1 & 0.8 & 1.0 & 1.0 & 1.0 & 1.0 & 0.04 & 1.0 & - & 0.04 & 0.1 \\
\hline $70-120=i n$ & $G$ & 0.3 & 0.06 & 0.03 & 0.5 & 0.9 & 0.9 & 0.9 & 0.8 & 0.03 & 0.3 & - & 0.03 & (d) \\
\hline 2-4 hrs & H & 0.2 & 0.01 & 0.03 & 0.2 & 0.8 & 0.8 & 0.7 & 0.7 & 0.03 & 0.2 & 0.004 & 0.03 & (d) \\
\hline 6-8 hrs & $\mathrm{J}$ & 0.04 & 0.01 & 0.03 & 0.03 & 0.6 & 0.6 & 0.5 & 0.5 & 0.03 & 0.04 & - & 0.03 & (d) \\
\hline$-24 \mathrm{hrs}$ & K & 0.003 & 0.007 & 0.001 & 0.02 & 0.4 & 0.4 & 0.1 & 0.1 & 0.001 & 0.003 & - & 0.001 & 0.001 \\
\hline
\end{tabular}

NOTES:

(a) Similar to RA-35 except accounted for additional reluctance in first 30 minutes to use this system since (1) it will put river water into the core and (2) operator's attention will be on other systems first.

(b) Based on actual experience (did not use HRA methodology).

(c) Assumed 4 hours response time for all rooms.

(d) Were not needed in analysis so not estimated. 
Table IV.7-4

Uncertainty Bounds for Dominant Non-Recovery Values

(see Note a)

\section{DESIGNATOR}

DESCRIPTION

MEAN VALUE

UPPER/LOWER

BOUNDS

$\begin{array}{rlll}\text { RA-1D } & \begin{array}{l}\text { Failure to recover offsite } \\ \text { power by } 30-40 \text { minutes }\end{array} & 0.4 & 1.0 / 0.1 \\ \text { RA-1J } & \begin{array}{l}\text { Failure to recover offsite } \\ \text { power by } 6-8 \text { hours }\end{array} & 0.04 & 0.2 / 0.004 \\ \text { RA-2D } & \begin{array}{l}\text { Failure to recover the PCS } \\ \text { by } 30-40 \text { minutes }\end{array} & 0.9 & 1.0 / 0.1 \\ \text { RA-14D } & \begin{array}{l}\text { Failure to recover from a DC } \\ \text { hardware fault by } 30-40 \text { minutes }\end{array} & 0.8 & 1.0 / 0.1 \\ \text { RA-16J } & \begin{array}{l}\text { Failure to recovery from a DG } \\ \text { hardware fault by } 6-8 \text { hours }\end{array} & 0.6 & 1.0 / 0.1 \\ \text { RA-17J } & \begin{array}{l}\text { Failure to recover from a DG } \\ \text { common cause fault by } 6-8 \text { hours }\end{array} & 0.5 & 1.0 / 0.1 \\ \text { RA-18J } & \begin{array}{l}\text { Failure to recover from a DG } \\ \text { maintenance outage by } 6-8 \text { hours }\end{array} & 0.5 & 1.0 / 0.1\end{array}$

NOTE :

(a) Uncertainty analyses were performed on only the dominant cut sets of the dominant sequences. These were the only non-recovery values which appeared in the above cut sets with values other than "1.0" and which required an estimate of the uncertainty bound. A maximum entropy distribution was used in all cases, with the bounds as indicated. (See Section IV.8.3 for further discussion.) 
Table IV. 7-5

Important Recovery Actions Explicitly Modeled in System Failure Models

\begin{tabular}{|c|c|c|c|}
\hline NOMENCLATURE & DESCRIPTION & $\begin{array}{l}\text { MEAN VALUE } \\
\text { (see Note a) }\end{array}$ & $\begin{array}{l}\text { UPPER/LOWER } \\
\text { BOUNDS } \\
\text { (see Note a) }\end{array}$ \\
\hline ECW-XHE-FO-ECWPP & $\begin{array}{l}\text { Operator failure to start } \\
\text { ECW pump in EHS path of } \\
\text { ESWS in less than } 5 \text { minutes }\end{array}$ & 1.0 & - \\
\hline ESF-XHE-FO-CRDRL & $\begin{array}{l}\text { Operator failure to operate } \\
\text { CRD system with } 2 \text { pumps }\end{array}$ & $\begin{array}{l}\text { used RA-36 } \\
\text { (see Note b) }\end{array}$ & -- \\
\hline ESF-XHE-FO-HSWIN & $\begin{array}{l}\text { Operator failure to realign } \\
\text { and operate HPSW in } \\
\text { inject mode to reactor }\end{array}$ & $\begin{array}{c}\text { used RA-9 } \\
\text { (see Note b) }\end{array}$ & -- \\
\hline SRV-XHE-FO-VLV & $\begin{array}{l}\text { Operator failure to operate } \\
\text { SRVs manually for } \\
\text { depressurization }\end{array}$ & $\begin{array}{c}1 \mathrm{E}-2 \\
\text { (see Note } c)\end{array}$ & $1 E-1 / 1 E-4$ \\
\hline VENT-XHE-TC & $\begin{array}{l}\text { Failure to vent in ATWS } \\
\text { sequences }\end{array}$ & 0.9 & $1.0 / 0.1$ \\
\hline VENT-XHE-LT & $\begin{array}{l}\text { Failure to vent in long-term } \\
\text { sequences }\end{array}$ & 0.001 & Not used \\
\hline VENT-XHE-TB & $\begin{array}{l}\text { Failure to vent in station } \\
\text { blackout sequences }\end{array}$ & $\begin{array}{c}0.9 \\
\text { (see Note } d)\end{array}$ & $1.0 / 0.5$ \\
\hline
\end{tabular}

NOTES:

(a) A maximum entropy distribution was used to define the uncertainty distributions with the bounds as indicated. (See Section IV.8.3 for further discussion.) "Not used" indicates that this event did not appear in a dominant sequence and, hence, the uncertainty analysis did not require an input for this event (uncertainty analyses were performed on only the dominant sequences).

(b) For cases when core cooling has been supplied by other systems for a period of time before they subsequently fail, 0.001 was used for these events, even though the response time is -3 hours, on the bas is of water level being a "critical parameter" as covered in Table 9 of Reference 26.

(c) This event is important when high pressure cooling systems and auto ADS have failed. Used "critical parameter" argument covered by Table 9 of Reference 26 (operator's response is virtually automatic) but increased value to 0.01 (upper bound value) to account for very high stress and short time period (minutes) for successful response.

(d) Actualiy affects consequences of accident (covered by containment analysis personnel) and not core damage probability. 
This section contains the data used in the system fault trees or Boolean failure expressions used to quantify the system failure probabilities. Table IV.8-1 presents the majority of the data used in the analysis. Sections IV.7 and IV.10 have additional data on recovery actions and Anticipated Transient Without Scram (ATWS) related events. The information in the table are presented in alphabetical order by major system heading. Data for the initiating events are presented at the end. Within each system category, the basic events are also listed alphabetically. In addition, Section IV.9.2.4 briefly discusses other data estimates used by the "back-end" containment analysts, particularly when considering core cooling system failure probabilities following containment failure.

\section{IV.8.1 Sources of Information for Data Base}

An extensive review of plant specific data was conducted. Major system pump and valve histories as well as "hi-spot" reports were reviewed. It was found in almost all cases that plant specific data fell within the bounds of current Accident Sequence Evaluation Program (ASEP) generic data. This was determined with help from the QCG data specialist who used statistical tests to demonstrate the viability of using the generic data. In a few cases, plant specific data were used as noted in the data table. Other sources of data included WASH-1400, other Probabilistic Risk Assessments (PRAs), and miscellaneous reports as indicated in the data table. Recovery data and other human error probabilities were derived from the HRA analyses and generic ASEP recovery data as already indicated in Section IV.7. Common mode Beta values came from the modified use of EPRI NP-3967 [23] as described in Section IV.6.2.

\section{IV.8.2 Assumptions and Limitations in the Data Base}

When plant specific data fell within the bounds of ASEP generic data, generic data were used. Plant specific failure values that were based on zero or one failure were not used. This is because it was felt that, in these instances, there were two few corresponding trials represented in only the Peach Bottom experience base. The generic data represent a much larger experience base leading to a more certain estimate in the failure probabilities for most components. Therefore, generic data were once again used. Also, with one exception, no plant specific maintenance unavailabilities were derived because of resource constraints. Generic ASEP data were used instead.

\section{IV.8.3 Uncertainty Distributions}

For nearly all the data used in the study, a log-normal distribution was assumed for the uncertainty distribution on the data estimates. This is a common assumption used in many of the PRAs conducted to date. Two general exceptions, however, were made to this standard practice. First, with the state-of-the-art in HRA being less than the current knowledge base available in component data analyses, it was felt (by the team leader and the "back-end" Peach Bottom analysts) that the uncertainty distribution for human error values had even less justification for being considered log-normal than the rest of the data. Some confidence did exist, however, in the mean estimates and the corresponding upper nd lower bounds. For this reason, a maximum entropy distribution was used which basically sets the distribution based on the inputs such that the uncertainty is maximized. This type of distribution was used for virtually all human-related 
data in the study other than for the second exception, the ATWS human-related error estimates. Since the ATWS analyses conducted by the Brookhaven National Laboratory specialists provided log-normal shaped distribution estimates for the human error uncertainties, these were used "as is" for most cases in the study. In a few cases, the mean/median values and error factors were such that probabilities of greater than 1.0 were possible out at the 97 th percentile or beyond if forced to fit the data to a log-normal distribution. In these cases, a log-uniform distribution was used which best fit the original distributions provided, but which limited the upper bound to 1.0 by virtue of the properties of a log-uniform distribution. This was done with the help of a statistical specialist at Sandia National Laboratories.

It should be noted that early in the program, some test cases of the preliminary study results were run using different distributions for the human error data. These test cases showed that in some sequences (particularly ATWS) the mean and uncertainty estimates for the sequence frequency were affected by non-trivial amounts. However, the differences were judged not to be large enough to be of concern and, relative to the entire core damage frequency, inconsequential differences were noted. In all cases, the overall conclusions of the study would not have changed. 


\begin{tabular}{|c|c|c|c|c|c|c|c|c|c|}
\hline BASIC EVENT & $\begin{array}{l}\text { COHPONENT FAILURE } \\
\text { MODE DESCRIPIION }\end{array}$ & $\begin{array}{l}\text { FAILURE } \\
\text { RATE (PER } \\
\text { DEMAND OR } \\
\text { HOUR) }\end{array}$ & $\begin{array}{l}\text { BIE } \\
\text { EF }\end{array}$ & $\begin{array}{l}\text { MISSION } \\
\text { TIME } \\
- \text { (HRS) }\end{array}$ & __. UNA & AILA & LIIY & DESCRIPTION & $\begin{array}{r}\text { SOURCE/ } \\
\text { COMHENTS }\end{array}$ \\
\hline \multicolumn{10}{|c|}{ ACIUAIION_AHD_CONTROL: } \\
\hline$E S F-A C S-F C-M D P A$ & $\begin{array}{l}\text { LPCI Pump A permis- } \\
\text { sive fails to over- } \\
\text { ride Unit } 3 \text { stop } \\
\text { signal }\end{array}$ & $20 E-3 / d$ & 3 & - & $2 O E-3$ & 3 & $250 E-3$ & single component event & WASH- 1400 \\
\hline ESF-ACS-FC-MDPB & $\begin{array}{l}\text { LPCI Pump B permis- } \\
\text { sive falls to over- } \\
\text { ride Unit } 3 \text { stop } \\
\text { signal }\end{array}$ & - & - & - & - & - & $250 E-3$ & same as ESF-ACS-FC-MDPA & -- \\
\hline ESF-ADS-FC-LI13A & $\begin{array}{l}\text { limit switch falls } \\
\text { to indicate Motor- } \\
\text { Operated Valve } 13 \mathrm{~A} \\
\text { fully open }\end{array}$ & $30 E-4 / d$ & 3 & - & $30 E-4$ & 3 & $375 E-4$ & -- & WASH -1400 \\
\hline$E S F-A D S-F C-L I 13 B$ & $\begin{array}{l}\text { limit switch falls } \\
\text { to indicate Motor- } \\
\text { Operated Valve } 13 \mathrm{~B} \\
\text { fully open }\end{array}$ & - & - & - & - & - & - & same as ESF-ASD-FC-LI13A & -- \\
\hline$E S F-A D S-F C-L I 13 C$ & $\begin{array}{l}\text { limit switch falls } \\
\text { to indicate Motor- } \\
\text { Operated Valve } 13 \mathrm{C} \\
\text { fully open }\end{array}$ & - & - & - & - & - & - & same aś ESF-ASD-FC-LI13A & -- \\
\hline$E S F-A D S-F C-L I 13 D$ & $\begin{array}{l}\text { limit switch falls } \\
\text { to indicate Motor- } \\
\text { Operated Valve 13D } \\
\text { fully open }\end{array}$ & - & - & - & - & - & - & same as ESF-ASD-FC-LI13A & -- \\
\hline
\end{tabular}


Table IV.8-1

Peach Bottom Event Data (Continued)

\begin{tabular}{|c|c|c|c|c|c|c|c|c|c|c|}
\hline \multirow[b]{2}{*}{ BASIC EVENT } & \multirow{2}{*}{$\begin{array}{l}\text { COHPONENT FAILURE } \\
\text { MODE DESCRIPTION }\end{array}$} & \multicolumn{2}{|c|}{ FAILURE_RAIE_ } & \multirow{2}{*}{$\begin{array}{l}\text { MISSION } \\
\text { TIME } \\
-(\text { HRS })\end{array}$} & \multicolumn{3}{|c|}{ WHAYAILABILIIY } & \multirow{2}{*}{\multicolumn{2}{|c|}{ DESCRIPTIOH }} & \multirow{2}{*}{$\begin{array}{r}\text { SOURCE/ } \\
\text { COMNENTS }\end{array}$} \\
\hline & & HOUR) & $\mathbf{E F}$ & & \multicolumn{3}{|l|}{ MEDIAN } & & & \\
\hline ESF-ASD-FC-SC15A & $\begin{array}{l}\text { limit switch fails } \\
\text { to indicate Motor- } \\
\text { Operated Valve } 15 \mathrm{~A} \\
\text { fully open }\end{array}$ & - & - & - & - & - & $3.75 E-4$ & same as & ESF-ASD-FC-LI13A & -- \\
\hline ESF-ASD-FC-SC15B & $\begin{array}{l}\text { limit switch fails } \\
\text { to indicate Motor- } \\
\text { Operated Valve 15B } \\
\text { fully open }\end{array}$ & - & - & - & - & - & $3.75 E-4$ & same as & ESF-ASD-FC-LI13A & -- \\
\hline ESF-ASD-FC-SC15C & $\begin{array}{l}\text { limit switch fails } \\
\text { to indicate Motor- } \\
\text { Operated Valve } 15 \mathrm{C} \\
\text { fully open }\end{array}$ & - & - & - & - & - & $3.75 E-4$ & same as & ESF-ASD-FC-LI13A & -- \\
\hline ESF-ASD-FC-SC15D & $\begin{array}{l}\text { limit switch fails } \\
\text { to indicate Motor- } \\
\text { Operated Valve } 150 \\
\text { fully open }\end{array}$ & - & - & - & - & - & $3.75 E-4$ & same as & ESF-ASD-FC-LI13A & -- \\
\hline ESF-ASD-FC-SDC17 & $\begin{array}{l}\text { limit switch fails } \\
\text { to indicate Motor- } \\
\text { Operated Valve } 17 \\
\text { fully open }\end{array}$ & - & - & - & - & - & $3.75 E-4$ & same as & ESF-ASD-FC-LI13A & -- \\
\hline ESF-ASD-FC-SDC 18 & $\begin{array}{l}\text { limit switch fails } \\
\text { to indicate Motor- } \\
\text { Operated Valve } 18 \\
\text { fully open }\end{array}$ & - & - & - & - & - & $3.75 E-4$ & same as & ESF-ASD-FC-LI13A & -- \\
\hline$E S F-A S L-F C-L H 72 A$ & $\begin{array}{l}\text { RCIC high reactor } \\
\text { water level Sensor } \\
\text { A fails }\end{array}$ & $2.0 E-3 / d$ & 3 & - & $2.0 E-3$ & 3 & $2.50 E-3$ & single & component event & $\begin{array}{l}\text { WASH-1400, } \\
\text { plant data }\end{array}$ \\
\hline
\end{tabular}




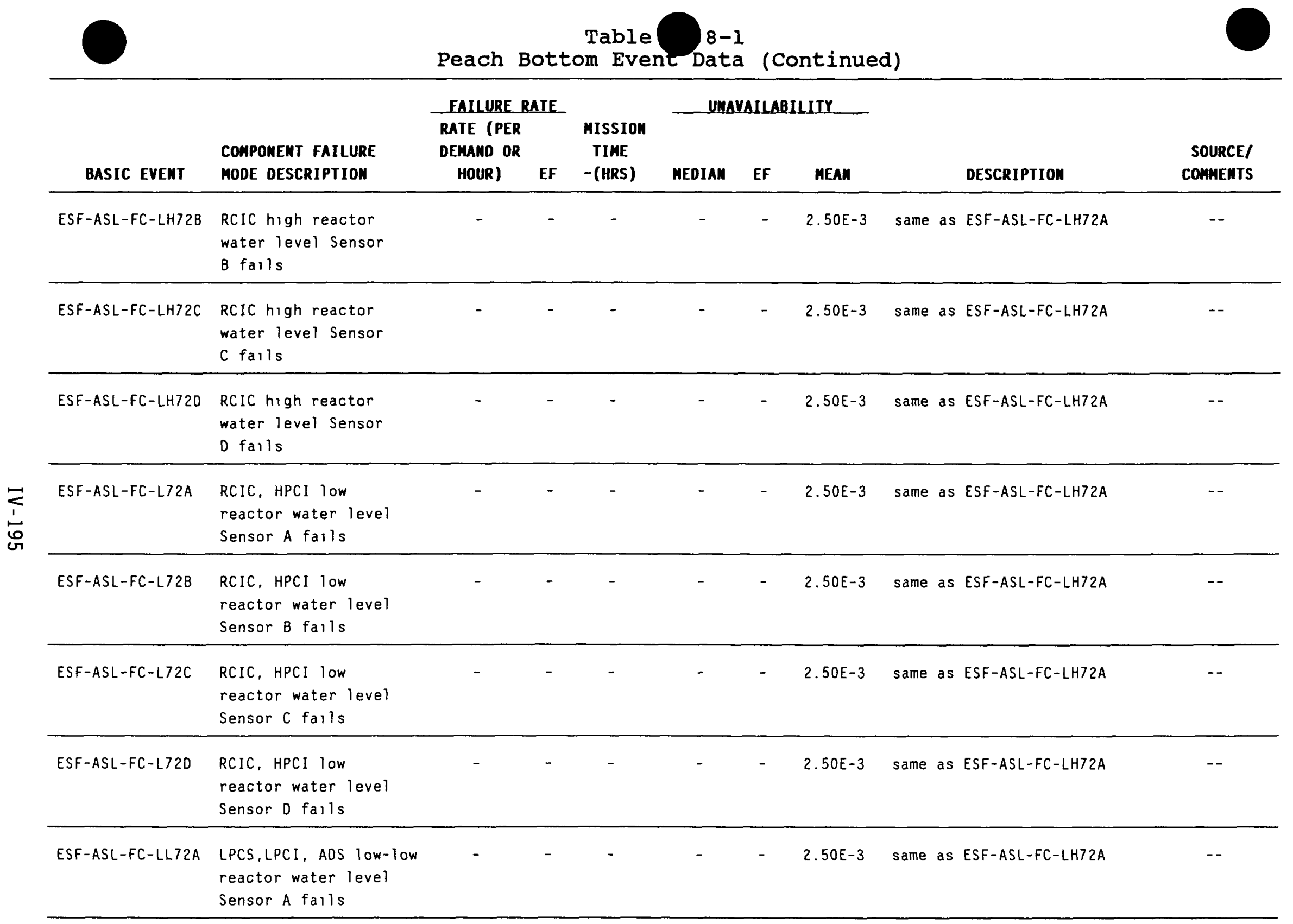


Table IV.8-1

Peach Bottom Event Data (Continued)

\begin{tabular}{|c|c|c|c|c|c|c|c|c|c|}
\hline \multirow[b]{2}{*}{ BASIC EVENT } & \multirow[b]{2}{*}{$\begin{array}{l}\text { COHPONENT FAILURE } \\
\text { MODE DESCRIPIION }\end{array}$} & \multicolumn{2}{|c|}{ FAILURE_RAIE } & \multirow{2}{*}{$\begin{array}{l}\text { MISSION } \\
\text { TIME } \\
\text {-(HRS) }\end{array}$} & \multicolumn{3}{|c|}{ UHAVAILABILIIY } & \multirow[b]{2}{*}{ DESCRIPTION } & \multirow[b]{2}{*}{$\begin{array}{r}\text { SOURCE/ } \\
\text { CONHENTS }\end{array}$} \\
\hline & & $\begin{array}{l}\text { DEHAND OR } \\
\text { HOUR) }\end{array}$ & EF & & MEOIAN & EF & MEAN & & \\
\hline$E S F-A S L-F C-L L 72 B$ & $\begin{array}{l}\text { LPCS,LPCI, ADS low-low } \\
\text { reactor water level } \\
\text { Sensor B fails }\end{array}$ & - & - & - & - & - & $2.50 E-3$ & same as ESF-ASL-FC-LH72A & -- \\
\hline ESF-ASL-FC-LL72C & $\begin{array}{l}\text { LPCS, LPCI, ADS low-low } \\
\text { reactor water level } \\
\text { Sensor C fails }\end{array}$ & - & - & - & - & - & $2.50 E-3$ & same as ESF-ASL-FC-LH72A & -- \\
\hline ESF-ASL-FC-LL72D & $\begin{array}{l}\text { LPCS, LPCI, ADS low-low } \\
\text { reactor water level } \\
\text { Sensor D fails }\end{array}$ & - & - & - & - & - & $2.50 \mathrm{E}-3$ & same as ESF-ASL-FC-LH72A & -- \\
\hline ESF-ASL-HW-CSTLI & $\begin{array}{l}\text { CST level Sensor } 1 \\
\text { fails }\end{array}$ & $2.0 E-3 / d$ & 3 & - & $2.0 E-3$ & 3 & $2.50 E-3$ & single component event & $\begin{array}{l}\text { WASH-1400, } \\
\text { plant data }\end{array}$ \\
\hline ESF-ASL-HW-CSTL2 & $\begin{array}{l}\text { CST level Sensor } 2 \\
\text { fails }\end{array}$ & - & - & - & - & - & $2.50 E-3$ & same as ESF-ASL-HW-CSTL1 & -- \\
\hline ESF-ASL-NO-RXSDA & $\begin{array}{l}\text { shroud water level } \\
\text { permissive fails }\end{array}$ & $2.0 E-3 / d$ & 3 & - & $2.0 E-3$ & 3 & $2.50 E-3$ & single component event & $\begin{array}{l}\text { WASH-1400, } \\
\text { plant data }\end{array}$ \\
\hline ESF-ASL-NO-RXSDB & $\begin{array}{l}\text { shroud water level } \\
\text { permissive fajls }\end{array}$ & - & - & - & - & - & $2.50 E-3$ & same as ESF-ASL-NO-RXSDA & -- \\
\hline ESF-ASP-FC-LSPHC & $\begin{array}{l}\text { HPCI pump suction } \\
\text { pressure sensor } \\
\text { fails }\end{array}$ & $2.0 \mathrm{E}-3 / \mathrm{d}$ & 3 & - & $2.0 E-3$ & 3 & $2.50 E-3$ & single component event & $\begin{array}{l}\text { WASH-1400, } \\
\text { plant data }\end{array}$ \\
\hline ESF-ASP-FC-LSPRC & $\begin{array}{l}\text { RCIC pump suction } \\
\text { pressure sensor fails }\end{array}$ & - & - & - & - & - & $2.50 E-3$ & same as ESF-ASP-FC-LSPHC & -- \\
\hline$E S F-A S P-F C-P L 52 A$ & $\begin{array}{l}\text { LPCS, LPCI low } \\
\text { reactor pressure } \\
\text { Sensor A fails }\end{array}$ & - & - & - & - & - & $2.50 E-3$ & same as ESF-ASL-FC-LH72A & -- \\
\hline
\end{tabular}




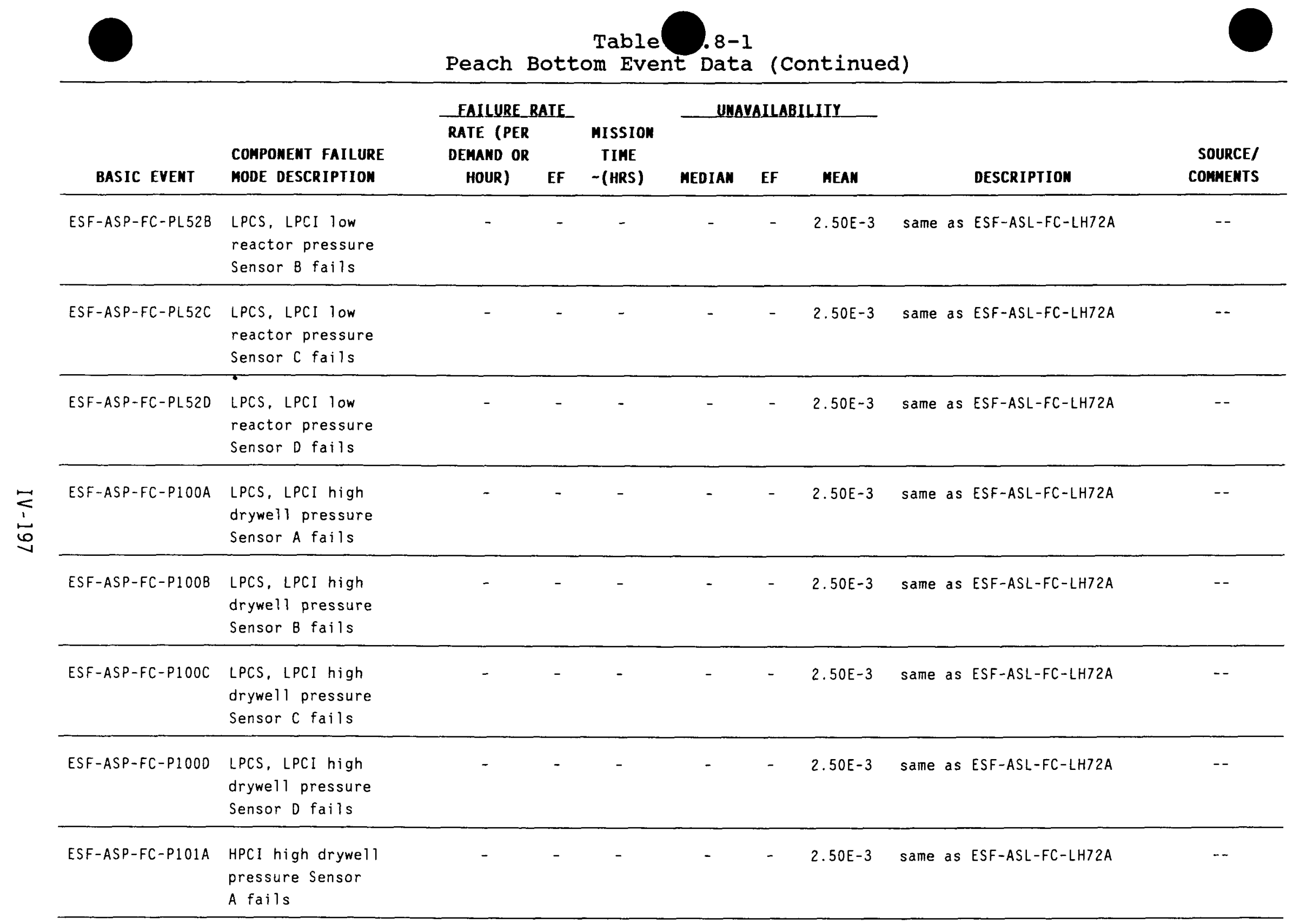


Table IV.8-1

Peach Bottom Event Data (Continued)

\begin{tabular}{|c|c|c|c|c|c|c|c|c|c|}
\hline \multirow[b]{2}{*}{ BASIC EVENT } & \multirow{2}{*}{$\begin{array}{l}\text { COMPONENT FAILURE } \\
\text { MODE DESCRIPTION }\end{array}$} & \multicolumn{2}{|c|}{ FAILURE_BAIE_ } & \multirow{2}{*}{$\begin{array}{l}\text { MISSION } \\
\text { TIME } \\
\text {-(HRS) }\end{array}$} & \multicolumn{3}{|c|}{ UNAVAILABILIIY } & \multirow[b]{2}{*}{ DESCRIPTION } & \multirow{2}{*}{$\begin{array}{l}\text { SOURCE/ } \\
\text { COMNENTS }\end{array}$} \\
\hline & & HOUR) & $\mathbf{E F}$ & & MEDIAN & EF & MEAN & & \\
\hline ESF-ASP-FC-P101B & $\begin{array}{l}\text { HPCI high drywell } \\
\text { pressure Sensor } \\
\text { B fails }\end{array}$ & - & - & - & - & - & $2.50 \mathrm{E}-3$ & same as ESF-ASL-FC-LH72A & -- \\
\hline ESF-ASP-FC-P101C & $\begin{array}{l}\text { HPCI high drywell } \\
\text { pressure Sensor } \\
\text { C fails }\end{array}$ & - & - & - & - & - & $2.50 E-3$ & same as ESF-ASL-FC-LH72A & -- \\
\hline ESF-ASP-FC-P1010 & $\begin{array}{l}\text { HPCI high drywell } \\
\text { pressure Sensor } \\
\text { D fails }\end{array}$ & - & - & - & - & - & $2.50 E-3$ & same as ESF-ASL-FC-LH72A & -- \\
\hline ESF-ASP-HW-EX72A & $\begin{array}{l}\text { RCIC high exhaust } \\
\text { pressure Sensor A } \\
\text { fails }\end{array}$ & $2.0 E-3 / d$ & 3 & - & $2.0 E-3$ & 3 & $2.50 E-3$ & single component event & $\begin{array}{l}\text { WASH-1400, } \\
\text { plant data }\end{array}$ \\
\hline ESF-ASP-HW-EX72B & $\begin{array}{l}\text { RCIC high exhaust } \\
\text { pressure Sensor B } \\
\text { fails }\end{array}$ & - & - & - & - & & $2.50 E-3$ & same as ESF-ASP-HW-EX72A & -- \\
\hline ESF-LOG-HW-RHRA & $\begin{array}{l}\text { RHR control Logic } \\
\text { A circuitry fails }\end{array}$ & $2.0 E-3 / d$ & 3 & - & $2.0 E-3$ & 3 & $2.50 E-3$ & single component event & $\begin{array}{l}\text { WASH-1400, } \\
\text { plant data }\end{array}$ \\
\hline ESF-LOG-HW-RHRB & $\begin{array}{l}\text { RHR control Logic } \\
\text { B circuitry fails }\end{array}$ & - & - & - & - & - & $2.50 \mathrm{E}-3$ & same as ESF-LOG-HW-RHRA & -- \\
\hline ESF-PWR-FC-4160A & $\begin{array}{l}\text { Bus } 4160 \mathrm{~A} \text { power } \\
\text { permissive sensor } \\
\text { fails }\end{array}$ & $2.0 E-3 / d$ & 3 & - & $2.0 E-3$ & 3 & $2.50 E-3$ & single component event & $\begin{array}{l}\text { WASH- } 1400 \text {, } \\
\text { plant data }\end{array}$ \\
\hline ESF-PWR-FC-4160B & $\begin{array}{l}\text { Bus } 4160 \mathrm{~B} \text { power } \\
\text { permissive sensor } \\
\text { fails }\end{array}$ & - & - & - & - & - & $2.50 E-3$ & same as ESF-PWR-FC-4160A & -- \\
\hline
\end{tabular}




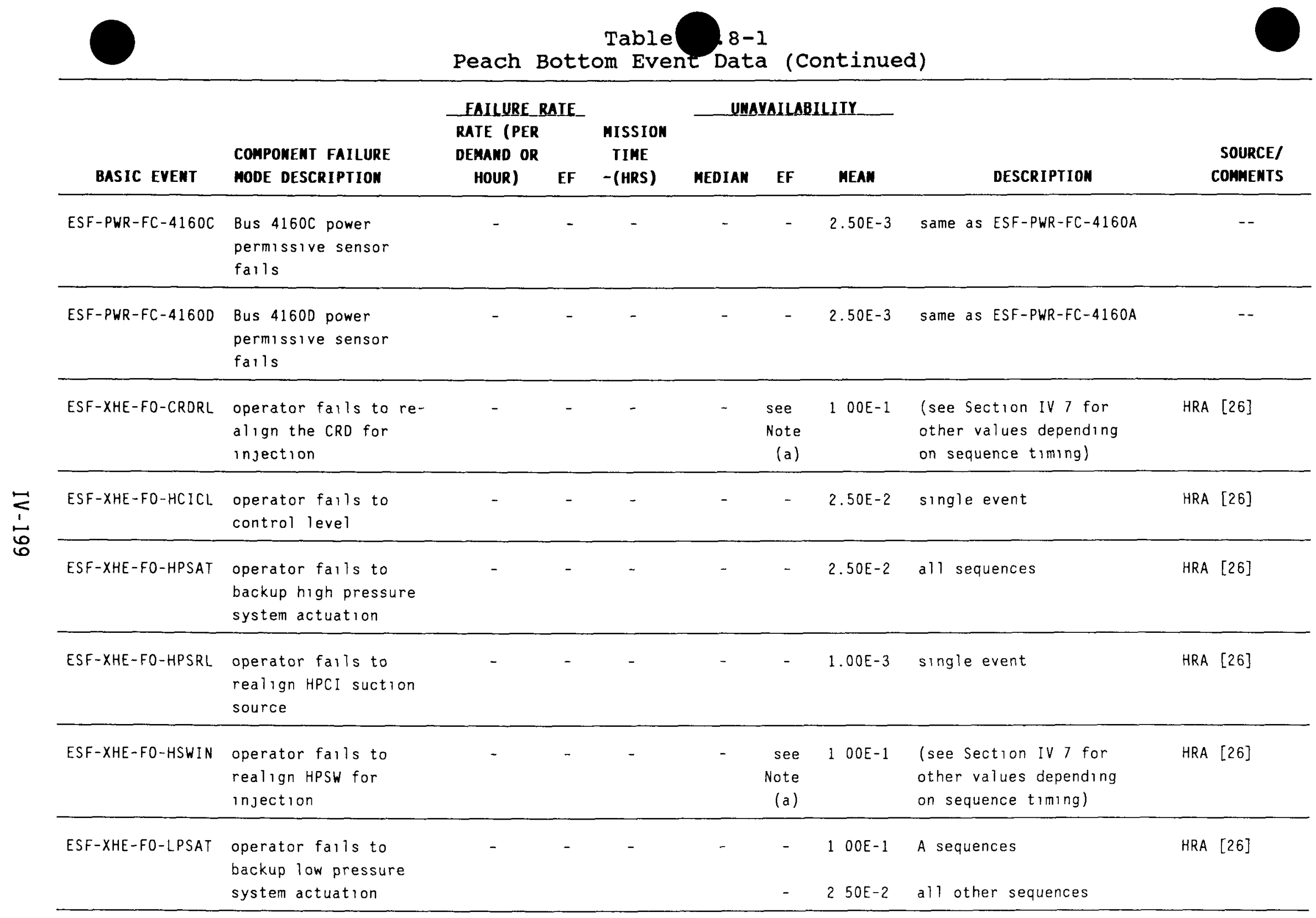

Note

(a) Used maximum entropy distribution with absolute bounds $10,1 E-3$ 
Table IV.8-I

Peach Bottom Event Data (Continued)

\begin{tabular}{|c|c|c|c|c|c|c|c|c|c|}
\hline BASIC EVEMT & $\begin{array}{l}\text { CONPONENT FAILURE } \\
\text { MODE DESCRIPIION }\end{array}$ & $\begin{array}{l}\text { FAILURE_B } \\
\text { RATE (PER } \\
\text { DEMAND OR } \\
\text { HOUR) }\end{array}$ & $\begin{array}{l}\text { AIE } \\
\text { EF }\end{array}$ & $\begin{array}{l}\text { MISSION } \\
\text { TIME } \\
\text {-(HRS) }\end{array}$ & UMA & AILA & LIIY & DESCRIPTION & $\begin{array}{r}\text { SOURCE/ } \\
\text { CONMENTS }\end{array}$ \\
\hline ESF-XHE-FO-OVRID & $\begin{array}{l}\text { operator falls to } \\
\text { override shroud } \\
\text { level permissive }\end{array}$ & - & - & - & - & - & $100 E-1$ & single event & HRA [26] \\
\hline ESF-XHE-FO-RCICL & $\begin{array}{l}\text { operator falls to } \\
\text { control level }\end{array}$ & - & - & - & - & - & $2.50 E-2$ & same as ESF-XHE-FO-HCICL & -- \\
\hline ESF-XHE-FO-RCICO & $\begin{array}{l}\text { operator fails to } \\
\text { isolate RCIC }\end{array}$ & - & - & - & - & - & $1.00 \mathrm{E}-1$ & single event & HRA [26] \\
\hline$E S F-X H E-F O-R C I R L$ & $\begin{array}{l}\text { operator fails to } \\
\text { realign RCIC } \\
\text { suction source }\end{array}$ & - & - & - & - & - & $1.00 \mathrm{E}-1$ & single event & HRA [26] \\
\hline ESF-XHE-FO-RHATA & $\begin{array}{l}\text { operator fails to } \\
\text { align RHR cooling } \\
\text { mode }\end{array}$ & - & - & - & - & 10 & $1.00 E-5$ & $W$ sequences, $\gg>2$ hours & HRA [26] \\
\hline ESF-XHE-FO-RHRAT & $\begin{array}{l}\text { operator falls to } \\
\text { align RHR cooling } \\
\text { mode }\end{array}$ & - & - & - & - & $\begin{array}{l}- \\
- \\
-\end{array}$ & $\begin{array}{ll}1 & 0 O E-1 \\
6 & 25 E-2 \\
2 & 50 E-2 \\
1 & 00 E-3\end{array}$ & $\begin{array}{l}\text { AE sequence, } 30 \text { minutes } \\
S, E \text { sequence, } 1 \text { hour } \\
S_{2} \text { E sequence, } 2 \text { hours } \\
\text { transient } w / \text { early melt, } \\
>2 \text { hours }\end{array}$ & HRA [26] \\
\hline ESF-XHE-MC-CSTLV & $\begin{array}{l}\text { common cause mis- } \\
\text { calibration of CST } \\
\text { low level sensors }\end{array}$ & - & - & - & - & 10 & $100 E-3$ & single event & HRA [25] \\
\hline ESF-XHE-MC-HDPRS & $\begin{array}{l}\text { common cause miscal- } \\
\text { lbration of high } \\
\text { drywell pressure } \\
\text { sensors }\end{array}$ & - & - & - & - & 10 & $100 E-4$ & same as ESF-XHE-MC-RXPRS & -- \\
\hline
\end{tabular}




\begin{tabular}{|c|c|c|c|c|c|c|c|c|c|}
\hline & & FAILURE_R & AIE & & UnA & MAILAE & LIIY & & \\
\hline BASIC EVENT & $\begin{array}{l}\text { CONPONENT FAILURE } \\
\text { MODE DESCRIPTION }\end{array}$ & $\begin{array}{l}\text { DEMAND OR } \\
\text { HOUR) }\end{array}$ & EF & $\begin{array}{c}\text { TIME } \\
- \text {-(HRS) }\end{array}$ & MEDIAN & EF & MEAN & DESCRIPIION & $\begin{array}{l}\text { SOURCE/ } \\
\text { COMMENTS }\end{array}$ \\
\hline ESF-XHE-MC-LEVEL & $\begin{array}{l}\text { common cause miscal- } \\
\text { lbration of reactor } \\
\text { water level sensors }\end{array}$ & - & - & - & - & - & $1.00 E-4$ & same as ESF-XHE-MC-RXPRS & -- \\
\hline ESF-XHE-MC-RXPRS & $\begin{array}{l}\text { common cause miscal- } \\
\text { ibration of reactor } \\
\text { pressure sensors }\end{array}$ & - & - & - & - & $\begin{array}{r}\text { see } \\
\text { Note } \\
\text { (a) }\end{array}$ & $1.00 \mathrm{E}-4$ & $\begin{array}{l}\text { single event } \\
\text { (see Section IV.7) }\end{array}$ & -- \\
\hline \multicolumn{10}{|c|}{ BEIA_FACIORS_VALUES : } \\
\hline DC Battery & common cause factor & - & - & - & - & 3 & $4.00 \mathrm{E}-2$ & -- & NUREG-0666 \\
\hline $\begin{array}{l}\text { Diesel } \\
\text { Generators }\end{array}$ & common cause factor & - & - & - & - & 3 & $208 \mathrm{E}-2$ & -- & $\begin{array}{l}\text { EPRI-NP3967 } \\
(\text { mod } 1 \text { fied })\end{array}$ \\
\hline $\begin{array}{l}\text { High Pressure } \\
\text { or Emergency } \\
\text { Service Water } \\
\text { Pumps }\end{array}$ & common cause factor & - & - & - & - & 3 & 1.25E-2 & -- & $\begin{array}{l}\text { EPRI-NP3967 } \\
(\text { modified) }\end{array}$ \\
\hline $\begin{array}{l}\text { LPCS/RHR Pumps } \\
\text { (any mode) }\end{array}$ & common cause factor & - & - & - & - & 3 & $4.58 \mathrm{E}-2$ & -- & $\begin{array}{l}\text { EPRI-NP3967 } \\
(\text { modifled })\end{array}$ \\
\hline $\begin{array}{l}\text { Motor Operated } \\
\text { Valves }\end{array}$ & common cause factor & - & - & - & - & 3 & $333 E-2$ & -- & $\begin{array}{l}\text { EPRI-NP3967 } \\
\left(\bmod 1 f_{7} \text { ed }\right)\end{array}$ \\
\hline $\begin{array}{l}\text { Safety Relief } \\
\text { Valves }\end{array}$ & common cause factor & - & - & - & - & 3 & $917 \mathrm{E}-2$ & -- & $\begin{array}{l}\text { EPRI-NP3967 } \\
\text { (modıfled) }\end{array}$ \\
\hline
\end{tabular}

Note.

(a) Used maximum entropy distribution with absolute bounds: 1E-3, 1E-6. 
Table IV. 8-I

Peach Bottom Event Data (Continued)

\begin{tabular}{|c|c|c|c|c|c|c|c|c|c|}
\hline BASIC EVENT & $\begin{array}{l}\text { CONPONENT FAILURE } \\
\text { MODE DESCRIPTION }\end{array}$ & $\begin{array}{c}\text { FAILURE_R } \\
\text { RATE (PER } \\
\text { DEMAMD OR } \\
\text { HOUR) }\end{array}$ & AIE & $\begin{array}{c}\text { MISSIOH } \\
\text { TIME } \\
\text {-(HRS) }\end{array}$ & MEDIAK & $\Delta I L A$ & MEAN & DESCRIPTION & $\begin{array}{l}\text { SOURCE/ } \\
\text { COMHENTS }\end{array}$ \\
\hline \multicolumn{10}{|c|}{ CONIROL_ROQ_DRIYE_SYSIES: } \\
\hline CRD-MOP-FR-2AP39 & $\begin{array}{l}\text { Motor-Driven Pump A } \\
\text { fails to run }\end{array}$ & $2.0 \mathrm{E}-5 / \mathrm{hr}$ & 10 & 24 & $4.8 \mathrm{E}-4$ & 10 & 1. $3 E-3$ & single component event & ASEP generic \\
\hline CRD-MDP-FR-2BP39 & $\begin{array}{l}\text { Motor-Diven Pump B } \\
\text { fails to run }\end{array}$ & - & - & - & - & - & 1. $3 E-3$ & same as CRD-MDP-FR-2AP39 & -- \\
\hline CRD-MDP-FS-2BP39 & $\begin{array}{l}\text { Motor-Driven Pump B } \\
\text { fails to start }\end{array}$ & $2.0 E-3 / d$ & 5 & - & $2.0 E-3$ & 5 & $3.23 E-3$ & single component event & ASEP generic \\
\hline CRD-MDP-MA-2AP39 & $\begin{array}{l}\text { Motor-Driven Pump A } \\
\text { out for maintenance }\end{array}$ & $1.0 E-3 / d$ & 10 & - & $1.0 \mathrm{E}-3$ & 10 & $2.66 E-3$ & single component event & ASEP generic \\
\hline CRD-MDP-MA-2BP39 & $\begin{array}{l}\text { Motor-Driven Pump B } \\
\text { out for maintenance }\end{array}$ & - & - & - & - & - & $2.66 E-3$ & same as CRD-MDP-MA-2AP39 & -- \\
\hline
\end{tabular}

\section{CONIAIHMENI SPRAY_SYSIEH_(RHR):}

\begin{tabular}{|c|c|c|c|c|c|c|c|c|c|}
\hline CSS-MOV-MA-MV26A & $\begin{array}{l}\text { Motor-Operated } \\
\text { Valve } 26 \mathrm{~A} \text { out for } \\
\text { maintenance }\end{array}$ & $3.0 E-4 / d$ & 10 & - & $3.0 E-4$ & 10 & $7.99 E-4$ & single component event & ASEP generic \\
\hline CSS-MOV-MA-MV26B & $\begin{array}{l}\text { Motor-Operated Valve } \\
26 \mathrm{~B} \text { out for maintenance }\end{array}$ & - & - & - & - & - & $7.99 E-4$ & same as CSS-MOV-MA-MV26A & -- \\
\hline
\end{tabular}




\begin{tabular}{|c|c|c|c|c|c|c|c|c|c|}
\hline BASIC EVENT & $\begin{array}{l}\text { COMPONEWT FAILURE } \\
\text { MODE DESCRIPIION }\end{array}$ & $\begin{array}{c}\text { FAILURE_B } \\
\text { RATE (PER } \\
\text { DEMAMD OR } \\
\text { HOUR) }\end{array}$ & $\begin{array}{l}\text { AIE } \\
\text { EF }\end{array}$ & $\begin{array}{l}\text { MISSION } \\
\text { IIME } \\
\text {-(HRS) }\end{array}$ & UMA & IAILA & ILIIY & DESCRIPTION & $\begin{array}{l}\text { SOURCE/ } \\
\text { COMMEMTS }\end{array}$ \\
\hline \multirow[t]{3}{*}{ CSS-PSF-HW-LOOPA } & Loop A fails & - & - & - & - & - & $7.5 E-3$ & $\begin{array}{l}\text { tabular OR of following } \\
\text { events }\end{array}$ & -- \\
\hline & $\begin{array}{l}\text { Motor-Operated Valve } \\
26 \mathrm{~A} \text { falls to open }\end{array}$ & $3.0 \mathrm{E}-3 / \mathrm{d}$ & 3 & - & $3.0 \mathrm{E}-3$ & 3 & - & see above & ASEP generic \\
\hline & $\begin{array}{l}\text { Motor-Operated Valve } \\
31 \mathrm{~A} \text { falls to open }\end{array}$ & $3.0 E-3 / d$ & 3 & - & $3.0 E-3$ & 3 & - & see above & ASEP generic \\
\hline \multicolumn{10}{|c|}{ ELECIRIC_POYER_SYSIEH : } \\
\hline$A C P-B A C-L P-416 A$ & $\begin{array}{l}\text { 4160vaC } \\
\text { Bus A fails }\end{array}$ & $1.0 \mathrm{E}-7 / \mathrm{hr}$ & 10 & 40 & $4.0 \mathrm{E}-6$ & 10 & $1.07 E-5$ & single component event & WASH-1400 \\
\hline$A C P-B A C-L P-416 B$ & $\begin{array}{l}\text { 4160VAC } \\
\text { Bus B falls }\end{array}$ & - & - & - & - & - & $1.07 E-5$ & same as $A C P-B A C-L P-416 A$ & -- \\
\hline$A C P-B A C-L P-416 C$ & $\begin{array}{l}\text { 4160VAC } \\
\text { Bus C falls }\end{array}$ & - & - & - & - & - & $1.07 E-5$ & same as $A C P-B A C-L P-416 A$ & -- \\
\hline$A C P-B A C-L P-416 D$ & $\begin{array}{l}4160 V A C \\
\text { Bus } D \text { falls }\end{array}$ & - & - & - & - & - & $1.07 E-5$ & same as $A C P-B A C-L P-416 A$ & -- \\
\hline
\end{tabular}


Table IV.8-1

Peach Bottom Event Data (Continued)

\begin{tabular}{|c|c|c|c|c|c|c|c|c|c|}
\hline \multirow[b]{2}{*}{ BASIC EVENT } & \multirow[b]{2}{*}{$\begin{array}{l}\text { CONPONENT FAILURE } \\
\text { MODE DESCRIPTION }\end{array}$} & \multicolumn{2}{|c|}{ FAILURE_BATE } & \multirow{2}{*}{$\begin{array}{l}\text { MISSION } \\
\text { TIME } \\
\text {-(HRS) }\end{array}$} & \multicolumn{3}{|c|}{ UHAYAILABILIIY } & \multirow[b]{2}{*}{ DESCRIPTION } & \multirow[b]{2}{*}{$\begin{array}{l}\text { SOURCE/ } \\
\text { CONHENTS }\end{array}$} \\
\hline & & $\begin{array}{l}\text { DENAND OR } \\
\text { HOUR) }\end{array}$ & EF & & MEDIAN & EF & MEAN & & \\
\hline \multirow[t]{3}{*}{$A C P-D G N-L P-E D G 1$} & EDG A fails & - & - & - & - & 3 & $1.13 \mathrm{E}-2$ & $\begin{array}{l}\text { tabular } O R \text { of following } \\
\text { events }\end{array}$ & - \\
\hline & EDG A fails to start & $3.0 \mathrm{E}-3 / \mathrm{d}$ & 3 & - & $3.0 E-3$ & 3 & - & see above & plant data \\
\hline & EDG A fails to run & $1.0 \mathrm{E}-3 / \mathrm{hr}$ & 3 & $\begin{array}{c}6 \\
\text { see } \\
\text { Note (a) }\end{array}$ & $6.0 \mathrm{E}-3$ & 3 & - & see above & ASEP generic \\
\hline$A C P-D G N-L P-E D G 2$ & EDG B fails & - & - & - & - & - & $1.13 E-2$ & same as $A C P-D G N-L P-E D G 1$ & -- \\
\hline$A C P-D G N-L P-E D G 3$ & EDG C fails & - & - & - & - & - & $1.13 \mathrm{E}-2$ & same as $A C P-D G N-L P-E D G 1$ & $\cdots$ \\
\hline$A C P-D G N-L P-E D G 4$ & EDG D fails & - & - & - & - & - & $1.13 E-2$ & same as $A C P-D G N-L P-E D G 1$ & -- \\
\hline$A C P-D G N-M A-E D G 1$ & $\begin{array}{l}\text { EDG A out for } \\
\text { maintenance }\end{array}$ & $6.0 E-3 / d$ & 6 & - & $6.0 E-3$ & 6 & 1. OSE-2 & single component event & ASEP generic \\
\hline$A C P-D G N-M A-E D G 2$ & $\begin{array}{l}\text { EDG } B \text { out for } \\
\text { maintenance }\end{array}$ & - & - & - & - & - & $1.09 E-2$ & same as $A C P-D G N-M A-E D G 1$ & -- \\
\hline$A C P-D G N-M A-E D G 3$ & $\begin{array}{l}\text { EDG C out for } \\
\text { maintenance }\end{array}$ & - & - & - & - & - & $1.09 E-2$ & same as $A C P-D G N-M A-E D G 1$ & -- \\
\hline$A C P-D G N-M A-E D G 4$ & $\begin{array}{l}\text { EDG } D \text { out for } \\
\text { maintenance }\end{array}$ & - & - & - & - & - & $1.09 \mathrm{E}-2$ & same as $A C P-D G N-M A-E D G 1$ & -- \\
\hline$A C P-P H N-L P-E S W G$ & $\begin{array}{l}\text { loss of AC caused } \\
\text { by failure of } \\
\text { emergency switch- } \\
\text { gear room due to } \\
\text { loss of ventilation }\end{array}$ & - & - & - & - & - & $1.0 \mathrm{E}-1$ & single component event & $\begin{array}{l}\text { conservative } \\
\text { screening } \\
\text { value }\end{array}$ \\
\hline
\end{tabular}

Note: 


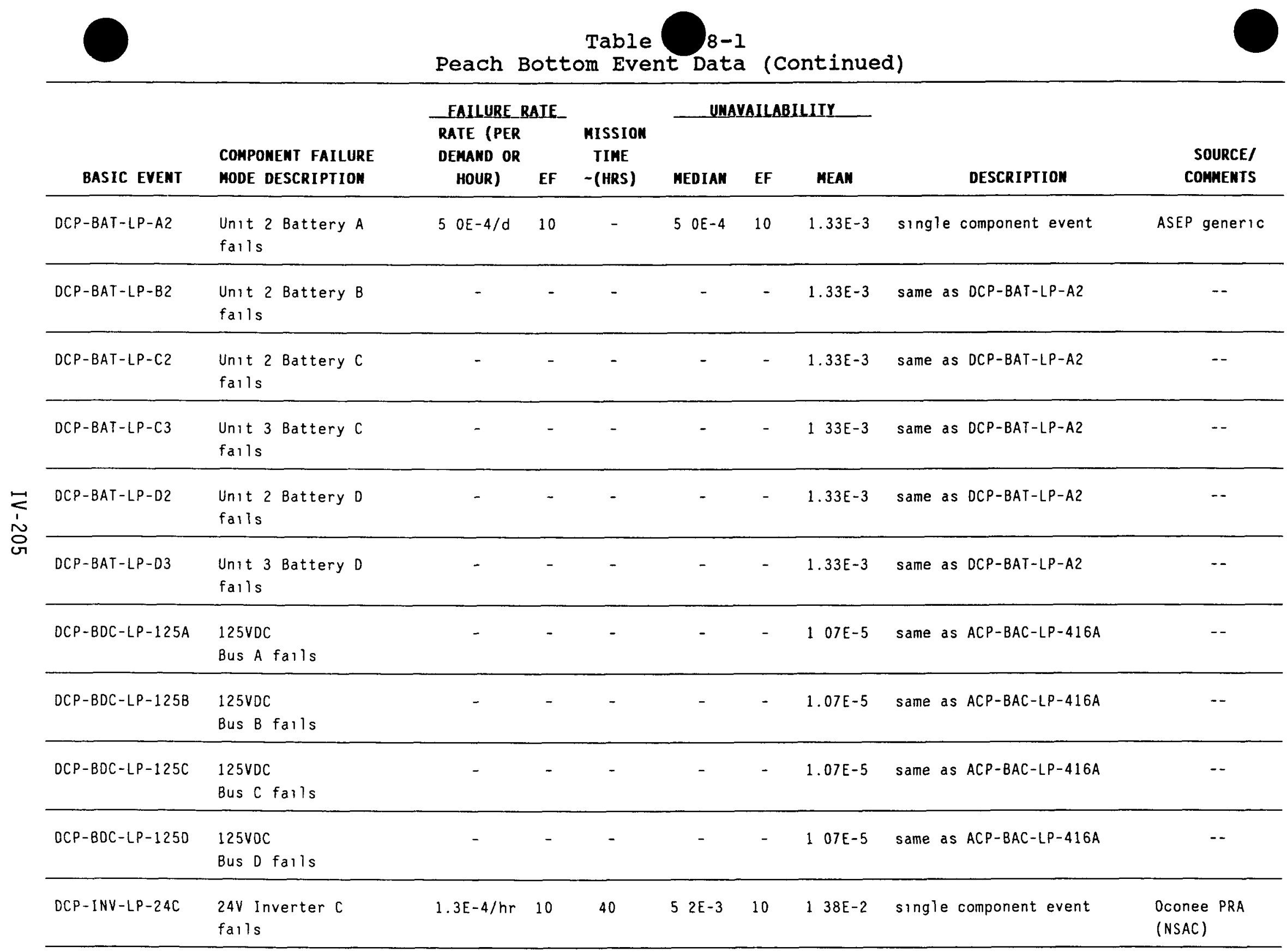


Table IV.8-1

Peach Bottom Event Data (Continued)

\begin{tabular}{|c|c|c|c|c|c|c|c|c|c|}
\hline \multirow[b]{2}{*}{ BASIC EVENT } & \multirow{2}{*}{$\begin{array}{l}\text { COAPONENT FAILURE } \\
\text { MODE DESCRIPTION }\end{array}$} & \multicolumn{3}{|c|}{ FAILURE RAIE_ } & \multicolumn{3}{|c|}{ UMAVAILABILIIY } & \multirow[b]{2}{*}{ DESCRIPTION } & \multirow{2}{*}{$\begin{array}{l}\text { SOURCE/ } \\
\text { COMHENTS }\end{array}$} \\
\hline & & HOUR) & EF & $-($ HRS $)$ & MEDIAN & EF & MEAN & & \\
\hline$D C P-I N V-L P-24 D$ & $\begin{array}{l}24 \mathrm{~V} \text { Inverter } D \\
\text { falls }\end{array}$ & - & - & - & - & - & $1.38 \mathrm{E}-2$ & same as $D C P-I N V-L P-24 C$ & -- \\
\hline$D C P-P H N-L P-B A T$ & $\begin{array}{l}\text { loss of } D C \text { caused } \\
\text { by fallure of battery } \\
\text { room due to loss of } \\
\text { ventilation }\end{array}$ & - & - & - & - & - & 1. $0 \mathrm{E}-1$ & single component event & $\begin{array}{l}\text { conservative } \\
\text { screening } \\
\text { value }\end{array}$ \\
\hline$D C P-R E C-L P-1$ & $\begin{array}{l}\text { Unit } 2 \text { Charger A } \\
\text { falls }\end{array}$ & $3.8 E-6 / h r$ & 3 & $\begin{array}{c}6 \\
\text { see } \\
\text { Note }(a)\end{array}$ & $2.3 E-5$ & 3 & $2.9 E-5$ & single component event & NUREG-0666 \\
\hline$D C P-R E C-L P-2$ & $\begin{array}{l}\text { Unit } 2 \text { Charger B } \\
\text { fails }\end{array}$ & - & - & - & - & - & $5.37 E-4$ & same as $D C P-R E C-L P-1$ & -- \\
\hline$D C P-R E C-L P-3$ & $\begin{array}{l}\text { Unit } 2 \text { Charger } C \\
\text { falls }\end{array}$ & - & - & - & - & - & $5.37 E-4$ & same as $D C P-R E C-L P-1$ & -- \\
\hline$D C P-R E C-L P-4$ & $\begin{array}{l}\text { Unit } 2 \text { Charger D } \\
\text { falls }\end{array}$ & - & - & - & - & - & $5.37 E-4$ & same as DCP-REC-LP-1 & -- \\
\hline DGACTA & $\begin{array}{l}\text { EDG A actuation } \\
\text { falls }\end{array}$ & $1.0 E-3 / d$ & 5 & - & $1.0 E-3$ & 5 & $1.61 E-3$ & single component event & ASEP generic \\
\hline DGACTB & $\begin{array}{l}\text { EDG } B \text { actuation } \\
\text { fails }\end{array}$ & - & - & - & - & - & $1.61 \mathrm{E}-3$ & same as DGACTA & -- \\
\hline DGACTC & $\begin{array}{l}\text { EDG C actuation } \\
\text { falls }\end{array}$ & - & - & - & - & - & $1.61 \mathrm{E}-3$ & same as DGACTA & -- \\
\hline DGACTD & $\begin{array}{l}\text { EDG D actuation } \\
\text { fails }\end{array}$ & - & - & - & - & - & $1.61 \mathrm{E}-3$ & same as DGACTA & -- \\
\hline
\end{tabular}

Note.

Based on 6 hours before the corresponding battery power d 


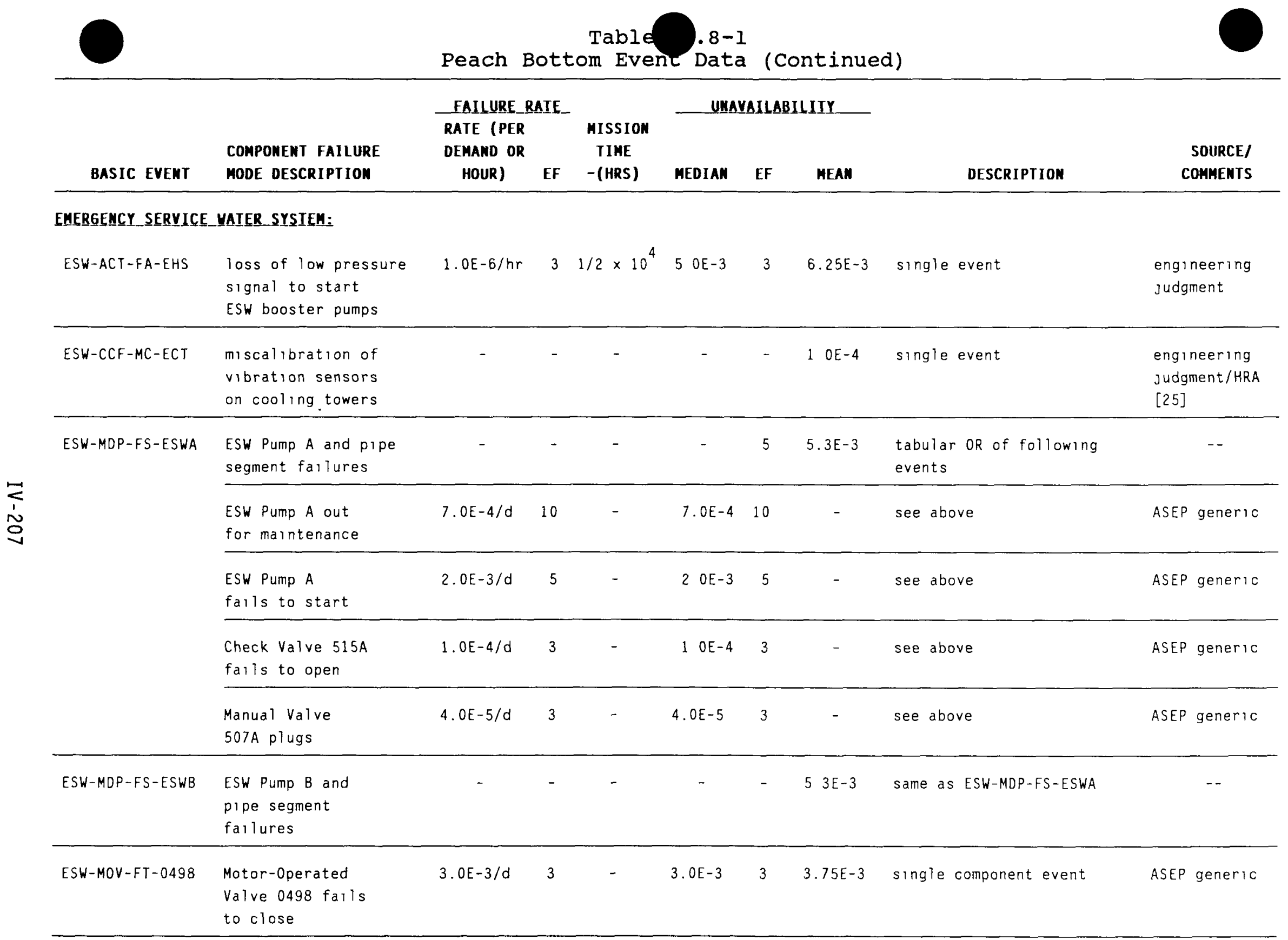


Table IV.8-I

Peach Bottom Event Data (Continued)

\begin{tabular}{|c|c|c|c|c|c|c|c|c|c|}
\hline BASIC EVENT & $\begin{array}{l}\text { COMPONENT FAILURE } \\
\text { MODE DESCRIPTION }\end{array}$ & $\begin{array}{c}\text { FALLURE_R } \\
\text { RATE (PER } \\
\text { DEMAND OR } \\
\text { HOUR) }\end{array}$ & AIE & $\begin{array}{l}\text { MISSION } \\
\text { TIME } \\
\text { - (HRS) }\end{array}$ & MEOIAN & AIL & MEAN & DESCRIPIION & $\begin{array}{l}\text { SOURCE/ } \\
\text { COMNENTS }\end{array}$ \\
\hline ESW-PSF-LF-01 & $\begin{array}{l}\text { ESW Pump A fails } \\
\text { to run }\end{array}$ & $2.0 \mathrm{E}-5 / \mathrm{hr}$ & 10 & 40 & $8.0 E-4$ & 10 & $2.10 E-3$ & single component event & ASEP generic \\
\hline ESW-PSF-LF-02 & $\begin{array}{l}\text { ESW Pump B fails } \\
\text { to run }\end{array}$ & - & - & - & - & - & $2.10 E-3$ & same as ESW-PSF-LF-01 & -- \\
\hline$E S W-P S F-L F-3$ & $\begin{array}{l}\text { Manual Valve } 517 \\
\text { plugs }\end{array}$ & $4.0 E-5 / d$ & 3 & - & $4.0 \mathrm{E}-5$ & 3 & $5.0 E-5$ & single component event & ASEP generic \\
\hline \multirow[t]{3}{*}{$E S W-P S F-L F-4$} & $\begin{array}{l}\text { Pipe Segment } 4 \\
\text { fails }\end{array}$ & - & - & - & - & - & $8.5 E-4$ & $\begin{array}{l}\text { tabular or of following } \\
\text { events }\end{array}$ & -- \\
\hline & $\begin{array}{l}\text { Motor-Operated } \\
\text { Valve } 2972 \text { plugs }\end{array}$ & $4.0 E-5 / d$ & 3 & - & $4.0 \mathrm{E}-5$ & 3 & - & see above & ASEP generic \\
\hline & $\begin{array}{l}\text { Motor-Operated } \\
\text { Valve } 2972 \text { out } \\
\text { for maintenance }\end{array}$ & $3.0 E-4 / d$ & 10 & - & $3.0 E-4$ & 10 & - & see above & ASEP generic \\
\hline \multirow[t]{3}{*}{ ESW-PSF-LF-5 } & $\begin{array}{l}\text { Pipe Segment } 5 \\
\text { fails }\end{array}$ & - & - & - & - & - & $1.75 E-4$ & $\begin{array}{l}\text { tabular } O R \text { of following } \\
\text { events }\end{array}$ & -- \\
\hline & $\begin{array}{l}\text { Check Valve } 513 \\
\text { fails to open }\end{array}$ & $1.0 E-4 / d$ & 3 & - & $1.0 E-4$ & 3 & - & see above & ASEP generic \\
\hline & $\begin{array}{l}\text { Manual Valve } \\
502 \text { plugs }\end{array}$ & $4.0 E-5 / d$ & 3 & - & 4. $0 E-5$ & 3 & - & see above & ASEP generic \\
\hline ESW-PSF-LF-6 & $\begin{array}{l}\text { Manual Valve } 509 \\
\text { plugs }\end{array}$ & - & - & - & - & - & $5.0 E-5$ & same as ESW-PSF-LF-3 & -- \\
\hline$E S W-P S F-L F-7$ & $\begin{array}{l}\text { Manual Valve } 510 \\
\text { plugs }\end{array}$ & - & - & - & - & - & $5.0 E-5$ & same as ESW-PSF-LF-3 & -- \\
\hline
\end{tabular}




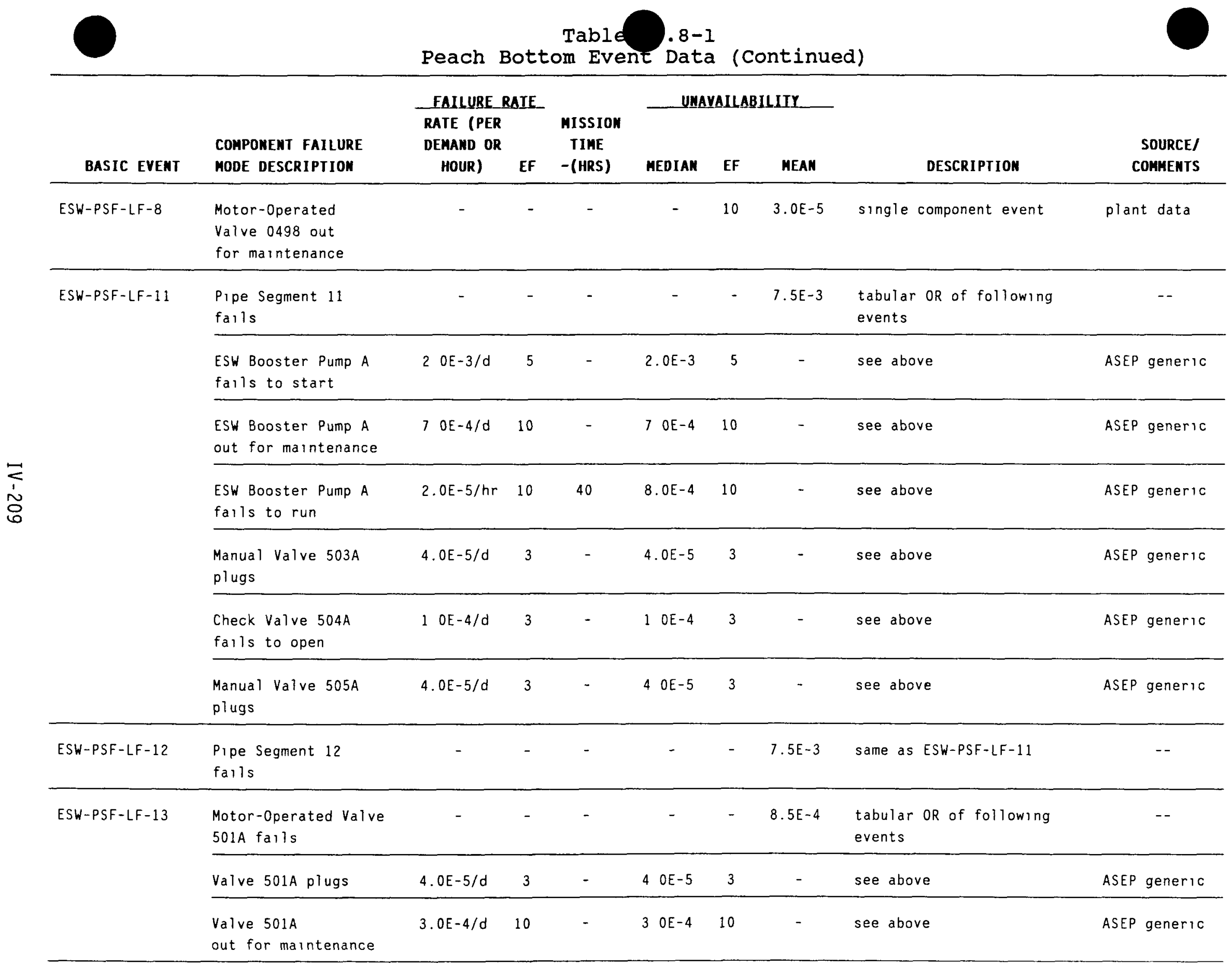


Table IV.8-1

Peach Bottom Event Data (Continued)

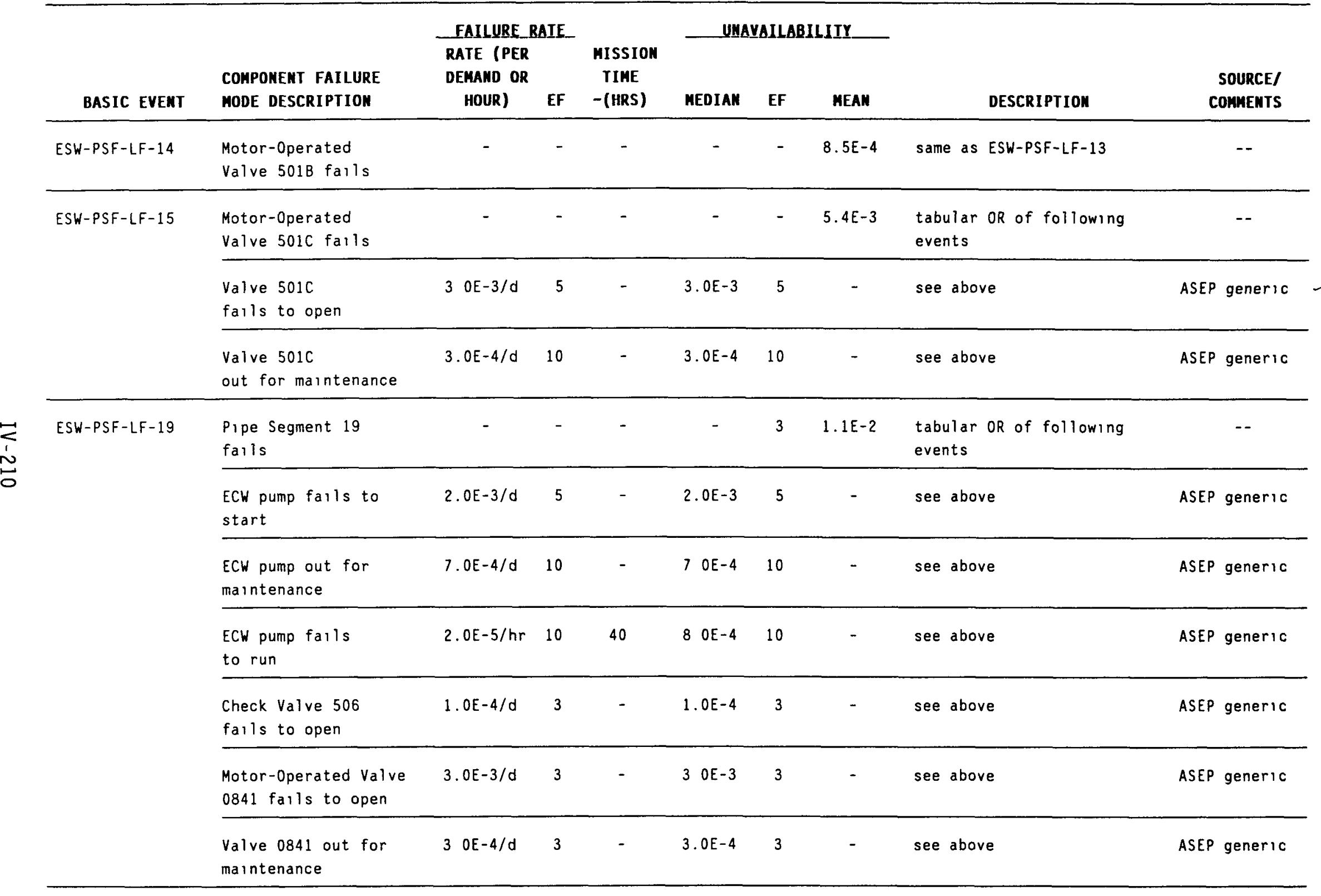




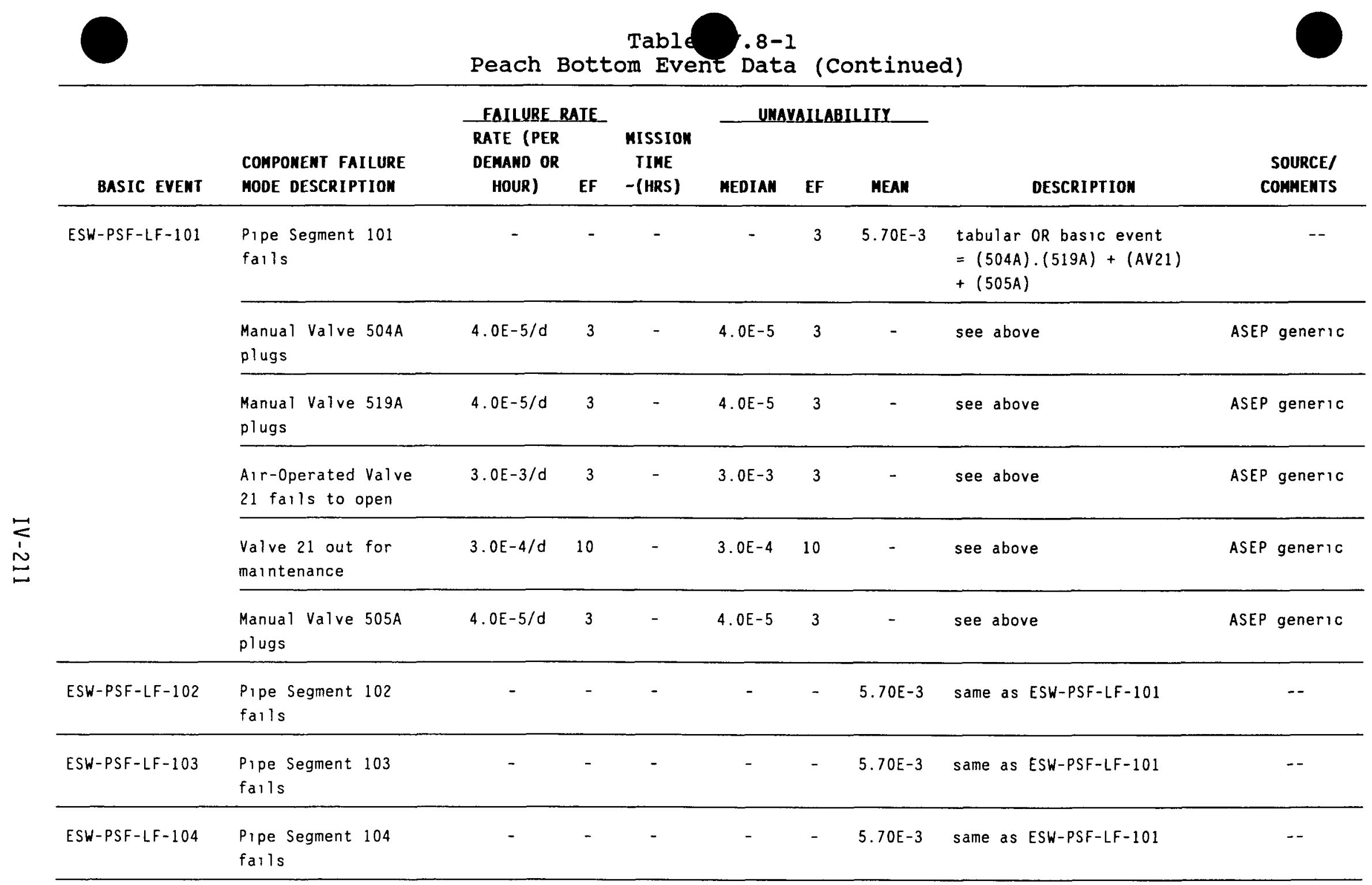


Table IV.8-1

Peach Bottom Event Data (Continued)

\begin{tabular}{|c|c|c|c|c|c|c|c|c|c|}
\hline \multirow[b]{2}{*}{ BASIC EVENT } & \multirow[b]{2}{*}{$\begin{array}{l}\text { COHPONENT FAILURE } \\
\text { MODE DESCRIPTIOH }\end{array}$} & \multicolumn{2}{|c|}{ FAILURE_RATE_ } & \multirow{2}{*}{$\begin{array}{l}\text { MISSION } \\
\text { TIME } \\
\text { - (HRS) }\end{array}$} & \multicolumn{3}{|c|}{ USAYAILABILIIY } & \multirow[b]{2}{*}{ DESCRIPTION } & \multirow{2}{*}{$\begin{array}{l}\text { SOURCE/ } \\
\text { CONHENTS }\end{array}$} \\
\hline & & $\begin{array}{l}\text { DEMAND OR } \\
\text { HOUR) }\end{array}$ & EF & & MEDIAN & EF & MEAN & & \\
\hline \multirow[t]{9}{*}{$E S W-P S F-L F-901$} & $\begin{array}{l}\text { Pipe Segment } 901 \\
\text { falls }\end{array}$ & - & - & - & - & - & $5.60 E-5$ & $\begin{array}{l}\text { basic event } \\
=\text { tab OR \#1 } 1 \text { tab OR \#2 }\end{array}$ & -- \\
\hline & $\begin{array}{l}\text { Manual Valve } 13 \\
\text { plugs }\end{array}$ & $4.0 E-5 / d$ & 3 & - & $4.0 E-5$ & 3 & - & $\begin{array}{l}\text { tabular OR \#1 (of } \\
\text { following events) } \\
\text { see Note (a) }\end{array}$ & ASEP generic \\
\hline & $\begin{array}{l}\text { Manual Valve } 14 \\
\text { plugs }\end{array}$ & $4.0 E-5 / d$ & 3 & - & $40 E-5$ & 3 & - & see above & ASEP generic \\
\hline & $\begin{array}{l}\text { Air-Operated Valve } \\
1 \text { falls to open }\end{array}$ & $3.0 E-3 / d$ & 3 & - & $3.0 E-3$ & 3 & - & see above & ASEP generic \\
\hline & $\begin{array}{l}\text { Valve } 1 \text { out for } \\
\text { maintenance }\end{array}$ & $3 O E-4 / d$ & 10 & - & $3.0 E-4$ & 10 & - & see above & ASEP generic \\
\hline & $\begin{array}{l}\text { fan unit falls } \\
\text { to start }\end{array}$ & $3.0 E-4 / d$ & 3 & - & $3.0 \mathrm{E}-4$ & 3 & - & see above & WASH-1400 \\
\hline & $\begin{array}{l}\text { fan unit out for } \\
\text { maintenance }\end{array}$ & $7.0 E-4 / d$ & 10 & - & 7 OE -4 & 10 & - & see above & WASH -1400 \\
\hline & $\begin{array}{l}\text { fan unit falls to } \\
\text { run }\end{array}$ & $1.0 \mathrm{E}-5 / \mathrm{hr}$ & 3 & 40 & $4.0 E-4$ & 3 & - & see above & WASH -1400 \\
\hline & $\begin{array}{l}\text { cooling coll unit } \\
\text { falls }\end{array}$ & 1. $0 \mathrm{E}-6 / \mathrm{hr}$ & 3 & 40 & $4.0 E-5$ & 3 & - & see above & IEEE -500 \\
\hline ESW-PSF-LF-902 & $\begin{array}{l}\text { Pipe Segment } 902 \\
\text { falls }\end{array}$ & - & - & - & - & - & $5.60 E-5$ & same as ESW-PSF-LF-901 & -- \\
\hline
\end{tabular}

Note: 


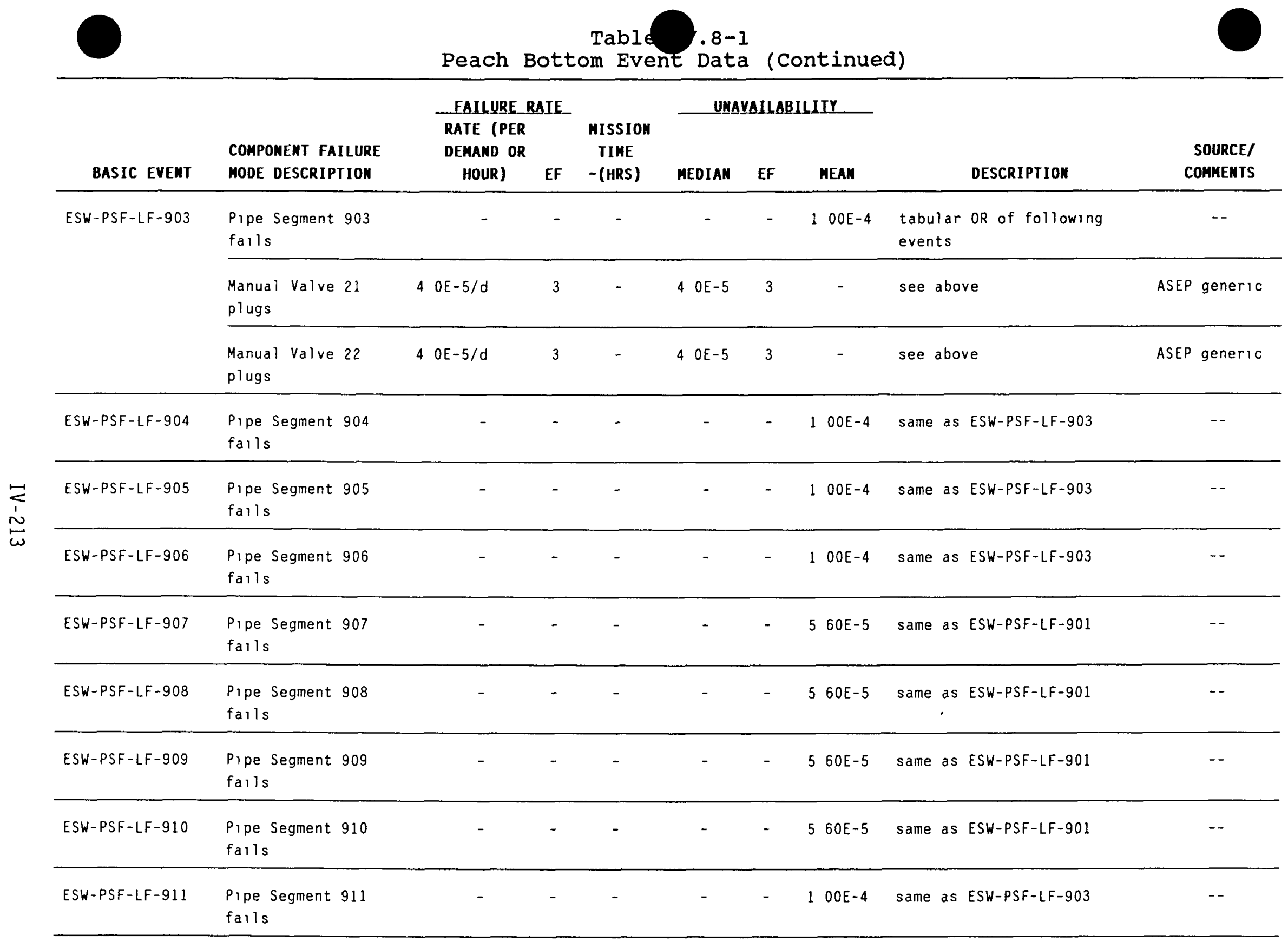


Table IV.8-1

Peach Bottom Event Data (Continued)

\begin{tabular}{|c|c|c|c|c|c|c|c|c|c|}
\hline \multirow[b]{2}{*}{ BASIC EVENT } & \multirow[b]{2}{*}{$\begin{array}{l}\text { CONPONENT FAILURE } \\
\text { MODE DESCRIPIION }\end{array}$} & \multicolumn{2}{|c|}{ FAILURE_RAIE } & \multirow{2}{*}{$\begin{array}{l}\text { MISSIOK } \\
\text { TIME } \\
\text {-(HRS) }\end{array}$} & \multicolumn{3}{|c|}{ UNAVAILABILIIY } & \multirow[b]{2}{*}{ DESCRIPTION } & \multirow[b]{2}{*}{$\begin{array}{r}\text { SOURCE/ } \\
\text { COHKENTS }\end{array}$} \\
\hline & & $\begin{array}{l}\text { DEMAND OR } \\
\text { HOUR) }\end{array}$ & EF & & MEDIAN & EF & MEAN & & \\
\hline ESW-PSF-LF-912 & $\begin{array}{l}\text { Pipe Segment } 912 \\
\text { falls }\end{array}$ & - & - & - & - & - & $100 E-4$ & same as ESW-PSF-LF-903 & -- \\
\hline ESW-PSF-LF-913 & $\begin{array}{l}\text { Pipe Segment } 913 \\
\text { falls }\end{array}$ & - & - & - & - & - & $100 E-4$ & same as ESW-PSF-LF- 903 & -- \\
\hline ESW-PSF-LF-914 & $\begin{array}{l}\text { Pipe Segment } 914 \\
\text { falls }\end{array}$ & - & - & - & - & - & $100 E-4$ & same as ESW-PSF-LF-903 & -- \\
\hline ESW-PSF-LF-915 & $\begin{array}{l}\text { Pipe Segment } 915 \\
\text { falls }\end{array}$ & - & - & - & - & - & $560 \mathrm{E}-5$ & same as ESW-PSF-LF-901 & -- \\
\hline ESW-PSF-LF-916 & $\begin{array}{l}\text { Pipe Segment } 916 \\
\text { falls }\end{array}$ & - & - & - & - & - & $560 \mathrm{E}-5$ & same as ESW-PSF-LF-901 & -- \\
\hline ESW-PSF-LF-917 & $\begin{array}{l}\text { Pipe Segment } 917 \\
\text { falls }\end{array}$ & - & - & - & - & - & $560 E-5$ & same as ESW-PSF-LF-901 & -- \\
\hline$E S W-P S F-L F-918$ & $\begin{array}{l}\text { Pipe Segment } 918 \\
\text { fails }\end{array}$ & - & - & - & - & - & $560 E-5$ & same as ESW-PSF-LF-901 & -- \\
\hline ESW-XHE-FO-ECWPP & $\begin{array}{l}\text { operator falls to } \\
\text { restart ECW pump }\end{array}$ & - & - & - & - & 1 & 10 & single event & $\begin{array}{l}\text { engineer ing } \\
\text { Judgment/HRA } \\
{[26]}\end{array}$ \\
\hline ESW-XHE-FO-EHS & $\begin{array}{l}\text { operator falls to } \\
\text { switch to emergency } \\
\text { heat sink mode }\end{array}$ & - & - & - & - & $\begin{array}{r}\text { see } \\
\text { Note } \\
\text { (a) }\end{array}$ & $10 E-2$ & single event & $\begin{array}{l}\text { engineering } \\
\text { judgment }\end{array}$ \\
\hline
\end{tabular}

Note

(a) Used maximum entropy distribution with 01 and $1 E-4$ as the absolute bounds 


\begin{tabular}{|c|c|c|c|c|c|c|c|c|c|}
\hline \multirow[b]{2}{*}{ BASIC EVEMT } & \multirow[b]{2}{*}{$\begin{array}{l}\text { CONPONENT FAILURE } \\
\text { MODE DESCRIPTION }\end{array}$} & \multicolumn{2}{|c|}{ FAILURE_RAIE } & \multirow{2}{*}{$\begin{array}{l}\text { MISSION } \\
\text { TIME } \\
-(\text { HRS })\end{array}$} & \multirow[b]{2}{*}{ MEDIAN } & \multirow[t]{2}{*}{ AILA } & \multirow[b]{2}{*}{ MEAN } & \multirow[b]{2}{*}{ DESCRIPIION } & \multirow[b]{2}{*}{$\begin{array}{l}\text { SOURCE/ } \\
\text { COMMENTS }\end{array}$} \\
\hline & & $\begin{array}{l}\text { DEMAND OR } \\
\text { HOUR) }\end{array}$ & EF & & & & & & \\
\hline \multicolumn{10}{|c|}{ EMERGENCY YEMIILAIION_SYSIEH: } \\
\hline$E H V-C C F-L K-A I R B T$ & $\begin{array}{l}\text { common cause leakage } \\
\text { of all alr bottles }\end{array}$ & - & - & - & $1 O E-4$ & 10 & $266 \mathrm{E}-4$ & single event & $\begin{array}{l}\text { engineering } \\
\text { judgment }\end{array}$ \\
\hline EHV-CCF-MC-TSCH & $\begin{array}{l}\text { miscalibration of } \\
\text { temperature switches }\end{array}$ & - & - & - & - & 10 & $1.0 E-4$ & single event & $\begin{array}{l}\text { engineering } \\
\text { judgment/HRA } \\
\text { [25] }\end{array}$ \\
\hline \multirow[t]{7}{*}{ EHV-PSF-LF-1 } & Duct Segment I falls & - & - & - & - & - & $41 E-3$ & $\begin{array}{l}\text { tabular } O R \text { of following } \\
\text { events }\end{array}$ & - \\
\hline & $\begin{array}{l}\text { Alr-Operated Valve } \\
19-1 \text { plugs }\end{array}$ & $4.0 E-5 / d$ & 3 & - & $4.0 E-5$ & 3 & - & see above & ASEP generic \\
\hline & $\begin{array}{l}\text { Valve } 19-1 \text { out for } \\
\text { maintenance }\end{array}$ & $3.0 E-4 / d$ & 10 & - & $30 E-4$ & 10 & - & see above & ASEP generic \\
\hline & $\begin{array}{l}\text { Fan 0AV34 falls } \\
\text { to run }\end{array}$ & 1. OE $-5 / h r$ & 3 & 40 & 4. $0 \mathrm{E}-4$ & 3 & - & see above & WASH- 1400 \\
\hline & $\begin{array}{l}\text { Fan } 0 \text { AV } 34 \text { out for } \\
\text { maintenance }\end{array}$ & $7.0 E-4 / d$ & 10 & - & $7.0 E-4$ & 10 & - & see above & ASEP generic \\
\hline & $\begin{array}{l}\text { Alr-Operated Valve } \\
19-2 \text { plugs }\end{array}$ & $4.0 E-5 / d$ & 3 & - & $4.0 E-5$ & 3 & - & see above & ASEP generic \\
\hline & $\begin{array}{l}\text { Valve } 19-2 \text { out for } \\
\text { maintenance }\end{array}$ & $3.0 E-4 / d$ & 10 & - & $3 O E-4$ & 10 & - & see above & ASEP generic \\
\hline
\end{tabular}


Table IV.8-1

Peach Bottom Event Data (Continued)

\begin{tabular}{|c|c|c|c|c|c|c|c|c|c|}
\hline \multirow[b]{2}{*}{ BASIC EVENT } & \multirow[b]{2}{*}{$\begin{array}{l}\text { COMPONENT FAILURE } \\
\text { MODE DESCRIPTION }\end{array}$} & \multicolumn{2}{|c|}{ FAILURE_RAIE } & \multirow{2}{*}{$\begin{array}{c}\text { MISSION } \\
\text { TIME } \\
\text { - (HRS) }\end{array}$} & \multicolumn{3}{|c|}{ UMAVAILABILIIY } & \multirow[b]{2}{*}{ DESCRIPTION } & \multirow[b]{2}{*}{$\begin{array}{l}\text { SOURCE/ } \\
\text { COMHENTS }\end{array}$} \\
\hline & & $\begin{array}{l}\text { DEMAND OR } \\
\text { HOUR) }\end{array}$ & EF & & MEDIAN & EF & MEAN & & \\
\hline \multirow[t]{9}{*}{ EHV-PSF-LF-2 } & Duct Segment 2 fails & - & - & - & - & - & $8.3 E-3$ & $\begin{array}{l}\text { tabular OR of following } \\
\text { events }\end{array}$ & -- \\
\hline & $\begin{array}{l}\text { Air-Operated Valve } \\
20-1 \text { fails to open }\end{array}$ & $3.0 E-3 / d$ & 3 & - & $3.0 E-3$ & 3 & - & see above & ASEP generic \\
\hline & $\begin{array}{l}\text { Valve } 20-1 \text { out for } \\
\text { maintenance }\end{array}$ & $3.0 E-4 / d$ & 10 & - & $3.0 E-4$ & 10 & - & see above & ASEP generic \\
\hline & $\begin{array}{l}\text { Fan } 08 V 34 \text { fails } \\
\text { to start }\end{array}$ & $3.0 E-4 / d$ & 3 & - & $3.0 E-4$ & 3 & - & see above & ASEP generic \\
\hline & $\begin{array}{l}\text { Fan } 08 V 34 \text { no start } \\
\text { signal }\end{array}$ & $1.0 E-4 / d$ & 3 & - & $1.0 E-4$ & 3 & - & see above & WASH -1400 \\
\hline & $\begin{array}{l}\text { Fan } 08 V 34 \text { fails to } \\
\text { run }\end{array}$ & $1.0 \mathrm{E}-5 / \mathrm{hr}$ & 3 & 40 & $4.0 E-4$ & 3 & - & see above & WASH -1400 \\
\hline & $\begin{array}{l}\text { Fan } 0 \text { BV } 34 \text { out for } \\
\text { maintenance }\end{array}$ & $7.0 E-4 / d$ & 10 & - & $7.0 E-4$ & 10 & - & see above & ASEP generic \\
\hline & $\begin{array}{l}\text { Air-0perated Valve } \\
20-2 \text { fails to open }\end{array}$ & $3.0 E-3 / d$ & 3 & - & $3.0 E-3$ & 3 & - & see above & ASEP generic \\
\hline & $\begin{array}{l}\text { Valve } 20-2 \text { out for } \\
\text { maintenance }\end{array}$ & $3.0 E-4 / d$ & 10 & - & $3.0 E-4$ & 10 & - & see above & ASEP generic \\
\hline$E H V-P S F-L F-3$ & Duct Segment $3 \mathrm{fails}$ & - & - & - & - & - & $4.10 E-3$ & same as EHV-PSF-LF-1 & -- \\
\hline EHV-PSF-LF-4 & Duct Segment 4 fails & - & - & - & - & - & $8.30 E-3$ & same as EHV-PSF-LF-2 & -- \\
\hline
\end{tabular}




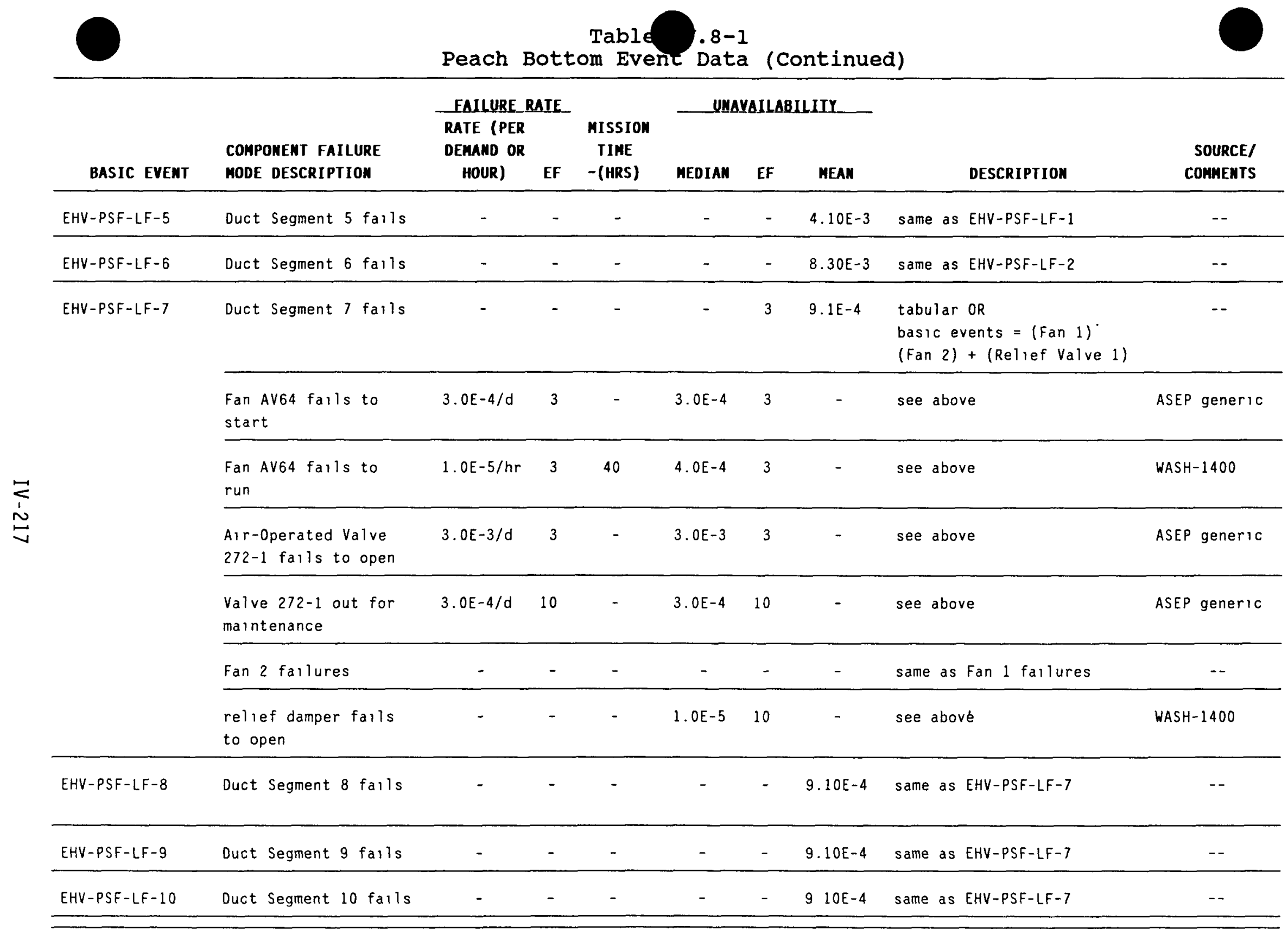


Table IV.8-1

Peach Bottom Event Data (Continued)

\begin{tabular}{|c|c|c|c|c|c|c|c|c|c|}
\hline BASIC EVENT & $\begin{array}{l}\text { CONPONENT FAILURE } \\
\text { MODE DESCRIPIION }\end{array}$ & $\begin{array}{c}\text { FAILURE_R } \\
\text { RATE (PER } \\
\text { DENAHD OR } \\
\text { HOUR) }\end{array}$ & $\begin{array}{l}\text { AIE } \\
\text { EF }\end{array}$ & $\begin{array}{l}\text { MISSION } \\
\text { TIME } \\
- \text { (HRS) }\end{array}$ & UNA & Blls & MEAN & DESCRIPTION & $\begin{array}{l}\text { SOURCE/ } \\
\text { COMMERTS }\end{array}$ \\
\hline \multicolumn{10}{|c|}{ HIGH_PRESSURE_COOLAHI_IMJECIION_SYSIEM: } \\
\hline$H C I-A C T-H W-H P C I$ & $\begin{array}{l}\text { actuation circuitry } \\
\text { fails }\end{array}$ & $2.0 E-3 / d$ & 5 & - & $2.0 E-3$ & 5 & $3.23 E-3$ & single component event & $\begin{array}{l}\text { ASEP generic, } \\
\text { plant data }\end{array}$ \\
\hline HCI-ACT-HW-LOCST & $\begin{array}{l}\text { failure of low CST } \\
\text { level circuitry for } \\
\text { HPCI }\end{array}$ & $2.0 E-3 / d$ & 5 & - & $2.0 E-3$ & 5 & $3.23 E-3$ & single component event & $\begin{array}{l}\text { ASEP generic, } \\
\text { plant data }\end{array}$ \\
\hline $\mathrm{HCI}-\mathrm{ICC}-\mathrm{HW}-\mathrm{FC} 108$ & $\begin{array}{l}\text { flow controller } \\
\text { fails }\end{array}$ & $1.0 E-4 / d$ & 3 & - & $1.0 E-4$ & 3 & $1.25 \mathrm{E}-4$ & single component event & WASH- 1400 \\
\hline HCI -MOV-HW-MV 15 & $\begin{array}{l}\text { Motor-0perated } \\
\text { Valve } 15 \text { plugs }\end{array}$ & $4.0 E-5 / d$ & 3 & - & $4.0 E-5$ & 3 & $5.0 E-5$ & single component event & ASEP generic \\
\hline HCI-MOV-HW-OUTO5 & $\begin{array}{l}\text { Motor-0perated } \\
\text { Valve } 20 \text { plugs }\end{array}$ & - & - & - & - & - & $5.0 E-5$ & same as HCI-MOV-HW-MV 15 & - \\
\hline HCI-MOV-MA-MV 14 & $\begin{array}{l}\text { Motor-Operated } \\
\text { Valve } 14 \text { out for } \\
\text { maintenance }\end{array}$ & $3.0 E-4 / d$ & 10 & - & $3.0 E-4$ & 10 & $7.99 E-4$ & single component event & ASEP generic \\
\hline HCI I-MOV-MA-MV17 & $\begin{array}{l}\text { Motor-Operated Valve } \\
17 \text { out for maintenance }\end{array}$ & - & - & - & - & - & 7.99E-4 & same as HCI-MOV-MA-MV14 & -- \\
\hline HCI-MOV-MA-MV 20 & $\begin{array}{l}\text { Motor-Operated Valve } \\
20 \text { out for maintenance }\end{array}$ & - & - & - & - & - & $7.99 E-4$ & same as HCI-MOV-MA-MVI4 & -- \\
\hline HCI-MOV-MA-MV 57 & $\begin{array}{l}\text { Motor-Operated Valve } \\
57 \text { out for maintenance }\end{array}$ & - & - & - & - & - & $7.99 E-4$ & same as HCI-MOV-MA-MV14 & -- \\
\hline
\end{tabular}




\begin{tabular}{|c|c|c|c|c|c|c|c|c|c|}
\hline & & FAILURE_R & AIE_ & & UWA & ALA & ILITY & & \\
\hline BASIC EVEMT & MODE DESCRIPIION & HOUR) & EF & $-($ HRS $)$ & MEDIAN & EF & MEAN & DESCRIPTION & COMMENTS \\
\hline HCI-MOV-MA-PCV5O & $\begin{array}{l}\text { Pressure Control Valve } \\
50 \text { out for maintenance }\end{array}$ & - & - & - & - & - & $7.99 \mathrm{E}-4$ & same as HCI-MOV-MA-MV14 & -- \\
\hline HCI I-PSF-HW-COL13 & $\begin{array}{l}\text { Pressure Control } \\
\text { Valve } 50 \text { plugs }\end{array}$ & $4.0 E-5 / d$ & 3 & - & $4.0 E-5$ & 3 & $5.0 E-5$ & single component event & ASEP generic \\
\hline \multirow[t]{4}{*}{ HCI -PSF-HW-CSTO2 } & Pipe Segment 2 falls & - & - & - & - & - & $2.25 \mathrm{E}-4$ & $\begin{array}{l}\text { tabular OR of following } \\
\text { events }\end{array}$ & -- \\
\hline & $\begin{array}{l}\text { Check Valve } 32 \\
\text { falls to open }\end{array}$ & $1.0 E-4 / d$ & 3 & - & $1.0 E-4$ & 3 & - & see above & ASEP generic \\
\hline & $\begin{array}{l}\text { Manual Valve } \\
23 \text { plugs }\end{array}$ & $4.0 E-5 / d$ & 3 & - & $4.0 E-5$ & 3 & - & see above & ASEP generic \\
\hline & $\begin{array}{l}\text { Motor-Operated } \\
\text { Valve } 17 \text { plugs }\end{array}$ & $4.0 E-5 / d$ & 3 & - & $4.0 E-5$ & 3 & - & see above & ASEP generic \\
\hline \multirow[t]{3}{*}{ HCI-PSF-HW-DISI5 } & $\begin{array}{l}\text { Pipe Segment } \\
15 \text { falls }\end{array}$ & - & - & - & - & - & $1.75 E-4$ & $\begin{array}{l}\text { tabular OR of following } \\
\text { events }\end{array}$ & -- \\
\hline & $\begin{array}{l}\text { Check Valve } 65 \\
\text { falls to open }\end{array}$ & $1.0 E-4 / d$ & 3 & - & $1.0 E-4$ & 3 & - & see above, & ASEP generic \\
\hline & $\begin{array}{l}\text { Manual Valve } \\
12 \text { plugs }\end{array}$ & $4.0 E-5 / d$ & 3 & - & 4. $0 E-5$ & 3 & - & see above & ASEP generic \\
\hline
\end{tabular}


Table IV.8-I

Peach Bottom Event Data (Continued)

\begin{tabular}{|c|c|c|c|c|c|c|c|c|c|}
\hline \multirow[b]{2}{*}{ BASIC EVENT } & \multirow{2}{*}{$\begin{array}{l}\text { COMPONENT FAILURE } \\
\text { MODE DESCRIPTION }\end{array}$} & \multicolumn{2}{|c|}{ FAILURE_RAIE_ } & \multirow{2}{*}{$\begin{array}{c}\text { MISSION } \\
\text { TIME } \\
\text { - (HRS) }\end{array}$} & \multicolumn{3}{|c|}{ UNAYAILABILIIY } & \multirow[b]{2}{*}{ DESCRIPTION } & \multirow{2}{*}{$\begin{array}{r}\text { SOURCE/ } \\
\text { COHAENTS }\end{array}$} \\
\hline & & HOUR) & EF & & MEDIAN & EF & MEAN & & \\
\hline \multirow[t]{3}{*}{ HCI-PSF-HW-INJ09 } & $\begin{array}{l}\text { Pipe Segment } \\
9 \text { fails }\end{array}$ & - & - & - & - & 3 & $3.8 \mathrm{E}-3$ & $\begin{array}{l}\text { tabular OR of following } \\
\text { events }\end{array}$ & -- \\
\hline & $\begin{array}{l}\text { Motor-Operated Valve } \\
19 \text { fails to open }\end{array}$ & $3.0 E-3 / d$ & 3 & - & $3.0 E-3$ & 3 & - & see above & ASEP generic \\
\hline & $\begin{array}{l}\text { Check Valve } 18 \\
\text { fails to open }\end{array}$ & $1.0 E-4 / d$ & 3 & - & $1.0 E-4$ & 3 & - & see above & ASEP generic \\
\hline \multirow[t]{4}{*}{ HCI - PSF-HW-SPO3 } & $\begin{array}{l}\text { Pipe Segment } 3 \\
\text { fails }\end{array}$ & - & - & - & - & - & $7.6 \mathrm{E}-3$ & $\begin{array}{l}\text { tabular } O R \text { of following } \\
\text { events }\end{array}$ & -- \\
\hline & $\begin{array}{l}\text { Motor-Operated Valve } \\
57 \text { fails to open }\end{array}$ & $3.0 E-3 / d$ & 3 & - & $3.0 E-3$ & 3 & - & see above & ASEP generic \\
\hline & $\begin{array}{l}\text { Motor-Operated Valve } \\
58 \text { fails to open }\end{array}$ & $3.0 E-3 / d$ & 3 & - & $3.0 E-3$ & 3 & - & see above & ASEP generic \\
\hline & $\begin{array}{l}\text { Check Valve } 61 \\
\text { fails to open }\end{array}$ & $1.0 E-4 / d$ & 3 & - & $1.0 E-4$ & 3 & - & see above & ASEP generic \\
\hline \multirow[t]{4}{*}{ HCI-PSF-HW-SUP12 } & Pipe Segment 12 fails & - & - & - & - & 3 & $3.90 \mathrm{E}-3$ & $\begin{array}{l}\text { tabular OR of following } \\
\text { events }\end{array}$ & -- \\
\hline & $\begin{array}{l}\text { Motor-Operated Valve } \\
14 \text { fails to open }\end{array}$ & $3.0 E-3 / d$ & 3 & - & $3.0 E-3$ & 3 & - & see above & ASEP generic \\
\hline & $\begin{array}{l}\text { Motor-Operated Valve } \\
16 \text { plugs }\end{array}$ & $4.0 E-5 / d$ & 3 & - & $4.0 E-5$ & 3 & - & see above & ASEP generic \\
\hline & $\begin{array}{l}2 \text { manual valves } \\
\text { plug }\end{array}$ & $8.0 E-5 / d$ & 3 & - & $8.0 E-5$ & 3 & - & see above & ASEP generic \\
\hline
\end{tabular}




\begin{tabular}{|c|c|c|c|c|c|c|c|c|c|}
\hline \multirow[b]{2}{*}{ BASIC EVEMT } & \multirow{2}{*}{$\begin{array}{l}\text { COMPONENT FAILURE } \\
\text { MODE DESCRIPIION }\end{array}$} & \multicolumn{2}{|c|}{ FALLURE_RAIE } & \multirow{2}{*}{$\begin{array}{l}\text { MISSIOH } \\
\text { TIME } \\
\text {-(HRS) }\end{array}$} & \multicolumn{3}{|c|}{ UMAYAILABILIIY } & \multirow[b]{2}{*}{ DESCRIPTION } & \multirow{2}{*}{$\begin{array}{l}\text { SOURCE/ } \\
\text { COMMENTS }\end{array}$} \\
\hline & & HOUR) & EF & & MEDIAM & EF & MEAM & & \\
\hline HCI-PTF-VF-NOSUC & $\begin{array}{l}\text { HPCI suction line } \\
\text { fallures (low suc- } \\
\text { tion sensors) }\end{array}$ & $2.0 E-3$ & 3 & - & $20 E-3$ & 3 & $2.50 E-3$ & single component event & $\begin{array}{l}\text { ASEP generic, } \\
\text { plant data }\end{array}$ \\
\hline HCI-TDP-FL-20S37 & $\begin{array}{l}\text { turbine-driven pump } \\
\text { falls to run }\end{array}$ & $5.0 \mathrm{E}-3 / \mathrm{hr}$ & 10 & 5 & - & 10 & $2.50 E-2$ & $\begin{array}{l}\text { S2 and most transient } \\
\text { sequences }--5 \text { hrs }\end{array}$ & plant data \\
\hline HCI-TDP-F0-20S37 & $\begin{array}{l}\text { turbine-driven pump } \\
\text { falls to run }\end{array}$ & $5.0 \mathrm{E}-3 / \mathrm{hr}$ & 10 & 05 & - & 10 & $2.50 E-3$ & $\begin{array}{l}\text { short term blackout } \\
--1 / 2 \text { hour }\end{array}$ & plant data \\
\hline HCI-TDP-FR-20S37 & $\begin{array}{l}\text { turbine-driven pump } \\
\text { falls to run }\end{array}$ & $5.0 \mathrm{E}-3 / \mathrm{hr}$ & 10 & 2 & - & 10 & $1.00 \mathrm{E}-2$ & $\begin{array}{l}\text { single component event } \\
\text { S1 sequences- }-2 \mathrm{hrs}\end{array}$ & plant data \\
\hline HCI-TDP-FS-20S37 & $\begin{array}{l}\text { turbine-driven pump } \\
\text { falls to start }\end{array}$ & $3.0 E-2 / d$ & 5 & - & $3.0 \mathrm{E}-2$ & 5 & $4.84 E-2$ & single component event & ASEP generic \\
\hline HCI-TDP-MA-20S37 & $\begin{array}{l}\text { turbine-driven pump } \\
\text { out for maintenance }\end{array}$ & $6.0 E-3 / d$ & 10 & - & $6.0 E-3$ & 10 & $1.6 \mathrm{E}-2$ & single component event & ASEP generic \\
\hline HCI-XVM-HW-CSTO1 & Manual Valve 1 plugs & $4.0 E-5 / d$ & 3 & - & $4 O E-5$ & 3 & $5.0 E-5$ & single component event & ASEP generic \\
\hline
\end{tabular}


Table IV.8-1

Peach Bottom Event Data (Continued)

\begin{tabular}{|c|c|c|c|c|c|c|c|c|c|}
\hline BASIC EVEnT & $\begin{array}{l}\text { COAPONENT FAILURE } \\
\text { MOOE DESCRIPTION }\end{array}$ & $\begin{array}{l}\text { FAILURE_B } \\
\text { RATE (PER } \\
\text { DEHAND OR } \\
\text { HOUR) }\end{array}$ & AIE_ & $\begin{array}{c}\text { MISSION } \\
\text { TIME } \\
\text {-(HRS) }\end{array}$ & UNA & ALL & MEAN & DESCRIPTION & $\begin{array}{l}\text { SOURCE/ } \\
\text { COMHENTS }\end{array}$ \\
\hline \multicolumn{10}{|c|}{ HI6H_PRESSURE_SERVICE_MAIER: } \\
\hline HSW-MOV-CC-2344 & $\begin{array}{l}\text { Motor-Operated } \\
\text { Valve } 2344 \text { fails }\end{array}$ & - & - & - & - & - & $4.60 E-3$ & same as HSW-MOV-FT-2803 & -- \\
\hline \multirow[t]{3}{*}{ HSW-MOV-FT-2803 } & $\begin{array}{l}\text { Motor-Operated } \\
\text { Valve } 2803 \text { fails }\end{array}$ & - & - & - & - & - & $4.60 E-3$ & $\begin{array}{l}\text { tabular OR of following } \\
\text { events }\end{array}$ & -- \\
\hline & $\begin{array}{l}\text { Valve } 2803 \text { fails } \\
\text { to open }\end{array}$ & $3.0 \mathrm{E}-3 / \mathrm{d}$ & 3 & - & $3.0 E-3$ & 3 & - & see above & ASEP generic \\
\hline & $\begin{array}{l}\text { Valve } 2803 \text { out for } \\
\text { maintenance }\end{array}$ & $3.0 E-4 / d$ & 10 & - & $3.0 E-4$ & 10 & - & see above & ASEP generic \\
\hline \multirow[t]{4}{*}{ HSW-PSF-LF-ECTA } & $\begin{array}{l}\text { emergency cooling } \\
\text { tower Fan A fails }\end{array}$ & - & - & - & - & - & $5.50 E-3$ & $\begin{array}{l}\text { tabular } O R \text { of following } \\
\text { events }\end{array}$ & -- \\
\hline & Fan A fails to start & $2.8 E-3 / d$ & 3 & - & $2.8 E-3$ & 3 & - & see above & IEEE -500 \\
\hline & $\begin{array}{l}\text { Fan } A \text { out for } \\
\text { maintenance }\end{array}$ & $7.0 E-4 / d$ & 10 & - & $7.0 E-4$ & 10 & - & see above & IEEE -500 \\
\hline & Fan A fails to run & $2.5 E-6 / h r$ & 10 & 40 & $1.0 E-4$ & 10 & - & see above & IEEE -500 \\
\hline HSW-PSF-LF-ECTB & $\begin{array}{l}\text { emergency cooling } \\
\text { tower Fan B fails }\end{array}$ & - & - & - & - & - & $5.50 E-3$ & same as HSW-PSF-LF-ECTA & -- \\
\hline HSW-PSF-LF-ECTC & $\begin{array}{l}\text { emergency cooling } \\
\text { tower Fan C fails }\end{array}$ & - & - & - & - & - & $5.50 E-3$ & same as HSW-PSF-LF-ECTA & -- \\
\hline
\end{tabular}




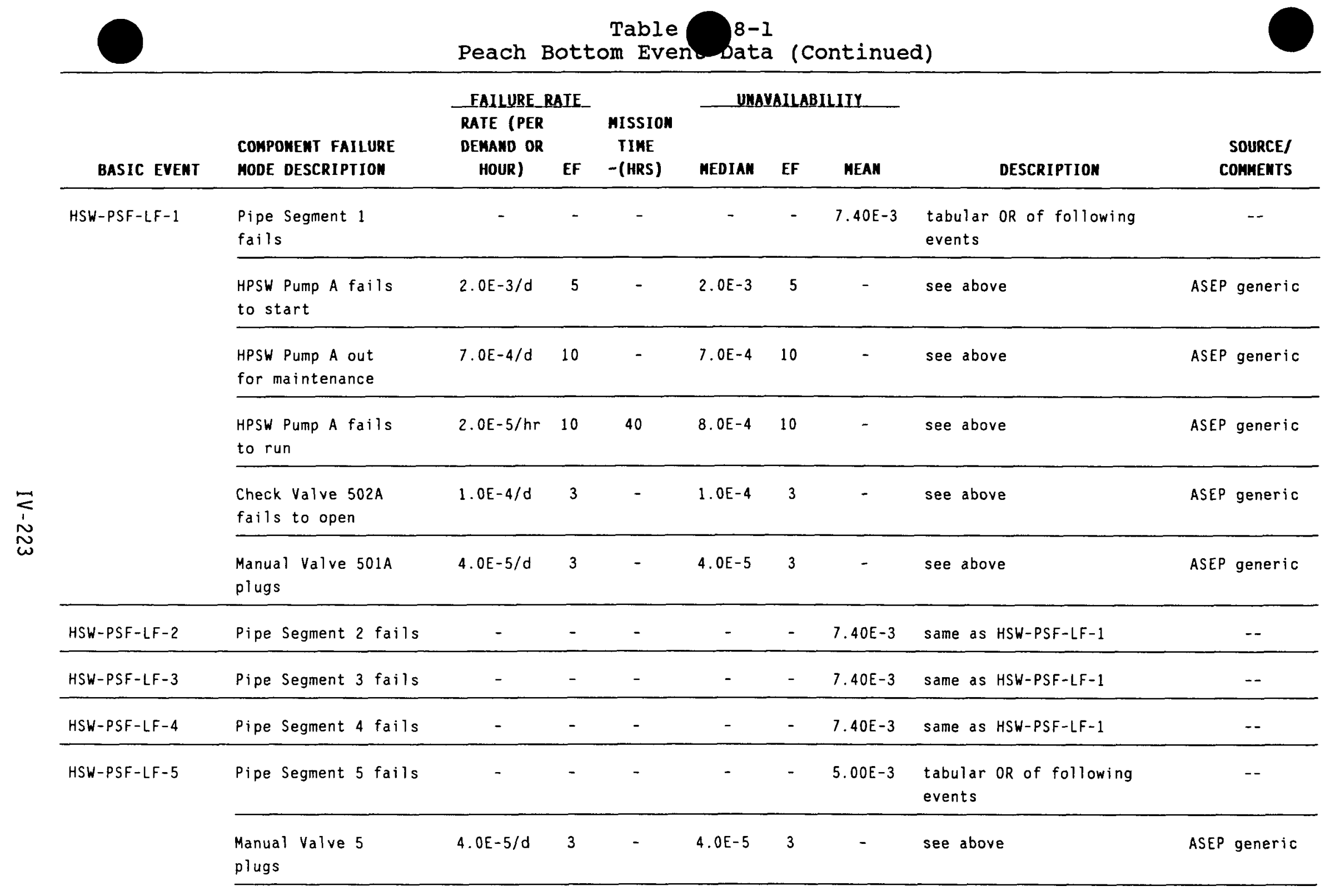


Table IV.8-1

Peach Bottom Event Data (Continued)

\begin{tabular}{|c|c|c|c|c|c|c|c|c|c|}
\hline BASIC EVENT & $\begin{array}{l}\text { COMPONENT FAILURE } \\
\text { MODE DESCRIPTION }\end{array}$ & $\begin{array}{c}\text { FAILURE_R } \\
\text { RATE (PER } \\
\text { DEMAND OR } \\
\text { MOUR) }\end{array}$ & AIE_ & $\begin{array}{c}\text { MISSION } \\
\text { TIME } \\
\text {-(HRS) }\end{array}$ & MEDIAN & AILA & MEAK & DESCRIPTION & $\begin{array}{l}\text { SOURCE/ } \\
\text { CONHEMTS }\end{array}$ \\
\hline \multirow[t]{3}{*}{$\begin{array}{l}\text { HSW-PSF-LF-5 } \\
\text { (Concl uded) }\end{array}$} & $\begin{array}{l}\text { Motor-Operated Valve } \\
1089 \mathrm{~A} \text { falls to open }\end{array}$ & $3.0 E-3 / d$ & 3 & - & $3.0 \mathrm{E}-3$ & 3 & - & see above & ASEP generic \\
\hline & $\begin{array}{l}\text { Valve } 1089 \mathrm{~A} \text { out for } \\
\text { maintenance }\end{array}$ & $3.0 E-4 / d$ & 3 & - & $3.0 E-4$ & 10 & - & see above & ASEP generic \\
\hline & $\begin{array}{l}\text { RHR Heat Exchanger } \\
\text { A falls }\end{array}$ & $3.4 \mathrm{E}-6 / \mathrm{hr}$ & 10 & 40 & $13 E-4$ & 10 & - & see above & IEEE-500 \\
\hline HSW-PSF-LF-6 & $\begin{array}{l}\text { Pipe Segment } 6 \\
\text { falls }\end{array}$ & - & - & - & - & - & $5.0 \mathrm{E}-3$ & same as HSW-PSF-LF-5 & -- \\
\hline HSW-PSF-LF-7 & $\begin{array}{l}\text { Pipe Segment } 7 \\
\text { falls }\end{array}$ & - & - & - & - & - & $5.0 E-3$ & same as HSW-PSF-LF-5 & -- \\
\hline HSW-PSF-LF-8 & $\begin{array}{l}\text { Pipe Segment } 8 \\
\text { fails }\end{array}$ & - & - & - & - & - & $5.0 \mathrm{E}-3$ & same as HSW-PSF-LF-5 & -- \\
\hline \multirow[t]{4}{*}{ HSW-PSF-LF-10 } & $\begin{array}{l}\text { Pipe Segment } 10 \\
\text { falls }\end{array}$ & - & - & - & - & - & $9.0 \mathrm{E}-4$ & $\begin{array}{l}\text { tabular OR of following } \\
\text { events }\end{array}$ & -- \\
\hline & $\begin{array}{l}\text { Motor-Operated Valve } \\
2486 \text { plugs }\end{array}$ & $4 O E-5 / d$ & 3 & - & $4 O E-5$ & 3 & - & see above & ASEP generic \\
\hline & $\begin{array}{l}\text { Valve } 2486 \text { out for } \\
\text { maintenance }\end{array}$ & $3.0 E-4 / d$ & 10 & - & $3 O E-4$ & 10 & - & see above & ASEP generic \\
\hline & $\begin{array}{l}\text { Manual Valve } \\
11 \text { plugs }\end{array}$ & $4 O E-5 / d$ & 3 & - & $4 O E-5$ & 3 & - & see above & ASEP generic \\
\hline
\end{tabular}




\begin{tabular}{|c|c|c|c|c|c|c|c|c|c|}
\hline & & FAILURE_R & AIE & & UNA & IILA & LIII & & \\
\hline BASIC EVEMT & MODE DESCRIPTION & HOUR) & $\mathbf{E F}$ & $-($ HRS $)$ & MEDIAN & EF & MEAN & DESCRIPIIOH & COMMENTS \\
\hline \multirow[t]{3}{*}{ HSW-PSF-LF-12 } & $\begin{array}{l}\text { Motor-Operated Valve } \\
502 \mathrm{~A} \text { falls }\end{array}$ & - & - & - & - & - & $8.5 E-4$ & $\begin{array}{c}\text { tabular OR of following } \\
\text { events }\end{array}$ & -- \\
\hline & Valve $502 \mathrm{~A}$ plugs & $4.0 E-5 / d$ & 3 & - & $4.0 E-5$ & 3 & - & see above & ASEP generic \\
\hline & $\begin{array}{l}\text { Valve } 502 \mathrm{~A} \text { out for } \\
\text { maintenance }\end{array}$ & $3.0 E-4 / d$ & 10 & - & $3.0 E-4$ & 10 & - & see above & ASEP generic \\
\hline$H S W-P S F-L F-13$ & $\begin{array}{l}\text { Motor-Operated Valve } \\
502 B \mathrm{falls}\end{array}$ & - & - & - & - & - & $8.5 E-4$ & same as HSW-PSF-LF-12 & -- \\
\hline \multirow[t]{3}{*}{ HSW-PSF-LF-14 } & $\begin{array}{l}\text { Motor-0perated } \\
\text { Valve } 502 \mathrm{C} \text { falis }\end{array}$ & - & - & - & - & - & $4.6 \mathrm{E}-3$ & $\begin{array}{l}\text { tabular } O R \text { of following } \\
\text { events }\end{array}$ & -- \\
\hline & $\begin{array}{l}\text { Valve } 502 \mathrm{C} \text { falls to } \\
\text { open }\end{array}$ & $3.0 \mathrm{E}-3 / \mathrm{d}$ & 3 & - & $30 E-3$ & 3 & - & see above & ASEP generic \\
\hline & $\begin{array}{l}\text { Valve } 502 C \text { out for } \\
\text { maintenance }\end{array}$ & $3.0 E-4 / d$ & 10 & - & $3.0 \mathrm{E}-4$ & 10 & - & see above & ASEP generic \\
\hline \multirow[t]{3}{*}{ HSW-PSF-LF-18 } & $\begin{array}{l}\text { Pipe Segment } 18 \\
\text { falls }\end{array}$ & - & - & - & - & - & $8.8 E-3$ & $\begin{array}{l}\text { tabular } O R \text { of following } \\
\text { events }\end{array}$ & -- \\
\hline & $\begin{array}{l}\text { Motor-Operated } \\
\text { Valve } 2804 \mathrm{~A} \\
\text { falls to open }\end{array}$ & $3.0 \mathrm{E}-3 / \mathrm{d}$ & 3 & - & $3.0 \mathrm{E}-3$ & 3 & - & see above & ASEP generic \\
\hline & $\begin{array}{l}\text { Valve } 2804 \mathrm{~A} \text { out } \\
\text { for maintenance }\end{array}$ & $3.0 E-4 / d$ & 10 & - & $3.0 \mathrm{E}-4$ & 10 & - & see above & ASEP generic \\
\hline
\end{tabular}


Table IV.8-1

Peach Bottom Event Data (Continued)

\begin{tabular}{|c|c|c|c|c|c|c|c|c|c|}
\hline \multirow[b]{2}{*}{ BASIC EVENT } & \multirow{2}{*}{$\begin{array}{l}\text { CONPONEAT FAILURE } \\
\text { MODE DESCRIPTION }\end{array}$} & \multicolumn{2}{|c|}{ FAILURE RAIE } & \multirow{2}{*}{$\begin{array}{l}\text { MISSION } \\
\text { TIME } \\
\text {-(HRS) }\end{array}$} & \multicolumn{3}{|c|}{ UNAVAILABILIIY } & \multirow[b]{2}{*}{ DESCRIPTION } & \multirow{2}{*}{$\begin{array}{l}\text { SOURCE/ } \\
\text { COAMENTS }\end{array}$} \\
\hline & & HOUR) & EF & & MEDIAN & EF & MEAK & & \\
\hline \multirow[t]{2}{*}{$\begin{array}{l}\text { HSW-PSF-LF-18 } \\
\text { (Concluded) }\end{array}$} & $\begin{array}{l}\text { Motor-Operated } \\
\text { Valve } 2804 \mathrm{~B} \\
\text { fails to open }\end{array}$ & $3.0 E-3 / d$ & 3 & - & $3.0 E-3$ & 3 & - & see above & ASEP generic \\
\hline & $\begin{array}{l}\text { Valve } 2804 B \text { out } \\
\text { for maintenance }\end{array}$ & $3.0 E-4 / d$ & 10 & - & $3.0 E-4$ & 10 & - & see above & ASEP generic \\
\hline \multirow[t]{6}{*}{$H S W-P S F-L F-20$} & $\begin{array}{l}\text { Pipe Segment } 20 \\
\text { fails }\end{array}$ & - & - & - & - & - & $8.9 E-3$ & $\begin{array}{l}\text { tabular } O R \text { or following } \\
\text { events }\end{array}$ & -- \\
\hline & $\begin{array}{l}\text { Motor-Operated } \\
\text { Valve } 174 \\
\text { fails to open }\end{array}$ & $3.0 E-3 / d$ & 3 & - & $3.0 E-3$ & 3 & - & see above & ASEP generic \\
\hline & $\begin{array}{l}\text { Valve } 174 \text { out for } \\
\text { maintenance }\end{array}$ & $3.0 E-4 / d$ & 10 & - & $3.0 \mathrm{E}-4$ & 10 & - & see above & ASEP generic \\
\hline & $\begin{array}{l}\text { Motor-0perated } \\
\text { Valve } 176 \\
\text { fails to open }\end{array}$ & $3.0 E-3 / d$ & 3 & - & $3.0 E-3$ & 3 & - & see above & ASEP generic \\
\hline & $\begin{array}{l}\text { Valve } 176 \text { out for } \\
\text { maintenance }\end{array}$ & $3.0 E-4 / d$ & 10 & - & $3.0 E-4$ & 10 & - & see above & ASEP generic \\
\hline & $\begin{array}{l}\text { Check Valve } 5 \\
\text { fails to open }\end{array}$ & $1.0 E-4 / d$ & 3 & - & $1.0 E-4$ & 3 & - & see above & ASEP generic \\
\hline HSW-TNK-LF-RESVR & reservoir fails & - & - & - & - & 10 & $1.00 E-5$ & single event & $\begin{array}{l}\text { engineering } \\
\text { judgment }\end{array}$ \\
\hline
\end{tabular}




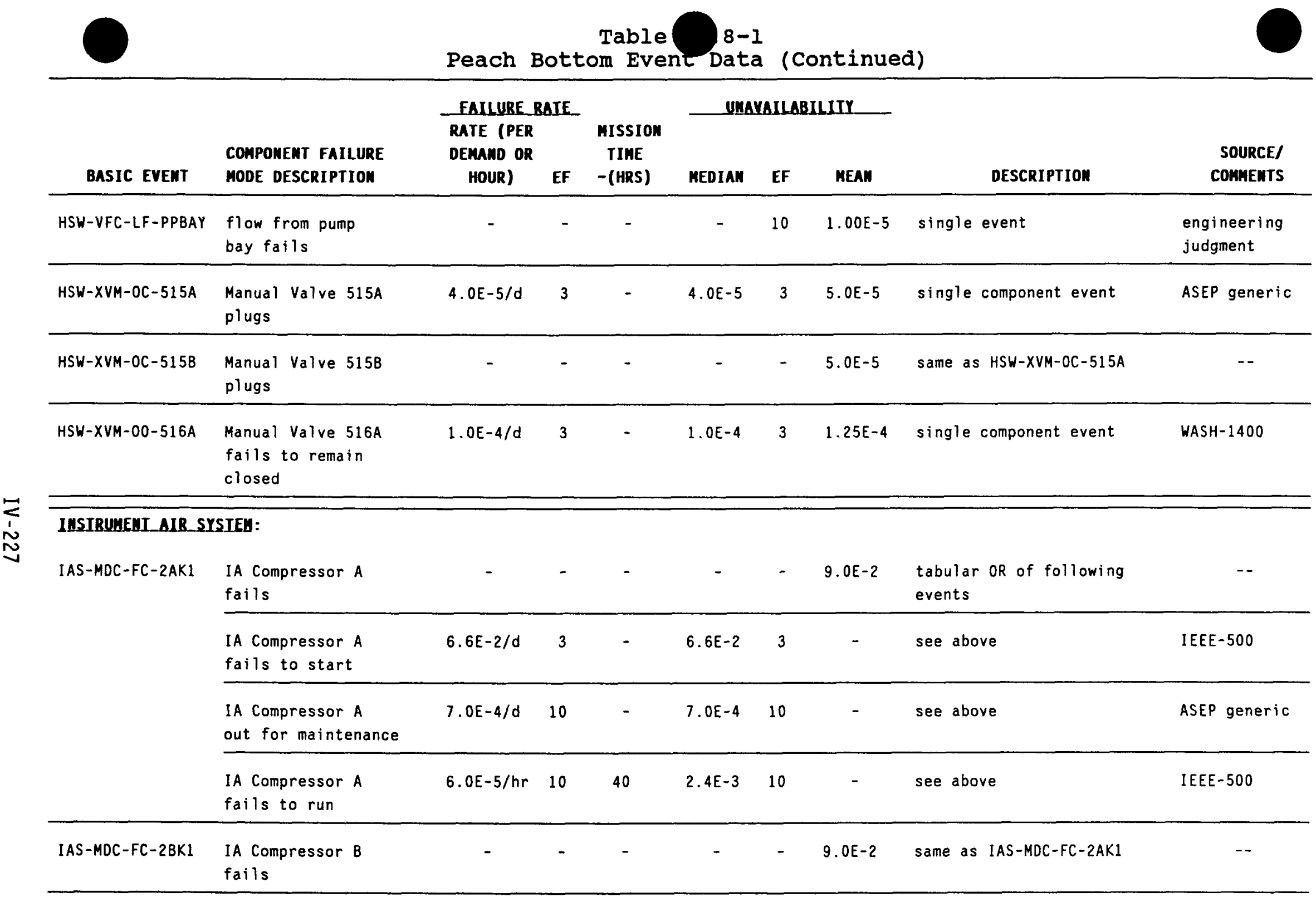


Table IV.8-1

Peach Bottom Event Data (Continued)

\begin{tabular}{|c|c|c|c|c|c|c|c|c|c|}
\hline \multirow[b]{2}{*}{ BASIC EYENT } & \multirow{2}{*}{$\begin{array}{l}\text { COHPONENT FAILURE } \\
\text { MODE DESCRIPTION }\end{array}$} & \multicolumn{2}{|c|}{ FAILURE_RAIE } & \multirow{2}{*}{$\begin{array}{c}\text { MISSION } \\
\text { TINE } \\
\text {-(HRS) }\end{array}$} & \multicolumn{3}{|c|}{ UMAVAILABILIIY } & \multirow[b]{2}{*}{ DESCRIPTION } & \multirow{2}{*}{$\begin{array}{l}\text { SOURCE/ } \\
\text { COHAENTS }\end{array}$} \\
\hline & & HOUR) & EF & & MEDIAN & $\mathbf{E F}$ & MEAN & & \\
\hline$I A S-M D C-F C-2 C K 1$ & $\begin{array}{l}\text { SA Compressor C } \\
\text { fails }\end{array}$ & - & - & - & - & - & $9.0 E-2$ & same as IAS-MDC-FC-2AKI & -- \\
\hline IAS-MDC-FC-OOKI & $\begin{array}{l}\text { SA Compressor D } \\
\text { fails }\end{array}$ & - & - & - & - & - & $9.0 \mathrm{E}-2$ & same as IAS-MDC-FC-2AKI & - \\
\hline \multirow[t]{3}{*}{ IAS-XVM-FT-XVI } & Manual Valve 1 & - & - & - & - & - & $1.0 E-1$ & $\begin{array}{l}\text { tabular } O R \text { of following } \\
\text { events }\end{array}$ & - \\
\hline & $\begin{array}{l}\text { Valve } 1 \text { fails to } \\
\text { open }\end{array}$ & $5.0 E-4 / d$ & 5 & - & $5.0 E-4$ & 5 & - & see above & ASEP generic \\
\hline & $\begin{array}{l}\text { operator fails } \\
\text { to open valve }\end{array}$ & - & - & - & - & 10 & 1. $O E-1$ & see above & $\begin{array}{l}\text { engineering } \\
\text { judgment }\end{array}$ \\
\hline IAS-XVM-FT-XV2 & $\begin{array}{l}\text { Manual Valve XV2 } \\
\text { fails }\end{array}$ & - & - & - & - & - & 1. $0 E-1$ & same as IAS-XVM-FT-XVI & -- \\
\hline
\end{tabular}

\section{LOY_PRESSURE_COOLAMI_IHJECIION_SYSIEM:}

\begin{tabular}{|c|c|c|c|c|c|c|c|c|c|}
\hline LCI-ACT-HW-DIVI & $\begin{array}{l}\text { actuation circuitry } \\
\text { Division } 1 \text { fails }\end{array}$ & $2.0 E-3 / d$ & 5 & - & $2.0 E-3$ & 5 & $3.23 E-3$ & single component event & $\begin{array}{l}\text { ASEP generic. } \\
\text { plant data }\end{array}$ \\
\hline LCI-ACT-HW-OIV2 & $\begin{array}{l}\text { actuation circuitry } \\
\text { Division } 2 \text { fails }\end{array}$ & - & - & - & - & - & $3.23 E-3$ & same as LCI-ACT-HW-DIVI & -- \\
\hline$L C I-M D P-F R-2 A P 35$ & $\begin{array}{l}\text { Motor-Driven Pump A } \\
\text { fails to run }\end{array}$ & $2.0 \mathrm{E}-5 / \mathrm{hr}$ & 10 & 40 & $8.0 E-4$ & 10 & $2.13 E-3$ & single component event & ASEP generic \\
\hline LCI-MDP-FR-2BP35 & $\begin{array}{l}\text { Motor-Driven Pump B } \\
\text { fails to run }\end{array}$ & - & - & - & - & - & $2.13 E-3$ & same as LCI-MDP-FR-2AP35 & -- \\
\hline
\end{tabular}




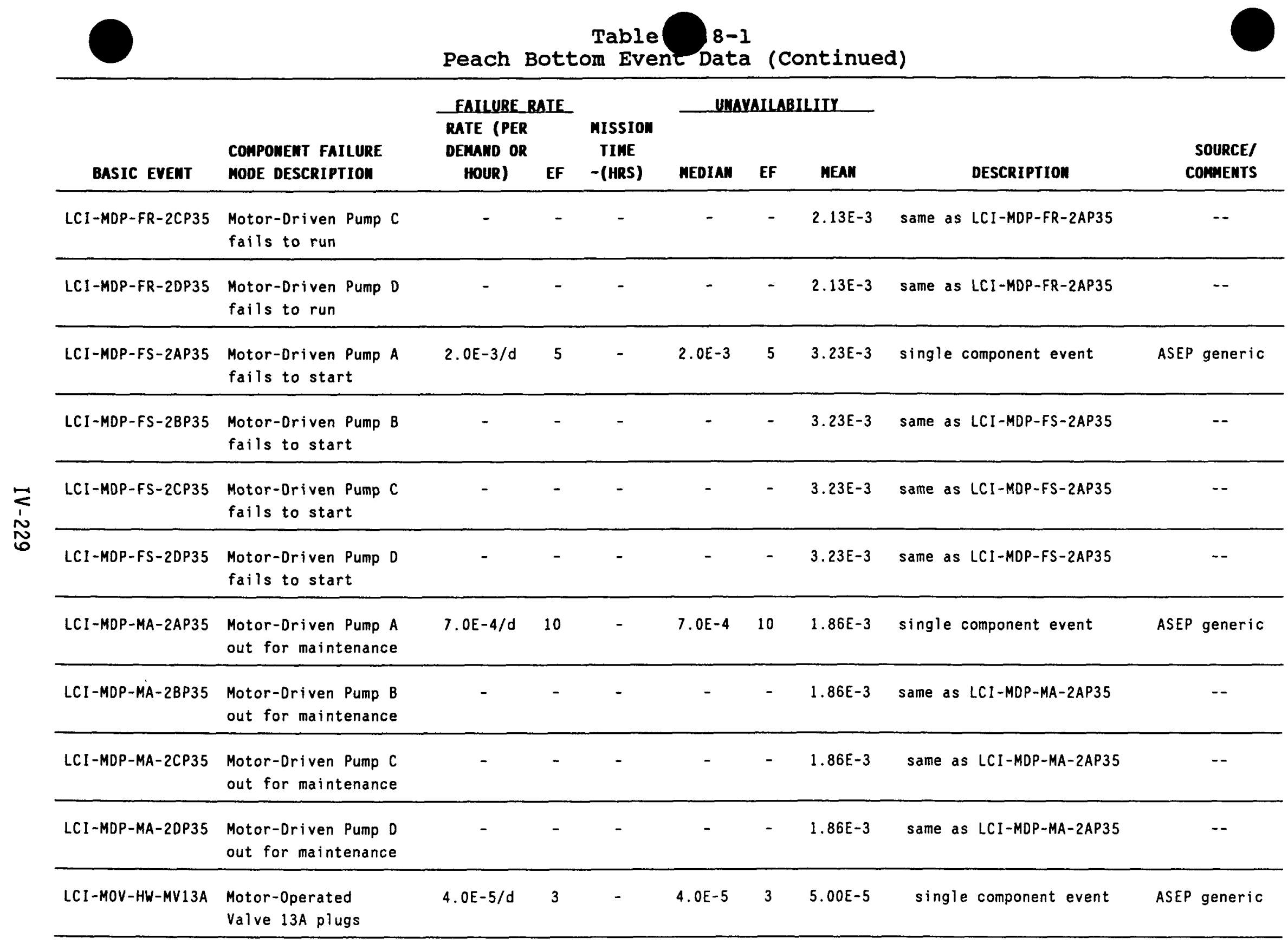


Table IV.8-1

Peach Bottom Event Data (Continued)

\begin{tabular}{|c|c|c|c|c|c|c|c|c|c|}
\hline BASIC EVENT & $\begin{array}{l}\text { COHPONENT FAILURE } \\
\text { MODE DESCRIPTION }\end{array}$ & $\begin{array}{l}\text { FAILURE_R } \\
\text { RATE (PER } \\
\text { DEMAND OR } \\
\text { HOUR) }\end{array}$ & $\begin{array}{l}\text { AIE } \\
\text { EF }\end{array}$ & $\begin{array}{l}\text { MISSION } \\
\text { TIHE } \\
- \text { (HRS) }\end{array}$ & MEDIAN & AILA & LIIY & DESCRIPTION & $\begin{array}{l}\text { SOURCE/ } \\
\text { CONMENTS }\end{array}$ \\
\hline LCI-MOV-HW-MV13B & $\begin{array}{l}\text { Notor-Operated } \\
\text { Valve 13B plugs }\end{array}$ & - & - & - & - & - & $5.00 \mathrm{E}-5$ & same as LCI-MOV-HW-MV13A & -- \\
\hline LCI-MOV-HW-MV13C & $\begin{array}{l}\text { Motor-Operated } \\
\text { Valve } 13 \mathrm{C} \text { plugs }\end{array}$ & - & - & - & - & - & $5.00 E-5$ & same as LCI-MOV-HW-MV13A & -- \\
\hline LCI-MOV-HW-MV13D & $\begin{array}{l}\text { Motor-0perated } \\
\text { Valve } 130 \text { plugs }\end{array}$ & - & - & - & - & - & $5.00 E-5$ & same as LCI-MOV-HW-MV13A & -- \\
\hline LCI-MOV-MA-MVI6A & $\begin{array}{l}\text { Motor-0perated } \\
\text { Valve } 16 \mathrm{~A} \text { out for } \\
\text { maintenance }\end{array}$ & $3.0 E-4 / d$ & 10 & - & $3.0 E-4$ & 10 & $7.99 E-4$ & single component event & ASEP generic \\
\hline LCI-MOV-MA-MVIGB & $\begin{array}{l}\text { Motor-Operated } \\
\text { Valve } 16 B \text { out for } \\
\text { maintenance }\end{array}$ & - & - & - & - & - & $7.99 E-4$ & same as LCI-MOV-MA-MVI6A & -- \\
\hline LCI-MOV-MA-MV $16 C$ & $\begin{array}{l}\text { Motor-Operated } \\
\text { Valve } 16 \mathrm{C} \text { out for } \\
\text { maintenance }\end{array}$ & - & - & - & - & - & $7.99 E-4$ & same as LCI-MOV-MA-MV16A & -- \\
\hline LCI-MOV-MA-MV16D & $\begin{array}{l}\text { Motor-Operated } \\
\text { Valve } 160 \text { out for } \\
\text { maintenance }\end{array}$ & - & - & - & - & - & $7.99 \mathrm{E}-4$ & same as LCI-MOV-MA-MV16A & -- \\
\hline LCI - MOV-MA-MV154A & $\begin{array}{l}\text { Motor-Operated } \\
\text { Valve } 154 \mathrm{~A} \text { out for } \\
\text { maintenance }\end{array}$ & - & - & - & - & - & $7.99 E-4$ & same as LCI-MOV-MA-MV16A & -- \\
\hline LCI-MOV-MA-MV154B & $\begin{array}{l}\text { Motor-Operated } \\
\text { Valve } 154 \mathrm{~B} \text { out for } \\
\text { maintenance }\end{array}$ & - & - & - & - & - & $7.99 \mathrm{E}-4$ & same as LCI-MOV-MA-MV16A & -- \\
\hline
\end{tabular}




\begin{tabular}{|c|c|c|c|c|c|c|c|c|c|}
\hline \multirow[b]{2}{*}{ BASIC EVERT } & \multirow{2}{*}{$\begin{array}{l}\text { COHPONEWT FAILURE } \\
\text { MOOE DESCRIPTION }\end{array}$} & \multicolumn{2}{|c|}{ FAILURE_RAIE_ } & \multirow{2}{*}{$\begin{array}{c}\text { MISSION } \\
\text { TIME } \\
\text { - (HRS) }\end{array}$} & \multicolumn{3}{|c|}{ UMAYAILABILIIY } & \multirow[b]{2}{*}{ DESCRIPTIOM } & \multirow{2}{*}{$\begin{array}{r}\text { SOURCE/ } \\
\text { COMMEMTS }\end{array}$} \\
\hline & & HOUR) & EF & & MEDIAM & EF & MEAM & & \\
\hline LCI-MOV-MA-2677A & $\begin{array}{l}\text { Motor-Operated } \\
\text { Valve } 2677 \mathrm{~A} \text { out for } \\
\text { maintenance }\end{array}$ & - & - & - & - & - & $7.99 E-4$ & same as LCI-MOV-MA-MVI6A & -- \\
\hline LCI-MOV-MA-26770 & $\begin{array}{l}\text { Motor-Operated } \\
\text { Valve } 26770 \text { out for } \\
\text { maintenance }\end{array}$ & - & - & - & - & - & $7.99 E-4$ & same as LCI-MOV-MA-MV16A & -- \\
\hline \multirow[t]{2}{*}{ LCI-PSF-HW-INJ09 } & Pipe Segment 9 fails & - & - & - & - & - & $3.8 E-3$ & $\begin{array}{l}\text { tabular } O R \text { of following } \\
\text { events }\end{array}$ & -- \\
\hline & $\begin{array}{l}\text { Motor-0perated } \\
\text { Valve } 154 \mathrm{~A} \text { plugs }\end{array}$ & 4. $0 E-5 / d$ & 3 & - & $4.0 E-5$ & 3 & - & see above & ASEP generic \\
\hline \multirow[t]{3}{*}{ LCI-PSF-HW-INJ10 } & Pipe Segment 10 fails & - & - & - & - & - & $1.75 E-4$ & $\begin{array}{l}\text { tabular } O R \text { of following } \\
\text { events }\end{array}$ & -- \\
\hline & $\begin{array}{l}\text { Check Valve } 46 \mathrm{~A} \\
\text { fails to open }\end{array}$ & $1.0 E-4 / d$ & 3 & - & $1.0 E-4$ & 3 & - & see above & ASEP generic \\
\hline & $\begin{array}{l}\text { Manual Vaive } 81 \mathrm{~A} \\
\text { plugs }\end{array}$ & $4.0 E-5 / d$ & 3 & - & $4.0 E-5$ & 3 & - & see above & ASEP generic \\
\hline LCI-PSF-HW-INJ19 & Pipe Segment 19 fails & - & - & - & - & - & $3.8 E-3$ & same as LCI-PSF-HW-INJ09 & -- \\
\hline
\end{tabular}


Table IV.8-1

Peach Bottom Event Data (Continued)

\begin{tabular}{|c|c|c|c|c|c|c|c|c|c|}
\hline \multirow[b]{2}{*}{ BASIC EVENT } & \multirow[b]{2}{*}{$\begin{array}{l}\text { COMPONENT FAILURE } \\
\text { HODE DESCRIPTIOA }\end{array}$} & \multicolumn{2}{|c|}{ FALLURE_RAIE_ } & \multirow{2}{*}{$\begin{array}{l}\text { MISSION } \\
\text { TIME } \\
\text {-(HRS) }\end{array}$} & \multicolumn{3}{|c|}{ UIAYAILABILITY } & \multirow[b]{2}{*}{ DESCRIPTION } & \multirow[b]{2}{*}{$\begin{array}{l}\text { SOURCE/ } \\
\text { COMHENTS }\end{array}$} \\
\hline & & $\begin{array}{l}\text { DEHAND OR } \\
\text { HOUR) }\end{array}$ & EF & & MEDIAN & EF & MEAH & & \\
\hline \multirow[t]{3}{*}{ LCI-PSF-HW-MNFOT } & Pipe Segment 7 fails & - & - & - & - & - & $1.75 E-4$ & $\begin{array}{l}\text { tabular OR of following } \\
\text { events }\end{array}$ & -- \\
\hline & $\begin{array}{l}\text { Check Valve } 19 \mathrm{~A} \\
\text { fails to open }\end{array}$ & $1.0 E-4 / d$ & 3 & - & $1.0 \mathrm{E}-4$ & 3 & - & see above & ASEP generic \\
\hline & $\begin{array}{l}\text { Motor-Operated } \\
\text { Valve } 16 \mathrm{~A} \text { plugs }\end{array}$ & $4.0 E-5 / d$ & 3 & - & $4.0 E-5$ & 3 & - & see above & ASEP generic \\
\hline LCI -PSF-HW-MNF 08 & Pipe Segment 8 fails & - & - & - & - & - & $1.75 E-4$ & same as LCI-PSF-HW-MNFOI & -- \\
\hline LCI-PSF-HW-MNF 17 & Pipe Segment 17 fails & - & - & - & - & - & $1.75 \mathrm{E}-4$ & same as LCI-PSF-HW-MNFOZ & -- \\
\hline LCI-PSF-HW-MNF 18 & Pipe Segment 18 fails & - & - & - & - & - & $1.75 \mathrm{E}-4$ & same as LCI-PSF-HW-MNFO7 & -- \\
\hline \multirow[t]{3}{*}{ LCI -PSF-HW-0UT05 } & Pipe Segment 5 fails & - & - & - & - & - & $1.75 \mathrm{E}-4$ & $\begin{array}{l}\text { tabular OR of following } \\
\text { events }\end{array}$ & -- \\
\hline & $\begin{array}{l}\text { Check Valve } 48 \mathrm{~A} \\
\text { fails to open }\end{array}$ & $1.0 E-4 / d$ & 3 & - & $1.0 E-4$ & 3 & - & see above & ASEP generic \\
\hline & Valve $3677 \mathrm{~A}$ plugs & $4.0 E-5 / d$ & 3 & - & $4.0 E-5$ & 3 & - & see above & ASEP generic \\
\hline LCI-PSF-HW-0UT06 & $\begin{array}{l}\text { Check Valve } 48 \mathrm{C} \\
\text { fails to open }\end{array}$ & $1.0 E-4 / d$ & 3 & - & $1.0 \mathrm{E}-4$ & 3 & $1.25 \mathrm{E}-4$ & single component event & ASEP generic \\
\hline LCI-PSF-HW-OUT 15 & $\begin{array}{l}\text { Check Valve } 48 B \\
\text { fails to open }\end{array}$ & - & - & - & - & - & $1.25 \mathrm{E}-4$ & same as LCI-PSF-HW-OUTO6 & -- \\
\hline LCI-PSF-HW-OUT 16 & $\begin{array}{l}\text { Pipe Segment } \\
16 \text { fails }\end{array}$ & - & - & - & - & - & $1.75 E-4$ & same as LCI-PSF-HW-OUTO5 & -- \\
\hline
\end{tabular}




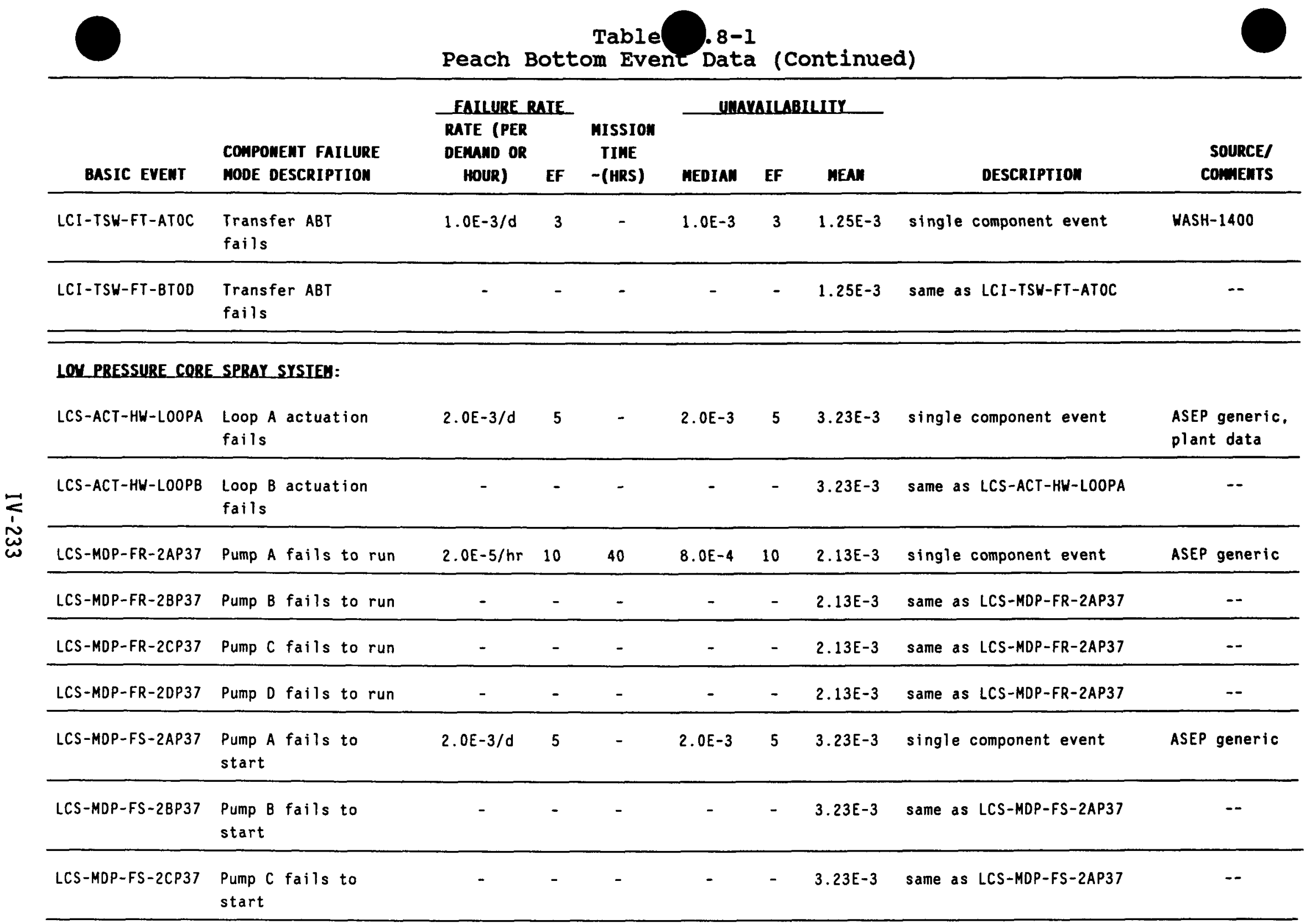


Table IV.8-1

Peach Bottom Event Data (Continued)

\begin{tabular}{|c|c|c|c|c|c|c|c|c|c|}
\hline \multirow[b]{2}{*}{ BASIC EVENT } & \multirow[b]{2}{*}{$\begin{array}{l}\text { COMPONEMT FAILURE } \\
\text { MODE DESCRIPTION }\end{array}$} & \multicolumn{2}{|c|}{ FAILURE_BAIE } & \multirow{2}{*}{$\begin{array}{l}\text { MISSION } \\
\text { TIME } \\
\text { - (HRS) }\end{array}$} & \multicolumn{3}{|c|}{ UNAYAILABILITY } & \multirow[b]{2}{*}{ DESCRIPTION } & \multirow[b]{2}{*}{$\begin{array}{l}\text { SOURCE/ } \\
\text { CONHENTS }\end{array}$} \\
\hline & & $\begin{array}{l}\text { DEMAND OR } \\
\text { HOUR }\end{array}$ & $\mathbf{E F}$ & & MEDIAN & EF & MEAN & & \\
\hline LCS-MDP-FS-2DP37 & $\begin{array}{l}\text { Pump D fails to } \\
\text { start }\end{array}$ & - & - & - & - & - & $3.23 \mathrm{E}-3$ & same as LCS-MDP-FS-2AP37 & -- \\
\hline LCS-MDP-MA-2AP37 & $\begin{array}{l}\text { Pump A out for } \\
\text { maintenance }\end{array}$ & $7.0 E-4 / d$ & 10 & - & $7.0 E-4$ & 10 & $1.86 \mathrm{E}-3$ & single component event & ASEP generic \\
\hline LCS-MDP-MA-2BP37 & $\begin{array}{l}\text { Pump B out for } \\
\text { maintenance }\end{array}$ & - & - & - & - & - & $1.86 \mathrm{E}-3$ & same as LCS-MDP-MA-2AP37 & -- \\
\hline LCS-MDP-MA-2CP37 & $\begin{array}{l}\text { Pump C out for } \\
\text { maintenance }\end{array}$ & - & - & - & - & - & $1.86 \mathrm{E}-3$ & same as LCS-MDP-MA-2AP37 & -- \\
\hline LCS-MDP-MA-2DP37 & $\begin{array}{l}\text { Pump } D \text { out for } \\
\text { maintenance }\end{array}$ & - & - & - & - & - & $1.86 \mathrm{E}-3$ & same as LCS-MDP-MA-2AP37 & -- \\
\hline LCS-MOV-CO-MV $26 A$ & $\begin{array}{l}\text { Motor-Operated } \\
\text { Valve } 26 \mathrm{~A} \text { fails } \\
\text { to remain closed }\end{array}$ & $1.0 E-4 / d$ & 3 & - & $1.0 E-4$ & 3 & $1.25 E-4$ & single component event & ASEP generic \\
\hline LCS-MOV-CO-MV26B & $\begin{array}{l}\text { Motor-Operated } \\
\text { Valve } 26 B \text { fails to } \\
\text { remain closed }\end{array}$ & - & - & - & - & - & $1.25 E-4$ & same as LCS-MOV-CO-MV26A & -- \\
\hline LCS-MOV-HW-MV7A & $\begin{array}{l}\text { Motor-Operated } \\
\text { Valve } 7 \mathrm{~A} \text { fails to } \\
\text { remain open }\end{array}$ & $1.0 E-4 / d$ & 3 & - & $1.0 E-4$ & 3 & $1.25 E-4$ & single component event & ASEP generic \\
\hline LCS-MOV-HW-MV7B & $\begin{array}{l}\text { Motor-Operated } \\
\text { Valve } 7 B \text { fails to } \\
\text { remain open }\end{array}$ & - & - & - & - & - & $1.25 \mathrm{E}-4$ & same as LCS-MOV-HW-MV7A & -- \\
\hline
\end{tabular}




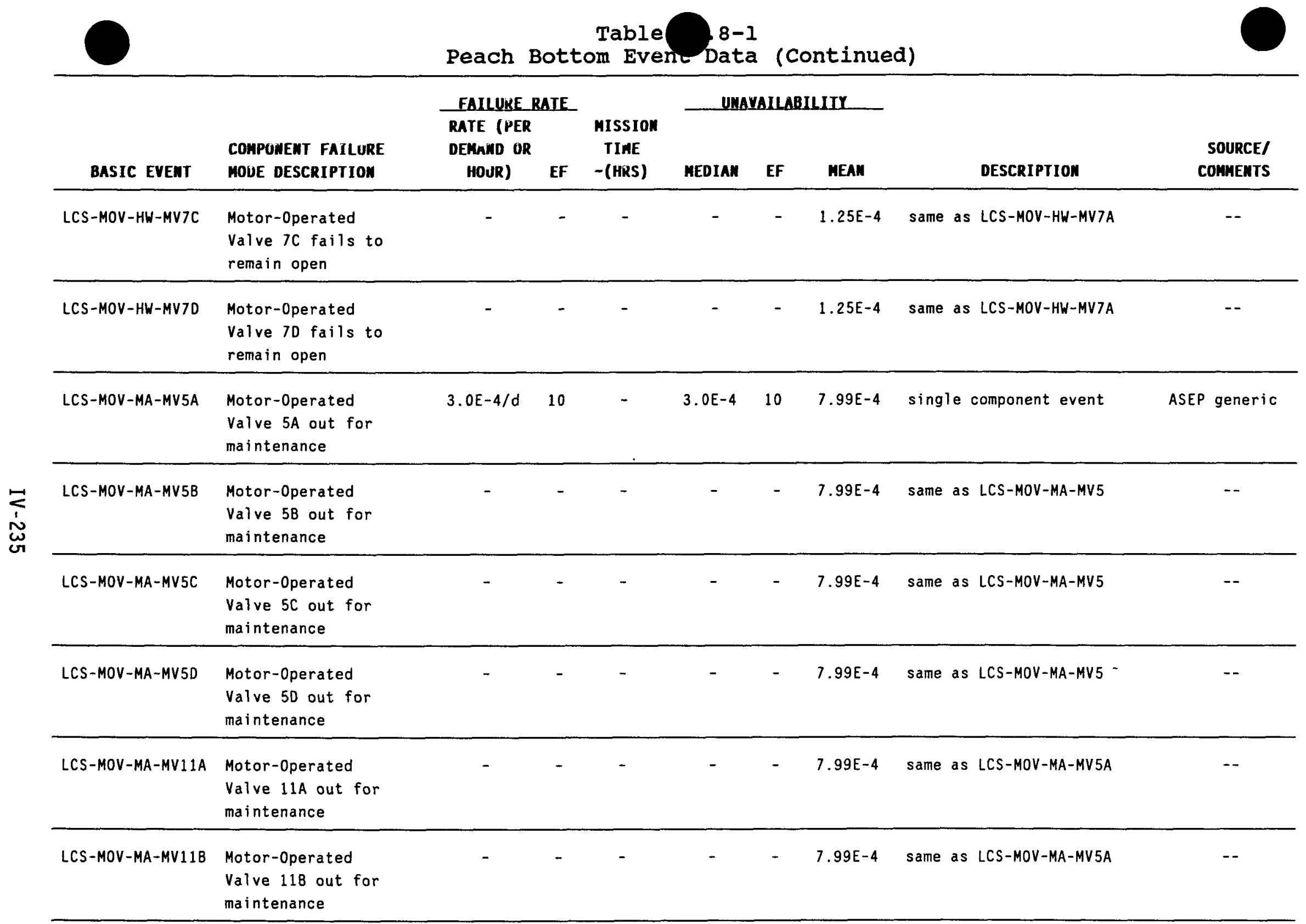


Table IV.8-1

Peach Bottom Event Data (Continued)

\begin{tabular}{|c|c|c|c|c|c|c|c|c|c|}
\hline \multirow[b]{2}{*}{ BASIC EVEHT } & \multirow{2}{*}{$\begin{array}{l}\text { COHPONEMT FAILURE } \\
\text { HODE DESCRIPTION }\end{array}$} & \multicolumn{2}{|c|}{ FAILURE_RAIE_ } & \multirow{2}{*}{$\begin{array}{c}\text { MISSION } \\
\text { TIME } \\
\text { - (HRS) }\end{array}$} & \multicolumn{3}{|c|}{ UMAYAILABILITY } & \multirow[b]{2}{*}{ DESCRIPTION } & \multirow{2}{*}{$\begin{array}{l}\text { SOURCE/ } \\
\text { COHMENTS }\end{array}$} \\
\hline & & HOUR) & EF & & MEDIAN & EF & MEAI & & \\
\hline \multirow[t]{3}{*}{ LCS-PSF-HW-INJ13 } & Pipe Segment 13 fails & - & - & - & - & - & $3.8 \mathrm{E}-3$ & $\begin{array}{l}\text { tabular } O R \text { of following } \\
\text { events }\end{array}$ & -- \\
\hline & $\begin{array}{l}\text { Motor-Operated Valve } \\
12 \mathrm{~A} \text { fails to open }\end{array}$ & $3.0 E-3 / d$ & 3 & - & $3.0 \mathrm{E}-3$ & 3 & - & see above & ASEP generic \\
\hline & $\begin{array}{l}\text { Motor-0perated } \\
\text { Valve } 11 \mathrm{~A} \text { plugs }\end{array}$ & $4.0 E-5 / d$ & 3 & - & $4.0 E-5$ & 3 & - & see above & ASEP generic \\
\hline \multirow[t]{3}{*}{ LCS-PSF-HW-INJ14 } & Pipe Segment 14 fails & - & - & - & - & - & $1.75 E-4$ & $\begin{array}{l}\text { tabular OR of following } \\
\text { events }\end{array}$ & -- \\
\hline & $\begin{array}{l}\text { Check Valve } 13 A \\
\text { fails to open }\end{array}$ & $1.0 \mathrm{E}-4 / \mathrm{d}$ & 3 & - & $1.0 E-4 / d$ & 3 & - & see above & ASEP generic \\
\hline & $\begin{array}{l}\text { Manual Valve } 14 \mathrm{~A} \\
\text { plugs }\end{array}$ & $4.0 E-5 / d$ & 3 & - & $4.0 E-5$ & 3 & - & see above & ASEP generic \\
\hline LCS-PSF-HW-INJ27 & Pipe Segment 27 fails & - & - & - & - & - & $3.8 E-3$ & same as LCS-PSF-HW-INJ13 & -- \\
\hline LCS-PSF-HW-INJ28 & Pipe Segment 28 fails & - & - & - & - & - & $1.75 \mathrm{E}-4$ & same as LCS-PSF-HW-INJ14 & -- \\
\hline \multirow[t]{3}{*}{ LCS-PSF-HW-MNFO8 } & Pipe Segment 8 fails & - & - & - & - & - & $1.75 \mathrm{E}-4$ & $\begin{array}{l}\text { tabular } O R \text { of following } \\
\text { events }\end{array}$ & -- \\
\hline & $\begin{array}{l}\text { Check Valve } 66 \mathrm{C} \\
\text { fails to open }\end{array}$ & $1.0 E-4 / d$ & 3 & - & $1.0 \mathrm{E}-4$ & 3 & - & see above & ASEP generic \\
\hline & $\begin{array}{l}\text { Motor-Operated } \\
\text { Valve } 5 C \text { plugs }\end{array}$ & $4.0 E-5 / d$ & 5 & - & $4.0 E-5$ & 3 & - & see above & ASEP generic \\
\hline LCS-PSF-HW-MNFO9 & Pipe Segment 9 fails & - & - & - & - & - & $1.75 E-4$ & same as LCS-PSF-HW-MNFO8 & -- \\
\hline
\end{tabular}




\begin{tabular}{|c|c|c|c|c|c|c|c|c|c|}
\hline & & FAILURE $R$ & AIE & & UMA & AlLA & ILITY & & \\
\hline BASIC EVEMT & $\begin{array}{l}\text { COMPOMEMT FAILURE } \\
\text { MODE DESCRIPTION }\end{array}$ & $\begin{array}{l}\text { DEMAND OR } \\
\text { HOUR) }\end{array}$ & EF & $\begin{array}{l}\text { TINE } \\
\text { - (HRS) }\end{array}$ & MEDIAK & EF & MEAM & DESCRIPIION & $\begin{array}{r}\text { SOURCE/ } \\
\text { COMMENTS }\end{array}$ \\
\hline LCS-PSF-HW-MNF22 & Pipe Segment 22 fails & - & - & - & - & - & $1.75 \mathrm{E}-4$ & same as LCS-PSF-HW-MNF08 & -- \\
\hline LCS-PSF-HW-MNF23 & Pipe Segment 23 fails & - & - & - & - & - & $1.75 \mathrm{E}-4$ & same as LCS-PSF-HW-MNF08 & -- \\
\hline \multirow[t]{3}{*}{ LCS-PSF-HW-OUT10 } & Pipe Segment 10 fails & - & - & - & - & - & $1.75 E-4$ & $\begin{array}{l}\text { tabular } O R \text { of following } \\
\text { events }\end{array}$ & -- \\
\hline & $\begin{array}{l}\text { Check Valve } 10 \mathrm{C} \\
\text { fails to open }\end{array}$ & $1.0 E-4 / d$ & 3 & - & $1.0 E-4$ & 3 & - & see above & ASEP generic \\
\hline & $\begin{array}{l}\text { Manual Valve } 63 \mathrm{C} \\
\text { plugs }\end{array}$ & $4.0 E-5 / d$ & 3 & - & $4.0 E-5$ & 3 & - & see above & ASEP generic \\
\hline LCS-PSF-HW-OUT11 & Pipe Segment 11 fails & - & - & - & - & - & $1.75 E-4$ & same as LCS-PSF-HW-OUT10 & - \\
\hline LCS-PSF-HW-OUT24 & Pipe Segment 24 fails & - & - & - & - & - & $1.75 E-4$ & same as LCS-PSF-HW-OUT10 & - \\
\hline LCS-PSF-HW-OUT25 & Pipe Segment 25 fails & - & - & - & - & - & $1.75 \mathrm{E}-4$ & same as LCS-PSF-HW-OUT10 & -- \\
\hline \multicolumn{10}{|l|}{ HISCELLAMEOUS: } \\
\hline CST-PSF-CSTLOST & CST inventory is lost & - & - & - & - & - & negligible & single component event & -- \\
\hline CST-PSF-DEPLETED & CST depleted & - & - & - & - & - & $\begin{array}{l}1.0 \\
\text { or } \\
0.0\end{array}$ & house event & -- \\
\hline ESF-ASL-LRXLEVEL & $\begin{array}{l}\text { reactor water leve? } \\
\text { is below the shroud }\end{array}$ & - & - & - & - & - & $\begin{array}{l}1.0 \\
\text { or } \\
0.0\end{array}$ & house event & -- \\
\hline
\end{tabular}


Table IV.8-1

Peach Bottom Event Data (Continued)

\begin{tabular}{|c|c|c|c|c|c|c|c|c|c|}
\hline BASIC EVENT & $\begin{array}{l}\text { CONPONENT FAILURE } \\
\text { MODE DESCRIPTION }\end{array}$ & $\begin{array}{l}\text { FBILURE_B } \\
\text { RATE (PER } \\
\text { DEMAND OR } \\
\text { HOUR) }\end{array}$ & AIE. & $\begin{array}{l}\text { MISSIOH } \\
\text { TINE } \\
\text {-(HRS) }\end{array}$ & UNA & AILAI & MEAN & DESCRIPTION & $\begin{array}{l}\text { SOURCE/ } \\
\text { COMHENTS }\end{array}$ \\
\hline ESF-ASP-HIDWPRES & $\begin{array}{l}\text { drywel1 pressure } \\
\text { above SDCS pressure } \\
\text { range }\end{array}$ & - & - & - & - & - & $\begin{array}{l}1.0 \\
\text { or } \\
0.0\end{array}$ & house event & -- \\
\hline ESF-ASP-NOHDPEL & $\begin{array}{l}\text { no high drywell } \\
\text { pressure signal } \\
\text { early }\end{array}$ & - & - & - & - & - & $\begin{array}{l}1.0 \\
\text { or } \\
0.0\end{array}$ & house event, 30 minutes & -- \\
\hline ESF-ASP-NOHDPLT & $\begin{array}{l}\text { no high drywell } \\
\text { pressure signal } \\
\text { late }\end{array}$ & - & - & - & - & - & $\begin{array}{l}1.0 \\
\text { or } \\
0.0\end{array}$ & house event, $>1$ hour & -- \\
\hline ESF-PER-LCI $3 A C T 2$ & $\begin{array}{l}\text { Unit } 2 \text { in RHR mode. } \\
\text { Unit } 3 \text { has LPCI } \\
\text { injection demand }\end{array}$ & - & - & - & - & 10 & $1.25 \mathrm{E}-5$ & $\begin{array}{l}\text { Unit } 3 \text { HPCI, RCIC, CRD } \\
\text { must all fail }\end{array}$ & $\begin{array}{l}\text { plant data \& } \\
\text { knowledge of } \\
\text { accident } \\
\text { probabilities }\end{array}$ \\
\hline ESF-PER-LCI $13 A C T$ & $\begin{array}{l}\text { Units } 2,3 \text { both } \\
\text { demand } L P C I \\
\text { injection }\end{array}$ & - & - & - & - & 10 & $5.00 E-4$ & $\begin{array}{l}\text { Unit } 3 \text { HPCI,RCIC, CRO } \\
\text { must all fail after } \\
\text { an LOSP }\end{array}$ & $\begin{array}{l}\text { plant data \& } \\
\text { knowledge of } \\
\text { accident } \\
\text { probabilities }\end{array}$ \\
\hline ESF-PER-LIA3TEST & $\begin{array}{l}\text { LPCI Pump A3 not in } \\
\text { test }\end{array}$ & - & - & - & - & 1 & 1.0 & single component event & plant data \\
\hline ESF-PER-LIB3TEST & $\begin{array}{l}\text { LPCI Pump B3 not in } \\
\text { test }\end{array}$ & - & - & - & - & 1 & 1.0 & same as ESF-PER-LIA3TEST & -- \\
\hline ESF-PER-LIC3TEST & $\begin{array}{l}\text { LPCI Pump C3 not in } \\
\text { test }\end{array}$ & - & - & - & - & 1 & 1.0 & same as ESF-PER-LIA3TEST & -- \\
\hline ESF-PER-LID3TEST & $\begin{array}{l}\text { LPCI Pump D3 not in } \\
\text { test }\end{array}$ & - & - & - & - & 1 & 1.0 & same as ESF-PER-LIA3TEST & -- \\
\hline
\end{tabular}




\begin{tabular}{|c|c|c|c|c|c|c|c|c|c|}
\hline \multirow[b]{2}{*}{ BASIC EVENT } & \multirow[b]{2}{*}{$\begin{array}{l}\text { COMPONENT FAILURE } \\
\text { MODE DESCRIPIION }\end{array}$} & \multicolumn{2}{|c|}{ FAILURE RATE } & \multirow{2}{*}{$\begin{array}{l}\text { MISSION } \\
\text { TIME } \\
\text {-(HRS) }\end{array}$} & \multicolumn{3}{|c|}{ UMAYAILABILIIY } & \multirow[b]{2}{*}{ DESCRIPTION } & \multirow[b]{2}{*}{$\begin{array}{l}\text { SOURCE/ } \\
\text { COMAEnTS }\end{array}$} \\
\hline & & $\begin{array}{l}\text { DEMAMD OR } \\
\text { HOUR) }\end{array}$ & $\mathbf{E F}$ & & MEOIAN & EF & MEAI & & \\
\hline ESF-PER-RXLNTMET & $\begin{array}{l}\text { reactor level is } \\
\text { below the shroud } \\
\text { level }\end{array}$ & - & - & - & - & - & $\begin{array}{l}1.00 \\
\text { or } \\
0.00\end{array}$ & house event & \\
\hline LOSP & $\begin{array}{l}\text { subsequent loss of } \\
\text { offsite power } \\
\text { following a plant } \\
\text { trip }\end{array}$ & $1.0 E-3 / d$ & 10 & N/A & $1.0 \mathrm{E}-3$ & 10 & $2.66 \mathrm{E}-3$ & -- & ASEP generic \\
\hline PCSLOST & $\begin{array}{l}\text { subsequent loss of } \\
\text { PCS following a } \\
\text { plant trip }\end{array}$ & $1.0 E-2 / d$ & 10 & $N / A$ & - & 10 & $1.0 E-2$ & -- & $\begin{array}{l}\text { WASH-1400, } \\
\text { ASEP generic }\end{array}$ \\
\hline $\begin{array}{l}\text { REACTOR_BUILDIMG } \\
\text { [see Note (a)] } \\
\text { RBC-VFC-FC-RBCWS }\end{array}$ & $\begin{array}{l}\text { COOLING NAIER_SYSIEM: } \\
\text { RBCWS fails }\end{array}$ & - & - & - & - & - & $5.00 E-3$ & $\begin{array}{l}\text { tabular OR basic event } \\
=(\text { Pump } A) \times \text { (Pump B) } \\
+ \text { (air-operated valve) }\end{array}$ & -- \\
\hline & $\begin{array}{l}\text { RBCW Pump A } \\
\text { fails to run }\end{array}$ & $2.0 \mathrm{E}-5 / \mathrm{hr}$ & 10 & 40 & $8.0 E-4$ & 10 & - & see above & ASEP generic \\
\hline & $\begin{array}{l}\text { RBCW Pump A out for } \\
\text { maintenance }\end{array}$ & $7.0 E-4 / d$ & 10 & - & $7.0 E-4$ & 10 & - & see above & ASEP generic \\
\hline
\end{tabular}

Note:

(a) Modeled in Instrument Air System tree. 
Table IV.8-1

Peach Bottom Event Data (Continued)

\begin{tabular}{|c|c|c|c|c|c|c|c|c|c|}
\hline \multirow[b]{2}{*}{ BASIC EVENT } & \multirow[b]{2}{*}{$\begin{array}{l}\text { CONPONENT FAILURE } \\
\text { MODE DESCRIPTION }\end{array}$} & \multicolumn{2}{|c|}{ FAILURE_RATE } & \multirow{2}{*}{$\begin{array}{l}\text { MISSION } \\
\text { TIME } \\
\text {-(HRS) }\end{array}$} & \multicolumn{3}{|c|}{ UNAYAILABILIIY } & \multirow[b]{2}{*}{ DESCRIPTION } & \multirow[b]{2}{*}{$\begin{array}{l}\text { SOURCE/ } \\
\text { CONMENTS }\end{array}$} \\
\hline & & $\begin{array}{l}\text { DOUR) } \\
\text { HOUN }\end{array}$ & $\mathbf{E F}$ & & MEDIAN & EF & MEAN & & \\
\hline \multirow[t]{4}{*}{$\begin{array}{l}\text { RBC-VFC-FC-RBCWS } \\
\text { (Concl uded) }\end{array}$} & $\begin{array}{l}\text { RBCW Pump B } \\
\text { fails to run }\end{array}$ & $2.0 \mathrm{E}-5 / \mathrm{hr}$ & 10 & 40 & $8.0 E-4$ & 10 & - & see above & ASEP generic \\
\hline & $\begin{array}{l}\text { RBCW Pump B out for } \\
\text { maintenance }\end{array}$ & $7.0 E-4 / d$ & 10 & - & $7.0 E-4$ & 10 & - & see above & ASEP generic \\
\hline & $\begin{array}{l}\text { Air-Operated Valve } \\
8156 \text { fails to open }\end{array}$ & $3.0 E-3 / d$ & 3 & - & $3.0 \mathrm{E}-3$ & 3 & - & see above & ASEP generic \\
\hline & $\begin{array}{l}\text { Valve } 8156 \text { out for } \\
\text { maintenance }\end{array}$ & $3.0 E-4 / d$ & 10 & - & $3.0 \mathrm{E}-4$ & 10 & - & see above & ASEP generic \\
\hline RBC-XHE-FO-SWCH & $\begin{array}{l}\text { operator fails to } \\
\text { switch to RBCWS } \\
\text { following LOSP }\end{array}$ & - & - & - & - & 10 & $1.0 E-2$ & single event, 30 minutes & $\begin{array}{l}\text { generic } \\
\text { experience/ } \\
\text { HRA [26] }\end{array}$ \\
\hline \multicolumn{10}{|c|}{ REACTOR_CORE_ISOLAIUON_COOLING_SYSIEY : } \\
\hline RCI-ACT-HW-LOCST & $\begin{array}{l}\text { failure of low CST } \\
\text { circuitry for RCIC }\end{array}$ & $2.0 E-3 / d$ & 5 & - & $2.0 E-3$ & 5 & $3.23 E-3$ & single component event & $\begin{array}{l}\text { WASH- } 1400, \\
\text { plant data }\end{array}$ \\
\hline$R C I-A C T-H W-R C I C$ & actuation fails & $2 . O E-3 / d$ & 5 & - & $2.0 E-3$ & 5 & $3.23 E-3$ & single component event & $\begin{array}{l}\text { ASEP generic. } \\
\text { plant data }\end{array}$ \\
\hline RCI-ICC-HW-FIC91 & $\begin{array}{l}\text { flow controller } \\
\text { fails }\end{array}$ & $1.0 E-4 / d$ & 3 & - & $1.0 E-4$ & 3 & $1.25 \mathrm{E}-4$ & single component event & WASH-1400 \\
\hline RCI-MOV-HW-MV15 & $\begin{array}{l}\text { Motor-Operated Valve } \\
15 \text { fails to remain } \\
\text { open }\end{array}$ & $1.0 E-4 / d$ & 3 & - & $1.0 E-4$ & 3 & $1.25 \mathrm{E}-4$ & single component event & ASEP generic \\
\hline
\end{tabular}




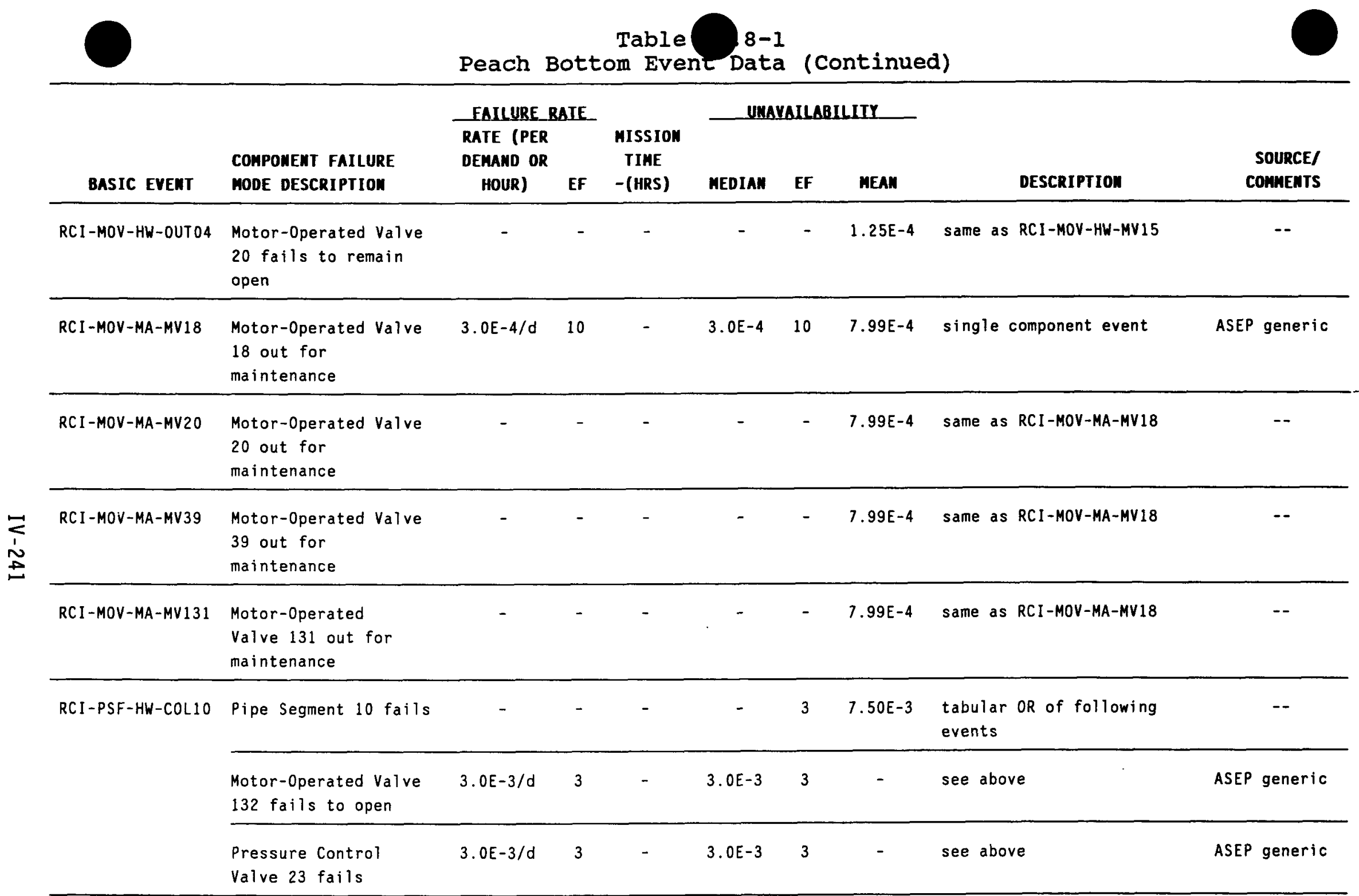


Table IV.8-1

Peach Bottom Event Data (Continued)

\begin{tabular}{|c|c|c|c|c|c|c|c|c|c|}
\hline \multirow[b]{2}{*}{ BASIC EVEMT } & \multirow[b]{2}{*}{$\begin{array}{l}\text { CONPONENT FAILURE } \\
\text { MODE DESCRIPTION }\end{array}$} & \multicolumn{2}{|c|}{ FAILURE BAIE } & \multirow{2}{*}{$\begin{array}{l}\text { MISSION } \\
\text { TIME } \\
\text { - (HRS) }\end{array}$} & \multicolumn{3}{|c|}{ UMAVALLBILIIY } & \multirow[b]{2}{*}{ DESCRIPTION } & \multirow[b]{2}{*}{$\begin{array}{l}\text { SOURCE/ } \\
\text { COMHEnTS }\end{array}$} \\
\hline & & $\begin{array}{l}\text { DEMAND OR } \\
\text { HOUR) }\end{array}$ & $\mathbf{E F}$ & & MEDIAN & EF & MEAN & & \\
\hline \multirow[t]{4}{*}{ RCI-PSF-HW-CSTOI } & Pipe Segment 1 fails & - & - & - & - & - & $2.25 E-4$ & $\begin{array}{l}\text { tabular } O R \text { of following } \\
\text { events }\end{array}$ & -- \\
\hline & $\begin{array}{l}\text { Check Valve } 19 \\
\text { fails to open }\end{array}$ & $1.0 E-4 / d$ & 3 & - & $1.0 E-4$ & 3 & - & see above & ASEP generic \\
\hline & $\begin{array}{l}\text { Manual Valve } 17 \\
\text { plugs }\end{array}$ & $4.0 E-5 / d$ & 3 & - & $4.0 E-5$ & 3 & - & see above & ASEP generic \\
\hline & $\begin{array}{l}\text { Motor-Operated } \\
\text { Valve } 18 \text { plugs }\end{array}$ & $4.0 E-5 / d$ & 3 & - & $4.0 E-5$ & 3 & - & see above & ASEP generic \\
\hline \multirow[t]{3}{*}{ RCI-PSF-HW-DIS12 } & Pipe Segment 12 fails & - & - & - & - & - & $1.75 E-4$ & $\begin{array}{l}\text { tabular } O R \text { of following } \\
\text { events }\end{array}$ & -- \\
\hline & $\begin{array}{l}\text { Check Valve } 50 \\
\text { fails to open }\end{array}$ & $1.0 E-4 / d$ & 3 & - & $1.0 E-4 / d$ & 3 & - & see above & ASEP generic \\
\hline & $\begin{array}{l}\text { Manual Valve } 9 \\
\text { plugs }\end{array}$ & 4. $0 E-5 / d$ & 3 & - & 4.0E-5 & 3 & - & see above & ASEP generic \\
\hline \multirow[t]{3}{*}{ RCI - PSF-HW-INJ06 } & Pipe Segment 6 fails & - & - & - & - & 3 & $3.8 E-3$ & $\begin{array}{l}\text { tabular OR of following } \\
\text { events }\end{array}$ & -- \\
\hline & $\begin{array}{l}\text { Motor-Operated Valve } \\
21 \text { fails to open }\end{array}$ & $3.0 E-3 / d$ & 3 & - & $3.0 E-3$ & 3 & - & see above & ASEP generic \\
\hline & $\begin{array}{l}\text { Check Valve } 22 \\
\text { fails to open }\end{array}$ & $1.0 E-4 / d$ & 3 & - & $1.0 E-4$ & 3 & - & see above & ASEP generic \\
\hline
\end{tabular}




\begin{tabular}{|c|c|c|c|c|c|c|c|c|c|}
\hline & & FAILURE R & AIE & & _ UMA & AILA & LLIIY & & \\
\hline BASIC EVEMT & MODE DESCRIPTION & HOUR) & $\mathrm{EF}$ & $-($ HRS $)$ & MEDIAM & EF & MEAN & DESCRIPTION & COHAREMTS \\
\hline \multirow[t]{4}{*}{ RCI-PSF-HW-SPO2 } & Pipe Segment 2 fails & - & - & - & - & - & $7.6 \mathrm{E}-3$ & $\begin{array}{l}\text { tabular } O R \text { of following } \\
\text { events }\end{array}$ & -- \\
\hline & $\begin{array}{l}\text { Motor-Operated Valve } \\
39 \mathrm{fails} \text { to open }\end{array}$ & $3.0 E-3 / d$ & 3 & - & $3.0 \mathrm{E}-3$ & 3 & - & see above & ASEP generic \\
\hline & $\begin{array}{l}\text { Motor-Operated Valve } \\
41 \mathrm{fails} \text { to open }\end{array}$ & $3.0 E-3 / d$ & 3 & - & $3.0 \mathrm{E}-3$ & 3 & - & see above & ASEP generic \\
\hline & $\begin{array}{l}\text { Check Valve } 40 \\
\text { fails to open }\end{array}$ & $1.0 E-4 / d$ & 3 & - & $1.0 E-4$ & 3 & - & see above & ASEP generic \\
\hline \multirow[t]{3}{*}{ RCI-PSF-HW-SUPO9 } & Pipe Segment 9 fails & - & - & - & - & 3 & $3.75 E-3$ & $\begin{array}{l}\text { tabular } O R \text { of following } \\
\text { events }\end{array}$ & -- \\
\hline & $\begin{array}{l}\text { Motor-Operated Valve } \\
131 \text { fails to open }\end{array}$ & $3.0 E-3 / d$ & 3 & - & $3.0 \mathrm{E}-3$ & 3 & - & see above & ASEP generic \\
\hline & Valve 131 plugs & $4.0 E-5 / d$ & 3 & - & $4.0 E-5$ & 3 & - & see above & ASEP generic \\
\hline \multirow[t]{3}{*}{ RCI-PSF-MA-COL10 } & $\begin{array}{l}\text { Pipe Segment } 10 \\
\text { out for maintenance }\end{array}$ & - & - & - & - & - & $1.60 E-3$ & $\begin{array}{l}\text { tabular } O R \text { of following } \\
\text { events }\end{array}$ & -- \\
\hline & $\begin{array}{l}\text { Motor-Operated } \\
\text { Valve } 132 \text { out for } \\
\text { maintenance }\end{array}$ & $3.0 E-4 / d$ & 10 & - & $3.0 E-4$ & 10 & - & see above & ASEP generic \\
\hline & $\begin{array}{l}\text { Pressure Control } \\
\text { Valve } 23 \text { out for } \\
\text { maintenance }\end{array}$ & $3.0 E-4 / d$ & 10 & - & $3.0 E-4$ & 10 & - & see above & ASEP generic \\
\hline
\end{tabular}


Table IV. 8-1

Peach Bottom Event Data (Continued)

\begin{tabular}{|c|c|c|c|c|c|c|c|c|c|}
\hline \multirow[b]{2}{*}{ BASIC EVENT } & \multirow[b]{2}{*}{$\begin{array}{l}\text { COMPONENT FAILURE } \\
\text { MODE DESCRIPTION }\end{array}$} & \multicolumn{2}{|c|}{ FAILURE RAIE } & \multirow{2}{*}{$\begin{array}{l}\text { MISSIOH } \\
\text { TIME } \\
\text {-(HRS) }\end{array}$} & \multicolumn{3}{|c|}{ UNAVALLABILITY } & \multirow[b]{2}{*}{ DESCRIPTION } & \multirow[b]{2}{*}{$\begin{array}{r}\text { SOURCE/ } \\
\text { COMHENTS }\end{array}$} \\
\hline & & $\begin{array}{l}\text { DERAMD OR } \\
\text { HOUR) }\end{array}$ & $\mathbf{E F}$ & & MEDIAK & EF & MEAN & & \\
\hline RCI - TOP-FR-20S38 & $\begin{array}{l}\text { turbine-driven } \\
\text { pump fails to run }\end{array}$ & $5.0 \mathrm{E}-3 / \mathrm{hr}$ & 10 & 5 & - & 10 & $2.5 E-2$ & single component event & plant data \\
\hline RCI -TDP-FS-20S38 & $\begin{array}{l}\text { turbine-driven } \\
\text { pump fails to } \\
\text { start }\end{array}$ & $3.0 E-2 / d$ & 5 & - & $3.0 E-2$ & 5 & $4.84 E-2$ & single component event & ASEP generic \\
\hline RCI-TDP-MA-20S38 & $\begin{array}{l}\text { turbine-driven } \\
\text { pump out for } \\
\text { maintenance }\end{array}$ & $6.0 E-3 / d$ & 10 & - & $6.0 E-3$ & 10 & $1.60 \mathrm{E}-2$ & single component event & ASEP generic \\
\hline
\end{tabular}

\section{SUPPRESSIOY POOL COOLIMG SYSTEY (RHR):}

to open

RHR-MOV-CC-MV34B Motor-Operated

Valve 348 fails

to open

\section{RHR-MOV-CC-MV39A Motor-Operated \\ Valve $39 \mathrm{~A}$ fails \\ to open}

RHR-MOV-CC-MV39B Motor-Operated

Valve 39B fails

to open 


\begin{tabular}{|c|c|c|c|c|c|c|c|c|c|}
\hline \multirow[b]{2}{*}{ BASIC EVERT } & \multirow{2}{*}{$\begin{array}{l}\text { COHPONEMT FAILURE } \\
\text { MOOE DESCRIPIION }\end{array}$} & \multicolumn{2}{|c|}{ FAILURE RAIE } & \multirow{2}{*}{$\begin{array}{l}\text { MISSION } \\
\text { TIME } \\
- \text { - (HRS) }\end{array}$} & \multicolumn{3}{|c|}{ UMAVAILABILITY } & \multirow[b]{2}{*}{ DESCRIPTION } & \multirow{2}{*}{$\begin{array}{l}\text { SOURCE/ } \\
\text { COMHEMTS }\end{array}$} \\
\hline & & HOUR) & EF & & MEDIAM & EF & MEAN & & \\
\hline RHR-MOV-MA-MV39A & $\begin{array}{l}\text { Motor-Operated } \\
\text { Valve } 39 \mathrm{~A} \text { out } \\
\text { for maintenance }\end{array}$ & $3.0 E-4 / d$ & 10 & - & $3.0 \mathrm{E}-4$ & 10 & $7.99 \mathrm{E}-4$ & single component event & ASEP generic \\
\hline RHR-MOV-MA-MV39B & $\begin{array}{l}\text { Motor-Operated } \\
\text { Valve } 39 B \text { out for } \\
\text { maintenance }\end{array}$ & - & - & - & - & - & $7.99 \mathrm{E}-4$ & same as RHR-MOV-MA-MV39A & -- \\
\hline \multicolumn{10}{|c|}{ SHUIDOYH_COOLIHG_SYSIEK_(RHR): } \\
\hline SOC-MOV-CC-MV15A & $\begin{array}{l}\text { Motor-Operated } \\
\text { Valve } 15 \mathrm{~A} \text { fails } \\
\text { to open }\end{array}$ & $3.0 E-3 / d$ & 3 & - & $3.0 \mathrm{E}-3$ & 3 & $3.75 \mathrm{E}-3$ & single component event & ASEP generic \\
\hline SDC-MOV-CC-MV15B & $\begin{array}{l}\text { Motor-Operated } \\
\text { Valve } 158 \text { fails } \\
\text { to open }\end{array}$ & - & - & - & - & - & $3.75 \mathrm{E}-3$ & same as SDC-MOV-CC-MV15A & - \\
\hline SDC-MOV-CC-MV15C & $\begin{array}{l}\text { Motor-Operated } \\
\text { Valve } 15 \mathrm{C} \text { fails } \\
\text { to open }\end{array}$ & - & - & - & - & - & $3.75 E-3$ & same as SOC-MOV-CC-MV15A & -- \\
\hline SDC-MOV-CC-MV15D & $\begin{array}{l}\text { Motor-Operated } \\
\text { Valve } 150 \text { fails } \\
\text { to open }\end{array}$ & - & - & - & - & - & $3.75 E-3$ & same as SDC-MOV-CC-MV15A & -- \\
\hline SDC-MOV-CC-MV17 & $\begin{array}{l}\text { Motor-Operated } \\
\text { Valve } 17 \text { fails } \\
\text { to open }\end{array}$ & - & - & - & - & - & $3.75 E-3$ & same as SDC-MOV-CC-MV15A & -- \\
\hline SDC-MOV-MA-MV15A & $\begin{array}{l}\text { Motor-Operated } \\
\text { Valve } 15 \mathrm{~A} \text { out } \\
\text { for maintenance }\end{array}$ & $3.0 E-4 / d$ & 10 & - & $3.0 E-4$ & 10 & $7.99 \mathrm{E}-4$ & single component event & ASEP generic \\
\hline
\end{tabular}


Table IV.8-1

Peach Bottom Event Data (Continued)

\begin{tabular}{|c|c|c|c|c|c|c|c|c|c|}
\hline \multirow[b]{2}{*}{ BASIC EVERT } & \multirow{2}{*}{$\begin{array}{l}\text { COAPONENT FAILURE } \\
\text { MODE DESCRIPIION }\end{array}$} & \multicolumn{2}{|c|}{ FAILURE_RAIE_ } & \multirow{2}{*}{$\begin{array}{l}\text { MISSIOR } \\
\text { TIME } \\
\text { - (HRS) }\end{array}$} & \multicolumn{3}{|c|}{ UMAVAILABILIIY } & \multirow[b]{2}{*}{ DESCRIPTION } & \multirow{2}{*}{$\begin{array}{l}\text { SOURCE/ } \\
\text { COHAEnTS }\end{array}$} \\
\hline & & HOUR) & EF & & MEDIAN & EF & MEAN & & \\
\hline SDC-MOV-MA-MV15B & $\begin{array}{l}\text { Motor-Operated } \\
\text { Valve } 158 \text { out } \\
\text { for maintenance }\end{array}$ & - & - & - & - & - & $7.99 \mathrm{E}-4$ & same as SDC-MOV-MA-MV15A & -- \\
\hline SDC-MOV-MA-MV $15 C$ & $\begin{array}{l}\text { Motor-Operated } \\
\text { Valve } 15 \mathrm{C} \text { out } \\
\text { for maintenance }\end{array}$ & - & - & - & - & - & $7.99 \mathrm{E}-4$ & same as SDC-MOV-MA-MV15A & -- \\
\hline SDC-MOV-MA-MV $15 D$ & $\begin{array}{l}\text { Motor-Operated } \\
\text { Valve } 150 \text { out } \\
\text { for maintenance }\end{array}$ & - & - & - & - & - & $7.99 E-4$ & same as SOC-MOV-MA-MV15A & -- \\
\hline SDC-MOV-00-MV13A & $\begin{array}{l}\text { Motor-Operated } \\
\text { Valve } 13 \mathrm{~A} \text { fails } \\
\text { to close }\end{array}$ & $3.0 E-3 / d$ & 3 & - & $3.0 E-3$ & 3 & $3.75 E-3$ & single component event & ASEP generic \\
\hline SOC-MOV-OO-MV $13 B$ & $\begin{array}{l}\text { Motor-Operated } \\
\text { Valve } 138 \text { fails } \\
\text { to close }\end{array}$ & - & - & - & - & - & $3.75 \mathrm{E}-3$ & same as SOC-MOV-00-MV $13 \mathrm{~A}$ & -- \\
\hline SDC-MOV-00-MV13C & $\begin{array}{l}\text { Motor-Operated } \\
\text { Valve } 13 \mathrm{C} \text { fails } \\
\text { to close }\end{array}$ & - & - & - & - & - & $3.75 \mathrm{E}-3$ & same as SOC-MOV-OO-MV13A & -- \\
\hline SDC-MOV-O0-MV13D & $\begin{array}{l}\text { Motor-Operated } \\
\text { Valve } 130 \text { fails } \\
\text { to close }\end{array}$ & - & - & - & - & - & $3.75 E-3$ & same as SDC-MOV-00-MV13A & -- \\
\hline
\end{tabular}


Peach Bottom Ever Data (Continued)

FAILURE_RAIE UMAVAILABILIIY

RATE (PER MISSION

DEMAND OR TIME

HOUR) EF -(HRS) MEDIAN EF MEAN

DESCRIPTION

SOURCE/

COMPONENT FAILURE

$-(\cos )$

$-\quad-\quad 3.75 E-3$

tabular OR of following events

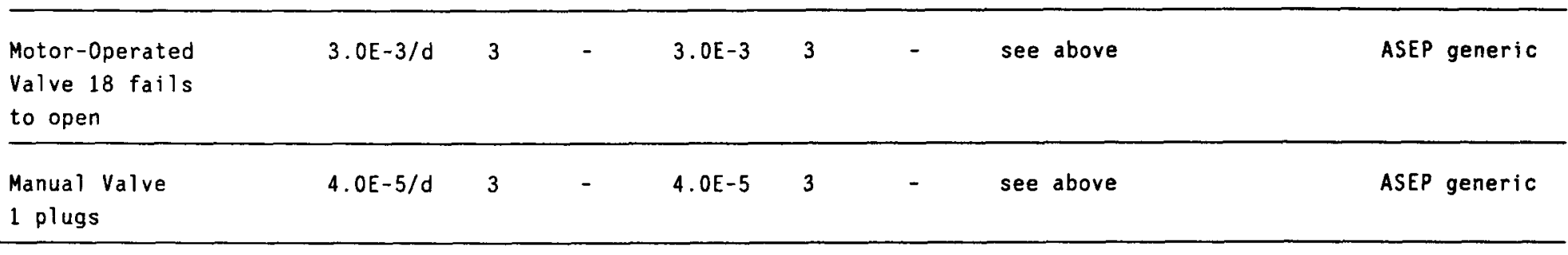

\section{IURBINE BUILDIMG COOLIMG YATER_SYSIEY:}

[see Note (a)]

+ (manual valves)

\begin{tabular}{|c|c|c|c|c|c|c|c|c|}
\hline fails to run & $2.0 \mathrm{E}-5 / \mathrm{hr}$ & 10 & 40 & $8.0 E-4$ & 10 & - & see above & ASEP generic \\
\hline $\begin{array}{l}\text { TBCW Pump A out for } \\
\text { maintenance }\end{array}$ & $7.0 E-4 / d$ & 10 & - & $7.0 E-4$ & 10 & - & see above & ASEP generic \\
\hline $\begin{array}{l}\text { TBCW Pump B } \\
\text { fails to run }\end{array}$ & 2.0E-5/hr & 10 & 40 & $8.0 E-4$ & 10 & - & see above & ASEP generic \\
\hline $\begin{array}{l}\text { TBCW Pump B out for } \\
\text { maintenance }\end{array}$ & $7.0 E-4 / d$ & 10 & - & $7.0 E-4$ & 10 & - & see above & ASEP generic \\
\hline $\begin{array}{l}3 \text { manual valves } \\
\text { plug }\end{array}$ & 1. $2 E-4$ & 3 & - & $1.2 E-4$ & 3 & - & see above & ASEP generic \\
\hline
\end{tabular}

Note:

(a) Modeled in Instrument Air System tree. 
Table IV.8-1

Peach Bottom Event Data (Continued)

\begin{tabular}{|c|c|c|c|c|c|c|c|c|c|}
\hline BASIC EVEMT & $\begin{array}{l}\text { COHPONEWT FAILURE } \\
\text { MODE DESCRIPTIOH }\end{array}$ & $\begin{array}{l}\text { FAILURE_ } \\
\text { RATE (PER } \\
\text { DEMAND OR } \\
\text { HOUR) }\end{array}$ & AIE & $\begin{array}{l}\text { MISSION } \\
\text { TIME } \\
\text {-(HRS) }\end{array}$ & UMA & AIL & ILITY & DESCRIPIION & $\begin{array}{l}\text { SOURCE/ } \\
\text { COMNEWTS }\end{array}$ \\
\hline \multicolumn{10}{|l|}{ IMIIIATIMG_EYEWIS: } \\
\hline Large LOCA (A) & - & N/A & N/A & N/A & $1.0 \mathrm{E}-4$ & 10 & $2.66 \mathrm{E}-4$ & -- & $\begin{array}{l}\text { WASH-1400, } \\
\text { other PRAs }\end{array}$ \\
\hline $\begin{array}{l}\text { Intermediate LOCA } \\
\left(S_{1}\right)\end{array}$ & -- & N/A & N/A & N/A & $3.0 E-4$ & 10 & $8.00 E-4$ & -- & $\begin{array}{l}\text { WASH-1400, } \\
\text { other PRAs }\end{array}$ \\
\hline Small LOCA $\left(\mathrm{S}_{2}\right)$ & - & N/A & $N / A$ & $N / A$ & $1.0 E-3$ & 10 & $2.66 \mathrm{E}-3$ & -- & $\begin{array}{l}\text { WASH- } 1400, \\
\text { ASEP generic }\end{array}$ \\
\hline $\begin{array}{l}\text { Small-Small LOCA } \\
\left(\mathrm{S}_{3}\right)\end{array}$ & -- & N/A & $N / A$ & $N / A$ & $1.0 \mathrm{E}-2$ & 10 & $2.66 \mathrm{E}-2$ & -- & $\begin{array}{l}\text { ASEP generic, } \\
\text { NRC summary } \\
\text { of actual } \\
\text { experience }\end{array}$ \\
\hline Interfacing LOCA & -- & $N / A$ & N/A & $N / A$ & - & - & $<1.0 E-8$ & -- & $\begin{array}{l}\text { see Section } \\
\text { IV. } 3\end{array}$ \\
\hline $\operatorname{LOSP}\left(T_{1}\right)$ & $=-$ & N/A & N/A & N/A & - & 3 & $7.0 \mathrm{E}-2$ & -- & $\begin{array}{l}\text { plant } \\
\text { specific }\end{array}$ \\
\hline \multirow[t]{3}{*}{ Loss of PCS $\left(T_{2}\right)$} & -- & $N / A$ & N/A & N/A & - & 3 & $1.5 \mathrm{E}+0$ & tabular OR & -- \\
\hline & MSIV closure events & $N / A$ & N/A & $N / A$ & - & 3 & $8.0 E-1$ & - & $\begin{array}{l}\text { plant } \\
\text { specific }\end{array}$ \\
\hline & loss of feedwater & N/A & N/A & N/A & - & 3 & $7.0 \mathrm{E}-1$ & -- & $\begin{array}{l}\text { plant } \\
\text { specific }\end{array}$ \\
\hline
\end{tabular}




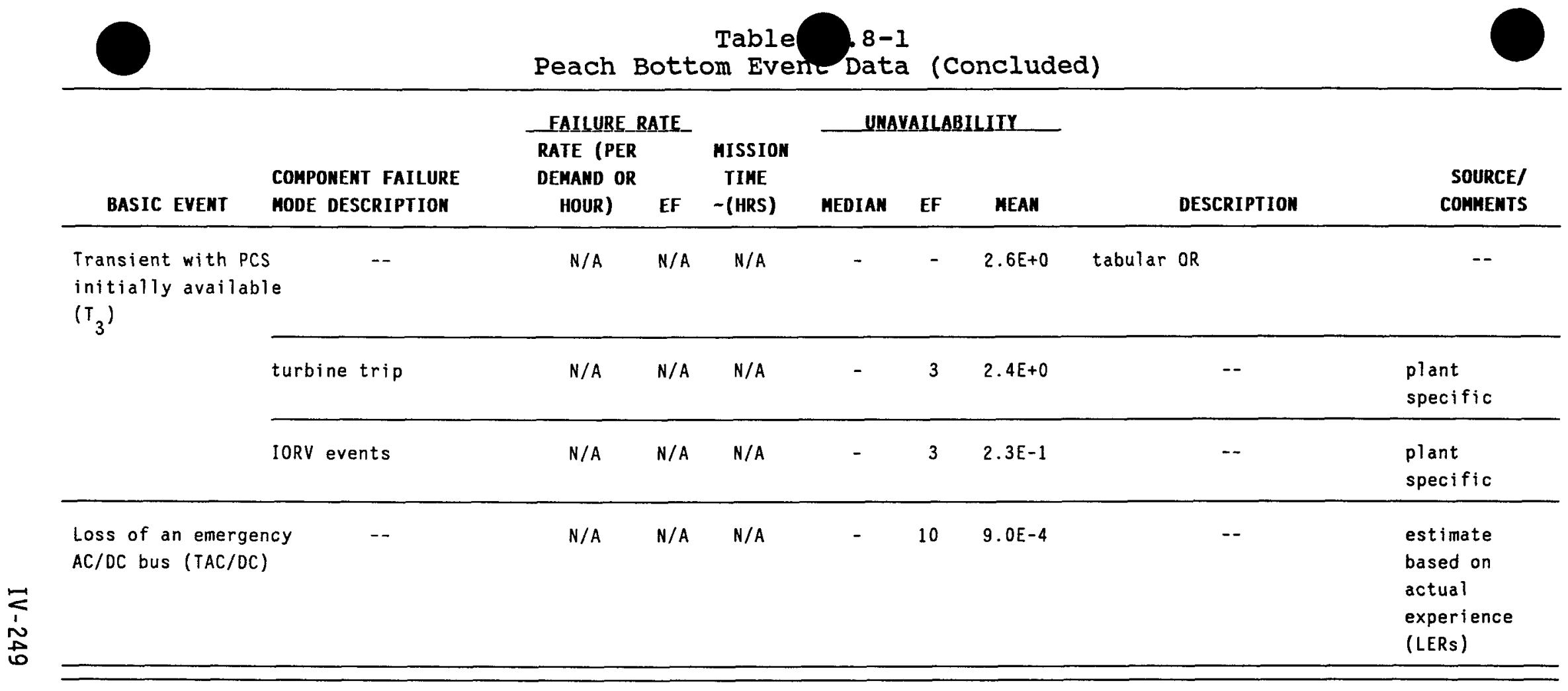


The accident sequences developed in the event tree analysis and discussed in Section IV. 4 were analyzed to determine the core damage sequences with the highest contributions to the total core damage frequency. The sequences were quantified by combining the Boolean equations derived from the system failure models using the event tree logic associated with the sequences and reducing the resultant equation to form minimal cut sets. System successes were explicitly included in the sequence logic. The sequence minimal cut sets were quantified using the data (mean values) provided in Sections IV.7 and IV.8 and the values for the Anticipated Transient Without Scram (ATWS) sequences described in Section IV.10.

The following sections provide the sequence quantification process and identify plant specific quantification issues. Quantification of the ATWS sequences is covered in Section IV.10.

\section{IV.9.1 Sequence Quantification Process}

The quantification of accident sequences was performed in a step-by-step approach, building upon small quantification efforts until whole sequences (where necessary) were quantified.

First, as part of each system failure model quality assurance check, system minimal cut sets were obtained without and then with support system (e.g. power, cooling, etc.) failures included. After being reviewed for accuracy, these models were then linked together so as to form portions of entire accident sequences presented by the event trees discussed in Section IV.4. As the linking process was performed, success states of certain systems were explicitly accounted for when forming these partial sequence Boolean expressions. The mean data values were applied to the basic events in these Boolean expressions. At this point in the quantification process, initiator frequencies and recovery actions were not yet included and only system successes and failures appearing ahead of the "Y" event (containment injection and venting) in the event tree were quantified. Examination of these partial sequence expressions showed that in some cases, combinations of system successes and failures were so sufficiently low in probability as to be insignificant. That is, it could be shown that even if additional system failures required to achieve core melt were assumed to fail at a probability of 1.0 and common mode failure cut sets and the initiator frequency (frequencies can be greater than 1.0 per year) were added, a sequence core damage frequency estimate of less than $1 E-8$ would result. These partial sequences were, therefore, dropped from further analysis. Remaining, then, were those partial sequence expressions which had the potential of being greater than $1 \mathrm{E}-8$ in core damage frequency when further analyzed.

The above remaining expressions were then combined with the initiator, common mode failure terms were added and quantified, and recovery actions (the RA-terms discussed in section IV.7) were included. This portion of the analys is was performed by adding appropriate terms and data to the sequence expressions, thereby creating quantified but still only partial accident sequence expressions which included the initiator, common cause, and recovery. Again, these expressions were screened and those with a core damage frequency less than 1E-8 were eliminated from further analysis. 
The results of the above process identified sequence expressions with the potential of leading to core damage frequency estimates of $1 E-8$ or greater. In some cases, the expressions already represented a core damage state. other expressions were of the AW-, SW-, or TW-type sequence in which core cooling was thus far successful but containment venting ("Y" event) success or failure could lead to a core damage state depending on the success or failure of continued core cooling.

At this point, the Peach Bottom analysts jointly analyzed the containment venting failure potential and resulting estimates for continued core cooling with the Sandia containment response analysts. This was done to account for the potentially significant interaction between the containment status and the survivability of long term core cooling in Boiling Water Reactors (BWRs). During these joint sessions, the partial sequence cut sets were examined individually to determine effects on containment venting and the success or failure of systems which could provide long term cooling. Phenomenological failures such as potential for pipe failures following containment failure were considered. The loss of the Low Pressure Core Spray and Low Pressure Coolant Injection systems under pool saturated conditions was assumed as per the general event tree assumptions in Section IV.4. Possible steam environments in the reactor building, such as containment venting success leading to ducting failure, were also considered as to their effects on long term cooling systems. The probabilities for containment venting success or failure, depending on the sequence, were agreed upon (see Section IV.7). Simple event trees to cover the above considerations were constructed by the Sandia containment analysts, and estimates of the core damage potential were made by combining the partial sequence frequencies from the Peach Bottom analyses with these simple event trees and performing simple hand calculations. The results of this combined effort identified those sequences worthy of complete analysis since core damage potentials appeared greater than 1E-8. These sequences were then fully quantified including the events that appear beyond the "Y" event in the event trees. In addition, terms were added to account for phenomenological failures to be included in the complete sequence expressions as identified by Sandia containment personnel.

The result of the above step-by-step process was identification of those sequences with core damage frequencies of $1 E-8$ or greater. These sequences were fully quantified using the mean data values and the TEMAC code [28] to obtain the mean estimate for core damage for the Peach Bottom-2 plant. Later in the analysis, uncertainty estimates were added for the dominant cut sets to perform the quantified uncertainty analysis also using TEMAC. Sensitivities were later defined and quantified again using the TEMAC code.

\section{IV.9.2 Plant Specific Quantification Issues}

During the quantification process, four plant specific quantification issues were addressed. These are the truncation methods used, the identification and application of recovery actions to the accident sequence expressions, the identification and application of common mode failures, and the joint quantification effort performed by the Peach Bottom analysts and the Sandia containment analysts.

\section{IV.9.2.1 Truncation of Accident Sequence Expressions}

Iruncation of sequence Boolean expressions based on cut set probability or cut set order is commonly performed in Probabilistic Risk Assessments. This is usually 
done during the accident sequence quantification in order to reduce the sequence cut sets to a manageable level, considering resources, and yet retain the major contributors to core damage frequency. In the Peach Bottom analysis, no truncation on cut set order was performed. However, truncation on probability was a necessary step and provided the initial partial sequence expressions upon which the entire quantification process was based. In general, sequence cut sets whose probability (without the initiator frequency or recovery considerations) was less than 1E-8 were discarded during formation of the initial partial sequence expressions. Since all initiator frequencies are less than 1.0 per year except for a few categories of transients (which at most are -2-to-3 per year for Peach Bottom), and since recovery actions were yet to be considered, it is likely that all sequence frequencies of $1 E-8$ or greater were identified. One exception was the treatment of the TAC/DC scenarios. Without the initiator frequency, a $1 E-7$ cut-off value was used since attempts at 1E-8 were consuming significant computer resources. However, the $9 \mathrm{E}-4 /$ year frequency of the initiator in these cases more than adequately assured that sequence frequencies of $1 E-8$ or greater for these initiators would be identified.

Contrasting with the above assurances that the truncation step did not discard important cut sets is the fact that the number of cut sets less then $1 \mathrm{E}-8$ is not known. For example, if thousands of $1 \mathrm{E}-9$ value cut sets were discarded, the potential for a missed 1E- 6 sequence frequency exists. While this is a limitation of the analysis process, it should be noted that many of the recovery actions applicable to cut sets above $1 E-8$ are likely to be applicable to cut sets below that value as well. This fact provides reasonable assurance that the discarded cut sets would not add significantly to the final results and that major sequences were not missed.

\section{IV.9.2.2 Recovery Actions}

The specific recovery actions used in the Peach Bottom analysis have been previously discussed in Section IV.7. As mentioned in Section IV.9.1, recovery actions were included at the cut set level for the partial sequence expressions during one of the screening steps in the quantification process. In each case, one or two non-recovery terms were added to the computerized Boolean expressions and the partial sequence expressions were re-quantified based on the appropriate non-recovery probability depending on sequence timing. As per the general methodology guidelines [2], no component hardware or test/maintenance unavailabilities were considered recoverable except for the few electrical cases identified by the recovery action table discussed in Section IV.7. Also, only one recovery action was applied to any one cut set except for the case of loss of offsite power. In this latter case, up to two simultaneous recovery actions were applied: recovery of offsite power and one other additional recovery action such as recovery of a failed diesel generator. In all cases, a non-recovery probability was applied to each cut set, where appropriate, depending on the timing of the sequence. Recovery actions were selected on the basis of that action which would (1) if successful, mitigate the potential core damage scenario depending on the specific cut set involved and (2) allow for the lowest non-recovery probability (or, in other words, the highest recovery potential) per the values in Section IV.7.

When applying the recovery actions, care was taken to assure that the actions could be performed when considering venting success or failure (if appropriate). This was done to assure that the recovery actions were still valid even under possible severe containment or reactor building conditions. 
IV.9.2.3 Application of Common Cause Failures

As per the general methodology guidelines [2], common cause failure terms were added to the sequence expressions after the initial computer runs. Section IV.6.2 contains a general discussion of the treatment of these failures and of the common cause failures considered.

In applying the common cause terms to the cut sets, a two-level examination was carried out to determine what common cause failure terms should be added to the existing partial sequence expressions. First, the existing cut sets were examined for clues of two or more component-level failures which might have common cause potential based on EPRI NP-3967 [23]. Additionally, the appropriate system schematics were surveyed by the Peach Bottom analysts to further define common cause failures since the number of independent failures of some components may have been truncated on the basis of probability. This process identified important common cause failure terms (e.g., common cause failure of two or more diesel generators) to be added to the sequence cut sets. In each case, the appropriate terms were added to the computerized cut sets and the quantification was re-performed to account for the additional failure probabilities represented by the common cause failure terms.

As per the data supplied in EPRI NP-3967 and the general methodology guidelines, common cause failures were included using a Beta factor approach applied within a system boundary. While the addition of these common modes provides for a more realistic analysis, its application in the Peach Bottom analysis has conservative and potentialiy non-conservative aspects. From the conservative standpoint, failure probabilities of 1.0 were assumed for the third or subsequent "like" components; that is, once two "like" components failed from common cause, other "like" components were assumed to fail with a probability of 1.0 . On the other hand, this process was applied to components only within a given system; similar valves, for instance, in two or more systems were not coupled together under the application of the common cause failure analysis. The sparse data do not suggest that such inter-system common cause failures exist; it is only mentioned here as a potential non-conservatism in the analysis.

\section{IV.9.2.4 Joint Front-End/Back-End Quantification}

A number of partial sequence expressions were examined jointly by the Peach Bottom analysts and the Sandia containment analysts as previously described in Section IV.9.1. Four general types of sequences were examined during this process. They were the AW-, SW- or TW-type sequences and ATWS sequences in which core cooling is successful up to the time of the containment venting question. These sequences were examined because the success or failure of containment venting could affect the success of continued core cooling in all these sequences (i.e., core cooling is successful up to the point of the containment venting question). Additionally, all other sequence types did not have to be jointly reviewed in this way since core cooling was already lost in the other types of sequences (i.e., a core damage state was already defined).

The types of concerns treated in this phase of the quantification included steam effects on equipment, injection line damage following containment failure, operator failure to initiate the use of Condensate if required, and others. ailure probabilities associated with these concerns typically ranged from $\sim 0.5$ to less than 0.01 based on expert judgment by both the "front-end" and "back-end" analysts. 
The results of this process can be summarized into two major categories. First, the results of the examinations of ATWS sequences are directly evident by reviewing the dominant TCSR and TCSAR sets of sequences described later in Section V. Second, all the AW-, SW-, and TW-type sequences were eliminated after the joint quantification effort on the basis that core damage frequencies were less than 1E-8 per year. This was because of two factors. First, failure to vent the containment was estimated at 0.001 for these sequences as described in Section IV.7. With additional system failures typically required before core cooling was totally lost, these scenarios became less than $1 \mathrm{E}-8$ and so were eliminated from further consideration. Successful venting scenarios typically required additional failures of the Control Rod Drive, High Pressure Service Water, and Condensate systems before core damage would occur. These probabilities, even considering phenomenological failures such as steam effects, were small enough to drive the sequence frequencies to less than $1 \mathrm{E}-8$ (e.g., not much can affect Condensate). So, while TW-type scenarios were originally considered major contributors to core damage in WASH-1400 [4], this update concluded that these type sequences are not significant contributors if one considers containment venting and the possibilities of successful core cooling after either venting or containment failure.

One other perspective can be provided regarding the conclusions reached for the AW, SW, and TW-type sequences. One of the sensitivities examined later in Section IV.11 includes the effect of assuming that containment failure or successful venting leads directly to core damage (because of phenomenological effects, etc.). This sensitivity shows that one TW-type sequence would become dominant, but this would only double the total core damage frequency estimated in this study. One can conclude, therefore, that the results of this study are not significantly affected by the joint front-end/back-end analys is and quantification performed as part of this study. 
IV.10 ANTICIPATED TRANSIENT WITHOUT SCRAM (ATWS) ANALYSIS

ATWS analyses were performed for the following two cases:

(1) Case A--Plant As Is

In Case A, ATWS was analyzed considering the current Standby Liquid Control (SLC) system configuration and the current emergency procedures. In Case $A$, the operator initiates only one of the two $43 \mathrm{gpm}$ SLC pumps. The emergency operating procedures currentiy at Peach Bottom are the Transient Response Implementation Plan (TRIP) procedures as of Fall 1985. The TRIP procedures are based on the generic Emergency Procedure Guidelines (EPGs), Revisions 3 and 4.

Modifications have been made at the plant on their Scram Discharge Volume (SDV). Increases in pipe sizes and improved level instrumentation were implemented. Reactor pump trip (RPT) was made automatic based on either high reactor vessel pressure or low reactor vessel water level. The plant is now adding an Automatic Depressurization System (ADS) bypass switch and changing the ADS time delay to -8 minutes.

(2) Case B--Plant with ATWS Rule Fixes in Place

In Case B, ATWS was analyzed assuming the "ATWS rule" fixes were implemented. In Case $B$, the ATWS rule requirement of "86 gpm equivalent" was assumed to be accomplished by enriching the SLC boron--10 percentage in the shutdown solution (onty one $43 \mathrm{gpm}$ pump is then required). It was also assumed that the operators would be using the same TRIP procedures as in Case $A$.

The analyses of the above two ATWS cases were performed by the Peach Bottom analysts with input on the Human Reliability Analys is (HRA) from Brookhaven National Laboratory (BNL) and from the plant personnel at Peach Bottom. Case $A$ is described in Section IV.10.1 and Case B in Section IV.10.2. While Case A represents the plant "today," Case B will be in place in the near future. Because the plant is required to achieve the $86 \mathrm{gpm}$ equivalent design and since it will soon be in place, Case $B$ is used to calculate the plant core damage frequency and is presented as part of the results in Section $V$. Case $A$ is presented here for comparative purposes only.

IV.10.1 Case A (43 gpm) ATWS Analysis

The core damage frequencies for the $43 \mathrm{gpm}$ case are the following:

\section{OUTCOME}

Core Damage--Containment Vulnerable

Containment Vulnerable (not analyzed

further for actual core damage

frequency)

\section{FREQUENCY}

$1.61 E-6$

$1.05 \mathrm{E}-6$ 
The ATWS accident sequence progression is given in Section IV.10.1.1. The event trees are presented in Section IV.10.1.2. A summary of pertinent parts of the HRA done by BNL is given in Section IV.10.1.3. The data and supporting calculation results are given in section IV.10.1.4. The results are presented in

Section IV.10.1.5.

\section{IV.10.1.1 Case A ATWS Accident Sequence Progression}

The response of the Peach Bottom plant to a postulated failure to insert the control rods following an anticipated transient involves several events. The first significant event is an initial pressure increase in the Reactor coolant System (RCS) caused by a power imbalance when the turbine is tripped. There is a small delay until the turbine bypass valves are open and RPT can take effect. However, this initial pressure increase does not present any immediate danger to the integrity of the reactor for the following reasons: (1) voiding is increased from tripping of the recirculation pumps (increased voiding causes a reduction in moderator effectiveness) and (2) the Safety Relief Valves (SRVs) can adequately control this pressure increase by discharging steam to the suppression pool. For ATWS, the power level tends to equilibrate at approximately seventeen to forty percent of full power depending on subsequent operator actions (i.e., controlling reactor water level and pressure*).

The next events to occur are initiation of those systems or actions to reduce core reactivity, to achieve reactor subcriticality, and to maintain coolant inventory. This analysis only examines the accident in the time period it takes to achieve reactor subcriticality. At that point, the accident is assumed to be "under control" and becomes a normal transient. Therefore, only those events (actions or systems) that are required in this interval are considered.

The power has equilibrated at some level from the net effect of the RPT, reactor water level decrease from SRV discharge, and voiding. The reactor is fully pressurized, the SRVs are therefore cycling, and the reactor water level is decreasing. Once the level reaches a low water level setting (Level 2), the Reactor Core Isolation Cooling (RCIC) and High Pressure Coolant Injection (HPCI) systems actuate automatically and start injecting into the reactor. The water level and the power adjust correspondingly until the injection to the reactor is equivalent to the power production (i.e., the steam production rate).

During this period, the steam produced is either entirely discharged to the suppression pool, if the Main Steam Isolation Valves (MSIVs) are closed, or discharged to both the main condenser via the turbine bypass valves and the suppression pool (depending on the power equilibration level) if the MSIVs are open. Peach Bottom's turbine bypass is designed for approximately twenty-five percent steam flow. Therefore, for ATWS events in which the feedwater is operating (MSIVs open), steam flow to the suppression pool is anywhere from zero to ten or fifteen percent. However, for those ATWS events in which the MSIVs are closed, all steam flow is directed to the suppression pool. A problem therefore arises because the Residual Heat Removal (RHR) system is designed for less than a

* Feedwater maintains a greater flow than high pressure injection systems and that flow introduces more moderator and a higher power equilibration which could be as high as forty percent. 
five percent decay heat removal capability. In the interval before reactor ubcriticality is achieved, this capacity is exceeded in many of the ATWS sequences and results in fast rising suppression pool temperatures. High suppression pool temperatures have the potential to fail injection. HPCI pump seals are assumed to fail at water temperatures of 210-to-2600 F. At Peach Bottom, HPCI automatically transfers suction from the Condensate Storage Tank (CST) on both low CST level and high suppression pool level. It becomes important to reduce power to below five percent as quickly as possible to keep the peak suppression pool temperature below the HPCI failure temperature range of 210 to $260^{\circ} \mathrm{F}$. If the operator initiates one SLC pump within about two minutes, the peak suppression pool temperature will likely be less than 2200F depending on such factors as water level control and when torus cooling is initiated.

\section{IV.10.1.2 Case A ATWS Event Tree}

The $43 \mathrm{gpm}$ Case A ATWS event trees are shown in Figures IV.10.1-1 and IV.10.1-2. The following sections define the event tree headings and describe the event tree sequences.

\section{IV.10.1.2.1 Event Tree Headings}

This section defines the event tree headings for Figures IV.10.1-1 and IV.10.1-2. It should be noted that some of the headings are divided into two parts. One part gives the actual tasks or steps that must be performed by the control room operators to perform the defined function for each heading. These operator actions are included in the following subsections that define the event tree headings; however, for more details, see the report by W. J. Luckas (Reference 9).

\section{Transient (T) --}

A transient occurs which requires the reactor to be tripped.

MSIV Open (MSIV-C, MSIV-0) --

The transient occurs with either the MSIVs closed (success) or open (failure).

\section{Reactor Protection System Mechanical (RPSM) --}

Reactor Protection System (RPS) mechanical failure assumes that all of the control rods are left in the position that they occupied before the transient occurred. By definition, whatever causes RPS mechanical failure is assumed to be non-recoverable (e.g., common faults within the drive mechanisms).

\section{Reactor Protection System Electrical (RPSE) --}

Failure of the RPS electrical includes failure of the sensors, logic, RPS trip relays, and trip contacts. An electrical failure is assumed to prevent the RPS trip relay contact from opening. This failure can occur at the contacts themselves or between the contacts and the sensors. Unlike RPS mechanical faults, RPS electrical faults are recoverable. 


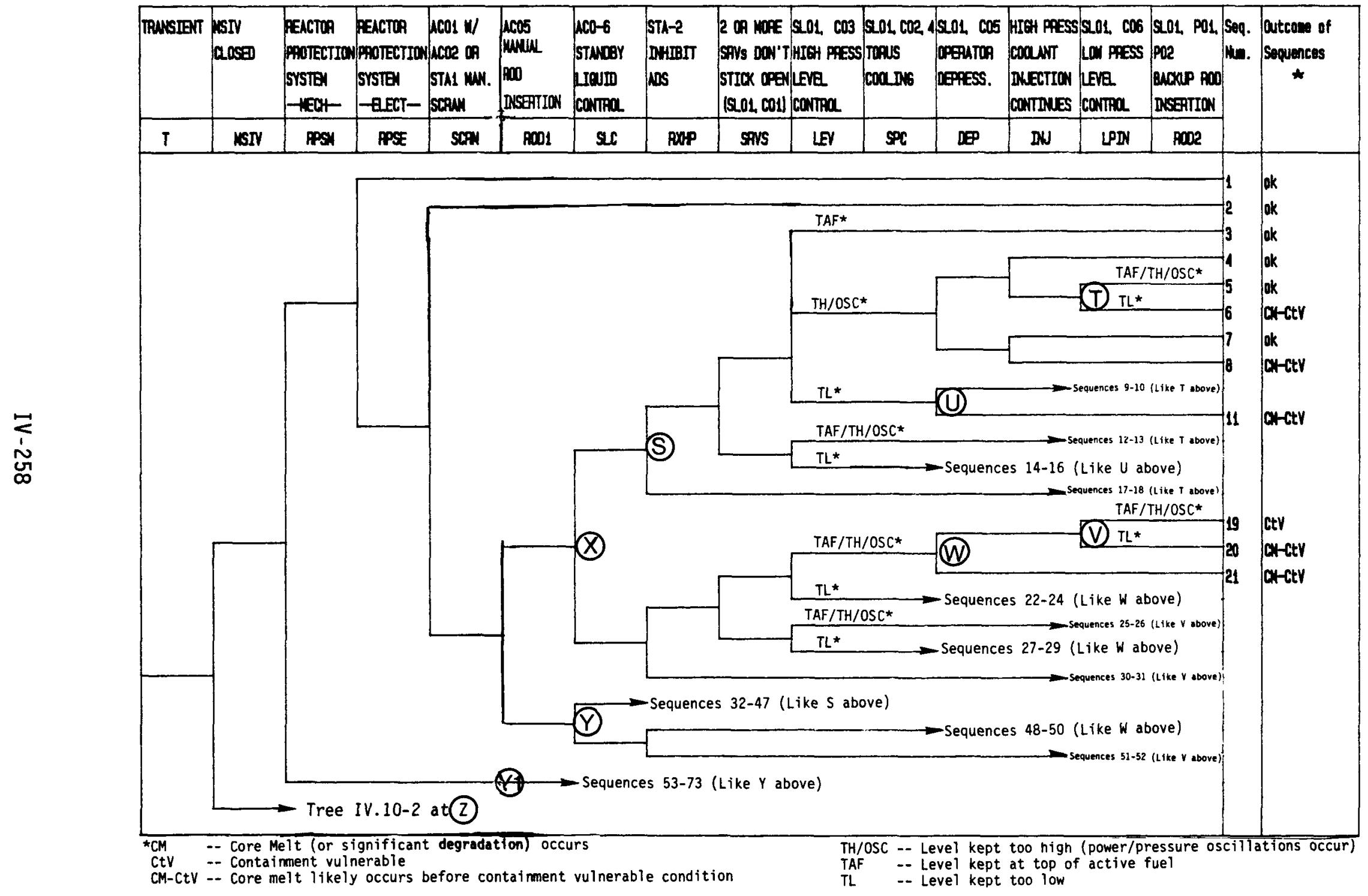

Figure IV.10.1-1. Peach Bottom Case A MSIV Closure ATWS Event Tree. 


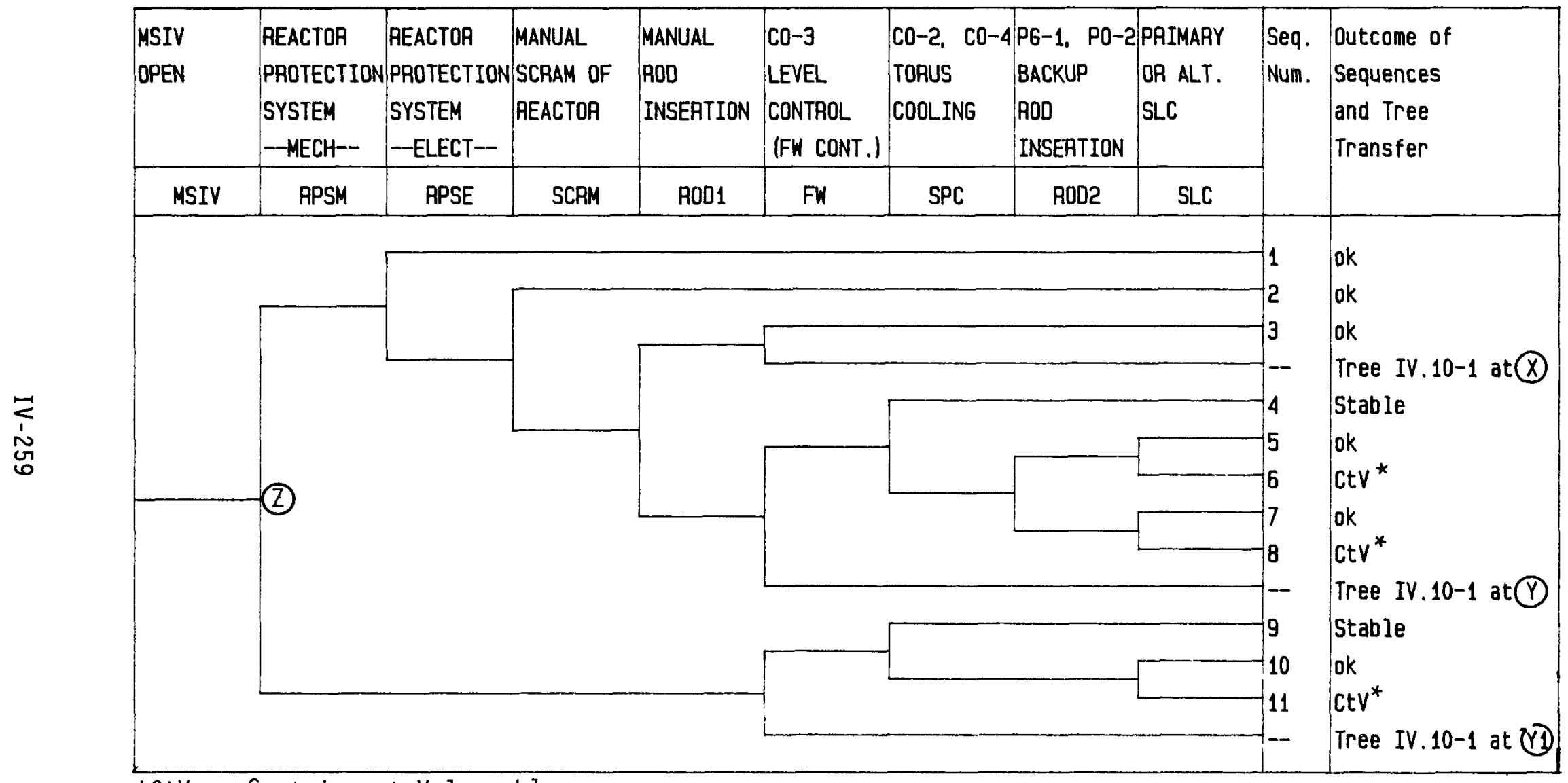

*CtV -- Containment Vulnerable

Figure IV.10.1-2. Peach Bottom Case A MSIV Open ATWS Event Tree. 
Manual Scram of the Reactor (SCRM) --

If the RPS failure is an electrical failure, the plant operators can attempt to manually scram the control rods into the reactor. The manual scram function at Peach Bottom is accomplished by the following operator tasks:

Task AC01--The Auxiliary Control Operator (ACO) recognizes the scram condition and checks for MSIV closure as well as automatic scram failure. He also observes that the recirculation pumps have tripped or trips the pumps himself under MSIV closure conditions (i.e., this event includes consideration of recirculation pump trip failure).

Task ACO2--The ACO attempts a manual scram by going to the "shutdown" position with the reactor mode switch and pushing the manual scram buttons. This will activate the scram pilot valves for each of the individual rod Hydraulic Control Units (HCUs) as well as the backup scram valves. Failure of manual scram would require failure of the scram signal or failure of one or two scram pilot valves in each of the HCUs as well as failure of the backup system valves.

Task STAl--Assuming the scram valves have not all been successfully operated (opened), the Shift Technical Advisor (STA) or other personnel will attempt to de-energize the scram solenoids of the scram pilot valves for each of the HCUs. This is done by going to a back panel in the control room and flipping all the individual rod scram toggle switches.

Task AC04--Assuming the scram valves have all been operated (opened), another attempt to use the reactor scram hydraulic system is made. The ACO tries to re-energize the scram solenoids (via the scram reset switch) and reestablish control rod drive (CRD) hydraulic pressure and then attempts to manually scram. However, if the signal that caused the original scram is still present (or if a new signal appears), the ACO will not be able to reset the scram logic.

Early Manual Rod Insertion (ROD1) --

If, after attempting manual scram, the control rods have not entered the reactor core, the ACO is instructed to attempt manual rod insertion (TASK ACO5). Assuming a successful SCRAM reset, the rod sequence control system (RSCS) and the rod worth minimizer (RWM) are defeated and the ACO attempts to insert individual rods guided by a rod priority list kept at the control panel. This task is continued after SLC is initiated. It is important to remember that manual rod insertion is not possible if SCRAM cannot be reset.

Standby Liquid Control (SLC) --

Should the reactor not be shutdown with control rods, the $A C O$ is instructed to initiate SLC before the torus temperature reaches $1100 \mathrm{~F}$. This is Task ACO6.

Reactor at High Pressure (RXHP) --

Immediately after SLC injection starts, the STA or other personnel is supposed to defeat ADS. ADS is changing such that there will be an eight minute timer that is actuated when the water level reaches Level 1 . The STA then has eight minutes 
before the ADS will actually function. An ADS inhibit switch will be available after the next refueling outage to permanently inhibit ADS without taking any further actions (i.e., the STA will not need to periodically push the inhibit ADS button to defeat the ADS). This is Task STA-2.

\section{Two or More SRVs Do Not Stay Open (SRVs) --}

During the ATWS, should it be noticed that any SRV is open or cycling, the Control Operator $(\mathrm{CO})$ is instructed, under the direction of the Senior Licensed Operator (SL0), to manually open SRVs until the reactor vessel pressure drops to 950 psig. These actions are included in Tasks SLO1 and CO1.

The event tree, as presently drawn, shows no choice for pressure control since its success or failure is considered to affect only the probability of failure of the two or more SRVs sticking open. Failure means that two or more SRVs have stuck open causing an uncontrolled depressurization of the reactor.

High Pressure Level Control (LEV) --

Operator Controls at TAF (LEV1), Operator Controls at TH/OSC (LEV2), Operator Controls at TL (LEV3) --

Level control is performed in Task C03 under the direction of the SLO (SLO1). At $110^{\circ} \mathrm{F}$ torus temperature (since power is above $3 \%$ and an SRV is open), the CO must lower reactor pressure vessel (RPV) level by terminating and preventing all injection into the RPV (except boron injection and CRD) until power is below $3 \%$ or all SRVs are shut or top of the active fuel (TAF) is reached. As TAF is approached, the CO throttles HPCI to maintain this level. Four different outcomes are allowed for this event. They include the level's being maintained too high (TH--e.g., no throttling of HPCI), near TAF, too low (TL--e.g., HPCI failure), or oscillating (OSC).

\section{Suppression Pool Cooling (SPC) --}

This event calls for alignment of the RHR and High Pressure Service Water (HPSW) systems into the torus cooling mode once the torus water reaches $110^{\circ} \mathrm{F}$. This action (Task CO2) and subsequent actions to maintain torus cooling (Task CO4) under the cognizance of the SLO (SLO1) are all treated under this event. RHR preference for the Low Pressure Coolant Injection (LPCI) mode alignment, once the reactor water level is brought down to the top of the core, further adds to the difficulties in using the torus cooling mode. Because of the low capability of the RHR system as compared to the achieved power level when the reactor water level is at TAF, no major differences occur with or without torus cooling so the event does not show any choices.

\section{Operator Depressurizes Reactor (DEP) --}

The Control Operator is to lower reactor pressure with SRVs in conformance to the Heat Capacity Temperature Limit (HCTL) curve as a function of the torus temperature. The CO starts this task (CO5) under SLO direction (SLO1) when the torus temperature reaches about $155^{\circ} \mathrm{F}$. Should HPCI be subsequently lost, this event also accounts for the depressurization which must follow in order to cool the core with low pressure systems. 
High Pressure Coolant Injection Continues (INJ) --

The HPCI system is initially used to maintain level control. It will fail or otherwise isolate if the torus temperature reaches $220^{\circ} \mathrm{F}$, if the reactor pressure decreases to $100 \mathrm{psig}$, or if the containment pressure reaches about $150 \mathrm{psia}$. The question whether any of these conditions that will terminate HPCI exists is considered at this branch in the event tree. Success implies that HPCI continues to operate and that the operator restores water level with this system once sufficient boron is injected or the reactor is otherwise shutdown.

Low Pressure Level Control (LPIN) --

Operator Controls at TAF (LPI1), Operator Controls at TH/OSC (LPI2), Operator Controls at TL (LPI3) --

This is Task C06. If HPCI fails, the CO will attempt to maintain water level at TAF via Condensate, LPCI, Low Pressure Core Spray (LPCS), or other systems. This will be possible when reactor pressure drops to $\sim 400$ psig. Success includes operation of one pump such that the water level is maintained to cool the core and eventually restored to normal levels after shutdown. As with High Pressure Level Control, four outcomes are possible.

Late Manual Rod Insertion (ROD2) --

This function consists of Tasks P01 and P02. Assuming that a 11 of the previous actions described in the "manual scram" event have been attempted, the plant operator is instructed to go to the CRD control units and try to get the control rods into the core. He does this by isolating and venting the scram air header. If this fails, he manually vents the CRD withdraw line vent valve of each rod. While this set of tasks was considered for the event tree, it is believed that success for these actions is negligible if previous attempts to manually scram have failed since both events are attempting to do essentially the same thing (operate the scram valves). No choices are explicitly shown on the tree.

Feedwater Continues (FW) --

This event appears only on Figure IV.10.1-2 and involves whether the MSIVs remain open and feedwater continues to operate. Failure of this event means the MSIVs have subsequently closed following the initiating event.

IV.10.1.2.2 Case A ATWS Sequence Description

This section describes the sequences for the Case $A$ event trees.

MSIV Initially Closed (Figure IV.10.1-1) Sequence Descriptions

Sequence 1: $T * M S I V-C * \overline{\operatorname{RPSM}} * \overline{\mathrm{RPSE}} \quad$..

In this sequence, a transient occurs that requires the reactor to SCRAM. The RPS mechanical portion of the system functions successfully. In addition, the electrical system that sends the scram signal to the HCUs functions successfully. All of the rods are assumed to go into the core and reactor shutdown is achieved. The event then becomes a normal transient and can be transferred to the appropriate transient event tree depending on the initiating event. This sequence is OK. 
This sequence is similar to Sequence 1 except that the RPS electrical function fails. Manual SCRAM, however, is successful. This sequence is then the same as Sequence 1 and is OK.

\section{Sequence 3: T*MSIV $-C * \overline{\operatorname{RPSM}} * \operatorname{RPSE} * S C R M * \overline{\mathrm{ROD} 1} * \overline{\mathrm{SLC}} * \overline{\mathrm{RXHP}} * \overline{\mathrm{SRV}} * \overline{\mathrm{LEV} 1}$}

In this sequence, SCRAM is not successful. Manual rod insertion by the ACO is successful; however, it could take -1 hour to shut down the reactor using this approach. SLC (also initiated by the ACO) is successful. It would be initiated since the torus would reach $110^{\circ} \mathrm{F}$ in - two minutes. The STA inhibits ADS according to procedure. In this sequence, two or more SRVs do not stick open. After SLC is initiated, the $\mathrm{CO}$ is instructed to lower the reactor water level to the TAF. Possibilities which are considered at this point are as follows:

(1) The CO does nothing to control HPCI and the water level remains high, or he may operate HPCI but not effectively enough to prevent major level oscillations.

(2) The co could effectively keep the water level near the TAF.

(3) The CO could shut off HPCI or the HPCI system could fail at onset of the transient. In either case, the water level in the core would be too low.

In this sequence, the $\mathrm{CO}$ is able to keep the water level at TAF. Once the SLC has injected the boron into the bottom of the core, the co will refill the reactor vessel and the ATWS will be successfully terminated.

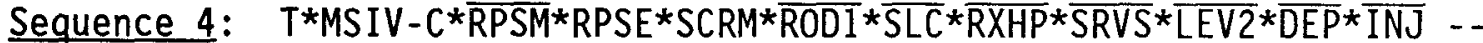

This is similar to Sequence 3 up to the high pressure level control option. In this sequence, the high pressure level control results in the water level's being either too high or in level oscillations, at least initially. Power could eventually decrease pending the eventual effects of getting SLC into the core, as well as an equilibrium state obtained given the nominal HPCI flow rate of $5000 \mathrm{gpm}$. The high water level will result in a high power level. Also, level oscillations will result in major power oscillations. Both conditions will result in a larger amount of heat being transferred to the suppression pool. Notice that torus cooling is not asked for this sequence since it only has the capacity to cool $\sim 3.5 \%$. In this case where the MSIVs are closed, there is -20-to-30\% power or higher (during oscillations) being transferred to the suppression pool. Therefore, torus cooling is not an important factor.

The CO begins depressurization with the SRVs via the HCTL curve once the suppression pool temperature reaches $1550 \mathrm{~F}$. In this sequence, the operator is continually using HPCI, which continues to operate to the end of the transient despite high power conditions, because of the rapid shutdown achieved by SLC. Once the SLC has injected the boron 
into the bottom of the core, the CO will refill the reactor vessel and the ATWS will be successfully terminated without having to use low pressure injection systems.

\section{Sequence 5: $\quad T * M S I V-C * \overline{\operatorname{RPSM}} * R P S E * S C R M * \overline{\operatorname{ROD1}} * \overline{\operatorname{SLC}} * \overline{\mathrm{RXHP}} * \overline{\operatorname{SRVS}} * \overline{\mathrm{LEV} 2} * \overline{\mathrm{DEP}} * I N J * \overline{\mathrm{LPIN}} \quad \ldots$}

This sequence is similar to Sequence 4 except that HPCI fails to continue functioning. In this case, the CO will use low pressure (LP) systems to maintain water level. As in the case where the co maintained water level with the HPCI system, there are three distinct possibilities that can occur:

(1) The Co can effectively keep the water level at the TAF with the low pressure systems.

(2) The co cannot control the LP system and the reactor vessel water level reaches a high level and/or oscillates.

(3) The CO can shut down the LP systems or these systems can fail to function. In either case, the reactor vessel water level is too low.

In this sequence, the water level is either kept at TAF or TH or it oscillates. As in Sequence 3, once the SLC has injected sufficient boron into the core, the CO will refill the reactor vessel and the ATWS will be successfully terminated.

Sequence 6: $T * M S I V-C * \overline{\operatorname{RPSM}} * R P S E * S C R M * \overline{\operatorname{ROD} 1} * \overline{\operatorname{SLC}} * \overline{\operatorname{RXHP}} * \overline{\operatorname{SRVS}} * \overline{[E V 2} * \overline{\overline{D E P}} * I N J * \operatorname{LPIN} \ldots$

Similar to Sequence 5 except that after the co depressurizes the reactor vessel, the water level in the reactor vessel is maintained too low or the low pressure systems fail. If the water level is too low, core damage (shown on tree as CM) will occur.

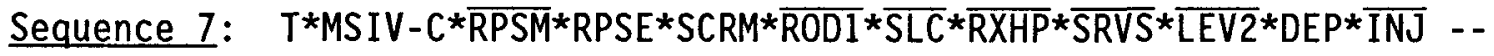

This sequence is similar to Sequence 4 except that the co fails to depressurize with SRVs via the Heat Capacity Temperature Limit (HCTL) curve.

\section{Sequence 8: $T * M S I V-C * \overline{\operatorname{RPSM}} * \operatorname{RPSE} * S C R M * \overline{\operatorname{ROD} 1} * \overline{\operatorname{SLC}} * \overline{\operatorname{RXHP}} * \overline{\operatorname{SRVS}} * \overline{\mathrm{LEV} 2} * \overline{D E P} * I N J \quad-$}

Similar to Sequence 7 except the HPCI system fails to continue to run until shutdown has been achieved. Even if the RCIC system is also operating, it too will fail (when the HPCI system switches to the suppression pool, the $C O$ is supposed to manually switch RCIC to the suppression pool). Both systems will therefore likely fail because of phenomenological considerations related to high suppression pool temperature. Without successful depressurization, core damage occurs. This sequence is given a CM-CtV outcome since core damage will likely occur before containment vulnerable (CtV) conditions become present. 
Sequences 9-11:--

Sequences 9, 10, and 11 are similar to Sequences 5, 6, and 8, respectively. The only difference is that HPCI fails initially instead of subsequently in the sequence.

Sequences 12-13: --

Sequences 12 and 13 are similar to Sequences 5 and 6 . The reactor vessel water level is either at TAF or too high or oscillations are occurring. In these sequences, two or more SRVs do stick open causing reactor vessel depressurization and the HPCI to fail from eventual low pressure in the primary system. As a result, operator depressurization is not needed to utilize the low pressure systems. Sequence 12 leads to an OK outcome while Sequence 13 (failure of LPIN) leads to core damage.

Sequences 14-16: --

Sequences 14 through 16 are similar to Sequences 9 through 11 . In these sequences, two or more SRVs stick open. The HPCI system fails initially to provide coolant to the reactor. It should be noted that, to prevent core damage, the C0 must depressurize quickly even though two or more SRVs stick open.

Sequences 17-18: --

In Sequences 17 and 18, even though SLC is functioning, the Shift Technical Advisor (STA) or other personnel do not inhibit ADS. Once the ADS functions, it will create a blowdown that requires the use of the low pressure systems. If the low pressure systems keep the water level at TAF, too high, or oscillating, the outcome is OK; otherwise core damage occurs.

\section{Sequence 19: $T * M S I V-C * \overline{R_{P S M}} * R P S E * S C R M * \overline{R O D 1} * S L C * \overline{R X H P} * \overline{S R V S} * \overline{L_{E V}} * \overline{D E P} * \overline{[P I N}$}

In this sequence, manual rod insertion is successful; however, the SLC system is unsuccessful. Shutting down in this mode could take $\sim 1$ hour to completely shut down the reactor. ADS is inhibited by the STA. Two or more SRVs do not stick open. The water level that is being maintained by HPCI is either too high or at the TAF, or there are major oscillations. HPCI fails before shutdown is achieved. The CO depressurizes and the water level is maintained at the TAF or too high, or oscillations occur with the low pressure systems. Though a stable condition is established, containment integrity may be threatened before the control rods are able to shut down the reactor which could fail the low pressure systems. This sequence is therefore given a CtV outcome with the possibility of core damage.

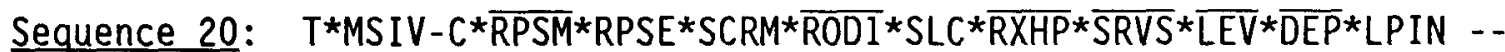

This sequence is similar to Sequence 19 except that after the co depressurizes the reactor vessel, the water level in the reactor vessel is too low. If the water level is too low, core damage will occur. This sequence is, therefore, given a CM-CtV outcome. 


\section{Sequence 21: $T * M S I V-C * \overline{\operatorname{RPSM}} * \operatorname{RPSE} * S C R M * \overline{\mathrm{ROD} 1} * S L C * \overline{\mathrm{RXHP}} * \overline{\mathrm{SRVS}} * \overline{\mathrm{LEV}} * \mathrm{DEP} \quad \ldots$}

This sequence is similar to Sequence 20 except that the operator fails to depressurize. Once the HPCI system fails, the low pressure systems cannot be used because of high pressure (operator did not depressurize) to prevent core damage. This sequence results in core damage.

Sequences 22-24: --

Sequences 22 through 24 are similar to Sequences 19 through 21 . The only major difference is that HPCI fails initially instead of later from high suppression pool temperature.

Sequences 25-29:

Sequences 25 through 29 are similar to Sequences 19 through 24 . The major difference is that two or more SRVs do stick open, causing reactor vessel depressurization and the HPCI system to fail from eventual low pressure in the primary system. Operator depressurization is not needed to utilize the low pressure systems unless HPCI fails initially.

Sequences 30-31: -.

In Sequences 30 and 31 , the STA or other personnel do not inhibit ADS. Once the ADS functions, it will create a blowdown that requires the use of the low pressure systems. The outcomes are the same as for Sequences 19 and 20.

Sequences $32-47$

Sequences 32 through 47 are similar to Sequences 3 through 18 . In these sequences, manual rod insertion is unsuccessful but SLC succeeds. It should be noticed that if SLC is successful, manual rod insertion success or failure is believed to have no discernible effect on the sequences because of the relative shutdown times.

Sequences 48-50:

Sequences 48 through 50 are similar to Sequences 22 through 24 . In these sequences, both manual rod insertion and SLC fail. ADS is inhibited by the $\mathrm{CO}$. The top events of two or more SRVs not sticking open, level control, and torus cooling are not queried. This is because HPCI will fail very early in the sequence, and the sequences are dominated by the success or failure of the LP systems.

Sequences 51-52: --

These sequences are similar to Sequences 30 and 31 . The only difference is that manual rod insertion fails; however, it does not change the outcome of the sequences. 


\section{Sequences 53-73: --}

In these sequences RPS mechanical fails; therefore, it is impossible to insert the control rods into the core. These sequences are similar to

Sequences 32 through 52 for the "RPS Electrical" failure case.

\section{MSIV Initially Open (Figure IV.10.1-2) Sequence Descriptions}

\section{Sequence 1: $\quad T * M S I V-0 * \overline{\mathrm{RPSM}} * \overline{\mathrm{RPSE}}$}

In this sequence, RPS mechanical and electrical succeed. This becomes a non-ATWS transient and is transferred to an appropriate transient event tree depending on the initiating event.

Sequence 2: $\quad T * M S I V-0 * \overline{\operatorname{RPSM}} *$ RPSE$* \overline{\text { SCRM }}$

This sequence is similar to Sequence 1 , except that manual scram is successful following RPS electrical failure.

Sequence 3: T*MSIV $-0 * \overline{\mathrm{RPSM}} * \mathrm{RPSE}^{*} \mathrm{SCRM} * \overline{\mathrm{RODI}} * \overline{\mathrm{FW}}-$

In this sequence, manual scram is unsuccessful but manual rod insertion is successful. Feedwater continues to operate while rod motion eventually shuts down the reactor. Water level is maintained above Level 1; therefore, there should be no ADS demand. This sequence is OK.

\section{Sequence $X: \quad T * M S I V-0 * R P S M * \overline{R P S E} * S C R M * \overline{R O D 1} * F W \ldots$}

This sequence is developed on Figure IV.10.1-1. See discussion of Sequences 3 through 31 .

In these sequences, manual rod insertion is successful but feedwater

fails to continue because of subsequent MSIV closure. Subsequent MSIV closure can occur for a number of reasons:

0 The onset of an ATWS is a very dynamic situation in which large feedwater oscillations and a Level I MSIV trip are possible. If Level 1 is reached, MSIV closure will occur since there is no time to bypass the Level 1 trip.

- Fuel damage could occur because of the large initial feedwater oscillations. A radiation release will result in MSIV closure because of high radiation.

- Turbine trip results in feedwater runback which could cause a decrease in the reactor water level below Level 1 causing a MSIV closure before HPCI can recover the level. The sequence then transfers to the MSIV closure ATWS event tree where manual rod insertion has been successful. 
Sequence 4: $\quad T * M S I V-0 * \overline{\mathrm{RPSM}} * \mathrm{RPSE} * S C R M * R O D 1 * \overline{\mathrm{FW}} * \overline{\mathrm{SPC}} \quad$ - -

In this sequence, manual rod insertion fails. Level control with feedwater continues. Torus cooling is initiated and is successful. Torus cooling is sufficient to cool the amount of heat being transferred to the suppression pool since the majority of the heat is being bypassed to the condenser. Therefore, a stable condition (but not yet shutdown) is present.

\section{Sequence 5: $\quad T * M S I V-0 * \overline{R_{P S M}} * R P S E * S C R M * R O D 1 * \overline{F W} * S P C * \overline{R O D 2} * \overline{S L C}$}

In this sequence, manual rod insertion fails and feedwater continues. Torus cooling is not successful. Backup rod insertion is successful; however, since torus cooling is not working, the suppression pool temperature will reach $110^{\circ} \mathrm{F}$ which calls for SLC initiation. SLC is successful and shutdown is achieved before critical containment conditions are reached. This sequence is OK.

Sequence 6: $T * M S I V-0 * \overline{R_{P S M}} * R P S E * S C R M * R O D 1 * \overline{F W} * S P C * \overline{R_{0 D 2}} * S L C$

This sequence is similar to Sequence 5 except that SLC is not successful. Containment venting is required (assuming it takes considerable time for event "ROD2"). This sequence is therefore considered CtV. This may be conservative depending on how long it takes backup rod insertion to shut down the reactor.

Sequences 7-8:

These sequences are similar to Sequences 5 and 6 except that backup rod insertion fails. Note that although Sequence 8 also results in a containment vulnerable state, it is no longer conservative since both backup rod insertion and SLC fail.

\section{Sequence $Y: \quad T * M S I V-0 * \overline{R P S M} * R P S E * S C R M * R O D 1 * F W \quad-$}

This sequence is developed on Figure IV.10.1-1. See discussion of Sequences 32 through 52 .

This sequence is similar to the sequence where manual rod insertion succeeds but feedwater fails to continue, except that this sequence transfers to the MSIV closure event tree where manual rod insertion has failed.

\section{Sequence 9: $\quad T * M S I V-0 * R P S M * \overline{F W} * \overline{S P C} \quad-$}

In this sequence, RPS mechanical fails. Feedwater continues to run. Torus cooling is initiated and is successful. Torus cooling is sufficient to cool the amount of heat being transferred to the suppression pool since the majority of the heat is being bypassed to the condenser. Therefore, a stable condition is present (but not shutdown). 
These sequences are similar to Sequences 7 and 8 . The only difference is that back up rod insertion is not given a chance to fail or succeed since the RPS has failed mechanically.

\section{Sequence Y1: T*MSIV-0*RPSM*FW - -}

This sequence is developed on Figure IV.10.1-1. See discussion of Sequences 53 through 73 .

This sequence is similar to the above sequence where manual rod insertion fails. The only difference is that the possibility of backup rod insertion does not exist.

IV.10.1.3 Human Reliability Analysis For Case A ATWS Event Trees

\section{IV.10.1.3.1 Summary}

As shown in the following quantification section, HEPs are provided for each branch point in the Peach Bottom ATWS event tree. BNL's effort involved only an examination of human reliability during each particular accident sequence. Sources of equipment failures or unavailabilities were not examined, nor were extensive thermal-hydraulic calculations made.

BNL assisted the Peach Bottom study effort by performing an HRA on the operations crew at Peach Bottom during an ATWS accident sequence with MSIV closure.

Visits by BNL were made to the Philadelphia Electric Company headquarters, Peach Bottom's control room panels mockup in Philadelphia, the Peach Bottom Atomic Power Station, and the Limerick Generating Station training simulator for the purpose of acquiring plant-specific data on (1) training, (2) procedures, (3) human engineering, and (4) experience and education levels of the operations crew. Interviews were conducted with Peach Bottom training instructors, former operators, and other staff; a meeting was held with the Superintendent - Plant Services. The training manuals were reviewed and copies of relevant emergency procedures were obtained.

A detailed task analysis was performed based on consideration of staffing, team interaction, and control room layout at Peach Bottom. ATWS scenarios developed by Oak Ridge National Laboratory (ORNL) and Idaho National Engineering Laboratory (INEL) were reviewed. Discussions were held with thermal-hydraulic/core neutronics engineers at BNL to determine the success criteria for tasks.

The Peach Bottom analysts provided a final ATWS event tree which identified five major operator tasks (i.e., branch points) that needed to be quantified:

o Initiating SLC (SLC),

o Defeating the ADS Initiation Signal (RXHP),

o Establishing and maintaining water level at top of active fuel at high pressure (LEV), 
- Manual depressurization of the reactor pressure vessel (DEP), and

0 Establishing and maintaining water level at top of active fuel at low pressure (LPIN).

Preconditions for each task differ as a result of the success or failure of previous tasks and safety systems. Each set of preconditions and relevant performance shaping factors (PSFs) were considered when human error probabilities (HEPs) were assigned to each branch point. The branch points of the ATWS event tree were quantified using procedures which included a review of HRA in other PRAs and subjective judgment methods based on the structured assessment of PSFs and use of a time-reliability correlation.

The tables containing information from Reference 29 of all HEPs, each interpreted as the median of a hypothetical $10 \mathrm{~g}$ normal distribution, are shown in Tables IV.10.1-1, IV.10.1-2, IV.10.1-3, IV.10.1-4, and IV.10.1-5, together with the 5th and 95 th quantiles of the distribution. Also, it should be noted that, in the above tables, mean values are calculated for the HEP numbers that are used in the quantification of the dominant scenarios in the ATWS event trees. These mean values are discussed in detail in Section IV.10.1.4.

\section{IV.10.1.3.2 Quantification}

The final event trees that identified the branch points where operator action needed to be assessed was given to BNL. Each such branch point involves the operation of a particular task (i.e., performing certain proceduralized steps) which one or more operators must undertake. Some tasks are represented at more than one branch point depending on previous events (or branch points) asked. For example, initiation of SLC is one task, but it may be performed under different sets of events (i.e., whether or not the MSIVs have closed), which represent different branch points. These tasks are discussed in the following paragraphs.

SLC Task - Operate SLC System (Event "SLC" in Event Tree) --

The HEP estimate for failure to initiate SLC is given in Table IV.10.1-1. SLC is supposed to be actuated by the time the torus temperature reaches $110-1150 \mathrm{~F}$ (which is predicted to occur within 120 seconds of MSIV closure initiation).

ADS Task -- Defeat ADS Initiation Signal (Event "RXHP" in Event Tree) --

The HEP estimate for failure to defeat the ADS initiation signal is given in Table IV.10.1-2. The ADS must be defeated within eight minutes of ADS alarm.

LEV1 Task - - Establish and Maintain Water Level at TAF while at High Pressure (Event "LEV" in Event Tree) --

The HEP estimate for failure to maintain RPV level at the TAF while the RPV pressure is greater than 500 psig is given in Table IV.10.1-3. The water level was assumed to be maintained within twelve inches of TAF for success of this event.

(Text continued on Page IV-279) 
Table IV.10.1-1

Initiate Standby Liquid Control (SLC) Human Error Probability (HEP)

Sensitivity to Time Available and Reluctance Factor For case A

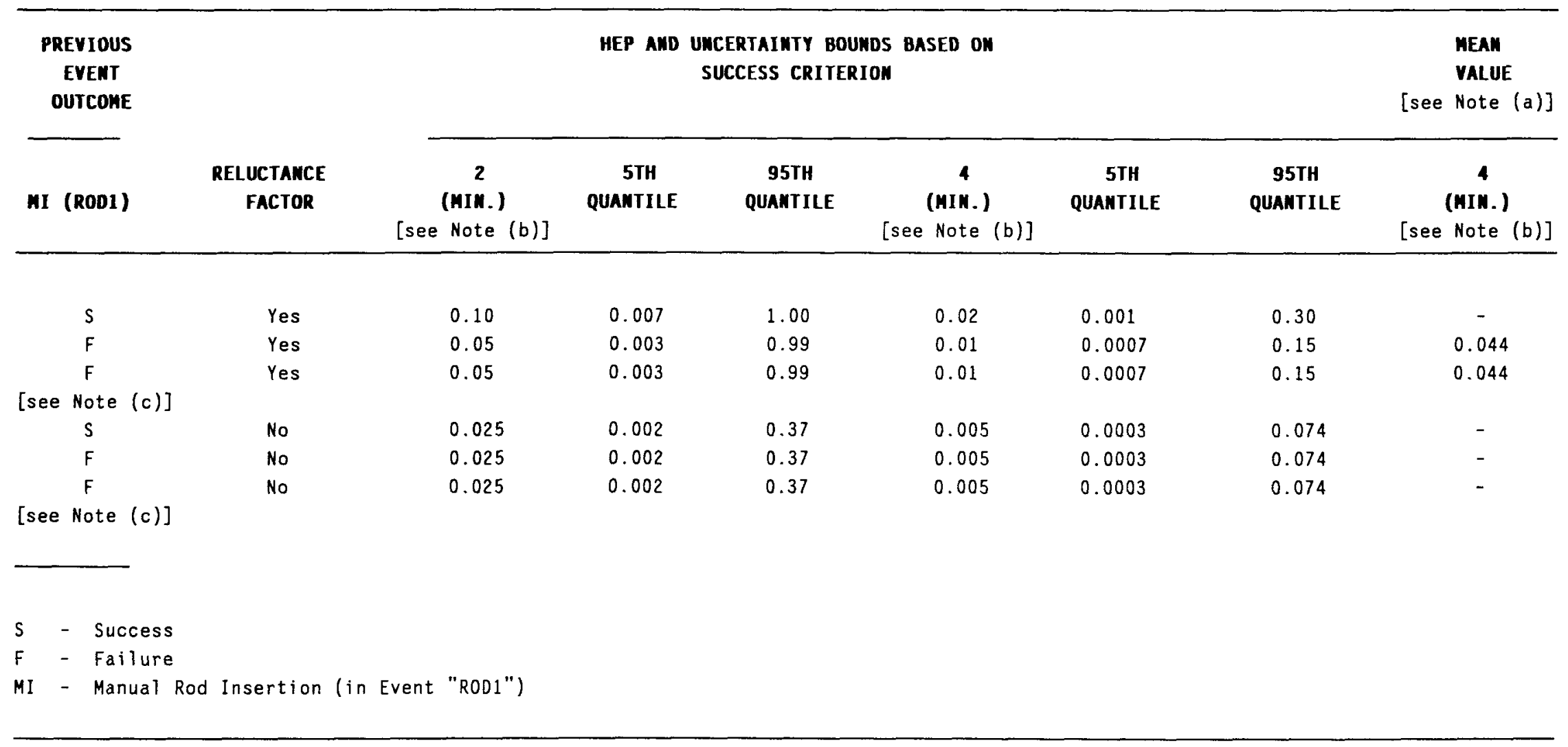

NOTES:

(a) Mean Values only calculated for medians that are used in dominant sequence quantifications.

(b) Minutes from ATWS.

(c) Reactor Protection System Mechanical (in Event "RPSM") failure instead. 
Table IV, 10.1-2

Human Error Probability (HEP) Estimates to Defeat Automatic Depressurization System Initiation (ADS) For Case A

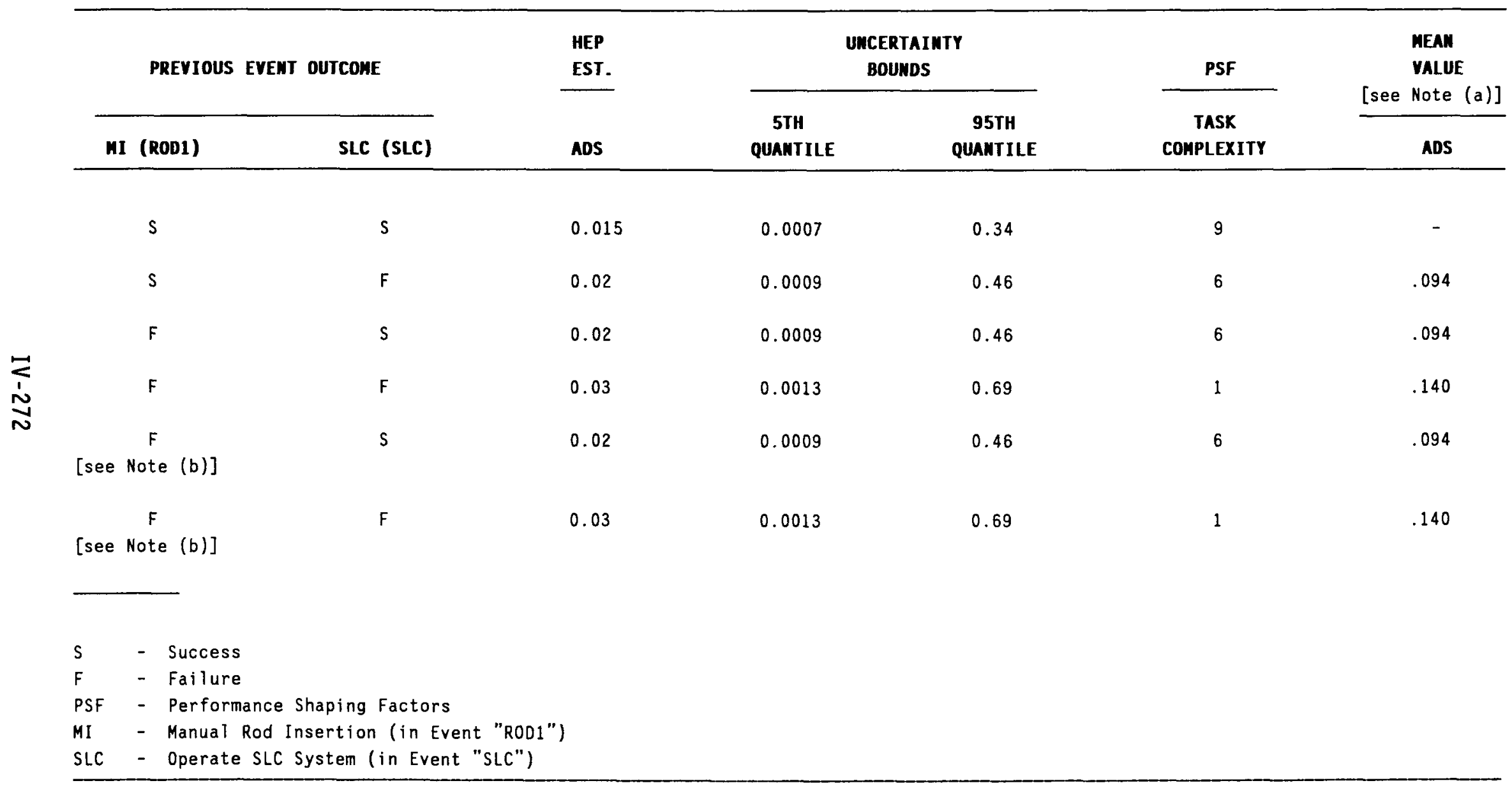

NOTES:

(a) Mean Values only calculated for medians that are used in quantification.

(b) Reactor Protection System Mechanical (in Event "RPSM") failure instead. 
Table IV. 10.1-3

Human Error Probability (HEP) Estimates to Establish and Maintain

Water Level at TAF While at High Pressure (LEV1) For Case A

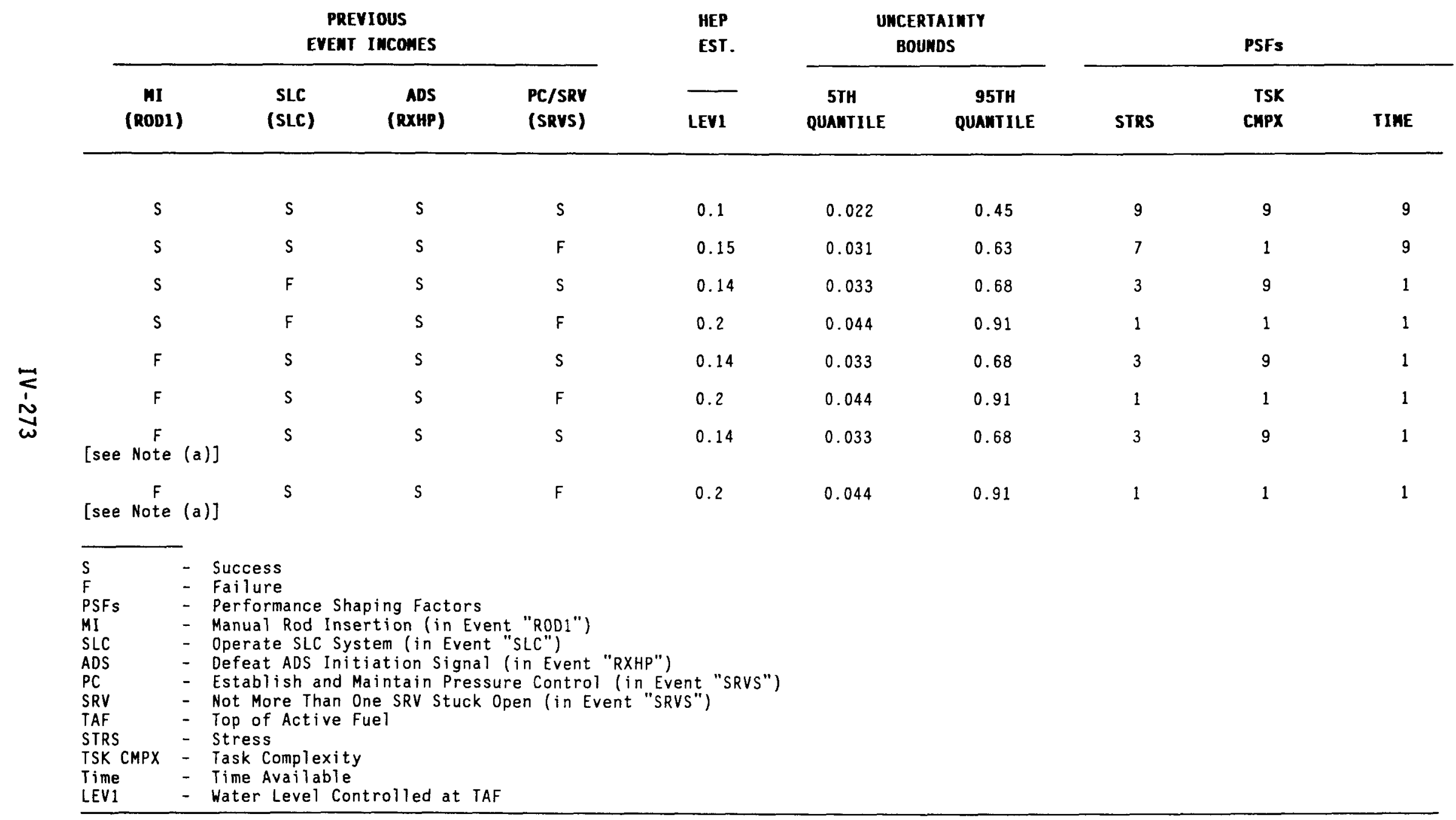

NOTE:

(a) Reactor Protection System Mechanical (in Event "RPSM") failure instead. 
Table IV. $10.1-4$

Human Error Probability (HEP) Estimates for Manual Depressurization (DEP) for Case A

\begin{tabular}{|c|c|c|c|c|c|c|c|c|}
\hline \multicolumn{5}{|c|}{ PREYIOUS EVEMT OUTCOMES } & \multirow{2}{*}{$\begin{array}{l}\text { HEP } \\
\text { EST. } \\
\overline{\text { DEP }}\end{array}$} & \multicolumn{2}{|c|}{$\begin{array}{l}\text { UMCERTAIKTY } \\
\text { BOUMDS }\end{array}$} & \multirow{2}{*}{$\begin{array}{c}\begin{array}{c}\text { MEAM } \\
\text { VALUE }\end{array} \\
\text { DEP }\end{array}$} \\
\hline$\underset{\text { (ROD1) }}{\text { MI }}$ & $\begin{array}{c}\text { SLC } \\
(S L C)\end{array}$ & $\begin{array}{c}\text { ADS } \\
\text { (RXHP) }\end{array}$ & $\begin{array}{l}\text { PC/SRY } \\
\text { (SRVS) }\end{array}$ & $\begin{array}{l}\text { HLC } \\
\text { (LEV) }\end{array}$ & & $\begin{array}{c}\text { 5TH } \\
\text { QUANTILE }\end{array}$ & $\begin{array}{c}\text { 95TH } \\
\text { QUAMTILE }\end{array}$ & \\
\hline s & $s$ & $s$ & $s$ & $T H / O S C(\overline{L E V 2})$ & 0.14 & 0.03 & 0.63 & 0.213 \\
\hline$s$ & $s$ & $s$ & s & TAF ( $\overline{\text { LEV } 1)}$ & 0.14 & 0.03 & 0.63 & 0.213 \\
\hline s & $s$ & s & $s$ & TL (LEV) & 0.14 & 0.03 & 0.63 & 0.213 \\
\hline$s$ & $s$ & s & $\mathrm{F}$ & TL (LEV) & 0.14 & 0.03 & 0.63 & 0.213 \\
\hline $\mathrm{s}$ & $\mathrm{F}$ & $s$ & $\mathrm{~s}$ & TAF/OSC/TH (LEV) & 0.14 & 0.03 & 0.63 & 0.213 \\
\hline$s$ & $F$ & s & $s$ & TL (LEV) & 0.14 & 0.03 & 0.63 & 0.213 \\
\hline s & $\mathrm{F}$ & s & $\mathrm{F}$ & TL (LEV) & 0.14 & 0.03 & 0.63 & 0.213 \\
\hline $\mathbf{F}$ & $s$ & s & s & $T H / O S C(\overline{L E V 2})$ & 0.14 & 0.03 & 0.63 & 0.213 \\
\hline $\mathrm{F}$ & $s$ & $s$ & s & $\operatorname{TAF}(\overline{\operatorname{LEV} 1})$ & 0.14 & 0.03 & 0.63 & 0.213 \\
\hline $\mathrm{F}$ & $s$ & s & $s$ & IL (LEV) & 0.14 & 0.03 & 0.63 & 0.213 \\
\hline$F$ & $s$ & S & $\mathrm{F}$ & TL (LEV) & 0.14 & 0.03 & 0.63 & 0.213 \\
\hline $\mathrm{F}$ & $F$ & s & - & - & 0.14 & 0.03 & 0.63 & 0.213 \\
\hline $\begin{array}{c}F \\
{[\text { see Note }(a)]}\end{array}$ & $s$ & s & s & $T H / O S C(\overline{\text { LEV2 }})$ & 0.14 & 0.03 & 0.63 & 0.213 \\
\hline $\begin{array}{c}F \\
{[\text { see Note }(a)]}\end{array}$ & $s$ & s & s & $\operatorname{TAF}(\overline{\operatorname{LEV} 1})$ & 0.14 & 0.03 & 0.63 & 0.213 \\
\hline $\begin{array}{c}F \\
{[\text { see Note }(a)]}\end{array}$ & $s$ & $s$ & $s$ & TL (LEV) & 0.14 & 0.03 & 0.63 & 0.213 \\
\hline $\begin{array}{c}F \\
{[\text { see Note }(a)]}\end{array}$ & $s$ & $s$ & $\mathrm{~F}$ & TL (LEV) & 0.14 & 0.03 & 0.63 & 0.213 \\
\hline $\begin{array}{c}F \\
{[\text { see Note }(a)]}\end{array}$ & $\mathrm{F}$ & $s$ & - & - & 0.14 & 0.03 & 0.63 & 0.213 \\
\hline
\end{tabular}

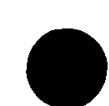




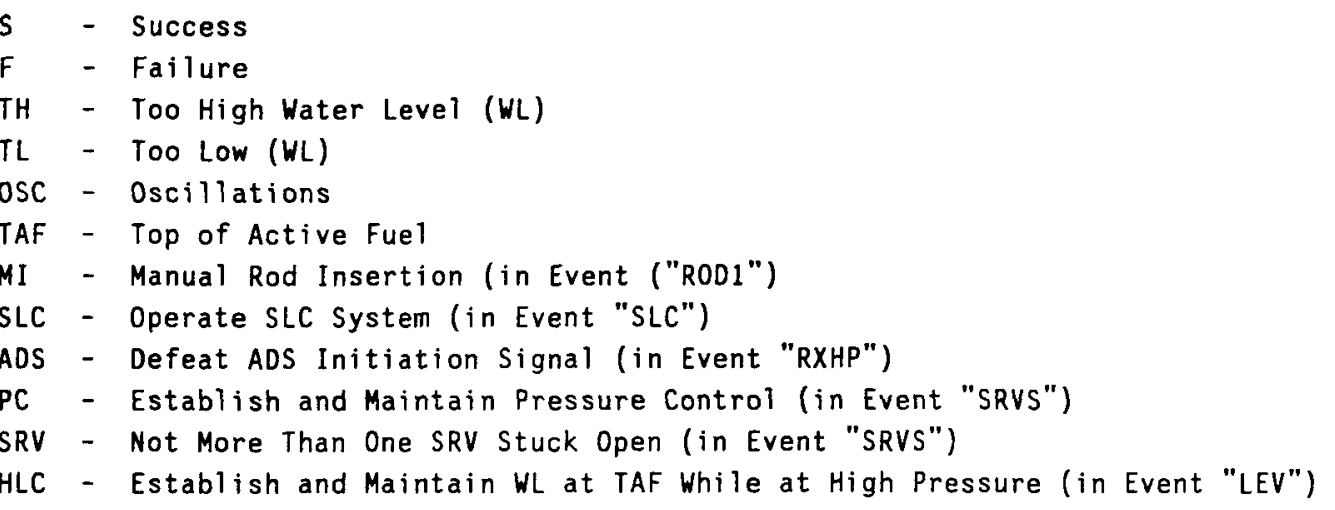

F $\overline{\text { LEV1 }}$ - Water Level Controlled at TAF

जั $\overline{\text { LEV2 }}$ - Water Level Controlled at TH/OSC

$\overline{L E V}$ - Water Level Controlled at TAF/TH/OSC

LEV - Water Level Kept Too Low

Notes for Table IV.10.1-4

NOTE:

(a) Reactor Protection System Mechanical (in Event "RPSM") failure instead. 
Table IV.10.1-5

Human Error Probability (HEP) Estimates to Establish and

Maintain Water Level at TAF While at Low Pressure (LPII) for Case A

\begin{tabular}{|c|c|c|c|c|c|c|c|c|c|c|c|}
\hline \multicolumn{6}{|c|}{ PREVIOUS EVENT OUTCONES } & \multirow[b]{2}{*}{$\begin{array}{c}\text { FLO } \\
\text { (INJ) }\end{array}$} & \multirow{2}{*}{$\begin{array}{l}\text { HEP } \\
\text { EST. } \\
\text { LPII }\end{array}$} & \multicolumn{2}{|c|}{$\begin{array}{l}\text { UHCERTAINTY } \\
\text { BOUMDS }\end{array}$} & \multicolumn{2}{|c|}{ PSFs } \\
\hline $\begin{array}{c}\text { MI } \\
\text { (ROD1) }\end{array}$ & $\begin{array}{l}\text { SLC } \\
(S L C)\end{array}$ & $\begin{array}{c}\text { ADS } \\
\text { (RXHP) }\end{array}$ & $\begin{array}{l}\text { PC/SRY } \\
\text { (SRYS) }\end{array}$ & $\begin{array}{c}\text { HLC } \\
\text { (LEV) }\end{array}$ & $\begin{array}{l}\text { DEP } \\
\text { (DEP) }\end{array}$ & & & $\begin{array}{c}\text { 5TH } \\
\text { QUANTILE }\end{array}$ & $\begin{array}{c}95 T H \\
\text { QUANTILE }\end{array}$ & STRS & $\begin{array}{r}\text { TSX } \\
\text { CHPX }\end{array}$ \\
\hline$S$ & $S$ & $S$ & $\mathrm{~S}$ & TH/OSC (LEV2) & S & $F$ & 0.45 & 0.099 & 1.00 & 5 & 1 \\
\hline$S$ & s & $S$ & $S$ & TAF (LEV1) & s & $\mathrm{F}$ & 0.45 & 0.099 & 1.00 & 5 & 1 \\
\hline $\mathrm{s}$ & S & $S$ & S & TL (LEV) & S & - & 0.2 & 0.044 & 0.91 & 9 & 9 \\
\hline $\mathrm{s}$ & $S$ & S & $\mathrm{F}$ & TAF/TH/OSC (LEV) & - & - & 0.2 & 0.044 & 0.91 & 9 & 9 \\
\hline$S$ & $\mathrm{~S}$ & $S$ & $\mathrm{~F}$ & TL (LEV) & S & - & 0.2 & 0.044 & 0.91 & 9 & 9 \\
\hline $\mathrm{s}$ & S & $\mathrm{F}$ & - & TL (LEV) & $S$ & - & 0.2 & 0.044 & 0.91 & 9 & 9 \\
\hline $\mathrm{S}$ & $\mathrm{F}$ & $S$ & S & TAF/OSC/TH (LEV) & s & - & 0.28 & 0.061 & 1.00 & 3 & 9 \\
\hline$s$ & $F$ & $S$ & S & TL (LEV) & s & - & 0.28 & 0.061 & 1.00 & 3 & 9 \\
\hline$S$ & $F$ & $S$ & $F$ & $\mathrm{TH} / \mathrm{TAF} / O \mathrm{OSC}$ (LEV) & - & - & 0.28 & 0.061 & 1.00 & 3 & 9 \\
\hline$S$ & $F$ & $S$ & $F$ & TL (LEV) & s & - & 0.28 & 0.061 & 1.00 & 3 & 9 \\
\hline$F$ & S & S & $\mathrm{S}$ & $\mathrm{TH} / 0 \mathrm{SC}$ (LEV2) & s & $F$ & 0.5 & 0.11 & 1.00 & 3 & 1 \\
\hline $\mathrm{F}$ & $S$ & $S$ & $S$ & $\operatorname{TAF}(\overline{\operatorname{LEV} 1})$ & S & $F$ & 0.5 & 0.11 & 1.00 & 3 & 1 \\
\hline$F$ & $S$ & $S$ & $F$ & TL (LEV) & S & - & 0.26 & 0.057 & 1.00 & 4 & 9 \\
\hline
\end{tabular}




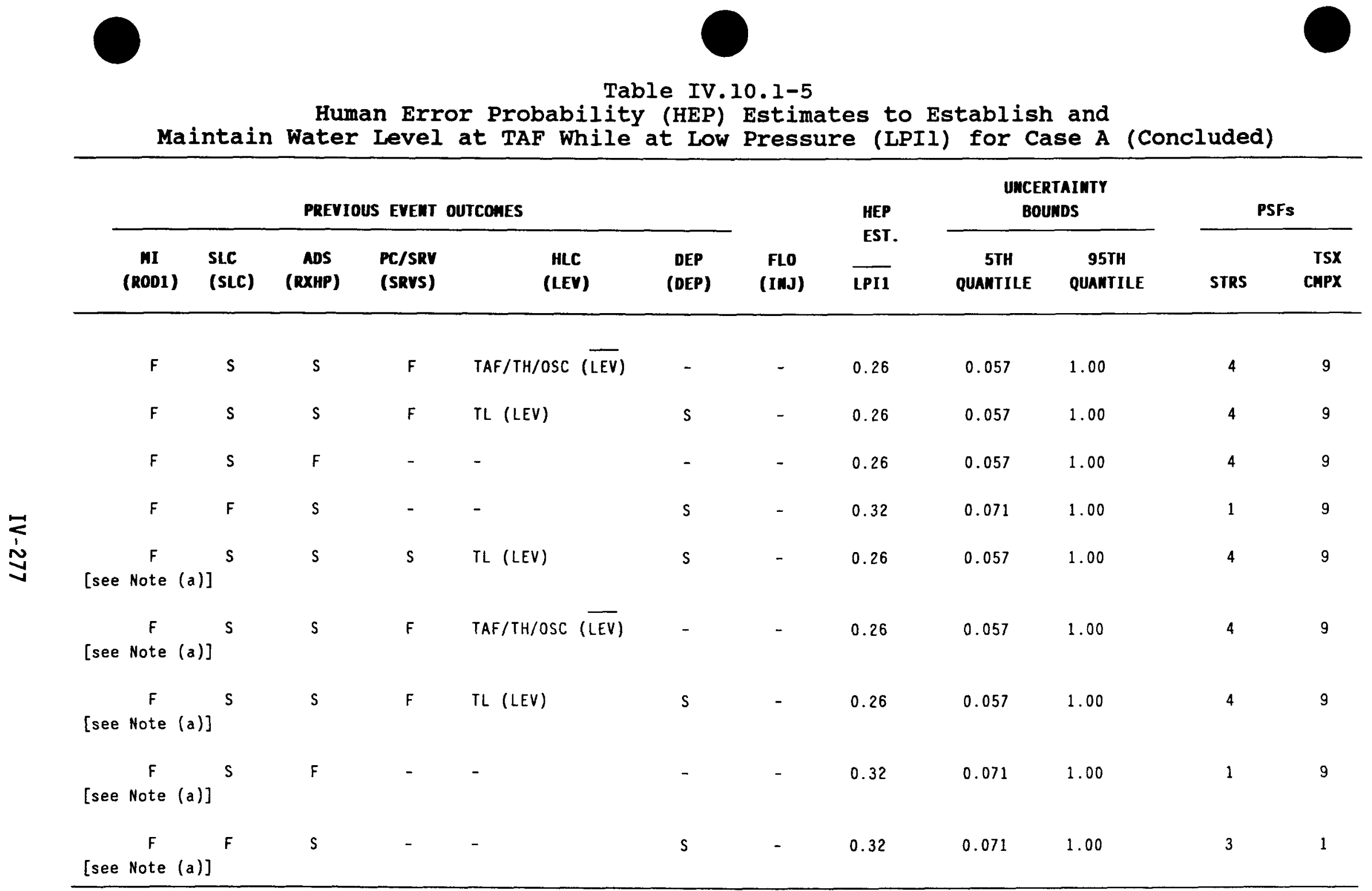

NOTE:

(a) Reactor Protection System Mechanical (in Event "RPSM") failure instead. 


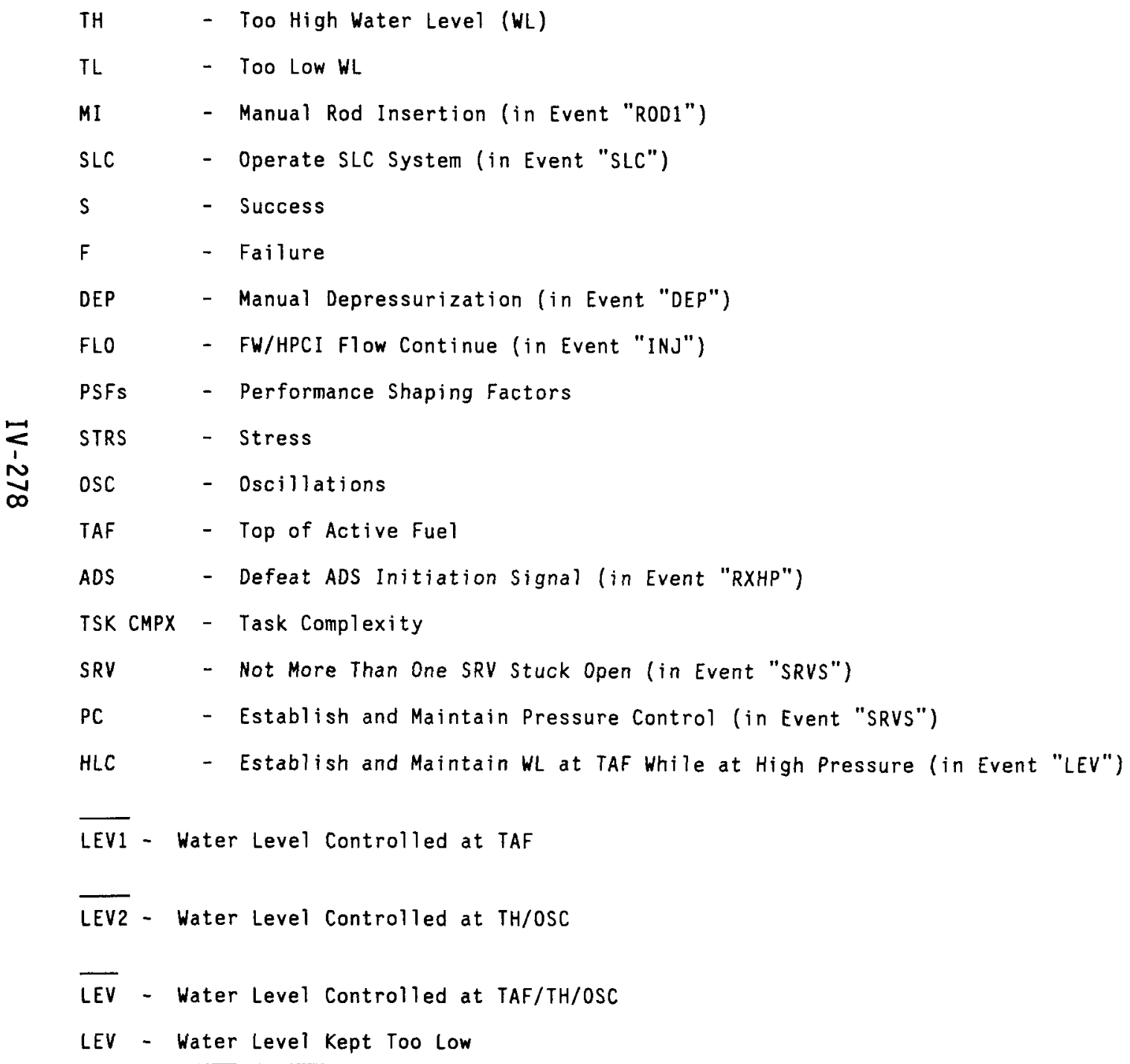


DEP Task -- Manual Depressurization (Event "DEP" in Event Tree) --

The HEP estimate for failure to manually depressurize the reactor vessel is given in Table IV.10.1-4.

\section{LPIl Task -- Estab1 ish and Maintain Water Level at TAF while at Low Pressure (Event "LPIN" in the Event Tree) --}

The HEP estimate for failure to maintain RPV level at the TAF while the RPV pressure is below 500 psig is given in Table IV.10.1-5. The basis for the values assumes that the water level is to be maintained within twelve inches of TAF for success of this event.

IV.10.1.4 Supporting Calculations and Data

This section presents the supporting calculations and data that were used in constructing and quantifying the ATWS event tree.

\section{IV.10.1.4.1 Supporting Calculations}

The information used to construct the ATWS event tree was obtained from ATWS code simulations performed for Peach Bottom and from related studies. The ATWS code simulations were performed using the LTAS code (Reference 31). LTAS code simulations were made for eight different ATWS scenarios. These are given in Table IV.10.1-6.

Another source of information was a report by ORNL which presents an ATWS with MSIV closure analysis using Brown's Ferry as the model plant (Reference 32). The analys is is applicable to Peach Bottom since both Peach Bottom and Brown's Ferry are BWR 4 reactors and MARK I containments. A summary of the study is given in Table IV.10.1-7.

Two other studies that were performed by General Electric (GE), (Reference 33) and INEL (Reference 34) were included in the analysis. The results of these two studies basically support the two previous studies.

It should be noted that, while the thermal-hydraulic calculations from these sources generaliy agree, specific results do vary somewhat. This represents uncertainties in sequence timing and success criteria which are not explicitly analyzed in this study because of resource limitations.

\section{IV.10.1.4.2 Data Used In Quantification}

Both HEPs and system failure rates were used to quantify the ATWS event tree in Figures IV.10.1-1 and IV.10.1-2. The data that were used to quantify the event tree are given in Table IV.10.1-8. The values in Table IV.10.1-8 are all mean values. Table IV.10.1-8 gives the top events with their associated HEPs and system failure rates separately, then combined, to obtain the total failure probabilities. 
Table IV.10.1-6

LTAS Code Runs For Various ATWS Scenarios at Peach Bottom

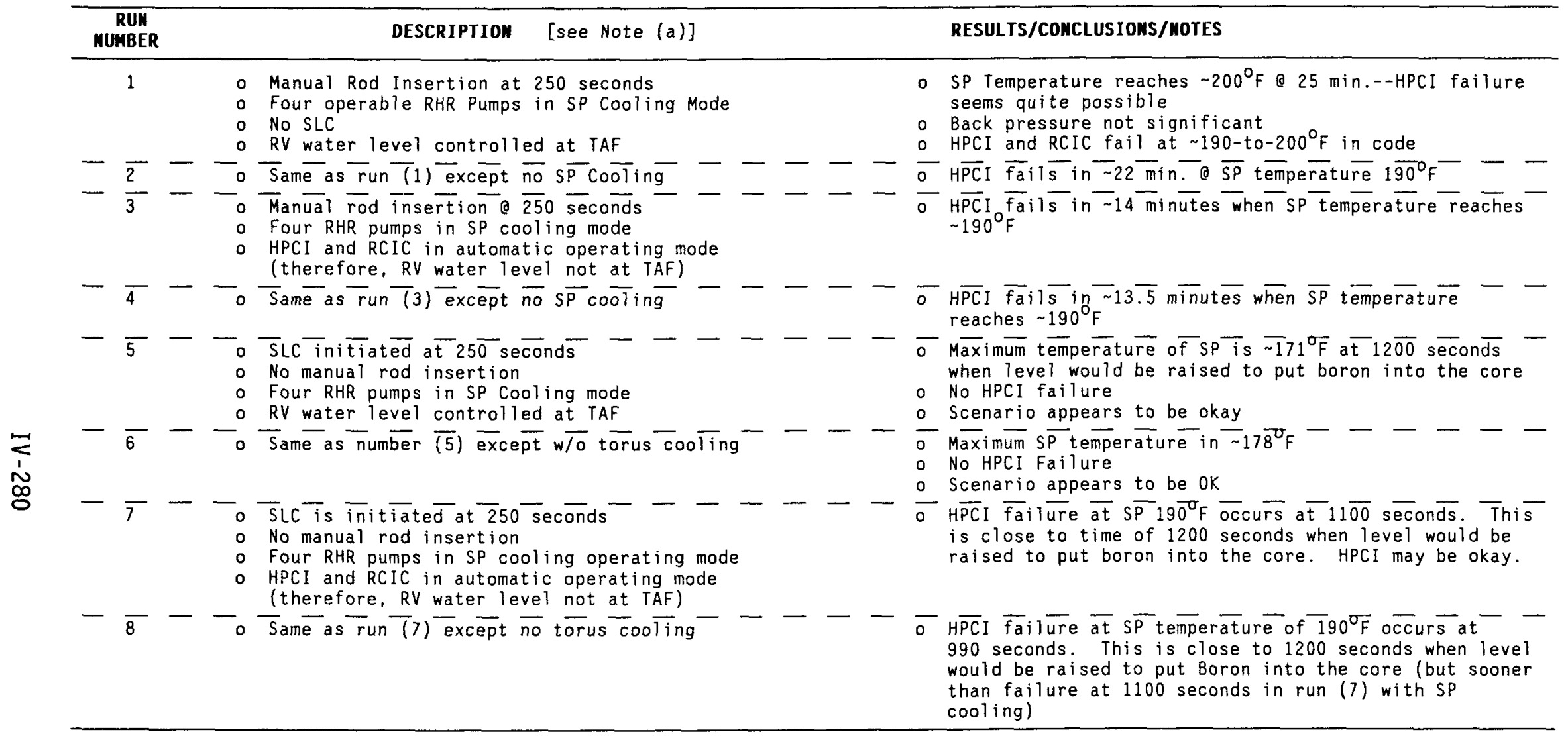

\section{NOTE}

(a) All runs had an ATYS followed by MSIV closure. 
Table IV.10.1-7

Summary of ITAS ATWS with MSIV Closure Runs Performed

At ORNI for Brown's Ferry

\section{Run \#1 - No Action}

- HPCI switches to pool $-8 \mathrm{~min}$ e $1500 \mathrm{~F}$

- HPCI fails $\sim 15$ minutes 0 2000F

- ADS actuates

$0 \quad$ LP systems on - cycling up and down

$0 \quad-30-45$ min. - containment pressure closes SRVs

$0 \quad-30-45 \mathrm{~min}$. - containment fails

Run \#2 - A11 0K

$0 \quad 35$ min - Rx shutdown

0 Pool temp max $-1600 \mathrm{~F}$

- HPCI/RCIC start

$0 \quad$ Man rod insertion starts 03 minutes

02 minutes - pool reaches $110^{\circ} \mathrm{F}$; by 5 minutes - SLC started

- Lower level \& control W/ HPCI \& control pressure -900 psia

- All RHR cooling started by 10 minutes

o By 17 minutes - RHR cooling exceeds power into pool - max temp. -1600F

- Drywell pressure very low

$0 \quad$ Increasing HPCI flow to put boron in core $-30 \mathrm{~min}$.

o All Over

Run \#3 - SLC OK - Rest Not OK (Including no level control)

$0 \quad H P C I$ shift to pool -8 min

$0 \quad$ HPCI fails due to pool temp $\sim 190^{\circ} \mathrm{F}$ by $\sim 15$ minutes

o RCIC/CRD still putting in water - SLC mixes water rises - RCIC trip on high level

o $\quad-50$ - 60 minutes - pool max $-2000 \mathrm{~F}$ and increasing slowly

$0 \quad$ Shutdown $-50-60$ minutes

Run \#4 - No Rod Insert, Rest OK

- Like (2) except:

1 Max pool temp $\sim 30$ min $\sim 1650 \mathrm{~F}$

2 Shutdown -35 minutes 
Table IV.10.1-7

Summary of LTAS ATWS with MSIV Closure Runs Performed

At ORNL for Brown's Ferry (Concluded)

Run \#5 - No SLC, rest OK

o Like (2) except:

$1-1 \mathrm{hr}$ to shutdown

2 By 30 minutes decay heat levels being reached

3 HCTL will be reached -20 minute - so depressurize and use LP systems

4 ADS inhibit not so important since depressurized anyway

5 Max pool temp $180^{\circ} \mathrm{F}-185^{\circ} \mathrm{F}$

Run \#6 - No SLC/No Rod Insertion (Rest OK)

o By 2 hours, pool at $2230^{\circ} \mathrm{F}$ pressure containment $\sim 30$ psia

$0 \quad$ By 10 hours, Temp $=345^{\circ} \mathrm{F}$ pressure fails containment

Run \#7 - № SLC/№ Rods/№ Pool Cooling

$0 \quad$ By $\sim 2$ hours - containment failure

Run \#8 - W/0 Pool Cooling, all else OK

- Still shutdown -35 min.

0 Max pool temp 060 min $\sim 1700 \mathrm{~F} \&$ rising slowly

$0 \quad$ Now a TW - type sequence, need cooling by $\sim 24$ hours

0 Pressure (containment) is -50 psig o 20 hours

Run \#9 - Stuck Open Valve(s)

- No big difference except run risk of low pressure injection

- 1 valve - HPCI keeps going

$0 \quad 2$ valves - HPCI isolates on low pressure $-15 \mathrm{~min}$.

$0 \quad$ Shutdown $-30-35$ minutes 
Table IV.10.1-8

Peach Bottom ATWS Date Used for Quantification

\begin{tabular}{|c|c|c|c|}
\hline $\begin{array}{c}\text { TOP } \\
\text { EVENT }\end{array}$ & $\begin{array}{c}\text { HUMAN } \\
\text { ERROR } \\
\text { PROBABILITY }\end{array}$ & $\begin{array}{c}\text { MECH/ELECT/T\&M } \\
\text { FAILURE } \\
\text { PROBABILITY }\end{array}$ & $\begin{array}{c}\text { TOTAL } \\
\text { FAILURE } \\
\text { PROBABILITY }\end{array}$ \\
\hline
\end{tabular}

AT

MSIV OPEN

RPS MECH

RPS ELECT

MANUAL SCRAM

MANUAL ROD INSERTION

SLC

INHIBIT ADS

TWO OR MORE SRVS

DO NOT STICK OPEN

H.P. LEVEL CONTROL
(1) $\mathrm{TL}$
(2) $\mathrm{TAF} / \mathrm{TH} / \mathrm{OSC}$

TORUS COOLING

OP. DEP

HPCI CONT.

L.P. LEVEL CONTROL
(1) $\mathrm{TL}$
(2) $\mathrm{TAF} / \mathrm{TH} / 0 \mathrm{SC}$

BACKUP ROD INSERTION

-
-
-
-
$<1 E-4$
$(a)$
0.034
(b)
-
$2.66 E-3$
$9.97 E-1$

(a)

$-$

$2.66 \mathrm{E}-3$

9. $97 \mathrm{E}-1$

(a) 4.2/year

0.37

1. OE-5

2.0E-5

$2 E-3$

$2 E-3$

(a)

(a)

0.01

0.044

(b)

(b)

0.01

0.01

$6.7 E-2$

$9.33 E-1$

$6.44 \mathrm{E}-2$

9. $36 \mathrm{E}-1$

(a)

0.213

0.1 (c)

0.2 (d)

(a)

2.66E-3

9.97E-1

(a)

NOTES:

(a) Not quantified (not in dominant scenarios).

(b) See Table IV.10.1-2.

(c) When operator depressurizes.

(d) When operator fails to depressurize. 
Top Event Frequencies and Probabilities

Anticipated Transient (T) --

The frequency of anticipated transients was derived from the following five initiators (see Section IV.8):

\section{INITIATOR}

Loss of Offsite Power (LOSP)

Loss of Feedwater (LOFW)

MSIV Closure

Inadvertent opening of a relief valve (IORV) (IORV)

Turbine Trip

Total

\section{FREQUENCY/YEAR}

0.07

0.7

0.8

0.23

2.4

4.2 transients/year

MSIV Open (MSIV-O) --

Three initiators lead to MSIV closure: MSIV closure, LOSP, and LOFW (assumed). The assumption that LOFW leads to MSIV closure is somewhat conservative. Therefore, the probability that a transient results in MSIV closure is the following:

Probability of $=$ [Frequency of MSIV closure events + Frequency of LOSP event + MSIV Closure Frequency of LOFW events] $\%$. Frequency of all transients $=[0.8+0.07+0.7] \cdot 4.2$

$=0.37$

RPS Mechanical (RPSM) --

The failure probability of the RPS mechanical system is $1 E-5$ using Nuclear Regulatory Commission (NRC) estimates [35].

RPS Electrical (RPSE) --

The failure probability of the RPS electrical system is 2E-5 using NRC estimates [35].

\section{Manual Scram (SCRM) --}

The manual scram system at Peach Bottom is essentially a parallel arrangement to the automatic logic. Successful scram requires that both logics function. Using the ASEP generic failure probability value for actuation circuitry of $1 E-3$ as the probability of failure of each logic yields a failure probability of 2E-3 for manual scram. Consideration of failure of the RPT function, accounting for diverse actuation signals and operator recovery, results in an estimate of -1E-4 for failure of RPT.

The probability that the control room operators will fail to attempt manual SCRAM (according to verbal communication with Bill Luckas at BNL) is <1E-4. Therefore, failure to manually scram is dominated by system failures. 
Manual Rod Insertion (ROD1) --

If scram is reset, the ACO must attempt to manually insert control rods one by one by operating the rod selection matrix pushbutton and the rod motion control switch. No credit is taken for this event in the ATWS event tree because it may not be possible to reset the scram signal.

\section{Standby Liquid Control (SLC) --}

A dominant failure probability of the SLC system's not being restored after testing is estimated at 1E-2 (see Section IV.7). The failure probability of the SLC to be initiated within 4 minutes is .034 (see Table IV.10.1-1). Therefore, the total unavailability of the SLC system is 0.044 . It should be noted that this is the mean value of SLC failure after manual rod insertion has failed. The mean value for the HEP shown in Table IV.10.1-1 was obtained by modifying the result from BNL with a log-uniform distribution instead of a log-normal distribution. This was done to avoid probabilities greater than 1.0.

Inhibit ADS (RXHP) -.

The mean values for failing to inhibit ADS are given in Table IV.10.1-2. As for the SLC case, a log-uniform distribution was used in the mean calculation to avoid probabilities greater than 1.0 . The mean values for the median values of .02 and .03 are .094 and .14 , respectively.

Two or More SRVs Do Not Stick Open (SRVs) --

he probability of two or more SRVs sticking open is estimated at 0.01 /ATWS event. This is based on the following analysis:

Step 1.

The failure probability of an SRV sticking open is equal to $1 \mathrm{E}-2 /$ demand

(ASEP generic data backed by Peach Bottom specific data).

Step 2.

Assume the following conditions:

- Five valves are demanded open after an ATWS;

- With operator pressure control, pressure isn't controlled until one valve cycles five more times;

- Without operator pressure control, one valve cycles approximately thirty times; and

- From Station Blackout Report (Reference 36 ), once a valve is cycling the probability of sticking open/demand is $1 E-3 /$ demand. 
Step 3.

The probability that the cycling valve sticks open later will depend on whether or not the operator controls pressure.

(a) The probability that a cycling valve sticks open if the operator controls pressure is equal to

1 valve $\times 5$ cycles/valve $\times 1 \mathrm{E}-3=5 \mathrm{E}-3$.

(b) The probability that a cycling valve sticks open if the operator does not control pressure is equal to

1 valve $\times 30$ cycles/valve $\times 1 \mathrm{E}-3=3 \mathrm{E}-2$.

(c) Assuming that the operator will control pressure $90 \%$ of the time, the probability that a cycling valve will stick open is equal to

$$
(0.9 \times 5 \mathrm{E}-3)+(0.1 \times 3 \mathrm{E}-2)=7.5 \mathrm{E}-3 \text {. }
$$

(d) Probability that at least one of the five SRVs initially stick open is equal to

5 valves $\times 1$ demand/valve $\times 1 \mathrm{E}-2 /$ demand $=5 \mathrm{E}-2$.

(e) Probability that two of the five SRVs initially stick open is equal to

(Valve $1 \times$ Valve 2$)+($ Valve $1 \times$ Valve 3 ) (Valve $1 \times$ Valve 4 )

+ (Valve $1 \times$ Valve 5 ) + (Valve $2 \times$ Valve 3 ) (Valve $2 \times$ Valve 4 )

+ (Valve $2 \times$ Valve 5$)+($ Valve $3 \times$ Valve 4 ) (Valve $3 \times$ Valve 5 )

+ (Valve $4 \times$ Valve 5 ) + (neglect triple terms)

= two valves sticking open.

Step 4.

The probability of one SRV sticking open is $1 E-2 /$ demand, the probability of two of the five demanded SRVs independently and initially sticking open is $1 \mathrm{E}-3$. This is just the sum of the double terms (i.e., $1 E-2 \times 1 E-2$ ) in the equation above.

\section{Step 5 .}

The common mode (or Beta value) for SRVs is 0.2 . The probability that one valve sticks open is $1 \mathrm{E}-2$. The probability that another valve sticks open is the product of the Beta and the failure probability of the valve sticking open; or equal to $(1 \mathrm{E}-2) \times(.2)$ or $2 \mathrm{E}-3$. There are four chances that another valve will stick open; therefore, the probability that two SRVs will stick open initially because of common mode is $8 E-3$. 
Step 6.

Consequently the total probability of two or more SRVs sticking open is approximately 1E-2. This is shown in the fault tree below.

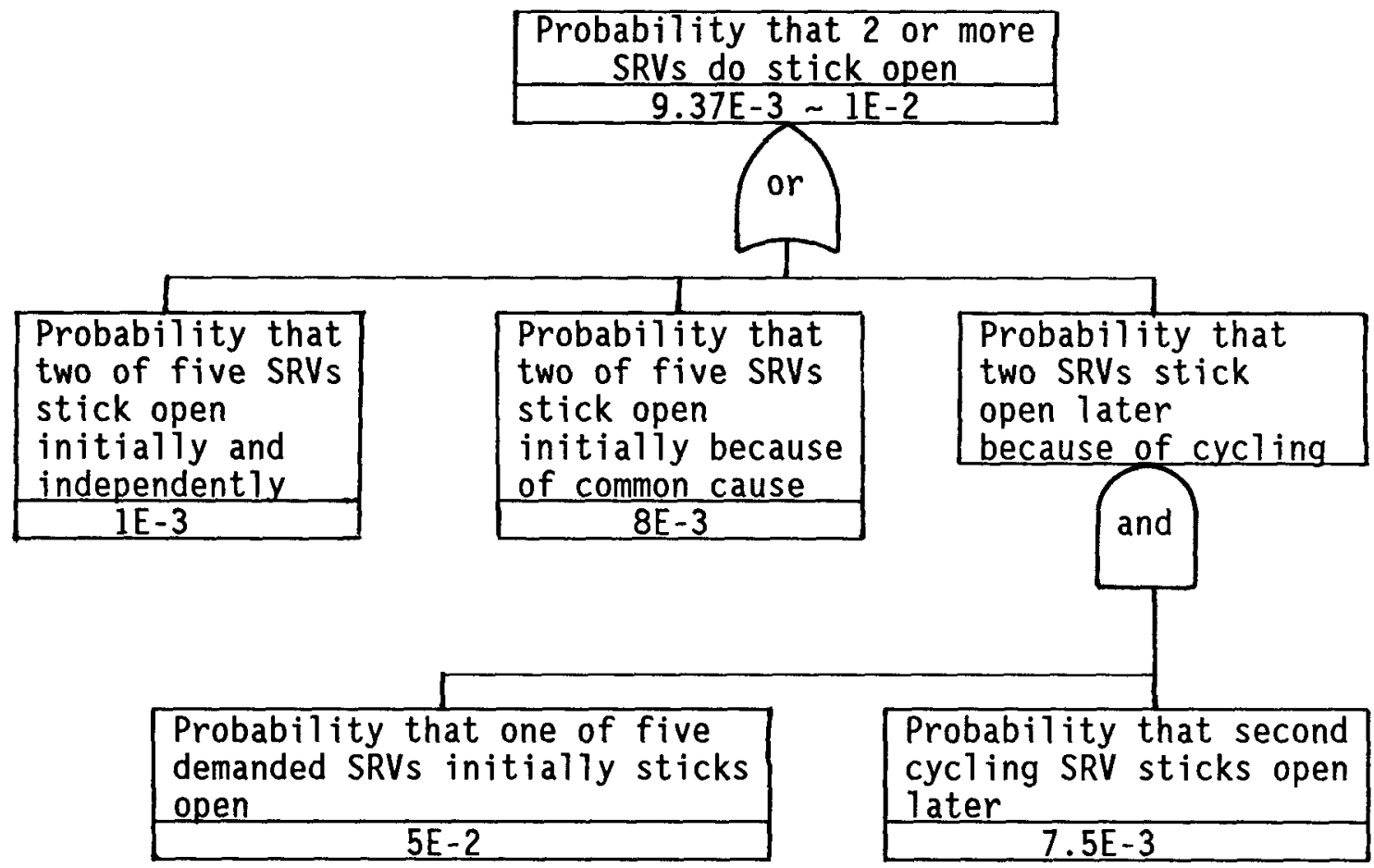

This value is treated as a mean value for calculation purposes.

High Pressure Level Control (LEV) --

(1) Water Level Maintained Too Low:

There are three reasons that the reactor water level would be too low:

- HPCI fails to start on demand

- HPCI unavailable because of maintenance

Probability

$4.84 \mathrm{E}-2$

$1.6 \mathrm{E}-2$

o Operator maintains water level too low

$2.66 \mathrm{E}-3$

Therefore, the probability that the water level will be too low is $6.7 \mathrm{E}-2$.

It should be noted that "TL" is defined here as the water level's being six feet below TAF in order to really cause core damage. Since BNL defined "too low" as being a water level more than one foot under TAF, a probability had to be assigned for the new definition of $T L$. In discussions with BNL personnel, it was judged that this probability could be expected to be quite small, but no detailed analys is was performed. A value of 0.001 was estimated to be representative of the median probability for this event. Assuming an error factor of ten on this "soft" value resulted in a mean value of $2.66 \mathrm{E}-3$. 
(2) Water Level Maintained at TAF:

The probability that the water level can be maintained at TAF can be determined by using Luckas' BNL report [29]. The failure probability is the failure to be at TAF. Therefore, the probability of successfully being at TAF is 1-p (TAF), where $p$ (TAF) is the value of TAF in the BNL report. The median value is used in the quantification to get an approximate value since the median and means would be-nearly the same.

(3) Water Level Maintained Too High or Oscillating:

The probability that the water level is too high or oscillating is the following:

$$
P(T H / O S C)=2 / 3 P(T A F, B N L)
$$

$P(T A F, B N L)$ is the probability that the water level is not maintained at TAF. Of that probability, it was estimated by BNL personnel that when the water level is not at TAF, two thirds of the time the water level would be too high or oscillating. This implies that one third of the time the water level would be below TAF.

(4) Water Level Maintained at TAF, Too High, or Oscillating:

The probability that the water level is either at TAF, too high or, oscillating is the following:

$$
\begin{aligned}
\mathrm{P}(\mathrm{TAF} / \mathrm{TH} / \mathrm{OSC}) & =[1-\mathrm{P}(\mathrm{TL}, \mathrm{BNL})] \times[\text { Probability HPCI is available }] \\
& =[1-2.66 \mathrm{E}-3] \times[9.36 \mathrm{E}-1] \\
& =9.33 \mathrm{E}-1
\end{aligned}
$$

where

$\mathrm{P}(\mathrm{TL}, \mathrm{BNL}) \quad=$ probability operator will keep the water level too

Torus Cooling (SPC) --

No probabilities were determined for torus cooling because it was determined that torus cooling had little (if any) effect in mitigating an MSIV closure ATWS event. It was kept in the ATWS event trees, however, for completeness and to show that it was considered in the analysis.

\section{Operator Depressurization (DEP) --}

As can be seen from Table IV.10.1-4, only one HEP value is used for operator depressurization. Using a log-uniform distribution (to eliminate probabilities for 1.0 ) on the median value results in a mean value of 0.213 .

HPCI Continues (INJ) --

Based on judgment using the LTAS runs, the probability of HPCI continuing succeed is given as $90 \%$ when the operator depressurizes and $80 \%$ when the operato fails to depressurize. 
Low Pressure Level Control (LPIN) --

Same as high pressure level control except that system failure for low pressure systems is epsilon because of a high degree of low pressure system redundancy.

Backup Rod Insertion (ROD2) --

This top event was not quantified because it is not considered likely to occur and it does not appear in dominant sequences.

IV.10.1.5 Results and Conclusions

The $43 \mathrm{gpm}$ ATWS event trees for Peach Bottom shown in Figures IV.10.1-1 and IV.10.1-2 were quantified using the mean values given in Table IV.10.1-8. The dominant sequences are given in Table IV.10.1-9.

The values in Table IV.10.1-9 include both cases when the MSIVs close initially and when they stay open initially. Two values that are not given in Table IV.10.1-8 were used to quantify the open MSIV ATWS event tree

(Figure IV.10.1-2). They are

Failure

Function

Probability

(Mean Value)

FW Continue to function

0.5

Torus Cooling

0.02

The probability of the feedwater system continuing to function is based on engineering judgment considering the points made in the earlier description of the MSIV-open tree. The failure of the torus cooling to function is based on judgment using ASEP's HEP values.

It should be noted that all of the dominant contributors to the core damage-containment vulnerable scenarios are a result of the operator's failing to depressurize the reactor. This appears reasonable since the HEP failure rate for the operator's keeping the water level too low (six feet below TAF) is very small. In addition, the system failure for the low pressure systems is negligible since there are several redundant low pressure systems.

The dominant sequences that result in containment vulnerable scenarios result from SLC failure followed by successful use of the low pressure systems.

IV.10.2 Case B (86 gpm) ATWS Analysis

The core damage frequencies for Case $B$ are the following:

\section{OUTCOME}

Core Damage--Containment Vulnerable

Containment Vulnerable--Core Damage

\section{FREQUENCY}

$6.5 E-7$

3.7E-7 
Table IV.10.1-9

Case A ATWS Dominant Sequences for Peach Bottom

\begin{tabular}{ccc}
\hline SEQUENCE & STATE OF & \\
MUMBER (S) & CORE/CONTAINHENT & FREQUENCY \\
\hline
\end{tabular}

58 Core Damage--Containment

Vulnerable (CM-CtV)

Core Damage--Containment

Vulnerable (CM-CtV)

69

Containment Vulnerable (CtV)

71

Core Damage--Containment

Vulnerable (CM-CtV)
72

Containment Vulnerable (CtV)

Total Core Damage--Containment Vulnerable

Total Containment Vulnerable
$1.01 E-6$

RPS Mechanical failure with SLC success followed by HPCI being either too high or oscillating. The operator fails to depressurize and HPCI fails to continue running. This is $63 \%$ of the total CM-CtV frequency.

$3.59 \mathrm{E}-7$

Same as Sequence 58 above except the HPCI system fails initially (due to human error or system failure) followed by the operator failing to depressurize. This is $22 \%$ of the total CM-CtV frequency.

8.67E-7 RPS mechanical \& SLC failure followed by successful ADS inhibit and operator depressurization. The water level is kept either at TAF, too high or oscillating with low pressure systems. This is $83 \%$ of the total CtV frequency.

2. $33 E-7$

Same as Sequence 69 above except that the operator fails to depressurize. Unable to use the low pressure system;

therefore, core damage results. This is $14 \%$ of the total CM-CtV frequency.

1.77E-7 RPS mechanical and SLC fails to succeed. ADS is not inhibited; however, the low pressure systems succeed to keep the water level at TAF, too high or oscillating. This is $17 \%$ of the total ctV frequency. 
The accident sequence progression is given in Section IV.10.2.1. The event trees re presented in Section IV.10.2.2. A summary of pertinent parts of the HRA done by BNL is given in Section IV.10.2.3. The data and supporting calculation results are given in Section IV.10.2.4. The results are presented in Section IV.10.2.5.

\section{IV.10.2.1 Case B ATWS Accident Sequence Progression}

The response of the Peach Bottom plant to a postulated failure to insert the control rods following an anticipated transient involves several events. The first significant event is an initial pressure increase in the RCS caused by a power imbalance when the turbine is tripped. There is a small delay until the turbine bypass valves are open and RPT can take effect. However, this initial pressure increase does not present any immediate danger to the integrity of the reactor for the following reasons: (1) voiding is increased from tripping of the recirculation pumps (increased voiding causes a reduction in moderator effectiveness) and (2) the SRVs can adequately control this pressure increase by discharging steam to the suppression pool. For ATWS, the power level tends to equilibrate at approximately seventeen to forty percent of full power depending on subsequent operator actions (i.e., controlling reactor water level and pressure*).

The next events to occur are initiation of those systems or actions to reduce core reactivity, to achieve reactor subcriticality, and to maintain coolant inventory. This analysis only examines the accident in the time period it takes to achieve reactor subcriticality. At that point the accident is assumed to be "under control" and becomes a normal transient. Therefore, only those events (actions or systems) that are required in this interval are considered.

he power has equilibrated at some level from the net effect of the RPT, reactor water level decrease from SRV discharge, and voiding. The reactor is fully pressurized, the SRVs are therefore cycling, and the reactor water level is decreasing. Once the level reaches a low water level setting (Level 2), the RCIC and HPCI systems actuate automatically and start injecting into the reactor. The water level and the power adjust correspondingly until the injection to the reactor is equivalent to the power production (i.e., the production steam rate).

During this period, the steam produced is either entirely discharged to the suppression pool, if the MSIVs are closed, or discharged to both the main condenser via the turbine bypass valves and the suppression pool (depending on the power equilibration level) if the MSIVs are open. Peach Bottom's turbine bypass is designed for approximately twenty-five percent steam flow. Therefore, for ATWS events in which the feedwater is operating (MSIVs open), steam flow to the suppression pool is anywhere from zero to ten/fifteen percent. However, for those ATWS events in which the MSIVs are closed, all steam flow is directed to the suppression pool. A problem therefore arises because the Residual Heat Removal (RHR) system is designed for less than a five percent decay heat removal capability. In the interval before reactor subcriticality is achieved, this

* Feedwater maintains a greater flow than high pressure injection systems and that flow introduces more moderator and a higher power equilibration which could be as high as forty percent. 
capacity is exceeded in many of the ATWS sequences and results in fast rising suppression pool temperatures. High suppression pool temperatures have the potential to fail injection. HPCI pump seals are assumed to fail at water temperatures of 210-to-2600 F. At Peach Bottom, HPCI automatically transfers suction from the CST on both low CST level and high suppression pool level. It becomes important to reduce power to below five percent as quickly as possible to keep the peak suppression pool temperature below the HPCI failure temperature range of $210-$ to-2600 $^{\circ}$. If the operator initiates both SLC pumps within four-tofive minutes, peak suppression pool temperature will be less than the failure temperature level of the HPCI system.

\section{IV.10.2.2}

\section{Case B ATWS Event Tree}

The $86 \mathrm{gpm}$ Case B ATWS event tree is shown in Figures IV.10.2-1 and IV.10.2-2. The following sections define the event tree headings and describe the event tree sequences.

\section{IV.10.2.2.1 Event Tree Headings}

This section defines the event tree headings for Figures IV.10.2-1 and IV.10.2-2. It should be noted that some of the headings are divided into two parts. One part gives the actual tasks or steps that must be performed by the control room operators to perform the defined function for each heading. These operator actions are included in the following subsections that define the event tree headings; however, for more details, see the report by W.J. Luckas (Reference 29).

\section{Transient (T) --}

A transient occurs which requires the reactor to be tripped.

\section{MSIV Open (MSIV-C, MSIV-0) --}

The transient occurs with either the MSIVs closed (success) or open (failure). In the event of an ATWS there is a possibility that the MSIVs will remain open.

\section{Reactor Protection System Mechanical (RPSM) --}

RPS mechanical failure assumes that all of the control rods are left in the position that they occupied before the transient occurred. By definition, whatever causes RPS mechanical failure is assumed to be non-recoverable (e.g., as common faults within the drive mechanisms).

\section{Reactor Protect System Electrical (RPSE) --}

Failure of the RPS electrical includes failure of the sensors, logic, RPS trip relays, and trip contacts. An electrical failure is assumed to prevent the RPS trip relay contact from opening. This failure can occur at the contacts themselves or between the contacts and the sensors. Unlike RPS mechanical faults, RPS electrical faults are recoverable. In the unlikely event that RPS electrical fails, the Alternate Rod Insertion (ARI) system provides another means of ensuring that the control rods receive the signal to insert. Please note that in the event tree RPS electrical includes the ARI function. 


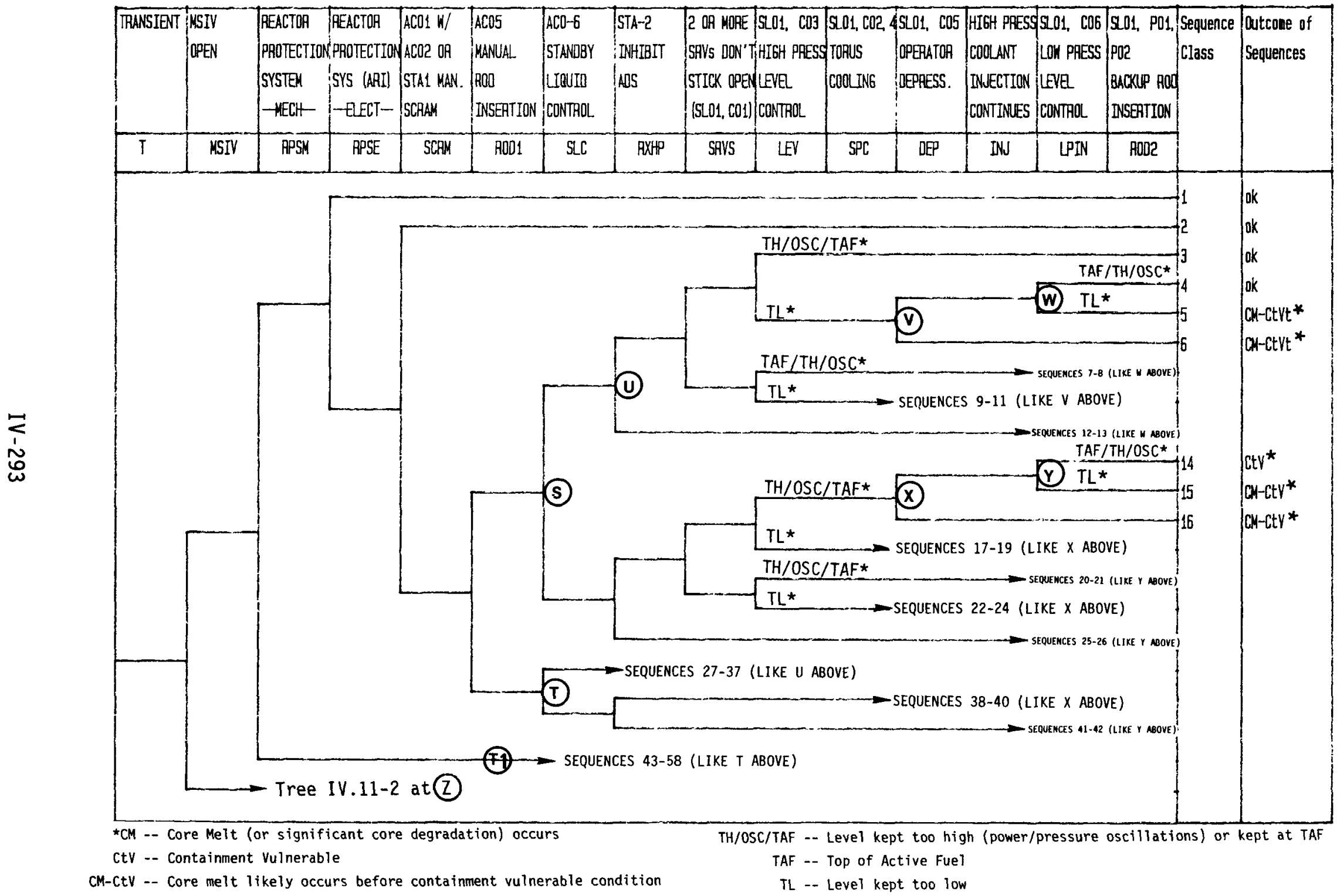

Figure IV.10.2-1. Peach Bottom Case B MSIV Closure ATWS Event Tree. 


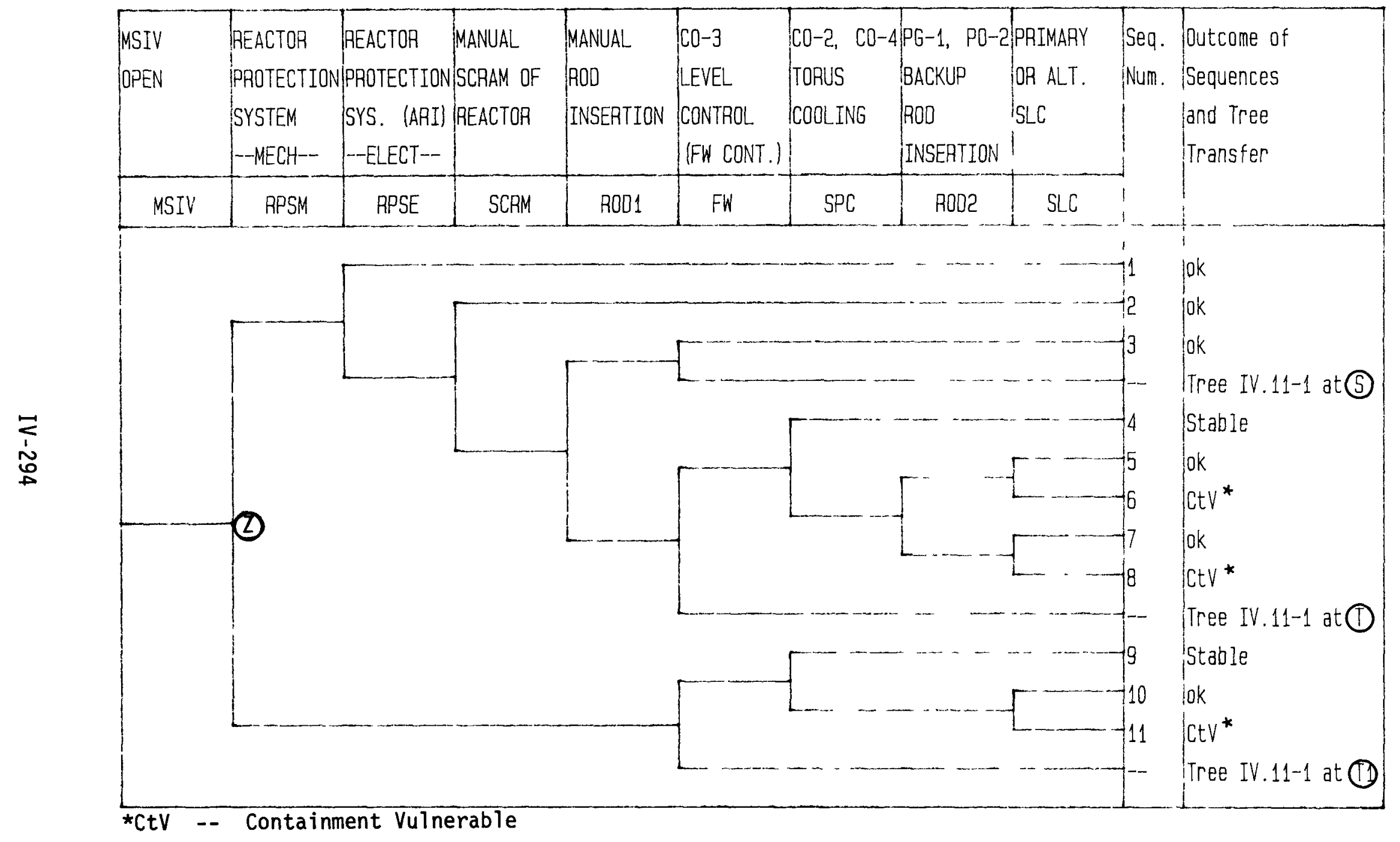

Figure IV.10.2-2. Peach Bottom Case B MSIV Open ATWS Event Tree. 
Manual Scram of the Reactor (SCRM) --

If the RPS failure is an electrical failure, the plant operators can attempt to manually scram the control rods into the reactor. The manual scram function at Peach Bottom is accomplished by the following operator tasks:

Task ACO1-- The Auxiliary Control Operator (ACO) recognizes the scram condition and checks for MSIV closure as well as automatic scram failure. He also observes that the recirculation pumps have tripped or trips the pumps himself under MSIV closure conditions (i.e., this event includes consideration of recirculation pump trip failure).

Task ACO2--The ACO attempts a manual scram by going to the "shutdown" position with the reactor mode switch and pushing the manual scram buttons. This will activate the scram pilot valves for each of the individual rod HCUs as well as the backup scram valves. Failure of manual scram would require failure of the scram signal or failure of one or two scram pilot valves in each of the HCUs as well as failure of the backup system valves.

Task STAl--Assuming the scram valves have not all been successfully operated (opened), the STA or other personnel will attempt to de-energize the scram solenoids of the scram pilot valves for each of the HCUs. This is done by going to a back panel in the control room and flipping all the individual rod scram toggle switches.

Task ACO4--Assuming the scram valves have all been operated (opened), another attempt to use the reactor scram hydraul ic system is made. The ACO tries to re-energize the scram solenoids (via the scram reset switch) and reestablish CRD hydraulic pressure and then attempts to manually scram. However, if the signal that caused the original scram is still present (or if a new signal appears), the ACO will not be able to reset the scram logic.

Early Manual Rod Insertion (ROD1) --

If, after attempting manual scram, the control rods have not entered the reactor core, the $A C O$ is instructed to attempt manual rod insertion (Task AC05). Assuming a successful SCRAM reset, the RSCS and the RWM are defeated and the ACO attempts to insert individual rods guided by a rod priority list kept at the control panel. This task is continued after SLC is initiated. It is important to remember that manual rod insertion is not possible if scram cannot be reset.

\section{Standby Liquid Control (SLC) --}

Should the reactor not be shut down with control rods, the ACO is instructed he is to initiate SLC before the torus temperature reaches $110^{\circ} \mathrm{F}$. This is Task ACO6.

\section{Reactor at High Pressure (RXHP) --}

Immediately after SLC is injected, the STA or other personnel are supposed to defeat ADS. ADS is changing such that there will be an eight minute timer that is tuated when the water level reaches Level 1. The STA then has eight minutes vefore the ADS will actually function. An ADS inhibit switch will be available 
after the next refueling outage to permanently inhibit ADS without taking any further actions (i.e., the STA will not have to periodically push the inhibit ADS button to defeat the ADS). This is Task STA2.

\section{Two or More SRVs Do Not Stay Open (SRVs) -.}

During the ATWS, should it be noticed that any SRV is open or cycling, the CO is instructed, under the direction of the SLO, to manually open SRVs until the reactor vessel pressure drops to $950 \mathrm{psig}$. These actions are included in Tasks SLO1 and C01.

The event tree, as presently drawn, shows no choice for pressure control since its success or failure is considered to affect only the probability of failure of the two or more SRVs sticking open. Failure means that two or more SRVs have stuck open causing a further uncontrolled depressurization of the reactor.

High Pressure Level Control (LEV) - Operator Controls at TAF (LEV1), Operator Controls at TH/OSC (LEV2), Operator Controls at TL (LEV3) --

Level control is performed in Task $\mathrm{CO} 3$ under the direction of the SLO (SLO-1). At $110^{\circ} \mathrm{F}$ torus temperature (since power is above $3 \%$ and an SRV is open), the CO must lower RPV level by terminating and preventing all injection into the RPV (except boron injection and CRD) until power is below 3\% or all SRVs are shut or TAF is reached. As TAF is approached, the Co throttles HPCI to maintain this level. Four different outcomes are allowed for this event. They include the level's being maintained very high (e.g., - no throttling of HPCI), near TAF, too lor (e.g., HPCI failure), or oscillating.

Suppression Pool Cooling (SPC) --

This event calls for alignment of the RHR and HPSW systems into the torus cooling mode once the torus water reaches $110^{\circ} \mathrm{F}$. This action (Task C02) and subsequent actions to maintain torus cooling (Task CO4) under the cognizance of the SLO (SLO-1) are all treated under this event. RHR preference for the LPCI mode alignment, once the reactor water level is brought down to the top of the core, further adds to the difficulties in using the torus cooling mode. Because of the low capability of the RHR system as compared to the achieved power level when the reactor water level is at TAF, no major differences occur with or without torus cooling so the event does not show any choices.

Operator Depressurizes Reactor (DEP) - -

The Control Operator is to lower reactor pressure with SRVs in conformance to the HCTL curve as a function of the torus temperature. The CO starts this task (CO5) under SLO direction (SLO-1) when the torus temperature reaches about $155^{\circ} \mathrm{F}$. Should HPCI be subsequently lost, this event also accounts for the depressurization which must follow in order to cool the core with low pressure systems.

\section{High Pressure Coolant Injection Continues (INJ) --}

The HPCI system is initially used to maintain level control. It will fail o otherwise isolate if the torus temperature reaches $-220^{\circ} \mathrm{F}$, if the reactor pressure 
decreases to $100 \mathrm{psig}$, or if the containment pressure reaches about 150 psia. The uestion whether any of these conditions that will terminate HPCI exists is considered at this branch in the event tree. Success implies that HPCI continues to operate and that the operator restores water level with this system once sufficient boron is injected or the reactor is otherwise shutdown.

Low Pressure Level Control (LPIN) --

Operator Controls at TAF (LPII), Operator Controls at TH/OSC (LPI2), Operator Controls at TL (LPI3) --

This is Task CO6. If HPCI fails, the CO will attempt to maintain water level at TAF via Condensate, LPCI, LPCS, or other systems. This will be possible when reactor pressure drops to -300 psig. Success includes operation of one pump such that the water level is maintained to cool the core and eventually restored to normal levels after shutdown. As with High Pressure Level Control, four outcomes are possible.

Late Manual Rod Insertion (ROD2) --

This function consists of Tasks P01 and P02. Assuming that all of the previous actions described in the "manual scram" event have been attempted, the plant operator is instructed to go to the CRD control units and try to get the control rods into the core. He does this by isolating and venting the scram air header. If this fails, he manually vents the CRD withdraw line vent valve of each rod. While this set of tasks was considered for the event tree, it is believed that success for these actions is negligible if previous attempts to manually scram ave failed since both events are attempting to do essentially the same thing operate the scram valves). No choices are explicitly shown on the event tree.

Feedwater Continues (FW) --

This event appears only on Figure IV.10.2-2 and involves whether the MSIVs remain open and feedwater continues to operate. Failure of this event means the MSIVs have subsequently closed following the initiating event.

IV.10.2.2.2 Case B ATWS Sequence Description

This section describes the sequences for the Case $B$ event trees.

\section{MSIV Initially Closed (Figure IV.10.2-1) Sequence Descriptions}

\section{Sequence 1: T*MSIV-C* $\overline{\operatorname{RPSM}} * \overline{\mathrm{RPSE}}$}

In this sequence, a transient occurs that requires the reactor to SCRAM. The RPS mechanical portion of the system functions successfully. In addition, the electrical system that sends the scram signal to the HCUs functions successfully. All of the rods are assumed to go into the core and reactor shutdown is achieved. The event then becomes a normal transient and can be transferred to the appropriate transient event tree depending on the initiating event. This sequence is $\mathrm{OK}$. 


\section{Sequence 2: $\quad T * M S I V-C * \overline{\operatorname{RPSM}} *$ RPSE $* \overline{\operatorname{SCRM}}$}

This sequence is similar to Sequence 1, except that RPS electrical and

ARI fail. Manual SCRAM, however, is successfur. This sequence is then the same as Sequence $l$ and is OK.

\section{Sequence 3: $T * M S I V-C * \overline{\operatorname{RPSM}} * R P S E * S C R M * \overline{\operatorname{ROD} 1} * \overline{\operatorname{SLC}} * \overline{\operatorname{RXHP}} * \overline{\operatorname{SRVS}} * \overline{\mathrm{LEV}} \quad-$}

In this sequence, SCRAM is not successful. Manual rod insertion by the ACO is successful; however, it could take one hour to shut down the reactor using this approach. SLC (also initiated by the $A C O$ ) is successful. It would be initiated since the torus would reach $110^{\circ} \mathrm{F}$ in - two minutes. The STA inhibits ADS according to procedure. In this sequence, two or more SRVs do not stick open. After SLC is initiated, the $C O$ is instructed to lower the reactor water level to the TAF. Possibilities which are considered at this point follow:

(1) The Co does nothing to control HPCI and the water level remains high, or he may operate HPCI but not effectively enough to prevent major level oscillations.

(2) The co could effectively keep the water level near the TAF.

(3) The CO could shut off HPCI or the HPCI system could fail at onset of the transient. In either case, the water level in the core would be too low ("too low" is defined as six feet below TAF).

In this sequence, the water level is either kept at TAF by the CO, or is too high, or is oscillating (TAF/TH/OSC). Before SLC is effective, if the water level is too high it will result in a high power level. Also, level oscillations will result in major power oscillations. Both conditions (either too high or oscillating) will result in a larger amount of heat being transferred to the suppression pool. Notice that torus cooling is not asked for this sequence since it only has the

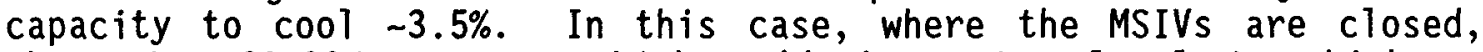
there is $-20-30 \%$ power or higher (during water level too high or oscillations) being transferred to the suppression pool. Torus cooling is not an important factor for any of water levels: TAF, TH or OSC. Once the SLC has injected the boron into the bottom of the core, the CO will refill the reactor vessel and the ATWS will be successfully terminated.

\section{Sequence 4: T*MSIV $-C * \overline{\operatorname{RPSM}} * R P S E * S C R M * \overline{\operatorname{ROD1}} * \overline{S L C} * \overline{\mathrm{RXHP}} * \overline{\mathrm{SRVS}} * \operatorname{LEV} * \overline{\overline{D E P}} * \overline{\mathrm{LPIN}} \quad-$}

This sequence is similar to Sequence 3 except that the HPCI initially fails to function. The CO quickly depressurizes the reactor vessel so that he can use the low pressure systems to maintain water level. As in the case where the Co maintained water level with the HPCI system, there are three distinct possibilities that can occur:

(1) The Co can effectively keep the water level at the TAF with the low pressure systems. 
(2) The CO cannot control the LP system and the reactor vessel water level reaches a high level and/or oscillates.

(3) The CO shut down the LP systems or these systems fail to function. In either case, the reactor vessel water level is too low ("too low" is defined as six feet below TAF).

In this sequence, the water level is either kept at TAF or TH or it oscillates. As in Sequence 3 , once the SLC has injected sufficient boron into the core, the CO will refill the reactor vessel and the ATWS will be successfully terminated.

\section{Sequence 5: $T * M S I V-C * \overline{\operatorname{RPSM}} * R P S E * S C R M * \overline{\mathrm{ROD} 1} * \overline{\mathrm{SLC}} * \overline{\mathrm{RXHP}} * \overline{\operatorname{SRVS}} * L E V * \overline{\mathrm{DEP}} * L P I N \quad$-.}

This sequence is similar to Sequence 4 except that after the co depressurizes the reactor vessel, the water level in the reactor vessel is maintained too low or the low pressure systems fail. If the water level is too low, core damage will occur.

\section{Sequence 6: $T * M S I V-C * \overline{\operatorname{RPSM}} * R P S E * S C R M * \overline{\operatorname{ROD} 1} * \overline{\operatorname{SLC}} * \overline{\mathrm{RXHP}} * \overline{\mathrm{SRVS}} * L E V * D E P \quad-$}

This sequence is similar to Sequence 4 except that the co fails to depressurize the reactor vessel. Therefore, there is no possibility of using the low pressure systems. This results in a core damage-containment vulnerable condition.

\section{Sequences 7-8: --}

Sequences 7 and 8 are similar to Sequences 4 and 5 . The reactor vessel water level is either at TAF or too high or oscillations are occurring. In these sequences, two or more SRVs do stick open causing reactor vessel depressurization and the HPCI to fail from eventual low pressure in the primary system. As a result, operator depressurization is not needed to utilize the low pressure systems.

\section{Sequences 9-11: --}

Sequences 9 through 11 are similar to Sequences 4 through 6 . In these sequences, two or more SRVs stick open. The HPCI system fails initially to provide coolant to the reactor. It should be noted that, to prevent core damage, the CO must depressurize quickly even though two or more SRVs stick open.

Sequences 12-13:

In Sequences 12 and 13, even though SLC is functioning, the Shift Technical Advisor (STA) or other personnel do not inhibit ADS. Once the ADS functions, it will create a blowdown that requires the use of the low pressure systems. If the low pressure systems keep the water level at TAF, too high, or oscillating, the outcome is OK; otherwise CM-CtV occurs. 
Sequence 14: $T * M S I V-C * \overline{\mathrm{RPSM}} * \operatorname{RPSE} * S C R M * \overline{\mathrm{ROD} 1} * S L C * \overline{\mathrm{RXHP}} * \overline{\mathrm{SRVS}} * \overline{\mathrm{LEV}} * \overline{\mathrm{DEP}} * \overline{\mathrm{LPIN}} \quad-$

In this sequence, manual rod insertion is successful; however, the SLC system is unsuccessful. ADS is inhibited by the STA. Two or more SRVs do not stick open. The water level that is being maintained by HPCI is either too high or at the TAF, or there are major oscillations. HPCI fails before shutdown is achieved because of high suppression pool temperature. The $\mathrm{CO}$ depressurizes and the water level is maintained at the TAF or too high, or oscillations occur with the LP systems. Though a stable condition is established, containment integrity may be threatened before the control rods are able to shut down the reactor which could fail the low pressure systems. This sequence is therefore given a CtV outcome with the possibility of core damage.

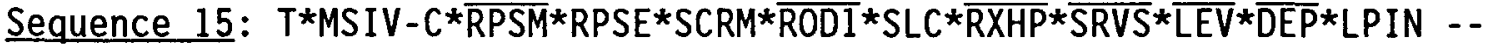

This sequence is similar to Sequence 14 except that after the c0 depressurizes the reactor vessel, the water level in the reactor vessel is too low. If the water level is too low, core damage will occur. This sequence is, therefore, given a CM-CtV outcome.

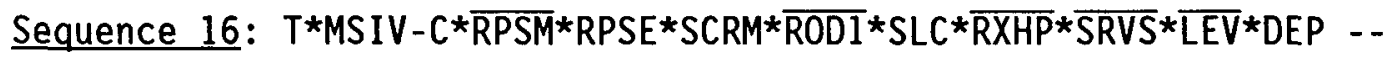

This sequence is similar to Sequence 15 except that the operator fails to depressurize. Once the HPCI system fails, the low pressure system cannot be used because of high pressure (operator did not depressurize), to prevent core damage. This sequence results in core damage.

Sequences 17-19: --

Sequences 17 through 19 are similar to Sequences 14 through 16 . The only major difference is that HPCI fails initially instead of later from high suppression pool temperature.

\section{Sequences 20-24: --}

Sequences 20 through 24 are similar to Sequences 14 through 19 . The major difference is that two or more SRVS do stick open, causing reactor vessel depressurization and the HPCI system to fail from eventual low pressure in the primary system. Operator depressurization is not needed to utilize the low pressure systems unless HPCI fails initially.

Sequences 25-26: --

In Sequences 25 and 26, the STA or other personnel do not inhibit ADS. Once the ADS functions, it will create a blowdown that requires the use of the low pressure systems. The outcomes are the same as for Sequences 14 and 15 .

\section{Sequences 27-37: - -}

These sequences are similar to Sequences 3 through 13 . In these sequences, manual rod insertion is unsuccessful but SLC succeeds. It IV -300 
should be noticed that if SLC is successful, manual rod insertion success or failure is believed to have no discernible effect on the sequences because of the relative shutdown times.

Sequences 38-40: --

These sequences are similar to Sequences 17 through 19 . In these sequences, both manual rod insertion and SLC fail. ADS is inhibited by the $\mathrm{CO}$. The top events of two or more SRVs not sticking open, leve1 control, and torus cooling are not queried. This is because HPCI will fail very early in the sequence, and the sequences are dominated by the success or failure of the LP systems.

Sequences 41-42: --

These sequences are similar to Sequences 25 and 26 . The only difference is that manual rod insertion fails; however, it does not change the outcome of the sequences.

Sequences 43-58:

In these sequences, RPS mechanical fails; therefore, it is impossible to insert the control rods into the core. These sequences are similar to Sequences 27 through 42 for the "RPS Electrical" failure case.

\section{MSIV Initially Open (Figure IV.10.2-2) Sequence Descriptions}

Sequence 1: T*MSIV-0* $\overline{\mathrm{RPSM}} * \overline{\mathrm{RPSE}}$

In this sequence, RPS mechanical and electrical succeed. This becomes a non-ATWS transient and is transferred to an appropriate transient event tree depending on the initiating event.

Sequence 2: $T * M S I V-0 * \overline{R_{P S M}} *$ RPSE* $\overline{\text { SCRM }}$

Similar to Sequence 1, except that manual scram is successful following RPS electrical (including ARI) failure.

\section{Sequence 3: T*MSIV-0* $\overline{R P S M} * R P S E * S C R M * \overline{R O D 1} * \overline{F W}$}

In this sequence, manual scram is unsuccessful but manual rod insertion is successful. Feedwater continues to operate while rod motion eventually shuts down the reactor. Water level is maintained above Level 1; therefore, there should be no ADS demand. This sequence is OK.

Sequence S: T*MSIV $-0 * \overline{\mathrm{RPSM}} * \mathrm{RPSE} * S C R M \star \overline{\mathrm{RODI}} * \mathrm{FW} \quad-$

This sequence is developed on Figure IV.10.2-1. See discussion of Sequences 3 through 26. 
In these sequences, manual rod insertion is successful but feedwater fails to continue because of subsequent MSIV closure. Subsequent MSIV closure can occur for a number of reasons:

0 The onset of an ATWS is a very dynamic situation in which large feedwater oscillations and a Level 1 MSIV trip are possible. If Level 1 is reached, MSIV closure will occur since there is no time to bypass the Level 1 trip.

- Fuel damage could occur because of the large initial feedwater oscillations. A radiation release will result in MSIV closure because of high radiation.

- Turbine trip results in feedwater runback which could cause decrease the reactor water level below Level 1 causing a MSIV closure before HPCI can recover the level. The sequence then transfers to the MSIV closure ATWS event tree where manual rod insertion has been successful.

\section{Sequence 4: T*MSIV $-0 * \overline{\mathrm{RPSM}} *$ RPSE$* S C R M * R 0 D 1 * \overline{\mathrm{FW}} * \overline{\mathrm{SPC}} \quad-$}

In this sequence, manual rod insertion fails. Level control with feedwater continues. Torus cooling is initiated and is successful. Torus cooling is sufficient to cool the amount of heat being transferred to the suppression pool since the majority of the heat is being bypassed to the condenser. Therefore, a stable condition (but not yet shutdown) is present.

\section{Sequence 5: T*MSIV $-0 * \overline{\mathrm{RPSM}} * \mathrm{RPSE} * S C R M * R O D 1 * \overline{\mathrm{FW}} * S P C * \overline{\mathrm{ROD} 2} * \overline{\mathrm{SLC}} \quad$ -}

In this sequence, manual rod insertion fails and feedwater continues. Torus cooling is not successful. Backup rod insertion is successful; however, since torus cooling is not working, the suppression pool temperature will reach $110^{\circ} \mathrm{F}$ which calls for SLC initiation. SLC is successful and shutdown is achieved before critical containment conditions are reached. This sequence is $0 K$.

\section{Sequence 6: T*MSIV $-0 * \overline{R P S M} * R P S E * S C R M * R O D 1 * \overline{F W} * S P C * \overline{R O D 2} * S L C$}

This sequence is similar to sequence 5 except that SLC is not successfut. Containment venting is required (assuming it takes considerable time for event "ROD2"). This sequence is therefore considered CtV. This may be conservative depending on how long it takes backup rod insertion to shut down the reactor.

\section{Sequences 7-8: --}

These sequences are similar to Sequences 5 and 6 except that backup rod insertion fails. Note that although Sequence 8 also results in a containment vulnerable state, it is no longer conservative since both backup rod insertion and SLC fail. 
Sequence $T: T * M S I V-0 * \overline{R P S M} * R P S E * S C R M * R 0 D 1 * F W \quad-$

This sequence is developed on Figure IV.10.2-1. See discussion of Sequences 27 through 42 .

This sequence is similar to the sequence where manual rod insertion succeeds but feedwater fails to continue, except that this sequence transfers to the MSIV closure event tree where manual rod insertion has failed.

Sequence 9: $T * M S I V-0 * R P S M * \overline{F W} * \overline{S P C} \quad-$

In this sequence, RPS mechanical fails. Feedwater continues to run. Torus cooling is initiated and is successful. Torus cooling is sufficient to cool the amount of heat being transferred to the suppression pool since the majority of the heat is being bypassed to the condenser. Therefore, a stable condition is present (but not shutdown).

Sequences 10-11: --

These sequences are similar to Sequences 7 and 8 . The only difference is that back up rod insertion is not given a chance to fail or succeed since the RPS has failed mechanically.

Sequence T1: T*MSIV-0*RPSM*FW -.

This sequence is developed on Figure IV.10.2-1. See discussion of Sequences 43 through 58 .

This sequence is similar to the above sequence where manual rod insertion fails. The only difference is that the possibility of backup rod insertion does not exist.

IV.10.2.3 Human Reliability Analysis for Case B ATWS Event Tree

IV.10.2.3.1 Summary

As shown in the above quantification section, HEPs are provided for each branch point in the Peach Bottom ATWS event tree. BNL's effort involved only an examination of human reliability during this particular accident sequence. Sources of equipment failures or unavailabilities were not examined, nor were extensive thermal-hydraulic calculations made.

BNL assisted the ASEP effort by performing an HRA on the operations crew at Peach Bottom during an ATWS accident sequence with MSIV closure.

Visits by BNL were made to the Philadelphia Electric Company headquarters, Peach Bottom's control room panels mockup in Philadelphia, the Peach Bottom Atomic Power Station, and the Limerick Generating Station training simulator for the purpose of cquiring plant-specific data on (1) training, (2) procedures, (3) human ngineering, and (4) experience and education levels of the operations crew. 
Interviews were conducted with Peach Bottom training instructors, former operators, and other staff; a meeting was held with the Superintendent - Plant Services. The training manuals were reviewed and copies of relevant emergency procedures were obtained.

A detailed task analysis was performed based on consideration of staffing, team interaction, and control room layout at Peach Bottom. ATWS scenarios developed by ORNL and INEL were reviewed. Discussions were held with thermal-hydraulic/core neutronics engineers at BNL to determine the success criteria for tasks.

The Peach Bottom analysts provided a final ATWS accident event tree which identified five major operator tasks (i.e., branch points) which needed to be quantified:

o Initiating the Standby Liquid Control (SLC),

- Defeating the Automatic Depressurization System Initiation Signal (RXHP),

o Establishing and maintaining water level at top of active fuel at high pressure (LEV),

- Manual depressurization of the reactor pressure vessel (DEP), and

$0 \quad$ Establishing and maintaining water level at top of active fuel at low pressure (LPIN).

Preconditions for each task differ as a result of the success or failure of previous tasks and safety systems. Each set of preconditions and relevant PSFs were considered when HEPs were assigned to each branch point. The branch points of the ATWS event tree were quantified using procedures which included a review of HRA in other Probabilistic Risk Assessments and subjective judgment methods based on the structured assessment of PSFs and use of a time-reliability correlation.

The tables with information from Reference 29 of all HEPs, each interpreted as the median of a hypothetical log normal distribution, are shown in Tables IV.10.2-1, IV.10.2-2, IV.10.2-3, IV.10.2-4, and IV.10.2-5 together with the 5th and 95th quantiles of the distribution.

Also, it should be noted that, in the above tables, mean values are calculated for the HEP numbers that are used in the quantification of the dominant scenarios in the ATWS event trees. These mean values are discussed in detail in Section IV.10.2.4.

\section{IV.10.2.3.2 Quantification}

The final event trees that identified the branch points where operator action needed to be assessed was given to BNL. Each such branch point involves the operation of a particular task (i.e., performing certain proceduralized steps) which one or more operators must undertake. Some tasks are represented at more than one branch point depending on previous events (or branch points) asked. For example, initiation of SLC is one task, but it may be performed under different

(Text continued on Page IV-313) 


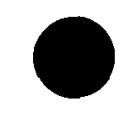

Table IV.10.2-1

Initiate Standby Liquid Control (SLC) Human Error Probability (HEP) Sensitivity to Time Available and Reluctance Factor For Case $B$

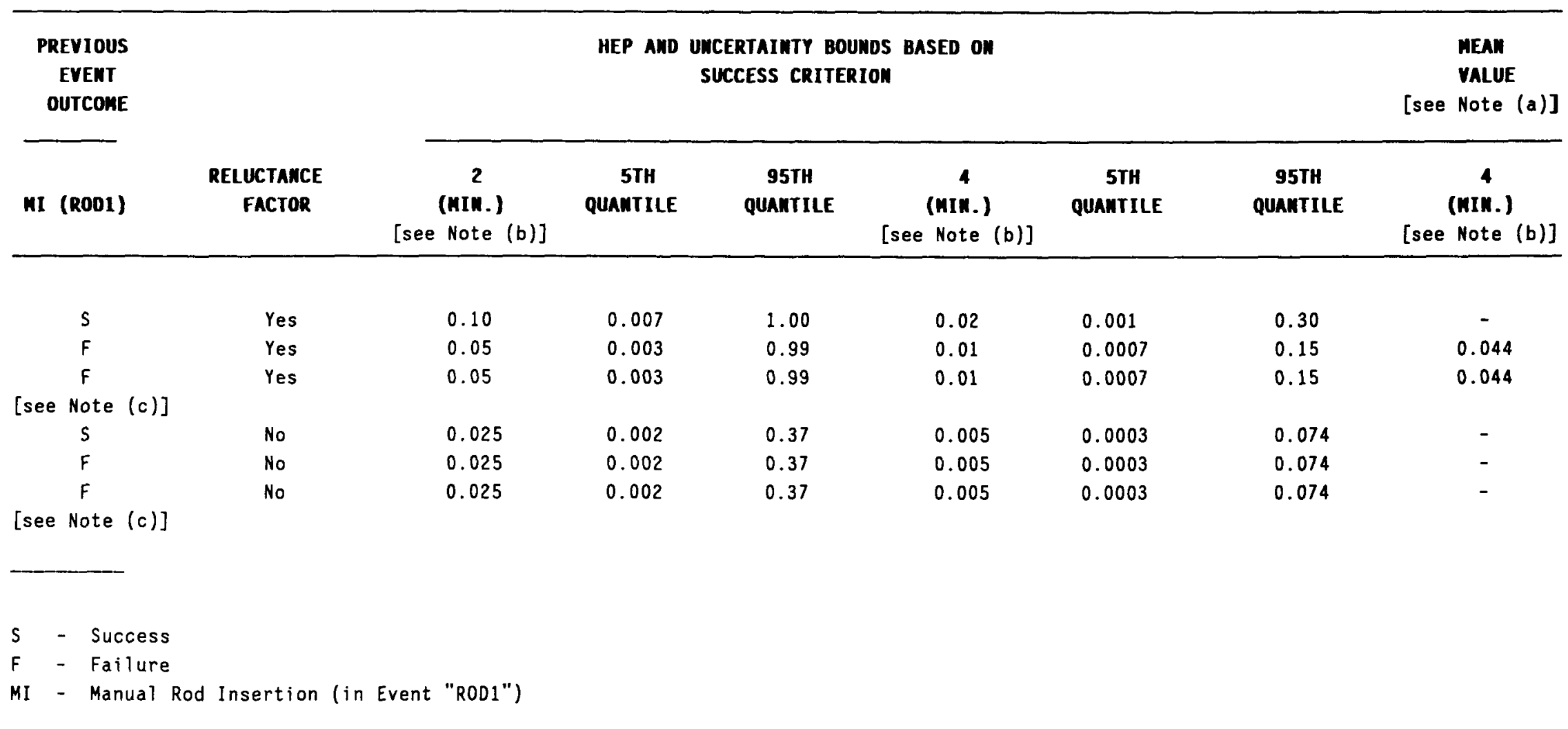

NOTES:

(a) Mean Values only calculated for medians that are used in dominant sequence quantifications.

(b) Minutes from ATWS.

(c) Reactor Protection System Mechanical (in Event "RPSM") failure instead. 
Table IV.10.2-2

Human Error Probability (HEP) Estimates to Defeat Automatic Depressurization System Initiation (ADS) For Case $B$

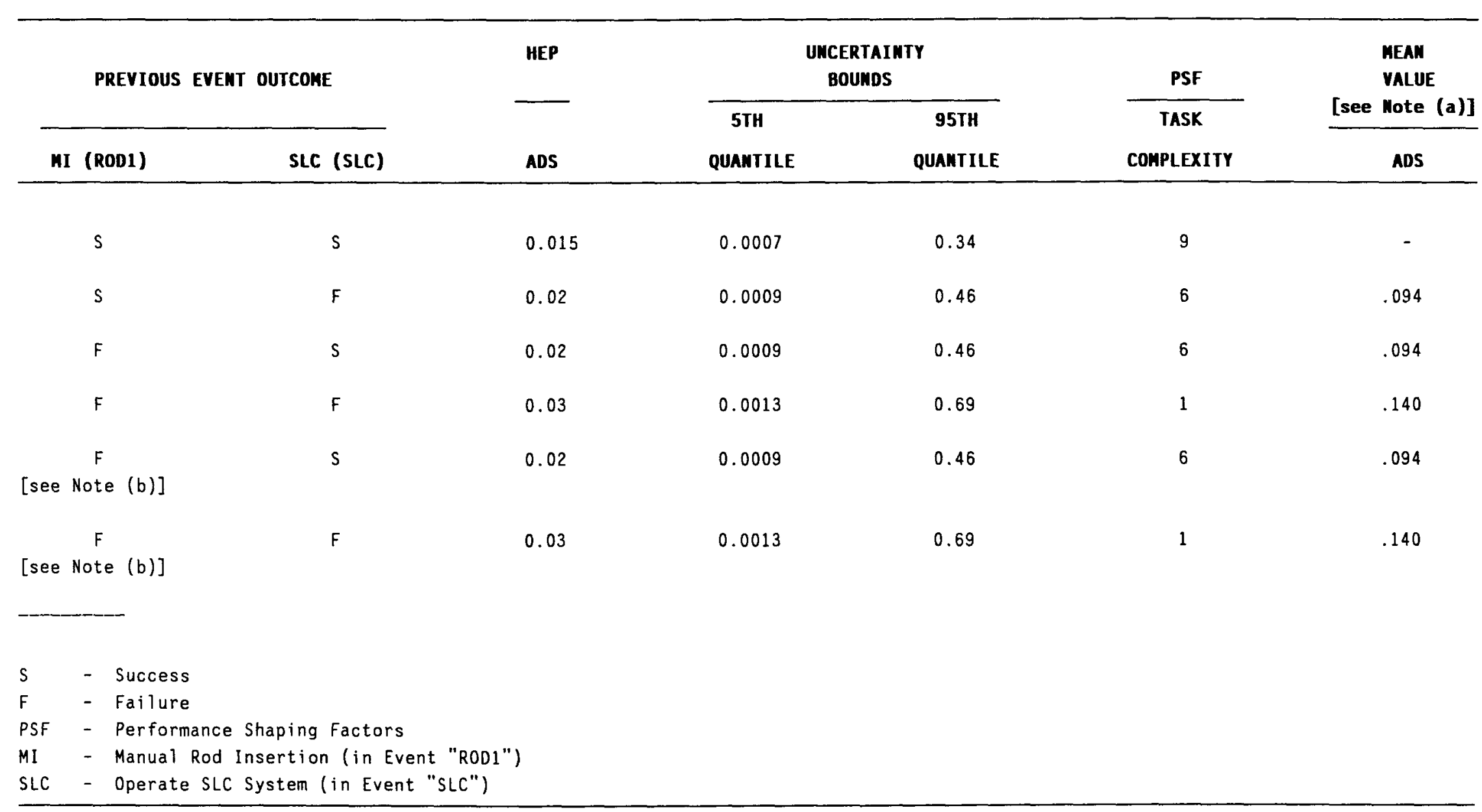

NOTES:

(a) Mean Values only calculated for medians that are used in quantification.

(b) Reactor Protection System Mechanical (in Event "RPSM") failure instead. 


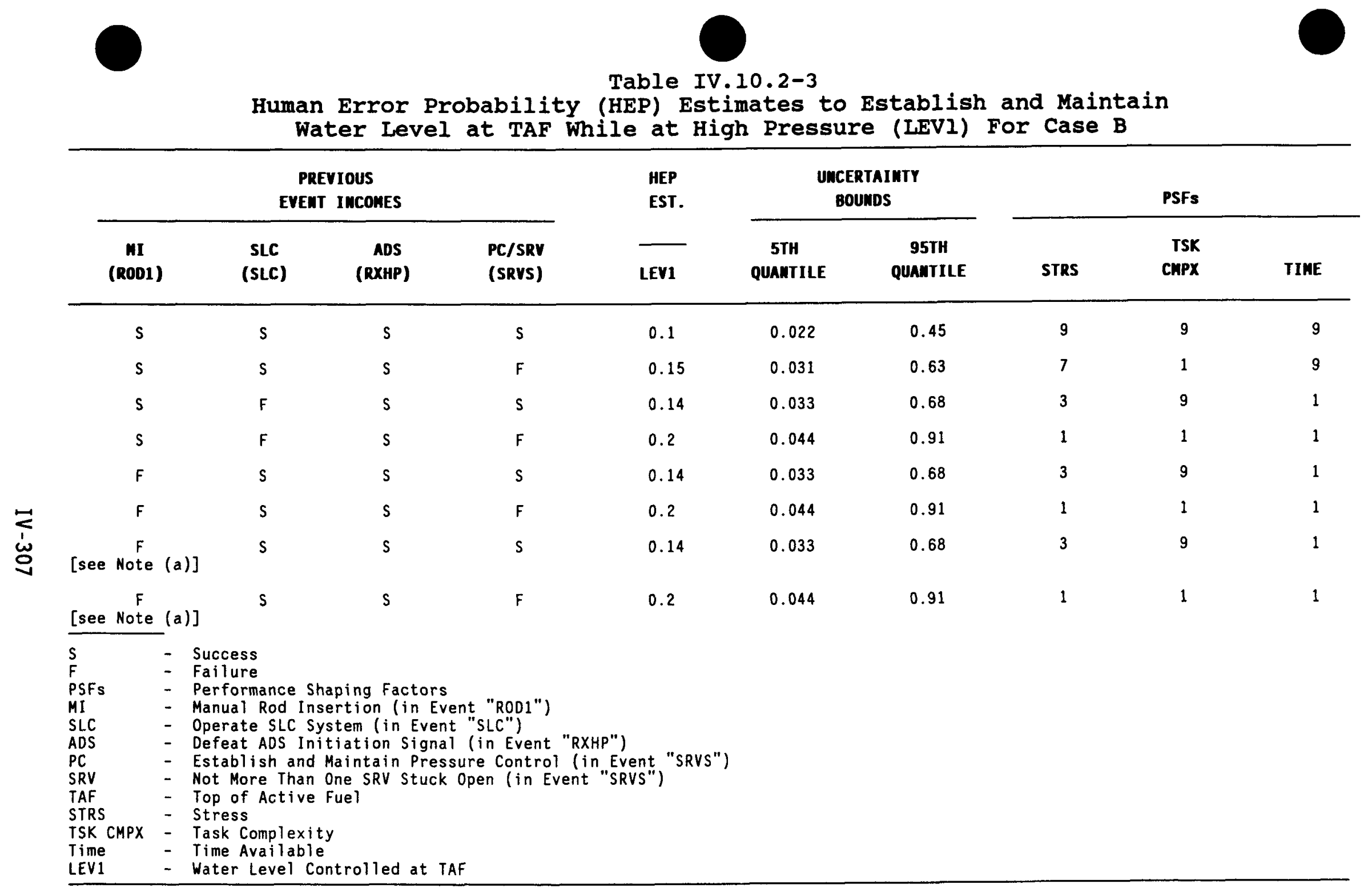

NOTE:

(a) Reactor Protection System Mechanical (in Event "RPSM") failure instead. 
Table IV. $10.2-4$

Human Error Probability (HEP) Estimates for Manual Depressurization (DEP) for Case B

\begin{tabular}{|c|c|c|c|c|c|c|c|c|}
\hline \multicolumn{5}{|c|}{ PREVIOUS EVEWT OUTCONES } & \multirow{2}{*}{$\begin{array}{l}\text { HEP } \\
\text { EST. } \\
\overline{\text { DEP }}\end{array}$} & \multicolumn{2}{|c|}{$\begin{array}{l}\text { UWCERTAIMTY } \\
\text { BOUWDS }\end{array}$} & \multirow{2}{*}{$\begin{array}{c}\begin{array}{l}\text { MEAN } \\
\text { VALUE }\end{array} \\
\text { DEP }\end{array}$} \\
\hline$\underset{\text { (ROD1) }}{M I}$ & $\begin{array}{c}\text { SLC } \\
(\text { SLC) }\end{array}$ & $\begin{array}{c}\text { ADS } \\
\text { (RXHP) }\end{array}$ & $\begin{array}{l}\mathrm{PC} / \mathrm{SRV} \\
\text { (SRVS) }\end{array}$ & $\begin{array}{c}\text { HLC } \\
\text { (LEV) }\end{array}$ & & $\begin{array}{c}\text { 5TH } \\
\text { QUANTILE }\end{array}$ & $\begin{array}{c}\text { 95TH } \\
\text { QUAMTILE }\end{array}$ & \\
\hline$s$ & $s$ & $\mathrm{~s}$ & $\mathrm{~s}$ & TH/OSC (LEV2) & 0.14 & 0.03 & 0.63 & 0.213 \\
\hline$s$ & $s$ & $s$ & $s$ & TAF (LEV1) & 0.14 & 0.03 & 0.63 & 0.213 \\
\hline$s$ & $s$ & s & $s$ & TL (LEV) & 0.14 & 0.03 & 0.63 & 0.213 \\
\hline$s$ & $s$ & $S$ & $F$ & TL (LEV) & 0.14 & 0.03 & 0.63 & 0.213 \\
\hline$S$ & $\mathrm{~F}$ & $S$ & $s$ & TAF/OSC/TH (LEV) & 0.14 & 0.03 & 0.63 & 0.213 \\
\hline s & $\mathrm{F}$ & $s$ & $s$ & TL (LEV) & 0.14 & 0.03 & 0.63 & 0.213 \\
\hline$s$ & $\mathrm{~F}$ & $s$ & $F$ & TL (LEV) & 0.14 & 0.03 & 0.63 & 0.213 \\
\hline$F$ & $s$ & $s$ & $s$ & TH/OSC (LEV2) & 0.14 & 0.03 & 0.63 & 0.213 \\
\hline$F$ & $\mathrm{~s}$ & $\mathrm{~S}$ & $s$ & TAF (LEV1) & 0.14 & 0.03 & 0.63 & 0.213 \\
\hline $\mathrm{F}$ & s & $\mathrm{s}$ & $\mathrm{s}$ & TL (LEV) & 0.14 & 0.03 & 0.63 & 0.213 \\
\hline$F$ & $s$ & $S$ & $F$ & TL (LEV) & 0.14 & 0.03 & 0.63 & 0.213 \\
\hline$F$ & $F$ & S & - & - & 0.14 & 0.03 & 0.63 & 0.213 \\
\hline $\begin{array}{c}\mathbf{F} \\
{[\text { see Note }(a)]}\end{array}$ & $s$ & $S$ & $s$ & TH/OSC (LEV2) & 0.14 & 0.03 & 0.63 & 0.213 \\
\hline $\begin{array}{c}F \\
{[\text { see Note }(a)]}\end{array}$ & $s$ & $S$ & s & TAF (LEV1) & 0.14 & 0.03 & 0.63 & 0.213 \\
\hline $\begin{array}{c}\mathbf{F} \\
{[\text { see Note }(a)]}\end{array}$ & $s$ & S & s & TL (LEV) & 0.14 & 0.03 & 0.63 & 0.213 \\
\hline $\begin{array}{c}F \\
{[\text { see Note }(a)]}\end{array}$ & $s$ & $S$ & $F$ & TL (LEV) & 0.14 & 0.03 & 0.63 & 0.213 \\
\hline $\begin{array}{c}F \\
{[\text { see Note }(a)]}\end{array}$ & $F$ & $s$ & - & - & 0.14 & 0.03 & 0.63 & 0.213 \\
\hline
\end{tabular}


Abbreviations for Table IV.10.2-4

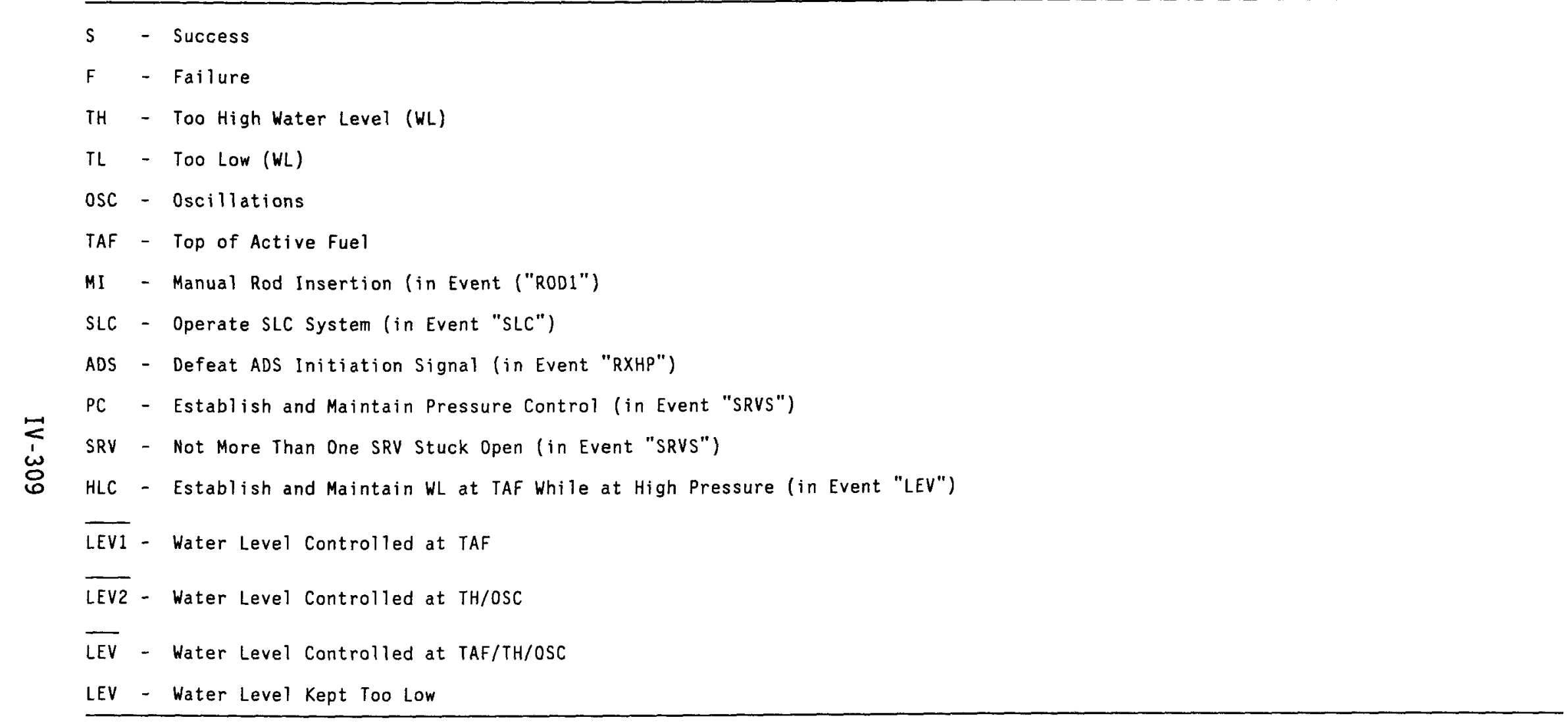

Notes for Table IV.10.2-4

NOTE:

(a) Reactor Protection System Mechanical (in Event "RPSM") failure instead. 
Table IV.10.2-5

Human Error Probability (HEP) Estimates to Establish and Maintain Water Level at TAF While at Low Pressure (LPII) for Case B

\begin{tabular}{|c|c|c|c|c|c|c|c|c|c|c|c|}
\hline \multicolumn{6}{|c|}{ PREVIOUS EVENT OUTCONES } & \multirow[b]{2}{*}{$\begin{array}{c}\text { FLO } \\
\text { (INJ) }\end{array}$} & \multirow{2}{*}{$\begin{array}{l}\text { HEP } \\
\text { EST. } \\
\text { LPI1 }\end{array}$} & \multicolumn{2}{|c|}{$\begin{array}{l}\text { UNCERTAIKTY } \\
\text { BOUNDS }\end{array}$} & \multicolumn{2}{|c|}{ PSFs } \\
\hline $\begin{array}{c}\text { MI } \\
\text { (ROD1) }\end{array}$ & $\begin{array}{l}\text { SLC } \\
(S L C)\end{array}$ & $\begin{array}{c}\text { ADS } \\
\text { (RXHP) }\end{array}$ & $\begin{array}{l}\text { PC/SRY } \\
\text { (SRVS) }\end{array}$ & $\begin{array}{c}\text { HLC } \\
\text { (LEV) }\end{array}$ & $\begin{array}{c}\text { DEP } \\
\text { (DEP) }\end{array}$ & & & $\begin{array}{c}\text { 5TH } \\
\text { QUANTILE }\end{array}$ & $\begin{array}{c}\text { 95TH } \\
\text { QUANTILE }\end{array}$ & STRS & $\begin{array}{r}\text { TSX } \\
\text { CAPX }\end{array}$ \\
\hline$s$ & $\mathrm{~S}$ & $s$ & $S$ & TH/OSC (LEV2) & $\mathrm{s}$ & $F$ & 0.45 & 0.099 & 1.00 & 5 & 1 \\
\hline $\mathrm{s}$ & $\mathrm{s}$ & $s$ & $S$ & TAF (LEV1) & $s$ & $F$ & 0.45 & 0.099 & 1.00 & 5 & 1 \\
\hline$s$ & $S$ & $s$ & $s$ & TL (LEV) & $S$ & - & 0.2 & 0.044 & 0.91 & 9 & 9 \\
\hline$s$ & $S$ & $s$ & $\mathrm{~F}$ & TAF/TH/OSC (LEV) & - & - & 0.2 & 0.044 & 0.91 & 9 & 9 \\
\hline$S$ & S & $\mathrm{S}$ & $F$ & TL (LEV) & $s$ & - & 0.2 & 0.044 & 0.91 & 9 & 9 \\
\hline $\mathrm{s}$ & $s$ & $F$ & - & TL (LEV) & $S$ & - & 0.2 & 0.044 & 0.91 & 9 & 9 \\
\hline$s$ & $F$ & $s$ & $s$ & TAF/OSC/TH (LEV) & $S$ & - & 0.28 & 0.061 & 1.00 & 3 & 9 \\
\hline$s$ & $F$ & $S$ & $S$ & TL (LEV) & $S$ & - & 0.28 & 0.061 & 1.00 & 3 & 9 \\
\hline$s$ & $F$ & $S$ & $F$ & $T H / T A F / O S C$ (LEV) & - & - & 0.28 & 0.061 & 1.00 & 3 & 9 \\
\hline$s$ & $F$ & $s$ & $F$ & $T L(L E V)$ & $s$ & - & 0.28 & 0.061 & 1.00 & 3 & 9 \\
\hline$F$ & $S$ & $s$ & $\mathrm{~s}$ & $\mathrm{TH} / \mathrm{OSC}(\overline{\mathrm{LEV} 2})$ & $s$ & $F$ & 0.5 & 0.11 & 1.00 & 3 & 1 \\
\hline$F$ & $\mathbf{S}$ & $\mathrm{S}$ & $\mathrm{S}$ & $\operatorname{TAF}(\overline{\operatorname{LEV} 1})$ & $\mathrm{S}$ & $F$ & 0.5 & 0.11 & 1.00 & 3 & 1 \\
\hline$F$ & $S$ & $s$ & $F$ & TL (LEV) & $S$ & - & 0.26 & 0.057 & 1.00 & 4 & 9 \\
\hline
\end{tabular}


Table IV.10.2-5

Human Error Probability (HEP) Estimates to Establish and Maintain water Level at TAF While at Low Pressure (LPII) for Case B (Concluded)

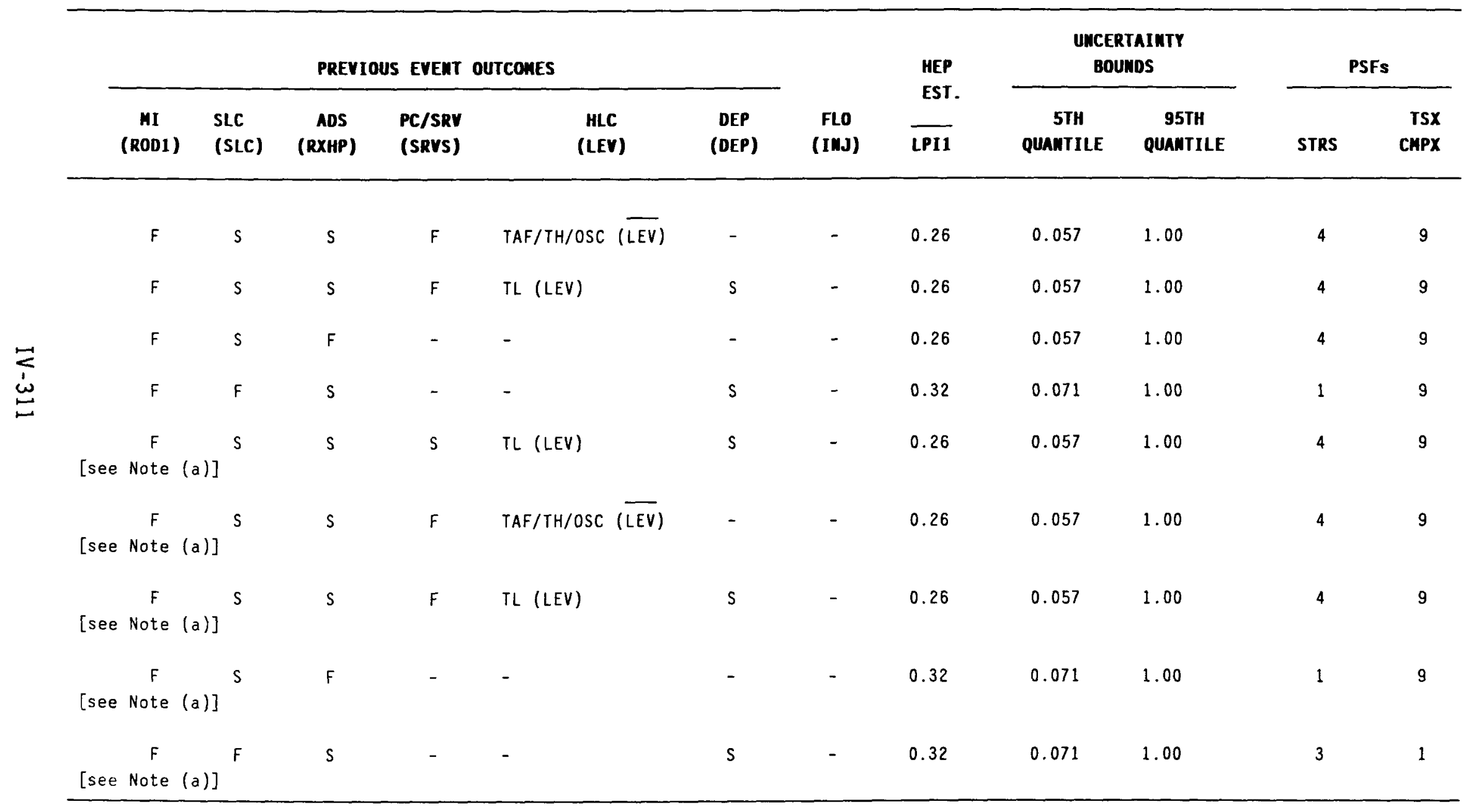

NOTE:

(a) Reactor Protection System Mechanical (in Event "RPSM") failure instead. 


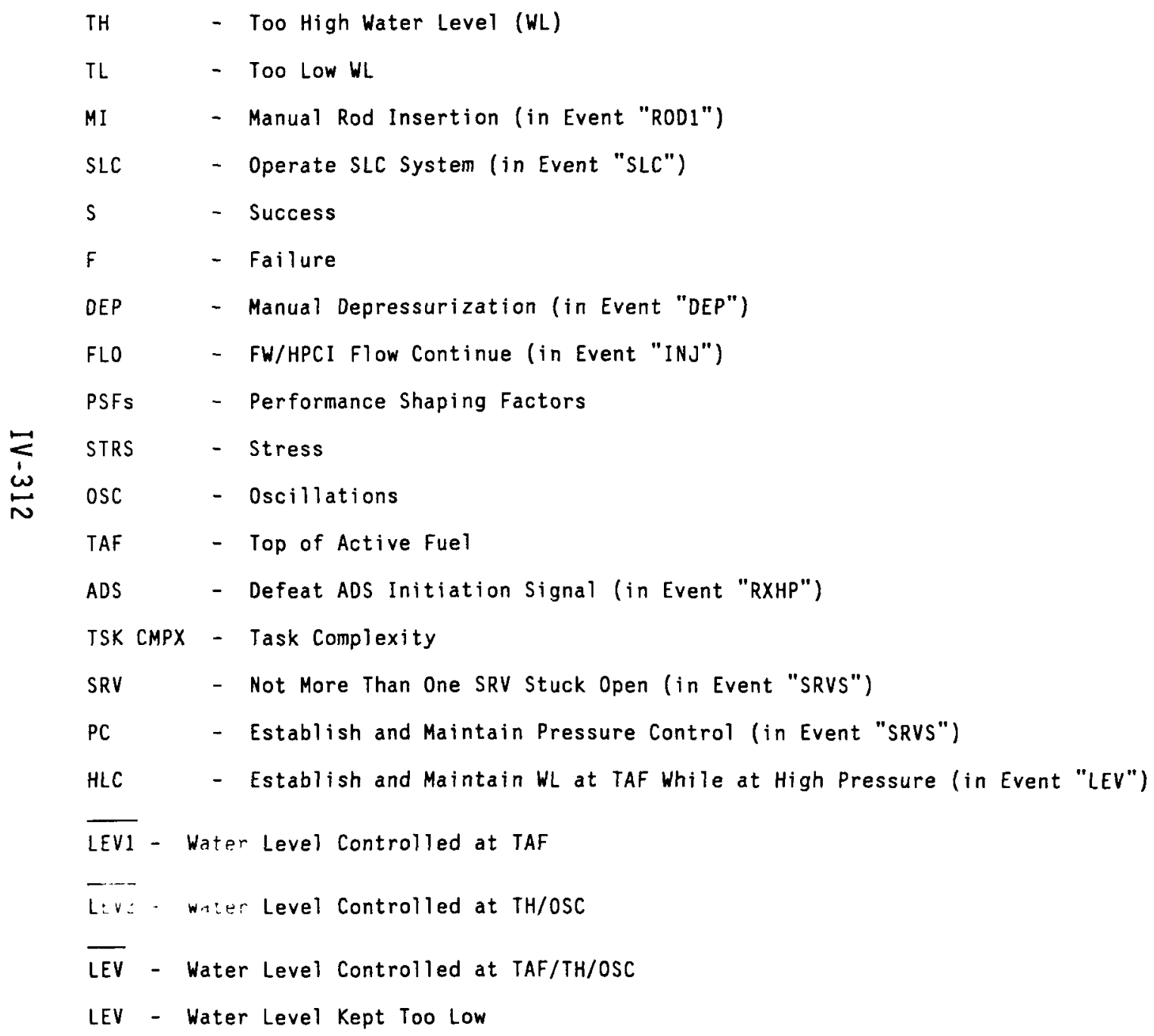


sets of events (i.e., whether or not the MSIVs have closed), which represent ifferent branch points. These tasks are discussed in the following paragraphs.

\section{SLC Task -- Operate SLC System (Event "SLC" in Event Tree) --}

The HEP estimate for failure to initiate SLC is given in Table IV.10.2-2. The SLC is supposed to be actuated by the time the torus temperature reaches $110-t_{0}-115^{\circ} \mathrm{F}$ (which is predicted to occur within 120 seconds of MSIV closure initiation).

However, SLC initiation in this analysis is modeled as needing to occur within four minutes of MSIV closure because of a draft report received from ORNL (Reference 30) which states that up to five minutes is acceptable under various conditions before SLC has to be initiated. To be conservative, one minute was taken away from the five minute time limit.

\section{ADS Task -- Defeat ADS Initiation Signal (Event "RXHP" in Event Tree) --}

The HEP estimate for failure to defeat the ADS initiation signal is given in Table IV.10.2-2. The ADS must be defeated within eight minutes of ADS alarm.

\section{LEV1 Task - Establish and Maintain Water Level at TAF while at High Pressure} (Event "LEV" in Event Tree) --

The HEP estimate for failure to maintain RPV level at the TAF while the RPV pressure is greater than $500 \mathrm{psig}$ is given in Table IV.10.2-3. The water level was assumed to be maintained within twelve inches of TAF for success of this quent.

DEP Task - - Manual Depressurization (Event "DEP" in Event Tree) --

The HEP estimate for failure to manually depressurize the reactor vessel is given in Table IV.10.2-4.

\section{LPIN Task -- Establish and Maintain Water Level at TAF while at Low Pressure} (Event "LPII" in Event Tree) --

The HEP estimate for failure to maintain RPV level at the TAF while the RPV pressure is below $500 \mathrm{psig}$ is given in Table IV.10.2-5. The basis for the values assumes that the water level is to be maintained within 12 inches of TAF for success of this event.

\section{IV.10.2.4 Supporting Calculations and Data}

This section presents the supporting calculations and data that were used in constructing and quantifying the ATWS event tree.

\section{IV.10.2.4.1 Supporting Calculations}

The information used to construct the ATWS event tree was obtained from ATWS code simulations performed for Peach Bottom and from related studies. The ATWS code simulations were performed using the LTAS code (Reference 31). LTAS code simulations were made for eight different ATWS scenarios. These are given in ble IV.10.1-6. These scenarios were based on a $43 \mathrm{gpm}$ SLC capability. The mulations were used for Case $B$ by using 10-to-15 minutes instead of 20-to-25 minutes for shutdown. 
Another source of information was a report by ORNL which presents an ATWS with MSIV closure analysis using Brown's Ferry as the model plant [32]. The analysis is applicable to Peach Bottom since both Peach Bottom and Brown's Ferry are BWR 4 reactors and Mark I containments. Brown's Ferry also has only a $43 \mathrm{gpm}$ SLC capability. A summary of the study is given in Table IV.10.1-7.

Two other studies were included in the analysis that were performed by General Electric [33] and INEL [34]. The results of these two studies basically support the two previous studies.

It should be noted that while the thermal-hydraulic calculations from these sources generally agree, specific results do vary somewhat. This represents uncertainties in sequence timing and success criteria which are not explicitly analyzed in this study because of resource limitations.

\section{IV.10.2.4.2 Data Used In Quantification}

Both HEPs and system failure rates were used to quantify the ATWS event tree in Figures IV.10.2-1 and IV.10.2-2. The data that were used to quantify the event trees are given in Tables IV.10.2-6, IV.10.2-7 and IV.10.2-8.

Table IV.10.2-6 gives the values for the top events in Figure IV.10.2-1. Two values were used to quantify the MSIV open event tree (Figure IV.10.2-2) that are not in Table IV.10.2-6; they are given in Table IV.10.2-8. The initiating events that were analyzed in this study are given in Table IV.10.2-7. The basis for the values given in Tables IV.10.2-6, IV.10.2-7 and IV.10.2-8 are discussed in detail in Case A ATWS, Section IV.10.1.4.

\section{IV.10.2.5 Results and Conclusions}

The Case B ATWS event trees for Peach Bottom shown in Figures IV.10.2-1 and IV.10.2-2 were quantified using the mean values given in Tables IV.10.2-6, IV.10.2-7 and IV.10.2-8. The dominant sequences are given in Table IV.10.2-9.

It should be noted that all of the dominant contributions to core damage-containment vulnerable scenarios are a result of the operator's failing to depressurize the reactor. This appears reasonable since the HEP failure rate for the operator's keeping the water level too low (six feet below TAF) is very small. In addition, the system failure for the low pressure systems is negligible since there are several redundant low pressure systems.

The dominant sequences that result in containment vulnerable scenarios result from SLC failure followed by interim successful use of the low pressure systems. 
able IV.10.2-6

Values Used for Top Events in Case B MSIV Closure ATWS Event Tree Quantification

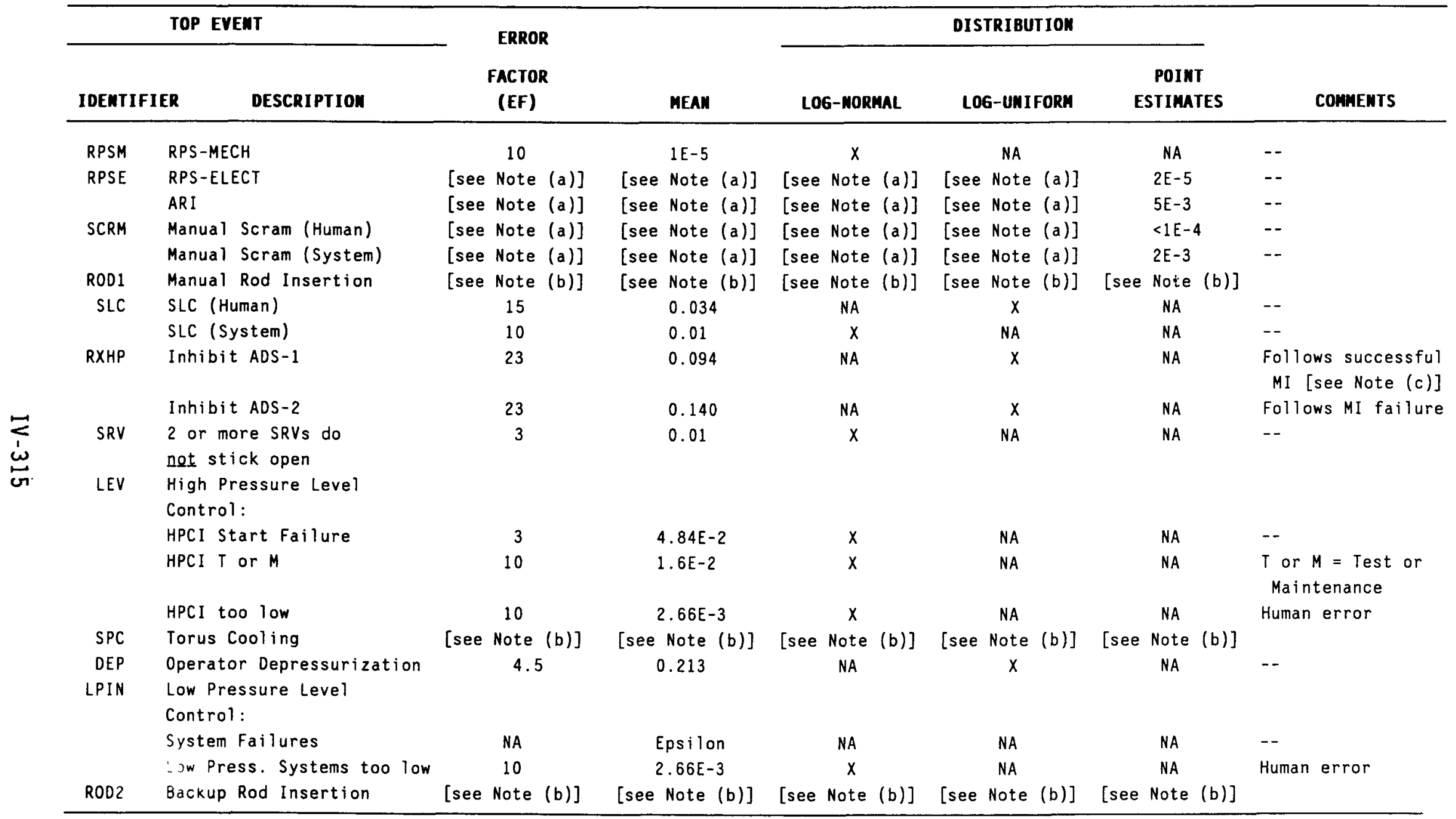

NA - Not Applicable.

NOTES:

(a) Top events with only point estimates did not appear in dominant sequences.

(b) Not quantified.

(c) MI = Manual Rod Insertion. 
Table IV.10.2-7

Values Used for Initiating Events in Case B Event Tree Quantification

\begin{tabular}{|c|c|c|c|}
\hline & & & DISTRIBUTIOM \\
\hline INITIATING EVEMT & MEAN VALUE & $\begin{array}{c}\text { ERROR } \\
\text { FACTOR } \\
\text { (EF) }\end{array}$ & LOG-MORMAL \\
\hline Loss of Feedwater (LOFW) & 0.7 & 3 & $x$ \\
\hline MSIV Closure & 0.8 & 3 & $x$ \\
\hline Inadvertent Opening of a Relief Valve (IORV) & 0.23 & 3 & $x$ \\
\hline Turbine Trip & 2.4 & 3 & $x$ \\
\hline
\end{tabular}


Table IV.10.2-8

Values Used for Top Events in Case B MSIV Open ATWS Event Tree Quantification

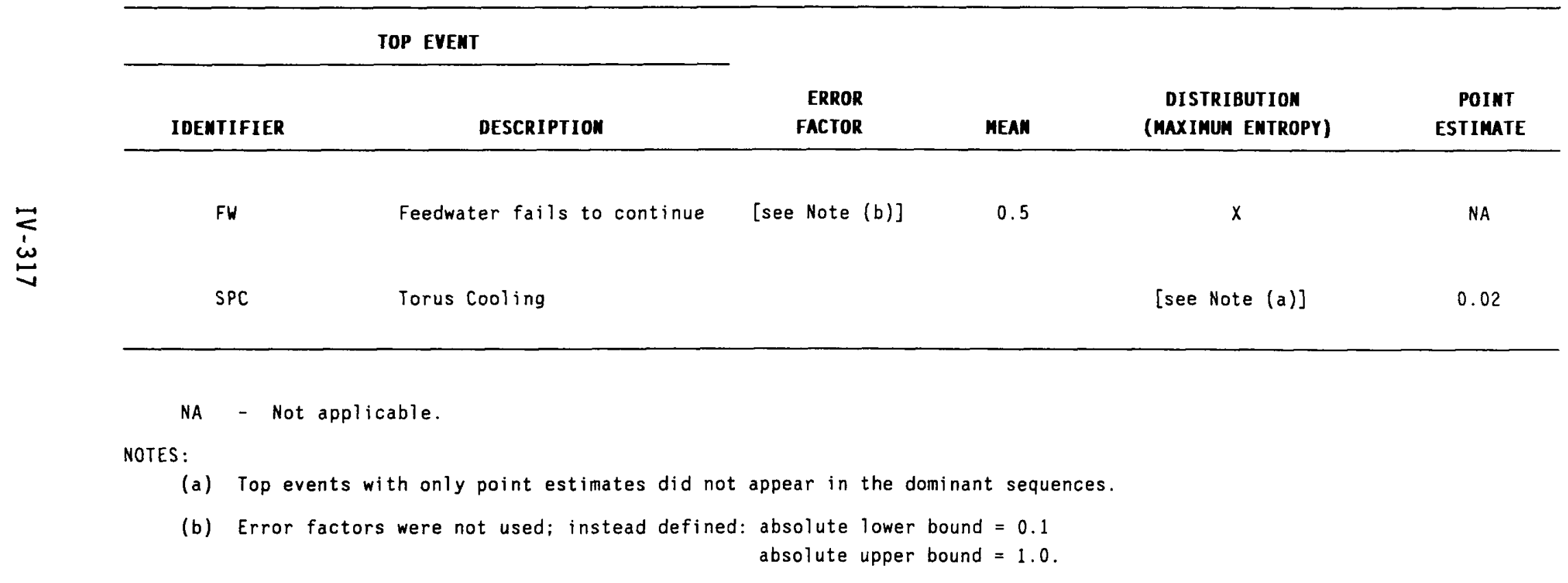


Table IV.10.2-9

Case B ATWS Dominant Sequences For Peach Bottom

\begin{tabular}{|c|c|c|c|}
\hline $\begin{array}{l}\text { SEQUEMCE } \\
\text { MUMBER(s) }\end{array}$ & $\begin{array}{c}\text { STATE OF } \\
\text { CORE/CONTAINHENT }\end{array}$ & FREQUENCY & SEQUENCE DESCRIPIION \\
\hline 46 & $\begin{array}{l}\text { Core Damage--Containment } \\
\text { Vulnerable (CM-CtV) }\end{array}$ & $48 E-7$ & $\begin{array}{l}\text { ATWS with SLC success but HPCI failure followed by fallure of } \\
\text { timely depressurization (hence, a core damage before containment } \\
\text { fallure-type scenario) This is } 74 \% \text { of the total CM-CtV frequency }\end{array}$ \\
\hline 54 & $\begin{array}{l}\text { Containment Vulnerable-- } \\
\text { Core Damage (CtV-CM) }\end{array}$ & $31 E-7$ & $\begin{array}{l}\text { ATWS with SLC fallure followed by successful high and low pressure } \\
\text { core cooling This is } 84 \% \text { of the total CtV frequency Core } \\
\text { cooling is ultimately lost following containment pressurization }\end{array}$ \\
\hline 57 & $\begin{array}{l}\text { Core Damage--Containment } \\
\text { Vulnerable (CM-CtV) }\end{array}$ & $17 \mathrm{E}-7$ & $\begin{array}{l}\text { ATWS with SLC fallure and fallure of depressurization following } \\
\text { HPCI fallure in } \sim 1 / 4-1 / 2 \text { hour due to high pool temperature This } \\
\text { leads to core damage before containment fallure type scenario } \\
\text { This is } 26 \% \text { of the total CM-CtV frequency }\end{array}$ \\
\hline 58 & $\begin{array}{l}\text { Containment Vulnerable-- } \\
\text { Core Damage (CtV-CM) }\end{array}$ & $58 \mathrm{E}-8$ & $\begin{array}{l}\text { ATWS with SLC failure, ADS is not inhibited, and low pressure } \\
\text { cooling is successful This is } 16 \% \text { of the total CtV frequency } \\
\text { Core cooling is ultimately lost following containment } \\
\text { pressurization }\end{array}$ \\
\hline Total Core Damage & e--Containment Vulnerable (CM-CtV) & $=65 \mathrm{E}-7$ & \\
\hline Total Containment & t Vulnerable--Core damage (CtV-CM) & $=37 \mathrm{E}-7$ & \\
\hline
\end{tabular}


There are various sources of uncertainty in the numerical results of this study. This section discusses the treatment and sources of uncertainty for the Peach Bottom study, the manner in which the uncertainties were evaluated, and the sensitivity issues addressed to determine the effect of certain key uncertainties.

\section{IV.11.1 Treatment of Uncertainties}

Two basic types of uncertainty were addressed in the Peach Bottom study: parameter value uncertainty and modeling uncertainty. The parameters of interest are those of the probability models for the basic events of the logic model and include failure rates, component unavailabilities, initiating event frequencies, and human error probabilities. The essential difference between the parameter value uncertainty and modeling uncertainty is the following: parameters can take on any of a continuous range of values and the fact that there is uncertainty as to which value is the correct one does not change the structure of the logic model. In general, only a few discrete modeling hypotheses are proposed and the different hypotheses may well lead to different logic models.

Parameter value uncertainties have been handled in past Probabilistic Risk Assessments (PRAs) by defining a probability distribution on the value of each parameter such that the nth percentile of the distribution represents the value below which the analyst has a degree of belief of $n / 100$ that the true value lies. This subjectivist approach to the representation of uncertainty makes the propagation of parameter value uncertainty through the evaluation of the bottom ine results mathematically straightforward using Monte Carlo or other sampling echniques.

Modeling uncertainties can be treated similarly be defining discrete probability distributions over the different modeling hypotheses. However, it is important to understand how the different assumptions can affect the results. This is the role of the sensitivity analyses which have been performed here for the modeling uncertainties identified as being potentially significant.

Some sensitivity analyses have also been performed on what would be regarded as parameter value uncertainties for reasons discussed below. The subjectivist approach of defining a probability distribution on parameter values was adopted. The uncertainty range characterized by the distributions varies in origin. If the estimates are based on plant specific data, the range should be characteristic of the statistical uncertainty. If the estimates are generic (or non-plant specific) the range should be characteristic of those factors which may affect the failure properties of the component in the different uses and environments from which the data for the estimates have been gathered. Thus, the range should include, for instance, plant-to-plant variation.

Two of the major areas where judgments are made with respect to parameter estimation are the definition of the population of components and the choice and interpretation of the applicable data. An example of the first type is the decision as to whether all motor driven pumps should constitute the population or whether the different sized pumps should form their own populations. Generally, unless there were compelling reasons from plant specific data, a generic pulation was defined, with an appropriate uncertainty range on the failure rameter estimate. 
An example of the second is the use of the licensee event report (LER) data to
estimate common cause failure parameters. There are differing opinions as to how events should be screened for applicability to a particular plant. Different schemes would lead to different estimators and each scheme would have its own uncertainty characterization. While the different schemes could be combined to give a broader distribution, it is also of interest to see explicitly the effect of certain assumptions. Consequently, for the common cause failure probabilities and certain other parameters whose estimates were felt to be less defensible, it was decided to perform sensitivity studies which essentially amounted to shifting the probability distributions. This can be regarded in a sense as representing analyst-to-analyst uncertainty.

\section{IV.11.2 Sources of Uncertainty}

All aspects of the Peach Bottom PRA were reviewed to identify sources of uncertainty, both conservative and non-conservative. Throughout the report, assumptions, sequence progression uncertainties, success criteria uncertainties, modeling conservatisms, etc. have been pointed out. These all represent sources of uncertainty in the results. With limited resources, a few key ones have been addressed as sensitivity studies which are discussed later.

\section{IV.11.3 Uncertainty/Sensitivity Analysis}

As discussed above, statistical uncertainty was evaluated using statistical sampling techniques. This was performed on the dominant cut sets for the dominant sequences presented Tater in Section $V$. Other uncertainties are handled through sensitivity studies. The specific sensitivity studies performed are addressed below.

\section{IV.11.3.1 Selection of Sensitivity Studies}

Having performed the base case core damage frequency analysis, little resources remained to perform sensitivity studies for evaluating the effects of important uncertainties on the core damage frequency. Because of this, a very limited number of sensitivity studies were performed. Their selection was based on primarily two criteria. First, that they impact either or both the station blackout-related or anticipated transient without scram (ATWS) type accident sequences since the base case analysis showed that these scenarios were, by far, the dominant contributors to the risk associated with Peach Bottom accidents. Secondly, that the studies address potentially important issues relative to those type of sequences in which additionally, sufficient uncertainty exists as to warrant that the sensitivity study be performed. It was on this basis that six sensitivity studies were defined and rigorously analyzed. In addition, a number of other studies were more superficially addressed. The following subsections discuss each sensitivity study.

\section{IV.11.3.2 Sensitivity Studies Rigorously Quantified}

Sensitivity Study \#1 (Eliminate Betas) and Study \#2 (Increase EPRI Beta Values)

Due in part to the redundancy of core cooling systems in a BWR such as Peach Bottom, it is not surprising that common cause failures contribute significantly to the estimated core damage frequency in the base case analysis. As will evident in the results presented in Section $V$, the common cause failures 
DC batteries, the diesel generators, and other components are significant to the esults of the analysis. In fact, the DC battery common mode, by itself, accounts or sequences which contribute more than $50 \%$ of the core damage frequency. The degree of the contribution from common cause failures, however, is highly dependent on very limited and hence uncertain data used to quantify common cause failures. As described earlier, a Beta factor approach was used to calculate the common cause failure probabilities (refer to Section IV.6.2). Using this approach, EPRI NP3967 [23] was used to estimate most of the Beta factors used in the study. As mentioned in Section IV.6.2, the Beta factor values from that report were judged to be $95 \%$ bound values and so new mean values were estimated on the basis of this interpretation. Two sensitivity studies were therefore defined to investigate the significance of all common cause failures as well as the modified use of EPRI's values. Accordingly, Sensitivity Study \#1 estimates the effects of eliminating all common cause failures from the analysis while Sensitivity Study \#2 uses the EPRI Beta factors as mean values (not 95\% bounds).

The results of these sensitivities are addressed in Section $V$. They show the relative importance of common cause failures in the study. In fact, this entire issue, of all those examined, has the most impact on both the core damage frequency and the relative importance of the dominant sequences.

Sensitivity Study \#3 (Increase Maintenance Unavailability of Emergency Service Water (ESW) System MOV-0498) and Study \#4 (Adjustment of ESW System Failure Modes)

As discussed in Section IV.5.13.8, it became apparent early in the base case analysis that the unavailability of MOV-0498 in the ESW system could be very important. This is based on the assumption that should this discharge valve have 0 be closed for maintenance, the ESW system pumps (upon a subsequent demand) might fail to deliver sufficient flow to necessary loads due to the following basis (refer to Figure IV.5.13-1). With ESW system pump operation under the conditions that MOV-0498 (MV-2 in the figure) is closed for maintenance, the Emergency Cooling Water (ECW) pump in the emergency heat sink path would automatically shut down (as per design), and the operator would most likely not use the ESW booster pumps thinking that the main ESW pumps are working properly (this also assumes that the interlock which starts the ESW booster pumps upon MOV-0498 closure would have been temporarily defeated for the duration of the maintenance activity). This would put the system in a configuration where the main ESW pumps would be supplying cooling water to the emergency loads from the pump bay, through the idle ESW booster pumps, and finally back to the pump bay through the fan basin letdown path (1abeled PS-20 in Figure IV.5.13-1). With the main ESW pumps supplying flow through the loads and through at least a portion of the emergency heat sink part of the system, it was not clear whether the system pressure drops (without the booster pumps) would cause too high a discharge pressure demand on the ESW pumps thus causing insufficient flow or even delayed failure of the pumps. Should this occur, manual start of the ECW pump and the booster pumps would then be required in a very short time (minutes) to avoid damage to the loads (particularly the diesels).

In discussing these issues with Philadelphia Electric Company (PECO) personnel, questions were raised about the need to close the MOV-0498 valve and whether the system could operate successfully in the configuration described above. While the base case analysis modeled the ESW system such that closure of MOV-0498 would ventually cause failure of the ESW function in the configuration above, two ensitivities were performed to analyze the importance of how the ESW system was 
modeled. These sensitivities were chosen because of the potential significance of ESW system failures on diesel generator cooling and hence on the station blackout sequences.

First, the maintenance unavailability estimated for the MOV-0498 valve in the base case analysis is 3.0E-5 due to PECO's input that this valve had never been closed for maintenance during plant operation. Sensitivity Study \#3, however, increases this value to the ASEP generic value of $8.0 \mathrm{E}-4$ to determine the effect of this more typical maintenance unavailability. Secondly, the ESW system failure model was drastically changed such that the proposed high discharge pressure failure of the ESW pumps could not occur and that instead, additional failures were required within the system to cause failure to cool the loads. This was done in Sensitivity Study \#4.

The results of these two sensitivities studies are discussed in Section $V$. Overall, it was determined that neither had a large effect on the base case core damage frequency; less than factors of two were observed.

\section{Sensitivity Study \#5 (Increasing Human Error Rates in ATWS Sequences)}

The outcomes and frequencies of ATWS scenarios are highly dependent on how well the operator responds to the accident. With current procedures calling for significant operator interaction such as initiating the Standby Liquid Control (SLC) system and taking over level control in the reactor vessel, it was judged to be important to examine the sensitivity of the ATWS sequence frequencies to critical human actions. For these reasons, Sensitivity Study \#5 examined the change in core damage frequency associated with (a) increasing the human error probability for failure to start the SLC system by, for instance, assuming a two minute start time was necessary instead of the four minutes used in the base case and (b) increasing the chances of controlling water level too $10 \mathrm{w}$ in the core by a factor of ten above the probability used in the base case analysis.

These were examined concurrently and the results are presented in Section $V$. In general, appreciable impacts were noted to certain ATWS scenarios. However, the overall core damage frequency is so dominated by station blackout that the overall result is not significantly affected.

Sensitivity Study \#6 (Combination of Studies \#4 and \#5)

Because of the observation that some ATWS sequences were appreciably affected by the above sensitivity study, Studies \#4 and \#5 were concurrently run to see the overall effect of lowering station blackout and raising ATWS sequence contributions to core damage. This is a realistic combination which appeared worthy of examination to determine if the relative significance of station blackout and ATWS contributions could significantly change.

The results are discussed in Section $V$. In general, no significant change was discerned in either the overall core damage frequency or in the relative ranking of station blackout versus ATWS. 


\section{IV.11.4 Integrated Sensitivity/Uncertainty Analysis}

As part of the "back-end" analysis, an integrated sensitivity study was also performed after the findings of this report were available. On the basis of the results of the above sensitivities and with additional analyses conducted on the potential uncertainties of such items as power recovery and battery common mode failure, a new set of sensitivity issues was chosen by mutual agreement of the "front-end" team leader and the "back-end" analysts. Since some of the issues here were found to be unimportant, the integrated sensitivity study reviewed additional sensitivity issues. The reader should refer to the "back-end" analysis reports in the "Related Documentation" Section of this report for the discussion of these issues.

\section{IV.11.5 Other Sensitivities}

A number of other "interesting" sensitivities are superficially addressed in this section. These are issues which might have been addressed more rigorously had resources been available. However, these qualitative assessments still provide valuable insights regarding the results.

\section{Battery Depletion Time (two versus six versus twelve hours)}

The base case analysis used six hours. Changing to either two or twelve hours would affect the long term station blackout scenarios. However, since the curve representing recovery of offsite power by time " $t$ " is already reasonably "flat" by these time periods, a significant change in core damage frequency is not expected.

\section{Gailure $=$ ten $X$ Present Values}

Peach Bottom's recent diesel failure history suggests availabilities ten times better than the industry average. In order to draw more generic conclusions from this report, a ten-fold increase in the diesel unavailabilities might be appropriate. Such a sensitivity would only further emphasize the importance of station blackout.

Low Pressure Core Spray/Low Pressure Coolant Injection (LPCS/LPCI) Pump Cooling Needs

As part of the discussions regarding ESW system failures, PECO noted that LPCS/LPCI pumps may not need cooling until the pool water used for suction reached $1600 \mathrm{~F}$ (refer to Section IV.5.13.8). Since this factor does not affect the dominant sequences, any specific sensitivity study to address this issue would only decrease already insignificant accident sequences; so qualitatively, this sensitivity is unimportant.

\section{More Credit for Condensate}

As noted in the event tree discussions, conservative treatment was given to the Condensate system (i.e., it was given no credit for continuing to operate after the initiators of interest). While additional credit would be more realistic, this would not affect the dominant scenarios which are station blackout-type quences and hence power does not exist to operate the system. 
The combination of the importance of the CRD system as an injection source and the assumption that the system does not realistically need pump cooling, calls for the need to look at the significance of that assumption. This sensitivity would seem not to have a significant effect on the results of the study on the basis that the relative probability of cooling system failure (Turbine Building Cooling Water backed by two trains of Reactor Building Cooling Water) is low when compared to the commonly used value of 0.1 for failure to align the CRD system into a two pump configuration in the first place. In addition, the failure of the CRD system most directly affects the loss of injection sequences (TUV-type discussed in Section V) which are two orders of magnitude below the frequencies of the dominant station blackout scenarios. Therefore, the CRD system failure probability would have to increase by almost the same amount before being significant.

\section{Successful Venting or Containment Failure $=$ Core Damage}

If one were to consider that successful containment venting always meant failure of core cooling equipment due to steam in the reactor building or that containment failure always led to loss of coolant injection, the effects of giving credit for venting and survivability of core cooling after containment failure can be determined. Overall, the TW-type scenario discussed in WASH-1400 would again become a dominant factor (a $\sim 1 E-5$ sequence would appear) but this would raise the overall core damage frequency by only a factor of two.

\section{Taking Credit for Containment Failure to Re-Initiate Low Pressure Core Cooling}

In the event tree structures and the corresponding analyses, credit has been given for the containment failing in failure-to-vent sequences such that containment pressure drops sufficiently below the maximum instrument air/nitrogen supply pressure ( $\left.-100-t_{0}-125 \mathrm{psig}\right)$. Because of this, the SRVs can be reopened and low pressure cooling re-initiated using HPSW or Condensate. (These sequence outcomes result in containment failure but the core is OK). However, if the containment were to only leak (i.e., not depressurize) or not fail at a11, the SRVs could not be reopened and core damage would result. In examining the effects of no containment failure or the containment only leaking, it is noted that the prior issue bounds the possible effects of this issue. That is, regardless of the success or failure of containment venting, if core damage is assumed when the venting question is even raised, the prior issue shows that the core damage frequency is only doubled. This impact bounds the hypothesis that high containment pressures following failure-to-vent could lead directly to core damage.

\section{Additional ATWS Issues}

Because of resource limitations and the relative importance of ATWS scenarios to station blackout in the base case analysis, few sensitivities for ATWS were examined. However, this is not meant to give the impression that ATWS core damage frequencies are not uncertain. On the contrary, uncertainties in areas such as the thermal-hydraulic calculations, human error estimates, and system success criteria could lead to potentially significant uncertainties in the core damage frequency estimates. As a way to bound these uncertainties on the high side, if it were assumed that scram failure and failure to start SLC by four minutes (using the $95 \%$ value) led to certain core damage (despite any other actions such as level 
control, delayed SLC operation, manual rod insertion, use of low pressure system looling, etc.), an ATWS core damage estimate of approximately $1 \mathrm{E}-5$ would result. Using such a bounding calculation, ATWS would be more important than station blackout but the overall core damage frequency would only increase by a factor of two to three. While such a calculation bounds the potential effect, the calculation is considered very conservative and somewhat unrealistic. However, it does provide the perspective that ATWS could be relatively more important than what is concluded using only the base case results. 
0

0

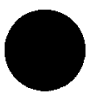




\section{RESULTS}

This section presents the final results of the Peach Bottom Probabilistic Risk Assessment (PRA) Update. These results include the dominant core damage sequences characterized by plant damage states, their frequencies and contributors, uncertainty analyses, and sensitivity studies on certain key issues. In addition, a comparison of these results with those of WASH-1400 [4] is presented.

Section V.l presents the results from the perspective of overall core damage frequency, statistical uncertainty, and sensitivity studies on key issues. Section V.2 presents results in more detail from the perspective of defined plant damage states and their corresponding dominant core damage sequences. Section V.3 briefly discusses how individual sequence frequencies can be derived from the results. Section V.4 compares the results of this study with the results of WASH-1400. Reasons for differences in the results are discussed.

\section{V.1 CHARACTERIZATION OF CORE DAMAGE FREQUENCY AT PEACH BOTTOM}

The base case Probabilistic Risk Assessment (PRA) Update resulted in the identification of thirteen groups of core damage sequences (plant damage states) with frequencies greater than 1.0E-8 per reactor year. These sets of sequences are referred to as the dominant core damage sequences. The plant damage states, their frequencies, and individual sequences are shown in Table V.1-1. A brief description of each group of sequences is provided in Table V.1-2. The individual sequences and plant damage states are discussed in more detail in Section V.2. The frequencies in Tables V.1-1 and V.1-2 are mean values.

he mean value for the frequency of core damage is $8.2 E-6$ per reactor year, as shown in Table V.1-1. An uncertainty analysis accounting for data uncertainties was performed on the total core damage frequency. The results follow:
Upper 95 Percent Bound
$2.4 \mathrm{E}-5$
Mean VaTue
$8.2 \mathrm{E}-6$
Median Value
$5.1 \mathrm{E}-6$
Lower 5 Percent Bound
$1.3 \mathrm{E}-6$.

These numbers represent the mean value and associated confidence limits of the total core damage frequency. Uncertainty analysis was performed on the frequency of each major plant damage state in a similar manner. These results are presented and discussed in Section V.2.

Using the mean values of each plant damage state, Table V.1-3 summarizes the percentage contribution of "similar" plant damage states (called accident types-refer to Table I.3-1) to the core damage frequency so as to get an overall perspective of the general type of accidents contributing most to the Peach Bottom frequency estimate for core damage. The information was determined by summing the mean frequencies of similar plant damage states and comparing the summed values to the overall core damage frequency. Clearly shown is the fact that station blackout-related sequences dominate the core damage potential for Peach Bottom. These type sequences contribute approximately $86 \%$ of the core damage frequency. Anticipated Transient Without Scram (ATWS) sequences contribute about $12 \%$ while 211 other sequences sum to about $2 \%$ of the core damage frequency estimate.

(Text Continued on Page V-8) 
Table V.1-l

Peach Bottom Dominant Accident Sequences

\begin{tabular}{|c|c|c|}
\hline $\begin{array}{l}\text { PLant Damage STate } \\
\text { [see Note (a)] } \\
\text { (See also Section IV.4.1) }\end{array}$ & SEQUENCES & $\begin{array}{l}\text { PLANT DAMAgE STATE } \\
\text { MEAN FREQUEMCY }\end{array}$ \\
\hline TBUX & $\begin{array}{c}T 1-T 2-T 3(Q) \cup 1 U 2 B 0 X \text { [see Note }(b)] \& \\
\text { T1-T2-T3(Q)U1U2BOXY }\end{array}$ & $4.2 E-6$ \\
\hline$T B$ & $\begin{array}{l}T 1-T 2-T 3(Q) B O \& \text { \& } T 1-T 2-T 3(Q) \cup 1 B O \& \\
T 1-T 2-T 3(Q) B O Y \text { \& } T 1-T 2-T 3(Q) \cup 1 B O Y\end{array}$ & $2.3 E-6$ \\
\hline TCUX & $\begin{array}{l}T^{\star} M S I V^{*} R P S M^{*} / S L C^{*} / R X H P^{*} / S R V S^{*} L E V^{*} D E P^{*}(/ \text { YorY }) \\
T^{*} / M S I V^{*} R P S M^{*} F^{*} / S L C^{*} / R X H P^{*} / S R V S^{*} L E V^{*} D E P(/ \text { Yor } Y)\end{array}$ & $4.8 E-7$ \\
\hline $\begin{array}{l}\text { TCSR made up of: } \\
\text { TCSRX2 } \\
\text { TCSRX3 } \\
\text { TCSRV23 }\end{array}$ & $\begin{array}{c}T^{*} M S I V^{*} R P S M^{*} S L C^{*} / R X H P^{*} / D E P^{*} / L P I N^{*} Y \\
T^{*} / M S I V^{\star} R P S M^{\star} F W^{\star} S L C^{\star} / R X H P^{*} / D E P^{*} / L P I N^{*} Y \\
\text { (both with three versions of contalnment fallure) } \\
{[\text { see Note (c)] }}\end{array}$ & $\begin{array}{l}3.1 E-7 \text { consisting of: } \\
2.4 E-7 \text { (Type } 1) \\
6.3 E-8 \text { (no failure) } \\
2.5 E-8 \text { (Type 2) }\end{array}$ \\
\hline TBUP & $\begin{array}{c}T 1-T 2-T 3(Q) P U 1 U 2 W 2 W 3 V 1 V 2 V 3 V 4 \text { [see Note }(d)] \& \\
\text { T1-T2-T3(Q)PU1U2W2W3V1V2V3V4Y }\end{array}$ & $2.0 \mathrm{E}-7$ \\
\hline $\operatorname{Tcs} x$ & $\begin{array}{l}T^{\star} M S I V^{\star} R P S M^{*} S L C^{\star} / R X H P^{*} D E P^{*}(/ \text { YorY }) \\
T^{\star} / M S I V^{*} R P S M^{\star} F W^{\star} S L C^{\star} / R X P^{\star} D E P^{\star}(/ \text { YorY })\end{array}$ & $1.7 \mathrm{E}-7$ \\
\hline TBU & $\begin{array}{l}T 1-T 2-T 3(Q) \cup 1 \cup 2 B O \& \\
T 1-T 2-T 3(Q) \cup 1 \cup 2 B O Y\end{array}$ & $1.6 E-7$ \\
\hline TBP & $\begin{array}{c}T 1-T 2-T 3(Q) P W 2 W 3 U 3 V 1 V 2 V 3 V 4 \text { [see Note }(e)] \& \\
T 1-T 2-T 3(Q) P U 1 W 2 W 3 U 3 V 1 V 2 V 3 V 4 \& \\
T 1-T 2-T 3(Q) P W 2 W 3 U 3 V 1 V 2 V 3 V 4 Y \& \\
T 1-T 2-T 3(Q) P U 1 W 2 W 3 U 3 V 1 V 2 V 3 V 4 Y\end{array}$ & 1. $2 \mathrm{E}-7$ \\
\hline SIV & S1V2V3V4 & $7.5 E-8$ \\
\hline $\begin{array}{l}\text { TCSAR made up of: } \\
\text { TCSARX2 } \\
\text { TCSARX3 }\end{array}$ & $\begin{array}{c}T^{\star} M S I V^{\star} R P S M^{\star} S L C^{\star} R X H P^{\star} / L P I N^{\star} Y \\
T^{*} / M S I V^{\star} R P S M^{\star} F W^{\star} S L C^{\star} R X P^{\star} / L P I N^{\star} Y \\
\text { (both with two version containment failure) }\end{array}$ & $\begin{array}{l}5.8 E-8 \text { consisting of: } \\
4.7 E-8 \text { (Type 1) } \\
1.1 E-8 \text { (no failure) }\end{array}$ \\
\hline
\end{tabular}


Table V.1-1

Peach Bottom Dominant Accident Sequences (Concluded)

\begin{tabular}{|c|c|c|}
\hline $\begin{array}{c}\text { PLant Damage SIate } \\
\text { [see Note (a)] } \\
\text { (See also Section IV } 4 \text { 1) }\end{array}$ & SEQUENCES & $\begin{array}{l}\text { PLANT DAMAGE STATE } \\
\text { MEAM FREQUEMCY }\end{array}$ \\
\hline TUV & $T 2-T 3 Q U 1 \cup 2 \cup 3 W 1 V 2 V 3 V 4$ & $4.9 E-8$ \\
\hline AV & AV2V3 & $3.2 E-8$ \\
\hline TUX & T2-T3QU1U2U3W1X & $1.9 \mathrm{E}-8$ \\
\hline TOTAL CORE DAMAGE & All of above & $8.2 E-6$ \\
\hline
\end{tabular}

(a) Designator used by analysts for sequence-containment analysis interface.

(b) T1-T2-T3(Q) indicates transients of the T1, T2, and T3 type contribute to the sequence with PCS(Q) fallure $1 \mathrm{mpl} 1 \mathrm{ed}$ for the $T 3$ type transient due to a subsequent loss of offsite power

(c) Three versions of contalnment fallure indicate different degrees of contalnment fallure No containment fallure or a Type 1 fallure does not allow depressurization of the reactor vessel (air supply to SRVs is 11 mited to $\sim 100-125$ psig). Therefore. continued low pressure cooling is prevented and core damage begins. Type 2 containment fallure is large enough to allow a significant drop in containment pressure and, hence, operation of the SRVs is at least possible. However, low pressure cooling is subsequently not restored and core damage results.

(d) Since these TP type transients transfer to $\$ 2$ tree, sequence nomenclature is derived from S2 event tree. These are actually station blackout sequences (loss of $A C$ power is causing $W$ and $V$ fallures). Therefore, the following shortened nomenclature could be used. T1-T2-T3(Q)PU1U2BO \& T1-T2-T3(Q)PU1U2BOY

(e) Since these TP type transients transfer to $S 2$ tree, sequence nomenclature is derived from S2 event tree. These are actually station blackout sequences (loss of AC power is causing W. U3, \& V fallures). Therefore, the following shortened nomenclature could be used. T1-T2-T3(Q)PBO \& T1-T2-T3(Q)PU1BO \& T1-T2-T3(Q)PBOY \& T1-T2-T3(Q)PU1BOY. 
Table V.1-2

Accident Scenarios Greater Than 1E-8/Reactor Year At Peach Bottom

\begin{tabular}{ccc}
\hline PLANT & MEAN & SEQUENCES II \\
DANAGE & FREQUEMCY & PLANT DAMAGE STATE \\
STATE & & \\
\hline
\end{tabular}

TBUX $\quad 4.2 E-6$

T1-T2-T3(Q)U1U2BOX

$T 1-T 2-T 3(Q) \cup 1 U 2 B O X Y$

Short-term station blackout with sufficient coincident $D C$ power failure such that all core cooling immediately fails and vessel depressurization is not possible. Non-recovery of $A C$ power in 30-to-40 minutes.

Two versions of above: (1) with successful containment venting (which is possible, locally, without $A C$ power) or (2) venting failure.

TB $\quad 2.3 E-6$

$\stackrel{1}{1}$ $T 1-T 2-T 3(Q) B 0$
$T 1-T 2-T 3(Q) \cup 1 B O$
$T 1-T 2-T 3(Q) B O Y$
$T 1-T 2-T 3(Q) \cup 1 B O Y$

Long-term station blackout with successful core cooling until battery depletion at 6 hours. Non-recovery of AC power within $\sim 3$ hours of battery depletion. Vessel repressurization occurs after battery depletion, because SRVs cannot be held open without DC power.

Four versions of above: (1) early core cooling with HPCI and/or RCIC and successful containment venting, (2) earty core cooling with RCIC since HPCI fails and with successful containment venting, and (3) \& (4) versions of previous two but with venting failure.

\begin{tabular}{|c|c|c|c|}
\hline TCuX & 4. $8 E-7$ & 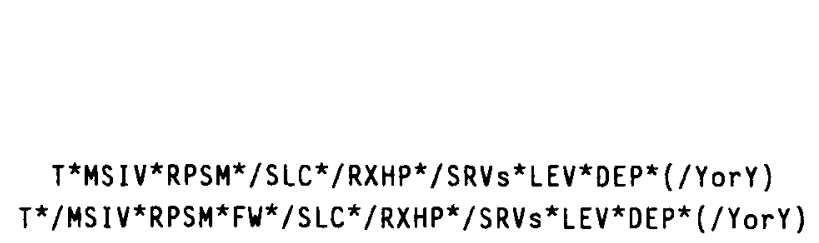 & $\begin{array}{l}\text { ATWS with SLC success but HPCI faiture followed by failure of } \\
\text { timely depressurization (hence, a core damage before containment } \\
\text { failure type scenario). } \\
\text { Four versions of above: successful containment venting or venting } \\
\text { failure, both with and without initial MSIV closure. }\end{array}$ \\
\hline \multirow[t]{2}{*}{ TCSR } & $3.1 E-7$ & & $\begin{array}{l}\text { ATWS with SLC failure and successful high then low pressure core } \\
\text { cooling. Inadequate or no containment heat removal causes a } \\
\text { containment vulnerable before core damage type scenario with } \\
\text { eventual loss of core cooling. }\end{array}$ \\
\hline & & $\begin{array}{c}T^{*} M S I V^{*} R P S M^{*} S L C^{*} / R X H P^{*} / D P^{*} / L P I N^{*} Y \\
T^{*} / M S I V^{*} R P S M^{*} F W^{*} S L C^{*} / R X H P^{*} / D E P * / L P I N^{*} Y \\
\text { (both with three versions of } \\
\text { containment failure) }\end{array}$ & $\begin{array}{l}\text { Six versions of above involving venting failure and different } \\
\text { degrees of containment failure. All sequences result in } \\
\text { subsequent loss of core cooling with the vessel likely at high } \\
\text { ressure. }\end{array}$ \\
\hline
\end{tabular}


Table V.1-2

Accident Scenarios Greater Than 1E-8/Reactor Year At Peach Bottom (Continued)

\begin{tabular}{rcc} 
PLANT & MEAN & SEQUENCES IN \\
DAMAGE & FREQUENCY & PLANT DAMAGE SIATE \\
STATE & & \\
\hline
\end{tabular}

TBUP $\quad 2.0 \mathrm{E}-7$

$T 1-T 2-T 3(Q) P U 1 U 2 W 2 W 3 V_{1} V_{2} V_{3} V_{4}$

$T 1-T 2-T 3(Q) P U 1 U 2 W 2 W 3 V 1 V 2 V 3 V 4 Y$

Short-term station blackout with early core cooling failure (with and without multiple $O C$ train failures) and a stuck-open relief valve which slowly depressurizes the vessel. Non-recovery of $A C$ power in $\sim 1 / 2$ hour.

Two versions of above: (1) with successful containment venting or (2) venting failure.

\section{$\operatorname{TCS} X \quad 1.7 \mathrm{E}-7$}

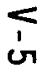

ATWS with SLC failure and failure of depressurization following HPCI failure in $\sim 1 / 4-1 / 2$ hour because of high pool temperature. This leads to a core damage before containment failure scenario.

$T^{\star} M S I V * R P S M^{*} S L C * / R X H P{ }^{*} D E P *(/ Y O r Y)$ $T^{\star} / M S I V^{*} R P S M^{*} F W^{*} S L C^{*} / R X H P^{*} D E P^{*}(/$ YorY $)$
Four versions of above: successful containment venting or venting failure, both with and without initial MSIV closure.

\begin{tabular}{|c|c|c|c|}
\hline \multirow[t]{2}{*}{ TBU } & 1. $6 E-7$ & & $\begin{array}{l}\text { Short-term station blackout with early core cooling failure (no } \\
\text { multiple } D C \text { train failures). Non-recovery of } A C \text { power in } \\
30-\text { to- } 40 \text { minutes. Vessel depressurization is likely. }\end{array}$ \\
\hline & & $\begin{array}{r}T 1-T 2-T 3(Q) \cup 1 \cup 2 B 0 \\
T 1-T 2-T 3(Q) \cup 1 \cup 2 B O Y\end{array}$ & $\begin{array}{l}\text { Two versions of above: (1) with successful containment venting or } \\
\text { (2) venting failure. }\end{array}$ \\
\hline \multirow[t]{2}{*}{ TBP } & 1. $2 E-7$ & & $\begin{array}{l}\text { Long-term station blackout with a stuck-open relief valve and with } \\
\text { successful core cooling until battery depletion at } 6 \text { hours. } \\
\text { Non-recovery of AC power within } \sim 3 \text { hours af battery depletion. } \\
\text { Vessel depressurized because of stuck-open valve. }\end{array}$ \\
\hline & & $\begin{array}{l}T 1-T 2-T 3(Q) P W 2 W 3 U 3 V 1 V 2 V 3 V 4 \\
T 1-T 2-T 3(Q) P U 1 W 2 W 3 U 3 V 1 V 2 V 3 V 4 \\
T 1-T 2-T 3(Q) P W 2 W 3 U 3 V 1 V 2 V 3 V 4 Y \\
T 1-T 2-T 3(Q) P U 1 W 2 W 3 U 3 V 1 V 2 V 3 V 4 Y\end{array}$ & $\begin{array}{l}\text { Four versions of above: (1) early core cooling with HPCI and/or } \\
\text { RCIC with successful containment venting. (2) early core cooling } \\
\text { with RCIC since HPCI fails and with successful containment venting, } \\
\text { and (3) (4) versions of previous two but with venting failure. }\end{array}$ \\
\hline
\end{tabular}


Table V.1-2

Accident Scenarios Greater Than 1E-8/Reactor Year At Peach Bottom (Concluded)

\begin{tabular}{|c|c|c|c|}
\hline $\begin{array}{r}\text { PLAMT } \\
\text { DAMAGE } \\
\text { STATE }\end{array}$ & $\begin{array}{l}\text { MEAN } \\
\text { FREQUENCY }\end{array}$ & $\begin{array}{l}\text { SEQUEMCES IN } \\
\text { PLANT DAMAGE STAIE }\end{array}$ & DESCRIPTION \\
\hline
\end{tabular}

S1V $\quad 7.5 E-8$

Intermediate LOCA with HPCI success for $\sim 2$ hours until vessel depressurizes. Low pressure core cooling falls.

S1V2V3V4

The only dominant sequence in this group is with successful containment venting.

TCSAR $58 \mathrm{E}-8$

$\stackrel{s}{\infty}$
T*MSIV*RPSM*SIC*RXHP*/LPIN*Y $T^{\star} / M S I V^{\star} R P S M^{\star} F W^{\star} S L C^{\star} R X H P^{\star} / L P I N^{\star} Y$

(both with two versions of containment fallure)

ATWS with SLC fallure. ADS is not inhibited, and low pressure core cooling is successful. Inadequate or no containment heat removal causes a containment fallure before core damage scenario with eventual loss of core cooling.

Four versions of above, all involving venting fallure and with either minor or no containment failure and with or without initial MSIV closure. All sequences result in subsequent loss of core cooling with the vessel likely at high pressure.

TUV $\quad 4 \quad 9 E-8$

Transient with early loss of all core cooling, but with vessel depressurized

T2-T3QU1U2U3W1V2V3V4

The only dominant sequence in this group is with successful containment venting

Large LOCA with early loss of core cooling.

AV2V3

The only dominant sequence in this group is with successful containment venting.

Transient with early loss of high pressure core cooling and fallure to depressurize

The only dominant sequence in this group is with successful containment venting 
Table V.1-3

Core Damage Frequency Contributors By Type of Accident

\begin{tabular}{|c|c|c|c|}
\hline $\begin{array}{l}\text { ACCIDENT } \\
\text { TYPE }\end{array}$ & $\begin{array}{c}\text { PLANT } \\
\text { DAMAGE STATE }\end{array}$ & $\begin{array}{c}\text { MEAN } \\
\text { FREQUENCY }\end{array}$ & $\begin{array}{l}\text { CONTRIBUTION TO } \\
\text { CORE DAMAGE } \\
\text { FREQUENCY (\%) }\end{array}$ \\
\hline $\begin{array}{l}\text { Station Blackout } \\
\text { (Loss of a } 11 \mathrm{AC} \text { ) }\end{array}$ & $\begin{array}{c}\text { TBUX } \\
\text { TB } \\
\text { TBUP } \\
\text { TBU } \\
\text { TBP } \\
\text { Subtotal }\end{array}$ & $\begin{array}{l}4.2 \mathrm{E}-6 \\
2.3 \mathrm{E}-6 \\
2.0 \mathrm{E}-7 \\
1.6 \mathrm{E}-7 \\
1.2 \mathrm{E}-7 \\
7.0 \mathrm{E}-6\end{array}$ & $\begin{array}{r}51 \\
28 \\
3 \\
2 \\
2 \\
86\end{array}$ \\
\hline ATWS & $\begin{array}{c}\text { TCUX } \\
\text { TCSR } \\
\text { TCSX } \\
\text { TCSAR } \\
\text { Subtota1 }\end{array}$ & $\begin{array}{l}4.8 E-7 \\
3.1 E-7 \\
1.7 E-7 \\
5.8 E-8 \\
1.0 E-6\end{array}$ & $\begin{array}{r}5 \\
4 \\
2 \\
1 \\
12\end{array}$ \\
\hline Other & $\begin{array}{c}\text { SIV } \\
\text { TUV } \\
\text { AV } \\
\text { TUX } \\
\text { Subtotal }\end{array}$ & $\begin{array}{l}7.5 E-8 \\
4.9 E-8 \\
3.2 E-8 \\
1.9 E-8 \\
1.8 E-7\end{array}$ & $\begin{array}{r}1 \\
<1 \\
<1 \\
<1 \\
2\end{array}$ \\
\hline
\end{tabular}


As part of the analysis results, three importance measures were evaluated by use of the TEMAC code [28]. These include risk reduction, risk increase, an uncertainty. Table V.1-4 contains brief descriptions of these importance measures. The reader is referred to Reference [28] for the specific mathematical definition of each measure in TEMAC. Table V.1-5 summarizes the results of these evaluations for the collective set of core damage scenarios. Section V.2 discusses similar results at the plant damage state level. Appendix B contains the detailed computer output for the importance calculations. Appendix $C$ contains additional perspective on the results, including comments from Philadelphia Electric Company (PECO).

The total core damage frequency at Peach Bottom is affected by a few key issues. Some of the issues are related to the study methodology and some are related to plant specific factors. Each of these issues became the subject of sensitivity studies which explored the impact of alternate parametric models and data development methods on the core damage frequency and the major plant damage states. The key issues and the plant damage states they affect are summarized in Table V.1-6. More information on the sensitivity studies is in section IV.11.

The total core damage frequency, as well as plant damage state frequencies, was recalculated for each sensitivity study. In addition, uncertainty analysis was performed for each sensitivity study. Calculating the uncertainty on each sensitivity study enables the construction of a "box and whisker" graphic presentation of core damage frequencies. The box and whisker results for total core damage frequency are shown in Figure V.1-1. Table V.1-7 summarizes the key values shown in Figure V.1-1. The "box" represents the range of the means of the sensitivity studies. The "whiskers" represent ranges of uncertainty arising frop the uncertainty in the values of the parameter estimates. The inner bars on th whiskers indicate the 95th and 5 th percentiles of the probability distribution calculated for the base case. The outer bars indicate the following: the upper bar is the 95th percentile of the probability distribution on the result of the sensitivity study whose mean value corresponds to the top of the box; the lower bar is the 5th percentile of the probability distribution on the result of the sensitivity study whose mean value corresponds to the bottom of the box. The range specified by the outer bars thus has no precise statistical meaning but is representative of the range within which the true result is expected to lie taking into account both parameter uncertainties and the other uncertainties addressed by the sensitivity studies. Table V.1-8 summarizes the changes in importance measure evaluations for each sensitivity with the detailed calculations provided in Appendix B. The box and whisker charts for individual plant damage states are provided in Section V.2. 
Table V.1-4

Importance Measures

Risk Reduction

A measure of how much the results are reduced given a specific event is assumed to be totally reliable. A large value indicates that a significant reduction in the core damage frequency is possible by improving the reliability associated with that event.

Risk Increase

- Opposite of risk reduction. A large effect indicates the importance of maintaining the reliability of the specific event and not letting it get worse.

Uncertainty

- A measure of how much the uncertainty in the results is affected by the uncertainty associated with a specific event. The larger the measure, the more the uncertainty in the results is driven by the uncertainty in the value of the specific event. 
Table V.1-5

Important Contributors to Core Damage Based on Results of

Importance Measure Evaluations

(in approximate order of importance)

\begin{tabular}{|c|c|c|c|}
\hline MEASURE & EVEMT & $\begin{array}{c}\text { IAPORIAMCE } \\
\text { VALUE }\end{array}$ & DESCRIPTION \\
\hline \multirow[t]{14}{*}{ Risk Reduction } & $D C P-B A T-L P-B 2$ & $4.6 E-6$ & Collectively represent $D C$ battery common mode failure \\
\hline & B-DCP-LP-BATS & $4.5 \mathrm{E}-6$ & \\
\hline & $\mathrm{RA}-1 \mathrm{~J}$ & $2.4 \mathrm{E}-6$ & Non-recovery of offsite and onsite $A C$ power in $6-$ to- 8 hours \\
\hline & RA-16J & $1.2 \mathrm{E}-6$ & \\
\hline & $A C P-D G N-L P-E D G 2$ & $1.2 \mathrm{E}-6$ & DG hardware faults including common mode beta factor \\
\hline & $A C P-D G N-L P-E D G 3$ & $8.1 E-7$ & \\
\hline & $B-A C P-L P-E D G S$ & $4.5 E-7$ & \\
\hline & RPS-M & $1.2 E-6$ & Mechanical failure of control rods \\
\hline & LOSP & $9.1 E-7$ & Subsequent loss of offsite power after a trip \\
\hline & SLC-XHE-FS & $6.0 E-7$ & Failure to start SLC \\
\hline & IE-TLOSP & $6.2 \mathrm{E}-6$ & Loss of offsite power \\
\hline & IE-TRTRIP & $1.0 \mathrm{E}-6$ & Turbine trip \\
\hline & IE-TMSIVC & $5.5 E-7$ & MSIV closure \\
\hline & IE-TLFW & $4.8 \mathrm{E}-7$ & Loss of feedwater \\
\hline
\end{tabular}


Table V.1-5

Important Contributors to Core Damage Based on Results of

Importance Measure Evaluations (Continued)

(in approximate order of importance)

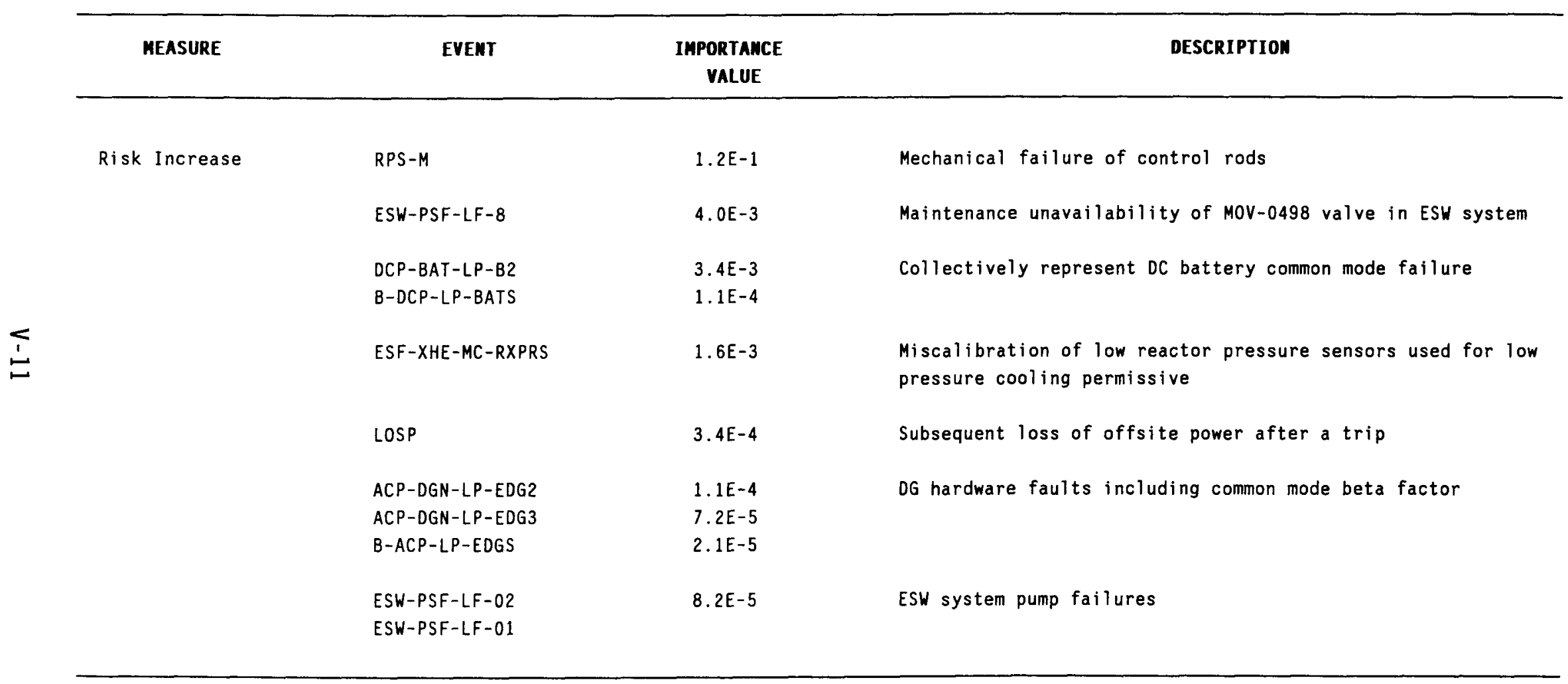


Table V.1-5

Important Contributors to Core Damage Based on Results of Importance Measure Evaluations (Concluded)

(in approximate order of importance)

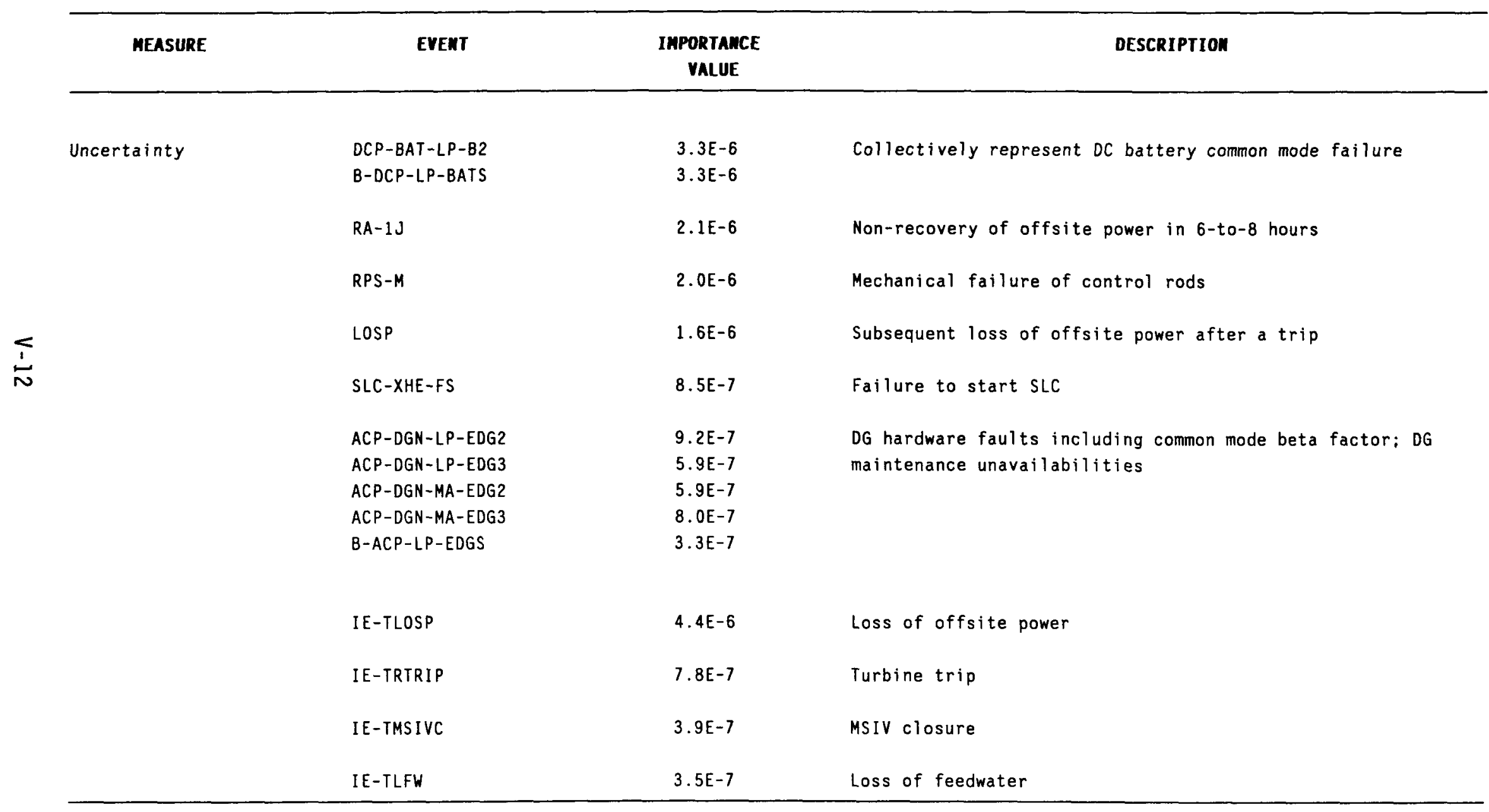


Table V.1-6

Summary of Key Sensitivity Issues

[see Note (a)]

ISSUE

SENSITIVITY STUDY

PLANT DAMAGE

STATES AFFECTED

Common Mode Beta Values

(1) Common mode eliminated

TBUX, TB, TBUP

from results

TBU, TBP, TUX

(2) Use of EPRI NP-3967 [23]

Beta values in this study

Maintenance Unavailability

Associated with ESW System

(3) Base case value of $3 E-5$

changed to ASEP generic

value of $8 \mathrm{E}-4$

TB, TBUP, TBU TBP

Valve MOV-0498

(MV-2 on schematic)

[see Note (b)]

Failure Modes of ESW System

(4) Change faults such that it takes at least 3 DG/ESW

TB, TBUP, TBU pump-valve combinations to fail system (i.e., EHS mode does not need booster pumps)

Key ATWS Operator Actions

(5) Use 2-minute SLC success criteria and increase probability of maintaining water level too low

TCUX, TCSR

TCSX, TCSAR [see Note (b)]

Combination of Issues

(6) Studies (4) and (5), concurrentiy

See above for Studies (4) and (5)

NOTES:

(a) See Section IV.11 for more information. Other issues, not explicitly quantified, are also discussed in Section IV.11.

(b) Other sequences and plant damage states may become $>1 E-8 / y r$, but the maximum effect on core damage is based on the plant damage states shown. 


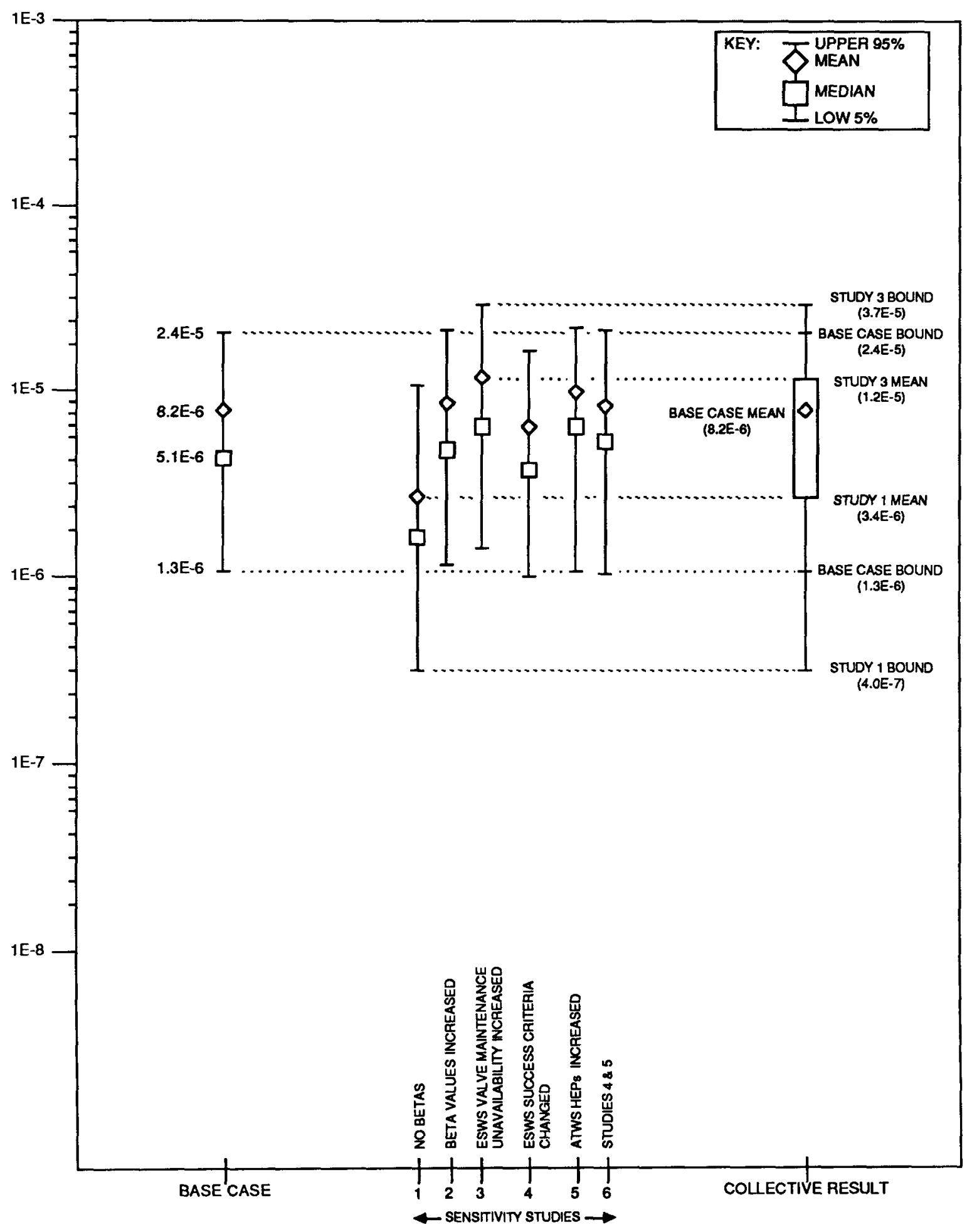

Figure V.1-l. Peach Bottom Total Core Damage Frequency. (including sensitivity study effects) 
Table V.I-7

Summary of Core Damage Frequency Estimates Including Sensitivity studies (see Figure V.1-1)

\begin{tabular}{|c|c|c|c|c|}
\hline Study & Lower $5 \%$ & Median & Mean & Upper 95\% \\
\hline Base Case & $1.3 E-6$ & $5.1 E-6$ & $8.2 E-6$ & $2.4 E-5$ \\
\hline Sensitivity 1 & $4.0 E-7$ & $1.8 E-6$ & $3.4 E-6$ & $1.2 E-5$ \\
\hline Sensitivity 2 & $1.4 \mathrm{E}-6$ & $5.6 E-6$ & $8.8 E-6$ & $2.5 E-5$ \\
\hline Sensitivity 3 & $1.6 E-6$ & $6.8 E-6$ & $1.2 E-5$ & $3.7 E-5$ \\
\hline Sensitivity 4 & $1.0 \mathrm{E}-6$ & $4.6 E-6$ & $6.9 E-6$ & $1.9 E-5$ \\
\hline Sensitivity 5 & $1.3 E-6$ & $6.8 E-6$ & $9.8 \mathrm{E}-6$ & $2.7 E-5$ \\
\hline Sensitivity 6 & $1.1 E-6$ & $5.8 E-6$ & $8.5 E-6$ & $2.5 E-5$ \\
\hline
\end{tabular}


Table V.1-8

Core Damage Importance Measure Results For Each Sensitivity (as compared with base case results in Table $\mathrm{V} \cdot 1-5$ )

\begin{tabular}{|c|c|c|c|c|c|c|}
\hline $\begin{array}{l}\text { IMPORTANCE } \\
\text { MEASURE }\end{array}$ & SENSITIVITY 1 & SENSITIVITY 2 & SEMSITIVITY 3 & SEMSITIVITY 4 & SENSITIVITY 5 & SEMSITIVITY 6 \\
\hline $\begin{array}{l}\text { Risk } \\
\text { Reduction: }\end{array}$ & $\begin{array}{l}\text { - No major } \\
\text { changes from } \\
\text { base case } \\
\text { except no } \\
\text { common mode }\end{array}$ & $\begin{array}{l}\text { - No major } \\
\text { changes from } \\
\text { base case }\end{array}$ & $\begin{array}{l}\text { - Maintenance of } \\
\text { ESWS MOV-0498 } \\
\text { and operator } \\
\text { failure to start } \\
\text { ECW pump follow- } \\
\text { ing possible } \\
\text { delayed failure } \\
\text { of primary ESWS } \\
\text { pumps are near } \\
\text { the top in the } \\
\text { ranking }\end{array}$ & $\begin{array}{l}\text { - Mechanical } \\
\text { failure of rods } \\
\text { rises somewhat } \\
\text { and operator } \\
\text { failure to } \\
\text { start ECW pump } \\
\text { and venting } \\
\text { becomes more } \\
\text { important }\end{array}$ & $\begin{array}{l}\text {-Mechanical } \\
\text { failure of rods } \\
\text { and failure to } \\
\text { start SLC rise } \\
\text { to near the top } \\
\text { in the ranking } \\
\text { and venting also } \\
\text { more important }\end{array}$ & $\begin{array}{l}\text { - Mechanical } \\
\text { failure of rods, } \\
\text { failure to } \\
\text { start SLC, and } \\
\text { venting rise to } \\
\text { near the top } \\
\text { in the ranking }\end{array}$ \\
\hline $\begin{array}{l}\text { Risk } \\
\text { Increase: }\end{array}$ & $\begin{array}{l}\text {--No major } \\
\text { changes from } \\
\text { base case } \\
\text { except no } \\
\text { common mode }\end{array}$ & $\begin{array}{l}\text { - No major } \\
\text { changes from } \\
\text { base case }\end{array}$ & $\begin{array}{l}\text { - No major } \\
\text { changes from } \\
\text { base case }\end{array}$ & $\begin{array}{c}\text { - Maintenance of } \\
\text { ESWS MOV-0498 } \\
\text { not important }\end{array}$ & $\begin{array}{l}\text { - No major } \\
\text { changes from } \\
\text { base case }\end{array}$ & $\begin{array}{c}\text { - Maintenance of } \\
\text { ESWS MOV-0498 } \\
\text { not important }\end{array}$ \\
\hline Uncertainty: & $\begin{array}{l}\text { - Mechanical } \\
\text { control rod } \\
\text { failure and } \\
\text { failure to start } \\
\text { SLC ranks } 1 \text { and } \\
3 \text {; no common } \\
\text { mode; offsite } \\
\text { power recovery } \\
\text { ranks 2nd }\end{array}$ & $\begin{array}{l}\text { - No major } \\
\text { changes from } \\
\text { base case }\end{array}$ & $\begin{array}{l}\text {--Maintenance of } \\
\text { ESWS MOV-0498 } \\
\text { ranks 1: } \\
\text { otherwise, no } \\
\text { major changes }\end{array}$ & $\begin{array}{l}\text {--Mechanical } \\
\text { failure of rods } \\
\text { and SLC fail- } \\
\text { ure to start } \\
\text { rise slightly } \\
\text { in rank }\end{array}$ & $\begin{array}{l}- \text { Mechanical } \\
\text { failure of rods } \\
\text { and failure to } \\
\text { start SLC rank } \\
1 \text { and } 2\end{array}$ & $\begin{array}{l}- \text {-Mechanical } \\
\text { failure of rods } \\
\text { and failure to } \\
\text { start SLC rank } \\
1 \text { and } 2\end{array}$ \\
\hline
\end{tabular}


In order to facilitate the subsequent containment response analysis being performed by Sandia personnel on the Peach Bottom dominant accident sequences, it was required that a mechanism be developed for properly binning the core damage sequences. A single binning mechanism was subsequently developed to translate the accident sequence information across the sequence-containment analysis interface. This mechanism consists of defining plant damage states as discussed in Section IV.4.1. The plant damage states generally correspond to the accident sequences discussed in WASH-1400 and other PRAs. This allows for a more direct comparison of this study's results to other work while still meeting the general interface requirements for the containment analyses. It is at the plant damage state level that this section addresses the results of the Peach Bottom study. 


\section{V.2.1 Plant Damage State TBUX}

This plant damage state is characterized by transients leading to station blackout (loss of all AC power) as a result of coincident DC power failures. The loss of DC power causes failure of the diesel, High Pressure Coolant Injection (HPCI), and Reactor Core Isolation Cooling (RCIC) systems which results in the loss of a 71 core and containment cooling. Without the restoration of AC/DC power in 30-to-40 minutes, primary system inventory boils off and core damage results. The core degradation process occurs under high pressure conditions in the reactor vessel since the loss of $D C$ power also disables operation of the Automatic Depressurization System (ADS) and Safety Relief Valves (SRVs). In addition, $A C$ power recovery is affected by the $D C$ power loss severely hampering the recovery process for reclosing breakers, etc. Instrumentation in the plant is also significantly degraded under these circumstances. For these reasons, the probability of power recovery was conservatively treated as negligible in the required 30 minute time frame to prevent core damage. (See Appendix $C$ for further discussion.)

The dominant sequences which contribute to this plant damage state are

$$
\begin{aligned}
& \text { T1-T2-T3(Q)U1U2BOX, } \\
& \text { T1-T2-T3 (Q)U1U2BOXY. }
\end{aligned}
$$

The collective frequency and the uncertainties of both sequences (i.e., of plant damage state TBUX) follow:

$\begin{array}{ll}\text { Upper } 95 \text { Percent Bound } & 1.5 \mathrm{E}-5 \\ \text { Mean Value } & 4.2 \mathrm{E}-6 \\ \text { Median Value } & 2.2 \mathrm{E}-6 \\ \text { Lower 5 Percent Bound } & 3.9 \mathrm{E}-7 .\end{array}$

The dominant cut sets (excluding the " $\gamma$ " event) for both sequences are listed in Table V.2-1.

Both sequences result in core damage whether or not containment venting (event " $Y$ ") is successful by performing local actions without the use of AC/DC power. The only difference in the two sequences is the addition of the $Y$ term to characterize the condition of the containment for the containment analysis. The split fraction for $Y$ success and $Y$ failure, which distinguish the two sequences, is $0.1 / 0.9$ respectively (i.e., venting is likely to fail).

The major contributors to the sequences in this plant damage state, on the basis of the importance measures analyzed, are listed (in approximate order of importance) in Table V.2-2.

The effects of the six sensitivity studies (described earlier) on plant damage state TBUX are summarized by Figure V.2-1 and Table V.2-3. Appendix B contains the detailed results for all the importance calculations. Appendix $C$ contains important additional information regarding TBUX.

The plant damage state frequency is driven by $D C$ common mode failure. The failur probability for the simultaneous loss of additional buses of DC power is subjed to considerable uncertainty and judgment because of insufficient common cause data available. Therefore, the treatment in this analysis represents an upper bound 
alculation (since the additional bus failures are estimated to occur at 1.0 probability). In addition, the possibility of cross-feeding any available DC buses (the plant has eight battery buses but the failure of five is sufficient to arrive at this plant damage state) has not been analyzed. This is a potential conservatism in the analysis.

Finally, credit has not been given for more extraordinary actions such as manual hook-up of a firepump or power from Conowingo Dam under loss of AC/DC conditions at Peach Bottom. (Specific procedures are apparentiy not available, but the appropriate actions could be performed with operator ingenuity). 
Table V.2-1

TBUX Dominant cut sets

\begin{tabular}{|c|c|c|}
\hline CUT SET & \multicolumn{2}{|c|}{$\begin{array}{l}\text { CUT SET } \\
\text { POINT ESTIMATE } \\
\text { FREQUEMCY }\end{array}$} \\
\hline \multicolumn{2}{|c|}{ IE-TLOSP*DCP-BAT-LP-B $2^{*} B-D C P-L P-B A T S$} & $3.7 \mathrm{E}-6$ \\
\hline IE-TRTRIP*LOSP*DCP-BAT-LP-B & \multicolumn{2}{|c|}{$3.4 E-7$} \\
\hline IE-TMSIVC*LOSP*DCP-BAT-LP-B & \multicolumn{2}{|c|}{$1.1 E-7$} \\
\hline \multicolumn{2}{|c|}{ IE-TLFW*LOSP*DCP-BAT-LP-B2*B-DCP-LP-BATS } & $9.9 E-8$ \\
\hline TERM & DESCRIPIION & MEAM YALUE \\
\hline IE-TLOSP & Loss of offsite power & $7.0 \mathrm{E}-2 /$ year \\
\hline IE-TRTRIP & Turbine Trip & $2.4 /$ year \\
\hline IE-TMSIVC & MSIV closure type initiators & $8.0 \mathrm{E}-1 /$ year \\
\hline IE-TLFW & Loss of feedwater & 7.0E-1/year \\
\hline LOSP & Loss of offsite power after reactor trip & $2.66 \mathrm{E}-3$ \\
\hline$D C P-B A T-L P-B 2^{*}$ & Battery B2 failure & $1.33 \mathrm{E}-3$ \\
\hline B-DCP-LP-BATS* & $\begin{array}{l}\text { Common mode Beta factor applied to above } \\
\text { term for failure of } 2 \text { nd battery }\end{array}$ & $4.0 E-2$ \\
\hline \multicolumn{3}{|c|}{$\begin{array}{l}\text { *Together make up the common mode failure of two } D C \text { buses (which also fail two diesels). Subsequen } \\
\text { common mode to sufficient other } D C \text { buses is applied at a Beta factor of } 1.0 \text { per methodology } \\
\text { guidelines. Failure to restore } D C \text { in this time period is } 1.0 \text { per non-recovery action RA-15D. }\end{array}$} \\
\hline
\end{tabular}


Table V.2-2

TBUX Major Contributors

\begin{tabular}{|c|c|c|c|}
\hline MEASURE & EVEMT & $\begin{array}{l}\text { IMPORTANCE } \\
\text { VALUE (POINT } \\
\text { ESTIMATE) }\end{array}$ & DESCRIPTION \\
\hline \multirow[t]{5}{*}{ Risk Reduction } & $D C P-B A T-L P-B 2$ & $4.3 E-6$ & Collectively represent common \\
\hline & $B-D C P-L P-B A T S$ & $4 \cdot 3 \mathrm{E}-6^{\}}$ & mode failure of DC power \\
\hline & LOSP & $5.5 E-7$ & $\begin{array}{l}\text { Subsequent loss of offsite power } \\
\text { after a trip }\end{array}$ \\
\hline & IE-TLOSP & $3.7 E-6$ & Loss of offsite power \\
\hline & IE-TRTRIP & $3.4 E-7$ & Turbine trip \\
\hline \multirow[t]{3}{*}{ Risk Increase } & $D C P-B A T-L P-B 2$ & $3.2 E-3\}$ & Collectively represent common \\
\hline & $B-D C P-L P-B A T S$ & $1.0 \mathrm{E}-4^{\}}$ & mode failure of $D C$ power \\
\hline & LOSP & $2.1 E-4$ & $\begin{array}{l}\text { Subsequent loss of offsite power } \\
\text { after a trip }\end{array}$ \\
\hline \multirow[t]{5}{*}{ Uncertainty } & $D C P-B A T-L P-B 2$ & $3.1 \mathrm{E}-6$ & Collectively represent common \\
\hline & $B-D C P-L P-B A T S$ & $3.1 \mathrm{E}-6^{\}}$ & mode failure of DC power \\
\hline & LOSP & $9.8 E-7$ & $\begin{array}{l}\text { Subsequent loss of offsite power } \\
\text { after a trip }\end{array}$ \\
\hline & IE-TLOSP & $2.6 \mathrm{E}-6$ & Loss of offsite power \\
\hline & IE-TRTRIP & $2.6 \mathrm{E}-7$ & Turbine trip \\
\hline
\end{tabular}




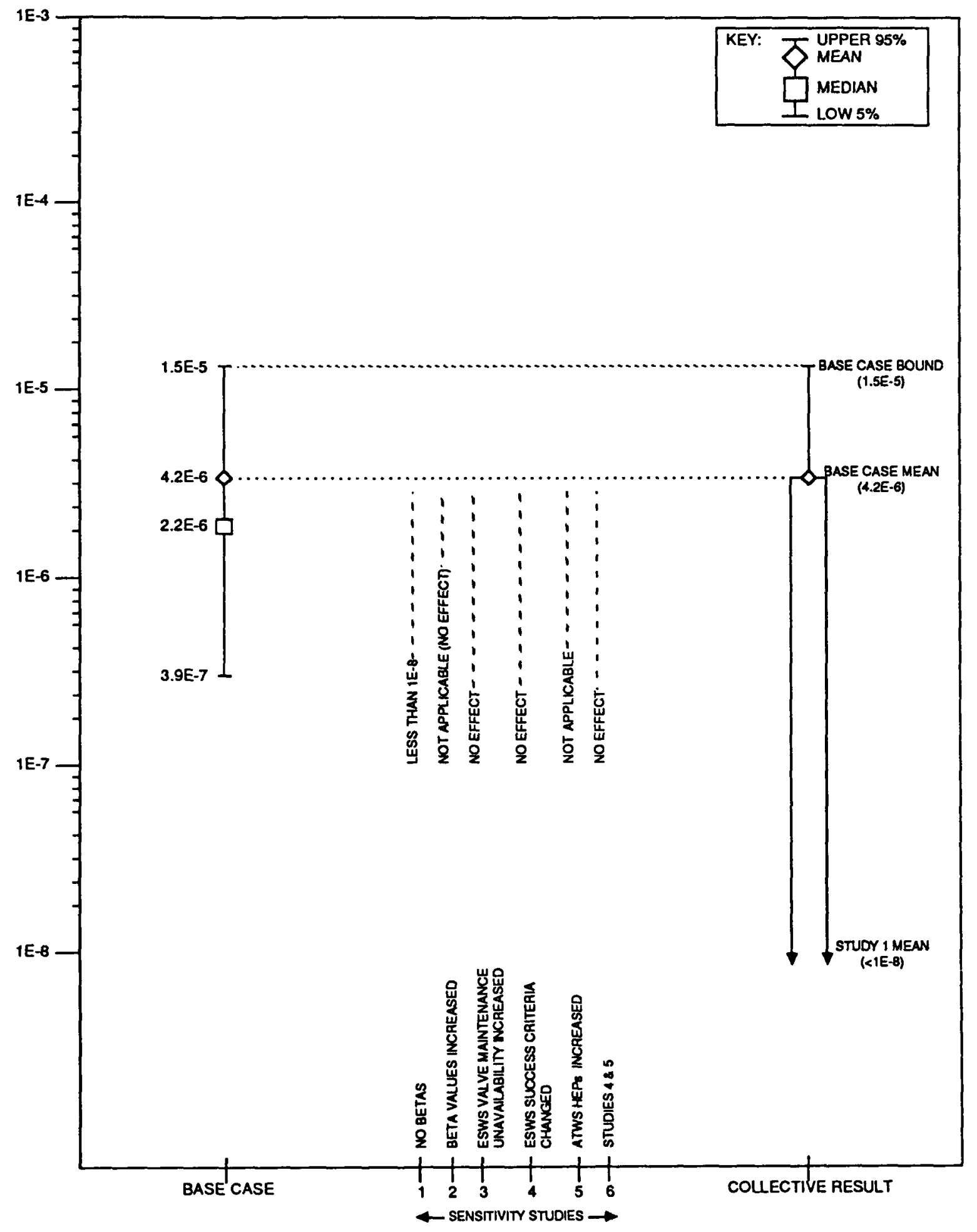

Figure V.2-1. Peach Bottom TBUX Core Damage Frequency. 
Table V.2-3

TBUX Importance Measure Results For Each Sensitivity (as compared with base case results)

\begin{tabular}{|c|c|c|c|c|c|c|}
\hline $\begin{array}{l}\text { IMPORTANCE } \\
\text { MEASURE }\end{array}$ & SEMSITIVITY 1 & SEMSITIVITY 2 & SENSITIVITY 3 & SENSITIVITY 4 & SEMSITIVITY 5 & SENSITIVITY 6 \\
\hline \multicolumn{7}{|l|}{ A11 3} \\
\hline Measures: & $\begin{array}{l}\text {-- Sequence drops } \\
\text { to }<1 \mathrm{E}-8\end{array}$ & - Not applicable & $\begin{array}{c}- \text {-No changes from } \\
\text { base case }\end{array}$ & $\begin{array}{l}\text { - No changes from } \\
\text { base case }\end{array}$ & - Not applicable & $\begin{array}{c}\text { - No changes from } \\
\text { base case }\end{array}$ \\
\hline
\end{tabular}




\section{V.2.2 Plant Damage State TB}

This plant damage state is characterized by transients leading to a long-term station blackout (loss of all AC power). Core cooling is successful with either HPCI or RCIC providing coolant injection until about six hours into the sequence. At that time, the batteries deplete, affecting the ability to continue operation of these systems. Without AC power recovery within three hours of battery depletion, core damage results. While the primary system may be initially at relatively low pressures, depletion of the batteries causes loss of ADS/SRV control. The vessel will therefore repressurize with core damage progressing under high pressure conditions.

The dominant sequences which contribute to this plant damage state are

$$
\begin{aligned}
& \text { T1-T2-T3(Q)BO, } \\
& \text { T1-T2-T3(Q)U1BO, } \\
& \text { T1-T2-T3(Q) BOY, } \\
& \text { T1-T2-T3(Q)U1BOY. }
\end{aligned}
$$

The collective frequency and the uncertainties of all four sequences (i.e., of plant damage state TB) follow:

$\begin{array}{ll}\text { Upper } 95 \text { Percent Bound } & 1.0 \mathrm{E}-5 \\ \text { Mean } & 2.3 \mathrm{E}-6 \\ \text { Median } & 1.0 \mathrm{E}-6 \\ \text { Lower } 5 \text { Percent Bound } & 1.5 \mathrm{E}-7 .\end{array}$

The dominant cut sets for each sequence are listed in Tables V.2-4 and V.2-5.

In these sequences, failures of DG2 and DG3 cause failure of the Emergency Service Water (ESW) pumps and ESW booster pumps. This is judged to lead to loss of both the primary and backup modes of the ESW system causing loss of jacket cooling to $D G 1$ and DG4 and hence station blackout. For one of the minor cut sets, closure of MOV-0498 is assumed to cause either a delayed failure of the ESW pumps on high discharge pressure or insufficient flow to the diesels. Operator failure to start the Emergency Cooling Water (ECW) and ESW booster pumps before all four diesels fail on loss of jacket cooling causes station blackout. The two sequences differ only as to whether containment venting (event "Y") is successful or not. The split fraction for $Y$ success and $Y$ failure is $0.1 / 0.9$ respectively.

As for the previous two sequences, station blackout is caused in the same way. HPCI has also failed in this case, requiring RCIC to provide the interim cooling until battery depletion. $Y$ success or failure is estimated at $0.1 / 0.9$ respectively.

The major contributors to the sequences in this plant damage state, on the basis of the importance measures analyzed, are listed (in approximate order of importance) in Table V.2-6.

The effects of the six sensitivity studies (described earlier) on plant damage state TB are summarized by Figure V.2-2 and Table V.2-7. Appendix B contains the detailed results for all the importance calculations. Appendix $C$ contai important additional information regarding TB. 
t should be noted that the plant damage state frequency may be conservative depending on the real need for the ESW booster pumps and the effects of an initially closed MOV-0498 valve in the ESW system. In addition, no consideration has been given for getting firewater into the reactor or obtaining other $A C$ power sources by wiring up a small diesel available on the site or obtaining a diesel from offsite. Six to eight hours are available before core damage which might allow for such actions if they are started early in the sequence. One non-conservatism in the analysis is that the offsite power non-recovery value for 6-to-8 hours was not adjusted upward to account for difficulties associated with restoring power after battery depletion. 
Table V.2-4

TB [Sequences $\mathrm{T} 1-\mathrm{T} 2-\mathrm{T} 3(\mathrm{Q}) \mathrm{BO}$ and $\mathrm{T} 1-\mathrm{T} 2-\mathrm{T} 3(\mathrm{Q}) \mathrm{BOY}$ ] Dominant Cut Sets

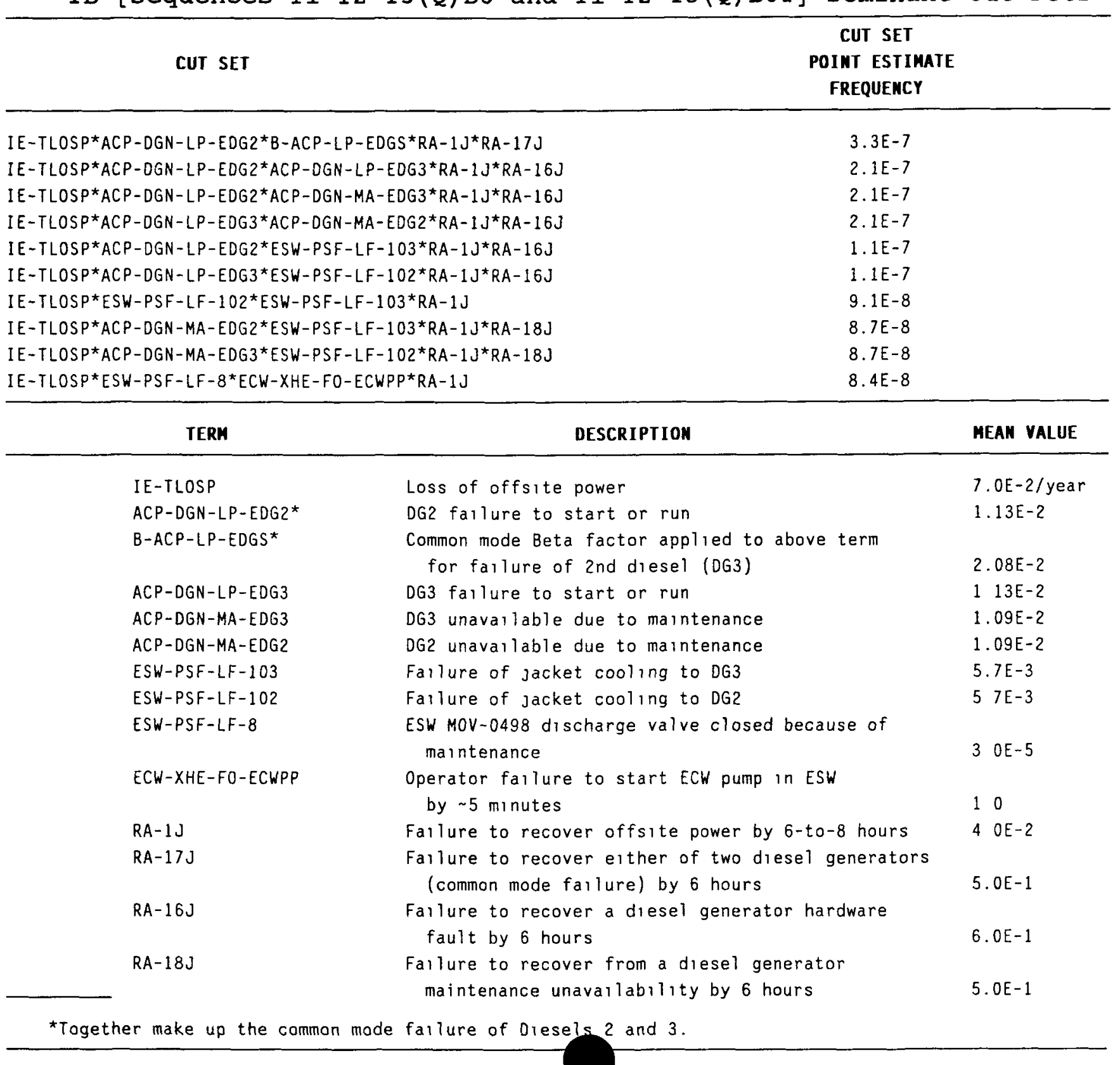


able V.2-5

TB [Sequences T1-T2-T3(Q) U1BO and T1-T2-T3(Q)U1B0Y] Dominant Cut Sets

\begin{tabular}{|c|c|c|c|}
\hline \multicolumn{2}{|l|}{ CUT SET } & \multicolumn{2}{|c|}{$\begin{array}{l}\text { CUT SET } \\
\text { POINT ESTIMATE } \\
\text { FREQUENCY }\end{array}$} \\
\hline \multicolumn{2}{|c|}{ IE $-T L O S P^{*} A C P-D G N-L P-E D G 2^{*} B-A C P-L P-E D G S^{*} H C I-T D P-F S-20 S 37^{*} R A-1 J * R A-17 \mathrm{~J}$} & \multicolumn{2}{|l|}{ 1. $6 \mathrm{E}-8$} \\
\hline \multicolumn{2}{|c|}{ IE-TLOSP*ACP-DGN-LP-EDG2*ACP-DGN-LP-EDG3*HCI-TOP-FS-20S37*RA-1J*RA-16J } & \multicolumn{2}{|l|}{$1.0 E-8$} \\
\hline \multicolumn{2}{|c|}{ IE-TLOSP*ACP-DGN-LP-EDG2*ACP-DGN-MA-EDG3*HCI-TDP-FS-20S37*RA-1J*RA-16J } & \multicolumn{2}{|l|}{$1.0 E-8$} \\
\hline \multicolumn{2}{|c|}{ IE-TLOSP*ACP-DGN-LP-EDG3*ACP-DGN-MA-EDG2*HCI-TDP-FS-20S37*RA-1J*RA-16J } & \multicolumn{2}{|l|}{$1.0 \mathrm{E}-8$} \\
\hline TERH & DESCRIPTION & & MEAN VALUE \\
\hline IE-TLOSP & Loss of offsite power & & $7.0 \mathrm{E}-2 /$ year \\
\hline$A C P-D G N-L P-E D G 2^{*}$ & DG2 failure to start or run & & $1.13 E-2$ \\
\hline$B-A C P-L P-E D G S^{*}$ & $\begin{array}{l}\text { Common mode Beta factor applied } t \\
\text { for failure of } 2 \text { nd diesel (DG3) }\end{array}$ & bove term & $2.08 \mathrm{E}-2$ \\
\hline$A C P-D G N-L P-E D G 3$ & DG3 failure to start or run & & $1.13 E-2$ \\
\hline$A C P-D G N-M A-E D G 3$ & DG3 unavailable due to maintenanc & & $1.09 E-2$ \\
\hline$A C P-D G N-M A-E D G 2$ & DG2 unavailable due to maintenanc & & $1.09 E-2$ \\
\hline $\mathrm{RA}-1 \mathrm{~J}$ & Failure to recover offsite power & 6 -to- 8 hours & $4.0 E-2$ \\
\hline$R A-17 \mathrm{~J}$ & $\begin{array}{l}\text { Failure to recover either of two } \\
\text { (common mode failure) by } 6 \text { hour }\end{array}$ & sel generators & 5. $0 \mathrm{E}-1$ \\
\hline RA-16J & $\begin{array}{l}\text { Failure to recover a diesel gener } \\
\text { fault by } 6 \text { hours }\end{array}$ & or hardware & $6.0 \mathrm{E}-1$ \\
\hline HCI I TDP-FS-20S37 & HPCI system fails to start & & $4.84 \mathrm{E}-2$ \\
\hline
\end{tabular}


Table V.2-6

TB Major Contributors

\begin{tabular}{|c|c|c|c|}
\hline MEASURE & EVENT & $\begin{array}{l}\text { IMPORTANCE } \\
\text { VALUE (POINT } \\
\text { ESTIMATE) }\end{array}$ & DESCRIPTION \\
\hline \multirow[t]{10}{*}{ Risk Reduction } & $R A-1 J$ & $23 E-6$ & Non-recovery of offsite \\
\hline & $R A-16 J$ & $12 E-6$ & $\begin{array}{l}\text { and onsite } A C \text { power in } \\
6 \text {-to- } 8 \text { hours }\end{array}$ \\
\hline & $A C P-D G N-L P-E D G 2$ & $11 E-6$ & DG hardware faults \\
\hline & $A C P-D G N-L P-E D G 3$ & $71 E-7$ & including common mode Beta \\
\hline & $A C P-O G N-M A-E D G 2$ & $41 E-7$ & factor. DG maintenance \\
\hline & $A C P-D G N-M A-E D G 3$ & $41 \mathrm{E}-7$ & unavalabılities \\
\hline & $B-A C P-L P-E D G S$ & $4 \mathrm{OE}-7$ & \\
\hline & ECW-XHE-FO-ECWPP & $43 E-7$ & $\begin{array}{l}\text { Fallure to restart ECW pump after } \\
\text { delayed loss of ESW cooling when } \\
\text { MOV-0498 is closed }\end{array}$ \\
\hline & IE-TLOSP & $2 O E-6$ & Loss of offsite power \\
\hline & IE-TRTRIP & $18 \mathrm{E}-7$ & Turbine trip \\
\hline \multirow[t]{3}{*}{ Risk Increase } & $E S W-P S F-L F-8$ & $36 E-3$ & Maıntenance unavallabılity \\
\hline & & & $\begin{array}{l}\text { of MOV-0498 valve in ESW } \\
\text { system }\end{array}$ \\
\hline & LOSP & $11 \mathrm{E}-4$ & $\begin{array}{l}\text { Subsequent loss of offsite } \\
\text { power after a trip }\end{array}$ \\
\hline \multirow[t]{9}{*}{ Uncertainty } & $R A-1 J$ & $20 \mathrm{E}-6$ & $\begin{array}{l}\text { Non-recovery of offsite } \\
\text { power in 6-to-8 hours }\end{array}$ \\
\hline & $A C P-D G N-L P-E D G 2$ & $83 E-7$ & DG hardware faults \\
\hline & $A C P-D G N-L P-E D G 3$ & $51 \mathrm{E}-7$ & including common mode \\
\hline & $A C P-D G N-M A-E D G 2$ & $54 \mathrm{E}-7$ & Beta factor, $D G$ \\
\hline & $A C P-D G N-M A-E D G 3$ & $69 E-7$ & maintenance \\
\hline & $B-A C P-L P-E D G S$ & $29 E-7$ & unavallabilities \\
\hline & LOSP & $52 E-7$ & $\begin{array}{l}\text { Subsequent loss of offsite } \\
\text { power after a trip }\end{array}$ \\
\hline & IE-TLOSP & $14 \mathrm{E}-6$ & Loss of offsite power \\
\hline & IE-TRTRIP & $14 E-7$ & Turbine trip \\
\hline
\end{tabular}

$\underset{\infty}{1}$ 


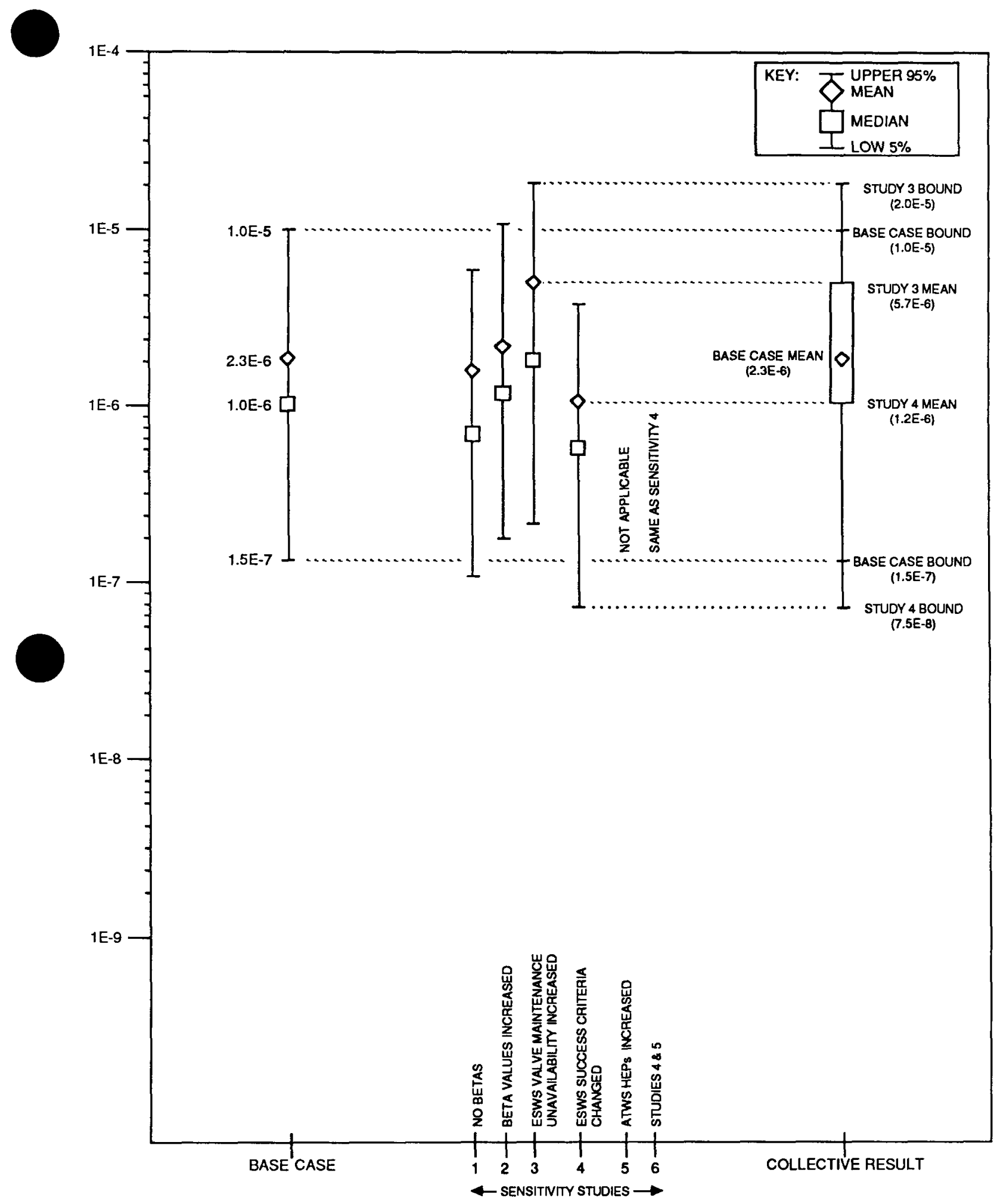

Figure V.2-2. Peach Bottom TB Core Damage Frequency. 
Table V.2-7

TB Importance Measure Results For Each Sensitivity

(as compared with base case results)

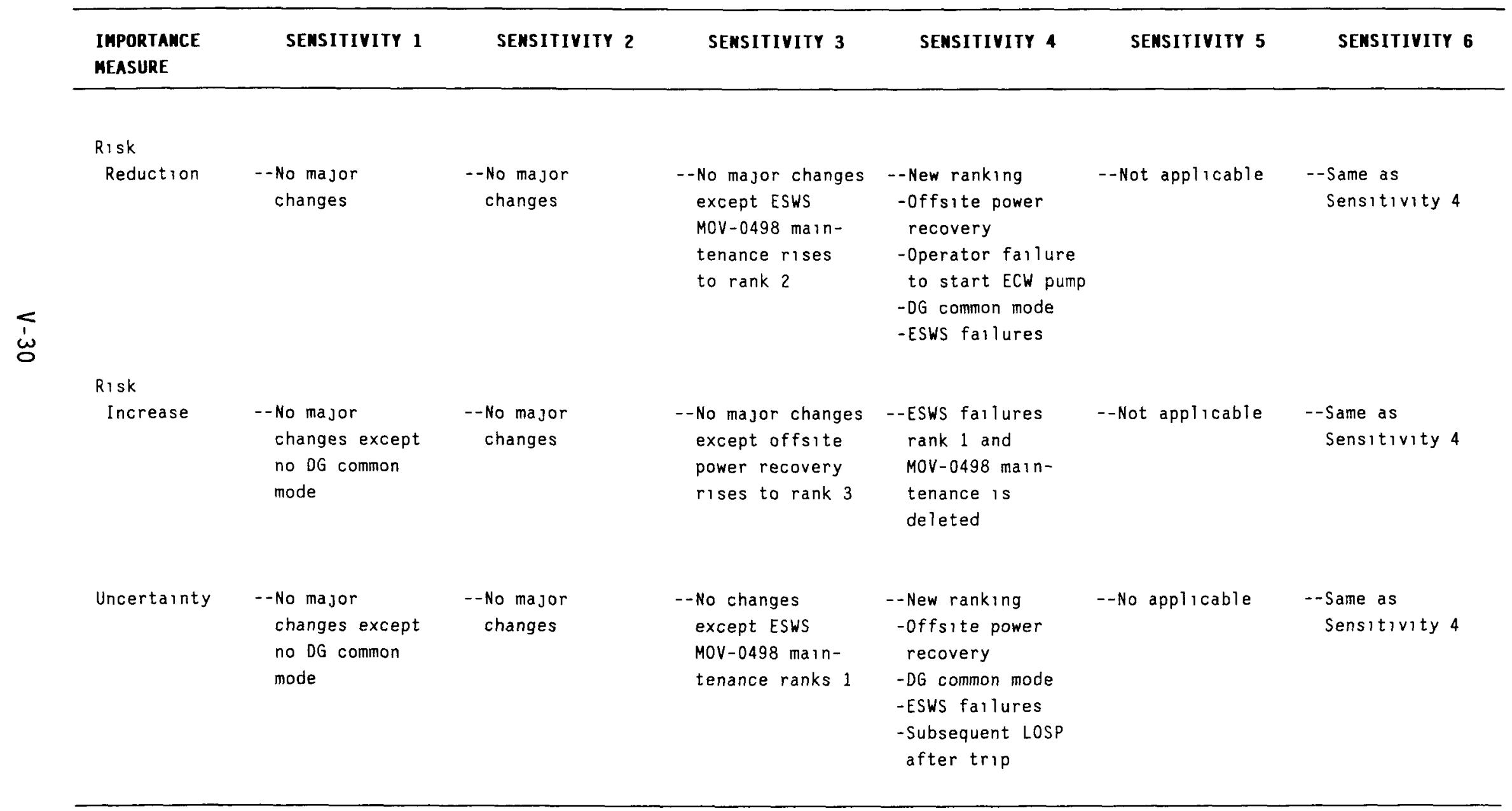




\section{$.2 .3 \quad$ Plant Damage State TCUX}

This plant damage state is characterized by an ATWS with either Main Steam Isolation Valve (MSIV) closure or an event with MSIVs initially open but subsequently closed. This isolates the primary system under high power conditions, thereby rapidly increasing the pressure and temperature conditions within containment since RHR cooling under these circumstances is inadequate. The Standby Liquid Control (SLC) system is started within four minutes into the accident, but initial HPCI failure under high power conditions and operator failure to rapidly depressurize the vessel (so that low pressure systems can be used immediately) lead to a core damage event. Subsequent containment failure may or may not occur depending on the need for, and success or failure of, containment venting.

The dominant sequences which contribute to this plant damage state are

$T * M S I V * R P S M * / S L C * / R X H P * / S R V S * L E V * D E P *(/$ YorY $)$,

$T * / M S I V * R P S M * F W * / S L C * / R X H P * / S R V S * L E V * D E P *(/ Y O r Y)$.

The collective frequency and the uncertainties of these four sequences (i.e., of plant damage state TCUX) follow:

$\begin{array}{ll}\text { Upper } 95 \text { Percent Bound } & 1.8 \mathrm{E}-6 \\ \text { Mean } & 4.8 \mathrm{E}-7 \\ \text { Median } & 6.0 \mathrm{E}-8 \\ \text { Lower } 5 \text { Percent Bound } & 3.3 \mathrm{E}-9 .\end{array}$

The dominant cut sets (excluding the "Y" event) for the collective set of MSIVs closed (MSIV) and MSIVs initially open (/MSIV) sequences are listed in Table V.2-8.

The only additional difference in the sequence cut sets is whether or not event " $Y$ " (containment venting) succeeds or fails. This assumes it is needed, even though RHR may be operable (i.e., Residual Heat Removal (RHR) has insufficient capacity), to handle non-condensibles and significant steam release. The split fraction for $Y$ success and failure is $0.1 / 0.9$ respectively.

The major contributors to the sequences in this plant damage state, on the basis of the importance measures analyzed, are listed (in approximate order of importance) in Table V.2-9.

Only one sensitivity study is applicable to this plant damage state: Study \#5 (described earlier). The effects of this sensitivity are summarized in Figure V.2-3 and Table V.2-10. Appendix B contains the detailed results for all the importance calculations.

Overall, the plant damage state frequency may be somewhat conservative because likely recovery action by the operator might succeed in mitigating the event after core damage has begun but before extensive core melt occurs. This would involve late vessel depressurization and then initiation of low pressure core cooling. wever, this does assume that high pressure in the containment and the subsequent ilure of containment would not prevent or otherwise fail late core cooling. 
Table V.2-8

TCUX Dominant cut sets

CUT SET

CUT SET

POINT ESTIMATE

FREQUENCY

IE-TRTRI I*CMS IVA *RPS-M*HCI -TDP-FS-20S37*DEP-XHE

IE-TMSIVC*RPS $-M * H C I-T D P-F S-20 S 37 * D E P-X H E$

IE-TLFW*RPS $-M^{*} H C I-T D P-F S-20 S 37^{*} D E P-X H E$

IE-TRTRI I*CMS IVA*RPS-M*HCI IDPP-MA-20S37*DEP-XHE

IE-TMSIVC*RPS $-M \star H C I-T D P-M A-20 S 37^{\star} D E P-X H E$

$1.1 \mathrm{E}-7$

$7.1 E-8$

$6.2 E-8$

IE-TLFW*RPS $-M^{*} H C I-T D P-M A-20 S 37^{\star} D E P-X H E$

$3.5 \mathrm{E}-8$

$2.3 E-8$

$2.1 \mathrm{E}-8$

IE-TIORV*CMSIVA*RPS-M*HCI-TDP-FS - 20S37*DEP-XHE

IE-TLOSP*RPS-M*HCI-TDP-FS-2OS37*DEP-XHE

IE-TRTRIP*CMSIVA*RPS-M*HCI-XHE-TL*DEP-XHE

6. $2 E-9$

$5.8 \mathrm{E}-9$

\begin{tabular}{|c|c|c|}
\hline TERM & DESCRIPTION & MEAI VALUE \\
\hline IE-TRTRIP & Turbine trip & $2.4 /$ year \\
\hline IE-TMSIVC & MSIV closure type initiators & 8.0E-1/year \\
\hline IE-TLFW & Loss of feedwater & $7.0 \mathrm{E}-1 /$ year \\
\hline IE-TIORV & Inadvertent open relief valve transient & 2.3E-1/year \\
\hline IE-TLOSP & Loss of offsite power & $7.0 E-2 /$ year \\
\hline CMSIVA & Subsequent closure of MSIVs & $5.0 E-1$ \\
\hline RPS - M & Mechanical fallure of all control rods & $1.0 E-5$ \\
\hline DEP-XHE & $\begin{array}{l}\text { Operator fallure to rapidly depressurize the } \\
\text { primary system }\end{array}$ & $2.13 \mathrm{E}-1$ \\
\hline HCI -TDP-FS-20S37 & HPCI falls to start & $4.84 E-2$ \\
\hline HCI -TDP-MA-20S37 & HPCI unavallable because of maintenance & $1.6 E-2$ \\
\hline HCI $-X H E-T L$ & Operator controls level with HPCI too low & $2.66 \mathrm{E}-3$ \\
\hline
\end{tabular}


Table V.2-9

TCuX Major Contributors

\begin{tabular}{|c|c|c|c|}
\hline MEASURE & EVENT & $\begin{array}{l}\text { IMPORTAUCE } \\
\text { VALUE (POINT } \\
\text { ESTIMATE) }\end{array}$ & DESCRIPTION \\
\hline \multirow[t]{6}{*}{ Risk Reduction } & RPS - M & $3.5 E-7$ & Mechanical failure of control rods \\
\hline & $D E P-X H E$ & $3.5 E-7$ & Operator fails to depressurize \\
\hline & HCI I TOP-FS-20S37 & $2.5 \mathrm{E}-7$ & HPCI fails to start \\
\hline & IE-TRTRIP & $1.5 E-7$ & Turbine trip \\
\hline & IE-TMSIVC & $9.8 \mathrm{E}-8$ & MSIV closure \\
\hline & IE-TLFW & $8.6 \mathrm{E}-8$ & Loss of feedwater \\
\hline Risk Increase & RPS-M & $3.5 E-2$ & Mechanical failure of control rods \\
\hline \multirow[t]{7}{*}{ Uncertainty } & RPS-M & $6.2 E-7$ & Mechanical failure of control rods \\
\hline & DEP-XHE & $3.2 E-7$ & Operator fails to depressurize \\
\hline & HCI -TDP-MA-20S37 & $2.3 E-7$ & HPCI maintenance unavailability \\
\hline & HCI-TDP-FS-20S37 & $2.0 E-7$ & HPCI fails to start \\
\hline & IE-TRTRIP & $1.1 E-7$ & Turbine trip \\
\hline & IE-TMSIVC & $7.0 E-8$ & MSIV closure \\
\hline & IE-TLFW & $6.2 E-8$ & Loss of feedwater \\
\hline
\end{tabular}




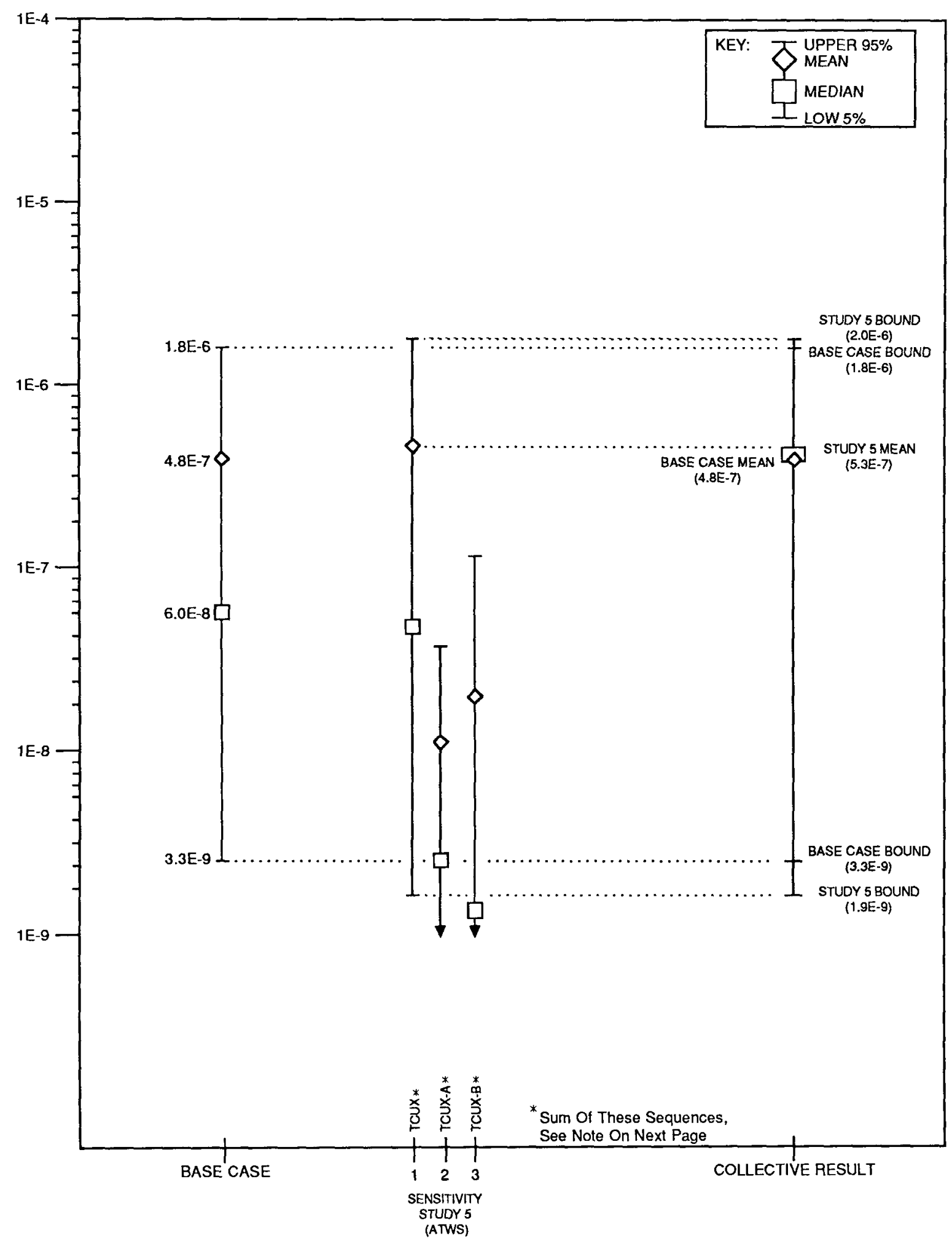

Figure V.2-3. Peach Bottom TCUX Core Damage Frequency. 
Sensitivity \#5 causes two additional sequences to become greater than 1.0E-8. The first sequence is characterized by the operator's successfully depressurizing after HPCI failure but core damage results because of controlling level too low. This occurs because of shutting off all low pressure injection or otherwise controlling the flow rate too low in an attempt to keep the water level low in the reactor vessel (this sequence is designated TCUX-A on the figure). The second sequence is characterized by the operator's failing to inhibit ADS followed by controlling level too low for the reasons described above (this sequence is designated TCUX-B on the figure). Venting failure occurs in both sequences. The collective result is approximated by adding the means for Study \#5 and estimating that the upper and lower bounds for the three summed sequences can be approximated by the bounds shown by the TCUX sensitivity case (i.e., the new sequences are relatively insignificant). 
Table V.2-10

TCUX Importance Measure Results For Each Sensitivity

(as compared with base case results)

\begin{tabular}{|c|c|c|c|}
\hline $\begin{array}{l}\text { IMPORTANCE } \\
\text { MEASURE }\end{array}$ & Tcux & $\begin{array}{c}\text { SEMSITIVITY } 5 \\
\text { IcuX-A }[\text { see Note }(a)]\end{array}$ & TCUX-B $[$ see Note $(a)]$ \\
\hline Risk Reduction & - -No major changes & $\begin{array}{l}\text {--Ranking } \\
\text {-RPS mechanical control rod fallure } \\
\text {-Operator controls low pressure } \\
\text { injection too low } \\
\text {-HPCI-fallure to start }\end{array}$ & $\begin{array}{l}\text {--Rankıng } \\
\text {-RPS mechanical control rod fallure } \\
\text {-Operator controls low pressure } \\
\text { pressure injection } \\
\text {-too low } \\
\text {-Operator falls to defeat ADS }\end{array}$ \\
\hline $\begin{array}{l}\text { Risk } \\
\text { Increase }\end{array}$ & --No major changes & $\begin{array}{l}\text {--Rankıng } \\
\text {-As above }\end{array}$ & $\begin{array}{l}\text { - Rankıng } \\
\text {-As above }\end{array}$ \\
\hline Uncertainty & --No major changes & $\begin{array}{l}\text {--Ranking } \\
\text {-RPS mechanical control rod fallure } \\
\text {-HPCI fallure to start, } \\
\text { maintenance } \\
\text {-SLC success }\end{array}$ & $\begin{array}{l}\text {--Ranking } \\
\text {-RPS mechanical control rod fallure } \\
\text {-Operator fails to defeat ADS } \\
\text {-SLC success }\end{array}$ \\
\hline
\end{tabular}

NOTE

(a) Sensitivity 5 causes 2 additional sequences to become greater than $10 E-8$ The first is characterized by the operator successfully depressurizing after HPCI fallure but core damage results because of controlling level too low This occurs due to shutting off all low pressure injection or otherwise controlling the flow rate too low in an attempt to keep the water level low in the reactor vesse? (this sequence is designated TCUX-A on the figure) The second is characterized by the operator fallure to inhibit ADS followed by subsequent too low a level control for the reasons described above (this sequence is designated TCUX-B on the figure) The collective result is approximated by adding the means for Study 5 and estimating that the upper and lower bounds for the three summed sequences can be approximated by the bounds shown by the TCux sensitivity case 


\section{.2.4 Plant Damage State TCSR}

This plant damage state is characterized by an ATWS with either MSIV closure or an event with MSIVs initially open but subsequently closed. This isolates the primary system under high power conditions, thereby rapidly increasing the pressure and temperature conditions within containment since RHR cooling under these circumstances is inadequate.

Timely SLC system start is not performed or it fails because the SLC system is left in an inappropriate configuration after the last test. Core cooling is maintained first by HPCI and then by low pressure cooling systems when HPCI fails in fifteen minutes because of high pool temperature. Venting of the containment (event " $Y$ ") is not successful. The description up to this point defines plant damage state TCSR as it was used by the containment analysts. However, because the condition of the containment must first be determined to see if core cooling can be maintained, three substates had to be defined (based on preliminary analyses by the containment analysts) to describe the ways core damage could ultimately occur. (In other words, the status of containment is a feedback to how core damage occurs.) The three general containment conditions provided by the containment analysts included (a) containment leak failures, (b) no containment failure at least up until vessel breach, and (c) catastrophic containment failure. Cases (a) and (b) preclude continued operation of the low pressure cooling systems. This is because maximum air pressure to the SRVs is -100-to-125 psig which is under the estimated $150+$ psig pressure for containment failure. Therefore, the vessel remains pressurized and all core cooling is lost. Case (c) depressurizes the containment but the saturated conditions in the pool cause ailure of Low Pressure Core Spray (LPCS) and RHR pumps. Condensate and High ressure Service Water (HPSW) are either not available or the operator fails to start their injection into the core; core damage results.

Because of the unique aspects of the containment failure modes and their effects on continued core cooling, the sequences (there are six in all) representing each scenario are handled by defining three groups of sequences in this section. These dominant sequences are

Substate TCSRX2 --

$T * M S I V * R P S M * S L C * / R X H P * / D E P * /$ LPIN*Y*Containment Leakage +

$T * / M S I V * R P S M * F W * S L C * / R X H P * / D E P * / L P I N * Y *$ Containment Leakage,

Substate TCSRX3 --

$T * M S I V * R P S M * S L C * / R X H P * / D E P * / L P I N * Y *$ No Containment Failure +

$T * / M S I V * R P S M * F W * S L C * / R X H P * / D E P * / L P I N * Y *$ No Containment Failure,

Substate TCSRV23 --

$T * M S I V * R P S M * S L C * / R X H P * / D E P * / L P I N * Y$

*Containment Failure with Loss of Injection +

$T * / M S I V * R P S M * F W * S L C * / R X H P * / D E P * / L P I N * Y$

*Containment Failure with Loss of Injection. 
The approximate mean frequency for plant damage state TCSR is $3.1 E-7$. The frequencies and the uncertainties of the three groups of sequences follow:

\section{ICSRX2}

$\begin{array}{ll}\text { Upper } 95 \text { Percent Bound } & 9.4 \mathrm{E}-7 \\ \text { Mean } & 2.4 \mathrm{E}-7 \\ \text { Median } & 5.4 \mathrm{E}-8 \\ \text { Lower } 5 \text { Percent Bound } & <1 \mathrm{E}-9\end{array}$

\section{$\underline{\operatorname{TCSRX3}}$}

$\begin{array}{ll}\text { Upper } 95 \text { Percent Bound } & 2.7 \mathrm{E}-7 \\ \text { Mean } & 6.3 \mathrm{E}-8 \\ \text { Median } & 6.5 \mathrm{E}-9 \\ \text { Lower } 5 \text { Percent Bound } & <1 \mathrm{E}-9\end{array}$

\section{TCSRV23}

$\begin{array}{ll}\text { Upper } 95 \text { Percent Bound } & 1.4 \mathrm{E}-7 \\ \text { Mean } & 2.5 \mathrm{E}-8 \\ \text { Median } & 2.9 \mathrm{E}-9 \\ \text { Lower } 5 \text { Percent Bound } & <1 \mathrm{E}-9\end{array}$

The dominant cut sets for each of the three groups of sequences are listed in Tables V.2-11 to V.2-13.

The major contributors to the sequences in this plant damage state, on the basis of the importance measures analyzed, are listed (in approximate order of importance) in Table V.2-14.

Only one sensitivity study is applicable to this plant damage state: Study \#5 (described earlier). The effects of this sensitivity are summarized in Figure V.2-4. No major changes occur in the importance measures as a result of the sensitivity. Appendix $B$ contains the detailed results for al1 the importance calculations.

Note that the SLC success criterion which applies to all the sequences (i.e., the need to start within four minutes) may make the sequence frequencies somewhat conservative. 
Table V.2-ll

TCSR (Substate TCSRX2) Dominant Cut Sets

\begin{tabular}{|c|c|c|}
\hline CUT SET & \multicolumn{2}{|c|}{$\begin{array}{l}\text { CUT SET } \\
\text { POINT ESTIMATE } \\
\text { FREQUENCY }\end{array}$} \\
\hline \multicolumn{2}{|c|}{ IE-TRTRIP*CMSIVA*RPS-M*SLC-XHE-FS*VENT-XHE-TC*CONTAINMENT LEAKAGE } & 1.1E-7 \\
\hline \multicolumn{2}{|c|}{ IE-TMSIVC*RPS-M*SLC-XHE-FS*VENT-XHE-TC*CONTAINMENT LEAKAGE } & $7.4 \mathrm{E}-8$ \\
\hline \multicolumn{2}{|c|}{ IE-TLFW*RPS $-M^{*} S L C-X H E-F S^{*} V E N T-X H E-T C^{\star}$ CONTAINMENT LEAKAGE } & $6.5 \mathrm{E}-8$ \\
\hline \multicolumn{2}{|c|}{ IE-TRTRIP*CMSIVA*RPS-M*SLC-XHE-REL*VENT-XHE-TC*CONTAINMENT LEAKAGE } & $3.2 E-8$ \\
\hline TERH & DESCRIPTION & MEAN vaLUE \\
\hline IE-TRTRIP & Turbine trip & $2.4 /$ year \\
\hline IE-TMSIVC & MSIV closure type initiators & 8.0E-1/year \\
\hline IE-TLFW & Loss of feedwater & 7.0E-1/year \\
\hline CMSIVA & Subsequent closure of MSIVs & $5.0 E-1$ \\
\hline RPS $-M$ & Mechanical failure of all control rods & $1.0 E-5$ \\
\hline$S L C-X H E-F S$ & Operator failure to start SLC by 4 minutes & $3.38 \mathrm{E}-2$ \\
\hline SLC-XHE-REL & after test & $1.0 E-2$ \\
\hline VENT-XHE-TC & Failure to vent containment & $9.0 \mathrm{E}-1$ \\
\hline CONTAINMENT LEAKAGE & Containment leaks & $\sim 0.45$ \\
\hline
\end{tabular}


Table V.2-12

TCSR (Substate TCSRX3) Dominant Cut Sets

\begin{tabular}{|c|c|c|c|}
\hline \multicolumn{2}{|l|}{ CUT SET } & \multicolumn{2}{|c|}{$\begin{array}{l}\text { CUT SET } \\
\text { POIMT ESTIMATE } \\
\text { FREQUEMCY }\end{array}$} \\
\hline \multicolumn{2}{|c|}{ IE-TRTRI $P^{\star} C M S I V A^{\star} R P S-M^{\star} S L C-X H E-F S^{\star} V E N T-X H E-T C^{*} N O$ CONTAINMENT FAILURE } & \multicolumn{2}{|l|}{$2.5 \mathrm{E}-8$} \\
\hline \multicolumn{2}{|c|}{ IE-TMSIVC*RPS-M*SLC-XHE-FS*VENT-XHE-TC*NO CONTAINMENT FAILURE } & \multicolumn{2}{|l|}{$1.6 \mathrm{E}-8$} \\
\hline \multicolumn{2}{|c|}{ IE-TLFW*RPS-M*SLC-XHE-FS*VENT-XHE-TC*NO CONTAINMENT FAILURE } & \multicolumn{2}{|l|}{$1.4 \mathrm{E}-8$} \\
\hline \multicolumn{2}{|c|}{ IE-TRTRIP*CMSIVA*RPS-M*SLC-XHE-REL*VENT-XHE-TC*NO CONTAINMENT FAILURE } & \multicolumn{2}{|l|}{$7.3 E-9$} \\
\hline TERM & \multicolumn{2}{|l|}{ DESCRIPTION } & MEAM VALUE \\
\hline IE-TRTRIP & \multicolumn{2}{|l|}{ Turbine trip } & $2.4 /$ year \\
\hline IE-TMSIVC & \multicolumn{2}{|l|}{ MSIV closure type initiators } & $8.0 E-1 /$ year \\
\hline IE-TLFW & \multicolumn{2}{|l|}{ Loss of feedwater } & $7.0 \mathrm{E}-1 /$ year \\
\hline CMSIVA & \multicolumn{2}{|c|}{ Subsequent closure of MSIVs } & $5.0 \mathrm{E}-1$ \\
\hline RPS-M & \multicolumn{2}{|c|}{ Mechanical failure of all control rods } & $1.0 E-5$ \\
\hline SLC-XHE-FS & & $3.38 E-2$ \\
\hline SLC-XHE-REL & \multicolumn{2}{|c|}{$\begin{array}{l}\text { SLC fails because of failure to realign properly } \\
\text { after test }\end{array}$} & $1.0 E-2$ \\
\hline VENT $-X H E-T C$ & \multicolumn{2}{|c|}{ Failure to vent containment } & $9.0 E-1$ \\
\hline NO CONTAINMENT FAILURE & \multicolumn{2}{|l|}{ Containment does not fail } & -0.1 \\
\hline
\end{tabular}


Table V.2-13

TCSR (Substate TCSRV23) Dominant cut sets

\begin{tabular}{|c|c|c|}
\hline CUT SET & \multicolumn{2}{|c|}{$\begin{array}{l}\text { CUT SET } \\
\text { POIMT ESTIHATE } \\
\text { FREQUENCY }\end{array}$} \\
\hline \multicolumn{3}{|c|}{ IE-TRTRIP*CMS IVA*RPS $-M^{*} S L C-X H E-F S^{*} V E N T-X H E-T C$} \\
\hline \multicolumn{3}{|c|}{${ }^{\star}$ CONTAINMENT FAILURE*COND-HPSW-XHE-TC } \\
\hline \multicolumn{3}{|c|}{ IE-TMS IVC*RPS - M*SLC-XHE-FS*VENT-XHE-TC } \\
\hline${ }^{*}$ CONTAINMENT FAILURE*COND & XHE-TC & \\
\hline \multicolumn{3}{|c|}{ IE-TLFW*RPS-M*SLC-XHE-FS*VENT-XHE-TC } \\
\hline${ }^{\star}$ CONTAINMENT FAILURE*COND & $6.5 E-9$ & \\
\hline \multicolumn{3}{|c|}{ IE-TRTRIP*CMSIVA*RPS $-M * S L C-X H E-R E L * V E N T-X H E-T C$} \\
\hline TERY & DESCRIPTIOH & MEAI YALUE \\
\hline IE-TRTRIP & Turbine trip & $2.4 /$ year \\
\hline IE-TMSIVC & MSIV closure type initiators & 8. OE-1/year \\
\hline IE-TLFW & Loss of feedwater & 7. OE-1/year \\
\hline CMSIVA & Subsequent closure of MSIVs & $5.0 E-1$ \\
\hline RPS $-M$ & Mechanical failure of all control rods & 1.0E-5 \\
\hline SLC-XHE-FS & Operator failure to start SLC by 4 minutes & $3.38 \mathrm{E}-2$ \\
\hline SLC-XHE-REL & $\begin{array}{l}\text { SLC fails because of failure to realign properly } \\
\text { after test }\end{array}$ & $1.0 E-2$ \\
\hline VENT-XHE-TC & Failure to vent containment & $9.0 E-1$ \\
\hline CONTAINMENT FAILURE & Containment fails & $\sim 0.45$ \\
\hline COND-HPSW-XHE-TC & Operator failure to inject with Condensate or HPSW & $1.0 E-1$ \\
\hline
\end{tabular}


Table V.2-14

TCSR Major Contributors

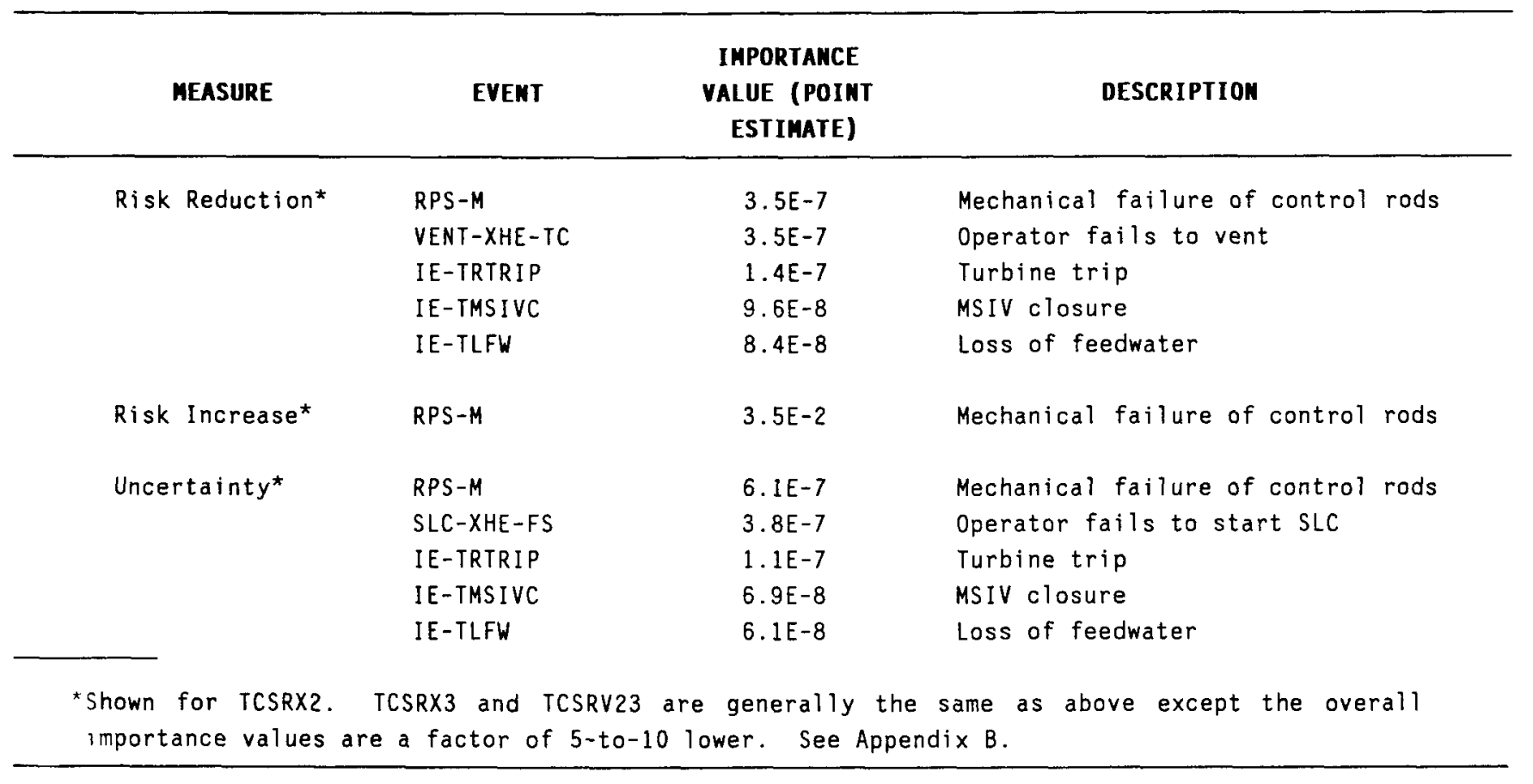




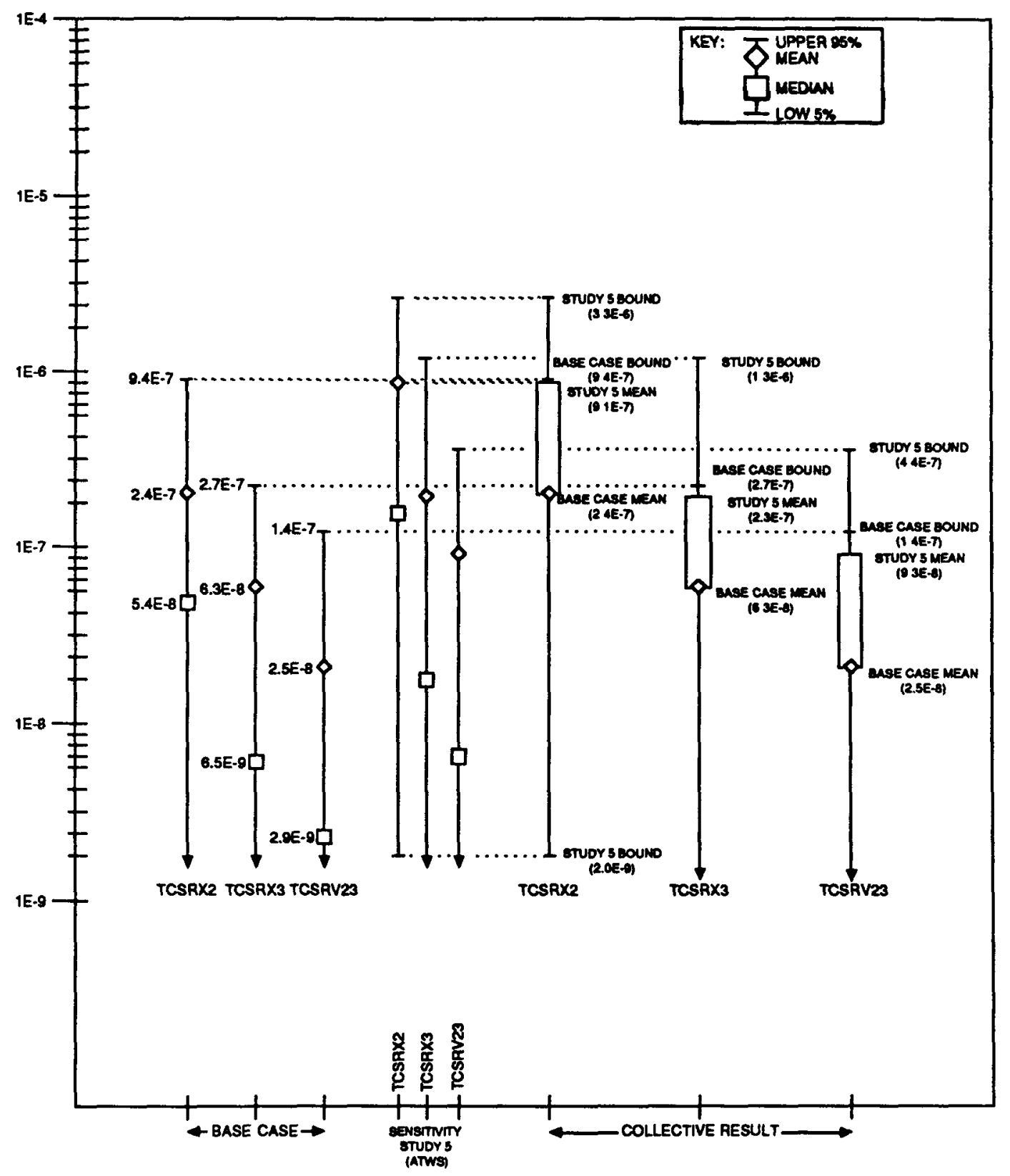

Figure V.2-4. Peach Bottom Core Damage Frequencies of TCSRX2, TCSRX3, TCSRV23 in Damage state TCSR. 


\section{V.2.5 Plant Damage State TBUP}

This plant damage state is characterized by transients leading to a station blackout as a result of a variety of $A C / D C$ power failures as well as failures of HPCI and RCIC in the short term. An SRV sticks open, thereby reducing primary system pressure. Without restoration of power in about thirty minutes, core damage results because all coolant injection has been lost. Core degradation occurs under low pressure conditions because of the stuck-open SRV. In general, this plant damage state is quite similar to plant damage state TBUX except for the stuck-open valve and the resulting low pressure in the reactor vessel during core degradation.

The dominant sequences which contribute to this plant damage state are

T1-T2-T3(Q) PU1U2W2W3V1V2V3V4,

T1-T2-T3(Q)PU1U2W2W3V1V2V3V4Y.

The collective frequency and the uncertainties of both sequences (i.e., of plant damage state TBUP) follow:

$\begin{array}{ll}\text { Upper } 95 \text { Percent Bound } & 8.0 \mathrm{E}-7 \\ \text { Mean } & 2.0 \mathrm{E}-7 \\ \text { Median } & 9.5 \mathrm{E}-8 \\ \text { Lower } 5 \text { Percent Bound } & 1.4 \mathrm{E}-8 .\end{array}$

The dominant cut sets for bath sequences are 1 isted in Table V.2-15.

The only difference in the two sequences is the split fraction for $Y$ success and failure which distinguish the two sequences. This fraction is $0.1 / 0.9$ respectively.

The major contributors to the sequences in this plant damage state, on the basis of the importance measures analyzed, are listed (in approximate order of importance) in Table V.2-16.

The effects of the six sensitivity studies (described earlier) on plant damage state TBUP are summarized by Figure V.2-5 and Table V.2-17. Appendix B contains the detailed results for all the importance calculations. Appendix $C$ contains important additional information regarding TBUP.

It should be noted that the plant damage state frequency may be conservative based on the same discussion provided for TBUX. In addition, the assumption that SRVs will be demanded during all the initiators indicated may be conservative. 

Table V.2-16

TBUP Major Contributors

\begin{tabular}{|c|c|c|c|}
\hline MEASURE & EVEMT & $\begin{array}{l}\text { IMPORTANCE } \\
\text { VALUE (POINT } \\
\text { ESTIMATE) }\end{array}$ & DESCRIPTION \\
\hline \multirow{6}{*}{ Risk Reduction } & SORV & $22 E-7$ & Stuck-open SRV \\
\hline & $D C P-B A T-L P-B 2$ & $22 E-7$ & Collectively represent \\
\hline & $B-D C P-L P-B A T S$ & $2.1 E-7^{\}}$ & common mode fallure of $D C$ power \\
\hline & LOSP & $29 E-8$ & $\begin{array}{l}\text { Subsequent loss of offsite power } \\
\text { after a trip }\end{array}$ \\
\hline & IE-TLOSP & $19 \mathrm{E}-7$ & Loss of offsite power \\
\hline & IE-TRTRIP & $18 E-8$ & Turbine trip \\
\hline \multirow[t]{5}{*}{ Risk Increase } & $D C P-B A T-L P-B 2$ & $16 E-4$ & Collectively represent \\
\hline & $B-D C P-L P-B A T S$ & $51 E-6^{3}$ & common mode fallure of $D C$ power \\
\hline & LOSP & $11 E-5$ & $\begin{array}{l}\text { Subsequent loss of offsite power } \\
\text { after a trip }\end{array}$ \\
\hline & $E S W-P S F-L F-8$ & $82 \mathrm{E}-6$ & $\begin{array}{l}\text { Malntenance unavallability of MOV-0498 } \\
\text { valve in ESW system }\end{array}$ \\
\hline & SORV & $4.2 E-6$ & Stuck-open SRV \\
\hline \multirow[t]{6}{*}{ Uncertainty } & SORV & $1.6 \mathrm{E}-7$ & Stuck-open SRV \\
\hline & $D C P-B A T-L P-B 2$ & $1.6 \mathrm{E}-7$ & Collectively represent \\
\hline & $B-D C P-L P-B A T S$ & $1.6 E-7\}$ & common mode faliure of $D C$ power \\
\hline & LOSP & $5.1 E-8$ & $\begin{array}{l}\text { Subsequent loss of offsite power } \\
\text { after a trip }\end{array}$ \\
\hline & IE-TLOSP & $14 E-7$ & Loss of offsite power \\
\hline & IE-TRTRIP & $1.3 E-8$ & Turbine trip \\
\hline
\end{tabular}




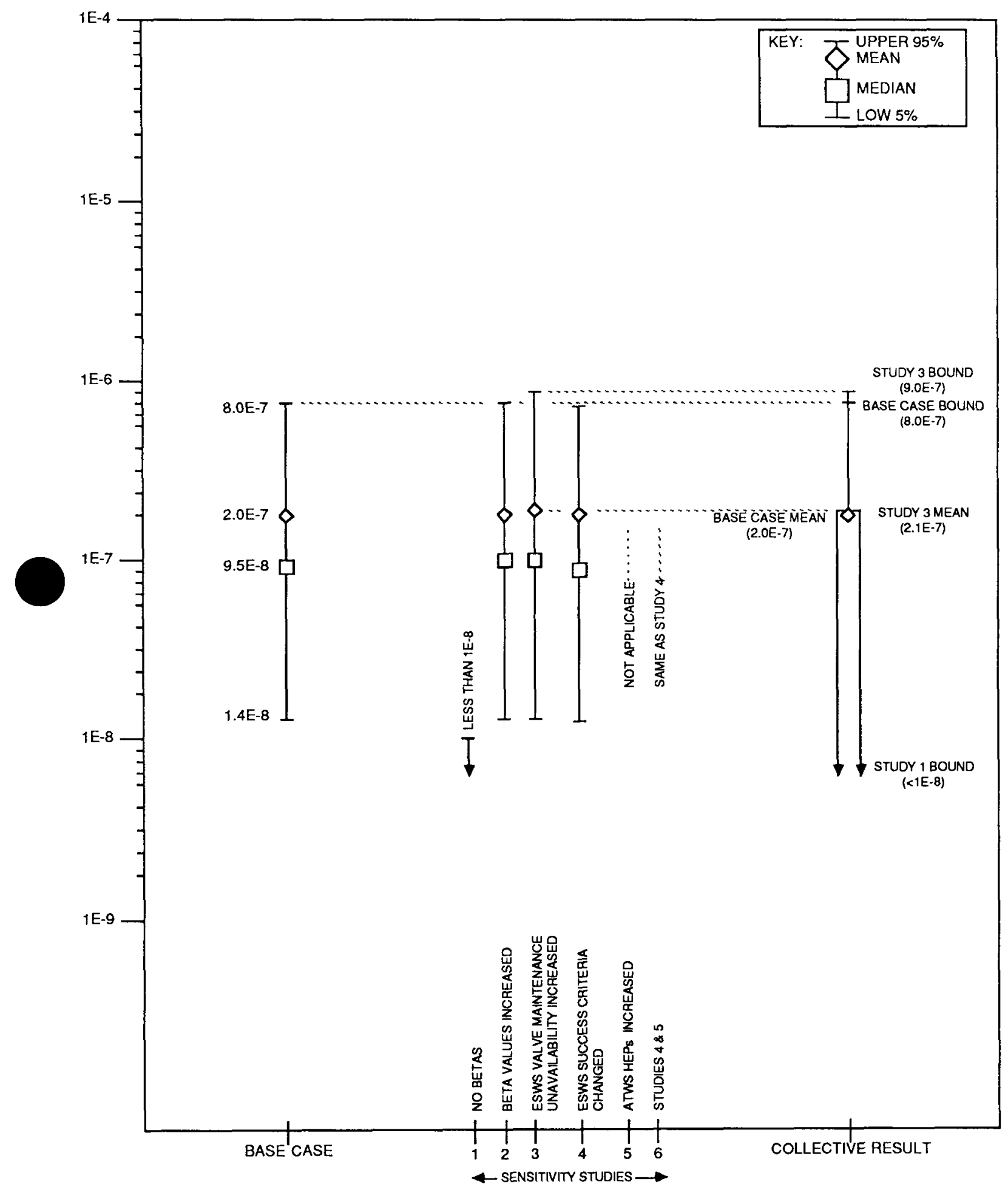

Figure V.2-5. Peach Bottom TBUP Core Damage Frequency. 
Table V.2-17

TBUP Importance Measure Results For Each Sensitivity

(as compared with base case results)

\begin{tabular}{|c|c|c|c|c|c|c|}
\hline $\begin{array}{l}\text { IMPORTANCE } \\
\text { MEASURE }\end{array}$ & SEMSITIVITY 1 & SENSITIVITY 2 & SENSITIVITY 3 & SERSITIVITY 4 & SEMSITIVITY 5 & SEMSIIIVIIY 6 \\
\hline \multicolumn{7}{|l|}{ Risk } \\
\hline Reduction. & $\begin{array}{l}- \text { Sequence drops } \\
\text { to }<1 \mathrm{E}-8\end{array}$ & $\begin{array}{l}\text { - No major } \\
\text { changes }\end{array}$ & $\begin{array}{c}\text { - No major } \\
\text { changes }\end{array}$ & $\begin{array}{c}\text { - No major } \\
\text { changes }\end{array}$ & - Not applicable & $\begin{array}{l}- \text {-Same as } \\
\quad \text { Sensitivity } 4\end{array}$ \\
\hline \multicolumn{7}{|l|}{ Risk } \\
\hline Increase: & $\begin{array}{l}- \text { - Sequence drops } \\
\text { to }<1 \mathrm{E}-8\end{array}$ & $\begin{array}{l}\text { - No major } \\
\text { changes }\end{array}$ & $\begin{array}{c}\text { - No major } \\
\text { changes }\end{array}$ & $\begin{array}{l}- \text {-ESW MOV-0498 } \\
\text { maintenance } \\
\text { drops signifi- } \\
\text { cantiy: DG-CM } \\
\text { among top events }\end{array}$ & - Not applicable & $\begin{array}{l}- \text {-Same as } \\
\text { Sensitivity } 4\end{array}$ \\
\hline Uncertainty: & $\begin{array}{c}-- \text { Sequence drops } \\
\text { to }<1 \mathrm{E}-8\end{array}$ & $\begin{array}{c}\text { - No major } \\
\text { changes }\end{array}$ & $\begin{array}{l}\text { - Maintenance of } \\
\text { ESW MOV-0498 } \\
\text { rises to just } \\
\text { among the domı- } \\
\text { nant events }\end{array}$ & $\begin{array}{c}\text { - No major } \\
\text { changes }\end{array}$ & - Not applicable & $\begin{array}{l}\text { - - Same as } \\
\quad \text { Sensitivity } 4\end{array}$ \\
\hline
\end{tabular}


This plant damage state is characterized by an ATWS with either MSIV closure or an event with MSIVs initially open but subsequently closed. This isolates the primary system under high power conditions, thereby rapidiy increasing the pressure and temperature conditions within containment since RHR cooling under these circumstances is inadequate. Timely start of the SLC system is not performed or it fails from being left in an inappropriate configuration after the last test of the system. Core cooling is maintained for a short time ( $-1 / 4$ hour $)$ before HPCI fails because of high pool temperature. The operator then fails to rapidly depressurize (so that low pressure systems can be used) which leads to core damage. Subsequent containment failure may or may not occur depending on the need for, and success or failure of, containment venting.

The dominant sequences which contribute to this plant damage state are

$$
\begin{aligned}
& T * M S I V * R P S M * S L C * / R X H P \star D E P *(/ Y \text { Yor } Y), \\
& T * / M S I V * R P S M * F W * S L C * / R X H P * D E P *(/ Y \text { OrY } Y) .
\end{aligned}
$$

The collective frequency and the uncertainties of these four sequences (i.e., of plant damage state T(SX) follow:

$\begin{array}{ll}\text { Upper } 95 \text { Percent Bound } & 6.9 \mathrm{E}-7 \\ \text { Mean } & 1.7 \mathrm{E}-7 \\ \text { Median } & 3.4 \mathrm{E}-8 \\ \text { Lower } 5 \text { Percent Bound } & <1 \mathrm{E}-9 .\end{array}$

The dominant cut sets (excluding the "Y" event) for the collective set of MSIVs closed (MSIV) and MSIVs initially open (/MSIV) sequences are listed in Table V.2-18.

The only additional difference in the sequence cut sets is whether or not event " $Y$ " (containment venting) succeeds or fails. This assumes it is needed even though RHR may be operable (i.e., RHR has insufficient capacity) to handle non-condensibles and significant steam release. The split fraction for $y$ success and failure is $0.1 / 0.9$ respectively.

The major contributors to the sequences in this plant damage state, on the basis of the importance measures analyzed, are listed (in approximate order of importance) in Table V.2-19.

Only one sensitivity study is applicable to this plant damage state: Study \#5 (described earlier). The effects of this sensitivity are summarized in Figure V.2-6. No major changes occur in the importance measures as a result of the sensitivity. Appendix B contains the detailed results for all the importance measure calculations. 
Table V.2-18

TCSX Dominant Cut sets

CUT SEI

CUT SET POINT ESTIMATE

FREQUENCY

IE-TRTRIP*CMSIVA*RPS-M*SLC-XHE-FS*DEP-XHE

$74 E-8$

IE-TMSIVC*RPS $-M^{\star}$ *SLC-XHE-FS*DEP-XHE

$49 E-8$

IE $-T L F W^{*} R P S-M * S L C-X H E-F S^{*} D E P-X H E$

$43 E-8$

IE-TRTRIP*CMS IVA*RPS-M*SLC-XHE-REL ${ }^{\star} D E P-X H E$

$22 E-8$

\begin{tabular}{lll}
\hline \multicolumn{1}{c}{ IERM } & \multicolumn{1}{c}{ DESCRIPIION } & MEAN VALUE \\
\hline IE-TRTRIP & Turbine Trip & 2 4/year \\
IE-TMSIVC & MSIV closure type initiators & 8 OE-1/year \\
IE-TLFW & Loss of Feedwater & 7 OE-1/year \\
CMSIVA & Subsequence closure of MSIVs & 5 OE-1 \\
RPS-M & Mechanical fallure of all control rods & 10 OE-5 \\
SLC-XHE-FS & Operator fallure to start SLC by 4 minutes & $338 E-2$ \\
SLC-XHE-REL & SLC falls because of failure to realign properly \\
after test & 1 OE-2 \\
DEP-XHE & Operator fallure to rapidly depressurize the & \\
& primary system & $213 E-1$ \\
\hline
\end{tabular}

í

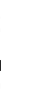


Table V.2-19

TCSX Major Contributors

\begin{tabular}{|c|c|c|c|}
\hline MEASURE & EVENT & $\begin{array}{c}\text { IMPORTANCE } \\
\text { VALUE (POINT } \\
\text { ESTIMATE) }\end{array}$ & DESCRIPTION \\
\hline \multirow[t]{6}{*}{ Risk Reduction } & RPS - M & $23 E-7$ & $\begin{array}{l}\text { Mechanical fallure of } \\
\text { control rods }\end{array}$ \\
\hline & DEP-XHE & $23 E-7$ & $\begin{array}{l}\text { Operator falls to } \\
\text { depressurize }\end{array}$ \\
\hline & SLC-XHE-FS & $18 E-7$ & $\begin{array}{l}\text { Operator falls to start } \\
\text { SLC }\end{array}$ \\
\hline & IE-TRTRIP & $96 \mathrm{E}-8$ & Turbine trip \\
\hline & IE-TMSIVC & $64 E-8$ & MSIV closure \\
\hline & IE-TLFW & $56 E-8$ & Loss of feedwater \\
\hline Risk Increase & RPS-M & $23 E-2$ & $\begin{array}{l}\text { Mechanical fallure of } \\
\text { control rods }\end{array}$ \\
\hline \multirow[t]{6}{*}{ Uncertainty } & RPS-M & $42 E-7$ & $\begin{array}{l}\text { Mechanical fallure of } \\
\text { control rods }\end{array}$ \\
\hline & SLC-XHE-FS & $25 E-7$ & $\begin{array}{l}\text { Operator falls to start } \\
\text { SLC }\end{array}$ \\
\hline & DEP-XHE & $21 E-7$ & $\begin{array}{l}\text { Operator falls to } \\
\text { depressurize }\end{array}$ \\
\hline & IE-TRTRIP & $73 E-8$ & Turbine trip \\
\hline & IE-TMSIVC & $46 E-8$ & MSIV closure \\
\hline & $I E-T L F W$ & $41 E-8$ & Loss of feedwater \\
\hline
\end{tabular}




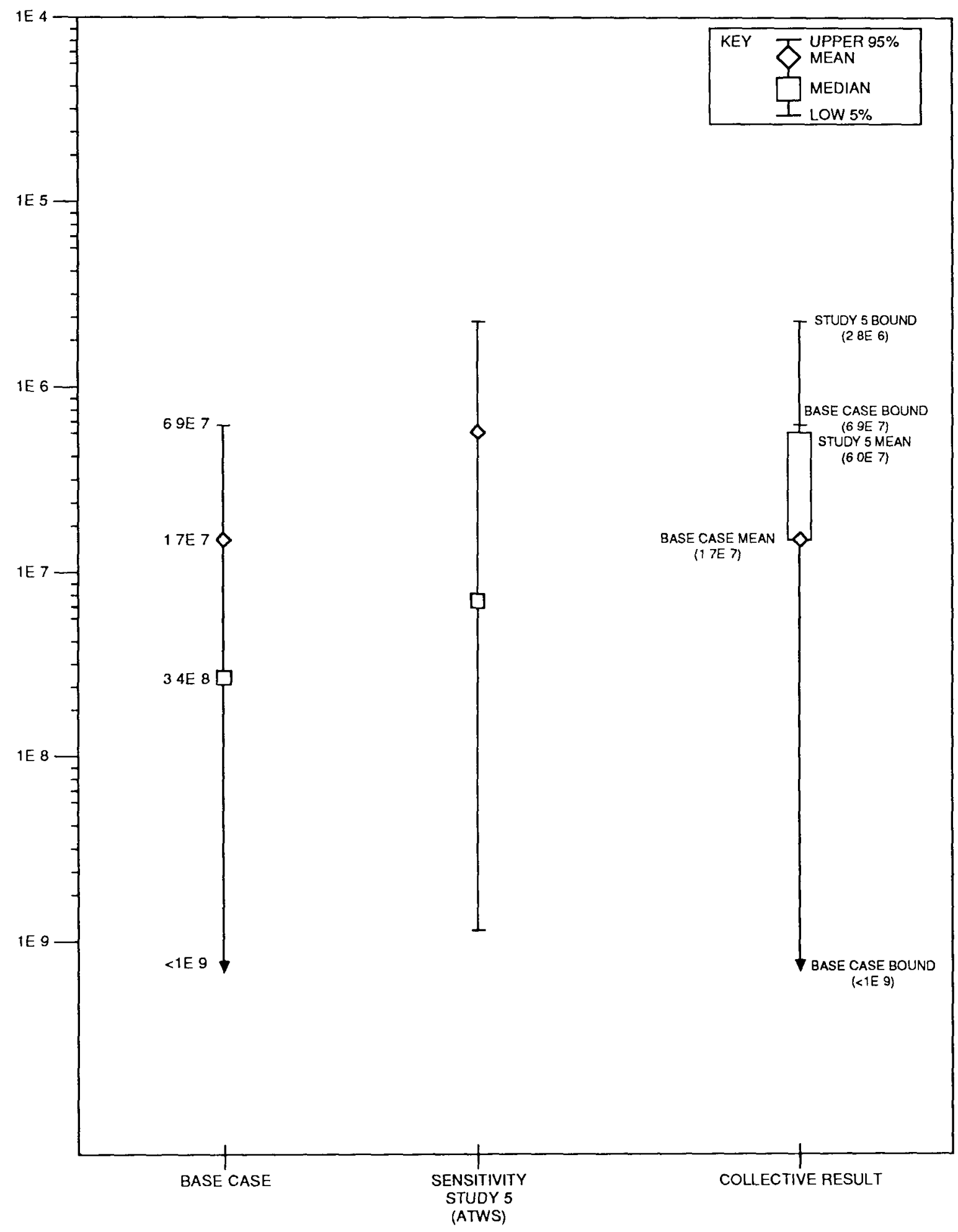

Figure V.2-6. Peach Bottom TCSX Core Damage Frequency. 


\section{V.2.7 Plant Damage State TBU}

This plant damage state is very similar to TBUX and TBUP except that there is no stuck-open SRV as in TBUP and there are no DC common mode failures. This latter distinction allows for vessel depressurization, and thus core damage is likely to occur under depressurized conditions in the reactor vessel. This plant damage state, TBUX, and TBUP collectively make up all the dominant short-term core damage scenarios caused by station blackout.

The dominant sequences which contribute to this plant damage state are

$$
\begin{aligned}
& \text { T1-T2-T3(Q)U1U2BO, } \\
& \text { T1-T2-T3(Q)U1U2BOY. }
\end{aligned}
$$

The collective frequency and the uncertainties of both sequences (i.e., of plant damage state TBU) follow:

$\begin{array}{ll}\text { Upper } 95 \text { Percent Bound } & 6.7 \mathrm{E}-7 \\ \text { Mean } & 1.6 \mathrm{E}-7 \\ \text { Median } & 9.0 \mathrm{E}-8 \\ \text { Lower } 5 \text { Percent Bound } & 9.0 \mathrm{E}-9 .\end{array}$

The dominant cut sets for both sequences are listed in Table V.2-20.

The two sequences in this plant damage state differ only as to whether the containment is vented or failed ( $Y$ event). The split fraction for $Y$ is $0.1 / 0.9$ for success and failure respectively.

The major contributors to both sequences in this plant damage state, on the basis of the importance measures analyzed, are listed (in approximate order of importance) in Table V.2-21.

The effects of the six sensitivity studies (described earlier) on plant damage state TBU are summarized by Figure V.2-7 and Table V.2-22. Appendix B contains the detailed results for all the importance calculations. Appendix $C$ contains additional information regarding TBU. 
Table V.2-20

TBU Dominant Cut sets

\begin{tabular}{|c|c|c|c|}
\hline CUT SEI & \multicolumn{3}{|c|}{$\begin{array}{l}\text { POINT ESTIMATE } \\
\text { FREQUENCY }\end{array}$} \\
\hline \multicolumn{2}{|c|}{ IE $-T L O S P^{\star} D C P-B A T-L P-B 2^{\star} A C P-D G N-L P-D G 3^{\star} R C I-T D P-F S-20 S 38^{\star} R A-1 D^{\star} R A-14 D$} & \multicolumn{2}{|l|}{$6 E-8$} \\
\hline \multicolumn{2}{|c|}{ IE $-T L O S P^{\star} D C P-B A T-L P-B 2^{\star} A C P-D G N-M A-D G 3^{\star} R C I-T D P-F S-20 S 38^{\star} R A-10^{\star} R A-14 D$} & \multicolumn{2}{|l|}{$6 E-8$} \\
\hline \multicolumn{4}{|c|}{ IE $-T L O S P^{*} A C P-D G N-L P-E D G 2^{*} B-A C P-L P-E D G S^{*} H C I-T D P-F S-20 S 37$} \\
\hline${ }^{\star} R C I-T D P-F S-20538^{\star} R A-10$ & \multicolumn{3}{|c|}{$15 E-8$} \\
\hline \multicolumn{4}{|c|}{ IE-TLOSP*ACP-DGN-LP-EDG2*ACP-DGN-LP-EDG3*HCI-TDP-FS-20S37 } \\
\hline${ }^{*} R C I-T D P-F S-20 S 38 * R A-10$ & \multicolumn{3}{|c|}{$83 E-9$} \\
\hline$I E-T L O S P^{\star} D C P-B A T-L P-B 2^{\star} E S W-P S$ & \multicolumn{3}{|l|}{$3^{*} R C I-T D P-F S-20 S 38^{\star} R A-1 D^{\star} R A-14 D$} \\
\hline \multicolumn{4}{|c|}{ IE-TLOSP*ACP-DGN-LP-EDG 3*ACP-DGN-MA-EDG2*HCI-TDP-FS-20S37 } \\
\hline${ }^{\star} R C I-T D P-F S-20 S 38{ }^{\star} R A-10$ & \multicolumn{3}{|c|}{$80 E-9$} \\
\hline \multirow{2}{*}{\multicolumn{4}{|c|}{ IE-TLOSP-ACP-DGN-LP-EDG2*ACP-DGN-MA-EDG ${ }^{\star} H C I-T D P-F S-20 S 37$}} \\
\hline${ }^{\star} R C I-T D P-F S-20 S 38 * R A-1 D$ & & & \\
\hline TERM & \multicolumn{2}{|l|}{ DESCRIPTION } & MEAN VALUE \\
\hline IE-TLOSP & \multicolumn{2}{|l|}{ Loss of offsite power } & $70 E-2 /$ year \\
\hline$D C P-B A T-L P-B 2$ & \multicolumn{2}{|l|}{ Battery B2 fallure (falls DG-2 and HPCI) } & $133 E-3$ \\
\hline$A C P-D G N-L P-D G 3$ & \multicolumn{2}{|l|}{ OG3 failure to start or run } & $113 E-2$ \\
\hline$A C P-D G N-L P-D G 2^{\star}$ & \multicolumn{2}{|l|}{ DG2 fallure to start or run } & $113 E-2$ \\
\hline$A C P-D G N-M A-D G 3$ & \multicolumn{2}{|l|}{ DG3 maintenance unavallability } & $109 E-2$ \\
\hline$A C P-D G N-M A-D G 2$ & \multicolumn{2}{|l|}{ DG2 maintenance unavallability } & $109 E-2$ \\
\hline$B-A C P-L P-E D G S^{*}$ & \multicolumn{2}{|c|}{ Common mode Beta factor applied to 2nd diesel (DG3) } & $208 E-2$ \\
\hline RCI-TDP-FS-20S38 & \multicolumn{2}{|c|}{ RCIC falls to start } & $484 \mathrm{E}-2$ \\
\hline$H C I-T D P-F S-20 S 37$ & \multicolumn{2}{|l|}{ HPCI falls to start } & $484 \mathrm{E}-2$ \\
\hline ESW-PSF-LF-103 & \multicolumn{2}{|l|}{ Fallure of jacket cooling to DG3 } & $57 E-3$ \\
\hline$R A-10$ & \multicolumn{2}{|c|}{ Fallure to recover offsite power by $30-$ to -40 minutes } & $4 O E-1$ \\
\hline$R A-14 D$ & \multicolumn{2}{|c|}{ Fallure to recover a battery fault by } & \\
\hline \multirow[b]{2}{*}{$\mathrm{RA}-16 \mathrm{D}$} & \multicolumn{2}{|l|}{$30-$ to-40 minutes } & $80 E-1$ \\
\hline & \multicolumn{2}{|l|}{ Fallure to recover a DG hardware fault by } & 10 \\
\hline
\end{tabular}


Table V.2-2I

TBU Major Contributors

\begin{tabular}{|c|c|c|c|}
\hline MEASURE & EVENT & $\begin{array}{l}\text { IMPORTANCE } \\
\text { VALUE (POINT } \\
\text { ESTIMATE) }\end{array}$ & DESCRIPTION \\
\hline \multirow[t]{7}{*}{ Risk Reduction } & $R A-10$ & $1.8 E-7$ & $\begin{array}{l}\text { Non-recovery of offsite power in } \\
\sim 1 / 2 \text { hour }\end{array}$ \\
\hline & RCI-TDP-FS $-20 S 38$ & 1. $4 \mathrm{E}-7$ & RCIC falls to start \\
\hline & HCI I TDP-FS - $20 S 37$ & $8.6 E-8$ & HPCI falls to start \\
\hline & $R A-140$ & $7.6 \mathrm{E}-8$ & $\begin{array}{l}\text { Non-recovery of battery fault in } \\
\sim 1 / 2 \text { hour }\end{array}$ \\
\hline & $D C P-B A T-L P-B 2$ & $7.6 \mathrm{E}-8$ & Battery B2 fallure \\
\hline & IE-TLOSP & $1.6 E-7$ & Loss of offsite power \\
\hline & IT -TRTRIP & $14 E-8$ & Turbone trip \\
\hline \multirow[t]{2}{*}{ Risk Increase } & $E S W-P S-L F-8$ & 1. $6 \mathrm{E}-4$ & $\begin{array}{l}\text { Maintenance unavallability of MOV-0498 } \\
\text { valve in ESW system }\end{array}$ \\
\hline & $D C P-B A T-L P-B 2$ & $57 \mathrm{E}-5$ & Battery 82 fallure \\
\hline \multirow[t]{4}{*}{ Uncertainty } & $R A-1 D$ & 1. $O E-7$ & $\begin{array}{l}\text { Non-recovery of offsite power in } \\
\sim 1 / 2 \text { hour }\end{array}$ \\
\hline & RCI-TDP-FS-20S38 & $9.9 E-8$ & RCIC falls to start \\
\hline & IE-TLOSP & 1.1E-7 & Loss of offsite power \\
\hline & IE-TRTRIP & 1. $1 E-8$ & Turbine trip \\
\hline
\end{tabular}




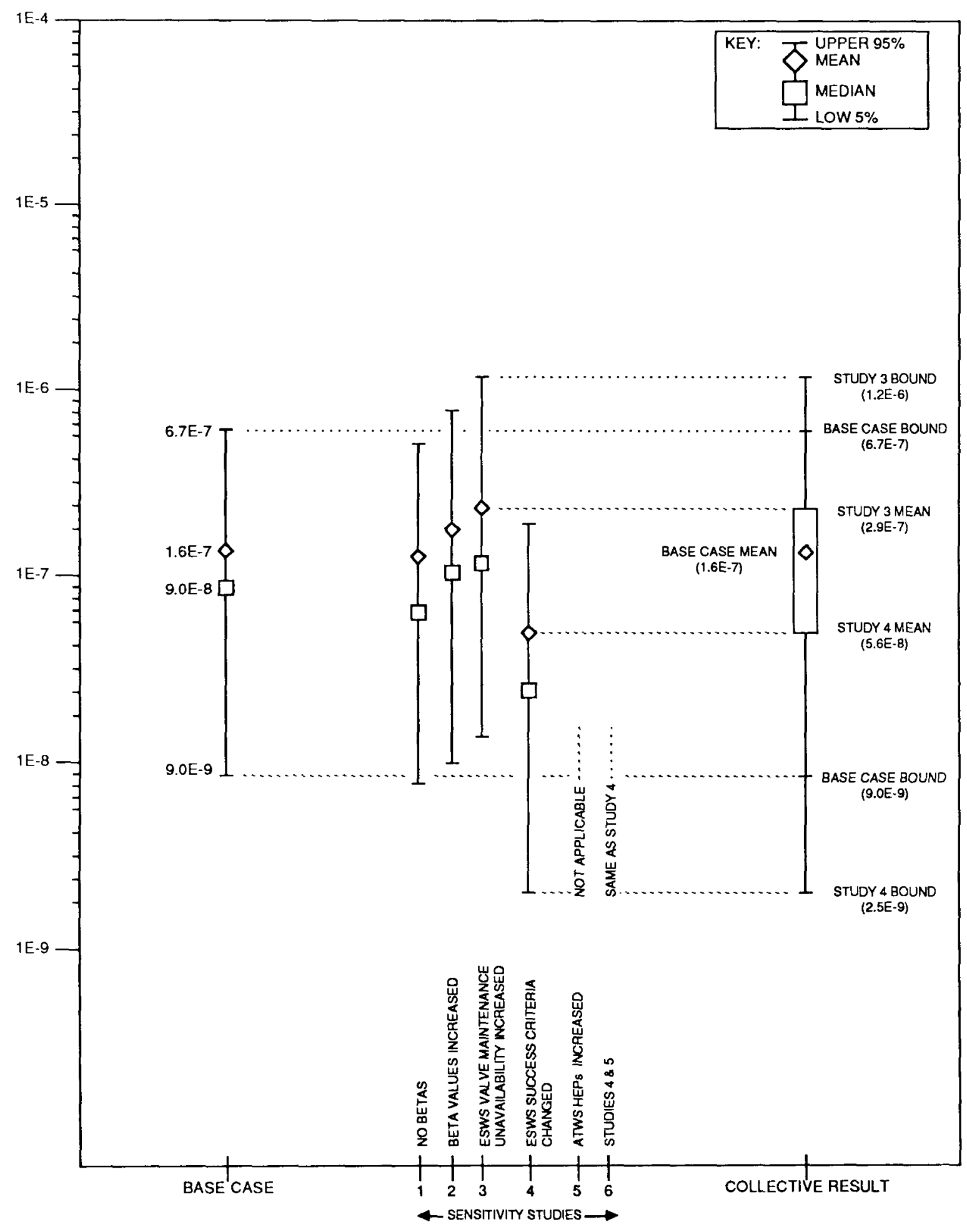

Figure V.2-7. Peach Bottom TBU Core Damage Frequency. 
Table V.2-22

TBU Importance Measure Results For Each Sensitivity

(as compared with base case results)

\begin{tabular}{|c|c|c|c|c|c|c|}
\hline $\begin{array}{l}\text { IMPORTANCE } \\
\text { MEASURE }\end{array}$ & SENSITIVITY 1 & SENSITIVITY 2 & SERSITIVITY 3 & SENSITIVITY 4 & SERSITIVITY 5 & SENSITIVITY 6 \\
\hline \multicolumn{7}{|l|}{ Risk } \\
\hline Reduction & $\begin{array}{c}\text { - No major } \\
\text { changes }\end{array}$ & $\begin{array}{c}\text { - No major } \\
\text { changes }\end{array}$ & $\begin{array}{l}\text { - Like base case } \\
\text { except operator } \\
\text { fallure to start } \\
\text { ECW pump among } \\
\text { dominant events }\end{array}$ & $\begin{array}{l}- \text { - L ke base case } \\
\text { except fallure } \\
\text { to start ECW } \\
\text { pump and } D G \\
\text { common mode } \\
\text { among top events }\end{array}$ & - Not applicable & $\begin{array}{l}\text { - Same as } \\
\text { Sensitivity } 4\end{array}$ \\
\hline \multicolumn{7}{|l|}{ Risk } \\
\hline Increase & $\begin{array}{c}\text { - No major } \\
\text { changes }\end{array}$ & $\begin{array}{c}\text { - No major } \\
\text { changes }\end{array}$ & $\begin{array}{c}\text {-No major } \\
\text { changes }\end{array}$ & $\begin{array}{l}\text { - -New ranking } \\
\text {-Battery B2 fall- } \\
\text { ure } \\
\text {-Jacket cool Ing } \\
\text { fallure to DGs } \\
2 \text { \& } 3 \\
\text {-Subsequent LOSP } \\
\text {-OG common mode }\end{array}$ & - Not applicable & $\begin{array}{l}\text { - Same as } \\
\text { Sensitivity } 4\end{array}$ \\
\hline Uncertaint. & $\begin{array}{l}\text { - No major } \\
\text { changes }\end{array}$ & $\begin{array}{c}- \text {-No major } \\
\text { changes }\end{array}$ & $\begin{array}{l}--S i m i l a r \text { to base } \\
\text { case except ESW } \\
\text { MoV-0498 main- } \\
\text { tenance ranks } 1\end{array}$ & $\begin{array}{l}- \text { - L ke base case } \\
\text { except DG common } \\
\text { mode among top } \\
\text { events }\end{array}$ & - -Not applicable & $\begin{array}{l}- \text {-Same as } \\
\text { Sensitivity } 4\end{array}$ \\
\hline
\end{tabular}




\section{V.2.8 Plant Damage State TBP}

This plant damage state is virtually identical to the TB plant damage state (refer to V.2.2) except there exists a stuck-open relief valve. Core damage, following battery depletion like in TB, will occur under low pressure in the vessel because of the stuck-open relief valve.

The dominant sequences which contribute to this plant damage state are

$$
\begin{aligned}
& \text { T1-T2-T3(Q) PW2W3U3VIV2V3V4, } \\
& \text { T1-T2-T3(Q)PU1W2W3U3V1V2V3V4, } \\
& T 1-T 2-T 3(Q) P W 2 W 3 U 3 V 1 V 2 V 3 V 4 Y, \\
& T 1-T 2-T 3(Q) P U 1 W 2 W 3 U 3 V 1 V 2 V 3 V 4 Y .
\end{aligned}
$$

The collective frequency and the uncertainties of all four sequences (i.e., of plant damage state TBP) follow:

$\begin{array}{ll}\text { Upper } 95 \text { Percent Bound } & 5.0 \mathrm{E}-7 \\ \text { Mean } & 1.2 \mathrm{E}-7 \\ \text { Median } & 4.0 \mathrm{E}-8 \\ \text { Lower } 5 \text { Percent Bound } & 4.1 \mathrm{E}-9 .\end{array}$

The dominant cut sets for each sequence are listed in Tables V.2-23 and V.2-24.

The major contributors to the sequences in this plant damage state are the same as for plant damage state TB (refer to V.2.2) except that the "SORV" term ranks at the top for risk reduction and near the top for the uncertainty importance measure (refer to Appendix B).

The effects of the six sensitivity studies (described earlier) on plant damage state TBP are summarized by Figure V.2-8 and Table V.2-25. Appendix B contains the detailed results for all the importance calculations. Appendix $C$ contains additional information regarding TBP.

Discussions regarding potential conservatisms and non-conservatisms for TB apply to plant damage state TBP as well. 
TBP [Sequences T1-T2-T3(Q) PW2W3U3V1V2V3V4 and $\mathrm{Tl}-\mathrm{T} 2-\mathrm{T} 3(\mathrm{Q}) \mathrm{PW} 2 \mathrm{~W} 3 \mathrm{I} 3 \mathrm{~V}$ IV2V3V4] Dominant cut sets

\section{CUT SET}

POINT ESTIMATE FREQUENCY

IE-TLOSP*SORV*ACP-DGN-LP-EDG2*B-ACP-LP-EDGS*RA-1J*RA-17J

IE $-T L O S P^{\star} S O R{ }^{\star} A C P-D G N-L P-E D G 2^{*} A C P-D G N-L P-E D G 3^{*} R A-1 J{ }^{*} R A-16 J$

IE-TLOSP*SORV $A C P-D G N-L P-E D G 2^{\star} A C P-D G N-M A-E D G 3^{\star} R A-1 J^{\star} R A-16 J$

IE -TLOSP*SORV*ACP-DGN-LP-EDG3*ACP-DGN-MA-EDG2*RA-1J*RA-16J

IE-TLOSP*SORV*ACP-DGN-LP-EDG2*ESW-PSF-LF-103*RA-1J*RA-16J

IE-TLOSP*SORV $A C P-D G N-L P-E D G 3^{\star} E S W-P S F-L F-102^{\star} R A-13 J^{\star} R A-163$

IE-TLOSP*SORV *ESW-PSF-LF-102*ESW-PSF-LF-103*RA-1J

IE-TLOSP*SORV*ACP-DGN-MA-EDG2*ESW-PSF-LF-103*RA-1J*RA-18J

IE $-T L O S P^{*} S O R V * A C P-D G N-M A-E D G 3^{*} E S W-P S F-L F-102^{*} R A-1 J^{*} R A-18 \mathrm{~J}$

IE-TLOSP*SORV*ESW-PSF-LF- ${ }^{\star} E C W-X H E-F O-E C W P P^{\star} R A-1 \mathrm{~J}$
1. $6 \mathrm{E}-8$
$1.1 \mathrm{E}-8$
1. $0 E-8$
$1.0 E-8$
5. $4 \mathrm{E}-9$
$5.4 E-9$
4. $6 E-9$
$4.4 \mathrm{E}-9$
$4.4 E-9$
4. $2 \mathrm{E}-9$

\begin{tabular}{|c|c|c|}
\hline TERM & DESCR I PIION & MEAN VALUE \\
\hline IE-TLOSP & Loss of offsite power & 7.0E-2/year \\
\hline$A C P-D G N-L P-E D G 2^{*}$ & DG2 fallure to start or run & 1.13E-2 \\
\hline$B-A C P-L P-E D G S^{*}$ & $\begin{array}{l}\text { Common mode Beta factor applied to above term } \\
\text { for fallure of } 2 \text { nd diesel (DG3) }\end{array}$ & $208 E-2$ \\
\hline$A C P-D G N-L P-E D G 3$ & DG3 fallure to start or run & $113 E-2$ \\
\hline$A C P-D G N-M A-E D G 3$ & DG3 unavallable due to maintenance & $109 E-2$ \\
\hline$A C P-D G N-M A-E D G 2$ & DG2 unavallable due to maintenance & $1.09 E-2$ \\
\hline$E S W-P S F-L F-1$ & 03 Fallure of jacket cooling to $D G 3$ & $57 E-3$ \\
\hline$E S W-P S F-L F-102$ & Fallure of jacket cooling to DG2 & $5.7 E-3$ \\
\hline$E S W-P S F-L F-8$ & $\begin{array}{l}\text { ESW MOV-0498 discharge valve closed because of } \\
\text { mantenance }\end{array}$ & $3 O E-5$ \\
\hline ECW-XHE-FO-ECWPP & $\begin{array}{l}\text { Operator fallure to start ECW pump in ESW system } \\
\text { by } \sim 5 \text { minutes }\end{array}$ & 10 \\
\hline $\mathrm{RA}-1 \mathrm{~J}$ & Fallure to recover offsite power by $6-$ to- 8 hours & $4.0 E-2$ \\
\hline$R A-17 \mathrm{~J}$ & $\begin{array}{l}\text { Fallure to recover either of two diesel generators } \\
\text { (common mode fallure) by } 6 \text { hours }\end{array}$ & $5 O E-1$ \\
\hline$R A-16 \mathrm{~J}$ & $\begin{array}{l}\text { Fallure to recover a diesel generator hardware } \\
\text { fault by } 6 \text { hours }\end{array}$ & $6.0 \mathrm{E}-1$ \\
\hline$R A-18 \mathrm{~J}$ & $\begin{array}{l}\text { Fall to recover from a diesel generator } \\
\text { maintenance unavallability by } 6 \text { hours }\end{array}$ & $5.0 E-1$ \\
\hline SORV & Stuck-open relief valve & $5.0 \mathrm{E}-2$ \\
\hline
\end{tabular}


Table $\mathrm{V} \cdot 2-24$

TBP [Sequences T1-T2-T3 (Q) PW2W3U3V1V2V3V4 and T1-T2-T3 (Q) PW2W3I3VIV2V3V4] Dominant Cut sets

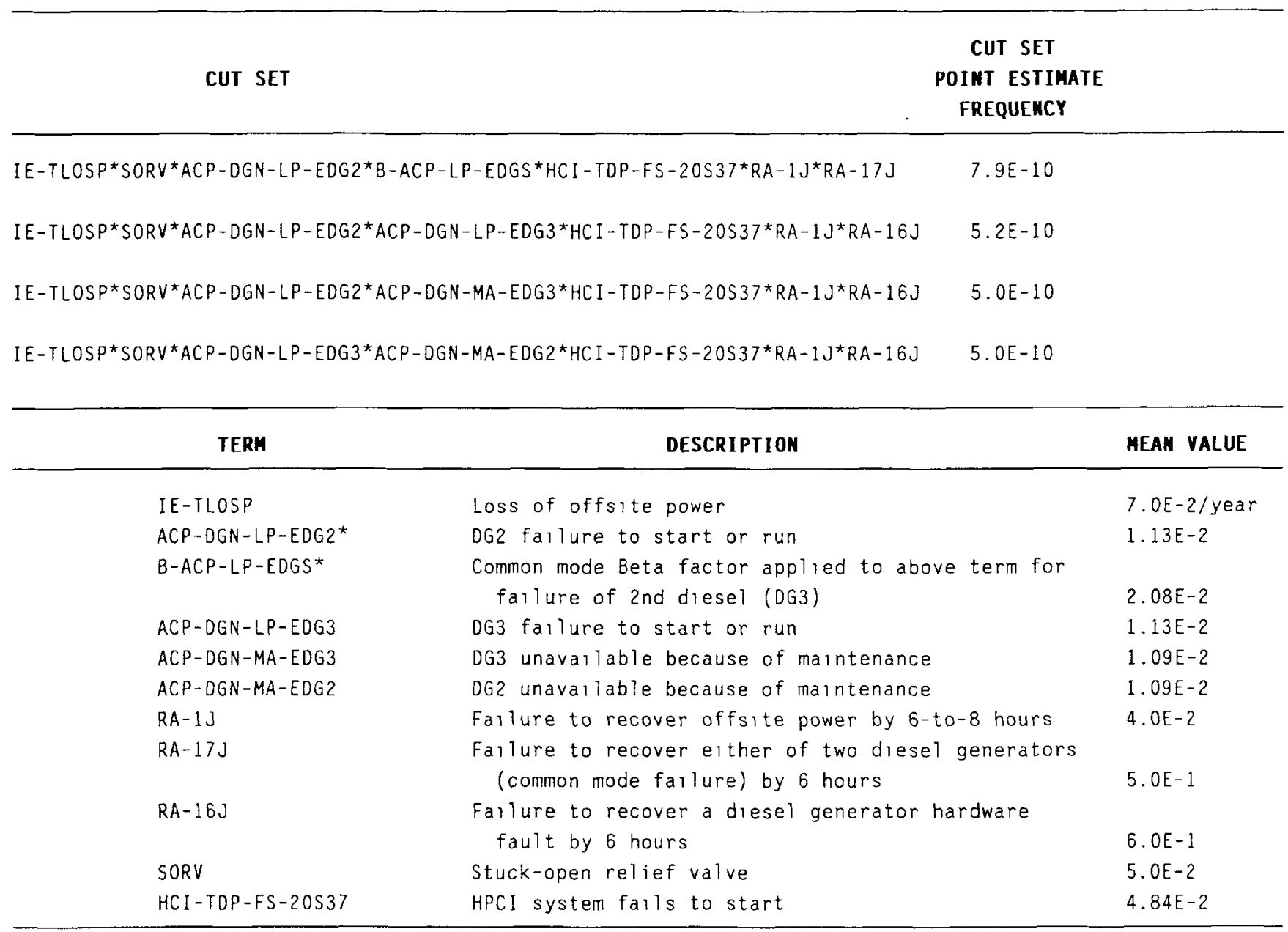




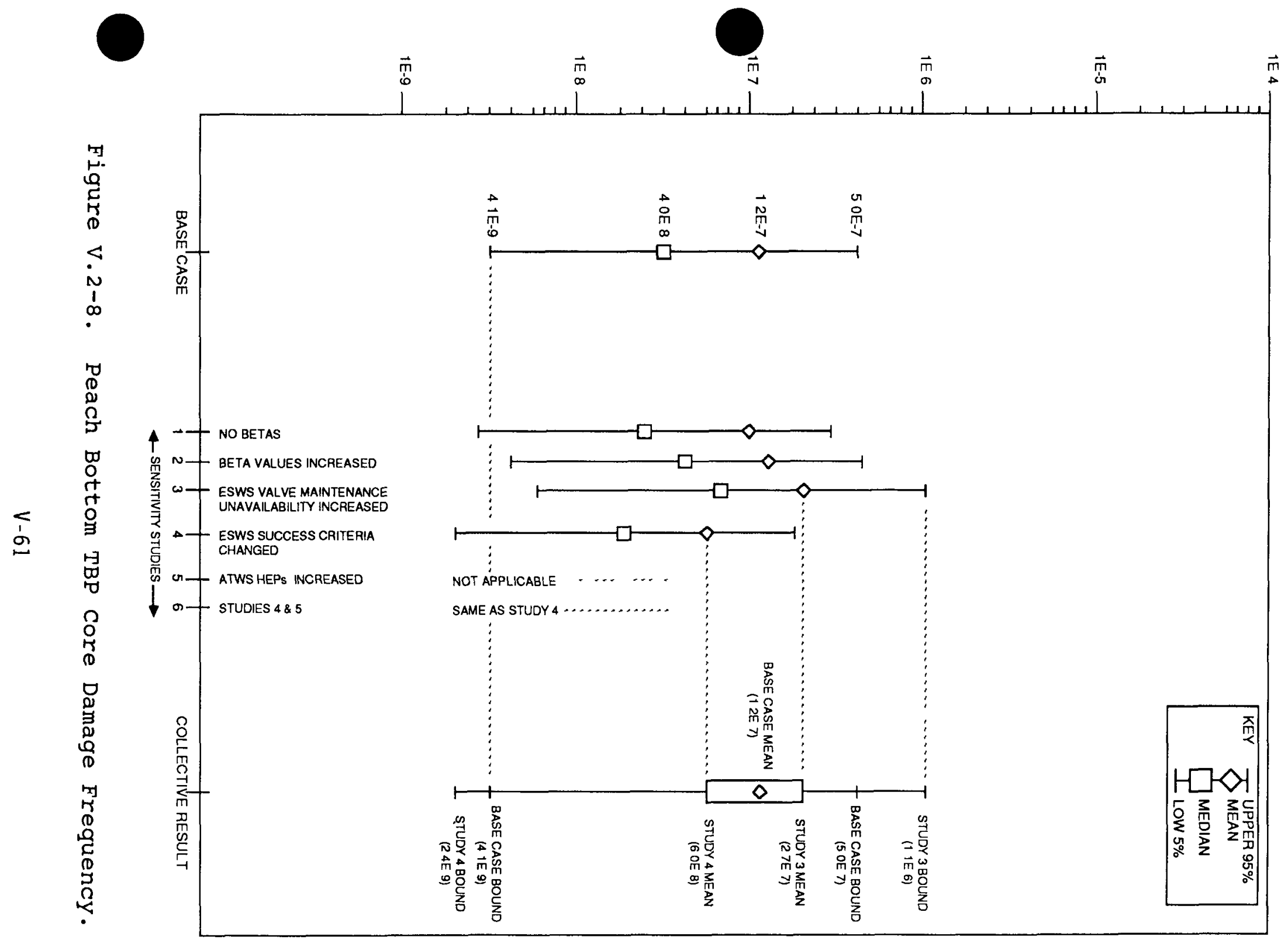


Table V.2-25

TBP Importance Measure Results For Each Sensitivity

(as compared with base case results)

\begin{tabular}{|c|c|c|c|c|c|c|}
\hline $\begin{array}{l}\text { IMPORTANCE } \\
\text { MEASURE }\end{array}$ & SENSITIVITY 1 & SENSITIYITY 2 & SENSITIVITY 3 & SEMSITIVITY 4 & SENSITIVITY 5 & SEMSITIVITY 6 \\
\hline \multicolumn{7}{|l|}{ Risk } \\
\hline Reduction: & $\begin{array}{c}\text { - No major } \\
\text { changes }\end{array}$ & $\begin{array}{c}\text { - No major } \\
\text { changes }\end{array}$ & $\begin{array}{l}\text { - No major changes } \\
\text { except ESW } \\
\text { MoV-0498 main- } \\
\text { tenance rises } \\
\text { to among top } \\
\text { events }\end{array}$ & $\begin{array}{l}\text { - ESW fallures } \\
\text { and operator } \\
\text { fallure to } \\
\text { start ECW pump } \\
\text { rank higher }\end{array}$ & - Not applicable & $\begin{array}{l}- \text {-Same as } \\
\quad \text { Sensitivity } 4\end{array}$ \\
\hline \multicolumn{7}{|l|}{ Risk } \\
\hline Increase: & $\begin{array}{l}\text { - No major } \\
\text { changes except } \\
\text { no } D G \text { common } \\
\text { mode }\end{array}$ & $\begin{array}{c}\text { - No major } \\
\text { changes }\end{array}$ & $\begin{array}{l}\text { - No major changes } \\
\text { except offsite } \\
\text { power recovery } \\
\text { and SORV rise } \\
\text { to among top } \\
\text { events }\end{array}$ & $\begin{array}{l}\text { - ESW fallures } \\
\text { rank } 1 \text { and } \\
\text { MoV-0498 main- } \\
\text { tenance is } \\
\text { deleted }\end{array}$ & -Not applicable & $\begin{array}{l}\text {--Same as } \\
\quad \text { Sensitivity } 4\end{array}$ \\
\hline Uncertainty: & $\begin{array}{l}\text { - - No major } \\
\text { changes except } \\
\text { no DG common } \\
\text { mode }\end{array}$ & $\begin{array}{c}\text { - No major } \\
\text { changes }\end{array}$ & $\begin{array}{l}\text { - No changes } \\
\text { except ESW } \\
\text { MoV-0498 main- } \\
\text { tenance ranks } 1\end{array}$ & $\begin{array}{l}\text {--ESW fallures } \\
\text { rank higher }\end{array}$ & --No applicable & $\begin{array}{l}- \text { - Same as } \\
\quad \text { Sensitivity } 4\end{array}$ \\
\hline
\end{tabular}




\section{.2.9 Plant Damage State S1V}

This plant damage state is characterized by an intermediate size LOCA. HPCI successfully operates for about two hours until pressure in the primary system can no longer support operation of the HPCI steam turbine. Low pressure injection systems are required to provide sufficient flow but they fail. Core damage results soon after.

The only sequence with an estimated frequency greater than 1E-8 which contributes to this plant damage state is

\section{S1V2V3V4.}

The frequency and the uncertainties of this sequence (i.e., of plant damage state SIV) follow:

$\begin{array}{ll}\text { Upper } 95 \text { Percent Bound } & 3.4 E-7 \\ \text { Mean } & 7.5 E-8 \\ \text { Median } & 2.0 E-8 \\ \text { Lower } 5 \text { Percent Bound } & 1.4 E-9 .\end{array}$

The dominant cut sets for this sequence are listed in Table V.2-26.

The major contributors to this sequence in this plant damage state, on the basis of the importance measures analyzed, are listed (in approximate order of -importance) in Table V.2-27.

None of the six sensitivity studies affects the SIV plant damage state. The detailed importance calculations for the base case are presented in Appendix B. 
Table V.2-26

SIV Dominant Cut Sets

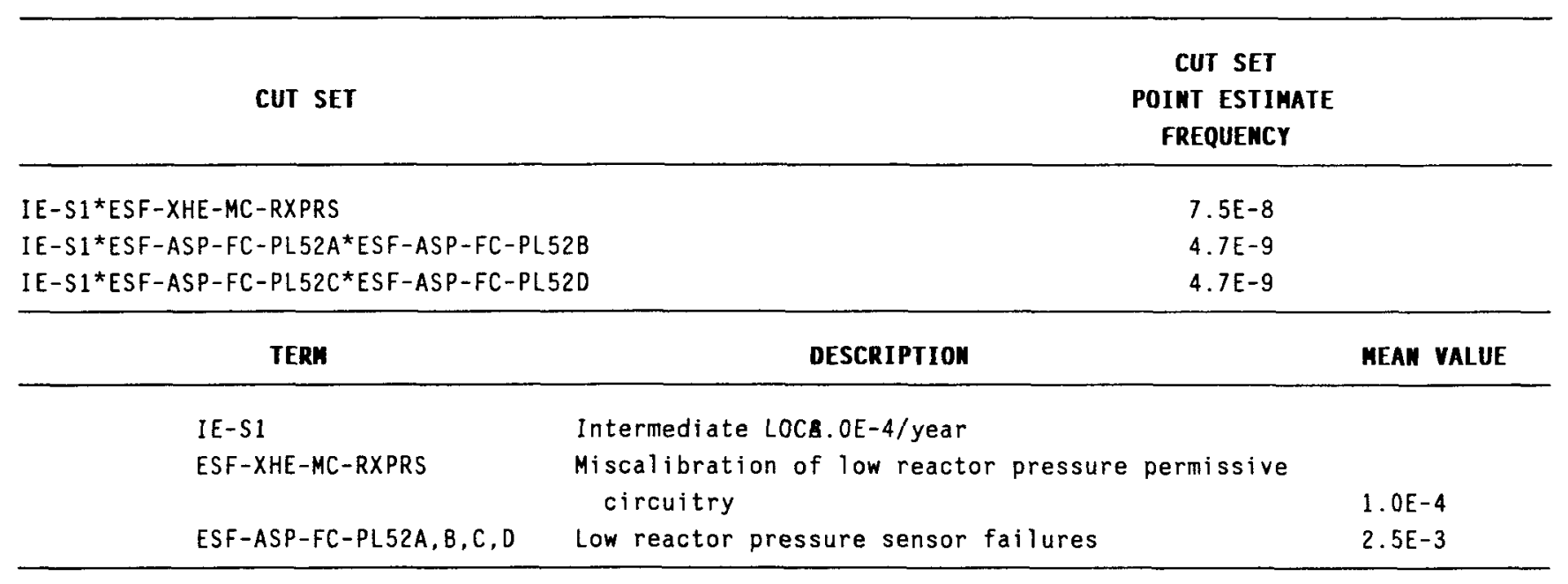


Table V.2-27

SIV Major Contributors

\begin{tabular}{llll}
\hline MEASURE & EVEMT & $\begin{array}{c}\text { IMPORTANCE } \\
\text { VALUE (POINT } \\
\text { ESTIMATE) }\end{array}$ & \multicolumn{1}{c}{ DESCRIPTION } \\
\hline Risk Reduction & ESF-XHE-MC-RXPRS & $75 E-8$ & $\begin{array}{l}\text { Miscalibration of low pressure } \\
\text { permissive circuitry } \\
\text { S1 LoCA }\end{array}$ \\
IE-S1 & $84 E-8$ & $\begin{array}{l}\text { Miscalibration of low pressure } \\
\text { permissive circuitry }\end{array}$ \\
Uncertainty & ESF-XHE-MC-RXPRS & $75 E-8$ & $\begin{array}{l}\text { Miscalibration of low pressure } \\
\text { permissive circuitry } \\
\text { S1 LoCA }\end{array}$ \\
\hline
\end{tabular}




\section{V.2.10 Plant Damage State TCSAR}

This plant damage state is characterized by an ATWS with either MSIV closure or an event with MSIVs initially open but subsequently closed. This isolates the primary system under high power conditions, thereby rapidly increasing the pressure and temperature conditions within containment since RHR cooling under these circumstances is inadequate. Timely SLC system start is not performed or it fails because it was left in an inappropriate configuration after the last test of the system. ADS is not inhibited, resulting in vessel blowdown. Low pressure system operation and control are successful. Venting of the containment (event "Y") is not successful. The description up to this point defines plant damage state TCSAR as it was used by the containment analysts. However, because the condition of the containment must first be determined to see if core cooling can be maintained, three substates had to be defined (based on preliminary analyses by the containment analysts) to describe the ways core damage could ultimately occur. (In other words, the status of containment is a feedback to how core damage occurs.) Only two of the three possible substates led to accident frequencies greater than $\sim 1 \mathrm{E}-8$; only those two substates are discussed here. Either the containment "fails" in such a way as to leak or it does not fail at least up until vessel breach; continued low pressure system operation is, therefore, precluded. This is because the SRV air pressure can achieve -100-to-125 psig which would not be sufficient to keep the SRVs open under the higher containment pressure conditions in both these cases. The vessel repressurizes, shutting off low pressure system injection with core damage resulting.

Two groups of sequences to cover the two cases above are defined as the dominant sequences (there are four in all) making up this plant damage state. These are

$$
\begin{aligned}
& \text { Substate TCSARX2 -- } \\
& T * M S I V * R P S M * S L C * R X H P * / L P I N * Y * \text { Containment Leakage }+ \\
& T * / M S I V * R P S M^{\star} F W^{*} S L C * R X H P * / L P I N{ }^{*}{ }^{*} \text { Containment Leakage, }
\end{aligned}
$$

The approximate mean frequency for plant damage state TCSAR is $5.8 \mathrm{E}-8$. The frequencies and the uncertainties of the two groups of sequences follow:

\section{ICSARX2}

$\begin{array}{ll}\text { Upper } 95 \text { Percent Bound } & 3.0 \mathrm{E}-7 \\ \text { Mean } & 4.7 \mathrm{E}-8 \\ \text { Median } & 2.6 \mathrm{E}-9 \\ \text { Lower } 5 \text { Percent Bound } & <\mathrm{E}-10\end{array}$

TCSARX3

$\begin{array}{ll}\text { Upper } 95 \text { Percent Bound } & 5.5 E-8 \\ \text { Mean } & 1.1 \mathrm{E}-8 \\ \text { Median } & 3.7 \mathrm{E}-10 \\ \text { Lower } 5 \text { Percent Bound } & <\mathrm{E}-10 .\end{array}$


The dominant cut sets for each of the two groups of sequences are listed in Tables V.2-28 and V.2-29.

The major contributors to the sequences in this plant damage state, on the basis of the importance measures analyzed, are listed (in approximate order of importance) in Table V.2-30.

Only one sensitivity study is applicable to this plant damage state: Study \#5 (described earlier). The effects of this sensitivity are summarized in Figure V.2-9. No major changes occur in the importance measures as a result of the sensitivity except that "failure to inhibit ADS" does rise in the ranking for risk increase. Appendix $B$ contains the detailed results for all the importance calculations. 
Table V.2-28

TCSAR (Substate TCSARX2) Dominant cut sets

\begin{tabular}{|c|c|c|c|}
\hline \multicolumn{2}{|l|}{ CUT SET } & \multicolumn{2}{|c|}{$\begin{array}{l}\text { CUT SET } \\
\text { POINT ESTIMATE } \\
\text { FREQUENCY }\end{array}$} \\
\hline \multicolumn{4}{|c|}{ IE-TRTRIP*CMSIVA*RPS $-M^{*} S L C-X H E-F S^{\star} A D S-X H E-I N H 2^{\star} V E N T-X H E-T C$} \\
\hline \multicolumn{2}{|c|}{${ }^{\star}$ CONTAINMENT LEAKAGE } & $2.3 E-8$ & \\
\hline \multirow{3}{*}{\multicolumn{2}{|c|}{ 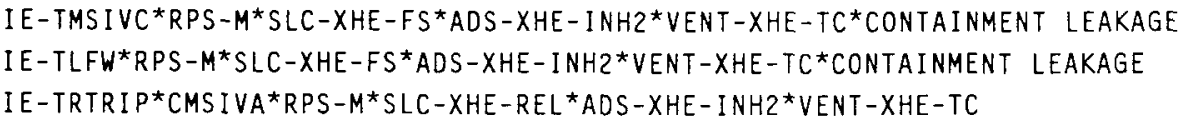 }} & $1.5 E-8$ & \\
\hline & & $1.3 E-8$ & \\
\hline & & & \\
\hline \multicolumn{2}{|c|}{${ }^{*}$ CONTAINMENT LEAKAGE } & $6.8 \mathrm{E}-9$ & \\
\hline TERM & \multicolumn{2}{|l|}{ DESCRIPIION } & MEAH VALUE \\
\hline IE-TRTRIP & \multicolumn{2}{|l|}{ Turbine trip } & $2.4 /$ year \\
\hline IE-TMSIVC & \multicolumn{2}{|l|}{ MSIV closure type initiators } & 8.0E-1/year \\
\hline IE-TLFW & \multicolumn{2}{|l|}{ Loss of feedwater } & $7.0 E-1 /$ year \\
\hline CMSIVA & \multicolumn{2}{|l|}{ Subsequent closure of MSIVs } & $5.0 E-1$ \\
\hline RPS-M & \multicolumn{2}{|c|}{ Mechanical fallure of all control rods } & $1.0 E-5$ \\
\hline$S L C-X H E-F S$ & \multicolumn{2}{|c|}{ Operator fallure to start SLC by $4 \mathrm{~min}$} & $3.38 E-2$ \\
\hline SLC-XHE-REL & \multicolumn{3}{|c|}{ SLC falls because of fallure to realign properly } \\
\hline ADS-XHE-INH2 & Fallure to inhibit ADS & & 1. $4 E-1$ \\
\hline VENT-XHE-TC & Failure to vent containment & & $9.0 \mathrm{E}-1$ \\
\hline CONTAINMENT LEAKAGE & Containment leaks & & $\sim 0 \quad 45$ \\
\hline
\end{tabular}


Table V.2-29

TCSAR (Substate TCSARX2) Dominant Cut sets

\begin{tabular}{|c|c|c|}
\hline CUT SET & \multicolumn{2}{|c|}{$\begin{array}{l}\text { CUT SET } \\
\text { POINT ESTIMATE } \\
\text { FREQUENCY }\end{array}$} \\
\hline \multicolumn{3}{|c|}{ IE $-T R T R I P^{\star} C M S$ IVA ${ }^{\star} R P S-M^{\star} S L C-X H E-F S^{\star} A D S-X H E-I N H 2 * V E N T-X H E-T C$} \\
\hline${ }^{*}$ NO CONTAINMENT FAILURE & & \\
\hline \multicolumn{3}{|c|}{ IE-TMS IVC *RPS $-M^{\star} S L C-X H E-F S^{*} A D S-X H E-I N H 2^{\star} V E N T-X H E-T C$} \\
\hline${ }^{*}$ NO CONTAINMENT FAILURE & & \\
\hline IE $-T L F W^{\star} R P S-M^{\star} S L C-X H E-F S^{\star} A D S-X H E-I N$ & *VENT-XHE-TC*NO CONTAINMENT FAILURE & \\
\hline \multirow{2}{*}{\multicolumn{3}{|c|}{$\begin{array}{l}\text { IE-TRTRIP*CMSIVA*RPS-M*SLC-XHE-REL*ADS-XHE-INH2*VENT-XHE-TC } \\
\text { *NO CONTAINMENT FAILURE }\end{array}$}} \\
\hline & & \\
\hline TERH & DESCRIPTION & MEAN VALUE \\
\hline IE-TRTRIP & Turbine trip & $2.4 /$ year \\
\hline IE-TMSIVC & MSIV closure type initiators & 8. $0 \mathrm{E}-1 /$ year \\
\hline IE-TLFW & Loss of feedwater & 7. OE-1/year \\
\hline CMSIVA & Subsequent closure of MSIVs & $5.0 E-1$ \\
\hline RPS-M & Mechanical fallure of all control rods & $1.0 E-5$ \\
\hline$S L C-X H E-F S$ & Operator fallure to start SLC by $4 \mathrm{~min}$ & $3.38 \mathrm{E}-2$ \\
\hline SLC-XHE-REL & $\begin{array}{l}\text { SLC falls because of fallure to realign } \\
\text { after test }\end{array}$ & $1.0 E-2$ \\
\hline ADS-XHE-INHZ & Farlure to inhibit ADS & $1.4 \mathrm{E}-1$ \\
\hline VENT - XHE-TC & Fallure to vent containment & $9.0 E-1$ \\
\hline NO CONTAINMENT FAILURE & Containment does not fall & $\sim 0.1$ \\
\hline
\end{tabular}


Table V.2-30

TCSAR Major Contributors

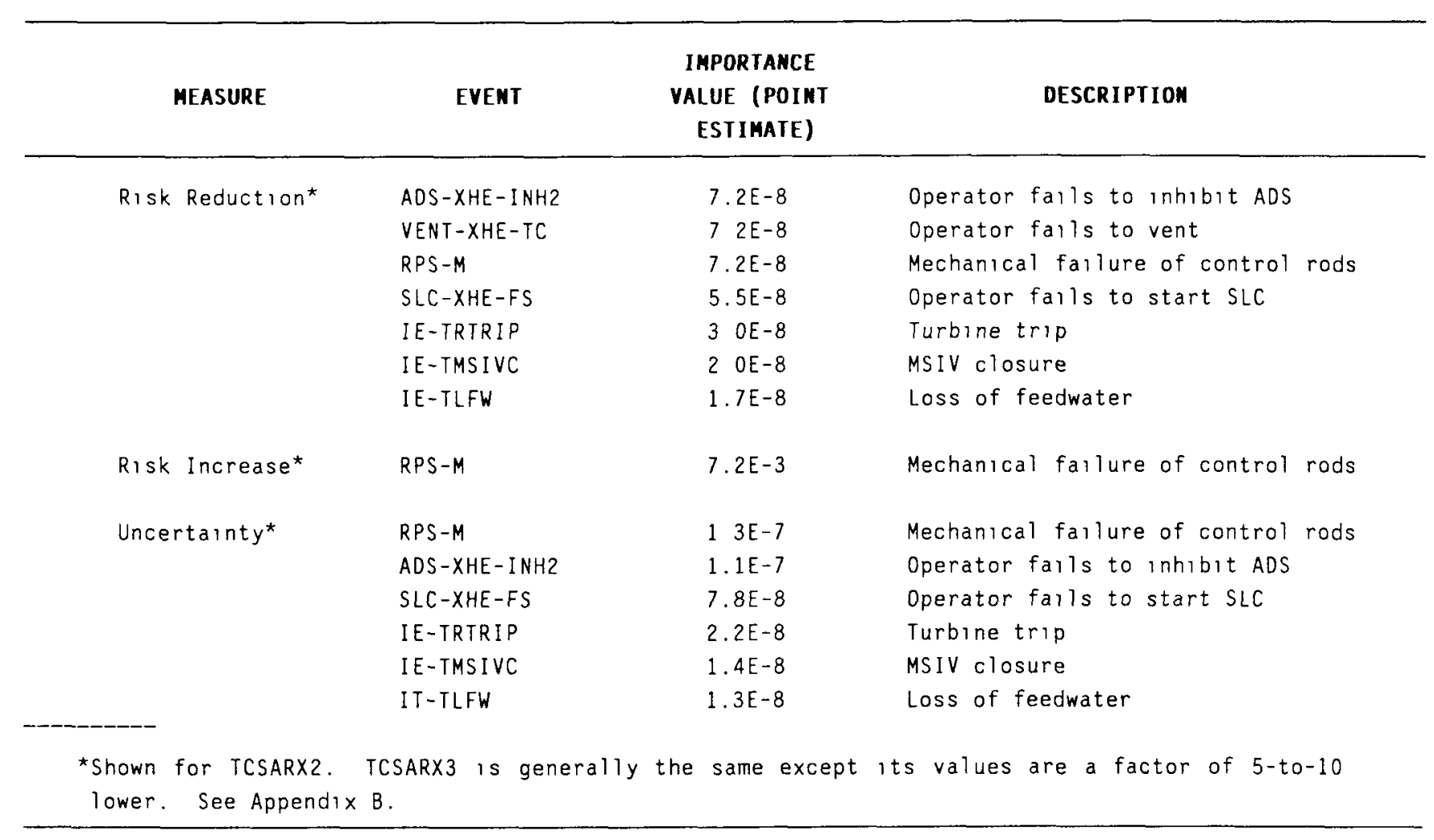




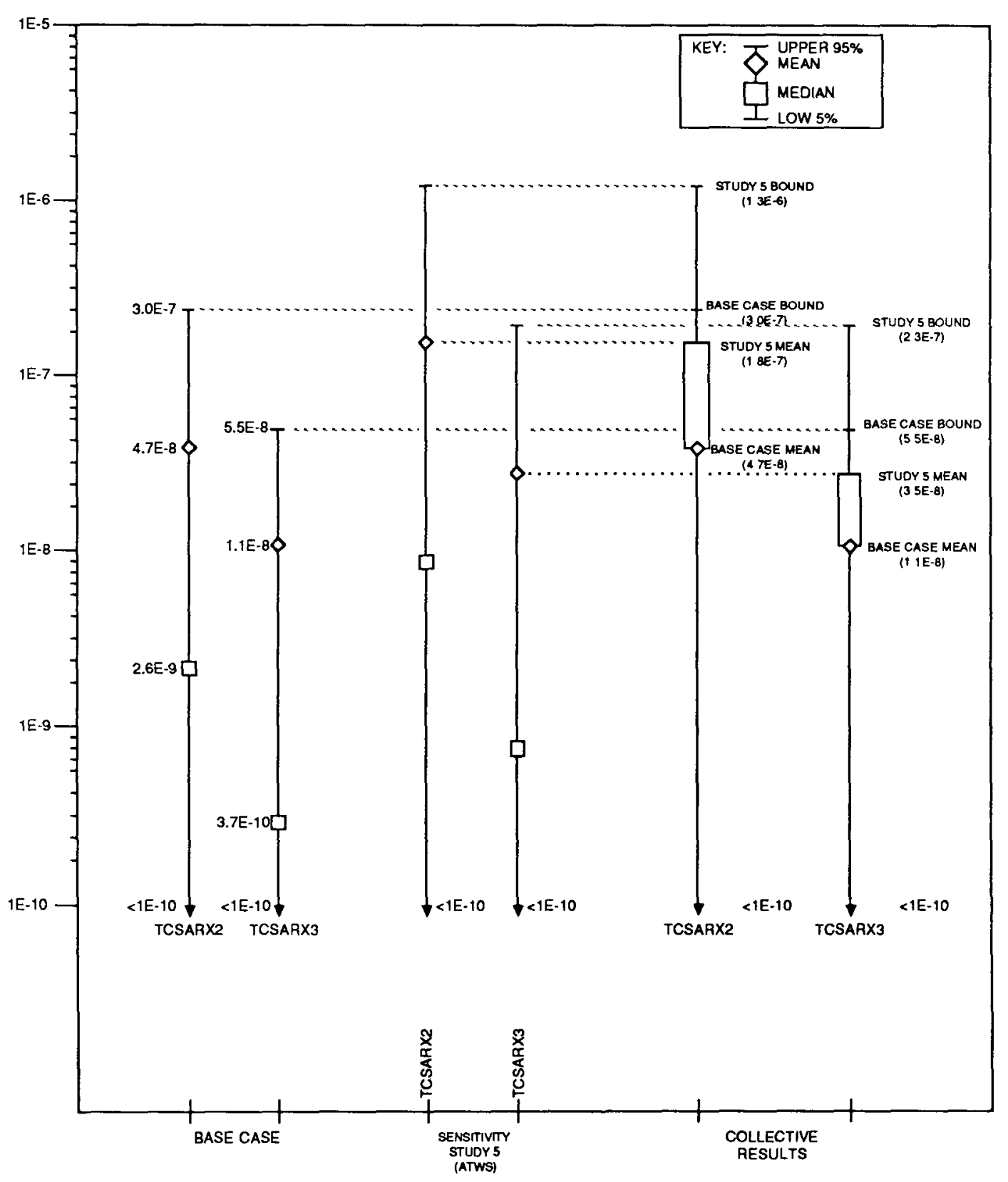

Figure V.2-9. Peach Bottom TCSAR Core Damage Frequency. 


\section{V.2.11 Plant Damage State TUV}

This plant damage state is characterized by a transient causing loss of the Power Conversion System (PCS). Early loss of all core cooling occurs because of failures associated with the high pressure systems and the inability of the available low pressure systems to inject because of miscalibration of the low reactor pressure permissive circuitry. This latter event disables LPCS and LPCI as well as HPSW injection which uses the LPCI injection paths. Without recovery of the PCS and accompanying condensate or feedwater in about thirty minutes, core damage results. The vessel can, and will likely be, depressurized with ADS leading to core damage under low pressure conditions in the reactor vessel.

The only dominant sequence which contributes to this plant damage state is

$$
\text { T2-T3QU1U2U3W1V2V3V4. }
$$

The frequency and the uncertainties of this sequence (i.e., of plant damage state TUV) follow:

$\begin{array}{ll}\text { Upper } 95 \text { Percent Bound } & 2.6 \mathrm{E}-7 \\ \text { Mean } & 4.9 \mathrm{E}-8 \\ \text { Median } & 1.3 \mathrm{E}-8 \\ \text { Lower } 5 \text { Percent Bound } & 7.6 \mathrm{E}-10 .\end{array}$

The dominant cut sets for the sequence are listed in Table V.2-31.

The major contributors to this plant damage state, on the basis of the importance measures analyzed, are listed (in approximate order of importance) in Table V.2-32.

None of the six sensitivity studies affects the TUV plant damage state. The detailed importance calculations for the base case are presented in Appendix $B$. It should be noted that the frequency of this type of accident is considerably lower than in past PRA estimates because of credit given to more injection systems (e.g., CRD, HPSW, etc.). 
Table V.2-3l

TUV Dominant Cut sets

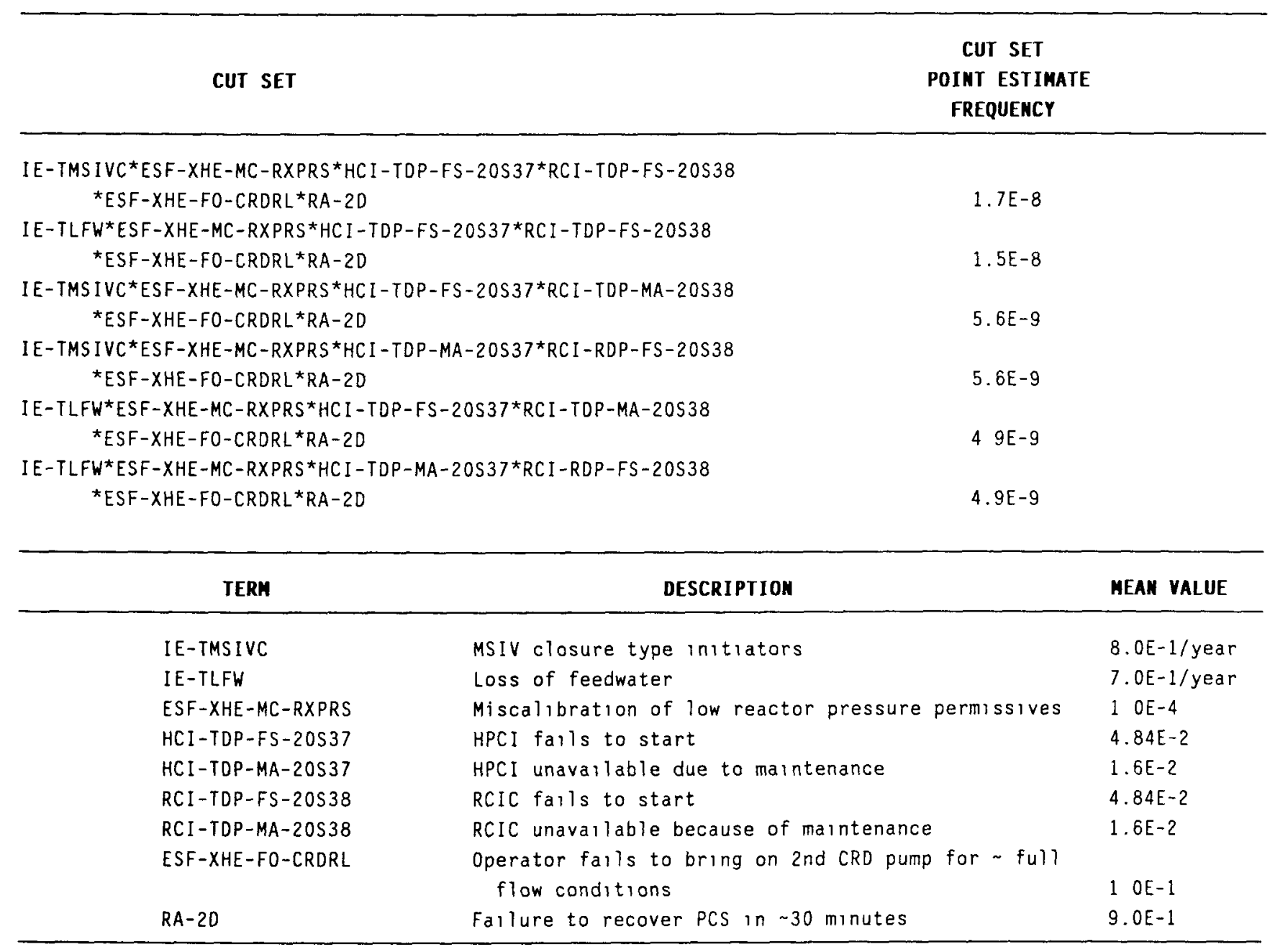


Table V.2-32

TUV Major Contributors

\begin{tabular}{|c|c|c|c|}
\hline MEASURE & EVENT & $\begin{array}{c}\text { IMPORTANCE } \\
\text { VALUE (POINT } \\
\text { ESTIMATE) }\end{array}$ & DESCRIPTION \\
\hline \multirow[t]{7}{*}{ Risk Reduction } & $R A-20$ & $5.6 E-8$ & $\begin{array}{l}\text { Non-recovery of offsite power in } \\
\sim 1 / 2 \text { hour }\end{array}$ \\
\hline & ESF-XHE-MC-RXPRS & $5.6 E-8$ & $\begin{array}{l}\text { Miscalibration of low pressure } \\
\text { permissives circuitry }\end{array}$ \\
\hline & ESF-XHE-FO-CRDRL & $5.3 E-8$ & Operator fails to start 2nd CRO pump \\
\hline & HCI -TDP-FS-20S37 & $4.6 E-8$ & HPCI fails to start \\
\hline & RCI-TDP-FS-20S38 & $4.6 \mathrm{E}-8$ & RCIC fails to start \\
\hline & IE-TMSIVC & $3.0 E-8$ & MSIV closure \\
\hline & IE-TLFW & $2.6 \mathrm{E}-8$ & Loss of feedwater \\
\hline Risk Increase & ESF-XHE-MC-RXPRS & $5.6 \mathrm{E}-4$ & $\begin{array}{l}\text { Miscalibration of low pressure } \\
\text { permissives circuitry }\end{array}$ \\
\hline \multirow[t]{6}{*}{ Uncertainty } & ESF-XHE-MC-RXPRS & $5.4 E-8$ & $\begin{array}{l}\text { Miscalibration of low pressure } \\
\text { permissives circuitry }\end{array}$ \\
\hline & ESF-XHE-FO-CRDRL & $5.2 E-8$ & Operator fails to start 2nd CRD pump \\
\hline & HCI -TDP-FS-20S37 & $3.6 \mathrm{E}-8$ & HPCI fails to start \\
\hline & RCI-TDP-FS-20S38 & $3.2 E-8$ & RCIC fails to start \\
\hline & IE-TMSIVC & $2.1 \mathrm{E}-8$ & MSIV closure \\
\hline & IE-TLFW & $1.9 E-8$ & Loss of feedwater \\
\hline
\end{tabular}




\section{V.2.12 Sequence Group AV}

This plant damage state is characterized by a large LOCA. There is failure of the low pressure systems resulting in a core damage event.

The only sequence in this plant damage state with a frequency greater than $1 E-8$ is AV2V3.

The frequency and the uncertainties of this sequence (i.e., of plant damage state AV) follow:
Upper 95 Percent Bound
$1.5 \mathrm{E}-7$
Mean
$3.2 E-8$
Median
$6.6 \mathrm{E}-9$
Lower 5 Percent Bound
$6.6 \mathrm{E}-10$.

The dominant cut sets for this sequence are listed in Table V.2-33.

The major contributors to this plant damage state are the same as for the SIV state (refer to V.2.9) and none of the sensitivity studies affects the AV group. The detailed importance calculations for the base case are presented in Appendix B. 
Table V.2-33

AV Dominant cut sets

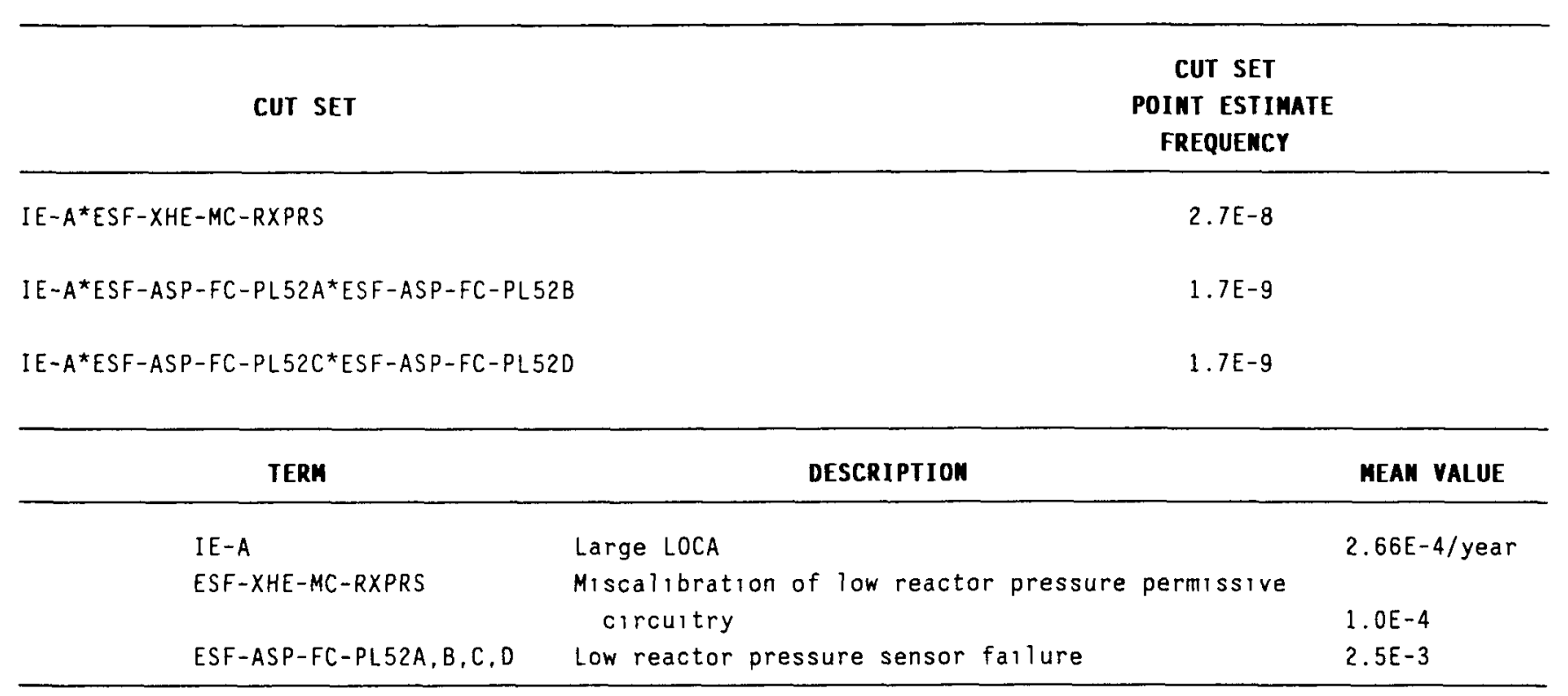




\section{V.2.13 Plant Damage State TUX}

Similar to the TUV plant damage state, this state involves a transient causing loss of the PCS and early failure of all injection. Injection loss is because of failures associated with the high pressure systems, ADS, and operator failure to manually depressurize so that low pressure systems can be used. Core damage results in about 30 minutes without recovery.

The only dominant sequence in this state is

T2-T3QU1U2U3W1X.

The frequency and the uncertainties of this sequence (i.e., of the plant damage state TUX) follow:

$\begin{array}{ll}\text { Upper } 95 \text { Percent Bound } & 1.1 \mathrm{E}-7 \\ \text { Mean } & 1.9 \mathrm{E}-8 \\ \text { Median } & 2.9 \mathrm{E}-9 \\ \text { Lower } 5 \text { Percent Bound } & <\mathrm{E}-10 .\end{array}$

The dominant cut sets for this sequence are listed in Table V.2-34.

The major contributors to this plant damage state, on the basis of the importance measures analyzed, are listed (in approximate order of importance) in Table V.2-35.

wo of the six sensitivities affect this plant damage state: Studies \#1 and \#2. igure V.2-10 shows the effects. None of the importance rankings changes significantly for Sensitivity \#2 but the ADS common mode term drops somewhat in ranking. Sensitivity \#1 makes the entire sequence drop to less than $1 E-8$. The detailed results of all the importance calculations are presented in Appendix $B$.

Modifications to the ADS at Peach Bottom have caused the estimated frequency of this type of accident to drop significantly. ADS will now operate automatically on only low water level (i.e., no longer needs coincident high drywell pressure). This prevents sole reliance on the operator to depressurize the vessel should the high pressure cooling systems fail. 
Table V.2-34

TUX Dominant cut sets

CUT SET

CUT SET

POINT ESTIMATE

FREQUENCY

IE-TMS IVC*ADS -VLV-FO-VALVE*B-ADS -FO-VLVS*SRV-XHE-FO-VLV*HCI-TDP-FS-20S37 ${ }^{\star} R C I-T D P-F S-20 S 38^{\star} E S F-X H E-F O-C R D R L{ }^{\star} R A-2 D$

7. $0 \mathrm{E}-9$

IE $-T L F W^{\star} A D S-V L V-F O-V A L V E * B-A D S-F O-V L V S * S R V-X H E-F O-V L V * H C I-T D P-F S-20 S 37$

${ }^{\star} R C I-T D P-F S-20 S 38 * E S F-X H E-F O-C R D R L * R A-2 D$

$6.1 E-9$

IE-TMSIVC*ADS-VLV-FO-VALVE*B-ADS -FO-VLVS*SRV-XHE-FO-VLV*HCI-TOP-MA-2OS37

${ }^{\star} R C I-T D P-F S-20 S 38^{\star} E S F-X H E-F O-C R D R L{ }^{*} R A-2 D$

$2.3 E-9$

IE-TMSIVC*ADS-VLV-FO-VALVE*B-ADS-FO-VLVS*SRV-XHE-FO-VLV*HCI-TOP-FS-20S37

${ }^{\star} R C I-T D P-M A-20 S 38^{\star} E S F-X H E-F O-C R D R{ }^{\star} R A-2 D$

IE $-T L F W^{\star} A D S-V L V-F O-V A L V E^{\star} B-A D S-F O-V L V S^{\star} S R V-X H E-F O-V L V^{\star} H C I-T D P-M A-20 S 37$

${ }^{\star} R C I-T D P-F S-20 S 38 * E S F-X H E-F O-C R D R L{ }^{*} R A-20$

$2.3 E-9$

$2.0 E-9$

IE-TLFW*ADS-VLV-FO-VALVE*B-ADS -FO-VLVS*SRV-XHE-FO-VLV*HCI-TOP-FS-20S37

${ }^{\star} R C I-T D P-M A-20 S 38^{\star} E S F-X H E-F O-C R D R L{ }^{\star} R A-2 D$

$20 E-9$

\begin{tabular}{|c|c|c|}
\hline TERH & DESCRIPTION & MEAN YALUE \\
\hline IE-TMSIVC & MSIV closure type initiators & $8.0 E-1 /$ year \\
\hline IE-TLFW & Loss of feedwater & $7.0 \mathrm{E}-1 /$ year \\
\hline ADS-VLV-FO-VALVE* & Hardware fallure (to open) of ADS valve & $5.0 \mathrm{E}-2$ \\
\hline$B-A D S-F 0-V L V S^{*}$ & $\begin{array}{l}\text { Common mode Beta factor applied to above term } \\
\text { for } 2 \text { nd valve }\end{array}$ & $8.33 E-2$ \\
\hline SRV-XHE-FO-VLV & Operator fallure to operate non-ADS SRVs manually & $10 \mathrm{E}-2$ \\
\hline ESF-XHE-FO-CRDRL & $\begin{array}{l}\text { Operator fallure to bring on } 2 \text { nd CRD pump for } \\
\sim \text { full flow conditions }\end{array}$ & $1.0 E-1$ \\
\hline HCI-TDP-FS-20S37 & HPCI fails to start & $4.84 \mathrm{E}-2$ \\
\hline HCI I TOP-MA-20S37 & HPCI unavallable because of maintenance & $1.6 E-2$ \\
\hline RCI-TDP-FS-20S38 & RCIC farls to start & $4.84 E-2$ \\
\hline RCI I TDP-MA-20S38 & RCIC unavallable because of maintenance & $1.6 E-2$ \\
\hline RA-2D & Fallure to recover PCS in $\sim 30$ minutes & $9.0 E-1$ \\
\hline
\end{tabular}

*Together make up common mode fallure of 2 ADS valves. Beta factor of 1.0 applied to remaining ADS valves per methodology guidelines. 



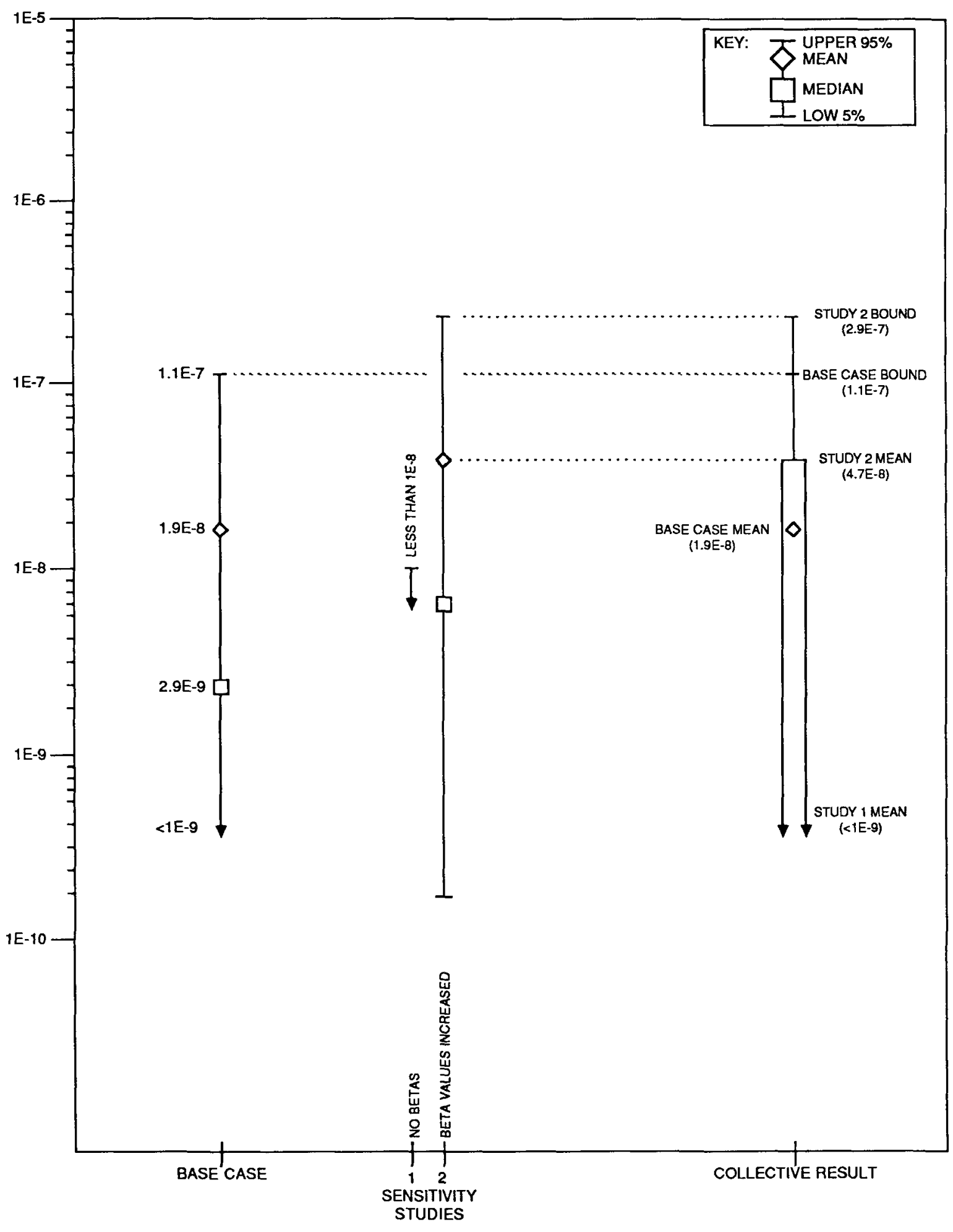

Figure V.2-10. Peach Bottom TUX Core Damage Frequency. 
In this study, individual sequences tended to be defined in a more detailed manner than has been done in other studies. For instance, an individual sequence from the event trees in this study often goes beyond defining a "core damage" outcome because choices are also provided which define the status of containment systems or whether the reactor vessel is or is not depressurized. This was done to better describe each sequence's properties to the "back-end" analysts for treatment in the containment and risk analyses. The plant damage states "collect" sequences with similar properties into one group which all tend to lead to core damage in about the same way. Therefore, the plant damage states more closely resemble the definitions of "sequences" in other studies. For this reason, as well as for the containment analysts, the results of this study have been reported at the overall and plant damage state levels.

If one is interested in determining an individual sequence frequency from the dominant plant damage states in this report, the process involves a simple multiplication in some cases and an extraction of the appropriate cut sets in other cases. Two examples are provided below.

\section{Example 1}

(Refer to Section V.2.1) --

Plant damage state TBUX has a mean frequency of $4.2 E-6$ and is made up of two sequences:

T1-T2-T3(Q)U1U2BOX,

T1-T2-T3(Q)U1U2BOXY.

The split fraction for "Y" success/failure is $0.1 / 0.9$. Therefore, the frequency of the first sequence above ( $Y$ success) can be approximated by $4.2 \mathrm{E}-6 \times 0.1=4.2 \mathrm{E}-7$.

Example 2

(Refer to Section V.2.4) --

TCSRX2 is one of the substates to plant damage state TCSR. This substate is made up of two sequences:

$T * M S I V * R P S M * S L C * / R X H P * / D E P * / L P I N * Y *$ Containment Leakage, $T^{*} /$ MSIV*RPSM*FW*SLC*/RXHP*/DEP*/LPIN*Y*Containment Leakage.

The collective cut sets for the two sequences are listed in Table V.3-1.

The first sequence above involves initial MSIV closure (MSIV) while the second involves MSIVs initially open (/MSIV). Looking at the cut sets, the 1 st and 4 th cut sets involve the term "CMSIVA" (subsequent closure of MSIVs). Therefore, these cut sets are for the MSIVs initially open sequence. Extracting these two cut sets and summing their respective values approximate the value for the MSIVs initially open sequence: $1.1 \mathrm{E}-7+3.2 \mathrm{E}-8=1.4 \mathrm{E}-7$.

Other individual sequence values can be approximated using the methods described pove. 
Table V.3-l

TCSRX2 Dominant Cut sets

\begin{tabular}{|c|c|c|}
\hline CUT SET & \multicolumn{2}{|c|}{$\begin{array}{l}\text { CUT SET } \\
\text { POINT ESTIMATE } \\
\text { FREQUENCY }\end{array}$} \\
\hline \multicolumn{2}{|c|}{ IE-TRTRIP*CMSIVA*RPS-M*SLC-XHE-FS*VENT-XHE-TC*CONTAINMENT LEAKAGE } & $1.1 E-7$ \\
\hline \multicolumn{2}{|c|}{ IE-TMS IVC*RPS-M*SLC-XHE-FS*VENT-XHE-TC*CONTAINMENT LEAKAGE } & $7.4 \mathrm{E}-8$ \\
\hline \multicolumn{2}{|c|}{ IE-TLFW*RPS-M*SLC-XHE-FS*VENT-XHE-TC*CONTAINMENT LEAKAGE } & $6.5 E-8$ \\
\hline \multicolumn{2}{|c|}{ IE-TRTRIP*CMSIVA*RPS-M*SLC-XHE-REL*VENT-XHE-TC*CONTAINMENT LEAKAGE } & $32 E-8$ \\
\hline TERM & DESCRIPTION & MEAK YALUE \\
\hline IE-TRTRIP & Turbine trip & $2.4 /$ year \\
\hline IE-TMSIVC & MSIV closure type initiators & 8.0E-1/year \\
\hline IE-TLFW & Loss of feedwater & 7.0E-1/year \\
\hline CMSIVA & Subsequent closure of MSIVs & $5.0 E-1$ \\
\hline RPS -M & Mechanical fallure of all control rods & $1.0 \mathrm{E}-5$ \\
\hline$S L C-X H E-F S$ & Operator fallure to start SLC by 4 minutes & $3.38 E-2$ \\
\hline SLC-XHE-REL & $\begin{array}{l}\text { SLC falls because of fallure to realign pr } \\
\text { after test }\end{array}$ & $1.0 E-2$ \\
\hline VENT-XHE -TC & Fallure to vent containment & $9.0 \mathrm{E}-1$ \\
\hline CONTAINMENT LEAKAGE & Containment leaks & $\sim 0.45$ \\
\hline
\end{tabular}


A comparison of the results of this study with those of WASH-1400 [4] must be done with full recognition of study differences in order to produce meaningful insights. In the ten years between WASH-1400 and this study, the Peach Bottom plant design, as well as the industry's understanding of reactor operation and safety, has changed substantially. Any comparison of dominant contributors to core damage frequency between these two studies must be balanced by a knowledge of the differences in plant design, study methodology, and success criteria.

It is difficult to directly compare the total core damage frequencies calculated in the two studies. WASH-1400 calculated a total core damage frequency of approximately $2.5 \mathrm{E}-5$ which is a sum of individual sequence median values (note that the sum is not necessarily a median value). This study has determined the median core damage frequency at Peach Bottom to be 5.1E-6 or a corresponding mean value of $8.2 \mathrm{E}-6$. The modifications in plant configuration and procedures at Peach Bottom, as well as the evolution of analysis insights since WASH-1400, have reduced the dominant results of that study considerably. In fact, the two most dominant scenarios from the WASH-1400 study (transient with loss of long term decay heat removal [TW] and ATWS [TC]) have been decreased by approximately a factor of 1000 and at least 10 respectively. However, more complete consideration of failures of DC-powered systems during station blackout and a more comprehensive treatment of common mode failures and support system (e.g. power, cooling...) failures combine to increase the core damage frequency to a mean value of $8.2 E-6$. Some of the significant comparisons leading to these insights are presented below:

- Transients with loss of long term decay heat removal are dominant in WASH-1400 but not in this study. This is primarily because of the consideration of containment venting procedures now in place at Peach Bottom as well as examining the survivability of core cooling systems even if the containment should fail.

- ATWS sequence frequencies are reduced by about an order of magnitude in this study as compared to WASH-1400 because a more detailed analysis was performed which accounts for the provisions of the ATWS rule that have been put in place since WASH-1400. The corresponding procedures and plant modifications have reduced the core damage contribution from these sequences.

- Station blackout (loss of all $\mathrm{AC}$ ) sequences are estimated to be almost two orders of magnitude higher than in WASH-1400 because of a more complete consideration of potential failures of DC-powered systems during a blackout, a more complete common mode failure analysis (e.g. includes DC battery common mode failures), and a more complete analysis of support system effects on the AC power system (e.g., diesel cooling).

- All other transient and LOCA sequences are similarly on the order of $1 \mathrm{E}-7$ or less in both studies, although this study's results are generally somewhat lower than WASH-1400 when individual sequences are compared one-to-one. 
- Based on the above, both studies conclude that transients, and not LOCAs, dominate the core damage frequency (and risk) at Peach Bottom. However, the types of transients are significantly different. WASH-1400 is dominated by ATWS and long term heat removal failure sequences while this study is dominated by station blackout scenarios with ATWS being approximately a $12 \%$ contributor to core damage frequency.

Table V.4-1 summarizes the comparable core damage frequencies for the most dominant sequences of both studies. Figures V.4-1 and V.4-2 pictorially demonstrate the differences for the most dominant sequences as well as for the total core damage frequency results of both studies.

The reader is referred to Appendix $C$ for information which provides additional perspective on the results of this study (and, hence, its comparison to WASH-1400). 
Table V.4-I

Comparison of NUREG/CR-4550 Update/WASH-1400 sequences (Most Dominant only)

\begin{tabular}{|c|c|c|c|c|}
\hline $\begin{array}{l}\text { GENERAL } \\
\text { ACCIDEMT } \\
\text { TYPE }\end{array}$ & $\begin{array}{l}4550 \text { UPDATE } \\
\text { PLANT DAMAGE } \\
\text { STATES }\end{array}$ & $\begin{array}{l}4550 \text { UPDATE } \\
\text { FREQUENCY } \\
\text { MEAN (MEDIAK) } \\
\text { [see Note (a)] }\end{array}$ & $\begin{array}{c}\text { SIMILAR } \\
\text { WASH-1400 } \\
\text { SEQUENCES }\end{array}$ & $\begin{array}{l}\text { APPROXIMATE } \\
\text { UASH-1400 } \\
\text { FREQUENCY } \\
\text { [see Note (b)] }\end{array}$ \\
\hline Station Blackout & $\begin{array}{l}\text { TBUX, TB, TBUP, } \\
\text { TBU, TBP }\end{array}$ & $7.0 E-6 \quad(3.4 E-6)$ & Part of TQUV \& TPQUV & 1.0E-7 \\
\hline ATWS & $\begin{array}{l}\text { TCUX, TCSR, } \\
\text { TCSX, TCSAR }\end{array}$ & $1.0 \mathrm{E}-6(1.6 \mathrm{E}-7)$ & TC & $1.0 E-5$ \\
\hline $\begin{array}{l}\text { Transient-loss } \\
\text { of long term } \\
\text { heat removal }\end{array}$ & Non-dominant & $<1 E-8$ & TW & 1. $4 E-5$ \\
\hline
\end{tabular}

NOTES:

(a) Sum of means (or medians) of individual plant damage states.

(b) Median values. 


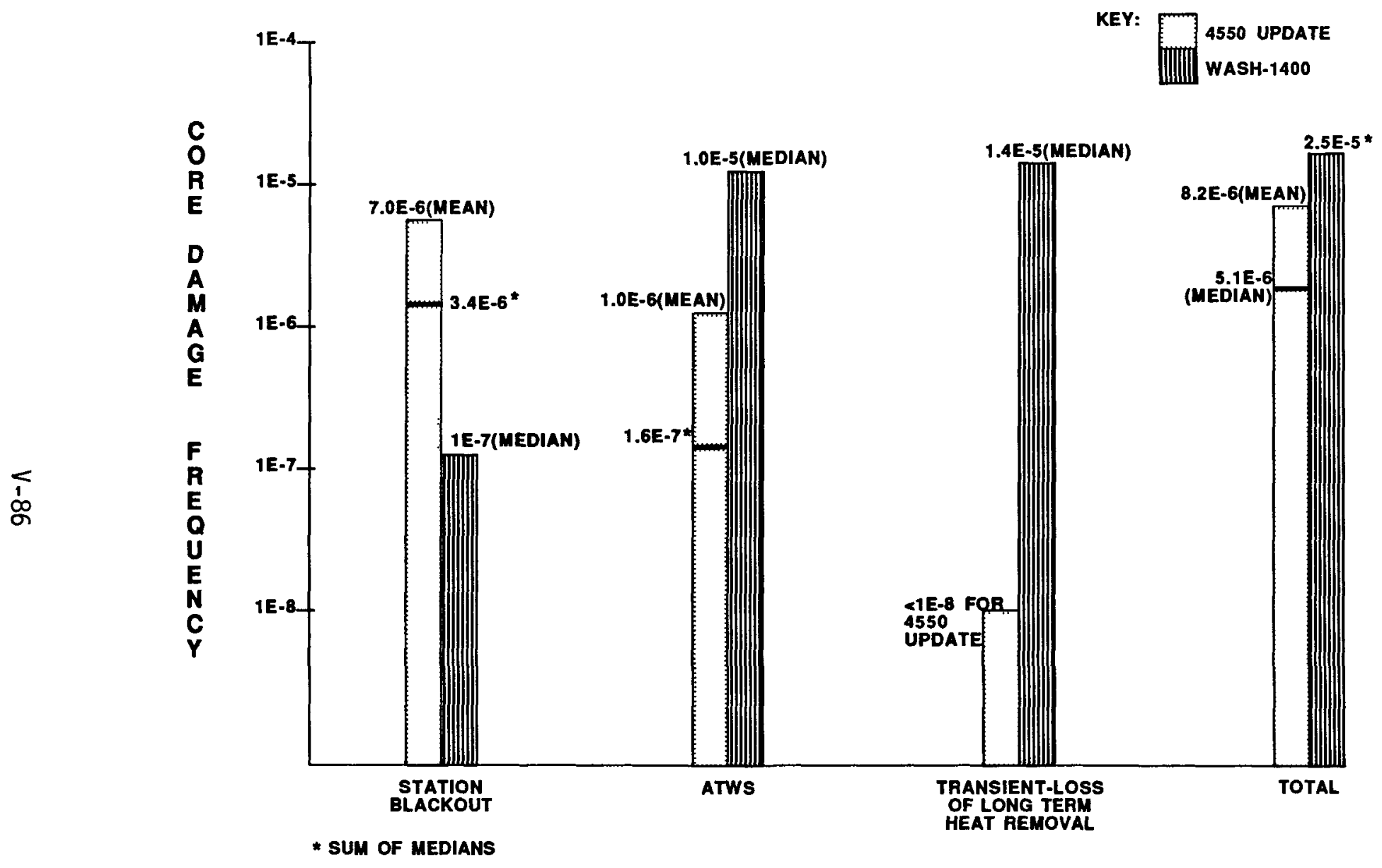

Figure V.4-1. Core Damage Frequency Comparison. 


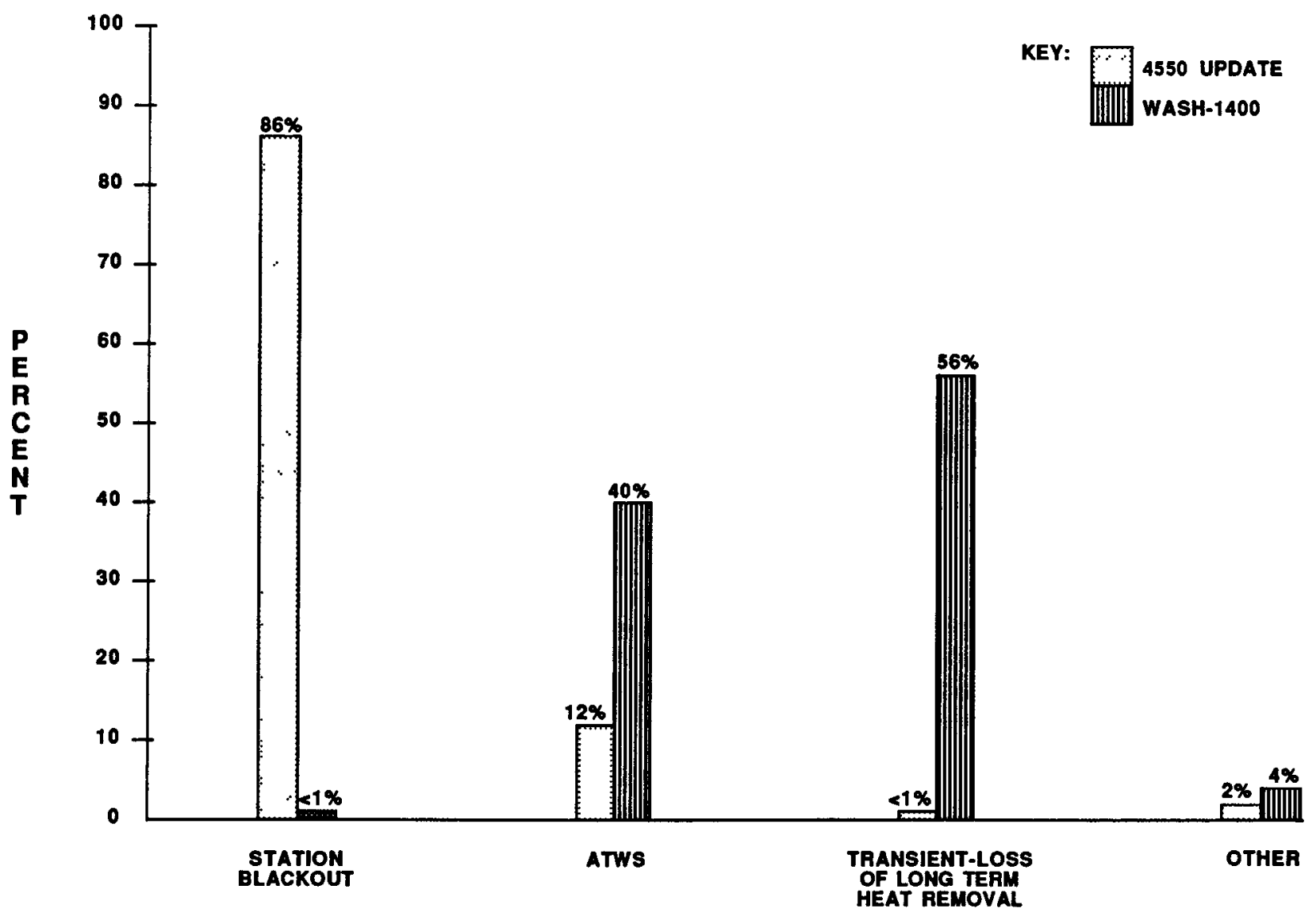

Figure V.4-2. Comparison of Accident-Type Contributions. 
0

○

○ 
The following subsections present conclusions and other insights based on the results of the Peach Bottom NUREG/CR-4550 update analysis.

\section{VI.1 GENERAL CONCLUSIONS}

One of the major purposes of the Peach Bottom analysis was to provide an updated perspective on our understanding of the risks from the $\mathrm{plant}$ relative to the results of the WASH-1400 analysis [4]. It has been determined that changes to the plant design and its procedures, the evolution of Probabilistic Risk Assessment (PRA) methodology, and our increasing understanding of severe accidents have all impacted our perspectives on the dominant risks for Peach Bottom. While both WASH-1400 and this study agree that transients (and not loss of coolant accidents) dominate the Peach Bottom core damage frequency, the most important types of transient scenarios have changed.

Unlike WASH-1400, this study concludes that station blackout (loss of all AC power) accidents are the dominant contributors to core damage. ATWS scenarios are of moderate importance and all other types of accidents are relatively insignificant. The possibility of successful containment venting and realistically allowing for successful core cooling after containment failure have considerably reduced the significance of the loss of long term heat removal accidents. Giving credit for more injection systems, using best estimate system success criteria, and plant modifications have also collectively reduced the importance of loss of injection type sequences.

Given the considerable redundancy and diversity of coolant injection and heat removal features at Peach Bottom, it is not surprising that common features of the plant tend to drive the core damage frequency. These include common cause failures of equipment, failure of common support systems ( $A C$ power and Emergency Service Water ESW), and to some extent - human error. In light of this conclusion, it must also be recognized that the calculated core damage frequency in this study is subject to the non-trivial uncertainties associated with the state-of-the-art in common cause and human error analyses. This calculated frequency is $8.2 \mathrm{E}-6$ (mean value) as compared to $2.5 \mathrm{E}-5$ (sum of individual sequence median values) in WASH-1400.

The above insights can be considered applicable to other Boiling Water Reactors of similar design to the extent that the redundancy arguments are true for other plants of interest. However, numerous subtleties in plant design and operational practices and procedures make it difficult to draw specific conclusions for other plants on the basis of this analysis without performing plant-specific reviews (particularly as related to common cause potential).

More specific conclusions and insights applicable to Peach Bottom are presented in the following subsections.

\section{VI.2 ACCIDENT SPECIFIC CONCLUSIONS}

As stated above, the core damage profile is primarily made up of two general types accidents as indicated below: 


\begin{tabular}{lcc}
\hline & $\begin{array}{c}\text { Mean } \\
\text { Frequency }\end{array}$ & $\begin{array}{c}\text { \% Contribution } \\
\text { to Core Damage } \\
\text { Frequency }\end{array}$ \\
\hline $\begin{array}{l}\text { Station Blackout } \\
\text { Anticipated Transient }\end{array}$ & $7.0 \mathrm{E}-6$ & 86 \\
$\begin{array}{l}\text { Without Scram (ATWS) } \\
\text { All Others }\end{array}$ & $1.0 \mathrm{E}-6$ & 12 \\
& $<2 \mathrm{E}-7$ & 2 \\
\hline
\end{tabular}

Making up these general accident types are thirteen plant damage states which were defined to properly bin "like" sequences with similar plant effects and to facilitate the subsequent containment analyses and development of risk profiles presented in other reports.

The plant damage state with the highest frequency is a loss of all AC power with coincident multiple DC division failures leading to core damage in approximately one half to one hour. This plant damage state represents approximately $51 \%$ of the total Peach Bottom base case core damage frequency. The second most dominant plant damage state is a long-term station blackout with successful core cooling until battery depletion in about six hours. This subsequent loss of DC power contributes to the loss of coolant injection at that time, resulting in core damage. This plant damage state contributes about $28 \%$ of the total base case core damage frequency. Four ATWS plant damage states are of two general types: core damage before containment failure and containment failure leading to subsequent loss of coolant injection and hence core damage. These collectively contribute approximately $12 \%$ to the core damage frequency.

Seven other plant damage states individually contribute from $3 \%$ to less than $1 \%$ of the core damage frequency. These remaining plant damage states include other station blackout scenarios, transients with early loss of injection, and intermediate and 1arge LOCAs with loss of injection.

\section{VI.3 UNCERTAINTY CONSIDERATIONS}

The above conclusions are incomplete without considering the results of the uncertainty and sensitivity calculations. The total base case mean core damage frequency $(8.2 \mathrm{E}-6)$ has a $95 \%$ upper bound value of $2.4 \mathrm{E}-5$ and a $5 \% 1$ ower bound of $1.3 \mathrm{E}-6$ because of statistical uncertainty in the failure data.

Apart from the calculation of statistical uncertainty, sensitivity studies were conducted to resolve the effects of specific data uncertainties and the uncertainty associated with modeling assumptions. The range of the means of total core damage frequencies resulting from these calculations is $3.4 \mathrm{E}-6$ to $1.2 \mathrm{E}-5$. The lowest $5 \%$ bound value calculated for any sensitivity analysis is $4.0 E-7$ and the highest $95 \%$ bound value calculated is $3.7 \mathrm{E}-5$.

Since the results show a significant contribution from $A C$ and $D C$ power system common cause failures, it is not surprising that changes to the generic Beta factor values used to assess common cause failures contribute most to the range of values indicated above. Other sensitivities generally have much less effect (typically a factor of two or less) on the more dominant plant damage states Some of the less dominant states are affected considerably by the sensitivities (factor of ten) but, because of their low overall contribution, still have no major impact on the general conclusions of the study.

VI-2 


\section{VI.4 OTHER INSIGHTS}

ased on three importance measures evaluated for the base case study, the following insights are noted. Failures which, if reduced significantly, would have the greatest effect in lowering the core damage potential include common cause failures of batteries and diesels, failure to recover power, common mechanical failure of the control rods, and failure to start Standby Liquid Control (SLC). There are features whose unavailabilities should not be allowed to increase significantly or they could increase the core damage frequency considerably. These include common mechanical failure of the control rods, maintenance of the common emergency service water discharge valve, diesel and battery common cause and independent hardware faults, and miscalibration of the low reactor pressure permissive circuitry for Low Pressure Core Spray and Low Pressure Coolant Injection. Finally, the uncertainty in the core damage frequency, from a data uncertainty perspective, is driven by battery and diesel hardware faults including common cause, offsite power recovery, mechanical failure of the control rods, and failure to start SLC.

Considering the above, some additional insights are noted by the team analyst's as a result of performing the PRA update of Peach Bottom. First, ESW fault contributions could be reduced if at least one ESW booster pump did not share the same power as the two main ESW pumps. This would prevent the same power loss from potentially affecting both the primary and emergency heat sink mode of the ESW system. Further, procedures addressing operation of the ESW system, should the common discharge valve (MOV-0498) ever be closed for maintenance, could further lower the contribution of the ESW system to station blackout. The recent vailabilities of the diesel generators at Peach Bottom generally are a factor of en better than the industry average. This appears to be based on a deliberate attention to detail in the test and maintenance practices as well as an attempt to determine the root causes of failures so that effective actions can be taken. Peach Bottom staff should continue to show the diligence and attention to detail that is required to maintain such good performance. Close scrutiny of DC battery surveillance and maintenance practices will assure that the estimated DC common mode potential in this report is not realized. The importance of the Control Rod Drive (CRD) and High Pressure Service Water systems as injection sources to the vessel (the latter as a last resort) came through clearly as the analysis evolved. This point should be stressed in operator training. The fact that loss of air could affect one of the CRD flow paths to the vessel may need further review. An air pressure limit of 125 psig could affect the capability to continue low pressure core cooling under accident conditions with the containment at high pressure (i.e., Safety Relief Valves will not stay open). The purpose for this limit should perhaps be reviewed. The conflicting requirements of first inhibiting the Automatic Depressurization System and then needing to rapidly depressurize in some ATWS sequences should be recognized. And finally, the apparent difficulties associated with venting the containment in the station blackout and ATWS scenarios could have significant core damage and consequence effects which may need to be addressed.

While these insights are provided here from the standpoint of the analysts' perspective, it should be noted that the implementation of any recommendations stemming from these or other insights should consider the need for such actions based on the overall core damage frequency and risk estimated for Peach Bottom. addition, the conservatisms and uncertainties associated with the analysis, as 1 as cost-benefit factors, should be considered. 
•

• 
United States Nuclear Regulatory Commission, "Categorization of Reactor Safety Issues From a Risk Perspective," NUREG-1115, March 1985.

[2] F. T. Harper, et a1., "Analysis of Core Damage Frequency From Internal Events: Methodology Guidelines," Sandia National Laboratories, NUREG/CR-4550, SAND86-2084, Vol. 1 of 10 (to be published).

[3] A. M. Kolaczkowski and M. T. Drouin, "Interim Report on Accident Sequence Likelihood Reassessment (Accident Sequence Evaluation Program), " Sandia National Laboratories, Science Applications, Inc., Draft Report, August 1983.

[4] United States Nuclear Regulatory Commission, "Reactor Safety Study," WASH-1400, October 1975.

[5] S. W. Hatch, et a1., "Reactor Safety Study Methodology Applications Program: Grand Gulf \#l BWR Power Plant," Sandia National Laboratories and Battelle Columbus Laboratories, NUREG/CR-1659/4 of 4, SAND80-1897/4 of 4, October 1981 .

[6] S. E. Mays, et al., "Interim Reliability Evaluation Program: Analysis of the Browns Ferry, Unit 1, Nuclear Plant," Idaho National Engineering Laboratory (EG\&G Idaho, Inc.) and Energy Incorporated (Seattle), NUREG/CR-2802, EGG2199, Ju1y 1982.

"Probabilistic Risk Assessment: Limerick Generating Station," Philadelphia Electric Co., Revision 4, June 1982.

[8] "Probabilistic Risk Assessment Shoreham Nuclear Power Station," Science Applications, Inc., SAI372-83-PAO1, June 1983.

[9] "Additional Information Required for NRC Staff, Generic Report on Boiling Water Reactors," General Electric, NED024708A, CLASS I, Revision 1, December 1980.

[10] Peach Bottom "Hi-Spot" Reports, 1975-1985.

[11] "Peach Bottom Updated Final Safety Analysis Report," Philadelphia Electric Co., 1985.

[12] J. Minarick, "BWR Event "V"," Presentation at ASEP SCG/0956 - NRC meeting, May 22, 1985.

[13] "ATWS: A Reappraisal, Part 3: Frequency of Anticipated Transients," EPRI NP-801, JuTy 1978.

[14] "ATWS: A Reappraisal, Part 3: Frequency of Anticipated Transients," EPRI NP-2230, Interim Report, January 1982.

[15] R. M. Harrington and S. A. Hodge, "Loss of Control Air at Brown Ferry Unit One - Accident Sequence Analysis," Oak Ridge National Laboratory, NUREG/CR-4413, Draft Report, December 1985. 
[16] A. J. Call, et al., "La Salle County Station Probabilistic Safety Analysis," General Electric, NEDO-31085, CLASS I, November 1985.

[17] C. E. Economos, et al., "Postulated SRV Line Break in the Wetwell Airspace of Mark I and Mark II Containments-A Risk Assessment," Brookhaven National Laboratory, BNL-NUREG-31940, October 1982.

[18] Note 19 of PECO Emergency Procedures, 1985.

[19] Letter from Terry Steam Turbine Company to General Electric Company, "Bearing Lube 0i1 Temperature," October 24, 1972.

[20] G. J. Kolb, et al., "Review and Evaluation of the Indian Point Probabilistic Safety Study," Sandia National Laboratories, NUREG/CR-2934, December 1982.

[21] Letter from G. J. Boyd (Safety and Reliability Optimization Services, Inc.) to F.T. Harper (Sandia National Laboratories), June 18, 1985.

[22] Letter from F. T. Harper and G. J. Kolb, "Subtle Interactions Found in Past PRAs and PRA Related Studies," to PRA Experts, July 2, 1985.

[23] K. N. Fleming, et al., Classification and Analys is of Reactor Experience Involving Dependent Events," Pickard, Lowe, and Garrick, Inc., NP-3967, Research Project 2169-4, June 1985.

[24] P.W. Baranowski, A. M. Kolaczkowski, and M. A. Fedele, "A Probabilistic Safety Analysis of DC Power Supply Requirements for Nuclear Power Plants," United States Nuclear Regulatory Commission, Sandia National Laboratories, Evaluation Associates, Inc., NUREG-0666, Apri1 1981.

[25] A. D. Swain, "Accident Sequence Evaluation Program Human Reliability Analys is Procedure," HRA Procedure for Pre-Accident Tasks, NUREG/CR-4772, Draft NUREG for Review, SAND86-1996, October 1986.

[26] A. D. Swain, "Accident Sequence Evaluation Program Human Reliability Analysis Procedure," HRA Procedure for Post-Accident Tasks, NUREG/CR-4772, Draft NUREG for Review, SAND86-1996, October 1986.

[27] United States Nuclear Regulatory Commission," Position Paper on Containment Venting," DRAFT, May 14, 1986.

[28] R. L. Iman and M. J. Shortencarier, "Top Event Matric Analysis Code," Sandia National Laboratories, Draft, June 1986.

[29] W. J. Luckas, et al., "A Human Reliability Analysis for the ATWS Accident Sequence with MSIV Closure at the Peach Bottom Atomic Power Station," Brookhaven National Laboratory, May 1986.

[30] R. M. Harrington, "Evaluation of Operator Action Strategies for Mitigation of MSIV Closure Initiated ATWS," Oak Ridge National Laboratory, Letter Report, November 11, 1985.

[31] R. M. Harrington and L. C. Fuller, "BWR-LTAS: A Boiling Water Reactor Long-Term Accident Simulation Code," Oak Ridge National Laboratory, NUREG/CR-3764, ORNL/TM9163, February 1985. 
32] R. M. Harrington and S. A. Hodge, "ATWS at Browns Ferry Unit One - Accident Sequence Analysis," Oak Ridge National Laboratory, NUREG/CR-3470, ORNL/TM-8902, JuTy 1984.

[33] "Assessment of BWR Mitigation of ATWS (NUREG 0460 A7ternate No. 3), " General Electric, NEDO-24222, 80NED021, CLASS I, February 1981.

[34] R. J. Dallman, et a1., "Severe Accident Sequence Analysis Program Anticipated Transient Without Scram Simulations for Browns Ferry Nuclear Plant Unit 1," Idaho National Engineering Laboratory (EG\&G Idaho), NUREG/CR-4165, EGG-2379 (Draft), February 1985.

[35] United States Nuclear Regulatory Commission, "Anticipated Transients Without Scram for Light Water Reactors," NUREG-0460, April 1978.

[36] A. M. Kolaczkowski and A. C. Payne, "Station Blackout Accident Analyses," Sandia National Laboratories, NUREG/CR-3226, SAND82-2450, May 1983. 
•

•

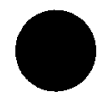


VIII. GLOSSARY OF ABBREVIATIONS

ACO..... Auxiliary Control Operator

ADS...... Automatic Depressurization System

ARI...... Alternate Rod Insertion System

ASEP..... Accident Sequence Evaluation Program

ATWS..... Anticipated Transient Without Scram

BCL...... Battelle Columbus Laboratory

BNL...... Brookhaven National Laboratory

BWR...... Boiling Water Reactor

CI\&V..... Containment Injection \& Venting System (same as PCVS)

CO...... Control Operator

COND..... Condensate System

CRD,

CRDS... Control Rod Drive System

CS,

CSS... Containment Spray System

CST..... Condensate Storage Tank

PEP...... Depressurization of Primary System

DG....... Diesel Generator

Dp....... Differential Pressure

ECW...... Emergency Cooling Water

EHS...... Emergency Heat Sink

EPG...... Emergency Procedure Guideline

EPS...... Electric Power System

ESF...... Emergency Safeguard (Actuation)

ESW,

ESWS... Emergency Service Water System

EVS...... Emergency Ventilation System

FSAR.... Final Safety Analys is Report

FW....... Feedwater

GE....... General Electric

HCTL..... Heat Capacity Temperature Limit

HCU...... Hydraulic Control Unit

HEP...... Human Error Probability

CI,

HPCIS.. High Pressure Coolant Injection System 


\section{GLOSSARY OF ABBREVIATIONS (Continued)}

HPSW,

HPSWS.. High Pressure Service Water System

HRA..... Human Reliability Anatysis

HtX..... Heat Exchanger(s)

HVAC.... Heating Ventilation System

IAS...... Instrument Air System

ILRT..... Integrated Leak Rate Test

INEL..... Idaho National Engineering Laboratory

IORV..... Inadvertent Open Relief Valve

IREP..... Interim Reliability Evaluation Program

LER...... License Event Report

LOCA..... Loss of Coolant Accident

LOFW..... Loss of Feedwater

LOSP..... Loss of Offsite Power

LPCI,

LPCIS. . Low Pressure Coolant Injection System LPCS,

LPCSS. . Low Pressure Core Spray System

LWR...... Light Water Reactor

MCC...... Motor Control Center

MOV...... Motor Operated Valve

MSIV..... Main Steam Isolation Valve

NPSH..... Net Positive Section Head

NRC...... Nuclear Regulatory Commission

NSW...... Normal Service Water System

OOS..... Out of Service

ORNL.... Oak Ridge National Laboratory

OSC...... Oscillating

PCS...... Power Conversion System

PCVS..... Power Containment Venting System

PECO..... Philadelphia Electric Company

PL\&G..... Pickard, Lowe, and Garrick

PRA...... Probabilistic Risk Assessment

PSF...... Performance Sharing Factor 


\section{GLOSSARY OF ABBREVIATIONS (Continued)}

QCG..... Quality Control Group

RBCW..... Reactor Building Cooling Water System

$\mathrm{RCIC}$,

RCICS. . Reactor Core Isolation Cooling System

RCS...... Reactor Coolant System

RHR,

RHRS... Residual Heat Removal System

RPS..... Reactor Protection System

RPT...... Recirculation Pump Trip

RPV...... Reactor Pressure Vesse]

RSCS..... Rod Sequence Control System

RSSMAP... Reactor Safety Study Methodology Applications Program

RWCU,

RWCUS.. Reactor Water Cleanup System

RWM...... Rod Worth Minimizer

SAIC.... Science Applications International Corporation

SAS...... Service Air System

SCG...... Senior Consultant Group

SDC,

SDCS... Shutdown Cooling System

SDV...... Scram Discharge Volume

SETS..... SET Equation Transformation System

SGTS.... Standby Gas Treatment System

SLC,

SLCS... Standby Liquid Control System

SLO..... Senior Licensed Operator

SNLA,

Sandia. Sandia National Laboratories-Albuquerque

SORV..... Stuck-Open Relief Valve

$S P C$,

SPCS... Suppression Pool Cooling System

SRV...... Safety Relief Valve

STA..... Shift Technical Advisor

AAF..... Top of Active Fue 


\section{GLOSSARY OF ABBREVIATIONS (Concluded)}

TBCW.... Turbine Building Cooling Water System

TDP...... Turbine Drive Pump

TEMAC.... Top Event Matrix Analysis Code

TH...... ToO High

TL...... Too Low

TRIP.... Transient Response Implementation Plan

TMI...... Three Mile Island Power Plant

UFSAR.... Updated Final Safety Analysis Report

VSS...... Vapor Suppression System 
APPENDIX A:

PEACH BOTTOM SYSTEM FAULT TREES 
HIGH PRESSURE COOLANT INJECTION SYSTEM FAULT TREE............... A-3

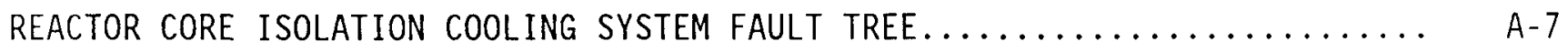

AUTOMATIC DEPRESSURIZATION SYSTEM FAULT TREE $\ldots \ldots \ldots \ldots \ldots \ldots \ldots \ldots \ldots \ldots \ldots \ldots$ A-11

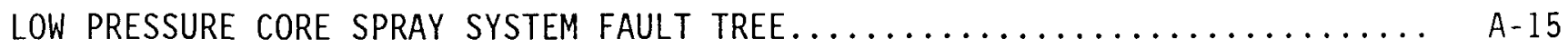

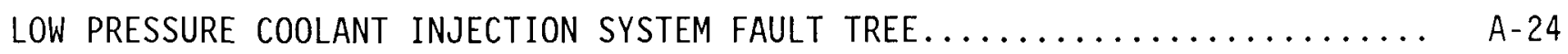

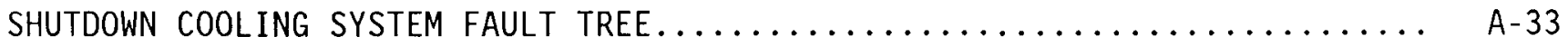

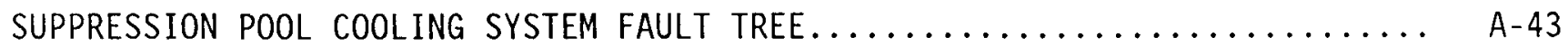

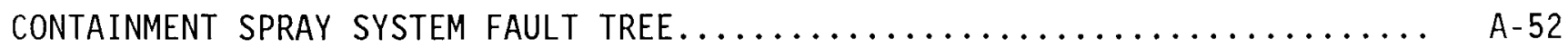

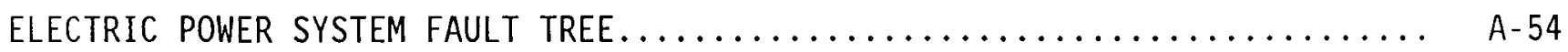

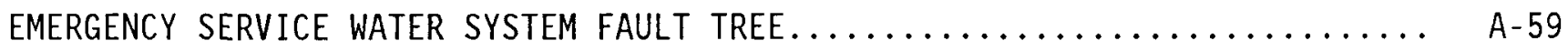

HIGH PRESSURE SERVICE WATER SYSTEM FAULT TREE .................. A-74

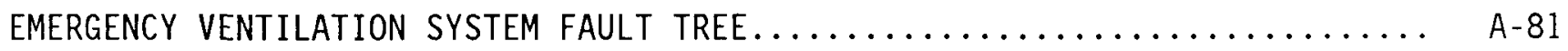

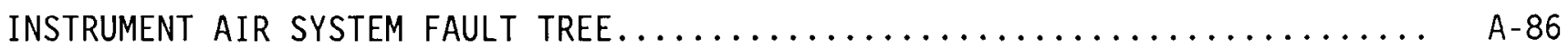

EMERGENCY SAFEGUARDS ACTUATION SYSTEM FAULT TREE ................ A-88 
HIGH PRESSURE COOLANT INJECTION SYSTEM

FAULT TREE

A-3 


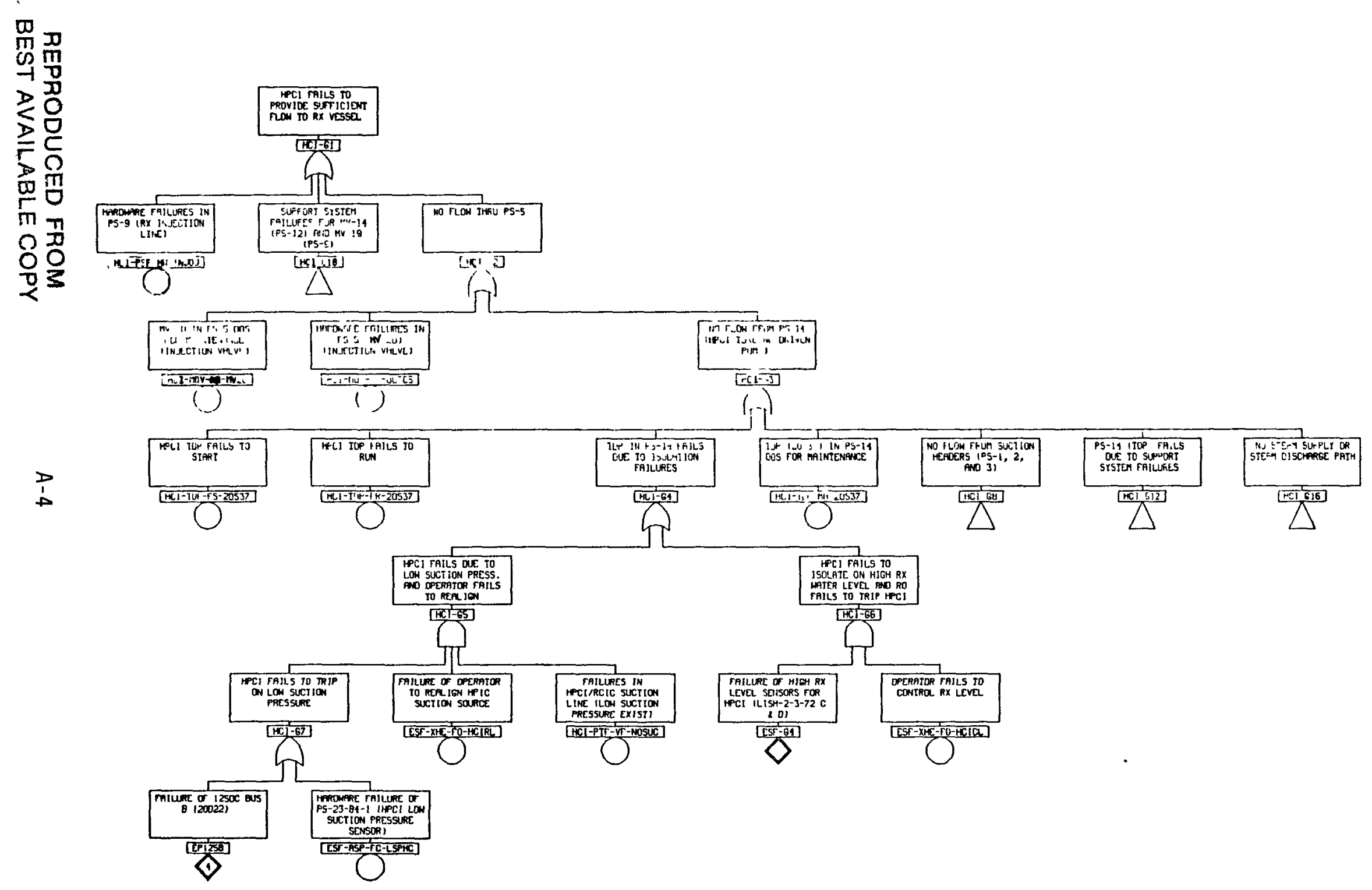




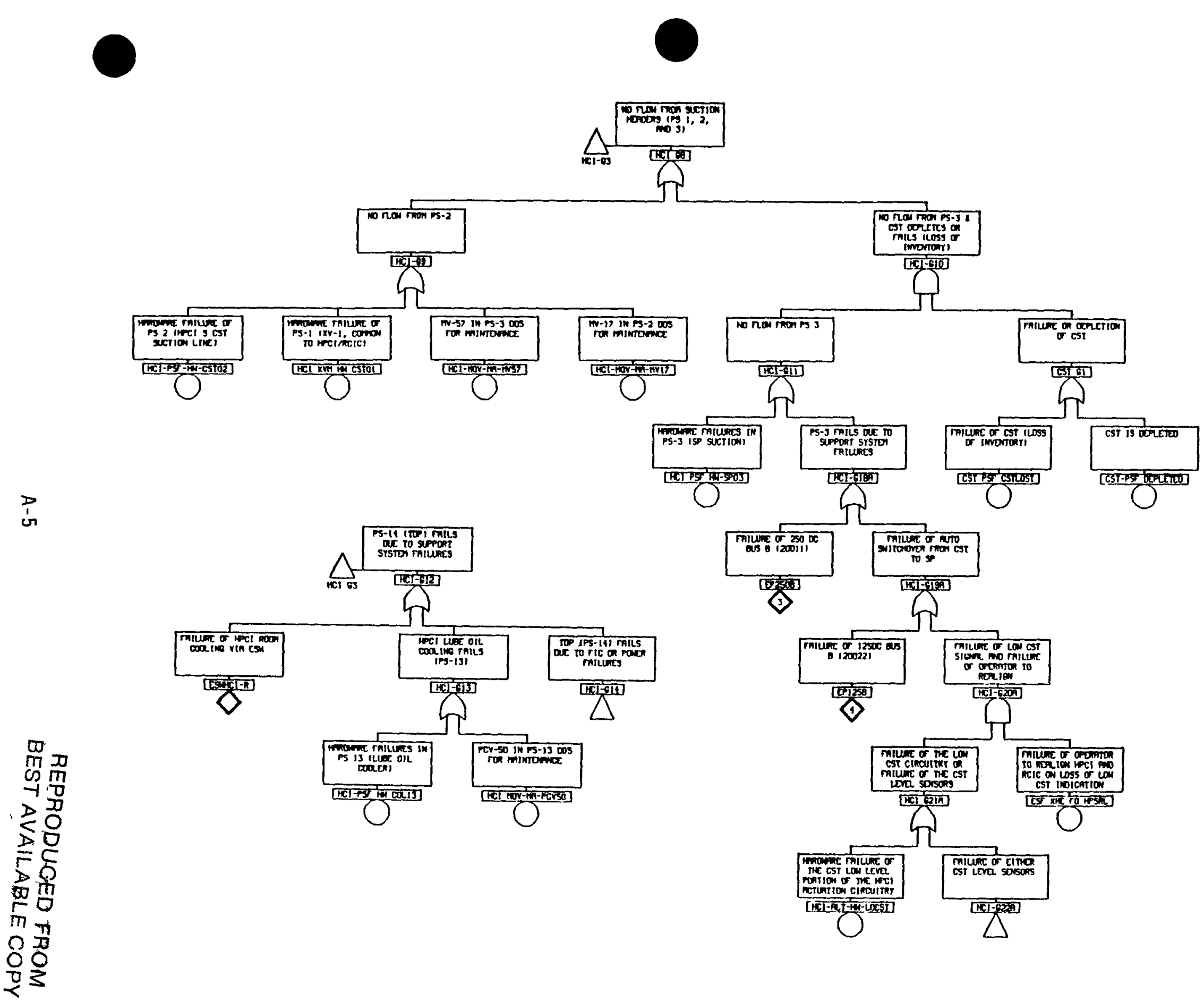




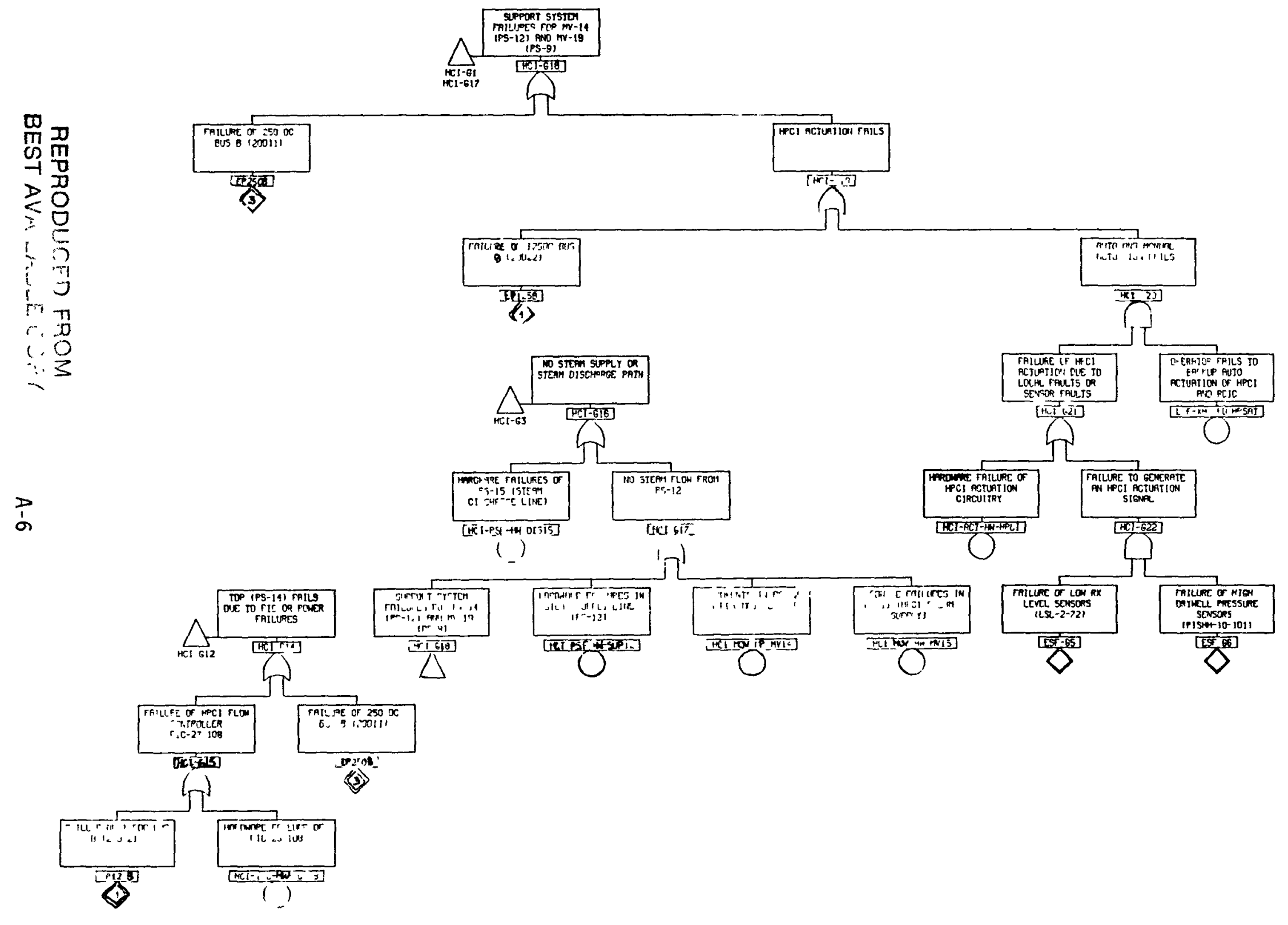


REACTOR CORE ISOLATION COOLING SYSTEM

FAULT TREE

A-7 


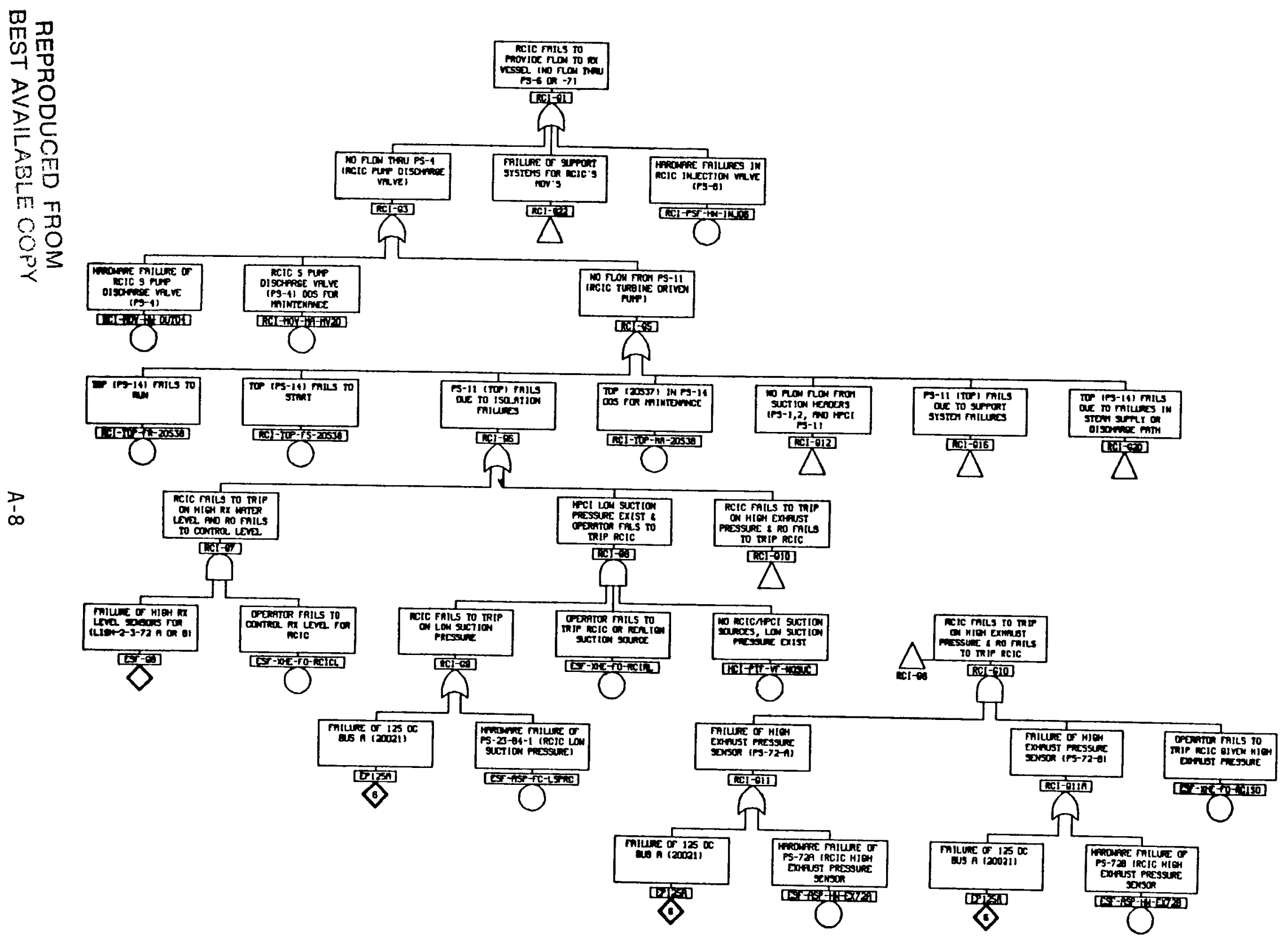




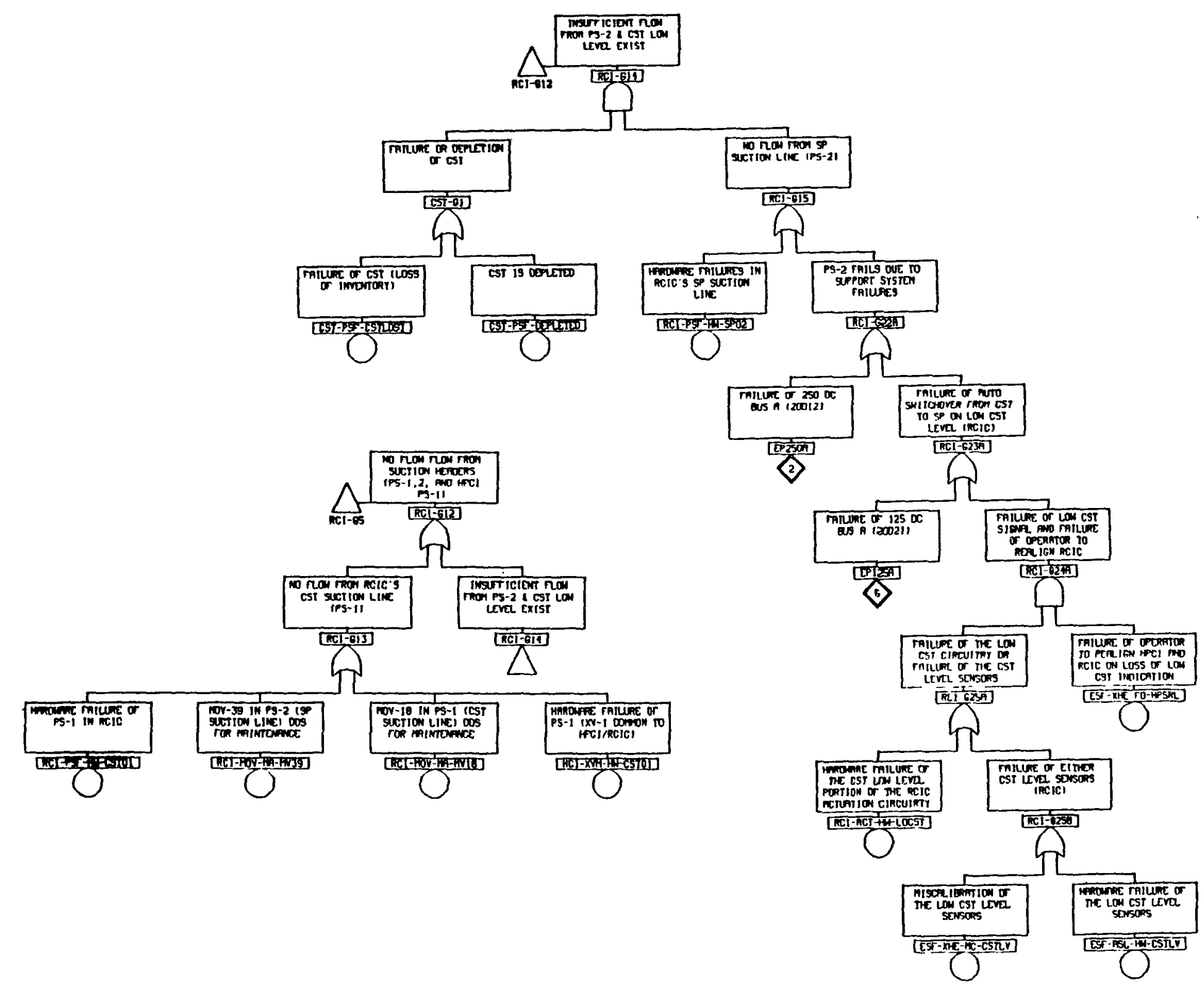

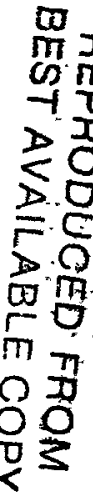




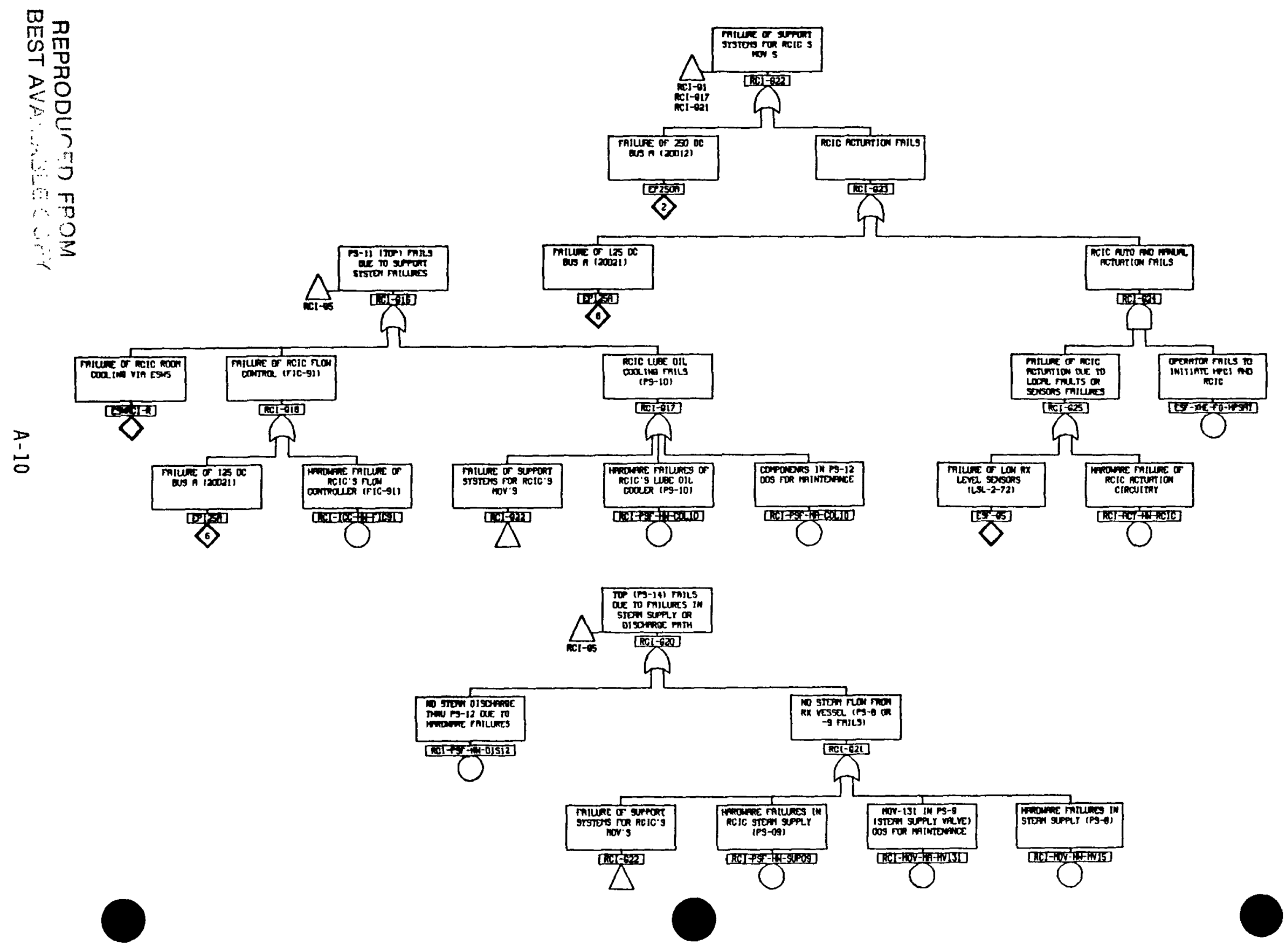


AUTOMATIC DEPRESSURIZATION SYSTEM

FAULT TREE

A-11 

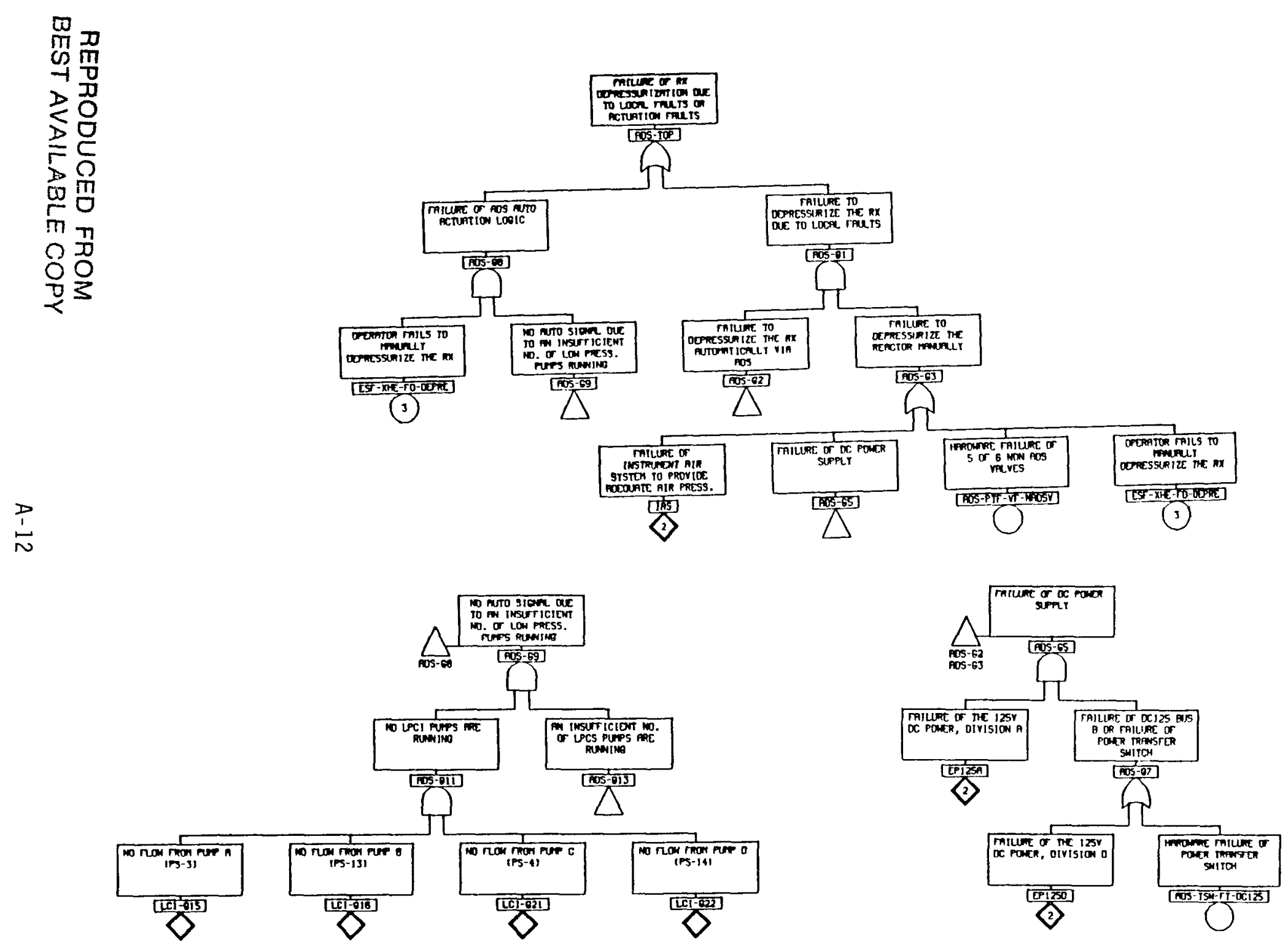

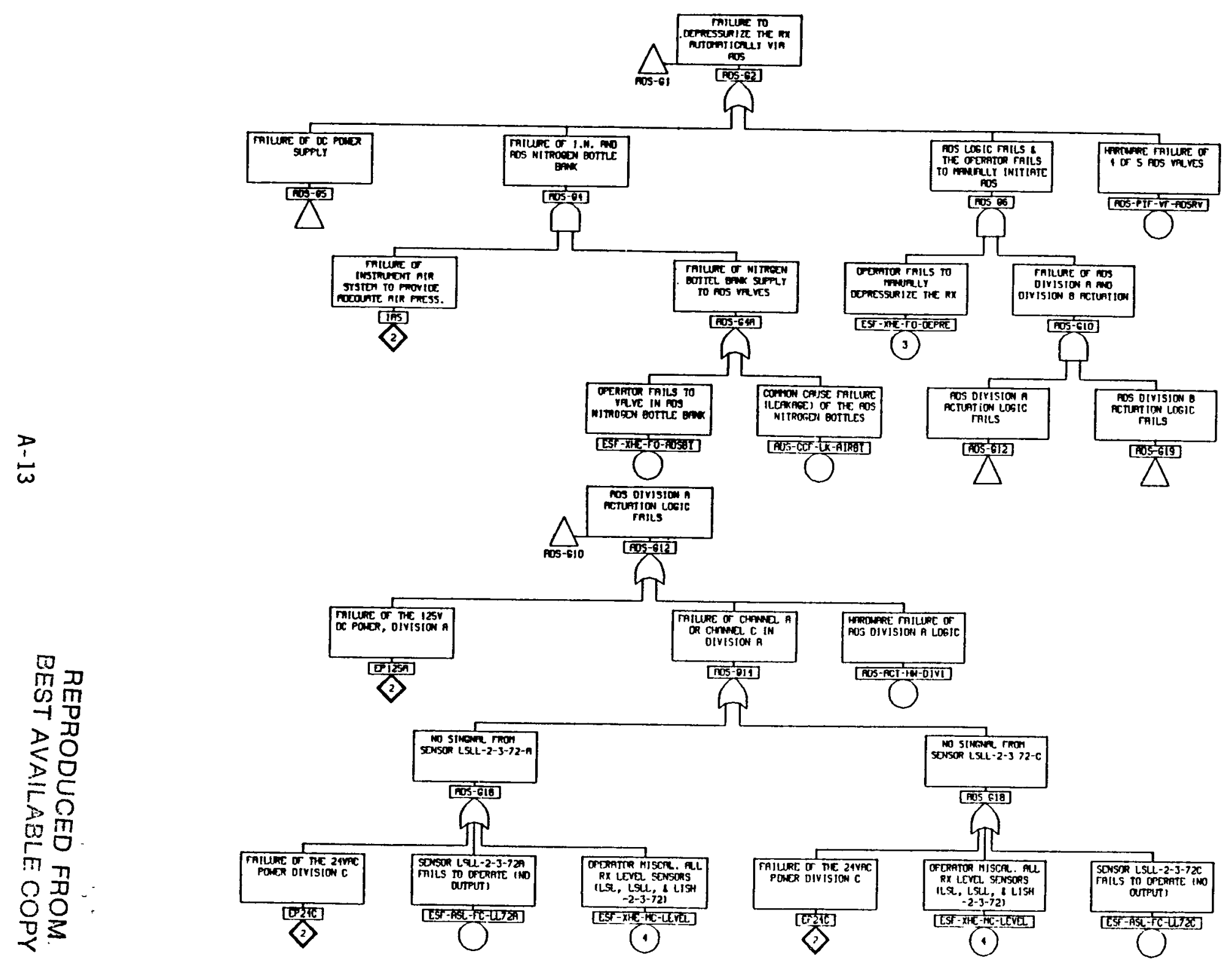


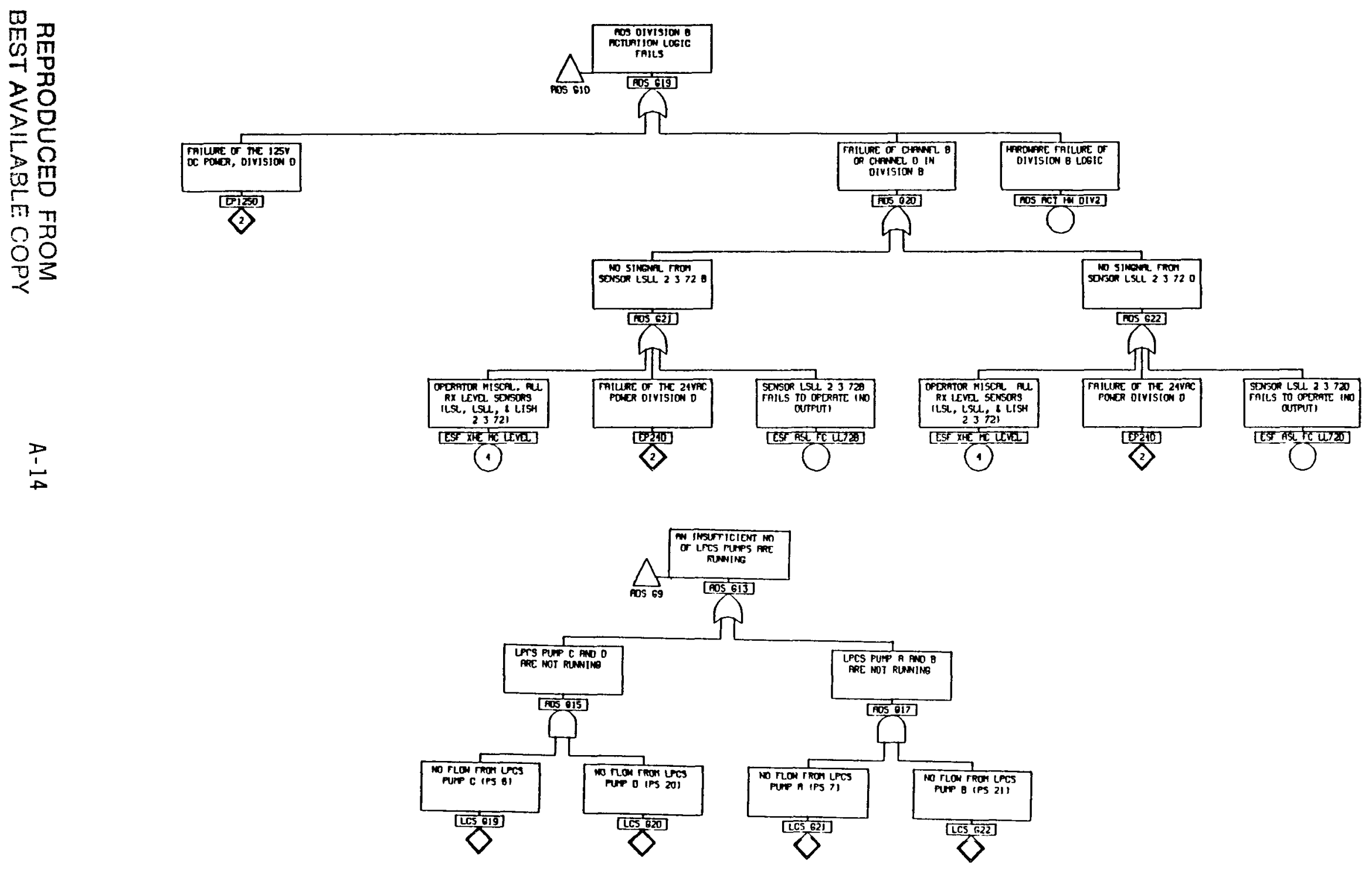


LOW PRESSURE CORE SPRAY SYSTEM

FAULT TREE

A-15 
-

○

○ 


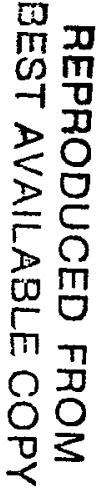
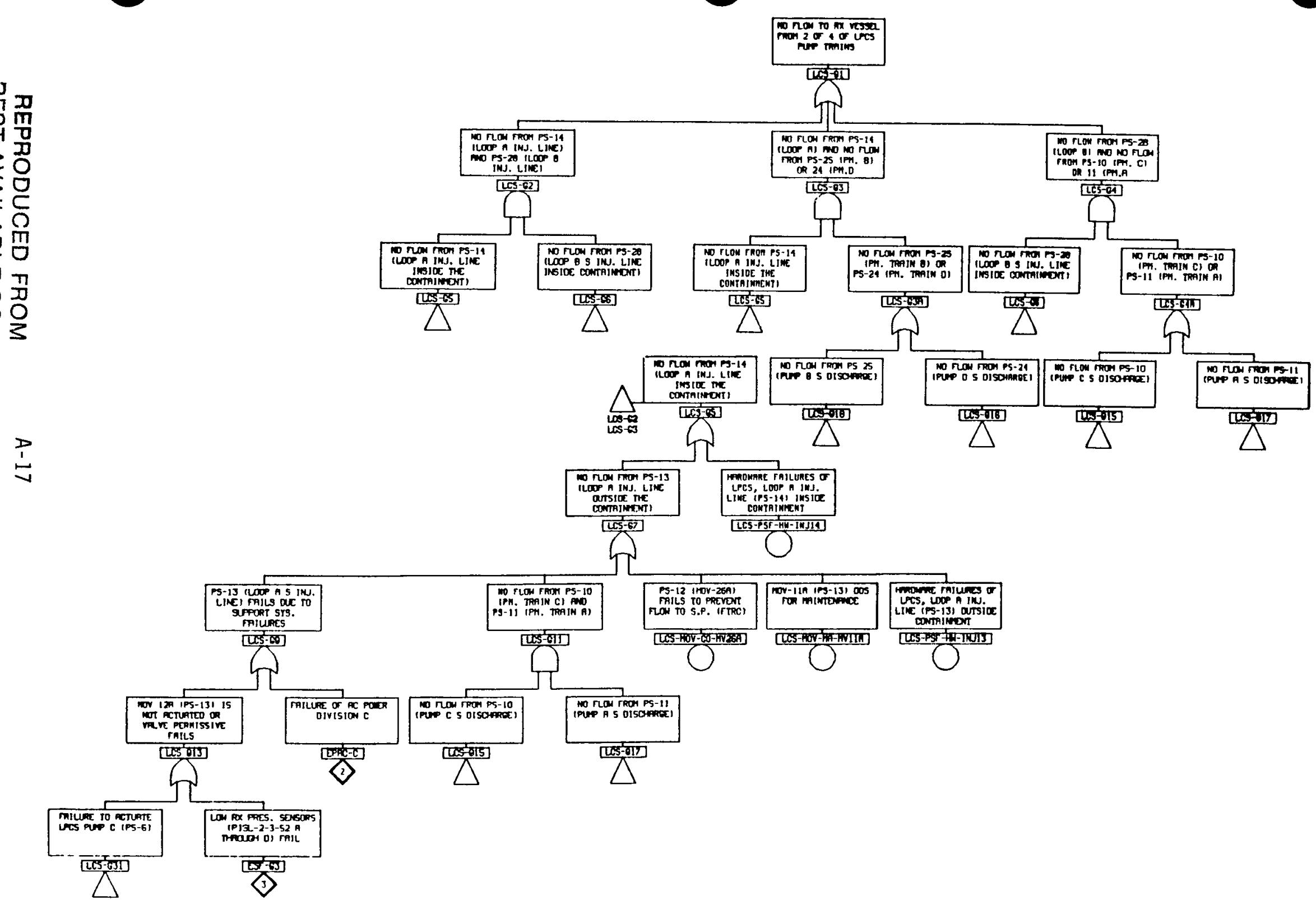


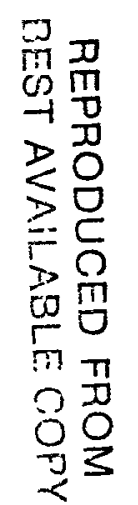

$\stackrel{P}{\dot{1}}$
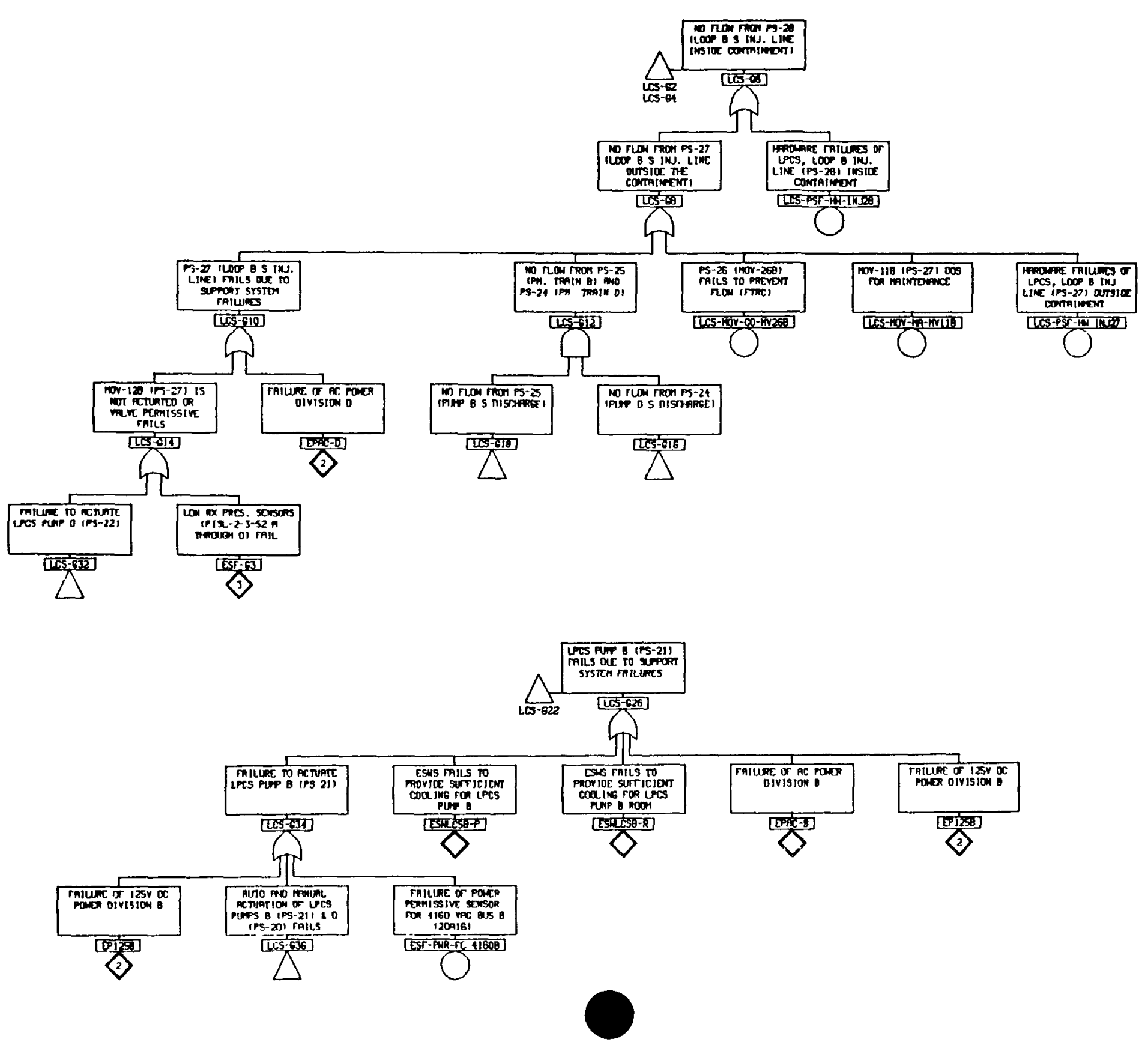

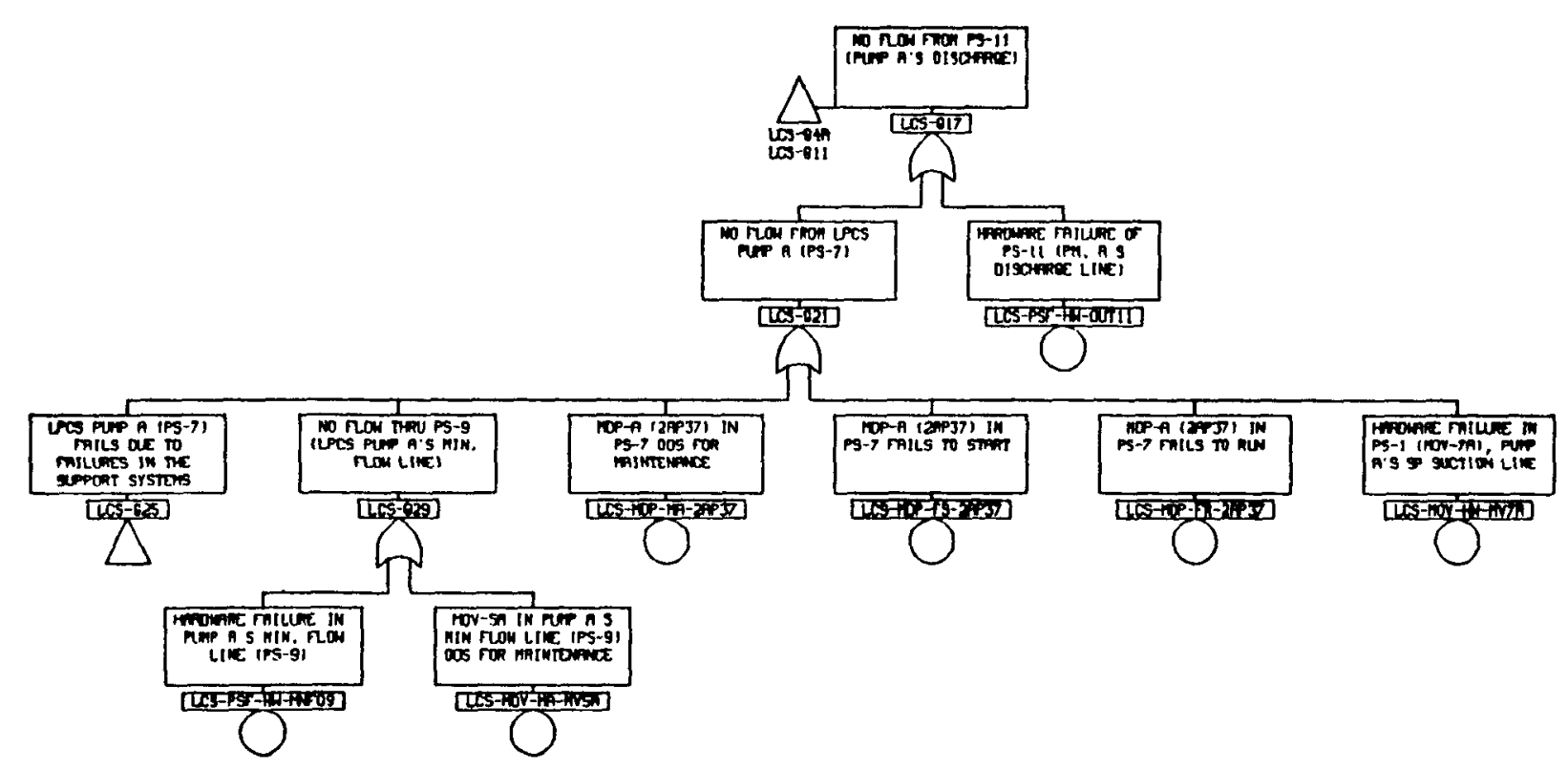

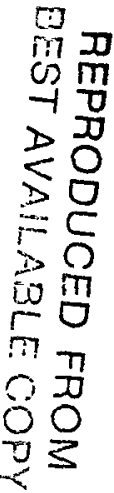
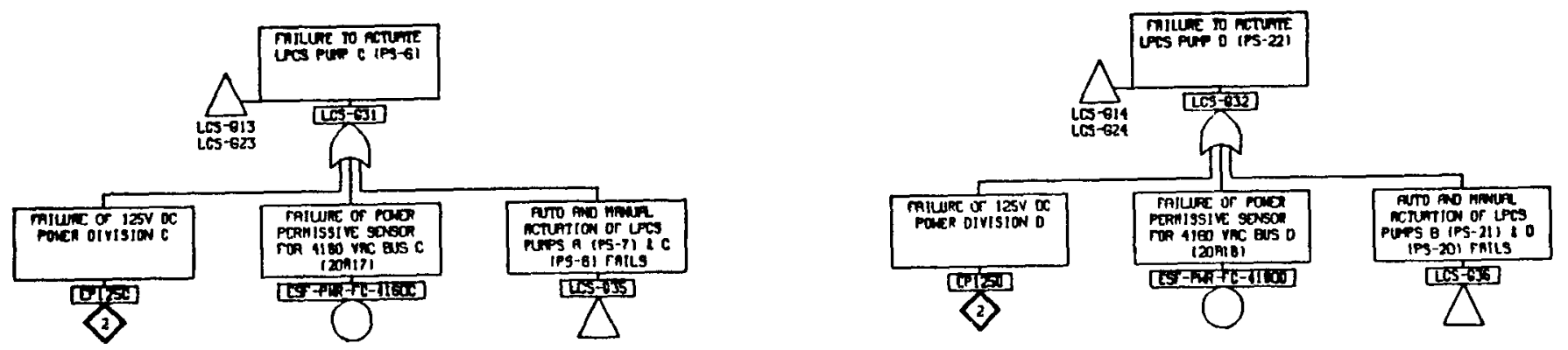


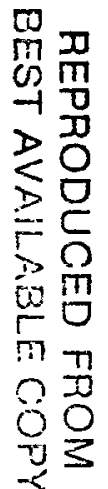

京
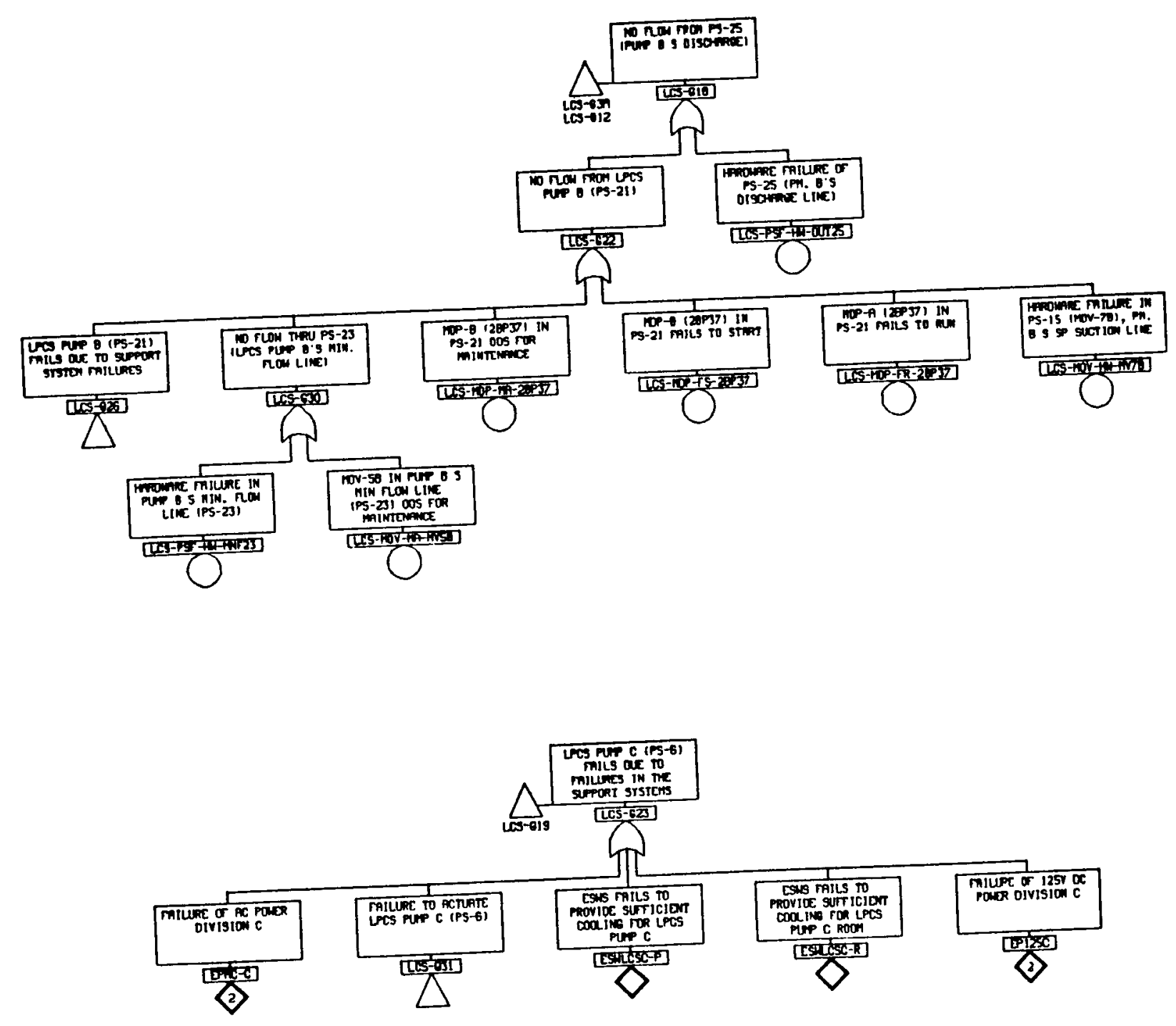

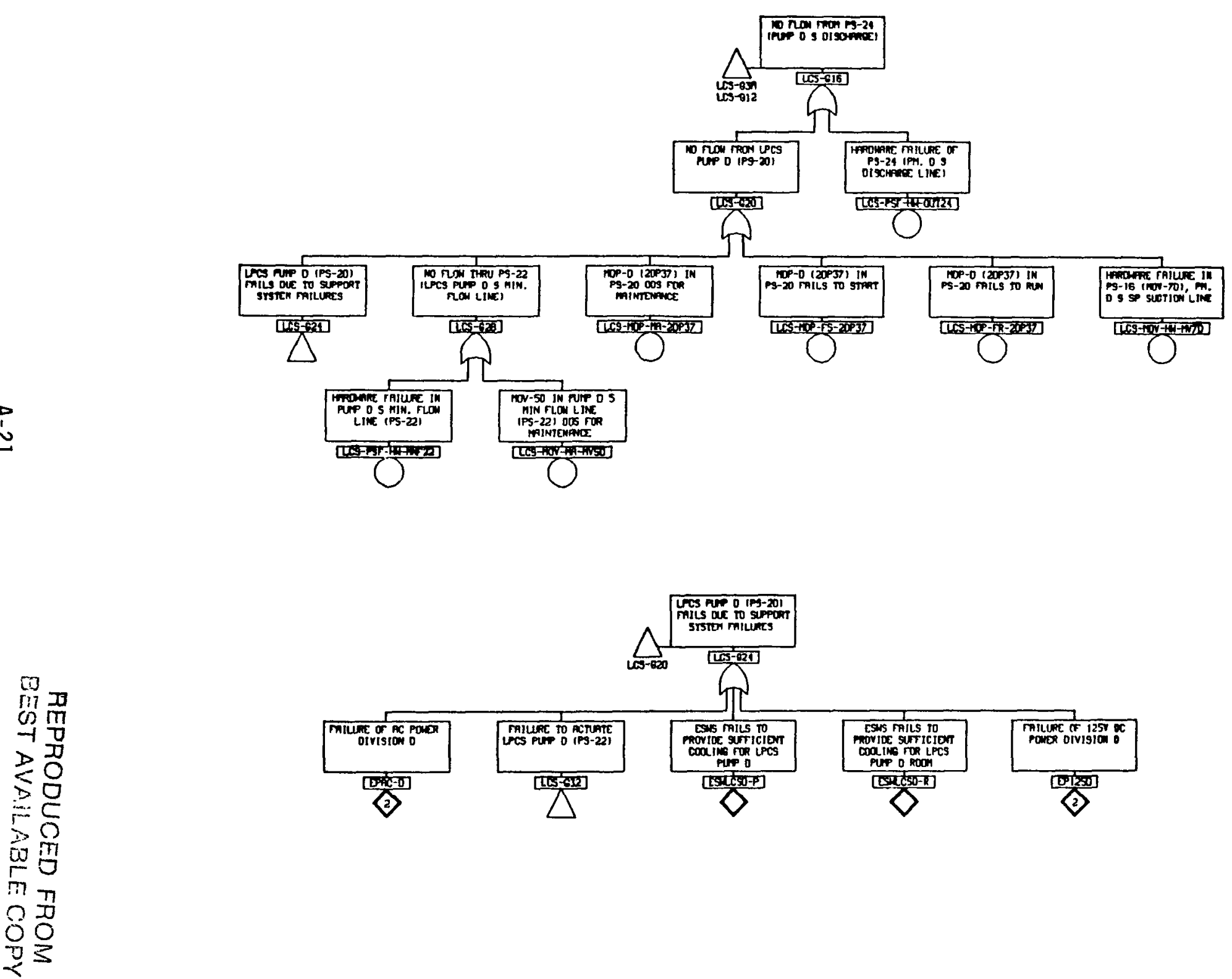

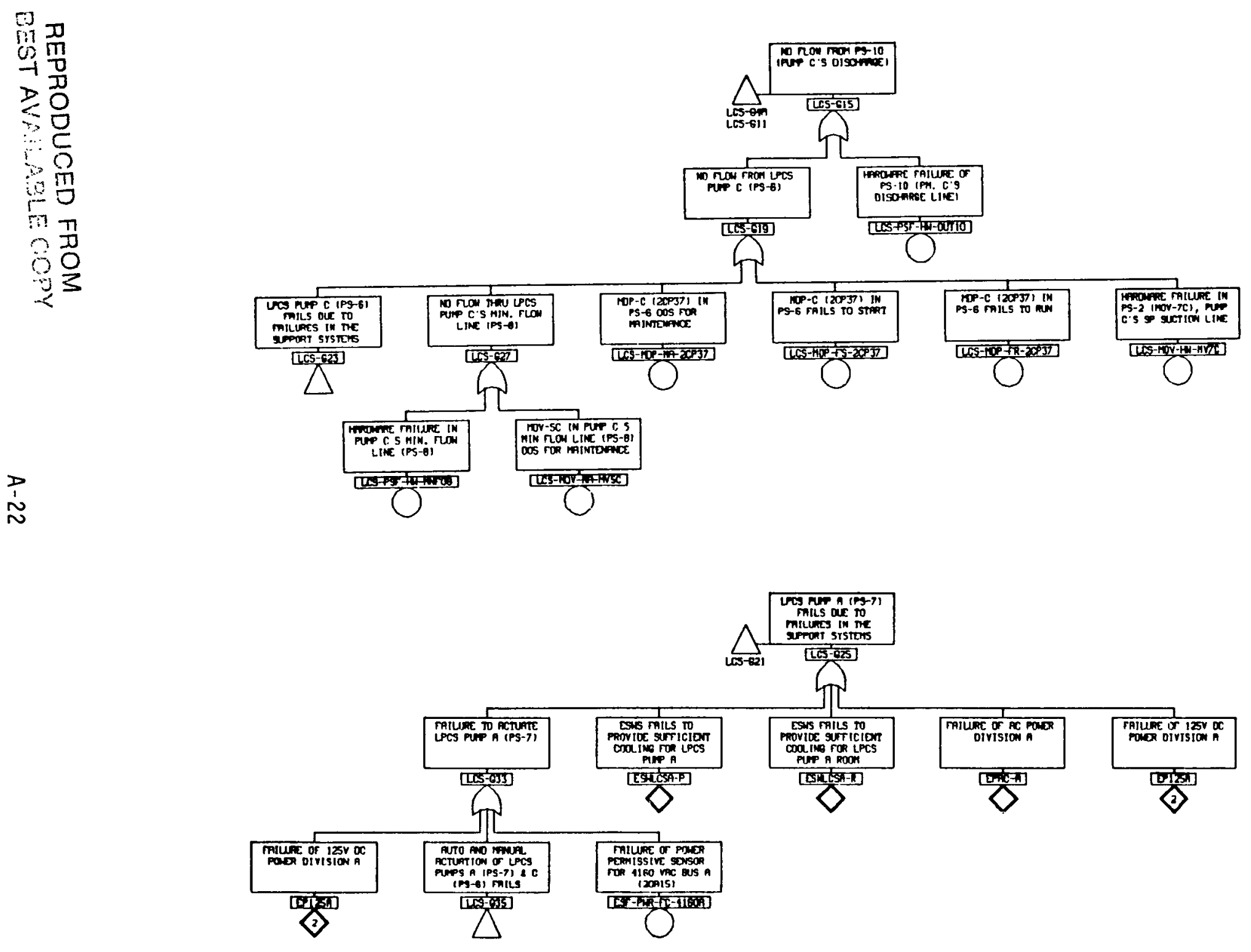

$\stackrel{D}{\sim}$ 


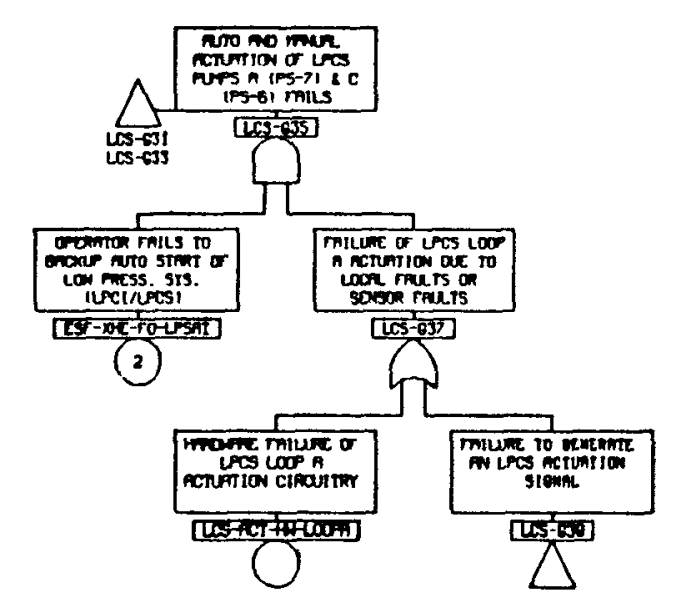

京
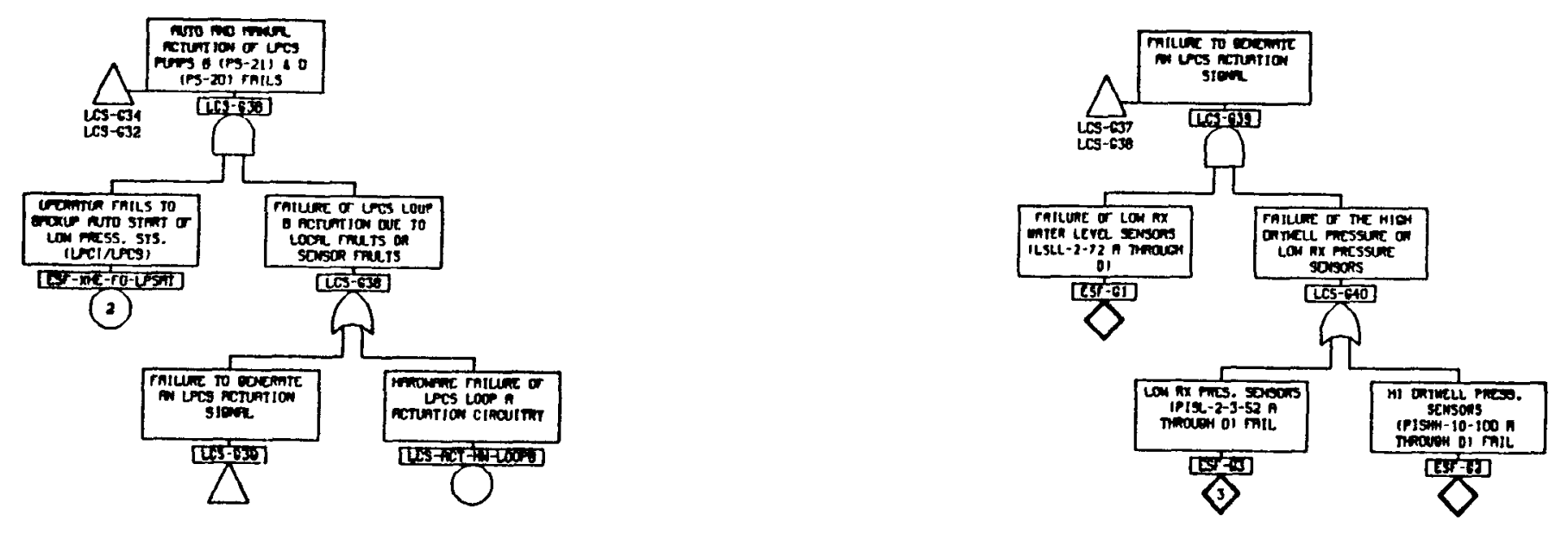

$0 \pi$

ต1

20

30

$\because 7$

而

$>D$

$\leq 0$

C

0

3 
LOW PRESSURE COOLANT INJECTION SYSTEM

FAULT TREE 


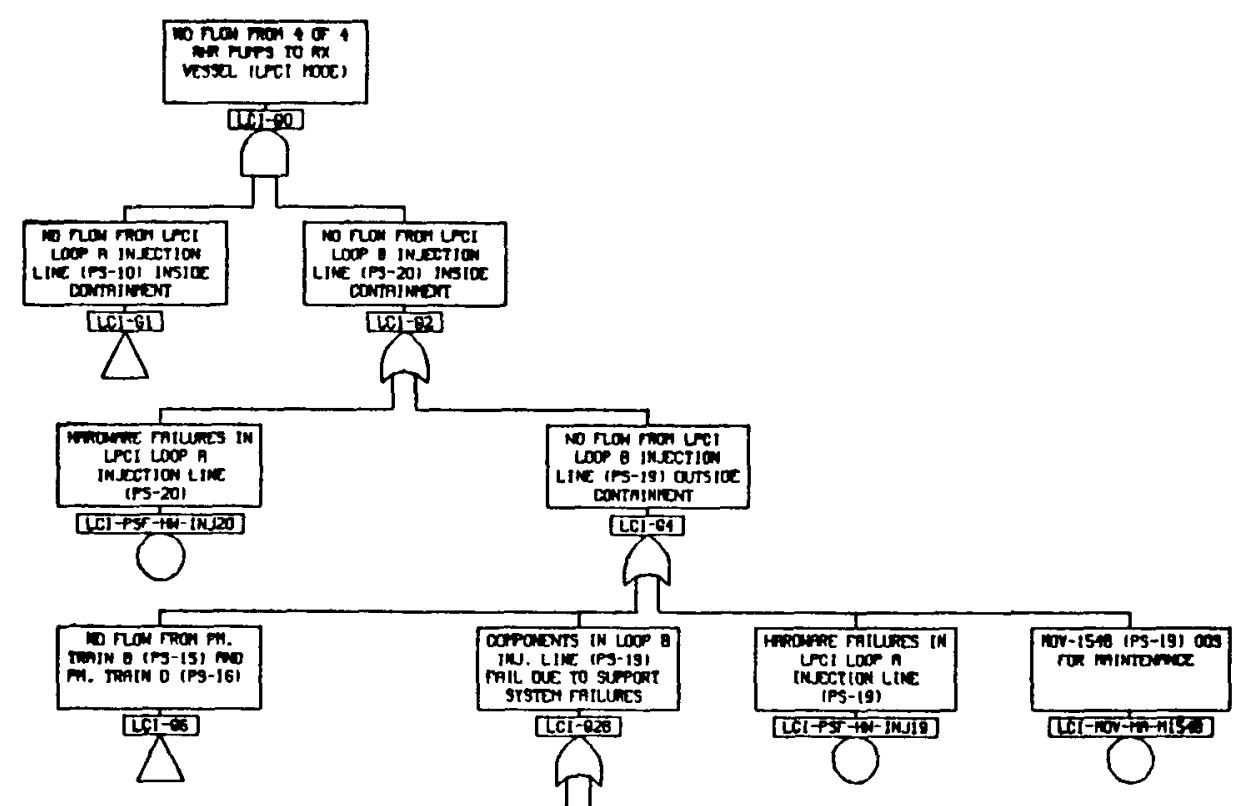

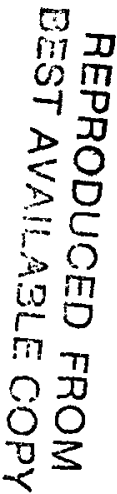

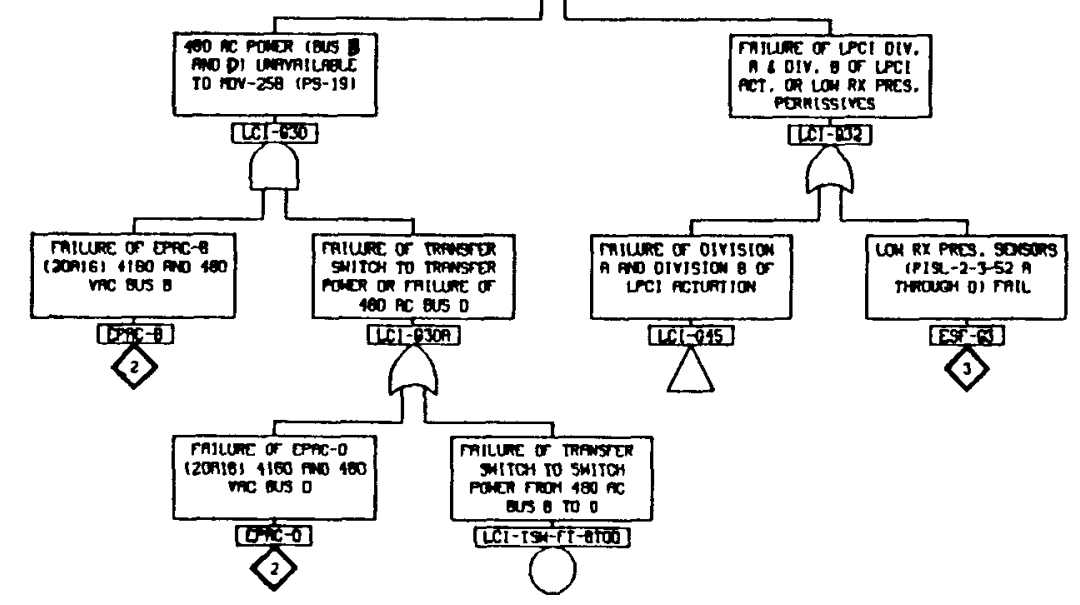




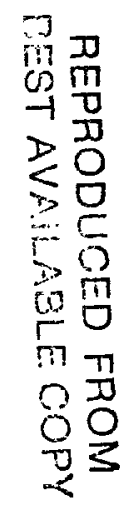

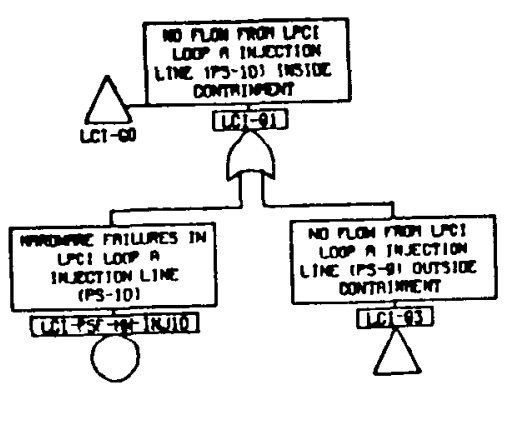

$>$

مَ

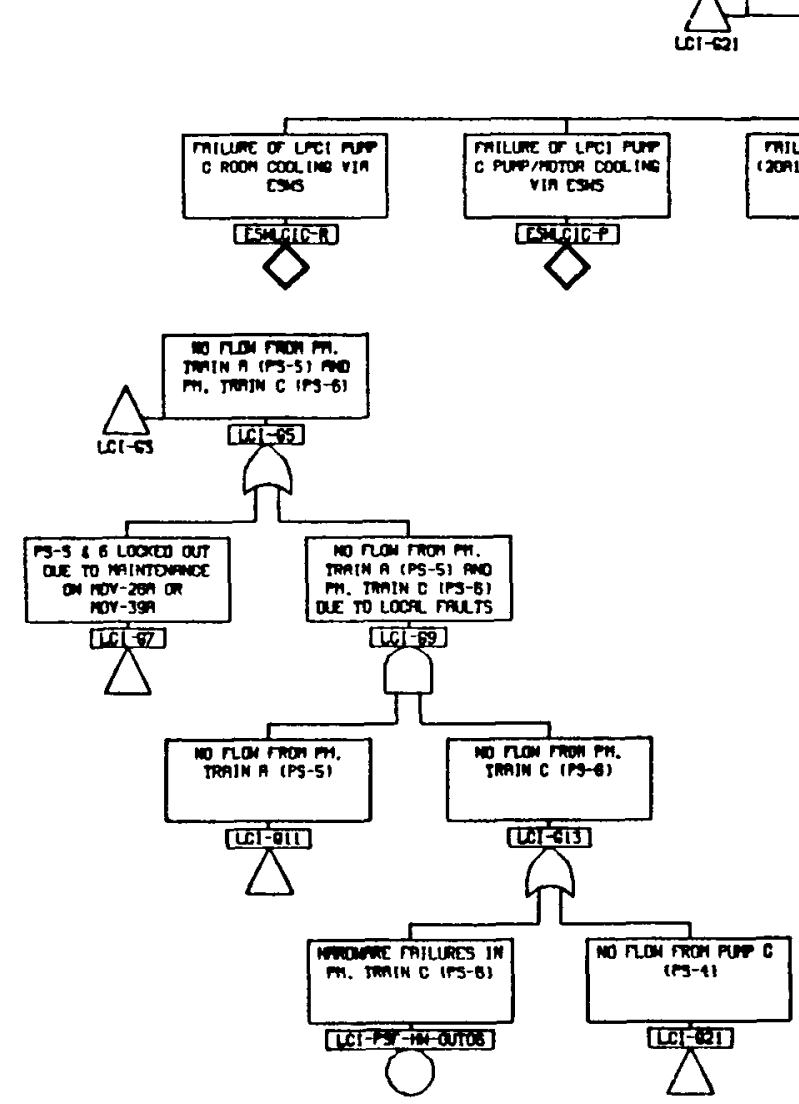

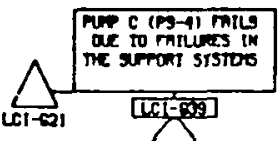
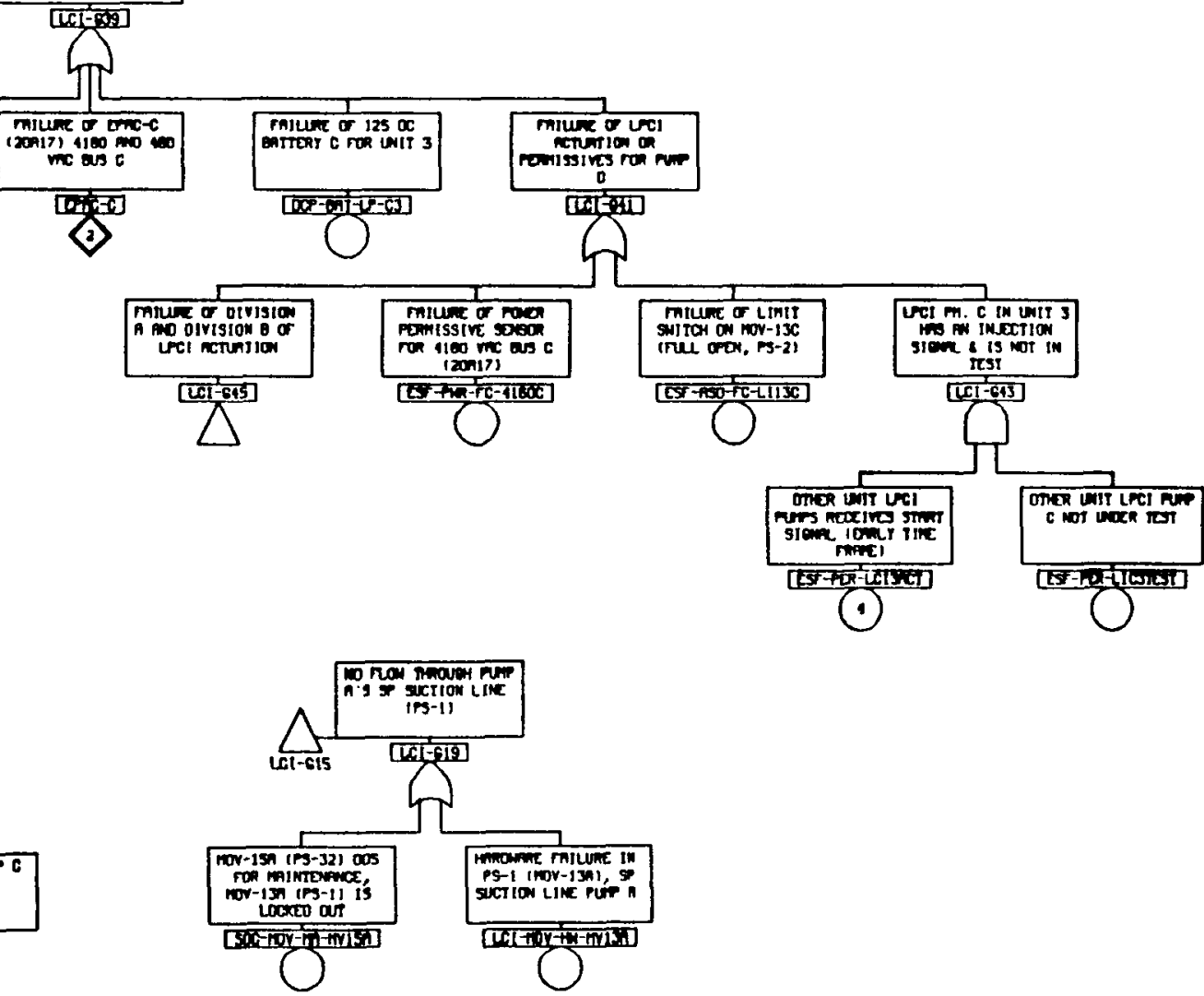


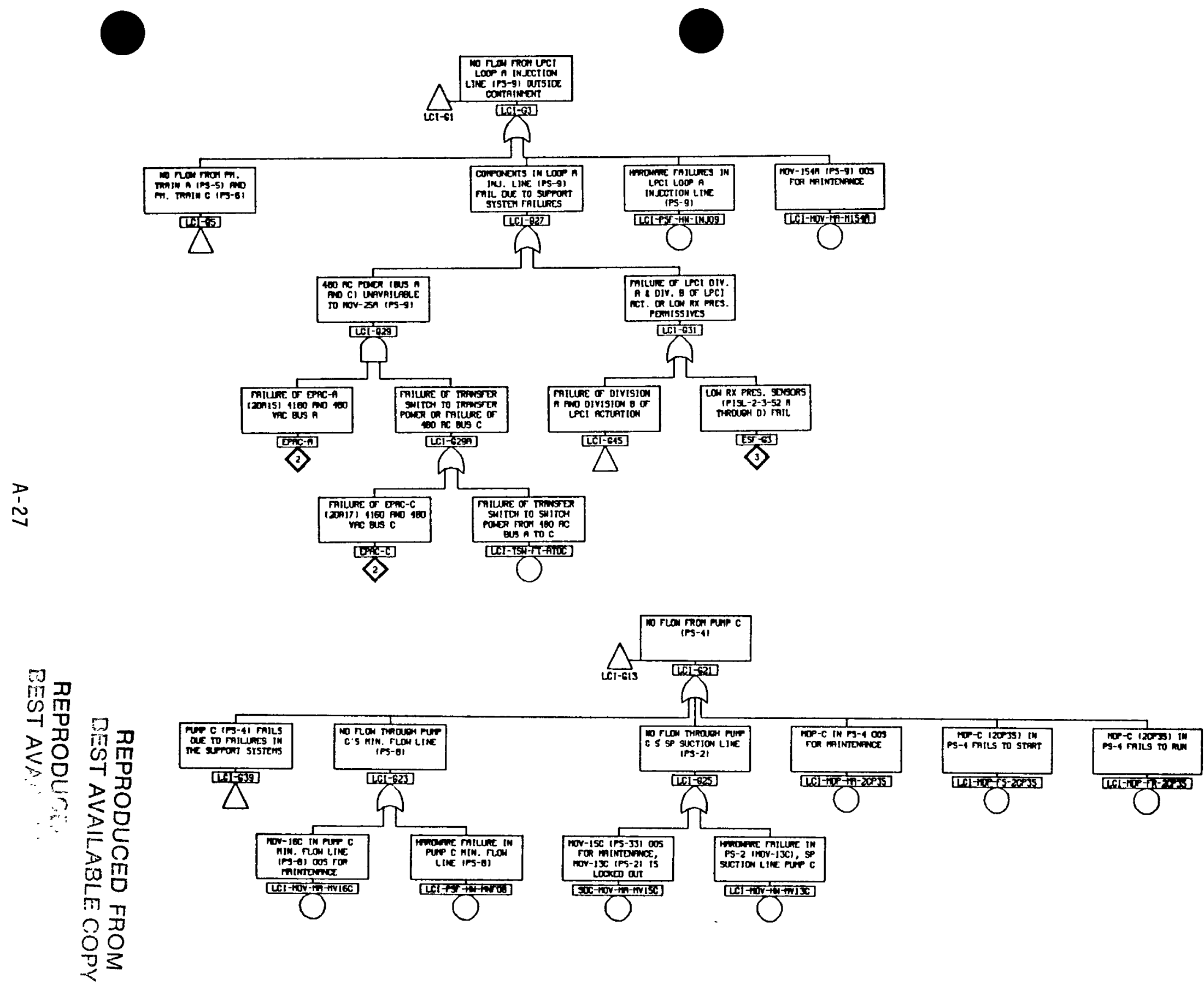




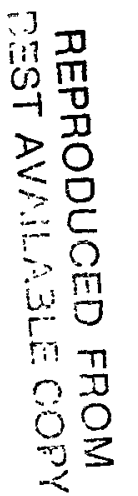

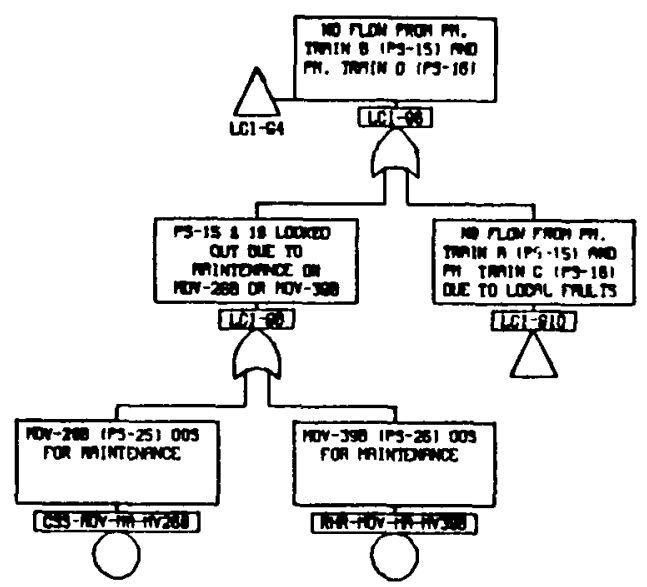

D
n.

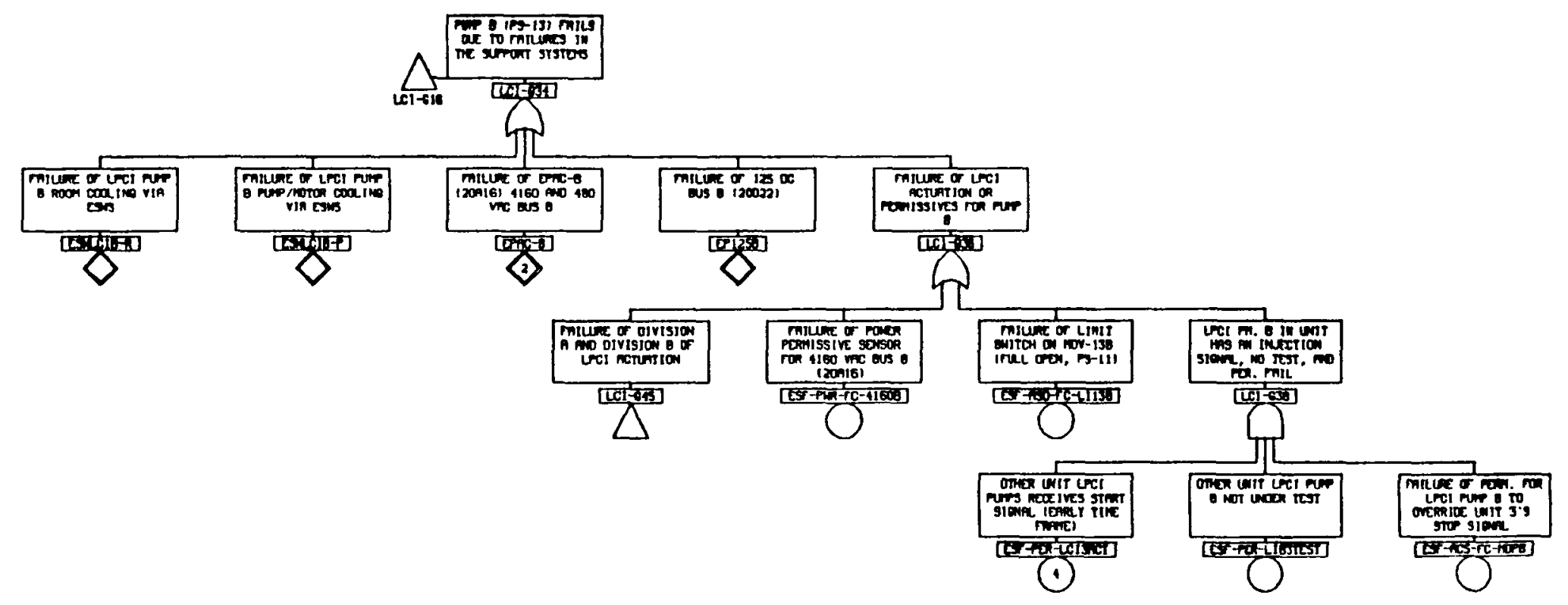




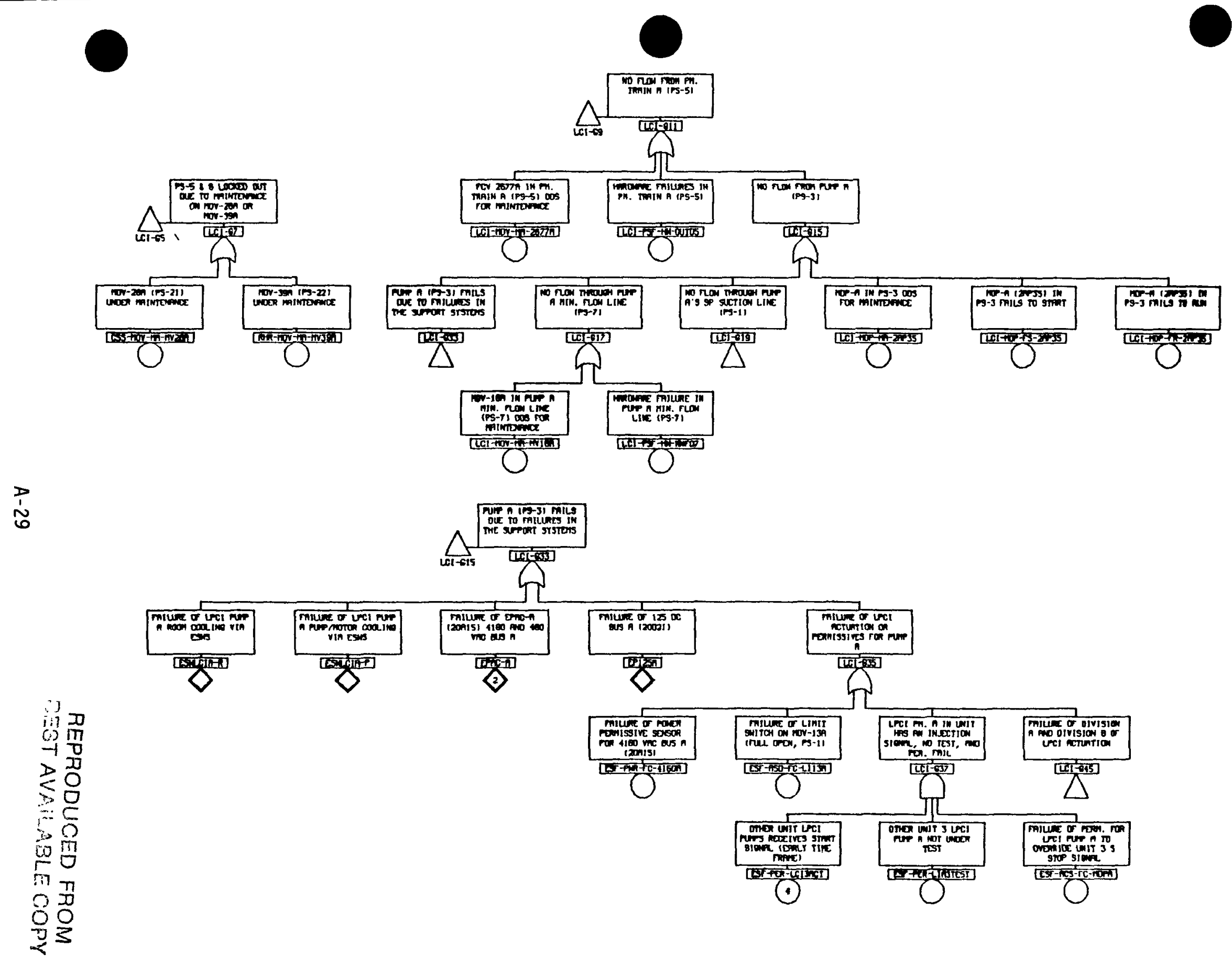




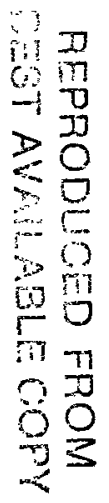
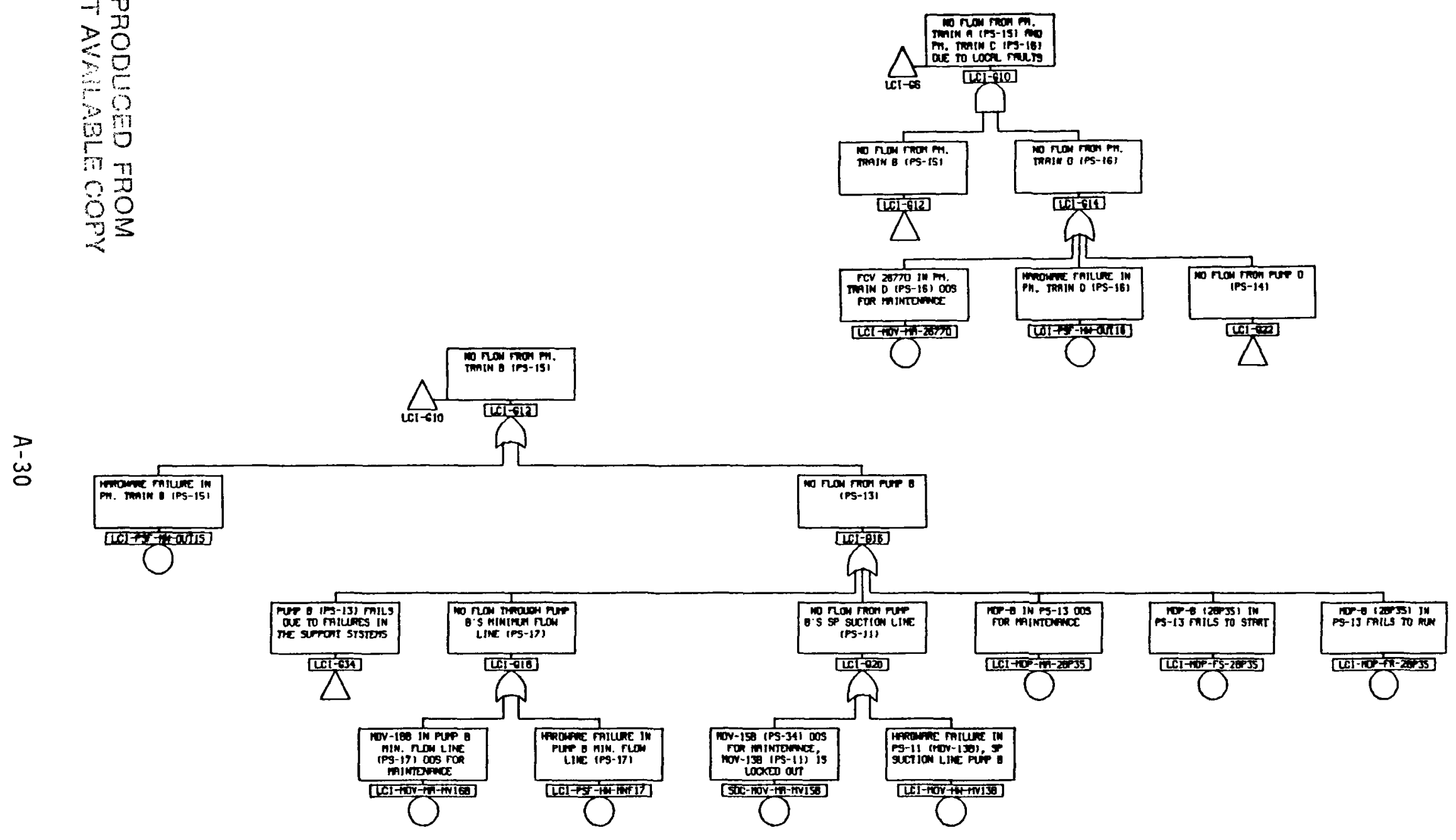


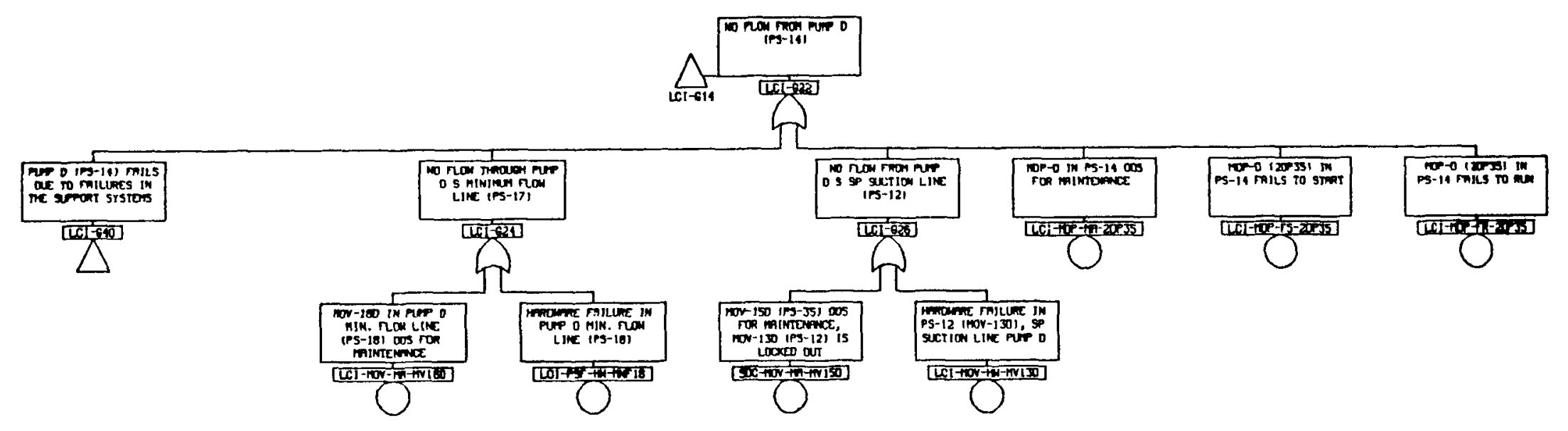

$\stackrel{P}{\omega}$

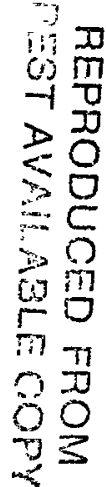

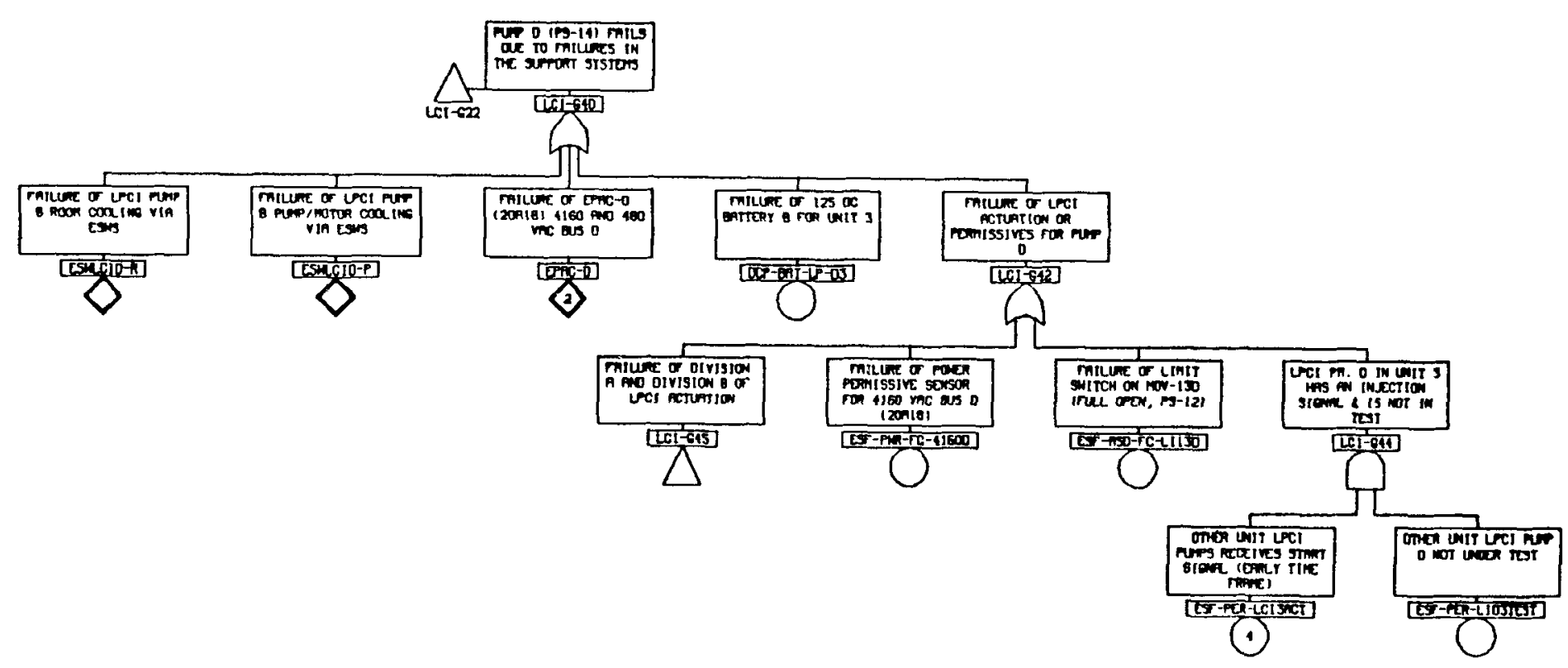




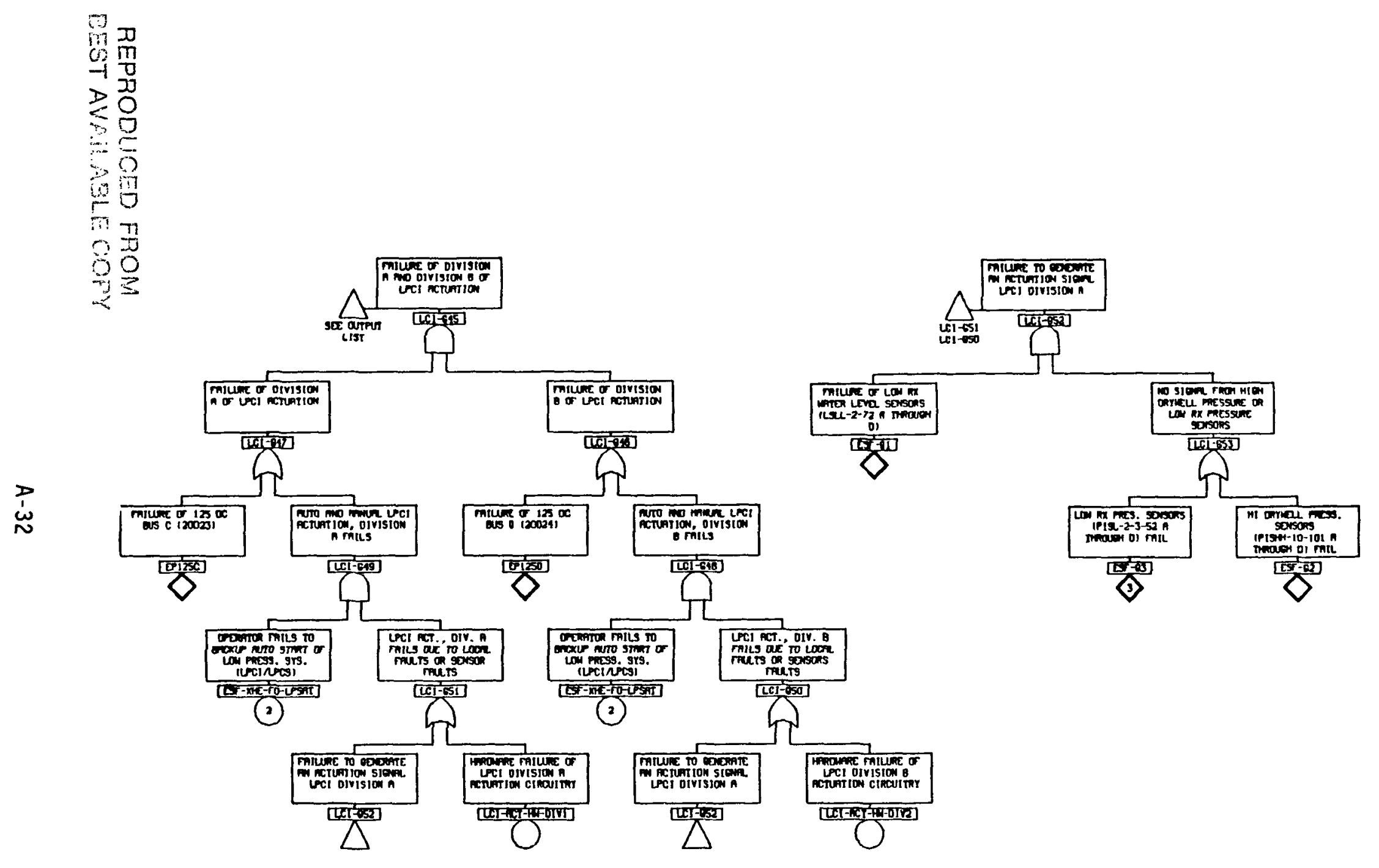


SHUTDOWN COOLING SYSTEM

FAULT TREE

A-33 


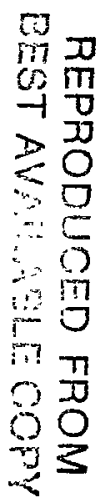

$\underset{\sim}{\stackrel{D}{\perp}}$

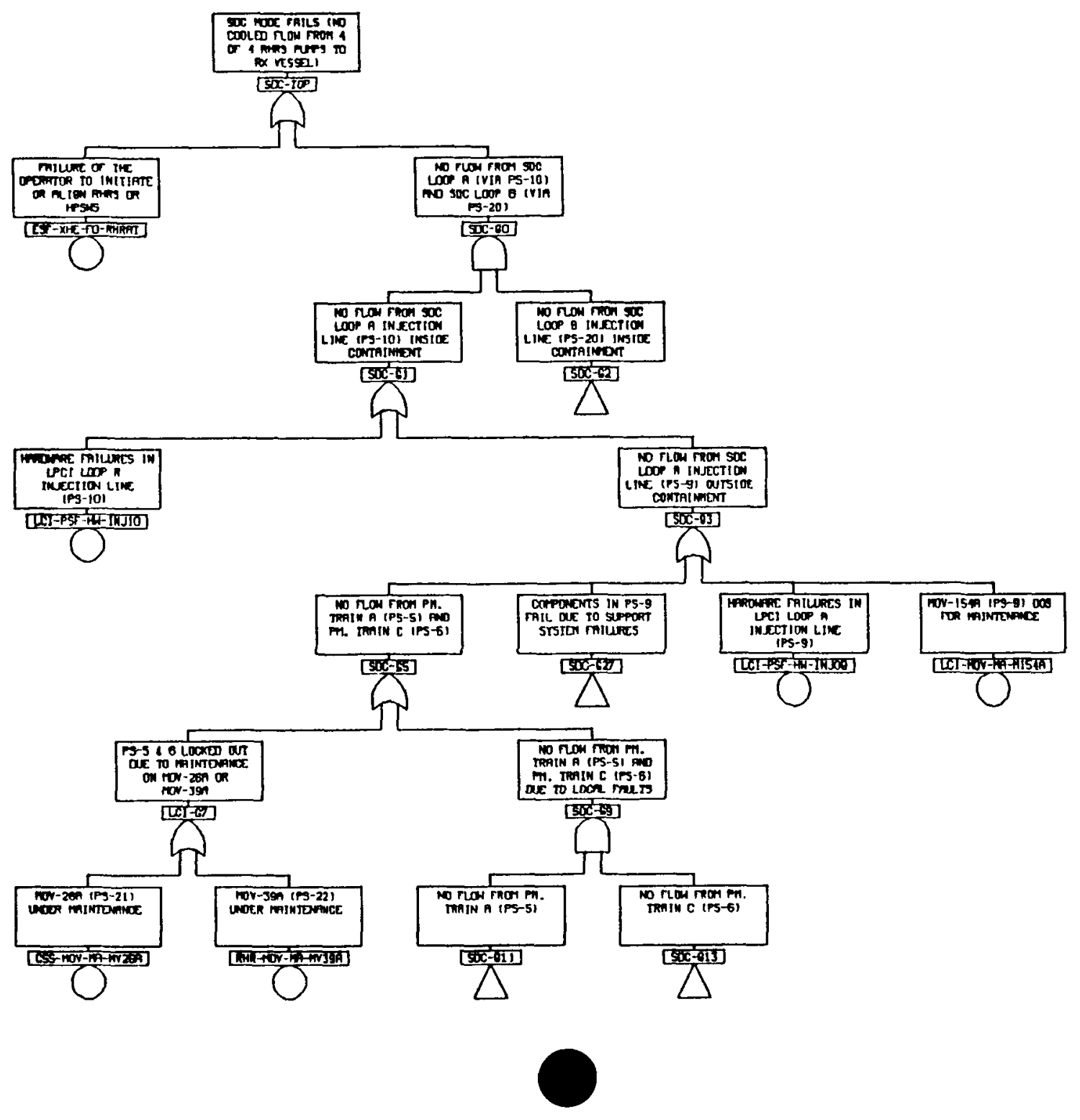




\section{$\bullet$}

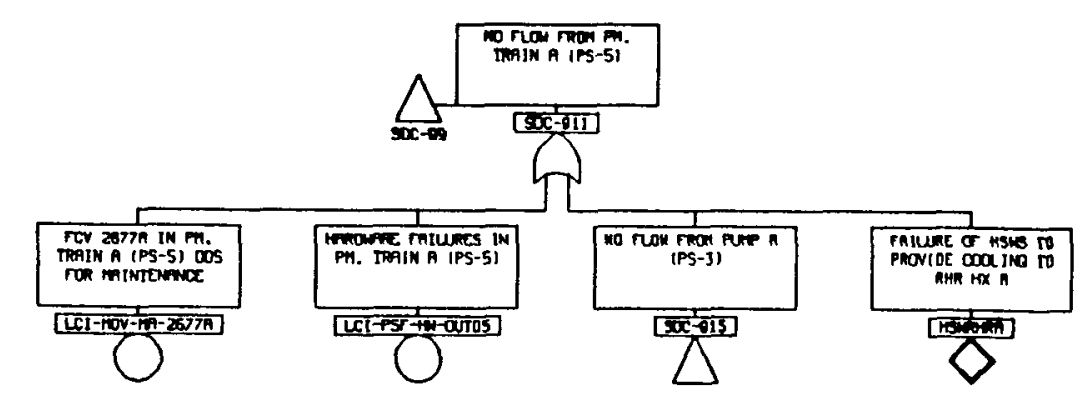

崩

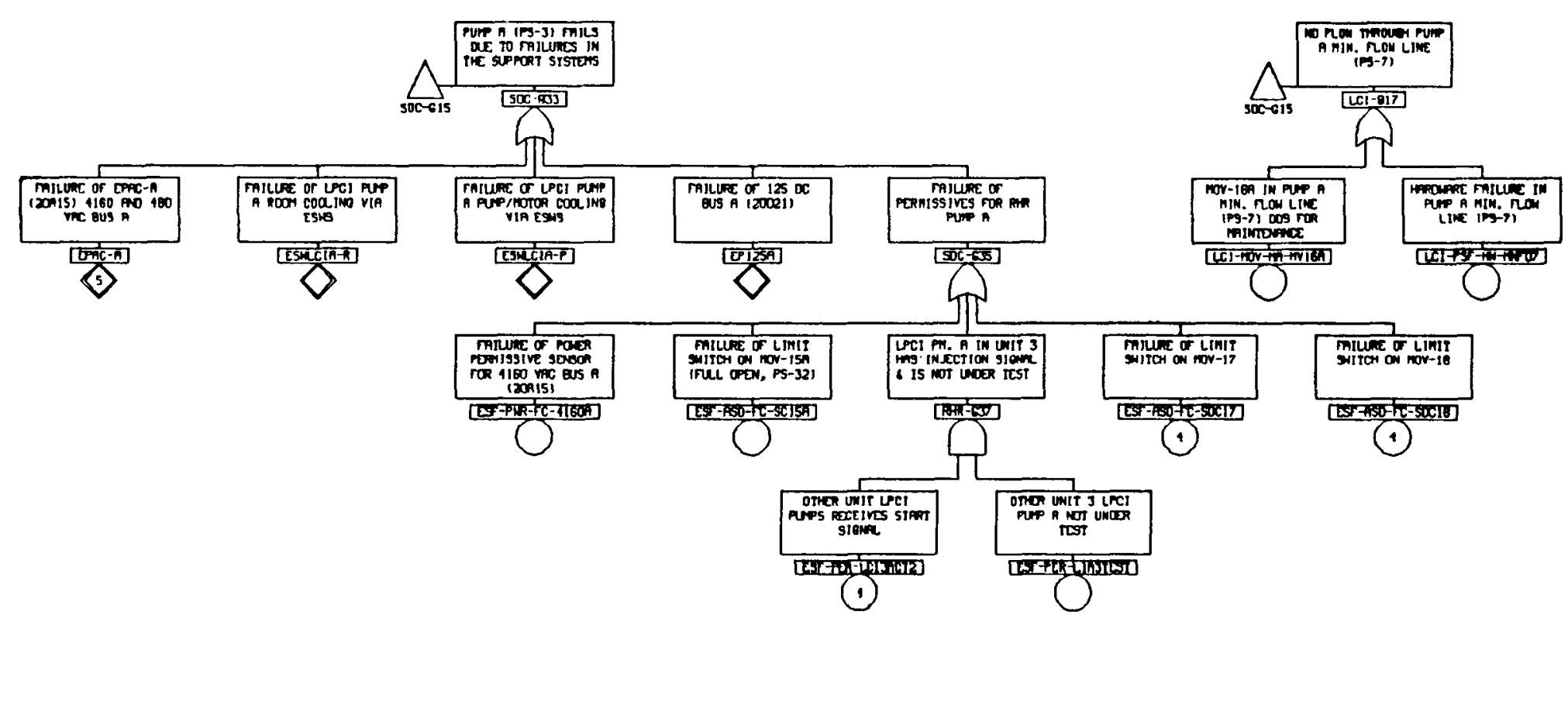




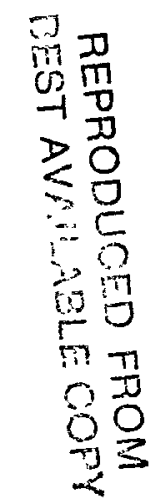

$p$
$\dot{\omega}$
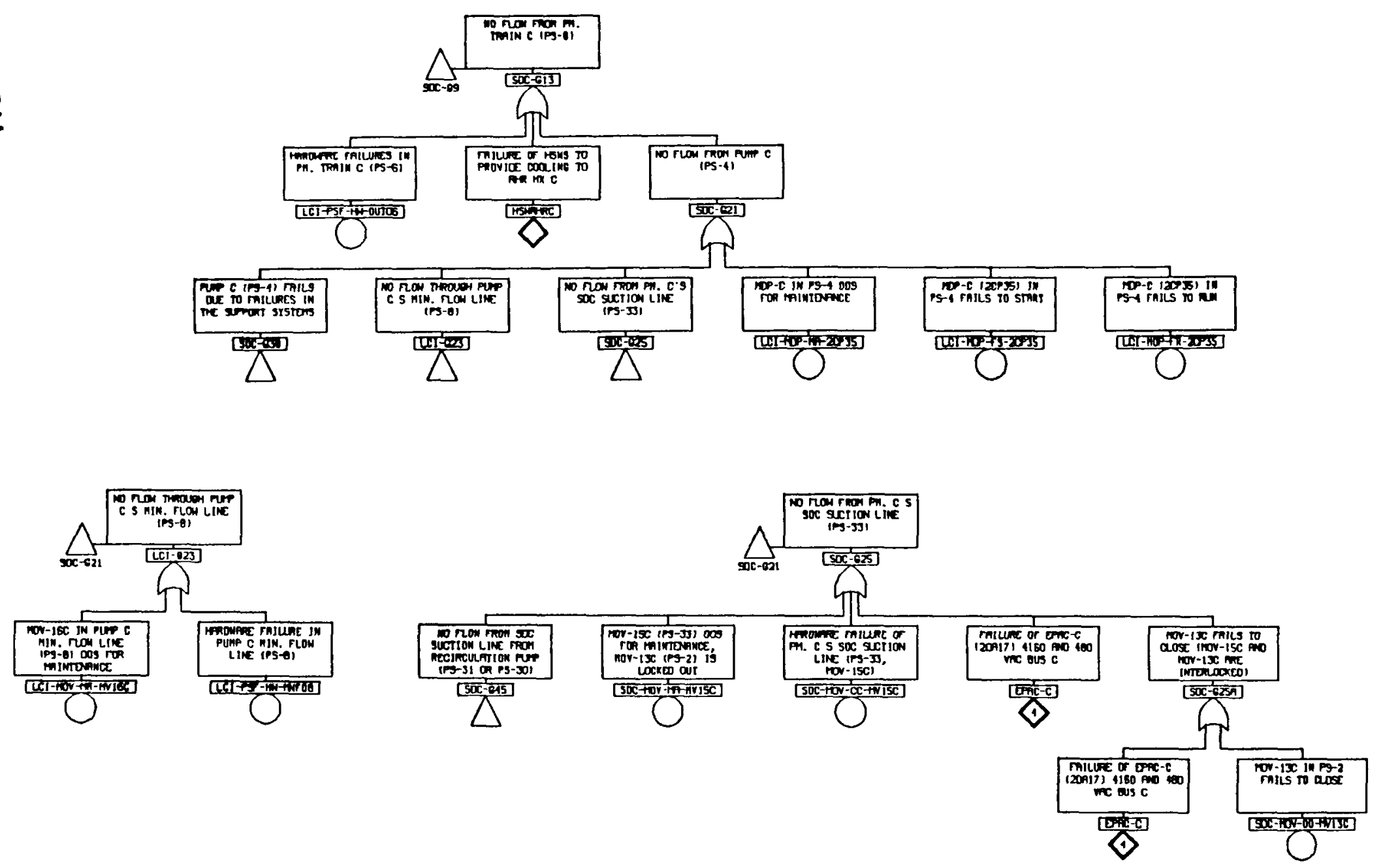

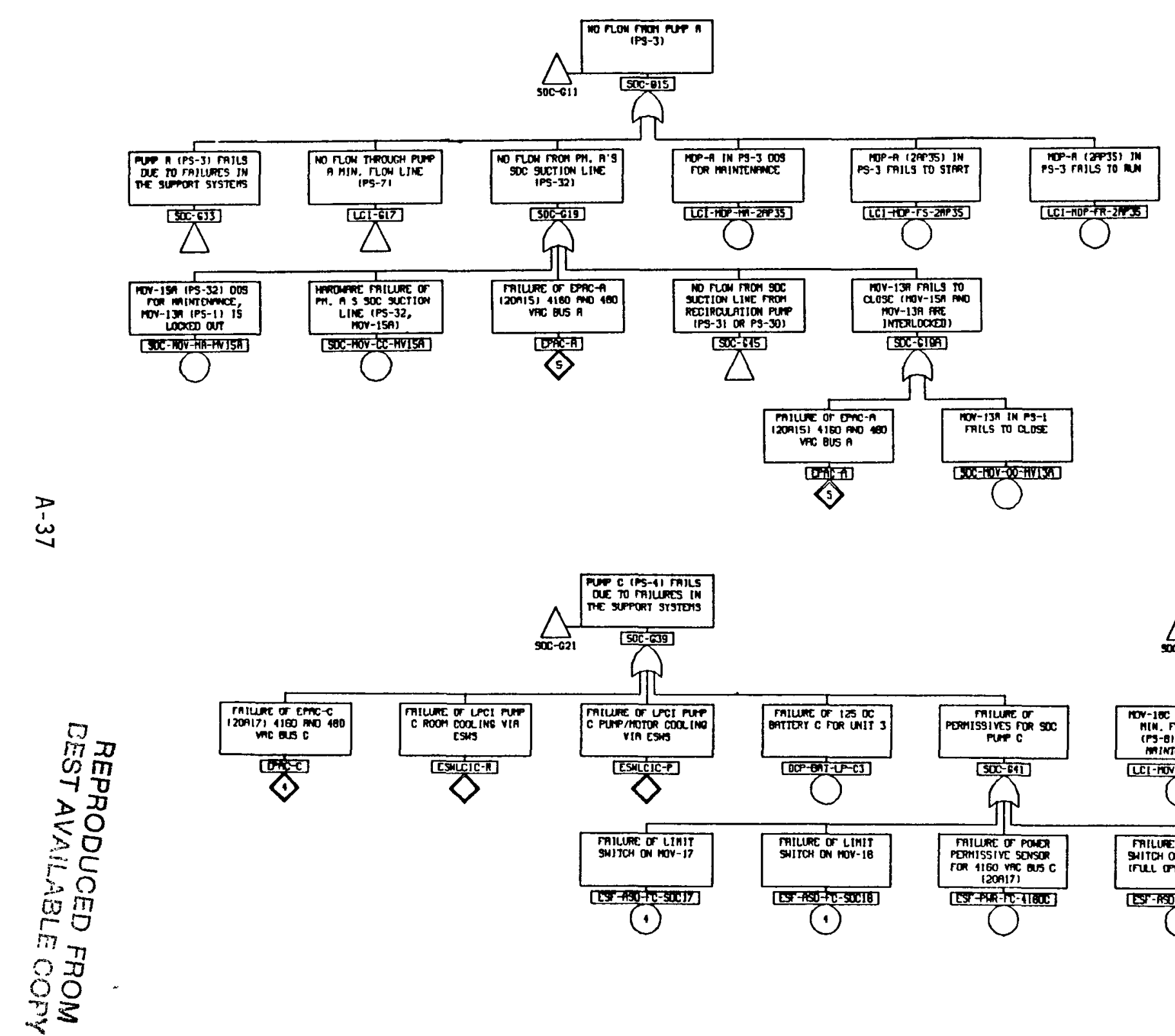

D

斗䎡

$\rightarrow 0$

$\leq 0$

F

而

$\pi$

8

3
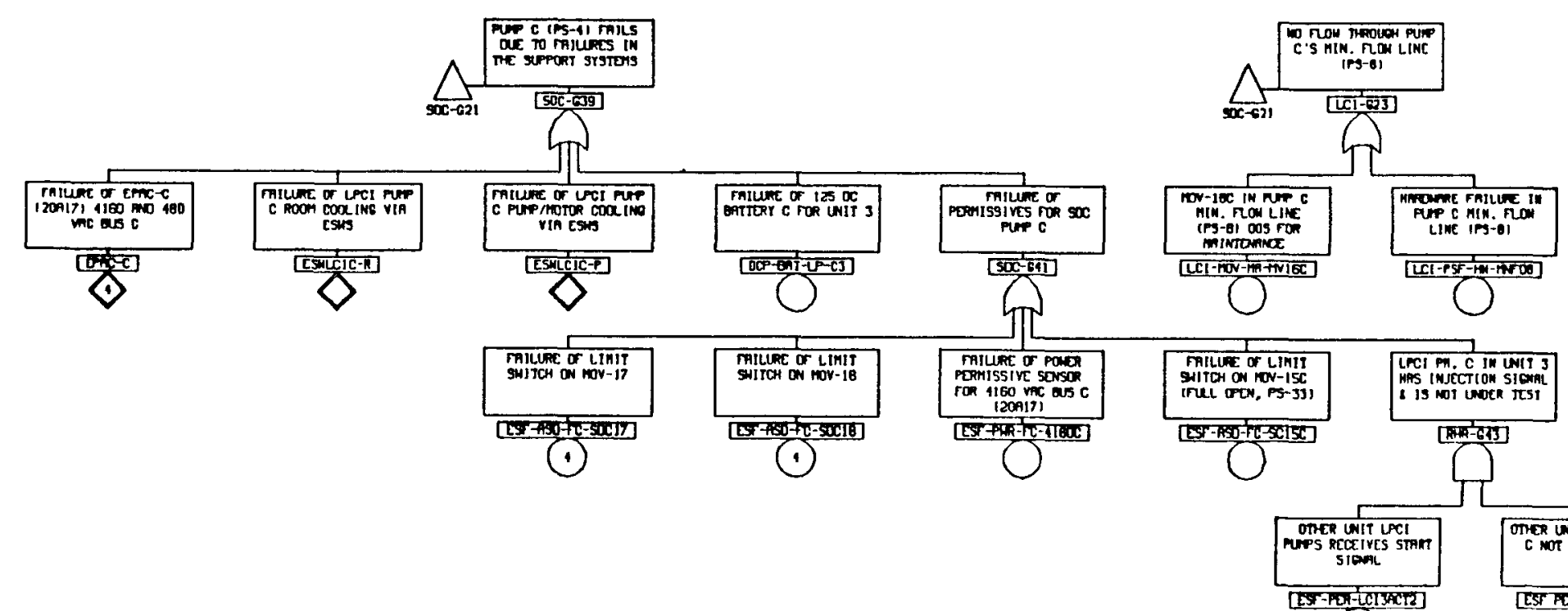

(1)

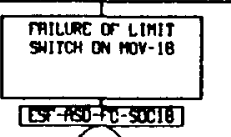

(4)

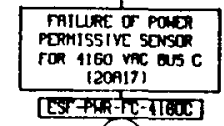

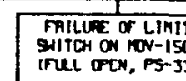

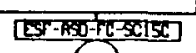

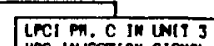

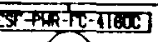

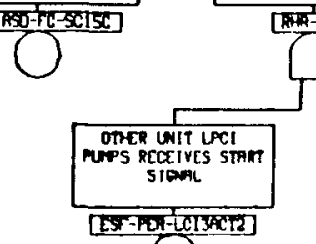

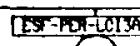

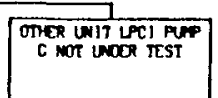

[Ex as [icitist] 


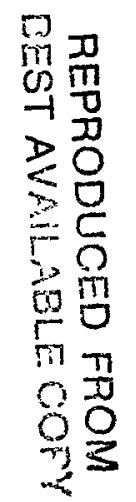

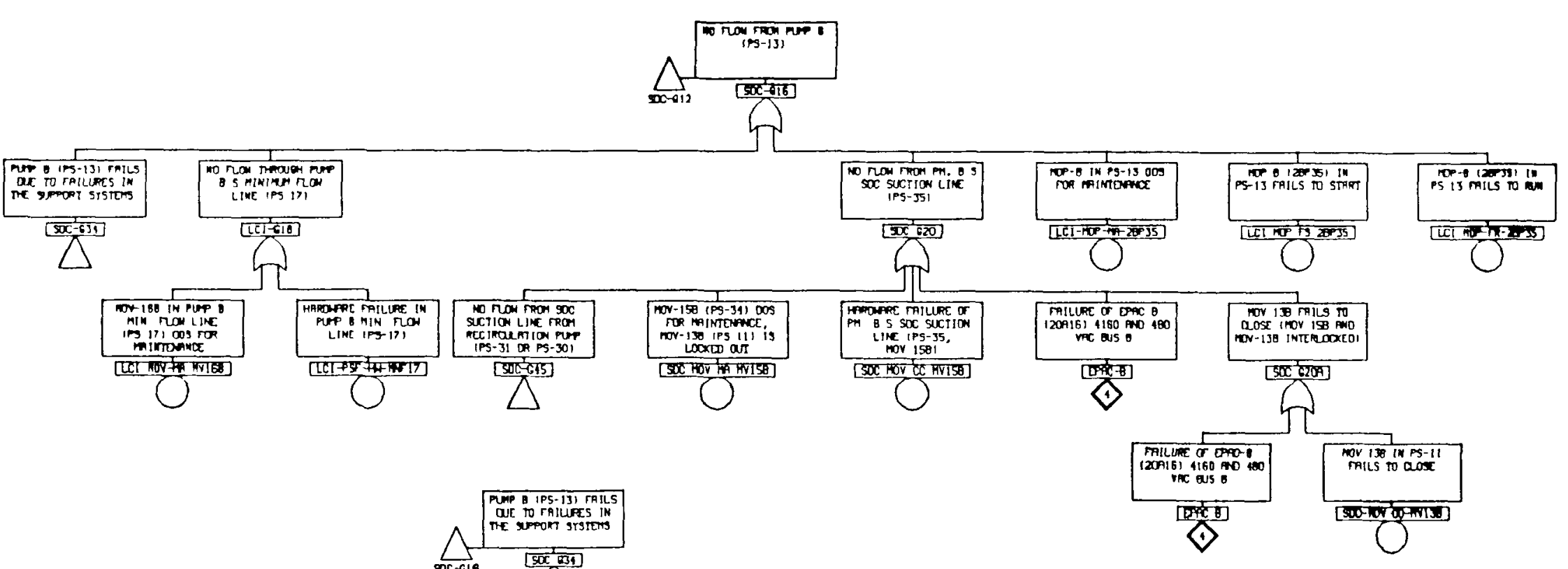

$\underset{\infty}{\stackrel{D}{\omega}}$

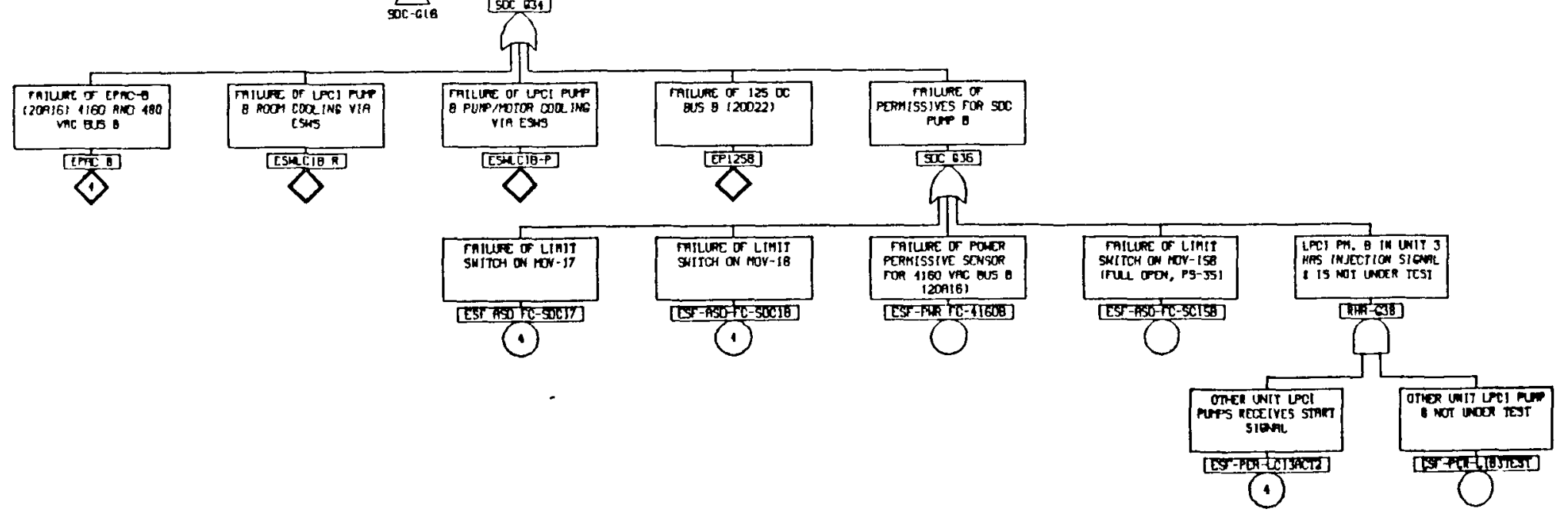





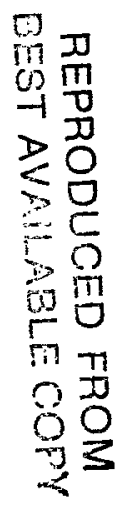

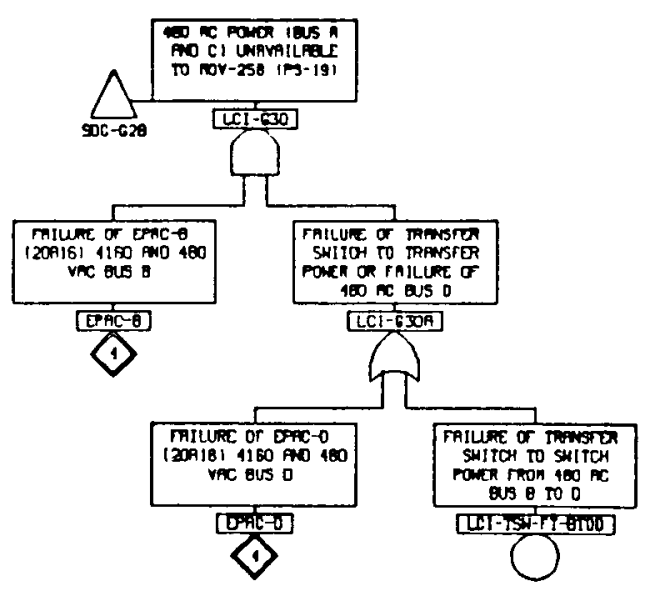

1
1
0

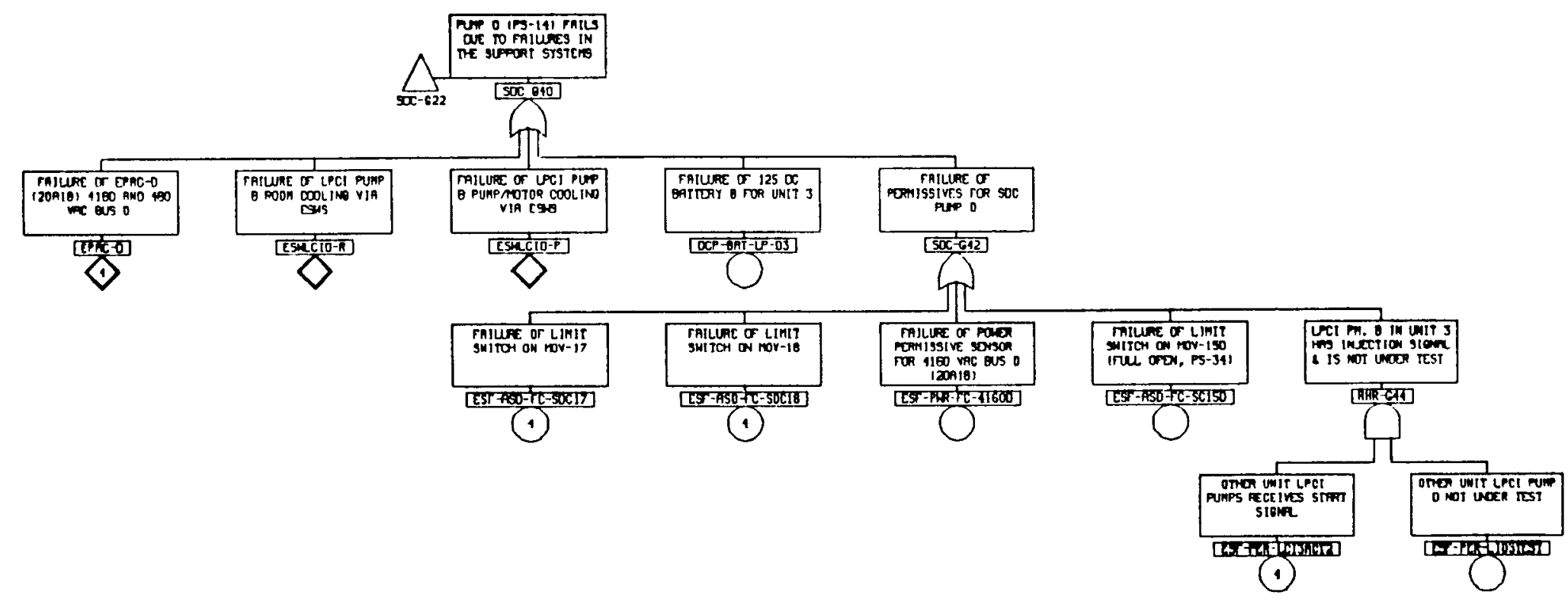




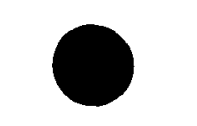

$\stackrel{?}{\underline{P}}$
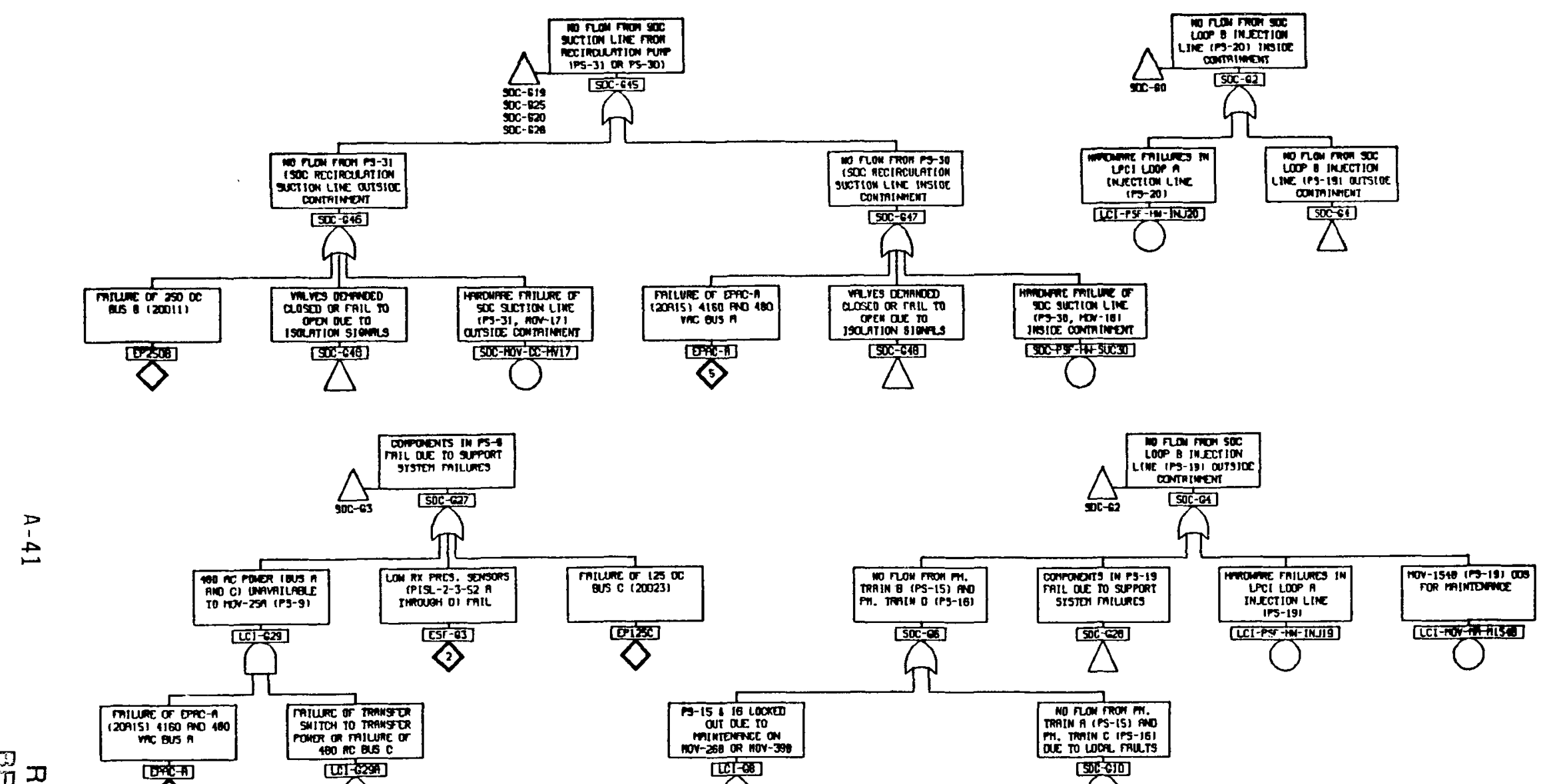

$\square$

监而

$\geqslant 0$

政

$=$

究管

고

군
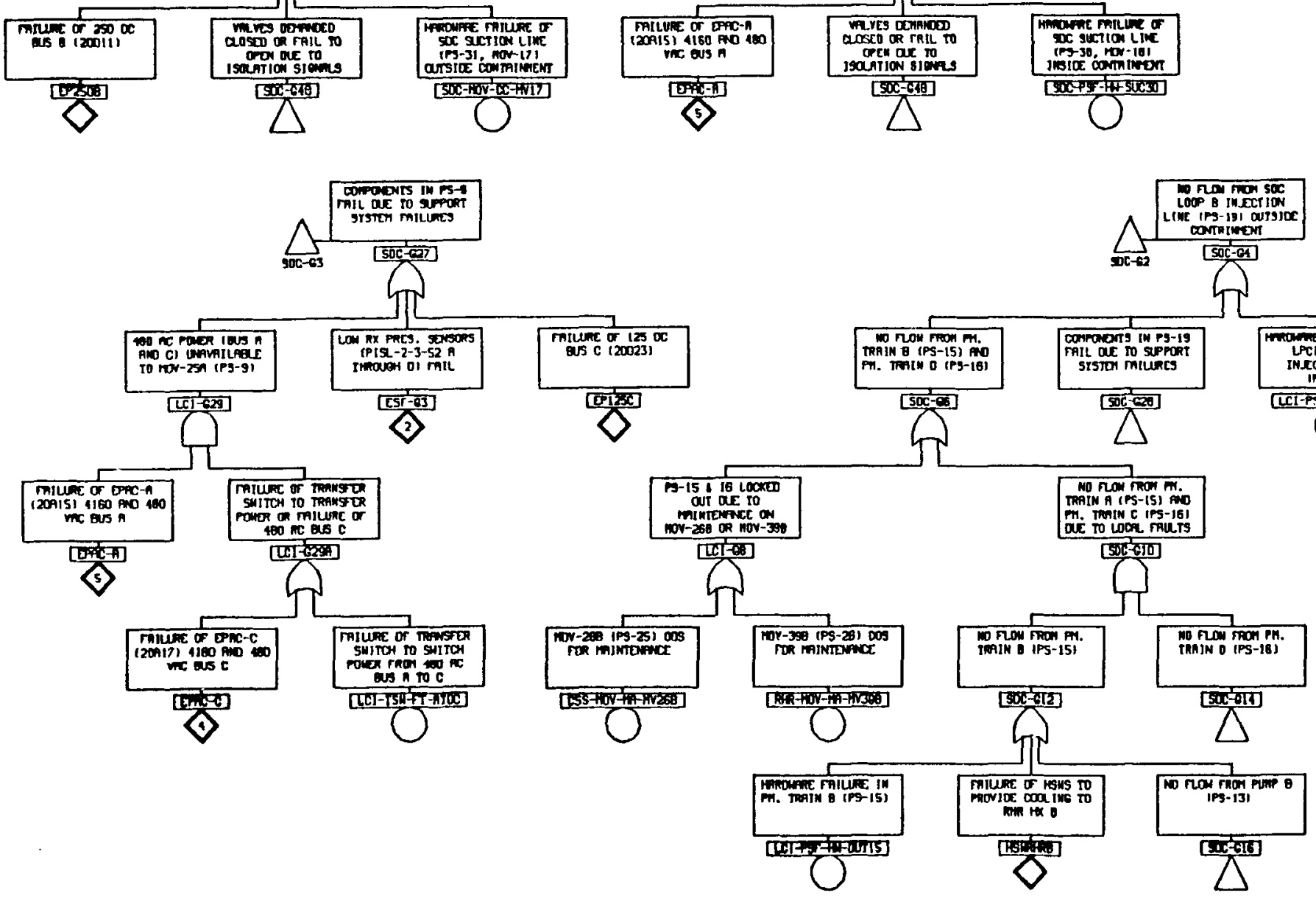

) 


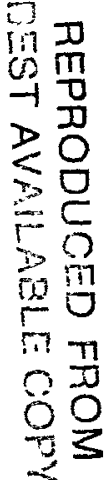

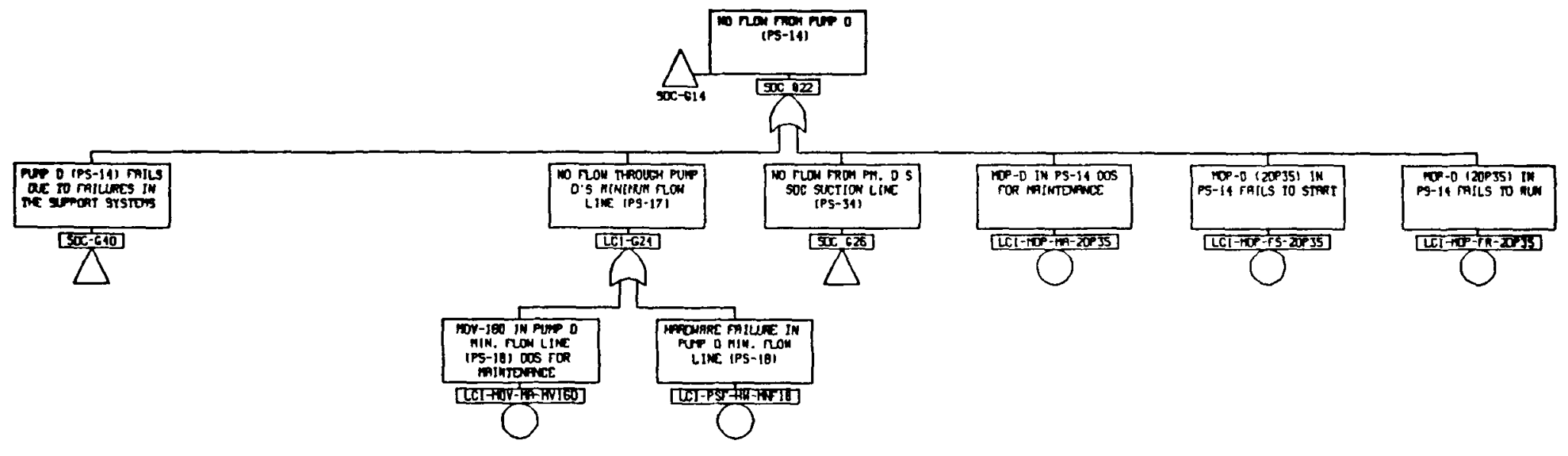

$P$
1
N

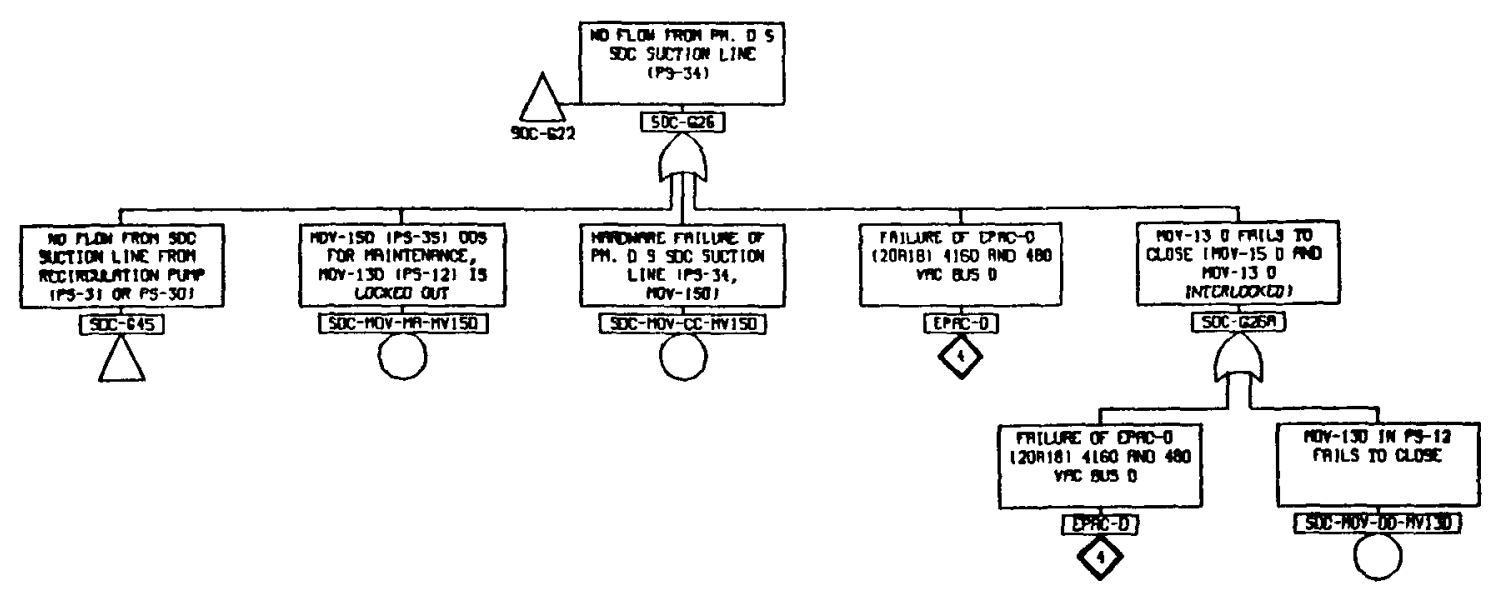


SUPPRESSION POOL COOLING SYSTEM

FAULT TREE 


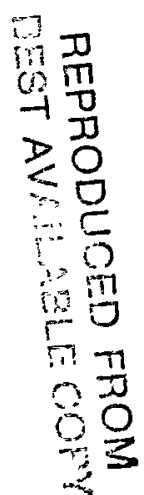

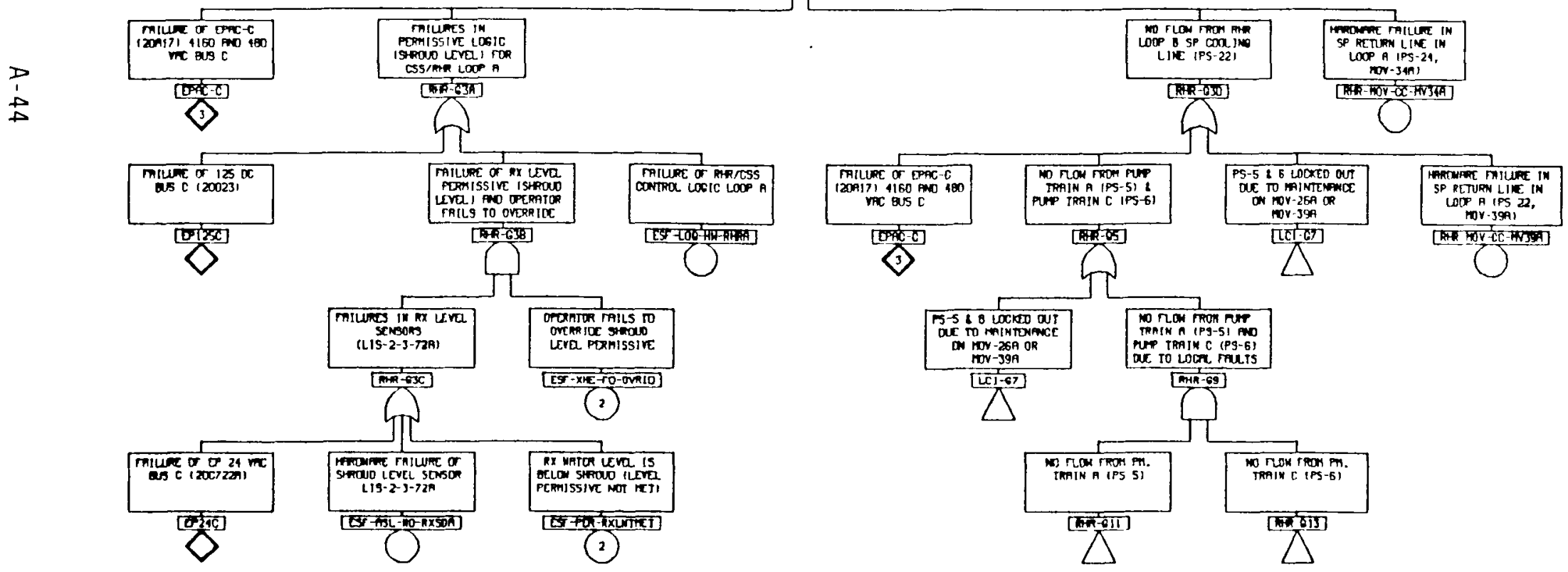





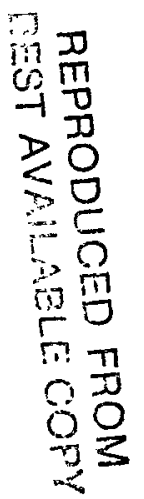
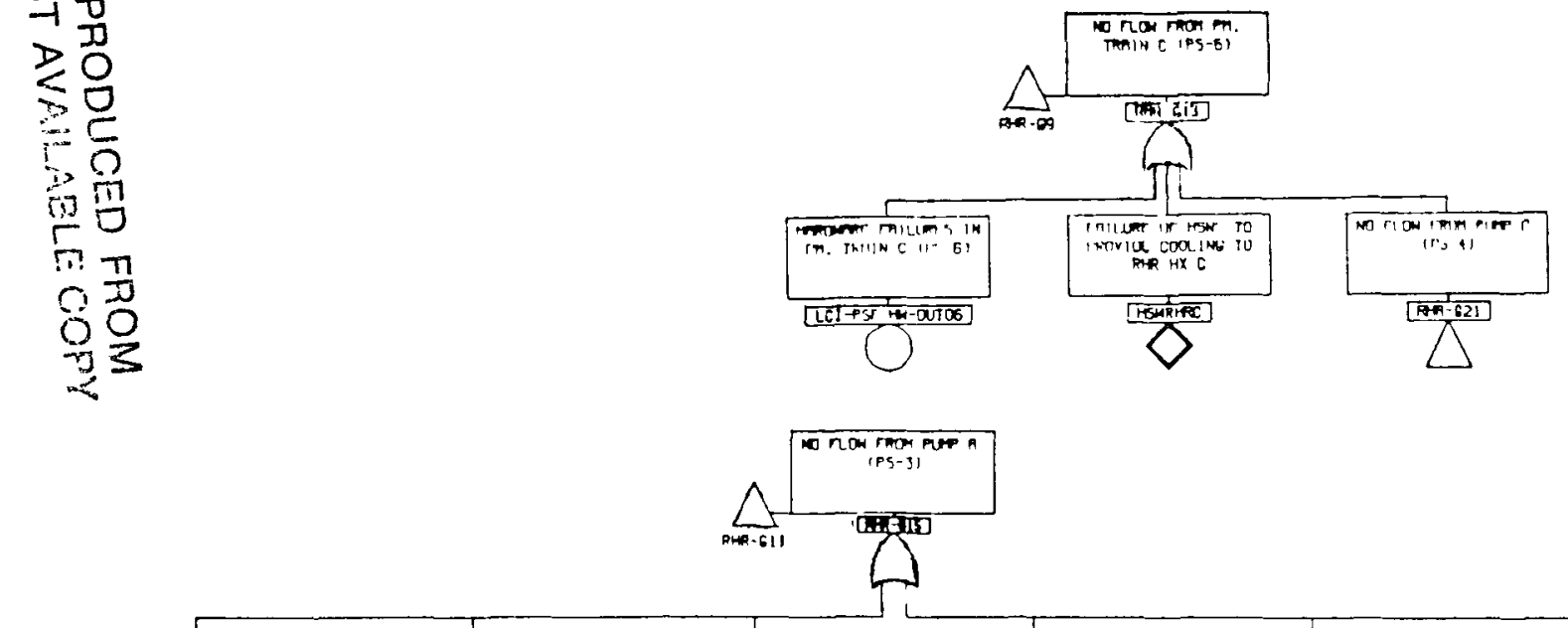

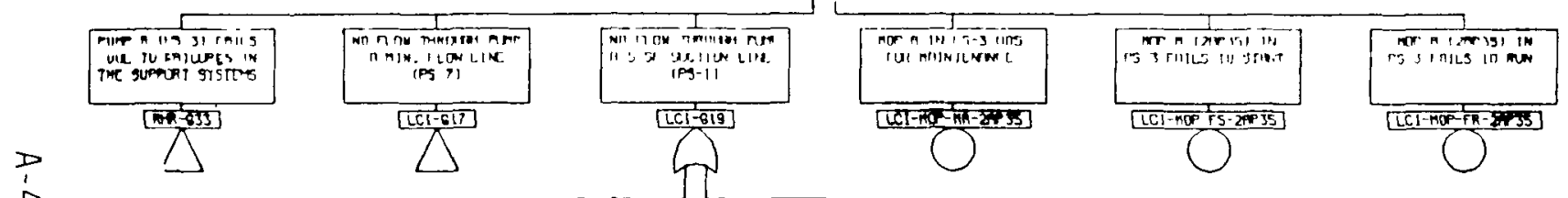

D
क
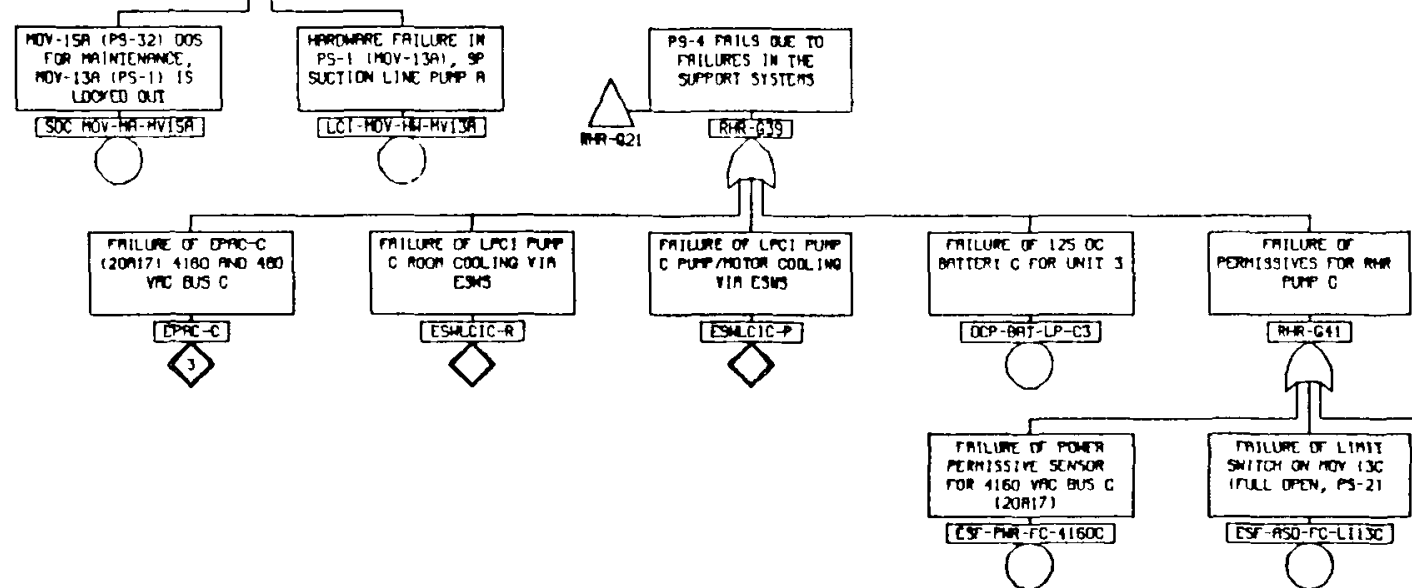

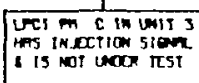

$0^{2}$

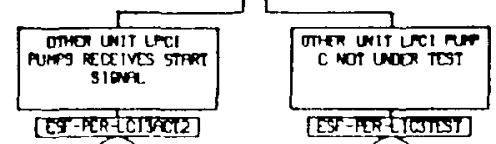

(1)

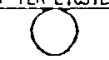




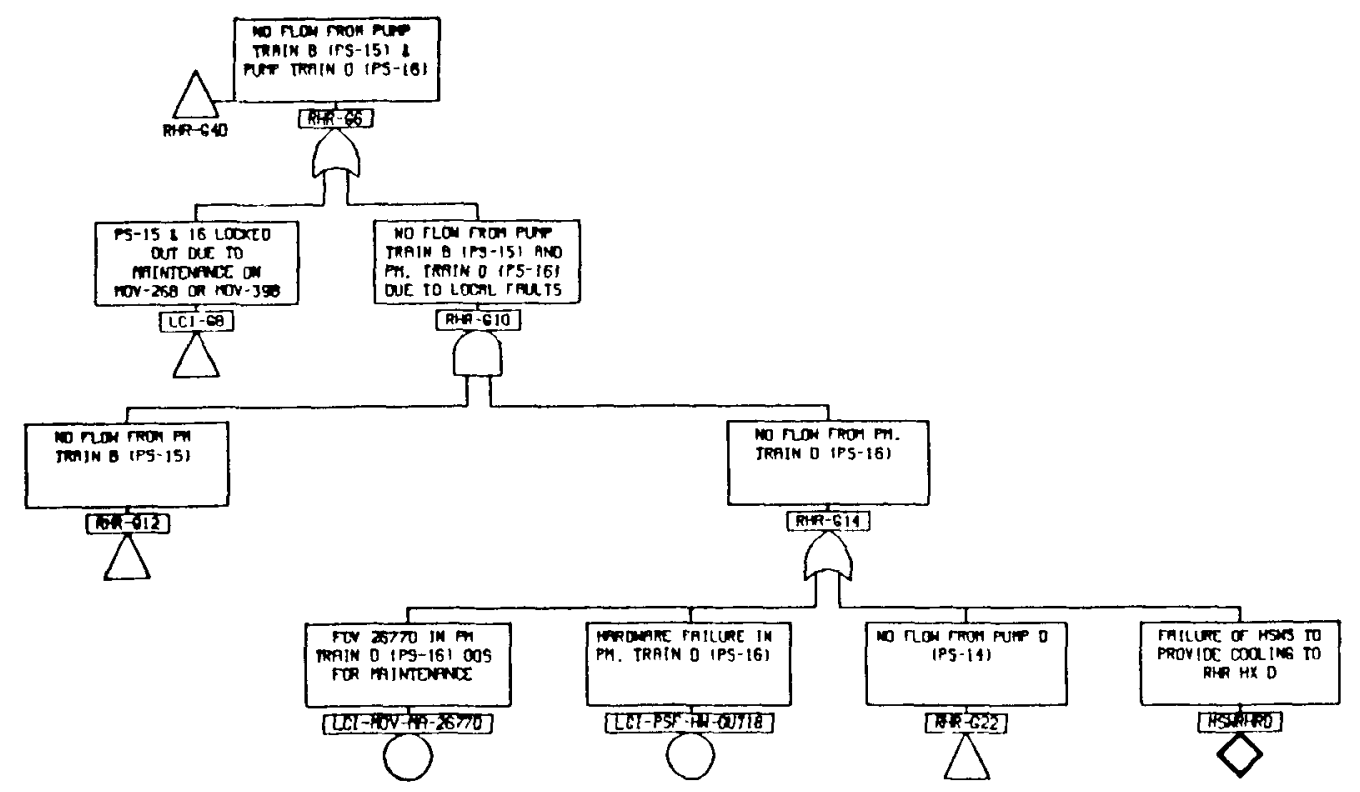

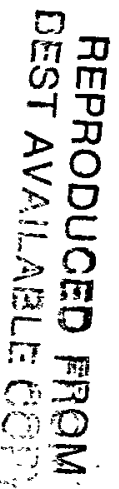

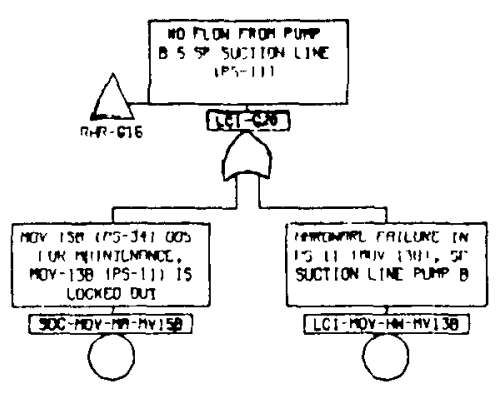



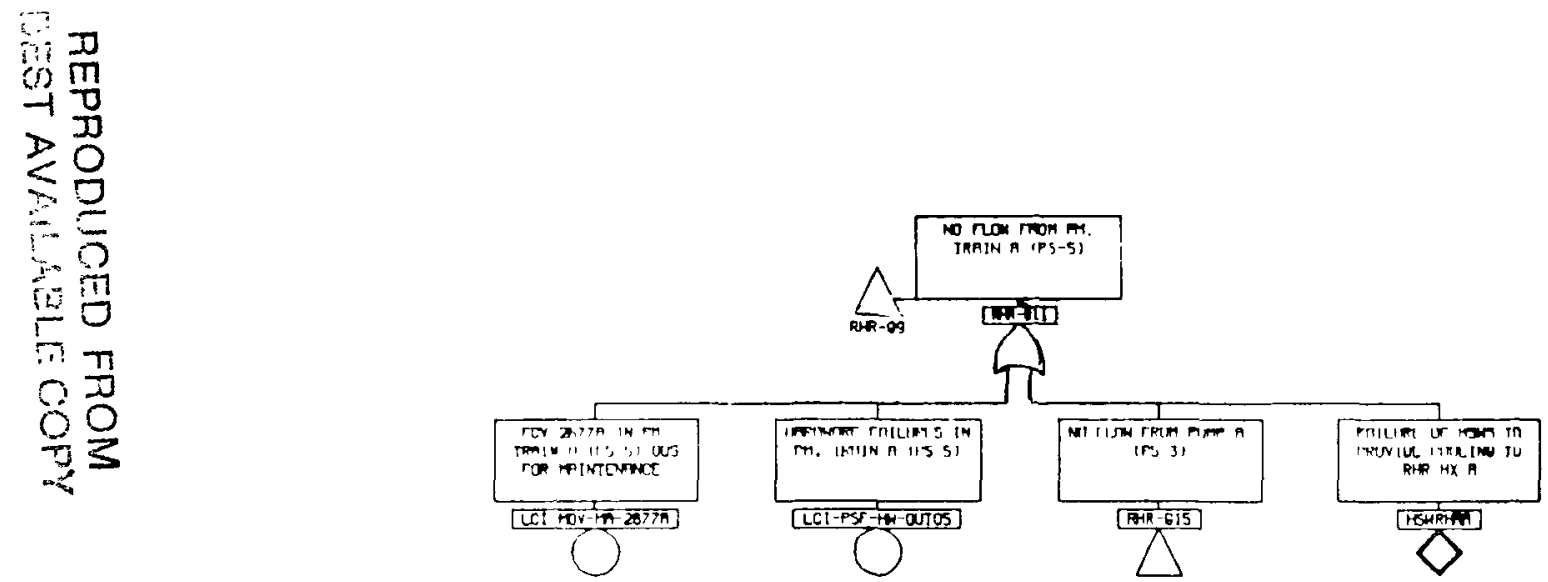

$p$
1
$\infty$

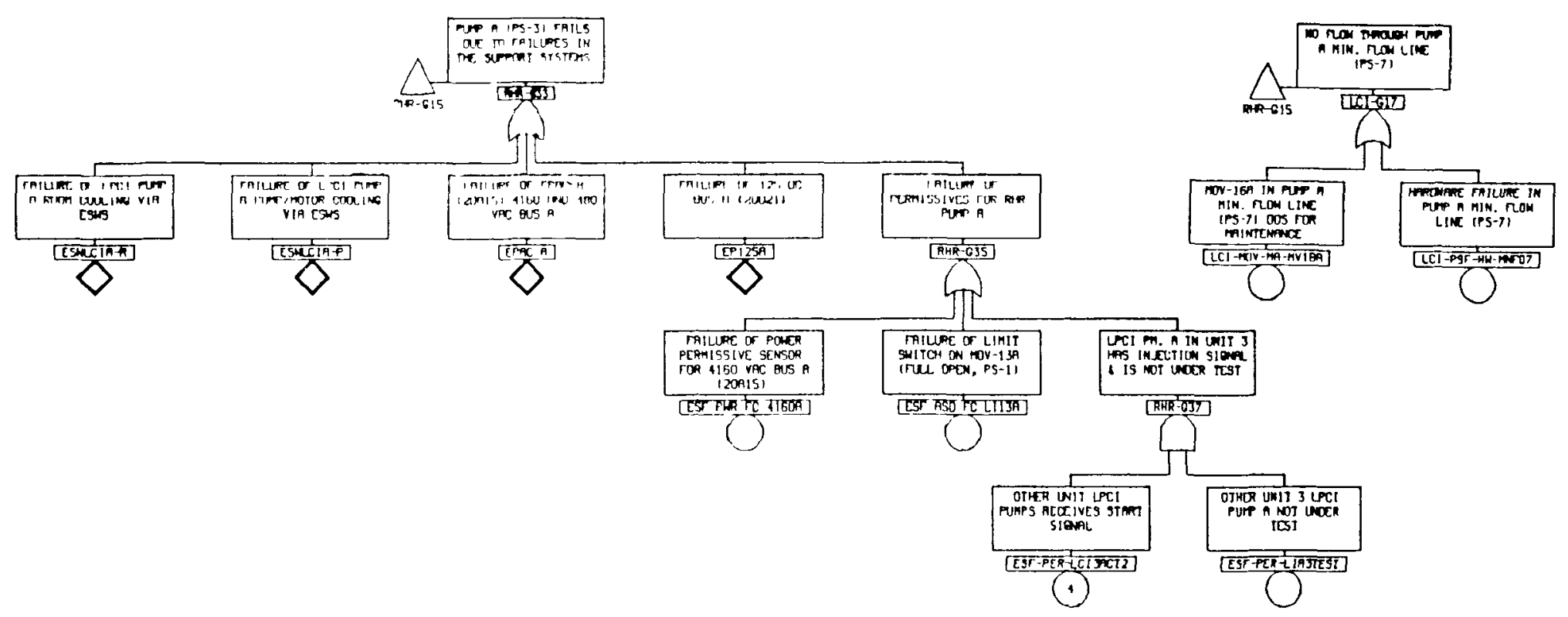




\section{$\bullet$}

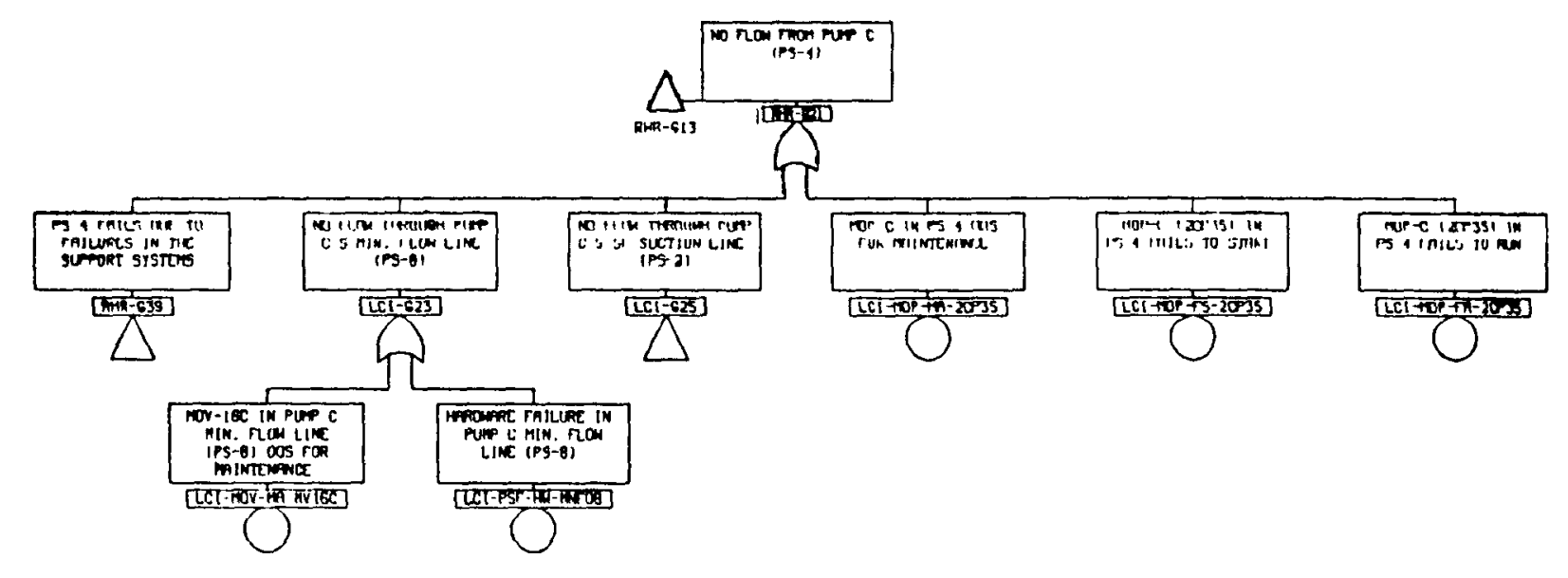

$\overrightarrow{1}$
$\dot{1}$
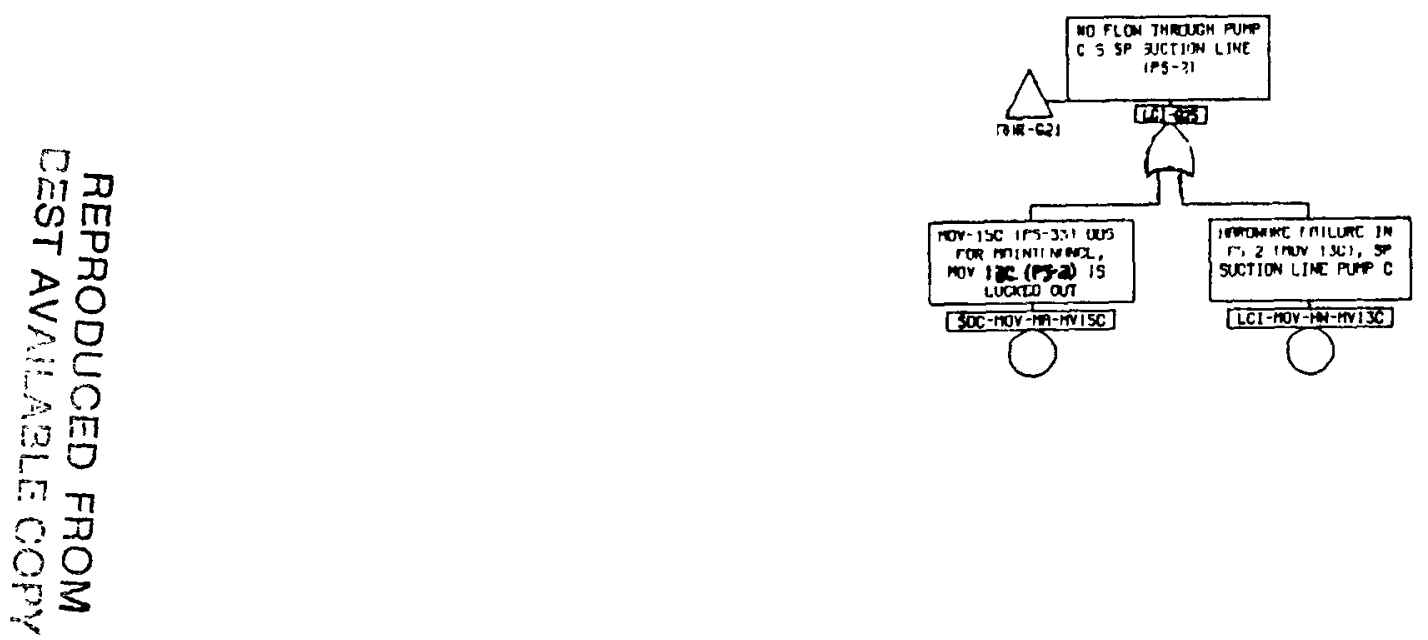


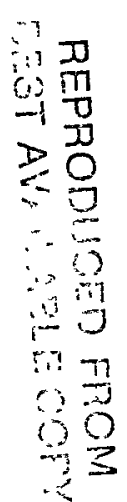
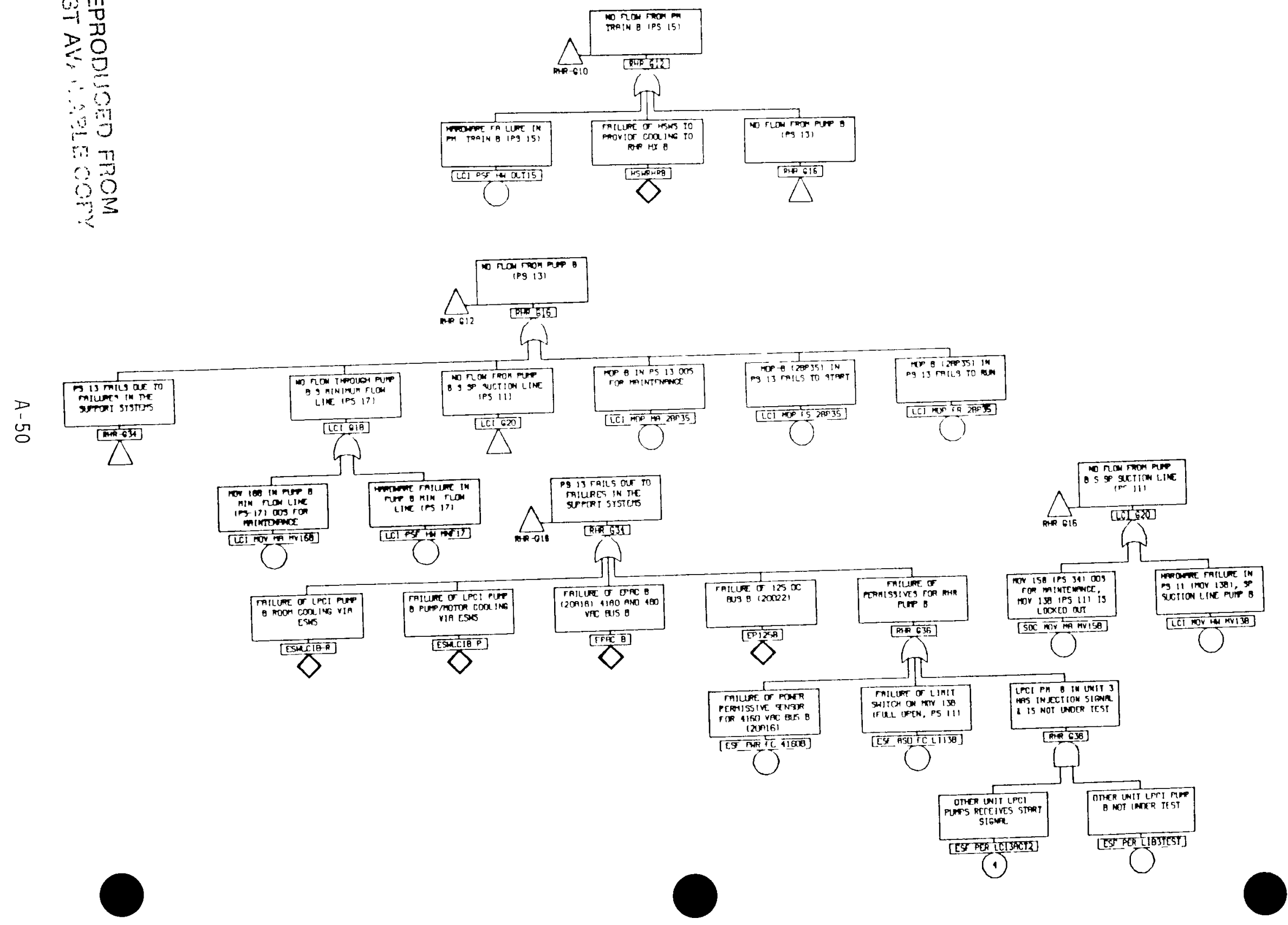

CONTAINMENT SPRAY SYSTEM

FAULT TREE 


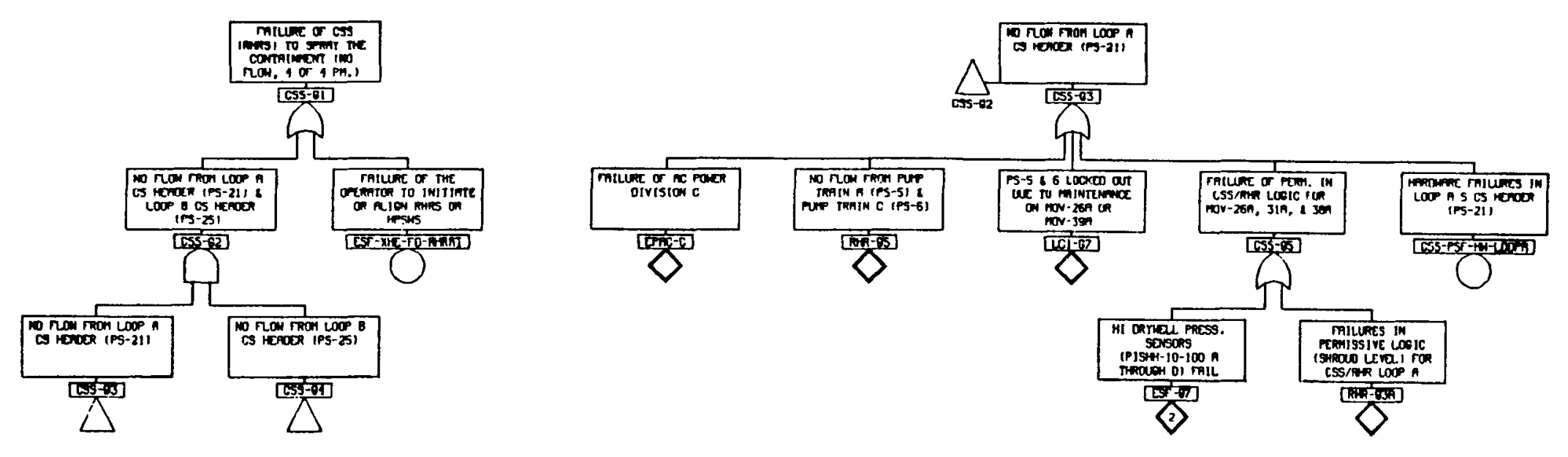

w

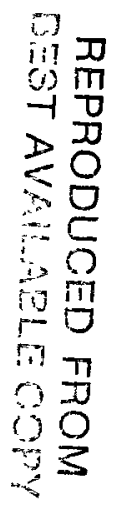

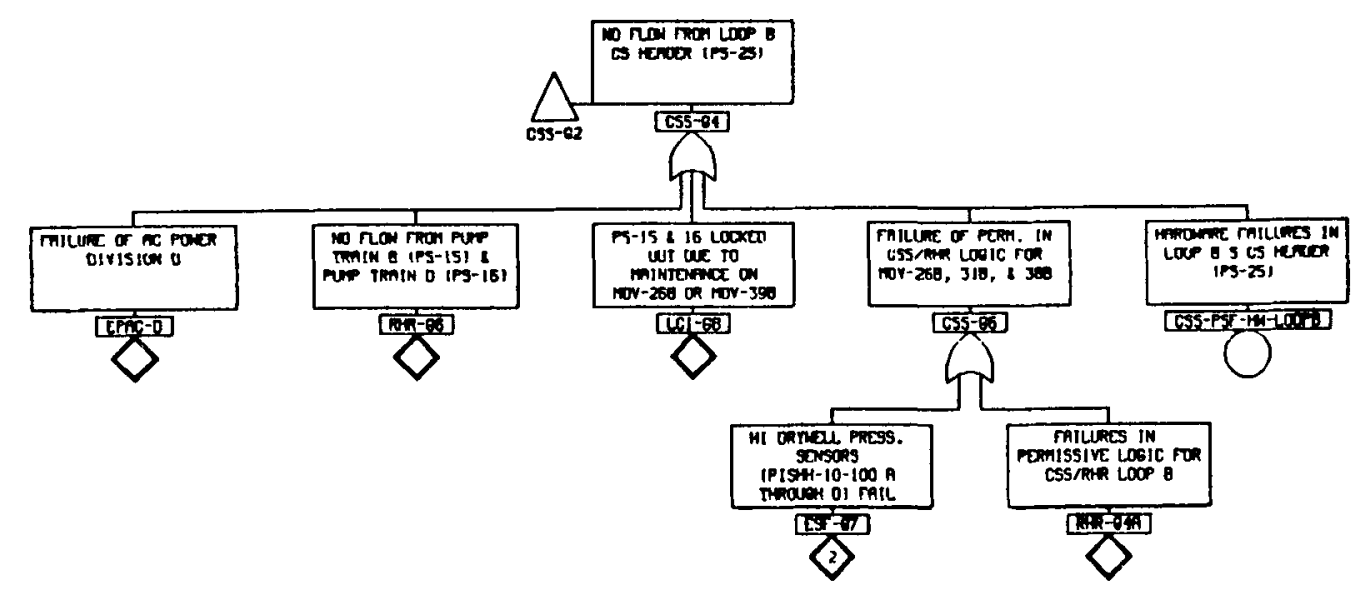


ELECTRIC POWER SYSTEM

FAULT TREE 

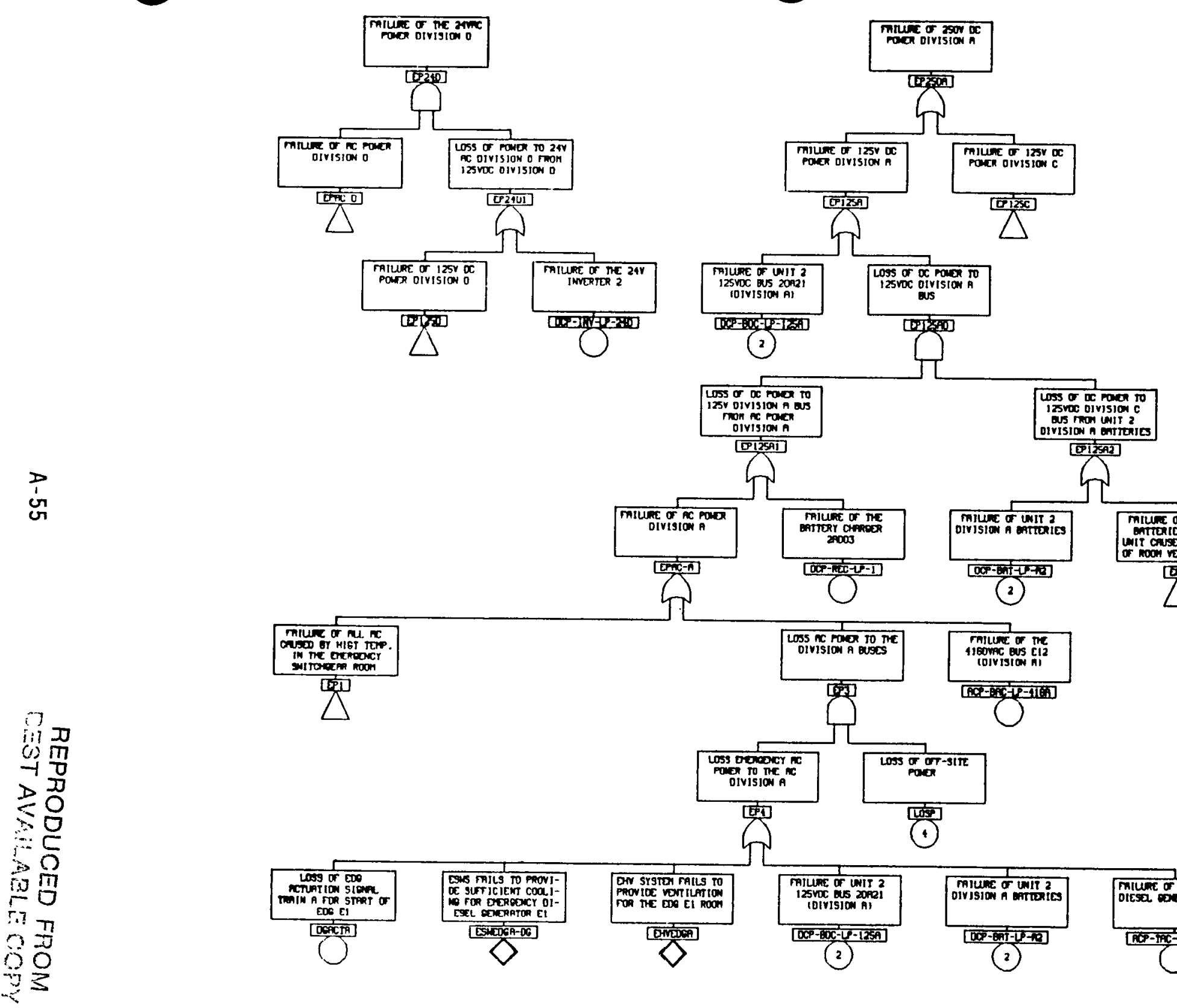

ज

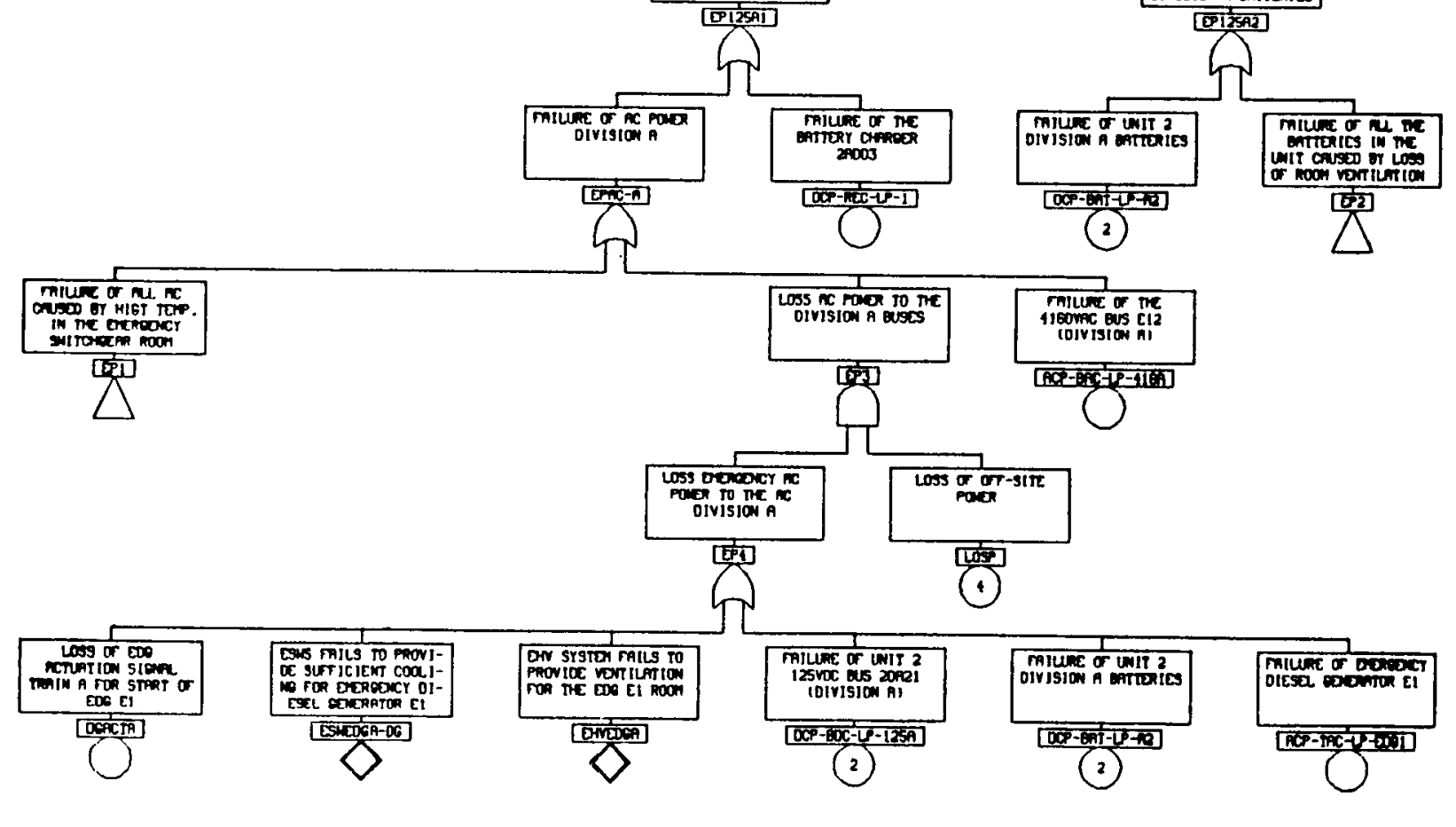




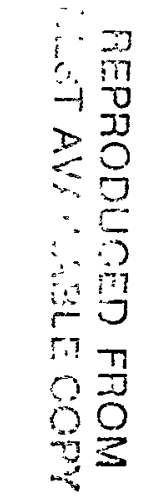

हू

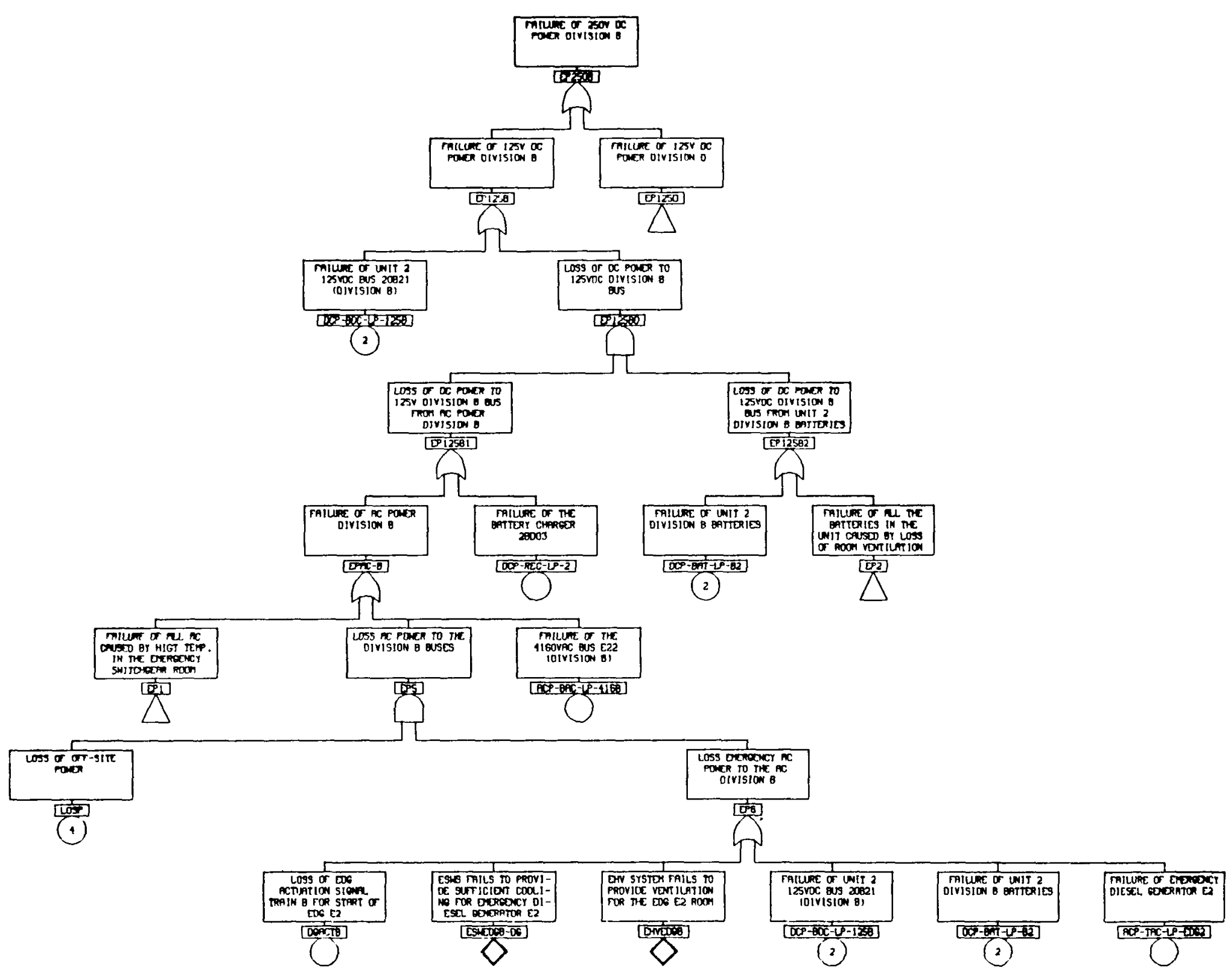




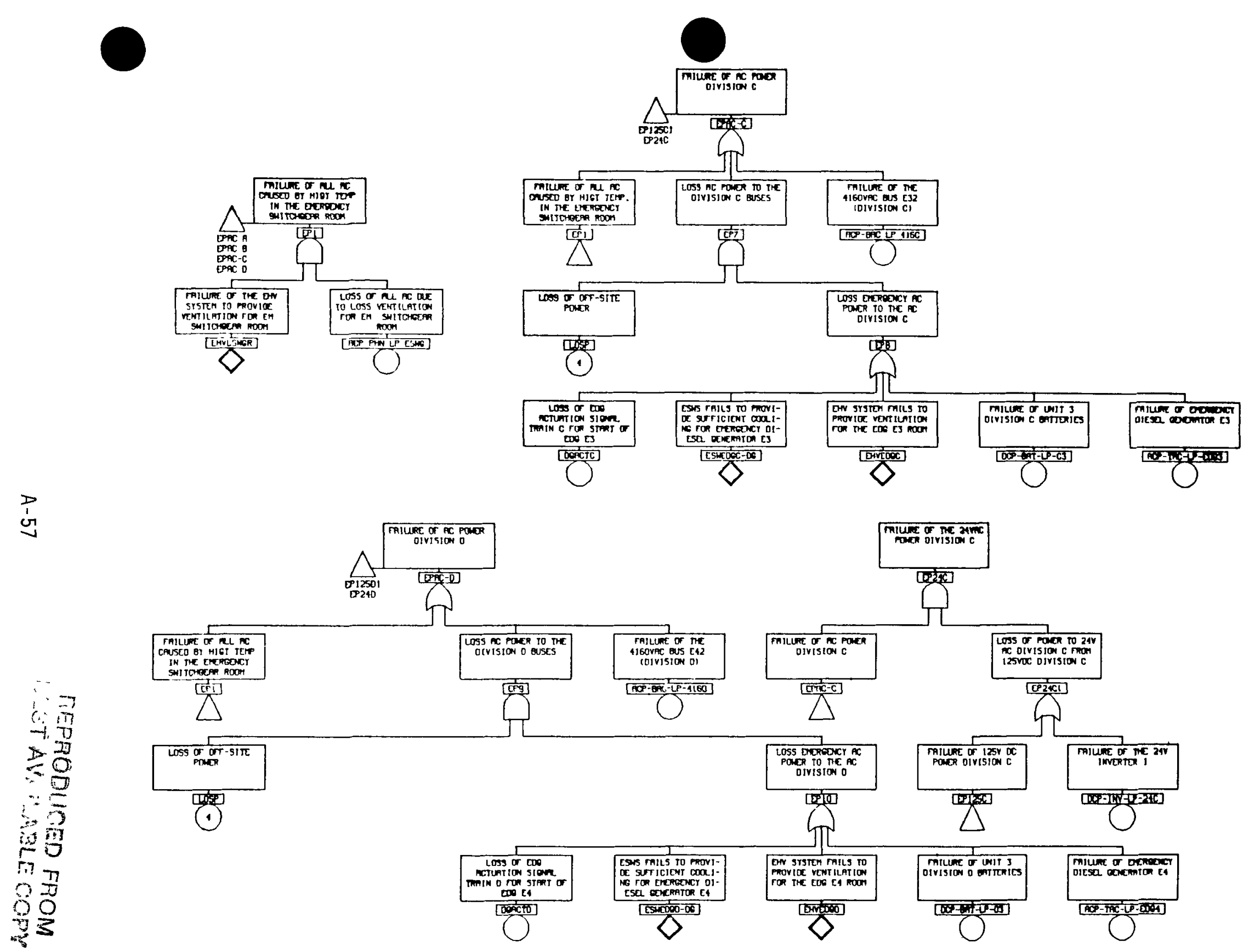




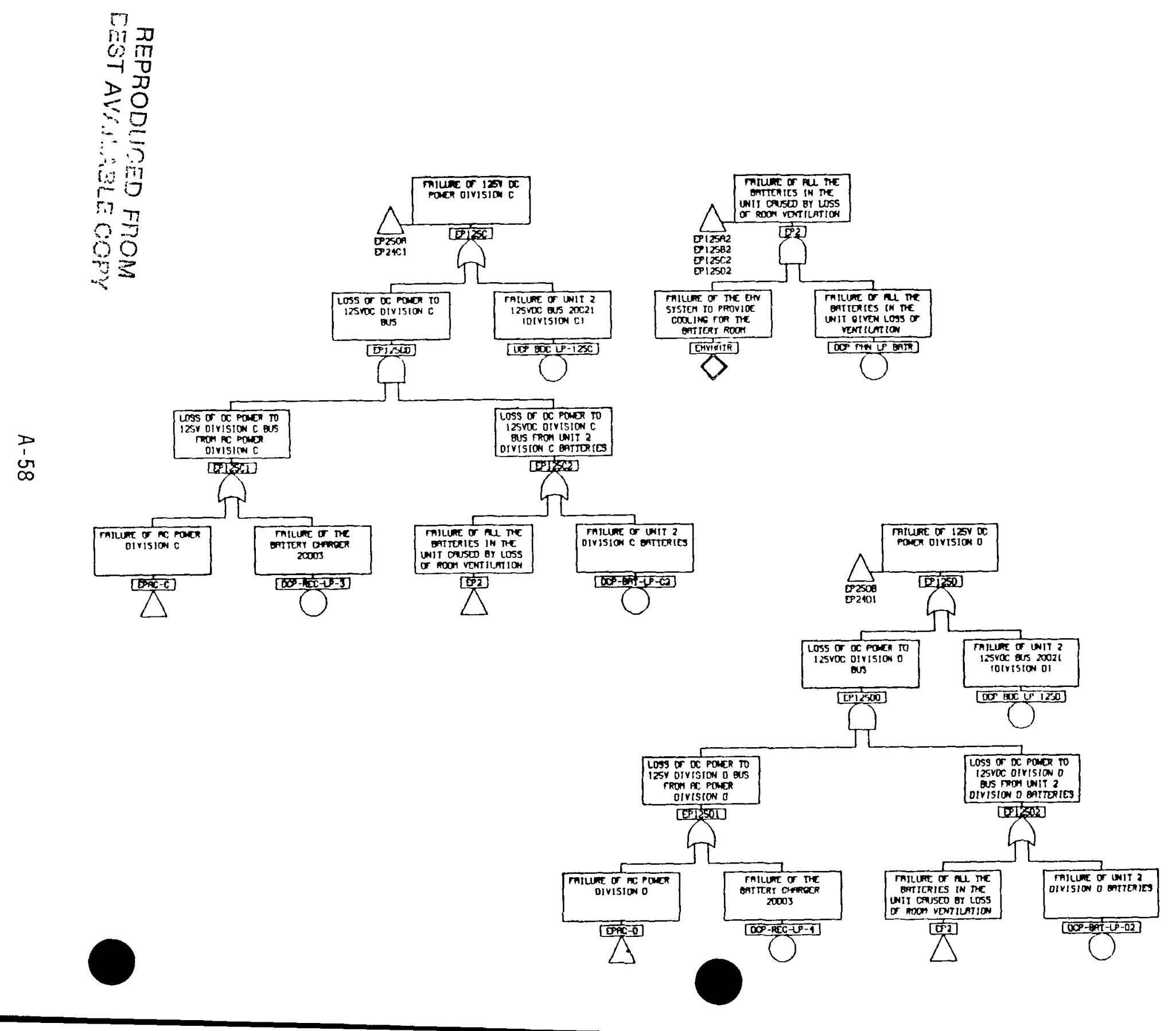


EMERGENCY SERVICE WATER SYSTEM

FAULT TREE 


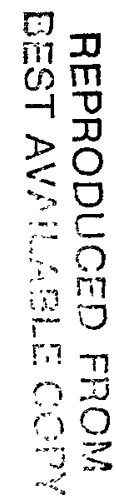
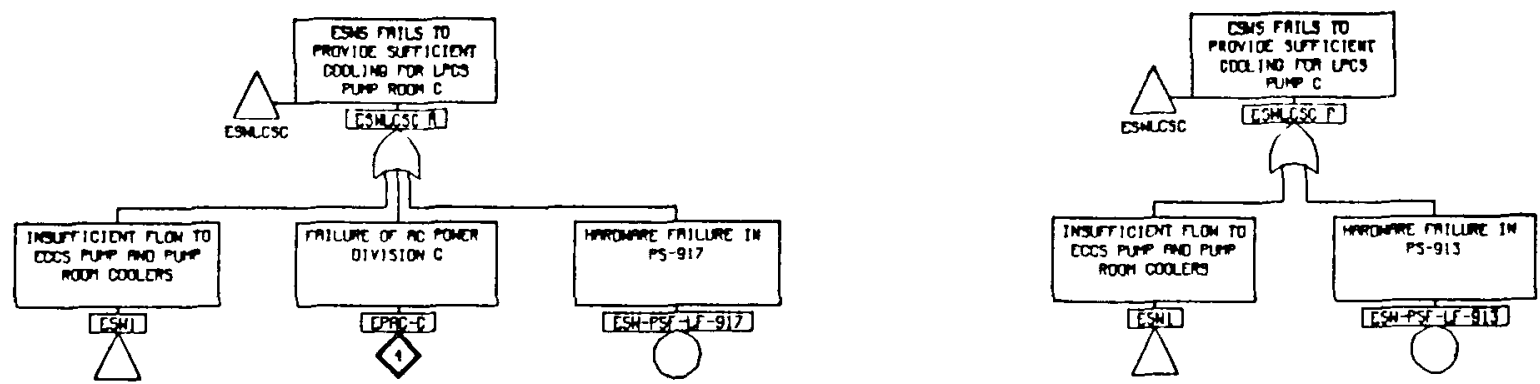

7
$\vdots$
0
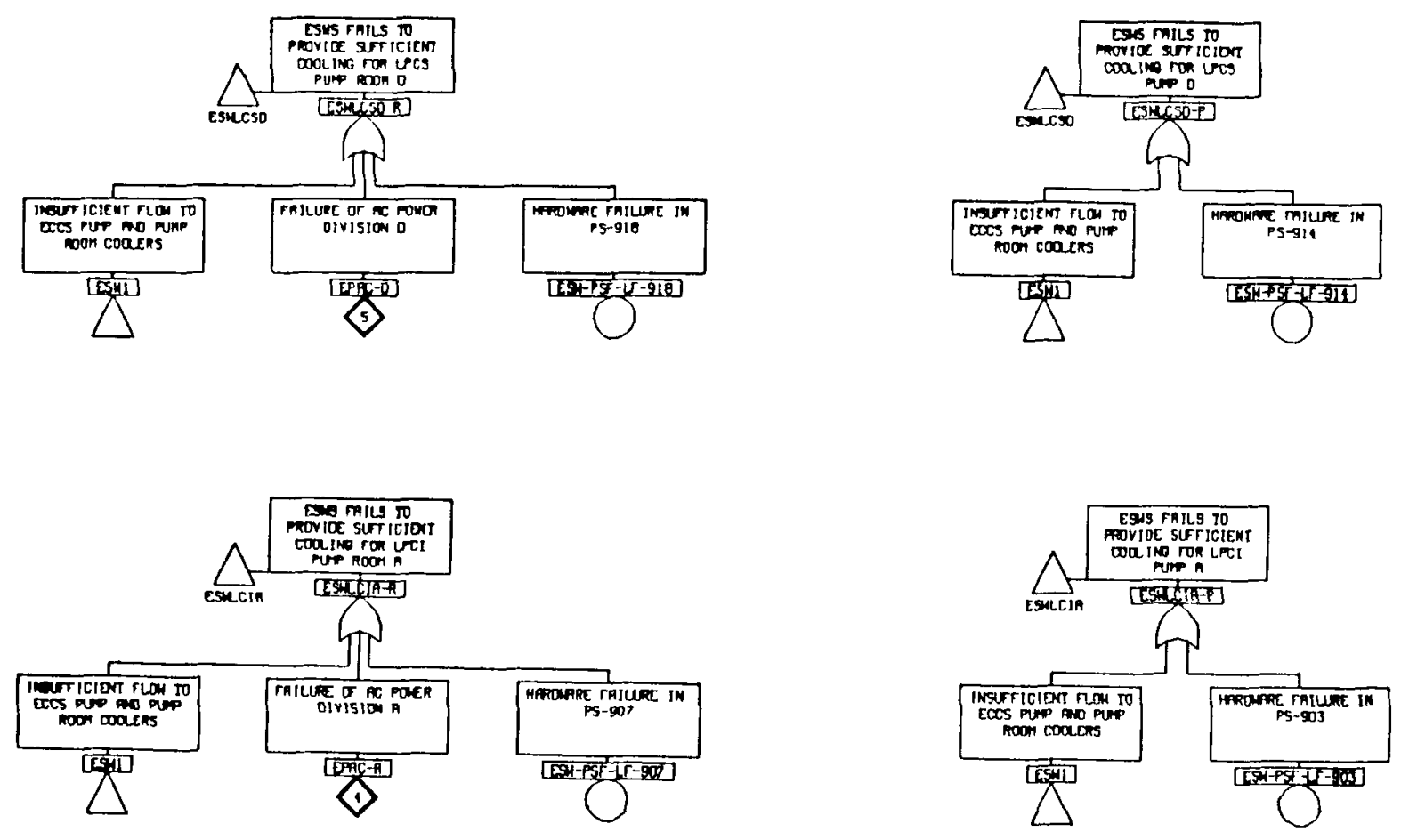

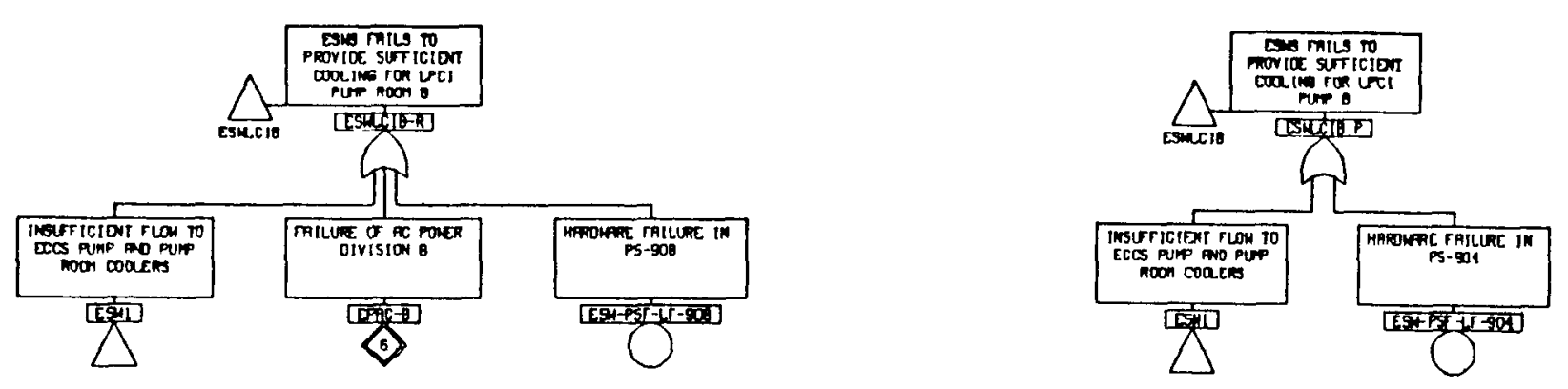

7
1
0
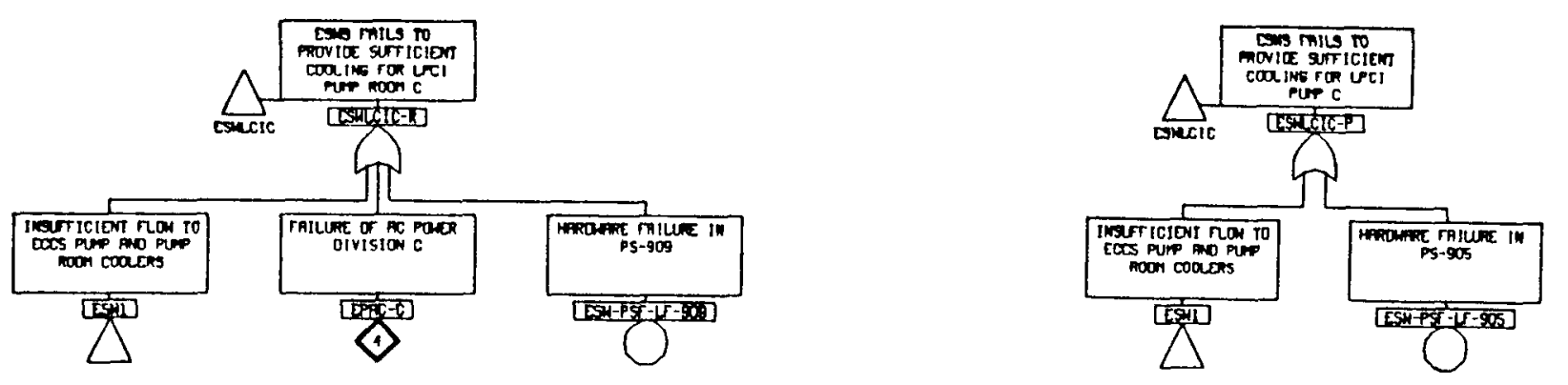

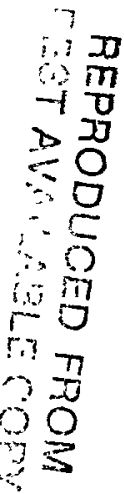
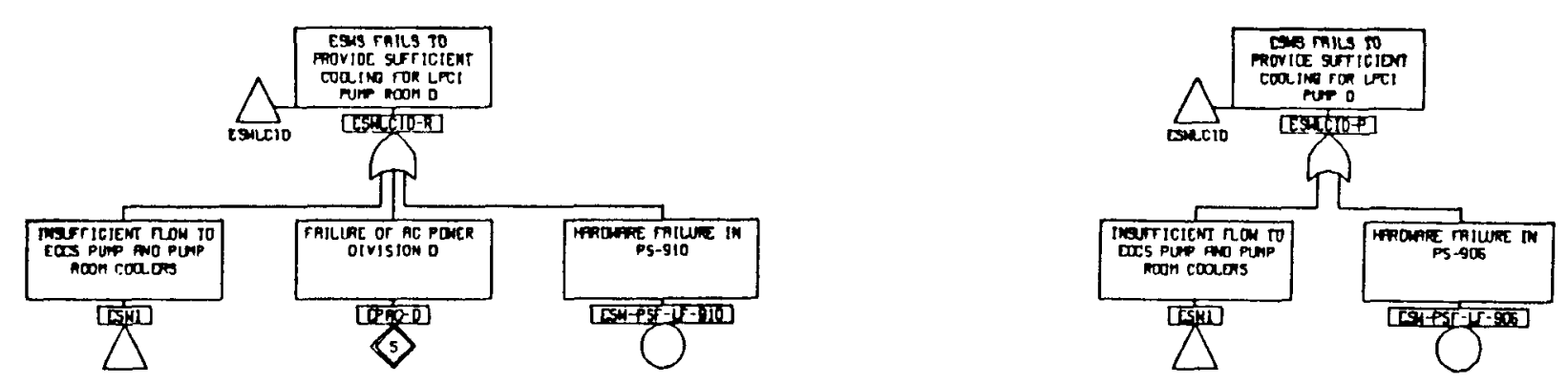


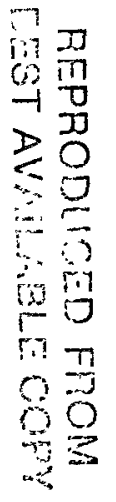
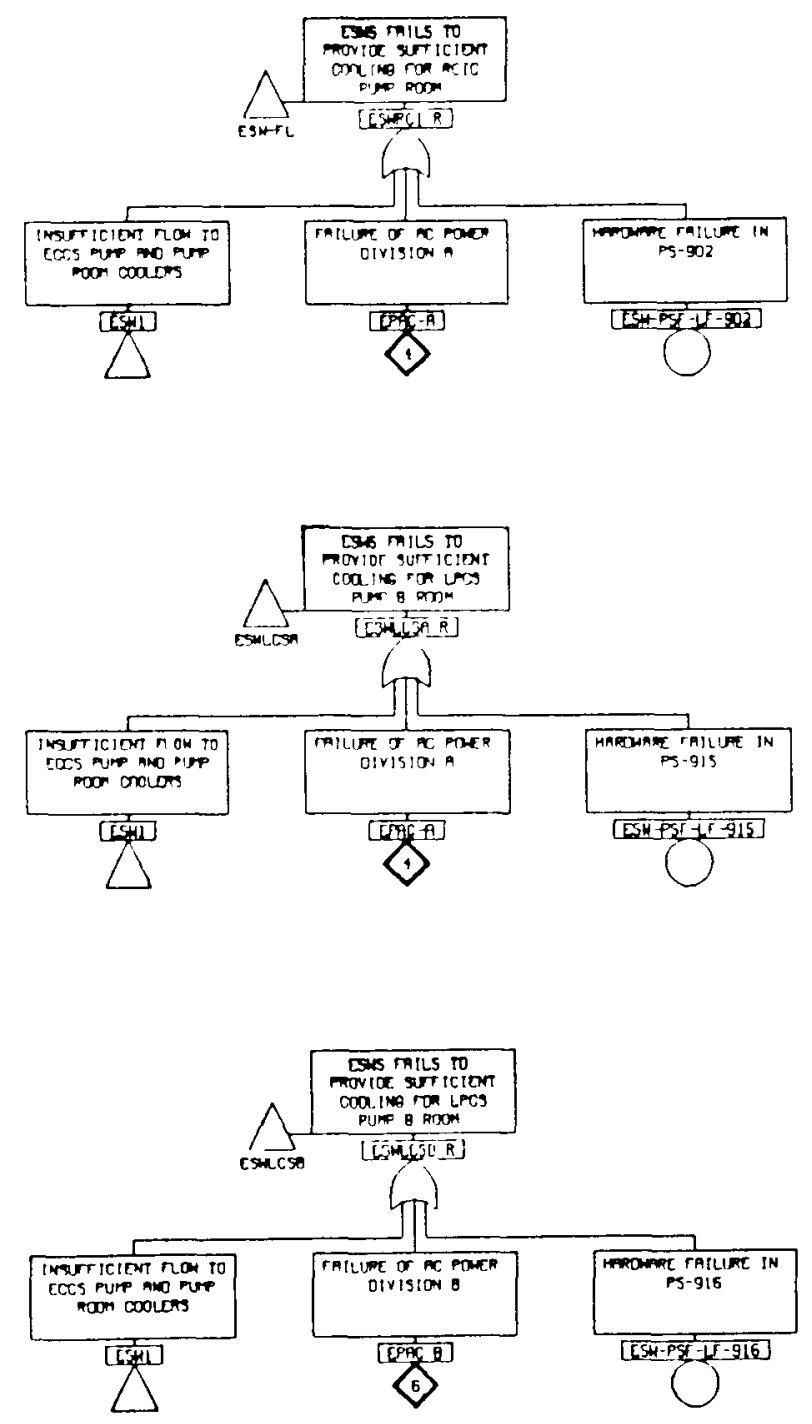
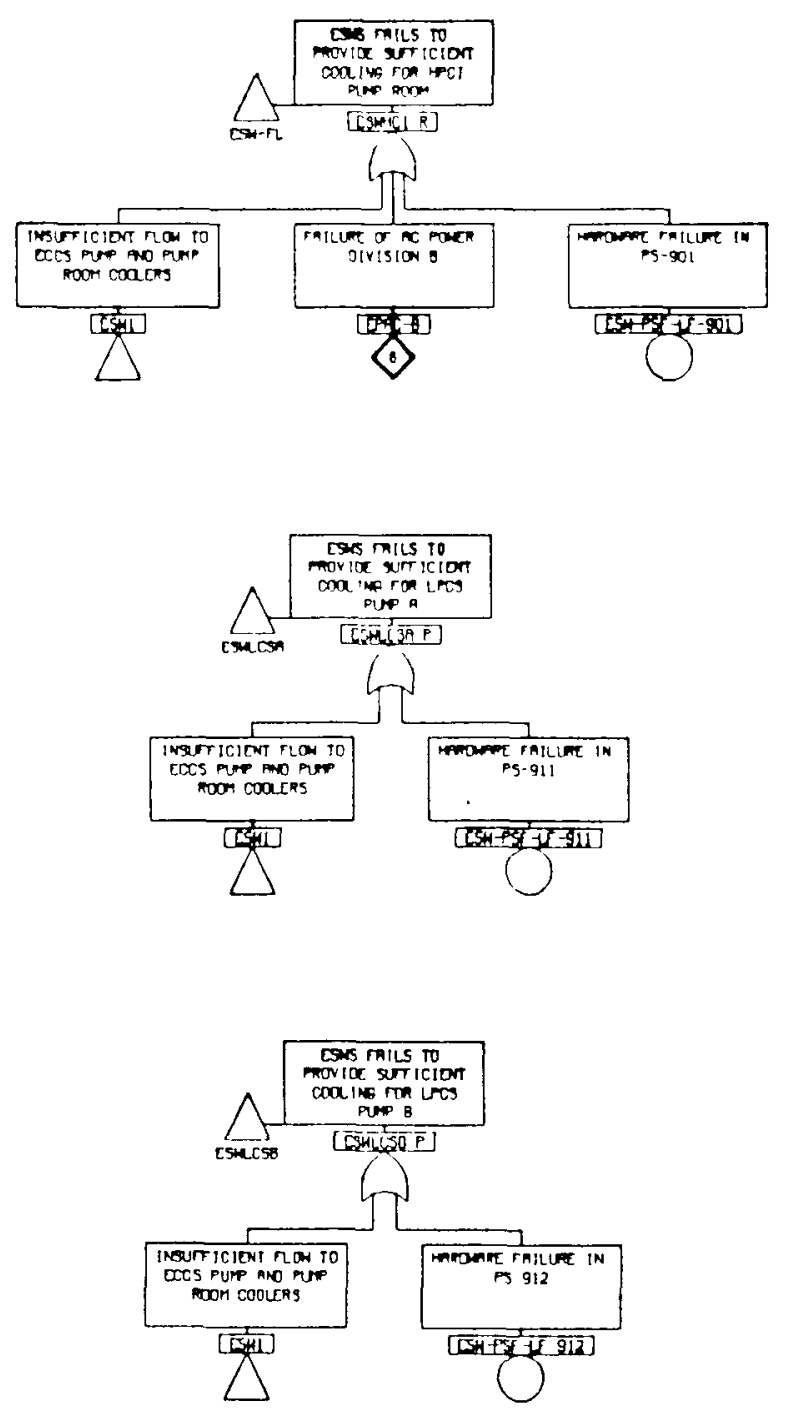


\section{$\bullet$}

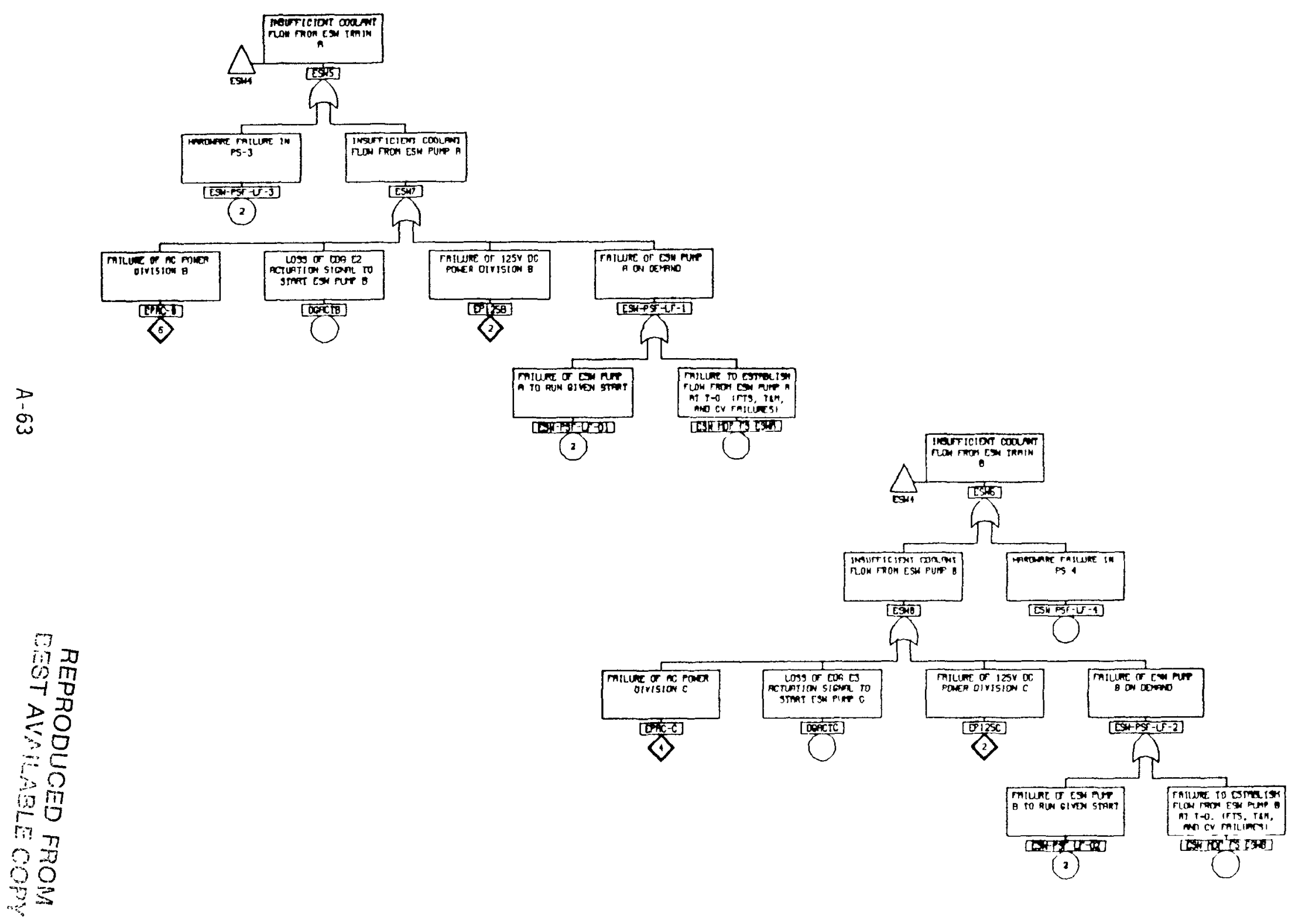




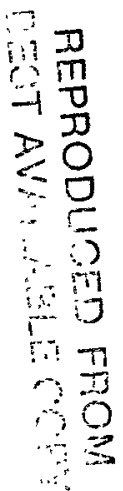
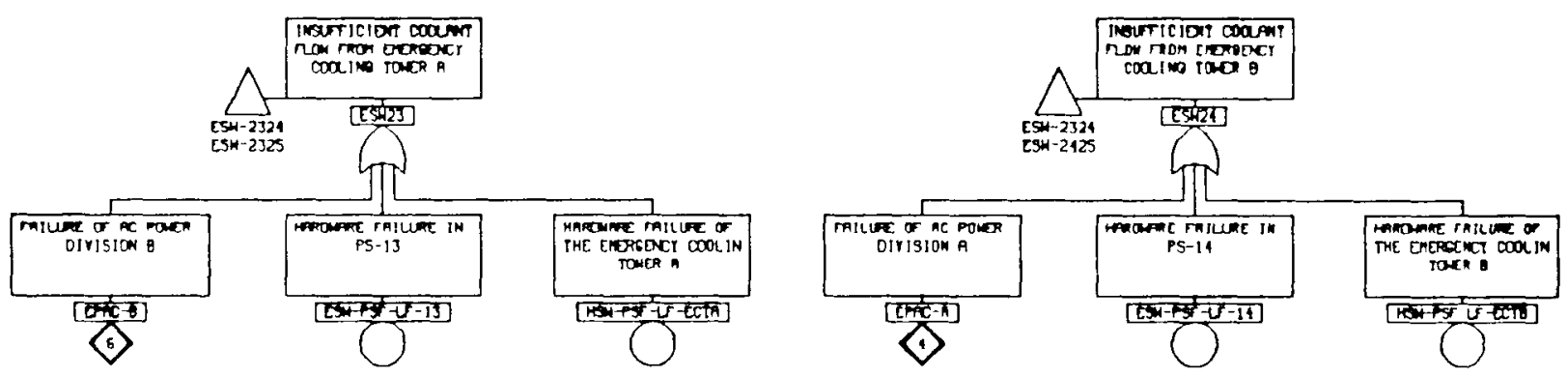

D
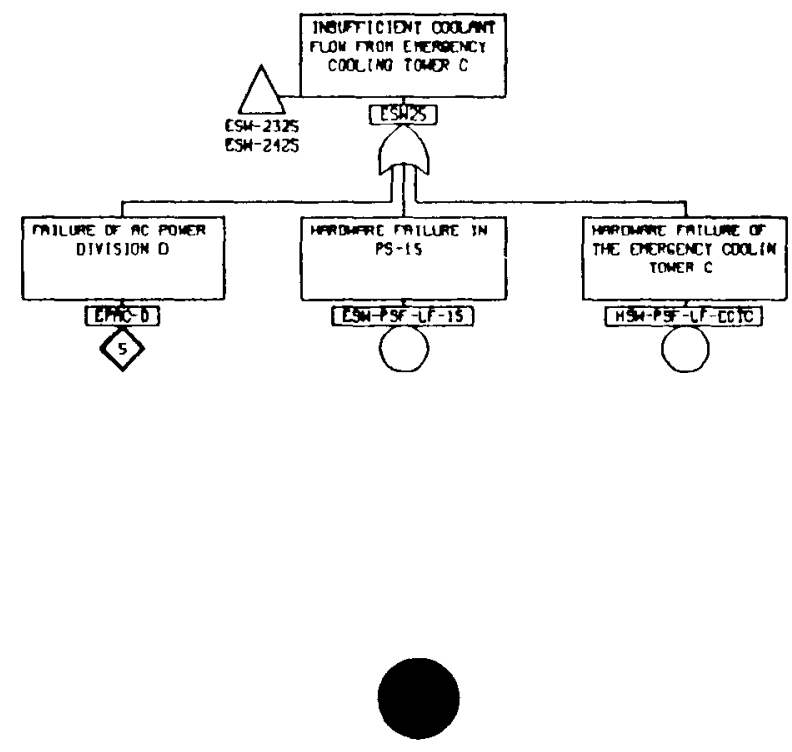



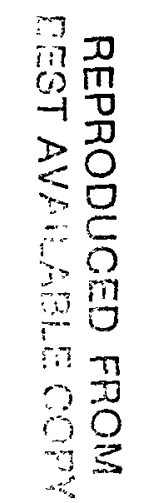

?
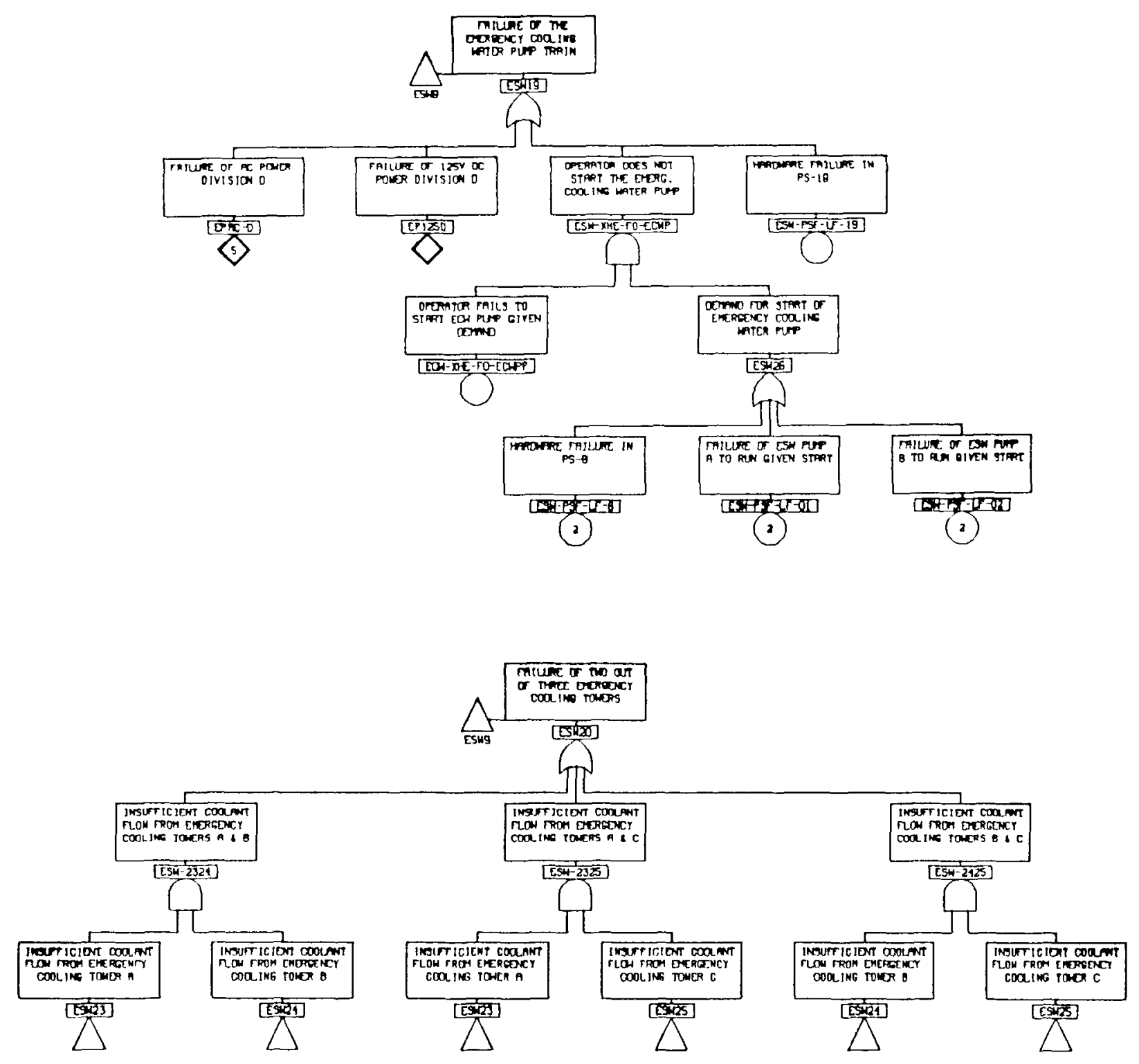


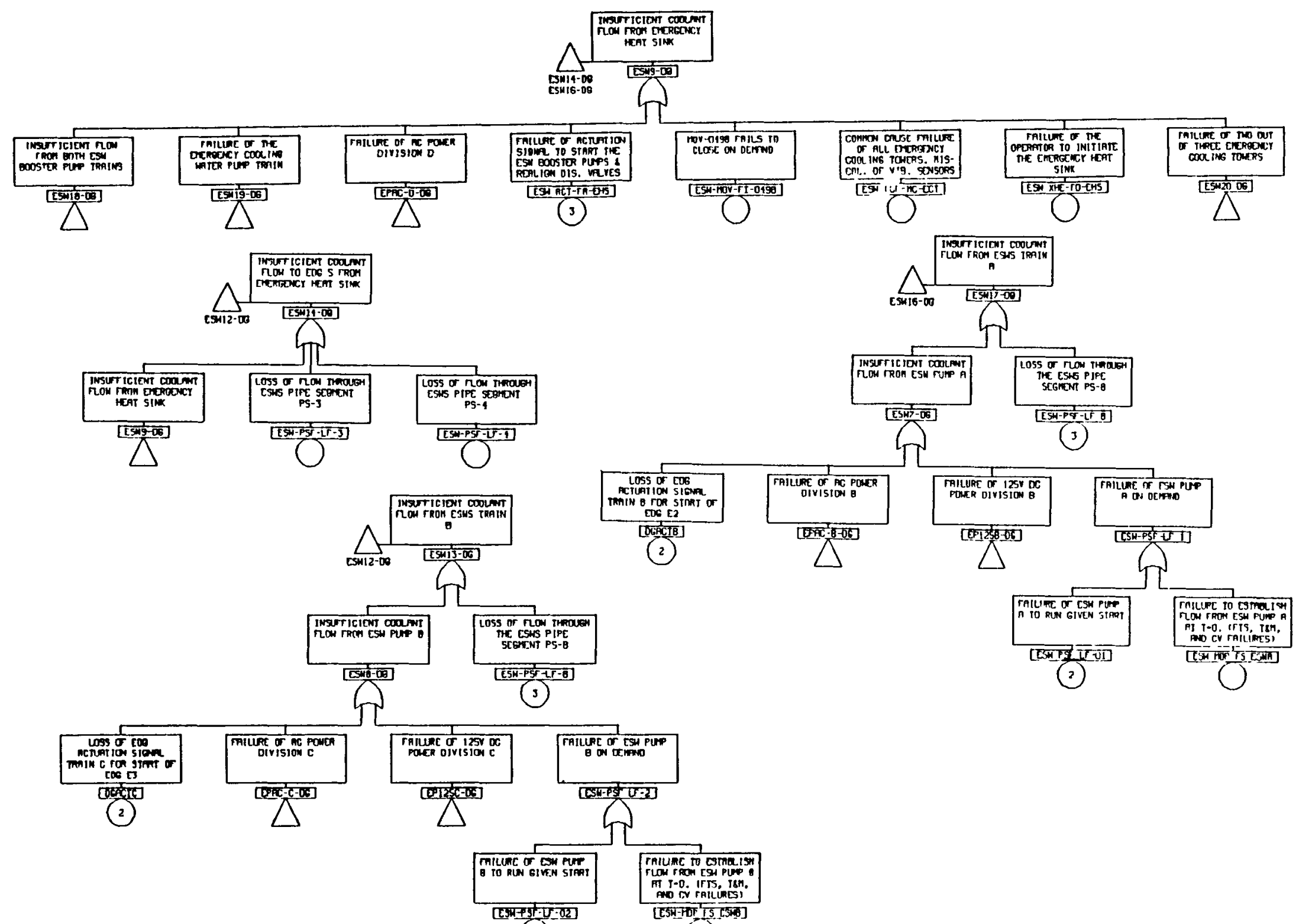

(2)

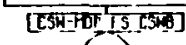




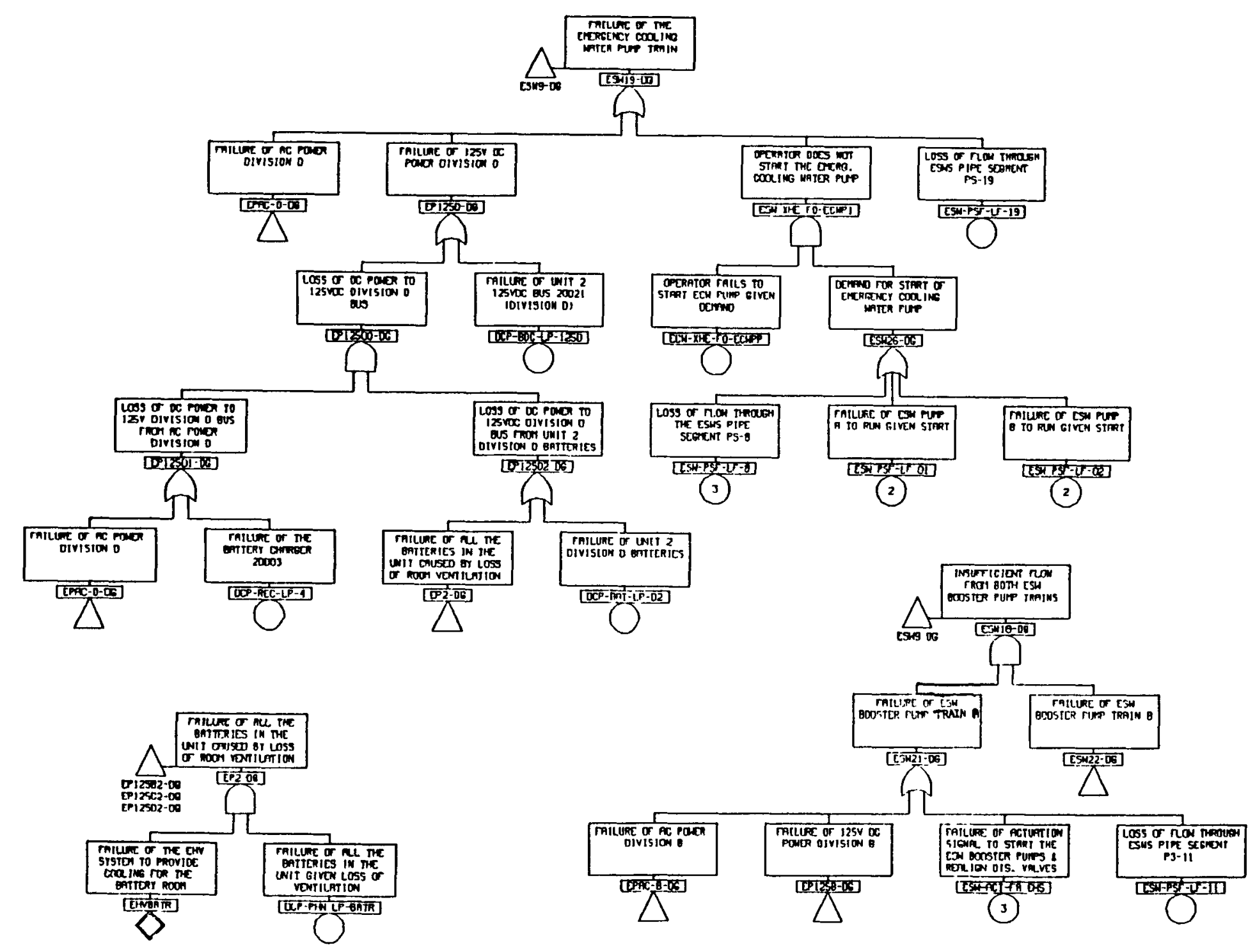


70

6 而

$-10$

$\geq 0$

$\therefore \frac{1}{0}$

$\therefore 8$

.

$\because=$

: 9

i

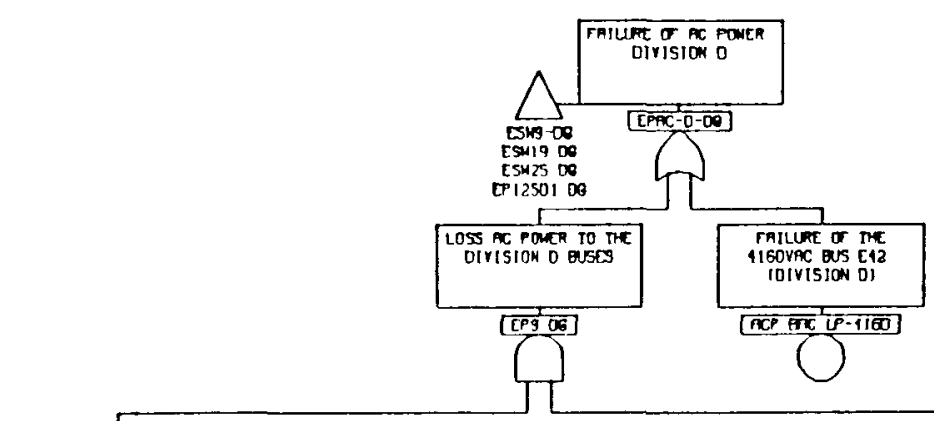

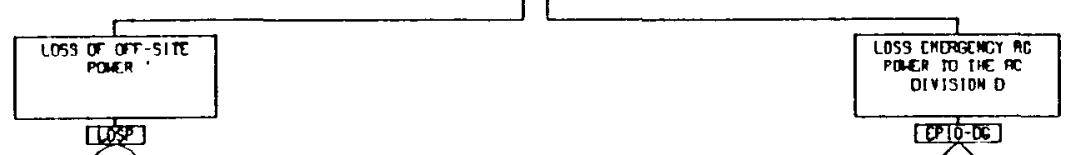

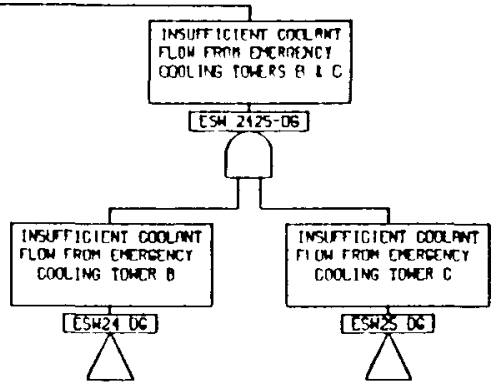

(1)

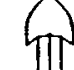

\begin{tabular}{|c|c|c|c|c|}
\hline 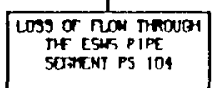 & 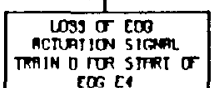 & 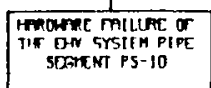 & 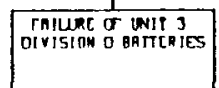 & 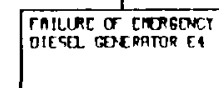 \\
\hline 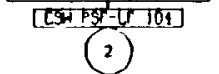 & 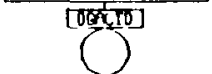 & 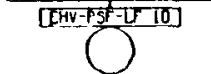 & $\int^{[D C}$ & 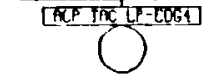 \\
\hline
\end{tabular}



7
-9
-0
09
0
0
0
0
0
0
0

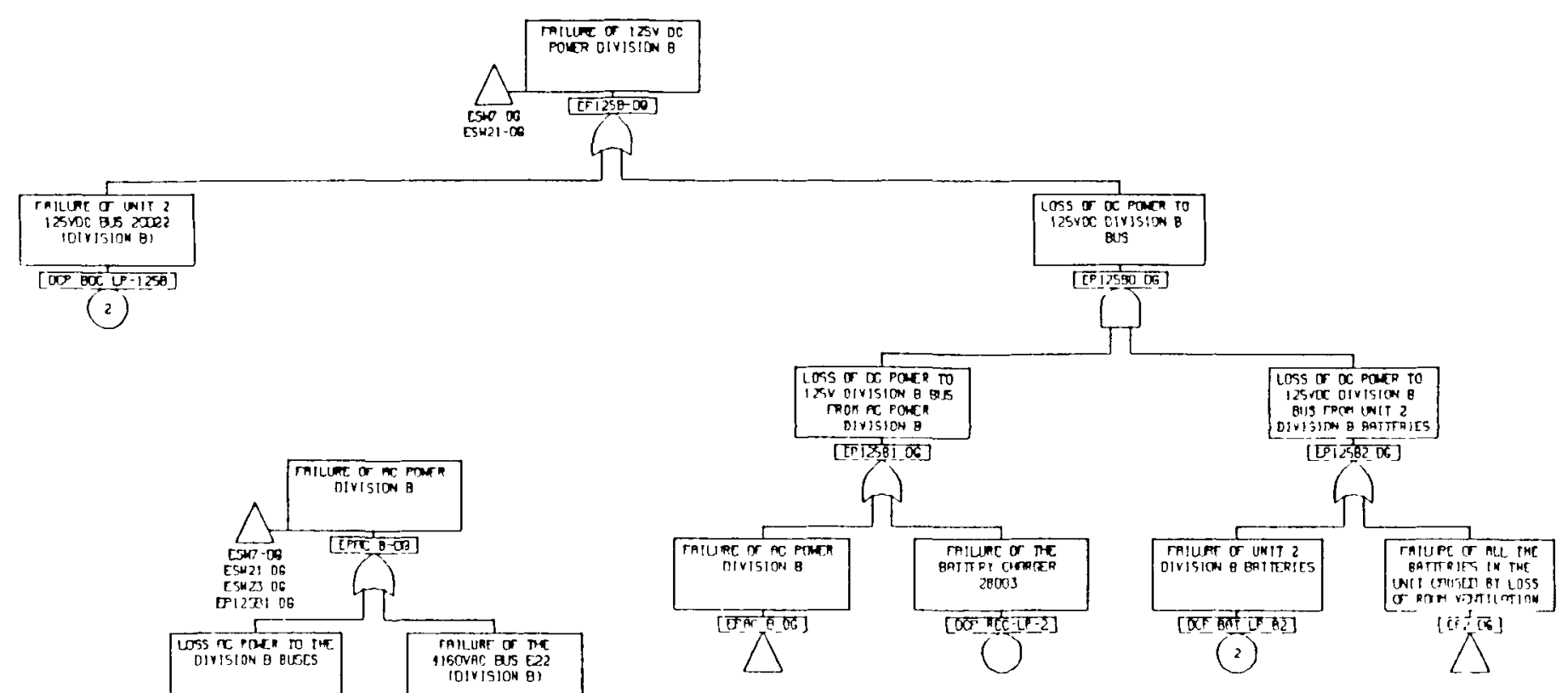

$\frac{D}{N}$

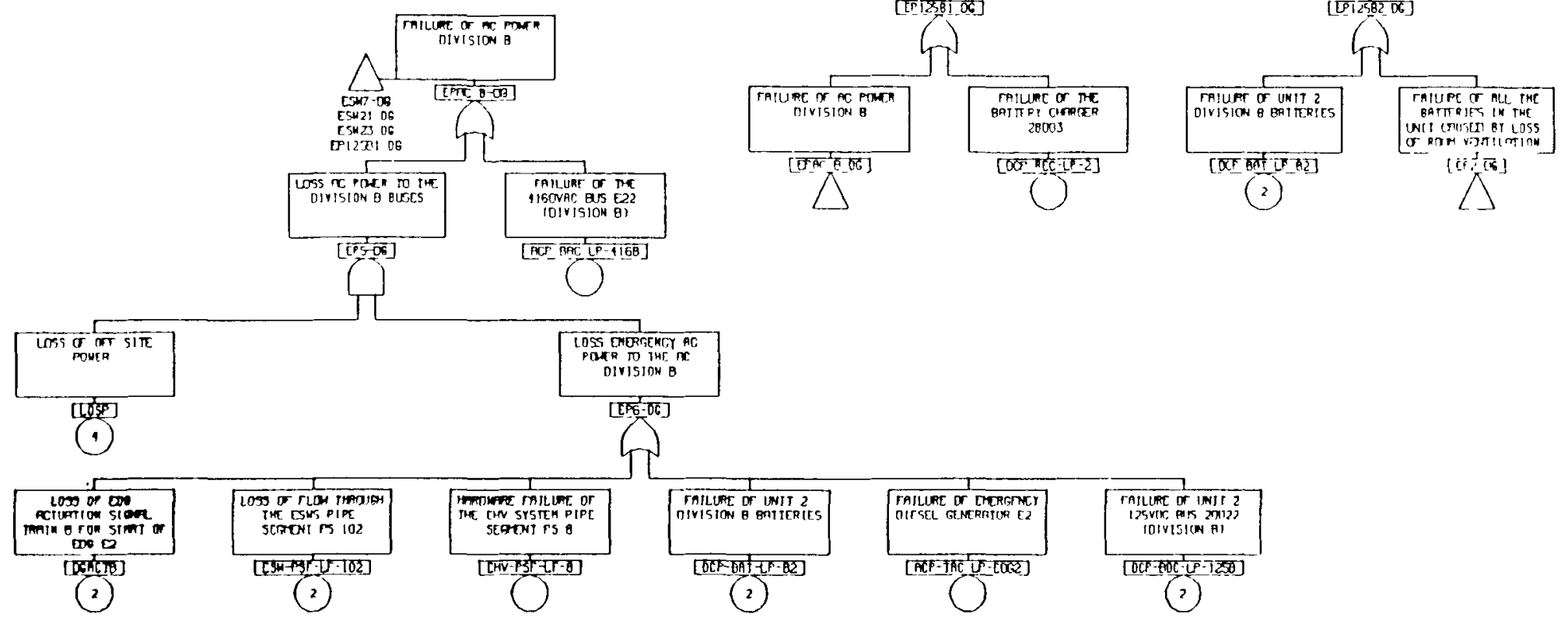




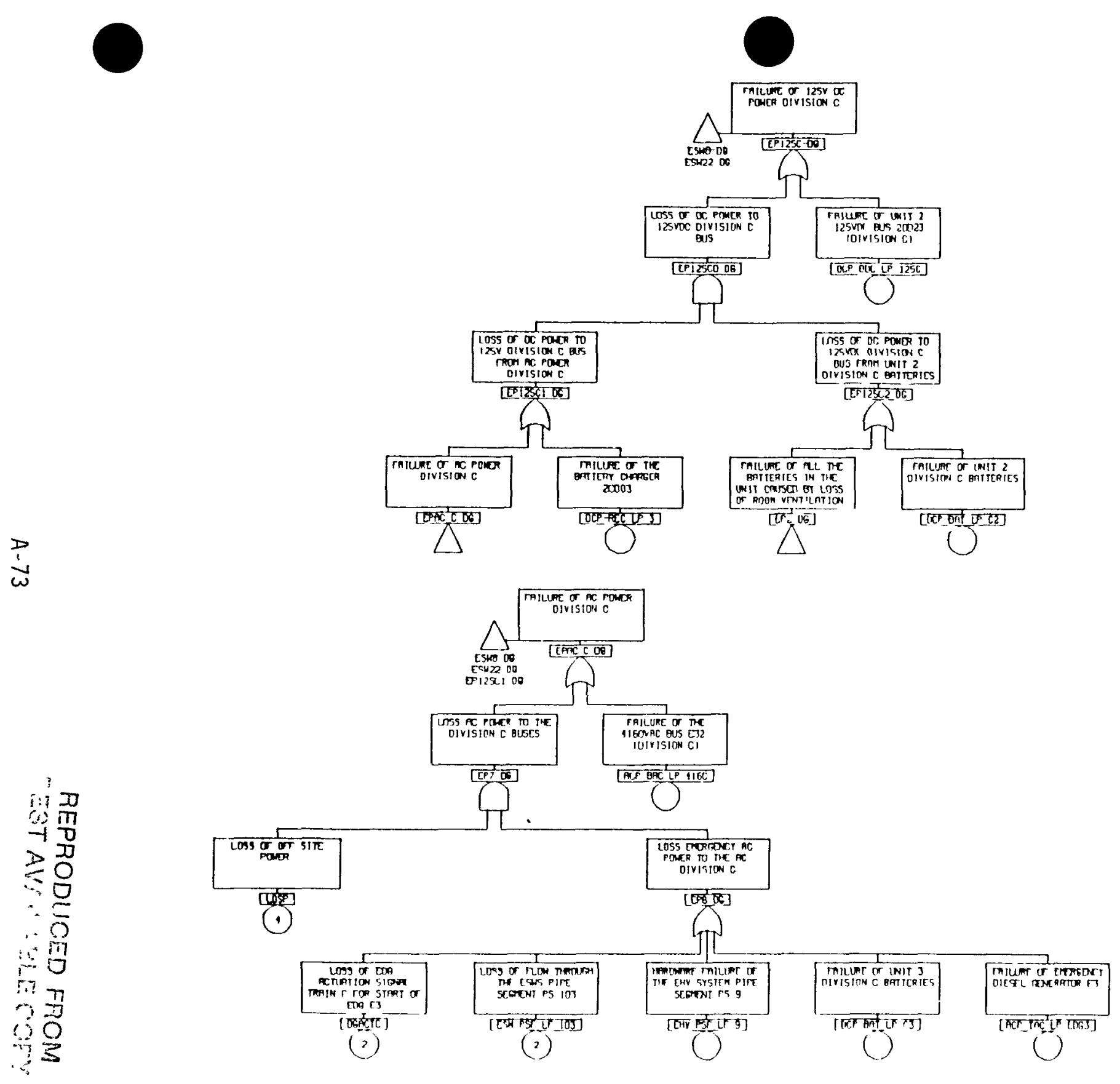


HIGH PRESSURE SERVICE WATER SYSTEM

FAULT TREE

A-74 


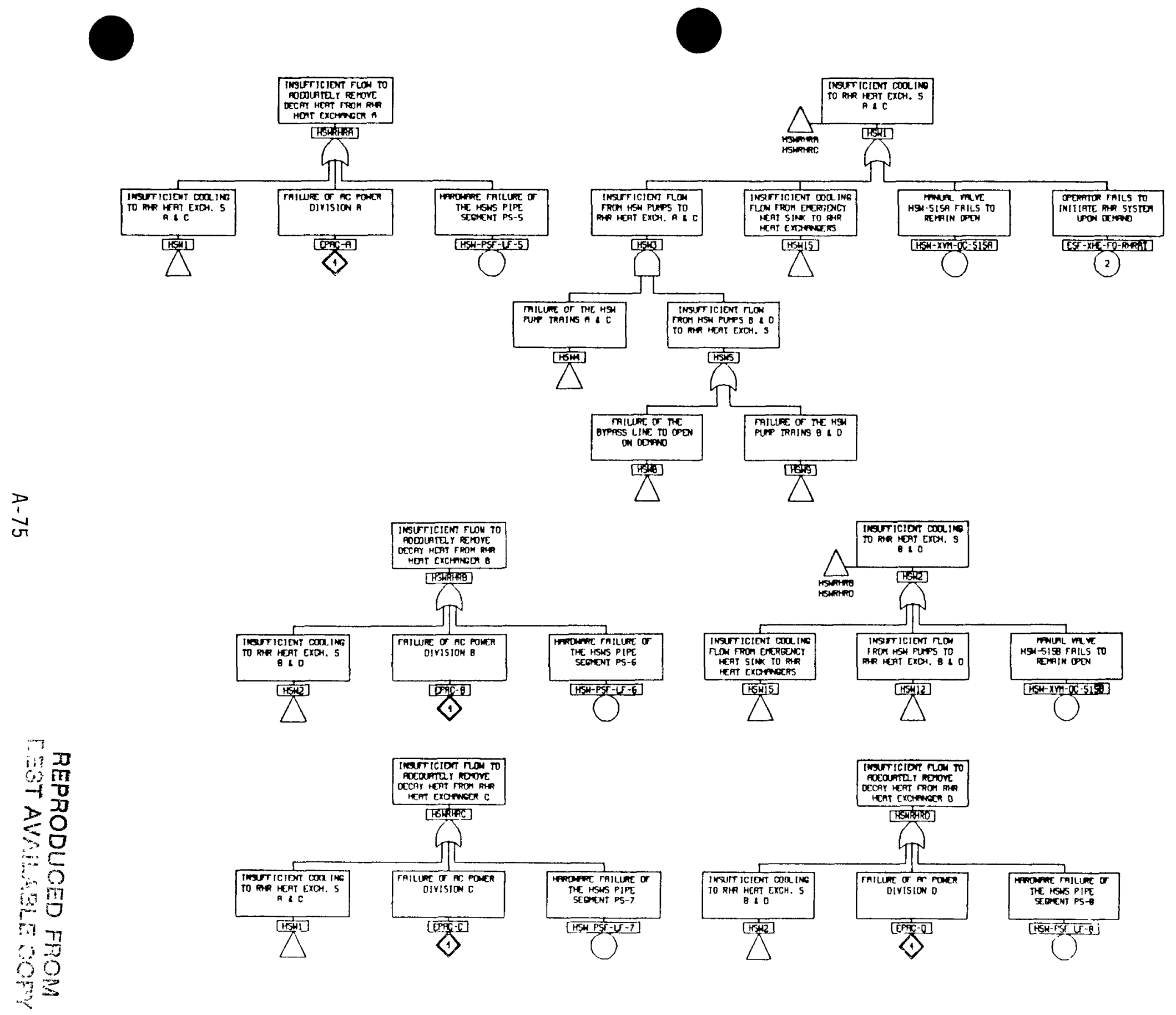



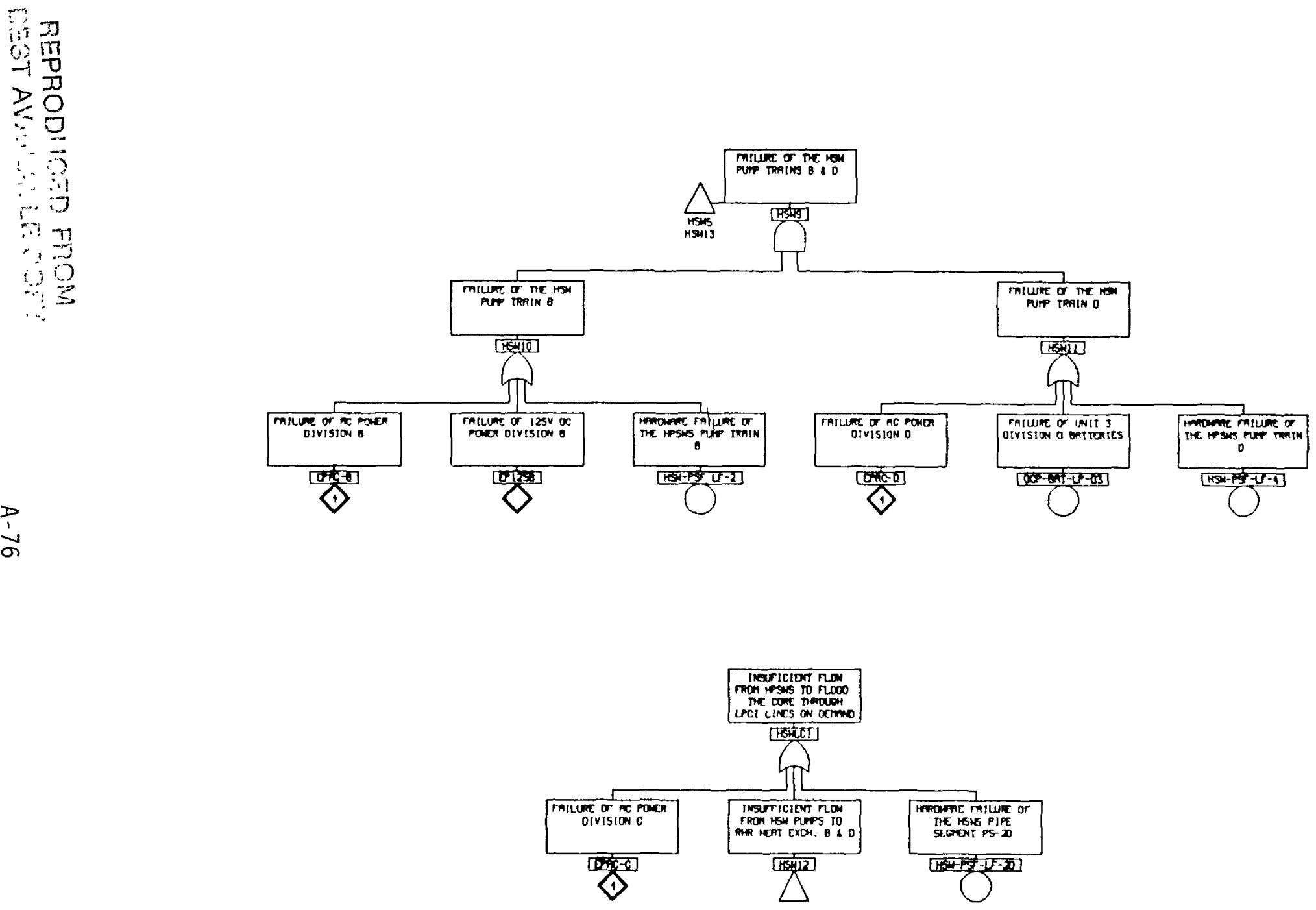

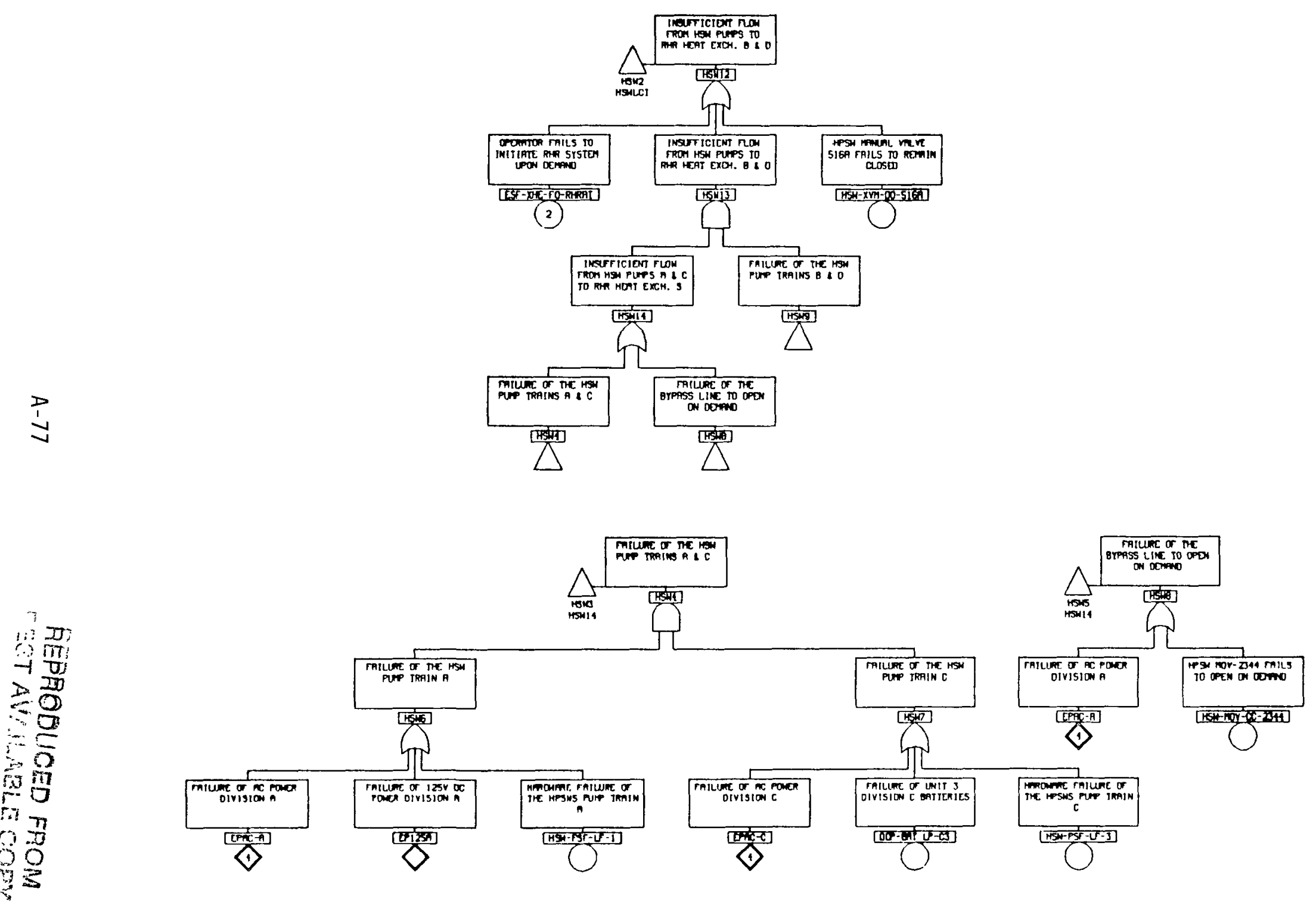


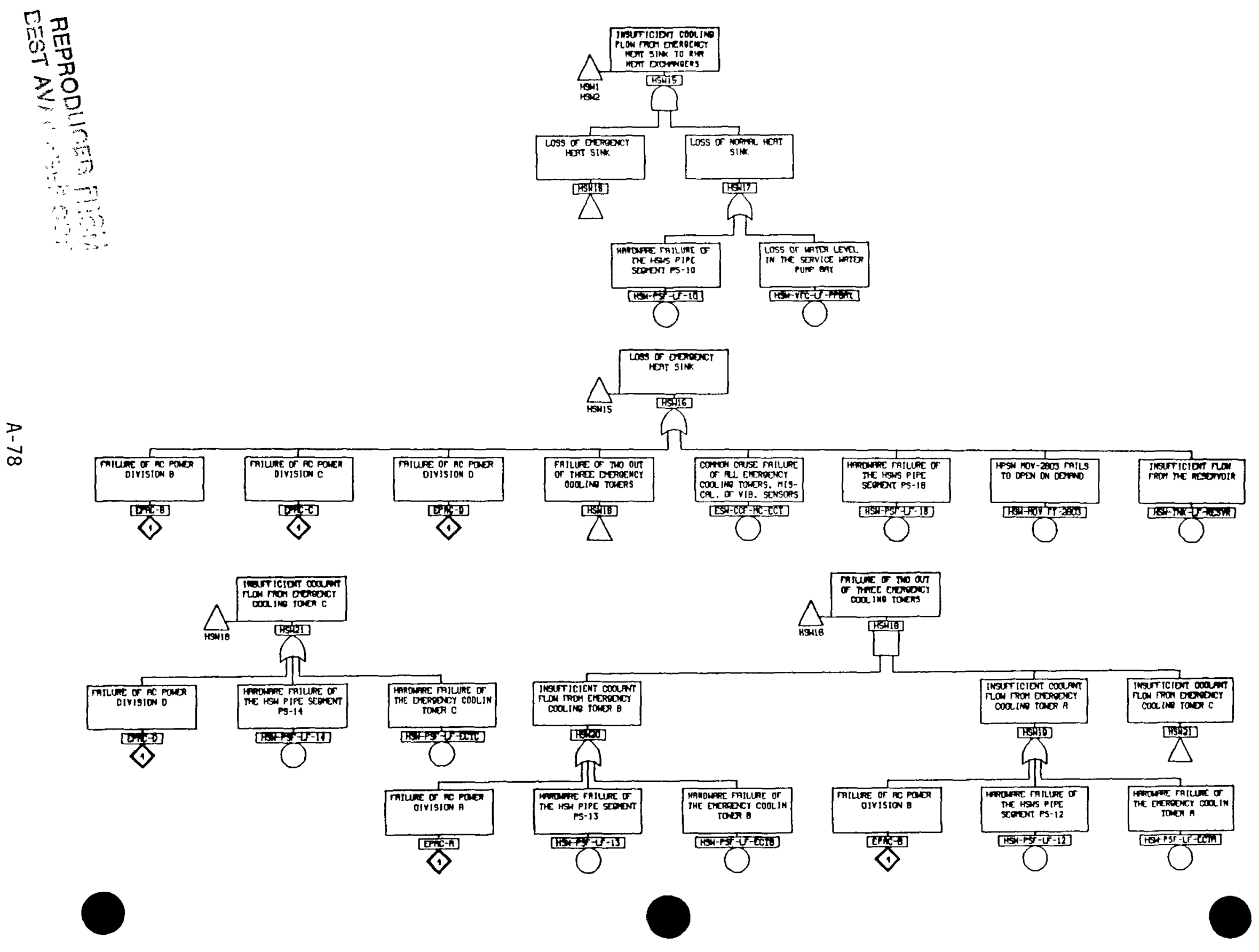




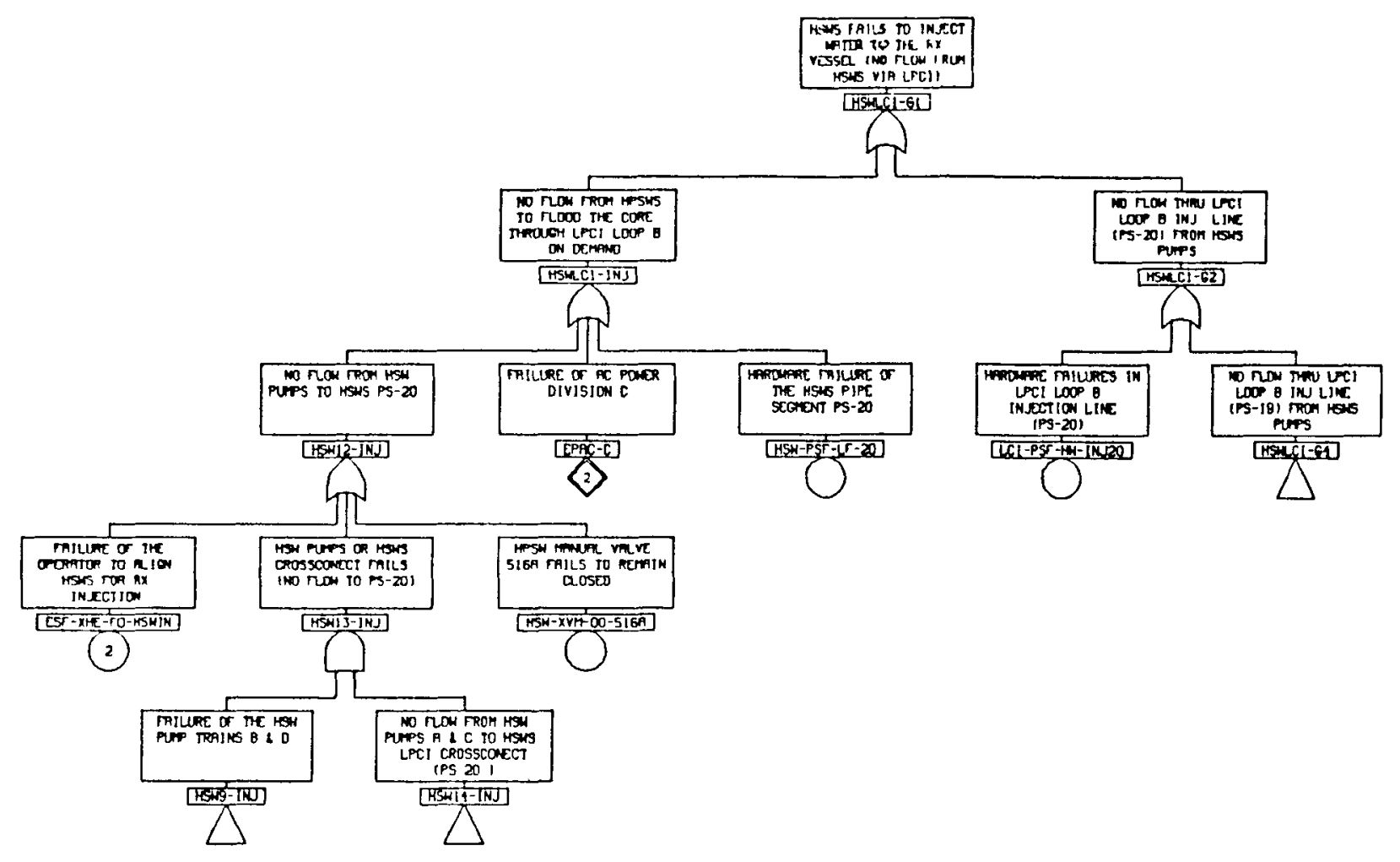

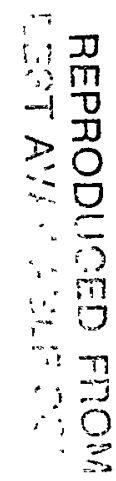

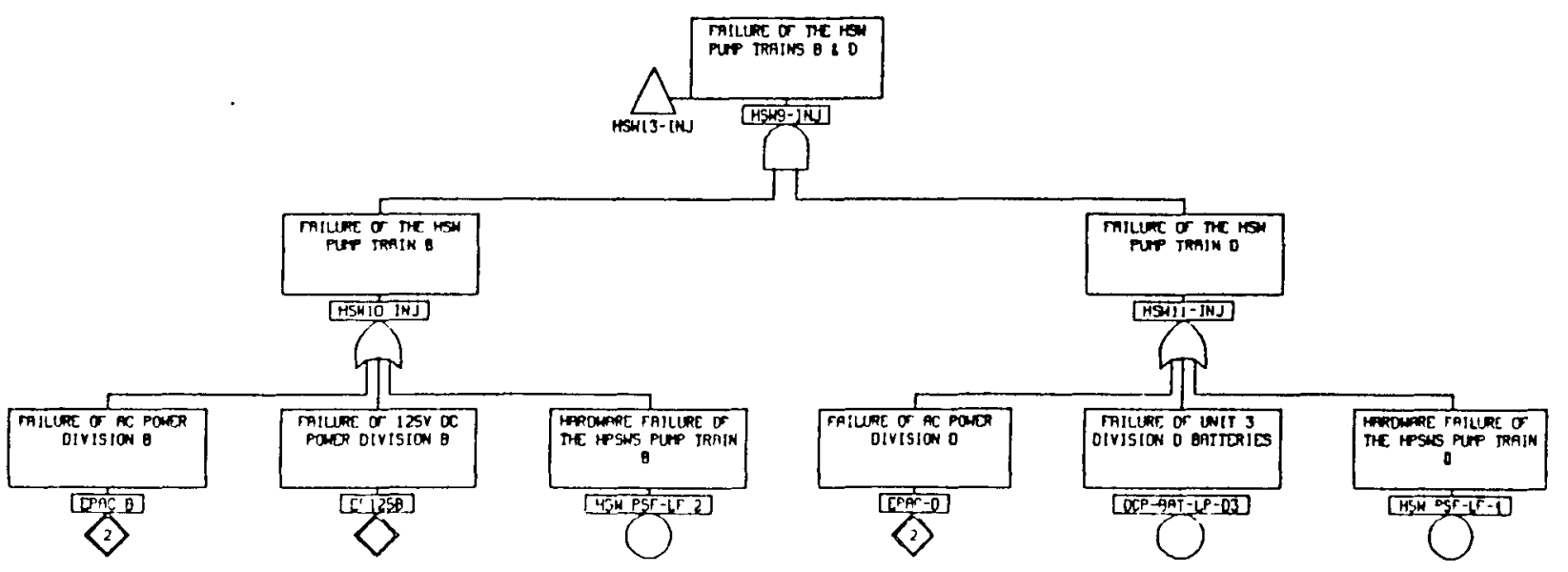




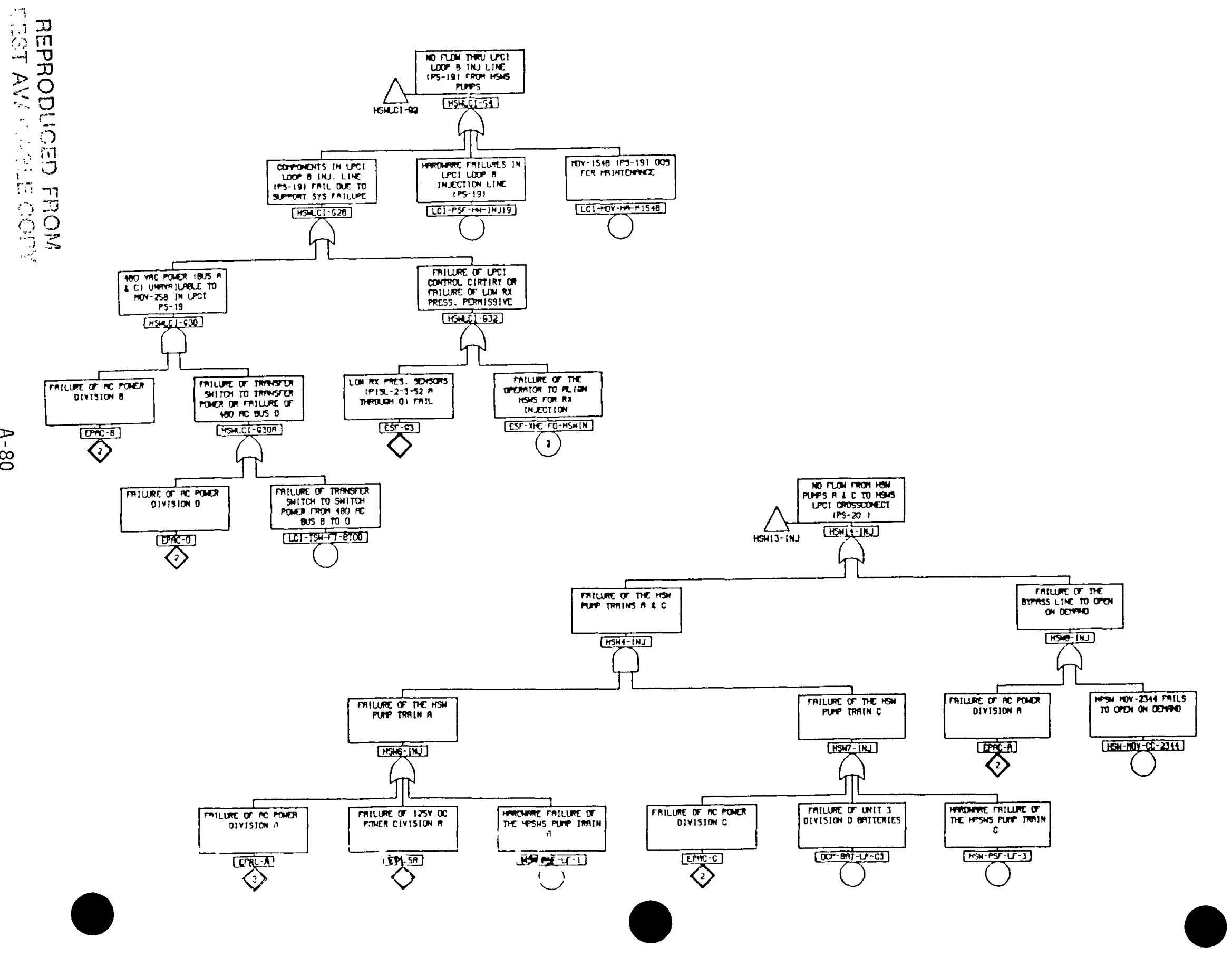


EMERGENCY VENTILATION SYSTEM

FAULT TREE

A-81 


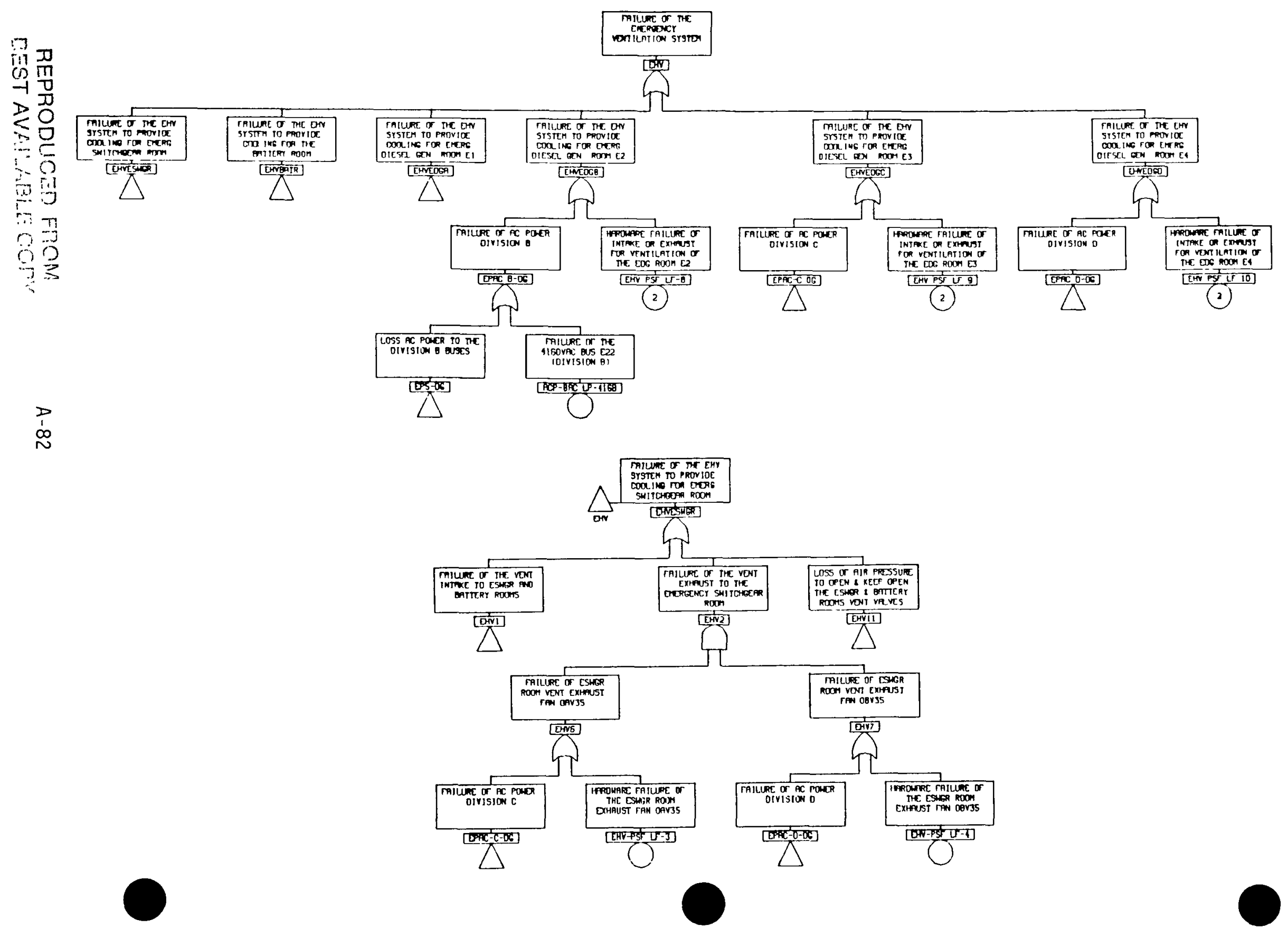



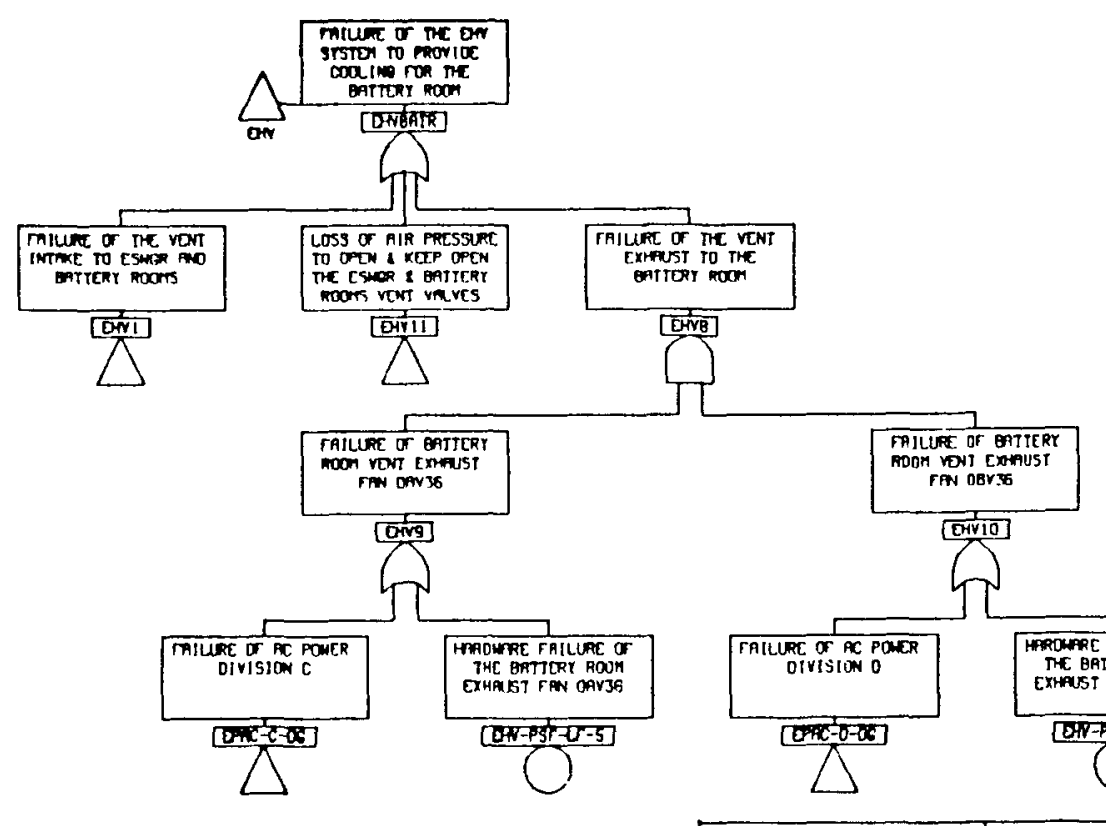

$p$
1
0
$w$
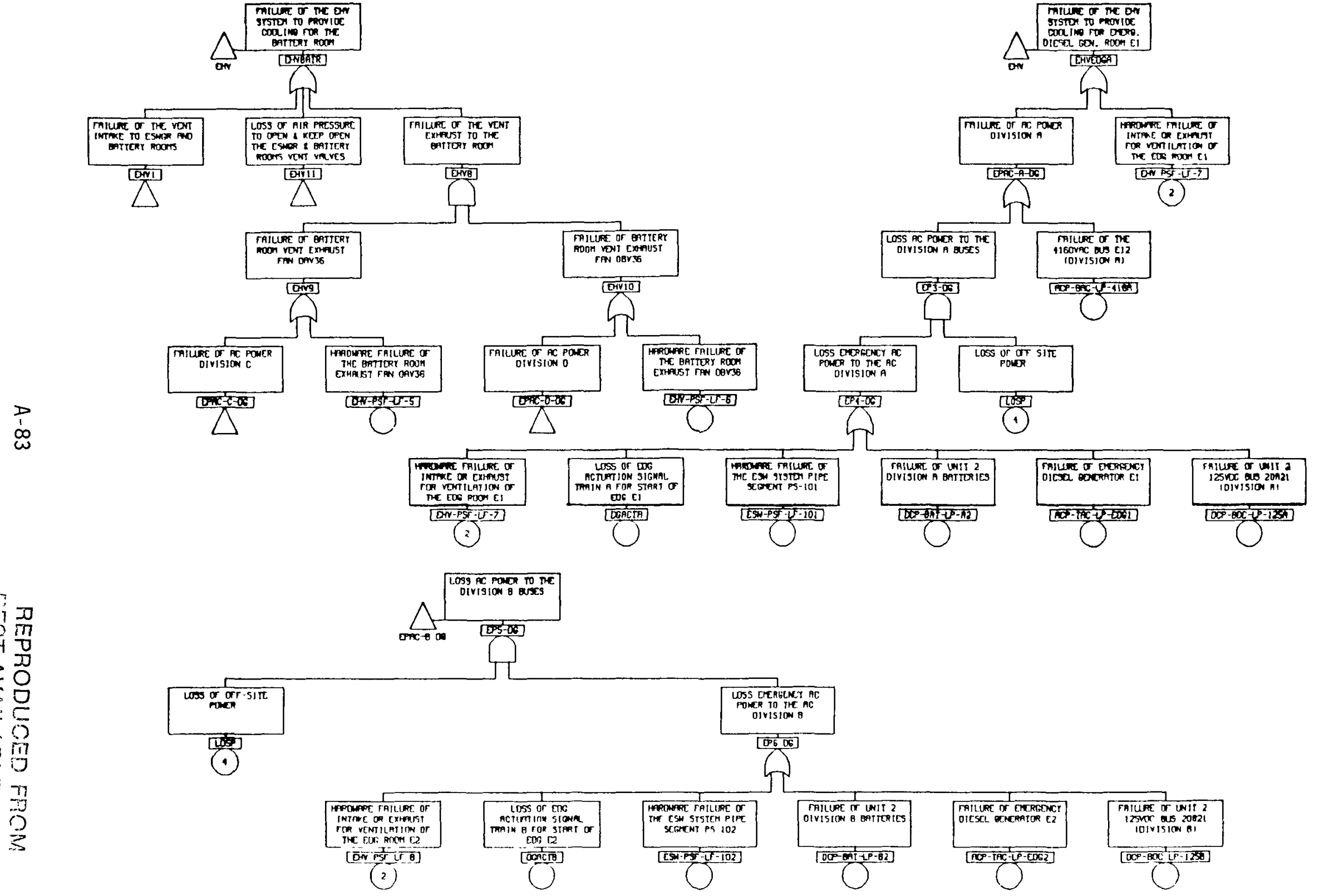


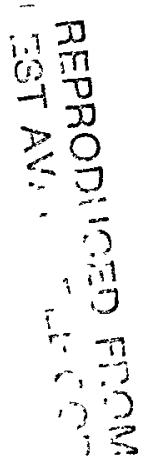

$P$
$\infty$
$\infty$
$\infty$
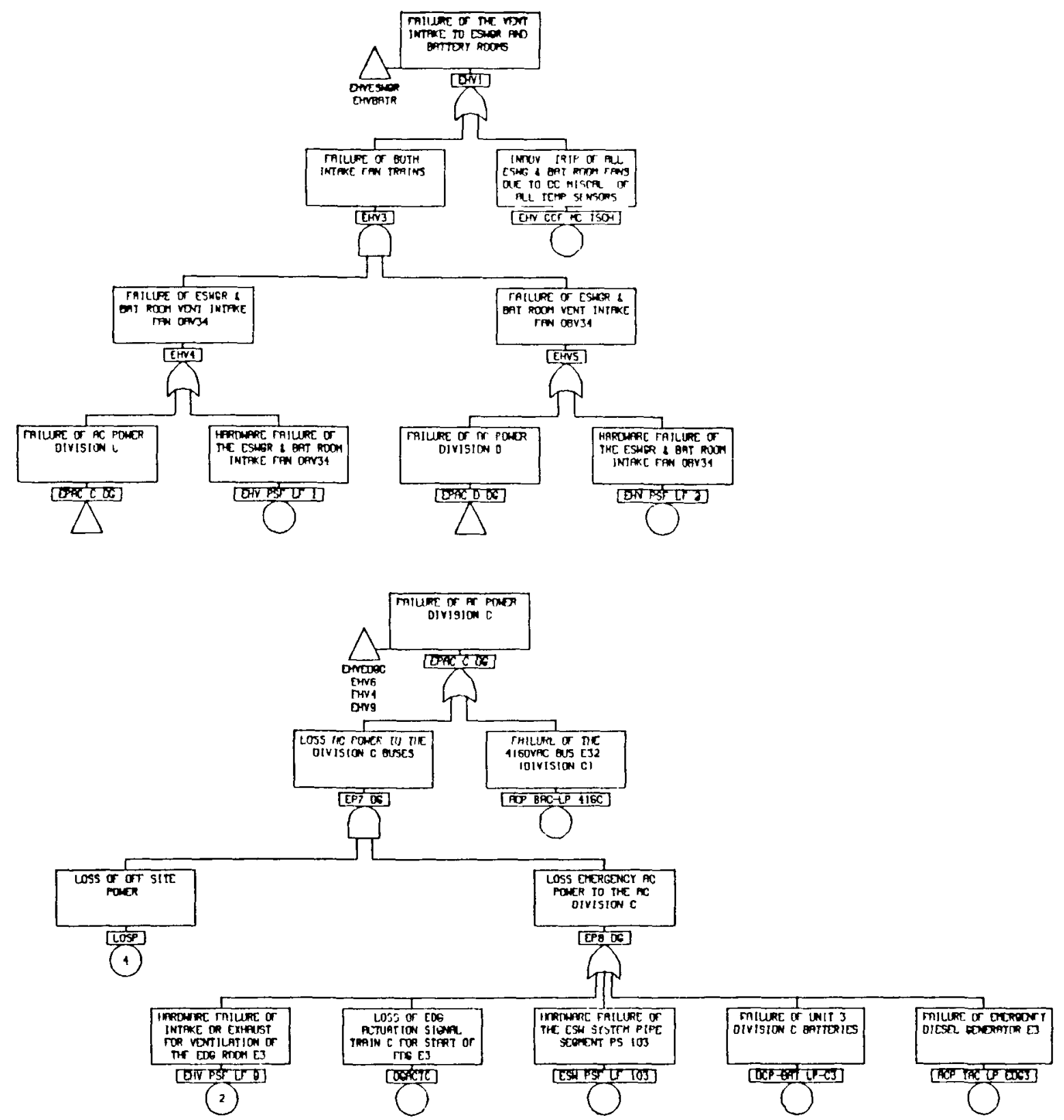



\section{INSTRUMENT AIR SYSTEM}

FAULT TREE 


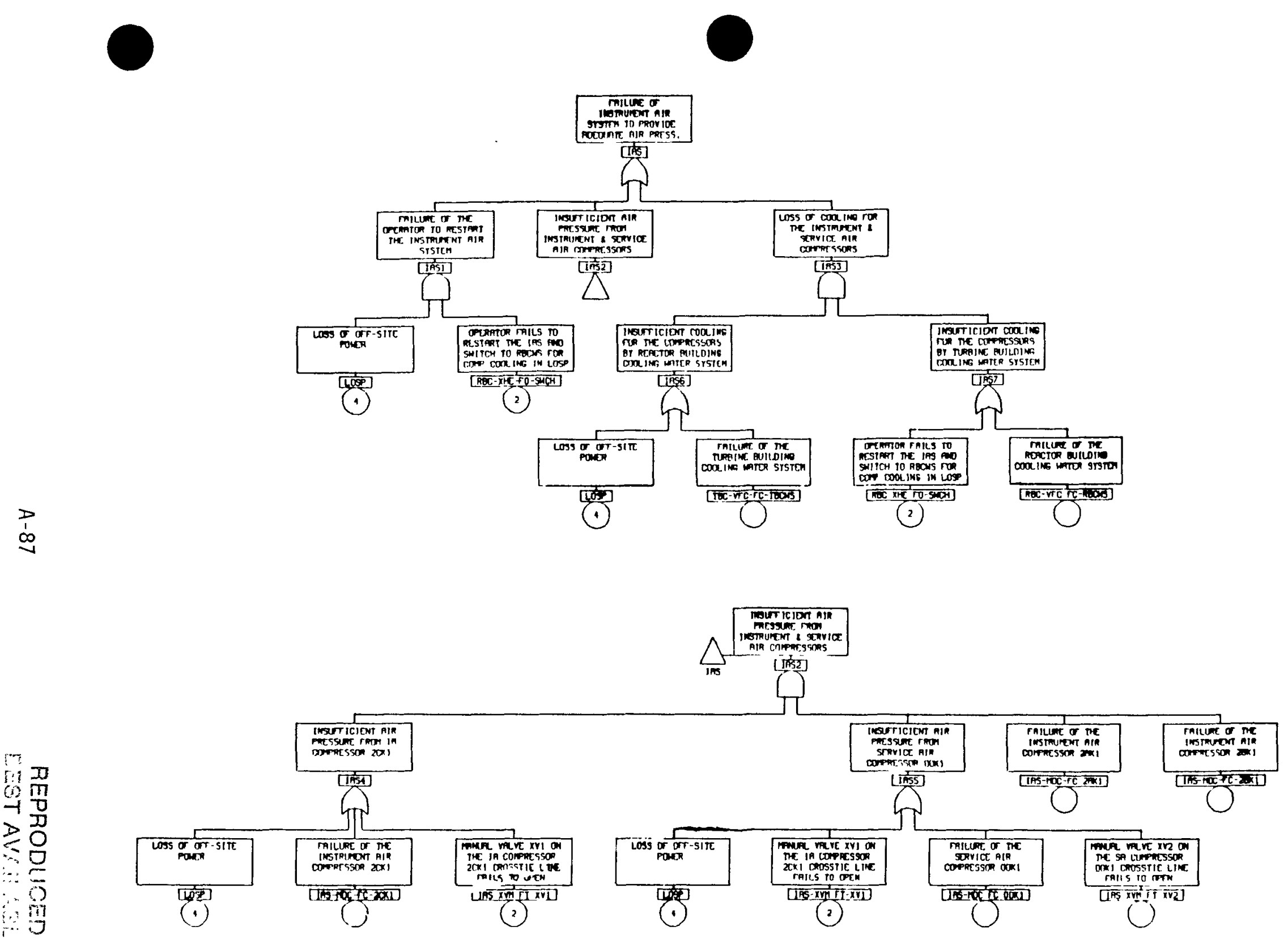


EMERGENCY SAFEGUARDS ACTUATION SYSTEM

FAULT TREE

(used in a number of the other fault trees) 

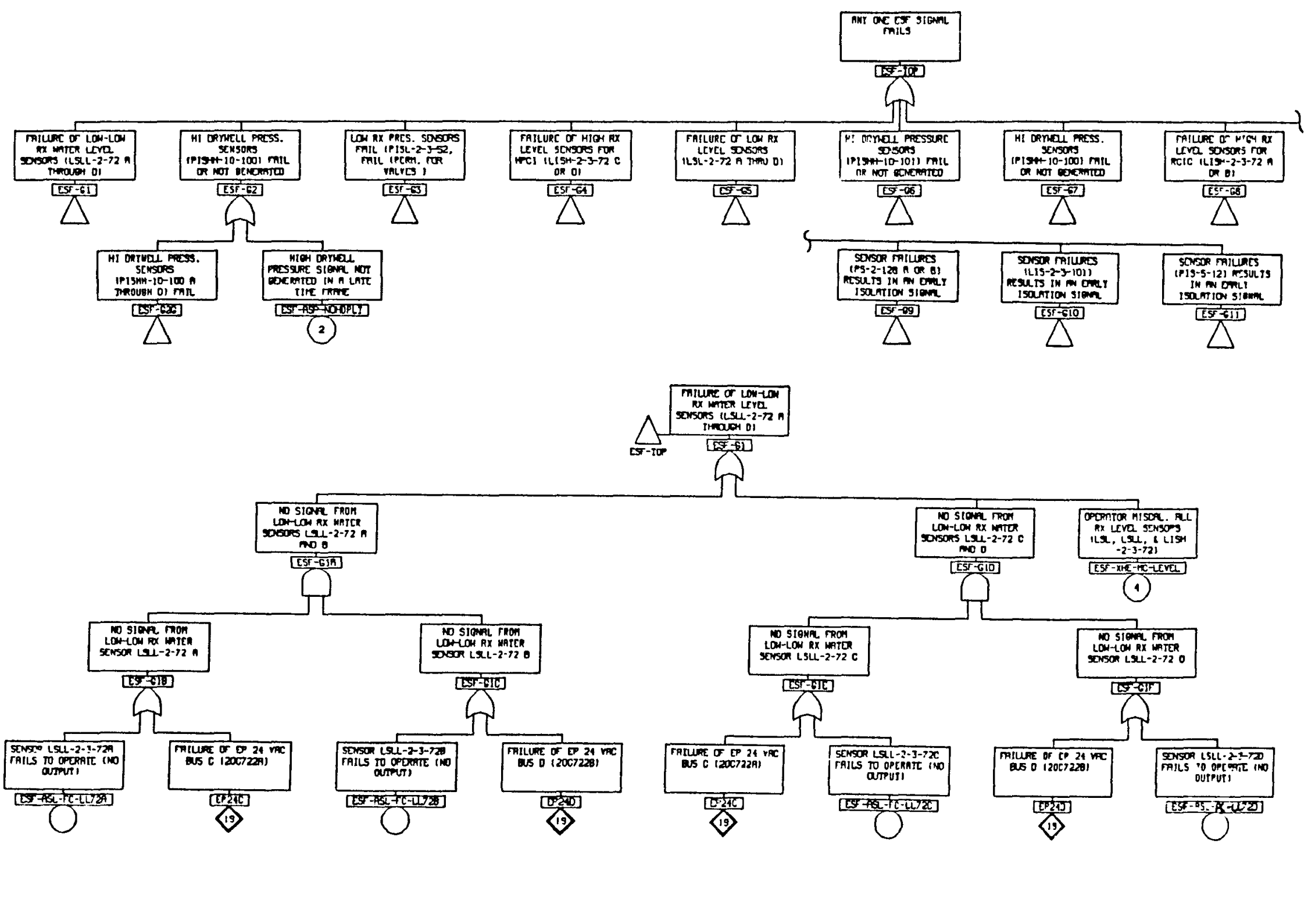


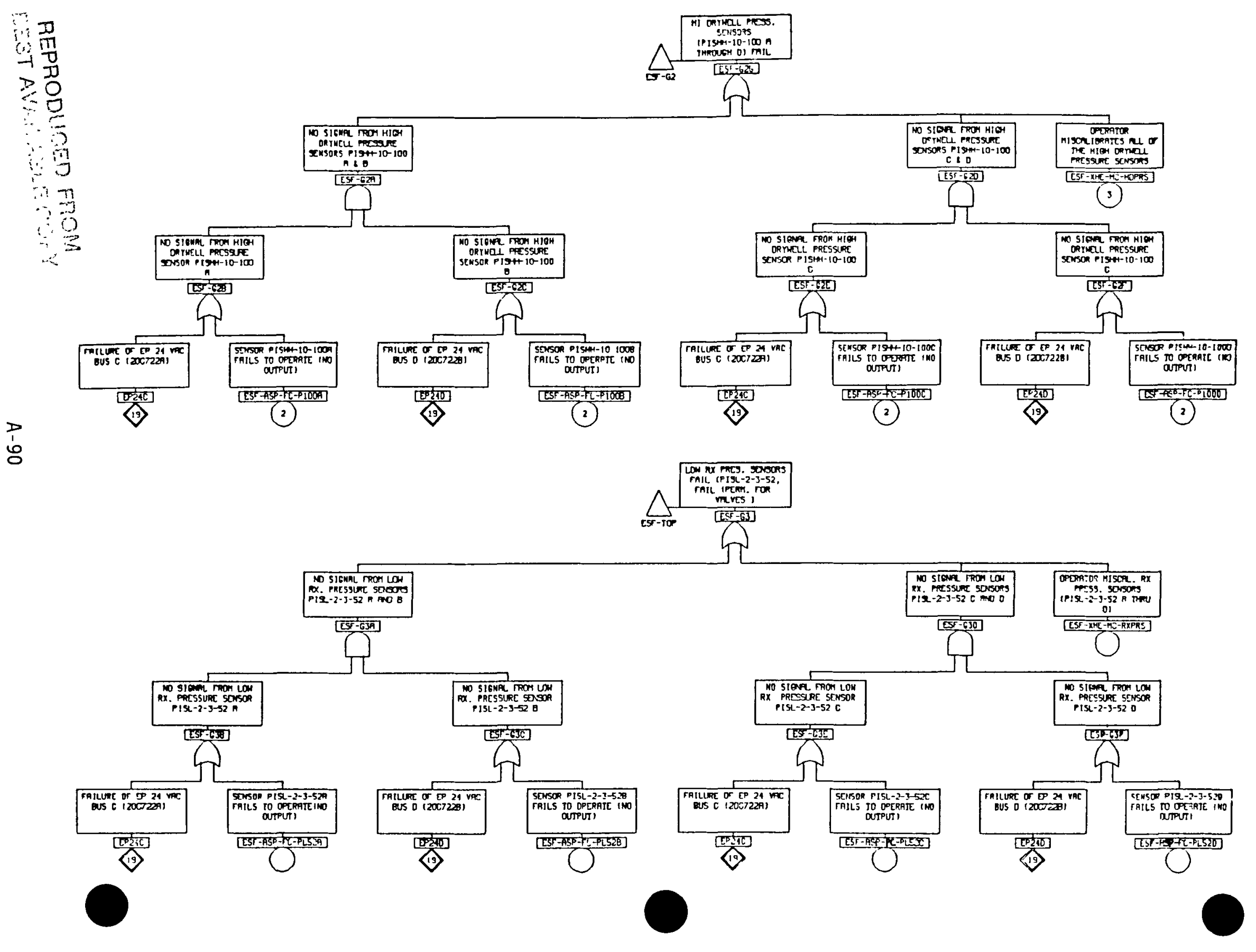





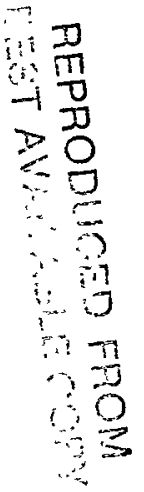

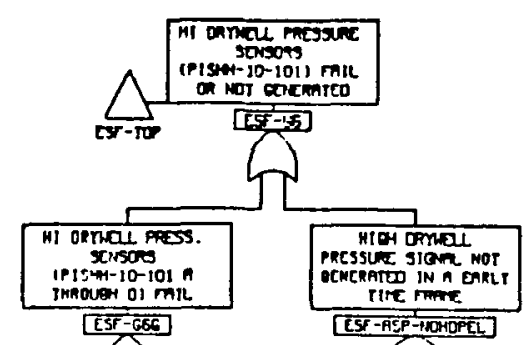

(

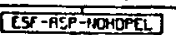
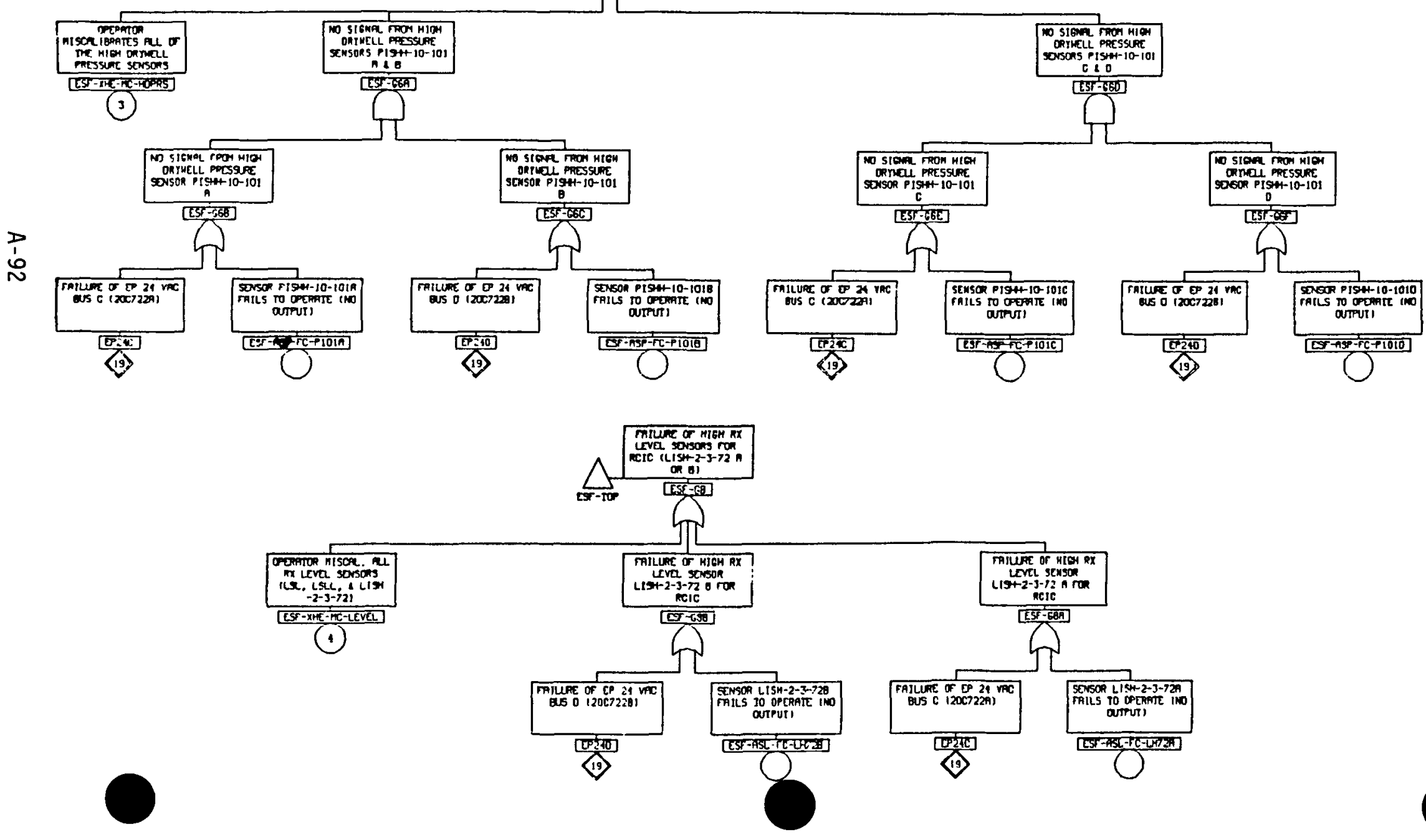

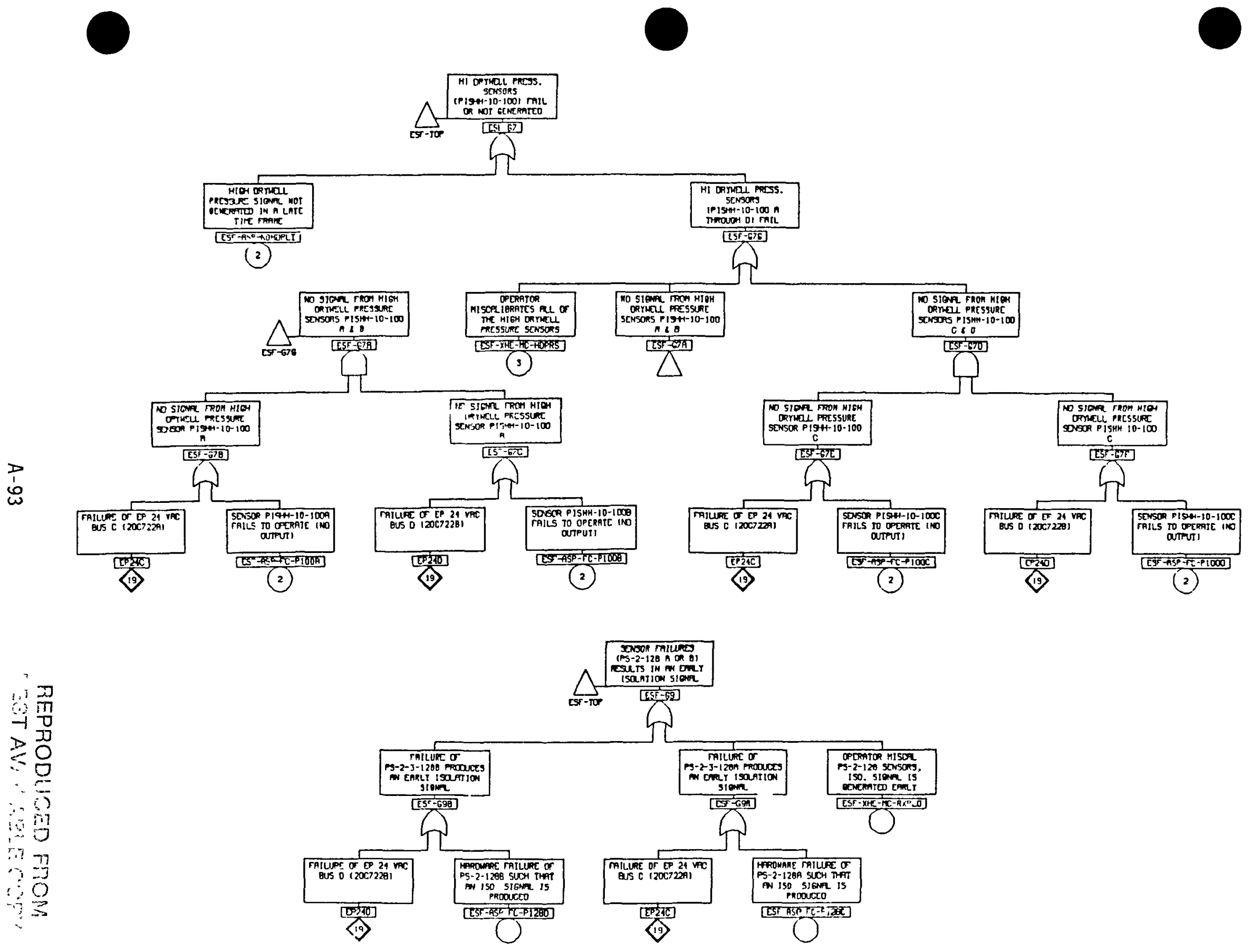


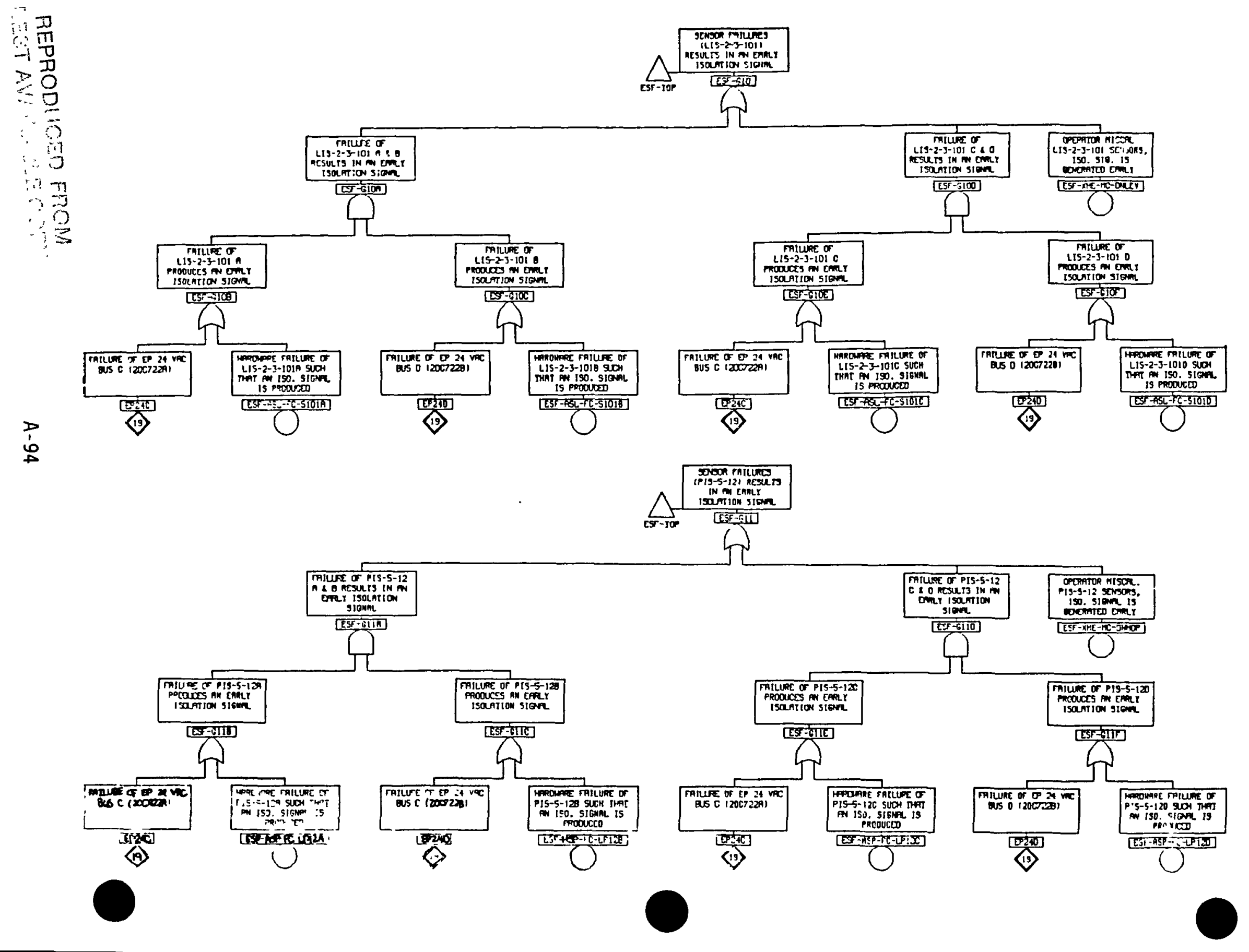


APPENDIX B:

IMPORTANCE VALUES FOR CUTSET EVENTS

(Results appear in the same order as discussed in Section V) 


\section{Section}

SEQUENCE PB - BASE CASE........................... B-4

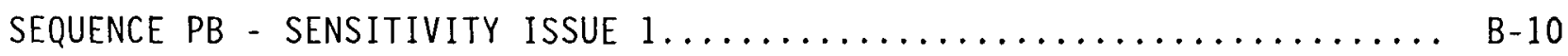

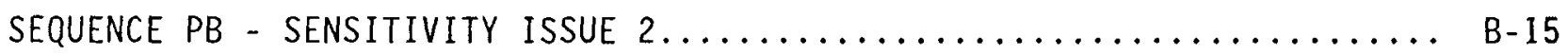

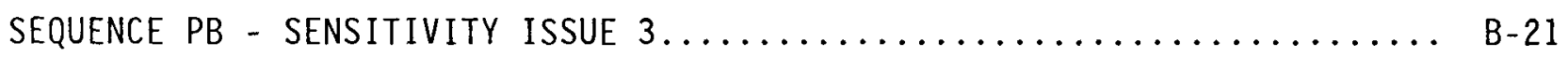

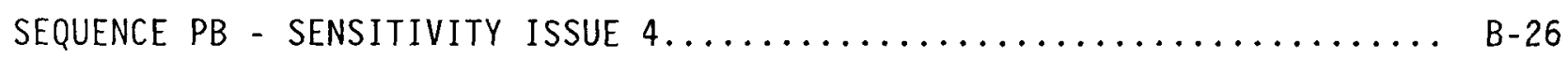

SEQUENCE PB - SENSITIVITY ISSUE $5 \ldots \ldots \ldots \ldots \ldots \ldots \ldots \ldots \ldots \ldots \ldots \ldots \ldots \ldots \ldots \ldots \ldots \ldots \ldots$

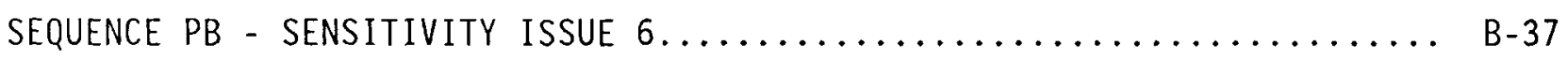

SEQUENCE TBUX - BASE CASE............................. B-42

SEQUENCE TB - BASE CASE.............................. B-43

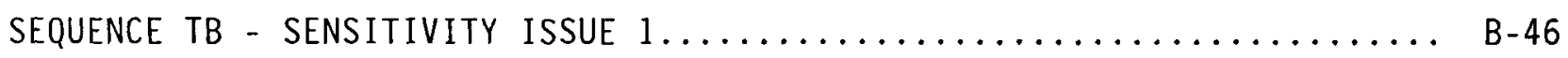

SEQUENCE TB - SENSITIVITY ISSUE $2 \ldots \ldots \ldots \ldots \ldots \ldots \ldots \ldots \ldots \ldots \ldots \ldots \ldots \ldots \ldots \ldots \ldots \ldots \ldots \ldots$

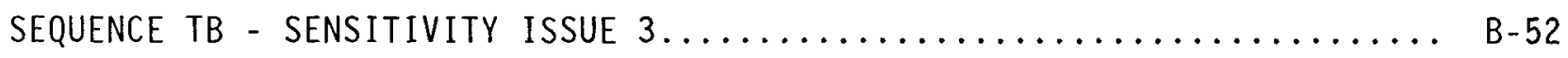

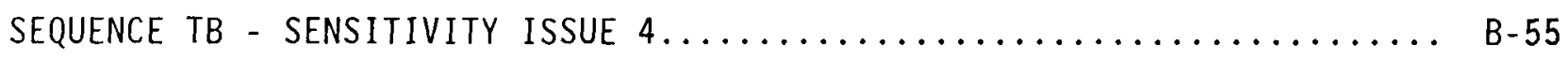

SEQUENCE TCUX - BASE CASE............................... B-57

SEQUENCE TCUX - SENSITIVITY ISSUE $5 \ldots \ldots \ldots \ldots \ldots \ldots \ldots \ldots \ldots \ldots \ldots \ldots \ldots \ldots \ldots \ldots \ldots \ldots$

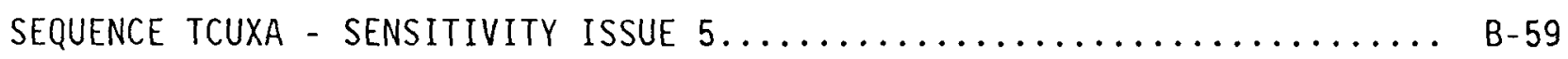

SEQUENCE TCUXB - SENSITIVITY ISSUE $5 \ldots \ldots \ldots \ldots \ldots \ldots \ldots \ldots \ldots \ldots \ldots \ldots \ldots \ldots \ldots \ldots$

SEQUENCE TCSRX2 - BASE CASE............................. B-61

SEQUENCE TCSRX3 - BASE CASE............................ B-62

SEQUENCE TCSRV 23 - BASE CASE............................ B-63

SEQUENCE TCSRX2 - SENSITIVITY ISSUE $5 \ldots \ldots \ldots \ldots \ldots \ldots \ldots \ldots \ldots \ldots \ldots \ldots \ldots \ldots \ldots \ldots \ldots$

SEQUENCE TCSRX3 - SENSITIVITY ISSUE $5 \ldots \ldots \ldots \ldots \ldots \ldots \ldots \ldots \ldots \ldots \ldots \ldots \ldots \ldots \ldots \ldots \ldots \ldots$

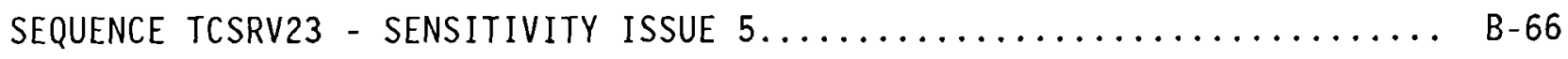

SEQUENCE TBUP - BASE CASE............................ B-67

SEQUENCE TBUP - SENSITIVITY ISSUE $2 \ldots \ldots \ldots \ldots \ldots \ldots \ldots \ldots \ldots \ldots \ldots \ldots \ldots \ldots \ldots \ldots$

SEQUENCE TBUP - SENSITIVITY ISSUE $3 \ldots \ldots \ldots \ldots \ldots \ldots \ldots \ldots \ldots \ldots \ldots \ldots \ldots \ldots \ldots \ldots$ 


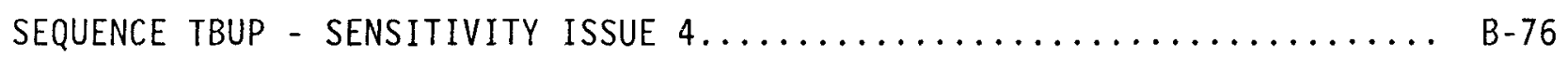

SEQUENCE TCSX - BASE CASE........................... B-78

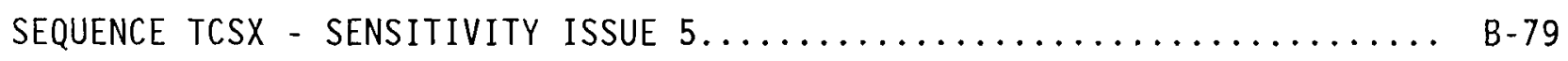

SEQUENCE TBU - BASE CASE................................. B 80

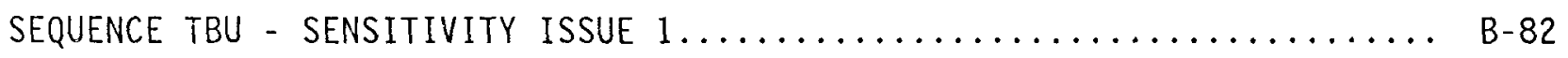

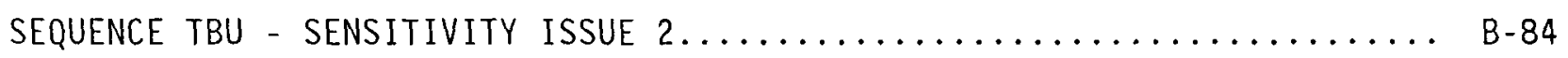

SEQUENCE TBU - SENSITIVITY ISSUE $3 \ldots \ldots \ldots \ldots \ldots \ldots \ldots \ldots \ldots \ldots \ldots \ldots \ldots \ldots \ldots \ldots \ldots$

SEQUENCE TBU - SENSITIVITY ISSUE. $4 \ldots \ldots \ldots \ldots \ldots \ldots \ldots \ldots \ldots \ldots \ldots \ldots \ldots \ldots \ldots \ldots \ldots$

SEQUENCE TBP - BASE CASE.............................. B- 90

SEQUENCE TBP - SENSITIVITY ISSUE $1 \ldots \ldots \ldots \ldots \ldots \ldots \ldots \ldots \ldots \ldots \ldots \ldots \ldots \ldots \ldots \ldots \ldots \ldots$

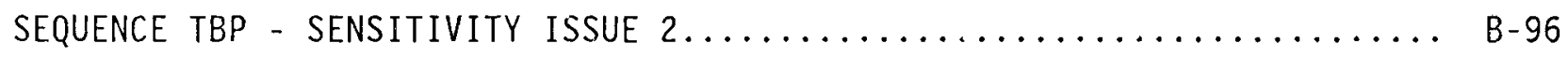

SEQUENCE TBP - SENSITIVITY ISSUE $3 \ldots \ldots \ldots \ldots \ldots \ldots \ldots \ldots \ldots \ldots \ldots \ldots \ldots \ldots \ldots \ldots \ldots \ldots$

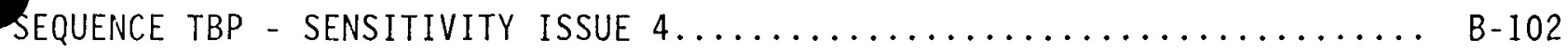

SEQUENCE SIV - BASE CASE................................ B-104

SEQUENCE TCSARX2 - BASE CASE................................ B-105

SEQUENCE TCSARX 3 - BASE CASE.............................. B-106

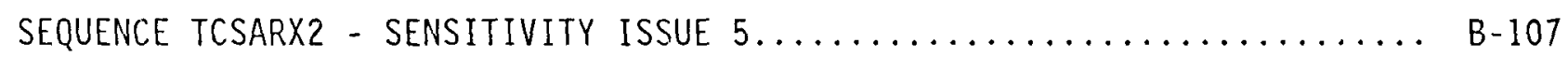

SEQUENCE TCSARX3 - SENSITIVITY ISSUE $5 \ldots \ldots \ldots \ldots \ldots \ldots \ldots \ldots \ldots \ldots \ldots \ldots \ldots \ldots \ldots \ldots \ldots$

SEQUENCE TUV - BASE CASE................................ B-109

SEQUENCE AV - BASE CASE................................ B-110

SEQUENCE TUX - BASE CASE................................. B-111

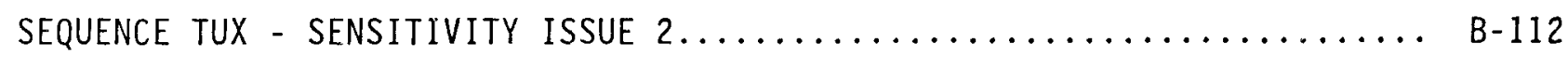


SEQUENCE PB - BASE CASE

\begin{tabular}{|c|c|c|}
\hline $\begin{array}{l}\text { IMPORTANCE } \\
\text { MEASURE }\end{array}$ & EVENT & VALUE \\
\hline Risk Reduction & $\begin{array}{l}\text { DCP-BAT-LP-B2 } \\
\text { B-DCP-LP-BATS } \\
\text { RA-1J } \\
\text { ACP-DGN-LP-EDG2 } \\
\text { RA-16J } \\
\text { RPS-M } \\
\text { LOSP } \\
\text { ACP-DGN-LP-EDG3 } \\
\text { SLC-XHE-FS } \\
\text { CMSIVA } \\
\text { HCI-TDP-FS-20S37 } \\
\text { ACP-DGN-MA-EDG3 } \\
\text { DEP-XHE } \\
\text { VENT-XHE-TC } \\
\text { ECW-XHE-F0-ECWPP } \\
\text { ACP-DGN-MA-EDG2 } \\
\text { B-ACP-LP-EDGS } \\
\text { ESW-PSF-LF-103 } \\
\text { ESW-PSF-LF-102 } \\
\text { RA-17J } \\
\text { SORV } \\
\text { RA-18J } \\
\text { RCI-TDP-FS-20S38 } \\
\text { RA-1D } \\
\text { SLC-XHE-REL } \\
\text { ESW-PSF-LF-02 } \\
\text { ESW-PSF-LF-01 } \\
\text { ESF-XHE-MC-RXPRS } \\
\text { HCI-TDP-MA-20S37 } \\
\text { ESW-PSF-LF-8 } \\
\text { RA-14D } \\
\text { RA-2D } \\
\text { ESF-XHE-FO-CRDRL } \\
\text { RA-16D } \\
\text { COND-HPSW-XHE-TC } \\
\text { EHV-PSF-LF-9 } \\
\text { EHV-PSF-LF-8 } \\
\text { RCI-TDP-MA-20S38 } \\
\text { ESW-MDP-FS-ESWB } \\
\text { ESW-MDP-FS-ESWA } \\
\text { B-ADS-FO-VLVS } \\
\text { ADS-VLV-F0-VALVE } \\
\text { SRV-XHE-FO-VLV } \\
\text { HCI -XHE-TL } \\
\text { RA-17D } \\
\text { RA-18D } \\
\text { RCI-PSF-HW-COL10 }\end{array}$ & $\begin{array}{l}4.57 \mathrm{E}-6 \\
4.49 \mathrm{E}-6 \\
2.40 \mathrm{E}-6 \\
1.23 \mathrm{E}-6 \\
1.22 \mathrm{E}-6 \\
1.15 \mathrm{E}-6 \\
9.13 \mathrm{E}-7 \\
8.13 \mathrm{E}-7 \\
6.00 \mathrm{E}-7 \\
5.23 \mathrm{E}-7 \\
5.07 \mathrm{E}-7 \\
4.83 \mathrm{E}-7 \\
4.59 \mathrm{E}-7 \\
4.59 \mathrm{E}-7 \\
4.56 \mathrm{E}-7 \\
4.53 \mathrm{E}-7 \\
4.51 \mathrm{E}-7 \\
4.49 \mathrm{E}-7 \\
4.36 \mathrm{E}-7 \\
4.20 \mathrm{E}-7 \\
3.37 \mathrm{E}-7 \\
3.36 \mathrm{E}-7 \\
2.12 \mathrm{E}-7 \\
1.87 \mathrm{E}-7 \\
1.77 \mathrm{E}-7 \\
1.72 \mathrm{E}-7 \\
1.69 \mathrm{E}-7 \\
1.58 \mathrm{E}-7 \\
1.46 \mathrm{E}-7 \\
1.19 \mathrm{E}-7 \\
8.01 \mathrm{E}-8 \\
7.95 \mathrm{E}-8 \\
7.56 \mathrm{E}-8 \\
5.90 \mathrm{E}-8 \\
5.20 \mathrm{E}-8 \\
5.15 \mathrm{E}-8 \\
5.15 \mathrm{E}-8 \\
4.77 \mathrm{E}-8 \\
3.76 \mathrm{E}-8 \\
3.76 \mathrm{E}-8 \\
2.34 \mathrm{E}-8 \\
2.34 \mathrm{E}-8 \\
2.34 \mathrm{E}-8 \\
1.40 \mathrm{E}-8 \\
1.22 \mathrm{E}-8 \\
9.83 \mathrm{E}-9 \\
6.46 \mathrm{E}-9\end{array}$ \\
\hline
\end{tabular}


SEQUENCE PB - BASE CASE (CONTINUED)

\begin{tabular}{|c|c|c|}
\hline $\begin{array}{l}\text { IMPORTANCE } \\
\text { MEASURE }\end{array}$ & EVENT & VALUE \\
\hline $\begin{array}{l}\text { Risk Reduction } \\
\text { (Concluded) }\end{array}$ & $\begin{array}{l}\text { ESF-ASP-FC-PL52D } \\
\text { ESF-ASP-FC-PL52C } \\
\text { ESF-ASP-FC-PL52B } \\
\text { ESF-ASP-FC-PL52A } \\
\text { DCP-BAT-LP-C3 } \\
\text { RA-14J } \\
\text { DGACTB } \\
\text { CRD-MDP-FS-2BP39 } \\
\text { PCSLOST } \\
\text { CRD-MDP-MA-2BP39 } \\
\text { CRD-MDP-MA-2AP39 } \\
\text { ACP-DGN-LP-EDG4 } \\
\text { ESW-PSF-LF-19 } \\
\text { ACP-DGN-MA-EDG4 } \\
\text { HCI-TDP-FR-20S37 } \\
\text { ESW-XHE-FO-EHS } \\
\text { HCI-PSF-HW-SUP12 } \\
\text { HCI-PSF-HW-INJ09 } \\
\text { RCI-PSF-HW-INJ06 } \\
\text { RCI-PSF-HW-SUP09 } \\
\text { RCI-TDP-FR-20S38 } \\
\text { LCI-XHE-TL } \\
\text { SORV2 } \\
\text { ADS-XHE-INH2 } \\
\text { ADS-XHE-INH1 } \\
\text { E3-CFP-TC } \\
\text { E3-CL3-TC } \\
\text { IE-TLOSP } \\
\text { IE-TRTRIP } \\
\text { IE-TMSIVC } \\
\text { IE-TLFW } \\
\text { IE-S1 } \\
\text { IE-TIORV } \\
\text { IE-A }\end{array}$ & $\begin{array}{l}6.34 \mathrm{E}-9 \\
6.34 \mathrm{E}-9 \\
6.34 \mathrm{E}-9 \\
6.34 \mathrm{E}-9 \\
3.26 \mathrm{E}-9 \\
2.98 \mathrm{E}-9 \\
2.80 \mathrm{E}-9 \\
1.47 \mathrm{E}-9 \\
1.25 \mathrm{E}-9 \\
1.21 \mathrm{E}-9 \\
1.21 \mathrm{E}-9 \\
1.10 \mathrm{E}-9 \\
1.11 \mathrm{E}-9 \\
1.14 \mathrm{E}-9 \\
1.01 \mathrm{E}-9 \\
1.01 \mathrm{E}-9 \\
5.64 \mathrm{E}-10 \\
5.64 \mathrm{E}-10 \\
1.84 \mathrm{E}-10 \\
1.84 \mathrm{E}-10 \\
1.23 \mathrm{E}-10 \\
-1.50 \mathrm{E}-9 \\
-3.57 \mathrm{E}-9 \\
-1.72 \mathrm{E}-8 \\
-3.67 \mathrm{E}-8 \\
-3.75 \mathrm{E}-7 \\
-3.75 \mathrm{E}-7 \\
6.19 \mathrm{E}-6 \\
1.04 \mathrm{E}-6 \\
5.47 \mathrm{E}-7 \\
4.79 \mathrm{E}-7 \\
8.43 \mathrm{E}-8 \\
4.57 \mathrm{E}-8 \\
2.99 \mathrm{E}-8\end{array}$ \\
\hline Risk Increase & $\begin{array}{l}\text { RPS-M } \\
\text { ESW-PSF-LF-8 } \\
\text { DCP-BAT-LP-B2 } \\
\text { ESF-XHE-MC-RXPRS } \\
\text { LOSP } \\
\text { ACP-DGN-LP-EDG2 } \\
\text { B-DCP-LP-BATS } \\
\text { ESW-PSF-LF-02 } \\
\text { ESW-PSF-LF-01 } \\
\text { ESW-PSF-LF-103 } \\
\text { ESW-PSF-LF-102 } \\
\text { ACP-DGN-LP-EDG3 }\end{array}$ & $\begin{array}{l}1.15 \mathrm{E}-1 \\
3.97 \mathrm{E}-3 \\
3.43 \mathrm{E}-3 \\
1.58 \mathrm{E}-3 \\
3.42 \mathrm{E}-4 \\
1.08 \mathrm{E}-4 \\
1.08 \mathrm{E}-4 \\
8.19 \mathrm{E}-5 \\
8.01 \mathrm{E}-5 \\
7.83 \mathrm{E}-5 \\
7.60 \mathrm{E}-5 \\
7.15 \mathrm{E}-5\end{array}$ \\
\hline
\end{tabular}


SEQUENCE PB - BASE CASE (CONTINUED)

IMPORTANCE MEASURE

Risk Increase

(Continued)
EHV - PSF - LF - 9

EHV-PSF - LF- 8

RA-1J

ACP-DGN-MA-EDG3

ACP-DGN-MA-EDG2

B-ACP-LP-EDGS

SLC-XHE-REL

SLC-XHE-FS

HCI - TDP - FS - 20537

HCI - TDP-MA-20S37

ESW-MDP-FS-ESWA

ESW-MDP-FS-ESWB

SORV

HCI - XHE-TL

RCI -TDP-FS - 20S38

RCI -TDP-MA-20S38

ESF-ASP-FC-PL52D

ESF-ASP-FC-PL52C

ESF-ASP-FC-PL52B

ESF-ASP-FC-PL52A

SRV-XHE-FO-VLV

DGACTB

DCP-BAT - LP - C3

DEP-XHE

RCI - PSF-HW-COL 10

RA-16J

ESF-XHE-FO-CRDRL

CMS IVA

COND-HPSW-XHE-TC

CRD-MDP-MA-2BP39

CRD-MDP-MA-2AP39

CRD-MDP-FS-2BP39

ADS-VLV-FO-VALVE

RA-17J

RA-18J

RA-1D

B-ADS-FO-VLVS

HCI -PSF-HW-SUP12

HCI - PSF-HW-INJO9

PCSLOST

HCI - TDP-FR-20S37

ESW-XHE-FO-EHS

ACP-DGN-MA-EDG4

ESW-PSF-LF-19

ACP-DGN-LP-EDG4

RA-14J

VENT - XHE-TC

\section{VALUE}

$6.43 E-5$

$6.43 E-5$

$5.75 \mathrm{E}-5$

4. $38 \mathrm{E}-5$

4. $11 \mathrm{E}-5$

2. $12 \mathrm{E}-5$

1. $76 \mathrm{E}-5$

1.71E-5

9. $97 \mathrm{E}-6$

8. $95 \mathrm{E}-6$

$7.05 \mathrm{E}-6$

7. 05E-6

$6.40 \mathrm{E}-6$

$5.26 \mathrm{E}-6$

4. $18 \mathrm{E}-6$

2. $93 \mathrm{E}-6$

2. $53 \mathrm{E}-6$

2. $53 \mathrm{E}-6$

2. $53 \mathrm{E}-6$

2. $53 \mathrm{E}-6$

2. $31 \mathrm{E}-6$

$1.74 \mathrm{E}-6$

$1.74 \mathrm{E}-6$

1.70E-6

8. $54 \mathrm{E}-7$

8. $11 E-7$

$6.80 E-7$

5. 23E-7

4. $68 \mathrm{E}-7$

4. $54 \mathrm{E}-7$

4. $54 \mathrm{E}-7$

4. $54 \mathrm{E}-7$

4. $44 \mathrm{E}-7$

4. $20 \mathrm{E}-7$

3. $36 \mathrm{E}-7$

2. $81 \mathrm{E}-7$

2. $57 \mathrm{E}-7$

1. $50 \mathrm{E}-7$

1. $50 \mathrm{E}-7$

1. $24 \mathrm{E}-7$

1.00E-7

1. $00 \mathrm{E}-7$

$1.00 \mathrm{E}-7$

1. $00 \mathrm{E}-7$

1. $00 \mathrm{E}-7$

9. $65 \mathrm{E}-8$

5. $10 \mathrm{E}-8$ 
SEQUENCE PB - BASE CASE (CONTINUED)

\section{IMPORTANCE}

MEASURE

EVENT

VALUE

Risk Increase

(Concluded)

Uncertainty
RCI - PSF-HW- INJ06

RCI - PSF-HW-SUPO9

RA-14D

RA-2D

RCI -TDP-FR-20S38

RA-18D

RA-17D

RA-16D

ECW-XHE-FO-ECWPP

E3-CFP-TC

ADS-XHE-INH2

ADS-XHE-INHI

SORV2

E3-CL3-TC

LCI-XHE-TL

DCP-BAT-LP-B2

B-DCP-LP-BATS

RA-1J

RPS-M

LOSP

ACP-DGN-LP-EDG2

SLC-XHE-FS

ACP-DGN-MA-EDG3

ACP-DGN-MA-EDG2

ACP-DGN-LP-EDG3

RA-16J

DEP-XHE

ESW-PSF-LF-02

HCI - TDP-FS-20S37

HCI - TDP-MA-20S37

ESW-PSF-LF-103

ESW-PSF-LF-01

B-ACP-LP-EDGS

ESW-PSF-LF-8

ESW-PSF-LF-102

CMSIVA

SORV

E3-CL3-TC

$\mathrm{RA}-17 \mathrm{~J}$

RA- $18 \mathrm{~J}$

SLC-XHE-REL

ESF-XHE-MC-RXPRS

RCI - TDP-FS-20S38

RA-1D

RCI - TDP-MA-20S38

ESF-XHE-FO-CRDRL
$4.88 \mathrm{E}-8$

$4.88 \mathrm{E}-8$

2. $00 \mathrm{E}-8$

$8.83 \mathrm{E}-9$

$4.78 \mathrm{E}-9$

$0.00 \mathrm{E}+0$

$0.00 \mathrm{E}+0$

$0.00 \mathrm{E}+0$

$0.00 \mathrm{E}+0$

$-4.17 \mathrm{E}-8$

$-1.06 \mathrm{E}-7$

$-3.54 \mathrm{E}-7$

$-3.54 \mathrm{E}-7$

$-3.75 \mathrm{E}-7$

$-5.62 \mathrm{E}-7$

3. $32 \mathrm{E}-6$

3. $28 \mathrm{E}-6$

$2.08 \mathrm{E}-6$

2.01E-6

$1.61 \mathrm{E}-6$

9. $23 \mathrm{E}-7$

$8.46 \mathrm{E}-7$

8. $00 \mathrm{E}-7$

$5.94 \mathrm{E}-7$

5.85E-7

5. $23 \mathrm{E}-7$

4. $15 \mathrm{E}-7$

4.07E-7

4.03E-7

$3.91 \mathrm{E}-7$

3. $51 \mathrm{E}-7$

3. $30 \mathrm{E}-7$

3. $26 \mathrm{E}-7$

3. $16 \mathrm{E}-7$

$3.12 \mathrm{E}-7$

2.69E-7

2. $48 \mathrm{E}-7$

2. $17 \mathrm{E}-7$

$2.17 \mathrm{E}-7$

$1.73 \mathrm{E}-7$

1. $57 \mathrm{E}-7$

1.52E-7

1. $49 \mathrm{E}-7$

$1.09 \mathrm{E}-7$

$9.06 \mathrm{E}-8$

7. $34 \mathrm{E}-8$ 


\begin{tabular}{|c|c|c|}
\hline $\begin{array}{c}\text { IMPORTANCE } \\
\text { MEASURE }\end{array}$ & EVENT & VALUE \\
\hline $\begin{array}{l}\text { Uncertainty } \\
\text { (Cont inued) }\end{array}$ & $\begin{array}{l}\text { ADS-XHE-INH1 } \\
\text { COND-HPSW-XHE-TC } \\
\text { ESW-MDP-FS-ESWA } \\
\text { VENT-XHE-TC } \\
\text { ESW-MDP-FS-ESWB } \\
\text { EHV-PSF-LF-9 } \\
\text { E3-CFP-TC } \\
\text { HCI-XHE-TL } \\
\text { EHV-PSF-LF-8 } \\
\text { ADS-XHE-INH2 } \\
\text { SRV-XHE-FO-VLV } \\
\text { RA-14D } \\
\text { ADS-VLV-FO-VALVE } \\
\text { B-ADS-FO-VLVS } \\
\text { RA-2D } \\
\text { RCI-PSF-HW-COL10 } \\
\text { ESF-ASP-FC-PL52A } \\
\text { ESF-ASP-FC-PL52D } \\
\text { ESF-ASP-FC-PL52C } \\
\text { ESF-ASP-FC-PL52B } \\
\text { LCI-XHE-TL } \\
\text { CRD-MDP-MA-2BP39 } \\
\text { DGACTB } \\
\text { SORV2 } \\
\text { DCP-BAT-LP-C3 } \\
\text { PCSLOST } \\
\text { CRD-MDP-MA-2AP39 } \\
\text { RA-14J } \\
\text { CRD-MDP-FS-2BP39 } \\
\text { ACP-DGN-MA-EDG4 } \\
\text { ESW-XHE-FO-EHS } \\
\text { ACP-DGN-LP-EDG4 } \\
\text { ESW-PSF-LF-19 } \\
\text { HCI-TDP-FR-20S37 } \\
\text { HCI-PSF-HW-SUP12 } \\
\text { HCI-PSF-HW-INJ09 } \\
\text { RCI-PSF-HW-INJ06 } \\
\text { RCI-PSF-HW-SUP09 } \\
\text { RCI-TDP-FR-20S38 } \\
\text { RA-18D } \\
\text { RA-17D } \\
\text { RA-16D } \\
\text { ECW-XHE-FO-ECWPP } \\
\text { IE-TLOSP } \\
\text { IE-TRTRIP } \\
\text { IE-TMSIVC }\end{array}$ & $\begin{array}{l}5.77 \mathrm{E}-8 \\
5.09 \mathrm{E}-8 \\
4.75 \mathrm{E}-8 \\
4.74 \mathrm{E}-8 \\
4.22 \mathrm{E}-8 \\
4.01 \mathrm{E}-8 \\
3.94 \mathrm{E}-8 \\
3.67 \mathrm{E}-8 \\
3.64 \mathrm{E}-8 \\
2.72 \mathrm{E}-8 \\
2.34 \mathrm{E}-8 \\
1.84 \mathrm{E}-8 \\
1.75 \mathrm{E}-8 \\
1.70 \mathrm{E}-8 \\
8.80 \mathrm{E}-9 \\
4.74 \mathrm{E}-9 \\
4.70 \mathrm{E}-9 \\
4.58 \mathrm{E}-9 \\
4.52 \mathrm{E}-9 \\
4.51 \mathrm{E}-9 \\
3.88 \mathrm{E}-9 \\
3.20 \mathrm{E}-9 \\
3.11 \mathrm{E}-9 \\
2.78 \mathrm{E}-9 \\
2.45 \mathrm{E}-9 \\
2.32 \mathrm{E}-9 \\
1.98 \mathrm{E}-9 \\
1.83 \mathrm{E}-9 \\
1.72 \mathrm{E}-9 \\
1.42 \mathrm{E}-9 \\
1.02 \mathrm{E}-9 \\
8.26 \mathrm{E}-10 \\
8.09 \mathrm{E}-10 \\
7.87 \mathrm{E}-10 \\
4.30 \mathrm{E}-10 \\
4.19 \mathrm{E}-10 \\
1.36 \mathrm{E}-10 \\
1.31 \mathrm{E}-10 \\
8.63 \mathrm{E}-11 \\
0.00 \mathrm{E}+0 \\
0.00 \mathrm{E}+0 \\
0.00 \mathrm{E}+0 \\
0.00 \mathrm{E}+0 \\
4.36 \mathrm{E}-6 \\
7.83 \mathrm{E}-7 \\
3.92 \mathrm{E}-7\end{array}$ \\
\hline
\end{tabular}


SEQUENCE PB - BASE CASE (CONCLUDED)

IMPORTANCE

MEASURE

EVENT

VALUE

Uncertainty

(Concluded)

IE-TLFW

IE-S1

IE-A

IE-TIORV

3.47E-7

$2.20 \mathrm{E}-7$

$5.76 E-8$

$3.22 E-8$ 
SEQUENCE PB - SENSITIVITY ISSUE 1

\begin{tabular}{|c|c|c|}
\hline $\begin{array}{l}\text { IMPORTANCE } \\
\text { MEASURE }\end{array}$ & EVENT & VALUE \\
\hline Risk Reduction & $\begin{array}{l}\text { RA-1J } \\
\text { RA-16J } \\
\text { RPS-M } \\
\text { ACP-DGN-LP-EDG3 } \\
\text { ACP-DGN-LP-EDG2 } \\
\text { SLC-XHE-FS } \\
\text { CMSIVA } \\
\text { ACP-DGN-MA-EDG3 } \\
\text { DEP-XHE } \\
\text { VENT-XHE-TC } \\
\text { ECW-XHE-FO-ECWPP } \\
\text { ACP-DGN-MA-EDG2 } \\
\text { ESW-PSF-LF-103 } \\
\text { HCI-TDP-FS-20S37 } \\
\text { ESW-PSF-LF-102 } \\
\text { RA-18J } \\
\text { LOSP } \\
\text { SLC-XHE-REL } \\
\text { ESW-PSF-LF-02 } \\
\text { RCI-TDP-FS-20S38 } \\
\text { ESW-PSF-LF-01 } \\
\text { ESF-XHE-MC-RXPRS } \\
\text { RA-1D } \\
\text { HCI-TDP-MA-20S37 } \\
\text { ESW-PSF-LF-8 } \\
\text { SORV } \\
\text { DCP-BAT-LP-B2 } \\
\text { RA-14D } \\
\text { RA-16D } \\
\text { RA-2D } \\
\text { ESF-XHE-FO-CRDRL } \\
\text { COND-HPSW-XHE-TC } \\
\text { EHV-PSF-LF-9 } \\
\text { EHV-PSF-LF-8 } \\
\text { ESW-MDP-FS-ESWA } \\
\text { ESW-MDP-FS-ESWB } \\
\text { RCI-TDP-MA-20S38 } \\
\text { HCI-XHE-TL } \\
\text { RA-18D } \\
\text { RCI-PSF-HW-COL10 } \\
\text { ESF-ASP-FC-PL52D } \\
\text { ESF-ASP-FC-PL52C } \\
\text { ESF-ASP-FC-PL52B } \\
\text { ESF-ASP-FC-PL52A } \\
\text { DCP-BAT-LP-C3 } \\
\text { RA-14J } \\
\text { DGACTB }\end{array}$ & $\begin{array}{l}1.98 \mathrm{E}-6 \\
1.22 \mathrm{E}-6 \\
1.15 \mathrm{E}-6 \\
8.13 \mathrm{E}-7 \\
7.83 \mathrm{E}-7 \\
6.00 \mathrm{E}-7 \\
5.23 \mathrm{E}-7 \\
4.83 \mathrm{E}-7 \\
4.59 \mathrm{E}-7 \\
4.59 \mathrm{E}-7 \\
4.56 \mathrm{E}-7 \\
4.53 \mathrm{E}-7 \\
4.49 \mathrm{E}-7 \\
4.44 \mathrm{E}-7 \\
4.36 \mathrm{E}-7 \\
3.36 \mathrm{E}-7 \\
2.75 \mathrm{E}-7 \\
1.77 \mathrm{E}-7 \\
1.72 \mathrm{E}-7 \\
1.69 \mathrm{E}-7 \\
1.69 \mathrm{E}-7 \\
1.58 \mathrm{E}-7 \\
1.57 \mathrm{E}-7 \\
1.29 \mathrm{E}-7 \\
1.19 \mathrm{E}-7 \\
1.02 \mathrm{E}-7 \\
8.31 \mathrm{E}-8 \\
8.01 \mathrm{E}-8 \\
5.90 \mathrm{E}-8 \\
5.61 \mathrm{E}-8 \\
5.34 \mathrm{E}-8 \\
5.20 \mathrm{E}-8 \\
5.15 \mathrm{E}-8 \\
5.15 \mathrm{E}-8 \\
3.76 \mathrm{E}-8 \\
3.76 \mathrm{E}-8 \\
3.71 \mathrm{E}-8 \\
1.40 \mathrm{E}-8 \\
9.83 \mathrm{E}-9 \\
6.46 \mathrm{E}-9 \\
6.34 \mathrm{E}-9 \\
6.34 \mathrm{E}-9 \\
6.34 \mathrm{E}-9 \\
6.34 \mathrm{E}-9 \\
3.26 \mathrm{E}-9 \\
2.98 \mathrm{E}-9 \\
2.80 \mathrm{E}-9\end{array}$ \\
\hline
\end{tabular}


SEQUENCE PB - SENSIVITITY ISSUE 1 (CONTINUED)

\begin{tabular}{|c|c|c|}
\hline $\begin{array}{l}\text { IMPORTANCE } \\
\text { MEASURE }\end{array}$ & EVENT & VALUE \\
\hline $\begin{array}{l}\text { Risk Reduction } \\
\text { (Concluded) }\end{array}$ & $\begin{array}{l}\text { ACP-DGN-LP-EDG4 } \\
\text { ESW-PSF-LF-19 } \\
\text { ACP-DGN-MA-EDG4 } \\
\text { CRD-MDP-FS-2BP39 } \\
\text { HCI-TDP-FR-20S37 } \\
\text { ESW-XHE-FO-EHS } \\
\text { PCSLOST } \\
\text { CRD-MDP-MA-2BP39 } \\
\text { CRD-MDP-MA-2AP39 } \\
\text { HCI-PSF-HW-SUP12 } \\
\text { HCI-PSF-HW-INJ09 } \\
\text { RCI-PSF-HW-SUP09 } \\
\text { RCI-PSF-HW-INJ06 } \\
\text { RCI-TDP-FR-20S38 } \\
\text { LCI-XHE-TL } \\
\text { SORV2 } \\
\text { ADS-XHE-INH2 } \\
\text { ADS-XHE-INH1 } \\
\text { E3-CFP-TC } \\
\text { E3-CL3-TC } \\
\text { IE-TLOSP } \\
\text { IE-TRTRIP } \\
\text { IE-TMSIVC } \\
\text { IE-TLFW } \\
\text { IE-S1 } \\
\text { IE-TIORV } \\
\text { IE-A }\end{array}$ & $\begin{array}{l}1.14 \mathrm{E}-9 \\
1.11 \mathrm{E}-9 \\
1.10 \mathrm{E}-9 \\
1.04 \mathrm{E}-9 \\
1.01 \mathrm{E}-9 \\
1.01 \mathrm{E}-9 \\
8.84 \mathrm{E}-10 \\
8.55 \mathrm{E}-10 \\
8.55 \mathrm{E}-10 \\
5.64 \mathrm{E}-10 \\
5.64 \mathrm{E}-10 \\
1.84 \mathrm{E}-10 \\
1.84 \mathrm{E}-10 \\
1.23 \mathrm{E}-10 \\
-1.50 \mathrm{E}-9 \\
-3.57 \mathrm{E}-9 \\
-1.72 \mathrm{E}-8 \\
-3.67 \mathrm{E}-8 \\
-3.75 \mathrm{E}-7 \\
-3.75 \mathrm{E}-7 \\
1.88 \mathrm{E}-6 \\
6.47 \mathrm{E}-7 \\
4.04 \mathrm{E}-7 \\
3.53 \mathrm{E}-7 \\
8.43 \mathrm{E}-8 \\
4.57 \mathrm{E}-8 \\
2.99 \mathrm{E}-8\end{array}$ \\
\hline Risk Increase & $\begin{array}{l}\text { RPS-M } \\
\text { ESW-PSF-LF-8 } \\
\text { ESF-XHE-MC-RXPRS } \\
\text { LOSP } \\
\text { ESW-PSF-LF-02 } \\
\text { ESW-PSF-LF-01 } \\
\text { ESW-PSF-LF-103 } \\
\text { ESW-PSF-LF-102 } \\
\text { ACP-DGN-LP-EDG3 } \\
\text { ACP-DGN-LP-EDG2 } \\
\text { EHV-PSF-LF-9 } \\
\text { EHV-PSF-LF-8 } \\
\text { DCP-BAT-LP-B2 } \\
\text { RA-1J } \\
\text { ACP-DGN-MA-EDG3 } \\
\text { ACP-DGN-MA-EDG2 } \\
\text { SLC-XHE-REL } \\
\text { SLC-XHE-FS } \\
\text { HCI-TDP-FS-20S37 } \\
\text { HCI-TDP-MA-20S37 }\end{array}$ & $\begin{array}{l}1.15 \mathrm{E}-1 \\
3.97 \mathrm{E}-3 \\
1.58 \mathrm{E}-3 \\
1.03 \mathrm{E}-4 \\
8.19 \mathrm{E}-5 \\
8.01 \mathrm{E}-5 \\
7.83 \mathrm{E}-5 \\
7.60 \mathrm{E}-5 \\
7.15 \mathrm{E}-5 \\
6.88 \mathrm{E}-5 \\
6.43 \mathrm{E}-5 \\
6.43 \mathrm{E}-5 \\
6.24 \mathrm{E}-5 \\
4.74 \mathrm{E}-5 \\
4.38 \mathrm{E}-5 \\
4.11 \mathrm{E}-5 \\
1.76 \mathrm{E}-5 \\
1.71 \mathrm{E}-5 \\
8.74 \mathrm{E}-6 \\
7.92 \mathrm{E}-6\end{array}$ \\
\hline
\end{tabular}


SEQUENCE PB - SENSITIVITY ISSUE 1 (CONTINUED)

IMPORTANCE MEASURE

Risk Increase

(Concluded)
EVENT

VALUE

ESW-MDP-FS-ESWB

ESW-MDP-FS-ESWA

HCI - XHE-TL

RCI -TDP-FS-20S38

ESF-ASP-FC-PL52C

ESF-ASP-FC-PL52B

ESF-ASP-FC-PL52A

ESF-ASP-FC-PL52D

RCI - TDP-MA-20S38

SORV

DGACTB

DCP-BAT-LP-C3

DEP-XHE

RCI - PSF-HW-COL 10

RA-16J

CMSIVA

ESF-XHE-FO-CRDRL

COND-HPSW-XHE-TC

RA-18J

CRD-MDP-MA-2BP39

CRD-MDP-MA-2AP39

CRD-MDP-FS-2BP39

RA-1D

HCI - PSF-HW-SUP12

HCI - PSF-HW-INJ09

HCI - TDP-FR-20S37

ESW-XHE-FO-EHS

ACP-DGN-MA-EDG4

ESW-PSF-LF-19

$A C P-D G N-L P-E D G 4$

RA-14J

PCSLOST

VENT-XHE-TC

RCI - PSF-HW-SUP09

RC I - PSF-HW-INJ06

RA-14D

RA-2D

RC I - TDP -FR- $20 S 38$

RA-18D

RA-16D

ECW-XHE-FO-ECWPP

E3-CFP-TC

ADS - XHE - INH2

ADS-XHE - INH1

SORV2

E3-CL3-TC

LCI - XHE-TL
7.05E-6

$7.05 \mathrm{E}-6$

5. $26 \mathrm{E}-6$

$3.32 \mathrm{E}-6$

$2.53 \mathrm{E}-6$

$2.53 \mathrm{E}-6$

2. $53 \mathrm{E}-6$

$2.53 \mathrm{E}-6$

2. $28 \mathrm{E}-6$

$1.93 \mathrm{E}-6$

$1.74 \mathrm{E}-6$

$1.74 \mathrm{E}-6$

1. $70 \mathrm{E}-6$

$8.54 \mathrm{E}-7$

8.11E-7

5. $23 \mathrm{E}-7$

$4.80 \mathrm{E}-7$

4. $68 \mathrm{E}-7$

3. $36 \mathrm{E}-7$

3. $20 \mathrm{E}-7$

$3.20 \mathrm{E}-7$

3. $20 \mathrm{E}-7$

2. $35 \mathrm{E}-7$

1.50E-7

1. $50 \mathrm{E}-7$

1.00E-7

1. $00 \mathrm{E}-7$

$1.00 \mathrm{E}-7$

$1.00 \mathrm{E}-7$

1. $00 \mathrm{E}-7$

$9.65 \mathrm{E}-8$

8. $75 \mathrm{E}-8$

5. $10 \mathrm{E}-8$

4. $88 \mathrm{E}-8$

$4.88 \mathrm{E}-8$

2. $00 \mathrm{E}-8$

$6.24 \mathrm{E}-9$

4.78E-9

$0.00 E+0$

$0.00 E+0$

$0.00 E+0$

$-4.17 \mathrm{E}-8$

$-1.06 E-7$

$-3.54 E-7$

$-3.54 E-7$

$-3.75 E-7$

$-5.62 E-7$ 
IMPORTANCE

MEASURE

Uncertainty
EVENT

VALUE

\begin{tabular}{|c|c|}
\hline $\begin{array}{l}\text { RPS-M } \\
\text { RA-1J } \\
\text { SLC-XHE-FS } \\
\text { ACP-DGN-MA-EDG3 } \\
\text { ACP-DGN-MA-EDG2 } \\
\text { ACP-DGN-LP-EDG2 } \\
\text { ACP-DGN-LP-EDG3 } \\
\text { RA-16J } \\
\text { LOSP } \\
\text { DEP-XHE } \\
\text { ESW-PSF-LF-02 } \\
\text { HCI-TDP-FS-20S37 } \\
\text { ESW-PSF-LF-103 } \\
\text { HCI-TDP-MA-20S37 } \\
\text { ESW-PSF-LF-01 } \\
\text { ESW-PSF-LF-8 } \\
\text { ESW-PSF-LF-102 } \\
\text { CMSIVA } \\
\text { E3-CL3-TC } \\
\text { RA-18J } \\
\text { SLC-XHE-REL } \\
\text { ESF-XHE-MC-RXPRS } \\
\text { RCI-TDP-FS-20S38 } \\
\text { RA-1D } \\
\text { SORV } \\
\text { RCI-TDP-MA-20S38 } \\
\text { DCP-BAT-LP-B2 } \\
\text { ADS-XHE-INH1 } \\
\text { ESF-XHE-FO-CRDRL } \\
\text { COND-HPSW-XHE-TC } \\
\text { ESW-MDP-FS-ESWA } \\
\text { VENT-XHE-TC } \\
\text { ESW-MDP-FS-ESWB } \\
\text { EHV-PSF-LF-9 } \\
\text { E3-CFP-TC } \\
\text { HCI-XHE-TL } \\
\text { EHV-PSF-LF-8 } \\
\text { ADS-XHE-INH2 } \\
\text { RA-14D } \\
\text { RA-2D } \\
\text { RCI-PSF-HW-COL10 } \\
\text { ESF-ASP-FC-PL52A } \\
\text { ESF-ASP-FC-PL52D } \\
\text { ESF-ASP-FC-PL52C } \\
\text { ESF-ASP-FC-PL52B } \\
\text { LCI-XHE-TL } \\
\text { DGACTB }\end{array}$ & $\begin{array}{l}2.01 \mathrm{E}-6 \\
1.71 \mathrm{E}-6 \\
8.46 \mathrm{E}-7 \\
8.00 \mathrm{E}-7 \\
5.94 \mathrm{E}-7 \\
5.85 \mathrm{E}-7 \\
5.85 \mathrm{E}-7 \\
5.23 \mathrm{E}-7 \\
4.86 \mathrm{E}-7 \\
4.15 \mathrm{E}-7 \\
4.07 \mathrm{E}-7 \\
3.53 \mathrm{E}-7 \\
3.51 \mathrm{E}-7 \\
3.45 \mathrm{E}-7 \\
3.30 \mathrm{E}-7 \\
3.16 \mathrm{E}-7 \\
3.12 \mathrm{E}-7 \\
2.69 \mathrm{E}-7 \\
2.17 \mathrm{E}-7 \\
1.73 \mathrm{E}-7 \\
1.57 \mathrm{E}-7 \\
1.52 \mathrm{E}-7 \\
1.18 \mathrm{E}-7 \\
9.15 \mathrm{E}-8 \\
7.46 \mathrm{E}-8 \\
7.06 \mathrm{E}-8 \\
6.04 \mathrm{E}-8 \\
5.77 \mathrm{E}-8 \\
5.18 \mathrm{E}-8 \\
5.09 \mathrm{E}-8 \\
4.75 \mathrm{E}-8 \\
4.74 \mathrm{E}-8 \\
4.22 \mathrm{E}-8 \\
4.01 \mathrm{E}-8 \\
3.94 \mathrm{E}-8 \\
3.67 \mathrm{E}-8 \\
3.64 \mathrm{E}-8 \\
2.72 \mathrm{E}-8 \\
1.84 \mathrm{E}-8 \\
6.21 \mathrm{E}-9 \\
4.74 \mathrm{E}-9 \\
4.70 \mathrm{E}-9 \\
4.58 \mathrm{E}-9 \\
4.52 \mathrm{E}-9 \\
4.51 \mathrm{E}-9 \\
3.88 \mathrm{E}-9 \\
3.11 \mathrm{E}-9\end{array}$ \\
\hline
\end{tabular}


SEQUENCE PB - SENSIVITITY ISSUE 1 (CONCLUDED)

\begin{tabular}{|c|c|c|}
\hline $\begin{array}{l}\text { IMPORTANCE } \\
\text { MEASURE }\end{array}$ & EVENT & VALUE \\
\hline $\begin{array}{l}\text { Uncertainty } \\
\text { (Concluded) }\end{array}$ & $\begin{array}{l}\text { SORV2 } \\
\text { DCP-BAT-LP-C3 } \\
\text { CRD-MDP-MA-2BP39 } \\
\text { RA-14J } \\
\text { PCSLOST } \\
\text { ACP-DGN-MA-EDG4 } \\
\text { CRD-MDP-MA-2AP39 } \\
\text { CRD-MDP-FS-2BP39 } \\
\text { ESW-XHE-FO-EHS } \\
\text { ACP-DGN-LP-EDG4 } \\
\text { ESW-PSF-LF-19 } \\
\text { HCI-TDP-FR-20S37 } \\
\text { HCI-PSF-HW-SUP12 } \\
\text { HCI-PSF-HW-INJ09 } \\
\text { RCI-PSF-HW-INJ06 } \\
\text { RCI-PSF-HW-SUPO9 } \\
\text { RCI-TDP-FR-20S38 } \\
\text { RA-18D } \\
\text { RA-16D } \\
\text { ECW-XHE-FO-ECWPP } \\
\text { IE-TLOSP } \\
\text { IE-TRTRIP } \\
\text { IE-TMSIVC } \\
\text { IE-TLFW } \\
\text { IE-S1 } \\
\text { IE-A } \\
\text { IE-TIORV }\end{array}$ & $\begin{array}{l}2.78 \mathrm{E}-9 \\
2.45 \mathrm{E}-9 \\
2.26 \mathrm{E}-9 \\
1.83 \mathrm{E}-9 \\
1.63 \mathrm{E}-9 \\
1.42 \mathrm{E}-9 \\
1.40 \mathrm{E}-9 \\
1.21 \mathrm{E}-9 \\
1.02 \mathrm{E}-9 \\
8.26 \mathrm{E}-10 \\
8.09 \mathrm{E}-10 \\
7.87 \mathrm{E}-10 \\
4.30 \mathrm{E}-10 \\
4.19 \mathrm{E}-10 \\
1.36 \mathrm{E}-10 \\
1.31 \mathrm{E}-10 \\
8.63 \mathrm{E}-11 \\
0.00 \mathrm{E}+0 \\
0.00 \mathrm{E}+0 \\
0.00 \mathrm{E}+0 \\
1.33 \mathrm{E}-6 \\
4.87 \mathrm{E}-7 \\
2.90 \mathrm{E}-7 \\
2.56 \mathrm{E}-7 \\
2.20 \mathrm{E}-7 \\
5.76 \mathrm{E}-8 \\
3.22 \mathrm{E}-8\end{array}$ \\
\hline
\end{tabular}




\begin{tabular}{|c|c|c|}
\hline $\begin{array}{l}\text { IMPORTANCE } \\
\text { MEASURE }\end{array}$ & EVENT & VALUE \\
\hline Risk Reduction & $\begin{array}{l}\text { DCP-BAT-LP-B2 } \\
\text { B-DCP-LP-BATS } \\
\text { RA-1J } \\
\text { ACP-DGN-LP-EDG2 } \\
\text { RA-16J } \\
\text { RPS-M } \\
\text { B-ACP-LP-EDGS } \\
\text { RA-17J } \\
\text { LOSP } \\
\text { ACP-DGN-LP-EDG3 } \\
\text { SLC-XHE-FS } \\
\text { HCI -TDP-FS-20S37 } \\
\text { CMSIVA } \\
\text { ACP-DGN-MA-EDG3 } \\
\text { DEP-XHE } \\
\text { VENT-XHE-TC } \\
\text { ECW-XHE-FO-ECWPP } \\
\text { ACP-DGN-MA-EDG2 } \\
\text { ESW-PSF-LF-103 } \\
\text { ESW-PSF-LF-102 } \\
\text { SORV } \\
\text { RA-18J } \\
\text { RCI-TDP-FS-20S38 } \\
\text { RA-1D } \\
\text { SLC-XHE-REL } \\
\text { ESW-PSF-LF-02 } \\
\text { HCI-TDP-MA-20S37 } \\
\text { ESW-PSF-LF-01 } \\
\text { ESF-XHE-MC-RXPRS } \\
\text { ESW-PSF-LF-8 } \\
\text { RA-2D } \\
\text { ESF-XHE-F0-CRDRL } \\
\text { RA-14D } \\
\text { RCI-TDP-MA-20S38 } \\
\text { RA-16D } \\
\text { ADS-VLV-FO-VALVE } \\
\text { B-ADS-FO-VLVS } \\
\text { SRV-XHE-FO-VLV } \\
\text { COND-HPSW-XHE-TC } \\
\text { EHV-PSF-LF-9 } \\
\text { EHV-PSF-LF-8 } \\
\text { ESW-MDP-FS-ESWB } \\
\text { ESW-MDP-FS-ESWA } \\
\text { RA-17D } \\
\text { HCI-XHE-TL } \\
\text { RA-18D } \\
\text { RCI-PSF-HW-COL10 }\end{array}$ & $\begin{array}{l}4.57 \mathrm{E}-6 \\
4.49 \mathrm{E}-6 \\
2.99 \mathrm{E}-6 \\
1.87 \mathrm{E}-6 \\
1.22 \mathrm{E}-6 \\
1.15 \mathrm{E}-6 \\
1.08 \mathrm{E}-6 \\
1.01 \mathrm{E}-6 \\
9.95 \mathrm{E}-7 \\
8.13 \mathrm{E}-7 \\
6.00 \mathrm{E}-7 \\
5.95 \mathrm{E}-7 \\
5.23 \mathrm{E}-7 \\
4.83 \mathrm{E}-7 \\
4.59 \mathrm{E}-7 \\
4.59 \mathrm{E}-7 \\
4.56 \mathrm{E}-7 \\
4.53 \mathrm{E}-7 \\
4.49 \mathrm{E}-7 \\
4.36 \mathrm{E}-7 \\
3.67 \mathrm{E}-7 \\
3.36 \mathrm{E}-7 \\
2.73 \mathrm{E}-7 \\
2.31 \mathrm{E}-7 \\
1.77 \mathrm{E}-7 \\
1.72 \mathrm{E}-7 \\
1.69 \mathrm{E}-7 \\
1.69 \mathrm{E}-7 \\
1.58 \mathrm{E}-7 \\
1.19 \mathrm{E}-7 \\
1.12 \mathrm{E}-7 \\
1.07 \mathrm{E}-7 \\
8.01 \mathrm{E}-8 \\
6.25 \mathrm{E}-8 \\
5.90 \mathrm{E}-8 \\
5.61 \mathrm{E}-8 \\
5.61 \mathrm{E}-8 \\
5.61 \mathrm{E}-8 \\
5.20 \mathrm{E}-8 \\
5.15 \mathrm{E}-8 \\
5.15 \mathrm{E}-8 \\
3.76 \mathrm{E}-8 \\
3.76 \mathrm{E}-8 \\
2.94 \mathrm{E}-8 \\
1.40 \mathrm{E}-8 \\
9.83 \mathrm{E}-9 \\
6.46 \mathrm{E}-9\end{array}$ \\
\hline
\end{tabular}


SEQUENCE PB - SENSITIVITY ISSUE 2 (CONTINUED)

\begin{tabular}{|c|c|c|}
\hline $\begin{array}{l}\text { IMPORTANCE } \\
\text { MEASURE }\end{array}$ & EVENT & VALUE \\
\hline $\begin{array}{l}\text { Risk Reduction } \\
\text { (Concluded) }\end{array}$ & $\begin{array}{l}\text { ESF-ASP-FC-PL52D } \\
\text { ESF-ASP-FC-PL52C } \\
\text { ESF-ASP-FC-PL52B } \\
\text { ESF-ASP-FC-PL52A } \\
\text { DCP-BAT-LP-C3 } \\
\text { RA-14J } \\
\text { DGACTB } \\
\text { CRD-MDP-FS-2BP39 } \\
\text { PCSLOST } \\
\text { CRD-MDP-MA-2BP39 } \\
\text { CRD-MDP-MA-2AP39 } \\
\text { ACP-DGN-LP-EDG4 } \\
\text { ESW-PSF-LF-19 } \\
\text { ACP-DGN-MA-EDG4 } \\
\text { HCI -TDP-FR-20S37 } \\
\text { ESW-XHE-FO-EHS } \\
\text { HCI -PSF-HW-SUP12 } \\
\text { HCI -PSF-HW-INJ09 } \\
\text { RCI -PSF-HW-INJ06 } \\
\text { RCI-PSF-HW-SUP09 } \\
\text { RCI - TDP-FR-20S38 } \\
\text { LCI-XHE-TL } \\
\text { SORV2 } \\
\text { ADS-XHE-INH2 } \\
\text { ADS-XHE-INH1 } \\
\text { E3-CFP-TC } \\
\text { E3-CL3-TC } \\
\text { IE-TLOSP } \\
\text { IE-TRTRIP } \\
\text { IE-TMSIVC } \\
\text { IE-TLFW } \\
\text { IE-S1 } \\
\text { IE-TIORV } \\
\text { IE-A }\end{array}$ & $\begin{array}{l}6.34 \mathrm{E}-9 \\
6.34 \mathrm{E}-9 \\
6.34 \mathrm{E}-9 \\
6.34 \mathrm{E}-9 \\
3.26 \mathrm{E}-9 \\
2.98 \mathrm{E}-9 \\
2.80 \mathrm{E}-9 \\
2.08 \mathrm{E}-9 \\
1.77 \mathrm{E}-9 \\
1.71 \mathrm{E}-9 \\
1.71 \mathrm{E}-9 \\
1.14 \mathrm{E}-9 \\
1.11 \mathrm{E}-9 \\
1.10 \mathrm{E}-9 \\
1.01 \mathrm{E}-9 \\
1.01 \mathrm{E}-9 \\
5.64 \mathrm{E}-10 \\
5.64 \mathrm{E}-10 \\
1.84 \mathrm{E}-10 \\
1.84 \mathrm{E}-10 \\
1.23 \mathrm{E}-10 \\
-1.50 \mathrm{E}-9 \\
-3.57 \mathrm{E}-9 \\
-1.72 \mathrm{E}-8 \\
-3.67 \mathrm{E}-8 \\
-3.75 \mathrm{E}-7 \\
-3.75 \mathrm{E}-7 \\
6.74 \mathrm{E}-6 \\
1.09 \mathrm{E}-6 \\
5.81 \mathrm{E}-7 \\
5.08 \mathrm{E}-7 \\
8.43 \mathrm{E}-8 \\
4.57 \mathrm{E}-8 \\
2.99 \mathrm{E}-8\end{array}$ \\
\hline Risk Increase & $\begin{array}{l}\text { RPS -M } \\
\text { ESW-PSF-LF-8 } \\
\text { DCP-BAT-LP-B2 } \\
\text { ESF-XHE-MC-RXPRS } \\
\text { LOSP } \\
\text { ACP-DGN-LP-EDG2 } \\
\text { B-DCP-LP-BATS } \\
\text { ESW-PSF-LF-02 } \\
\text { ESW-PSF-LF-01 } \\
\text { ESW-PSF-LF-103 } \\
\text { ESW-PSF-LF-102 } \\
\text { RA-1J } \\
\text { ACP-DGN-LP-EDG3 }\end{array}$ & $\begin{array}{l}1.15 \mathrm{E}-1 \\
3.97 \mathrm{E}-3 \\
3.43 \mathrm{E}-3 \\
1.58 \mathrm{E}-3 \\
3.73 \mathrm{E}-4 \\
1.64 \mathrm{E}-4 \\
1.08 \mathrm{E}-4 \\
8.19 \mathrm{E}-5 \\
8.01 \mathrm{E}-5 \\
7.83 \mathrm{E}-5 \\
7.60 \mathrm{E}-5 \\
7.17 \mathrm{E}-5 \\
7.15 \mathrm{E}-5\end{array}$ \\
\hline
\end{tabular}


SEQUENCE PB - SENSITIVITY ISSUE 2 (CONTINUED)

IMPORTANCE MEASURE

Risk Increase

(Continued)

\section{EVENT}

EHV - PSF - LF - 8

EHV - PSF - LF -9

ACP-DGN-MA-EDG3

$A C P-D G N-M A-E D G 2$

$B-A C P-L P-E D G S$

$S L C-X H E-R E L$

SLC-XHE-FS

HCI - TDP-FS - 20S37

HCI I TDP-MA-20S37

ESW-MDP-FS-ESWB

ESW-MDP-FS-ESWA

SORV

SRV-XHE-FO-VLV

RCI - TDP-FS - 20 S38

HC I - XHE - TL

RCI -TDP-MA-20S38

ESF-ASP-FC-PL52D

ESF-ASP-FC-PL52C

ESF-ASP-FC-PL52B

ESF-ASP-FC-PL52A

DGACTB

DCP-BAT - LP-C3

DEP-XHE

ADS-VLV-FO-VALVE

RA-17J

ESF-XHE-FO-CRDRL

RC I - PSF - HW - COL 10

RA-16J

CRD-MDP-MA-2BP39

CRD-MDP-MA-2AP39

CRD-MDP-FS - 2BP39

CMSIVA

COND-HPSW-XHE-TC

RA-1D

RA-18J

B-ADS-FO-VLVS

PCSLOST

HCI -PSF-HW-SUP12

HCI - PSF-HW-INJ09

HC I - TDP - FR - 20S37

ESW-XHE-FO-EHS

ACP-DGN-MA-EDG4

ESW-PSF-LF - 19

ACP-DGN-MA-EDG4

RA-14J

VENT - XHE - TC
VALUE

$6.43 E-5$

$6.43 E-5$

4. $38 E-5$

4. $11 \mathrm{E}-5$

$2.06 \mathrm{E}-5$

$1.76 \mathrm{E}-5$

$1.71 \mathrm{E}-5$

$1.17 E-5$

$1.04 E-5$

7.05E-6

$7.05 \mathrm{E}-6$

6. $97 E-6$

$5.56 \mathrm{E}-6$

5. $38 \mathrm{E}-6$

5. $26 \mathrm{E}-6$

$3.84 \mathrm{E}-6$

2. $53 \mathrm{E}-6$

2. $53 \mathrm{E}-6$

2. $53 \mathrm{E}-6$

2. $53 \mathrm{E}-6$

1. $74 \mathrm{E}-6$

$1.74 \mathrm{E}-6$

$1.70 \mathrm{E}-6$

$1.07 \mathrm{E}-6$

1. $01 E-6$

9.61E-7

8. $54 E-7$

8.11E-7

6. $41 \mathrm{E}-7$

$6.41 \mathrm{E}-7$

$6.41 \mathrm{E}-7$

$5.23 E-7$

$4.68 \mathrm{E}-7$

$3.46 \mathrm{E}-7$

3. $36 \mathrm{E}-7$

2. $24 \mathrm{E}-7$

$1.75 \mathrm{E}-7$

1. $50 \mathrm{E}-7$

1. $50 \mathrm{E}-7$

1. $00 \mathrm{E}-7$

1. $00 \mathrm{E}-7$

1. $00 \mathrm{E}-7$

1. $00 \mathrm{E}-7$

$1.00 \mathrm{E}-7$

9. $65 \mathrm{E}-8$

5. $10 \mathrm{E}-8$ 
SEQUENCE PB - SENSITIVITY ISSUE 2 (CONTINUED)

\begin{tabular}{|c|c|c|}
\hline $\begin{array}{l}\text { IMPORTANCE } \\
\text { MEASURE }\end{array}$ & EVENT & VALUE \\
\hline $\begin{array}{l}\text { Risk Increase } \\
\text { (Concluded) }\end{array}$ & $\begin{array}{l}\text { RCI - PSF - HW- INJ06 } \\
\text { RCI - PSF-HW-SUP09 } \\
\text { RA- 14D } \\
\text { RA-2D } \\
\text { RCI - TDP-FR-20S38 } \\
\text { RA-18D } \\
\text { RA-17D } \\
\text { RA-16D } \\
\text { ECW-XHE-FO-ECWPP } \\
\text { E3-CFP-TC } \\
\text { ADS-XHE-INH2 } \\
\text { ADS-XHE-INH1 } \\
\text { SORV2 } \\
\text { E3-CL3-TC } \\
\text { LCI-XHE-TL }\end{array}$ & $\begin{array}{r}4.88 \mathrm{E}-8 \\
4.88 \mathrm{E}-8 \\
2.00 \mathrm{E}-8 \\
1.25 \mathrm{E}-8 \\
4.78 \mathrm{E}-9 \\
0.00 \mathrm{E}+0 \\
0.00 \mathrm{E}+0 \\
0.00 \mathrm{E}+0 \\
0.00 \mathrm{E}+0 \\
-4.17 \mathrm{E}-8 \\
-1.06 \mathrm{E}-7 \\
-3.54 \mathrm{E}-7 \\
-3.54 \mathrm{E}-7 \\
-3.75 \mathrm{E}-7 \\
-5.62 \mathrm{E}-7\end{array}$ \\
\hline Uncertainty & $\begin{array}{l}\text { DCP-BAT-LP-B2 } \\
\text { B-DCP-LP-BATS } \\
\text { RA-1J } \\
\text { RPS-M } \\
\text { LOSP } \\
\text { ACP-DGN-LP-EDG2 } \\
\text { SLC-XHE-FS } \\
\text { ACP-DGN-MA-EDG3 } \\
\text { B-ACP-LP-EDGS } \\
\text { ACP-DGN-MA-EDG2 } \\
\text { ACP-DGN-LP-EDG3 } \\
\text { RA-16J } \\
\text { RA-17J } \\
\text { HCI-TDP-FS-20S37 } \\
\text { HCI-TDP-MA-20S37 } \\
\text { DEP-XHE } \\
\text { ESW-PSF-LF-02 } \\
\text { ESW-PSF-LF-103 } \\
\text { ESW-PSF-LF-01 } \\
\text { ESW-PSF-LF-8 } \\
\text { ESW-PSF-LF-102 } \\
\text { SORV } \\
\text { CMSIVA } \\
\text { E3-CL3-TC } \\
\text { RCI-TDP-FS-20S38 } \\
\text { RA-18J } \\
\text { SLC-XHE-REL } \\
\text { ESF-XHE-MC-RXPRS } \\
\text { RA-1D } \\
\text { RCI-TDP-MA-20S38 }\end{array}$ & $\begin{array}{l}3.32 \mathrm{E}-6 \\
3.28 \mathrm{E}-6 \\
2.59 \mathrm{E}-6 \\
2.01 \mathrm{E}-6 \\
1.76 \mathrm{E}-6 \\
1.40 \mathrm{E}-6 \\
8.46 \mathrm{E}-7 \\
8.00 \mathrm{E}-7 \\
7.83 \mathrm{E}-7 \\
5.94 \mathrm{E}-7 \\
5.85 \mathrm{E}-7 \\
5.23 \mathrm{E}-7 \\
5.21 \mathrm{E}-7 \\
4.72 \mathrm{E}-7 \\
4.54 \mathrm{E}-7 \\
4.15 \mathrm{E}-7 \\
4.07 \mathrm{E}-7 \\
3.51 \mathrm{E}-7 \\
3.30 \mathrm{E}-7 \\
3.16 \mathrm{E}-7 \\
3.12 \mathrm{E}-7 \\
2.70 \mathrm{E}-7 \\
2.69 \mathrm{E}-7 \\
2.17 \mathrm{E}-7 \\
1.92 \mathrm{E}-7 \\
1.73 \mathrm{E}-7 \\
1.57 \mathrm{E}-7 \\
1.52 \mathrm{E}-7 \\
1.35 \mathrm{E}-7 \\
1.19 \mathrm{E}-7\end{array}$ \\
\hline
\end{tabular}


SEQUENCE PB - SENSITIVITY ISSUE 2 (CONTINUED)

IMPORTANCE MEASURE

Uncertainty

(Cont inued)

\section{EVENT}

ESF-XHE-FO-CRDRL

ADS-XHE-INHI

SRV-XHE-FO-VLV

COND-HPSW-XHE-TC

ESW-MDP-FS-ESWA

VENT-XHE-TC

ESW-MDP-FS-ESWB

ADS-VLV-FO-VALVE

EHV-PSF-LF-9

E3-CFP-TC

HCI - XHE - TL

EHV-PSF-LF-8

B-ADS-FO-VLVS

ADS - XHE - INH2

RA-14D

RA-2D

RCI-PSF-HW-COL 10

ESF-ASP-FC-PL52A

ESF-ASP-FC-PL52D

CRD-MDP-MA-2BP39

ESF-ASP-FC-PL52C

ESF-ASP-FC-PL52B

LCI-XHE-TL

PCSLOST

DGACTB

CRD-MDP-MA-2AP39

SORV2

DCP-BAT-LP-C3

CRD-MDP-FS-2BP39

RA-14J

ACP-DGN-MA-EDG4

ESW-XHE- FO-EHS

ACP-DGN-LP-EDG4

ESW-PSF-LF-19

HCI - TDP-FR-20S37

HCI - PSF-HW-SUP12

HCI - PSF-HW-INJOG

RCI - PSF-HW-INJ06

RCI - PSF-HW-SUPO 9

RCI - TDP-FR-20S38

RA-18D

\section{VALUE}

$1.04 E-7$

$5.77 E-8$

$5.62 \mathrm{E}-8$

$5.09 \mathrm{E}-8$

$4.75 E-8$

4. $74 E-8$

$4.22 E-8$

4.21E-8

$4.01 E-8$

$3.94 \mathrm{E}-8$

$3.67 \mathrm{E}-8$

$3.64 \mathrm{E}-8$

3. $43 \mathrm{E}-8$

$2.72 \mathrm{E}-8$

$1.84 \mathrm{E}-8$

$1.24 \mathrm{E}-8$

$4.74 \mathrm{E}-9$

4. $70 \mathrm{E}-9$

4. $58 \mathrm{E}-9$

4. $53 \mathrm{E}-9$

4. $52 E-9$

4.51E-9

3. $88 \mathrm{E}-9$

$3.27 E-9$

3. $11 \mathrm{E}-9$

$2.79 E-9$

$2.78 \mathrm{E}-9$

$2.45 \mathrm{E}-9$

$2.43 \mathrm{E}-9$

$1.83 \mathrm{E}-9$

$1.42 \mathrm{E}-9$

1. $02 \mathrm{E}-9$

8. $26 \mathrm{E}-10$

$8.09 \mathrm{E}-10$

7. $87 \mathrm{E}-10$

4. $30 \mathrm{E}-10$

4. $19 \mathrm{E}-10$

1. $36 \mathrm{E}-10$

1. $31 \mathrm{E}-10$

8. $63 \mathrm{E}-11$

$0.00 E+0$ 
SEQUENCE PB - SENSITIVITY ISSUE 2 (CONCLUDED)

\begin{tabular}{lll}
\hline $\begin{array}{c}\text { IMPORTANCE } \\
\text { MEASURE }\end{array}$ & \multicolumn{1}{c}{ EVENT } & VALUE \\
\hline & & \\
Uncertainty & RA-17D & $0.00 E+0$ \\
(Concluded) & RA-16D & $0.00 E+0$ \\
& ECW-XHE-FO-ECWPP & $0.00 \mathrm{E}+0$ \\
& IE-TLOSP & $4.75 \mathrm{E}-6$ \\
& IE-TRTRIP & $8.22 \mathrm{E}-7$ \\
& IE-TMSIVC & $4.16 \mathrm{E}-7$ \\
& IE-TLFW & $3.68 \mathrm{E}-7$ \\
& IE-SI & $2.20 \mathrm{E}-7$ \\
& IE-A & $5.76 \mathrm{E}-8$ \\
& IE-TIORV & $3.22 \mathrm{E}-8$ \\
& & \\
\hline
\end{tabular}


SEQUENCE PB - SENSITIVITY ISSUE 3

IMPORTANCE MEASURE

Risk Reduction

\section{EVENT}

\section{VALUE}

5. $32 \mathrm{E}-6$

4. $57 \mathrm{E}-6$

4. $49 \mathrm{E}-6$

$3.40 \mathrm{E}-6$

$3.18 \mathrm{E}-6$

1. $31 \mathrm{E}-6$

1. $23 \mathrm{E}-6$

$1.22 \mathrm{E}-6$

1. $15 \mathrm{E}-6$

8.13E-7

$7.36 \mathrm{E}-7$

$6.00 \mathrm{E}-7$

5. $23 \mathrm{E}-7$

$4.83 \mathrm{E}-7$

4. $83 \mathrm{E}-7$

4. $59 \mathrm{E}-7$

4. $59 \mathrm{E}-7$

4. $53 \mathrm{E}-7$

4. $51 \mathrm{E}-7$

4. $49 \mathrm{E}-7$

4. $36 \mathrm{E}-7$

4. $20 \mathrm{E}-7$

3. $36 \mathrm{E}-7$

3. $20 \mathrm{E}-7$

$3.03 \mathrm{E}-7$

2. $10 \mathrm{E}-7$

$1.77 \mathrm{E}-7$

1. $72 \mathrm{E}-7$

$1.69 \mathrm{E}-7$

1. $58 \mathrm{E}-7$

$8.01 \mathrm{E}-8$

$7.95 \mathrm{E}-8$

$7.56 \mathrm{E}-8$

$6.78 \mathrm{E}-8$

$5.90 \mathrm{E}-8$

5. $20 \mathrm{E}-8$

$5.15 \mathrm{E}-8$

$5.15 E-8$

$3.76 \mathrm{E}-8$

$3.76 \mathrm{E}-8$

$3.04 \mathrm{E}-8$

2. $97 \mathrm{E}-8$

2. $94 \mathrm{E}-8$

$2.70 E-8$

2. $70 \mathrm{E}-8$

2. $34 \mathrm{E}-8$

2. $34 \mathrm{E}-8$ 
SEQUENCE PB - SENSITIVITY ISSUE 3 (CONTINUED)

IMPORTANCE MEASURE

Risk Reduction

(Concluded)

\section{EVENT}

SRV-XHE-FO-VLV

RCI - PSF-HW-COL 10

HCI - PSF-HW-SUP12

HCI - PSF-HW-INJ09

HCI - XHE-TL

RA-17D

RA-18D

ESF-ASP-FC-PL52D

ESF-ASP-FC-PL52C

ESF-ASP-FC-PL52B

ESF-ASP-FC-PL52A

RCI - PSF-HW-INJ06

RCI - PSF-HW-SUP09

RCI - TDP - FR - 20S38

DCP-BAT-LP-C3

RA-14J

DGACTB

CRD-MDP-FS-2BP39

PCSLOST

CRD-MDP-MA-2BP39

CRD-MDP-MA-2AP39

LCI-XHE-TL

SORV2

ADS - XHE - INH2

ADS - XHE - INHI

E3-CFP-TC

E3-CL3-TC

IE-TLOSP

IE-TRTRIP

IE-TMSIVC

IE-TLFW

IE-S1

IE-TIORV

IE-A

RPS-M

ESW-PSF-LF- 8

DCP-BAT-LP-B2

ESF-XHE-MC-RXPRS

LOSP

RA-1J

ACP-DGN-LP-EDG2

B-DCP-LP-BATS

ESW-PSF-LF-02

ESW-PSF-LF-01

ESW-PSF-LF-103

ESW-PSF-LF- 102

ACP-DGN-LP-EDG3
VALUE

2. $34 \mathrm{E}-8$

$1.90 \mathrm{E}-8$

$1.50 \mathrm{E}-8$

$1.50 \mathrm{E}-8$

$1.40 E-8$

$1.22 \mathrm{E}-8$

$9.83 \mathrm{E}-9$

$6.34 \mathrm{E}-9$

$6.34 \mathrm{E}-9$

$6.34 \mathrm{E}-9$

$6.34 \mathrm{E}-9$

4. $90 \mathrm{E}-9$

4. $90 \mathrm{E}-9$

3. $27 \mathrm{E}-9$

3. $26 \mathrm{E}-9$

2. $98 \mathrm{E}-9$

2. $80 \mathrm{E}-9$

$1.47 \mathrm{E}-9$

1. $25 \mathrm{E}-9$

$1.21 \mathrm{E}-9$

$1.21 \mathrm{E}-9$

$-1.50 E-9$

$-3.57 E-9$

$-1.72 E-8$

$-3.67 E-8$

$-3.75 \mathrm{E}-7$

$-3.75 E-7$

8. $85 \mathrm{E}-6$

1. $28 \mathrm{E}-6$

$6.28 \mathrm{E}-7$

$5.49 \mathrm{E}-7$

8. $43 \mathrm{E}-8$

4. $57 \mathrm{E}-8$

$2.99 \mathrm{E}-8$

1.15E-1

$3.97 \mathrm{E}-3$

$3.43 \mathrm{E}-3$

$1.58 \mathrm{E}-3$

4. $90 E-4$

$1.28 \mathrm{E}-4$

$1.08 \mathrm{E}-4$

$1.08 \mathrm{E}-4$

8. $19 \mathrm{E}-5$

8.01E-5

$7.83 E-5$

$7.60 \mathrm{E}-5$

$7.15 \mathrm{E}-5$ 


\section{IMPORTANCE} MEASURE

Risk Increase

(Continued)
EVENT

VALUE

EHV-PSF-LF -8

EHV-PSF-LF-9

ACP-DGN-MA-EDG3

ACP-DGN-MA-EDG2

B-ACP-LP-EDGS

SLC - XHE-REL

SLC-XHE-FS

HCI - TDP-FS - 20S37

HCI - TDP-MA-20S37

SORV

ESW-MDP-FS-ESWB

ESW-MDP-FS-ESWA

RCI -TDP-FS - 20538

HCI $-X H E-T L$

RCI - TDP-MA-20S38

HCI - PSF-HW-SUP 12

HCI -PSF - HW-INJ09

HCI -TDP-FR-20S37

ESW-XHE-FO-EHS

ACP-DGN-LP-EDG4

ESW-PSF-LF-19

ACP-DGN-LP-EDG4

ESF-ASP-FC-PL52B

ESF-ASP-FC-PL52D

ESF-ASP-FC-PL52C

ESF-ASP-FC-PL52A

RC I -PSF - HW-COL 10

SRV-XHE-FO-VLV

DGACTB

DCP-BAT-LP-C3

DEP-XHE

RCI-PSF-HW-INJ06

RCI - PSF-HW-SUP09

RA-16J

ESF-XHE-FO-CRDRL

CMSIVA

RA-1D

COND-HPSW-XHE-TC

CRD-MDP-MA-2BP39

CRD-MDP-MA-2AP39

CRD-MDP-FS-2BP39

ADS-VLV-FO-VALVE

RA-17J

RA-18J

B-ADS-FO-VLVS

RCI - TDP-FR-20\$38

PCSLOST
$6.43 E-5$

$6.43 \mathrm{E}-5$

4. $38 \mathrm{E}-5$

4. $11 \mathrm{E}-5$

2. $12 \mathrm{E}-5$

$1.76 \mathrm{E}-5$

1.71E-5

$1.45 \mathrm{E}-5$

1. $29 \mathrm{E}-5$

9. $17 \mathrm{E}-6$

7. $05 \mathrm{E}-6$

$7.05 \mathrm{E}-6$

$5.95 E-6$

5. $26 \mathrm{E}-6$

$4.17 \mathrm{E}-6$

$3.99 \mathrm{E}-6$

$3.99 E-6$

2. $67 \mathrm{E}-6$

2. $67 \mathrm{E}-6$

2. $67 \mathrm{E}-6$

$2.67 \mathrm{E}-6$

2. $67 \mathrm{E}-6$

2. $53 \mathrm{E}-6$

2. $53 \mathrm{E}-6$

2. $53 \mathrm{E}-6$

2. $53 \mathrm{E}-6$

2. $52 \mathrm{E}-6$

2. $31 \mathrm{E}-6$

1. $74 \mathrm{E}-6$

$1.74 \mathrm{E}-6$

1. $70 \mathrm{E}-6$

1. $30 E-6$

1. $30 \mathrm{E}-6$

8.11E-7

$6.80 \mathrm{E}-7$

$5.23 \mathrm{E}-7$

4. $80 \mathrm{E}-7$

4. $68 \mathrm{E}-7$

4. $54 \mathrm{E}-7$

4. $54 \mathrm{E}-7$

4. $54 \mathrm{E}-7$

4. $44 \mathrm{E}-7$

4. $20 \mathrm{E}-7$

$3.36 \mathrm{E}-7$

$2.57 \mathrm{E}-7$

1. $27 \mathrm{E}-7$

1. $24 \mathrm{E}-7$ 
SEQUENCE PB - SENSITIVITY ISSUE 3 (CONTINUED)

\begin{tabular}{|c|c|c|}
\hline $\begin{array}{l}\text { IMPORTANCE } \\
\text { MEASURE }\end{array}$ & EVENT & VALUE \\
\hline $\begin{array}{l}\text { Risk Increase } \\
\text { (Concluded) }\end{array}$ & $\begin{array}{l}\text { RA-14J } \\
\text { VENT-XHE-TC } \\
\text { RA-14D } \\
\text { RA-2D } \\
\text { RA-18D } \\
\text { RA-17D } \\
\text { RA-16D } \\
\text { ECW-XHE-FO-ECWPP } \\
\text { E3-CFP-TC } \\
\text { ADS-XHE-INH2 } \\
\text { ADS-XHE-INH1 } \\
\text { SORV2 } \\
\text { E3-CL3-TC } \\
\text { LCI-XHE-TL }\end{array}$ & $\begin{array}{r}9.65 \mathrm{E}-8 \\
5.10 \mathrm{E}-8 \\
2.00 \mathrm{E}-8 \\
8.83 \mathrm{E}-9 \\
0.00 \mathrm{E}+0 \\
0.00 \mathrm{E}+0 \\
0.00 \mathrm{E}+0 \\
0.00 \mathrm{E}+0 \\
-4.17 \mathrm{E}-8 \\
-1.06 \mathrm{E}-7 \\
-3.54 \mathrm{E}-7 \\
-3.54 \mathrm{E}-7 \\
-3.75 \mathrm{E}-7 \\
-5.62 \mathrm{E}-7\end{array}$ \\
\hline Uncertainty & $\begin{array}{l}\text { ESW-PSF-LF-8 } \\
\text { RA-1J } \\
\text { DCP-BAT-LP-B2 } \\
\text { B-DCP-LP-BATS } \\
\text { LOSP } \\
\text { RPS-M } \\
\text { ACP-DGN-LP-EDG2 } \\
\text { SLC-XHE-FS } \\
\text { ACP-DGN-MA-EDG3 } \\
\text { ACP-DGN-MA-EDG2 } \\
\text { ACP-DGN-LP-EDG3 } \\
\text { HCI-TDP-FS-20S37 } \\
\text { HCI-TDP-MA-20S37 } \\
\text { RA-16J } \\
\text { DEP-XHE } \\
\text { ESW-PSF-LF-02 } \\
\text { SORV } \\
\text { ESW-PSF-LF-103 } \\
\text { ESW-PSF-LF-01 } \\
\text { B-ACP-LP-EDGS } \\
\text { ESW-PSF-LF-102 } \\
\text { CMSIVA } \\
\text { E3-CL3-TC } \\
\text { RA-17J } \\
\text { RCI-TDP-FS-20S38 } \\
\text { RA-1D } \\
\text { RA-18J } \\
\text { SLC-XHE-REL } \\
\text { ESF-XHE-MC-RXPRS } \\
\text { RCI-TDP-MA-20S38 } \\
\text { ESF-XHE-FO-CRDRL } \\
\text { ADS-XHE-INH1 } \\
\text { COND-HPSW-XHE-TC } \\
\text { ESW-MDP-FS-ESWA }\end{array}$ & $\begin{array}{l}8.44 \mathrm{E}-6 \\
4.61 \mathrm{E}-6 \\
3.32 \mathrm{E}-6 \\
3.28 \mathrm{E}-6 \\
2.31 \mathrm{E}-6 \\
2.01 \mathrm{E}-6 \\
9.23 \mathrm{E}-7 \\
8.46 \mathrm{E}-7 \\
8.00 \mathrm{E}-7 \\
5.94 \mathrm{E}-7 \\
5.85 \mathrm{E}-7 \\
5.84 \mathrm{E}-7 \\
5.65 \mathrm{E}-7 \\
5.23 \mathrm{E}-7 \\
4.15 \mathrm{E}-7 \\
4.07 \mathrm{E}-7 \\
3.55 \mathrm{E}-7 \\
3.51 \mathrm{E}-7 \\
3.30 \mathrm{E}-7 \\
3.26 \mathrm{E}-7 \\
3.12 \mathrm{E}-7 \\
2.69 \mathrm{E}-7 \\
2.17 \mathrm{E}-7 \\
2.17 \mathrm{E}-7 \\
2.12 \mathrm{E}-7 \\
1.87 \mathrm{E}-7 \\
1.73 \mathrm{E}-7 \\
1.57 \mathrm{E}-7 \\
1.52 \mathrm{E}-7 \\
1.29 \mathrm{E}-7 \\
7.34 \mathrm{E}-8 \\
5.77 \mathrm{E}-8 \\
5.09 \mathrm{E}-8 \\
4.75 \mathrm{E}-8\end{array}$ \\
\hline
\end{tabular}


IMPORTANCE MEASURE

Uncertainty

(Concluded)

\section{EVENT}

VENT - XHE - TC

ESW-MDP-FS-ESWB

EHV-PSF-LF-9

E3-CFP-TC

ACP-DGN-MA-EDG4

HCI - XHE-TL

EHV-PSF-LF-8

ADS - XHE - INH2

ESW-XHE-FO-EHS

SRV-XHE-FO-VLV

ACP-DGN-LP-EDG4

ESW-PSF-LF-19

HCI - TDP-FR-20S37

RA-14D

ADS-VLV-FO-VALVE

B-ADS-FO-VLVS

RCI - PSF-HW-COL 10

HCI - PSF-HW-SUP12

HC I - PSF - HW - INJ09

RA-2D

ESF-ASP-FC-PL52A

ESF-ASP-FC-PL52D

ESF-ASP-FC-PL52C

ESF-ASP-FC-PL52B

LCI - XHE-TL

RCI - PSF - HW - INJ06

RCI - PSF-HW-SUP09

CRD-MDP-MA-2BP39

DGACTB

SORV2

DCP-BAT-LP-C3

PCSLOST

RCI - TDP -FR-20S38

CRD-MDP-MA-2AP39

RA- 14J

CRD-MDP-FS-2BP39

RA-18D

RA-17D

RA-16D

ECW-XHE-FO-ECWPP

IE-TLOSP

IE-TRTRIP

IE-TMSIVC

IE-TLFW

IE-SI

IE-A

IE-TIORV
VALUE

4.74E-8

4. $22 \mathrm{E}-8$

4.01E-8

$3.94 \mathrm{E}-8$

$3.79 \mathrm{E}-8$

$3.67 \mathrm{E}-8$

3. $64 \mathrm{E}-8$

2. $72 \mathrm{E}-8$

2.71E-8

2. $34 \mathrm{E}-8$

2. $20 \mathrm{E}-8$

2. $16 \mathrm{E}-8$

2. $10 \mathrm{E}-8$

$1.84 \mathrm{E}-8$

1. $75 \mathrm{E}-8$

1. $70 \mathrm{E}-8$

1. $39 \mathrm{E}-8$

1. $15 \mathrm{E}-8$

1. $12 \mathrm{E}-8$

8. $80 E-9$

$4.70 E-9$

$4.58 \mathrm{E}-9$

4. $52 \mathrm{E}-9$

4. $51 \mathrm{E}-9$

$3.88 \mathrm{E}-9$

$3.62 \mathrm{E}-9$

$3.49 \mathrm{E}-9$

3. $20 \mathrm{E}-9$

$3.11 \mathrm{E}-9$

2. $78 \mathrm{E}-9$

$2.45 \mathrm{E}-9$

2. $32 \mathrm{E}-9$

2. $30 \mathrm{E}-9$

$1.98 \mathrm{E}-9$

1. $83 \mathrm{E}-9$

$1.72 \mathrm{E}-9$

$0.00 E+0$

$0.00 E+0$

$0.00 E+0$

$0.00 E+0$

6. $24 \mathrm{E}-6$

$9.66 \mathrm{E}-7$

4. $50 \mathrm{E}-7$

$3.98 \mathrm{E}-7$

2. $20 \mathrm{E}-7$

$5.76 \mathrm{E}-8$

$3.22 E-8$ 


\begin{tabular}{|c|c|c|}
\hline $\begin{array}{l}\text { IMPORTANCE } \\
\text { MEASURE }\end{array}$ & EVENT & VALUE \\
\hline Risk Reduction & $\begin{array}{l}\text { DCP-BAT-LP-B2 } \\
\text { B-DCP-LP-BATS } \\
\text { RA-1J } \\
\text { RPS-M } \\
\text { ECW-XHE-FO-ECWPP } \\
\text { LOSP } \\
\text { ACP-DGN-LP-EDG2 } \\
\text { SLC-XHE-FS } \\
\text { CMSIVA } \\
\text { DEP-XHE } \\
\text { VENT-XHE-TC } \\
\text { B-ACP-LP-EDGS } \\
\text { ESW-PSF-LF-103 } \\
\text { ESW-PSF-LF-102 } \\
\text { RA-17J } \\
\text { RA-16J } \\
\text { HCI-TDP-FS-20S37 } \\
\text { RA-18J } \\
\text { SORV } \\
\text { ACP-DGN-LP-EDG3 } \\
\text { SLC-XHE-REL } \\
\text { ESW-PSF-LF-02 } \\
\text { ESW-PSF-LF-01 } \\
\text { ACP-DGN-MA-EDG3 } \\
\text { ESF-XHE-MC-RXPRS } \\
\text { ACP-DGN-MA-EDG2 } \\
\text { RCI-TDP-FS-20S38 } \\
\text { HCI - TDP-MA-20S37 } \\
\text { RA-2D } \\
\text { ESF-XHE-FO-CRDRL } \\
\text { RA-1D } \\
\text { COND-HPSW-XHE-TC } \\
\text { ESW-MDP-FS-ESWA } \\
\text { ESW-MDP-FS-ESWB } \\
\text { RCI -TDP-MA-20S38 } \\
\text { B-ADS-FO-VLVS } \\
\text { ADS-VLV-F0-VALVE } \\
\text { SRV-XHE-F0-VLV } \\
\text { ACP-DGN-LP-EDG4 } \\
\text { ESW-PSF -LF-19 } \\
\text { RA-14D } \\
\text { HCI-XHE-TL } \\
\text { RA-17D } \\
\text { RA-16D } \\
\text { ACP-DGN-MA-EDG4 } \\
\text { RA-18D }\end{array}$ & $\begin{array}{l}4.51 \mathrm{E}-6 \\
4.49 \mathrm{E}-6 \\
1.35 \mathrm{E}-6 \\
1.15 \mathrm{E}-6 \\
9.44 \mathrm{E}-7 \\
7.63 \mathrm{E}-7 \\
6.29 \mathrm{E}-7 \\
6.00 \mathrm{E}-7 \\
5.23 \mathrm{E}-7 \\
4.59 \mathrm{E}-7 \\
4.59 \mathrm{E}-7 \\
4.26 \mathrm{E}-7 \\
4.23 \mathrm{E}-7 \\
4.09 \mathrm{E}-7 \\
3.95 \mathrm{E}-7 \\
3.87 \mathrm{E}-7 \\
3.64 \mathrm{E}-7 \\
2.93 \mathrm{E}-7 \\
2.81 \mathrm{E}-7 \\
2.04 \mathrm{E}-7 \\
1.77 \mathrm{E}-7 \\
1.70 \mathrm{E}-7 \\
1.69 \mathrm{E}-7 \\
1.58 \mathrm{E}-7 \\
1.58 \mathrm{E}-7 \\
1.57 \mathrm{E}-7 \\
1.25 \mathrm{E}-7 \\
1.04 \mathrm{E}-7 \\
7.95 \mathrm{E}-8 \\
7.56 \mathrm{E}-8 \\
7.02 \mathrm{E}-8 \\
5.20 \mathrm{E}-8 \\
3.88 \mathrm{E}-8 \\
3.88 \mathrm{E}-8 \\
2.50 \mathrm{E}-8 \\
2.34 \mathrm{E}-8 \\
2.34 \mathrm{E}-8 \\
2.34 \mathrm{E}-8 \\
2.04 \mathrm{E}-8 \\
1.94 \mathrm{E}-8 \\
1.54 \mathrm{E}-8 \\
1.40 \mathrm{E}-8 \\
1.22 \mathrm{E}-8 \\
1.14 \mathrm{E}-8 \\
1.05 \mathrm{E}-8 \\
1.00 \mathrm{E}-8\end{array}$ \\
\hline
\end{tabular}


SEQUENCE PB - SENSITIVITY ISSUE 4 (CONTINUED)

\section{IMPORTANCE} MEASURE

Risk Reduction

(Concluded)

Risk Increase

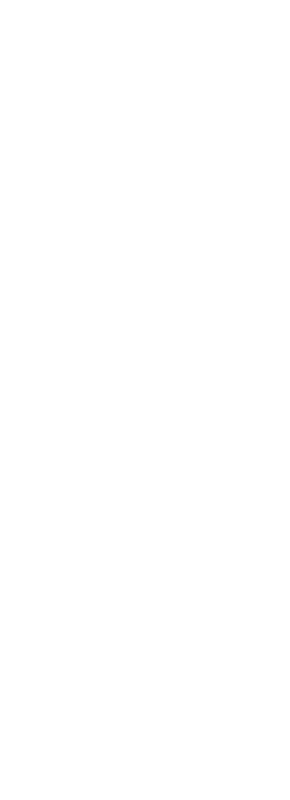

ESF-ASP-FC-PL52D

ESF-ASP-FC-PL52C

ESF-ASP-FC-PL52B

ESF-ASP-FC-PL52A

CRD-MDP-FS-2BP39

PCSLOST

CRD-MDP-MA-2BP39

CRD-MDP-MA-2AP39

RCI - PSF-HW-COL 10

DCP-BAT-LP-C3

DGACTB

LCI - XHE-TL

SORV2

ADS - XHE - INH2

ADS-XHE - INHI

E3-CFP-TC

E3-CL3-TC

IE-TLOSP

IE-TRTRIP

IE-TMSIVC

IE-TLFW

IE-S1

IE-TIORV

IE-A

RPS - M

DCP-BAT-LP-B2

ESF-XHE-MC-RXPRS

LOSP

B-DCP-LP-BATS

ESW-PSF-LF-02

ESW-PSF-LF-01

ESW-PSF-LF- 103

ESW-PSF-LF-102

ACP-DGN-LP-EDG2

RA- $1 \mathrm{~J}$

B-ACP-LP-EDGS

ACP-DGN-LP-EDG3

SLC-XHE-REL

SLC-XHE-FS

ACP-DGN-MA-EDG3

ACP-DGN-MA-EDG2

ESW-MDP-FS-ESWA

ESW-MDP-FS-ESWB

HCI - TDP-FS-20S37

HCI -TDP-MA-20S37

VALUE

$6.34 \mathrm{E}-9$

$6.34 \mathrm{E}-9$

$6.34 \mathrm{E}-9$

$6.34 \mathrm{E}-9$

$1.47 \mathrm{E}-9$

1. $25 \mathrm{E}-9$

$1.21 E-9$

1. $21 E-9$

$1.66 \mathrm{E}-10$

$1.08 \mathrm{E}-10$

9. $28 \mathrm{E}-11$

$-1.50 \mathrm{E}-9$

$-3.57 \mathrm{E}-9$

$-1.72 E-8$

$-3.67 E-8$

$-3.75 E-7$

$-3.75 E-7$

$5.17 \mathrm{E}-6$

$9.48 \mathrm{E}-7$

$5.16 \mathrm{E}-7$

4. $52 \mathrm{E}-7$

$8.43 \mathrm{E}-8$

4. $57 \mathrm{E}-8$

2. $99 \mathrm{E}-8$

1. $15 \mathrm{E}-1$

$3.38 \mathrm{E}-3$

$1.58 \mathrm{E}-3$

$2.86 \mathrm{E}-4$

$1.08 \mathrm{E}-4$

$8.06 \mathrm{E}-5$

$8.05 E-5$

$7.38 \mathrm{E}-5$

$7.14 \mathrm{E}-5$

5. $53 E-5$

3. $24 E-5$

2. $00 \mathrm{E}-5$

1. $80 \mathrm{E}-5$

$1.76 \mathrm{E}-5$

1.71E-5

$1.43 E-5$

$1.43 E-5$

$7.29 \mathrm{E}-6$

$7.29 \mathrm{E}-6$

7. $15 \mathrm{E}-6$

$6.42 \mathrm{E}-6$ 
SEQUENCE PB - SENSITIVITY ISSUE 4 (CONTINUED)

\begin{tabular}{|c|c|c|}
\hline $\begin{array}{l}\text { IMPORTANCE } \\
\text { MEASURE }\end{array}$ & EVENT & VALUE \\
\hline $\begin{array}{l}\text { Risk Increase } \\
\text { (Concluded) }\end{array}$ & $\begin{array}{l}\text { SORV } \\
\text { HCI -XHE-TL } \\
\text { ESF-ASP-FC-PL52D } \\
\text { ESF-ASP-FC-PL52A } \\
\text { ESF-ASP-FC-PL52B } \\
\text { ESF-ASP-FC-PL52C } \\
\text { RCI-TDP-FS-20S38 } \\
\text { SRV-XHE-FO-VLV } \\
\text { ACP-DGN-LP-EDG4 } \\
\text { ESW-PSF-LF-19 } \\
\text { DEP-XHE } \\
\text { RCI-TDP-MA-20S38 } \\
\text { ACP-DGN-MA-EDG4 } \\
\text { ESF-XHE-FO-CRDRL } \\
\text { CMSIVA } \\
\text { COND-HPSW-XHE-TC } \\
\text { CRD-MDP-MA-2BP39 } \\
\text { CRD-MDP-MA-2AP39 } \\
\text { CRD-MDP-FS-2BP39 } \\
\text { ADS-VLV-FO-VALVE } \\
\text { RA-17J } \\
\text { RA-18J } \\
\text { RA-16J } \\
\text { B-ADS-FO-VLVS } \\
\text { PCSLOST } \\
\text { RA-1D } \\
\text { DGACTB } \\
\text { DCP-BAT-LP-C3 } \\
\text { VENT-XHE-TC } \\
\text { RCI-PSF-HW-COL10 } \\
\text { RA-2D } \\
\text { RA-14D } \\
\text { RA-18D } \\
\text { ECW-XHE-F0-ECWPP } \\
\text { RA-17D } \\
\text { RA-16D } \\
\text { E3-CFP-TC } \\
\text { ADS-XHE-INH2 } \\
\text { ADS-XHE-INH1 } \\
\text { SORV2 } \\
\text { E3-CL3-TC } \\
\text { LCI-XHE-TL }\end{array}$ & $\begin{array}{l}5.35 \mathrm{E}-6 \\
5.26 \mathrm{E}-6 \\
2.53 \mathrm{E}-6 \\
2.53 \mathrm{E}-6 \\
2.53 \mathrm{E}-6 \\
2.53 \mathrm{E}-6 \\
2.45 \mathrm{E}-6 \\
2.31 \mathrm{E}-6 \\
1.79 \mathrm{E}-6 \\
1.75 \mathrm{E}-6 \\
1.70 \mathrm{E}-6 \\
1.54 \mathrm{E}-6 \\
9.48 \mathrm{E}-7 \\
6.80 \mathrm{E}-7 \\
5.23 \mathrm{E}-7 \\
4.68 \mathrm{E}-7 \\
4.54 \mathrm{E}-7 \\
4.54 \mathrm{E}-7 \\
4.54 \mathrm{E}-7 \\
4.44 \mathrm{E}-7 \\
3.95 \mathrm{E}-7 \\
2.93 \mathrm{E}-7 \\
2.58 \mathrm{E}-7 \\
2.57 \mathrm{E}-7 \\
1.24 \mathrm{E}-7 \\
1.05 \mathrm{E}-7 \\
5.75 \mathrm{E}-8 \\
5.75 \mathrm{E}-8 \\
5.10 \mathrm{E}-8 \\
2.19 \mathrm{E}-8 \\
8.83 \mathrm{E}-9 \\
3.84 \mathrm{E}-9 \\
0.00 \mathrm{E}+0 \\
0.00 \mathrm{E}+0 \\
0.00 \mathrm{E}+0 \\
0.00 \mathrm{E}+0 \\
-4.17 \mathrm{E}-8 \\
-1.06 \mathrm{E}-7 \\
-3.54 \mathrm{E}-7 \\
-3.54 \mathrm{E}-7 \\
-3.75 \mathrm{E}-7 \\
-5.62 \mathrm{E}-7\end{array}$ \\
\hline Uncertainty & $\begin{array}{l}\text { B-DCP-LP-BATS } \\
\text { DCP-BAT-LP-B2 } \\
\text { RPS-M } \\
\text { LOSP }\end{array}$ & $\begin{array}{l}3.28 E-6 \\
3.27 E-6 \\
2.01 E-6 \\
1.35 E-6\end{array}$ \\
\hline
\end{tabular}


SEQUENCE PB - SENSITIVITY ISSUE 4 (CONTINUED)

IMPORTANCE

MEASURE

Uncertainty

(Cont inued)
EVENT

VALUE

RA- $1 \mathrm{~J}$

SLC-XHE-FS

ACP-DGN-LP-EDG2

DEP-XHE

ESW-PSF-LF-02

ESW-PSF-LF-01

ESW-PSF-LF-103

$B-A C P-L P-E D G S$

ESW-PSF-LF-102

HCI - TOP - FS - 20 S 37

HC $i$-TDP-MA-20S37

CMSIVA

ACP-DGN-MA-EDG3

E3-CL3-TC

SORV

ACP-DGN-MA-EDG2

RA- 17J

RA- $16 \mathrm{~J}$

SLC-XHE-REL

ESF-XHE-MC-RXPRS

RA-18J

ACP-DGN-LP-EDG3

RC I - TDP-FS - 20 S38

ESF-XHE-FO-CRDRL

ADS - XHE - INH1

COND-HPSW-XHE-TC

ESW-MDP-FS-ESWA

RCI - TDP-MA-20S38

VENT-XHE-TC

ESW-MDP-FS-ESWS

RA-1D

E3-CFP-TC

HCI $-X H E-T L$

ADS-XHE-INH2

SRV-XHE-FO-VLV

ADS-VLV-FO-VALVE

B-ADS - FO-VLVS

ACP-DGN-LP-EDG4

ESW-PSF-LF-19

ACP-DGN-MA-EDG4

RA-2D

ESF-ASP-FC-PL52A

ESF-ASP-FC-PL52D

ESF-ASP-FC-PL52C

ESF-ASP-FC-PL52B

LCI - XHE-TL
1. $17 \mathrm{E}-6$

$8.46 \mathrm{E}-7$

4.71E-7

$4.15 \mathrm{E}-7$

4. $00 \mathrm{E}-7$

3. $31 \mathrm{E}-7$

3. $31 \mathrm{E}-7$

3. $08 \mathrm{E}-7$

2. $93 \mathrm{E}-7$

2. $89 \mathrm{E}-7$

2. $80 \mathrm{E}-7$

2. $69 \mathrm{E}-7$

2. $62 \mathrm{E}-7$

2. $17 \mathrm{E}-7$

2.07E-7

2.06E-7

2. $04 \mathrm{E}-7$

1. $66 \mathrm{E}-7$

1. $57 \mathrm{E}-7$

1. $52 \mathrm{E}-7$

1. $51 \mathrm{E}-7$

$1.47 \mathrm{E}-7$

8. $73 \mathrm{E}-8$

7. $34 \mathrm{E}-8$

$5.77 \mathrm{E}-8$

$5.09 E-8$

$4.91 E-8$

$4.76 E-8$

$4.74 E-8$

$4.36 \mathrm{E}-8$

4. $10 \mathrm{E}-8$

$3.94 E-8$

$3.67 \mathrm{E}-8$

2. $72 E-8$

2. $34 \mathrm{E}-8$

$1.75 \mathrm{E}-8$

1. $70 \mathrm{E}-8$

$1.48 \mathrm{E}-8$

1. $41 \mathrm{E}-8$

1. $35 \mathrm{E}-8$

8. $80 \mathrm{E}-9$

4. $70 \mathrm{E}-9$

4. $58 \mathrm{E}-9$

4. $52 \mathrm{E}-9$

4. $51 \mathrm{E}-9$

3. $88 \mathrm{E}-9$ 
SEQUENCE PB - SENSITIVITY ISSUE 4 (CONCLUDED)

\begin{tabular}{lll}
\hline $\begin{array}{c}\text { IMPORTANCE } \\
\text { MEASURE }\end{array}$ & \multicolumn{1}{c}{ EVENT } & VALUE \\
\hline & & \\
Uncertainty & RA-14D & $3.54 \mathrm{E}-9$ \\
(Concluded) & CRD-MDP-MA-2BP39 & $3.20 \mathrm{E}-9$ \\
& SORV2 & $2.78 \mathrm{E}-9$ \\
& PCSLOST & $2.32 \mathrm{E}-9$ \\
CRD-MDP-MA-2AP39 & $1.98 \mathrm{E}-9$ \\
& CRD-MDP-FS-2BP39 & $1.72 \mathrm{E}-9$ \\
& RCI-PSF-HW-COL10 & $1.22 \mathrm{E}-10$ \\
& DGACTB & $1.03 \mathrm{E}-10$ \\
& DCP-BAT-LP-C3 & $8.11 \mathrm{E}-11$ \\
& RA-18D & $0.00 \mathrm{E}+0$ \\
& ECW-XHE-FO-ECWPP & $0.00 \mathrm{E}+0$ \\
& RA-17D & $0.00 \mathrm{E}+0$ \\
& RA-16D & $0.00 \mathrm{E}+0$ \\
& IE-TLOSP & $3.65 \mathrm{E}-6$ \\
& IE-TRTRIP & $7.14 \mathrm{E}-7$ \\
& IE-TMSIVC & $3.70 \mathrm{E}-7$ \\
& IE-TLFW & $3.27 \mathrm{E}-7$ \\
& IE-S1 & $2.20 \mathrm{E}-7$ \\
& IE-A & $5.76 \mathrm{E}-8$ \\
& IE-TIORV & $3.22 \mathrm{E}-8$ \\
\hline
\end{tabular}




\section{IMPORTANCE} MEASURE

Risk Reduction

\section{EVENT}

VALUE

\author{
DCP-BAT-LP-B2 \\ B-DCP-LP-BATS \\ RPS $-M$ \\ SLC-XHE-FS \\ RA- IJ \\ VENT - XHE - TC \\ CMSIVA \\ $A C P-D G N-L P-E D G 2$ \\ RA-16J \\ LOSP \\ $A C P-D G N-L P-E D G 3$ \\ DEP-XHE \\ ACP-DGN-MA-EDG3 \\ HCI - TDP-FS - 20S37 \\ ECW-XHE-FO-ECWPP \\ ACP-DGN-MA-EDG2 \\ B-ACP-LP-EDGS \\ ESW-PSF-LF-103 \\ ESW-PSF-LF-102 \\ RA-17J \\ SORV
}

RA-18J

RCI - TDP -FS - 20 S38

COND-HPSW-XHE-TC

RA-1D

SLC-XHE-REL

ESW-PSF-LF-02

ESW-PSF-LF-01

ESF-XHE-MC-RXPRS

HCI - TDP - MA-20S37

ESW-PSF-LF-8

RA-14D

RA-2D

ESF-XHE-FO-CRDRL

RA-16D

EHV - PSF - LF - 9

EHV-PSF-LF-8

RCI - TDP-MA-20S38

HCI - XHE -TL

LCI - XHE - TL

ESW-MDP-FS-ESWB

ESW-MDP-FS-ESWA

B-ADS-FO-VLVS

ADS-VLV-FO-VALVE

SRV-XHE-FO-VLV

RA-17D

RA-18D
4.57E-6

$4.49 E-6$

$3.52 \mathrm{E}-6$

$2.89 E-6$

2. $40 \mathrm{E}-6$

$1.80 E-6$

$1.61 \mathrm{E}-6$

1. $23 E-6$

1. $22 \mathrm{E}-6$

$9.13 \mathrm{E}-7$

8.13E-7

7. $48 \mathrm{E}-7$

$4.83 E-7$

4. $81 \mathrm{E}-7$

4. $56 \mathrm{E}-7$

4. $53 \mathrm{E}-7$

4. $51 \mathrm{E}-7$

4. $49 \mathrm{E}-7$

4. $36 E-7$

4. $20 \mathrm{E}-7$

3. $37 \mathrm{E}-7$

$3.36 \mathrm{E}-7$

2. $12 \mathrm{E}-7$

2. $04 \mathrm{E}-7$

1. $87 \mathrm{E}-7$

$1.78 \mathrm{E}-7$

1. $72 \mathrm{E}-7$

$1.69 \mathrm{E}-7$

1. $58 \mathrm{E}-7$

1. $37 \mathrm{E}-7$

1. $19 \mathrm{E}-7$

8.01E-8

$7.95 \mathrm{E}-8$

$7.56 \mathrm{E}-8$

$5.90 \mathrm{E}-8$

$5.15 E-8$

$5.15 E-8$

$4.77 E-8$

$4.74 \mathrm{E}-8$

$4.66 \mathrm{E}-8$

$3.76 \mathrm{E}-8$

$3.76 \mathrm{E}-8$

2. $34 \mathrm{E}-8$

2. $34 \mathrm{E}-8$

2. $34 \mathrm{E}-8$

1. $22 \mathrm{E}-8$

$9.83 \mathrm{E}-9$ 
SEQUENCE PB - SENSITIVITY ISSUE 5 (CONTINUED)

IMPORTANCE MEASURE

Risk Reduction

(Concluded)
RCI - PSF-HW-COL10

ESF-ASP-FC-PL52D

ESF-ASP-FC-PL52C

ESF-ASP-FC-PL52B

ESF-ASP-FC-PL52A

DCP-BAT-LP-C3

RA-14J

DGACTB

CRD-MDP-FS-2BP39

PCSLOST

CRD-MDP-MA-2BP39

CRD-MDP-MA-2AP39

ACP-DGN-LP-EDG4

ESW-PSF-LF-19

ACP-DGN-MA-EDG4

HCI - TDP-FR-20S37

ESW-XHE-FO-EHS

HCI-PSF-HW-SUP12

HCI-PSF-HW-INJ09

RCI-PSF-HW-INJ06

RCI-PSF-HW-SUP09

RCI - TDP-FR-20S38

SORV2

ADS-XHE-INHI

ADS-XHE-INH2

E3-CL3-TC

E3-CFP-TC

IE-TLOSP

IE-TRTRIP

IE-TMSIVC

IE-TLFW

IE-TIORV

IE-SI

IE-A

RPS-M

ESW-PSF-LF-8

DCP-BAT-LP-B2

ESF-XHE-MC-RXPRS

LOSP

ACP-DGN-LP-EDG2

B-DCP-LP-BATS

ESW-PSF-LF-02

ESW-PSF-LF-01

ESW-PSF-LF-103

ESW-PSF-LF-102

ACP-DGN-LP-EDG 3
VALUE

$6.46 \mathrm{E}-9$

$6.34 E-9$

$6.34 \mathrm{E}-9$

$6.34 \mathrm{E}-9$

$6.34 E-9$

$3.26 \mathrm{E}-9$

2. $98 \mathrm{E}-9$

2. $80 \mathrm{E}-9$

$1.47 \mathrm{E}-9$

$1.25 \mathrm{E}-9$

$1.21 \mathrm{E}-9$

$1.21 \mathrm{E}-9$

1. $14 \mathrm{E}-9$

1. $11 \mathrm{E}-9$

1. $10 \mathrm{E}-9$

1.01E-9

$1.01 E-9$

5. $64 \mathrm{E}-10$

5. $64 \mathrm{E}-10$

1. $84 \mathrm{E}-10$

$1.84 \mathrm{E}-10$

$1.23 \mathrm{E}-10$

$-3.56 E-9$

$-1.41 \mathrm{E}-8$

$-7.40 \mathrm{E}-8$

$-1.47 \mathrm{E}-6$

$-1.47 \mathrm{E}-6$

$6.25 \mathrm{E}-6$

2. $03 \mathrm{E}-6$

$1.21 \mathrm{E}-6$

$1.06 \mathrm{E}-6$

$1.40 \mathrm{E}-7$

$8.43 \mathrm{E}-8$

2. $99 \mathrm{E}-8$

3. $52 \mathrm{E}-1$

3. $97 E-3$

$3.43 E-3$

$1.58 \mathrm{E}-3$

3. $42 \mathrm{E}-4$

$1.08 \mathrm{E}-4$

$1.08 \mathrm{E}-4$

8. 19E-5

8.01E-5

$7.83 \mathrm{E}-5$

$7.60 \mathrm{E}-5$

$7.15 \mathrm{E}-5$ 


\section{IMPORTANCE} MEASURE

Risk Increase (Continued)

\section{EVENT}

VALUE

\begin{tabular}{|c|c|}
\hline $\begin{array}{l}\text { EHV-PSF-LF-9 } \\
\text { EHV-PSF-LF-8 } \\
\text { RA-1J } \\
\text { ACP-DGN-MA-EDG3 } \\
\text { ACP-DGN-MA-EDG2 } \\
\text { B-ACP-LP-EDGS } \\
\text { SLC-XHE-REL } \\
\text { SLC-XHE-FS } \\
\text { HCI-TDP-FS-20S37 } \\
\text { HCI-TDP-MA-20S37 } \\
\text { ESW-MDP-FS-ESWA } \\
\text { ESW-MDP-FS-ESWB } \\
\text { SORV } \\
\text { HCI-XHE-TL } \\
\text { LCI-XHE-TL } \\
\text { RCI-TDP-FS-20S38 } \\
\text { RCI-TDP-MA-20S38 } \\
\text { DEP-XHE } \\
\text { ESF-ASP-FC-PL52D } \\
\text { ESF-ASP-FC-PL52A } \\
\text { ESF-ASP-FC-PL52C } \\
\text { ESF-ASP-FC-PL52B } \\
\text { SRV-XHE-FO-VLV } \\
\text { COND-HPSW-XHE-TC } \\
\text { DGACTB } \\
\text { DCP-BAT-LP-C3 } \\
\text { CMSIVA } \\
\text { RCI-PSF-HW-COL10 } \\
\text { RA-16J } \\
\text { ESF-XHE-FO-CRDRL } \\
\text { CRD-MDP-MA-2BP39 } \\
\text { CRD-MDP-MA-2AP39 } \\
\text { CRD-MDP-FS-2BP39 } \\
\text { ADS-VLV-FO-VALVE } \\
\text { RA-17J } \\
\text { RA-18J } \\
\text { RA-1D } \\
\text { B-ADS-F0-VLVS } \\
\text { VENT-XHE-TC } \\
\text { HCI-PSF-HW-SUP12 } \\
\text { HCI-PSF-HW-INJ09 } \\
\text { PCSLOST } \\
\text { HCI-TDP-FR-20S37 } \\
\text { ESW-XHE-FO-EHS } \\
\text { ACP-DGN-MA-EDG4 } \\
\text { ESW-PSF-LF-19 } \\
\text { ACP-DGN-LP-EDG4 }\end{array}$ & $\begin{array}{l}6.43 \mathrm{E}-5 \\
6.43 \mathrm{E}-5 \\
5.75 \mathrm{E}-5 \\
4.38 \mathrm{E}-5 \\
4.11 \mathrm{E}-5 \\
2.12 \mathrm{E}-5 \\
1.76 \mathrm{E}-5 \\
1.49 \mathrm{E}-5 \\
9.46 \mathrm{E}-6 \\
8.43 \mathrm{E}-6 \\
7.05 \mathrm{E}-6 \\
7.05 \mathrm{E}-6 \\
6.40 \mathrm{E}-6 \\
4.69 \mathrm{E}-6 \\
4.61 \mathrm{E}-6 \\
4.18 \mathrm{E}-6 \\
2.93 \mathrm{E}-6 \\
2.76 \mathrm{E}-6 \\
2.53 \mathrm{E}-6 \\
2.53 \mathrm{E}-6 \\
2.53 \mathrm{E}-6 \\
2.53 \mathrm{E}-6 \\
2.31 \mathrm{E}-6 \\
1.83 \mathrm{E}-6 \\
1.74 \mathrm{E}-6 \\
1.74 \mathrm{E}-6 \\
1.61 \mathrm{E}-6 \\
8.54 \mathrm{E}-7 \\
8.11 \mathrm{E}-7 \\
6.80 \mathrm{E}-7 \\
4.54 \mathrm{E}-7 \\
4.54 \mathrm{E}-7 \\
4.54 \mathrm{E}-7 \\
4.44 \mathrm{E}-7 \\
4.20 \mathrm{E}-7 \\
3.36 \mathrm{E}-7 \\
2.81 \mathrm{E}-7 \\
2.57 \mathrm{E}-7 \\
2.00 \mathrm{E}-7 \\
1.50 \mathrm{E}-7 \\
1.50 \mathrm{E}-7 \\
1.24 \mathrm{E}-7 \\
1.00 \mathrm{E}-7 \\
1.00 \mathrm{E}-7 \\
1.00 \mathrm{E}-7 \\
1.00 \mathrm{E}-7 \\
1.00 \mathrm{E}-7\end{array}$ \\
\hline
\end{tabular}

$6.43 E-5$

$6.43 \mathrm{E}-5$

$5.75 \mathrm{E}-5$

$4.11 E-5$

$2.12 E-5$

$1.76 \mathrm{E}-5$

$1.49 \mathrm{E}-5$

$9.46 \mathrm{E}-6$

$8.43 \mathrm{E}-6$

$7.05 \mathrm{E}-6$

$7.05 \mathrm{E}-6$

$6.40 \mathrm{E}-6$

4. $61 \mathrm{E}-6$

$4.18 \mathrm{E}-6$

$2.93 \mathrm{E}-6$

2. $76 \mathrm{E}-6$

$2.53 E-6$

2. $53 \mathrm{E}-6$

2. $53 \mathrm{E}-6$

2. $53 \mathrm{E}-6$

. $31 E-6$

$74 E-6$

$1.74 E-6$

1.61E-6

8. $54 \mathrm{E}-7$

8. $11 \mathrm{E}-7$

$6.80 \mathrm{E}-7$

$4.54 \mathrm{E}-7$

4. $54 \mathrm{E}-7$

4. $54 \mathrm{E}-7$

4. $44 \mathrm{E}-7$

4. $20 \mathrm{E}-7$

$3.36 \mathrm{E}-7$

.81E-7

2. OOE -7

1. $50 \mathrm{E}-7$

1. $50 \mathrm{E}-7$

1. $24 \mathrm{E}-7$

$1.00 \mathrm{E}-7$

1. $00 \mathrm{E}-7$

1. $00 \mathrm{E}-7$

$1.00 \mathrm{E}-7$ 
SEQUENCE PB - SENSITIVITY ISSUE 5 (CONTINUED)

\begin{tabular}{|c|c|c|}
\hline $\begin{array}{l}\text { IMPORTANCE } \\
\text { MEASURE }\end{array}$ & EVENT & VALUE \\
\hline $\begin{array}{l}\text { Risk Increase } \\
\text { (Concluded) }\end{array}$ & $\begin{array}{l}\text { RA-14J } \\
\text { RCI - PSF-HW-INJ06 } \\
\text { RCI - PSF-HW-SUP09 } \\
\text { RA-14D } \\
\text { RA-2D } \\
\text { RCI - TDP-FR-20S38 } \\
\text { RA-18D } \\
\text { RA-17D } \\
\text { RA-16D } \\
\text { ECW-XHE-FO-ECWPP } \\
\text { ADS-XHE-INH1 } \\
\text { E3-CFP-TC } \\
\text { SORV2 } \\
\text { ADS-XHE-INH2 } \\
\text { E3-CL3-TC }\end{array}$ & $\begin{array}{l}9.65 \mathrm{E}-8 \\
4.88 \mathrm{E}-8 \\
4.88 \mathrm{E}-8 \\
2.00 \mathrm{E}-8 \\
8.83 \mathrm{E}-9 \\
4.78 \mathrm{E}-9 \\
0.00 \mathrm{E}+0 \\
0.00 \mathrm{E}+0 \\
0.00 \mathrm{E}+0 \\
0.00 \mathrm{E}+0 \\
-1.36 \mathrm{E}-7 \\
-1.63 \mathrm{E}-7 \\
-3.52 \mathrm{E}-7 \\
-4.54 \mathrm{E}-7 \\
-1.47 \mathrm{E}-6\end{array}$ \\
\hline Uncertainty & $\begin{array}{l}\text { RPS-M } \\
\text { SLC-XHE-FS } \\
\text { DCP-BAT-LP-B2 } \\
\text { B-DCP-LP-BATS } \\
\text { RA-1J } \\
\text { LOSP } \\
\text { ACP-DGN-LP-EDG2 } \\
\text { E3-CL3-TC } \\
\text { CMSIVA } \\
\text { ACP-DGN-MA-EDG3 } \\
\text { DEP-XHE } \\
\text { ACP-DGN-MA-EDG2 } \\
\text { ACP-DGN-LP-EDG3 } \\
\text { RA-16J } \\
\text { ESW-PSF-LF-02 } \\
\text { HCI-TDP-FS-20S37 } \\
\text { HCI-TDP-MA-20S37 } \\
\text { ESW-PSF-LF-103 } \\
\text { ESW-PSF-LF-01 } \\
\text { B-ACP-LP-EDGS } \\
\text { ESW-PSF-LF-8 } \\
\text { ESW-PSF-LF-102 } \\
\text { SORV } \\
\text { RA-17J } \\
\text { COND-HPSW-XHE-TC } \\
\text { VENT-XHE-TC } \\
\text { RA-18J } \\
\text { SLC-XHE-REL } \\
\text { E3-CFP-TC } \\
\text { ESF-XHE-MC-RXPRS } \\
\text { RCI-TDP-FS-20S38 }\end{array}$ & $\begin{array}{l}6.19 \mathrm{E}-6 \\
4.16 \mathrm{E}-6 \\
3.32 \mathrm{E}-6 \\
3.28 \mathrm{E}-6 \\
2.08 \mathrm{E}-6 \\
1.61 \mathrm{E}-6 \\
9.23 \mathrm{E}-7 \\
8.53 \mathrm{E}-7 \\
8.28 \mathrm{E}-7 \\
8.00 \mathrm{E}-7 \\
6.77 \mathrm{E}-7 \\
5.94 \mathrm{E}-7 \\
5.85 \mathrm{E}-7 \\
5.23 \mathrm{E}-7 \\
4.07 \mathrm{E}-7 \\
3.82 \mathrm{E}-7 \\
3.68 \mathrm{E}-7 \\
3.51 \mathrm{E}-7 \\
3.30 \mathrm{E}-7 \\
3.26 \mathrm{E}-7 \\
3.16 \mathrm{E}-7 \\
3.12 \mathrm{E}-7 \\
2.48 \mathrm{E}-7 \\
2.17 \mathrm{E}-7 \\
2.00 \mathrm{E}-7 \\
1.86 \mathrm{E}-7 \\
1.73 \mathrm{E}-7 \\
1.58 \mathrm{E}-7 \\
1.54 \mathrm{E}-7 \\
1.52 \mathrm{E}-7 \\
1.49 \mathrm{E}-7\end{array}$ \\
\hline
\end{tabular}


SEQUENCE PB - SENSITIVITY ISSUE 5 (CONTINUED)

IMPORTANCE

MEASURE

Uncertainty

(Cont inued)
ADS-XHE - INH2

RA-1D

RCI - TDP - MA-20S38

ESF-XHE-FO-CRDRL

ESW-MDP-FS-ESWA

ESW-MDP-FS-ESWB

EHV-PSF-LF-9

EHV-PSF-LF-8

SRV-XHE-FO-VLV

ADS-XHE-INH1

RA- 14D

ADS - VLV-FO-VALVE

$B-A D S-F O-V L V S$

RA-2D

RC I - PSF-HW-COL 10

ESF-ASP-FC-PL52A

ESF-ASP-FC-PL52D

ESF-ASP-FC-PL52C

ESF-ASP-FC-PL52B

CRD-MDP-MA-2BP39

DGACTB

SORV2

DCP-BAT-LP-C3

PCSLOST

CRD-MDP-MA-2AP39

RA-14J

CRD-MDP-FS-2BP39

ACP-DGN-MA-EDG4

ESW-XHE-FO-EHS

ACP-DGN-LP-EDG4

ESW-PSF-LF-19

HCI - TDP-FR-20S37

HCI - PSF-HW-SUP 12

HCI - PSF-HW-INJO9

RCI - PSF-HW-INJ06

RCI -PSF - HW - SUPO 9

RCI - TDP-FR-20S38

RA-18D

RA-17D

RA-16D

LCI - XHE - TL

ECW-XHE-FO-ECWPP

HCI - XHE-TL

IE-TLOSP

IE-TRTRIP

IE-TMSIVC
VALUE

$1.17 \mathrm{E}-7$

1. $09 \mathrm{E}-7$

9.06E-8

7. $34 \mathrm{E}-8$

$4.75 \mathrm{E}-8$

4. $22 \mathrm{E}-8$

4.01E-8

3. $64 \mathrm{E}-8$

2. $34 \mathrm{E}-8$

2. $21 \mathrm{E}-8$

$1.84 \mathrm{E}-8$

$1.75 \mathrm{E}-8$

1. $70 \mathrm{E}-8$

8. $80 \mathrm{E}-9$

4. $74 \mathrm{E}-9$

4. $70 \mathrm{E}-9$

$4.58 \mathrm{E}-9$

4. $52 \mathrm{E}-9$

4. $51 \mathrm{E}-9$

3. $20 \mathrm{E}-9$

3. $11 \mathrm{E}-9$

2. $77 \mathrm{E}-9$

$2.45 \mathrm{E}-9$

2. $32 \mathrm{E}-9$

$1.98 \mathrm{E}-9$

$1.83 E-9$

1. $72 \mathrm{E}-9$

$1.42 \mathrm{E}-9$

$1.02 \mathrm{E}-9$

8. $26 \mathrm{E}-10$

8. $09 \mathrm{E}-10$

$7.87 \mathrm{E}-10$

$4.30 E-10$

4. $19 E-10$

$1.36 \mathrm{E}-10$

1. $31 \mathrm{E}-10$

8. $63 E-11$

$0.00 E+0$

$0.00 E+0$

$0.00 E+0$

$0.00 E+0$

$0.00 E+0$

$0.00 E+0$

4. $40 \mathrm{E}-6$

1. $53 \mathrm{E}-6$

8. $65 \mathrm{E}-7$ 
SEQUENCE PB - SENSITIVITY ISSUE 5 (CONCLUDED)

\begin{tabular}{lll}
\hline $\begin{array}{c}\text { IMPORTANCE } \\
\text { MEASURE }\end{array}$ & EVENT & VALUE \\
\hline & & \\
Uncertainty & IE-TLFW & $7.64 E-7$ \\
(Concluded) & IE-S1 & $2.20 E-7$ \\
& IE-TIORV & $9.89 E-8$ \\
& IE-A & $5.76 E-8$ \\
\hline
\end{tabular}


IMPORTANCE MEASURE

Risk Reduction

$$
\begin{aligned}
& \text { DCP-BAT-LP-B2 } \\
& \text { B-DCP-LP-BATS } \\
& \text { RPS-M } \\
& \text { SLC-XHE-FS } \\
& \text { VENT-XHE-TC } \\
& \text { CMSIVA }
\end{aligned}
$$

RA-1J

ECW-XHE-FO-ECWPP

LOSP

DEP-XHE

$A C P-D G N-L P-E D G 2$

B-ACP-LP-EDGS

ESW-PSF-LF-103

ESW-PSF-LF- 102

RA-17J

RA-16J

HCI -TDP-FS-20S37

RA-18J

SORV

ACP-DGN-LP-EDG3

COND-HPSW-XHE-TC

SLC-XHE-REL

ESW-PSF-LF-02

ESW-PSF-LF-01

ACP-DGN-MA-EDG3

ESF-XHE-MC-RXPRS

ACP-DGN-MA-EDG2

RCI -TDP-FS-20S38

HCI - TDP-MA-20S37

RA-2D

ESF-XHE-FO-CRDRL

RA-1D

HCI - XHE -TL

LCI - XHE-TL

ESW-MDP-FS-ESWA

ESW-MDP-FS-ESWB

RCI I TDP-MA-20S38

B-ADS-FO-VLVS

ADS-VLV-FO-VALVE

SRV-XHE-FO-VLV

ACP-DGN-LP-EDG4

ESW-PSF-LF-19

RA-14D

RA-17D

RA-16D

ACP-DGN-MA-EDG4

RA- 18D

\section{VALUE}

4. $51 \mathrm{E}-6$

$4.49 \mathrm{E}-6$

$3.52 \mathrm{E}-6$

2. $89 \mathrm{E}-6$

1. $80 \mathrm{E}-6$

$1.61 \mathrm{E}-6$

$1.35 E-6$

$9.44 \mathrm{E}-7$

$7.63 \mathrm{E}-7$

7. $48 \mathrm{E}-7$

$6.29 E-7$

4. $26 \mathrm{E}-7$

4. $23 E-7$

4.09E-7

$3.95 \mathrm{E}-7$

3. $87 \mathrm{E}-7$

3. $38 \mathrm{E}-7$

2. $93 \mathrm{E}-7$

2.81E-7

2. $04 \mathrm{E}-7$

2. $04 \mathrm{E}-7$

1. $78 \mathrm{E}-7$

1. $70 \mathrm{E}-7$

1. $69 \mathrm{E}-7$

1. $58 \mathrm{E}-7$

1. $58 \mathrm{E}-7$

1. $57 \mathrm{E}-7$

1. $25 \mathrm{E}-7$

9. $58 \mathrm{E}-8$

$7.95 \mathrm{E}-8$

7. $56 \mathrm{E}-8$

$7.02 \mathrm{E}-8$

$4.74 \mathrm{E}-8$

$4.66 \mathrm{E}-8$

$3.88 \mathrm{E}-8$

$3.88 \mathrm{E}-8$

2. $50 \mathrm{E}-8$

2. $34 \mathrm{E}-8$

2. $34 \mathrm{E}-8$

2. $34 \mathrm{E}-8$

$2.04 \mathrm{E}-8$

1. $94 \mathrm{E}-8$

1. $54 \mathrm{E}-8$

1. $22 \mathrm{E}-8$

1. $14 \mathrm{E}-8$

1. $05 \mathrm{E}-8$

1. $00 \mathrm{E}-8$ 
SEQUENCE PB - SENSITIVITY ISSUE 6 (CONTINUED)

IMPORTANCE MEASURE

Risk Reduction

(Concluded)

Risk Increase

EVENT

\section{VALUE}

$6.34 \mathrm{E}-9$

ESF-ASP-FC-PL52D

$6.34 \mathrm{E}-9$

ESF-ASP-FC-PL52C

ESF-ASP-FC-PL52B

$6.34 \mathrm{E}-9$

ESF-ASP-FC-PL52A

CRD-MDP-FS-2BP39

PCSLOST

CRD-MDP-MA-2BP39

CRD-MDP-MA-2AP39

RCI I PSF-HW-COL 10

DCP-BAT-LP-C3

DGACTB

SORV2

ADS - XHE - INH1

ADS-XHE-INH2

E3-CL3-TC

E3-CFP-TC

IE-TLOSP

IE-TRTRIP

IE-TMSIVC

IE-TLFW

IE-TIORV

IE-S1

IE-A

$6.34 \mathrm{E}-9$

$1.47 \mathrm{E}-9$

$1.25 \mathrm{E}-9$

$1.21 E-9$

$1.21 E-9$

1. $66 \mathrm{E}-10$

$1.08 \mathrm{E}-10$

9. $28 \mathrm{E}-11$

$-3.56 E-9$

$-1.41 \mathrm{E}-8$

$-7.40 \mathrm{E}-8$

$-1.47 \mathrm{E}-6$

$-1.47 \mathrm{E}-6$

$5.23 \mathrm{E}-6$

$1.94 \mathrm{E}-6$

$1.18 \mathrm{E}-6$

$1.03 \mathrm{E}-6$

$1.40 \mathrm{E}-7$

8. $43 \mathrm{E}-8$

$2.99 \mathrm{E}-8$

RPS-M

DCP-BAT-LP-B2

3. $52 \mathrm{E}-1$

$3.38 \mathrm{E}-3$

ESF-XHE-MC-RXPRS

LOSP

B-DCP-LP-BATS

ESW-PSF-LF-02

ESW-PSF-LF-01

ESW-PSF-LF-103

ESW-PSF-LF-102

ACP-DGN-LP-EDG2

RA-1J

B-ACP-LP-EDGS

ACP-DGN-LP-EDG3

SLC-XHE-REL

SLC-XHE-FS

ACP-DGN-MA-EDG3

ACP-DGN-MA-EDG2

ESW-MDP-FS-ESWA

ESW-MDP-FS-ESWB

HCI - TDP - FS - 20S37

HC I - TDP-MA-20S37

SORV

HC I - XHE - TL
$1.58 \mathrm{E}-3$

$2.86 E-4$

$1.08 \mathrm{E}-4$

$8.06 E-5$

$8.05 E-5$

7. $38 \mathrm{E}-5$

$7.14 E-5$

$5.53 E-5$

$3.24 E-5$

$2.00 E-5$

$1.80 \mathrm{E}-5$

$1.76 E-5$

$1.49 \mathrm{E}-5$

$1.43 \mathrm{E}-5$

$1.43 \mathrm{E}-5$

$7.29 E-6$

$7.29 \mathrm{E}-6$

$6.64 E-6$

$5.89 E-6$

$5.35 \mathrm{E}-6$

4. $69 \mathrm{E}-6$ 
SEQUENCE PB - SENSITIVITY ISSUE 6 (CONTINUED)

IMPORTANCE MEASURE

Risk Increase

(Concluded)
LCI-XHE-TL

DEP-XHE

ESF-ASP-FC-PL52C

ESF-ASP-FC-PL52D

ESF-ASP-FC-PL52B

ESF-ASP-FC-PL52A

RCI - TDP-FS - $20 S 38$

SRV-XHE-FO-VLV

COND-HPSW-XHE-TC

ACP-DGN-LP-EDG4

ESW-PSF-LF-19

CMSIVA

RCI - TDP-MA-20S38

ACP-DGN-MA-EDG4

ESF-XHE-FO-CRDRL

CRD-MDP-MA-2BP39

CRD-MDP-MA-2AP39

CRD-MDP-FS-2BP39

ADS-VLV-FO-VALVE

RA-17J

RA- $18 \mathrm{~J}$

RA-16J

B-ADS-F0-VLVS

VENT-XHE-TC

PCSLOST

RA-1D

DGACTB

DCP-BAT-LP-C3

RCI - PSF-HW-COL 10

RA-2D

RA-14D

RA-18D

ECW-XHE-FO-ECWPP

RA- 170

RA-16D

ADS-XHE-INH1

E3-CFP-TC

SORV2

ADS-XHE-INH2

E3-CL3-TC

RPS-M

SLC-XHE-FS

B-DCP-LP-BATS

DCP-BAT-LP-B2

LOSP

RA-1J

E3-CL3-TC
VALUE

4. $61 \mathrm{E}-6$

2. $76 \mathrm{E}-6$

$2.53 \mathrm{E}-6$

$2.53 \mathrm{E}-6$

2. $53 \mathrm{E}-6$

2. $53 \mathrm{E}-6$

2. $45 \mathrm{E}-6$

2. $31 \mathrm{E}-6$

$1.83 \mathrm{E}-6$

$1.79 \mathrm{E}-6$

$1.75 \mathrm{E}-6$

$1.61 \mathrm{E}-6$

1. $54 \mathrm{E}-6$

$9.48 \mathrm{E}-7$

$6.80 \mathrm{E}-7$

4. $54 \mathrm{E}-7$

4. $54 \mathrm{E}-7$

$4.54 \mathrm{E}-7$

4. $44 \mathrm{E}-7$

$3.95 \mathrm{E}-7$

2. $93 \mathrm{E}-7$

2. $58 \mathrm{E}-7$

2. $57 \mathrm{E}-7$

2. $00 \mathrm{E}-7$

1. $24 \mathrm{E}-7$

1. $05 \mathrm{E}-7$

$5.75 \mathrm{E}-8$

$5.75 E-8$

2. $19 E-8$

8. $83 \mathrm{E}-9$

$3.84 E-9$

$0.00 E+0$

$0.00 E+0$

$0.00 E+0$

$0.00 E+0$

$-1.36 \mathrm{E}-7$

$-1.63 \mathrm{E}-7$

$-3.52 E-7$

$-4.54 E-7$

$-1.47 E-6$

6. $19 E-6$

4. $16 \mathrm{E}-6$

$3.28 E-6$

$3.27 \mathrm{E}-6$

1. $35 \mathrm{E}-6$

1. $17 \mathrm{E}-6$

8. $53 \mathrm{E}-7$ 
SEQUENCE PB - SENSITIVITY ISSUE 6 (CONTINUED)

\begin{tabular}{|c|c|c|}
\hline $\begin{array}{l}\text { IMPORTANCE } \\
\text { MEASURE }\end{array}$ & EVENT & VALUE \\
\hline $\begin{array}{l}\text { Uncertainty } \\
\text { (Continued) }\end{array}$ & $\begin{array}{l}\text { CMSIVA } \\
\text { DEP-XHE } \\
\text { ACP-DGN-LP-EDG2 } \\
\text { ESW-PSF-LF-02 } \\
\text { ESW-PSF-LF-01 } \\
\text { ESW-PSF-LF-103 } \\
\text { B-ACP-LP-EDGS } \\
\text { ESW-PSF-LF-102 } \\
\text { HCI-TDP-FS-20S37 } \\
\text { ACP-DGN-MA-EDG3 } \\
\text { HCI -TDP-MA-20S37 } \\
\text { SORV } \\
\text { ACP-DGN-MA-EDG2 } \\
\text { RA-17J } \\
\text { COND-HPSW-XHE-TC } \\
\text { VENT-XHE-TC } \\
\text { RA-16J } \\
\text { SLC-XHE-REL } \\
\text { E3-CFP-TC } \\
\text { ESF-XHE-MC-RXPRS } \\
\text { RA-18J } \\
\text { ACP-DGN-LP-EDG3 } \\
\text { ADS-XHE-INH2 } \\
\text { RCI-TDP-FS-20S38 } \\
\text { ESF-XHE-FO-CRDRL } \\
\text { ESW-MDP-FS-ESWA } \\
\text { RCI-TDP-MA-20S38 } \\
\text { ESW-MDP-FS-ESWB } \\
\text { RA-1D } \\
\text { SRV-XHE-FO-VLV } \\
\text { ADS-XHE-INH1 } \\
\text { ADS-VLV-FO-VALVE } \\
\text { B-ADS-FO-VLVS } \\
\text { ACP-DGN-LP-EDG4 } \\
\text { ESW-PSF-LF-19 } \\
\text { ACP-DGN-MA-EDG4 } \\
\text { RA-2D } \\
\text { ESF-ASP-FC-PL52A } \\
\text { ESF-ASP-FC-PL52D } \\
\text { ESF-ASP-FC-PL52C } \\
\text { ESF-ASP-FC-PL52B } \\
\text { RA-14D } \\
\text { CRD-MDP-MA-2BP39 } \\
\text { SORV2 } \\
\text { PCSLOST } \\
\text { CRD-MDP-MA-2AP39 } \\
\text { CRD-MDP-FS-2BP39 }\end{array}$ & $\begin{array}{l}8.28 \mathrm{E}-7 \\
6.77 \mathrm{E}-7 \\
4.71 \mathrm{E}-7 \\
4.00 \mathrm{E}-7 \\
3.31 \mathrm{E}-7 \\
3.31 \mathrm{E}-7 \\
3.08 \mathrm{E}-7 \\
2.93 \mathrm{E}-7 \\
2.68 \mathrm{E}-7 \\
2.62 \mathrm{E}-7 \\
2.57 \mathrm{E}-7 \\
2.07 \mathrm{E}-7 \\
2.06 \mathrm{E}-7 \\
2.04 \mathrm{E}-7 \\
2.00 \mathrm{E}-7 \\
1.86 \mathrm{E}-7 \\
1.66 \mathrm{E}-7 \\
1.58 \mathrm{E}-7 \\
1.54 \mathrm{E}-7 \\
1.52 \mathrm{E}-7 \\
1.51 \mathrm{E}-7 \\
1.47 \mathrm{E}-7 \\
1.17 \mathrm{E}-7 \\
8.73 \mathrm{E}-8 \\
7.34 \mathrm{E}-8 \\
4.91 \mathrm{E}-8 \\
4.76 \mathrm{E}-8 \\
4.36 \mathrm{E}-8 \\
4.10 \mathrm{E}-8 \\
2.34 \mathrm{E}-8 \\
2.21 \mathrm{E}-8 \\
1.75 \mathrm{E}-8 \\
1.70 \mathrm{E}-8 \\
1.48 \mathrm{E}-8 \\
1.41 \mathrm{E}-8 \\
1.35 \mathrm{E}-8 \\
8.80 \mathrm{E}-9 \\
4.70 \mathrm{E}-9 \\
4.58 \mathrm{E}-9 \\
4.52 \mathrm{E}-9 \\
4.51 \mathrm{E}-9 \\
3.54 \mathrm{E}-9 \\
3.20 \mathrm{E}-9 \\
2.77 \mathrm{E}-9 \\
2.32 \mathrm{E}-9 \\
1.98 \mathrm{E}-9 \\
1.72 \mathrm{E}-9\end{array}$ \\
\hline
\end{tabular}


SEQUENCE PB - SENSITIVITY ISSUE 6 (CONCLUDED)

\section{IMPORTANCE}

MEASURE

\section{EVENT}

VALUE

Uncertainty

(Concluded)

DGACTB
RCI - PSF-HW-COL 10

DCP-BAT-LP-C3

RA-18D

ECW-XHE-F0-ECWPP

RA-17D

RA- 160

LCI - XHE-TL

HCI - XHE-TL

IE-TLOSP

IE-TRTRIP

IE-TMSIVC

IE-TLFW

IE-S1

IE-TIORV

IE-A
1. $22 \mathrm{E}-10$

$1.03 \mathrm{E}-10$

8. $11 \mathrm{E}-11$

$0.00 \mathrm{E}+0$

$0.00 E+0$

$0.00 \mathrm{E}+0$

$0.00 E+0$

$0.00 \mathrm{E}+0$

$0.00 \mathrm{E}+0$

$3.69 \mathrm{E}-6$

$1.46 \mathrm{E}-6$

8. $43 \mathrm{E}-7$

$7.45 \mathrm{E}-7$

2. $20 \mathrm{E}-7$

9. $89 \mathrm{E}-8$

$5.76 \mathrm{E}-8$ 


\begin{tabular}{clc}
\hline $\begin{array}{c}\text { IMPORTANCE } \\
\text { MEASURE }\end{array}$ & \multicolumn{1}{c}{ EVENT } & VALUE \\
\hline \multirow{3}{*}{ Risk Reduction } & B-DCP-LP-BATS & \\
& DCP-BAT-LP-B2 & $4.28 E-6$ \\
& LOSP & $4.28 \mathrm{E}-6$ \\
& IE-TLOSP & $5.52 \mathrm{E}-7$ \\
& IE-TRTRIP & $3.72 \mathrm{E}-6$ \\
& IE-TMSIVC & $3.40 \mathrm{E}-7$ \\
& IE-TLFW & $1.13 \mathrm{E}-7$ \\
& & $9.91 \mathrm{E}-8$ \\
& DCP-BAT-LP-B2 & $3.21 \mathrm{E}-3$ \\
Risk Increase & LOSP & $2.07 \mathrm{E}-4$ \\
& B-DCP-LP-BATS & $1.03 \mathrm{E}-4$ \\
& B-DCP-LP-BATS & $3.12 \mathrm{E}-6$ \\
& DCP-BAT-LP-B2 & $3.11 \mathrm{E}-6$ \\
& LOSP & $9.76 \mathrm{E}-7$ \\
& IE-TLOSP & $2.62 \mathrm{E}-6$ \\
& IE-TRTRIP & $2.56 \mathrm{E}-7$ \\
& IE-TMSIVC & $8.12 \mathrm{E}-8$ \\
& IE-TLFW & $7.17 \mathrm{E}-8$ \\
& & \\
\hline
\end{tabular}


SEQUENCE TB - BASE CASE

\section{IMPORTANCE}

MEASURE

Risk Reduction

RA-1J

RA-16J-

ACP-DGN-LP-EDG2

ACP-DGN-LP-EDG3

ECW-XHE-FO-ECWPP

ACP-DGN-MA-EDG3

ACP-DGN-MA-EDG2

ESW-PSF-LF-102

ESW-PSF-LF-103

B-ACP-LB-EDGS

RA-17J

RA-18J

LOSP

ESW-PSF - LF- 01

ESW-PSF-LF-02

ESW-PSF-LF-8

HCI - TDP-FS - 20S37

EHV-PSF-LF-8

EHV-PSF-LF-9

ESW-MDP-FS-ESWA

ESW-MDP-FS-ESWB

HCI - TDP - MA-20S37

DCP-BAT-LP-B2

RA-14J

ACP-DGN-LP-EDG4

ESW-PSF-LF-19

ACP-DGN-MA-EDG4

ESW-XHE-FO-EHS

HCI - TDP-FR-20S37

HCI -PSF-HW-SUP12

HCI - PSF-HW-INJ09

RCI - TDP-FR-20S38

IE-TLOSP

IE-TRTRIP

IE-TMSIVC

IE-TLFW

Risk Increase
ESW-PSF-LF-8

LOSP

ACP-DGN-LP-EDG2

ESW-PSF-LF-01

ESW-PSF-LF-02

ESW-PSF-LF-102

ESW-PSF-LF-103

ACP-DGN-LP-EDG3

EHV-PSF-LF-8

EHV-PSF-LF-9
VALUE

$2.28 \mathrm{E}-6$

$1.16 \mathrm{E}-6$

$1.11 \mathrm{E}-6$

$7.12 \mathrm{E}-7$

4. $26 \mathrm{E}-7$

$4.14 \mathrm{E}-7$

$4.12 \mathrm{E}-7$

4.03E-7

4.03E-7

4. $00 \mathrm{E}-7$

4. $00 \mathrm{E}-7$

3. $20 \mathrm{E}-7$

$2.95 \mathrm{E}-7$

$1.61 \mathrm{E}-7$

1. $61 \mathrm{E}-7$

$1.09 \mathrm{E}-7$

$9.68 \mathrm{E}-8$

$4.90 \mathrm{E}-8$

$4.90 \mathrm{E}-8$

$3.58 \mathrm{E}-8$

3. $58 \mathrm{E}-8$

2. $93 \mathrm{E}-8$

4.01E-9

4.01E-9

$1.09 E-9$

$1.06 \mathrm{E}-9$

1. $05 \mathrm{E}-9$

9. $64 \mathrm{E}-10$

9. $64 E-10$

3. $62 \mathrm{E}-10$

3. $62 \mathrm{E}-10$

1. $17 \mathrm{E}-10$

1. $99 \mathrm{E}-6$

$1.81 \mathrm{E}-7$

$6.04 \mathrm{E}-8$

$5.29 E-8$

$3.62 \mathrm{E}-3$

1. $10 \mathrm{E}-4$

9. $76 \mathrm{E}-5$

$7.63 E-5$

$7.63 \mathrm{E}-5$

$7.03 E-5$

$7.03 E-5$

$6.25 E-5$

$6.12 \mathrm{E}-5$

$6.12 \mathrm{E}-5$ 
SEQUENCE TB - BASE CASE (CONTINUED)

\begin{tabular}{|c|c|c|}
\hline $\begin{array}{l}\text { IMPORTANCE } \\
\text { MEASURE }\end{array}$ & EVENT & VALUE \\
\hline $\begin{array}{l}\text { Risk Increase } \\
\text { (Concluded) }\end{array}$ & $\begin{array}{l}\text { RA-1J } \\
\text { ACP-DGN-MA-EDG3 } \\
\text { ACP-DGN-MA-EDG2 } \\
\text { B-ACP-LP-EDGS } \\
\text { ESW-MDP-FS-ESWA } \\
\text { ESW-MDP-FS-ESWB } \\
\text { DCP-BAT-LP-B2 } \\
\text { HCI-TDP-FS-20S37 } \\
\text { HCI-TDP-MA-20S37 } \\
\text { RA-16J } \\
\text { RA-17J } \\
\text { RA-18J } \\
\text { RA-14J } \\
\text { HCI-PSF-HW-SUP12 } \\
\text { C]HCI-PSF-HW-INJ09 } \\
\text { ESW-XHE-FO-EHS } \\
\text { HCI-TDP-FR-20S37 } \\
\text { ACP-DGN-MA-EDG4 } \\
\text { ESW-PSF-LF-19 } \\
\text { ACP-DGN-LP-EDG4 } \\
\text { RCI-TDP-FR-20S38 } \\
\text { ECW-XHE-FO-ECWPP }\end{array}$ & $\begin{array}{l}5.48 \mathrm{E}-5 \\
3.75 \mathrm{E}-5 \\
3.73 \mathrm{E}-5 \\
1.88 \mathrm{E}-5 \\
6.72 \mathrm{E}-6 \\
6.72 \mathrm{E}-6 \\
2.13 \mathrm{E}-6 \\
1.90 \mathrm{E}-6 \\
1.80 \mathrm{E}-6 \\
7.73 \mathrm{E}-7 \\
4.00 \mathrm{E}-7 \\
3.20 \mathrm{E}-7 \\
1.30 \mathrm{E}-7 \\
9.61 \mathrm{E}-8 \\
9.61 \mathrm{E}-8 \\
9.55 \mathrm{E}-8 \\
9.55 \mathrm{E}-8 \\
9.54 \mathrm{E}-9 \\
9.54 \mathrm{E}-9 \\
9.54 \mathrm{E}-9 \\
4.55 \mathrm{E}-9 \\
0.00 \mathrm{E}+00\end{array}$ \\
\hline Uncertainty & $\begin{array}{l}\text { RA-1J } \\
\text { ACP-DGN-LP-EDG2 } \\
\text { ACP-DGN-MA-EDG3 } \\
\text { ACP-DGN-MA-EDG2 } \\
\text { LOSP } \\
\text { ACP-DGN-LP-EDG3 } \\
\text { RA-16J } \\
\text { ESW-PSF-LF-02 } \\
\text { ESW-PSF-LF-103 } \\
\text { ESW-PSF-LF-01 } \\
\text { B-ACP-LP-EDGS } \\
\text { ESW-PSF-LF-102 } \\
\text { ESW-PSF-LF-8 } \\
\text { RA-17J } \\
\text { RA-18J } \\
\text { HCI-TDP-MA-20S37 } \\
\text { HCI-TDP-FS-20S37 } \\
\text { ESW-MDP-FS-ESWA } \\
\text { ESW-MDP-FS-ESWB } \\
\text { EHV-PSF-LF-9 } \\
\text { EHV-PSF-LF-8 } \\
\text { DCP-BAT-LP-B2 } \\
\text { RA-14J } \\
\text { ACP-DGN-MA-EDG4 }\end{array}$ & $\begin{array}{l}1.98 \mathrm{E}-6 \\
8.30 \mathrm{E}-7 \\
6.85 \mathrm{E}-7 \\
5.39 \mathrm{E}-7 \\
5.21 \mathrm{E}-7 \\
5.12 \mathrm{E}-7 \\
4.98 \mathrm{E}-7 \\
3.79 \mathrm{E}-7 \\
3.15 \mathrm{E}-7 \\
3.14 \mathrm{E}-7 \\
2.89 \mathrm{E}-7 \\
2.89 \mathrm{E}-7 \\
2.88 \mathrm{E}-7 \\
2.06 \mathrm{E}-7 \\
1.65 \mathrm{E}-7 \\
7.87 \mathrm{E}-8 \\
7.69 \mathrm{E}-8 \\
4.53 \mathrm{E}-8 \\
4.02 \mathrm{E}-8 \\
3.82 \mathrm{E}-8 \\
3.47 \mathrm{E}-8 \\
2.91 \mathrm{E}-9 \\
2.46 \mathrm{E}-9 \\
1.35 \mathrm{E}-9\end{array}$ \\
\hline
\end{tabular}


SEQUENCE TB - BASE CASE (CONCLUDED)

IMPORTANCE MEASURE

Uncertainty

(Concluded)
ESW-XHE-FO-EHS

ACP-DGN-LP-EDG4

ESW-PSF-LF-19

HC I - TDP-FR-20S37

HCI - PSF-HW-SUP12

HCI - PSF - HW - INJ09

RCI -TDP-FR-20S38

ECW-XHE-FO-ECWPP

IE-TLOSP

IE-TRTRIP

IE-TMSIVC

IE-TLFW
VALUE

$9.70 \mathrm{E}-10$

$7.87 \mathrm{E}-10$

$7.70 \mathrm{E}-10$

7. $50 \mathrm{E}-10$

2. $76 \mathrm{E}-10$

2. $69 \mathrm{E}-10$

$8.22 \mathrm{E}-11$

$0.00 E+00$

$1.40 \mathrm{E}-6$

1. $37 \mathrm{E}-7$

4. $33 \mathrm{E}-8$

$3.83 \mathrm{E}-8$ 
SEQUENCE TB - SENSITIVITY ISSUE 1

IMPORTANCE MEASURE

Risk Reduction

Risk Increase
RA-1J

RA-16J

ACP-DGN-LP-EDG3

$A C P-D G N-L P-E D G 2$

ECW-XHE-FO-ECWPP

$A C P-D G N-M A-E D G 3$

$A C P-D G N-M A-E D G 2$

ESW-PSF-LF-103

ESW-PSF-LF-102

RA-18J

LOSP

ESW-PSF-LF-02

ESW-PSF-LF-01

ESW-PSF-LF-8

HCI -TDP-FS - 20S37

EHV-PSF-LF - 8

EHV-PSF-LF- 9

ESW-MDP-FS-ESWB

ESW-MDP-FS-ESWA

HCI - TDP-MA-20S37

RA-14J

DCP-BAT-LP-B2

ACP-DGN-LP-EDG4

ESW-PSF-LF-19

ACP-DGN-MA-EDG4

HCI - TDP-FR-20S37

ESW-XHE-FO-EHS

HCI-PSF-HW-SUP12

HCI - PSF-HW-INJ09

RC I - TDP-FR-20S38

IE-TLOSP

IE-TRTRIP

IE-TMS IVC

IE-TLFW

ESW-PSF-LF-8

LOSP

ESW-PSF-LF-02

ESW-PSF-LF-01

ESW-PSF-LF-102

ESW-PSF-LF-103

ACP-DGN-LP-EDG3

ACP-DGN-LP-EDG2

EHV-PSF-LF-8

EHV-PSF-LF-9

RA-1J
VALUE

$1.88 \mathrm{E}-6$

$1.16 \mathrm{E}-6$

7. $12 \mathrm{E}-7$

$7.10 \mathrm{E}-7$

4. $26 \mathrm{E}-7$

4. $14 \mathrm{E}-7$

4. $12 \mathrm{E}-7$

4. $03 \mathrm{E}-7$

4.03E-7

3. $20 \mathrm{E}-7$

2. $43 \mathrm{E}-7$

$1.61 \mathrm{E}-7$

1. $61 \mathrm{E}-7$

1. $09 \mathrm{E}-7$

$7.86 \mathrm{E}-8$

4. $90 \mathrm{E}-8$

$4.90 \mathrm{E}-8$

$3.58 \mathrm{E}-8$

3. $58 \mathrm{E}-8$

2. $33 \mathrm{E}-8$

4.01E-9

4.01E-9

$1.09 \mathrm{E}-9$

$1.06 \mathrm{E}-9$

$1.05 \mathrm{E}-9$

9. $64 \mathrm{E}-10$

9. $64 \mathrm{E}-10$

3. $62 \mathrm{E}-10$

3. $62 \mathrm{E}-10$

1. $17 \mathrm{E}-10$

$1.64 \mathrm{E}-6$

1. $50 \mathrm{E}-7$

4. $98 \mathrm{E}-8$

4. $36 \mathrm{E}-8$

$3.62 E-3$

9. $11 \mathrm{E}-5$

7. $63 \mathrm{E}-5$

7. $63 \mathrm{E}-5$

$7.03 \mathrm{E}-5$

$7.03 \mathrm{E}-5$

$6.25 \mathrm{E}-5$

$6.24 \mathrm{E}-5$

$6.12 E-5$

$6.12 \mathrm{E}-5$

4. 52E-5 
SEQUENCE TB - SENSITIVITY ISSUE 1 (CONTINUED)

\begin{tabular}{|c|c|c|}
\hline $\begin{array}{l}\text { IMPORTANCE } \\
\text { MEASURE }\end{array}$ & EVENT & VALUE \\
\hline $\begin{array}{l}\text { Risk Increase } \\
\text { (Concluded) }\end{array}$ & $\begin{array}{l}\text { ACP-DGN-MA-EDG3 } \\
\text { ACP-DGN-MA-EDG2 } \\
\text { ESW-MDP-FS-ESWB } \\
\text { ESW-MDP-FS-ESWA } \\
\text { DCP-BAT-LP-B2 } \\
\text { HCI-TDP-FS-20S37 } \\
\text { HCI-TDP-MA-20S37 } \\
\text { RA-16J } \\
\text { RA-18J } \\
\text { RA-14J } \\
\text { HCI-PSF-HW-SUP12 } \\
\text { HCI-PSF-HW-INJ09 } \\
\text { HCI-TDP-FR-20S37 } \\
\text { ESW-XHE-FO-EHS } \\
\text { ACP-DGN-MA-EDG4 } \\
\text { ESW-PSF-LF-19 } \\
\text { ACP-DGN-LP-EDG4 } \\
\text { RCI-TDP-FR-20S38 } \\
\text { ECW-XHE-FO-ECWPP }\end{array}$ & $\begin{array}{l}3.75 \mathrm{E}-5 \\
3.73 \mathrm{E}-5 \\
6.72 \mathrm{E}-6 \\
6.72 \mathrm{E}-6 \\
2.13 \mathrm{E}-6 \\
1.55 \mathrm{E}-6 \\
1.43 \mathrm{E}-6 \\
7.73 \mathrm{E}-7 \\
3.20 \mathrm{E}-7 \\
1.30 \mathrm{E}-7 \\
9.61 \mathrm{E}-8 \\
9.61 \mathrm{E}-8 \\
9.55 \mathrm{E}-8 \\
9.55 \mathrm{E}-8 \\
9.54 \mathrm{E}-8 \\
9.54 \mathrm{E}-8 \\
9.54 \mathrm{E}-8 \\
4.55 \mathrm{E}-9 \\
0.00 \mathrm{E}+0\end{array}$ \\
\hline Uncertainty & $\begin{array}{l}\text { RA-1J } \\
\text { ACP-DGN-MA-EDG3 } \\
\text { ACP-DGN-MA-EDG2 } \\
\text { ACP-DGN-LP-EDG2 } \\
\text { ACP-DGN-LP-EDG3 } \\
\text { RA-16J } \\
\text { LOSP } \\
\text { ESW-PSF-LF-02 } \\
\text { ESW-PSF-LF-103 } \\
\text { ESW-PSF-LF-01 } \\
\text { ESW-PSF-LF-102 } \\
\text { ESW-PSF-LF-8 } \\
\text { RA-18J } \\
\text { HCI-TDP-MA-20S37 } \\
\text { HCI-TDP-FS-20S37 } \\
\text { ESW-MDP-FS-ESWA } \\
\text { ESW-MDP-FS-ESWB } \\
\text { EHV-PSF-LF-9 } \\
\text { EHV-PSF-LF-8 } \\
\text { DCP-BAT-LP-B2 } \\
\text { RA-14J } \\
\text { ACP-DGN-MA-EDG4 } \\
\text { ESW-XHE-FO-EHS } \\
\text { ACP-DGN-LP-EDG4 } \\
\text { ESW-PSF-LF-19 } \\
\text { HCI-TDP-FR-20S37 }\end{array}$ & $\begin{array}{l}1.63 \mathrm{E}-6 \\
6.85 \mathrm{E}-7 \\
5.39 \mathrm{E}-7 \\
5.31 \mathrm{E}-7 \\
5.12 \mathrm{E}-7 \\
4.98 \mathrm{E}-7 \\
4.29 \mathrm{E}-7 \\
3.79 \mathrm{E}-7 \\
3.15 \mathrm{E}-7 \\
3.14 \mathrm{E}-7 \\
2.89 \mathrm{E}-7 \\
2.88 \mathrm{E}-7 \\
1.65 \mathrm{E}-7 \\
6.26 \mathrm{E}-8 \\
6.24 \mathrm{E}-8 \\
4.53 \mathrm{E}-8 \\
4.02 \mathrm{E}-8 \\
3.82 \mathrm{E}-8 \\
3.47 \mathrm{E}-8 \\
2.91 \mathrm{E}-9 \\
2.46 \mathrm{E}-9 \\
1.35 \mathrm{E}-9 \\
9.70 \mathrm{E}-10 \\
7.87 \mathrm{E}-10 \\
7.70 \mathrm{E}-10 \\
7.50 \mathrm{E}-10\end{array}$ \\
\hline
\end{tabular}


SEQUENCE TB - SENSITIVITY ISSUE 1 (CONCLUDED)

\begin{tabular}{clc}
\hline $\begin{array}{c}\text { IMPORTANCE } \\
\text { MEASURE }\end{array}$ & EVENT & VALUE \\
\hline & & \\
Uncertainty & HCI-PSF-HW-SUP12 & $2.76 \mathrm{E}-10$ \\
(Concluded) & HCI-PSF-HW-INJ09 & $2.69 \mathrm{E}-10$ \\
& RCI-TDP-FR-20S38 & $8.22 \mathrm{E}-11$ \\
& ECW-XHE-FO-ECWPP & $0.00 \mathrm{E}+0$ \\
& IE-TLOSP & $1.16 \mathrm{E}-6$ \\
& IE-TRTRIP & $1.13 \mathrm{E}-7$ \\
& IE-TMSIVC & $3.57 \mathrm{E}-8$ \\
& IE-TLFW & $3.16 \mathrm{E}-8$ \\
& & \\
\hline
\end{tabular}




\section{IMPORTANCE}

MEASURE

Risk Reduction

Risk Increase
EVENT

VALUE

\begin{tabular}{|c|c|}
\hline $\begin{array}{l}\text { RA-1J } \\
\text { ACP-DGN-LP-EDG2 } \\
\text { RA-16J } \\
\text { B-ACP-LP-EDGS } \\
\text { RA-17J } \\
\text { ACP-DGN-LP-EDG3 } \\
\text { ECW-XHE-FO-ECWPP } \\
\text { ACP-DGN-MA-EDG3 } \\
\text { ACP-DGN-MA-EDG2 } \\
\text { ESW-PSF-LF-102 } \\
\text { ESW-PSF-LF-103 } \\
\text { LOSP } \\
\text { RA-18J } \\
\text { ESW-PSF-LF-O1 } \\
\text { ESW-PSF-LF-02 } \\
\text { HCI -TDP-FS-20S37 } \\
\text { ESW-PSF-LF-8 } \\
\text { EHV-PSF-LF-8 } \\
\text { EHV-PSF-LF-9 } \\
\text { HCI -TDP-MA-20S37 } \\
\text { ESW-MDP-FS-ESWA } \\
\text { ESW-MDP-FS-ESWB } \\
\text { DCP-BAT-LP-B2 } \\
\text { RA-14J } \\
\text { ACP-DGN-LP-EDG4 } \\
\text { ESW-PSF-LF-19 } \\
\text { ACP-DGN-MA-EDG4 } \\
\text { ESW-XHE-F0-EHS } \\
\text { HCI-TDP-FR-20S37 } \\
\text { HCI -PSF-HW-SUP12 } \\
\text { HCI-PSF-HW-INJ09 } \\
\text { RCI-TDP-FR-20S38 } \\
\text { IE-TLOSP } \\
\text { IE-TRTRIP } \\
\text { IE-TMSIVC } \\
\text { IE-TLFW }\end{array}$ & $\begin{array}{l}2.84 \mathrm{E}-6 \\
1.67 \mathrm{E}-6 \\
1.16 \mathrm{E}-6 \\
9.62 \mathrm{E}-7 \\
9.62 \mathrm{E}-7 \\
7.12 \mathrm{E}-7 \\
4.26 \mathrm{E}-7 \\
4.14 \mathrm{E}-7 \\
4.12 \mathrm{E}-7 \\
4.03 \mathrm{E}-7 \\
4.03 \mathrm{E}-7 \\
3.67 \mathrm{E}-7 \\
3.20 \mathrm{E}-7 \\
1.61 \mathrm{E}-7 \\
1.61 \mathrm{E}-7 \\
1.22 \mathrm{E}-7 \\
1.09 \mathrm{E}-7 \\
4.90 \mathrm{E}-8 \\
4.90 \mathrm{E}-8 \\
3.78 \mathrm{E}-8 \\
3.58 \mathrm{E}-8 \\
3.58 \mathrm{E}-8 \\
4.01 \mathrm{E}-9 \\
4.01 \mathrm{E}-9 \\
1.09 \mathrm{E}-9 \\
1.06 \mathrm{E}-9 \\
1.05 \mathrm{E}-9 \\
9.64 \mathrm{E}-10 \\
9.64 \mathrm{E}-10 \\
3.62 \mathrm{E}-10 \\
3.62 \mathrm{E}-10 \\
1.17 \mathrm{E}-10 \\
2.48 \mathrm{E}-6 \\
2.26 \mathrm{E}-7 \\
7.53 \mathrm{E}-8 \\
6.59 \mathrm{E}-8\end{array}$ \\
\hline $\begin{array}{l}\text { ESW-PSF-LF-8 } \\
\text { ACP-DGN-LP-EDG2 } \\
\text { LOSP } \\
\text { ESW-PSF-LF-01 } \\
\text { ESW-PSF-LF-02 } \\
\text { ESW-PSF-LF-102 } \\
\text { ESW-PSF-LF- } 103 \\
\text { RA-1J } \\
\text { ACP-DGN-LP-EDG3 } \\
\text { EHV-PSF-LF-8 }\end{array}$ & $\begin{array}{l}3.62 E-3 \\
1.47 E-4 \\
1.38 E-4 \\
7.63 E-5 \\
7.63 E-5 \\
7.03 E-5 \\
7.03 E-5 \\
6.83 E-5 \\
6.25 E-5 \\
6.12 E-5\end{array}$ \\
\hline
\end{tabular}


SEQUENCE TB - SENSITIVITY ISSUE 2 (CONTINUED)

\begin{tabular}{|c|c|c|}
\hline $\begin{array}{l}\text { IMPORTANCE } \\
\text { MEASURE }\end{array}$ & EVENT & VALUE \\
\hline $\begin{array}{l}\text { Risk Increase } \\
\text { (Concluded) }\end{array}$ & $\begin{array}{l}\text { EHV-PSF-LF-9 } \\
\text { ACP-DGN-MA-EDG3 } \\
\text { ACP-DGN-MA-EDG2 } \\
\text { B-ACP-LP-EDGS } \\
\text { ESW-MDP-FS-ESWA } \\
\text { ESW-MDP-FS-ESWB } \\
\text { HCI -TDP-FS-20S37 } \\
\text { HCI-TDP-MA-20S37 } \\
\text { DCP-BAT-LP-B2 } \\
\text { RA-I7J } \\
\text { RA-16J } \\
\text { RA-18J } \\
\text { RA-14J } \\
\text { HCI-PSF-HW-SUP12 } \\
\text { HCI-PSF-HW-INJ09 } \\
\text { ESW-XHE-FO-EHS } \\
\text { HCI-TDP-FR-20S37 } \\
\text { ACP-DGN-MA-EDG4 } \\
\text { ESW-PSF-LF-19 } \\
\text { ACP-DGN-LP-EDG4 } \\
\text { RCI-TDP-FR-20S38 } \\
\text { ECW-XHE-FO-ECWPP }\end{array}$ & $\begin{array}{l}6.12 \mathrm{E}-5 \\
3.75 \mathrm{E}-5 \\
3.73 \mathrm{E}-5 \\
1.83 \mathrm{E}-5 \\
6.72 \mathrm{E}-6 \\
6.72 \mathrm{E}-6 \\
2.41 \mathrm{E}-6 \\
2.32 \mathrm{E}-6 \\
2.13 \mathrm{E}-6 \\
9.62 \mathrm{E}-7 \\
7.73 \mathrm{E}-7 \\
3.20 \mathrm{E}-7 \\
1.30 \mathrm{E}-7 \\
9.61 \mathrm{E}-8 \\
9.61 \mathrm{E}-8 \\
9.55 \mathrm{E}-8 \\
9.55 \mathrm{E}-8 \\
9.54 \mathrm{E}-8 \\
9.54 \mathrm{E}-8 \\
9.54 \mathrm{E}-8 \\
4.55 \mathrm{E}-9 \\
0.00 \mathrm{E}+00\end{array}$ \\
\hline Uncertainty & $\begin{array}{l}\text { RA-1J } \\
\text { ACP-DGN-LP-EDG2 } \\
\text { B-ACP-LP-EDGS } \\
\text { ACP-DGN-MA-EDG3 } \\
\text { LOSP } \\
\text { ACP-DGN-MA-EDG2 } \\
\text { ACP-DGN-LP-EDG3 } \\
\text { RA-16J } \\
\text { RA-17J } \\
\text { ESW-PSF-LF-02 } \\
\text { ESW-PSF-LF-103 } \\
\text { ESW-PSF-LF-01 } \\
\text { ESW-PSF-LF-102 } \\
\text { ESW-PSF-LF-8 } \\
\text { RA-18J } \\
\text { HCI-TDP-MA-20S37 } \\
\text { HCI-TDP-FS-20S37 } \\
\text { ESW-MDP-FS-ESWA } \\
\text { ESW-MDP-FS-ESWB } \\
\text { EHV-PSF-LF-9 } \\
\text { EHV-PSF-LF-8 } \\
\text { DCP-BAT-LP-B2 } \\
\text { RA-14J } \\
\text { ACP-DGN-MA-EDG4 }\end{array}$ & $\begin{array}{l}2.47 E-6 \\
1.25 E-6 \\
6.95 E-7 \\
6.85 E-7 \\
6.49 E-7 \\
5.39 E-7 \\
5.12 E-7 \\
4.98 E-7 \\
4.96 E-7 \\
3.79 E-7 \\
3.15 E-7 \\
3.14 E-7 \\
2.89 E-7 \\
2.88 E-7 \\
1.65 E-7 \\
1.01 E-7 \\
9.71 E-8 \\
4.53 E-8 \\
4.02 E-8 \\
3.82 E-8 \\
3.47 E-8 \\
2.91 E-9 \\
2.46 E-9 \\
1.35 E-9\end{array}$ \\
\hline
\end{tabular}


SEQUENCE TB - SENSITIVITY ISSUE 2 (CONCLUDED)

\begin{tabular}{|c|c|c|}
\hline $\begin{array}{l}\text { IMPORTANCE } \\
\text { MEASURE }\end{array}$ & EVENT & value \\
\hline $\begin{array}{l}\text { Uncertainty } \\
\text { (Concluded) }\end{array}$ & $\begin{array}{l}\text { ESW-XHE-FO-EHS } \\
\text { ACP-DGN-LP-EDG4 } \\
\text { ESW-PSF-LF-19 } \\
\text { HCI-TDP-FR-20S37 } \\
\text { HCI-PSF-HW-SUP12 } \\
\text { HCI-PSF-HW-INJ09 } \\
\text { RCI-TDP-FR-20S38 } \\
\text { ECW-XHE-FO-ECWPP } \\
\text { IE-TLOSP } \\
\text { IE-TRTRIP } \\
\text { IE-TMSIVC } \\
\text { IE-TLFW }\end{array}$ & $\begin{array}{l}9.70 \mathrm{E}-10 \\
7.87 \mathrm{E}-10 \\
7.70 \mathrm{E}-10 \\
7.50 \mathrm{E}-10 \\
2.76 \mathrm{E}-10 \\
2.69 \mathrm{E}-10 \\
8.22 \mathrm{E}-11 \\
0.00 \mathrm{E}+00 \\
1.75 \mathrm{E}-6 \\
1.70 \mathrm{E}-7 \\
5.40 \mathrm{E}-8 \\
4.77 \mathrm{E}-8\end{array}$ \\
\hline
\end{tabular}




\begin{tabular}{|c|c|c|}
\hline $\begin{array}{l}\text { IMPORTANCE } \\
\text { MEASURE }\end{array}$ & EVENT & VALUE \\
\hline Risk Reduction & $\begin{array}{l}\text { RA-1J } \\
\text { ECW-XHE-FO-ECWPP } \\
\text { ESW-PSF-LF-8 } \\
\text { RA-16J } \\
\text { ACP-DGN-LP-EDG2 } \\
\text { ACP-DGN-LP-EDG3 } \\
\text { LOSP } \\
\text { ACP-DGN-MA-EDG3 } \\
\text { ACP-DGN-MA-EDG2 } \\
\text { ESW-PSF-LF-102 } \\
\text { ESW-PSF-LF-103 } \\
\text { B-ACP-LP-EDGS } \\
\text { RA-17J } \\
\text { RA-18J } \\
\text { HCI-TDP-FS-20S37 } \\
\text { ESW-PSF-LF-01 } \\
\text { ESW-PSF-LF-02 } \\
\text { HCI-TDP-MA-20S37 } \\
\text { EHV-PSF-LF-8 } \\
\text { EHV-PSF-LF-9 } \\
\text { ESW-MDP-FS-ESWA } \\
\text { ESW-MDP-FS-ESWB } \\
\text { ACP-DGN-LP-EDG4 } \\
\text { ESW-PSF-LF-19 } \\
\text { ACP-DGN-MA-EDG4 } \\
\text { ESW-XHE-FO-EHS } \\
\text { HCI-TDP-FR-20S37 } \\
\text { HCI-PSF-HW-SUP12 } \\
\text { HCI-PSF-HW-INJ09 } \\
\text { DCP-BAT-LP-B2 } \\
\text { RA-14J } \\
\text { RCI-TDP-FR-20S38 } \\
\text { IE-TLOSP } \\
\text { IE-TRTRIP } \\
\text { IE-TMSIVC } \\
\text { IE-TLFW }\end{array}$ & $\begin{array}{l}5.07 \mathrm{E}-6 \\
3.11 \mathrm{E}-6 \\
2.90 \mathrm{E}-6 \\
1.16 \mathrm{E}-6 \\
1.11 \mathrm{E}-6 \\
7.12 \mathrm{E}-7 \\
6.55 \mathrm{E}-7 \\
4.14 \mathrm{E}-7 \\
4.12 \mathrm{E}-7 \\
4.03 \mathrm{E}-7 \\
4.03 \mathrm{E}-7 \\
4.00 \mathrm{E}-7 \\
4.00 \mathrm{E}-7 \\
3.20 \mathrm{E}-7 \\
2.20 \mathrm{E}-7 \\
1.61 \mathrm{E}-7 \\
1.61 \mathrm{E}-7 \\
6.89 \mathrm{E}-8 \\
4.90 \mathrm{E}-8 \\
4.90 \mathrm{E}-8 \\
3.58 \mathrm{E}-8 \\
3.58 \mathrm{E}-8 \\
2.89 \mathrm{E}-8 \\
2.83 \mathrm{E}-8 \\
2.80 \mathrm{E}-8 \\
2.57 \mathrm{E}-8 \\
2.57 \mathrm{E}-8 \\
9.64 \mathrm{E}-9 \\
9.64 \mathrm{E}-9 \\
4.01 \mathrm{E}-9 \\
4.01 \mathrm{E}-9 \\
3.11 \mathrm{E}-9 \\
4.42 \mathrm{E}-6 \\
4.03 \mathrm{E}-7 \\
1.34 \mathrm{E}-7 \\
1.17 \mathrm{E}-7\end{array}$ \\
\hline Risk Increase & $\begin{array}{l}\text { ESW-PSF-LF-8 } \\
\text { LOSP } \\
\text { RA-1J } \\
\text { ACP-DGN-LP-EDG2 } \\
\text { ESW-PSF-LF-01 } \\
\text { ESW-PSF-LF-02 } \\
\text { ESW-PSF-LF-102 } \\
\text { ESW-PSF-LF-103 } \\
\text { ACP-DGN-LP-EDG3 }\end{array}$ & $\begin{array}{l}3.62 \mathrm{E}-3 \\
2.45 \mathrm{E}-4 \\
1.22 \mathrm{E}-4 \\
9.76 \mathrm{E}-5 \\
7.63 \mathrm{E}-5 \\
7.63 \mathrm{E}-5 \\
7.03 \mathrm{E}-5 \\
7.03 \mathrm{E}-5 \\
6.25 \mathrm{E}-5\end{array}$ \\
\hline
\end{tabular}


SEQUENCE TB - SENSITIVITY ISSUE 3 (CONTINUED)

\section{IMPORTANCE} MEASURE

VALUE

Risk Increase

(Concluded)

Uncertainty
EHV - PSF-LF-8

EHV-PSF-LF-9

ACP-DGN-MA-EDG3

$A C P-D G N-M A-E D G 2$

$B-A C P-L P-E D G S$

ESW-MDP-FS-ESWA

ESW-MDP-FS-ESWB

HCI - TDP-FS - 20S37

HCI -TDP-MA-20S37

HCI -PSF-HW-SUP 12

HCI - PSF-HW-INJ09

ESW-XHE-FO-EHS

HCI I TDP-FR-20S37

ACP-DGN-MA-EDG4

ESW-PSF-LF- 19

ACP-DGN-LP-EDG4

DCP-BAT-LP-B2

RA-16J

$\mathrm{RA}-17 \mathrm{~J}$

$R A-18 \mathrm{~J}$

RA-14J

RCI - TDP - FR - 20S38

ECW-XHE-FO-ECWPP

ESW-PSF-LF-8

RA-1J

LOSP

$A C P-D G N-L P-E D G 2$

$A C P-D G N-M A-E D G 3$

$A C P-D G N-M A-E D G 2$

ACP-DGN-LP-EDG3

RA-16J

ESW-PSF-LF-02

ESW-PSF-LF-103

ESW-PSF-LF-01

B-ACP-LP-EDGS

ESW-PSF-LF-102

RA-17J

HCI - TDP-MA-20\$37

HCI -TDP-FS-20S37

RA-18J

ESW-MDP-FS-ESWA

ESW-MDP-FS-ESWB

EHV-PSF-LF-9

ACP-DGN-MA-EDG4

EHV-PSF-LF-8

ESW-XHE-FO-EHS
$6.12 \mathrm{E}-5$

$6.12 \mathrm{E}-5$

$3.75 \mathrm{E}-5$

3. $73 \mathrm{E}-5$

1. $88 \mathrm{E}-5$

$6.72 \mathrm{E}-6$

$6.72 \mathrm{E}-6$

4. $32 \mathrm{E}-6$

4. $24 \mathrm{E}-6$

$2.56 \mathrm{E}-6$

2. $56 \mathrm{E}-6$

2. $55 \mathrm{E}-6$

2. $55 \mathrm{E}-6$

2. $54 \mathrm{E}-6$

2. $54 \mathrm{E}-6$

$2.54 \mathrm{E}-6$

$2.13 \mathrm{E}-6$

$7.73 \mathrm{E}-7$

$4.00 \mathrm{E}-7$

3. $20 \mathrm{E}-7$

$1.30 \mathrm{E}-7$

1. $21 \mathrm{E}-7$

$0.00 \mathrm{E}+0$

7.69E-6

4. $39 \mathrm{E}-6$

$1.16 \mathrm{E}-6$

8. $30 \mathrm{E}-7$

$6.85 \mathrm{E}-7$

$5.39 \mathrm{E}-7$

$5.12 \mathrm{E}-7$

4. $98 \mathrm{E}-7$

$3.79 \mathrm{E}-7$

3. $15 \mathrm{E}-7$

3. $14 \mathrm{E}-7$

2. $89 \mathrm{E}-7$

2.89E-7

$2.06 \mathrm{E}-7$

$1.85 \mathrm{E}-7$

1. $74 \mathrm{E}-7$

$1.65 \mathrm{E}-7$

4. $53 \mathrm{E}-8$

4. $02 \mathrm{E}-8$

$3.82 \mathrm{E}-8$

3. $61 \mathrm{E}-8$

3. $47 \mathrm{E}-8$

2. $59 \mathrm{E}-8$ 
SEQUENCE TB - SENSITIVITY ISSUE 3 (CONCLUDED)

\begin{tabular}{lll}
\hline $\begin{array}{c}\text { IMPORTANCE } \\
\text { MEASURE }\end{array}$ & \multicolumn{1}{c}{ EVENT } & VALUE \\
\hline \multirow{3}{*}{$\begin{array}{l}\text { Uncertainty } \\
\text { (Concluded) }\end{array}$} & ACP-DGN-LP-EDG4 & $2.10 \mathrm{E}-8$ \\
& ESW-PSF-LF-19 & $2.05 \mathrm{E}-8$ \\
& HCI-TDP-FR-20S37 & $2.00 \mathrm{E}-8$ \\
& HCI-PSF-HW-SUP12 & $7.36 \mathrm{E}-9$ \\
& HCI-PSF-HW-INJ09 & $7.17 \mathrm{E}-9$ \\
& DCP-BAT-LP-B2 & $2.91 \mathrm{E}-9$ \\
& RA-14J & $2.46 \mathrm{E}-9$ \\
& RCI-TDP-FR-20S38 & $2.19 \mathrm{E}-9$ \\
& ECW-XHE-FO-ECWPP & $0.00 \mathrm{E}+0$ \\
& IE-TLOSP & $3.11 \mathrm{E}-6$ \\
& IE-TRTRIP & $3.03 \mathrm{E}-7$ \\
& IE-TMSIVC & $9.63 \mathrm{E}-8$ \\
& IE-TLFW & $8.51 \mathrm{E}-8$ \\
\hline
\end{tabular}




\section{IMPORTANCE}

MEASURE

Risk Reduction

RA-1J

ECW-XHE-FO-ECWPP

$A C P-D G N-L P-E D G 2$

ESW-PSF-LF- 103

ESW-PSF-LF-102

RA-17J

B-ACP-LP-EDGS

RA-16J

RA- 18J

$A C P-D G N-L P-E D G 3$

LOSP

ESW-PSF-LF-01

ESW-PSF-LF-02

$A C P-D G N-M A-E D G 3$

$A C P-D G N-M A-E D G 2$

ESW-MDP-FS-ESWB

ESW-MDP-FS-ESWA

ACP-DGN-LP-EDG4

ESW-PSF - LF - 19

ACP-DGN-MA-EDG4

IE-TLOSP

IE-TRTRIP

IE-TMSIVC

IE-TLFW

Risk Increase
ESW-PSF-LF-01

ESW-PSF-LF-02

ESW-PSF-LF-102

ESW-PSF-LF-103

LOSP

ACP-DGN-LP-EDG2

RA-1J

B-ACP-LP-EDGS

ACP-DGN-LP-EDG3

ACP-DGN-MA-EDG3

ACP-DGN-MA-EDG2

ESW-MDP-FS-ESWA

ESW-MDP-FS-ESWB

ESW-PSF-LF-19

ACP-DGN-LP-EDG4

$A C P-D G N-M A-E D G 4$

$\mathrm{RA}-17 \mathrm{~J}$

RA- $18 \mathrm{~J}$

RA- 16J

ECW-XHE-FO-ECWPP
VALUE

1.29E-6

$8.65 \mathrm{E}-7$

$5.64 \mathrm{E}-7$

$3.78 \mathrm{E}-7$

$3.78 \mathrm{E}-7$

$3.76 \mathrm{E}-7$

$3.76 \mathrm{E}-7$

$3.68 \mathrm{E}-7$

2. $79 \mathrm{E}-7$

$1.88 \mathrm{E}-7$

$1.66 \mathrm{E}-7$

1. $61 \mathrm{E}-7$

$1.61 \mathrm{E}-7$

1. $45 \mathrm{E}-7$

$1.45 \mathrm{E}-7$

$3.70 \mathrm{E}-8$

$3.70 \mathrm{E}-8$

$1.78 \mathrm{E}-8$

$1.74 \mathrm{E}-8$

$9.11 E-9$

1. $12 \mathrm{E}-6$

$1.02 \mathrm{E}-7$

$3.40 \mathrm{E}-8$

$2.98 E-8$

$7.67 \mathrm{E}-5$

$7.67 \mathrm{E}-5$

$6.59 \mathrm{E}-5$

$6.59 E-5$

$6.22 E-5$

$4.96 \mathrm{E}-5$

$3.08 \mathrm{E}-5$

$1.77 E-5$

1. $65 \mathrm{E}-5$

1. $32 \mathrm{E}-5$

1. $32 \mathrm{E}-5$

$6.94 \mathrm{E}-6$

$6.94 \mathrm{E}-6$

$1.56 \mathrm{E}-6$

1. $56 \mathrm{E}-6$

8. $27 \mathrm{E}-7$

3.76E-7

2. $79 \mathrm{E}-7$

2. $46 \mathrm{E}-7$

$0.00 E+0$ 
SEQUENCE TB - SENSITIVITY ISSUE 4 (CONCLUDED)

\begin{tabular}{|c|c|c|}
\hline $\begin{array}{l}\text { IMPORTANCE } \\
\text { MEASURE }\end{array}$ & EVENT & VALUE \\
\hline Uncertainty & $\begin{array}{l}R A-1 J \\
\text { ACP-DGN-LP-EDG2 } \\
\text { ESW-PSF-LF-02 } \\
\text { ESW-PSF-LF-01 } \\
\text { ESW-PSF-LF-103 } \\
\text { LOSP } \\
\text { B-ACP-LP-EDGS } \\
\text { ESW-PSF-LF-102 } \\
\text { ACP-DGN-MA-EGD3 } \\
\text { RA-17J } \\
\text { ACP-DGN-MA-EDG2 } \\
\text { RA-I6J } \\
\text { RA-18J } \\
\text { ACP-DGN-LP-EDG3 } \\
\text { ESW-MDP-FS-ESWA } \\
\text { ESW-MDP-FS-ESWB } \\
\text { ACP-DGN-LP-EDG4 } \\
\text { ESW-PSF-LF-19 } \\
\text { ACP-DGN-MA-EDG4 } \\
\text { ECW-XHE-FO-ECWPP } \\
\text { IE-TLOSP } \\
\text { IE-TRTRIP } \\
\text { IE-TMSIVC } \\
\text { IE-TLFW }\end{array}$ & $\begin{array}{l}1.11 \mathrm{E}-6 \\
4.22 \mathrm{E}-7 \\
3.81 \mathrm{E}-7 \\
3.15 \mathrm{E}-7 \\
2.95 \mathrm{E}-7 \\
2.93 \mathrm{E}-7 \\
2.72 \mathrm{E}-7 \\
2.70 \mathrm{E}-7 \\
2.40 \mathrm{E}-7 \\
1.94 \mathrm{E}-7 \\
1.90 \mathrm{E}-7 \\
1.58 \mathrm{E}-7 \\
1.44 \mathrm{E}-7 \\
1.35 \mathrm{E}-7 \\
4.68 \mathrm{E}-8 \\
4.15 \mathrm{E}-8 \\
1.29 \mathrm{E}-8 \\
1.26 \mathrm{E}-8 \\
1.17 \mathrm{E}-8 \\
0.00 \mathrm{E}+0 \\
7.89 \mathrm{E}-7 \\
7.69 \mathrm{E}-8 \\
2.44 \mathrm{E}-8 \\
2.16 \mathrm{E}-8\end{array}$ \\
\hline
\end{tabular}


SEQUENCE TCUX - BASE CASE

\begin{tabular}{|c|c|c|}
\hline $\begin{array}{l}\text { IMPORTANCE } \\
\text { MEASURE }\end{array}$ & EVENT & VALUE \\
\hline Risk Reduction & $\begin{array}{l}\text { DEP-XHE } \\
\text { RPS-M } \\
\text { HCI -TDP-FS-20S37 } \\
\text { CMSIVA } \\
\text { HCI-TDP-MA-20S37 } \\
\text { HCI - XHE-TL } \\
\text { SORV2 } \\
\text { SLC-XHE-REL } \\
\text { SLC-XHE-FS } \\
\text { ADS-XHE-INH1 } \\
\text { IE-TRTRIP } \\
\text { IE-TMSIVC } \\
\text { IE-TLFW } \\
\text { IE-TIORV } \\
\text { IE-TLOSP }\end{array}$ & $\begin{array}{l}3.45 \mathrm{E}-7 \\
3.45 \mathrm{E}-7 \\
2.55 \mathrm{E}-7 \\
1.61 \mathrm{E}-7 \\
8.44 \mathrm{E}-8 \\
1.40 \mathrm{E}-8 \\
-3.57 \mathrm{E}-9 \\
-3.57 \mathrm{E}-9 \\
-1.24 \mathrm{E}-8 \\
-3.67 \mathrm{E}-8 \\
1.47 \mathrm{E}-7 \\
9.80 \mathrm{E}-8 \\
8.58 \mathrm{E}-8 \\
1.41 \mathrm{E}-8 \\
8.58 \mathrm{E}-9\end{array}$ \\
\hline Risk Increase & $\begin{array}{l}\text { RPS - M } \\
\text { HCI - XHE-TL } \\
\text { HCI - TDP-MA-20S37 } \\
\text { HCI - TDP-FS-20S37 } \\
\text { DEP-XHE } \\
\text { CMSIVA } \\
\text { SORV2 } \\
\text { SLC-XHE-FS } \\
\text { SLC-XHE-REL } \\
\text { ADS-XHE-INHI }\end{array}$ & $\begin{array}{r}3.54 \mathrm{E}-2 \\
5.26 \mathrm{E}-6 \\
5.19 \mathrm{E}-6 \\
5.02 \mathrm{E}-6 \\
1.31 \mathrm{E}-6 \\
1.61 \mathrm{E}-7 \\
-3.54 \mathrm{E}-7 \\
-3.54 \mathrm{E}-7 \\
-3.54 \mathrm{E}-7 \\
-3.54 \mathrm{E}-7\end{array}$ \\
\hline Uncertainty & $\begin{array}{l}\text { RPS-M } \\
\text { DEP-XHE } \\
\text { HCI - TDP-MA-20S37 } \\
\text { HCI -TDP-FS-20S37 } \\
\text { CMSIVA } \\
\text { ADS-XHE-INH1 } \\
\text { HCI-XHE-TL } \\
\text { SLC-XHE-FS } \\
\text { SLC-XHE-REL } \\
\text { SORV2 } \\
\text { IE-TRTRIP } \\
\text { IE-TMSIVC } \\
\text { IE-TLFW } \\
\text { IE-TIORV } \\
\text { IE-TLOSP }\end{array}$ & $\begin{array}{l}6.21 \mathrm{E}-7 \\
3.20 \mathrm{E}-7 \\
2.26 \mathrm{E}-7 \\
2.03 \mathrm{E}-7 \\
8.31 \mathrm{E}-8 \\
5.77 \mathrm{E}-8 \\
3.67 \mathrm{E}-8 \\
1.75 \mathrm{E}-8 \\
3.17 \mathrm{E}-9 \\
2.78 \mathrm{E}-9 \\
1.11 \mathrm{E}-7 \\
7.03 \mathrm{E}-8 \\
6.21 \mathrm{E}-8 \\
9.92 \mathrm{E}-9 \\
6.05 \mathrm{E}-9\end{array}$ \\
\hline
\end{tabular}


SEQUENCE TCUX - SENSITIVITY ISSUE 5

\begin{tabular}{|c|c|c|}
\hline $\begin{array}{l}\text { IMPORTANCE } \\
\text { MEASURE }\end{array}$ & EVENT & VALUE \\
\hline Risk Reduction & $\begin{array}{l}\text { DEP-XHE } \\
\text { RPS-M } \\
\text { HCI -TDP-FS-20S37 } \\
\text { CMSIVA } \\
\text { HCI -TDP-MA-20S37 } \\
\text { HCI -XHE-TL } \\
\text { SORV2 } \\
\text { SLC-XHE-REL } \\
\text { ADS-XHE-INH1 } \\
\text { SLC-XHE-FS } \\
\text { IE-TRTRIP } \\
\text { IE-TMSIVC } \\
\text { IE-TLFW } \\
\text { IE-TIORV } \\
\text { IE-TLOSP }\end{array}$ & $\begin{array}{r}3.40 \mathrm{E}-7 \\
3.40 \mathrm{E}-7 \\
2.21 \mathrm{E}-7 \\
1.55 \mathrm{E}-7 \\
7.31 \mathrm{E}-8 \\
4.57 \mathrm{E}-8 \\
-3.43 \mathrm{E}-9 \\
-3.43 \mathrm{E}-9 \\
-3.53 \mathrm{E}-8 \\
-6.62 \mathrm{E}-8 \\
1.41 \mathrm{E}-7 \\
9.42 \mathrm{E}-8 \\
8.24 \mathrm{E}-8 \\
1.35 \mathrm{E}-8 \\
8.24 \mathrm{E}-9\end{array}$ \\
\hline Risk Increase & $\begin{array}{l}\text { RPS-M } \\
\text { HCI - XHE-TL } \\
\text { HCI - TDP-MA-20S37 } \\
\text { HCI - TDP-FS-20S37 } \\
\text { DEP-XHE } \\
\text { CMSIVA } \\
\text { ADS-XHE-INHI } \\
\text { SORV2 } \\
\text { SLC-XHE-REL } \\
\text { SLC-XHE-FS }\end{array}$ & $\begin{array}{r}3.40 \mathrm{E}-2 \\
4.52 \mathrm{E}-6 \\
4.49 \mathrm{E}-6 \\
4.35 \mathrm{E}-6 \\
1.26 \mathrm{E}-6 \\
1.55 \mathrm{E}-7 \\
-3.40 \mathrm{E}-7 \\
-3.40 \mathrm{E}-7 \\
-3.40 \mathrm{E}-7 \\
-3.40 \mathrm{E}-7\end{array}$ \\
\hline Uncertainty & $\begin{array}{l}\text { RPS-M } \\
\text { DEP-XHE } \\
\text { HCI -TDP-MA-20S37 } \\
\text { HCI -TDP-FS-20S37 } \\
\text { SLC-XHE-FS } \\
\text { CMSIVA } \\
\text { ADS-XHE-INH1 } \\
\text { SLC-XHE-REL } \\
\text { SORV2 } \\
\text { HCI-XHE-TL } \\
\text { IE-TRTRIP } \\
\text { IE-TMSIVC } \\
\text { IE-TLFW } \\
\text { IE-TIORV } \\
\text { IE-TLOSP }\end{array}$ & $\begin{array}{l}5.97 \mathrm{E}-7 \\
3.07 \mathrm{E}-7 \\
1.96 \mathrm{E}-7 \\
1.75 \mathrm{E}-7 \\
9.52 \mathrm{E}-8 \\
7.98 \mathrm{E}-8 \\
5.54 \mathrm{E}-8 \\
3.04 \mathrm{E}-9 \\
2.67 \mathrm{E}-9 \\
0.00 \mathrm{E}+0 \\
1.06 \mathrm{E}-7 \\
6.76 \mathrm{E}-8 \\
5.97 \mathrm{E}-8 \\
9.53 \mathrm{E}-9 \\
5.81 \mathrm{E}-9\end{array}$ \\
\hline
\end{tabular}


SEQUENCE TCUXA - SENSITIVITY ISSUE 5

IMPORTANCE

MEASURE

Risk Reduction

Risk Increase

Uncertainty

\section{EVENT}

VALUE

LCI -XHE-TL

RPS - $M$

HC I - TDP -FS - 20537

CMSIVA

HC I - TDP - MA-20\$37

HCI - XHE-TL

SLC-XHE-REL

SORV2

ADS-XHE - INH1

SLC-XHE-FS

DEP-XHE

IE-TRTRIP

IE-TMS IVC

IE-TLFW

IE-TIORV

IE-TLOSP

RPS -M

LCI - XHE-TL

HCI - XHE-TL

HCI I TDP-MA-20S37

HCI - TDP-FS - 20S37

CMSIVA

SLC-XHE-REL

SORV2

DEP-XHE

ADS - XHE - INHI

SLC-XHE-FS

RPS-M

HCI - TDP-MA-20S37

HCI - TDP-FS-20S37

SLC-XHE-FS

DE-XHE

CMSIVA

ADS-XHE-INH1

SLC-XHE-REL

SORV2

LCI - XHE-TL

HCI - XHE-TL

IE-TRTRIP

IE-TMSIVC

IE-TLFW

IE-TIORV

IE-TLOSP
1. $26 \mathrm{E}-8$

1. $26 \mathrm{E}-8$

$8.17 \mathrm{E}-9$

$5.72 \mathrm{E}-9$

2. $70 \mathrm{E}-9$

$1.69 \mathrm{E}-9$

$-1.27 \mathrm{E}-10$

$-1.27 E-10$

$-1.30 \mathrm{E}-9$

$-2.45 E-9$

$-3.40 \mathrm{E}-9$

$5.22 \mathrm{E}-9$

$3.48 \mathrm{E}-9$

$3.05 \mathrm{E}-9$

$5.00 \mathrm{E}-10$

$3.05 \mathrm{E}-10$

$1.26 \mathrm{E}-3$

1. $24 \mathrm{E}-6$

$1.67 \mathrm{E}-7$

1. $66 \mathrm{E}-7$

$1.61 \mathrm{E}-7$

$5.72 E-9$

$-1.26 \mathrm{E}-8$

$-1.26 \mathrm{E}-8$

$-1.26 \mathrm{E}-8$

$-1.26 \mathrm{E}-8$

$-1.26 \mathrm{E}-8$

2. $21 E-8$

$7.25 E-9$

$6.48 \mathrm{E}-9$

$3.52 \mathrm{E}-9$

$3.07 \mathrm{E}-9$

2. $95 \mathrm{E}-9$

2. $05 \mathrm{E}-9$

1. $12 \mathrm{E}-10$

$9.87 \mathrm{E}-11$

$0.00 \mathrm{E}+0$

$0.00 \mathrm{E}+0$

$3.93 \mathrm{E}-9$

2. $50 \mathrm{E}-9$

2. $21 \mathrm{E}-9$

$3.52 \mathrm{E}-10$

$2.15 \mathrm{E}-10$ 
SEQUENCE TCUXB - SENSITIVITY ISSUE 5

\begin{tabular}{|c|c|c|}
\hline $\begin{array}{l}\text { IMPORTANCE } \\
\text { MEASURE }\end{array}$ & EVENT & VALUE \\
\hline Risk Reduction & $\begin{array}{l}\text { LCI-XHE-TL } \\
\text { RPS-M } \\
\text { ADS-XHE-INH1 } \\
\text { CMSIVA } \\
\text { SLC-XHE-REL } \\
\text { SLC-XHE-FS } \\
\text { IE-TRTRIP } \\
\text { IE-TMSIVC } \\
\text { IE-TLFW } \\
\text { IE-TIORV } \\
\text { IE-TLOSP }\end{array}$ & $\begin{array}{c}2.25 \mathrm{E}-8 \\
2.25 \mathrm{E}-8 \\
2.25 \mathrm{E}-8 \\
1.02 \mathrm{E}-8 \\
-2.27 \mathrm{E}-10 \\
-4.38 \mathrm{E}-9 \\
9.35 \mathrm{E}-9 \\
6.23 \mathrm{E}-9 \\
5.45 \mathrm{E}-9 \\
8.96 \mathrm{E}-10 \\
5.45 \mathrm{E}-10\end{array}$ \\
\hline Risk Increase & $\begin{array}{l}\text { RPS-M } \\
\text { LCI-XHE-TL } \\
\text { ADS-XHE-INH1 } \\
\text { CMSIVA } \\
\text { SLC-XHE-REL } \\
\text { SLC-XHE-FS }\end{array}$ & $\begin{array}{r}2.25 \mathrm{E}-3 \\
2.22 \mathrm{E}-6 \\
2.17 \mathrm{E}-7 \\
1.02 \mathrm{E}-8 \\
-2.25 \mathrm{E}-8 \\
-2.25 \mathrm{E}-8\end{array}$ \\
\hline Uncertainty & $\begin{array}{l}\text { RPS-M } \\
\text { ADS-XHE-INHI } \\
\text { SLC-XHE-FS } \\
\text { CMSIVA } \\
\text { SLC-XHE-REL } \\
\text { LCI-XHE-TL } \\
\text { IE-TRTRIP } \\
\text { IE-TMSIVC } \\
\text { IE-TLFW } \\
\text { IE-TIORV } \\
\text { IE-TLOSP }\end{array}$ & $\begin{array}{l}3.95 \mathrm{E}-8 \\
3.53 \mathrm{E}-8 \\
6.29 \mathrm{E}-9 \\
5.28 \mathrm{E}-9 \\
2.01 \mathrm{E}-10 \\
0.00 \mathrm{E}+0 \\
7.04 \mathrm{E}-9 \\
4.47 \mathrm{E}-9 \\
3.95 \mathrm{E}-9 \\
6.31 \mathrm{E}-10 \\
3.84 \mathrm{E}-10\end{array}$ \\
\hline
\end{tabular}


SEQUENCE TCSRX2 - BASE CASE

\begin{tabular}{|c|c|c|}
\hline $\begin{array}{c}\text { IMPORTANCE } \\
\text { MEASURE }\end{array}$ & EVENT & VALUE \\
\hline Risk Reduction & $\begin{array}{l}\text { VENT-XHE-TC } \\
\text { E3-CFP-TC } \\
\text { RPS-M } \\
\text { SLC-XHE-FS } \\
\text { CMSIVA } \\
\text { SLC-XHE-REL } \\
\text { LCI-XHE-TL } \\
\text { ADS-XHE-INH2 } \\
\text { DEP-XHE } \\
\text { E3-CL3-TC } \\
\text { IE-TRTRIP } \\
\text { IE-TMSIVC } \\
\text { IE-TLFW } \\
\text { IE-TIORV } \\
\text { IE-TLOSP }\end{array}$ & $\begin{array}{c}3.45 \mathrm{E}-7 \\
3.45 \mathrm{E}-7 \\
3.45 \mathrm{E}-7 \\
2.67 \mathrm{E}-7 \\
1.57 \mathrm{E}-7 \\
7.89 \mathrm{E}-8 \\
-9.21 \mathrm{E}-10 \\
-5.62 \mathrm{E}-8 \\
-9.35 \mathrm{E}-8 \\
-3.45 \mathrm{E}-7 \\
1.44 \mathrm{E}-7 \\
9.58 \mathrm{E}-8 \\
8.38 \mathrm{E}-8 \\
1.38 \mathrm{E}-8 \\
8.38 \mathrm{E}-9\end{array}$ \\
\hline Risk Increase & $\begin{array}{l}\text { RPS-M } \\
\text { SLC-XHE-REL } \\
\text { SLC-XHE-FS } \\
\text { CMSIVA } \\
\text { VENT-XHE-TC } \\
\text { E3-CFP-TC } \\
\text { LCI-XHE-TL } \\
\text { E3-CL3-TC } \\
\text { DEP-XHE } \\
\text { ADS-XHE-INH2 }\end{array}$ & $\begin{array}{r}3.45 \mathrm{E}-2 \\
7.81 \mathrm{E}-6 \\
7.62 \mathrm{E}-6 \\
1.57 \mathrm{E}-7 \\
3.84 \mathrm{E}-8 \\
3.84 \mathrm{E}-8 \\
-3.45 \mathrm{E}-7 \\
-3.45 \mathrm{E}-7 \\
-3.45 \mathrm{E}-7 \\
-3.45 \mathrm{E}-7\end{array}$ \\
\hline Uncertainty & $\begin{array}{l}\text { RPS-M } \\
\text { SLC-XHE-FS } \\
\text { E3-CL3-TC } \\
\text { ADS-XHE-INH2 } \\
\text { DEP-XHE } \\
\text { CMSIVA } \\
\text { SLC-XHE-REL } \\
\text { E3-CFP-TC } \\
\text { VENT-XHE-TC } \\
\text { LCI-XHE-TL } \\
\text { IE-TRTRIP } \\
\text { IE-TMSIVC } \\
\text { IE-TLFW } \\
\text { IE-TIORV } \\
\text { IE-TLOSP }\end{array}$ & $\begin{array}{l}6.07 \mathrm{E}-7 \\
3.76 \mathrm{E}-7 \\
2.00 \mathrm{E}-7 \\
8.90 \mathrm{E}-8 \\
8.46 \mathrm{E}-8 \\
8.12 \mathrm{E}-8 \\
7.00 \mathrm{E}-8 \\
3.63 \mathrm{E}-8 \\
3.57 \mathrm{E}-8 \\
2.39 \mathrm{E}-9 \\
1.08 \mathrm{E}-7 \\
6.87 \mathrm{E}-8 \\
6.07 \mathrm{E}-8 \\
9.69 \mathrm{E}-9 \\
5.91 \mathrm{E}-9\end{array}$ \\
\hline
\end{tabular}


SEQUENCE TCSRX3 - BASE CASE

\begin{tabular}{|c|c|c|}
\hline $\begin{array}{l}\text { IMPORTANCE } \\
\text { MEASURE }\end{array}$ & EVENT & VALUE \\
\hline Risk Reduction & $\begin{array}{l}\text { VENT-XHE-TC } \\
\text { RPS-M } \\
\text { SLC-XHE-FS } \\
\text { CMSIVA } \\
\text { SLC-XHE-REL } \\
\text { LCI-XHE-TL } \\
\text { ADS-XHE-INH2 } \\
\text { DEP-XHE } \\
\text { E3-CFP-TC } \\
\text { IE-TRTRIP } \\
\text { IE-TMSIVC } \\
\text { IE-TLFW } \\
\text { IE-TIORV } \\
\text { IE-TLOSP }\end{array}$ & $\begin{array}{l}7.68 \mathrm{E}-8 \\
7.68 \mathrm{E}-8 \\
5.92 \mathrm{E}-8 \\
3.50 \mathrm{E}-8 \\
1.75 \mathrm{E}-8 \\
-2.05 \mathrm{E}-10 \\
-1.25 \mathrm{E}-8 \\
-2.08 \mathrm{E}-8 \\
-6.91 \mathrm{E}-7 \\
3.19 \mathrm{E}-8 \\
2.13 \mathrm{E}-8 \\
1.86 \mathrm{E}-8 \\
3.06 \mathrm{E}-9 \\
1.86 \mathrm{E}-9\end{array}$ \\
\hline Risk Increase & $\begin{array}{l}\text { RPS-M } \\
\text { SLC-XHE-REL } \\
\text { SLC-XHE-FS } \\
\text { CMSIVA } \\
\text { VENT-XHE-TC } \\
\text { LCI-XHE-TL } \\
\text { E3-CFP-TC } \\
\text { DEP-XHE } \\
\text { ADS-XHE-INH2 }\end{array}$ & $\begin{array}{r}7.68 \mathrm{E}-3 \\
1.74 \mathrm{E}-6 \\
1.69 \mathrm{E}-6 \\
3.50 \mathrm{E}-8 \\
8.53 \mathrm{E}-9 \\
-7.68 \mathrm{E}-8 \\
-7.68 \mathrm{E}-8 \\
-7.68 \mathrm{E}-8 \\
-7.68 \mathrm{E}-8\end{array}$ \\
\hline Uncertainty & $\begin{array}{l}\text { RPS-M } \\
\text { SLC-XHE-FS } \\
\text { E3-CFP-TC } \\
\text { ADS-XHE-INH2 } \\
\text { DEP-XHE } \\
\text { CMSIVA } \\
\text { SLC-XHE-REL } \\
\text { VENT-XHE-TC } \\
\text { LCI-XHE-TL } \\
\text { IE-TRTRIP } \\
\text { IE-TMSIVC } \\
\text { IE-TLFW } \\
\text { IE-TIORV } \\
\text { IE-TLOSP }\end{array}$ & $\begin{array}{l}1.35 \mathrm{E}-7 \\
8.36 \mathrm{E}-8 \\
7.26 \mathrm{E}-8 \\
1.98 \mathrm{E}-8 \\
1.88 \mathrm{E}-8 \\
1.80 \mathrm{E}-8 \\
1.55 \mathrm{E}-8 \\
7.94 \mathrm{E}-9 \\
5.31 \mathrm{E}-10 \\
2.41 \mathrm{E}-8 \\
1.53 \mathrm{E}-8 \\
1.35 \mathrm{E}-8 \\
2.15 \mathrm{E}-9 \\
1.31 \mathrm{E}-9\end{array}$ \\
\hline
\end{tabular}


IMPORTANCE MEASURE

Risk Reduction

Risk Increase

Uncertainty

\section{EVENT}

VENT - XHE-TC

E3-CFP-TC

COND-HPSW-XHE-TC

RPS-M

E3-CL3-TC

SLC-XHE-FS

CMSIVA

SLC-XHE-REL

LCI-XHE-TL

ADS-XHE-INH2

DEP-XHE

IE-TRTRIP

IE-TMSIVC

IE-TLFW

IE-TIORV

IE-TLOSP

RPS-M

SLC-XHE-REL

SLC-XHE-FS

COND-HPSW-XHE-TC

E3-CL3-TC

CMSIVA

VENT-XHE-TC

E3-CFP-TC

LCI-XHE-TL

DEP-XHE

ADS-XHE-INH2

RPS-M

SLC-XHE-FS

COND-HPSW-XHE-TC

E3-CL3-TC

ADS-XHE-INH2

DEP-XHE

CMSIVA

SLC-XHE-REL

E3-CFP-TC

VENT - XHE-TC

LCI-XHE-TL

IE-TRTRIP

IE-TMSIVC

IE-TLFW

IE-TIORV

IE-TLOSP
VALUE

3. $45 \mathrm{E}-8$

$3.45 \mathrm{E}-8$

$3.45 \mathrm{E}-8$

$3.45 \mathrm{E}-8$

$3.45 \mathrm{E}-8$

$2.67 \mathrm{E}-8$

1. $57 \mathrm{E}-8$

$7.89 E-9$

$-9.21 \mathrm{E}-11$

$-5.62 \mathrm{E}-9$

$-9.35 E-9$

$1.44 E-8$

$9.58 \mathrm{E}-9$

$8.38 E-9$

$1.38 \mathrm{E}-9$

8. $38 \mathrm{E}-10$

3. $45 \mathrm{E}-3$

$7.81 \mathrm{E}-7$

$7.62 \mathrm{E}-7$

3. $11 \mathrm{E}-7$

$3.45 \mathrm{E}-8$

1. $57 \mathrm{E}-8$

3. $84 \mathrm{E}-9$

$3.84 \mathrm{E}-9$

$-3.45 E-8$

$-3.45 E-8$

$-3.45 E-8$

$6.07 E-8$

$3.76 \mathrm{E}-8$

$3.38 \mathrm{E}-8$

$2.00 \mathrm{E}-8$

$8.90 \mathrm{E}-9$

$8.46 \mathrm{E}-9$

$8.12 \mathrm{E}-9$

$7.00 \mathrm{E}-9$

$3.63 E-9$

$3.57 \mathrm{E}-9$

2. $39 E-10$

$1.08 \mathrm{E}-8$

$6.87 E-9$

$6.07 \mathrm{E}-9$

9. $69 \mathrm{E}-10$

5. $91 \mathrm{E}-10$ 
SEQUENCE TCSRX2 - SENSITIVITY ISSUE 5

\begin{tabular}{|c|c|c|}
\hline $\begin{array}{l}\text { IMPORTANCE } \\
\text { MEASURE }\end{array}$ & EVENT & VALUE \\
\hline Risk Reduction & $\begin{array}{l}\text { VENT-XHE-TC } \\
\text { E3-CFP-TC } \\
\text { RPS-M } \\
\text { SLC-XHE-FS } \\
\text { CMSIVA } \\
\text { SLC-XHE-REL } \\
\text { LCI-XHE-TL } \\
\text { ADS-XHE-INH2 } \\
\text { DEP-XHE } \\
\text { E3-CL3-TC } \\
\text { IE-TRTRIP } \\
\text { IE-TMSIVC } \\
\text { IE-TLFW } \\
\text { IE-TIORV } \\
\text { IE-TLOSP }\end{array}$ & $\begin{array}{r}1.35 \mathrm{E}-6 \\
1.35 \mathrm{E}-6 \\
1.35 \mathrm{E}-6 \\
1.28 \mathrm{E}-6 \\
6.17 \mathrm{E}-7 \\
7.83 \mathrm{E}-8 \\
-1.37 \mathrm{E}-8 \\
-2.20 \mathrm{E}-7 \\
-3.67 \mathrm{E}-7 \\
-1.35 \mathrm{E}-6 \\
5.63 \mathrm{E}-7 \\
3.76 \mathrm{E}-7 \\
3.29 \mathrm{E}-7 \\
5.40 \mathrm{E}-8 \\
3.29 \mathrm{E}-8\end{array}$ \\
\hline Risk Increase & $\begin{array}{l}\text { RPS-M } \\
\text { SLC-XHE-REL } \\
\text { SLC-XHE-FS } \\
\text { CMSIVA } \\
\text { VENT-XHE-TC } \\
\text { E3-CFP-TC } \\
\text { ADS-XHE-INH2 } \\
\text { E3-CL3-TC } \\
\text { DEP-XHE } \\
\text { LCI-XHE-TL }\end{array}$ & $\begin{array}{r}1.35 E-1 \\
7.75 E-6 \\
6.55 E-6 \\
6.17 E-7 \\
1.50 E-7 \\
1.50 E-7 \\
-1.35 E-6 \\
-1.35 E-6 \\
-1.35 E-6 \\
-1.35 E-6\end{array}$ \\
\hline Uncertainty & $\begin{array}{l}\text { RPS-M } \\
\text { SLC-XHE-FS } \\
\text { E3-CL3-TC } \\
\text { ADS-XHE-INH2 } \\
\text { DEP-XHE } \\
\text { CMSIVA } \\
\text { E3-CFP-TC } \\
\text { VENT-XHE-TC } \\
\text { SLC-XHE-REL } \\
\text { LCI-XHE-TL } \\
\text { IE-TRTRIP } \\
\text { IE-TMSIVC } \\
\text { IE-TLFW } \\
\text { IE-TIORV } \\
\text { IE-TLOSP }\end{array}$ & $\begin{array}{l}2.38 E-6 \\
1.84 E-6 \\
7.85 E-7 \\
3.49 E-7 \\
3.32 E-7 \\
3.18 E-7 \\
1.42 E-7 \\
1.40 E-7 \\
6.94 E-8 \\
0.00 E+0 \\
4.24 E-7 \\
2.69 E-7 \\
2.38 E-7 \\
3.80 E-8 \\
2.32 E-8\end{array}$ \\
\hline
\end{tabular}


SEQUENCE TCSRX3 - SENSITIVITY ISSUE 5

\begin{tabular}{|c|c|c|}
\hline $\begin{array}{l}\text { IMPORTANCE } \\
\text { MEASURE }\end{array}$ & EVENT & VALUE \\
\hline Risk Reduction & $\begin{array}{l}\text { VENT-XHE-TC } \\
\text { RPS-M } \\
\text { SLC-XHE-FS } \\
\text { CMSIVA } \\
\text { SLC-XHE-REL } \\
\text { LCI-XHE-TL } \\
\text { ADS-XHE-INH2 } \\
\text { DEP-XHE } \\
\text { E3-CFP-TC } \\
\text { IE-TRTRIP } \\
\text { IE-TMSIVC } \\
\text { IE-TLFW } \\
\text { IE-TIORV } \\
\text { IE-TLOSP }\end{array}$ & $\begin{array}{r}3.01 \mathrm{E}-7 \\
3.01 \mathrm{E}-7 \\
2.84 \mathrm{E}-7 \\
1.37 \mathrm{E}-7 \\
1.74 \mathrm{E}-8 \\
-3.04 \mathrm{E}-9 \\
-4.90 \mathrm{E}-8 \\
-8.15 \mathrm{E}-8 \\
-2.71 \mathrm{E}-6 \\
1.25 \mathrm{E}-7 \\
8.35 \mathrm{E}-8 \\
7.30 \mathrm{E}-8 \\
1.20 \mathrm{E}-8 \\
7.30 \mathrm{E}-9\end{array}$ \\
\hline Risk Increase & $\begin{array}{l}\text { RPS -M } \\
\text { SLC-XHE-REL } \\
\text { SLX-XHE-FS } \\
\text { CMSIVA } \\
\text { VENT-XHE-TC } \\
\text { E3-CFP-TC } \\
\text { ADS-XHE-INH2 } \\
\text { DEP-XHE } \\
\text { LCI - XHE-TL }\end{array}$ & $\begin{array}{r}3.01 E-2 \\
1.72 E-6 \\
1.46 E-6 \\
1.37 E-7 \\
3.34 E-8 \\
-3.01 E-7 \\
-3.01 E-7 \\
-3.01 E-7 \\
-3.01 E-7\end{array}$ \\
\hline Uncertainty & $\begin{array}{l}\text { RPS-M } \\
\text { SLC-XHE-FS } \\
\text { E3-CFP-TC } \\
\text { ADS-XHE-INH2 } \\
\text { DEP-XHE } \\
\text { CMSIVA } \\
\text { VENT-XHE-TC } \\
\text { SLC-XHE-REL } \\
\text { LCI-XHE-TL } \\
\text { IE-TRTRIP } \\
\text { IE-TMSIVC } \\
\text { IE-TLFW } \\
\text { IE-TIORV } \\
\text { IE-TLOSP }\end{array}$ & $\begin{array}{l}5.29 E-7 \\
4.08 E-7 \\
2.84 E-7 \\
7.76 E-8 \\
7.37 E-8 \\
7.07 E-8 \\
3.11 E-8 \\
1.54 E-8 \\
0.00 E+0 \\
9.43 E-8 \\
5.98 E-8 \\
5.29 E-8 \\
8.45 E-9 \\
5.15 E-9\end{array}$ \\
\hline
\end{tabular}


SEQUENCE TCSRV23 - SENSITIVITY ISSUE 5

\begin{tabular}{|c|c|c|}
\hline $\begin{array}{c}\text { IMPORTANCE } \\
\text { MEASURE }\end{array}$ & EVENT & VALUE \\
\hline Risk Reduction & $\begin{array}{l}\text { VENT-XHE-TC } \\
\text { E3-CFP-TC } \\
\text { COND-HPSW-XHE-TC } \\
\text { RPS-M } \\
\text { E3-CL3-TC } \\
\text { SLC-XHE-FS } \\
\text { CMSIVA } \\
\text { SLC-XHE-REL } \\
\text { LCI-XHE-TL } \\
\text { ADS-XHE-INH2 } \\
\text { DEP-XHE } \\
\text { IE-TRTRIP } \\
\text { IE-TMSIVC } \\
\text { IE-TLFW } \\
\text { IE-TIORV } \\
\text { IE-TLOSP }\end{array}$ & $\begin{array}{r}1.35 \mathrm{E}-7 \\
1.35 \mathrm{E}-7 \\
1.35 \mathrm{E}-7 \\
1.35 \mathrm{E}-7 \\
1.35 \mathrm{E}-7 \\
1.28 \mathrm{E}-7 \\
6.17 \mathrm{E}-8 \\
7.83 \mathrm{E}-9 \\
-1.37 \mathrm{E}-9 \\
-2.20 \mathrm{E}-8 \\
-3.67 \mathrm{E}-8 \\
5.63 \mathrm{E}-8 \\
3.76 \mathrm{E}-8 \\
3.29 \mathrm{E}-8 \\
5.40 \mathrm{E}-9 \\
3.29 \mathrm{E}-9\end{array}$ \\
\hline Risk Increase & $\begin{array}{l}\text { RPS -M } \\
\text { COND-HPSE-XHE-TC } \\
\text { SLC-XHE-REL } \\
\text { SLC-XHE-FS } \\
\text { E3-CL3-TC } \\
\text { CMSIVA } \\
\text { VENT-XHE-TC } \\
\text { E3-CFP-TC } \\
\text { LCI-XHE-TL } \\
\text { DEP-XHE } \\
\text { ADS-XHE-INH2 }\end{array}$ & $\begin{array}{l}1.35 \mathrm{E}-2 \\
1.22 \mathrm{E}-6 \\
7.75 \mathrm{E}-7 \\
6.55 \mathrm{E}-7 \\
1.35 \mathrm{E}-7 \\
6.17 \mathrm{E}-8 \\
1.50 \mathrm{E}-8 \\
1.50 \mathrm{E}-8 \\
-1.35 \mathrm{E}-7 \\
-1.35 \mathrm{E}-7 \\
-1.35 \mathrm{E}-7\end{array}$ \\
\hline Uncertainty & $\begin{array}{l}\text { RPS-M } \\
\text { SLC-XHE-FS } \\
\text { COND-HPSW-XHE-TC } \\
\text { E3-CL3-TC } \\
\text { ADS-XHE-INH2 } \\
\text { DEP-XHE } \\
\text { CMSIVA } \\
\text { E3-CFP-TC } \\
\text { VENT-XHE-TC } \\
\text { SLC-XHE-REL } \\
\text { LCI-XHE-TL } \\
\text { IE-TRTRIP } \\
\text { IE-TMSIVC } \\
\text { IE-TLFW } \\
\text { IE-TIORV } \\
\text { IE-TLOSP }\end{array}$ & $\begin{array}{l}2.38 E-7 \\
1.84 E-7 \\
1.33 E-7 \\
7.85 E-8 \\
3.49 E-8 \\
3.32 E-8 \\
3.18 E-8 \\
1.42 E-8 \\
1.40 E-8 \\
6.94 E-9 \\
0.00 E+0 \\
4.24 E-8 \\
2.69 E-8 \\
2.38 E-8 \\
3.80 E-9 \\
2.32 E-9\end{array}$ \\
\hline
\end{tabular}


SEQUENCE TBUP - BASE CASE

\begin{tabular}{|c|c|c|}
\hline $\begin{array}{l}\text { IMPORTANCE } \\
\text { MEASURE }\end{array}$ & EVENT & VALUE \\
\hline Risk Reduction & $\begin{array}{l}\text { SORV } \\
\text { DCP-BAT-LP-B2 } \\
\text { B-DCP-LP-BATS } \\
\text { LOSP } \\
\text { RA-1D } \\
\text { RCI -TDP-FS-20S38 } \\
\text { HCI-TDP-FS-20S37 } \\
\text { RA-14D } \\
\text { ACP-DGN-LP-EDG2 } \\
\text { ACP-DGN-LP-EDG3 } \\
\text { RA-16D } \\
\text { ACP-DGN-MA-EDG3 } \\
\text { RCI-TDP-MA-20S38 } \\
\text { B-ACP-LP-EDGS } \\
\text { ESW-PSF-LF-103 } \\
\text { ACP-DGN-MA-EDG2 } \\
\text { HCI-TDP-MA-20S37 } \\
\text { ESW-PSF-LF-102 } \\
\text { RA-17D } \\
\text { RA-18D } \\
\text { ECW-XHE-FO-ECWPP } \\
\text { RCI-PSF-HW-COL10 } \\
\text { ESW-PSF-LF-8 } \\
\text { ESW-PSF-LF-02 } \\
\text { DCP-BAT-LP-C3 } \\
\text { DGACTB } \\
\text { RCI-PSF-HW-SUP09 } \\
\text { RCI-PSF-HW-INJ06 } \\
\text { HCI-PSF-HW-INJ09 } \\
\text { HCI-PSF-HW-SUP12 } \\
\text { IE-TLOSP } \\
\text { IE-TRTRIP } \\
\text { IE-TMSIVC } \\
\text { IE-TLFW }\end{array}$ & $\begin{array}{l}2.23 \mathrm{E}-7 \\
2.18 \mathrm{E}-7 \\
2.14 \mathrm{E}-7 \\
2.87 \mathrm{E}-8 \\
8.92 \mathrm{E}-9 \\
7.04 \mathrm{E}-9 \\
4.29 \mathrm{E}-9 \\
3.81 \mathrm{E}-9 \\
3.26 \mathrm{E}-9 \\
3.18 \mathrm{E}-9 \\
2.81 \mathrm{E}-9 \\
2.34 \mathrm{E}-9 \\
1.55 \mathrm{E}-9 \\
1.46 \mathrm{E}-9 \\
1.23 \mathrm{E}-9 \\
1.00 \mathrm{E}-9 \\
7.97 \mathrm{E}-10 \\
5.98 \mathrm{E}-10 \\
5.83 \mathrm{E}-10 \\
4.68 \mathrm{E}-10 \\
4.20 \mathrm{E}-10 \\
3.07 \mathrm{E}-10 \\
2.46 \mathrm{E}-10 \\
1.74 \mathrm{E}-10 \\
1.55 \mathrm{E}-10 \\
1.33 \mathrm{E}-10 \\
8.75 \mathrm{E}-12 \\
8.75 \mathrm{E}-12 \\
8.75 \mathrm{E}-12 \\
8.75 \mathrm{E}-12 \\
1.94 \mathrm{E}-7 \\
1.77 \mathrm{E}-8 \\
5.90 \mathrm{E}-9 \\
5.16 \mathrm{E}-9\end{array}$ \\
\hline Risk Increase & $\begin{array}{l}\text { DCP-BAT-LP-B2 } \\
\text { LOSP } \\
\text { ESW-PSF-LF-8 } \\
\text { B-DCP-LP-BATS } \\
\text { SORV } \\
\text { ACP-DGN-LP-EDG2 } \\
\text { ACP-DGN-LP-EDG3 } \\
\text { ESW-PSF-LF-103 } \\
\text { ACP-DGN-MA-EDG3 } \\
\text { RCI-TDP-FS-20S38 } \\
\text { ESW-PSF-LF-102 } \\
\text { RCI-TDP-MA-20S38 }\end{array}$ & $\begin{array}{l}1.63 \mathrm{E}-4 \\
1.08 \mathrm{E}-5 \\
8.20 \mathrm{E}-6 \\
5.13 \mathrm{E}-6 \\
4.23 \mathrm{E}-6 \\
2.87 \mathrm{E}-7 \\
2.80 \mathrm{E}-7 \\
2.14 \mathrm{E}-7 \\
2.12 \mathrm{E}-7 \\
1.38 \mathrm{E}-7 \\
1.04 \mathrm{E}-7 \\
9.55 \mathrm{E}-8\end{array}$ \\
\hline
\end{tabular}


SEQUENCE TBUP - BASE CASE (CONTINUED)

\begin{tabular}{|c|c|c|}
\hline $\begin{array}{l}\text { IMPORTANCE } \\
\text { MEASURE }\end{array}$ & EVENT & VALUE \\
\hline $\begin{array}{l}\text { Risk Increase } \\
\text { (Cocluded) }\end{array}$ & $\begin{array}{l}\text { ACP-DGN-MA-EDG2 } \\
\text { HCI -TDP-FS-20S37 } \\
\text { DGACTB } \\
\text { DCP-BAT-LP-C3 } \\
\text { ESW-PSF-LF-02 } \\
\text { B-ACP-LP-EDGS } \\
\text { HCI -TDP-MA-20S37 } \\
\text { RCI - PSF-HW-COL10 } \\
\text { RA-1D } \\
\text { RCI-PSF-HW-SUP09 } \\
\text { RCI-PSF-HW-INJ06 } \\
\text { HCI -PSF-HW-INJ09 } \\
\text { HCI -PSF-HW-SUP12 } \\
\text { RA-14D } \\
\text { RA-18D } \\
\text { RA-17D } \\
\text { RA-16D } \\
\text { ECW-XHE-FO-ECWPP }\end{array}$ & $\begin{array}{l}9.08 \mathrm{E}-8 \\
8.44 \mathrm{E}-8 \\
8.26 \mathrm{E}-8 \\
8.26 \mathrm{E}-8 \\
8.26 \mathrm{E}-8 \\
6.89 \mathrm{E}-8 \\
4.90 \mathrm{E}-8 \\
4.07 \mathrm{E}-8 \\
1.34 \mathrm{E}-8 \\
2.33 \mathrm{E}-9 \\
2.33 \mathrm{E}-9 \\
2.33 \mathrm{E}-9 \\
2.33 \mathrm{E}-9 \\
9.54 \mathrm{E}-10 \\
0.00 \mathrm{E}+0 \\
0.00 \mathrm{E}+0 \\
0.00 \mathrm{E}+0 \\
0.00 \mathrm{E}+0\end{array}$ \\
\hline Uncertainty & $\begin{array}{l}\text { SORV } \\
\text { DCP-BAT-LP-B2 } \\
\text { B-DCP-LP-BATS } \\
\text { LOSP } \\
\text { RA-1D } \\
\text { RCI - TDP-FS-20S38 } \\
\text { ACP-DGN-MA-EDG3 } \\
\text { HCI-TDP-FS-20S37 } \\
\text { RCI -TDP-MA-20S38 } \\
\text { ACP-DGN-LP-EDG2 } \\
\text { ACP-DGN-LP-EDG3 } \\
\text { HCI-TDP-MA-20S37 } \\
\text { ACP-DGN-MA-EDG2 } \\
\text { B-ACP-LP-EDGS } \\
\text { ESW-PSF-LF-103 } \\
\text { RA-14D } \\
\text { ESW-PSF-LF-8 } \\
\text { ESW-PSF-LF-102 } \\
\text { ESW-PSF-LF-02 } \\
\text { RCI - PSF-HW-COL10 } \\
\text { DGACTB } \\
\text { DCP-BAT-LP-C3 } \\
\text { HCI-PSF-HW-SUP12 } \\
\text { HCI-PSF-HW-INJ09 } \\
\text { RCI - PSF-HW-INJ06 } \\
\text { RCI -PSF-HW-SUP09 } \\
\text { RA-18D }\end{array}$ & $\begin{array}{l}1.64 \mathrm{E}-7 \\
1.58 \mathrm{E}-7 \\
1.56 \mathrm{E}-7 \\
5.08 \mathrm{E}-8 \\
5.21 \mathrm{E}-9 \\
4.94 \mathrm{E}-9 \\
3.88 \mathrm{E}-9 \\
3.41 \mathrm{E}-9 \\
2.95 \mathrm{E}-9 \\
2.44 \mathrm{E}-9 \\
2.29 \mathrm{E}-9 \\
2.14 \mathrm{E}-9 \\
1.31 \mathrm{E}-9 \\
1.06 \mathrm{E}-9 \\
9.58 \mathrm{E}-10 \\
8.78 \mathrm{E}-10 \\
6.53 \mathrm{E}-10 \\
4.28 \mathrm{E}-10 \\
4.10 \mathrm{E}-10 \\
2.26 \mathrm{E}-10 \\
1.48 \mathrm{E}-10 \\
1.17 \mathrm{E}-10 \\
6.68 \mathrm{E}-12 \\
6.50 \mathrm{E}-12 \\
6.47 \mathrm{E}-12 \\
6.24 \mathrm{E}-12 \\
0.00 \mathrm{E}+0\end{array}$ \\
\hline
\end{tabular}


SEQUENCE TBUP - BASE CASE (CONCLUDED)

\begin{tabular}{rlr}
\hline $\begin{array}{c}\text { IMPORTANCE } \\
\text { MEASURE }\end{array}$ & EVENT & VALUE \\
\hline & & \\
Uncertainty & & $0.00 E+0$ \\
(Concluded) & RA-170 & $0.00 \mathrm{E}+0$ \\
& RA-16D & $0.00 \mathrm{E}+0$ \\
& ECW-XHE-FO-ECWPP & $1.37 \mathrm{E}-7$ \\
& IE-TLOSP & $1.33 \mathrm{E}-8$ \\
& IE-TRTRIP & $4.23 \mathrm{E}-9$ \\
& IE-TMSIVC & $3.74 \mathrm{E}-9$ \\
\hline
\end{tabular}


SEQUENCE TBUP - SENSITIVITY ISSUE 2

\begin{tabular}{|c|c|c|}
\hline $\begin{array}{l}\text { IMPORTANCE } \\
\text { MEASURE }\end{array}$ & EVENT & VALUE \\
\hline Risk Reduction & $\begin{array}{l}\text { SORV } \\
\text { DCP-BAT-LP-B2 } \\
\text { B-DCP-LP-BATS } \\
\text { LOSP } \\
\text { RA-1D } \\
\text { RCI-TDP-FS-20S38 } \\
\text { HCI -TDP-FS-20S37 } \\
\text { ACP-DGN-LP-EDG2 } \\
\text { RA-14D } \\
\text { B-ACP-LP-EDGS } \\
\text { ACP-DGN-LP-EDG3 } \\
\text { RA-16D } \\
\text { ACP-DGN-MA-EDG3 } \\
\text { RCI-TDP-MA-20S38 } \\
\text { RA-17D } \\
\text { ESW-PSF-LF-103 } \\
\text { HCI-TDP-MA-20S37 } \\
\text { ACP-DGN-MA-EDG2 } \\
\text { ESW-PSF-LF-102 } \\
\text { RA-18D } \\
\text { ECW-XHE-FO-ECWPP } \\
\text { RCI-PSF-HW-COL10 } \\
\text { ESW-PSF-LF-8 } \\
\text { ESW-PSF-LF-O2 } \\
\text { DCP-BAT-LP-C3 } \\
\text { DGACTB } \\
\text { RCI-PSF-HW-SUP09 } \\
\text { RCI-PSF-HW-INJ06 } \\
\text { HCI -PSF-HW-INJ09 } \\
\text { HCI -PSF-HW-SUP12 } \\
\text { IE-TLOSP } \\
\text { IE-TRTRIP } \\
\text { IE-TMSIVC } \\
\text { IE-TLFW }\end{array}$ & $\begin{array}{l}2.25 \mathrm{E}-7 \\
2.18 \mathrm{E}-7 \\
2.14 \mathrm{E}-7 \\
2.90 \mathrm{E}-8 \\
1.10 \mathrm{E}-8 \\
8.69 \mathrm{E}-9 \\
5.94 \mathrm{E}-9 \\
5.32 \mathrm{E}-9 \\
3.81 \mathrm{E}-9 \\
3.52 \mathrm{E}-9 \\
3.18 \mathrm{E}-9 \\
2.81 \mathrm{E}-9 \\
2.34 \mathrm{E}-9 \\
1.96 \mathrm{E}-9 \\
1.40 \mathrm{E}-9 \\
1.23 \mathrm{E}-9 \\
1.21 \mathrm{E}-9 \\
1.00 \mathrm{E}-9 \\
5.98 \mathrm{E}-10 \\
4.68 \mathrm{E}-10 \\
4.20 \mathrm{E}-10 \\
3.07 \mathrm{E}-10 \\
2.46 \mathrm{E}-10 \\
1.74 \mathrm{E}-10 \\
1.55 \mathrm{E}-10 \\
1.33 \mathrm{E}-10 \\
8.75 \mathrm{E}-12 \\
8.75 \mathrm{E}-12 \\
8.75 \mathrm{E}-12 \\
8.75 \mathrm{E}-12 \\
1.96 \mathrm{E}-7 \\
1.79 \mathrm{E}-8 \\
5.95 \mathrm{E}-9 \\
5.21 \mathrm{E}-9\end{array}$ \\
\hline Risk Increase & $\begin{array}{l}\text { DCP-BAT-LP-B2 } \\
\text { LOSP } \\
\text { ESW-PSF-LF-8 } \\
\text { B-DCP-LP-BATS } \\
\text { SORV } \\
\text { ACP-DGN-LP-EDG2 } \\
\text { ACP-DGN-LP-EDG3 } \\
\text { ESW-PSF-LF-103 } \\
\text { ACP-DGN-MA-EDG3 } \\
\text { RCI-TDP-FS-20S38 } \\
\text { RCI-TDP-MA-20S38 } \\
\text { HCI-TDP-FS-20S37 } \\
\text { ESW-PSF-LF-102 }\end{array}$ & $\begin{array}{l}1.63 \mathrm{E}-4 \\
1.09 \mathrm{E}-5 \\
8.20 \mathrm{E}-6 \\
5.13 \mathrm{E}-6 \\
4.27 \mathrm{E}-6 \\
4.67 \mathrm{E}-7 \\
2.80 \mathrm{E}-7 \\
2.14 \mathrm{E}-7 \\
2.12 \mathrm{E}-7 \\
1.71 \mathrm{E}-7 \\
1.21 \mathrm{E}-7 \\
1.17 \mathrm{E}-7 \\
1.04 \mathrm{E}-7\end{array}$ \\
\hline
\end{tabular}


SEQUENCE TBUP - SENSITIVITY ISSUE 2 (CONTINUED)

\section{IMPORTANCE MEASURE}

Risk Increase

(Concluded)

Uncertainty

\section{EVENT}

$A C P-D G N-M A-E D G 2$

DGACTB

DCP-BAT-LP-C3

ESW-PSF-LF-02

HCI - TDP-MA-20S37

B-ACP-LP-EDGS

RCI-PSF-HW-COL 10

RA-1D

RCI - PSF - HW-SUPO9

RCI-PSF-HW-INJ06

HCI - PSF-HW-INJ09

HCI-PSF-HW-SUP12

RA-14D

RA-18D

RA-17D

RA-160

ECW-XHE-FO-ECWPP

SORV

DCP-BAT-LP-B2

B-DCP-LP-BATS

LOSP

RA-1D

RCI - TDP-FS-20\$38

HCI - TDP-FS - 20S37

ACP-DGN-LP-EDG2

ACP-DGN-MA-EDG3

RCI - TDP-MA-20S38

HCI - TDP-MA-20S37

B-ACP-LP-EDGS

ACP-DGN-LP-EDG3

ACP-DGN-MA-EDG2

ESW-PSF-LF-103

RA-14D

ESW-PSF-LF-8

ESW-PSF-LF-102

ESW-PSF-LF-02

RCI - PSF-HW-COL10

DGACTB

DCP-BAT-LP-C3

HCI - PSF-HW-SUP12

HCI - PSF-HW-INJ09

RCI-PSF-HW-INJ06

RCI - PSF-HW-SUP09

RA-18D

RA-17D

RA-16D

\section{VALUE}

$9.08 \mathrm{E}-8$

8. $26 \mathrm{E}-8$

$8.26 \mathrm{E}-8$

$8.26 \mathrm{E}-8$

$7.42 \mathrm{E}-8$

$6.69 \mathrm{E}-8$

4. $07 \mathrm{E}-8$

1. $65 \mathrm{E}-8$

2. $33 \mathrm{E}-9$

2. $33 \mathrm{E}-9$

2. $33 \mathrm{E}-9$

2. $33 \mathrm{E}-9$

$9.54 \mathrm{E}-10$

$0.00 \mathrm{E}+0$

$0.00 E+0$

$0.00 E+0$

$0.00 E+0$

1. $65 \mathrm{E}-7$

1. $58 \mathrm{E}-7$

1. $56 \mathrm{E}-7$

5. $13 \mathrm{E}-8$

$6.42 E-9$

$6.09 \mathrm{E}-9$

4.71E-9

$3.98 E-9$

$3.88 \mathrm{E}-9$

$3.73 E-9$

3. $24 E-9$

2. $54 \mathrm{E}-9$

2. $29 E-9$

1. $31 \mathrm{E}-9$

9. $58 \mathrm{E}-10$

$8.78 \mathrm{E}-10$

$6.53 E-10$

$4.28 \mathrm{E}-10$

4. $10 \mathrm{E}-10$

2. $26 \mathrm{E}-10$

1. $48 \mathrm{E}-10$

1. $17 \mathrm{E}-10$

$6.68 \mathrm{E}-12$

6. $50 \mathrm{E}-12$

$6.47 \mathrm{E}-12$

$6.24 \mathrm{E}-12$

$0.00 \mathrm{E}+0$

$0.00 E+0$

$0.00 E+0$ 
SEQUENCE TBUP - SENSITIVITY ISSUE 2 (CONCLUDED)

\begin{tabular}{clc}
\hline $\begin{array}{c}\text { IMPORTANCE } \\
\text { MEASURE }\end{array}$ & EVENT & VALUE \\
\hline & ECW-XHE-FO-ECWPP & $0.00 \mathrm{E}+0$ \\
Uncertainty & IE-TLOSP & $1.38 \mathrm{E}-7$ \\
(Concluded) & IE-TRTRIP & $1.34 \mathrm{E}-8$ \\
& IE-TMSIVC & $4.27 \mathrm{E}-9$ \\
& IE-TLFW & $3.77 \mathrm{E}-9$ \\
\hline
\end{tabular}


SEQUENCE TBUP - SENSITIVITY ISSUE 3

IMPORTANCE

MEASURE

Risk Reduction

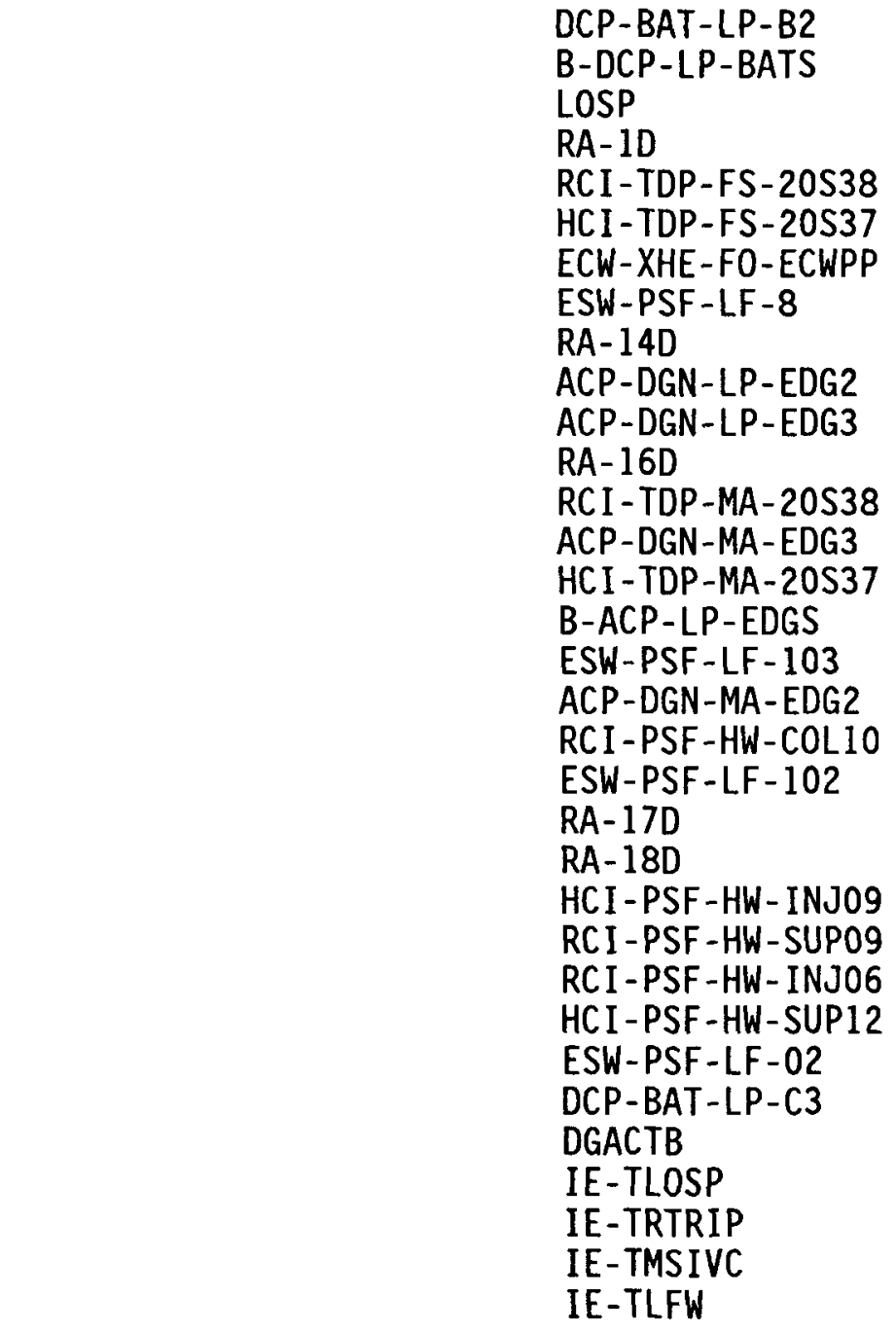

Risk Increase
VALUE

2.29E-7

2. $18 \mathrm{E}-7$

2. $14 \mathrm{E}-7$

$2.96 \mathrm{E}-8$

$1.52 \mathrm{E}-8$

1. $14 \mathrm{E}-8$

9.05E-9

$6.73 E-9$

$6.56 E-9$

$3.81 \mathrm{E}-9$

$3.26 \mathrm{E}-9$

$3.18 \mathrm{E}-9$

2.81E-9

$2.51 \mathrm{E}-9$

2. $34 \mathrm{E}-9$

$1.90 \mathrm{E}-9$

$1.46 \mathrm{E}-9$

$1.23 E-9$

$1.00 \mathrm{E}-9$

$9.05 \mathrm{E}-10$

$5.98 \mathrm{E}-10$

$5.83 \mathrm{E}-10$

$4.68 E-10$

2. $33 \mathrm{E}-10$

2. $33 \mathrm{E}-10$

2. $33 \mathrm{E}-10$

2. $33 \mathrm{E}-10$

$1.74 \mathrm{E}-10$

$1.55 \mathrm{E}-10$

1. $33 \mathrm{E}-10$

$1.99 \mathrm{E}-7$

1. $82 \mathrm{E}-8$

$6.06 \mathrm{E}-9$

5. $31 E-9$

$1.63 \mathrm{E}-4$

1. $11 \mathrm{E}-5$

8. $19 \mathrm{E}-6$

5. $13 \mathrm{E}-6$

4. $35 \mathrm{E}-6$

2. $87 \mathrm{E}-7$

2. $80 \mathrm{E}-7$

2. $23 \mathrm{E}-7$

2. $14 \mathrm{E}-7$

2. $12 \mathrm{E}-7$

$1.78 \mathrm{E}-7$

1. $54 \mathrm{E}-7$ 
SEQUENCE TBUP - SENSITIVITY ISSUE 3 (CONTINUED)

\begin{tabular}{|c|c|c|}
\hline $\begin{array}{l}\text { IMPORTANCE } \\
\text { MEASURE }\end{array}$ & EVENT & VALUE \\
\hline $\begin{array}{l}\text { Risk Increase } \\
\text { (Concluded) }\end{array}$ & $\begin{array}{l}\text { RCI-PSF-HW-COL10 } \\
\text { HCI-TDP-MA-20S37 } \\
\text { ESW-PSF-LF-102 } \\
\text { ACP-DGN-MA-EDG2 } \\
\text { DGACTB } \\
\text { DCP-BAT-LP-C3 } \\
\text { ESW-PSF-LF-02 } \\
\text { B-ACP-LP-EDGS } \\
\text { HCI-PSF-HW-INJ09 } \\
\text { RCI-PSF-HW-SUP09 } \\
\text { RCI-PSF-HW-INJ06 } \\
\text { HCI-PSF-HW-SUP12 } \\
\text { RA-1D } \\
\text { RA-14D } \\
\text { RA-18D } \\
\text { RA-17D } \\
\text { RA-16D } \\
\text { ECW-XHE-F0-ECWPP }\end{array}$ & $\begin{array}{l}1.20 \mathrm{E}-7 \\
1.17 \mathrm{E}-7 \\
1.04 \mathrm{E}-7 \\
9.08 \mathrm{E}-8 \\
8.26 \mathrm{E}-8 \\
8.26 \mathrm{E}-8 \\
8.26 \mathrm{E}-8 \\
6.89 \mathrm{E}-8 \\
6.20 \mathrm{E}-8 \\
6.20 \mathrm{E}-8 \\
6.20 \mathrm{E}-8 \\
6.20 \mathrm{E}-8 \\
2.29 \mathrm{E}-8 \\
9.54 \mathrm{E}-10 \\
0.00 \mathrm{E}+0 \\
0.00 \mathrm{E}+0 \\
0.00 \mathrm{E}+0 \\
0.00 \mathrm{E}+0\end{array}$ \\
\hline Uncertainty & $\begin{array}{l}\text { SORV } \\
\text { DCP-BAT-LP-B2 } \\
\text { B-DCP-LP-BATS } \\
\text { LOSP } \\
\text { ESW-PSF-LF-8 } \\
\text { RA-1D } \\
\text { RCI-TDP-FS-20S38 } \\
\text { HCI-TDP-FS-20S37 } \\
\text { HCI-TDP-MA-20S37 } \\
\text { RCI - TDP-MA-20S38 } \\
\text { ACP-DGN-MA-EDG3 } \\
\text { ACP-DGN-LP-EDG2 } \\
\text { ACP-DGN-LP-EDG3 } \\
\text { ACP-DGN-MA-EDG2 } \\
\text { B-ACP-LP-EDGS } \\
\text { ESW-PSF-LF-103 } \\
\text { RA-14D } \\
\text { RCI-PSF-HW-COL10 } \\
\text { ESW-PSF-LF-102 } \\
\text { ESW-PSF-LF-02 } \\
\text { HCI-PSF-HW-SUP12 } \\
\text { HCI-PSF-HW-INJ09 } \\
\text { RCI-PSF-HW-INJ06 } \\
\text { RCI-PSF-HW-SUP09 } \\
\text { DGACTB } \\
\text { DCP-BAT-LP-C3 } \\
\text { RA-18D } \\
\text { RA-17D }\end{array}$ & $\begin{array}{l}1.68 \mathrm{E}-7 \\
1.58 \mathrm{E}-7 \\
1.56 \mathrm{E}-7 \\
5.23 \mathrm{E}-8 \\
1.74 \mathrm{E}-8 \\
8.90 \mathrm{E}-9 \\
7.96 \mathrm{E}-9 \\
7.18 \mathrm{E}-9 \\
5.11 \mathrm{E}-9 \\
4.78 \mathrm{E}-9 \\
3.88 \mathrm{E}-9 \\
2.44 \mathrm{E}-9 \\
2.29 \mathrm{E}-9 \\
1.31 \mathrm{E}-9 \\
1.06 \mathrm{E}-9 \\
9.58 \mathrm{E}-10 \\
6.64 \mathrm{E}-10 \\
4.28 \mathrm{E}-10 \\
4.10 \mathrm{E}-10 \\
8.78 \mathrm{E}-10 \\
1.78 \mathrm{E}-10 \\
1.73 \mathrm{E}-10 \\
1.72 \mathrm{E}-10 \\
1.66 \mathrm{E}-10 \\
1.48 \mathrm{E}-10 \\
1.17 \mathrm{E}-10 \\
0.00 \mathrm{E}+0 \\
0.00 \mathrm{E}+0\end{array}$ \\
\hline
\end{tabular}


SEQUENCE TBUP - SENSITIVITY ISSUE 3 (CONCLUDED)

\begin{tabular}{rlr}
\hline $\begin{array}{c}\text { IMPORTANCE } \\
\text { MEASURE }\end{array}$ & EVENT & VALUE \\
\hline & & \\
Uncertainty & RA-16D & $0.00 E+0$ \\
(Concluded) & ECW-XHE-FO-ECWPP & $0.00 E+0$ \\
& IE-TLOSP & $1.41 E-7$ \\
& IE-TRTRIP & $1.37 \mathrm{E}-8$ \\
& IE-TMSIVC & $4.35 \mathrm{E}-9$ \\
& IE-TLFW & $3.84 \mathrm{E}-9$ \\
\hline
\end{tabular}


SEQUENCE TBUP - SENSITIVITY ISSUE 4

IMPORTANCE MEASURE

Risk Reduction
EVENT

SORV

DCP-BAT - LP-B2

B-DCP-LP-BATS

LOSP

RA-1D

RCI - TDP - FS - 20538

HCI -TDP-FS-20S37

ACP-DGN-LP-EDG2

ECW-XHE-FO-ECWPP

B-ACP-LP-EDGS

ESW-PSF-LF-103

RA-14D

ESW-PSF-LF-102

RA-17D

RA-16D

RA-18D

RC I - TDP-MA-20S38

ACP-DGN-LP-EDG3

HCI -TDP-MA-20S37

ACP-DGN-MA-EDG3

$A C P-D G N-M A-E D G 2$

ACP-DGN-LP-EDG4

ESW-PSF-LF - 19

ACP-DGN-MA-EDG4

RCI - PSF - HW-COL 10

DCP-BAT-LP-C3

DGACTB

ESW-PSF-LF-02

IE-TLOSP

IE-TRTRIP

IE-TMSIVC

IE-TLFW

Risk Increase

$$
\begin{aligned}
& \text { DCP-BAT-LP-B2 } \\
& \text { LOSP } \\
& \text { B-DCP-LP-BATS } \\
& \text { SORV } \\
& \text { ESW-PSF-LF-103 } \\
& \text { ACP-DGN-LP-EDG2 } \\
& \text { ESW-PSF-LF-102 } \\
& \text { B-ACP-LP-EDGS } \\
& \text { RCI -TDP-FS-20S38 } \\
& \text { HCI-TDP-FS-20S37 } \\
& \text { RCI-TDP-MA-20S38 } \\
& \text { ACP-DGN-LP-EDG3 } \\
& \text { ACP-DGN-MA-EDG3 } \\
& \text { ACP-DGN-MA-EDG2 }
\end{aligned}
$$

2. $17 \mathrm{E}-7$

2. $15 \mathrm{E}-7$

$2.14 \mathrm{E}-7$

2. $80 \mathrm{E}-8$

$3.34 \mathrm{E}-9$

2. $86 \mathrm{E}-9$

$2.31 \mathrm{E}-9$

$1.75 \mathrm{E}-9$

$1.70 \mathrm{E}-9$

$1.46 \mathrm{E}-9$

1. $26 \mathrm{E}-9$

7. $31 \mathrm{E}-10$

$6.15 \mathrm{E}-10$

$5.83 \mathrm{E}-10$

$5.44 \mathrm{E}-10$

$4.78 \mathrm{E}-10$

$4.75 \mathrm{E}-10$

$3.25 \mathrm{E}-10$

$3.03 E-10$

$2.78 \mathrm{E}-10$

$2.51 E-10$

8. $11 \mathrm{E}-11$

$5.54 \mathrm{E}-11$

4. $22 E-11$

7. $89 \mathrm{E}-12$

$5.15 \mathrm{E}-12$

4. $42 E-12$

3. $85 \mathrm{E}-12$

1. $89 \mathrm{E}-7$

$1.72 \mathrm{E}-8$

$5.75 \mathrm{E}-9$

$5.03 E-9$

$1.61 E-4$

1. $05 \mathrm{E}-5$

5. $13 E-6$

4. $13 \mathrm{E}-6$

2. $20 \mathrm{E}-7$

1. $53 \mathrm{E}-7$

$1.07 \mathrm{E}-7$

$6.89 E-8$

$5.62 \mathrm{E}-8$

4. $54 \mathrm{E}-8$

2. $92 \mathrm{E}-8$

$2.86 \mathrm{E}-8$

2. $52 \mathrm{E}-8$

2. $28 \mathrm{E}-8$ 
SEQUENCE TBUP - SENSITIVITY ISSUE 4 (CONCLUDED)

IMPORTANCE MEASURE

Risk Increase (Concluded)

Uncertainty

\section{EVENT}

VALUE

HC I -TDP-MA-20S37

$1.87 \mathrm{E}-8$

ACP-DGN-LP-EDG4

$7.13 \mathrm{E}-9$

RA-1D

ESW-PSF - LF - 19

ACP-DGN-MA-EDG4

DGACTB

DCP-BAT-LP-C3

ESW-PSF-LF-02

RC I - PSF-HW-COL 10

RA-14D

ECW-XHE-FO-ECWPP

RA-18D

RA-17D

RA-16D

SORV

B-DCP-LP-BATS

DCP-BAT-LP-B2

LOSP

RCI - TDP-FS - 20538

RA- 1D

HCI - TDP-FS-20S37

ACP-DGN-LP-EDG2

B-ACP-LP-EDGS

ESW-PSF-LF- 103

RCI -TDP-MA-20S38

HCI -TDP-MA-20S37

ACP-DGN-MA-EDG3

ESW-PSF-LF- 102

ACP-DGN-MA-EDG2

$A C P-D G N-L P-E D G 3$

RA-14D

ACP-DGN-LP-EDG4

ACP-DGN-MA-EDG4

ESW-PSF-LF-19

ESW-PSF-LF-02

RCI - PSF - HW-COL 10

DGACTB

DCP-BAT-LP-C3

ECW-XHE-FO-ECWPP

RA-18D

RA-17D

RA-16D

IE-TLOSP

IE-TRTRIP

IE-TMSIVC

IE-TLFW
$5.02 \mathrm{E}-9$

4. $98 \mathrm{E}-9$

$3.83 \mathrm{E}-9$

2. $74 \mathrm{E}-9$

$2.74 \mathrm{E}-9$

$1.83 \mathrm{E}-9$

$1.04 \mathrm{E}-9$

$1.83 E-10$

$0.00 E+0$

$0.00 E+0$

$0.00 \mathrm{E}+0$

$0.00 \mathrm{E}+0$

1. $60 \mathrm{E}-7$

1. $56 \mathrm{E}-7$

1. $56 \mathrm{E}-7$

4. $95 \mathrm{E}-8$

2. $01 \mathrm{E}-9$

$1.95 \mathrm{E}-9$

$1.83 E-9$

1. $31 \mathrm{E}-9$

$1.06 \mathrm{E}-9$

9. $88 \mathrm{E}-10$

$9.02 \mathrm{E}-10$

8. $14 \mathrm{E}-10$

4. $60 \mathrm{E}-10$

4. $40 \mathrm{E}-10$

3. $29 \mathrm{E}-10$

2. $34 \mathrm{E}-10$

$1.68 \mathrm{E}-10$

5. $88 \mathrm{E}-11$

$5.44 \mathrm{E}-11$

4.02E-11

$9.09 \mathrm{E}-12$

5. $79 \mathrm{E}-12$

4. $91 \mathrm{E}-12$

$3.86 \mathrm{E}-12$

$0.00 \mathrm{E}+0$

$0.00 \mathrm{E}+0$

$0.00 \mathrm{E}+0$

$0.00 \mathrm{E}+0$

1. $33 \mathrm{E}-7$

1. $30 \mathrm{E}-8$

4. $12 \mathrm{E}-9$

3. $64 \mathrm{E}-9$ 
SEQUENCE TCSX - BASE CASE

\begin{tabular}{|c|c|c|}
\hline $\begin{array}{l}\text { IMPORTANCE } \\
\text { MEASURE }\end{array}$ & EVENT & VALUE \\
\hline Risk Reduction & $\begin{array}{l}\text { DEP-XHE } \\
\text { RPS-M } \\
\text { SLC-XHE-FS } \\
\text { CMSIVA } \\
\text { SLC-XHE-REL } \\
\text { ADS-XHE-INH2 } \\
\text { IE-TRTRIP } \\
\text { IE-TMSIVC } \\
\text { IE-TLFW } \\
\text { IE-TIORV } \\
\text { IE-TLOSP }\end{array}$ & $\begin{array}{r}2.31 \mathrm{E}-7 \\
2.31 \mathrm{E}-7 \\
1.79 \mathrm{E}-7 \\
1.06 \mathrm{E}-7 \\
5.28 \mathrm{E}-8 \\
-3.77 \mathrm{E}-8 \\
9.63 \mathrm{E}-8 \\
6.42 \mathrm{E}-8 \\
5.62 \mathrm{E}-8 \\
9.23 \mathrm{E}-9 \\
5.62 \mathrm{E}-9\end{array}$ \\
\hline Risk Increase & $\begin{array}{l}\text { RPS -M } \\
\text { SLC-XHE-REL } \\
\text { SLC-XHE-FS } \\
\text { DEP-XHE } \\
\text { CMSIVA } \\
\text { ADS-XHE-INH2 }\end{array}$ & $\begin{array}{r}2.31 \mathrm{E}-2 \\
5.23 \mathrm{E}-6 \\
5.11 \mathrm{E}-6 \\
8.55 \mathrm{E}-7 \\
1.06 \mathrm{E}-7 \\
-2.31 \mathrm{E}-7\end{array}$ \\
\hline Uncertainty & $\begin{array}{l}\text { RPS-M } \\
\text { SLC-XHE-FS } \\
\text { DEP-XHE } \\
\text { ADS-XHE-INH2 } \\
\text { CMSIVA } \\
\text { SLC-XHE-REL } \\
\text { IE-TRTRIP } \\
\text { IE-TMSIVC } \\
\text { IE-TLFW } \\
\text { IE-TIORV } \\
\text { IE-TLOSP }\end{array}$ & $\begin{array}{l}4.07 E-7 \\
2.52 E-7 \\
2.09 E-7 \\
5.97 E-8 \\
5.44 E-8 \\
4.69 E-8 \\
7.25 E-8 \\
4.60 E-8 \\
4.07 E-8 \\
6.50 E-9 \\
3.69 E-9\end{array}$ \\
\hline
\end{tabular}


SEQUENCE TCSX - SENSITIVITY ISSUE 5

\begin{tabular}{|c|c|c|}
\hline $\begin{array}{l}\text { IMPORTANCE } \\
\text { MEASURE }\end{array}$ & EVENT & VALUE \\
\hline Risk Reduction & $\begin{array}{l}\text { RPS-M } \\
\text { DEP-XHE } \\
\text { SLC-XHE-FS } \\
\text { CMSIVA } \\
\text { SLC-XHE-REL } \\
\text { ADS-XHE-INH2 } \\
\text { IE-TRTRIP } \\
\text { IE-TMSIVC } \\
\text { IE-TLFW } \\
\text { IE-TIORV } \\
\text { IE-TLOSP }\end{array}$ & $\begin{array}{r}9.14 \mathrm{E}-7 \\
9.14 \mathrm{E}-7 \\
8.61 \mathrm{E}-7 \\
4.17 \mathrm{E}-7 \\
5.28 \mathrm{E}-8 \\
-1.49 \mathrm{E}-7 \\
3.80 \mathrm{E}-7 \\
2.54 \mathrm{E}-7 \\
2.22 \mathrm{E}-7 \\
3.64 \mathrm{E}-8 \\
2.22 \mathrm{E}-8\end{array}$ \\
\hline Risk Increase & $\begin{array}{l}\text { RPS -M } \\
\text { SLC-XHE-REL } \\
\text { SLC-XHE-FS } \\
\text { DEP-XHE } \\
\text { CMSIVA } \\
\text { ADS-XHE-INH2 }\end{array}$ & $\begin{array}{r}9.14 \mathrm{E}-2 \\
5.23 \mathrm{E}-6 \\
4.42 \mathrm{E}-6 \\
3.38 \mathrm{E}-6 \\
4.17 \mathrm{E}-7 \\
-9.14 \mathrm{E}-7\end{array}$ \\
\hline Uncertainty & $\begin{array}{l}\text { RPS-M } \\
\text { SLC-XHE-FS } \\
\text { DEP-XHE } \\
\text { ADS-XHE-INH2 } \\
\text { CMSIVA } \\
\text { SLC-XHE-REL } \\
\text { IE-TRTRIP } \\
\text { IE-TMSIVC } \\
\text { IE-TLFW } \\
\text { IE-TIORV } \\
\text { IE-TLOSP }\end{array}$ & $\begin{array}{l}1.61 \mathrm{E}-6 \\
1.24 \mathrm{E}-6 \\
8.27 \mathrm{E}-7 \\
2.36 \mathrm{E}-7 \\
2.15 \mathrm{E}-7 \\
4.69 \mathrm{E}-8 \\
2.86 \mathrm{E}-7 \\
1.82 \mathrm{E}-7 \\
1.61 \mathrm{E}-7 \\
2.57 \mathrm{E}-8 \\
1.56 \mathrm{E}-8\end{array}$ \\
\hline
\end{tabular}


SEQUENCE TBU - BASE CASE

IMPORTANCE MEASURE

EVENT

VALUE

Risk Reduction

RA-1D

RCI -TDP-FS-20S38

$1.78 \mathrm{E}-7$

$1.41 \mathrm{E}-7$

HCI - TDP-FS-20S37

$8.59 E-8$

RA-14D

DCP-BAT - LP-B2

$A C P-D G N-L P-E D G 2$

ACP-DGN-LP-EDG3

$7.63 \mathrm{E}-8$

$7.53 E-8$

RA-16D

$6.53 \mathrm{E}-8$

ACP-DGN-MA-EDG3

$6.37 \mathrm{E}-8$

RCI - TDP-MA-20\$38

$5.62 \mathrm{E}-8$

$4.68 \mathrm{E}-8$

B-ACP-LP-EDGS

ESW-PSF-LF-103

3. $11 \mathrm{E}-8$

$2.93 \mathrm{E}-8$

$2.45 \mathrm{E}-8$

LOSP

2. $30 \mathrm{E}-8$

ACP-DGN-MA-EDG2

2. $00 E-8$

HCI - TDP-MA-20S37

$1.59 \mathrm{E}-8$

ESW-PSF-LF-102

1. $20 \mathrm{E}-8$

RA-17D

$1.17 \mathrm{E}-8$

RA-18D

$9.36 \mathrm{E}-9$

ECW-XHE-FO-ECWPP

$8.40 \mathrm{E}-9$

RCI - PSF-HW-COL 10

$6.15 \mathrm{E}-9$

ESW-PSF-LF-8

4. $92 \mathrm{E}-9$

ESW-PSF-LF-02

$3.48 \mathrm{E}-9$

DCP-BAT-LP-C3

3. $10 \mathrm{E}-9$

DGACTB

$2.67 \mathrm{E}-9$

RCI I PSF - HW-SUPOS

1. $75 \mathrm{E}-10$

RC I - PSF - HW - INJ06

$1.75 \mathrm{E}-10$

HCI-PSF-HW-SUP12

$1.75 \mathrm{E}-10$

HCI-PSF-HW-INJ09

$1.75 \mathrm{E}-10$

IE-TLOSP

IE-TRTRIP

$1.55 \mathrm{E}-7$

IE-TMSIVC

$1.42 \mathrm{E}-8$

4.72E-9

IE-TLFW

$4.13 E-9$

Risk Increase

ESW-PSF-LF-8

$1.64 \mathrm{E}-4$

DCP-BAT-LP-B2

$5.73 \mathrm{E}-5$

LOSP

$8.64 \mathrm{E}-6$

ACP-DGN-LP-EDG2

$5.74 \mathrm{E}-6$

ACP-DGN-LP-EDG3

$5.60 \mathrm{E}-6$

ESW-PSF-LF-103

4. $28 \mathrm{E}-6$

ACP-DGN-MA-EDG3

4. $25 \mathrm{E}-6$

RCI - TDP-FS-20S38

$2.77 \mathrm{E}-6$

ESW-PSF-LF - 102

$2.09 \mathrm{E}-6$

RCI - TDP-MA-20S38

$1.91 \mathrm{E}-6$

ACP-DGN-MA-EDG2

$1.82 \mathrm{E}-6$

HCI - TDP-FS - 20S37

$1.69 \mathrm{E}-6$

DGACTB

$1.65 E-6$

DCP-BAT-LP-C3

$1.65 \mathrm{E}-6$

ESW-PSF-LF-02

$1.65 \mathrm{E}-6$ 
SEQUENCE TBU - BASE CASE (CONCLUDED)

\section{IMPORTANCE}

MEASURE

Risk Increase

(Concluded)

Uncertainty
EVENT

$B-A C P-L P-E D G S$

HC I - TDP-MA-20S37

RCI-PSF-HW-COL10

RA-1D

RCI - PSF - HW-SUPO9

RCI - PSF-HW-INJO6

HCI -PSF-HW-SUP12

HCI - PSF-HW-INJ09

RA-14D

RA- $18 D$

RA-17D

RA-16D

ECW-XHE-FO-ECWPP

RA-1D

RCI - TDP-FS-20S38

$A C P-D G N-M A-E D G 3$

HCI -TDP-FS-20S37

RCI I TDP-MA-20S38

DCP-BAT-LP-B2

ACP-DGN-LP-EDG2

ACP-DGN-LP-EDG3

HCI -TDP-MA-20S37

LOSP

ACP-DGN-MA-EDG2

B-ACP-LP-EDGS

ESW-PSF-LF-103

RA-14D

ESW-PSF-LF-8

ESW-PSF-LF-102

ESW-PSF-LF-02

RCI-PSF-HW-COL10

DGACTB

DCP-BAT- LP-C3

HCI -PSF-HW-SUP12

HCI - PSF - HW - INJ09

RCI - PSF-HW-INJO9

RCI - PSF-HW-SUPO9

RA-18D

RA-17D

RA-16D

ECW-XHE-FO-ECWPP

IE-TLOSP

IE-TRTRIP

IE-TMSIVC

IE-TLFW
VALUE

1. $38 \mathrm{E}-6$

9.81E-7

8. $14 \mathrm{E}-7$

$2.68 \mathrm{E}-7$

$4.65 \mathrm{E}-8$

$4.65 E-8$

4. $65 \mathrm{E}-8$

$4.65 E-8$

$1.91 \mathrm{E}-8$

$0.00 E+0$

$0.00 \mathrm{E}+0$

$0.00 E+0$

$0.00 E+0$

$1.04 \mathrm{E}-7$

$9.88 \mathrm{E}-8$

$7.76 \mathrm{E}-8$

$6.82 \mathrm{E}-8$

$5.91 E-8$

$5.54 \mathrm{E}-8$

$4.88 \mathrm{E}-8$

$4.58 \mathrm{E}-8$

4. $28 \mathrm{E}-8$

$4.07 \mathrm{E}-8$

2. $62 \mathrm{E}-8$

$2.11 \mathrm{E}-8$

$1.92 \mathrm{E}-8$

$1.76 \mathrm{E}-8$

1. $31 \mathrm{E}-8$

8. $56 E-9$

8. $20 E-9$

4.51E-9

2. $96 E-9$

2. $33 E-9$

1. $34 \mathrm{E}-10$

1. $30 \mathrm{E}-10$

$1.29 E-10$

$1.25 \mathrm{E}-10$

$0.00 E+0$

$0.00 E+0$

$0.00 E+0$

$0.00 \mathrm{E}+0$

1. $10 \mathrm{E}-7$

1.07E-8

3. $39 \mathrm{E}-9$

$2.99 E-9$ 
SEQUENCE TBU - SENSITIVITY ISSUE 1

\begin{tabular}{|c|c|c|}
\hline $\begin{array}{l}\text { IMPORTANCE } \\
\text { MEASURE }\end{array}$ & EVENT & VALUE \\
\hline Risk Reduction & $\begin{array}{l}\text { RA-1D } \\
\text { RCI-TDP-FS-20S38 } \\
\text { RA-14D } \\
\text { DCP-BAT-LP-B2 } \\
\text { ACP-DGN-LP-EDG3 } \\
\text { HCI-TDP-FS-20S37 } \\
\text { RA-16D } \\
\text { ACP-DGN-MA-EDG3 } \\
\text { ACP-DGN-LP-EDG2 } \\
\text { RCI -TDP-MA-20S38 } \\
\text { ESW-PSF-LF-103 } \\
\text { ACP-DGN-MA-EDG2 } \\
\text { LOSP } \\
\text { ESW-PSF-LF-102 } \\
\text { HCI -TDP-MA-20S37 } \\
\text { RA-18D } \\
\text { ECW-XHE-FO-ECWPP } \\
\text { RCI-PSF-HW-COL10 } \\
\text { ESW-PSF-LF-8 } \\
\text { ESW-PSF-LF-02 } \\
\text { DCP-BAT-LP-C3 } \\
\text { DGACTB } \\
\text { RCI - PSF-HW-SUP09 } \\
\text { RCI -PSF-HW-INJ06 } \\
\text { HCI - PSF-HW-SUP12 } \\
\text { HCI -PSF-HW-INJ09 } \\
\text { IE-TLOSP } \\
\text { IE-TRTRIP } \\
\text { IE-TMSIVC } \\
\text { IE-TLFW }\end{array}$ & $\begin{array}{l}1.49 \mathrm{E}-7 \\
1.17 \mathrm{E}-7 \\
7.63 \mathrm{E}-8 \\
7.63 \mathrm{E}-8 \\
6.37 \mathrm{E}-8 \\
6.24 \mathrm{E}-8 \\
5.62 \mathrm{E}-8 \\
4.68 \mathrm{E}-8 \\
3.60 \mathrm{E}-8 \\
2.52 \mathrm{E}-8 \\
2.45 \mathrm{E}-8 \\
2.00 \mathrm{E}-8 \\
1.93 \mathrm{E}-8 \\
1.20 \mathrm{E}-8 \\
1.01 \mathrm{E}-8 \\
9.36 \mathrm{E}-9 \\
8.40 \mathrm{E}-9 \\
6.15 \mathrm{E}-9 \\
4.92 \mathrm{E}-9 \\
3.48 \mathrm{E}-9 \\
3.10 \mathrm{E}-9 \\
2.67 \mathrm{E}-9 \\
1.75 \mathrm{E}-10 \\
1.75 \mathrm{E}-10 \\
1.75 \mathrm{E}-10 \\
1.75 \mathrm{E}-10 \\
1.30 \mathrm{E}-7 \\
1.18 \mathrm{E}-8 \\
3.95 \mathrm{E}-9 \\
3.46 \mathrm{E}-9\end{array}$ \\
\hline Risk Increase & $\begin{array}{l}\text { ESW-PSF-LF-8 } \\
\text { DCP-BAT-LP-B2 } \\
\text { LOSP } \\
\text { ACP-DGN-LP-EDG3 } \\
\text { ESW-PSF-LF-103 } \\
\text { ACP-DGN-MA-EDG3 } \\
\text { ACP-DGN-LP-EDG2 } \\
\text { RCI-TDP-FS-20S38 } \\
\text { ESW-PSF-LF-102 } \\
\text { ACP-DGN-MA-EDG2 } \\
\text { DGACTB } \\
\text { DCP-BAT-LP-C3 } \\
\text { ESW-PSF-LF-02 } \\
\text { RCI-TDP-MA-20S38 } \\
\text { HCI-TDP-FS-20S37 } \\
\text { RCI-PSF-HW-COL10 }\end{array}$ & $\begin{array}{l}1.64 \mathrm{E}-4 \\
5.73 \mathrm{E}-5 \\
7.22 \mathrm{E}-6 \\
5.60 \mathrm{E}-6 \\
4.28 \mathrm{E}-6 \\
4.25 \mathrm{E}-6 \\
3.16 \mathrm{E}-6 \\
2.31 \mathrm{E}-6 \\
2.09 \mathrm{E}-6 \\
1.82 \mathrm{E}-6 \\
1.65 \mathrm{E}-6 \\
1.65 \mathrm{E}-6 \\
1.65 \mathrm{E}-6 \\
1.55 \mathrm{E}-6 \\
1.23 \mathrm{E}-6 \\
8.14 \mathrm{E}-7\end{array}$ \\
\hline
\end{tabular}


SEQUENCE TBU - SENSITIVITY ISSUE 1 (CONCLUDED)

\begin{tabular}{|c|c|c|}
\hline $\begin{array}{l}\text { IMPORTANCE } \\
\text { MEASURE }\end{array}$ & EVENT & VALUE \\
\hline $\begin{array}{l}\text { Risk Increase } \\
\text { (Concluded) }\end{array}$ & $\begin{array}{l}\text { HCI -TDP-MA-20S37 } \\
\text { RA-1D } \\
\text { RCI-PSF-HW-SUP09 } \\
\text { RCI-PSF-HW-INJ06 } \\
\text { HCI-PSF-HW-SUP12 } \\
\text { HCI-PSF-HW-INJ09 } \\
\text { RA-14D } \\
\text { RA-18D } \\
\text { RA-16D } \\
\text { ECW-XHE-FO-ECWPP }\end{array}$ & $\begin{array}{l}6.22 \mathrm{E}-7 \\
2.24 \mathrm{E}-7 \\
4.65 \mathrm{E}-8 \\
4.65 \mathrm{E}-8 \\
4.65 \mathrm{E}-8 \\
4.65 \mathrm{E}-8 \\
1.91 \mathrm{E}-8 \\
0.00 \mathrm{E}+0 \\
0.00 \mathrm{E}+0 \\
0.00 \mathrm{E}+0\end{array}$ \\
\hline Uncertainty & $\begin{array}{l}\text { RA-1D } \\
\text { RCI-TDP-FS-20S33 } \\
\text { ACP-DGN-MA-EDG3 } \\
\text { DCP-BAT-LP-B2 } \\
\text { HCI-TDP-FS-20S37 } \\
\text { RCI-TDP-MA-20S38 } \\
\text { ACP-DGN-LP-EDG3 } \\
\text { LOSP } \\
\text { HCI-TDP-MA-20S37 } \\
\text { ACP-DGN-LP-EDG2 } \\
\text { ACP-DGN-MA-EDG2 } \\
\text { ESW-PSF-LF-103 } \\
\text { RA-14D } \\
\text { ESW-PSF-LF-8 } \\
\text { ESW-PSF-LF-102 } \\
\text { RCI-PSF-HW-COL10 } \\
\text { DGACTB } \\
\text { DCP-BAT-LP-C3 } \\
\text { HCI-PSF-HW-SUP12 } \\
\text { HCI-PSF-HW-INJ09 } \\
\text { RCI-PSF-HW-INJ06 } \\
\text { RCI-PSF-HW-SUP09 } \\
\text { RA-18D } \\
\text { RA-16D } \\
\text { ECW-XHE-FO-ECWPP } \\
\text { IE-TLOSP } \\
\text { IE-TRTRIP } \\
\text { IE-TMSIVC } \\
\text { IE-TLFW }\end{array}$ & $\begin{array}{l}8.72 \mathrm{E}-8 \\
8.24 \mathrm{E}-8 \\
7.76 \mathrm{E}-8 \\
5.54 \mathrm{E}-8 \\
4.95 \mathrm{E}-8 \\
4.80 \mathrm{E}-8 \\
4.58 \mathrm{E}-8 \\
3.40 \mathrm{E}-8 \\
2.72 \mathrm{E}-8 \\
2.69 \mathrm{E}-8 \\
2.62 \mathrm{E}-8 \\
1.92 \mathrm{E}-8 \\
1.76 \mathrm{E}-8 \\
1.31 \mathrm{E}-8 \\
8.56 \mathrm{E}-9 \\
4.51 \mathrm{E}-9 \\
2.96 \mathrm{E}-9 \\
2.33 \mathrm{E}-9 \\
1.34 \mathrm{E}-10 \\
1.30 \mathrm{E}-10 \\
1.29 \mathrm{E}-10 \\
1.25 \mathrm{E}-10 \\
0.00 \mathrm{E}+0 \\
0.00 \mathrm{E}+0 \\
0.00 \mathrm{E}+0 \\
9.16 \mathrm{E}-8 \\
8.93 \mathrm{E}-9 \\
2.83 \mathrm{E}-9 \\
2.50 \mathrm{E}-9\end{array}$ \\
\hline
\end{tabular}


SEQUENCE TBU - SENSITIVITY ISSUE 2

\begin{tabular}{|c|c|c|}
\hline $\begin{array}{l}\text { IMPORTANCE } \\
\text { MEASURE }\end{array}$ & EVENT & VALUE \\
\hline Risk Reduction & $\begin{array}{l}\text { RA-10 } \\
\text { RCI-TDP-FS-20S38 } \\
\text { HCI-TDP-FS-20S37 } \\
\text { ACP-DGN-LP-EDG2 } \\
\text { RA-14D } \\
\text { DCP-BAT-LP-B2 } \\
\text { B-ACP-LP-EDGS } \\
\text { ACP-DGN-LP-EDG3 } \\
\text { RA-16D } \\
\text { ACP-DGN-MA-EDG3 } \\
\text { RCI-TDP-MA-20S38 } \\
\text { LOSP } \\
\text { RA-17D } \\
\text { ESW-PSF-LF-103 } \\
\text { HCI-TDP-MA-20S37 } \\
\text { ACP-DGN-MA-EDG2 } \\
\text { ESW-PSF-LF-102 } \\
\text { RA-18D } \\
\text { ECW-XHE-FO-ECWPP } \\
\text { RCI -PSF-HW-COL10 } \\
\text { ESW-PSF-LF-8 } \\
\text { ESW-PSF-LF-02 } \\
\text { DCP-BAT-LP-C3 } \\
\text { DGACTB } \\
\text { RCI-PSF-HW-SUPO9 } \\
\text { RCI-PSF-HW-INJ06 } \\
\text { HCI-PSF-HW-SUP12 } \\
\text { HCI-PSF-HW-INJ09 } \\
\text { IE-TLOSP } \\
\text { IE-TRTRIP } \\
\text { IE-TMSIVC } \\
\text { IE-TLFW }\end{array}$ & $\begin{array}{l}2.20 \mathrm{E}-7 \\
1.74 \mathrm{E}-7 \\
1.19 \mathrm{E}-7 \\
1.06 \mathrm{E}-7 \\
7.63 \mathrm{E}-8 \\
7.63 \mathrm{E}-8 \\
7.04 \mathrm{E}-8 \\
4.68 \mathrm{E}-8 \\
6.37 \mathrm{E}-8 \\
5.62 \mathrm{E}-8 \\
3.93 \mathrm{E}-8 \\
2.83 \mathrm{E}-8 \\
2.80 \mathrm{E}-8 \\
2.45 \mathrm{E}-8 \\
2.41 \mathrm{E}-8 \\
2.00 \mathrm{E}-8 \\
1.20 \mathrm{E}-8 \\
9.36 \mathrm{E}-9 \\
8.40 \mathrm{E}-9 \\
6.15 \mathrm{E}-9 \\
4.92 \mathrm{E}-9 \\
3.48 \mathrm{E}-9 \\
3.10 \mathrm{E}-9 \\
2.67 \mathrm{E}-9 \\
1.75 \mathrm{E}-10 \\
1.75 \mathrm{E}-10 \\
1.75 \mathrm{E}-10 \\
1.75 \mathrm{E}-10 \\
1.91 \mathrm{E}-7 \\
1.74 \mathrm{E}-8 \\
5.81 \mathrm{E}-9 \\
5.09 \mathrm{E}-9\end{array}$ \\
\hline Risk Increase & $\begin{array}{l}\text { ESW-PSF-LF-8 } \\
\text { DCP-BAT-LP-B2 } \\
\text { LOSP } \\
\text { ACP-DGN-LP-EDG2 } \\
\text { ACP-DGN-LP-EDG3 } \\
\text { ESW-PSF-LF-103 } \\
\text { ACP-DGN-MA-EDG3 } \\
\text { RCI-TDP-FS-20S38 } \\
\text { RCI-TDP-MA-20S38 } \\
\text { HCI-TDP-FS-20S37 } \\
\text { ESW-PSF-LF-102 } \\
\text { ACP-DGN-MA-EDG2 } \\
\text { DGACTB } \\
\text { DCP-BAT-LP-C3 }\end{array}$ & $\begin{array}{l}1.64 \mathrm{E}-4 \\
5.73 \mathrm{E}-5 \\
1.06 \mathrm{E}-5 \\
9.35 \mathrm{E}-6 \\
5.60 \mathrm{E}-6 \\
4.28 \mathrm{E}-6 \\
4.25 \mathrm{E}-6 \\
3.42 \mathrm{E}-6 \\
2.41 \mathrm{E}-6 \\
2.34 \mathrm{E}-6 \\
2.09 \mathrm{E}-6 \\
1.82 \mathrm{E}-6 \\
1.65 \mathrm{E}-6 \\
1.65 \mathrm{E}-6\end{array}$ \\
\hline
\end{tabular}


SEQUENCE TBU - SENSITIVITY ISSUE 2 (CONCLUDED)

\section{IMPORTANCE MEASURE}

Risk Increase

(Concluded)

Uncertainty

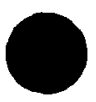

\section{VALUE}

\section{EVENT}

$1.65 \mathrm{E}-6$

$1.48 \mathrm{E}-6$

$1.34 \mathrm{E}-6$

8.14E-7

$3.29 \mathrm{E}-7$

$4.65 \mathrm{E}-8$

$4.65 \mathrm{E}-8$

$4.65 E-8$

$4.65 E-8$

$1.91 E-8$

$0.00 E+0$

$0.00 \mathrm{E}+0$

$0.00 \mathrm{E}+0$

$0.00 E+0$

$1.28 \mathrm{E}-7$

1. $22 \mathrm{E}-7$

$9.43 \mathrm{E}-8$

$7.95 \mathrm{E}-8$

$7.76 \mathrm{E}-8$

$7.46 \mathrm{E}-8$

$6.47 \mathrm{E}-8$

$5.54 \mathrm{E}-8$

$5.08 \mathrm{E}-8$

$5.01 \mathrm{E}-8$

$4.58 \mathrm{E}-8$

2. $62 \mathrm{E}-8$

1. $92 \mathrm{E}-8$

$1.76 \mathrm{E}-8$

1. $31 \mathrm{E}-8$

8. $56 \mathrm{E}-9$

8. $20 \mathrm{E}-9$

4. $51 E-9$

2. $96 \mathrm{E}-9$

2. $33 E-9$

1. $34 \mathrm{E}-10$

1. $30 \mathrm{E}-10$

1. $29 \mathrm{E}-10$

$1.25 E-10$

$0.00 E+0$

$0.00 E+0$

$0.00 E+0$

$0.00 E+0$

1.35E-7

1.31E-8

4. $17 \mathrm{E}-9$

3. $68 \mathrm{E}-9$ 
SEQUENCE TBU - SENSITIVITY ISSUE 3

IMPORTANCE MEASURE

Risk Reduction

\section{EVENT}

RA-10

RCI - TDP-FS-20S38

HCI - TDP -FS-20S37

ECW-XHE-FO-ECWPP

ESW-PSF-LF-8

RA-14D

DCP-BAT-LP-B2

$A C P-D G N-L P-E D G 2$

$A C P-D G N-L P-E D G 3$

RA-16D

RCI - TDP-MA-20S38

ACP-DGN-MA-EDG3

LOSP

HCI - TDP-MA-20S37

B-ACP-LP-EDGS

ESW-PSF-LF-103

ACP-DGN-MA-EDG2

RCI - PSF-HW-COL10

ESW-PSF-LF-102

RA-170

RA-180

RCI - PSF - HW-SUP09

RCI - PSF - HW-INJ06

HCI - PSF-HW-SUP12

HCI - PSF-HW-INJ09

ESW-PSF-LF-02

DCP-BAT-LP-C3

DGACTB

IE-TLOSP

IE-TRTRIP

IE-TMSIVC

IE-TLFW

Risk Increase
ESW-PSF - LF - 8
DCP-BAT-LP-B2
LOSP
ACP-DGN-LP-EDG2
$A C P-D G N-L P-E D G 3$
RCI - TDP-FS-20S38
ESW-PSF-LF-103
ACP-DGN-MA-EDG3
HCI - TDP -FS - 20S37
RCI I TDP-MA-20S38
RCI - PSF-HW-COL 10
HCI - TDP-MA-20S37
ESW-PSF-LF-102
ACP-DGN-MA-EDG2
DGACTB

\section{VALUE}

$3.05 \mathrm{E}-7$

$2.27 \mathrm{E}-7$

$1.81 E-7$

$1.35 \mathrm{E}-7$

$1.31 \mathrm{E}-7$

$7.63 \mathrm{E}-8$

$7.63 \mathrm{E}-8$

$6.53 E-8$

$6.37 E-8$

$5.62 E-8$

$5.02 \mathrm{E}-8$

$4.68 \mathrm{E}-8$

$3.93 \mathrm{E}-8$

3. $81 \mathrm{E}-8$

$2.93 \mathrm{E}-8$

2. $45 \mathrm{E}-8$

2. $00 \mathrm{E}-8$

$1.81 \mathrm{E}-8$

$1.20 \mathrm{E}-8$

1. $17 \mathrm{E}-8$

$9.36 \mathrm{E}-9$

4. $67 \mathrm{E}-9$

4. $67 \mathrm{E}-9$

4. $67 \mathrm{E}-9$

$4.67 \mathrm{E}-9$

$3.48 \mathrm{E}-9$

3. $10 \mathrm{E}-9$

$2.67 E-9$

2. $65 \mathrm{E}-7$

2. $42 \mathrm{E}-8$

8. $07 \mathrm{E}-9$

$7.06 \mathrm{E}-9$

$1.64 E-4$

$5.73 \mathrm{E}-5$

$1.47 \mathrm{E}-5$

$5.74 E-6$

5. $60 \mathrm{E}-6$

4. $46 \mathrm{E}-6$

4. $28 \mathrm{E}-6$

4. $25 \mathrm{E}-6$

$3.56 \mathrm{E}-6$

$3.09 \mathrm{E}-6$

2. $40 \mathrm{E}-6$

2. $34 \mathrm{E}-6$

$2.09 \mathrm{E}-6$

$1.82 \mathrm{E}-6$

1. $65 \mathrm{E}-6$ 
SEQUENCE TBU - SENSITIVITY ISSUE 3 (CONCLUDED)

IMPORTANCE

MEASURE

Risk Increase

(Concluded)

Uncertainty
EVENT

DCP-BAT-LP-C3

ESW-PSF-LF-02

B-ACP-LP-EDGS

RCI - PSF-HW-SUPO9

RCI - PSF-HW-INJ06

HCI - PSF-HW-SUP12

HCI - PSF-HW-INJO9

RA-1D

RA-14D

RA-18D

RA-17D

RA-16D

ECW-XHE-FO-ECWPP

ESW-PSF-LF-8

RA-1D

RCI - TDP - FS - $20 \$ 38$

HCI I TDP-FS-20S37

HCI - TDP-MA-20S37

RCI - TDP - MA-20S38

ACP-DGN-MA-EDG3

LOSP

DCP-BAT-LP-B2

$A C P-D G N-L P-E D G 2$

ACP-DGN-LP-EDG3

ACP-DGN-MA-EDG2

B-ACP-LP-EDGS

ESW-PSF-LF-103

RA-14D

RCI -PSF-HW-COL10

ESW-PSF-LF-102

ESW-PSF-LF-02

HCI - PSF-HW-SUP12

HCI - PSF-HW-INJ09

RCI - PSF-HW-INJ06

RCI - PSF-HW-SUPO 9

DGACTB

DCP-BAT-LP-C3

RA-18D

RA-17D

RA-16D

ECW-XHE-FO-ECWPP

IE-TLOSP

IE-TRTRIP

IE-TMSIVC

IE-TLFW
VALUE

$1.65 E-6$

1. $65 \mathrm{E}-6$

1. $38 \mathrm{E}-6$

1. $24 \mathrm{E}-6$

1. $24 \mathrm{E}-6$

$1.24 \mathrm{E}-6$

1. $24 \mathrm{E}-6$

4. $57 \mathrm{E}-7$

1. $91 \mathrm{E}-8$

$0.00 E+0$

$0.00 E+0$

$0.00 E+0$

$0.00 E+0$

$3.48 \mathrm{E}-7$

1.78E-7

$1.59 \mathrm{E}-7$

1. $44 \mathrm{E}-7$

$1.02 \mathrm{E}-7$

9. $55 \mathrm{E}-8$

$7.76 E-8$

$6.95 \mathrm{E}-8$

$5.54 E-8$

$4.88 E-8$

4. $58 \mathrm{E}-8$

2. $62 E-8$

2.1IE-8

$1.92 E-8$

$1.76 \mathrm{E}-8$

1. $33 \mathrm{E}-8$

8. $56 \mathrm{E}-9$

8. $20 E-9$

$3.56 \mathrm{E}-9$

$3.47 \mathrm{E}-9$

$3.45 \mathrm{E}-9$

3. $33 \mathrm{E}-9$

2. $96 \mathrm{E}-9$

2. $33 \mathrm{E}-9$

$0.00 E+0$

$0.00 E+0$

$0.00 E+0$

$0.00 E+0$

$1.87 \mathrm{E}-7$

1. $82 E-8$

$5.78 \mathrm{E}-9$

5.11E-9 
SEQUENCE TBU - SENSITIVITY ISSUE 4

IMPORTANCE MEASURE

Risk Reduction

Risk Increase
RA-10

RCI -TDP-FS- 20 S 38

HCI - TDP-FS-20S37

ACP-DGN-LP-EDG2

ECW-XHE-FO-ECWPP

B-ACP-LP-EDGS

ESW-PSF-LF-103

RA-14D

DCP-BAT-LP-B2

ESW-PSF-LF-102

RA-17D

RA-16D

$\mathrm{RA}-18 \mathrm{D}$

RC I - TDP-MA-20S38

LOSP

ACP-DGN-LP-EDG3

HCI - TDP-MA-20S37

ACP-DGN-MA-EDG3

$A C P-D G N-M A-E D G 2$

ACP-DGN-LP-EDG4

ESW-PSF-LF- 19

ACP-DGN-MA-EDG4

RCI - PSF-HW-COL10

DCP-BAT-LP-C3

DGACTB

ESW-PSF-LF-02

IE-TLOSP

IE-TRTRIP

IE-TMSIVC

IE-TLFW

DCP-BAT-LP-B2

ESW-PSF-LF-103

LOSP

ACP-DGN-LP-EDG2

ESW-PSF-LF- 102

B-ACP-LP-EDGS

RCI - TDP-FS-20S38

HCI - TDP-FS-20S37

RCI - TDP-MA-20S38

ACP-DGN-LP-EDG3

ACP-DGN-MA-EDG3

ACP-DGN-MA-EDG2

HCI - TDP-MA-20S37

ACP-DGN-LP-EDG4

RA-1D
VALUE

$6.69 E-8$

$5.72 \mathrm{E}-8$

$4.62 E-8$

$3.49 \mathrm{E}-8$

3. $41 \mathrm{E}-8$

2. $93 E-8$

2. $53 \mathrm{E}-8$

$1.46 \mathrm{E}-8$

$1,46 \mathrm{E}-8$

1. $23 \mathrm{E}-8$

$1.17 \mathrm{E}-8$

$1.09 \mathrm{E}-8$

9. $57 \mathrm{E}-9$

$9.49 E-9$

$8.63 E-9$

$6.50 \mathrm{E}-9$

$6.07 E-9$

$5.55 \mathrm{E}-9$

$5.02 E-9$

$1.62 \mathrm{E}-9$

1. $11 \mathrm{E}-9$

8. $44 \mathrm{E}-10$

1. $58 \mathrm{E}-10$

1. $03 \mathrm{E}-10$

8. $84 \mathrm{E}-11$

$7.70 \mathrm{E}-11$

$5.82 \mathrm{E}-8$

5. $31 E-9$

1.77E-9

1. $55 \mathrm{E}-9$

$1.10 \mathrm{E}-5$

4. $41 \mathrm{E}-6$

3. $24 \mathrm{E}-6$

$3.07 \mathrm{E}-6$

2. $15 \mathrm{E}-6$

1. $38 \mathrm{E}-6$

$1.12 \mathrm{E}-6$

$9.08 \mathrm{E}-7$

5.84E-7

5.71E-7

$5.04 \mathrm{E}-7$

4. 56E-7

$3.73 \mathrm{E}-7$

1. $43 \mathrm{E}-7$

1.00E-7 
SEQUENCE TBU - SENSITIVITY ISSUE 4 (CONCLUDED)

IMPORTANCE MEASURE

Risk Increase

(Concluded)

Uncertainty

\section{EVENT}

\section{VALUE}

$9.96 \mathrm{E}-8$

$7.66 \mathrm{E}-8$

$5.48 E-8$

$5.48 E-8$

$3.66 E-8$

$2.09 E-8$

$3.66 \mathrm{E}-9$

$0.00 E+0$

$0.00 E+0$

$0.00 E+0$

$0.00 E+0$

RA-160

RCI - TDP-FS - 20 S38

RA-1D

HCI -TDP-FS - 20S37

ACP-DGN-LP-EDG2

B-ACP-LP-EDGS

ESW-PSF-LF- 103

RCI -TDP-MA-20S38

HCI -TDP-MA-20S37

L.OSP

DCP-BAT-LP-B2

$A C P-D G N-M A-E D G 3$

ESW-PSF-LF- 102

ACP-DGN-MA-EDG2

ACP-DGN-LP-EDG3

RA-14D

ACP-DGN-LP-EDG4

ACP-DGN-MA-EDG4

ESW-PSF-LF-I9

ESW-PSF-LF-02

RCI - PSF-HW-COL 10

DGACTB

DCP-BAT-LP-C3

RA-18D

ECW-XHE-FO-ECWPP

RA-17D

RA-160

IE-TLOSP

IE-TRTRIP

IE-TMSIVC

IE-TLFW
4.01E-8

$3.91 \mathrm{E}-8$

$3.67 \mathrm{E}-8$

$2.61 \mathrm{E}-8$

$2.11 \mathrm{E}-8$

$1.98 \mathrm{E}-8$

1. $80 \mathrm{E}-8$

$1.63 \mathrm{E}-8$

1. $53 \mathrm{E}-8$

1. $06 \mathrm{E}-8$

9. $20 \mathrm{E}-9$

$6.58 \mathrm{E}-9$

4.67E-9

8.81E-9

3. $37 \mathrm{E}-9$

$1.18 \mathrm{E}-9$

$1.09 E-9$

$8.04 E-10$

$1.82 E-10$

1. $16 \mathrm{E}-10$

9. $82 \mathrm{E}-11$

$7.73 \mathrm{E}-11$

$0.00 E+0$

$0.00 E+0$

$0.00 E+0$

$0.00 E+0$

4. $10 \mathrm{E}-8$

4. $00 \mathrm{E}-9$

1. $27 \mathrm{E}-9$

$1.12 \mathrm{E}-9$ 
SEQUENCE TBP - BASE CASE

\begin{tabular}{|c|c|c|}
\hline $\begin{array}{l}\text { IMPORTANCE } \\
\text { MEASURE }\end{array}$ & EVENT & VALUE \\
\hline Risk Reduction & $\begin{array}{l}\text { SORV } \\
\text { RA-1J } \\
\text { RA-16J } \\
\text { ACP-DGN-LP-EDG2 } \\
\text { ACP-DGN-LP-EDG3 } \\
\text { ECW-XHE-FO-ECWPP } \\
\text { ACP-DGN-MA-EDG3 } \\
\text { ACP-DGN-MA-EDG2 } \\
\text { ESW-PSF-LF-102 } \\
\text { ESW-PSF-LF-103 } \\
\text { B-ACP-LP-EDGS } \\
\text { RA-17J } \\
\text { RA-18J } \\
\text { LOSP } \\
\text { ESW-PSF-LF-01 } \\
\text { ESW-PSF-LF-02 } \\
\text { ESW-PSF-LF-8 } \\
\text { HCI-TDP-FS-20S37 } \\
\text { EHV-PSF-LF-8 } \\
\text { EHV-PSF-LF-9 } \\
\text { ESW-MDP-FS-ESWA } \\
\text { ESW-MDP-FS-ESWB } \\
\text { HCI-TDP-MA-20S37 } \\
\text { DCP-BAT-LP-B2 } \\
\text { RA-14J } \\
\text { ACP-DGN-LP-EDG4 } \\
\text { ESW-PSF-LF-19 } \\
\text { ACP-DGN-MA-EDG4 } \\
\text { ESW-XHE-FO-EHS } \\
\text { HCI-TDP-FR-20S37 } \\
\text { HCI-PSF-HW-SUP12 } \\
\text { HCI-PSF-HW-INJ09 } \\
\text { RCI-TDP-FR-20S38 } \\
\text { IE-TLOSP } \\
\text { IE-TRTRIP } \\
\text { IE-TMSIVC } \\
\text { IE-TLFW }\end{array}$ & $\begin{array}{l}1.14 \mathrm{E}-7 \\
1.14 \mathrm{E}-7 \\
5.80 \mathrm{E}-8 \\
5.55 \mathrm{E}-8 \\
3.56 \mathrm{E}-8 \\
2.13 \mathrm{E}-8 \\
2.07 \mathrm{E}-8 \\
2.06 \mathrm{E}-8 \\
2.02 \mathrm{E}-8 \\
2.02 \mathrm{E}-8 \\
2.00 \mathrm{E}-8 \\
2.00 \mathrm{E}-8 \\
1.60 \mathrm{E}-8 \\
1.47 \mathrm{E}-8 \\
8.03 \mathrm{E}-9 \\
8.03 \mathrm{E}-9 \\
5.43 \mathrm{E}-9 \\
4.84 \mathrm{E}-9 \\
2.45 \mathrm{E}-9 \\
2.45 \mathrm{E}-9 \\
1.79 \mathrm{E}-9 \\
1.79 \mathrm{E}-9 \\
1.47 \mathrm{E}-9 \\
2.00 \mathrm{E}-10 \\
2.00 \mathrm{E}-10 \\
5.43 \mathrm{E}-11 \\
5.30 \mathrm{E}-11 \\
5.26 \mathrm{E}-11 \\
4.82 \mathrm{E}-11 \\
4.82 \mathrm{E}-11 \\
1.81 \mathrm{E}-11 \\
1.81 \mathrm{E}-11 \\
5.84 \mathrm{E}-12 \\
9.94 \mathrm{E}-8 \\
9.07 \mathrm{E}-9 \\
3.02 \mathrm{E}-9 \\
2.64 \mathrm{E}-9\end{array}$ \\
\hline Risk Increase & $\begin{array}{l}\text { ESW-PSF-LF-8 } \\
\text { LOSP } \\
\text { ACP-DGN-LP-EDG2 } \\
\text { ESW-PSF-LF-01 } \\
\text { ESW-PSF-LF-02 } \\
\text { ESW-PSF-LF-102 } \\
\text { ESW-PSF-LF-103 } \\
\text { ACP-DGN-LP-EDG3 } \\
\text { EHV-PSF-LF-9 }\end{array}$ & $\begin{array}{l}1.81 E-4 \\
5.52 E-6 \\
4.88 E-6 \\
3.82 E-6 \\
3.82 E-6 \\
3.52 E-6 \\
3.52 E-6 \\
3.13 E-6 \\
3.06 E-6\end{array}$ \\
\hline
\end{tabular}


SEQUENCE TBP - BASE CASE (CONTINUED)

IMPORTANCE MEASURE

Risk Increase

(Concluded)

Uncertainty

VALUE

EHV-PSF-LF-8

$3.06 \mathrm{E}-6$

RA-1J

SORV

ACP-DGN-MA-EDG3

ACP-DGN-MA-EDG2

B-ACP-LP-EDGS

ESW-MDP-FS-ESWA

ESW-MDP-FS-ESWB

DCP-BAT-LP-B2

HCI - TDP-FS-20S37

HCI - TDP-MA-20S37

RA-16J

$\mathrm{RA}-17 \mathrm{~J}$

RA-18J

RA-14J

HCI - PSF-HW-SUP12

HCI - PSF-HW-INJ09

ESW-XHE-FO-EHS

HCI -TDP-FR-20S37

ACP-DGN-MA-EDG4

ESW-PSF-LF-19

ACP-DGN-LP-EDG4

RCI - TDP-FR-20S38

ECW-XHE-FO-ECWPP

RA-IJ

SORV

ACP-DGN-LP-EDG2

ACP-DGN-MA-EDG3

ACP-DGN-MA-EDG2

LOSP

ACP-DGN-LP-EDG3

RA-16J

ESW-PSF-LF-02

ESW-PSF-LF-103

ESW-PSF-LF-01

B-ACP-LP-EDGS

ESW-PSF-LF-102

ESW-PSF-LF-8

RA-17J

$\mathrm{RA}-18 \mathrm{~J}$

HCI - TDP-MA-20S37

HCI - TDP-FS-20S37

ESW-MDP-FS-ESWA

ESW-MDP-FS-ESWB

EHV-PSF-LF- 9

EHV-PSF-LF-8
$2.74 E-6$

$2.17 \mathrm{E}-6$

$1.88 \mathrm{E}-6$

$1.87 \mathrm{E}-6$

9.42E-7

3. $36 \mathrm{E}-7$

3. $36 \mathrm{E}-7$

$1.07 \mathrm{E}-7$

9.52E-8

9. $02 \mathrm{E}-8$

$3.86 \mathrm{E}-8$

2. $00 \mathrm{E}-8$

1. $60 \mathrm{E}-8$

$6.48 \mathrm{E}-9$

4. $80 \mathrm{E}-9$

4. $80 \mathrm{E}-9$

4.77E-9

4.77E-9

4.77E-9

4.77E-9

4.77E-9

2. $28 \mathrm{E}-10$

$0.00 E+00$

9.89E- 8

8. $39 \mathrm{E}-8$

4. $15 \mathrm{E}-8$

$3.43 E-8$

$2.70 E-8$

2. $60 \mathrm{E}-8$

2. $56 \mathrm{E}-8$

$2.49 \mathrm{E}-8$

$1.89 \mathrm{E}-8$

$1.58 \mathrm{E}-8$

$1.57 \mathrm{E}-8$

$1.45 \mathrm{E}-8$

$1.44 \mathrm{E}-8$

$1.44 \mathrm{E}-8$

$1.03 \mathrm{E}-8$

8. $24 \mathrm{E}-9$

3. $94 \mathrm{E}-9$

3. $84 \mathrm{E}-9$

2. $26 \mathrm{E}-9$

2.01E-9

1.91E-9

$1.74 \mathrm{E}-9$ 
SEQUENCE TBP - BASE CASE (CONCLUDED)

\begin{tabular}{lll}
\hline $\begin{array}{c}\text { IMPORTANCE } \\
\text { MEASURE }\end{array}$ & \multicolumn{1}{c}{ EVENT } & VALUE \\
\hline & & \\
Uncertainty & DCP-BAT-LP-B2 & $1.45 E-10$ \\
(Concluded) & RA-14J & $1.23 E-10$ \\
& ACP-DGN-MA-EDG4 & $6.77 E-11$ \\
& ESW-XHE-FO-EHS & $4.85 E-11$ \\
ACP-DGN-LP-EDG4 & $3.93 E-11$ \\
ESW-PSF-LF-19 & $3.85 E-11$ \\
& HCI-TDP-FR-20S37 & $3.75 E-11$ \\
& HCI-PSF-HW-SUP12 & $1.38 E-11$ \\
& HCI-PSF-HW-INJ09 & $1.34 E-11$ \\
& RCI-TDP-FR-20S38 & $4.11 E-12$ \\
& ECW-XHE-FO-ECWPP & $0.00 E+00$ \\
& IE-TLOSP & $7.01 E-8$ \\
& IE-TRTRIP & $6.83 E-9$ \\
IE-TMSIVC & $2.17 E-9$ \\
& IE-TLFW & $1.91 E-9$ \\
\hline
\end{tabular}


SEQUENCE TBP - SENSITIVITY ISSUE 1

IMPORTANCE

MEASURE

Risk Reduction

SORV

RA-1J

RA-16J

ACP-DGN-LP-EDG3

ACP-DGN-LP-EDG2

ECW-XHE-FO-ECWPP

ACP-DGN-MA-EDG3

ACP-DGN-MA-EDG2

ESW-PSF-LF-103

ESW-PSF-LF-102

RA-18J

LOSP

ESW-PSF-LF-02

ESW-PSF-LF-01

ESW-PSF-LF-8

HCI -TDP-FS - 20537

EHV-PSF-LF-8

EHV-PSF-LF- 9

ESW-MDP-FS-ESWB

ESW-MDP-FS-ESWA

HCI - TDP-MA-20S37

RA-14J

DCP-BAT-LP-B2

ACP-DGN-LP-EDG4

ESW-PSF-LF- 19

ACP-DGN-MA-EDG4

HCI -TDP-FR-20S37

ESW-XHE-FO-EHS

HCI-PSF-HW-SUP12

HCI -PSF-HW-INJ09

RCI-TDP-FR-20S38

IE-TLOSP

IE-TRTRIP

IE-TMSIVC

IE-TLFW

Risk Increase

\section{VALUE}

9. $41 \mathrm{E}-8$

$9.41 \mathrm{E}-8$

$5.80 \mathrm{E}-9$

3. $56 \mathrm{E}-8$

$3.55 \mathrm{E}-8$

$2.13 \mathrm{E}-8$

$2.07 \mathrm{E}-8$

$2.06 \mathrm{E}-8$

$2.02 E-8$

$2.02 \mathrm{E}-8$

$1.60 \mathrm{E}-8$

1. $21 \mathrm{E}-9$

8.03E-9

8.03E-9

$5.43 \mathrm{E}-9$

3. $93 \mathrm{E}-9$

2. $45 \mathrm{E}-9$

$2.45 \mathrm{E}-9$

$1.79 \mathrm{E}-9$

$1.79 \mathrm{E}-9$

$1.17 \mathrm{E}-9$

2. $00 \mathrm{E}-10$

2. $00 \mathrm{E}-10$

5. $43 \mathrm{E}-11$

5. 30E-11

5. $26 \mathrm{E}-11$

4. $82 \mathrm{E}-11$

$4.82 \mathrm{E}-11$

$1.81 \mathrm{E}-11$

$1.81 \mathrm{E}-11$

5. $84 \mathrm{E}-12$

8. $20 \mathrm{E}-8$

$7.48 \mathrm{E}-9$

2. $49 \mathrm{E}-9$

2. 18E-9

1.81E-4

4. $55 \mathrm{E}-6$

3. $82 \mathrm{E}-6$

3. $82 \mathrm{E}-6$

3. 52E- 6

3. $52 \mathrm{E}-6$

3. $13 \mathrm{E}-6$

3. $12 \mathrm{E}-6$

$3.06 \mathrm{E}-6$

$3.06 \mathrm{E}-6$ 
SEQUENCE TBP - SENSITIVITY ISSUE I (CONTINUED)

\begin{tabular}{|c|c|c|}
\hline $\begin{array}{l}\text { IMPORTANCE } \\
\text { MEASURE }\end{array}$ & EVENT & VALUE \\
\hline $\begin{array}{l}\text { Risk Increase } \\
\text { (Concluded) }\end{array}$ & $\begin{array}{l}\text { RA-1J } \\
\text { ACP-DGN-MA-EDG3 } \\
\text { ACP-DGN-MA-EDG2 } \\
\text { SORV } \\
\text { ESW-MDP-FS-ESWB } \\
\text { ESW-MDP-FS-ESWA } \\
\text { DCP-BAT-LP-B2 } \\
\text { HCI-TDP-FS-20S37 } \\
\text { HCI-TDP-MA-20S37 } \\
\text { RA-16J } \\
\text { RA-18J } \\
\text { RA-14J } \\
\text { HCI-PSF-HW-SUP12 } \\
\text { HCI-PSF-HW-INJ09 } \\
\text { HCI-TDP-FR-20S37 } \\
\text { ESW-XHE-FO-EHS } \\
\text { ACP-DGN-MA-EDG4 } \\
\text { ESW-PSF-LF-19 } \\
\text { ACP-DGN-LP-EDG4 } \\
\text { RCI-TDP-FR-20S38 } \\
\text { ECW-XHE-F0-ECWPP }\end{array}$ & $\begin{array}{l}2.26 \mathrm{E}-6 \\
1.88 \mathrm{E}-6 \\
1.87 \mathrm{E}-6 \\
1.79 \mathrm{E}-6 \\
3.36 \mathrm{E}-7 \\
3.36 \mathrm{E}-7 \\
1.07 \mathrm{E}-7 \\
7.73 \mathrm{E}-8 \\
7.17 \mathrm{E}-8 \\
3.86 \mathrm{E}-8 \\
1.60 \mathrm{E}-8 \\
6.48 \mathrm{E}-9 \\
4.80 \mathrm{E}-9 \\
4.80 \mathrm{E}-9 \\
4.77 \mathrm{E}-9 \\
4.77 \mathrm{E}-9 \\
4.77 \mathrm{E}-9 \\
4.77 \mathrm{E}-9 \\
4.77 \mathrm{E}-9 \\
2.28 \mathrm{E}-10 \\
0.00 \mathrm{E}+0\end{array}$ \\
\hline Uncertainty & $\begin{array}{l}\text { RA-1J } \\
\text { SORV } \\
\text { ACP-DGN-MA-EDG3 } \\
\text { ACP-DGN-MA-EDG2 } \\
\text { ACP-DGN-LP-EDG2 } \\
\text { ACP-DGN-LP-EDG3 } \\
\text { RA-16J } \\
\text { LOSP } \\
\text { ESW-PSF-LF-02 } \\
\text { ESW-PSF-LF-103 } \\
\text { ESW-PSF-LF-01 } \\
\text { ESW-PSF-LF-102 } \\
\text { ESW-PSF-LF-8 } \\
\text { RA-18J } \\
\text { HCI-TDP-MA-20S37 } \\
\text { HCI-TDP-FS-20S37 } \\
\text { ESW-MDP-FS-ESWA } \\
\text { ESW-MDP-FS-ESWB } \\
\text { EHV-PSF-LF-9 } \\
\text { EHV-PSF-LF-8 } \\
\text { DCP-BAT-LP-B2 } \\
\text { RA-14J } \\
\text { ACP-DGN-MA-EDG4 } \\
\text { ESW-XHE-FO-EHS }\end{array}$ & $\begin{array}{l}8.16 \mathrm{E}-8 \\
6.92 \mathrm{E}-8 \\
3.43 \mathrm{E}-8 \\
2.70 \mathrm{E}-8 \\
2.65 \mathrm{E}-8 \\
2.56 \mathrm{E}-8 \\
2.49 \mathrm{E}-8 \\
2.15 \mathrm{E}-8 \\
1.89 \mathrm{E}-8 \\
1.58 \mathrm{E}-8 \\
1.57 \mathrm{E}-8 \\
1.44 \mathrm{E}-8 \\
1.44 \mathrm{E}-8 \\
8.24 \mathrm{E}-9 \\
3.13 \mathrm{E}-9 \\
3.12 \mathrm{E}-9 \\
2.26 \mathrm{E}-9 \\
2.01 \mathrm{E}-9 \\
1.91 \mathrm{E}-9 \\
1.74 \mathrm{E}-9 \\
1.45 \mathrm{E}-10 \\
1.23 \mathrm{E}-10 \\
6.77 \mathrm{E}-11 \\
4.85 \mathrm{E}-11\end{array}$ \\
\hline
\end{tabular}


SEQUENCE TBP - SENSITIVITY ISSUE 1 (CONCLUDED)

\begin{tabular}{lll}
\hline $\begin{array}{c}\text { IMPORTANCE } \\
\text { MEASURE }\end{array}$ & \multicolumn{1}{c}{ EVENT } & VALUE \\
\hline & ACP-DGN-LP-EDG4 & \\
Uncertainty & ESW-PSF-LF-19 & $3.93 E-11$ \\
(Concluded) & HCI -TDP-FR-20S37 & $3.85 E-11$ \\
& HCI -PSF-HW-SUP12 & $3.75 E-11$ \\
& HCI -PSF-HW-INJ09 & $1.38 E-11$ \\
RCI -TDP-FR-20S38 & $1.34 E-11$ \\
& ECW-XHE-FO-ECWPP & $4.11 \mathrm{E}-12$ \\
& IE-TLOSP & $0.00 \mathrm{E}+0$ \\
& IE-TRTRIP & $5.78 \mathrm{E}-8$ \\
& IE-TMSIVC & $5.63 \mathrm{E}-9$ \\
& IE-TLFW & $1.79 \mathrm{E}-9$ \\
& & $1.58 \mathrm{E}-9$ \\
\hline
\end{tabular}


SEQUENCE TBP - SENSITIVITY ISSUE 2

IMPORTANCE MEASURE
EVENT

VALUE

Risk Reduction

SORV

RA-1J

ACP-DGN-LP-EDG2

RA-16J

B-ACP-LP-EDGS

RA-17J

$A C P-D G N-L P-E D G 3$

ECW-XHE-FO-ECWPP

$A C P-D G N-M A-E D G 3$

$A C P-D G N-M A-E D G 2$

ESW-PSF-LF-102

ESW - PSF - LF - 103

LOSP

RA-18J

ESW-PSF-.LF-01

ESW-PSF-LF-02

HCI - TDP-FS - 20S37

ESW-PSF-LF-8

EHV-PSF-LF-8

EHV-PSF-LF- 9

HCI - TDP-MA-20S37

ESW-MDP-FS-ESWA

ESW-MDP-FS-ESWB

DCP-BAT - LP-B2

RA-14J

ACP-DGN-LP-EDG4

ESW-PSF-LF-19

ACP-DGN-MA-EDG4

ESW-XHE-FO-EHS

HCI - TDP-FR-20S37

HCI - PSF-HW-SUP12

HCI - PSF-HW-INJ09

RCI - TDP-FR-20S38

IE-TLOSP

IE-TRTRIP

IE-TMSIVC

IE-TLFW

Risk Increase

ESW-PSF-LF-8

$A C P-D G N-L P-E D G 2$

LOSP

ESW-PSF-LF-01

ESW-PSF-LF-02

ESW-PSF-LF-102

ESW-PSF-LF-103

RA-1J

$A C P-D G N-L P-E D G 3$

$1.42 \mathrm{E}-7$

$1.42 \mathrm{E}-7$

8. $36 \mathrm{E}-8$

$5.80 \mathrm{E}-8$

$4.81 E-8$

$4.81 E-8$

$3.56 \mathrm{E}-8$

2. $13 \mathrm{E}-8$

$2.07 \mathrm{E}-8$

2. $06 \mathrm{E}-8$

2. $02 \mathrm{E}-8$

$2.02 \mathrm{E}-8$

1. $84 \mathrm{E}-8$

1. $60 \mathrm{E}-8$

8.03E-9

8.03E-9

$6.12 \mathrm{E}-9$

$5.43 E-9$

$2.45 \mathrm{E}-9$

2. $45 \mathrm{E}-9$

1. $89 \mathrm{E}-9$

1. $79 \mathrm{E}-9$

1. $79 \mathrm{E}-9$

2. $00 \mathrm{E}-10$

2. $00 \mathrm{E}-10$

5. $43 \mathrm{E}-11$

5. $30 \mathrm{E}-11$

$5.26 \mathrm{E}-11$

4.82E-11

4. $82 \mathrm{E}-11$

$1.81 \mathrm{E}-11$

$1.81 \mathrm{E}-11$

$5.84 \mathrm{E}-12$

1. $24 \mathrm{E}-7$

1. $13 \mathrm{E}-8$

3. $77 \mathrm{E}-9$

$3.30 E-9$

1.81E-4

7. $35 E-6$

$6.88 \mathrm{E}-6$

$3.82 \mathrm{E}-6$

3. $82 E-6$

3. $52 \mathrm{E}-6$

$3.52 \mathrm{E}-6$

$3.41 \mathrm{E}-6$

$3.13 E-6$ 
SEQUENCE TBP - SENSITIVITY ISSUE 2 (CONTINUED)

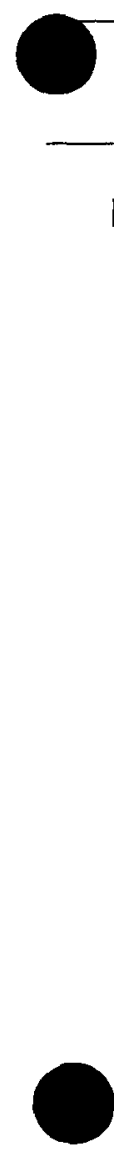

IMPORTANCE

MEASURE

EVENT

VALUE

Risk Increase

(Concluded)

Uncertainty

EHV-PSF-LF-8

EHV-PSF-LF-9

SORV

ACP-DGN-MA-EDG3

$A C P-D G N-M A-E D G 2$

B-ACP-LP-EDGS

ESW-MDP-FS-ESWA

ESW-MDP-FS-ESWB

HCI -TDP-FS - 20S37

HCI - TDP-MA-20S37

DCP-BAT-LP-B2

RA-17J

RA-16J

RA-18J

RA-14J

HCI - PSF-HW-SUP12

HCI -PSF-HW-INJO9

ESW-XHE-FO-EHS

HCI - TDP -FR-20S37

ACP-DGN-MA-EDG4

ESW-PSF-LF- 19

ACP-DGN-LP-EDG4

RCI - TDP-FR-20S38

ECW-XHE-FO-ECWPP

RA-1J

SORV

$A C P-D G N-L P-E D G 2$

B-ACP-LP-EDGS

$A C P-D G N-M A-E D G 3$

LOSP

ACP-DGN-MA-EDG2

ACP-DGN-LP-EDG3

RA-16J

$R A-17 \mathrm{~J}$

ESW-PSF-LF-02

ESW-PSF-LF-103

ESW-PSF-LF-01

ESW-PSF-LF-102

ESW-PSF-LF-8

RA-18J

HCI - TDP-MA-20S37

HCI - TDP-FS - 20S37

ESW-MDP-FS-ESWA

ESW-MDP-FS-ESWB

EHV-PSF-LF- 9

EHV-PSF-LF-8
$3.06 E-6$

3. $06 \mathrm{E}-6$

2. $70 \mathrm{E}-6$

$1.88 \mathrm{E}-6$

$1.87 \mathrm{E}-6$

9. $14 \mathrm{E}-7$

$3.36 \mathrm{E}-7$

$3.36 \mathrm{E}-7$

1. $20 \mathrm{E}-7$

1. $16 \mathrm{E}-7$

$1.07 \mathrm{E}-7$

$4.81 E-8$

$3.86 E-8$

$1.60 E-8$

$6.48 \mathrm{E}-9$

$4.80 E-9$

4. $80 E-9$

4.77E-9

4.77E-9

4.77E-9

4.77E-9

4. $77 \mathrm{E}-9$

2. $28 \mathrm{E}-10$

$0.00 E+00$

\section{$1.23 \mathrm{E}-7$}

$1.05 \mathrm{E}-7$

$6.25 E-8$

$3.48 \mathrm{E}-8$

$3.43 \mathrm{E}-8$

$3.25 \mathrm{E}-8$

2. $70 \mathrm{E}-8$

$2.56 \mathrm{E}-8$

$2.49 \mathrm{E}-8$

$2.48 \mathrm{E}-8$

$1.89 \mathrm{E}-8$

$1.58 \mathrm{E}-8$

1. $57 \mathrm{E}-8$

$1.44 \mathrm{E}-8$

$1.44 \mathrm{E}-8$

8. $24 \mathrm{E}-9$

$5.07 \mathrm{E}-9$

$4.86 \mathrm{E}-9$

2. $26 \mathrm{E}-9$

2.01E-9

$1.91 \mathrm{E}-9$

1. $74 \mathrm{E}-9$ 
SEQUENCE TBP - SENSITIVITY ISSUE 2 (CONCLUDED)

\begin{tabular}{clc}
\hline $\begin{array}{c}\text { IMPORTANCE } \\
\text { MEASURE }\end{array}$ & \multicolumn{1}{c}{ EVENT } & VALUE \\
\hline & & \\
Uncertainty & DCP-BAT-LP-B2 & $1.45 E-10$ \\
(Concluded) & RA-14J & $1.23 E-10$ \\
& ACP-DGN-MA-EDG4 & $6.77 E-11$ \\
ESW-XHE-FO-EHS & $4.85 E-11$ \\
ACP-DGN-LP-EDG4 & $3.93 E-11$ \\
ESW-PSF-LF-19 & $3.85 E-11$ \\
HCI-TDP-FR-20S37 & $3.75 E-11$ \\
& HCI-PSF-HW-SUP12 & $1.38 E-11$ \\
& HCI-PSF-HW-INJO9 & $1.34 E-11$ \\
& RCI-TDP-FR-20S38 & $4.11 E-12$ \\
& ECW-XHE-FO-ECWPP & $0.00 E+00$ \\
& IE-TLOSP & $8.73 E-8$ \\
& IE-TRTRIP & $8.51 E-9$ \\
IE-TMSIVC & $2.70 E-9$ \\
& IE-TLFW & $2.39 E-9$ \\
\hline
\end{tabular}


SEQUENCE TBP - SENSITIVITY ISSUE 3

\begin{tabular}{|c|c|c|}
\hline $\begin{array}{c}\text { IMPORTANCE } \\
\text { MEASURE }\end{array}$ & EVENT & VALUE \\
\hline Risk Reduction & $\begin{array}{l}\text { RA-1J } \\
\text { SORV } \\
\text { ECW-XHE-FO-ECWPP } \\
\text { ESW-PSF-LF-8 } \\
\text { RA-16J } \\
\text { ACP-DGN-LP-EDG2 } \\
\text { ACP-DGN-LP-EDG3 } \\
\text { LOSP } \\
\text { ACP-DGN-MA EDG3 } \\
\text { ACP-DGN-MA-EDG2 } \\
\text { ESW-PSF-LF-102 } \\
\text { ESW-PSF-LF-103 } \\
\text { B-ACP-LP-EDGS } \\
\text { RA-17J } \\
\text { RA-18J } \\
\text { HCI-TDP-FS-20S37 } \\
\text { ESW-PSF-LF-01 } \\
\text { ESW-PSF-LF-02 } \\
\text { HCI-TDP-MA-20S37 } \\
\text { EHV-PSF-LF-8 } \\
\text { EHV-PSF-LF-9 } \\
\text { ESW-MDP-FS-ESWA } \\
\text { ESW-MDP-FS-ESWB } \\
\text { ACP-DGN-LP-EDG4 } \\
\text { ESW-PSF-LF-19 } \\
\text { ACP-DGN-MA-EDG4 } \\
\text { ESW-XHE-FO-EHS } \\
\text { HCI-TDP-FR-20S37 } \\
\text { HCI-PSF-HW-SUP12 } \\
\text { HCI -PSF-HW-INJ09 } \\
\text { DCP-BAT-LP-B2 } \\
\text { RA-14J } \\
\text { RCI-TDP-FR-20S38 } \\
\text { IE-TLOSP } \\
\text { IE-TRTRIP } \\
\text { IE-TMSIVC } \\
\text { IE-TLFW }\end{array}$ & $\begin{array}{l}2.54 \mathrm{E}-7 \\
2.54 \mathrm{E}-7 \\
1.55 \mathrm{E}-7 \\
1.45 \mathrm{E}-7 \\
5.80 \mathrm{E}-8 \\
5.55 \mathrm{E}-8 \\
3.56 \mathrm{E}-8 \\
3.27 \mathrm{E}-8 \\
2.07 \mathrm{E}-8 \\
2.06 \mathrm{E}-8 \\
2.02 \mathrm{E}-8 \\
2.02 \mathrm{E}-8 \\
2.00 \mathrm{E}-8 \\
2.00 \mathrm{E}-8 \\
1.60 \mathrm{E}-8 \\
1.10 \mathrm{E}-8 \\
8.03 \mathrm{E}-9 \\
8.03 \mathrm{E}-9 \\
3.45 \mathrm{E}-9 \\
2.45 \mathrm{E}-9 \\
2.45 \mathrm{E}-9 \\
1.79 \mathrm{E}-9 \\
1.79 \mathrm{E}-9 \\
1.45 \mathrm{E}-9 \\
1.41 \mathrm{E}-9 \\
1.40 \mathrm{E}-9 \\
1.29 \mathrm{E}-9 \\
1.29 \mathrm{E}-9 \\
4.82 \mathrm{E}-10 \\
4.82 \mathrm{E}-10 \\
2.00 \mathrm{E}-10 \\
2.00 \mathrm{E}-10 \\
1.56 \mathrm{E}-10 \\
2.21 \mathrm{E}-7 \\
2.01 \mathrm{E}-8 \\
6.71 \mathrm{E}-9 \\
5.87 \mathrm{E}-9\end{array}$ \\
\hline Risk Increase & $\begin{array}{l}\text { ESW-PSF-LF-8 } \\
\text { LOSP } \\
\text { RA-1J } \\
\text { ACP-DGN-LP-EDG2 } \\
\text { SORV } \\
\text { ESW-PSF-LF-01 } \\
\text { ESW-PSF-LF-02 } \\
\text { ESW-PSF-LF-102 }\end{array}$ & $\begin{array}{l}1.81 E-4 \\
1.23 E-5 \\
6.09 E-6 \\
4.88 E-6 \\
4.82 E-6 \\
3.82 E-6 \\
3.82 E-6 \\
3.52 E-6\end{array}$ \\
\hline
\end{tabular}


SEQUENCE TBP - SENSITIVITY ISSUE 3 (CONTINUED)

\begin{tabular}{|c|c|c|}
\hline $\begin{array}{l}\text { IMPORTANCE } \\
\text { MEASURE }\end{array}$ & EVENT & VALUE \\
\hline $\begin{array}{l}\text { Risk Increase } \\
\text { (Concluded) }\end{array}$ & $\begin{array}{l}\text { ESW-PSF-LF-103 } \\
\text { ACP-DGN-LP-EDG3 } \\
\text { EHV-PSF-LF-8 } \\
\text { EHV-PSF-LF-9 } \\
\text { ACP-DGN-MA-EDG3 } \\
\text { ACP-DGN-MA-EDG2 } \\
\text { B-ACP-LP-EDGS } \\
\text { ESW-MDP-FS-ESWA } \\
\text { ESW-MDP-FS-ESWB } \\
\text { HCI-TDP-FS-20S37 } \\
\text { HCI -TDP-MA-20S37 } \\
\text { HCI-PSF-HW-SUP12 } \\
\text { HCI-PSF-HW-INJ09 } \\
\text { ESW-XHE-FO-EHS } \\
\text { HCI -TDP-FR-20S37 } \\
\text { ACP-DGN-MA-EDG4 } \\
\text { ESW-PSF-LF-19 } \\
\text { ACP-DGN-LP-EDG4 } \\
\text { DCP-BAT-LP-B2 } \\
\text { RA-16J } \\
\text { RA-17J } \\
\text { RA-18J } \\
\text { RA-14J } \\
\text { RCI-TDP-FR-20S38 } \\
\text { ECW-XHE-FO-ECWPP }\end{array}$ & $\begin{array}{l}3.52 \mathrm{E}-6 \\
3.13 \mathrm{E}-6 \\
3.06 \mathrm{E}-6 \\
3.06 \mathrm{E}-6 \\
1.88 \mathrm{E}-6 \\
1.87 \mathrm{E}-6 \\
9.42 \mathrm{E}-7 \\
3.36 \mathrm{E}-7 \\
3.36 \mathrm{E}-7 \\
2.16 \mathrm{E}-7 \\
2.12 \mathrm{E}-7 \\
1.28 \mathrm{E}-7 \\
1.28 \mathrm{E}-7 \\
1.27 \mathrm{E}-7 \\
1.27 \mathrm{E}-7 \\
1.27 \mathrm{E}-7 \\
1.27 \mathrm{E}-7 \\
1.27 \mathrm{E}-7 \\
1.07 \mathrm{E}-7 \\
3.86 \mathrm{E}-8 \\
2.00 \mathrm{E}-8 \\
1.60 \mathrm{E}-8 \\
6.48 \mathrm{E}-9 \\
6.07 \mathrm{E}-9 \\
0.00 \mathrm{E}+0\end{array}$ \\
\hline Uncertainty & $\begin{array}{l}\text { ESW-PSF-LF-8 } \\
\text { RA-1J } \\
\text { SORV } \\
\text { LOSP } \\
\text { ACP-DGN-LP-EDG2 } \\
\text { ACP-DGN-MA-EDG3 } \\
\text { ACP-DGN-MA-EDG2 } \\
\text { ACP-DGN-LP-EDG3 } \\
\text { RA-16J } \\
\text { ESW-PSF-LF-02 } \\
\text { ESW-PSF-LF-103 } \\
\text { ESW-PSF-LF-01 } \\
\text { B-ACP-LP-EDGS } \\
\text { ESW-PSF-LF-102 } \\
\text { RA-17J } \\
\text { HCI-TDP-MA-20S37 } \\
\text { HCI-TDP-FS-20S37 } \\
\text { RA-18J } \\
\text { ESW-MDP-FS-ESWA } \\
\text { ESW-MDP-FS-ESWB } \\
\text { EHV-PSF-LF-9 }\end{array}$ & $\begin{array}{l}3.84 \mathrm{E}-7 \\
2.20 \mathrm{E}-7 \\
1.86 \mathrm{E}-7 \\
5.78 \mathrm{E}-8 \\
4.15 \mathrm{E}-8 \\
3.43 \mathrm{E}-8 \\
2.70 \mathrm{E}-8 \\
2.56 \mathrm{E}-8 \\
2.49 \mathrm{E}-8 \\
1.89 \mathrm{E}-8 \\
1.58 \mathrm{E}-8 \\
1.57 \mathrm{E}-8 \\
1.45 \mathrm{E}-8 \\
1.44 \mathrm{E}-8 \\
1.03 \mathrm{E}-8 \\
9.25 \mathrm{E}-9 \\
8.72 \mathrm{E}-9 \\
8.24 \mathrm{E}-9 \\
2.26 \mathrm{E}-9 \\
2.01 \mathrm{E}-9 \\
1.91 \mathrm{E}-9\end{array}$ \\
\hline
\end{tabular}


SEQUENCE TBP - SENSITIVITY ISSUE 3 (CONTINUED)

\section{IMPORTANCE}

MEASURE

EVENT

VALUE

Uncertainty

(Concluded)
ACP-DGN-MA-EDG4

EHV-PSF - LF - 8

ESW-XHE-FO-EHS

ACP-DGN-LP-EDG4

ESW-PSF-LF-19

HCI - TDP-FR-20S37

HCI -PSF-HW-SUP12

HCI - PSF-HW-INJ09

DCP-BAT-LP-B2

$\mathrm{RA}-14 \mathrm{~J}$

RCI - TDP-FR-20S38

ECW-XHE-FO-ECWPP

IE-TLOSP

IE-TRTRIP

IE-TMSIVC

IE-TLFW
$1.81 \mathrm{E}-9$

$1.74 \mathrm{E}-9$

$1.29 \mathrm{E}-9$

$1.05 \mathrm{E}-9$

$1.03 E-9$

1. $00 \mathrm{E}-9$

$3.68 E-10$

$3.58 \mathrm{E}-10$

1. $45 \mathrm{E}-10$

$1.23 \mathrm{E}-10$

1. $10 \mathrm{E}-10$

$0.00 \mathrm{E}+0$

$1.56 \mathrm{E}-7$

1. $52 \mathrm{E}-8$

$4.81 E-9$

$4.25 \mathrm{E}-9$ 
SEQUENCE TBP - SENSITIVITY ISSUE 4

\begin{tabular}{|c|c|c|}
\hline $\begin{array}{l}\text { IMPORTANCE } \\
\text { MEASURE }\end{array}$ & EVENT & VALUE \\
\hline Risk Reduction & $\begin{array}{l}\text { RA-1J } \\
\text { SORV } \\
\text { ECW-XHE-FO-ECWPP } \\
\text { ACP-DGN-LP-EDG2 } \\
\text { ESW-PSF-LF-103 } \\
\text { ESW-PSF-LF-102 } \\
\text { B-ACP-LP-EDGS } \\
\text { RA-17J } \\
\text { RA-16J } \\
\text { RA-18J } \\
\text { ACP-DGN-LP-EDG3 } \\
\text { LOSP } \\
\text { ESW-PSF-LF-01 } \\
\text { ESW-PSF-LF-02 } \\
\text { ACP-DGN-MA-EDG3 } \\
\text { ACP-DGN-MA-EDG2 } \\
\text { ESW-MDP-FS-ESWB } \\
\text { ESW-MDP-FS-ESWA } \\
\text { ACP-DGN-LP-EDG4 } \\
\text { ESW-PSF-LF-19 } \\
\text { ACP-DGN-MA-EDG4 } \\
\text { IE-TLOSP } \\
\text { IE-TRTRIP } \\
\text { IE-TMSIVC } \\
\text { IE-TLFW }\end{array}$ & $\begin{array}{l}6.43 \mathrm{E}-8 \\
6.43 \mathrm{E}-8 \\
4.32 \mathrm{E}-8 \\
2.82 \mathrm{E}-8 \\
1.89 \mathrm{E}-8 \\
1.89 \mathrm{E}-8 \\
1.88 \mathrm{E}-8 \\
1.88 \mathrm{E}-8 \\
1.84 \mathrm{E}-8 \\
1.40 \mathrm{E}-8 \\
9.41 \mathrm{E}-9 \\
8.29 \mathrm{E}-9 \\
8.07 \mathrm{E}-9 \\
8.07 \mathrm{E}-9 \\
7.25 \mathrm{E}-9 \\
7.25 \mathrm{E}-9 \\
1.85 \mathrm{E}-9 \\
1.85 \mathrm{E}-9 \\
8.90 \mathrm{E}-10 \\
8.70 \mathrm{E}-10 \\
4.55 \mathrm{E}-10 \\
5.60 \mathrm{E}-8 \\
5.10 \mathrm{E}-9 \\
1.70 \mathrm{E}-9 \\
1.49 \mathrm{E}-9\end{array}$ \\
\hline Risk Increase & $\begin{array}{l}\text { ESW-PSF-LF-01 } \\
\text { ESW-PSF-LF-02 } \\
\text { ESW-PSF-LF-102 } \\
\text { ESW-PSF-LF-103 } \\
\text { LOSP } \\
\text { ACP-DGN-LP-EDG2 } \\
\text { RA-1J } \\
\text { SORV } \\
\text { B-ACP-LP-EDGS } \\
\text { ACP-DGN-LP-EDG3 } \\
\text { ACP-DGN-MA-EDG3 } \\
\text { ACP-DGN-MA-EDG2 } \\
\text { ESW-MDP-FS-ESWA } \\
\text { ESW-MDP-FS-ESWB } \\
\text { ESW-PSF-LF-19 } \\
\text { ACP-DGN-LP-EDG4 } \\
\text { ACP-DGN-MA-EDG4 } \\
\text { RA-17J } \\
\text { RA-18J } \\
\text { RA-16J } \\
\text { ECW-XHE-FO-ECWPP }\end{array}$ & $\begin{array}{l}3.84 \mathrm{E}-6 \\
3.84 \mathrm{E}-6 \\
3.29 \mathrm{E}-6 \\
3.29 \mathrm{E}-6 \\
3.11 \mathrm{E}-6 \\
2.48 \mathrm{E}-6 \\
1.54 \mathrm{E}-6 \\
1.22 \mathrm{E}-6 \\
8.85 \mathrm{E}-7 \\
8.27 \mathrm{E}-7 \\
6.58 \mathrm{E}-7 \\
6.58 \mathrm{E}-7 \\
3.47 \mathrm{E}-7 \\
3.47 \mathrm{E}-7 \\
7.82 \mathrm{E}-8 \\
7.82 \mathrm{E}-8 \\
4.13 \mathrm{E}-8 \\
1.88 \mathrm{E}-8 \\
1.40 \mathrm{E}-8 \\
1.23 \mathrm{E}-8 \\
0.00 \mathrm{E}+0\end{array}$ \\
\hline
\end{tabular}


SEQUENCE TBP - SENSITIVITY ISSUE 4 (CONCLUDED)

\begin{tabular}{|c|c|c|}
\hline $\begin{array}{l}\text { IMPORTANCE } \\
\text { MEASURE }\end{array}$ & EVENT & VALUE \\
\hline Uncertainty & $\begin{array}{l}\text { RA-1J } \\
\text { SORV } \\
\text { ACP-DGN-LP-EDG2 } \\
\text { EXW-PSF-LF-02 } \\
\text { EXW-PSF-LF-01 } \\
\text { ESW-PSF-LF-103 } \\
\text { LOSP } \\
\text { B-ACP-LP-EDGS } \\
\text { ESW-PSF-LF-102 } \\
\text { ACP-DGN-MA-EDG3 } \\
\text { RA-17J } \\
\text { ACP-DGN-MA-EDG2 } \\
\text { RA-16J } \\
\text { RA-18J } \\
\text { ACP-DGN-LP-EDG3 } \\
\text { ESW-MDP-FS-ESWA } \\
\text { ESW-MDP-FS-ESWB } \\
\text { ACP-DGN-LP-EDG4 } \\
\text { ESW-PSF-LF-19 } \\
\text { ACP-DGN-MA-EDG4 } \\
\text { ECW-XHE-FO-ECWPP } \\
\text { IE-TLOSP } \\
\text { IE-TRTRIP } \\
\text { IE-TMSIVC } \\
\text { IE-TLFW }\end{array}$ & $\begin{array}{l}5.57 \mathrm{E}-8 \\
4.72 \mathrm{E}-8 \\
2.11 \mathrm{E}-8 \\
1.90 \mathrm{E}-8 \\
1.58 \mathrm{E}-8 \\
1.48 \mathrm{E}-8 \\
1.47 \mathrm{E}-8 \\
1.36 \mathrm{E}-8 \\
1.35 \mathrm{E}-8 \\
1.20 \mathrm{E}-8 \\
9.69 \mathrm{E}-9 \\
9.50 \mathrm{E}-9 \\
7.92 \mathrm{E}-9 \\
7.20 \mathrm{E}-9 \\
6.77 \mathrm{E}-9 \\
2.34 \mathrm{E}-9 \\
2.08 \mathrm{E}-9 \\
6.45 \mathrm{E}-10 \\
6.32 \mathrm{E}-10 \\
5.87 \mathrm{E}-10 \\
0.00 \mathrm{E}+0 \\
3.94 \mathrm{E}-8 \\
3.84 \mathrm{E}-9 \\
1.22 \mathrm{E}-9 \\
1.08 \mathrm{E}-9\end{array}$ \\
\hline
\end{tabular}


SEQUENCE SIV - BASE CASE

\begin{tabular}{|c|c|c|}
\hline $\begin{array}{l}\text { IMPORTANCE } \\
\text { MEASURE }\end{array}$ & EVENT & VALUE \\
\hline Risk Reduction & $\begin{array}{l}\text { ESF-XHE-MC-RXPRS } \\
\text { ESF-ASP-FC-PL52D } \\
\text { ESF-ASP-FC-PL52C } \\
\text { ESF-ASP-FC-PL52A } \\
\text { ESF-ASP-FC-PL52B } \\
\text { HCI-TDP-MA-20S37 } \\
\text { HCI -TDP-FS-20S37 } \\
\text { IE-SI }\end{array}$ & $\begin{array}{r}7.49 \mathrm{E}-8 \\
4.68 \mathrm{E}-9 \\
4.68 \mathrm{E}-9 \\
4.68 \mathrm{E}-9 \\
4.68 \mathrm{E}-9 \\
-1.37 \mathrm{E}-9 \\
-4.29 \mathrm{E}-9 \\
8.43 \mathrm{E}-8\end{array}$ \\
\hline Risk Increase & $\begin{array}{l}\text { ESF-XHE-MC-RXPRS } \\
\text { ESF-ASP-FC-PL52D } \\
\text { ESF-ASP-FC-PF52C } \\
\text { ESF-ASP-FC-PL52A } \\
\text { ESF-ASP-FC-PL52B } \\
\text { HCI - TDP-FS- } 20 S 37 \\
\text { HCI - TDP-MA-20S37 }\end{array}$ & $\begin{array}{r}7.49 E-4 \\
1.87 E-6 \\
1.87 E-6 \\
1.87 E-6 \\
1.87 E-6 \\
-8.43 E-8 \\
-8.43 E-8\end{array}$ \\
\hline Uncertainty & $\begin{array}{l}\text { ESF-XHE-MC-RXPRS } \\
\text { HCI -TDP-MA-20S37 } \\
\text { ESF-ASP-FC-PL52A } \\
\text { HCI -TDP-FS-20S37 } \\
\text { ESF-ASP-FC-PL52D } \\
\text { ESF-ASP-FC-PL52C } \\
\text { ESF-ASP-FC-PL52B } \\
\text { IE-S1 }\end{array}$ & $\begin{array}{l}7.23 E-8 \\
3.68 E-9 \\
3.47 E-9 \\
3.40 E-9 \\
3.38 E-9 \\
3.33 E-9 \\
3.33 E-9 \\
2.20 E-7\end{array}$ \\
\hline
\end{tabular}


SEQUENCE TCSARX2 - BASE CASE

\begin{tabular}{|c|c|c|}
\hline $\begin{array}{l}\text { IMPORTANCE } \\
\text { MEASURE }\end{array}$ & EVENT & VALUE \\
\hline Risk Reduction & $\begin{array}{l}\text { ADS-XHE-INH2 } \\
\text { E3-CFP-TC } \\
\text { VENT-XHE-TC } \\
\text { RPS-M } \\
\text { SLC-XHE-FS } \\
\text { CMSIVA } \\
\text { SLC-XHE-REL } \\
\text { LCI-XHE-TL } \\
\text { E3-CL3-TC } \\
\text { IE-TRTRIP } \\
\text { IE-TMSIVC } \\
\text { IE-TLFW } \\
\text { IE-TIORV } \\
\text { IE-TLOSP }\end{array}$ & $\begin{array}{c}7.15 \mathrm{E}-8 \\
7.15 \mathrm{E}-8 \\
7.15 \mathrm{E}-8 \\
7.15 \mathrm{E}-8 \\
5.51 \mathrm{E}-8 \\
3.26 \mathrm{E}-8 \\
1.63 \mathrm{E}-8 \\
-1.91 \mathrm{E}-10 \\
-7.15 \mathrm{E}-8 \\
2.97 \mathrm{E}-8 \\
1.98 \mathrm{E}-8 \\
1.73 \mathrm{E}-8 \\
2.85 \mathrm{E}-9 \\
1.73 \mathrm{E}-9\end{array}$ \\
\hline Risk Increase & $\begin{array}{l}\text { RPS-M } \\
\text { SLC-XHE-REL } \\
\text { SLC-XHE-FS } \\
\text { ADS-XHE-INH2 } \\
\text { CMSIVA } \\
\text { VENT-XHE-TC } \\
\text { E3-CFP-TC } \\
\text { E3-CL3-TC } \\
\text { LCI-XHE-TL }\end{array}$ & $\begin{array}{r}7.15 \mathrm{E}-3 \\
1.62 \mathrm{E}-6 \\
1.58 \mathrm{E}-6 \\
4.39 \mathrm{E}-7 \\
3.26 \mathrm{E}-8 \\
7.94 \mathrm{E}-9 \\
7.94 \mathrm{E}-9 \\
-7.15 \mathrm{E}-8 \\
-7.15 \mathrm{E}-8\end{array}$ \\
\hline Uncertainty & $\begin{array}{l}\text { RPS-M } \\
\text { ADS-XHE-INH2 } \\
\text { SLC-XHE-FS } \\
\text { E3-CL3-TC } \\
\text { CMSIVA } \\
\text { SLC-XHE-REL } \\
\text { E3-CFP-TC } \\
\text { VENT-XHE-TC } \\
\text { LCI-XHE-TL } \\
\text { IE-TRTRIP } \\
\text { IE-TMSIVC } \\
\text { IE-TLFW } \\
\text { IE-TIORV } \\
\text { IE-TLOSP }\end{array}$ & $\begin{array}{l}1.26 \mathrm{E}-7 \\
1.13 \mathrm{E}-7 \\
7.78 \mathrm{E}-8 \\
4.14 \mathrm{E}-8 \\
1.68 \mathrm{E}-8 \\
1.45 \mathrm{E}-8 \\
7.50 \mathrm{E}-9 \\
7.39 \mathrm{E}-9 \\
4.94 \mathrm{E}-10 \\
2.24 \mathrm{E}-8 \\
1.42 \mathrm{E}-8 \\
1.26 \mathrm{E}-8 \\
2.01 \mathrm{E}-9 \\
1.22 \mathrm{E}-9\end{array}$ \\
\hline
\end{tabular}


SEQUENCE TCSARX3 - BASE CASE

\begin{tabular}{|c|c|c|}
\hline $\begin{array}{l}\text { IMPORTANCE } \\
\text { MEASURE }\end{array}$ & EVENT & VALUE \\
\hline Risk Reduction & $\begin{array}{l}\text { VENT-XHE-TC } \\
\text { RPS-M } \\
\text { ADS-XHE-INH2 } \\
\text { SLC-XHE-FS } \\
\text { CMSIVA } \\
\text { SLC-XHE-REL } \\
\text { LCI-XHE-TL } \\
\text { E3-CFP-TC } \\
\text { IE-TRTRIP } \\
\text { IE-TMSIVC } \\
\text { IE-TLFW } \\
\text { IE-TIORV } \\
\text { IE-TLOSP }\end{array}$ & $\begin{array}{c}1.59 \mathrm{E}-8 \\
1.59 \mathrm{E}-8 \\
1.59 \mathrm{E}-8 \\
1.23 \mathrm{E}-8 \\
7.24 \mathrm{E}-9 \\
3.63 \mathrm{E}-9 \\
-4.24 \mathrm{E}-11 \\
-1.43 \mathrm{E}-7 \\
6.60 \mathrm{E}-9 \\
4.40 \mathrm{E}-9 \\
3.85 \mathrm{E}-9 \\
6.33 \mathrm{E}-10 \\
3.85 \mathrm{E}-10\end{array}$ \\
\hline Risk Increase & $\begin{array}{l}\text { RPS - M } \\
\text { SLC-XHE-REL } \\
\text { SLC-XHE-FS } \\
\text { ADS-XHE-INH2 } \\
\text { CMSIVA } \\
\text { VENT-XHE-TC } \\
\text { LCI-XHE-TL } \\
\text { E3-CFP-TC }\end{array}$ & $\begin{array}{r}1.59 E-3 \\
3.59 E-7 \\
3.50 E-7 \\
9.75 E-8 \\
7.24 E-9 \\
1.76 E-9 \\
-1.59 E-8 \\
-1.59 E-8\end{array}$ \\
\hline Uncertainty & $\begin{array}{l}\text { RPS-M } \\
\text { ADS-XHE-INH2 } \\
\text { SLC-XHE-FS } \\
\text { E3-CFP-TC } \\
\text { CMSIVA } \\
\text { SLC-XHE-REL } \\
\text { VENT-XHE-TC } \\
\text { LCI-XHE-TL } \\
\text { IE-TRTRIP } \\
\text { IE-TMSIVC } \\
\text { IE-TLFW } \\
\text { IE-TIORV } \\
\text { IE-TLOSP }\end{array}$ & $\begin{array}{l}2.79 \mathrm{E}-8 \\
2.51 \mathrm{E}-8 \\
1.73 \mathrm{E}-8 \\
1.50 \mathrm{E}-8 \\
3.73 \mathrm{E}-9 \\
3.22 \mathrm{E}-9 \\
1.64 \mathrm{E}-9 \\
1.10 \mathrm{E}-10 \\
4.97 \mathrm{E}-9 \\
3.16 \mathrm{E}-9 \\
2.79 \mathrm{E}-9 \\
4.46 \mathrm{E}-10 \\
2.72 \mathrm{E}-10\end{array}$ \\
\hline
\end{tabular}


SEQUENCE TCSARX2 - SENSITIVITY ISSUE 5

\begin{tabular}{|c|c|c|}
\hline $\begin{array}{l}\text { IMPORTANCE } \\
\text { MEASURE }\end{array}$ & EVENT & VALUE \\
\hline Risk Reduction & $\begin{array}{l}\text { VENT-XHE-TC } \\
\text { RPS-M } \\
\text { E3-CFP-TC } \\
\text { ADS-XHE-INH2 } \\
\text { SLC-XHE-FS } \\
\text { CMSIVA } \\
\text { SLC-XHE-REL } \\
\text { LCI-XHE-TL } \\
\text { E3-CL3-TC } \\
\text { IE-TRTRIP } \\
\text { IE-TMSIVC } \\
\text { IE-TLFW } \\
\text { IE-TIORV } \\
\text { IE-TLOSP }\end{array}$ & $\begin{array}{r}2.80 \mathrm{E}-7 \\
2.80 \mathrm{E}-7 \\
2.80 \mathrm{E}-7 \\
2.80 \mathrm{E}-7 \\
2.64 \mathrm{E}-7 \\
1.28 \mathrm{E}-7 \\
1.62 \mathrm{E}-8 \\
-2.83 \mathrm{E}-9 \\
-2.80 \mathrm{E}-7 \\
1.17 \mathrm{E}-7 \\
7.77 \mathrm{E}-8 \\
6.80 \mathrm{E}-8 \\
1.12 \mathrm{E}-8 \\
6.80 \mathrm{E}-9\end{array}$ \\
\hline Risk Increase & $\begin{array}{l}\text { RPS-M } \\
\text { ADS-XHE-INH2 } \\
\text { SLC-XHE-REL } \\
\text { SLC-XHE-FS } \\
\text { CMSIVA } \\
\text { VENT-XHE-TC } \\
\text { E3-CFP-TC } \\
\text { LCI-XHE-TL } \\
\text { E3-CL3-TC }\end{array}$ & $\begin{array}{r}2.80 E-2 \\
1.72 E-6 \\
1.60 E-6 \\
1.36 E-6 \\
1.28 E-7 \\
3.11 E-8 \\
3.11 E-8 \\
-2.80 E-7 \\
-2.80 E-7\end{array}$ \\
\hline Uncertainty & $\begin{array}{l}\text { RPS-M } \\
\text { ADS-XHE-INH2 } \\
\text { SLC-XHE-FS } \\
\text { E3-CL3-TC } \\
\text { CMSIVA } \\
\text { E3-CFP-TC } \\
\text { VENT-XHE-TC } \\
\text { SLC-XHE-REL } \\
\text { LCI-XHE-TL } \\
\text { IE-TRTRIP } \\
\text { IE-TMSIVC } \\
\text { IE-TLFW } \\
\text { IE-TIORV } \\
\text { IE-TLOSP }\end{array}$ & $\begin{array}{l}4.92 \mathrm{E}-7 \\
4.44 \mathrm{E}-7 \\
3.80 \mathrm{E}-7 \\
1.62 \mathrm{E}-7 \\
6.58 \mathrm{E}-8 \\
2.94 \mathrm{E}-8 \\
2.90 \mathrm{E}-8 \\
1.44 \mathrm{E}-8 \\
0.00 \mathrm{E}+0 \\
8.78 \mathrm{E}-8 \\
5.57 \mathrm{E}-8 \\
4.92 \mathrm{E}-8 \\
7.86 \mathrm{E}-9 \\
4.79 \mathrm{E}-9\end{array}$ \\
\hline
\end{tabular}


SEQUENCE TCSARX3 - SENSITIVITY ISSUE 5

\begin{tabular}{|c|c|c|}
\hline $\begin{array}{l}\text { IMPORTANCE } \\
\text { MEASURE }\end{array}$ & EVENT & VALUE \\
\hline Risk Reduction & $\begin{array}{l}\text { VENT-XHE-TC } \\
\text { RPS-M } \\
\text { ADS-XHE-INH2 } \\
\text { SLC-XHE-FS } \\
\text { CMSIVA } \\
\text { SLC-XHE-REL } \\
\text { LCI-XHE-TL } \\
\text { E3-CFP-TC } \\
\text { IE-TRTRIP } \\
\text { IE-TMSIVC } \\
\text { IE-TLFW } \\
\text { IE-TIORV } \\
\text { IE-TLOSP }\end{array}$ & $\begin{array}{c}6.23 \mathrm{E}-8 \\
6.23 \mathrm{E}-8 \\
6.23 \mathrm{E}-8 \\
5.87 \mathrm{E}-8 \\
2.84 \mathrm{E}-8 \\
3.60 \mathrm{E}-9 \\
-6.29 \mathrm{E}-10 \\
-5.60 \mathrm{E}-7 \\
2.59 \mathrm{E}-8 \\
1.73 \mathrm{E}-8 \\
1.51 \mathrm{E}-8 \\
2.48 \mathrm{E}-9 \\
1.51 \mathrm{E}-9\end{array}$ \\
\hline Risk Increase & $\begin{array}{l}\text { RPS-M } \\
\text { ADS-XHE-INH2 } \\
\text { SLC-XHE-REL } \\
\text { SLX-XHE-FS } \\
\text { CMSIVA } \\
\text { VENT-XHE-TC } \\
\text { LCI-XHE-TL } \\
\text { E3-CFP-TC }\end{array}$ & $\begin{array}{r}6.23 \mathrm{E}-3 \\
3.82 \mathrm{E}-7 \\
3.56 \mathrm{E}-7 \\
3.01 \mathrm{E}-7 \\
2.84 \mathrm{E}-8 \\
6.92 \mathrm{E}-9 \\
-6.23 \mathrm{E}-8 \\
-6.23 \mathrm{E}-8\end{array}$ \\
\hline Uncertainty & $\begin{array}{l}\text { RPS-M } \\
\text { ADS-XHE-INH2 } \\
\text { SLC-XHE-FS } \\
\text { E3-CFP-TC } \\
\text { CMSIVA } \\
\text { VENT-XHE-TC } \\
\text { SLC-XHE-REL } \\
\text { LCI-XHE-TL } \\
\text { IE-TRTRIP } \\
\text { IE-TMSIVC } \\
\text { IE-TLFW } \\
\text { IE-TIORV } \\
\text { IE-TLOSP }\end{array}$ & $\begin{array}{l}1.09 \mathrm{E}-7 \\
9.86 \mathrm{E}-8 \\
8.43 \mathrm{E}-8 \\
5.88 \mathrm{E}-8 \\
1.46 \mathrm{E}-8 \\
6.44 \mathrm{E}-9 \\
3.19 \mathrm{E}-9 \\
0.00 \mathrm{E}+0 \\
1.95 \mathrm{E}-8 \\
1.24 \mathrm{E}-8 \\
1.09 \mathrm{E}-8 \\
1.75 \mathrm{E}-9 \\
1.06 \mathrm{E}-9\end{array}$ \\
\hline
\end{tabular}


Risk Reduction

Risk Increase

Uncertainty
RA-2D

ESF - XHE-MC-RXPRS

ESF-XHE-FO-CRDRL

HCI - TDP-FS - 20S37

RCI - TDP-FS - 20538

RCI - TDP-MA-20S38

HCI -TDP-MA-20S37

CRD-MDP-FS-2BP39

PCSLOST

CRD-MDP-MA-2AP39

CRD-MDP-MA-2BP39

IE-TMS IVC

IE-TLFW

IE-TRTRIP

ESF-XHE-MC-RXPRS

HCI - TDP-FS - 20537

RCI I TDP-FS - $20 S 38$

RCI - TDP-MA-20S38

HCI - TDP-MA-20S37

ESF-XHE-FO-CRDRL

CRD-MDP-MA-2BP39

CRD-MDP-MA-2AP39

CRD-MDP-FS-2BP39

PCSLOST

RA-2D

ESF-XHE-MC-RXPRS

ESF-XHE-FO-CRDRL

HCI - TDP-FS-20S37

RCI - TDP - FS - 20538

HCI I TDP-MA-20S37

RCI - TDP-MA-20S38

RA-2D

CRD-MDP-MA-2BP39

PCSLOST

CRD-MDP-MA-2AP39

CRD-MDP-FS-2BP39

IE-TMSIVC

IE-TLFW

IE-TRTRIP
$5.61 \mathrm{E}-8$

$5.61 E-8$

$5.34 \mathrm{E}-8$

$4.55 E-8$

$4.55 \mathrm{E}-8$

$1.06 \mathrm{E}-8$

$1.06 \mathrm{E}-8$

$1.04 \mathrm{E}-9$

$8.84 \mathrm{E}-10$

$8.55 \mathrm{E}-10$

8. $55 \mathrm{E}-10$

$2.95 \mathrm{E}-8$

2. $58 \mathrm{E}-8$

$8.84 \mathrm{E}-10$

$5.61 \mathrm{E}-4$

8. $95 \mathrm{E}-7$

8. $95 \mathrm{E}-7$

$6.53 \mathrm{E}-7$

$6.53 \mathrm{E}-7$

4. $80 \mathrm{E}-7$

3. $20 \mathrm{E}-7$

3. $20 \mathrm{E}-7$

3. $20 \mathrm{E}-7$

8. $75 \mathrm{E}-8$

$6.24 E-9$

$5.42 \mathrm{E}-8$

$5.18 \mathrm{E}-8$

$3.61 \mathrm{E}-8$

3. $19 \mathrm{E}-8$

$2.85 E-8$

2. $02 \mathrm{E}-8$

$6.21 E-9$

$2.26 E-9$

$1.63 E-9$

$1.40 \mathrm{E}-9$

$1.21 \mathrm{E}-9$

$2.11 \mathrm{E}-8$

$1.87 \mathrm{E}-8$

$6.66 \mathrm{E}-10$ 
SEQUENCE AV - BASE CASE

\begin{tabular}{ccc}
\hline $\begin{array}{c}\text { IMPORTANCE } \\
\text { MEASURE }\end{array}$ & \multicolumn{1}{c}{ EVENT } & VALUE \\
\hline \multirow{2}{*}{ Risk Reduction } & ESF-XHE-MC-RXPRS & $2.66 \mathrm{E}-8$ \\
& ESF-ASP-FC-PL52D & $1.66 \mathrm{E}-9$ \\
& ESF-ASP-FC-PL52C & $1.66 \mathrm{E}-9$ \\
& ESF-ASP-FC-PL52B & $1.66 \mathrm{E}-9$ \\
& ESF-ASP-FC-PL52A & $1.66 \mathrm{E}-9$ \\
& IE-A & $2.99 \mathrm{E}-8$ \\
Risk Increase & ESF-XHE-MC-RXPRS & $2.66 \mathrm{E}-4$ \\
& ESF-ASP-FC-PL52D & $6.63 \mathrm{E}-7$ \\
& ESF-ASP-FC-PL52C & $6.63 \mathrm{E}-7$ \\
& ESF-ASP-FC-PL52B & $6.63 \mathrm{E}-7$ \\
& ESF-ASP-FC-PL52A & $6.63 \mathrm{E}-7$ \\
& & \\
& ESF-XHE-MC-RXPRS & $2.57 \mathrm{E}-8$ \\
Uncertainty & ESF-ASP-FC-PL52A & $1.23 \mathrm{E}-9$ \\
& ESF-ASP-FC-PL52D & $1.20 \mathrm{E}-9$ \\
& ESF-ASP-FC-PL52C & $1.18 \mathrm{E}-9$ \\
& ESF-ASP-FC-PL52B & $1.18 \mathrm{E}-9$ \\
& IE-A & $5.76 \mathrm{E}-8$ \\
\hline
\end{tabular}


SEQUENCE TUX - BASE CASE

\section{IMPORTANCE MEASURE}

Risk Reduction

Risk Increase

Uncertainty

\section{EVENT}

ADS-VLV-FO-VALVE

B-ADS-FO-VLVS

RA-2D

SRV-XHE-FO-VLV

ESF-XHE-FO-CRDRL

RCI - TDP-FS-20S38

HCI - TDP - FS - 20 S37

RCI - TDP-MA-20S38

HCI - TDP-MA-20S37

CRD-MDP-FS-28P39

PCSLOST

CRD-MDP-MA-2BP39

CRD-MDP-MA-2AP39

IE-TMSIVC

IE-TLFW

IE-TRTRIP

SRV-XHE-FO-VLV

ADS-VLV-FO-VALVE

RCI - TDP-FS-20S38

HCI - TDP-FS-20S37

RCI - TDP-MA-20S38

HCI - TDP-MA-20S37

B-ADS-FO-VLVS

ESF-XHE-FO-CRDRL

CRD-MDP-MA-2AP39

CRD-MDP-MA-2BP39

CRD-MDP-FS-2BP39

PCSLOST

RA-2D

SRV-XHE-FO-VLV

ESF-XHE-FO-CRDRL

ADS-VLV-FO-VALVE

B-ADS-FO-VLVS

HCI - TDP-FS-20S37

RCI-TDP-FS-20S38

HCI - TDP-MA-20S37

RCI - TDP-MA- 20 S38

RA-2D

CRD-MDP-MA-2BP39

PCSLOST

CRD-MDP-MA-2AP39

CRD-MDP-FS-2BP39

IE-TMSIVC

IE-TLFW

IE-TRTRIP
VALUE

2. $34 \mathrm{E}-8$

$2.34 \mathrm{E}-8$

2. $34 \mathrm{E}-8$

2. $34 \mathrm{E}-8$

$2.22 \mathrm{E}-8$

$1.90 \mathrm{E}-8$

1. $90 \mathrm{E}-8$

4. $42 E-9$

4. $42 \mathrm{E}-9$

$4.32 \mathrm{E}-10$

3. $68 \mathrm{E}-10$

3. $56 \mathrm{E}-10$

3. $56 \mathrm{E}-10$

$1.23 \mathrm{E}-8$

$1.07 \mathrm{E}-8$

$3.68 \mathrm{E}-10$

2.31E-6

4. $44 \mathrm{E}-7$

$3.73 \mathrm{E}-7$

3. $73 \mathrm{E}-7$

2. $72 \mathrm{E}-7$

2. $72 \mathrm{E}-7$

$2.57 \mathrm{E}-7$

2. $00 \mathrm{E}-7$

1. $33 \mathrm{E}-7$

1. $33 \mathrm{E}-7$

1. $33 \mathrm{E}-7$

3. $64 \mathrm{E}-8$

2. $60 \mathrm{E}-9$

$2.34 E-8$

2. $16 \mathrm{E}-8$

1. $75 \mathrm{E}-8$

$1.70 \mathrm{E}-8$

$1.50 E-8$

1. $33 \mathrm{E}-8$

$1.19 \mathrm{E}-8$

$8,41 E-9$

2. $59 \mathrm{E}-9$

$9.42 E-10$

$6.81 E-10$

$5.82 E-10$

$5.06 E-10$

8. $80 \mathrm{E}-9$

$7.77 \mathrm{E}-9$

2.77E-10 
SEQUENCE TUX - SENSITIVITY ISSUE 2

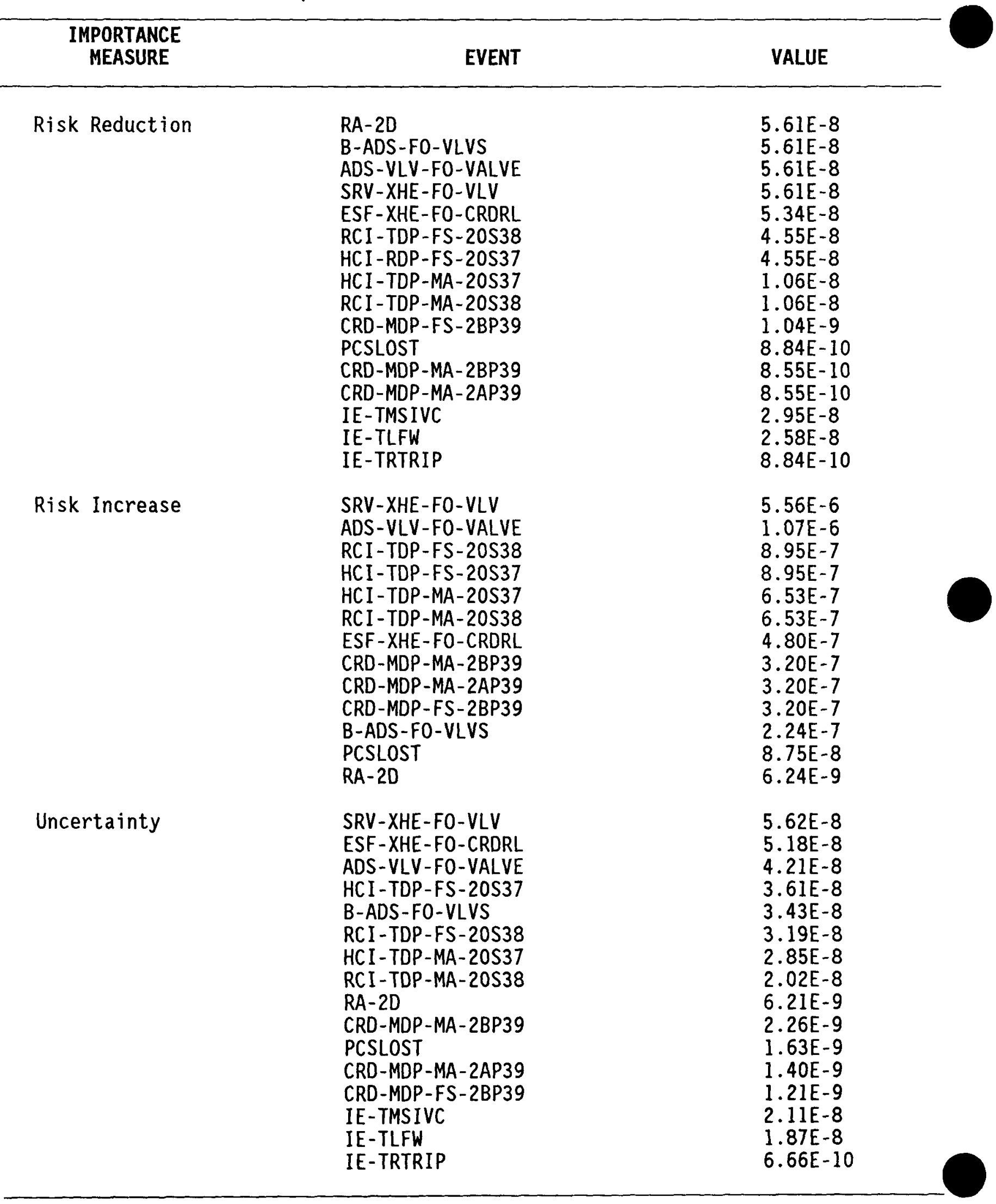


APPENDIX C:

PHILADELPHIA ELECTRIC COMPANY REVIEW 
TABLE OF CONTENTS

Section

Page

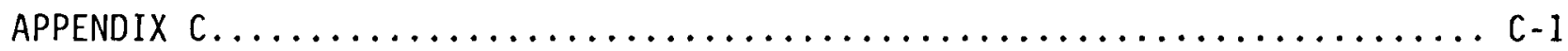

C.1 INTRODUCTION................................

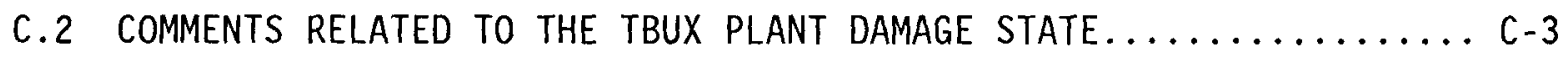

C. 3 COMMENTS RELATED TO THE MODELING OF THE EMERGENCY SERVICE WATER (ESW) SYSTEM................................... 


\section{C. $1 \quad$ INTRODUCTION}

Following the issue of this report in its draft form, Philadelphia Electric Company (PECO) was asked to provide their comments on the report. This was done to add confidence to the results and provide PECO with the opportunity to add additional perspectives to the study.

PECO supplied a variety of technical and editorial comments, most of which were addressed in the firal version of the report. There were two general comments, however, which are particularly important and yet could not be specifically factored into the study because of the time and resources that would be required. These are discussed below.

\section{C.2 COMMENTS RELATED TO THE TBUX PLANT DAMAGE STATE}

As discussed in Section $V$, the TBUX plant damage state is the most dominant state identified in the study, with a core damage frequency of approximately $4 \mathrm{E}-6$. This plant damage state involves a loss of offsite power with coincident failure (because of common cause) of at least five batteries so as to cause diesel generator start failures and the inability to depressurize the reactor vessel. This state results in a relatively "fast" station blackout scenario with core damage expected to begin in less than an hour. Depending on the containment analyses including the ability to restore power at some later time, containment failure could be expected with the consequences potentially being severe.

Because of a lack of sufficient data and the resources to obtain and analyze additional data, the common cause failure of the batteries was estimated using a Beta factor approach. The approach, per the methodology guidelines, applied a "best estimate" Beta factor to the second battery failure (given the first battery is failed) and failure probabilities of 1.0 to each additional failure of "like" components. This approach results in an estimate of the core damage frequency which should be no worse than that estimated herein (i.e., failure estimates of 1.0 maximize the probability of additional failures). The question, as related by PECO's comments, is whether this is really a "best estimate" analysis.

One argument, in particular, suggests that the approach might be considered a "best estimate" calculation. If the failures are based on a true common cause failure (e.g., improper charging), it might be expected that the subsequent failure probabilities of additional batteries could be quite high. On the other hand, PECO's concerns about whether the batteries would all be at the same level of degradation, whether insufficient power would exist to start at least one diesel as the batteries are drawn down, etc. provide impetus for considering the 1.0 Beta factors as too conservative. Besides these points, the initial and second battery failure probabilities are based on extremely few failures. This data should be reanalyzed and updated for use at Peach Bottom.

Section $V$ shows the results of Sensitivity Study \#1, in which the Beta factors were assumed to be negligible. While the corresponding reduction of TBUX would have a moderate effect on the core damage frequency, it could have a significant impact on the risk for Peach Bottom (depending on subsequent containment analyses). It seems crucial, therefore, that this plant damage state be examined in further detail before actions are taken on the basis of the analysis herein. This study has served to focus attention on this possibly important plant damage 
state. However, additional data collection on battery failures and analysis of the data is strongly recommended before further actions are taken as a result of the TBUX analysis.

\section{C.3 \\ COMMENTS RELATED TO THE MODELING OF THE EMERGENCY SERVICE WATER (ESW) SYSTEM}

During much of the analysis, considerable discussion occurred which related to whether the ESW system could be operated in the emergency heat sink (EHS) mode without the ESW booster pumps (see Section IV.5.13 for further details). If not, it meant that the ESW system is particularly sensitive to Diesel $B$ and $C$ failures which would cause a loss of the ESW system and subsequent failure of Diesels $A$ and $D$ (because of the loss of diesel jacket cooling by the ESW system). If the system could be operated without the booster pumps in the EHS mode, at least three failures (not just the two diesel failures above) would be required to fail the ESW system. This impacts many of the station blackout scenarios as evidenced by the results of Sensitivity Study \#4 in Section $V$.

In PECO's review of this issue, they recently found ESW system test data that confirm the operability of the ESW system without the booster pumps. The ESW loads were not adversely affected during the tests although somewhat reduced ESW flows and higher load temperatures were noted. This information was received too late to be incorporated into the study. The results seem to provide reasonable evidence that the ESW system should have been modeled as requiring three failures instead of just two failures as per the base case. Therefore, the results of Sensitivity \#4 for the core damage frequency estimate and corresponding plant damage state frequencies appear more indicative of the Peach Bottom plant. This consideration should be factored in before using the results of this study. 


\section{DISTR IBUTION :}

U. S. Government Printing office

Receiving Branch (Attn: NRC stock)

8610 Cherry Lane

Laurel. MD 20707

100 copies for AN

Author Selected Distribution (162)

3141 S. A. Landenberger (5)

3151 W. L. Garner

6400 A. W. Snyder

6410 J. W. Hickman

6411 A. S. Benjamin

6412 A. L. Camp

6412 M. P. Bohn

6412 F. T. Harper (32)

6412 D. M. Kunsman

6412 J. A. Lambright

6412 A. C. Payne, Jr.

6412 T. A. Wheeler

6415 F. E. Haskin

6422 D. A. Powers

8024 P. W. Dean 


\begin{tabular}{|c|c|}
\hline $\begin{array}{l}\text { NAC FORM } 335 \\
\begin{array}{l}2881 \\
\text { NRCM } 1102 . \\
32013202\end{array} \\
\text { BS. NUCLEAR REGULATOAY COMMISSION } \\
\text { BIBLIOGRAPHIC DATA SHEET }\end{array}$ & 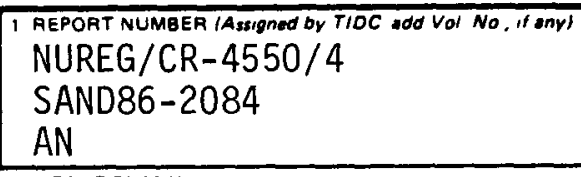 \\
\hline \multirow{2}{*}{$\begin{array}{l}\text { ANALYSIS OF CORE DAMAGE FREQUENCY FROM INTERNAL EVENTS: } \\
\text { PEACH BOTTOM, UNIT } 2\end{array}$} & \\
\hline & 4 DATE REPORT COMPLETED \\
\hline \multirow{2}{*}{$\begin{array}{l}\text { A. M. Kolaczkowski, J. A. Lambright, W. L. Ferrel1, } \\
\text { N. G. Cathej, B. Najafi, F. T. Harper }\end{array}$} & September \\
\hline & \begin{tabular}{|r|r}
\multicolumn{2}{|c|}{ 6 DATE REPOAT ISSUED } \\
MONTH & YEAA \\
October & 1986
\end{tabular} \\
\hline \multirow{2}{*}{$\begin{array}{l}7 \text { PEAFOAMING ORGANIZATION NAME AND MAILING ADOAESS Inelude Zip Codel } \\
\text { Science Applications International Corporation } \\
2109 \text { Air Park Road SE } \\
\text { Albuquerque, New Mexico } 87106 \\
\text { (Under contract to Sandia National Laboratories) }\end{array}$} & 8 PAOJECT/TASK/WORK UNIT NUMBER \\
\hline & 9 FIN OA GRANT NUMBEA \\
\hline $\begin{array}{l}10 \text { SPONSOAING ORGANIZATION NAME ANO MAILING ADDAESS (InClude Zip Code) } \\
\text { Nuclear Regulatory Commission } \\
\text { Division of Reactor System Safety } \\
\text { Office of Nuclear Regulatory Research } \\
\text { Washington, DC } 20555\end{array}$ & $\begin{array}{l}\text { 11. TYPE OF AEPORT } \\
\text { Fina } 1 \\
\text { DPEAIOD COVEAED (InCliusive datoul }\end{array}$ \\
\hline
\end{tabular}

12 SUPPLEMENTARY NOTES

This document contains the internal event initiated accident sequence analyses for each Bottom, Unit 2; one of the reference plants being examined as part of the NUREG-1150 effort by the Nuclear Regulatory Commission. NUREG-1150 will document the risk of a selected group of nuclear power plants. As part of that work, this report contains the overall core damage frequency estimate for Peach Bottom, Unit 2, and the accompanying plant damage state frequencies. Sensitivity and uncertainty analyses provide additional insights regarding the dominant contributors to the Peach Bottom core damage frequency estimate.

The mean core damage frequency at Peach Bottom was calculated to be $8.2 E-6$. Station Blackout type accidents (loss of all AC power) were found to dominate the overall results. Anticipated Transients Without Scram accidents were also found to be non-negligible contributors.

The numerical results are largely driven by common mode failure probability estimates and to some extent, human error. Because of significant data and analysis

uncertainties in these two areas (important, for instance, to the most dominant

scenario in this study), it is recommended that the results of the uncertainty and sensitivity analyses be considered before any actions are taken based on this analysis

14 DOCUMENT ANALYSIS - a KEYWOAOS/DESCAIPTORS

PRA, Safety Analys is

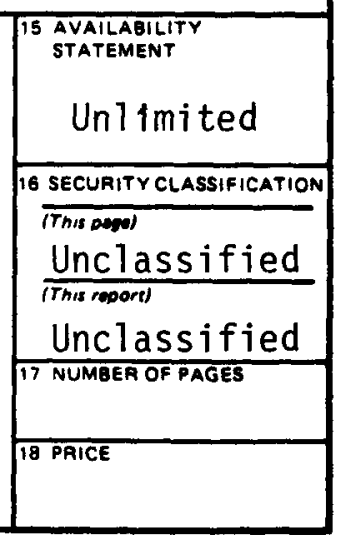

